DOC.20050825.0008

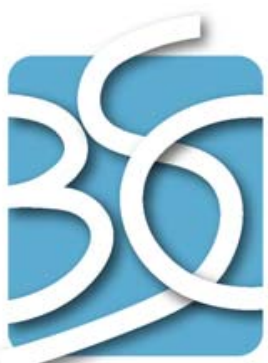

BECHTEL SAIC COMPANYLC
QA: QA

ANL-WIS-PA-000001 REV 02

August 2005

\title{
EBS Radionuclide Transport Abstraction
}

NOTICE OF OPEN CHANGE DOCUMENTS - THIS DOCUMENT IS IMPACTED BY THE LISTED CHANGE DOCUMENT AND CANNOT BE USED WITHOUT IT.

1) ACN-001, APPROVED 07/14/2006

Prepared for:

U.S. Department of Energy

Office of Civilian Radioactive Waste Management

Office of Repository Development

1551 Hillshire Drive

Las Vegas, Nevada 89134-6321

Prepared by:

Bechtel SAIC Company, LLC

1180 Town Center Drive

Las Vegas, Nevada 89144

Under Contract Number

DE-AC28-01RW12101 


\section{DISCLAIMER}

This report was prepared as an account of work sponsored by an agency of the United States Government. Neither the United States Government nor any agency thereof, nor any of their employees, nor any of their contractors, subcontractors or their employees, makes any warranty, express or implied, or assumes any legal liability or responsibility for the accuracy, completeness, or any third party's use or the results of such use of any information, apparatus, product, or process disclosed, or represents that its use would not infringe privately owned rights. Reference herein to any specific commercial product, process, or service by trade name, trademark, manufacturer, or otherwise, does not necessarily constitute or imply its endorsement, recommendation, or favoring by the United States Government or any agency thereof or its contractors or subcontractors. The views and opinions of authors expressed herein do not necessarily state or reflect those of the United States Government or any agency thereof. 
QA: QA

EBS Radionuclide Transport Abstraction ANL-WIS-PA-000001 REV 02 August 2005 


\section{BSC \\ Model Signature Page/Change History \\ Page iii \\ Complete only applicable items. \\ 1. Total Pages: 630}

2. Type of Mathematical Model

$\square$ Process Model

$\triangle$ Abstraction Model

System Model

Describe Intended Use of Model

The abstraction for flow and transport of radionuclides in the Engineered Barrier Sfystem (EBS) will be incorporated into the GoldSim model for TSPA-LA.

\section{Title}

EBS Radionuclide Transport Abstraction

4. DI (including Rev. No.):

ANL-WIS-PA-000001 REV 02

\begin{tabular}{|l|l|}
\hline & Printed Name \\
\hline $\begin{array}{l}\text { 5. } \text { Originator } \\
\text { Reviewer }\end{array}$ & James D. Schreiber \\
\hline 7. Checker & Rob Howard \\
\hline 8. QER & Joshua S. Stein (Lead) \\
\hline 9. Responsible Manager/Lead & William Duffy \\
\hline 10. Responsible Manager & Ernest Hardin \\
\hline 11. Remarks & Rarrell Svalstad \\
\hline
\end{tabular}

11. Remarks

\section{Change History}

\begin{tabular}{|l|l|}
\hline \multicolumn{1}{|c|}{ 12. Revision No. } & \multicolumn{1}{|c|}{ 13. Description of Change } \\
\hline REV 00 & Initial issue. \\
\hline REV 00, ICN 01 & $\begin{array}{l}\text { Changed functional dependence of diffusion coefficient on liquid saturation } \\
\text { and porosity. }\end{array}$ \\
\hline REV 00, ICN 02 & $\begin{array}{l}\text { Modified EBS flow and transport abstraction to include an EBS design } \\
\text { without backfill; modified thermal and mechanical response of drip shield to } \\
\text { reflect new drip shield design and rockfall analyses. }\end{array}$ \\
\hline
\end{tabular}




\begin{tabular}{|l|l|}
\hline REV 01 & Complete revision. Revisions are too extensive to use change lines. Modified \\
& flux splitting model, incorporating experimental data; added model validation. \\
& Added in-package retardation and diffusion models, with validation. \\
& Modified invert diffusion properties model and added data qualification and \\
& validation. Included general mathematical description of EBS transport. \\
& Expanded treatment of colloid-facilitated transport. Updated YMRP \\
& Acceptance Criteria and FEPs list. Modified flow pathways and flow and \\
& transport abstractions. Added alternative conceptual models, including dual- \\
& continuum invert. Added DIRS numbers to references. Added summary of \\
& barrier capability. Added discussion of parameter and model uncertainty. \\
& Added list of nomenclature. Added appendices describing spreadsheets used \\
& to develop and validate models. Added output DTN. Added sorption in the \\
& invert. Revised and expanded discretization of EBS RT Abstraction. Added \\
& UZ input parameters for EBS-UZ boundary condition model. Addressed an \\
& error documented in CR 3980. \\
\hline REV 02 & $\begin{array}{l}\text { This revision addresses CR-5141, CR-5293, and CR-5442. This is a complete } \\
\text { revision; due to extensive changes, change bars were not used. }\end{array}$ \\
\hline
\end{tabular}




\section{CONTENTS}

Page

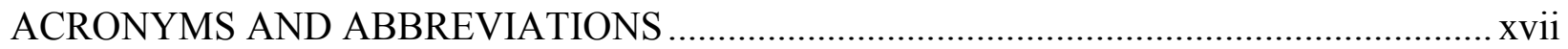

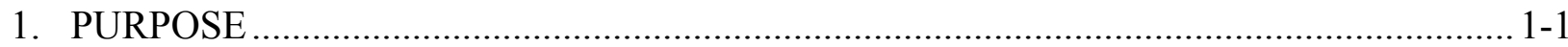

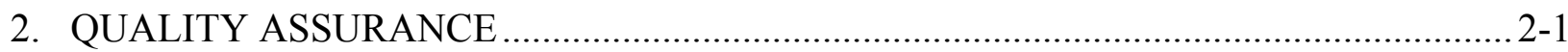

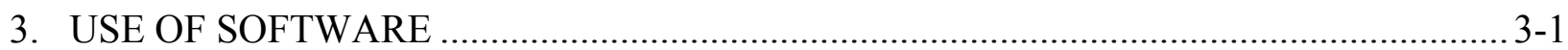

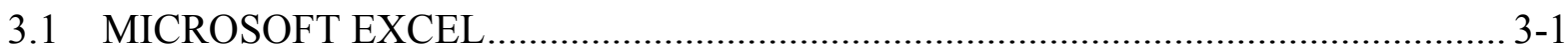

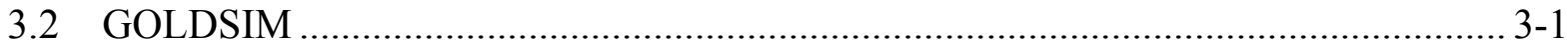

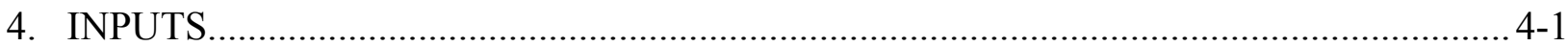

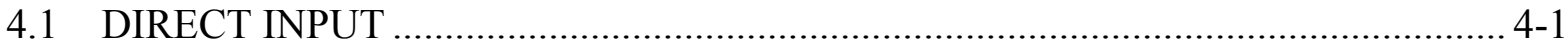

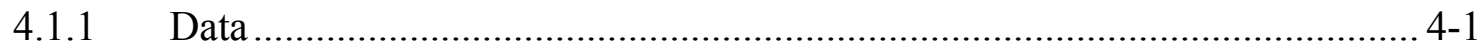

4.1.2 Parameters and Other Technical Information ............................................ 4-6

4.1.3 Design Information ....................................................................... 4-27

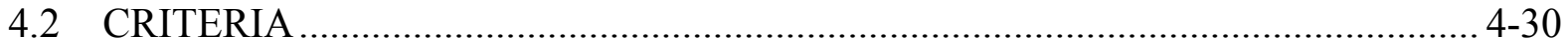

4.2.1 Yucca Mountain Review Plan Criteria ....................................................... 4-31

4.2.1.1 Applicable Acceptance Criteria from Section 2.2.1.3.3, "Quantity and Chemistry of Water Contacting Engineered Barriers and Waste Forms"

4.2.1.2 Applicable Acceptance Criteria from Section 2.2.1.3.4, "Radionuclide Release Rates and Solubility Limits"..................... 4-35

4.3 CODES, STANDARDS, AND REGULATIONS ................................................. 4-38

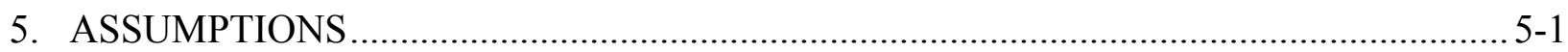

5.1 ALL SEEPAGE FALLS ONTO DRIP SHIELD/WASTE PACKAGE ....................... 5-1

5.2 EVAPORATION FROM A DRIP SHIELD DOES NOT OCCUR ………................... 5-1

5.3 EVAPORATION FROM A WASTE PACKAGE DOES NOT OCCUR ……............. 5-2

5.4 PRODUCTION OR CONSUMPTION OF WATER BY CHEMICAL

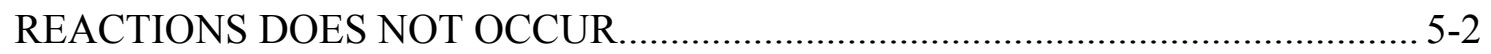

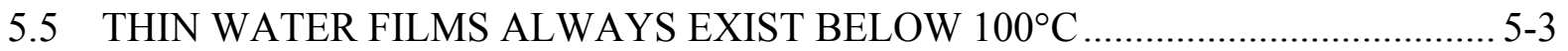

5.6 NO CORROSION PRODUCTS EXIST IN THE INVERT ......................................... 5-4

5.7 NO PHYSICAL FILTRATION OR GRAVITATIONAL SETTLING

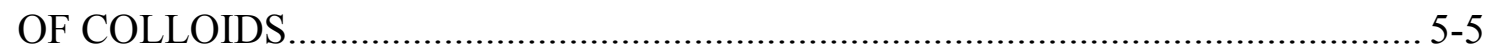

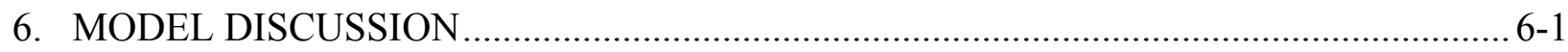

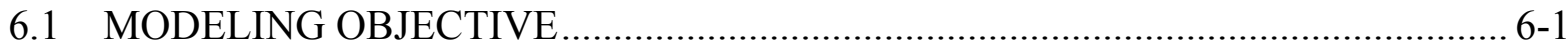

6.1.1 Engineered Barrier System Components ………........................................... 6-1

6.1.2 Scenario Classes for TSPA-LA ………….................................................. 6-2

6.2 FEATURES, EVENTS, AND PROCESSES INCLUDED IN THE MODEL.............. 6-4

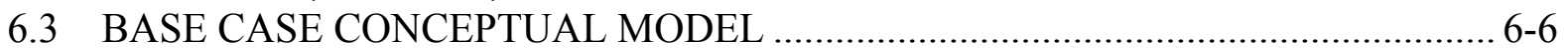

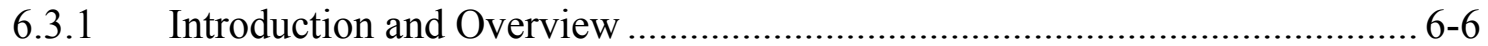

6.3.1.1 EBS Flow Abstraction............................................................. 6-6 


\section{CONTENTS (Continued)}

Page

6.3.1.2 EBS Transport Abstraction

6-9

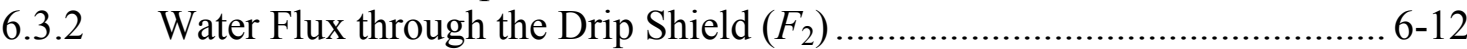

6.3.2.1 Water Movement into and through a $\operatorname{Drift}\left(F_{1}\right.$ and $\left.F_{3}\right) \ldots \ldots \ldots \ldots \ldots \ldots . . .6-12$

6.3.2.1.1 Seepage and Condensation Flux $\left(F_{1}\right) \ldots \ldots \ldots \ldots \ldots \ldots \ldots \ldots . . . . .6-12$

6.3.2.1.2 Diversion around the Drip Shield $\left(F_{3}\right) \ldots \ldots \ldots \ldots \ldots \ldots \ldots \ldots . . .6-13$

6.3.2.2 Drip Shield Effectiveness ............................................................. 6-13

6.3.2.3 Drip Shield Breaching .............................................................. 6-14

6.3.2.4 Water Flux through and around a Breached Drip Shield

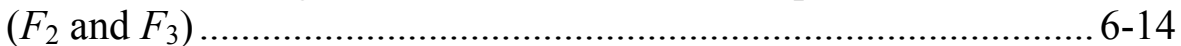

6.3.3 Water Flux through the Waste Package $\left(F_{4}\right)$........................................... 6-18

6.3.3.1 Breaching of the Waste Package .................................................... 6-19

6.3.3.1.1 Waste Package Design .............................................. 6-19

6.3.3.1.2 Types of Openings ..................................................... 6-20

6.3.3.1.3 Impact of Heat Generation Inside Waste Package...... 6-22

6.3.3.2 Water Flux through and around the Breached Waste Package

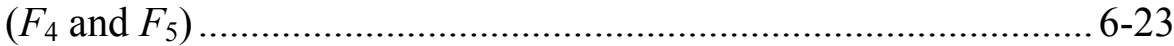

6.3.3.3 Condensation on the Drip Shield................................................... 6-25

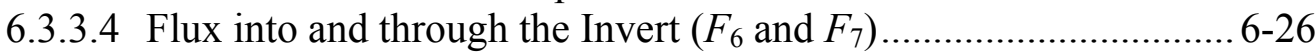

6.3.4 Transport through the EBS ............................................................. 6-26

6.3.4.1 Invert Diffusion Submodel ....................................................... 6-28

6.3.4.1.1 Modification of Diffusion Coefficient for Porosity and Saturation of the Invert......................................... 6-28

6.3.4.1.2 Modification for Temperature..................................... 6-37

6.3.4.1.3 Modification for Concentrated Aqueous Solutions .... 6-39

6.3.4.2 Retardation in the Engineered Barrier System ............................... 6-39

6.3.4.2.1 Conceptual Model for the In-Drift

Sorption Environment .................................................. 6-41

6.3.4.2.2 Sorption Parameters for the Invert ................................ 6-44

6.3.4.2.3 Sorption Parameters for the Waste Package ............... 6-46

6.3.4.3 In-Package Diffusion Submodel for Commercial Spent

Nuclear Fuel Waste Packages ..................................................... 6-68

6.3.4.3.1 Adsorption of Water Vapor in Commercial Spent

Nuclear Fuel Waste Packages ....................................... 6-69

6.3.4.3.2 Hematite Water Vapor Adsorption Isotherm ............... 6-82

6.3.4.3.3 Specific Surface Area of Metal Oxides....................... 6-84

6.3.4.3.4 Interior Surface Area, Volume, and Porosity of

21-PWR Waste Package .............................................. 6-86

6.3.4.3.5 Diffusion Coefficient in Corrosion Products .............. 6-90

6.3.4.4 Colloidal Transport.................................................................. 6-94

6.3.4.5 Transport through Stress Corrosion Cracks .................................. 6-98

6.4 CONSIDERATION OF ALTERNATIVE CONCEPTUAL MODELS .................... 6-98

6.4.1 Bathtub Model for the Waste Package..................................................... 6-99

6.4.2 Limited Water Vapor Diffusion Rate into Waste Package......................... 6-100

6.4.3 Limited Oxygen Diffusion Rate into Waste Package .................................. 6-101 


\section{CONTENTS (Continued)}

Page

6.4.4 Dual-Continuum Invert

6-101

6.4.5 Alternative Invert Diffusion Coefficient Models 6-101

6.4.6 Reversible Sorption of Radionuclides onto Waste Package

Corrosion Products

6.4.7 Pu Sorption from Stationary Corrosion Products and Colloids .................. 6-102

6.5 MODEL FORMULATION FOR BASE CASE MODEL ...................................... 6-102

6.5.1 Mathematical Description of Base Case Conceptual Model ..................... 6-102

6.5.1.1 EBS Flow Model ...................................................................... 6-102

6.5.1.1.1 Water Flux through a Breached Drip Shield............. 6-104

6.5.1.1.2 Breached Drip Shield Experiments ........................... 6-107

6.5.1.1.3 Water Flux through a Breached Waste Package....... 6-125

6.5.1.2 EBS Transport Model................................................................ 6-127

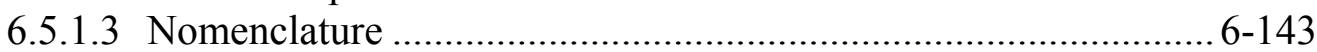

6.5.2 Base Case Model Inputs..................................................................... 6-158

6.5.2.1 Invert Diffusion Coefficient ....................................................... 6-163

6.5.2.2 Irreversible Sorption onto Iron Oxyhydroxides ........................... 6-163

6.5.2.3 Sorption Distribution Coefficients for Calculating

Invert Sorption............................................................................ 6-163

6.5.2.4 In-Package Diffusion Submodel ................................................ 6-164

6.5.2.5 EBS-UZ Boundary Condition Implementation in TSPA-LA ...... 6-164

6.5.2.5.1 Matrix and Fracture Percolation Fluxes.................... 6-165

6.5.2.5.2 Fracture Frequency ……………………………...... 6-165

6.5.2.5.3 Fracture Fraction....................................................... 6-166

6.5.2.5.4 Fracture Flow-Focusing Factor ................................. 6-166

6.5.2.5.5 Matrix Porosity ........................................................ 6-166

6.5.2.5.6 Fracture Saturation................................................ 6-166

6.5.2.5.7 Fracture Residual Saturation..................................... 6-166

6.5.2.5.8 Matrix Intrinsic Permeability and

Relative Permeability ................................................ 6-166

6.5.3 Summary of Computational Model …………........................................ 6-167

6.5.3.1 Waste Form and Waste Package Diffusion Properties.................. 6-167

6.5.3.1.1 CSNF Waste Packages Properties............................... 6-168

6.5.3.1.2 Codisposal Waste Packages Properties...................... 6-170

6.5.3.2 Calculation of Corrosion Products Mass and Saturation............... 6-172

6.5.3.3 Invert Domain Properties ……………………........................... 6-175

6.5.3.4 Irreversible Sorption onto Iron Oxyhydroxide Colloids and

Stationary Corrosion Products........................................................ 6-178

6.5.3.5 Discretization and Development of Computational Model

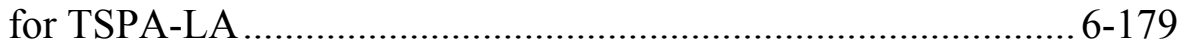

6.5.3.6 EBS-UZ Boundary Condition Implementation in TSPA-LA ...... 6-188

6.6 MODEL FORMULATION FOR ALTERNATIVE CONCEPTUAL MODELS.... 6-193

6.6.1 Bathtub Flow Model ........................................................................... 6-193

6.6.1.1 Primary Case ........................................................................ 6-194

6.6.1.1.1 Dissolution-Rate-Limited Radionuclide ................... 6-194 


\section{CONTENTS (Continued)}

Page

6.6.1.1.2 Solubility-Limited Radionuclide.............................. 6-196

6.6.1.2 Secondary Cases.... 6-197

6.6.1.2.1 Change in Inflow Rate .......................................... 6-198

6.6.1.2.2 Change in Inflow Chemistry .................................. 6-199

6.6.1.2.3 Change in Patch Geometry .................................... 6-202

6.6.1.3 Summary

6-203

6.6.2 Limited Water Vapor Diffusion Rate into Waste Package....................... 6-205

6.6.3 Limited Oxygen Diffusion Rate into Waste Package ............................... 6-212

6.6.4 Dual-Continuum Invert ................................................................... 6-214

6.6.4.1 Invert Dual Continuum Interface Transfer ................................ 6-219

6.6.4.2 Discretization of Dual-Continuum Invert Alternative

Computational Model........................................................... 6-221

6.6.4.3 Dual-Continuum EBS-UZ Boundary Condition ........................ 6-228

6.6.4.4 Verification of Dual Invert/Dual UZ Diffusive Flux Bifurcation ....................................................................... 6-228

6.6.4.5 Summary of Dual-Continuum Invert Alternative Conceptual Model ................................................................ 6-231

6.6.5 Alternative Invert Diffusion Coefficient Models................................... 6-231

6.6.5.1 Alternative Single-Continuum Invert Diffusion Coefficient Model.

6.6.5.2 Alternative Dual-Continuum Invert Diffusion Coefficient Model.................................................................... 6-236

6.6.5.3 Summary of Alternative Invert Diffusion Coefficient Conceptual Models

6.6.6 Reversible Sorption of Radionuclides onto Waste Package Corrosion Products.

6.6.7 Pu Sorption onto Stationary Corrosion Products and Colloids.................. 6-245

6.6.7.1 Yucca Mountain Project Experimental Sorption-Desorption Data for Pu.

6.6.7.2 Sorption Dependence on Solution Composition $6-261$

6.6.7.3 Summary of Alternative Conceptual Model for Pu Adsorption... 6-264

6.7 DESCRIPTION OF BARRIER CAPABILITY 6-266

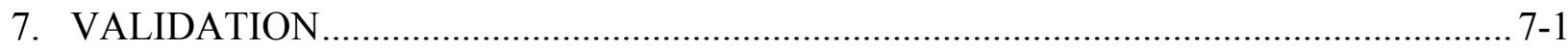

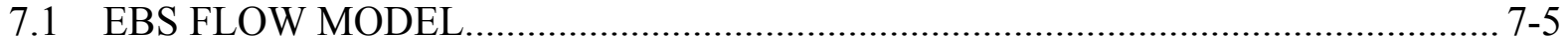

7.1.1 Flux Splitting Submodel ....................................................................... 7-6

7.1.1.1 Drip Shield Flux Splitting Submodel ......................................... 7-7

7.1.1.2 Waste Package Flux Splitting Submodel ................................... 7-14

7.1.2 Results of Independent Model Validation Technical Review of the EBS Flow Model........................................................................................ 7-19

7.2 EBS TRANSPORT MODEL …....................................................................... 7-19

7.2.1 In-Package Diffusion Submodel .......................................................... 7-20

7.2.1.1 Comparison with Electric Power Research Institute 2000 ............ 7-22

7.2.1.2 Comparison with Lee et al. 1996............................................ 7-24 


\section{CONTENTS (Continued)}

7.2.2 Invert Diffusion Submodel ............................................................. 7-26

7.2.2.1 Self-Diffusion Coefficient of Water................................................. 7-27

7.2.2.2 Modification for Porosity and Saturation ........................................ 7-31

7.2.3 Results of Independent Model Validation Technical Review of the EBS Flow and Transport Models................................................................ 7-34

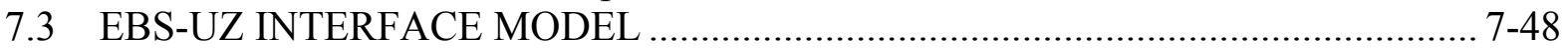

7.3.1 Validation of EBS-UZ Boundary Condition Implementation

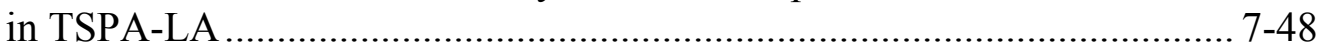

7.3.1.1 Description of Fracture-Matrix Partitioning Model ........................ 7-49

7.3.1.2 Comparison of Results from Fracture-Matrix Partitioning Model with Results from the Modified EBS RT Abstraction .......... 7-50

7.3.1.3 Applicability of EBS-UZ Interface Model in TSPA-LA in Comparison with Fracture-Matrix Partitioning Model .................. 7-52

7.3.2 Results of Independent Model Validation Technical Review of the EBS-UZ Interface Model.................................................................... 7-54

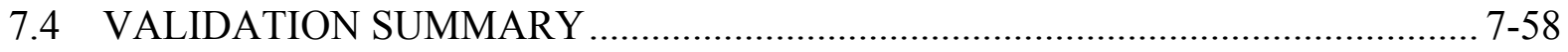

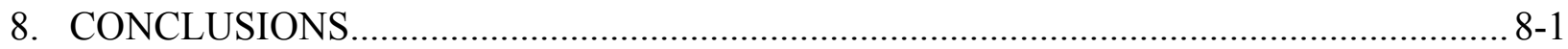

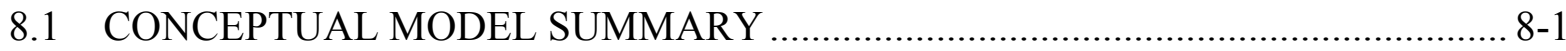

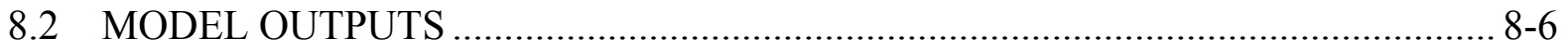

8.3 EVALUATION OF YUCCA MOUNTAIN REVIEW PLAN CRITERIA ………..... 8-21

8.4 RESTRICTIONS FOR SUBSEQUENT USE .................................................... 8-34

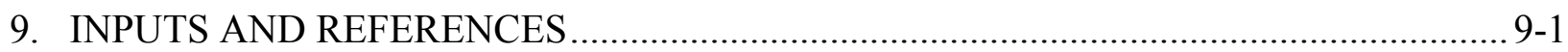

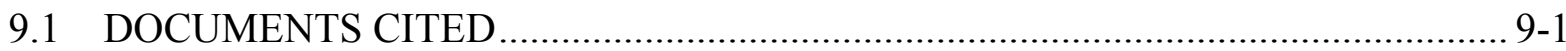

9.2 CODES, STANDARDS, REGULATIONS, AND PROCEDURES ………….......... 9-24

9.3 SOURCE DATA, LISTED BY DATA TRACKING NUMBER …………............. 9-26

9.4 OUTPUT DATA, LISTED BY DATA TRACKING NUMBER …….................... 9-28

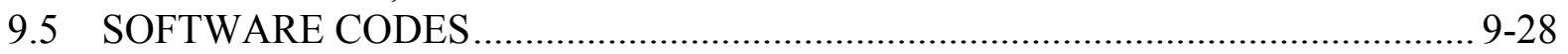

9.6 UNQUALIFIED OUTPUT DATA, LISTED BY DATA TRACKING NUMBER

APPENDIX A: MICROSOFT EXCEL SPREADSHEET “MASSES OF MATERIALS”..... A-1

APPENDIX B: IMPLEMENTATION OF RADIONUCLIDE SORPTION ONTO COLLOIDAL AND STATIONARY PHASES WITH FINITE DIFFERENCE SOLUTION

APPENDIX C: MICROSOFT EXCEL SPREADSHEET "FLUX SPLIT DRIP SHIELD MODEL"

APPENDIX D: MICROSOFT EXCEL SPREADSHEET "FLUX SPLIT WASTE PACKAGE MODEL", 
CONTENTS (Continued)

Page

APPENDIX E: MICROSOFT EXCEL SPREADSHEET "FLUX SPLITTING

VALIDATION" ........................................................................................

APPENDIX F: MICROSOFT EXCEL SPREADSHEETS

"TRANSPORT_CALC_ALL_COLLOIDS,"

"FLUX_OUT_RATIO.XLS,”AND "TIME_TO_CONV.XLS” ......................F-1

APPENDIX G: MICROSOFT EXCEL SPREADSHEET "INVERT DIFFUSION

COEFFICIENT" ................................................................................... G-1

APPENDIX H: QUALIFICATION OF DIFFUSION COEFFICIENT DATA ........................ H-1

APPENDIX I: COMPARISON OF OUTPUT DTNS ……………......................................

APPENDIX J: SORPTION DATA USED IN TSPA-LA …………………………………........ 


\section{FIGURES}

4.1-1. Dimensions of Drip Shield Mock-Up Used in Breached Drip Shield Experiments on Smooth Drip Shield Surface

6.1-1. Schematic Diagram of a Typical Emplacement Drift and the Major Components

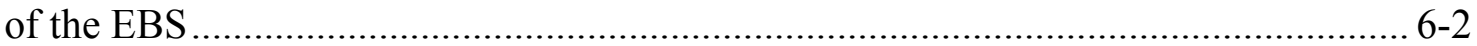

6.3-1. Schematic of the Potential Flow Pathways in the EBS .............................................. 6-6

6.3-2. Illustration of Spreading for Rivulet Flow on the Drip Shield ................................. 6-16

6.3-3. Schematic of the Dimensions for an Ellipsoidal Crack ......................................... 6-21

6.3-4. Uncertainty in the Statistical Fit for the Effective Diffusion Coefficient.................... 6-37

6.3-5. Temperature Dependence of the Invert Diffusion Coefficient

(Equation 6.3.4.1.2-4) ..................................................................................... 6-38

6.3-6. Comparison of Adsorption Isotherms for Water Vapor on $\mathrm{Fe}_{2} \mathrm{O}_{3}, \mathrm{NiO}$, and $\mathrm{ZrO}_{2} \ldots$. 6-71

6.3-7. Comparison of Adsorption Isotherms for Water Vapor on Goethite and HFO with Isotherm for Hematite....................................................................................... 6-72

6.3-8. Comparison of the Hematite Water Adsorption Isotherm with Water Adsorption Behavior of Seven Clay-Dominated Soils ............................................................... 6-74

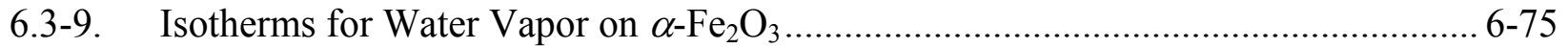

6.3-10. Water Content versus Temperature at Four Constant Suction Values ........................ 6-78

6.3-11. Total Suction versus Temperature at Six Constant Water Contents.......................... 6-79

6.3-12. Water Content (Expressed as Fraction, or $\mathrm{m}^{3} \mathrm{~m}^{-3}$ ) versus Matric Potential at $20^{\circ} \mathrm{C}$ and $80^{\circ} \mathrm{C}$ Hysteresis Curves for a Sand and a Nonwelded Tuff.....

6.3-13. Water Content (Expressed as Fraction, or $^{3} \mathrm{~m}^{-3}$ ) versus Temperature at Constant Matric Potential for a Sand and a Nonwelded Tuff..................................... 6-81

6.5-1. Geometry and Nomenclature for a Centrally Located Breach with $\ell>x \tan \alpha$...... 6-109

6.5-2. Geometry and Nomenclature for a Centrally Located Breach with $\ell<x \tan \alpha \ldots \ldots . .6-113$

6.5-3. Geometry and Nomenclature for an End-Located Breach with $\ell>x \tan \alpha$............ 6-115

6.5-4. Computational Grid in the EBS-UZ Interface Model............................................. 6-190

6.6-1. Schematic of the Bathtub Geometry for the Waste Package ..................................... 6-194

6.6-2. Schematic of the Potential Flow Pathways in the EBS ……................................ 6-216

6.6-3. Computational Grid in the EBS-UZ Interface Model (Dual-Continuum Invert) ..... 6-229

6.6-4. Relative Error of Mass-in-Place for Microsoft Excel Approximate Solution .......... 6-232

6.6-5. Comparison of Microsoft Excel and GoldSim Flux Bifurcation Solutions.............. 6-233

6.6-6. Range of the Bulk Diffusion Coefficients for Crushed Tuff ................................... 6-235

6.6-7. Desorption of Pu from Hematite (a) and Goethite (b) .......................................... 6-251

6.6-8. Reinterpretation of Lu et al. (1998 [DIRS 100946]) Desorption Data for (a) Hematite and (b) Goethite.............................................................................. 6-253

6.6-9. Two-Site Model of Painter et al. (2002 [DIRS 174071]), Fitted to Pu Sorption Data for Hematite and Goethite Using Two-Step Fitting Process of Painter et al. .. 6-258

6.6-10. Two-site model of Painter et al. (2002 [DIRS 174071]), applied to Pu sorption data for hematite and goethite, and fitted in a single step.

6.6-11. Kinetic data for Pu Adsorption onto Hematite and Goethite at $\mathrm{pH} \sim 8-8.5$ from DTN: LA0004NL831352.001 [DIRS 150272] Showing the Linear Fits to the Elovich Equation (see text). 


\section{FIGURES (Continued)}

Page

6.6-12. $\mathrm{pH}$ Dependence of $\mathrm{Pu}$ (IV) Sorption onto Goethite for the $\mathrm{pH}$ Range 2 to 5 $6-263$

6.6-13. $\mathrm{pH}$ Dependence of $\mathrm{Pu}(\mathrm{IV})$ Sorption in a Carbonate-Free System ........................... 6-264

7.1-1. Splash Radius Dependence on Number of Drips for Rough Drip Shield Tests ........ 7-10

7.2-1. Adsorption Isotherms for Water Vapor on $\alpha-\mathrm{Fe}_{2} \mathrm{O}_{3}$

7.2-2. Limiting Diffusion Coefficients for Anions and Simple (Non-Complexed) Cations

7.2-3. Comparison of EBS Radionuclide Transport Abstraction Invert Diffusion Submodel (Equation 7.2.2.2-1) with Measured Diffusion Coefficients for Tuff

7.3-1. Fracture-Matrix Partitioning for No Seepage Case 7-53 


\section{TABLES}

Page

4.1-1. Input Data for EBS RT Abstraction ................................................................ 4-1

4.1-2. Atlas Breached Drip Shield Experiments on Smooth Drip Shield Surface Dripping on Crown - Flow into Breaches ................................................................... 4-2

4.1-3. Atlas Breached Drip Shield Experiments on Smooth Drip Shield Surface Dripping on Crown - Rivulet Spread Data $-33^{\circ}$ from Crown

4.1-4. Atlas Breached Drip Shield Experiments on Smooth Drip Shield Surface Dripping on Crown - Splash Radius Tests ........................................................... 4-3

4.1-5. Atlas Breached Drip Shield Experiments on Smooth Drip Shield Surface Dripping at Off-Crown Locations - Flow into Breaches

4.1-6. Atlas Breached Drip Shield Experiments on Smooth Drip Shield Surface Dripping off Crown - Rivulet Spread Data $-33^{\circ}$ from Crown and at Transition....... 4-5

4.1-7. Parameters for EBS RT Abstraction (Established Fact) ........................................... 4-6

4.1-8. $\quad$ Parameters for EBS RT Abstraction (Project Sources) ............................................. 4-7

4.1-9. $\quad$ Parameters for EBS RT Abstraction (Various Sources) .......................................... 4-8

4.1-10. Specific Surface Areas and Adsorption Site Densities for Goethite, Hematite, and HFO................................................................................................ 4-15

4.1-11. Low- and High-Affinity Site Densities for Goethite ............................................ 4-20

4.1-12. High-Affinity Site Densities for HFO ............................................................ 4-20

4.1-13. Total Site Densities for HFO .......................................................................... 4-21

4.1-14. Elemental Composition (Weight Percent) of Waste Package Materials ................... 4-22

4.1-15. Sorption Distribution Coefficient $\left(K_{d}\right)$ Ranges on Devitrified Tuff for Unsaturated Zone Units

4.1-16. Correlations for Sampling Sorption Distribution Coefficient $\left(K_{d}\right)$ Probability Distributions for Devitrified Tuff ........................................................................ 4-23

4.1-17. Diffusion Coefficient for Granular Materials for Volumetric Moisture Content Between 1.5 and $66.3 \%$................................................................................ 4-24

4.1-18. Design Information for EBS Components........................................................ 4-28

4.1-19. Component Dimensions in a 21-PWR (Absorber Plate) Waste Package .................. 4-29

4.1-20. Masses and Numbers of Components in Waste Packages......................................... 4-29

6.2-1. Included FEPs for This Report ......................................................................... 6-5

6.3-1. Summary of Parameters for EBS Flow Pathways ................................................ 6-9

6.3-2. Summary of Transport Modes and Parameters for the EBS Transport Pathways...... 6-11

6.3-3. Calculated Gap Width for a Range of Residual Stresses at $400^{\circ} \mathrm{F}$ (Approximately $200^{\circ} \mathrm{C}$ ) in a 21-PWR Container.

6.3-4. Estimated Masses of Steels and Iron Content in Waste Packages and Equivalent Masses $(\mathrm{kg})$ of Iron Corrosion Products $\left(\mathrm{Fe}_{2} \mathrm{O}_{3}\right)$ for Use in Modeling Retardation in the Waste Package $6-48$

6.3-4a. Site Densities Conversions for Goethite ............................................................ 6-53

6.3-4b. Percentage of High-Affinity Sites for Goethite ............................................... 6-55

6.3-5. Percentage of High-Affinity Sites for HFO ...................................................... 6-57

6.3-6. Sample Ranges and Distributions Used for Irreversible Sorption on Stationary Corrosion Products 


\section{TABLES (Continued)}

Page

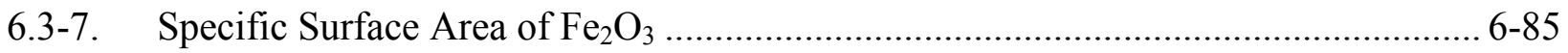

6.3-8. Specific Surface Area of Various Waste Package Corrosion Products ....................... 6-85

6.3-9. Characteristics of a 21-PWR Waste Package .......................................................... 6-86

6.3-10. Values of Effective Water Saturation and Diffusion Coefficient in Corrosion

Products from Equations 6.3.4.3.5-5 and 6.3.4.3.5-6, Respectively, over a Range of Relative Humidities for Various Specific Surface Areas and Porosities .... 6-93

6.3-11. Sorption Distribution Coefficient $\left(K_{d}\right)$ Values and Interval Probabilities Used for Reversible Radionuclide Sorption on Colloids in TSPA-LA Calculations

6.4-1. Alternative Conceptual Models Considered .............................................................. 6-98

6.5-1. Dimensions Used in the Analysis of Breached Drip Shield Experiments, Based on Dimensions Shown in Figure 4.1-1 ............................................................. 6-118

6.5-2. Comparison of Experimental Breach Inflow Fractions with Model Calculations from Appendix C.....

6.5-3. Additional Comparisons of Experimental Breach Inflow Fractions with Model Calculations from Appendix C.....

6.5-4. Water Collected in Drip Shield Experiment Q(film); Drip Location:

Patch 4, $8 \mathrm{~cm}$ Right of Center, Crown.................................................................. 6-123

6.5-5. Nomenclature.

6.5-6. Sampled Model Inputs Used in the EBS Radionuclide Transport Abstraction.

6.6-1. Summary of Release Delays Resulting from Limitations on Diffusion of Water Vapor Through Stress Corrosion Cracks

6.6-2. Summary of Transport Modes and Parameters for the EBS Transport Pathways with Dual-Continuum Invert.

6.6-3. Parameters Developed for Crushed Tuff.

6.6-4. Tuff Matrix Properties for TSw35 and TSw36.

6.6-5. Sorption Distribution Coefficient $\left(K_{d}\right)$ Ranges on Iron Oxide in Unsaturated Zone Units; All Distributions Are Uniform Except as Noted

6.6-6. Influences Over Radionuclide Sorption in Soils.

6.6-7. Summary of Partition Coefficient $\left(K_{d}\right)$ Ranges and Distributions for Retardation in the Waste Package Corrosion Products

6.6-8. Sorption of $\mathrm{Pu}(\mathrm{V})$ onto Hematite and Goethite Colloids.......................................... 6-249

6.6-9. Lu Data for Desorption of $\mathrm{Pu}(\mathrm{V})$ from Hematite and Goethite Colloids ................. 6-252

6.6-10. Lu Data for Desorption of $\mathrm{Pu}(\mathrm{V})$ from Hematite and Goethite Colloids ................. 6-254

6.6-11. Fitting Pu Sorption Data of Lu et al. (1998 [DIRS 174714]) with the Two-Site Model of Painter et al. (2002 [DIRS 174071]); Two Steps....

6.6-12. Fitting Pu Sorption Data of Lu et al. (1998 [DIRS 174714]) Using the Two-Site Model of Painter et al. (2002 [DIRS 174071]), One Step

6.6-13. $K_{d}$ Values for $\mathrm{Pu}(\mathrm{IV})$ Sorption onto Goethite 6-263

7.1-1. Atlas Breached Drip Shield Experiments on Rough Drip Shield Surface - Dripping on Crown - Splash Radius Tests.

7.1-2. Atlas Breached Drip Shield Experiments on Rough Drip Shield Surface - Dripping on Crown - Rivulet Spread Data - 33 $3^{\circ}$ from Crown .................. 7-10

7.1-3. Atlas Breached Drip Shield Experiments on Rough Drip Shield Surface - Dripping on Crown - Flow into Breaches. 


\section{TABLES (Continued)}

7.1-4. Atlas Breached Drip Shield Experiments on Rough Drip Shield Surface - Dripping on Crown - Fraction of Dripping That Flowed into Breaches and Rivulet Spread Angle 7-11

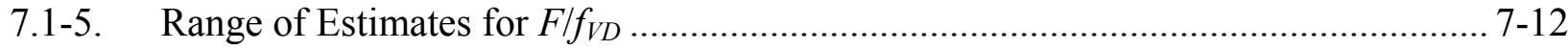

7.1-6. Comparison of $f_{\text {expt }}$ Statistics for Smooth and Rough Drip Shield Surfaces.............. 7-13

7.1-7. Summary of $f_{D S}$ and $f_{V D}$ Values.................................................................. 7-14

7.1-8. Atlas Breached Waste Package Experiments on Rough Mock-Up Surface - Dripping off Crown - Rivulet Spread Data........................................... 7-15

7.1-9. Atlas Breached Waste Package Experiments on Rough Mock-Up Surface - Dripping off Crown - Splash Radius Tests ............................................ 7-16

7.1-10. Atlas Breached Waste Package Experiments on Rough Mock-Up Surface - Dripping off Crown - Flow into Breaches ............................................ 7-17

7.1-11. Comparison of $f_{\text {expt }}$ Statistics for Smooth and Rough Surfaces .............................. 7-18

7.1-12. Summary of $f_{W P}$ and $f_{V W}$ Values................................................................. 7-18

7.2-1. Compilation of Diffusion Coefficients for Yttrium, Technetium, Molecular Iodine, and Lanthanide and Actinide Species...................................................... 7-29

7.2-2. Diffusion Coefficient of Crushed Tuff Invert Materials.......................................... 7-32

8.1-1. Summary of EBS Flow Abstraction ....................................................................... 8-3

8.1-2. Summary of EBS Transport Abstraction ................................................................. 8-5

8.2-1. Parameters for EBS Transport Abstraction .................................................... 8-7

8.2-2. Sampled Model Inputs Used in the EBS Radionuclide Transport Abstraction......... 8-12

8.2-3. Fixed Model Inputs Used in the EBS Radionuclide Transport Abstraction.............. 8-14

8.2-4. Calculated Model Inputs Used in the EBS Radionuclide Transport Abstraction....... 8-17

8.2-5. Invert Diffusion Coefficient Alternative Conceptual Model Parameters .................. 8-20

8.2-6. Calculated Model Inputs Used in the EBS Radionuclide Transport Abstraction Invert Diffusion Coefficient Alternative Conceptual Model 
INTENTIONALLY LEFT BLANK 


\section{ACRONYMS AND ABBREVIATIONS}

ASM

ASTM

BSC

BWR

CDSP

CFR

$\mathrm{CP}$

CR

CSNF

DIRS

DOE

DSNF

DTN

EBS

ECDF

EPA

EPRI

FEP

FHH

HFO

HLW

IED

LA

LA-ICP-MS

LANL

LSC

NRC

$\mathrm{RH}$

RT

SCM

SNF

SR
American Society for Metals

American Society for Testing and Materials

Bechtel SAIC Company, LLC

boiling water reactor

codisposal

Code of Federal Regulations

corrosion products

condition report

commercial spent nuclear fuel

Document Input Reference System

U.S. Department of Energy

defense spent nuclear fuel

data tracking number

engineered barrier system

empirical cumulative distribution function

U.S. Environmental Protection Agency

Electric Power Research Institute

features, events, and processes

Frenkel-Halsey-Hill adsorption isotherm equation

hydrous ferric oxide

high-level radioactive waste

information exchange drawing

license application

laser ablation coupled with inductively coupled plasma-mass spectrometry

Los Alamos National Laboratory

liquid scintillation counting

U.S. Nuclear Regulatory Commission

relative humidity

radionuclide transport

surface complexation model

spent nuclear fuel

Site Recommendation 


\section{ACRONYMS AND ABBREVIATIONS (Continued)}

TSPA total system performance assessment

TWP technical work plan

UZ unsaturated zone

WE Westinghouse Electric

YMP Yucca Mountain Project 


\section{PURPOSE}

The purpose of this report is to develop and analyze the engineered barrier system (EBS) radionuclide transport abstraction model, consistent with Level I and Level II model validation, as identified in Technical Work Plan for: Near-Field Environment and Transport: Engineered Barrier System: Radionuclide Transport Abstraction Model Report Integration (BSC 2005 [DIRS 173617]). The EBS radionuclide transport abstraction (or EBS RT Abstraction) is the conceptual model used in the total system performance assessment for the license application (TSPA-LA) to determine the rate of radionuclide releases from the EBS to the unsaturated zone (UZ).

The EBS RT Abstraction conceptual model consists of two main components: a flow model and a transport model. Both models are developed mathematically from first principles in order to show explicitly what assumptions, simplifications, and approximations are incorporated into the models used in the TSPA-LA.

The flow model defines the pathways for water flow in the EBS and specifies how the flow rate is computed in each pathway. Input to this model includes the seepage flux into a drift. The seepage flux is potentially split by the drip shield, with some (or all) of the flux being diverted by the drip shield and some passing through breaches in the drip shield that might result from corrosion or seismic damage. The flux through drip shield breaches is potentially split by the waste package, with some (or all) of the flux being diverted by the waste package and some passing through waste package breaches that might result from corrosion or seismic damage. Neither the drip shield nor the waste package survives an igneous intrusion, so the flux splitting submodel is not used in the igneous scenario class. The flow model is validated in an independent model validation technical review. The drip shield and waste package flux splitting algorithms are developed and validated using experimental data.

The transport model considers advective transport and diffusive transport from a breached waste package. Advective transport occurs when radionuclides that are dissolved or sorbed onto colloids (or both) are carried from the waste package by the portion of the seepage flux that passes through waste package breaches. Diffusive transport occurs as a result of a gradient in radionuclide concentration and may take place while advective transport is also occurring, as well as when no advective transport is occurring. Diffusive transport is addressed in detail because it is the sole means of transport when there is no flow through a waste package, which may dominate during the regulatory compliance period in the nominal and seismic scenarios. The advective transport rate, when it occurs, is generally greater than the diffusive transport rate. Colloid-facilitated advective and diffusive transport is also modeled and is presented in detail in Appendix B of this report.

Additional submodels and model parameters developed in this model report include:

- Diffusion inside a waste package. The time-dependent quantity of corrosion products inside a breached waste package is estimated; this enables the surface area available for adsorption of water to be approximated, which in turn gives the water volume through which diffusion of radionuclides may occur.

- Irreversible sorption onto stationary corrosion products in a breached waste package. 
- Diffusion in the invert, accounting for the dependence of diffusion on porosity, saturation, and temperature.

- Sorption in the invert.

- EBS-UZ interface model. Implementation in the TSPA-LA includes this model to provide a realistic concentration boundary condition.

Parameter uncertainty associated with each model and submodel is discussed. The transport model and the EBS-UZ interface model are validated using corroborative data and models as well as an independent model validation technical review.

Alternative conceptual models considered include:

- A "bathtub" flow model in which water must fill a breached waste package before any can flow out, as opposed to the flow-through model that is used

- Models that show the effect of limitations on diffusion of water vapor and oxygen into a breached waste package and consequential delays in releases of radionuclides

- A dual-continuum invert flow and transport submodel

- Alternative invert diffusion coefficient submodels

- Reversible sorption of radionuclides onto waste package corrosion products

- $\mathrm{Pu}$ sorption onto stationary corrosion products and colloids.

Output from the EBS RT Abstraction includes:

- The flow model - the algorithms for computing the flow in each flow path within the EBS, with parameter values or sources for those parameters used in the model

- The transport model - a model for advective and diffusive transport, specifying the computational procedure for both commercial spent nuclear fuel (CSNF) and codisposal waste packages in both the seep environment (where seepage into the drift and condensation on drift walls occur) and the no-seep environment (where no seepage into the drift or condensation on drift walls occurs), with parameter values or sources for those parameters used in the model

- Ranges and distributions for parameters that are uncertain and are sampled in the TSPA-LA implementation of the EBS RT Abstraction.

Changes from the previous revision:

- The corrosion products formed in the waste package are assumed to be a mixed assemblage of iron (hydr)oxides, namely hydrous ferric oxide (HFO), goethite, and hematite. These are the solid phases most likely to form from the corrosion of all internal waste package components, except for fuel rods and spent nuclear fuel (SNF), under the anticipated moist and oxidizing repository conditions. 
- The method of calculating sorption of radionuclides onto stationary corrosion products has been modified. First, reversible sorption of radionuclides onto stationary corrosion products has been eliminated from the calculation. Second, the number of sites available for irreversible sorption of $\mathrm{Pu}$ and $\mathrm{Am}$ onto stationary corrosion products has been reduced (to a range sampled in TSPA-LA calculations). These modifications were made in response to calculations that resulted in the prediction of excessive amounts of radionuclide sorption under certain conditions of waste package chemistry. The changes to the calculational method now predict that greater quantities of radionuclides remain unretarded in solution.

- Corrosion product properties used in radionuclide sorption calculations have been modified to those of goethite and HFO. These phases will likely be present along with hematite in the corrosion product assemblage in the waste package. Using the aggregate surface properties of goethite and HFO in TSPA-LA calculations of radionuclide sorption allows the implementation of a more realistic model for retardation.

- The implementation for codisposal (CDSP) waste packages in TSPA-LA has been revised. Previously, DSNF was modeled in TSPA-LA as part of the corrosion products domain, but now DSNF is modeled as a separate sub-domain as part of the waste form domain.

The scope of this abstraction and report is limited to flow and transport processes. Specifically, this report provides the algorithms that are implemented in TSPA-LA for transporting radionuclides using the flow geometry and radionuclide concentrations determined by other elements of the TSPA-LA model. The EBS RT Abstraction also identifies the important processes that are evaluated at the process level or component level using analytical or numerical solutions. Restrictions on the use of this abstraction are discussed in Section 8.4.

This report was prepared to comply with the U.S. Nuclear Regulatory Commission (NRC) rule for high-level radioactive waste (HLW), 10 CFR Part 63 [DIRS 173273], which requires the U.S. Department of Energy (DOE) to conduct a performance assessment to demonstrate compliance with postclosure performance objectives. The results from this conceptual model allow Bechtel SAIC Company, LLC (BSC) to address portions of the acceptance criteria presented in Yucca Mountain Review Plan, Final Report (NRC 2003 [DIRS 163274]).

The following reports provide input to the EBS RT Abstraction:

- Multiscale Thermohydrologic Model

- Thermal Conductivity of the Potential Repository Horizon

- Calibrated Properties Model

- UZ Flow Models and Submodels

- Radionuclide Transport Models Under Ambient Conditions 
- Analysis of Hydrologic Properties Data

- Drift-Scale Radionuclide Transport.

The following documents use output from the EBS RT Abstraction as direct input:

- In-Package Chemistry Abstraction

- Total System Performance Assessment (TSPA) Model/Analysis for the License Application. 


\section{QUALITY ASSURANCE}

Development of this model report and the supporting analyses have been determined to be subject to the Office of Civilian Radioactive Waste Management quality assurance program, as discussed in Technical Work Plan for: Near-Field Environment and Transport: Engineered Barrier System: Radionuclide Transport Abstraction Model Report Integration (BSC 2005 [DIRS 173617], Section 8). Approved quality assurance procedures identified in Section 4 of the technical work plan have been used to conduct and document the activities described in this report. Section 8 of the technical work plan also identifies the methods used to control the electronic management of data during the analysis and documentation activities.

This report provides models for evaluating the performance of the engineered barrier system, including the drip shields, waste packages, and invert, which are classified in Q-List (BSC 2005 [DIRS 174269]) as Safety Category because they are important to waste isolation, as defined in AP-2.22Q, Classification Analyses and Maintenance of the Q-List. The results of this report are important to the demonstration of compliance with the postclosure performance objectives prescribed in 10 CFR Part 63 [DIRS 173273]. The report contributes to the analysis data used to support performance assessment; the conclusions do not directly impact engineered features important to safety, as defined in AP-2.22Q. This report was prepared in accordance with LP-SIII.10Q-BSC, Models. 
INTENTIONALLY LEFT BLANK 


\section{USE OF SOFTWARE}

\subsection{MICROSOFT EXCEL}

Microsoft Excel 2002 "Add Trendline" capability was used to perform a statistical analysis of diffusion coefficient values reported in Section 6.3.4.1.1. Microsoft Excel 2002 was also used to analyze experimental data used to develop and validate the drip shield and waste package flux splitting submodels (Sections 6.5.1.1.2.4, 6.5.1.1.3, and 7.1.1). A calculation of the potential mass of corrosion products in fully degraded waste packages, summarized in Table 6.3-4, is described in Appendix A. A sample calculation to demonstrate the solution procedure used in the colloid transport model, described in Appendix B, was also carried out using Microsoft Excel 2002. A complete description of the formulas, inputs, and outputs used in the Microsoft Excel analysis of the drip shield experimental data is provided in Appendices $\mathrm{C}$ (the drip shield flux splitting submodel), D (the waste package flux splitting submodel), and E (validation of the flux splitting submodels). The formulas, inputs, and outputs used in Microsoft Excel to perform the sample colloid transport calculation are presented in Appendix F, and the invert diffusion properties model analysis is described in Appendix G.

\subsection{GOLDSIM}

GoldSim V8.01 Service Pack 1 (STN: 10344-8.01 SP1-00) (Golder Associates 2003 [DIRS 166572]) is run on Microsoft Windows 2000 on a Dell workstation with Intel Xeon processor and was developed to perform dynamic, probabilistic simulations. GoldSim V8.01 was used in accordance with LP-SI.11Q-BSC, Software Management. GoldSim calculations were done in support of validation of models developed in the EBS RT Abstraction (see Section 7.3.1). GoldSim calculations were also run to verify an alternative model implementation in Section 6.6.4.4. GoldSim V8.01 is used in these validation calculations because it is used in the TSPA-LA model. This software was obtained from Configuration Management. The use of this software was consistent with the intended use and within the range of validation of the software. The range of validation is defined by the documented functionality (i.e., requirements) and the range of acceptable input. The requirements are located in the Requirements Document for: GoldSim V8.02, Rev. No. 00, Document ID: 10344-RD-8.02-00 (DOE 2004 [DIRS 169875]). The range of acceptable inputs is element-specific. The rules for the use of each type of element are discussed in User's Guide, GoldSim Probabilistic Simulation Environment (GoldSim Technology Group 2003 [DIRS 166226]). 
INTENTIONALLY LEFT BLANK 


\section{INPUTS}

\subsection{DIRECT INPUT}

\subsubsection{Data}

Inputs in this section are used as direct input data for the models and analyses presented in Section 6. Tables 4.1-1 through 4.1-6 and Figure 4.1-1 summarize the relevant input data and the sources for these values. Data in this section are presented as found in the source documents; unit conversions and manipulation of data are not done in this section, but are performed as needed in Section 6.

Data uncertainty is addressed in Section 6. In particular, corrosion rates of carbon and stainless steels are listed in Table 6.5-6 as model input with ranges and distributions determined from the data in Table 4.1-1. The breached drip shield experimental test data in Tables 4.1-2 through 4.1-6 and Figure 4.1-1 are evaluated in Section 6.5.1, resulting in uncertain model input parameters listed in Table 6.5-6.

Table 4.1-1. Input Data for EBS RT Abstraction

\begin{tabular}{|c|c|c|c|}
\hline \multirow[b]{2}{*}{ Model Input } & \multicolumn{2}{|c|}{ Value } & \multirow[b]{2}{*}{ Source } \\
\hline & $\begin{array}{c}\text { Rate } \\
\left(\mu \mathrm{m} \mathrm{yr}^{-1}\right)\end{array}$ & ECDF & \\
\hline $\begin{array}{l}\text { Rate of corrosion of A } 516 \text { and A } 27 \\
\text { carbon steels in simulated dilute well J-13 } \\
\text { water at } 60^{\circ} \mathrm{C} \text {, long term ( } \geq 1 \mathrm{yr} \text { ); ECDF }\end{array}$ & $\begin{array}{r}65.77 \\
66.75 \\
69.84 \\
70.00 \\
71.25 \\
72.21 \\
72.64 \\
72.87 \\
72.89 \\
73.47 \\
74.29 \\
74.51 \\
74.60 \\
75.41 \\
77.31 \\
79.29 \\
80.00 \\
80.87 \\
83.26 \\
83.66 \\
83.74 \\
85.68 \\
90.97 \\
106.93\end{array}$ & $\begin{array}{l}0.042 \\
0.083 \\
0.125 \\
0.167 \\
0.208 \\
0.250 \\
0.292 \\
0.333 \\
0.375 \\
0.417 \\
0.458 \\
0.500 \\
0.542 \\
0.583 \\
0.625 \\
0.667 \\
0.708 \\
0.750 \\
0.792 \\
0.833 \\
0.875 \\
0.917 \\
0.958 \\
1.000\end{array}$ & $\begin{array}{l}\text { DTN: MO0409SPAACRWP.000 } \\
\text { [DIRS 172059], spreadsheet } \\
\text { ECDF_metals2.x/s, worksheet } \\
\text { "A516-Carbon Steel," columns B and } \\
\text { C, rows } 5 \text { through } 30\end{array}$ \\
\hline
\end{tabular}


Table 4.1-1. Input Data for EBS RT Abstraction (Continued)

\begin{tabular}{|l|c|c|c|}
\hline \multirow{2}{*}{ Model Input } & \multicolumn{2}{|c|}{ Value } & \\
\cline { 2 - 3 } & $\begin{array}{c}\text { Rate } \\
\left(\mu \mathrm{m} \mathrm{yr}^{-1}\right)\end{array}$ & ECDF & \multicolumn{2}{c|}{ Source } \\
\hline Rate of corrosion of 316L stainless steel in & 0.037 & 0.063 & DTN: MO0409SPAACRWP.000 \\
fresh water at 50-100 $\mathrm{C}$; ECDF & 0.1016 & 0.125 & [DIRS 172059], spreadsheet \\
& 0.109 & 0.188 & ECDF_metals2.x/s, worksheet \\
& 0.1524 & 0.250 & "316 ss," columns L and M, \\
& 0.154 & 0.313 & rows 5 through 15 \\
& 0.1778 & 0.375 & \\
& 0.2032 & 0.438 & \\
& 0.2286 & 0.563 & \\
& 0.254 & 0.750 & \\
& 0.2794 & 0.813 & \\
& 0.51 & 1.000 & \\
\hline
\end{tabular}

ECDF= empirical cumulative distribution function.

Table 4.1-2. Atlas Breached Drip Shield Experiments on Smooth Drip Shield Surface - Dripping on Crown - Flow into Breaches

\begin{tabular}{|c|c|c|c|c|c|}
\hline \multirow[b]{2}{*}{ Drip Location } & \multicolumn{2}{|c|}{ Water Input Mass (g) } & \multirow{2}{*}{$\begin{array}{c}\text { Breach } \\
\text { Where } \\
\text { Water Was } \\
\text { Collected }\end{array}$} & \multicolumn{2}{|c|}{ Water Collection Mass (g) } \\
\hline & Tare & Final & & Initial & Final \\
\hline \multicolumn{6}{|c|}{ Single Patch Q(film) Tests (DTN: MO0207EBSATBWP.023 [DIRS 163402]) } \\
\hline $8 \mathrm{~cm}$ right of Patch 4 centerline & -50.32 & -228.52 & B4 & 107.60 & 129.62 \\
\hline Patch 5 centerline & -12.66 & -176.40 & B5 & 109.40 & 130.52 \\
\hline $4 \mathrm{~cm}$ left of Patch 5 centerline & -210.48 & -344.27 & B5 & 109.18 & 118.28 \\
\hline Patch 4 centerline & 52.77 & -135.86 & B4 & 107.57 & 129.82 \\
\hline \multicolumn{6}{|c|}{ Multiple Patch Tests (DTN: MO0207EBSATBWP.024 [DIRS 163401]) } \\
\hline $27 \mathrm{~cm}$ right of drip shield center & -0.51 & -276.65 & B5 & 109.10 & 113.59 \\
\hline $27 \mathrm{~cm}$ left of drip shield center & 710.10 & 433.27 & B4 & 107.77 & 110.40 \\
\hline $81 \mathrm{~cm}$ left of drip shield center & 755.52 & 529.3 & B4 & 107.18 & 110.63 \\
\hline $81 \mathrm{~cm}$ right of drip shield center & 768.79 & 547.67 & B5 & 107.99 & 111.53 \\
\hline \multicolumn{6}{|c|}{ Bounding Flow Rate Tests (DTN: MO0207EBSATBWP.025 [DIRS 163403]) } \\
\hline $54 \mathrm{~cm}$ left of drip shield center & 853.83 & 516.11 & B4 & 107.35 & 153.76 \\
\hline $54 \mathrm{~cm}$ left of drip shield center & 769.21 & 680.32 & B4 & 107.73 & 115.61 \\
\hline $27 \mathrm{~cm}$ left of drip shield center & 857.57 & 524.88 & B4 & 107.22 & 110.57 \\
\hline $27 \mathrm{~cm}$ left of drip shield center & 872.20 & 771.25 & B4 & 107.00 & 107.65 \\
\hline $27 \mathrm{~cm}$ right of drip shield center & 907.84 & 529.11 & B5 & 109.81 & 112.26 \\
\hline $27 \mathrm{~cm}$ right of drip shield center ${ }^{a}$ & 782.29 & 644.57 & B5 & 109.55 & 114.00 \\
\hline
\end{tabular}

${ }^{a}$ Drip location shown incorrectly as $7 \mathrm{~cm}$ in DTN: MO0207EBSATBWP.025 [DIRS 163403]; correct value of $27 \mathrm{~cm}$ obtained from Howard 2002 [DIRS 161522], p. 33. 
Table 4.1-3. Atlas Breached Drip Shield Experiments on Smooth Drip Shield Surface - Dripping on

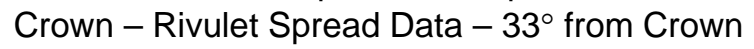

\begin{tabular}{|c|c|c|c|}
\hline Drip Location & Left $(\mathrm{cm})$ & Right (cm) & $\begin{array}{c}\text { Relevant } \\
\text { Patch }\end{array}$ \\
\hline \multicolumn{4}{|c|}{ Single Patch Q(film) Tests (DTN: MO0207EBSATBWP.023 [DIRS 163402]) } \\
\hline $8 \mathrm{~cm}$ right of Patch 4 centerline & 15.0 & 28.5 & 4 \\
\hline Patch 5 centerline & 28.0 & 0 & 5 \\
\hline $4 \mathrm{~cm}$ left of Patch 5 centerline & Not recorded & 21 & 5 \\
\hline Patch 4 centerline & 11.0 & 26.5 & 4 \\
\hline \multicolumn{4}{|c|}{ Multiple Patch Tests (DTN: MO0207EBSATBWP.024 [DIRS 163401]) } \\
\hline $27 \mathrm{~cm}$ right of drip shield center & 13.0 & 29.0 & 5 \\
\hline $27 \mathrm{~cm}$ left of drip shield center & 21.0 & 21.5 & 4 \\
\hline $81 \mathrm{~cm}$ left of drip shield center & 17.0 & 23.5 & 4 \\
\hline $81 \mathrm{~cm}$ right of drip shield center & 20.0 & 18.0 & 5 \\
\hline \multicolumn{4}{|c|}{ Bounding Flow Rate Tests (DTN: MO0207EBSATBWP.025 [DIRS 163403]) } \\
\hline $54 \mathrm{~cm}$ left of drip shield center (High Flow Rate) & 22.0 & 32.0 & 4 \\
\hline $54 \mathrm{~cm}$ left of drip shield center (Low Flow Rate) & 10.5 & 30.0 & 4 \\
\hline $27 \mathrm{~cm}$ left of drip shield center (High Flow Rate) & 24 & 19 & 4 \\
\hline $27 \mathrm{~cm}$ left of drip shield center (Low Flow Rate) & 10.0 & 8.0 & 4 \\
\hline $27 \mathrm{~cm}$ right of drip shield center (High Flow Rate) & 24.0 & 16.5 & 5 \\
\hline $27 \mathrm{~cm}$ right of drip shield center (Low Flow Rate) ${ }^{a}$ & 20.0 & 13.5 & 5 \\
\hline
\end{tabular}

${ }^{\text {a }}$ Drip location shown incorrectly as $7 \mathrm{~cm}$ in DTN: MO0207EBSATBWP.025 [DIRS 163403]; correct value of $27 \mathrm{~cm}$ obtained from Howard 2002 [DIRS 161522], p. 33.

Table 4.1-4. Atlas Breached Drip Shield Experiments on Smooth Drip Shield Surface - Dripping on Crown - Splash Radius Tests

\begin{tabular}{|c|c|c|c|}
\hline \multirow[t]{2}{*}{ No. Drips } & \multicolumn{2}{|c|}{ Splash Radius (cm) } & \multirow[t]{2}{*}{ Comments } \\
\hline & Left & Right & \\
\hline \multicolumn{4}{|c|}{ Splash Radius Test \#1 (DTN: MO0207EBSATBWP.022 [DIRS 163400]) } \\
\hline 1 & 1.6 & 1.6 & Measured at outer fringe \\
\hline 2 & 26.5 & 18.4 & Measured outer fringe \\
\hline 5 & 37.5 & 18.4 & Measured outer fringe \\
\hline 13 & 37.5 & 27.8 & Measured outer fringe \\
\hline 21 & 37.5 & 31.5 & Measured outer fringe \\
\hline 27 & 52.8 & 35.0 & Measured outer fringe \\
\hline 38 & 59.9 & 54.2 & Measured outer fringe \\
\hline 49 & 25.0 & 29.0 & Measured inner cluster \\
\hline 49 & 72.0 & 63.2 & Measured outer fringe \\
\hline 60 & 40.0 & 40.0 & Measured inner cluster \\
\hline 60 & 72.5 & 54.2 & Measured outer fringe \\
\hline 90 & 48.0 & 43.0 & Measured inner cluster \\
\hline \multicolumn{4}{|c|}{ Single Patch Q(film) Tests (DTN: MO0207EBSATBWP.023 [DIRS 163402]) } \\
\hline- & - & 54.5 & Patch 5, center, crown \\
\hline - & - & 82 & Patch 4, center, crown \\
\hline - & - & 86 & Patch $4,8 \mathrm{~cm}$ right of center, crown \\
\hline
\end{tabular}

NOTE: Dash ("-") indicates that no measurements were made. 
Table 4.1-5. Atlas Breached Drip Shield Experiments on Smooth Drip Shield Surface - Dripping at Off-Crown Locations - Flow into Breaches

\begin{tabular}{|c|c|c|c|c|c|}
\hline \multirow[b]{2}{*}{ Drip Location } & \multicolumn{2}{|c|}{ Water Input Mass (g) } & \multirow{2}{*}{$\begin{array}{c}\text { Breach } \\
\text { Where Water } \\
\text { Was } \\
\text { Collected }\end{array}$} & \multicolumn{2}{|c|}{ Water Collection Mass (g) } \\
\hline & Tare & Final & & Initial & Final \\
\hline \multicolumn{6}{|c|}{ Single Patch Q(splash) Tests (DTN: MO0207EBSATBWP.023 [DIRS 163402]) } \\
\hline Patch $5,17.5 \mathrm{~cm}$ left of center, $33^{\circ}$ & 529.45 & 439.68 & B5 & 108.57 & 108.86 \\
\hline Patch 4, center, $33^{\circ}$ & 685.41 & 548.20 & B4 & 106.86 & 216.70 \\
\hline Patch $4,17.5 \mathrm{~cm}$ right of center, $33^{\circ}$ & 670.30 & 538.88 & B4 & 106.75 & 115.71 \\
\hline Patch $4,17.5 \mathrm{~cm}$ right of center, $16.5^{\circ}$ & 667.12 & 516.36 & B4 & 106.80 & 108.59 \\
\hline Patch 4 , centerline, $16.5^{\circ}$ & 669.72 & 529.82 & B4 & 106.98 & 191.33 \\
\hline Patch $5,17.5 \mathrm{~cm}$ left of center, $16.5^{\circ}$ & 661.50 & 474.00 & B5 & 109.13 & 111.79 \\
\hline Patch $6,35.5 \mathrm{~cm}$ left of center, $16.5^{\circ}$ & 661.82 & 519.54 & B4 & 107.31 & 108.90 \\
\hline Patch 5 , centerline, $16.5^{\circ}$ & 676.13 & 551.39 & B5 & 108.60 & 199.16 \\
\hline $\begin{array}{l}\text { Patch } 6,36.5 \mathrm{~cm} \text { left of center, } \\
\text { between crown and } 16.5^{\circ}\end{array}$ & 660.40 & 531.13 & B4 & 107.60 & 113.69 \\
\hline \multicolumn{6}{|c|}{ Single Patch Q(film) Tests (DTN: MO0207EBSATBWP.023 [DIRS 163402]) } \\
\hline Patch $4,8 \mathrm{~cm}$ right of center, $16.5^{\circ}$ & -0.90 & -173.28 & B4 & 107.16 & 199.69 \\
\hline Patch $2,15 \mathrm{~cm}$ right of center, $16.5^{\circ}$ & 36.10 & -141.12 & B5 & 109.40 & 109.79 \\
\hline Patch $5,4 \mathrm{~cm}$ left of center, $16.5^{\circ}$ & -37.20 & -210.37 & B5 & 117.40 & 301.94 \\
\hline Patch $4,8 \mathrm{~cm}$ right of center, $33^{\circ}$ & 53.74 & -83.70 & B4 & 114.89 & 222.27 \\
\hline \multicolumn{6}{|c|}{ Bounding Flow Rate Tests (DTN: MO0207EBSATBWP.025 [DIRS 163403]) } \\
\hline $54 \mathrm{~cm}$ left of drip shield center, $16.5^{\circ}$ & 850.06 & 496.63 & B4 & 107.44 & 277.21 \\
\hline $54 \mathrm{~cm}$ left of drip shield center, $16.5^{\circ}$ & 822.71 & 715.70 & B4 & 107.71 & 192.26 \\
\hline $27 \mathrm{~cm}$ left of drip shield center, $16.5^{\circ}$ & 768.00 & 646.24 & B5 & 109.21 & 109.79 \\
\hline $27 \mathrm{~cm}$ left of drip shield center, $16.5^{\circ}$ & 868.59 & 498.18 & B4 & 107.27 & 110.65 \\
\hline $27 \mathrm{~cm}$ right of drip shield center, $16.5^{\circ}$ & 862.08 & 522.34 & B5 & 109.33 & 113.57 \\
\hline $27 \mathrm{~cm}$ right of drip shield center, $16.5^{\circ}$ & 808.93 & 713.52 & B5 & 109.30 & 110.41 \\
\hline $27 \mathrm{~cm}$ left of drip shield center, $33^{\circ}$ & 907.89 & 540.78 & B4 & 107.17 & 108.13 \\
\hline $27 \mathrm{~cm}$ right of drip shield center, $33^{\circ}$ & 835.68 & 518.08 & B5 & 109.94 & 113.52 \\
\hline $54 \mathrm{~cm}$ left of drip shield center, $33^{\circ}$ & 890.39 & 561.54 & B4 & 107.28 & 294.13 \\
\hline $54 \mathrm{~cm}$ left of drip shield center, $33^{\circ}$ & 685.39 & 584.26 & B4 & 107.32 & 190.42 \\
\hline $27 \mathrm{~cm}$ left of drip shield center, $33^{\circ}$ & -1.99 & -98.20 & B4 & 109.88 & 111.06 \\
\hline $27 \mathrm{~cm}$ right of drip shield center, $33^{\circ}$ & -121.69 & -217.44 & B5 & 110.83 & 110.96 \\
\hline
\end{tabular}


Table 4.1-6. Atlas Breached Drip Shield Experiments on Smooth Drip Shield Surface - Dripping off Crown - Rivulet Spread Data $-33^{\circ}$ from Crown and at Transition

\begin{tabular}{|c|c|c|c|c|}
\hline \multirow[b]{2}{*}{ Drip Location } & \multicolumn{2}{|c|}{ At $33^{\circ}$} & \multicolumn{2}{|c|}{ At Transition } \\
\hline & Right (cm) & Left (cm) & Right $(\mathrm{cm})$ & Left (cm) \\
\hline \multicolumn{5}{|c|}{ Q(film) Single Patch Tests (DTN: MO0207EBSATBWP.023 [DIRS 163402]) } \\
\hline Patch $4,8 \mathrm{~cm}$ right of patch center, $16.5^{\circ}$ & 5.5 & 3.5 & 13.5 & N/A \\
\hline Patch 2, patch center, $16.5^{\circ}$ & 7.5 & 4.5 & 19.5 & 22.0 \\
\hline Patch $2,15 \mathrm{~cm}$ right of patch center, $16.5^{\circ}$ & 11.5 & 9.0 & 18.0 & 15.0 \\
\hline Patch $5,4 \mathrm{~cm}$ left of patch center, $16.5^{\circ}$ & 8.5 & 8.5 & N/A & N/A \\
\hline \multicolumn{5}{|c|}{ Bounding Flow Rate Tests (DTN: MO0207EBSATBWP.025 [DIRS 163403]) } \\
\hline $54 \mathrm{~cm}$ left of drip shield center, $16.5^{\circ}$ & 31.0 & 46.0 & 35.0 & 46.0 \\
\hline $54 \mathrm{~cm}$ left of drip shield center, $16.5^{\circ}$ & 8.5 & 10.0 & 19.0 & 27.0 \\
\hline $27 \mathrm{~cm}$ left of drip shield center, $16.5^{\circ}$ & 6.0 & 8.0 & 17.0 & 16.0 \\
\hline $27 \mathrm{~cm}$ left of drip shield center, $16.5^{\circ}$ & 18.0 & 24.0 & 22.0 & 19.0 \\
\hline $27 \mathrm{~cm}$ right of drip shield center, $16.5^{\circ}$ & 13.0 & 27.0 & 14.0 & 23.0 \\
\hline $27 \mathrm{~cm}$ right of drip shield center, $16.5^{\circ}$ & 12.0 & 17.0 & 16.0 & 19.0 \\
\hline $27 \mathrm{~cm}$ left of drip shield center, $33^{\circ}$ & $\mathrm{N} / \mathrm{A}$ & $\mathrm{N} / \mathrm{A}$ & 11.0 & 17.0 \\
\hline $27 \mathrm{~cm}$ right of drip shield center, $33^{\circ}$ & $\mathrm{N} / \mathrm{A}$ & $\mathrm{N} / \mathrm{A}$ & 15.0 & 17.0 \\
\hline $54 \mathrm{~cm}$ left of drip shield center, $33^{\circ}$ & $N / A$ & $N / A$ & 17.0 & 17.0 \\
\hline $27 \mathrm{~cm}$ left of drip shield center, $33^{\circ}$ & $N / A$ & $N / A$ & 9.0 & 9.5 \\
\hline $27 \mathrm{~cm}$ right of drip shield center, $33^{\circ}$ & N/A & N/A & 8.5 & 10.0 \\
\hline
\end{tabular}

NOTE: $\quad$ N/A indicates that rivulet spread measurements at drop location are not applicable to this analysis.

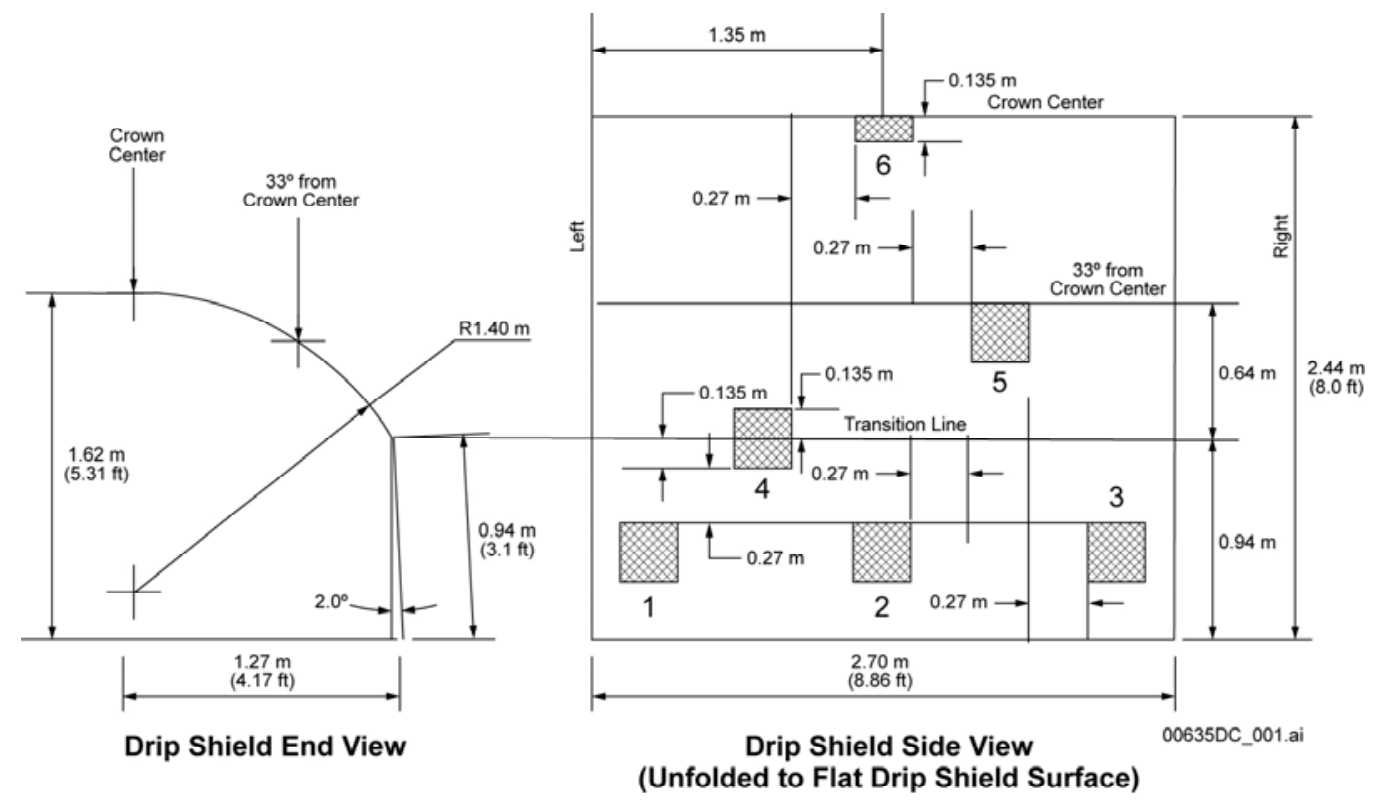

Source: Howard 2002 [DIRS 161516], p. 14.

NOTE: Figure modified from reference by labeling patches (1-6), adding labels for left and right (side view), and labeling crown center and transition lines (side view).

Figure 4.1-1. Dimensions of Drip Shield Mock-Up Used in Breached Drip Shield Experiments on Smooth Drip Shield Surface 


\subsubsection{Parameters and Other Technical Information}

Parameters in Tables 4.1-7 through 4.1-17 are used as inputs for the analyses in Section 6. Uncertainty in certain parameters is discussed in Section 6.

Parameters in Table 4.1-7 are from various editions of the CRC Handbook of Chemistry and Physics (Weast 1985 [DIRS 111561]); handbooks are established fact and are therefore justified for use in this report. Input parameters in Table 4.1-8 were developed on the Yucca Mountain Project (YMP). Input parameters in Table 4.1-9 are from various outside sources, such as journals and textbooks. A description of each parameter is given following Table 4.1-9, together with the justification for its use. These inputs thus are considered qualified for their intended use within this report.

Table 4.1-7. Parameters for EBS RT Abstraction (Established Fact)

\begin{tabular}{|c|c|c|}
\hline Model Input & Value & Source \\
\hline Avogadro's number, $N_{A}$ & $6.0221419947 \times 10^{23} \mathrm{~mol}^{-1}$ & Lide 2002 [DIRS 160832], p. 1-7 \\
\hline $\begin{array}{ll}\text { Water density: } & \text { at } 25^{\circ} \mathrm{C} \\
& \text { at } 50^{\circ} \mathrm{C}\end{array}$ & $\begin{array}{l}997.0449 \mathrm{~kg} \mathrm{~m}^{-3} \\
988.0363 \mathrm{~kg} \mathrm{~m}^{-3}\end{array}$ & Weast 1985 [DIRS 111561], p. F-5 \\
\hline Water viscosity at $25^{\circ} \mathrm{C}$ & $0.890 \mathrm{mPa}-\mathrm{s}$ & Lide 2000 [DIRS 162229], p. 6-180 \\
\hline Density of hematite $\left(\alpha-\mathrm{Fe}_{2} \mathrm{O}_{3}\right)$ & $5240 \mathrm{~kg} \mathrm{~m}^{-3}$ & Weast 1985 [DIRS 111561], p. B-104 \\
\hline Molecular weight of water $\left(\mathrm{H}_{2} \mathrm{O}\right)$ & $0.01801528 \mathrm{~kg} \mathrm{~mol}^{-1}$ & Lide 2002 [DIRS 160832], p. 6-4 \\
\hline Molecular weight of hematite $\left(\mathrm{Fe}_{2} \mathrm{O}_{3}\right)$ & $0.15969 \mathrm{~kg} \mathrm{~mol}^{-1}$ & Weast 1985 [DIRS 111561], p. B-104 \\
\hline Atomic weight of iron $(\mathrm{Fe})$ & $0.055847 \mathrm{~kg} \mathrm{~mol}^{-1}$ & Weast 1985 [DIRS 111561], p. B-102 \\
\hline Atomic weight of molybdenum (Mo) & $0.09594 \mathrm{~kg} \mathrm{~mol}^{-1}$ & Weast 1985 [DIRS 111561], p. B-116 \\
\hline Atomic weight of chromium (Cr) & $0.051996 \mathrm{~kg} \mathrm{~mol}^{-1}$ & Weast 1985 [DIRS 111561], p. B-88 \\
\hline Atomic weight of nickel (Ni) & $0.05869 \mathrm{~kg} \mathrm{~mol}^{-1}$ & Weast 1985 [DIRS 111561], p. B-118 \\
\hline Atomic weight of aluminum (Al) & $0.02698154 \mathrm{~kg} \mathrm{~mol}^{-1}$ & Weast 1985 [DIRS 111561], p. B-68 \\
\hline
\end{tabular}

NOTE: Dependence of viscosity on temperature, $T\left({ }^{\circ} \mathrm{C}\right), 20^{\circ} \mathrm{C} \leq T \leq 100^{\circ} \mathrm{C}$, reference temperature $=20^{\circ} \mathrm{C}$ (Weast and Astle 1981 [DIRS 100833], p. F-42):

$$
\log _{10}\left(\frac{\eta_{T}}{\eta_{20}}\right)=\frac{1.3272(20-T)-0.001053(T-20)^{2}}{T+105} .
$$


Table 4.1-8. Parameters for EBS RT Abstraction (Project Sources)

\begin{tabular}{|c|c|c|}
\hline Model Input & Value & Source \\
\hline $\begin{array}{l}\text { Modulus of elasticity for Alloy } \\
22 \text { at } 204^{\circ} \mathrm{C}\end{array}$ & $196 \mathrm{GPa}$ & DTN: MO0107TC239753.000 [DIRS 169973] \\
\hline $\begin{array}{l}\text { Size of patches in Breached } \\
\text { Drip Shield Experiments drip } \\
\text { shield mock-up }\end{array}$ & $0.27 \mathrm{~m} \times 0.27 \mathrm{~m}$ & Howard 2002 [DIRS 161516], p. 13 \\
\hline $\begin{array}{l}\text { Outer lid surface hoop stress } \\
\text { at depth } 0.3988 \mathrm{~mm}\end{array}$ & $385.0522 \mathrm{MPa}$ & BSC 2004 [DIRS 172203], Table 6-9 \\
\hline $\begin{array}{l}\text { Porosity of TSw35 tuff rock } \\
\text { matrix }\end{array}$ & $\begin{array}{l}0.131 \mathrm{~m}^{3} \text { pore vol. } \\
\mathrm{m}^{-3} \text { bulk vol. }\end{array}$ & $\begin{array}{l}\text { DTN: LB0207REVUZPRP.002 [DIRS 159672], } \\
\text { spreadsheet Matrix_Props.x/s, row 20, } \\
\text { column C }\end{array}$ \\
\hline $\begin{array}{l}\text { Intergranular porosity of } \\
\text { crushed tuff invert ballast }\end{array}$ & $\begin{array}{l}0.45 \mathrm{~m}^{3} \text { pore vol. } \\
\mathrm{m}^{-3} \text { bulk vol. }\end{array}$ & BSC 2005 [DIRS 173944], Appendix X \\
\hline $\begin{array}{l}\text { Unsaturated zone fracture } \\
\text { frequency for TSw35 }\end{array}$ & $\begin{array}{l}\text { Mean }=3.16 \mathrm{~m}^{-1} \\
\text { Std Dev }=2.63 \mathrm{~m}^{-1} \\
\text { Log-normal }\end{array}$ & $\begin{array}{l}\text { BSC } 2004 \text { [DIRS 170040], Appendix A, } \\
\text { Table A-1 }\end{array}$ \\
\hline $\begin{array}{l}\text { Unsaturated zone fracture } \\
\text { porosity for TSw35 }\end{array}$ & $\begin{array}{l}\text { Range: } 0-1 \\
\text { Distribution: Beta } \\
\text { Mean }=9.6 \times 10^{-3} \\
\text { Std Dev }=2.82 \times 10^{-3}\end{array}$ & $\begin{array}{l}\text { BSC } 2004 \text { [DIRS 170040], Appendix D, } \\
\text { Table D-1 }\end{array}$ \\
\hline $\begin{array}{l}\text { Unsaturated zone matrix } \\
\text { porosity for TSw35 }\end{array}$ & $\begin{array}{l}\text { Range: } 0-1 \\
\text { Distribution: Beta } \\
\text { Mean }=0.131 \\
\text { Std Dev }=0.031\end{array}$ & $\begin{array}{l}\text { BSC } 2004 \text { [DIRS 170040], Appendix D, } \\
\text { Table D-1 }\end{array}$ \\
\hline $\begin{array}{l}\text { Unsaturated zone fracture } \\
\text { saturation }\end{array}$ & $\begin{array}{l}\text { Uniform sampling from } 433 \\
\text { locations for each infiltration } \\
\text { case }\end{array}$ & $\begin{array}{l}\text { DTN: LB0307FMRADTRN.001 [DIRS 165451], } \\
\text { folder U0230_excel_files.zip, spreadsheet Flow } \\
\text { and Saturation Data from UZ Flow Model.xls, } \\
\text { column D }\end{array}$ \\
\hline $\begin{array}{l}\text { Unsaturated zone fracture } \\
\text { residual saturation }\end{array}$ & $\begin{array}{l}\text { Uniform sampling from } 433 \\
\text { locations }\end{array}$ & $\begin{array}{l}\text { DTN: LB0307FMRADTRN.001 [DIRS 165451], } \\
\text { folder U0230_excel_files.zip, spreadsheet } \\
\text { Fracture Residual Saturation.xls, column E }\end{array}$ \\
\hline $\begin{array}{l}\text { Unsaturated zone fracture } \\
\text { percolation flux }\end{array}$ & $\begin{array}{l}\text { Uniform sampling from } 433 \\
\text { locations for each infiltration } \\
\text { case }\end{array}$ & $\begin{array}{l}\text { DTN: LB0307FMRADTRN.001 [DIRS 165451], } \\
\text { folder U0230_excel_files.zip, spreadsheet Flow } \\
\text { and Saturation Data from UZ Flow Model.xIs, } \\
\text { column C }\end{array}$ \\
\hline $\begin{array}{l}\text { Unsaturated zone fracture } \\
\text { interface area }\end{array}$ & $9.68 \mathrm{~m}^{2} \mathrm{~m}^{-3}$ & $\begin{array}{l}\text { DTN: LB0205REVUZPRP.001 [DIRS 159525], } \\
\text { spreadsheet FRACTURE_PROPERTY.xIs, } \\
\text { row 20, column R }\end{array}$ \\
\hline $\begin{array}{l}\text { Unsaturated zone active } \\
\text { fracture parameter for TSw35 } \\
\text { for all three infiltration cases }\end{array}$ & $\begin{array}{l}\text { Low }=0.476 \\
\text { Mean }=0.569 \\
\text { High }=0.570\end{array}$ & $\begin{array}{l}\text { DTN: LB03013DSSCP3I.001 [DIRS 162379]; } \\
\text { BSC } 2004 \text { [DIRS 169861], Tables A-1, A-2, } \\
\text { and A-3 }\end{array}$ \\
\hline $\begin{array}{l}\text { Unsaturated zone fracture } \\
\text { aperture }\end{array}$ & $1.5 \times 10^{-4} \mathrm{~m}$ & $\begin{array}{l}\text { DTN: LB0205REVUZPRP.001 [DIRS 159525], } \\
\text { spreadsheet FRACTURE_PROPERTY.xIs, } \\
\text { row 20, column L }\end{array}$ \\
\hline $\begin{array}{l}\text { Unsaturated zone fracture } \\
\text { diffusion coefficient }\end{array}$ & $\begin{array}{l}\text { Function of matrix water } \\
\text { content and effective } \\
\text { permeability; same as matrix } \\
\text { diffusion coefficient }\end{array}$ & $\begin{array}{l}\text { BSC } 2004 \text { [DIRS 170040], Section 6.4.5, } \\
\text { p. } 6-42\end{array}$ \\
\hline $\begin{array}{l}\text { Unsaturated zone matrix } \\
\text { saturation }\end{array}$ & $\begin{array}{l}\text { Uniform sampling from } 433 \\
\text { locations for each infiltration } \\
\text { case }\end{array}$ & $\begin{array}{l}\text { DTN: LB0307FMRADTRN.001 [DIRS 165451], } \\
\text { folder U0230_excel_files.zip, spreadsheet Flow } \\
\text { and Saturation Data from UZ Flow Model.xls, } \\
\text { column G }\end{array}$ \\
\hline
\end{tabular}


Table 4.1-8. Parameters for EBS RT Abstraction (Project Sources) (Continued)

\begin{tabular}{|l|l|l|}
\hline \multicolumn{1}{|c|}{ Model Input } & \multicolumn{1}{|c|}{ Value } & \multicolumn{1}{c|}{ Source } \\
\hline $\begin{array}{l}\text { Unsaturated zone matrix } \\
\text { percolation flux }\end{array}$ & $\begin{array}{l}\text { Uniform sampling from 433 } \\
\text { locations for each infiltration } \\
\text { case }\end{array}$ & $\begin{array}{l}\text { DTN: LB0307FMRADTRN.001 [DIRS 165451], } \\
\text { folder U0230_excel_files.zip, spreadsheet Flow } \\
\text { and Saturation Data from UZ Flow Model.xIs, } \\
\text { column F }\end{array}$ \\
\hline $\begin{array}{l}\text { Unsaturated zone matrix } \\
\text { effective permeability }\end{array}$ & $\begin{array}{l}\text { Function of matrix permeability } \\
\text { and relative permeability }\end{array}$ & BSC 2004 [DIRS 170040], Equation 6-57 \\
\hline $\begin{array}{l}\text { Unsaturated zone matrix } \\
\text { permeability for TSw35 for all } \\
\text { three infiltration cases }\end{array}$ & $\begin{array}{l}\text { Low }=2.33 \times 10^{-18} \mathrm{~m}^{2} \\
\text { Mean }=4.48 \times 10^{-18} \mathrm{~m}^{2}\end{array}$ & $\begin{array}{l}\text { DTNs: LB0208UZDSCPLI.002 [DIRS 161788], } \\
\text { LB0208UZDSCPMI.002 [DIRS 161243], } \\
\text { and LB0302UZDSCPUI.002 [DIRS 161787]; } \\
\text { BSC 2004 [DIRS 170040], Table 4-6 }\end{array}$ \\
\hline $\begin{array}{l}\text { Unsaturated zone matrix } \\
\text { relative permeability }\end{array}$ & $\begin{array}{l}\text { Uniform sampling from 433 } \\
\text { locations for each infiltration } \\
\text { case }\end{array}$ & $\begin{array}{l}\text { DTN: LB0307FMRADTRN.001 [DIRS 165451], } \\
\text { folder U0230_excel_files.zip, spreadsheet Flow } \\
\text { and Saturation Data from UZ Flow Model.xIs, } \\
\text { column H }\end{array}$ \\
\hline $\begin{array}{l}\text { Unsaturated zone dry matrix } \\
\text { density for TSw35 } \\
\text { (stratigraphic unit Tptpll) }\end{array}$ & 1.9793 $\mathrm{g} \mathrm{cm}{ }^{-3}$ & $\begin{array}{l}\text { DTN: SN0404T0503102.011 [DIRS 169129], } \\
\text { file ReadMe.doc, Table 7-10 }\end{array}$ \\
\hline $\begin{array}{l}\text { Unsaturated zone fracture } \\
\text { percolation flow-focusing } \\
\text { factor }\end{array}$ & $\begin{array}{l}\text { Uniform sampling from 433 } \\
\text { locations for each infiltration } \\
\text { case }\end{array}$ & $\begin{array}{l}\text { DTN: LB0307FMRADTRN.001 [DIRS 165451], } \\
\text { folder U0230_excel_files.zip, spreadsheet } \\
\text { Fracture Flux and Water Content with Flow } \\
\text { Focusing r1.xIs, Column D }\end{array}$ \\
\hline
\end{tabular}

$\mathrm{UZ}=$ unsaturated zone.

Table 4.1-9. Parameters for EBS RT Abstraction (Various Sources)

\begin{tabular}{|c|c|c|}
\hline Model Input & Value & Source \\
\hline Self-diffusion coefficient of water at $25^{\circ} \mathrm{C}$ & $2.299 \times 10^{-9} \mathrm{~m}^{2} \mathrm{~s}^{-1}$ & Mills 1973 [DIRS 133392], Table III \\
\hline $\begin{array}{l}\text { Parameter } k \text { in } \mathrm{FHH} \text { water vapor } \\
\text { adsorption isotherm for } \mathrm{Fe}_{2} \mathrm{O}_{3}\end{array}$ & 1.1 (dimensionless) & Jurinak 1964 [DIRS 154381], p. 486 \\
\hline $\begin{array}{l}\text { Parameter } s \text { in } \mathrm{FHH} \text { water vapor } \\
\text { adsorption isotherm for } \mathrm{Fe}_{2} \mathrm{O}_{3}\end{array}$ & 2.45 (dimensionless) & Jurinak 1964 [DIRS 154381], p. 486 \\
\hline Water molecule cross-sectional area, $A_{w}$ & $10.6 \AA^{2}$ & $\begin{array}{l}\text { McCafferty and Zettlemoyer } 1970 \\
\text { [DIRS 154382], p. } 454\end{array}$ \\
\hline $\begin{array}{l}\text { Cementation factor (exponent on porosity } \\
\text { in Archie's law) }\end{array}$ & 1.3 (dimensionless) & Bear 1988 [DIRS 101379], p. 116 \\
\hline Saturation exponent in Archie's law & 2 (dimensionless) & Bear 1988 [DIRS 101379], p. 116 \\
\hline $\begin{array}{l}\text { Specific surface area of natural hematite } \\
\left(\mathrm{Fe}_{2} \mathrm{O}_{3}\right)\end{array}$ & $1.8 \mathrm{~m}^{2} \mathrm{~g}^{-1}$ & $\begin{array}{l}\text { Langmuir } 1997 \text { [DIRS 100051], Table } 10.2 \\
\text { (natural hematite) }\end{array}$ \\
\hline Specific surface area of hematite $\left(\mathrm{Fe}_{2} \mathrm{O}_{3}\right)$ & $21.4 \mathrm{~m}^{2} \mathrm{~g}^{-1}$ & Briand et al. 2001 [DIRS 161617], Table 4 \\
\hline Fuel rod outside diameter $($ WE $17 \times 17)$ & 0.374 in. & DOE 1992 [DIRS 102588], Volume 1, p. 2A-30 \\
\hline Fuel rod length $($ WE $17 \times 17)$ & $151.560 \mathrm{in.}$ & DOE 1992 [DIRS 102588], Volume 1, p. 2A-30 \\
\hline Fuel rods per assembly (WE $17 \times 17$ ) & 264 & DOE 1992 [DIRS 102588], Volume 1, p. 2A-30 \\
\hline \multicolumn{2}{|c|}{$\begin{array}{l}\text { Tuff matrix diffusion coefficient: } \\
\qquad \begin{array}{l}\log _{10} \text { Diffusion Coefficient }\left(\mathrm{cm}^{2} \mathrm{~s}^{-1}\right)=-3.49+ \\
1.38 \times \text { Porosity }+1.65 \times \log _{10} \text { Permeability }\left(\mathrm{m}^{2}\right)\end{array}\end{array}$} & $\begin{array}{l}\text { Reimus et al. } 2002 \text { [DIRS 163008], p. 2.25, } \\
\text { Equation } 2.5\end{array}$ \\
\hline
\end{tabular}

$\mathrm{FHH}=$ Frenkel-Halsey-Hill adsorption isotherm equation; WE = Westinghouse Electric; DOE = U.S. Department of Energy. 
Fuel rod dimensions-The fuel rod dimensions for assembly Westinghouse Electric (WE) $17 \times 17$ are given in Characteristics of Potential Repository Wastes (DOE 1992 [DIRS 102588]). This four-volume report is the definitive compilation of the characteristics of potential repository wastes. The concerns raised by Deficiency Report VAMO-98-D-132 (DOE 1998 [DIRS 123628]) regarding inconsistencies between data reported in Characteristics of Potential Repository Wastes (DOE 1992 [DIRS 102588]) and its data sources do not impact the data used in this analysis with regard to the WE $17 \times 17$ fuel rods; thus, these data are considered reliable and are justified as suitable for intended use in this analysis. The WE $17 \times 17$ fuel assembly is used as the representative fuel assembly because (1) Westinghouse fuel assemblies comprise a large fraction (about 21 percent) of all fuel assemblies, (2) the $17 \times 17$ configuration comprises about 34 percent of discharged fuel assemblies (Faruque 1993 [DIRS 170706]), and (3) 21-pressurized water reactor (PWR) waste packages that will contain the WE $17 \times 17$ fuel assemblies are the most common type of waste package, nominally comprising 4,299 of the 11,184 waste packages planned for the repository (BSC 2005 [DIRS 173501], Table 13).

Initial Radionuclide Inventories (BSC 2004 [DIRS 170022], Section 5.1) uses a Babcock and Wilcox Mark B PWR assembly as representative of PWR systems instead of the WE $17 \times 17$ assembly used in this analysis. Because the number and dimensions of fuel rods used in the Babcock and Wilcox Mark B differ from those of the WE $17 \times 17$ assembly, the choice of a representative assembly could impact the initial waste package void volume calculation in Section 6.3.4.3.4. The calculation in that section is used to establish an approximate upper bound on the porosity of corrosion products and to validate the value of porosity used in TSPA-LA calculations. Because the estimated bound is not used as output from this analysis, a variation of a few percentage points is of no consequence. The Babcock and Wilcox Mark B PWR assembly contains 208 fuel rods, with each rod having a length of 153.68 in. and an outside diameter of 0.430 in. (DOE 1992 [DIRS 102588], p. 2A-7). Thus, the total volume of fuel rods in 21 Babcock and Wilcox Mark B assemblies is $1.597 \mathrm{~m}^{3}$, versus $1.513 \mathrm{~m}^{3}$ in $21 \mathrm{WE} 17 \times 17$ assemblies (see Table 6.3-9). The initial porosity of a 21-PWR waste package using Babcock and Wilcox Mark B assemblies will then be 0.58, which, to two significant digits, is identical to the estimated initial porosity using WE $17 \times 17$ assemblies obtained in Section 6.3.4.3.4. Therefore, the choice of representative assembly has no impact on this analysis.

The fuel rod length is reported in Characteristics of Potential Repository Wastes (DOE 1992 [DIRS 102588], Volume 1, p. 2A-30) as ranging from 151.560 in. to 151.635 in. Because no distribution for length is given in the reference (which would give some guidance on selecting a single representative value for length) and because the range is small (less than 0.05 percent variation from minimum to maximum), the minimum length is used as representative of the range.

Water molecule cross-sectional area-The cross-sectional area of the water molecule is taken from the paper "Adsorption of Water Vapour on $\alpha-\mathrm{Fe}_{2} \mathrm{O}_{3}$ " (McCafferty and Zettlemoyer 1970 [DIRS 154382]). The paper was published in Discussions of the Faraday Society, a publication started in 1947 and continuing to this day as the Faraday Discussions under the sponsorship of the Royal Society of Chemistry. The Royal Society of Chemistry is the largest organization in Europe for advancing the chemical sciences and is supported by a network of 45,000 members 
worldwide. The McCafferty and Zettlemoyer paper is directly relevant to the Yucca Mountain repository because hematite $\left(\mathrm{Fe}_{2} \mathrm{O}_{3}\right)$ is assumed to be part of a mixed assemblage of iron oxides that comprise the corrosion products in the waste package.

The value of $10.6 \AA^{2}$ per molecule reported by McCafferty and Zettlemoyer (1970 [DIRS 154382], p. 454) is corroborated by Holmes et al. (1974 [DIRS 154379], p. 368), who also use a value of $10.6 \AA^{2}$ for the cross-sectional area of a water molecule. Jurinak (1964 [DIRS 154381]) assumes a cross-sectional area of $10.8 \AA^{2}$ for a water molecule. Gregg and Sing (1982 [DIRS 153010], p. 188) state that a "close-packed" monolayer of water corresponds to a figure of $10.5 \AA^{2}$ for the cross-sectional area of a water molecule.

Self-diffusion coefficient of water at $25^{\circ} \mathrm{C}$ - The value for the self-diffusion coefficient of water at $25^{\circ} \mathrm{C}$ is $2.299 \times 10^{-9} \mathrm{~m}^{2} \mathrm{~s}^{-1}$ and comes from the paper "Self-diffusion in Normal and Heavy Water in the Range 1-45" (Mills 1973 [DIRS 133392]) in the Journal of Physical Chemistry. The Journal of Physical Chemistry has been published since 1896. Articles are reviewed by experts in the field, so this coefficient can be considered reliable.

Parameter $k$ in Frenkel-Halsey-Hill (FHH) adsorption isotherm equation water vapor adsorption isotherm for $\mathbf{F e}_{2} \mathbf{O}_{3}$-The value of the parameter $k$ in the $\mathrm{FHH}$ water vapor adsorption isotherm for $\mathrm{Fe}_{2} \mathrm{O}_{3}$ is 1.1 and comes from the paper, "Interaction of Water with Iron and Titanium Oxide Surfaces: Goethite, Hematite, and Anatase" (Jurinak 1964 [DIRS 154381]) in the Journal of Colloid Science. The Journal of Colloid Science, now the Journal of Colloid and Interface Science, has been published since 1947 and is a refereed journal; therefore, the data in the articles can be considered reliable.

Parameter $s$ in $\mathrm{FHH}$ water vapor adsorption isotherm for $\mathrm{Fe}_{2} \mathrm{O}_{3}$ - The value of the parameter $s$ in the $\mathrm{FHH}$ water vapor adsorption isotherm for $\mathrm{Fe}_{2} \mathrm{O}_{3}$ is 2.45 and comes from the paper "Interaction of Water with Iron and Titanium Oxide Surfaces: Goethite, Hematite, and Anatase" (Jurinak 1964 [DIRS 154381]) in the Journal of Colloid Science. The Journal of Colloid Science, now the Journal of Colloid and Interface Science, has been published since 1947 and is a refereed journal; therefore, the data in the paper can be considered reliable.

Cementation factor (exponent on porosity in Archie's law) - The value of 1.3 for the porosity exponent in Archie's law for unconsolidated sand is taken from the book Dynamics of Fluids in Porous Media (Bear 1988 [DIRS 101379], p. 116). The value 1.3 is corroborated by the Handbook of Well Log Analysis for Oil and Gas Formation Evaluation (Pirson 1963 [DIRS 111477]).

Saturation exponent in Archie's law-The value 2.0 for the saturation exponent in Archie's law for unconsolidated sand is taken from the book Dynamics of Fluids in Porous Media (Bear 1988 [DIRS 101379], p. 116). The value 2.0 is corroborated by Electrical Methods in Geophysical Prospecting, Volume 10 of International Series in Electromagnetic Waves (Keller and Frischknecht 1966 [DIRS 111470]).

Specific surface area of hematite - The specific surface area (surface area per unit mass) of hematite depends on several factors, including the source of the sample (whether natural or artificial), preparation of the sample, and the measurement technique. Because in the $E B S R T$ 
Abstraction the specific surface area of hematite represents that of corrosion products, which will form under a wide range of conditions, this is a sampled parameter in TSPA-LA. The values of specific surface area of hematite in Table 4.1-9 establish lower and upper bounds of the range to be sampled. The lower bound value, for natural hematite, is provided by Langmuir (1997 [DIRS 100051]), a widely used textbook on aqueous geochemistry by a reputable, extensively published author and environmental chemistry researcher. The upper bound value is provided by a study of catalytic behavior of metal oxides (Briand et al. 2001 [DIRS 161617]) published in the Journal of Catalysis, a reputable refereed journal. Further discussion and corroboration of the range of specific surface area of hematite is provided in Section 6.3.4.3.3.

Tuff matrix diffusion coefficient correlation-The diffusion coefficient correlation for tuff matrix, used as direct input in Section 6.6.5-2 (Equation 6.6.5.2-4), was developed by Reimus et al. (2002 [DIRS 163008]). The qualification of this report and the use of the equation are given here in accordance with item 5.2.1(k) of LP-SIII.10Q-BSC: Reliability of data source; and qualifications of personnel or organizations generating the data.

The diffusion equation was developed by Reimus et al. (2002 [DIRS 163008]) at Los Alamos National Laboratory (LANL), a nationally recognized scientific institution, supported by DOE, National Nuclear Security Administration, Nevada Operations Office, as part of the Underground Test Area Project. LANL is a DOE multidisciplinary science institution managed by the University of California and is highly regarded among the scientific community for both quality and the reliability of scientific work. Scientists at LANL are among the most highly respected in their scientific fields. Furthermore, the diffusion data used in the development of Equation 6.6.5.2-4 was collected under adequate QA procedures and protocol, comparable to the YMP QA program. Thus, the data source is considered reliable, and Equation 6.6.5.2-4 is justified for its intended use as direct input in this report.

Sorption site density and specific surface area of goethite and ferrihydrite - The sorption density and specific surface area data for goethite listed in Table 4.1-10 were compiled from many laboratory studies mainly addressing the single metal sorption from aqueous solutions. The data for ferrihydrite (designated as amorphous hydrous ferric oxide [HFO] in this report) were compiled from Dzombak and Morel (1990 [DIRS 105483]). The site densities for many ferric oxyhydroxide solids have been obtained mainly through the evaluation of sorption data using models such as the Surface Complexation Model (SCM) and other similar models. Given the difficulties in obtaining site density data, this parameter is usually constrained by either fitting the experimental sorption data or just using an accepted value for metal sorption models onto certain types of solids. Site density data have been obtained experimentally from acid-base surface titration measurements assuming complete surface saturation of ionic species that sorb to the oxyhydroxide surface (Villalobos et al. 2003 [DIRS 173017]). Other approaches include estimations of surface site densities on the basis of properties of the sorbent at distinct crystal planes (see Hiemstra and Van Riemsdijk 1996 [DIRS 173023]; Pivovarov 1997 [DIRS 173714]) and tritium exchange experiments.

Since most of the estimated site density values in these sources are obtained from single metal sorption and SCM studies, competitive effects are not taken into account. The assessment of competitive sorption in multi-component systems remains a subject of ongoing research and is restricted to a limited number of studies on few metal species. Therefore, it is reasonable to say 
that the range of largest values obtained from single metal sorption studies are close to upper bound values of the sorptive capacity of the solid. The validity of this argument still needs to be proved due to the specific behavior of some metals as observed in some competitive sorption experiments. It is generally accepted that tritium exchange experiments yield the largest site densities, but these will not be considered here due their large deviation from those estimated by SCMs and their scant adoption by researchers in the field. However, it is reasonable to say that the range of site density values based mainly on SCMs captures upper and lower bounds as delineated by their overall correspondence with those obtained from theoretical or crystallographic arguments.

For the purpose of this data qualification, the gathered data on sorption site density and specific surface area in iron oxyhydroxides will be qualified on the grounds of prior uses of data and data corroboration (when possible) in accord with item 5.2.1 (k) of LP-SIII.10Q-BSC, Models. The use of data corroboration is exemplified by comparison of values from a large set of independent studies, thus establishing a valid range of site densities and specific surface areas. Therefore, this provides a valid range of values consistent with those reported for site densities and/or those often adopted in SCMs. The sorption data were obtained through extensive literature searches spanning for about 20 years, and all these sorption studies were published in peer-reviewed journals. Most site density values considered were obtained experimentally in either surface titration or metal ion sorption experiments. Theoretically-determined values are based on crystal chemistry arguments. In general, all these approaches generate data that resulted in a welldefined range of values, thus establishing minimum and maximum bounds in the data. Given the overall consistency in the experimental and modeling approaches to evaluate surface site densities, the analytical methodologies used to examine specific surface areas, and the observed range of values, these data demonstrate the properties of interest for their intended use in this report.

The evaluation of Villalobos et al. (2003 [DIRS 173017]) outlines the range of reported site densities for goethite emphasizing the differences observed from various studies, suggesting that these are probably due to the formation of polynuclear species or solid precipitation on the surface, among other factors. Even with all these differences in the observed site densities, the authors advanced qualitative arguments to suggest trends that indicate some relationship between site density and surface area. For the case of goethite, the compilation of values for this parameter indicates that minimum and maximum bounds can be established in good agreement with the range used in the evaluation of experimental data using sorption models such as SCM.

As stated above, site densities can be measured or estimated through fitting in a SCM. Christl and Kretzschmar (1999 [DIRS 173811]) investigated the effect of varying hematite surface site densities on SCM predictions of metal sorption. These authors consider the range of 2.2-16.6 sites $\mathrm{nm}^{-2}$ for the different model test cases. For acid-based titrations, they pointed out that complete surface saturation is not attained in surface titration experiments. Their modeling results indicate that full surface saturation is attained at low $\mathrm{pH}$ only for the case of low surface site density $\left(2.2\right.$ sites $\left.\mathrm{nm}^{-2}\right)$. Overall, the range of site densities from 2.2-16.6 sites nm $\mathrm{nm}^{-2}$ provides excellent model fits to their data for the cases of acid-base surface titration and of single and competitive metal sorption. For each adopted site density value in their model, there are other adjustable parameters corresponding to intrinsic stability constants for surface complexes. Again, this emphasizes the model dependency on these parameters but also outlines the range of 
surface site density values used for hematite. This range of values closely corresponds to or captures the one adopted for goethite and HFO in this model report. Christl and Kretzschmar (1999 [DIRS 173811]) observed that for competitive sorption between two metal species onto hematite, a surface site density range of $5-10$ sites $\mathrm{nm}^{-2}$ provides better fits to the data and conclude that modeling of competitive sorption could provide more helpful information to constrain surface site densities.

For the case of goethite and ferrihydrite/HFO, the same argument applies for the observed valid range of surface site densities for these phases. This is substantiated by the range of values ( 1 to 8.83 sites $\mathrm{nm}^{-2}$ ) adopted in many studies listed in Table 4.1-10, whether constrained by model fitting, acid-base titration, or just metal sorption data. This surface site density range for goethite corresponds to that given by Villalobos et al. (2003 [DIRS 173017]), not including measurements based on tritium exchange experiments that yield much larger values.

Tritium exchange measurements yield site densities that are larger than those estimated from acid-base titration or metal sorption data (Sahai and Sverjensky, 1997 [DIRS 173812]). The use of metal sorption and acid-base titration data tends to underestimate site densities due the inherent specificity of a certain ion to sorb onto particular sites of the sorbent or the inability to ionize all surface sites due to limitations on measurements at extreme pHs (Sahai and Sverjensky 1997 [DIRS 173812]). Tritium exchange is known to be the best method for estimating total site densities since it captures all exchangeable ${ }^{3} \mathrm{H}$ hydrogens coordinated with oxygens in the solid. Pivovarov (1997 [DIRS 173714]) suggested that tritium exchange data provide information on the total amount of protons on the surface but little information on those participating in the actual sorption process. For this reason, Pivovarov (1997 [DIRS 173714]) advanced a method of estimating site densities based on the crystallographic structure of the sorbent and suggested corrections to site densities derived from tritium exchange data. The result was a decrease (by an order of magnitude) relative to the experimentally determined tritium exchange values. The corrected values also fall within the range obtained from metal sorption data. Data based on this method were not considered, but the largest observed site density of between 15 and 16 sites $\mathrm{nm}^{-2}$ by Rustad et al. (1996 [DIRS 173766]) captures this upper limit corresponding to the consistent range of values observed for tritium exchange data.

Overall, the list of goethite site densities provided in Table 4.1-10 encompasses a widely adopted range of values for a broad set of specific surface areas. The observed consistency of these data values from numerous sources within the range adopted in this report and the results of the sensitivity studies by Christl and Kretzschmar (1999 [DIRS 173811], p. 2929) closely corresponding to this range render the data suitable for their intended use in the model.

Site densities for HFO are from Dzombak and Morel (1990 [DIRS 105483]), which has been referenced extensively in many sorption studies of this phase. The authors are recognized peers in the field, and, therefore, their data evaluation and resulting parameters are considered suitable for use in the YMP.

The ratio of low to high affinity sites for goethite was estimated based on the studies of Rodda et al. (1996 [DIRS 173710]), Hiemstra and Van Riemsdijk (1996 [DIRS 173023]), Christophi and Axe (2000 [DIRS 173020]), and Trivedi et al. (2001 [DIRS 173021]). In these studies, the sorption data were evaluated using Langmuir-type models, and the ratios are based 
on the assignment of low vs. high affinity site densities evaluated by the model fitting of the sorption data. Table 4.1-11 lists the ratio of low to high affinity along with the percentage of high affinity sites and sources. Overall, experimental sorption studies, along with modeling efforts focusing on competitive sorption, are scarce. Many competitive metal sorption models have been advanced in the form of Langmuir-type approaches (e.g., Rodda et al. 1996 [DIRS 173710]; Christophi and Axe (2000 [DIRS 173020]); Trivedi et al. 2001 [DIRS 173021]) and SCMs (e.g., Buerge-Weirich 2002 [DIRS 173752], and Christl and Kretzschmar 1999 [DIRS 173811]). In this report, we considered those of the Langmuir-type based on the amount of studies devoted to goethite and the reasonable results obtained in their modeling of the data. Only one value given by Hiemstra and Van Riemsdijk (1996 [DIRS 173023]) is based on crystal plane structural relations. The percentage range of high affinity sites ranges from 8.8 percent to 74 percent, which covers the range observed in four studies. Given the partial correspondence in the obtained values to define the range for the percentage of high affinity sites, these data demonstrate the properties of interest for their intended use in this report.

For HFO, the range of values for high affinity sites is taken directly from the analysis of Dzombak and Morel (1990 [DIRS 105483], Table 5.2). These data are shown in Table 4.1-10. The evaluated high-affinity site density data in Dzombak and Morel (1990) are representative of the isotherm region at which sorption is not proportional to added metal in solution (Dzombak and Morel 1990 [DIRS 105483]). The total site densities from the evaluation of Dzombak and Morel (1990) are given in Table 4.1-13. The study by Hofmann et al. (2005 [DIRS 173711]) evaluated site density based on acid-base titrations and optimized parameters for Sr sorption in their SCM. The result of the Dzombak and Morel (1990 [DIRS 105483]) examination of the compiled data indicates a reasonable degree of consistency among the values and the use of a single value to represent the site density in modeling high affinity sites. Therefore, they adopt a value of $0.005 \mathrm{~mol} / \mathrm{mol} \mathrm{Fe}$ in their work, noting that this value is close to the average of their tabulated range. These data appropriately demonstrate the parameters of interest, which are the result of a comprehensive evaluation of experimental data from multiple sources. The source from Dzombak and Morel (1990 [DIRS 105483]) is widely referenced in the sorption modeling literature and is accepted as a representative example of the application of SCM on HFO. Moreover, the two authors have published extensively on the subject of metal sorption and the use and application of SCM on metal sorption onto metal oxides. 
Table 4.1-10. Specific Surface Areas and Adsorption Site Densities for Goethite, Hematite, and HFO

\begin{tabular}{|c|c|c|c|c|c|}
\hline Substrate & $\begin{array}{c}\text { Site } \\
\text { Density }\end{array}$ & $\begin{array}{l}\text { Site Density } \\
\text { Units }\end{array}$ & $\begin{array}{l}\text { Specific } \\
\text { Surface Area } \\
\left(\mathrm{m}^{2} \mathrm{~g}^{-1}\right)\end{array}$ & Source & Comments \\
\hline Goethite & $3.28 \times 10^{-6}$ & $\mathrm{~mol} \mathrm{~m} \mathrm{~m}^{-2}$ & 55 & $\begin{array}{l}\text { Rodda et al. } 1996 \\
\text { [DIRS 173710], Table } 1\end{array}$ & $\begin{array}{l}\text { Model fitting (2-site Langmuir adsorption model for } \mathrm{Zn} \text { at } 25^{\circ} \mathrm{C} \text { ). } \\
\text { Tabulated site density denotes sum of low- and high-affinity sites: } \\
2.90 \times 10^{-6}+3.75 \times 10^{-7}=3.28 \times 10^{-6} \mathrm{~mol} \mathrm{~m} \mathrm{~m}^{-2} \text {. Site density } \\
\text { converted to sites } \mathrm{nm}^{-2} \text { in Table } 6.3-4 \mathrm{a} \text {. }\end{array}$ \\
\hline Goethite & $1.43 \times 10^{-5}$ & $\mathrm{~mol} \mathrm{~m}^{-2}$ & 55 & $\begin{array}{l}\text { Rodda et al. } 1996 \\
\text { [DIRS 173710], Table } 1\end{array}$ & $\begin{array}{l}\text { Model fitting (2-site Langmuir adsorption model for } \mathrm{Zn} \text { at } 25^{\circ} \mathrm{C} \text { ). } \\
\text { Tabulated site density denotes sum of low- and high-affinity sites: } \\
1.30 \times 10^{-5}+1.26 \times 10^{-6}=1.43 \times 10^{-5} \mathrm{~mol} \mathrm{~m} \mathrm{~m}^{-2} \text {. Site density } \\
\text { converted to sites } \mathrm{nm}^{-2} \text { in Table } 6.3-4 \mathrm{a} \text {. }\end{array}$ \\
\hline Goethite & $2.2 \times 10^{-6}$ & $\mathrm{~mol} \mathrm{~m}^{-2}$ & 55 & $\begin{array}{l}\text { Rodda et al. } 1996 \\
\text { [DIRS 173710], Table } 5\end{array}$ & $\begin{array}{l}\text { Model fitting (BET adsorption model for } \mathrm{Zn} \text { at } 25^{\circ} \mathrm{C} \text { ). Site density } \\
\text { converted to sites } \mathrm{nm}^{-2} \text { in Table } 6.3-4 \mathrm{a} \text {. }\end{array}$ \\
\hline Goethite & 6.15 & sites $\mathrm{nm}^{-2}$ & - & $\begin{array}{l}\text { Hiemstra and Van Riemsdijk } 1996 \\
\text { [DIRS 173023], p. } 498\end{array}$ & $\begin{array}{l}\text { Total site density obtained from crystal plane structural relations } \\
\text { for } 021 \text { and } 110 \text { goethite faces in corresponding proportions } \\
\text { described by Hiemstra and Van Riemsdijk } 1996 \text { [DIRS } 173023 \text { ], } \\
\text { p. } 498 \text {. The listed value of } 6.15 \text { sites } \mathrm{nm}^{-2} \text { is the total of low- and } \\
\text { high-affinity sites given by the source: } 3.45+2.7=6.15 \\
\text { sites } \mathrm{nm}^{-2} \text {. A value of } 5.92 \text { sites } \mathrm{nm}^{-2} \text { for site density is listed in } \\
\text { preliminary output DTN: SN0503T0503305.001 and used in } \\
\text { TSPA-LA; see Appendix J. }\end{array}$ \\
\hline Goethite & 8.00 & sites $\mathrm{nm}^{-2}$ & 52 & $\begin{array}{l}\text { Villalobos et al. } 2003 \\
\text { [DIRS 173017], Table } 2\end{array}$ & Calculated from maximum sorption data for $\mathrm{Pb}^{2+}$ \\
\hline Goethite & 4.90 & sites $\mathrm{nm}^{-2}$ & 45 & $\begin{array}{l}\text { Villalobos et al. } 2003 \\
\text { [DIRS 173017], Table } 2\end{array}$ & Calculated from maximum sorption data for $\mathrm{Pb}^{2+}$ \\
\hline Goethite & 7.40 & sites $\mathrm{nm}^{-2}$ & 28.5 & $\begin{array}{l}\text { Villalobos et al. } 2003 \\
\text { [DIRS 173017], Table } 2\end{array}$ & $\begin{array}{l}\text { Calculated from maximum sorption data for } \mathrm{F}^{-} \text {(assumed } \\
\text { mononuclear complex) }\end{array}$ \\
\hline Goethite & 4.60 & sites $\mathrm{nm}^{-2}$ & 32 & $\begin{array}{l}\text { Villalobos et al. } 2003 \\
\text { [DIRS 173017], Table } 2\end{array}$ & $\begin{array}{l}\text { Calculated from maximum sorption data for } \mathrm{F}^{-} \text {(assumed } \\
\text { mononuclear complex) }\end{array}$ \\
\hline Goethite & 7.20 & sites $\mathrm{nm}^{-2}$ & 30.8 & $\begin{array}{l}\text { Villalobos et al. } 2003 \\
\text { [DIRS 173017], Table } 2\end{array}$ & $\begin{array}{l}\text { Calculated from maximum sorption data for } \mathrm{F}^{-} \text {(assumed } \\
\text { mononuclear complex) }\end{array}$ \\
\hline Goethite & 3.40 & sites $\mathrm{nm}^{-2}$ & 32 & $\begin{array}{l}\text { Villalobos et al. } 2003 \\
\text { [DIRS 173017], Table } 2\end{array}$ & $\begin{array}{l}\text { Calculated from maximum sorption data for phosphate (assumed } \\
\text { binuclear) }\end{array}$ \\
\hline
\end{tabular}


Table 4.1-10. Specific Surface Areas and Adsorption Site Densities for Goethite, Hematite, and HFO (Continued)

\begin{tabular}{|c|c|c|c|c|c|}
\hline Substrate & $\begin{array}{c}\text { Site } \\
\text { Density }\end{array}$ & $\begin{array}{c}\text { Site } \\
\text { Density } \\
\text { Units }\end{array}$ & $\begin{array}{c}\text { Specific } \\
\text { Surface Area } \\
\left(\mathrm{m}^{2} \mathrm{~g}^{-1}\right)\end{array}$ & Source & Comments \\
\hline Goethite & 4.00 & sites $\mathrm{nm}^{-2}$ & 38 & $\begin{array}{l}\text { Villalobos et al. } 2003 \\
\text { [DIRS 173017], Table } 2\end{array}$ & $\begin{array}{l}\text { Calculated from maximum sorption data for phosphate (assumed } \\
\text { binuclear) }\end{array}$ \\
\hline Goethite & 6.60 & sites $\mathrm{nm}^{-2}$ & 28.5 & $\begin{array}{l}\text { Villalobos et al. } 2003 \\
\text { [DIRS 173017], Table } 2\end{array}$ & $\begin{array}{l}\text { Calculated from maximum sorption data for phosphate (assumed } \\
\text { binuclear) }\end{array}$ \\
\hline Goethite & 2.60 & sites $\mathrm{nm}^{-2}$ & 66 & $\begin{array}{l}\text { Villalobos et al. } 2003 \\
\text { [DIRS 173017], Table } 2\end{array}$ & $\begin{array}{l}\text { Calculated from maximum sorption data for oxalate (assumed } \\
\text { binuclear) }\end{array}$ \\
\hline Goethite & 2.90 & sites $\mathrm{nm}^{-2}$ & 66 & $\begin{array}{l}\text { Villalobos et al. } 2003 \\
\text { [DIRS 173017], Table } 2\end{array}$ & $\begin{array}{l}\text { Calculated from maximum sorption data for chromate (assumed } \\
\text { binuclear complex) }\end{array}$ \\
\hline Goethite & 4.20 & sites $\mathrm{nm}^{-2}$ & 105 & $\begin{array}{l}\text { Villalobos et al. } 2003 \\
\text { [DIRS 173017], Table } 2\end{array}$ & $\begin{array}{l}\text { Calculated from maximum sorption data for } \mathrm{F}^{-} \text {(assumed } \\
\text { binuclear complex) }\end{array}$ \\
\hline Goethite & 3.00 & sites $\mathrm{nm}^{-2}$ & 105 & $\begin{array}{l}\text { Villalobos et al. } 2003 \\
\text { [DIRS 173017], Table } 2\end{array}$ & $\begin{array}{l}\text { Calculated from maximum sorption data for phosphate (assumed } \\
\text { binuclear complex) }\end{array}$ \\
\hline Goethite & 2.90 & sites $\mathrm{nm}^{-2}$ & 80 & $\begin{array}{l}\text { Villalobos et al. } 2003 \\
\text { [DIRS 173017], Table } 2\end{array}$ & $\begin{array}{l}\text { Calculated from maximum sorption data for phosphate (assumed } \\
\text { binuclear complex) }\end{array}$ \\
\hline Goethite & 2.70 & sites $\mathrm{nm}^{-2}$ & 80 & $\begin{array}{l}\text { Villalobos et al. } 2003 \\
\text { [DIRS 173017], Table } 2\end{array}$ & $\begin{array}{l}\text { Calculated from maximum sorption data for citrate (assumed } \\
\text { trinuclear complex) }\end{array}$ \\
\hline Goethite & 3.30 & sites $\mathrm{nm}^{-2}$ & 81 & $\begin{array}{l}\text { Villalobos et al. } 2003 \\
\text { [DIRS 173017], Table } 2\end{array}$ & $\begin{array}{l}\text { Calculated from maximum sorption data for selenite (assumed } \\
\text { binuclear complex) }\end{array}$ \\
\hline Goethite & 3.30 & sites $\mathrm{nm}^{-2}$ & 81 & $\begin{array}{l}\text { Villalobos et al. } 2003 \\
\text { [DIRS 173017], Table } 2\end{array}$ & $\begin{array}{l}\text { Calculated from maximum sorption data for selenite (assumed } \\
\text { binuclear complex) }\end{array}$ \\
\hline Goethite & 2.60 & sites $\mathrm{nm}^{-2}$ & 81 & $\begin{array}{l}\text { Villalobos et al. } 2003 \\
\text { [DIRS 173017], Table } 2\end{array}$ & $\begin{array}{l}\text { Calculated from maximum sorption data for molybdate (assumed } \\
\text { binuclear) }\end{array}$ \\
\hline Goethite & $1.79 \times 10^{-4}$ & $\mathrm{~mol} \mathrm{~g}^{-1}$ & 55.4 & $\begin{array}{l}\text { Trivedi et al. } 2001 \\
\text { [DIRS 173021], Table } 3\end{array}$ & $\begin{array}{l}\text { Fe adsorption edges; site density converted to sites } \mathrm{nm}^{-2} \text { in } \\
\text { Table } 6.3-4 \mathrm{a}\end{array}$ \\
\hline Goethite & $4.22 \times 10^{-5}$ & $\mathrm{~mol} \mathrm{~g}^{-1}$ & 21 & $\begin{array}{l}\text { Trivedi et al. 2001 } \\
\text { [DIRS 173021], Table } 3\end{array}$ & $\begin{array}{l}\text { NiEDTA adsorption edges; site density converted to sites } \mathrm{nm}^{-2} \text { in } \\
\text { Table } 6.3-4 \mathrm{a}\end{array}$ \\
\hline Goethite & $3.54 \times 10^{-5}$ & $\mathrm{~mol} \mathrm{~g}^{-1}$ & 21 & $\begin{array}{l}\text { Trivedi et al. } 2001 \\
\text { [DIRS 173021], Table } 3\end{array}$ & $\begin{array}{l}\text { PbEDTA adsorption edges; site density converted to sites } \mathrm{nm}^{-2} \\
\text { in Table } 6.3-4 \mathrm{a}\end{array}$ \\
\hline Goethite & 1.87 & sites $\mathrm{nm}^{-2}$ & 20 & $\begin{array}{l}\text { Naveau et al. } 2005 \\
\text { [DIRS 173018], p. } 6\end{array}$ & Acid-base surface titration \\
\hline
\end{tabular}


Table 4.1-10. Specific Surface Areas and Adsorption Site Densities for Goethite, Hematite, and HFO (Continued)

\begin{tabular}{|c|c|c|c|c|c|}
\hline Substrate & $\begin{array}{c}\text { Site } \\
\text { Density }\end{array}$ & $\begin{array}{c}\text { Site Density } \\
\text { Units }\end{array}$ & $\begin{array}{c}\text { Specific } \\
\text { Surface Area } \\
\left(\mathrm{m}^{2} \mathrm{~g}^{-1}\right)\end{array}$ & Source & Comments \\
\hline Goethite & 7 & sites $\mathrm{nm}^{-2}$ & 47.5 & $\begin{array}{l}\text { Coughlin and Stone } 1995 \\
\text { [DIRS 173030], Table } 1\end{array}$ & Adopted from Hayes and Leckie 1986 [DIRS 173817] \\
\hline Goethite & 2.3 & sites $\mathrm{nm}^{-2}$ & 50 & $\begin{array}{l}\text { Grossl et al. 1997 } \\
\text { [DIRS 173032], p. } 322\end{array}$ & Chromate and arsenate adsorption isotherms \\
\hline Goethite & 2.3 & sites $\mathrm{nm}^{-2}$ & 54 & $\begin{array}{l}\text { Fendorf et al. } 1996 \text { [DIRS } \\
\text { 173034], p. } 100\end{array}$ & Assumed value \\
\hline Goethite & 1.5 & sites $\mathrm{nm}^{-2}$ & 20 & $\begin{array}{l}\text { Duc et al. } 2003 \\
\text { [DIRS 173019], Table } 2\end{array}$ & Acid-base surface titration \\
\hline Goethite & 1.66 & sites $\mathrm{nm}^{-2}$ & - & $\begin{array}{l}\text { Pivovarov 1997 } \\
\text { [DIRS 173714], Table } 1\end{array}$ & $\begin{array}{l}\text { Average of calculated site density at (110) and (120) crystal } \\
\text { planes (see Table } 1 \text { of the source) }\end{array}$ \\
\hline Goethite & 3.2 & $\mu \mathrm{mol} \mathrm{m}{ }^{-2}$ & 70 & $\begin{array}{l}\text { Gräfe et al. 2004 } \\
\text { [DIRS 173751], p. } 6561\end{array}$ & $\begin{array}{l}\text { Arsenate isotherm }(\mathrm{pH} 4) \text {; site density converted to sites } \mathrm{nm}^{-2} \text { in } \\
\text { Table 6.3-4a }\end{array}$ \\
\hline Goethite & 2.2 & $\mu \mathrm{mol} \mathrm{m} \mathrm{m}^{-2}$ & 70 & $\begin{array}{l}\text { Gräfe et al. 2004 } \\
\text { [DIRS 173751], p. } 6561\end{array}$ & $\begin{array}{l}\text { Arsenate isotherm }(\mathrm{pH} 7) \text {; site density converted to sites } \mathrm{nm}^{-2} \text { in } \\
\text { Table 6.3-4a }\end{array}$ \\
\hline Goethite & 2.20 & sites $\mathrm{nm}^{-2}$ & 35 & $\begin{array}{l}\text { Missana et al. } 2003 \\
\text { [DIRS 173759], p. } 296\end{array}$ & Acid-base surface titration \\
\hline Goethite & 6.3 & sites $\mathrm{nm}^{-2}$ & - & $\begin{array}{l}\text { Lützenkirchen et al. } 2002 \\
\text { [DIRS 173757], p. 3394, Table } 1\end{array}$ & $\begin{array}{l}\text { Acid-base surface titration; total site density for each crystal face } \\
\{001\} \text { and }\{110\} \text { for two surface groups that represent a mixture } \\
\text { of two crystallographic planes for one singly and one triply } \\
\text { coordinated surface complex on goethite: } 3.61+2.7=6.3 \\
\text { sites } \mathrm{nm}^{-2}\end{array}$ \\
\hline Goethite & $9.18 \times 10^{-6}$ & $\mathrm{~mol} \mathrm{~m}{ }^{-2}$ & 14.7 & $\begin{array}{l}\text { Müller and Sigg } 1992 \\
\text { [DIRS 173760], p } 519\end{array}$ & $\begin{array}{l}\text { Acid-base surface titration; site density converted to sites } \mathrm{nm}^{-2} \text { in } \\
\text { Table } 6.3-4 \mathrm{a}\end{array}$ \\
\hline Goethite & 1.68 & sites $\mathrm{nm}^{-2}$ & 33 & $\begin{array}{l}\text { Randall et al. } 1999 \\
\text { [DIRS 173709], Table } 1\end{array}$ & Assumed value adopted from Lövgren et al. 1990 [DIRS 173771] \\
\hline Goethite & 2.89 & sites $\mathrm{nm}^{-2}$ & 86 & $\begin{array}{l}\text { Felmy and Rustad } 1998 \\
\text { [DIRS 173708], p. } 26\end{array}$ & $\begin{array}{l}\text { Total site density calculated from crystallographic dimensions } \\
\text { assuming } 90 \% \text { for }\{110\}\left(3.0 \text { sites } \mathrm{nm}^{-2}\right) \text { and } 10 \% \text { for }\{021\}(1.86 \\
\left.\text { sites } \mathrm{nm}^{-2}\right) \text { planes: }\left(0.9^{\star} 3.0\right)+\left(0.1^{\star} 1.86\right)=2.89 \text { sites } \mathrm{nm}^{-2}\end{array}$ \\
\hline Goethite & 3.13 & sites $\mathrm{nm}^{-2}$ & 20 & $\begin{array}{l}\text { Hongshao and Stanforth } 2001 \\
\text { [DIRS 173754], p. } 4754\end{array}$ & Assumed value \\
\hline Goethite & 2.3 & sites $\mathrm{nm}^{-2}$ & 21.4 & $\begin{array}{l}\text { Buerge-Weirich et al. } 2002 \\
\text { [DIRS 173752], p. } 329\end{array}$ & Estimated (no specific information given in the source) \\
\hline Goethite & 6.31 & sites $\mathrm{nm}^{-2}$ & 37 & $\begin{array}{l}\text { Boily et al. } 2001 \\
\text { [DIRS 173707], Table } 3\end{array}$ & $\begin{array}{l}\text { Total site density estimated from crystallographic data at three } \\
\text { different crystal planes }\end{array}$ \\
\hline
\end{tabular}


Table 4.1-10. Specific Surface Areas and Adsorption Site Densities for Goethite, Hematite, and HFO (Continued)

\begin{tabular}{|c|c|c|c|c|c|}
\hline Substrate & $\begin{array}{c}\text { Site } \\
\text { Density }\end{array}$ & $\begin{array}{l}\text { Site Density } \\
\text { Units }\end{array}$ & $\begin{array}{c}\text { Specific } \\
\text { Surface Area } \\
\left(\mathrm{m}^{2} \mathrm{~g}^{-1}\right)\end{array}$ & Source & Comments \\
\hline Goethite & 6.31 & sites $\mathrm{nm}^{-2}$ & 85 & $\begin{array}{l}\text { Boily et al. 2001 } \\
\text { [DIRS 173707], Table } 3\end{array}$ & $\begin{array}{l}\text { Total site density estimated from crystallographic data at three } \\
\text { different crystal planes }\end{array}$ \\
\hline Goethite & 2.31 & sites $\mathrm{nm}^{-2}$ & 49 & $\begin{array}{l}\text { Robertson and Leckie } 1997 \\
\text { [DIRS 173763], Table } 4\end{array}$ & Range obtained from SCMs sensitivity analyses \\
\hline Goethite & 8.38 & sites $\mathrm{nm}^{-2}$ & 49 & $\begin{array}{l}\text { Robertson and Leckie } 1997 \\
\text { [DIRS 173763], Table } 4\end{array}$ & $\begin{array}{l}\text { Range obtained from SCMs sensitivity analyses. } \\
\text { A value of } 8.83 \text { sites } \mathrm{nm}^{-2} \text { for site density is listed in preliminary } \\
\text { output DTN: SN0503T0503305.001 and used in TSPA-LA; see } \\
\text { Appendix J. }\end{array}$ \\
\hline Goethite & 8.16 & sites $\mathrm{nm}^{-2}$ & 49 & $\begin{array}{l}\text { Robertson and Leckie } 1997 \\
\text { [DIRS 173763], Table } 4\end{array}$ & Range obtained from SCMs sensitivity analyses \\
\hline Goethite & 1.68 & sites $\mathrm{nm}^{-2}$ & 39.9 & $\begin{array}{l}\text { Lövgren et al. } 1990 \\
\text { [DIRS 173771], p. } 1303\end{array}$ & Acid-base surface titration \\
\hline Goethite & 2.3 & sites $\mathrm{nm}^{-2}$ & 45 & $\begin{array}{l}\text { van Geen et al. } 1994 \\
\text { [DIRS 144702], Table } 1\end{array}$ & $\begin{array}{l}\text { Adopted value is the same as that given by Davis } \\
\text { and Kent (1990 [DIRS 143280]) and Dzombak and Morel } \\
\text { (1990 [DIRS 105483]) }\end{array}$ \\
\hline Goethite & 1.7 & sites $\mathrm{nm}^{-2}$ & 43 & $\begin{array}{l}\text { Persson et al. } 1998 \\
\text { [DIRS 173762], p. } 261\end{array}$ & Acid-base surface titration \\
\hline Goethite & 5 & sites $\mathrm{nm}^{-2}$ & 110 & $\begin{array}{l}\text { Davis and Upadhyaya } 1996 \\
\text { [DIRS 173743], p. } 1895\end{array}$ & Assumed value based on Stumm 1992 [DIRS 141778] \\
\hline Goethite & 4.84 & sites $\mathrm{nm}^{-2}$ & 64.3 & $\begin{array}{l}\text { Xue and Traina } 1996 \\
\text { [DIRS 173713], p. } 3163\end{array}$ & $\begin{array}{l}\text { Calculated value from the smallest average for constant } \\
\text { capacitance model (CCM) }\end{array}$ \\
\hline
\end{tabular}


Table 4.1-10. Specific Surface Areas and Adsorption Site Densities for Goethite, Hematite, and HFO (Continued)

\begin{tabular}{|c|c|c|c|c|c|}
\hline Substrate & $\begin{array}{c}\text { Site } \\
\text { Density }\end{array}$ & $\begin{array}{l}\text { Site Density } \\
\text { Units }\end{array}$ & $\begin{array}{c}\text { Specific } \\
\text { Surface Area } \\
\left(\mathrm{m}^{2} \mathrm{~g}^{-1}\right)\end{array}$ & Source & Comments \\
\hline Goethite & 140 & $\mu \mathrm{mol} \mathrm{g}^{-1}$ & 33 & $\begin{array}{l}\text { Hansmann and Anderson } 1985 \\
\text { [DIRS 173742], p. } 547\end{array}$ & $\begin{array}{l}\text { Maximum theoretical value estimated from crystal morphology; } \\
\text { site density converted to sites } \mathrm{nm}^{-2} \text { in Table 6.3-4a }\end{array}$ \\
\hline Goethite & 80 & $\mu \mathrm{mol} \mathrm{g}^{-1}$ & 33 & $\begin{array}{l}\text { Hansmann and Anderson } 1985 \\
\text { [DIRS 173742], p. } 547\end{array}$ & $\begin{array}{l}\text { Estimated from maximum sorption data for selenite; site density } \\
\text { converted to sites } \mathrm{nm}^{-2} \text { in Table } 6.3-4 \mathrm{a}\end{array}$ \\
\hline Goethite & 0.31 & $\mathrm{mmol} \mathrm{g}^{-1}$ & 80.5 & $\begin{array}{l}\text { Gabriel et al. } 1998 \\
\text { [DIRS 130407], pp. 124, } 126\end{array}$ & Uranyl adsorption SCM \\
\hline HFO & 4.00 & sites $\mathrm{nm}^{-2}$ & 600 & $\begin{array}{l}\text { Hofmann et al. } 2005 \\
\text { [DIRS 173711], Table } 2\end{array}$ & Acid-base surface titration \\
\hline
\end{tabular}


Table 4.1-11. Low- and High-Affinity Site Densities for Goethite

\begin{tabular}{|c|c|c|c|}
\hline $\begin{array}{l}\text { Low-Affinity } \\
\text { Site Density }\end{array}$ & $\begin{array}{l}\text { High-Affinity } \\
\text { Site Density }\end{array}$ & $\begin{array}{c}\text { Site Density } \\
\text { Units }\end{array}$ & Source \\
\hline $7.70 \times 10^{-7}$ & $2.52 \times 10^{-7}$ & $\mathrm{~mol} \mathrm{~m}^{-2}$ & Rodda et al. 1996 [DIRS 173710], Table 1 \\
\hline $2.90 \times 10^{-6}$ & $3.75 \times 10^{-7}$ & $\mathrm{~mol} \mathrm{~m}^{-2}$ & Rodda et al. 1996 [DIRS 173710], Table 1 \\
\hline $1.30 \times 10^{-5}$ & $1.26 \times 10^{-6}$ & $\mathrm{~mol} \mathrm{~m}^{-2}$ & Rodda et al. 1996 [DIRS 173710], Table 1 \\
\hline $1.00 \times 10^{-6}$ & $1.41 \times 10^{-7}$ & $\mathrm{~mol} \mathrm{~m}^{-2}$ & Rodda et al. 1996 [DIRS 173710], Table 1 \\
\hline 3.45 & 2.7 & sites $\mathrm{nm}^{-2}$ & Hiemstra and Van Riemsdijk 1996 [DIRS 173023], p. 498 \\
\hline $2.40 \times 10^{-5}$ & $8.80 \times 10^{-6}$ & $\mathrm{~mol} \mathrm{~g}^{-1}$ & Christophi and Axe 2000 [DIRS 173020], Table 5 \\
\hline $7.50 \times 10^{-6}$ & $7.40 \times 10^{-6}$ & $\mathrm{~mol} \mathrm{~g}^{-1}$ & Christophi and Axe 2000 [DIRS 173020], Table 5 \\
\hline $2.40 \times 10^{-6}$ & $6.80 \times 10^{-6}$ & $\mathrm{~mol} \mathrm{~g}^{-1}$ & Christophi and Axe 2000 [DIRS 173020], Table 5 \\
\hline $3.47 \times 10^{-5}$ & $1.04 \times 10^{-5}$ & $\mathrm{~mol} \mathrm{~g}^{-1}$ & Trivedi et al. 2001 [DIRS 173021], Table 3 \\
\hline $3.88 \times 10^{-5}$ & $1.14 \times 10^{-5}$ & $\mathrm{~mol} \mathrm{~g}^{-1}$ & Trivedi et al. 2001 [DIRS 173021], Table 3 \\
\hline
\end{tabular}

Table 4.1-12. High-Affinity Site Densities for HFO

\begin{tabular}{|c|}
\hline $\begin{array}{c}\text { High-Affinity Site Density } \\
\text { (mol Sites/mol Fe) }\end{array}$ \\
\hline 0.005 \\
\hline 0.003 \\
\hline 0.01 \\
\hline 0.002 \\
\hline 0.002 \\
\hline 0.005 \\
\hline 0.002 \\
\hline 0.001 \\
\hline 0.005 \\
\hline 0.001 \\
\hline 0.002 \\
\hline 0.003 \\
\hline 0.007 \\
\hline 0.005 \\
\hline 0.01 \\
\hline 0.001 \\
\hline 0.003 \\
\hline 0.005 \\
\hline 0.001 \\
\hline 0.005 \\
\hline 0.001 \\
\hline 0.005 \\
\hline
\end{tabular}

Source: Dzombak and Morel 1990 [DIRS 105483], Table 5.2.

NOTE: Data compiled from various metal sorption isotherms; specific surface area $=600 \mathrm{~m}^{2} \mathrm{~g}^{-1}$. These data are for high-affinity cation binding sites corresponding to the trend where the measured sorption density becomes nearly independent from the dissolved metal concentration. 
Table 4.1-13. Total Site Densities for HFO

\begin{tabular}{|c|}
\hline $\begin{array}{c}\text { Total Site Density } \\
\text { (mol sites/mol Fe) }\end{array}$ \\
\hline 0.2 \\
\hline 0.1 \\
\hline 0.2 \\
\hline 0.2 \\
\hline 0.18 \\
\hline 0.23 \\
\hline 0.24 \\
\hline 0.14 \\
\hline 0.2 \\
\hline 0.15 \\
\hline 0.2 \\
\hline 0.5 \\
\hline 0.15 \\
\hline 0.16 \\
\hline 0.05 \\
\hline 0.18 \\
\hline 0.1 \\
\hline 0.13 \\
\hline
\end{tabular}

Source: Dzombak and Morel 1990 [DIRS 105483], Table 5.3.

NOTE: Data compiled from various metal sorption isotherms; specific surface area $=600 \mathrm{~m}^{2} \mathrm{~g}^{-1}$. These data were retrieved from metal sorption maxima.

The elemental composition of metals in a CSNF waste package is given in Table 4.1-14. The composition is used in Section 6.3.4.2.3.1 to calculate the mass of corrosion products in a waste package. The sources for these data are ASTM standard specifications for manufacturing the metals (in the case of 316 stainless steel and A 516 carbon steel, as given in DTNs: MO0003RIB00076.000 [DIRS 153044] and MO0107TC240032.000 [DIRS 169970], respectively), manufacturer's specifications (in the case of Neutronit A 978; Kügler 1991 [DIRS 155761]), and the American Society for Metals (ASM) properties handbook (in the case of aluminum 6061; ASM 1979 [DIRS 154085]). ASTM standards and the ASM handbook are established fact and are therefore justified for use in this report. The Neutronit specifications, as vendor data, are also justified for use in this report. 
Table 4.1-14. Elemental Composition (Weight Percent) of Waste Package Materials

\begin{tabular}{|c|c|c|c|c|}
\hline Element & 316 Stainless Steel $^{a}$ & A 516 Carbon Steel $^{b}$ & Neutronit A $978^{c}$ & Aluminum $6061^{d}$ \\
\hline $\mathrm{Fe}$ & Balance & Balance & Balance & 0.7 \\
\hline Mo & 3.00 & - & 2.2 & - \\
\hline $\mathrm{Cr}$ & 18.00 & - & 18.5 & 0.35 \\
\hline $\mathrm{Ni}$ & 14.00 & - & 13.0 & - \\
\hline $\mathrm{Al}$ & - & - & - & Remainder \\
\hline $\mathrm{Co}$ & - & - & 0.20 & - \\
\hline W & - & - & - & - \\
\hline $\mathrm{Mn}$ & 2.00 & 1.30 & - & 0.15 \\
\hline $\mathrm{C}$ & 0.08 & 0.26 & 0.04 & - \\
\hline $\mathrm{P}$ & 0.045 & 0.035 & - & - \\
\hline $\mathrm{S}$ & 0.030 & 0.035 & - & - \\
\hline $\mathrm{Si}$ & 0.75 & - & - & 0.8 \\
\hline $\mathrm{N}$ & 0.16 & - & - & - \\
\hline $\mathrm{Cu}$ & - & - & - & 0.4 \\
\hline $\mathrm{Mg}$ & - & - & - & 1.2 \\
\hline $\mathrm{Zn}$ & - & - & - & 0.25 \\
\hline $\mathrm{Ti}$ & - & - & - & 0.15 \\
\hline $\mathrm{V}$ & - & - & - & - \\
\hline Residuals & - & - & - & 0.15 \\
\hline
\end{tabular}

NOTES: "--" indicates that the alloy chemical composition specification does not include this element. Compositions listed are the maximum specified for each element in the data source. "Balance" and "Remainder" are specified in the data source for the principal component of the alloy.

${ }^{a}$ DTN: MO0003RIB00076.000 [DIRS 153044].

${ }^{\mathrm{b}}$ DTN: MO0107TC240032.000 [DIRS 169970].

${ }^{c}$ Kügler 1991 [DIRS 155761], p. 15 (vendor-supplied data).

${ }^{d}$ ASM 1979 [DIRS 154085], p. 115.

Input values for sorption distribution coefficient $\left(K_{d}\right)$ ranges on devitrified tuff for unsaturated zone units are listed in Table 4.1-15. These data are used for calculating retardation in the invert. The data are appropriate for this use because the crushed tuff to be used in the invert is the same material that is mined from the drifts when the repository is constructed. The repository will be located primarily in the TSw35 horizon in which the host rock is devitrified tuff. These sorption distribution coefficient data are correlated using the correlation matrix in Table 4.1-16.

Diffusion coefficient data for granular materials are listed in Table 4.1-17. These data are used to develop an effective diffusion coefficient for the invert in Section 6.3.4.1.1. The data are qualified for use in this report in Appendix H. 
Table 4.1-15. Sorption Distribution Coefficient $\left(K_{d}\right)$ Ranges on Devitrified Tuff for Unsaturated Zone Units

\begin{tabular}{|c|l|l|}
\hline Species $^{\mathbf{a}}$ & Distribution Type & \multicolumn{1}{c|}{ Coefficients Describing Distribution $^{\mathbf{b}}$} \\
\hline $\mathrm{U}$ & Cumulative & $(0,0)(0.2,0.5)(4 ., 1.0)$ \\
\hline $\mathrm{Np}$ & Cumulative & $(0,0)(0.5,0.5)(6 ., 1.0)$ \\
\hline $\mathrm{Pu}$ & Cumulative & $(10 ., 0)(70 ., 0.5)(200 ., 1.0)$ \\
\hline $\mathrm{Am}$ & Truncated Normal & $\begin{array}{l}\text { Range }=1,000-10,000 \mathrm{ml} \mathrm{g}^{-1} \\
\text { Mean }=5,500 \mathrm{ml} \mathrm{g}^{-1} \\
\text { Std. Dev. }=1500 \mathrm{ml} \mathrm{g}^{-1}\end{array}$ \\
\hline $\mathrm{Pa}$ & Truncated Normal & $\begin{array}{l}\text { Range }=1,000-10,000 \mathrm{ml} \mathrm{g}^{-1} \\
\text { Mean }=5,500 \mathrm{ml} \mathrm{g}^{-1} \\
\text { Std. Dev. }=1,500 \mathrm{ml} \mathrm{g}^{-1}\end{array}$ \\
\hline $\mathrm{Cs}$ & Uniform & $1-15 \mathrm{ml} \mathrm{g}$ \\
\hline $\mathrm{Sr}$ & Uniform & $10-70 \mathrm{ml} \mathrm{g}^{-1}$ \\
\hline $\mathrm{Ra}$ & Uniform & $100-1,000 \mathrm{ml} \mathrm{g}^{-1}$ \\
\hline $\mathrm{Th}$ & Uniform & $1,000-10,000 \mathrm{ml} \mathrm{g}^{-1}$ \\
\hline
\end{tabular}

a DTN: LA0408AM831341.001 [DIRS 171584].

${ }^{\mathrm{b}}$ For cumulative distribution: $\left(K_{d}\right.$ value, $\mathrm{ml} \mathrm{g}^{-1}$; probability) and for uniform distribution: $K_{d}$ range.

Table 4.1-16. Correlations for Sampling Sorption Distribution Coefficient $\left(K_{d}\right)$ Probability Distributions for Devitrified Tuff

\begin{tabular}{|c|c|c|c|c|c|c|c|c|c|}
\hline Element & $\mathbf{A m}$ & $\mathbf{C s}$ & $\mathbf{N p}$ & $\mathbf{P a}$ & $\mathbf{P u}$ & $\mathbf{R a}$ & $\mathbf{S r}$ & $\mathbf{T h}$ & $\mathbf{U}$ \\
\hline $\mathrm{Am}$ & 100 & - & - & - & - & - & - & - & - \\
\hline $\mathrm{Cs}$ & 0 & 100 & - & - & - & - & - & - & - \\
\hline $\mathrm{Np}$ & 25 & 0 & 100 & - & - & - & - & - & - \\
\hline $\mathrm{Pa}$ & 75 & 0 & 0 & 100 & - & - & - & - & - \\
\hline $\mathrm{Pu}$ & 10 & 0 & 10 & 0 & 100 & - & - & - & - \\
\hline $\mathrm{Ra}$ & 0 & 100 & 0 & 0 & 0 & 100 & - & - & - \\
\hline $\mathrm{Sr}$ & 0 & 25 & 50 & 0 & 0 & 25 & 100 & - & - \\
\hline $\mathrm{Th}$ & 0 & 0 & 50 & 0 & 0 & 0 & 75 & 100 & - \\
\hline $\mathrm{U}$ & 0 & 0 & 0 & 0 & 0 & 0 & 0 & 0 & 100 \\
\hline
\end{tabular}

DTN: LA0311AM831341.001 [DIRS 167015]. 
Table 4.1-17. Diffusion Coefficient for Granular Materials for Volumetric Moisture Content Between 1.5 and $66.3 \%$

\begin{tabular}{|c|c|c|}
\hline Sample & \begin{tabular}{|c|} 
Volumetric Moisture Content \\
$(\%)$
\end{tabular} & $\begin{array}{c}\text { Diffusion Coefficient } \\
\left(\mathrm{cm}^{2} \mathrm{~s}^{-1}\right)\end{array}$ \\
\hline 1 & 1.50 & $1.39 \times 10^{-8}$ \\
\hline 2 & 1.70 & $6.60 \times 10^{-9}$ \\
\hline 3 & 1.90 & $8.60 \times 10^{-9}$ \\
\hline 4 & 2.17 & $2.77 \times 10^{-8}$ \\
\hline 5 & 2.20 & $3.63 \times 10^{-8}$ \\
\hline 6 & 2.29 & $1.09 \times 10^{-8}$ \\
\hline 7 & 2.50 & $2.50 \times 10^{-8}$ \\
\hline 8 & 3.10 & $3.30 \times 10^{-8}$ \\
\hline 9 & 3.14 & $3.06 \times 10^{-8}$ \\
\hline 10 & 3.20 & $1.35 \times 10^{-8}$ \\
\hline 11 & 3.27 & $2.79 \times 10^{-8}$ \\
\hline 12 & 3.33 & $6.35 \times 10^{-8}$ \\
\hline 13 & 3.34 & $2.60 \times 10^{-8}$ \\
\hline 14 & 3.57 & $3.37 \times 10^{-8}$ \\
\hline 15 & 3.70 & $3.70 \times 10^{-8}$ \\
\hline 16 & 3.70 & $6.60 \times 10^{-8}$ \\
\hline 17 & 4.00 & $5.22 \times 10^{-8}$ \\
\hline 18 & 4.20 & $5.94 \times 10^{-8}$ \\
\hline 19 & 4.60 & $6.21 \times 10^{-8}$ \\
\hline 20 & 4.90 & $7.20 \times 10^{-8}$ \\
\hline 21 & 5.10 & $1.32 \times 10^{-7}$ \\
\hline 22 & 5.30 & $2.40 \times 10^{-8}$ \\
\hline 23 & 5.40 & $7.60 \times 10^{-8}$ \\
\hline 24 & 5.51 & $7.68 \times 10^{-8}$ \\
\hline 25 & 5.83 & $1.23 \times 10^{-7}$ \\
\hline 26 & 5.90 & $9.30 \times 10^{-8}$ \\
\hline 27 & 6.00 & $8.92 \times 10^{-8}$ \\
\hline 28 & 6.30 & $1.06 \times 10^{-7}$ \\
\hline 29 & 6.90 & $6.00 \times 10^{-8}$ \\
\hline 30 & 6.93 & $1.50 \times 10^{-7}$ \\
\hline 31 & 7.30 & $1.60 \times 10^{-7}$ \\
\hline 32 & 7.40 & $2.50 \times 10^{-7}$ \\
\hline 33 & 7.60 & $2.60 \times 10^{-7}$ \\
\hline 34 & 7.60 & $1.10 \times 10^{-7}$ \\
\hline 35 & 7.60 & $2.69 \times 10^{-7}$ \\
\hline 36 & 7.70 & $1.10 \times 10^{-7}$ \\
\hline 37 & 8.00 & $1.98 \times 10^{-7}$ \\
\hline 38 & 8.10 & $1.70 \times 10^{-7}$ \\
\hline 39 & 8.32 & $4.10 \times 10^{-7}$ \\
\hline 40 & 8.35 & $2.15 \times 10^{-7}$ \\
\hline 41 & 8.60 & $3.20 \times 10^{-7}$ \\
\hline 42 & 8.80 & $2.30 \times 10^{-7}$ \\
\hline
\end{tabular}


Table 4.1-17. Diffusion Coefficient for Granular Materials for Volumetric Moisture Content Between 1.5 Percent and 66.3 Percent (Continued)

\begin{tabular}{|c|c|c|}
\hline Sample & \begin{tabular}{|c|} 
Volumetric Moisture Content \\
$(\%)$
\end{tabular} & $\begin{array}{c}\text { Diffusion Coefficient } \\
\left(\mathrm{cm}^{2} \mathrm{~s}^{-1}\right)\end{array}$ \\
\hline 43 & 9.24 & $2.55 \times 10^{-7}$ \\
\hline 44 & 9.24 & $2.55 \times 10^{-7}$ \\
\hline 45 & 9.56 & $3.00 \times 10^{-7}$ \\
\hline 46 & 9.64 & $3.07 \times 10^{-7}$ \\
\hline 47 & 9.75 & $3.20 \times 10^{-7}$ \\
\hline 48 & 10.1 & $3.51 \times 10^{-7}$ \\
\hline 49 & 10.1 & $3.62 \times 10^{-7}$ \\
\hline 50 & 10.2 & $3.54 \times 10^{-7}$ \\
\hline 51 & 10.2 & $3.30 \times 10^{-7}$ \\
\hline 52 & 10.3 & $3.34 \times 10^{-7}$ \\
\hline 53 & 10.3 & $2.10 \times 10^{-7}$ \\
\hline 54 & 10.4 & $3.40 \times 10^{-7}$ \\
\hline 55 & 10.9 & $3.62 \times 10^{-7}$ \\
\hline 56 & 11.1 & $3.72 \times 10^{-7}$ \\
\hline 57 & 11.1 & $4.22 \times 10^{-7}$ \\
\hline 58 & 11.1 & $4.27 \times 10^{-7}$ \\
\hline 59 & 11.2 & $4.19 \times 10^{-7}$ \\
\hline 60 & 11.2 & $5.48 \times 10^{-7}$ \\
\hline 61 & 11.4 & $4.27 \times 10^{-7}$ \\
\hline 62 & 11.4 & $4.12 \times 10^{-7}$ \\
\hline 63 & 11.6 & $5.40 \times 10^{-7}$ \\
\hline 64 & 11.7 & $2.60 \times 10^{-7}$ \\
\hline 65 & 11.8 & $4.80 \times 10^{-7}$ \\
\hline 66 & 12.0 & $2.40 \times 10^{-7}$ \\
\hline 67 & 12.0 & $4.47 \times 10^{-7}$ \\
\hline 68 & 12.2 & $4.09 \times 10^{-7}$ \\
\hline 69 & 12.3 & $5.05 \times 10^{-7}$ \\
\hline 70 & 12.3 & $4.40 \times 10^{-7}$ \\
\hline 71 & 12.3 & $3.60 \times 10^{-7}$ \\
\hline 72 & 12.3 & $4.50 \times 10^{-7}$ \\
\hline 73 & 12.5 & $2.90 \times 10^{-7}$ \\
\hline 74 & 12.7 & $4.37 \times 10^{-7}$ \\
\hline 75 & 12.7 & $4.90 \times 10^{-7}$ \\
\hline 76 & 12.7 & $5.32 \times 10^{-7}$ \\
\hline 77 & 13.1 & $4.77 \times 10^{-7}$ \\
\hline 78 & 13.9 & $5.39 \times 10^{-7}$ \\
\hline 79 & 13.9 & $7.80 \times 10^{-7}$ \\
\hline 80 & 14.1 & $5.12 \times 10^{-7}$ \\
\hline 81 & 14.2 & $5.52 \times 10^{-7}$ \\
\hline 82 & 14.4 & $4.50 \times 10^{-7}$ \\
\hline 83 & 14.4 & $5.20 \times 10^{-7}$ \\
\hline 84 & 14.4 & $4.50 \times 10^{-7}$ \\
\hline
\end{tabular}


Table 4.1-17. Diffusion Coefficient for Granular Materials for Volumetric Moisture Content Between 1.5 Percent and 66.3 Percent (Continued)

\begin{tabular}{|c|c|c|}
\hline Sample & \begin{tabular}{|c|} 
Volumetric Moisture Content \\
$(\%)$
\end{tabular} & $\begin{array}{c}\text { Diffusion Coefficient } \\
\left(\mathrm{cm}^{2} \mathrm{~s}^{-1}\right)\end{array}$ \\
\hline 85 & 14.6 & $6.82 \times 10^{-7}$ \\
\hline 86 & 14.7 & $9.00 \times 10^{-7}$ \\
\hline 87 & 14.8 & $6.54 \times 10^{-7}$ \\
\hline 88 & 16.0 & $1.47 \times 10^{-6}$ \\
\hline 89 & 16.1 & $6.82 \times 10^{-7}$ \\
\hline 90 & 16.5 & $5.45 \times 10^{-7}$ \\
\hline 91 & 16.7 & $6.60 \times 10^{-7}$ \\
\hline 92 & 17.0 & $1.20 \times 10^{-6}$ \\
\hline 93 & 17.1 & $8.20 \times 10^{-7}$ \\
\hline 94 & 17.3 & $1.76 \times 10^{-6}$ \\
\hline 95 & 17.5 & $1.10 \times 10^{-6}$ \\
\hline 96 & 18.8 & $1.60 \times 10^{-6}$ \\
\hline 97 & 18.9 & $8.19 \times 10^{-7}$ \\
\hline 98 & 19.4 & $9.89 \times 10^{-7}$ \\
\hline $99 *$ & 20.4 & $4.19 \times 10^{-6}$ \\
\hline 100 & 20.8 & $3.58 \times 10^{-6}$ \\
\hline 101 & 21.0 & $2.34 \times 10^{-6}$ \\
\hline 102 & 21.5 & $1.23 \times 10^{-6}$ \\
\hline 103 & 21.6 & $1.29 \times 10^{-6}$ \\
\hline 104 & 23.1 & $2.40 \times 10^{-6}$ \\
\hline 105 & 23.1 & $1.90 \times 10^{-6}$ \\
\hline 106 & 24.0 & $2.90 \times 10^{-6}$ \\
\hline $107^{*}$ & 25.3 & $5.82 \times 10^{-6}$ \\
\hline 108 & 25.4 & $2.50 \times 10^{-6}$ \\
\hline $109^{*}$ & 25.7 & $9.26 \times 10^{-6}$ \\
\hline 110 & 28.2 & $3.50 \times 10^{-6}$ \\
\hline 111 & 28.5 & $1.00 \times 10^{-6}$ \\
\hline 112 & 30.9 & $1.51 \times 10^{-6}$ \\
\hline $113^{*}$ & 31.7 & $1.23 \times 10^{-5}$ \\
\hline 114 & 32.3 & $4.60 \times 10^{-6}$ \\
\hline $115^{*}$ & 33.8 & $1.34 \times 10^{-5}$ \\
\hline $116^{*}$ & 35.8 & $1.57 \times 10^{-5}$ \\
\hline 117 & 38.5 & $4.33 \times 10^{-6}$ \\
\hline $118^{*}$ & 39.3 & $1.36 \times 10^{-5}$ \\
\hline $119^{*}$ & 39.5 & $1.13 \times 10^{-5}$ \\
\hline 120 & 40.0 & $6.90 \times 10^{-6}$ \\
\hline 121 & 42.0 & $5.80 \times 10^{-6}$ \\
\hline
\end{tabular}


Table 4.1-17. Diffusion Coefficient for Granular Materials for Volumetric Moisture Content Between 1.5 Percent and 66.3 Percent (Continued)

\begin{tabular}{|c|c|c|}
\hline Sample & $\begin{array}{c}\text { Volumetric Moisture Content } \\
(\mathbf{\%})\end{array}$ & $\begin{array}{c}\text { Diffusion Coefficient } \\
\left(\mathbf{c m}^{\mathbf{2}} \mathbf{~ s}^{-\mathbf{1}}\right)\end{array}$ \\
\hline 122 & 42.5 & $3.22 \times 10^{-6}$ \\
\hline $123^{\star}$ & 43.4 & $1.02 \times 10^{-5}$ \\
\hline 124 & 49.0 & $6.09 \times 10^{-6}$ \\
\hline 125 & 66.3 & $1.83 \times 10^{-5}$ \\
\hline
\end{tabular}

NOTE: $\quad$ All values are from Conca and Wright 1992 [DIRS 100436], Figure 2, except for those indicated by an asterisk, which are from Conca et al. 1993 [DIRS 170709], Figure 2.

\subsubsection{Design Information}

Some of the information necessary for the model presented in this document consists of parameters and other descriptions based on the license application (LA) conceptual design of the repository. Included are dimensions, material amounts and properties, and physical configuration of the drifts and their contents, listed in Tables 4.1-18 through 4.1-20. For TSPA-LA analyses, this information was obtained from information exchange drawings (IEDs) and design drawings cited on IEDs.

In Table 4.1-20, the component materials in a 21-PWR waste package are obtained from Design and Engineering, 21-PWR Waste Package Configuration (BSC 2004 [DIRS 167394]), which is the design version preceding the current version (BSC 2004 [DIRS 170710]). In addition, the masses, thicknesses, and numbers of components in a 21-PWR waste package, listed in Tables 4.1-18 through 4.1-20, are obtained from Revision 00C of D\&E/PA/C IED Typical Waste Package Components Assembly (BSC 2004 [DIRS 169472]), which has been superseded by IED [information exchange drawing] Typical Waste Package Configuration (BSC 2005 [DIRS 173501]). Justification for using the previous design data and the impact on TSPA-LA calculations is provided in Section 6.3.4.2.3, where the impact is shown to be negligible.

In Table 4.1-20, the masses and numbers of components in a 5 DHLW/DOE - Short waste package are obtained from Revision $00 \mathrm{~B}$ of $D \& E / P A / C$ IED Typical Waste Package Components Assembly (BSC 2004 [DIRS 167207]), which is the version of the IED preceding Revision 00C (BSC 2004 [DIRS 169472]), used for the 21-PWR waste packages, which in turn has been superseded by IED Typical Waste Package Configuration (BSC 2005 [DIRS 173501]). Minor changes in component masses were made in the 5 DHLW/DOE - Short waste package from Revision 00B (BSC 2004 [DIRS 167207]) to Revision 00C (BSC 2004 [DIRS 169472]) to BSC 2005 [DIRS 173501]. The impacts of the changes in component masses in the $5 \mathrm{DHLW} / \mathrm{DOE}$ - Short waste package are analyzed in Section 6.3.4.2.3 and are shown to be negligible. 
Table 4.1-18. Design Information for EBS Components

\begin{tabular}{|l|c|l|}
\hline \multicolumn{1}{|c|}{ Model Input } & Value & \multicolumn{1}{c|}{ Source } \\
\hline Diameter of the drift & $5.5 \mathrm{~m}$ & BSC 2004 [DIRS 169503] \\
\hline Length of drip shield & $5805 \mathrm{~mm}$ & BSC 2005 [DIRS 173303], Table 1 \\
\hline Maximum depth of invert & $2 \mathrm{ft} 10 \mathrm{in}$ & BSC 2004 [DIRS 169503] \\
\hline \multicolumn{2}{|c|}{ 21-PWR (Absorber Plate) } & Waste Package Characteristics \\
\hline Outer barrier outside diameter & $1637 \mathrm{~mm}$ & BSC 2004 [DIRS 166953], Section B-B \\
\hline Maximum outside diameter around trunnion collars & $1718.3 \mathrm{~mm}$ & BSC 2004 [DIRS 166953] \\
\hline Outer barrier inside diameter & $1597 \mathrm{~mm}$ & BSC 2004 [DIRS 166953], Section B-B \\
\hline Inner vessel inside diameter & $1485.9 \mathrm{~mm}$ & BSC 2004 [DIRS 166953], Section B-B \\
\hline Total outside length & $5024.4 \mathrm{~mm}$ & BSC 2004 [DIRS 166953], Section A-A \\
\hline Inner vessel cavity length & $4584.7 \mathrm{~mm}$ & BSC 2004 [DIRS 166953], Section A-A \\
\hline Outer barrier thickness & $20 \mathrm{~mm}$ & BSC 2004 [DIRS 169472], Table 1 \\
\hline Middle lid thickness & $12.7 \mathrm{~mm}$ & BSC 2004 [DIRS 167394], Detail A \\
\hline Middle lid to outer lid gap & $30.16 \mathrm{~mm}$ & BSC 2004 [DIRS 167394], Detail A \\
\hline Outer lid thickness & $25.4 \mathrm{~mm}$ & BSC 2004 [DIRS 167394], Details A and B \\
\hline Inner vessel bottom lid thickness & $50.8 \mathrm{~mm}$ & BSC 2004 [DIRS 167394], Detail B \\
\hline Inner vessel top lid thickness & $50.8 \mathrm{~mm}$ & BSC 2004 [DIRS 167394], Detail A \\
\hline Top lid lifting device thickness & $25.4 \mathrm{~mm}$ & BSC 2004 [DIRS 167394], Detail C \\
\hline Bottom skirt length & $101.6 \mathrm{~mm}$ & BSC 2004 [DIRS 167394], Detail B \\
\hline \multicolumn{1}{|c|}{$\mathbf{5}$ DHLWIDOE SNF - Short Waste Package Characteristics } \\
\hline Nominal diameter & $2126.0 \mathrm{~mm}$ & BSC 2004 [DIRS 169472], Table 1 \\
\hline Nominal length & $3452.8 \mathrm{~mm}$ & BSC 2004 [DIRS 169472], Table 1 \\
\hline Outer barrier thickness & $25.4 \mathrm{~mm}$ & BSC 2004 [DIRS 169472], Table 1 \\
\hline Outer barrier outside diameter & $2044.7 \mathrm{~mm}$ & BSC 2004 [DIRS 166946], Section B-B \\
\hline Outer barrier inside diameter & $1993.9 \mathrm{~mm}$ & BSC 2004 [DIRS 166946], Section B-B \\
\hline Total length & $3452.8 \mathrm{~mm}$ & BSC 2004 [DIRS 166946], Section A-A \\
\hline DHLW = & \\
\hline
\end{tabular}

$\mathrm{DHLW}=$ defense high-level (radioactive) waste, $\mathrm{SNF}=$ spent nuclear fuel 
Table 4.1-19. Component Dimensions in a 21-PWR (Absorber Plate) Waste Package

\begin{tabular}{|l|l|}
\hline \multicolumn{1}{|c|}{ Component } & \multicolumn{1}{c|}{ Dimensions } \\
\hline Basket Side Guide & $3 / 8$ in. thickness \\
\hline Basket Side Guide Stiffener & $3 / 8$ in. thickness \\
\hline Basket End Side Guide & $3 / 8$ in. thickness \\
\hline Basket End Guide Stiffener & $3 / 8$ in. thickness \\
\hline Basket Corner Guide & $3 / 8$ in. thickness \\
\hline Basket Corner Guide Stiffener & $3 / 8$ in. thickness \\
\hline Fuel Basket A-Plate & 7 mm thickness \\
\hline Fuel Basket B-Plate & 7 mm thickness \\
\hline Fuel Basket C-Plate & $7 \mathrm{~mm}$ thickness \\
\hline Fuel Basket D-Plate & $1 / 4$ in. thickness \\
\hline Fuel Basket E-Plate & $1 / 4$ in. thickness \\
\hline Basket Tube & 180 in. length; \\
& 9.12 in. interior dimension; \\
& $3 / 16$ in. thickness \\
\hline
\end{tabular}

Sources: Thickness: BSC 2004 [DIRS 169472], Table 2.

Basket Tube Length: BSC 2004 [DIRS 166953], Section A-A.

Basket Tube Interior Dimension: BSC 2004 [DIRS 166953], Section B-B.

Table 4.1-20. Masses and Numbers of Components in Waste Packages

\begin{tabular}{|c|c|c|c|}
\hline \multicolumn{4}{|c|}{$\begin{array}{l}\text { 21-PWR (Absorber Plate) } \\
\text { (BSC } 2004 \text { [DIRS 167394], material table; BSC } 2004 \text { [DIRS 169472], Table 2) }\end{array}$} \\
\hline Material & Component & Mass (kg) & Number \\
\hline \multirow{7}{*}{$\begin{array}{l}\text { Carbon Steel Type A } \\
516\end{array}$} & Basket - Side Guide & 24.9 & 16 \\
\hline & Basket - Side Guide Stiffener & 0.615 & 32 \\
\hline & Basket - End Side Guide & 32.7 & 32 \\
\hline & Basket End Side Guide Stiffener & 1.38 & 64 \\
\hline & Basket Corner Guide & 40.1 & 16 \\
\hline & Basket Corner Guide Stiffener & 2.07 & 32 \\
\hline & Fuel Basket Tube & 159 & 21 \\
\hline \multirow[t]{3}{*}{ Neutronit A 978} & Fuel Basket A - Plate & 86.8 & 8 \\
\hline & Fuel Basket B - Plate & 86.8 & 8 \\
\hline & Fuel Basket C - Plate & 45.8 & 16 \\
\hline \multirow[t]{2}{*}{ Al 6061} & Fuel Basket D - Plate & 27.4 & 8 \\
\hline & Fuel Basket E - Plate & 27.4 & 8 \\
\hline \multirow[t]{5}{*}{ Stainless Steel Type 316} & Inner Vessel w/o Guides & 9,920 & 1 \\
\hline & Inner Lid w/ LLF & 739 & 1 \\
\hline & Interface Ring & 35.6 & 1 \\
\hline & Spread Ring & 25.3 & 1 \\
\hline & Total 316 Welds & 81.0 & - \\
\hline \multirow[t]{4}{*}{ Alloy 22} & OCB with trunnion sleeves & 5,730 & 1 \\
\hline & Middle Lid w/ LLF & 226 & 1 \\
\hline & Outer Lid w/ LLF & 445 & 1 \\
\hline & Total Alloy 22 Welds & 51.8 & - \\
\hline
\end{tabular}


Table 4.1-20. Masses and Numbers of Components in Waste Packages (Continued)

\begin{tabular}{|c|c|c|c|}
\hline \multicolumn{4}{|c|}{$\begin{array}{l}5 \text { DHLW/DOE - Short } \\
\text { (BSC } 2004 \text { [DIRS 166947], material table; BSC } 2004 \text { [DIRS 167207], Table 5) }\end{array}$} \\
\hline Material & Component & Mass (kg) & Number \\
\hline $\begin{array}{l}\text { Carbon Steel Type } \\
\text { A } 516\end{array}$ & Divider Plate Assembly & 3,720 & $16^{\mathrm{a}}$ \\
\hline \multirow[t]{5}{*}{ Stainless Steel Type 316} & Inner Vessel & 8,860 & 1 \\
\hline & Inner Lid w/ LLF & 1,170 & 1 \\
\hline & Interface Ring & 44.6 & 1 \\
\hline & Spread Ring & 31.9 & $4^{b}$ \\
\hline & Total 316 Welds & 102 & - \\
\hline \multirow[t]{4}{*}{ Alloy 22} & OCB with trunnion sleeves & 6,540 & 1 \\
\hline & Middle Lid w/ LLF & 350 & 1 \\
\hline & Outer Lid w/ LLF & 693 & 1 \\
\hline & Total Alloy 22 Welds & 64.2 & - \\
\hline
\end{tabular}

${ }^{a}$ Divider Plate Assembly is assembled from 16 pieces: five Divider Plates, five Outer Brackets, five Inner Brackets, and one Support Tube (BSC 2004 [DIRS 166947]) having a total mass of 3,720 kg (BSC 2004 [DIRS 167207], Table 5).

b Spread Ring is assembled from four pieces (BSC 2004 [DIRS 166947]) having a combined mass of $31.9 \mathrm{~kg}$ (BSC 2004 [DIRS 167207], Table 5).

NOTES: "- " indicates that the number of welds is not specified in the source IED.

BWR = boiling water reactor, DHLW = defense high-level (radioactive) waste, IED = information exchange drawing, LLF = lid lifting feature, PWR = pressurized water reactor; DOE = U.S. Department of Energy.

\subsection{CRITERIA}

This report was prepared to comply with 10 CFR Part 63 [DIRS 173273]. Relevant requirements for performance assessment from Section 114 of that document are: "Any performance assessment used to demonstrate compliance with Sec. 113(b) shall: (a) Include data related to the geology, hydrology, and geochemistry ... used to define parameters and conceptual models used in the assessment. (b) Account for uncertainties and variabilities in parameter values and provide the technical basis for parameter ranges, probability distributions, or bounding values used in the performance assessment ... (g) Provide the technical basis for models used in the performance assessment such as comparisons made with outputs of detailed process-level models."

Programmatic requirements for this document are listed in Technical Work Plan for: Near-Field Environment and Transport: Engineered Barrier System: Radionuclide Transport Abstraction Model Report Integration (BSC 2005 [DIRS 173617]). This technical work plan (TWP) specifies that this document and all analyses described herein must adhere to the requirements of LP-SIII.10Q-BSC, Models, and to the requirements mentioned in the Project Requirements Document (Canori and Leitner 2003 [DIRS 166275]). The TWP also specifies that Yucca Mountain Review Plan, Final Report (NRC 2003 [DIRS 163274]) acceptance criteria must be addressed. In addition, the TWP specifies that the requirements of AP-16.1Q, Condition Reporting and Resolution, to enable closure of Condition Report (CR)-5141 and CR-5293 and any other relevant CRs that may be generated by the Corrective Action Program, including CR-5442, must be satisfied. 


\subsubsection{Yucca Mountain Review Plan Criteria}

The acceptance criteria that concern flow and transport related to the EBS are presented in Section 2.2.1.3 of the Yucca Mountain Review Plan, Final Report (NRC 2003 [DIRS 163274]). Of the 14 model abstraction sections in the review plan, Sections 2.2.1.3.3 and 2.2.1.3.4 are applicable to this abstraction. The pertinent acceptance criteria from those two sections are listed in Sections 4.2.1.1 and 4.2.1.2, respectively.

\subsubsection{Applicable Acceptance Criteria from Section 2.2.1.3.3, “Quantity and Chemistry of Water Contacting Engineered Barriers and Waste Forms”}

The following acceptance criteria, listed in Section 2.2.1.3.3.3 of Yucca Mountain Review Plan, Final Report (NRC 2003 [DIRS 163274]), apply to this abstraction. These acceptance criteria are based on meeting the requirements of 10 CFR 63.114(a)-(c) and (e)-(g) [DIRS 173273], relating to the quantity and chemistry of water contacting engineered barriers and waste forms model abstraction.

\section{Acceptance Criterion 1-System Description and Model Integration Are Adequate.}

(1) Total system performance assessment adequately incorporates important design features, physical phenomena, and couplings, and uses consistent and appropriate assumptions throughout the quantity and chemistry of water contacting engineered barriers and waste forms abstraction process.

(2) The abstraction of the quantity and chemistry of water contacting engineered barriers and waste forms uses assumptions, technical bases, data, and models, that are appropriate and consistent with other related U.S. Department of Energy abstractions. For example, the assumptions used for the quantity and chemistry of water contacting engineered barriers and waste forms are consistent with the abstractions of "Degradation of Engineered Barriers" (NRC 2003 [DIRS 163274], Section 2.2.1.3.1); "Mechanical Disruption of Engineered Barriers" (NRC 2003 [DIRS 163274], Section 2.2.1.3.2); "Radionuclide Release Rates and Solubility Limits" (Section 2.2.1.3.4); “Climate and Infiltration" (NRC 2003 [DIRS 163274], Section 2.2.1.3.5); and "Flow Paths in the Unsaturated Zone" (NRC 2003 [DIRS 163274], Section 2.2.1.3.6). The descriptions and technical bases provide transparent and traceable support for the abstraction of quantity and chemistry of water contacting engineered barriers and waste forms.

(3) Important design features, such as waste package design and material selection, backfill, drip shield, ground support, thermal loading strategy, and degradation processes, are adequate to determine the initial and boundary conditions for calculations of the quantity and chemistry of water contacting engineered barriers and waste forms.

(4) Spatial and temporal abstractions appropriately address physical couplings (thermal-hydrologic-mechanical-chemical). For example, the U.S. Department of Energy evaluates the potential for focusing of water flow into drifts, caused by coupled thermal-hydrologic-mechanical-chemical processes. 
(5) Sufficient technical bases and justification are provided for total system performance assessment assumptions and approximations for modeling coupled thermal-hydrologic mechanical-chemical effects on seepage and flow, the waste package chemical environment, and the chemical environment for radionuclide release. The effects of distribution of flow on the amount of water contacting the engineered barriers and waste forms are consistently addressed, in all relevant abstractions.

(6) The expected ranges of environmental conditions within the waste package emplacement drifts, inside of breached waste packages, and contacting the waste forms and their evolution with time, are identified. These ranges may be developed to include: (i) the effects of the drip shield and backfill on the quantity and chemistry of water (e.g., the potential for condensate formation and dripping from the underside of the shield); (ii) conditions that promote corrosion of engineered barriers and degradation of waste forms; (iii) irregular wet and dry cycles; (iv) gamma-radiolysis; and (v) size and distribution of penetrations of engineered barriers.

(7) The model abstraction for quantity and chemistry of water contacting engineered barriers and waste forms is consistent with the detailed information on engineered barrier design and other engineered features. For example, consistency is demonstrated for: (i) dimensionality of the abstractions; (ii) various design features and site characteristics; and (iii) alternative conceptual approaches. Analyses are adequate to demonstrate that no deleterious effects are caused by design or site features that the U.S. Department of Energy does not take into account in this abstraction.

(8) Adequate technical bases are provided, including activities such as independent modeling, laboratory or field data, or sensitivity studies, for inclusion of any thermal-hydrologic-mechanical-chemical couplings and features, events, and processes.

(9) Performance-affecting processes that have been observed in thermal-hydrologic tests and experiments are included into the performance assessment. For example, the U.S. Department of Energy either demonstrates that liquid water will not reflux into the underground facility or incorporates refluxing water into the performance assessment calculation, and bounds the potential adverse effects of alteration of the hydraulic pathway that result from refluxing water.

\section{Acceptance Criterion 2-Data Are Sufficient for Model Justification.}

(1) Geological, hydrological, and geochemical values used in the license application are adequately justified. Adequate description of how the data were used, interpreted, and appropriately synthesized into the parameters is provided.

(2) Sufficient data were collected on the characteristics of the natural system and engineered materials to establish initial and boundary conditions for conceptual models of thermal-hydrologic-mechanical-chemical coupled processes, that affect seepage and flow and the engineered barrier chemical environment. 
(4) Sufficient information to formulate the conceptual approach(es) for analyzing water contact with the drip shield, engineered barriers, and waste forms is provided.

\section{Acceptance Criterion 3-Data Uncertainty Is Characterized and Propagated Through the Model Abstraction.}

(1) Models use parameter values, assumed ranges, probability distributions, and bounding assumptions that are technically defensible, reasonably account for uncertainties and variabilities, and do not result in an under representation of the risk estimate.

(2) Parameter values, assumed ranges, probability distributions, and bounding assumptions used in the total system performance assessment calculations of quantity and chemistry of water contacting engineered barriers and waste forms are technically defensible and reasonable, based on data from the Yucca Mountain region (e.g., results from large block and drift-scale heater and niche tests), and a combination of techniques that may include laboratory experiments, field measurements, natural analog research, and process-level modeling studies.

(3) Input values used in the total system performance assessment calculations of quantity and chemistry of water contacting engineered barriers (e.g., drip shield and waste package) are consistent with the initial and boundary conditions and the assumptions of the conceptual models and design concepts for the Yucca Mountain site. Correlations between input values are appropriately established in the U.S. Department of Energy total system performance assessment. Parameters used to define initial conditions, boundary conditions, and computational domain in sensitivity analyses involving coupled thermal-hydrologic-mechanical-chemical effects on seepage and flow, the waste package chemical environment, and the chemical environment for radionuclide release, are consistent with available data. Reasonable or conservative ranges of parameters or functional relations are established.

(4) Adequate representation of uncertainties in the characteristics of the natural system and engineered materials is provided in parameter development for conceptual models, process-level models, and alternative conceptual models. The U.S. Department of Energy may constrain these uncertainties using sensitivity analyses or conservative limits. For example, the U.S. Department of Energy demonstrates how parameters used to describe flow through the engineered barrier system bound the effects of backfill and excavation-induced changes.

\section{Acceptance Criterion 4-Model Uncertainty Is Characterized and Propagated Through the Model Abstraction.}

(1) Alternative modeling approaches of features, events, and processes are considered and are consistent with available data and current scientific understanding, and the results and limitations are appropriately considered in the abstraction.

(2) Alternative modeling approaches are considered and the selected modeling approach is consistent with available data and current scientific understanding. A description that 
includes a discussion of alternative modeling approaches not considered in the final analysis and the limitations and uncertainties of the chosen model is provided.

(3) Consideration of conceptual model uncertainty is consistent with available site characterization data, laboratory experiments, field measurements, natural analog information and process-level modeling studies; and the treatment of conceptual model uncertainty does not result in an under-representation of the risk estimate.

(4) Adequate consideration is given to effects of thermal-hydrologic-mechanical-chemical coupled processes in the assessment of alternative conceptual models. These effects may include: (i) thermal-hydrologic effects on gas, water, and mineral chemistry; (ii) effects of microbial processes on the engineered barrier chemical environment and the chemical environment for radionuclide release; (iii) changes in water chemistry that may result from the release of corrosion products from the engineered barriers and interactions between engineered materials and groundwater; and (iv) changes in boundary conditions (e.g., drift shape and size) and hydrologic properties, relating to the response of the geomechanical system to thermal loading.

\section{Acceptance Criterion 5-Model Abstraction Output Is Supported by Objective Comparisons.}

(1) The models implemented in this total system performance assessment abstraction provide results consistent with output from detailed process-level models and/or empirical observations (laboratory and field testings and/or natural analogs).

(2) Abstracted models for coupled thermal-hydrologic-mechanical-chemical effects on seepage and flow and the engineered barrier chemical environment, as well as on the chemical environment for radionuclide release, are based on the same assumptions and approximations demonstrated to be appropriate for process-level models or closely analogous natural or experimental systems. For example, abstractions of processes, such as thermally induced changes in hydrological properties, or estimated diversion of percolation away from the drifts, are adequately justified by comparison to results of process-level modeling, that are consistent with direct observations and field studies.

(3) Accepted and well-documented procedures are used to construct and test the numerical models that simulate coupled thermal-hydrologic-mechanical-chemical effects on seepage and flow, engineered barrier chemical environment, and the chemical environment for radionuclide release. Analytical and numerical models are appropriately supported. Abstracted model results are compared with different mathematical models, to judge robustness of results. 


\subsubsection{Applicable Acceptance Criteria from Section 2.2.1.3.4, "Radionuclide Release Rates and Solubility Limits"}

The following acceptance criteria, listed in Section 2.2.1.3.4.3 of Yucca Mountain Review Plan, Final Report (NRC 2003 [DIRS 163274]), apply to this abstraction. These acceptance criteria are based on meeting the relevant requirements of 10 CFR 63.114(a)-(c) and (e)-(g) [DIRS 173273], as they relate to the radionuclide release rates and solubility limits model abstraction.

\section{Acceptance Criterion 1-System Description and Model Integration Are Adequate.}

(1) Total system performance assessment adequately incorporates important design features, physical phenomena, and couplings, and uses consistent and appropriate assumptions throughout the radionuclide release rates and solubility limits abstraction process.

(2) The abstraction of radionuclide release rates uses assumptions, technical bases, data, and models that are appropriate and consistent with other related U.S. Department of Energy abstractions. For example, the assumptions used for this model abstraction are consistent with the abstractions of "Degradation of Engineered Barriers" (NRC 2003 [DIRS 163274], Section 2.2.1.3.1); "Mechanical Disruption of Engineered Barriers" (NRC 2003 [DIRS 163274], Section 2.2.1.3.2); "Quantity and Chemistry of Water Contacting Engineered Barriers and Waste Forms" (NRC 2003 [DIRS 163274], Section 2.2.1.3.3); "Climate and Infiltration" (NRC 2003 [DIRS 163274], Section 2.2.1.3.5); and "Flow Paths in the Unsaturated Zone" (NRC 2003 [DIRS 163274], Section 2.2.1.3.6). The descriptions and technical bases provide transparent and traceable support for the abstraction of radionuclide release rates.

(3) The abstraction of radionuclide release rates provides sufficient, consistent design information on waste packages and engineered barrier systems. For example, inventory calculations and selected radionuclides are based on the detailed information provided on the distribution (both spatially and by compositional phase) of the radionuclide inventory, within the various types of high-level radioactive waste.

(4) The U.S. Department of Energy reasonably accounts for the range of environmental conditions expected inside breached waste packages and in the engineered barrier environment surrounding the waste package. For example, the U.S. Department of Energy should provide a description and sufficient technical bases for its abstraction of changes in hydrologic properties in the near field, caused by coupled thermal-hydrologic-mechanical-chemical processes.

(5) The description of process-level conceptual and mathematical models is sufficiently complete, with respect to thermal-hydrologic processes affecting radionuclide release from the emplacement drifts. For example, if the U.S. Department of Energy uncouples coupled processes, the demonstration that uncoupled model results bound predictions of fully coupled results is adequate. 
(6) Technical bases for inclusion of any thermal-hydrologic-mechanical-chemical couplings and features, events, and processes in the radionuclide release rates and solubility Review Plan for Safety Analysis Report limits model abstraction are adequate. For example, technical bases may include activities, such as independent modeling, laboratory or field data, or sensitivity studies.

\section{Acceptance Criterion 2-Data Are Sufficient for Model Justification.}

(1) Geological, hydrological, and geochemical values used in the license application are adequately justified. Adequate description of how the data were used, interpreted, and appropriately synthesized into the parameters is provided.

(2) Sufficient data have been collected on the characteristics of the natural system and engineered materials to establish initial and boundary conditions for conceptual models and simulations of thermal-hydrologic-chemical coupled processes. For example, sufficient data should be provided on design features, such as the type, quantity, and reactivity of materials, that may affect radionuclide release for this abstraction.

(4) The corrosion and radionuclide release testing program for high-level radioactive waste forms intended for disposal provides consistent, sufficient, and suitable data for the in-package and in-drift chemistry used in the abstraction of radionuclide release rates and solubility limits. For expected environmental conditions, the U.S. Department of Energy provides sufficient justification for the use of test results, not specifically collected from the Yucca Mountain site, for engineered barrier components, such as high-level radioactive waste forms, drip shield, and backfill.

\section{Acceptance Criterion 3-Data Uncertainty Is Characterized and Propagated Through the Model Abstraction.}

(1) Models use parameter values, assumed ranges, probability distributions, and bounding assumptions that are technically defensible, reasonably account for uncertainties and variabilities, and do not result in an under representation of the risk estimate.

(2) Parameter values, assumed ranges, probability distributions, and bounding assumptions used in the abstractions of radionuclide release rates and solubility limits in the total system performance assessment are technically defensible and reasonable based on data from the Yucca Mountain region, laboratory tests, and natural analogs. For example, parameter values, assumed ranges, probability distributions, and bounding assumptions adequately reflect the range of environmental conditions expected inside breached waste packages.

(3) DOE uses reasonable or conservative ranges of parameters or functional relations to determine effects of coupled thermal-hydrologic-chemical processes on radionuclide release. These values are consistent with the initial and boundary conditions and the assumptions for the conceptual models and design concepts for natural and engineered barriers at the Yucca Mountain site. If any correlations between the input values exist, they are adequately established in the total system performance assessment. For 
example, estimations are based on a thermal loading and ventilation strategy; engineered barrier system design (including drift liner, backfill, and drip-shield); and natural system masses and fluxes that are consistent with those used in other abstractions.

(4) Uncertainty is adequately represented in parameter development for conceptual models, process models, and alternative conceptual models considered in developing the abstraction of radionuclide release rates and solubility limits, either through sensitivity analyses or use of bounding analyses.

(5) Parameters used to describe flow through and out of the engineered barrier, sufficiently bound the effects of backfill, excavation-induced changes, and thermally induced mechanical changes that affect flow.

(8) DOE adequately considers the uncertainties, in the characteristics of the natural system and engineered materials, such as the type, quantity, and reactivity of material, in establishing initial and boundary conditions for conceptual models and simulations of thermal-hydrologic-chemical coupled processes that affect radionuclide release.

\section{Acceptance Criterion 4-Model Uncertainty Is Characterized and Propagated Through the Model Abstraction.}

(1) Alternative modeling approaches of features, events, and processes are considered and are consistent with available data and current scientific understanding, and the results and limitations are appropriately considered in the abstraction.

(2) In considering alternative conceptual models for radionuclide release rates and solubility limits, DOE uses appropriate models, tests, and analyses that are sensitive to the processes modeled for both natural and engineering systems. Conceptual model uncertainties are adequately defined and documented, and effects on conclusions regarding performance are properly assessed. For example, in modeling flow and radionuclide release from the drifts, DOE represents significant discrete features, such as fault zones, separately, or demonstrates that their inclusion in the equivalent continuum model produces a conservative effect on calculated performance.

(3) Consideration of conceptual model uncertainty is consistent with available site characterization data, laboratory experiments, field measurements, natural analog information and process-level modeling studies; and the treatment of conceptual model uncertainty does not result in an under-representation of the risk estimate.

(4) The effects of thermal-hydrologic-chemical coupled processes that may occur in the natural setting, or from interactions with engineered materials, or their alteration products, on radionuclide release, are appropriately considered. 


\section{Acceptance Criterion 5-Model Abstraction Output Is Supported by Objective Comparisons.}

(1) The models implemented in this total system performance assessment abstraction provide results consistent with output from detailed process-level models and/or empirical observations (laboratory and field testings and/or natural analogs);

(3) DOE adopts well-documented procedures that have been accepted by the scientific community to construct and test the numerical models, used to simulate coupled thermal-hydrologic-chemical effects on radionuclide release. For example, DOE demonstrates that the numerical models used for high-level radioactive waste degradation and dissolution, and radionuclide release from the engineered barrier system, are adequate representations; include consideration of uncertainties; and are not likely to underestimate radiological exposures to the reasonably maximally exposed individual and releases of radionuclides into the accessible environment; and

\subsection{CODES, STANDARDS, AND REGULATIONS}

The relevant codes, standards, and regulations for the development of the EBS RT Abstraction are listed in Section 9.2. 


\section{ASSUMPTIONS}

\subsection{ALL SEEPAGE FALLS ONTO DRIP SHIELD/WASTE PACKAGE}

Assumption: It is assumed that the locations of seeps in the emplacement drifts are random with respect to waste package locations, but that once a seep occurs, its location does not change over time. It is also assumed that fragments of the drip shield that may rest on the waste package, or fallen rock that may rest on the drip shield or waste package, do not divert any seepage flux. In addition, it is assumed that all seepage into the drift falls on the crown of the drip shield, and in the absence of a drip shield, all seepage falls on the crown of the waste package. In the event of a breach in the drip shield, all the seepage that penetrates the drip shield contacts the waste package.

Basis: Once seepage occurs during cooldown, the fracture characteristics that control the location of seepage are not expected to change. If such changes occur, they are likely to be limited in extent, or to occur in a random manner for many waste packages such that there is no overall, significant effect on the interaction of seepage water with waste forms. The mean seepage for the degraded drift is greater than for the non-degraded case, but the factors controlling seep locations are still likely to occur in a random manner for many waste packages.

Confirmation Status: This assumption does not require confirmation because it maximizes the duration of seepage contact with drip shields and waste packages as represented in TSPA-LA. It also maximizes the flux of dripping water available to flow through breaches in the drip shield or waste package, once such flow is initiated as represented in the TSPA-LA.

Use in the Model: This assumption is used throughout Sections 6 and 7.

\subsection{EVAPORATION FROM A DRIP SHIELD DOES NOT OCCUR}

Assumption: It is assumed that there is no evaporation of seepage water from the surface of the drip shield.

Basis: The heat output from the waste package will cause the drip shield generally to be hotter than the drift wall from which seepage water is dripping. Some seepage water that drips onto the drip shield may be evaporated, thereby reducing the flux of water through the drip shield. A reduction in the quantity of water flux through the drip shield reduces the potential for advective transfer and subsequent release and transport of radionuclides from the waste packages. Ignoring the process of evaporation in this analysis therefore bounds (maximizes) the impacts of the seepage flux on waste packages.

Although some splashing or splattering can occur as water droplets impinge on the drip shield, the splash distance would be limited, and the water would effectively be redistributed over the top of the drip shield. If water droplets were to fall near the edge of the top plate, some splashes could fall onto the invert or lower walls of the drift and drain directly into the invert. This situation would minimize the degrading effects of water dripping on the drip shield and therefore is eliminated from consideration in order to bound the impacts of the seepage flux on waste packages. 
Confirmation Status: This assumption does not require confirmation because it provides for a reasonable upper bound on the flux available to interact with the drip shield and waste package, and bounds (maximizes) the potential degrading effects of seepage water on the drift environment.

Use in the Model: This assumption is used in Sections 6.3.2.4, 6.5.1.1, and 7.2.1.

\subsection{EVAPORATION FROM A WASTE PACKAGE DOES NOT OCCUR}

Assumption: It is assumed that evaporation of water from the surface or interior of a waste package does not occur.

Basis: Although heat released by spent nuclear fuel (SNF) will evaporate seepage water that drips onto the surface of or flows into breaches in a waste package, this process is not included in the analysis. Advective transport within the EBS is not possible if evaporation eliminates liquid fluxes. Therefore, evaporative processes are eliminated from this analysis to maximize the potential for advective transport of radionuclides. In addition to maximizing the advective flux of radionuclides from a waste package, this assumption also allows the water saturation inside a failed waste package to be set at 100 percent (fully saturated) in a codisposal waste package or in the degraded waste rind inside a failed fuel rod in a CSNF waste package, thereby maximizing the amount of water available for dissolving radionuclides. This assumption comes into play only after the thermal peak period of roughly 1,000 years (BSC 2005 [DIRS 173944], Figure 6.3-67), since dripping onto a waste package will not occur until the drift has cooled sufficiently for liquid water to be present. Because the relative humidity in the drift is low during the thermal peak period, condensation on cooler waste packages is unlikely, precluding evaporation from those surfaces.

Confirmation Status: This assumption does not require confirmation because it is used to ensure the maximum potential for advective transport of radionuclides.

Use in the Model: This assumption is used in Sections 6.3.3, 6.5.1.1.3, and 7.2.2.

\subsection{PRODUCTION OR CONSUMPTION OF WATER BY CHEMICAL REACTIONS DOES NOT OCCUR}

Assumption: It is assumed that chemical reactions in the EBS neither produce nor consume water and therefore do not effect on the water mass balance in the EBS.

Basis: Chemical processes in the EBS could produce or consume water. This is generally a small effect. Although unlikely, water could possibly be produced by the decomposition of hydrated salts or minerals. However, this phenomenon would only occur at elevated temperatures where liquid water would not be present; this would result in the release of water vapor rather than liquid water, and therefore would not directly affect liquid water fluxes. Water absorption by hygroscopic salts deposited on the drip shield and waste package surfaces as dust or as precipitates from earlier drift seepage may lead to the formation of aqueous solutions when the relative humidity reaches the deliquescence point of the salts (BSC 2004 [DIRS 169863], Sections 6.3 and 6.6). While this phenomenon may have important implications for corrosion processes, the quantity of liquid potentially produced by deliquescence is minimal and thus 
assumed to be negligible, limited by the amount of salts that can be deposited on the waste package and drip shield surfaces. It is therefore reasonable to neglect the formation of aqueous solutions due to water absorption by hygroscopic salts as a source of water for advective transport.

However, consumption of water, particularly by corrosion reactions, is likely to occur. Anoxic corrosion of iron inside a waste package is a prime example of a water-consuming process that can consume enough water to impact flow through a waste package. Formation of hydrated corrosion products may also consume negligibly small amounts of water. Water absorption by hygroscopic salts deposited on the drip shield and waste package surfaces as dust or as precipitates would consume water as long as the relative humidity remains below the deliquescence point of the salts, although the quantity of water consumed is likely to be negligible. Neglecting consumption of water in the EBS radionuclide transport analysis is a bounding assumption, providing more water for dissolution and transport of radionuclides, and potentially greater releases, than would otherwise occur.

Confirmation Status: This assumption does not require confirmation because it bounds (maximizes) the amount of water potentially available for advective transport and release of radionuclides.

Use in the Model: This assumption is used throughout Sections 6 and 7.

\subsection{THIN WATER FILMS ALWAYS EXIST BELOW $100^{\circ} \mathrm{C}$}

Assumption: A thin film of adsorbed water is assumed always to exist on the surfaces of internal waste package components and corrosion products in a breached waste package. This water film is assumed to be continuous and to behave as bulk liquid insofar as allowing radionuclides to dissolve in and diffuse through it. Colloids are also assumed to diffuse through this film. At and above $100^{\circ} \mathrm{C}$, the thin film is assumed to evaporate, and no transport of radionuclides takes place.

Basis: All surfaces exposed to water vapor will adsorb water. The amount of adsorbed water vapor depends principally on the nature of the sorbing material and the ambient relative humidity.

The first layers of adsorbed water often do not contain ions from the sorbing solid (Lee 1994 and Staehle [DIRS 154380], p. 73). This indicates that multiple water layers are needed in order for solid species (such as radionuclides) to dissolve and diffuse. Thus, to assume that radionuclides will dissolve in and diffuse through the adsorbed water film regardless of its thickness will overestimate releases of radionuclides. It is also necessary to assume that the water film is continuous, i.e., there are no gaps in the film from one particle or surface to the next, so that radionuclides can diffuse throughout the waste package interior and through corrosion products. In determining the amount of water adsorbed on surfaces inside the waste package, the relative humidity inside a degraded waste package is assumed to be the same as in the drift.

Above the boiling point of water, the thin films are assumed to evaporate. Due to the lack of a continuous water film, transport cannot take place. The boiling point is nominally $100^{\circ} \mathrm{C}$, but 
may vary due to the elevation of the repository or to dissolved salts in the water film. Temperatures above the boiling point will exist at least through the thermal peak period of roughly 1,000 years (BSC 2005 [DIRS 173944], Figure 6.3-67), and may continue to exist on certain waste packages well beyond that time.

Confirmation Status: This assumption does not require confirmation because it allows for radionuclide transport due to the presence of a continuous thin film of water on the surfaces of internal waste package components and corrosion products.

Use in the Model: This assumption is used in Section 6.3.4.

\subsection{NO CORROSION PRODUCTS EXIST IN THE INVERT}

Assumption: It is assumed that no corrosion products exist in the invert.

Basis: Neglecting the corrosion products in the invert is an assumption that maximizes the potential transport of radionuclides through the invert. The invert consists of a carbon steel structural frame supported on the lower drift walls, and of crushed tuff ballast placed below and between the steel frame members. The invert steel structure consists of transverse beams anchored at each end on the drift wall, and of three longitudinal beams which directly support the waste package pallet. When the invert steel beams corrode, most of the iron oxide corrosion products will end up in the crushed tuff component of the invert. In addition, communication cables will eventually corrode, leaving copper oxide corrosion products in the invert. The crushed tuff has little radionuclide sorptive capacity compared to the metal oxide corrosion products, which are capable of sorbing large amounts of radionuclides, potentially enhancing the barrier capability of the invert. However, the corrosion products in the invert will tend to be localized and widely separated. For example, the transverse support beams in the invert are

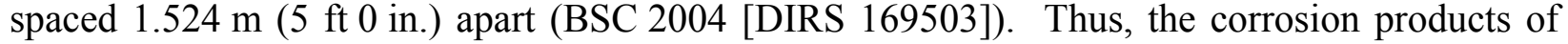
the support beams will reside in a strip a few centimeters wide separated by $1.524 \mathrm{~m}$ of crushed tuff containing little or no corrosion products. Compared with the length of a waste package [3.45 m (5 DHLW/DOE SNF - Short) to $5.84 \mathrm{~m}$ (Naval long) (BSC 2004 [DIRS 169472], Table 1)], the width of regions within the invert that would potentially contain corrosion products is small. Therefore, the chance of radionuclides being released from the waste package and passing through corrosion products in the invert is proportionately small. Although the invert will contain steel corrosion products, it is bounding in terms of radionuclide releases to neglect their presence.

Confirmation Status: This assumption does not require confirmation because it is a bounding assumption that reduces the potential effectiveness of the invert as a transport barrier; i.e., the potential for radionuclide sorption by steel corrosion products is ignored.

Use in the Model: This assumption is used in Section 6.3.4.2. 


\subsection{NO PHYSICAL FILTRATION OR GRAVITATIONAL SETTLING OF COLLOIDS}

Assumption: It is assumed that physical filtration and gravitational settling of colloids will not occur within the waste package and the drift.

Basis: Filtration processes may affect transport of radionuclide-bearing colloids in the waste and EBS. Colloid filtration as discussed here refers to the physical removal of colloids from a flow system by pore clogging, sieving, and straining. Filtration of colloids generally means the retention of colloids moving with the suspending fluid in pores, channels, and fracture apertures that are too small or dry to allow passage of the colloids.

In the EBS RT Abstraction, the assumption is made that all stable colloids formed within the waste package (the calculated colloid source term) exit the package and enter the invert without filtration. These colloids will then move through the invert material without being subjected to filtration until they reach the underlying UZ.

Filtration is excluded on the basis of low consequence. Since filtration within the waste package and the invert will actually occur to some extent, the modeling approach of neglecting filtration overestimates the potential impact of colloid-facilitated transport of radionuclides in the TSPA-LA dose calculations and is considered bounding.

In the EBS RT Abstraction, it is assumed that all stable radionuclide-bearing colloids will not be subject to gravitational settling. Assuming that gravitational settling will not occur results in an overestimation of the potential consequences of colloid-facilitated transport of radionuclides and is considered bounding.

Confirmation Status: This assumption does not require confirmation because it is a bounding assumption that reduces the potential effectiveness of the invert as a transport barrier.

Use in the Model: This assumption is used in Section 6.5.1.2. 
INTENTIONALLY LEFT BLANK 


\section{MODEL DISCUSSION}

\subsection{MODELING OBJECTIVE}

The objective of the EBS RT Abstraction is to provide the conceptual model used to determine the time-dependent flux of radionuclides from the EBS to the unsaturated zone in the TSPA-LA. In particular, this model is used to quantify such releases from a failed waste package and the subsequent transport of those radionuclides through the EBS to the emplacement drift wall/unsaturated zone interface. The basic time-dependent inputs to the EBS RT Abstraction in TSPA-LA calculations consist of the drift seepage influx, the environmental conditions in the drift (temperature, relative humidity, and water chemistry), and the degradation state of the EBS components. Outputs consist of the rates of radionuclide fluxes to the unsaturated zone as a result of advective and diffusive transport, radionuclide solubility, retardation, the degree of liquid saturation of the waste form and invert materials, and the impact of colloids on potential radionuclide transport. The EBS RT Abstraction is implemented directly into the TSPA-LA GoldSim model to compute the release rates; details of the implementation are provided in Section 6.5.3.

\subsubsection{Engineered Barrier System Components}

The EBS consists of the emplacement drift, waste form, cladding, drip shield, the waste package on an emplacement pallet, and an invert constructed with steel supports and filled between the steel framework with crushed tuff (BSC 2005 [DIRS 173978], Table A-1). The EBS RT Abstraction focuses on the drip shield, waste package, and invert. Each of the components of the EBS is designed to act as a barrier to prevent or delay the mobilization and release of radionuclides into the geologic environment (see Section 6.7 for a summary of barrier capabilities). For example, the drip shield is designed to redirect any seepage that flows into the drift away from the waste package. The invert supports the waste package and emplacement pallet. It acts as a barrier to diffusive transport of radionuclides in liquids if the liquid saturation in the crushed tuff is low. Figure 6.1-1 presents a typical cross-section of an emplacement drift and the major components of the EBS.

The drip shield is fabricated from titanium, a corrosion-resistant material to provide long-term effectiveness. The waste package outer corrosion barrier is comprised of Alloy 22. The major corrosive processes are stress corrosion cracking in the closure lid welds of the waste package, localized corrosion in the waste package outer corrosion barrier, and general corrosion for both the drip shield and waste package.

Once the drip shield fails (i.e., is initially breached), a portion of the total dripping flux can drip onto the waste package. It is possible for breaches to occur at the gap between adjacent waste packages. If breaches in the drip shield occur at the gap between two drip shield segments, which happens to be above a gap between waste packages, the dripping flux would fall directly to the invert, avoiding the waste package. The possibility that breaches in the drip shield can occur over a gap, allowing liquid to bypass the waste package, is not considered in the $E B S$ RT Abstraction. 


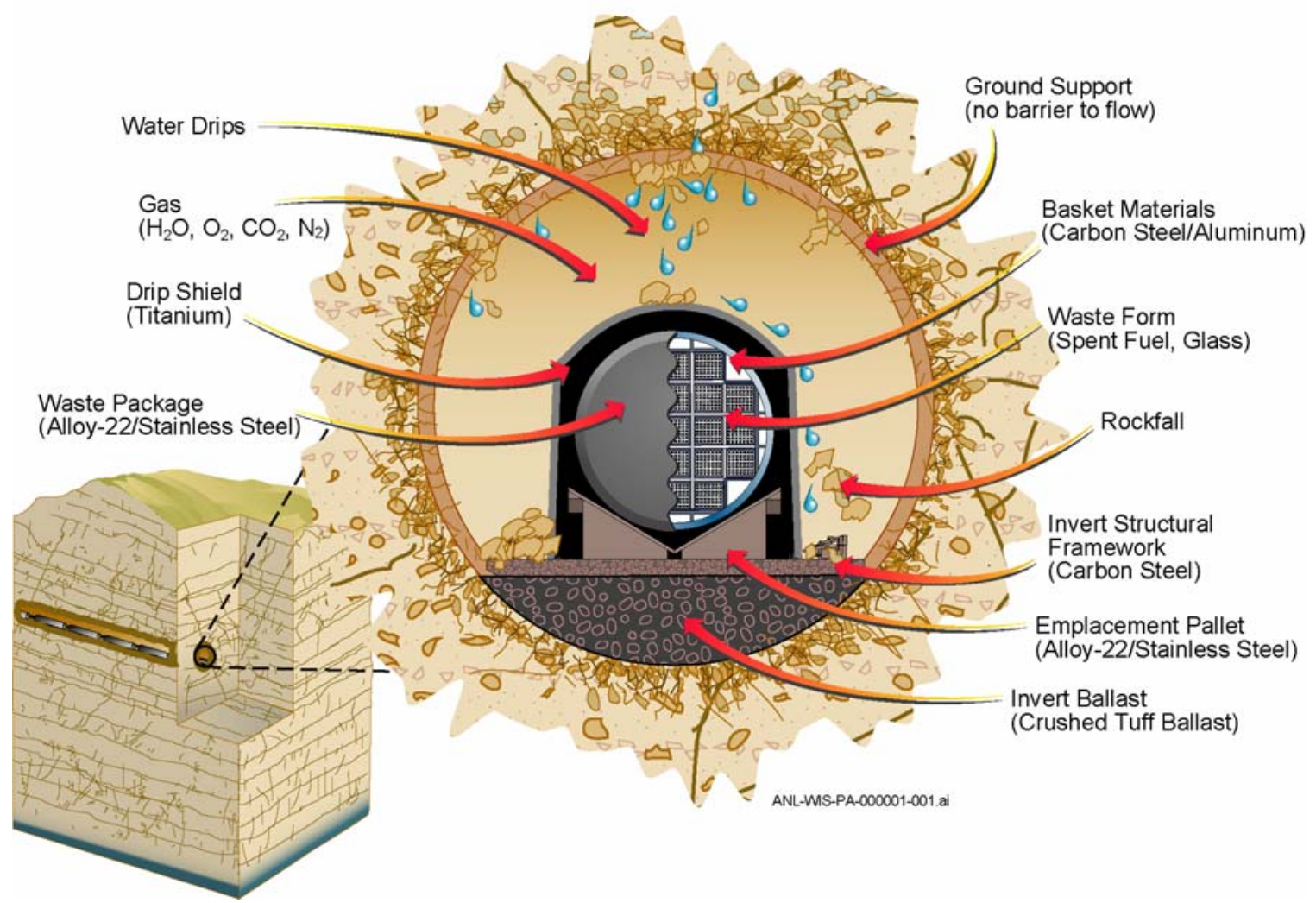

Figure 6.1-1. Schematic Diagram of a Typical Emplacement Drift and the Major Components of the EBS

After the waste package fails (breached by corrosion, seismic damage, igneous intrusion, or early failure mechanisms), a portion of the water that flows through the drip shield can enter the waste package, mobilizing radionuclides in any degraded waste form, and transporting these radionuclides into the unsaturated zone. Diffusion is the primary transport mechanism when the flux into the waste package is small or zero, or if stress corrosion cracks are the only penetrations through the waste package. Advective transport is important when the dripping flux occurs. In this case, advective fluxes can pass through the breaches in the drip shield and waste package.

\subsubsection{Scenario Classes for TSPA-LA}

A modeling case is a well-defined, connected sequence of features, events, and processes (FEPs) that can be thought of as an outline of a possible future condition in the repository system. Modeling cases can be designated as undisturbed, in which case the performance would be the expected or nominal performance of the system. Or, modeling cases can be designated as disturbed, if altered by disruptive events, such as human intrusion, or by natural phenomena, such as volcanism or nuclear criticality. A scenario class is a set of related modeling cases that share sufficient similarities to aggregate them usefully for the purposes of screening or analysis. 
The scenario classes included in TSPA-LA are the nominal scenario class, igneous scenario class, and seismic scenario class.

The three scenario classes are described briefly below. The EBS RT Abstraction applies to the nominal scenario class. Further information on the Igneous Scenario Class may be found in Atmospheric Dispersal and Deposition of Tephra from a Potential Volcanic Eruption at Yucca Mountain, Nevada (BSC 2004 [DIRS 170026]) and Dike/Drift Interactions (BSC 2004 [DIRS 170028]). Further information on the Seismic Scenario Class may be found in Seismic Consequence Abstraction (BSC 2005 [DIRS 173247]) and Characterize Framework for Seismicity and Structural Deformation at Yucca Mountain, Nevada (BSC 2004 [DIRS 168030]).

Nominal Scenario Class-The nominal scenario class for TSPA-LA encompasses all of the FEPs that are screened in, except for those FEPs related to igneous or seismic activity. This scenario class therefore incorporates the important effects and system perturbations caused by climate change and repository heating that are projected to occur over the 10,000-year regulatory-compliance period. In addition, the nominal scenario class considers that the waste packages and drip shields will be subject to EBS environments and will degrade with time until they are breached and expose the waste forms to percolating groundwater. Then the waste forms will degrade, releasing and mobilizing radionuclides that subsequently will be transported out of the repository. Radionuclides released from the repository then will be transported to the saturated zone by the groundwater percolating through the unsaturated zone below the repository, and then transported to the accessible environment by water flowing in the saturated zone.

The nominal scenario class is represented by two modeling cases. The first modeling case is for those waste packages that degrade by corrosion (general corrosion, stress corrosion cracking, and localized corrosion) under expected repository conditions. The second modeling case is for those waste packages that fail early due to manufacturing and material defects and pre-emplacement operations including improper heat treatment.

Igneous Scenario Class-The igneous scenario class describes performance of the repository system in the event of igneous activity that disrupts the repository and is represented by two modeling cases: (1) igneous intrusion into the repository emplacement drifts that results in release of radionuclides to the groundwater and (2) volcanic eruption through the repository resulting in release of radionuclides to the atmosphere. Both modeling cases assume that the igneous event consists of a magmatic penetration of the repository at some time after permanent closure.

The igneous intrusion modeling case assumes that an igneous dike intersects drifts of the repository and destroys drip shields and waste packages in those drifts intruded by magma, exposing the waste forms to percolating water and mobilizing radionuclides. The released radionuclides can then be transported out of the repository, and flow down through the unsaturated zone to the saturated zone, and then be transported through the saturated zone flow and transport system to the accessible environment. Radionuclide releases occur only as a result of igneous interactions with EBS components and not as a result of drip shield or waste package corrosion processes or early waste package failure. 
The volcanic eruption modeling case assumes that the magma flow associated with a dike intersects the repository and destroys a limited number of waste packages, transports waste from the destroyed waste packages to the land surface through one or more eruptive conduits, and then discharges tephra and entrained waste into the atmosphere and transports it downwind.

Seismic Scenario Class - The seismic scenario class describes performance of the repository system in the event of seismic activity that could disrupt the repository system. The seismic scenario class represents the direct effects of vibratory ground motion and fault displacement associated with seismic activity by considering the effects of the seismic hazards on drip shields, waste packages, and cladding. The seismic scenario class also takes into account changes in seepage, waste package degradation, and flow in the engineered barrier system that might be associated with a seismic event. The conceptual models and abstractions for the mechanical response of engineered barrier system components to seismic hazards are documented in Seismic Consequence Abstraction (BSC 2005 [DIRS 173247]).

The seismic scenario class is represented by two modeling cases. The first modeling case includes those waste packages that fail solely due to the ground motion damage associated with the seismic event. Only stress corrosion cracks appear on the waste packages from ground motion damage; these only allow diffusive transport of radionuclides. The presence of damaged areas and possible stress corrosion cracks on the drip shields are excluded from the TSPA-LA model (Seismic Consequence Abstraction, BSC 2005 [DIRS 173247], Sections 6.5.4 and 6.3.6). The primary cladding failure mechanism from vibratory ground motion is perforation due to accelerations when a waste package impacts an emplacement pallet or when there is an end-to-end impact between adjacent waste packages. The failed cladding fraction varies as a function of peak ground velocity.

The second modeling case includes only those waste packages that fail due to fault displacement damage. The drip shields over the waste packages that are damaged by fault displacement are completely degraded. Therefore, this group of waste packages could also be potentially damaged by crown seepage-induced localized corrosion after the seismic event has occurred. The cladding is fully failed in this modeling case while the damage area from the fault displacement on the waste package varies. The resulting damage is modeled as allowing flow into the waste package (if seepage is present) and allowing advective and diffusive transport out of the waste package.

\subsection{FEATURES, EVENTS, AND PROCESSES INCLUDED IN THE MODEL}

The development of a comprehensive list of FEPs potentially relevant to postclosure performance of the Yucca Mountain repository is an ongoing, iterative process based on site-specific information, design, and regulations. The approach for developing an initial list of FEPs, in support of TSPA-Site Recommendation (SR) (CRWMS M\&O 2000 [DIRS 153246]), was documented in The Development of Information Catalogued in REV00 of the YMP FEP Database (Freeze et al. 2001 [DIRS 154365]). The initial features, events and processes (FEP) list contained 328 FEPs, of which 176 were included in TSPA-SR models (CRWMS M\&O 2000 [DIRS 153246], Tables B-9 through B-17). To support TSPA-LA, the FEP list was re-evaluated in accordance with The Enhanced Plan for Features, Events, and Processes (FEPs) at Yucca Mountain (BSC 2002 [DIRS 158966], Section 3.2), resulting in the LA FEP list 
(DTN: MO0407SEPFEPLA.000 [DIRS 170760]). Table 6.2-1 provides a list of FEPs that are included in TSPA-LA models described in this model document, summarizes the details of their implementation in TSPA-LA, and provides specific references to sections within this document. Screening arguments for both included and excluded FEPs are summarized in Engineered Barrier System Features, Events, and Processes (BSC 2005 [DIRS 173781]). The following excluded FEPs listed in the TWP (BSC 2005 [DIRS 173617], Table 1) as being associated with this report are summarized in Engineered Barrier System Features, Events, and Processes (BSC 2005 [DIRS 173781]) and are not addressed in this report:

- 2.1.06.05.0A - Mechanical degradation of emplacement pallet

- 2.1.08.01.0B - Effects of rapid influx into the repository

- 2.1.08.14.0A - Condensation on underside of drip shield

- 2.2.07.06.0A - Episodic/pulse release from repository

- 2.2.07.21.0A - Drift shadow forms below repository.

Table 6.2-1. Included FEPs for This Report

\begin{tabular}{|c|l|l|}
\hline FEP No. & \multicolumn{1}{|c|}{ FEP Name/FEP Description } & \multicolumn{1}{|c|}{$\begin{array}{c}\text { Section Where Disposition } \\
\text { Is Described }\end{array}$} \\
\hline $2.1 .06 .06 .0 \mathrm{~A}$ & Effects of drip shield on flow & $\begin{array}{l}6.3 .2 .4 \\
6.5 .1 .1\end{array}$ \\
\hline $2.1 .08 .04 .0 \mathrm{~A}$ & $\begin{array}{l}\text { Condensation forms on roofs of drifts (drift-scale } \\
\text { cold traps) }\end{array}$ & 6.3 \\
\hline $2.1 .08 .04 .0 \mathrm{~B}$ & $\begin{array}{l}\text { Condensation forms at repository edges } \\
\text { (repository-scale cold traps) }\end{array}$ & 6.3 \\
\hline $2.1 .08 .05 .0 \mathrm{~A}$ & Flow through invert & 6.3 \\
& & 6.5 \\
\hline $2.1 .08 .06 .0 \mathrm{~A}$ & Capillary effects (wicking) in EBS & 6.3 \\
& & 6.5 \\
\hline $2.1 .08 .07 .0 \mathrm{~A}$ & Unsaturated flow in the EBS & 6.3 \\
& & 6.5 \\
\hline $2.1 .09 .05 .0 \mathrm{~A}$ & Sorption of dissolved radionuclides in EBS & 6.3 .4 .2 \\
& & 6.5 .1 .2 \\
\hline $2.1 .09 .08 .0 \mathrm{~A}$ & Diffusion of dissolved radionuclides in EBS & 6.5 .3 \\
\hline & & 6.3 .1 .2 \\
& & 6.3 .4 .1 \\
\hline $2.1 .09 .08 .0 \mathrm{~B}$ & Advection of dissolved radionuclides in EBS & 6.5 .1 .2 \\
\hline $2.1 .09 .19 .0 \mathrm{~B}$ & Advection of colloids in EBS & 6.5 .3 .1 \\
\hline & & 6.3 .1 .2 \\
\hline $2.1 .09 .24 .0 \mathrm{~A}$ & Diffusion of colloids in EBS & 6.5 .1 .2 \\
& & 6.5 .3 \\
\hline $2.1 .11 .09 .0 \mathrm{~A}$ & Thermal effects on flow in the EBS & 6.3 .4 .4 \\
\hline $2.2 .07 .06 .0 \mathrm{~B}$ & Long-term release of radionuclides from & 6.5 .1 .2 \\
& the repository & 6.5 .3 \\
\hline
\end{tabular}




\subsection{BASE CASE CONCEPTUAL MODEL}

\subsubsection{Introduction and Overview}

\subsubsection{EBS Flow Abstraction}

The primary source of inflow to the EBS is the dripping flux from the crown (roof) of the drift and includes seepage flux and any condensation that may occur on the walls of the drift above the drip shield. The seepage flux is driven by downward infiltration through the existing fracture system at Yucca Mountain. The seepage flux is conceptualized to flow from discrete fractures above the roof of the drift, falling vertically downward, and is represented in the TSPA-LA model through Abstraction of Drift Seepage (BSC 2004 [DIRS 169131]). Condensation on the drift walls is represented in the TSPA-LA model through the In-Drift Natural Convection and Condensation Model (BSC 2004 [DIRS 164327]). A secondary source of inflow to the EBS is imbibition into the invert crushed tuff particles from the surrounding UZ rock matrix. The inflow from these sources can flow through the EBS along eight pathways, as shown in Figure 6.3-1.

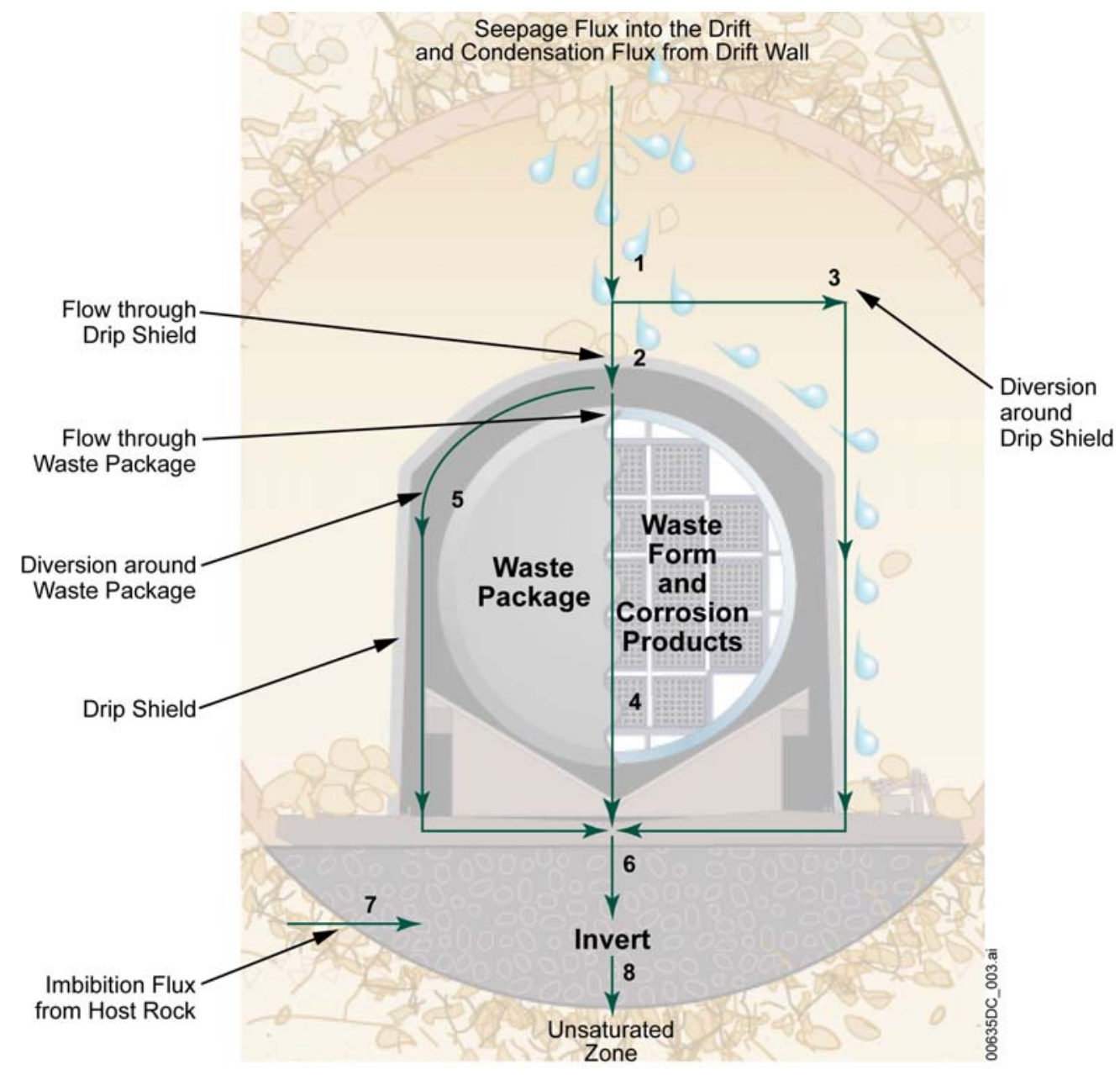

Figure 6.3-1. Schematic of the Potential Flow Pathways in the EBS 
The eight pathways are (with the volumetric water flux through pathway $j$ designated by $F_{j}$ ):

1. Total dripping flux $\left(\boldsymbol{F}_{\mathbf{1}}\right)$-This is the seepage inflow (dripping flux) from the crown (roof) of the drift plus any condensation that may occur on the walls of the drift above the drift shield.

2. Flux through the drip shield $\left(\boldsymbol{F}_{2}\right)$-The flux through the drip shield is based on the presence of patches due to general corrosion; localized corrosion on the drip shield is not expected to occur within the regulatory time period for repository performance (10,000 years) (BSC 2005 [DIRS 173978], Section 6.2.5), and stress corrosion cracking on the drip shield has been screened out on the basis of low consequence (BSC 2005 [DIRS 173781], Section 6.2.64). The liquid flux through corrosion patches is proportional to the ratio of the axial length of the penetration(s) in the drip shield to the total axial length of a drip shield section (see Section 6.3.2.4). This flux splitting submodel for the drip shield should only be applied when there is a time-varying failure of the drip shield.

3. Diversion around the drip shield $\left(\boldsymbol{F}_{3}\right)$-The portion of the flux that does not flow through the drip shield is assumed to flow directly into the invert.

4. Flux through the waste package $\left(\boldsymbol{F}_{4}\right)$-The flux through the waste package is based on the presence of patches due to general corrosion and localized corrosion in the waste package outer barrier. The number of patches in the waste package is calculated independently of the EBS RT Abstraction by the WAPDEG code (BSC 2004 [DIRS 169996]). The flux through waste package corrosion patches is proportional to the ratio of the axial length of the penetration(s) in the waste package to the total axial length of a waste package (see Section 6.3.3.2).

5. Diversion around the waste package $\left(\boldsymbol{F}_{5}\right)$-The portion of the flux that does not flow into the waste package bypasses the waste form and flows directly into the invert.

6. Flux into the Invert $\left(\boldsymbol{F}_{\mathbf{6}}\right)$-All water flux from the waste package is modeled as flowing directly into the invert, independent of patch location on the waste package. In addition, the fluxes that were diverted around the waste package $\left(F_{5}\right)$ and around the drip shield $\left(F_{3}\right)$ flow into the invert. Only a portion of the total flux to the invert (the flux through the waste package, $F_{4}$ ) will contain radionuclides.

7. Imbibition Flux to the Invert $\left(\boldsymbol{F}_{7}\right)$-Water can be imbibed from the host rock matrix into the invert.

8. Flux from the Invert to the Unsaturated Zone $\left(\boldsymbol{F}_{\mathbf{8}}\right)-\mathrm{A}$ portion of the advective flux from the invert equal to the total dripping flux $\left(F_{1}\right)$ flows directly into the unsaturated zone (UZ) fractures. The portion of the advective flux from the invert equal to the imbibition flux to the invert $\left(F_{7}\right)$ flows into the UZ matrix. 
These pathways are time dependent, in the sense that total dripping flux, drip shield gaps, drip shield penetrations, and waste package penetrations will vary with time and local conditions in the repository.

The conceptual model for flow through the EBS includes three domains associated with radionuclides: the waste form domain (composed of either fuel rods, HLW glass, or DSNF), waste package corrosion products domain, and the invert domain. The waste form domain for the codisposal packages is divided into two subdomains, HLW glass and DSNF, due to different degradation characteristics of the waste form and associated transport parameters. The waste form domain is conceptualized to have a concentric cylindrical geometry for volume calculations, with one-dimensional flow. The waste form domain is part of the waste package that contains fuel rods or glass logs and DSNF, which undergo alteration to form a rind. The thickness of the rind changes as the degradation of the fuel rod or glass log continues; the DSNF degrades almost instantaneously and the rind thickness remains fixed. The second domain (corrosion products from degradation of steel internal components) fills the inside of a waste package within the Alloy 22 outer corrosion barrier, so its thickness is uncertain and can be as much as the radius of the waste package. The third domain (invert) is modeled as being in intimate contact with the waste package and has a thickness of $0.597 \mathrm{~m}$ (see Section 6.5.3). This is the average thickness of the invert, and appropriate for the one-dimensional transport calculation. Because the presence of the emplacement pallet is ignored, water and radionuclides pass directly from the waste package to the invert.

The waste form domain represents the source term for the TSPA-LA. Source term abstractions are defined in other model reports or design documents for radionuclide solubility (BSC 2005 [DIRS 174566]), HLW glass dissolution rate (BSC 2004 [DIRS 169988]), cladding response (BSC 2005 [DIRS 172895]), and inventory by waste package type (BSC 2004 [DIRS 169472], Table 11). The source term represents input data or boundary conditions for the EBS $R T$ Abstraction and is not discussed in this document.

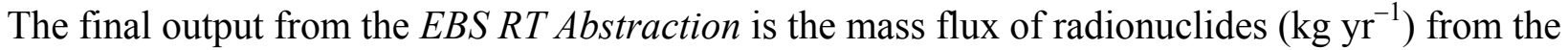
EBS into the unsaturated zone. The parameters and formulas for calculating the water fluxes in the various pathways are summarized in Table 6.3-1. 
Table 6.3-1. Summary of Parameters for EBS Flow Pathways

\begin{tabular}{|c|c|c|}
\hline Flow Pathway, Pathway Flux $F_{j}$ & Flow Parameters & Data Sources \& Notes \\
\hline $\begin{array}{l}\text { 1. Total dripping flux (seepage }+ \\
\text { wall condensation), } F_{1}\end{array}$ & $\begin{array}{l}\text { Total dripping flux is a function of } \\
\text { fracture properties, rock properties, } \\
\text { air and water properties, and the } \\
\text { percolation flux. }\end{array}$ & $\begin{array}{l}\text { Abstraction of Drift Seepage (BSC } \\
2004 \text { [DIRS 169131]) and In-Drift } \\
\text { Natural Convection and Condensation } \\
\text { (BSC } 2004 \text { [DIRS 164327]) provide } \\
\text { time- and location-dependent values } \\
\text { of total dripping flux. }\end{array}$ \\
\hline $\begin{array}{l}\text { 2. Flux through the drip shield, } \\
F_{2}\end{array}$ & $\begin{array}{l}L_{D S} \text { Patch is the axial half-length of } \\
\text { each patch due to general corrosion } \\
\text { of titanium. } \\
L_{D S} \text { is the axial length of the drip } \\
\text { shield. } \\
N_{b D S} \text { is the number of corrosion } \\
\text { patches of length } L_{D S \_P a t c h} \text { in the drip } \\
\text { shield. } \\
f_{D S}^{\prime} \text { is sampled uncertain parameter, } \\
\quad \text { Flux_Split_DS_Uncert. } \\
F_{2}=\min \left[F_{1} N_{b D S} L_{D S} \text { Patch } f_{D S}^{\prime} / L_{D S}, F_{1}\right]\end{array}$ & $\begin{array}{l}\text { This flux splitting submodel for the drip } \\
\text { shield should only be applied when } \\
\text { there is a time-varying failure of the } \\
\text { drip shield. For the seismic scenario } \\
\text { class, the opening area is computed } \\
\text { based on the drip shield damage } \\
\text { fraction multiplied by the area of the } \\
\text { drip shield. }\end{array}$ \\
\hline $\begin{array}{l}\text { 3. Diversion around drip } \\
\text { shield, } F_{3}\end{array}$ & $F_{3}=F_{1}-F_{2}$ & Continuity of liquid flux. \\
\hline 4. Flux into the WP, $F_{4}$ & $\begin{array}{l}L_{W P} \text { Patch is the axial half-length of } \\
\text { each patch due to general corrosion } \\
\text { of Alloy } 22 . \\
L_{W P} \text { is the axial length of the WP. } \\
N_{b W P} \text { is the number of corrosion } \\
\text { patches in the waste package. } \\
f^{\prime}{ }_{W P} \text { is sampled uncertain parameter, } \\
\text { Flux_Split_WP_Uncert. } \\
F_{4}=\min \left[F_{2} N_{b W P} L_{W P}{ }_{\text {Patch }} f_{W P}^{\prime} / L_{W P}, F_{2}\right]\end{array}$ & $\begin{array}{l}\text { WAPDEG (BSC } 2004 \text { [DIRS 169996]) } \\
\text { provides the number of patches and } \\
\text { stress corrosion cracks on the WP. } \\
\text { No significant flow through stress } \\
\text { corrosion cracks due to plugging (BSC } \\
2005 \text { [DIRS 173781], Section 6.2.63). } \\
\text { Steady state flow through WP (outflow } \\
=\text { inflow in steady state; this is } \\
\text { bounding for release). }\end{array}$ \\
\hline 5. Diversion around the WP, $F_{5}$ & $F_{5}=F_{2}-F_{4}$ & Continuity of liquid flux. \\
\hline 6. Flux to the invert, $F_{6}$ & $\begin{aligned} F_{6} & =F_{5}+F_{4}+F_{3} \\
& =F_{1}\end{aligned}$ & $\begin{array}{l}\text { All advective flux enters the invert. } \\
\text { Only } F_{4} \text { can transport radionuclides } \\
\text { into the invert. }\end{array}$ \\
\hline $\begin{array}{l}\text { 7. Imbibition flux from the host } \\
\text { rock matrix into the invert, } F_{7}\end{array}$ & $F_{7}$ is an input to the EBS flow model. & $\begin{array}{l}\text { Imbibition flux is provided by } \\
\text { Multiscale Thermohydrologic Model } \\
\text { calculations (BSC } 2005 \\
\text { [DIRS 173944]). }\end{array}$ \\
\hline $\begin{array}{l}\text { 8. Flux from the invert into the } \\
\text { unsaturated zone, } F_{8}\end{array}$ & $\begin{aligned} F_{8} & =F_{6}+F_{7} \\
& =F_{1}+F_{7}\end{aligned}$ & $\begin{array}{l}\text { Total dripping flux portion }\left(F_{1}\right) \text { of } \\
\text { advective flux from the invert flows into } \\
\text { the UZ fractures, imbibition flux }\left(F_{7}\right) \\
\text { flows into the UZ matrix. }\end{array}$ \\
\hline
\end{tabular}

WP=waste package; UZ=unsaturated zone

\subsubsection{EBS Transport Abstraction}

The waste form is the source of all radionuclides considered for the EBS. Radionuclides can be transported downward, through the invert and into the unsaturated zone. Transport can occur through advection when there is a liquid flux through the waste package and invert, via pathways 4, 6, and 8 in Figure 6.3-1. Transport can also occur by diffusion in the waste form, in the waste package corrosion products, in stress corrosion cracks in the lid of the waste package, and in the invert, even in the absence of a liquid flux, because it is assumed (Assumption 5.5) 
that there is a continuous liquid pathway via thin films. Diffusive transport may occur via flow pathways 4,6 , and 8 even when no advection occurs on those pathways in the EBS flow model.

A detailed mathematical description of transport in the EBS is presented in Section 6.5.1.2. Retardation of radionuclides occurs in the waste package. Transport occurs by diffusion and by advection. Table 6.3-2 summarizes the modes and parameters for the transport pathways in the EBS.

Lateral and longitudinal dispersion are neglected in modeling radionuclide transport in the EBS. Because the EBS radionuclide transport model is a one-dimensional model, the lateral dispersion effects cannot be considered. This also maximizes the concentration in a given domain for greater mass flux. Longitudinal dispersion could potentially be considered in the invert, where advection is expected to occur due to imbibition flux, even when there is no drift seepage flux. However, the longitudinal dispersivity is uncertain, being dependent on the scale of transport (Anderson and Woessner 1992 [DIRS 123665], p. 326) and on porous media characteristics that are not well-defined. Since the thickness of the invert is less than one meter, longitudinal dispersion is expected to be small and to have negligible effect on the breakthrough times through the invert compared to the simulated time-steps considered in TSPA (tens of years). In addition, as shown in Section 6.3.4.1, the uncertainty in the invert diffusion coefficient ranges over a factor of 20 and essentially encompasses the variable breakthrough times that could occur from including the longitudinal dispersion. The dispersivity of the waste form and waste package corrosion product domains is also difficult to characterize; however, because the scale of these domains is comparable to that of the invert, and because the diffusion coefficients in these domains are similar (or larger) than those in the invert, it is reasonable to neglect dispersivity in these domains as well as in the invert.

There is no upward transport of radionuclides because there is no solid medium with a liquid pathway above the drip shield. After the drip shield is breached, upward diffusion is negligible in comparison to the downward advective flux through the drip shield. Gas transport in the EBS (FEP 2.1.12.06.0A) is excluded due to low consequence (BSC 2005 [DIRS 173781], Section 6.2.78).

Colloid-facilitated transport of radionuclides is included in the EBS RT Abstraction. Radionuclide transport from the waste package occurs in a liquid containing colloids and dissolved radionuclides. There are three types of colloids in the EBS: (a) waste form colloids from degradation of HLW glass, (b) iron oxyhydroxide colloids due to products from the corrosion of steel waste package components, and (c) groundwater or seepage water colloids. All three types of colloids may have reversibly sorbed radionuclides. The waste form colloids may have irreversibly attached (embedded) radionuclides and the corrosion products colloids may have reversibly attached (sorbed) radionuclides. However, some radionuclides, such as $\mathrm{Pu}$ and Am, can be so strongly sorbed onto iron oxyhydroxide that for modeling purposes they can be considered to be irreversibly sorbed. Colloids may be transported by diffusion as well as by advection. The diffusion coefficient for colloids is less than that of dissolved species, but colloids are not excluded from diffusion due to size. 
Table 6.3-2. Summary of Transport Modes and Parameters for the EBS Transport Pathways

\begin{tabular}{|c|c|c|}
\hline Transport Pathway & Transport Modes & Transport Parameters and Data Sources \\
\hline $\begin{array}{l}\text { 1. Waste form and } \\
\text { corrosion products } \\
\text { domains }\end{array}$ & $\begin{array}{l}\text { Diffusion through stress } \\
\text { corrosion cracks (no } \\
\text { advective transport through } \\
\text { stress corrosion cracks). } \\
\text { Diffusion and advection } \\
\text { through corrosion products } \\
\text { and corrosion patches. }\end{array}$ & $\begin{array}{l}\text { No lateral or forward dispersion. } \\
\text { Colloidal particles will transport radionuclides. } \\
\text { Diffusive area for each stress corrosion crack is } \\
7.7 \times 10^{-6} \mathrm{~m}^{2} \text { (see Section } 6.3 .3 .1 .2 .1 \text { ). } \\
\text { Diffusive area for each patch is provided by WAPDEG } \\
\text { (BSC } 2004 \text { [DIRS } 169996 \text { ]). } \\
\text { Diffusion coefficient (all radionuclides): } \\
\qquad \quad 2.299 \times 10^{-5} \mathrm{~cm}^{2} \mathrm{~s}^{-1} \text { at } 25^{\circ} \mathrm{C} \text { (Mills } 1973 \\
\text { [DIRS } 133392 \text { ], Table III) } \\
\text { Modified for porosity and saturation (see } \\
\quad \text { Section } 6.3 .4 .3 .5 \text { ); not modified for } \\
\text { temperature } \\
\quad \text { Reduced by a factor of } 100 \text { if radionuclide is } \\
\text { bound to a colloid (Section } 6.3 .4 .4 \text { ) } \\
\text { The flow cross-sectional area is given by the interface } \\
\text { between the waste package corrosion products } \\
\text { domain and the invert domain. } \\
\text { See Section } 6.5 .3 \text { for further details. }\end{array}$ \\
\hline 2. Invert & $\begin{array}{l}\text { Diffusion and advection } \\
\left(F_{6}\right) \text { from corrosion } \\
\text { products domain through } \\
\text { the invert. } \\
\text { Advection from the UZ into } \\
\text { the invert }\left(F_{7}\right) \text {. }\end{array}$ & 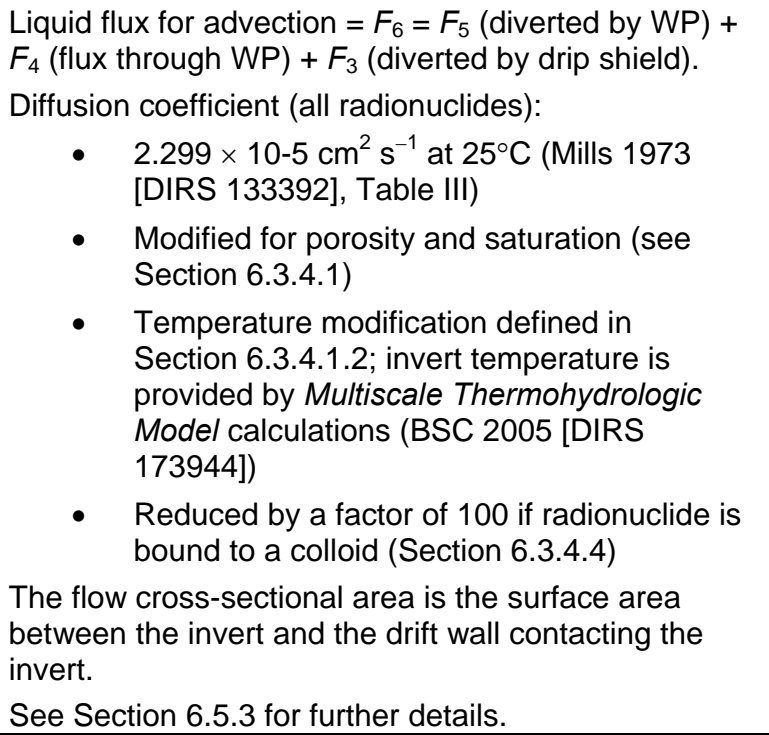 \\
\hline 3. Invert-UZ interface & $\begin{array}{l}\text { Advection from the invert } \\
\text { to } \cup Z \text { fractures }\left(F_{6}\right) \text { and } \cup Z \\
\text { matrix }\left(F_{7}\right) \text {; total flux is } F_{8} \text {. } \\
\text { Diffusion from the invert to } \\
\text { UZ fractures and matrix. }\end{array}$ & $\begin{array}{l}\text { The invert diffusion calculation uses radionuclide } \\
\text { concentrations in the WP corrosion products domain } \\
\text { as the boundary condition at the top of the invert and a } \\
\text { series of unsaturated zone computational cells below } \\
\text { the invert that provide a gradient to a zero radionuclide } \\
\text { concentration at some distance from the bottom of the } \\
\text { invert (Section 6.5.3.6). }\end{array}$ \\
\hline
\end{tabular}

$\mathrm{WP}=$ waste package; $\mathrm{UZ}=$ unsaturated zone

The diffusion coefficient in the invert is based on the self-diffusion coefficient of water at $25^{\circ} \mathrm{C}$ as a bounding value for all radionuclides. The effects of variable porosity, liquid saturation, temperature, and uncertainty in the effect of these parameters are also included in calculating the diffusion coefficient. 
The corrosion products from the waste package and SNFs have the potential to be strong sorbers for the actinides. Including sorption in the waste package and invert is beneficial to performance because this process can retain radionuclides in the EBS and delay release to the unsaturated zone. Because the waste package corrosion products are in intimate contact with or directly in the flow or diffusion path of the radionuclide source inside the waste package, retardation by corrosion products inside the waste package will occur. However, because corrosion products in the invert are more localized and not necessarily in any flow path from the waste package, sorption onto corrosion products in the invert is ignored (Assumption 5.6).

\subsubsection{Water Flux through the Drip Shield $\left(F_{2}\right)$}

\subsubsection{Water Movement into and through a Drift $\left(F_{1}\right.$ and $\left.F_{3}\right)$}

Water movement from the land surface and down through the unsaturated zone at Yucca Mountain is conceptualized to occur through a dual continuum of the rock matrix and a system of fractures (Liu et al. 1998 [DIRS 105729]). Simulations of water movement through the mountain yield estimates of percolation fluxes in the vicinity of the emplacement drifts that are a function of drift location, the geologic unit in which the drift resides, and the climate, which varies over time (BSC 2004 [DIRS 167652]). Consideration of the interactions between water moving through the mountain and the EBS form the basis of this abstraction for performance assessment.

The basic EBS design concept is shown in Figure 6.1-1 (Canori and Leitner 2003 [DIRS 166275], Figure 7-14). The drifts are $5.5 \mathrm{~m}$ in diameter. The bottom of the drift, commonly referred to as the invert, is filled with a ballast material of crushed tuff. The waste packages are to be placed on emplacement pallets that hold them in place above the invert. A titanium drip shield surrounds the waste packages. The space between the waste package and the drip shield, which is referred to as the axial space, is designed to remain air filled. The current repository design does not include an engineered backfill material (Canori and Leitner 2003 [DIRS 166275]); all of the analyses in this report reflect the no-backfill design.

At early times, any water that enters the drift is vaporized and expelled due to the heat output from the waste packages. According to modeling of water movement through the EBS using Multiscale Thermohydrologic Model (BSC 2005 [DIRS 173944]), much of the water that enters the drift remains as liquid once thermal output has subsided after approximately 2,000 years. Water that does seep into the drift can drip onto the drip shield and is diverted around the waste package, into the invert.

Water enters the drift by seepage from the roof of the drift. In this section, this mechanism is considered, followed by a discussion of water diversion around the drip shield.

\subsection{Seepage and Condensation Flux $\left(F_{1}\right)$}

Seepage Model for PA Including Drift Collapse (BSC 2004 [DIRS 167652]) presents results of drift-scale UZ flow modeling of the interaction between host rock containing a fracture continuum and a drift for a variety of percolation flux rates and several sets of representative host rock hydraulic parameters. The seepage flux was found to be related to the percolation flux. However, the air-filled space below the roof of the drift acts as a capillary barrier that diverts 
water around the drift and limits seepage. These findings are consistent with the theory for seepage exclusion around cylindrical cavities introduced by Philip et al. (1989 [DIRS 105743]). Philip et al. showed that for given capillary properties of the host rock and a given drift diameter, there exists a critical percolation flux beneath which water will not enter the drift. The drift-scale unsaturated zone flow modeling results show a propensity for flow to diverge around the drifts.

Abstraction of Drift Seepage (BSC 2004 [DIRS 169131]) provides the rationale for calculating the seepage flux into the repository, accounting for thermal effects, spatial variability, and uncertainty of properties. The fraction of drifts that experience water seepage as a function of infiltration are given as a function of percolation rate. Across the range of percolation fluxes expected, a large majority of the drifts remain dry. In-Drift Natural Convection and Condensation Model (BSC 2004 [DIRS 164327], Section 8.3.1) provides the abstraction for determining the amount of condensation on the drift walls. This condensation is added to the seepage flux, resulting in the total dripping flux, $F_{1}$. The effects of repository-scale condensation are captured within this model.

\subsection{Diversion around the Drip Shield $\left(F_{3}\right)$}

The drip shield has been designed to divert liquid water that may enter the drift away from the waste package. If the drip shield works as designed (this issue is discussed in detail below), it then acts as a no flow boundary. Any seepage that enters the drift moves downward under the force of gravity. As water migrates downward around the drip shield, it encounters the invert. The diversion around the drip shield occurs as droplets or rivulets, and any flow that enters the invert is concentrated at the sides of the drip shield while the drip shield is intact.

Once in the invert, water migrates quickly into the unsaturated zone host rock at the bottom of the drift.

The algorithm for calculating the flux diversion around a breached drip shield is discussed in Section 6.3.2.4.

\subsubsection{Drip Shield Effectiveness}

Design drawings for the drip shield are given in $D \& E$ / PA/C IED Interlocking Drip Shield and Emplacement Pallet (BSC 2005 [DIRS 173303]) with details in drawings 000-M00-SSE000102-000-00B (BSC 2004 [DIRS 168067]), 000-M00-SSE0-02001-000-00A (BSC 2004 [DIRS 168326]), and other drawings cited on the information exchange drawing (IED). The drip shield has roughly the shape of the top of a mailbox with vertical sides and a top section that is curved for strength and to shed water. On one end, a drip shield connector guide is attached to the top of the curved section. The connector guide is a square rib, $50 \mathrm{~mm}$ wide (BSC 2004 [DIRS 168326]), that is attached to and extends across the curved top section. This connector guide provides extra stiffness to the end of the drip shield and can deflect seepage down the sides of the drip shield. On the other end of the drip shield, a connector plate is attached. The connector plate is $15 \mathrm{~mm}$ thick (BSC 2005 [DIRS 173303], Table 5) and also has a 50-mm-wide square connector guide (BSC 2004 [DIRS 168326]) that is attached to the underside of the connector plate. 
Adjacent drip shields are interlocked with one another. This is accomplished during installation by lowering the connector plate of one drip shield over the upward extending connector guide of the previously emplaced drip shield. The minimum overlap is the width of two connector guides, $100 \mathrm{~mm}$ (BSC 2004 [DIRS 168067]), and the maximum overlap between adjacent drip shields is $320 \mathrm{~mm}$ (BSC 2004 [DIRS 168067], Section A-A).

The gaps that exist between drip shields in this interlocking design can, potentially, provide a pathway for water to penetrate the drip shield system. The potential for such leakage under design conditions is considered here, followed by consideration of the ways in which the integrity of the drip shield might become compromised. This discussion is limited to considering the top of the drip shield because any water entering the contact between drip shields from the side would simply flow down the vertical sides of the drip shields, never contacting the waste.

Consider a system where the titanium walls of the drip shield form a barrier to flow. Water flux through the drip shield will now be limited to the gap where adjacent drip shields interlock. If high seepage flux conditions exist, then the flow can be driven into this gap. First, the water must travel laterally up to $320 \mathrm{~mm}$ to get beyond the overlap between the drip shields. As this water travels, it must remain precisely along the crown of this gap between the drip shields. If there is any deviation, the sloping sides of the drip shield impose gravity forces that will cause the water to flow down the sides and into the invert. Second, the upward extending drip shield connector guide provides a barrier to flow along the crown. Sufficient water pressure must be provided to push water up and over this barrier. Furthermore, the connector guides provide surfaces of contact with the drip shield and the connector plate. These contact surfaces maintain continuity down along the sloping sides of the top portion of the drip shield. These contacting surfaces will act akin to fractures in the sense that they impart capillarity and are able to transmit water. Any water reaching this point would run down the contact between the drip shields. Note also that the air-filled voids (having no capillarity) in between and beyond the connector guides provide an additional barrier to flow.

\subsubsection{Drip Shield Breaching}

The advective flow of water into the EBS has been shown to be effectively segregated from the waste packages as long as the integrity of the drip shield is maintained. Once corrosion patches form in the drip shield or adjacent drip shields separate, seepage can drip through the drip shield onto the waste package. The consequence of such drip shield failure is that a portion of the seepage water flux now migrates through the drip shield and comes into contact with the waste package. The thermal and mechanical response of the drip shield may produce gaps between adjacent sections of drip shield. These breaching mechanisms are screened out in Engineered Barrier System Features, Events, and Processes (BSC 2005 [DIRS 173781], Section 6.2.27, FEP 2.1.11.07.0A; Section 6.2.27, FEP 2.1.06.07.0B).

\subsubsection{Water Flux through and around a Breached Drip Shield $\left(F_{2}\right.$ and $\left.F_{3}\right)$}

Once the drip shield has been breached, a portion of the water flux $\left(F_{2}\right)$ will pass through the drip shield and have access to the waste package. In this section, a flux splitting algorithm is developed to determine the fraction of the seepage flux that can pass through a degraded drip shield. A similar algorithm is developed in a later section to determine the fraction of the liquid 
flux through the drip shield that can enter a waste package. The flux splitting algorithm is important to TSPA-LA because the liquid flux into the waste package determines in part the transport of radionuclides by advection, an important release mechanism from the waste package and from the repository.

Once the flux through the drip shield is known, the flux diverted around the drip shield, $F_{3}$, is calculated using a quasi-static continuity of flow approach:

$$
F_{3}=F_{1}-F_{2} .
$$

Key features of the drip shield flux splitting algorithm include: (1) the dripping flux (seepage plus condensation) into the drift falls as droplets from the top of the drift onto the crown of the drip shield (Assumption 5.1); (2) droplets fall randomly along the length of the drip shield; (3) only flow through general corrosion patches is considered; (4) evaporation from the drip shield is neglected (Assumption 5.2); all of the seepage flux either flows through corrosion patches or drains down the sides of the drip shield; and (5) all water that flows through breaches in the drip shield flows onto or into the waste package.

Some aspects of the flux splitting algorithm have been defined or clarified by experiments. The breached drip shield experiments (BSC 2003 [DIRS 163406]) were performed to validate the drip shield flux splitting algorithm and to examine in more detail the real behavior of seepage water impinging on and flowing over a drip shield. The tests were conducted by dripping water onto a mock-up portion of a full-scale drip shield made of stainless steel. The mock-up section included slightly more than half of the shield from the top/center down the curvature to the side. The side was shortened along the longitudinal and vertical axes. Simulated corrosion patches-square holes $27 \mathrm{~cm}$ wide, the size of nodes in an earlier version of the WAPDEG corrosion model (CRWMS M\&O 2000 [DIRS 151566], p. 36)-were cut into the drip shield at various locations to enable measurements of flow through breaches in the drip shield. Tests were performed with both smooth (machined stainless steel) and rough (silica anti-slip coating) surfaces. Data from the tests on the smooth surface were used to develop parameter values for the flux splitting submodel, whereas the rough surface test data were used to validate the submodel. Tests were conducted in a test chamber in an environment that would minimize evaporation (i.e., relative humidity of at least 80 percent). Water was dripped at various rates intended to cover the expected range of seepage rates within the repository. The dripping distance was the full-scale distance from the top of the drift to the crown of the drip shield, 2.17 m (BSC 2003 [DIRS 163406], Figure 10), based on repository design.

The tests that were conducted included (BSC 2003 [DIRS 163406]): (1) splash radius tests to determine the distance from the point of impact and a rough distribution of splattered water when drops impinge on the surface of the drip shield; (2) spread factor tests to determine the lateral rivulet spread distance from the drip impact point; (3) single patch splash tests to determine the amount of water that enters targeted breaches as a result of splashing; (4) single patch flow tests to determine the amount of water that flows down the surface of the drip shield and into patches; (5) multiple patch tests to collect both splashed water and rivulet flows that entered all affected patches; and (6) bounding flow rate tests to provide data for extreme drift seepage conditions to compare with the nominal seepage rate. 
Observations during the breached drip shield tests revealed that the primary mechanism for water to enter breaches is via rivulet flow that originates from an area around the point of drip impact. Following droplet impact at the crown, water splatters within some distance from the point of impact. The splattered water coalesces, forming beads that increase in size around the center of impact with each successive drop. After a time, the beads closest to the downhill curvature reach a critical mass and roll down the face of the drip shield in the form of a rivulet. The rivulet flow area spreads out in a delta formation (i.e., the maximum spread is located on the vertical section of the drip shield and the minimum spread is located at the point of impact). No film flow was observed during tests on the smooth or the rough drip shield surfaces.

Evaporation could occur in two forms during the test-from a freely falling drop and from a flow surface on the drip shield. The loss from a falling droplet is negligible; however, losses from the drip shield surface can be large. Experimental measurements included determination of evaporative losses. Although these data could be used to develop or validate a drip shield evaporation model, evaporation is not considered in the current model, which maximizes the potential for flow through breaches (Assumption 5.2).

For a given drip location onto the crown of the drip shield (see Assumption 5.1), the spreading of the rivulet flow is defined by a spread angle, $\alpha$, which is half of the total spread angle, formed with the vertical plane through the impact point (Figure 6.3-2). The total lateral spread of the rivulet flow is given by $2 x \tan \alpha$, where $x$ is the arc length from the crown of the drip shield down to a location of interest (e.g., a corrosion patch). In the breached drip shield experiments (BSC 2003 [DIRS 163406]), the lateral rivulet spread to each side of the vertical plane, or $x \tan \alpha$, was measured. For $N_{b}$ breaches in the drip shield of length $L_{D S}$, with each patch having a width of $2 \ell(\mathrm{m})$, the flux through the drip shield is given by:

$$
F_{2}=F_{1} \frac{N_{b} \ell}{L_{D S}}\left(1+\frac{\tan \alpha}{2}\right) f_{D S} .
$$

For details of the mathematical development of this expression, see Section 6.5.1.1.2.4.

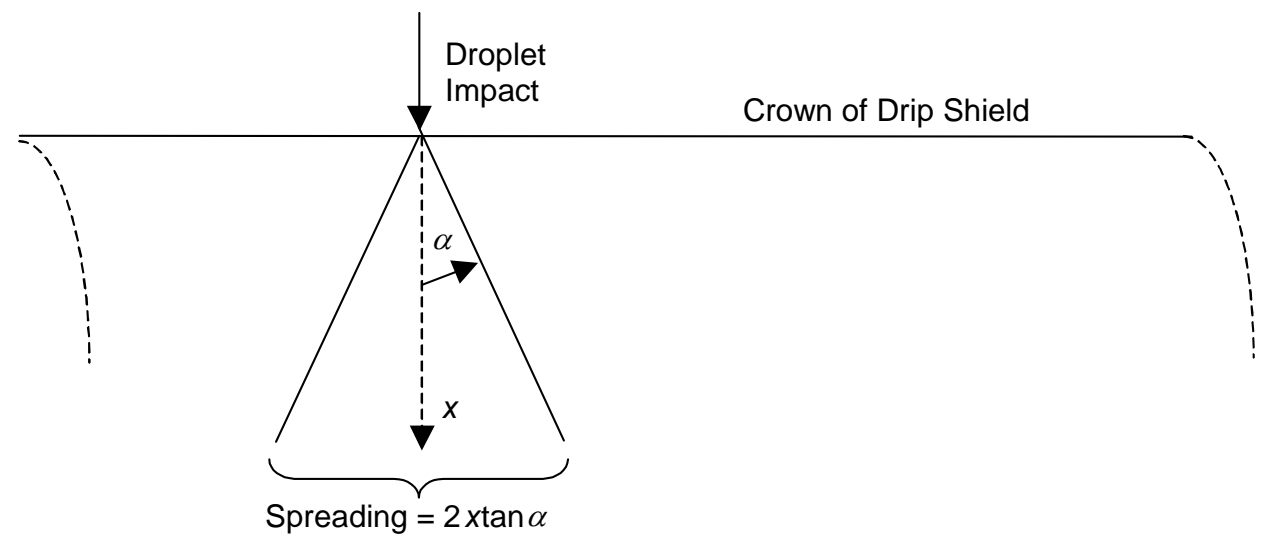

NOTE: Curvature not shown.

Figure 6.3-2. Illustration of Spreading for Rivulet Flow on the Drip Shield 
The factor $f_{D S}$ accounts for the uncertainty in the submodel and is a sampled parameter in TSPA-LA simulations. Sources of uncertainty include:

1. Drip location with respect to the crown of the drip shield-Drops that fall to either side of the crown will not divide exactly in half, as assumed by this submodel.

2. Patch location-Patches located on the crown will allow the entire dripping flux to pass through, whereas Equation 6.3.2.4-2 considers all patches to be located off the crown. For a given value of $f_{D S}$, Equation 6.3.2.4-2 underestimates the flux into crown patches because $f_{D S}<1$, so $F_{2}<F_{1}$, i.e., not all of the total dripping flux can flow through breaches. Since most of the randomly-located breaches occurring will not be located on the drip shield crown, this is a reasonable approximation, but not a bounding estimate of flow through drip shield breaches.

3. Splattering distribution-Although splattering of drops when they impinge on the drip shield is a random process, preferential directions or distributions could develop, for example, due to surface alteration as a result of corrosion or drift degradation (rockfall).

4. Rivulet spread-The breached drip shield experiments showed that a range of rivulet spread factors or spread angles can occur even on smooth surfaces. Surface roughness also affects the rivulet spread angle. Precipitation of salts or accumulation of dust on the drip shield surface could also affect rivulet flow.

5. Interference among multiple patches-Implicit in this submodel is that the patches do not interfere with each other, i.e., that no patch is lower on the drip shield surface than another patch. Patches located below another patch will see reduced or zero flux through the patch. By ignoring patch interference, water flux through the drip shield will be overestimated.

6. Patches outside the footprint of the waste package-Flux through these patches will pass directly to the invert. Since the conceptual model requires that all flow through the drip shield goes onto or into the waste package, Equation 6.3.2.4-2 will overestimate that flow.

7. Evaporation from the surface of the drip shield-Evaporation is neglected (Assumption 5.2); if it occurs, the flux through the drip shield is less than predicted by Equation 6.3.2.4-2.

8. Size of corrosion patches-The WAPDEG model assumes a fixed size and shape for all corrosion patches. In reality, the patches will vary widely in size and shape randomly as well as over time.

Bounds and a distribution for $f_{D S}$ must be established for use in TSPA-LA calculations. Because, under some of these uncertain conditions, the flux through the drip shield may be zero even when breaches exist, an appropriate lower bound on $f_{D S}$ is zero. Under some other 
circumstances mentioned above, the entire seepage flux could flow through the drip shield. Thus, an upper bound on $f_{D S}$ cannot be specified a priori, but should be given by:

$$
f_{D S}=\frac{1}{\frac{N_{b} \ell}{L_{D S}}\left(1+\frac{\tan \alpha}{2}\right)},
$$

which makes $F_{2}=F_{1}$. Since the number of patches, $N_{b}$, varies over time, $f_{D S}$ should be a function of time, with a starting value of zero and potentially reaching a value equal to the total number of nodes in the WAPDEG corrosion model of the drip shield (BSC 2004 [DIRS 169996]). A uniform distribution is appropriate given that the uncertainty is difficult to quantify. To ensure that the flux through the drip shield is not greater than the seepage flux, the flux through the drip shield is computed as:

$$
F_{2}=\min \left[F_{1} \frac{N_{b} \ell}{L_{D S}}\left(1+\frac{\tan \alpha}{2}\right) f_{D S}, F_{1}\right]
$$

The uncertainty in spread angle $\alpha$ can be lumped in with $f_{D S}$ since both would otherwise be sampled independently. A lumped uncertainty factor $f_{D S}^{\prime}$ is defined as:

$$
f_{D S}^{\prime}=\left(1+\frac{\tan \alpha}{2}\right) f_{D S},
$$

with the flux through the drip shield to be computed as:

$$
F_{2}=\min \left[F_{1} \frac{N_{b} \ell}{L_{D S}} f_{D S}^{\prime}, F_{1}\right] \text {. }
$$

In Section 6.5.1.1.2.4, an upper bound on $f_{D S}^{\prime}$ is developed based on results of the breached drip shield experiments, and is used in the TSPA-LA model.

\subsubsection{Water Flux through the Waste Package $\left(F_{4}\right)$}

The conceptual model for the TSPA-LA is based on the assumed presence of continuous flow paths through the patches that penetrate the waste package. More specifically, in the TSPA-LA conceptual model, vertical flow of seepage into the waste package, through the waste form, and out of the waste package is not impeded by the location of patches on the surface of the waste package. In other words, there is no long-term build-up and retention of liquid within the waste package for flow and transport. (An alternative conceptual model in which water fills the waste package before any water flows out-the "bathtub" model-is evaluated in Section 6.4.1). There is also no resistance to the flow through the waste form. The TSPA-LA approach attempts to maximize the immediate release and mobilization of radionuclides, while retaining as much realism as justified by the data and understanding of the physical and chemical processes that take place. 
Radionuclides cannot be released from the waste package if there is insufficient water or if there are no openings through either the wall or lid of the waste package. Section 6.3.3.1 describes the types of openings that can form, how and where they form, the timing of their formation, and the flow through these openings. The dimensions of these openings have implications for whether water is able to flow into and through the waste package or whether transport out of the waste package is by advection and/or diffusion. Section 6.3.3.2 describes the flux of liquid around or through the waste package. Section 6.3.3.3 describes the alternative pathway for liquid to reach the waste package; namely, evaporation from the invert and condensation on the inside of the drip shield can provide a source of liquid to the exterior of the waste package even when there are no openings in the drip shield. Section 6.3.3.4 describes the flux of liquid through the invert.

\subsubsection{Breaching of the Waste Package}

\subsection{Waste Package Design}

Ten waste package configurations are planned for the waste to be emplaced in the repository, where the nominal quantity for LA is shown in parentheses (BSC 2004 [DIRS 169472], Tables 1 and 11):

1. 21-PWR with absorber plates $(4,299)$

2. 21-PWR with control rods (95)

3. $12-\mathrm{PWR}(163)$

4. 44-BWR $(2,831)$

5. 24-BWR (84)

6. 5 DHLW/DOE SNF - Long $(1,406)$

7. 5 DHLW/DOE SNF - Short $(1,147)$

8. 2-MCO/2-DHLW (149)

9. Naval Short (144)

10. Naval Long (156).

Waste packages are broadly categorized as CSNF waste packages (21-PWR and 44-BWR are the most common), codisposal waste packages (5 DHLW/DOE SNF-Short and Long), and Naval Short and Long waste packages. Although waste packages vary depending on the waste form they contain, the majority of designs have features in common. These commonalties are described here. The waste package consists of a cylindrical inner stainless steel vessel, which is sealed with a stainless steel lid. The inner vessel is placed into an Alloy 22 outer corrosion barrier, which is sealed with a middle and outer lid. The inner vessel has 5-cm-thick walls and lid that provide structural integrity for the waste package. The Alloy 22 outer corrosion barrier has a wall approximately $2 \mathrm{~cm}$ thick, a middle lid approximately $13 \mathrm{~mm}$ thick, and a 2.5-cm-thick outer lid, that provide resistance to corrosion. Design information for waste packages is provided on IED, D\&E / PA/C IED Typical Waste Package Components Assembly (BSC 2004 [DIRS 169472]), which identifies detailed design drawings, including drawings of the 21-PWR, 44-BWR, the 5 DHLW/DOE SNF - Short, and the Naval Short and Long waste packages, among others.

The stainless steel inner vessel of the waste package is modeled as having no resistance to corrosion as reflected in WAPDEG Analysis of Waste Package and Drip Shield Degradation, 
(BSC 2004 [DIRS 169996] Section 6.3), forming an immediate flow pathway once the outer (Alloy 22) corrosion barrier has been breached. Similarly, as modeled, the closure weld on the inner stainless steel lid, as part of the stainless steel inner vessel, has no resistance to corrosion, and the inner lid fails once the outer lids have failed.

\subsection{Types of Openings}

Three general types of openings can exist in the waste package due to corrosion. These are (1) radial stress corrosion cracks that penetrate the welds of the lids, (2) patches resulting from general corrosion, and (3) localized corrosion. Stress corrosion cracks and general corrosion patches are discussed in turn below. The opening area from localized corrosion is described in the General Corrosion and Localized Corrosion of Waste Package Outer Barrier (BSC 2004 [DIRS 169984], Section 8.3.1).

\subsection{1 $\quad$ Radial Stress Corrosion Cracks in Lid Welds}

Stress corrosion cracks can appear because of the residual tensile stresses generated during the process of welding the lids in place. It is not possible to anneal the final closure welds, although laser peening has been proposed as a means to mitigate residual stress in waste package closure lid welds (BSC 2004 [DIRS 172203], Section 6.4.4). Stress corrosion cracks will typically form along two orientations. Radial stresses can generate circumferential cracks while hoop stresses can generate radial cracks. Only radial stress corrosion cracks are considered in the $E B S R T$ Abstraction because circumferential cracks are unlikely to penetrate the thickness of the lids. Cracks require the presence of tensile stress for initiation and propagation. Detailed finite-element analyses of the welding process demonstrate that only compressive radial stresses exist at the inner surface (BSC 2004 [DIRS 172203], Figure 6-11, Cross-Section 1-1). In this condition, circumferential cracks cannot propagate through the thicknesses of the lid welds and are therefore not considered in the EBS RT Abstraction.

Radial cracks are transverse to the weld and cannot be much longer than the weld width. A radial crack opening has an elliptical shape with length $2 a$ and a gap width $\delta$ (BSC 2004 [DIRS 172203], Section 6.5.2). The equation given by Tada et al. (1973 [DIRS 118706], p. B.5) can be used to calculate the gap width, $\delta(\mathrm{m})$, for a crack with length $2 a$ in an infinite sheet under plane stress load:

$$
\delta=\frac{4 a \sigma_{a}}{E}
$$

where $E$ is the modulus of elasticity $(\mathrm{Pa}), 2 a$ is the crack length $(\mathrm{m})$, and $\sigma_{a}$ is the applied stress (Pa). Values for $E$ for Alloy 22 are given in DTN: MO0107TC239753.000 [DIRS 169973].

The residual hoop stress in the as-welded waste package outer lid is higher on the outside surface than on the inside surface (BSC 2004 [DIRS 172203], Table 6-9). The resulting shape of the crack is then an ellipsoidal cone where $2 a$ is the length of the long axis, and short axis lengths $\delta_{o}$ and $\delta_{i}$ are the gap widths for the outside and inside surfaces, respectively. The depth $d$ of the 
crack is taken to be the lid thickness. Figure 6.3-3 is a schematic diagram of the geometry of the ellipsoidal cone crack.

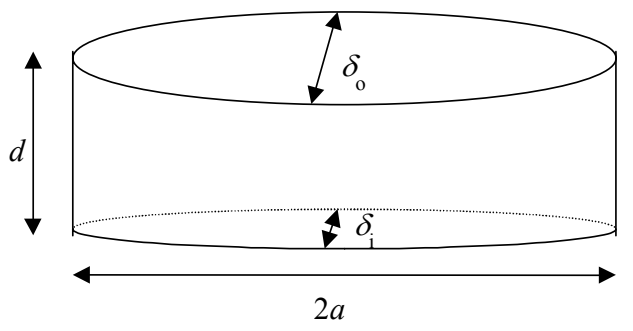

Figure 6.3-3. Schematic of the Dimensions for an Ellipsoidal Crack

A range of values of $\sigma_{a}$, the residual stress, and the maximum length $2 a$ of a radial crack can be estimated. The region of high residual stress is identified from finite-element simulations (BSC 2004 [DIRS 172203], Section 6.4). The expected maximum length of a radial crack is approximately two times the lid thickness (BSC 2004 [DIRS 172203], Section 6.5.1). For an outer lid thickness of $25.4 \mathrm{~mm}$ (BSC 2004 [DIRS 167394]), the maximum crack length is approximately $50 \mathrm{~mm}$. Table 6.3-3 gives the calculated gap width, based on Equation 6.3.3.1-1 and typical residual stresses at the inner and outer surface of the lid for a 21-PWR waste package (BSC 2004 [DIRS 172203], Table 6-9).

The cross-sectional area of the stress corrosion crack is important for transport by diffusion. The bounding (largest) cross-sectional area is defined by conditions at the outer surface of the 5-cm-long crack. The area of this ellipse is $\pi a b$, where $2 a$ is $5 \mathrm{~cm}$ and $b$ is one-half of the larger gap width on the outer surface (in Table 6.3-3). The cross-sectional area of a single stress corrosion crack is then $\pi(0.025 \mathrm{~m})\left(9.8 \times 10^{-5} \mathrm{~m}\right)$ or $7.7 \times 10^{-6} \mathrm{~m}^{2}$.

An updated analysis of stress corrosion cracking is given in Stress Corrosion Cracking of the Drip Shield, the Waste Package Outer Barrier, and the Stainless Steel Structural Material (BSC 2004 [DIRS 172203]). For the base conceptual model (BSC 2004 [DIRS 172203], Appendix B, Table B-2), the estimated crack opening is smaller than the crack opening of $7.7 \times 10^{-6} \mathrm{~m}^{2}$ obtained in this section. Therefore, use of this value in TSPA-LA calculations when stress corrosion cracking occurs will overestimate the rate of release of radionuclides compared with the updated values in (BSC 2004 [DIRS 172203]).

Table 6.3-3. Calculated Gap Width for a Range of Residual Stresses at $400^{\circ} \mathrm{F}$ (Approximately $200^{\circ} \mathrm{C}$ ) in a 21-PWR Container

\begin{tabular}{|l|c|c|}
\hline \multicolumn{1}{|c|}{ Parameter } & Inner Surface & Outer Surface \\
\hline Hoop stress, $\sigma_{a}$ (BSC 2004 [DIRS 172203], Table 6-9) & $231.1380 \mathrm{MPa}$ & $385.0522 \mathrm{MPa}$ \\
\hline Gap width for crack length 2a=50 mm & $118 \mu \mathrm{m}$ & $196 \mu \mathrm{m}$ \\
\hline
\end{tabular}

Advective flow into stress corrosion cracks is unlikely because the waste package is not oriented in such a way that water can flow in. Dripping water is capable of contacting a stress corrosion crack only if the waste package is tilted upward. A possible mechanism for tilting is emplacement pallet collapse due to corrosion that causes one end of the waste package to fall off 
its emplacement pallet. This maximum angle of tilt occurs when the lid end of the waste package is elevated to the height of the inside of the drip shield while the other end rests against the invert. However, as stated in Engineered Barrier System Features, Events, and Processes (BSC 2005 [DIRS 173781], Section 6.2.23), the corrosion of the stainless steel connector tubes, which support the pallet, over the regulatory period is expected to be low enough that the connector tubes retain their structural integrity. Furthermore, chemical degradation of the pallet is excluded on the basis of low consequence (BSC 2005 [DIRS 173781], Section 6.2.23). Also, mechanical degradation of the pallet, including degradation from seismic loading, is excluded on the basis of low consequence (BSC 2005 [DIRS 173781], Section 6.2.21). In additional, an analysis of the pallet behavior during seismic events shows that the pallet will deform (bulge) under dynamic loads imposed by the waste package but will continue to fulfill its function of supporting the waste package (Structural Calculations of Waste Package Exposed to Vibratory Ground Motion, BSC 2004 [DIRS 167083], Section 6.2.4, and Figure 9).

Advective flow of water through stress corrosion cracks can be neglected (BSC 2005 [DIRS 173781], Section 6.2.63, FEP 2.1.03.10.0A). This is realistic for several reasons. First, a film that completely spans the opening of a stress corrosion crack creates a differential in capillary forces that will prevent any further ingress of flowing water into the waste package. Second, the presence of corrosion products in the small stress corrosion crack may provide a capillary barrier for advective flux into the waste package. Third, in addition to a capillary barrier, corrosion products filling the corrosion cracks will provide resistance to flow, requiring a large head or pressure gradient that is unlikely to exist. Fourth, because corrosion patches are orders of magnitude larger in cross section and may appear in the same time frame, flow through corrosion cracks is negligibly small compared to flow through patches.

The potential for atmospheric pumping, hygroscopic salts in the waste package, and the uncertainty about film thickness make it difficult unequivocally to exclude liquid flow into the waste package. In any case, the more important question is how much liquid flows out of the waste package, advectively transporting radionuclides. Given the resistance to flow into the waste package through stress corrosion cracks, flow out is even less likely. The exclusion of flow through corrosion cracks in the conceptual flow model is compensated for at least in part by the assumption that a continuous water film is always present in corrosion cracks through which diffusion can occur (see Assumption 5.5) and by no restrictions on water vapor diffusing through the cracks, which provides a mechanism for water to enter a waste package once stress corrosion cracks exist.

\subsection{Patches from General Corrosion}

The main corrosion mechanisms for the outer corrosion barrier are general corrosion and localized corrosion. The size and timing of patches resulting from general corrosion are predicted by the WAPDEG analysis (BSC 2004 [DIRS 169996]).

\subsection{Impact of Heat Generation Inside Waste Package}

Heat generated by the waste form has the potential to evaporate water within the waste package. In this situation, water cannot collect inside the waste package and cannot support advective transport of radionuclides. Preliminary estimates using Multiscale Thermohydrologic Model 
(BSC 2005 [DIRS 173944], Section 6.3) indicate that the available heat can evaporate incoming water for several thousand years. However, although evaporation is expected to occur, complexities in the internal geometry of the waste packages (particularly the response of any water pooled at the bottom of the package and the potential presence of small conduits for water vapor to escape through stress corrosion cracks) make it difficult to say definitively that all incoming water is evaporated.

The expected evaporation in the waste package is ignored in the TSPA-LA. This approach is bounding because evaporation might eliminate advection as a transport mechanism. In addition, by ignoring evaporation from a waste package, it becomes possible to specify a water saturation of 1.0 (fully saturated) inside a failed waste package whenever dripping occurs. If evaporation were accounted for, the water saturation inside a waste package would generally be less than 1.0, which would reduce the amount of radionuclides that could dissolve in the water and be advectively transported from the waste package. Lower water saturations would also reduce estimates of diffusive releases, since both the diffusion coefficient and the cross-sectional area for diffusion would be less. Thus, without these simplifying assumptions, the amount of radionuclides transported from a waste package would be expected to be less.

As a simplification, it is assumed that no radionuclide transport occurs when the temperature in the waste package is above $100^{\circ} \mathrm{C}$ (Assumption 5.5), when a continuous film of water needed for transport is not expected to exist.

\subsubsection{Water Flux through and around the Breached Waste Package $\left(F_{4}\right.$ and $\left.F_{5}\right)$}

The flux through (into and out of) the waste package, $F_{4}$, is conceptualized to be the flux through patches, which originates from the flux thorough the drip shield $\left(F_{2}\right)$. Advective flux of water through stress corrosion cracks is unlikely and therefore is neglected (Section 6.3.3.1.2.1). A quasi-steady state approach is used. The presence of a gap between adjacent waste packages is neglected in the TSPA-LA model. Dripping onto the waste package from condensation on the underside of the drip shield is screened out (BSC 2005 [DIRS 173781], Section 6.2.43).

A flux splitting algorithm analogous to the drip shield flux splitting algorithm (Section 6.3.2.4) is developed here. The analogy is appropriate based on similarities in geometry and assumptions regarding the source of liquid flux falling onto the waste package. The surface of the waste package is a horizontal cylinder, as is the top of the drip shield, the primary difference that impacts liquid flow on the curved surface being that the radius of curvature of the waste package is smaller than that of the drip shield. Thus, flow behavior on the surface of the waste package should be similar to that on the drip shield. In particular, if any water is available, it is expected to flow over the surface of the waste package in rivulets rather than as film flow, based on findings of the breached drip shield experiments (BSC 2003 [DIRS 163406]).

Whereas drip locations on the drip shield could reasonably be confined to the crown of the drip shield (because the drift seepage flux will most likely originate from the crown of the drift), the drip locations may be more widely dispersed on the waste package. This is the case for drips that fall from breaches in the drip shield, which are randomly located on the drip shield. Since breaches (mainly general corrosion patches) in the waste package are also randomly located, the fraction of dripping flux falling on the waste package that flows into the waste package might be 
expected to be proportional to the total area of waste package patches. However, since drips that fall onto an intact waste package surface will drain down the surface, the flux of water, if any, entering a waste package is proportional to the total length of patches. Again, the analogy to the drip shield applies. Rivulets flowing down the surface of the waste package are intercepted in proportion to the lengths of the patches (ignoring interference by multiple patches).

Two other considerations reinforce the comparison with the drip shield. First, any condensation on the underside of the drip shield that falls onto the waste package will fall from the crown of the drip shield. Thus, for condensation at least, the geometry is completely analogous to that of the drip shield inside the drift. Second, the drip shield is modeled as a single entity and all drip shields in the repository fail by general corrosion at the same time in the model for a given realization (BSC 2004 [DIRS 169996], Section 6.3), with uncertainty in the corrosion rate of the drip shield resulting in different failure times in each realization. Once the drip shield is gone, the seepage flux will now fall directly from the drift crown onto the waste package crown, again completing the analogy with the drip shield under the drift crown. Since the corrosion rate of the titanium drip shield is higher than that of the Alloy 22 waste package outer corrosion barrier, the situation where a breached waste package lies unprotected under seepage from the drift crown should be more likely than a breached waste package underneath a breached but still partially effective drip shield. Therefore, within the uncertainty of the model, it is an appropriate simplification to model the flux impinging on the waste package as falling entirely on the crown of the waste package. One implication of this simplification is that, as with the drip shield, half of this flux flows down each side of the waste package.

Based on these arguments, a flux splitting algorithm for the waste package can be given that is completely analogous to the drip shield flux splitting algorithm:

$$
F_{4}=\min \left[F_{2}\left(\frac{N_{b W P} \ell_{W P}}{L_{W P}}\right)\left(1+\frac{\tan \alpha}{2}\right) f_{W P}, F_{2}\right] \text {, }
$$

where $F_{4}$ is the flux through the waste package, $F_{2}$ is the flux through the drip shield, and $L_{W P}$ is the total axial length of the waste package. $N_{b W P}$ patches each of length $2 \ell_{W P}$ comprise the breaches in the waste package. Flow through stress corrosion cracks is neglected as being unlikely to occur (see Section 6.3.3.1.2.1).

The factor $f_{W P}$ accounts for the uncertainty in this algorithm. As with the corresponding factor $f_{D S}$ for the drip shield, bounds can be established for $f_{W P}$ based on the dimensions of the patches and the waste package and the uncertain rivulet spread angle. A lower bound of zero is necessary to account for the possibility that seepage through the drip shield is completely diverted by an intact portion of the waste package outer corrosion barrier.

For an upper bound on $f_{W P}$, the drip shield experiments (BSC 2003 [DIRS 163406]) provide some guidance. Since the radius of curvature of the waste packages is smaller than that of the drip shield, the rivulet spread angle on the waste packages would be expected to differ from, and probably be smaller than, the spread angle on the drip shield. In some experiments, the drip location on the drip shield mock-up was well away from the crown on more steeply inclined 
regions of the drip shield. Rivulets flowing from those drip locations may simulate more closely the behavior on a surface having a smaller radius, such as a waste package. Because the waste package has a smaller radius and more curvature than the drip shield surface, more of the surface is sloped to such a degree that water will readily flow down it by gravity. Only a larger cylindrical surface (the drip shield mock-up) was available on which to observe gravity flow behavior. Observations away from the crown, where the slope is steep enough to initiate flow as readily as on a more highly curved surface, are appropriate analogs to measurements on an actual smaller cylinder. An analysis of drip shield experimental data for off-crown drip locations (Section 6.5.1.1.3) gives a mean spread angle of $13.7^{\circ}$ and a range from $5.5^{\circ}$ to $22.0^{\circ}$. In analogy to $f_{D S}$, an upper bound on $f_{W P}$ can be obtained using the minimum rivulet spread angle $\alpha$ of $5.5^{\circ}$ and the known values for $N_{b W P}$ (BSC 2004 [DIRS 169996]), $2 \ell_{W P}$, and $L_{W P}$ :

$$
f_{W P}=\frac{1}{\frac{N_{b W P} \ell_{W P}}{L_{W P}}\left(1+\frac{\tan \alpha}{2}\right)} .
$$

As with the drip shield, the term $\left(1+\frac{\tan \alpha}{2}\right)$, which is uncertain itself, can be factored in with $f_{W P}$ to simplify the model, resulting in:

$$
F_{4}=\min \left[F_{2}\left(\frac{N_{b W P} \ell_{W P}}{L_{W P}}\right) f_{W P}^{\prime}, F_{2}\right],
$$

where

$$
f_{W P}^{\prime}=\left(1+\frac{\tan \alpha}{2}\right) f_{W P}
$$

is assigned a uniform distribution. In Section 6.5.1.1.3, an upper bound on $f_{W P}^{\prime}$ is developed based on results of the breached drip shield experiments. The range for $f_{W P}^{\prime}$ based entirely on experimental results is used in TSPA-LA.

Finally, the flux that is diverted around the waste package, $F_{5}$, is calculated using continuity of the quasi-static flow around and into the waste package:

$$
F_{5}=F_{2}-F_{4} \text {. }
$$

\subsubsection{Condensation on the Drip Shield}

Condensation of water on the underside of the drip shield is discussed in Engineered Barrier System Features, Events, and Processes (BSC 2005 [DIRS 173781], Section 6.2.43, FEP Number 2.1.08.14.0A). A review of the temperature profiles calculated using the results described in In-Drift Natural Convection and Condensation Model (BSC 2004 [DIRS 164327], 
Section 6.3) indicates that the radial temperatures of the drip shield are highest at the crown of this component and slightly cooler on the sides. This temperature profile would support condensation of any water vapor convected upward from the invert along the sides of the drip shield. The condensate will be a weak carbonic acid solution (pH approximately 5) (BSC 2005 [DIRS 173727]), with condensation occurring when the drip shield temperatures drop below about $96^{\circ} \mathrm{C}$. These conditions do not initiate corrosion of the waste package's Alloy 22 outer corrosion barrier (BSC 2004 [DIRS 169984]). Therefore, the presence of any condensate on the underside of the drip shield does not impact the barrier capability of the drip shield.

Condensate waters present on the underside of the drip shield have a small potential to drip onto exposed waste packages. Analysis of advective flux through stress corrosion cracks (BSC 2004 [DIRS 172203], Section 6.3.7), an analogous situation that similarly accounts for water on the underside of the drip shield, excludes this process on the basis of low consequence (BSC 2004 [DIRS 173978], Section 6.2.5, FEP 2.1.03.02.0B; BSC 2005 [DIRS 173781], Section 6.2.64, FEP 2.1.03.10.0B).

\subsubsection{Flux into and through the Invert $\left(F_{6}\right.$ and $\left.F_{7}\right)$}

The flux leaving the waste package is equal to the flux entering the waste package, $F_{4}$, by the quasi-steady-state flow assumption (the net effect of Assumptions 5.1 through 5.4 and 5.7). The total flux entering the invert from above is equal to the sum of the diversion around the waste package, $F_{5}$, the flux leaving the waste package (equal to $F_{4}$ ), and the diversion around the drip shield, $F_{3}$. The liquid flux leaving the invert, $F_{8}$, is equal to the total flux entering the invert from above plus the imbibition flux from the UZ matrix into the invert. That is,

$$
F_{6}=F_{5}+F_{4}+F_{3},
$$

and

$$
F_{8}=F_{6}+F_{7} .
$$

Only the flux leaving the waste package, $F_{4}$, can transport radionuclides to the invert.

Multiscale Thermohydrologic Model (BSC 2005 [DIRS 173944]) determines the imbibition flux from the UZ host rock matrix into the invert, $F_{7}$, as well as the water saturation in the invert. The imbibition flux from the UZ matrix into the invert exits the invert back into the UZ matrix. The advective flux that flows into the invert from above, $F_{6}$, exits the invert into the UZ fractures.

\subsubsection{Transport through the EBS}

The conceptual model for transport through the EBS consists of transport through three separate domains: (1) waste form, (2) waste package corrosion products, and (3) the invert. Transport through each of these domains occurs by advection and diffusion. Radionuclides travel in sequence through each of these domains. In other words, all radionuclides entering the corrosion 
products domain come from the waste form domain, and all radionuclides exiting the corrosion products domain enter the invert domain. Advection in each domain is modeled as steady state flow; i.e., the flow rate may vary over time, but no accumulation occurs. Diffusion through each domain is considered to be transient.

The rate of diffusive transport through each domain is dependent upon the following parameters: the effective diffusion coefficient, the cross-sectional area available for diffusive transport, and the diffusion path length across which a concentration gradient exists. The effective diffusion coefficient for assumed transport through thin water films adsorbed to materials is taken as a bounding value to be the free-water diffusion coefficient, modified to account for porosity, saturation, and, in the case of the invert, temperature, and the uncertainty associated with the dependence on these parameters. The cross-sectional area for transport in each domain is dependent upon the geometry of the domain, the relative humidity, and the specific surface area and adsorption isotherm for the given material. A range of diffusion path lengths is determined from the geometry of the domain.

The waste form is the source of all radionuclides in the repository system. If sufficient water is available, radionuclides mobilized from the waste form can be transported out of the waste package, downward through the invert, and into the UZ, as shown in Figure 6.3-1. Transport out of the waste package can occur by advection, when there is a liquid flux through the waste package, and by diffusion through assumed continuous liquid pathways in the waste package, including thin films of adsorbed water. These two transport processes (diffusion and advection) are each a function of the type of penetrations through the drip shield and waste package and the local seepage conditions. Diffusion can occur through stress corrosion cracks or through general corrosion patches in the waste package both with and without liquid flux through the waste package. Advection is not considered through stress-corrosion cracks or through corrosion patches in the absence of seepage flux.

The diffusion coefficient for radionuclide transport is based on the self-diffusion coefficient of liquid water at $25^{\circ} \mathrm{C}$. This is a bounding value for all radionuclides at $25^{\circ} \mathrm{C}$. The effects of temperature on this bounding value are accounted for in the invert domain using the formulation in Section 6.3.4.1.2; for other domains, temperature effects are not accounted for, as discussed in Section 6.3.4.3.5. The effects of porosity, liquid saturation, and uncertainty on the invert diffusion coefficient are incorporated using the formulation in Section 6.3.4.1.1. For the waste form and corrosion product domains, the effects of porosity and water saturation on the diffusion coefficient are accounted for using the formulation in Section 6.3.4.3.5.

Advective transport is straightforward in the EBS RT Abstraction. In particular, mobilized radionuclides are transported with the local liquid flux from the waste package $\left(F_{4}\right)$ through the invert $\left(F_{6}\right)$ to the unsaturated zone fractures $\left(F_{8}\right)$. There are no modifications for dispersive effects (see Section 6.3.1.2); because the flow is modeled as one-dimensional vertically downward, lateral dispersion is not considered in the EBS RT Abstraction.

Diffusive transport depends on concentration gradients. The concentrations of radionuclides in the waste form domain are determined from the degree of waste form degradation and the solubility limit for each radionuclide. The concentrations in the waste package corrosion products domain take into account radionuclide solubility limits, sorption of radionuclides onto 
the corrosion products, sorption and desorption onto colloids, and colloid stability. The concentrations in the invert domain depend on the radionuclide solubility limits, colloid stability in the invert, the transfer of radionuclides between the corrosion products domain and the invert, and the boundary concentrations at the invert-unsaturated zone interface. The boundary condition at the unsaturated zone interface is implemented by defining multiple grid cells in the unsaturated zone that provide a diffusive path length that is sufficiently long such that the concentration at the outlet of the farthest cell from the drift wall can realistically be assigned a value of zero (Section 6.5.3.6).

The emphasis in this EBS RT Abstraction is on transport of radionuclides through the EBS after the radionuclides are mobilized. This abstraction does not define related elements of the TSPA-LA, such as corrosion processes, radionuclide solubility limits, waste form dissolution rates and concentrations of colloidal particles, that are generally represented as boundary conditions or input parameters for the EBS RT Abstraction. This abstraction provides the algorithms for determining radionuclide transport in the EBS using the flow and radionuclide concentrations determined by other elements of the TSPA-LA.

\subsubsection{Invert Diffusion Submodel}

The TSPA-LA model requires an abstraction for the effective diffusion coefficient in granular materials as a function of radionuclide, porosity, saturation, temperature, and concentration. This submodel is intended specifically to apply to the invert. The abstraction is as follows:

- Use the free water diffusion coefficient for self-diffusion of water, $2.299 \times 10^{-5} \mathrm{~cm}^{2} \mathrm{~s}^{-1}$ (Mills 1973 [DIRS 133392], Table III), as a bounding value for all radionuclides at $25^{\circ} \mathrm{C}$.

- Modify the free water diffusion coefficient for the porosity and liquid saturation of the invert. The modification for porosity and saturation is based on Archie's law and experimental data for granular media, and is presented in Section 6.3.4.1.1.

- Further modify the diffusion coefficient for variation of the invert temperature using the formulation in Section 6.3.4.1.2. The invert temperature is provided by the Multiscale Thermohydrologic Model (BSC 2005 [DIRS 173944]).

- Ignore the increase in the diffusion coefficient with increasing ionic strength of concentrated solutions (see Section 6.3.4.1.3). The maximum modification for a highly concentrated solution of potassium iodide is a factor of 1.27. This factor is almost within the bounding approximation inherent in using the self-diffusion coefficient for all radionuclides. It is neglected for the TSPA-LA.

\subsection{Modification of Diffusion Coefficient for Porosity and Saturation of the Invert}

The modified diffusion coefficient for a partly saturated porous medium can be estimated from Archie's law and the relationship between electrical conductance and diffusivity in a liquid. This relationship enables diffusion coefficients to be obtained from experimental measurements of the electrical conductivity of samples of the porous medium. From these measurements, an 
empirical function is developed that relates the diffusion coefficient to the porosity and saturation of the porous medium.

Archie's law is an empirical function relating the electrical resistivity and porosity of a porous medium (Archie 1942 [DIRS 154430], p. 57; Keller and Frischknecht 1966 [DIRS 111470], p. 21):

$$
\rho_{s}=a \rho_{w}^{e} \phi^{-m}
$$

where $\rho_{s}$ is the bulk resistivity (or specific resistance) of the fully water-saturated porous medium $(\Omega \mathrm{m}), \rho_{w}^{e}$ is the resistivity of liquid water $(\Omega \mathrm{m}), \phi$ is the porosity $\left(\mathrm{m}^{3}\right.$ pore volume $\mathrm{m}^{-3}$ total volume), $m$ is a cementation factor (dimensionless), and $a$ is an empirical parameter (dimensionless) that, to a first approximation, may be assumed to have a value of 1 (Keller and Frischknecht 1966 [DIRS 111470], p. 21).

For a partially saturated porous medium, the resistivity is given by (Bear 1988 [DIRS 101379], p. 116; Keller and Frischknecht 1966 [DIRS 111470], p. 28; Pirson 1963 [DIRS 111477], p. 24):

$$
\rho_{t}=\rho_{s} S_{w}^{-n}
$$

where $\rho_{t}$ is the bulk resistivity (or specific resistance) of the partially saturated porous medium $(\Omega \mathrm{m}), S_{w}$ is the water saturation $\left(\mathrm{m}^{3}\right.$ water $\mathrm{m}^{-3}$ pore volume), and $n$ is a saturation exponent (dimensionless).

The cementation factor $m$ "is somewhat larger than 2 for cemented and well-sorted granular rocks and somewhat less than 2 for poorly sorted and poorly cemented granular rocks" (Keller and Frischknecht 1966 [DIRS 111470], p. 21). For unconsolidated sand, a value of 1.3 has been reported for the cementation factor (Bear 1988 [DIRS 101379], p. 116; Pirson 1963 [DIRS 111477], p. 24). The invert, being composed of well-graded crushed tuff (BSC 2004 [DIRS 170559]), should have cementation characteristics similar to unconsolidated sand and poorly cemented granular rock, with a cementation factor of 1.3 or slightly higher, but less than 2 .

For unconsolidated sand, a value of 2 is accepted for the saturation exponent $n$ (Bear 1988 [DIRS 101379], p. 116; Keller and Frischknecht 1966 [DIRS 111470], p. 28; Pirson 1963 [DIRS 111477], p. 24).

Combining and simplifying Equations 6.3.4.1.1-1 and 6.3.4.1.1-2 results in an Archie's law formulation that gives the bulk resistivity of a partially saturated porous medium:

$$
\rho_{t}=\rho_{w}^{e} \phi^{-m} S_{w}^{-n}
$$

The resistance, $R_{t}(\Omega)$, of a porous medium of length $L$ and cross-sectional area $A$ is given by:

$$
R_{t}=\rho_{t} L / A
$$


Since the electrical conductance, $G\left(\mathrm{~S}=\Omega^{-1}\right)$, is defined as the reciprocal of resistance (Atkins 1990 [DIRS 111464], p. 750), Archie's law can be written for a partially saturated porous medium in terms of the conductance of the bulk porous medium, $G_{t}(\mathrm{~S})$ and the conductance of water, $G_{w}(\mathrm{~S})$ :

$$
G_{t}=G_{w} \phi^{m} S_{w}^{n} .
$$

The last step is to rewrite Archie's law in terms of diffusion coefficients. The diffusion coefficient of an ion in solution is related to the conductivity through the Nernst-Haskell equation (Perry and Chilton 1973 [DIRS 104946], p. 3-235) for diffusion in a binary electrolyte mixture at infinite dilution:

$$
D=\frac{R T}{F^{2}}\left(\frac{l_{+}^{0} l_{-}^{0}}{\Lambda_{0}}\right)\left(\frac{z_{+}+z_{-}}{z_{+} z_{-}}\right) .
$$

where:

$$
\begin{aligned}
D= & \text { diffusion coefficient }\left(\mathrm{m}^{2} \mathrm{~s}^{-1}\right) \\
R= & \text { molar gas constant }=8.314472 \mathrm{~J} \mathrm{~mol}^{-1} \mathrm{~K}^{-1} \text { (Lide } 2002 \text { [DIRS 160832], p. 1-8) } \\
T= & \text { temperature }(\mathrm{K}) \\
F \quad & \text { Faraday constant }=96485.3415 \mathrm{C} \mathrm{mol}^{-1} \text { (Lide } 2002 \text { [DIRS 160832], p. 1-7) } \\
l_{+}^{0} l_{-}^{0}= & \text { cationic and anionic molar conductivity, respectively, at infinite dilution } \\
& \left(\mathrm{S} \mathrm{m}^{2} \mathrm{~mol}^{-1}\right) \\
\Lambda_{0}= & \text { equivalent electrolyte molar conductivity at infinite dilution }\left(\mathrm{S} \mathrm{m}^{2} \mathrm{~mol}^{-1}\right) \\
z_{+}, z_{-}= & \text {valence of cation and anion, respectively; magnitude only-no sign } \\
& \text { (dimensionless). }
\end{aligned}
$$

This equation can be simplified by making use of the average ionic molar conductivity at infinite dilution, $\bar{l}$, where

$$
\bar{l}=\frac{\Lambda_{0}}{2}=\frac{l_{+}^{0}+l_{-}^{0}}{2} .
$$


Since the ionic molar conductivities $l_{+}^{0}$ and $l_{-}^{0}$ are non-negative numbers, $\bar{l}^{2} \geq\left(l_{+}^{0}\right)\left(l_{-}^{0}\right)$, which can be seen as follows:

$$
\begin{aligned}
\bar{l}^{2} & =\left(\frac{l_{+}^{0}+l_{-}^{0}}{2}\right)^{2} \\
& =\frac{\left(l_{+}^{0}\right)^{2}+2\left(l_{+}^{0}\right)\left(l_{-}^{0}\right)+\left(l_{-}^{0}\right)^{2}}{4} \\
& =\frac{\left(l_{+}^{0}\right)^{2}+\left(l_{-}^{0}\right)^{2}}{4}+\frac{\left(l_{+}^{0}\right)\left(l_{-}^{0}\right)}{2} \\
& =\frac{\left(l_{+}^{0}\right)^{2}+\left(l_{-}^{0}\right)^{2}}{4}+\frac{\left(l_{+}^{0}\right)\left(l_{-}^{0}\right)}{2}+\frac{\left(l_{+}^{0}\right)\left(l_{-}^{0}\right)}{2}-\frac{\left(l_{+}^{0}\right)\left(l_{-}^{0}\right)}{2} \\
& =\frac{\left(l_{+}^{0}\right)^{2}+\left(l_{-}^{0}\right)^{2}}{4}-\frac{\left(l_{+}^{0}\right)\left(l_{-}^{0}\right)}{2}+\left(l_{+}^{0}\right)\left(l_{-}^{0}\right) \\
& =\frac{1}{4}\left(l_{+}^{0}-l_{-}^{0}\right)^{2}+\left(l_{+}^{0}\right)\left(l_{-}^{0}\right) \\
& \geq\left(l_{+}^{0}\right)\left(l_{-}^{0}\right) .
\end{aligned}
$$

Thus, the square of the average ionic molar conductivity can be substituted for the product of the individual conductivity. This substitution will generally overestimate the diffusion coefficient given by Equation 6.3.4.1.1-6. At the same time, the valence of the ions $z_{+}$and $z_{-}$are given a value one, because this, too, maximizes the diffusion coefficient. With these substitutions, Equation 6.3.4.1.1-5 simplifies to give the maximum diffusivity in a binary electrolyte mixture at infinite dilution:

$$
\begin{aligned}
D & =\frac{R T}{F^{2}}\left(\frac{\bar{l}^{2}}{2 \bar{l}}\right)(2) \\
& =\frac{R T \bar{l}}{F^{2}} \\
& =\frac{R T \Lambda_{0}}{2 F^{2}}
\end{aligned}
$$

This shows that the diffusion coefficient for ions in an infinitely dilute binary mixture is proportional to the molar conductivity and therefore to the conductance of the electrolyte. For multicomponent solutions at other than infinite dilution, this equation represents an approximation with an associated uncertainty that can be estimated by comparison with experimental data, which is discussed later.

The relationship between diffusion coefficient and the measured conductivity of samples is dependent on the experimental method and apparatus used to obtain the conductivity of the porous medium. Conductivity is determined by measuring the electrical resistance of a sample in a conductivity cell. The cell is calibrated using a solution of known conductivity, and a cell constant. With no interfering porous medium, the conductance of water, $G_{w}$, is directly proportional to the equivalent electrolyte molar conductivity at infinite dilution $\left(\Lambda_{0}\right)$, which in 
turn, from Equation 6.3.4.1.1-9, is proportional to $D_{0}$. Due to the interference of the solid, the conductance of the bulk porous medium, $G_{t}$ is more complicated and is proportional to the porosity, saturation, the diffusivity of the ion and the tortuosity, as explained in the following discussion of diffusion coefficient measurements.

Conca and Wright (1992 [DIRS 100436]) and Conca et al. (1993 [DIRS 170709]) measured the diffusion coefficient of unsaturated soil, gravel, bentonite, rock, and crushed tuff from Yucca Mountain over a broad range of water contents by measuring the electrical conductivity of samples. These measured data are qualified in Appendix $\mathrm{H}$ and have been used to analyze the dependence of the diffusion coefficient on volumetric moisture content for a variety of granular materials. Figure 6.3-4 presents a summary of the diffusivity data for various granular media at volumetric moisture contents ranging between 1.5 percent and 66.3 percent.

The measurements of Conca and Wright are based on the Nernst-Einstein relationship:

$$
D_{i}=\frac{R T}{F^{2}} \frac{\kappa_{w} t_{i}}{z_{i} c_{i}},
$$

where $D_{i}$ is the diffusion coefficient of the $i^{\text {th }}$ ion in a dilute aqueous solution $\left(\mathrm{m}^{2} \mathrm{~s}^{-1}\right), F$ is the Faraday constant $\left(\mathrm{C} \mathrm{mol}^{-1}\right), R$ is the universal gas constant $\left(\mathrm{J} \mathrm{mol}^{-1} \mathrm{~K}^{-1}\right), T$ is the absolute temperature $(\mathrm{K}), \kappa_{w}$ is the electrical conductivity $\left(\mathrm{S} \mathrm{m}^{-1}\right)$ of the solution, $t_{i}$ is the transport number for the $i^{\text {th }}$ ion (which is the portion of the total electrical current carried by the $i^{\text {th }}$ ion), $z_{i}$ is the charge valence of the $i^{\text {th }}$ ion, and $c_{i}$ is the concentration of radionuclide species $i$ (mol m${ }^{-1}$ ). Equation (2) in Conca and Wright (1992 [DIRS 100436]) shows that $D_{i}$ can be determined from the measured conductance (an extensive quantity dependent on the physical dimensions or mass of the sample equal to the reciprocal of resistance) of the soil or rock sample. In fact, what Conca and Wright measured and what the left-hand side of the equation should be is $\phi S_{w} D_{i}$, the effective or bulk diffusion coefficient in the porous medium.

There is much literature on how to measure the conductivity and/or salinity of soil water from bulk measurements of the sample conductance. For example, Rhoades and Oster (1986 [DIRS 173846]), Rhoades et al. (1976 [DIRS 173835]), and Shainberg et al. (1980 [DIRS 173836]) present a two parameter model for representing the bulk soil or rock conductivity, $\kappa_{a}\left(\mathrm{~S} \mathrm{~m}^{-1}\right)$, in terms of the interstitial solution conductivity, $\kappa_{w}$, and the surface conductivity (conductivity of the double layer), $\kappa_{s}$. The quantity $\kappa_{a}$ is the experimentally measured quantity, which is equal to the actual conductance measurement of the impedance bridge or electrode array, multiplied by the cell constant, which is the geometric factor that converts the extensive quantity, conductance, to the intensive quantity, conductivity. Conca and Wright incorrectly substitute $\kappa_{a}$ directly into the Nernst-Einstein equation (Eq. 6.3.4.1.1-10). What needs to be substituted into the Nernst-Einstein equation is $\kappa_{w}$, which can be determined from $\kappa_{a}$ with the linear, two-resistor model of Rhoades et al. (1976 [DIRS 173835]) and Rhoades and Oster (1986 [DIRS 173846]): 


$$
\kappa_{a}=\kappa_{w} \phi S_{w} T^{*}+\kappa_{s}
$$

where $\phi S_{w}$ is the water content; $T^{*}$ is the transmission coefficient, which incorporates tortuosity effects and varies as a function of water content. The transmission coefficient is related to formation factor, $F_{R}$ (dimensionless), at high solution concentrations, through the relationship $F_{R}=\left(\phi S_{w} T^{*}\right)^{-1}$ (Shainberg et al. 1980 [DIRS 173836]). The quantity $\kappa_{s}$ is the conductivity of the surface or solid (i.e., the double layer). Rhoades et al. (1976 [DIRS 173835]) have correctly shown in their Equation 11 the relationship between the measured $\kappa_{a}$ and $\kappa_{w}\left(=1 / R_{b}\right.$ in their equation), if the conductivity of the surface or solid, $\kappa_{s}$, is ignored. In particular, consider the case where the $\kappa_{s}$ electrical pathway is effectively an insulator (i.e., does not contribute to the overall bulk sample conductance). Then the above equation reduces to:

$$
\kappa_{a}=\kappa_{w} \phi S_{w} T^{*}
$$

which can be solved for $\kappa_{w}$ as $\kappa_{w}=\kappa_{a} / \phi S_{w} T^{*}$ and then substituted back into the Nernst-Einstein equation:

$$
D_{i}=\frac{R T}{F^{2}} \frac{\kappa_{a}}{\phi S_{w} T^{*}} \frac{t_{i}}{z_{i} c_{i}} .
$$

The above equation solves for the ionic diffusion coefficient in terms of the measured conductivity, $\kappa_{a}$, of the rock sample. Replacing this conductivity with the corresponding extensive quantity, the conductance $G$, as designated by Conca and Wright, and the geometric factor or cell constant, $\Theta\left(\mathrm{m}^{-1}\right)$, gives the following:

$$
D_{i}=\frac{R T}{F^{2}} \frac{G \Theta}{\phi S_{w} T^{*}} \frac{t_{i}}{z_{i} c_{i}} .
$$

However, as is clear from the equation on p. A-8 in Wright's report (CRWMS M\&O 2000 [DIRS 156680]) and the associated Table A-1, this was not what was done by these researchers, and the factor $\phi S_{w} T^{*}$ was left out of this equation by Wright. In fact, Wright tabulated the quantity:

$$
\frac{R T}{F^{2}} \frac{G \Theta t_{i}}{z_{i} c_{i}},
$$

in Table A-1, which implies that they actually solved for $D_{i} \phi S_{w} T^{*}$, the bulk diffusivity, not the ionic diffusivity, which can be seen by multiplying both sides of Equation 6.3.4.1.1-14 by $\phi S_{w} T^{*}$. Thus, the tabulated diffusion coefficients of Conca and Wright (1990 [DIRS 100436] and 1992 [DIRS 100436]) must be used as the quantity $\phi S_{w} D_{i}$ in the mass conservation equation (Equation 6.5.1.2-11), i.e., the Conca and Wright reported diffusion coefficients are in fact the 
bulk diffusivity in the mass conservation equation. Since the free water diffusivity is used as a bounding value for all radionuclides, the diffusion coefficient is not dependent on the species $i$. For the invert, the diffusion coefficient is denoted by $D_{I}$, where the subscript I refers to the invert, rather than to species $i$.

Archie's law (Equation 6.3.4.1.1-5) can then be written in terms of the effective diffusivity of the bulk porous medium and the free water diffusivity:

$$
\phi S_{w} D_{I}=D_{0} \phi^{m} S_{w}^{n} .
$$

This is the form of Archie's law that is generally applied for determination of the effective diffusion coefficient, $D_{I}$, as a function of porosity and saturation in a partly saturated, granular medium. Note that the diffusion coefficient, $D_{I}$, as introduced here and used throughout this section, is an effective value that implicitly includes the effects of tortuosity. With values of the cementation factor, $m$, of 1.3 and the saturation exponent, $n$, of 2 for unconsolidated sand, Archie's law becomes as:

$$
\phi S_{w} D_{I}=D_{0} \phi^{1.3} S_{w}^{2} .
$$

Because the diffusion coefficients were measured by Conca and Wright as a function of volumetric water content, they have been analyzed using an alternative form of Archie's law in which the cementation factor and saturation exponent are equal (i.e., $n=m$ ). The effective diffusion coefficient is then a function of $\theta$, the percent volumetric moisture content, defined as $\theta=100 \phi S_{w}$ :

$$
\begin{aligned}
\phi S_{w} D_{I} & =D_{0} \phi^{n} S_{w}^{n} \\
& =D_{0}\left(\frac{\theta}{100}\right)^{n} .
\end{aligned}
$$

A statistical analysis using Microsoft Excel (Appendix G) produces an excellent fit to the diffusivity data (Conca and Wright 1992 [DIRS 100436], Figure 2; Conca et al. 1993 [DIRS 170709], Figure 2; listed in Table 4.1-17) using Equation 6.3.4.1.1-18 for moisture content in the range of 1.5 percent to 66.3 percent. The statistical fit to the effective diffusion coefficient, $D_{I}$, is based on a linearizing transformation to the variables $X$ and $Y$, defined as:

where

$$
\begin{aligned}
& Y=\log _{10}\left(\phi S_{w} D_{I} / D_{0}\right) \\
& X=\log _{10} \theta-2,
\end{aligned}
$$

$$
\begin{aligned}
& D_{I}=\text { the effective invert diffusion coefficient }\left(\mathrm{m}^{2} \mathrm{~s}^{-1}\right) \\
& D_{0}=\text { free water diffusivity }\left(\mathrm{m}^{2} \mathrm{~s}^{-1}\right) \\
& \phi=\text { porosity }\left(\mathrm{m}^{3} \text { void volume } \mathrm{m}^{-3} \text { bulk volume }\right) \\
& S_{w}=\text { water saturation }\left(\mathrm{m}^{3} \text { water volume } \mathrm{m}^{-3}\right. \text { void volume) }
\end{aligned}
$$




$$
\theta=\text { volumetric moisture content (percent). }
$$

The slope of the $X-Y$ relationship is found to be 1.863, leading to the following linear equation for $Y$ as a function of $X$ :

$$
\begin{aligned}
Y & =1.863 X \\
\log _{10}\left(\frac{\phi S_{w} D_{I}}{D_{0}}\right) & =1.863\left(\log _{10} \theta-2\right),
\end{aligned}
$$

or

$$
\begin{aligned}
\phi S_{w} D_{I} & =D_{0} \phi^{1.863} S_{w}^{1.863} \\
& =D_{0}\left(\frac{\theta}{100}\right)^{1.863} .
\end{aligned}
$$

The statistical fit for the effective invert diffusion coefficient has uncertainty, which is represented by the scatter of data points around the fit in Figure 6.3-4. This uncertainty is approximated by a normal distribution for the residuals (data-model) in log-log space. This normal distribution of residuals has a mean value of 0.033 and a standard deviation of 0.218 . The uncertainty can be incorporated into the statistical fit as an additional factor on the full statistical fit.

$$
\phi S_{w} D_{I}=D_{0} \phi^{1.863} S_{w}^{1.863} 10^{N D(\mu=0.033, \sigma=0.218)}
$$

where $N D$ represents a normal distribution with a mean, $\mu$, of 0.033 and a standard deviation, $\sigma$, of 0.218. $N D$ is in the exponent because the residuals are calculated in the log-log space of the statistical fit. This statistical fit is the submodel for the invert diffusion coefficient to be used for TSPA-LA. Since the normal distribution is theoretically unbounded, unrealistic values for the diffusion coefficient could potentially be obtained. To avoid this potential problem, the implementation in TSPA-LA will use a truncated normal distribution, limited to plus or minus three standard deviations from the mean.

Figure 6.3-4 presents the statistical fit (solid line) and the upper and lower bounds (dashed lines) at three standard deviations above and below the fit. The dashed lines encompass almost all the data points, because \pm 3 standard deviations includes 99.7 percent of the area under a normal distribution. Equation 6.3.4.1.1-22, therefore, accurately represents the uncertainty in the diffusivity data for the TSPA-LA calculations.

Because the saturation exponent (1.863) is less than the generally accepted value (2), the fit to the data provides less of a bounding estimate for the effective diffusion coefficient than if the accepted value were used. However, the estimate using Equation 6.3.4.1.1-22 is realistic instead of simply bounding the diffusion coefficient because it is developed from measured data rather than using the general behavior of unconsolidated sand as its basis. Furthermore, being based on a large number of measured data, the uncertainty in effective diffusion coefficient using 
Equation 6.3.4.1.1-22 is quantified, which provides additional support for use of this equation instead of a more bounding approach using the accepted value for saturation exponent.

One element of the uncertainty in the diffusion coefficient is the uncertainty in the porosity of the invert. The bulk porosity of the invert crushed tuff is expected to vary between 0.27 and 0.39 , with an average of 0.31 (BSC 2004 [DIRS 168138], Table 5). From Equation 6.3.4.1.1-22, the diffusion coefficient would vary due to variations in porosity by a factor of:

$$
\frac{\left(\phi S_{w} D\right)_{\max }}{\left(\phi S_{w} D\right)_{\min }}=\frac{\phi_{\max }^{1.863}}{\phi_{\min }^{1.863}}=\left(\frac{0.39}{0.27}\right)^{1.863}=1.98 \text {. }
$$

The range about the mean diffusion coefficient, $\left(\overline{\phi S_{w} D}\right)$, would be:

$$
\frac{\left(\phi S_{w} D\right)_{\min }}{\left(\overline{\phi S_{w} D}\right)}=\left(\frac{0.27}{0.31}\right)^{1.863}=0.77
$$

to

$$
\frac{\left(\phi S_{w} D\right)_{\max }}{\left(\overline{\phi S_{w} D}\right)}=\left(\frac{0.39}{0.31}\right)^{1.863}=1.53
$$

This range of uncertainty resulting from variation in the invert porosity is well within the range of the uncertain factor in Equation 6.3.4.1.1-22, which ranges from:

to

$$
10^{0.033-3(0.218)}=0.24
$$

$$
10^{0.033+3(0.218)}=4.86
$$

The uncertainty associated with the porosity of the invert is included in the uncertainty associated with the measurements of the diffusion coefficient, which were made on a variety of geologic materials having a range of porosities; thus the porosity uncertainty can be considered to be accounted for in the effective diffusion coefficient. The same conclusion is reached if the nominal value of intergranular porosity ( 0.45 as given in Tables $4.1-8,6.6-2$, and $8.2-3)$ is substituted for the mean, with the same spread for the uncertainty range. 


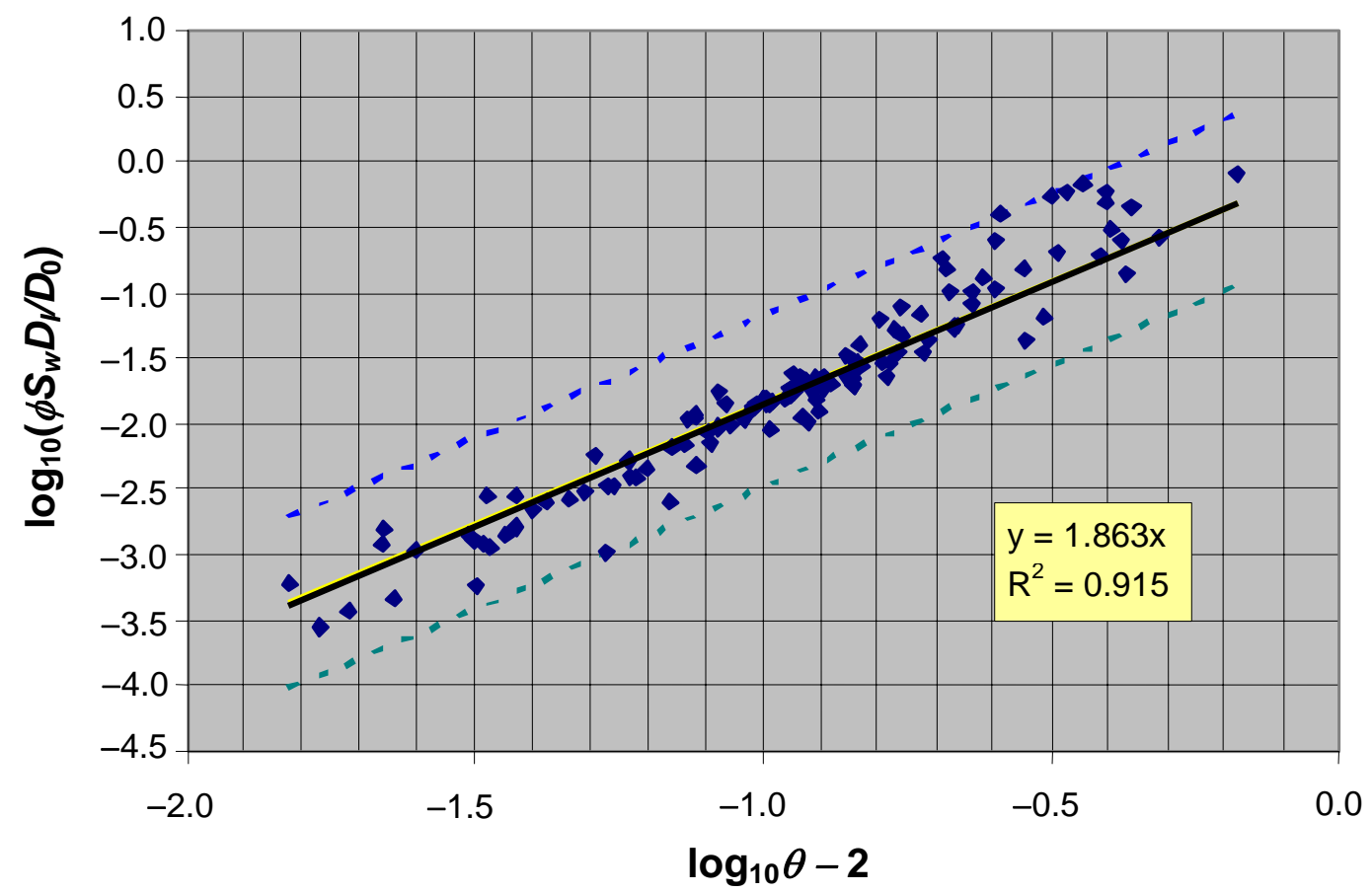

Source: Conca And Wright 1992 [DIRS 100436], Figure 2; Conca et al. 1993 [DIRS 170709], Figure 2.

NOTE: The dashed lines correspond to three standard deviations above and below the statistical fit to the data.

Figure 6.3-4. Uncertainty in the Statistical Fit for the Effective Diffusion Coefficient

For each realization of the TSPA-LA calculations, the normal distribution is sampled, thereby incorporating the uncertainty of the experimental data into the diffusivity.

\subsection{Modification for Temperature}

The diffusivity $D_{T}$ is proportional to absolute temperature and inversely proportional to viscosity $\eta_{T}$; i.e., $D_{T} \propto T / \eta_{T}$ (Cussler 1997 [DIRS 111468], p. 114). It follows that if the diffusivity is known at some temperature $T_{0}$, the diffusivity at temperature $T$ can be found by:

$$
\frac{D_{T}}{D_{T_{0}}}=\frac{\frac{T}{T_{0}}}{\frac{\eta_{T}}{\eta_{T_{0}}}},
$$

where $D_{T}$ is the diffusion coefficient $\left(\mathrm{m}^{2} \mathrm{~s}^{-1}\right)$ at temperature $T(\mathrm{~K}), D_{T_{0}}$ is the diffusion coefficient $\left(\mathrm{m}^{2} \mathrm{~s}^{-1}\right)$ at temperature $T_{0}(\mathrm{~K}), \eta_{T}$ is the viscosity of water ( $\mathrm{Pa} \mathrm{s}$ ) at temperature $T$ $(\mathrm{K})$, and $\eta_{T_{0}}$ is the viscosity of water ( $\mathrm{Pa} \mathrm{s}$ ) at temperature $T_{0}$. The dependence of viscosity on temperature $T(\mathrm{~K})(293.15 \mathrm{~K} \leq T \leq 373.15 \mathrm{~K})$ is given by (Weast and Astle 1981 [DIRS 100833], p. F-42): 


$$
\log _{10}\left(\frac{\eta_{T}}{\eta_{20}}\right)=\frac{1.3272(293.15-T)-0.001053(T-293.15)^{2}}{T-168.15}
$$

where $\eta_{20}$ is the viscosity of water at $20^{\circ} \mathrm{C}(293.15 \mathrm{~K})$. Then

$$
\frac{\eta_{T}}{\eta_{T_{0}}}=\frac{10^{\left[\frac{1.3272(293.15-T)-0.001053(T-293.15)^{2}}{T-168.15}\right]}}{10^{\left[\frac{1.3272\left(293.15-T_{0}\right)-0.001053\left(T_{0}-293.15\right)^{2}}{T_{0}-168.15}\right]}},
$$

and the diffusion coefficient at temperature $T$ is given by:

$$
\begin{aligned}
D_{T} & =D_{T_{0}} \frac{T}{T_{0}} \frac{\eta_{T_{0}}}{\eta_{T}} \\
& =D_{T_{0}} \frac{T}{T_{0}} 10^{\left[\frac{1.3272\left(293.15-T_{0}\right)-0.001053\left(T_{0}-293.15\right)^{2}}{T_{0}-168.15}\right]-\left[\frac{1.3272(293.15-T)-0.001053(T-293.15)^{2}}{T-168.15}\right]} .
\end{aligned}
$$

This equation is not valid above $100^{\circ} \mathrm{C}(373.15 \mathrm{~K})$, where it is assumed that no transport occurs (Assumption 5.5). The invert temperature is provided by the Multiscale Thermohydrologic Model (BSC 2005 [DIRS 173944]). This temperature modification of the diffusion coefficient, shown in Figure 6.3-5, is applied only to the invert, not to waste package corrosion products (Section 6.3.4.3.5) or to the waste form.

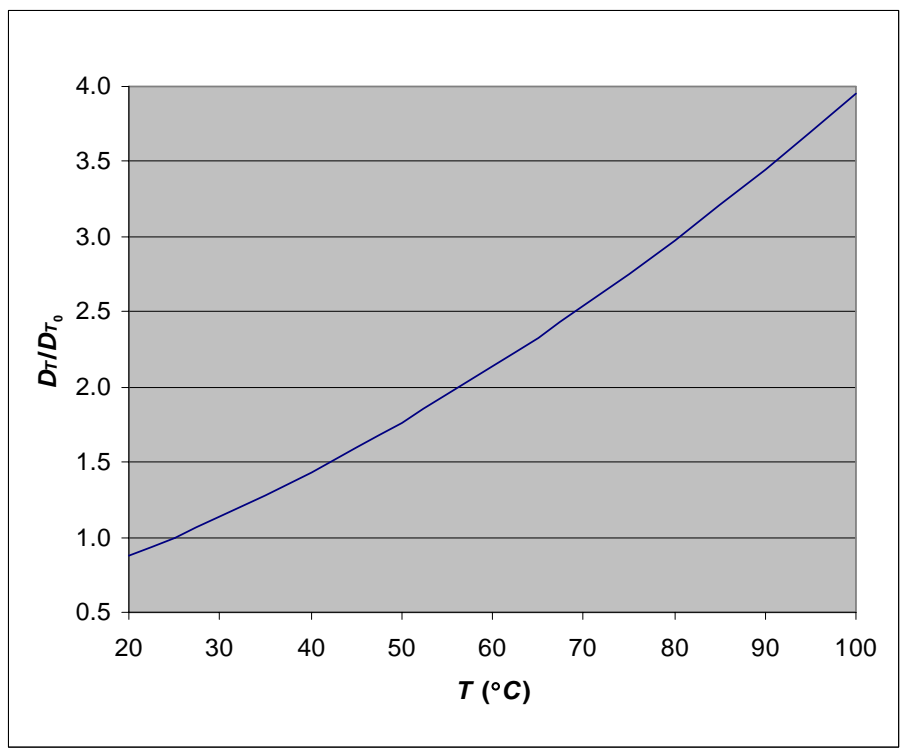

Figure 6.3-5. Temperature Dependence of the Invert Diffusion Coefficient (Equation 6.3.4.1.2-4) 


\subsection{Modification for Concentrated Aqueous Solutions}

Data in American Institute of Physics Handbook (Gray 1972 [DIRS 138541], Table 2p-2) show that the majority of the diffusion coefficients increase with increasing solution strength. For example, the diffusion coefficient of sodium iodide increases from 1.616 in a dilute solution to 1.992 for a $3 \mathrm{M}$ solution and the coefficient for potassium iodide increases from 2.00 in a dilute solution to 2.533 at $3.5 \mathrm{M}$. The percent increase for potassium iodide, 26.7 percent, is the greatest of any in Gray's Table 2p-2, (Gray 1972 [DIRS 138541]) excluding $\mathrm{HCl}$. $\mathrm{HCl}$ has been excluded from consideration because, being volatile, it is not representative of the type of radionuclides released from the waste package.

Although the diffusion coefficients of aqueous solutions increase with increasing ionic strength, the self-diffusion coefficient of water is still higher. Therefore, using the self-diffusion coefficient for water is a bounding value for all radionuclides at a given temperature. The modification for concentrated aqueous solutions is therefore neglected in the TSPA-LA.

\subsubsection{Retardation in the Engineered Barrier System}

In this section, parameters are developed to enable the impact of sorption processes on radionuclide transport through the EBS to be quantified. Transport through the EBS is affected by the adsorption and desorption of radionuclides on the materials in the waste package and invert. Adsorption describes the uptake of a radionuclide by a solid surface when in contact with a radionuclide-laden aqueous solution. This uptake typically occurs when a bond is formed by surface sites that have a chemical affinity for the radionuclide. Progressive inflow of fluids with low radionuclide concentrations would thermodynamically favor desorption of the original population of sorbed radionuclides back into solution, a process referred to as reversible sorption. Fully reversible sorption and desorption of radionuclides is often described by a linear isotherm, using a sorption distribution coefficient $\left(K_{d}\right)$.

Irreversible sorption refers to the tendency in natural systems for desorption to be incomplete. In other words, the amount of sorbed contaminant available for desorption in natural systems is typically less than the total sorbed mass due to chemical and physical processes occurring at or beneath the mineral surface. Irreversible sorption is described by a reaction rate coupled with some limit on the amount of sorption that is possible.

Sorption processes are referred to as adsorption if the process occurs on the surface or absorption if the process occurs beneath the surface. Retardation in the EBS results from adsorption of radionuclides on surfaces of corrosion product or tuff particles that comprise a porous bulk mass.

This section defines a conceptual model and parameters for transport through the degraded EBS, including appropriate $K_{d}$ values and a description of irreversible sorption of radionuclides. In addition to adsorption of radionuclides, water is expected to adsorb on corrosion products inside a breached, degraded waste package. This adsorbed water will provide a diffusive transport pathway under conditions where no seepage occurs into the drift. This in-package diffusion submodel is described in more detail in Section 6.3.4.3. Section 6.5.1.2 and Appendix B show the mathematical incorporation of the $K_{d}$ approach in the transport model. 
The TSPA-SR transport model for the EBS assumed no sorption or retardation of dissolved species of radionuclides (CRWMS M\&O 2000 [DIRS 153246], p. 3-134). This assumption was bounding (i.e., underestimating retardation) for several reasons:

- A large mass of iron oxyhydroxides is generated through corrosion of mild steel and stainless steels within the waste package and invert. The iron oxyhydroxides are known to be excellent sorbers (as indicated by their high $K_{d}$ values) of many radionuclide species (see, for example, Table 6.6-5).

- Some sorbed radionuclides, such as plutonium, appear not to desorb in many geologic environments (Brady et al. 1999 [DIRS 154421], Appendix F). In effect, the sorption process appears partly irreversible, and a large percentage of sorbed radionuclides appears to be permanently attached to the corrosion products in the EBS, although the short-term data may provide misleading information about long-term irreversibility. The net effect of irreversible sorption on EBS transport will depend on two competing effects: (1) irreversible sorption on the in-drift materials will decrease releases from the EBS, and (2) irreversible sorption to stable colloidal particles will increase transport through the EBS.

The National Research Council 2000 [DIRS 174394] states that irreversible sorption models should not be applied to quantitative models of environmental contamination. With regard to the report on contaminant attenuation of Brady et al. 1999 [DIRS 154421], the National Research Council (2000 [DIRS 174394], p. 224) states: "irreversible sorption...is not understood for either organic or inorganic contaminants; much more scientific research is needed before this process can be quantified." In addition, the National Research Council (2000 [DIRS 174394], Table ES-1, p. 9) judged the likelihood of success of long-term $\mathrm{Pu}$ immobilization as low, at the current level of knowledge. The National Research Council (2000 [DIRS 174394], p. 13) refers to Brady et al. (1999 [DIRS 154421]) as follows: "Furthermore, although the DOE document [Brady et al. 1999] proposes a method for assessing natural attenuation processes for inorganic contaminants, such processes are extremely complex, and the DOE document does not adequately reflect this complexity. The DOE document has to be peer reviewed and substantially revised before it is used as a decision-making tool."

As described in Section 6.3.4.2.3.2, however, field and laboratory measurements indicate that the fraction of sorbed plutonium that is available for desorption rarely exceeds one percent (Brady et al. 1999 [DIRS 154421], Appendix F, pp. 141 to 142; Davis and Kent 1990 [DIRS 143280]). Models for watershed transport (Graf 1994 [DIRS 154419]) focus solely on particulate transport; desorption is ignored because aqueous plutonium is rarely seen. At the Rocky Flats site in Colorado, Litaor and Ibrahim (1996 [DIRS 161667]) measured plutonium in Rocky Flats soil to be 0.04 to 0.08 percent exchangeable. Transport of colloidal plutonium over hundreds of meters was observed at the Nevada Test Site (Kersting et al. 1999 [DIRS 103282]); although these data indicate sequestration or irreversible sorption of $\mathrm{Pu}$, the presence of organics limits the relevance of these data to Yucca Mountain. Laboratory experiments of plutonium sorption onto iron oxide colloids have shown that one percent or less of the initially sorbed plutonium can be desorbed into solution after months of time have 
elapsed (Lu et al. 2000 [DIRS 166315]; BSC 2004 [DIRS 170025], Section 6.3.3.2). The detailed desorption data (observations out to five months) are reported in $\mathrm{Lu}$ et al. 1998 (DIRS 100946]. Overall, the data show that plutonium binds strongly to iron oxide substrates and is persistently (although not necessarily irreversibly) stabilized, at least over the time frames of observations (up to about 60 years). For purposes of modeling, therefore, a large fraction of plutonium sorbed to iron oxides can be considered irreversibly attached.

- Copper is present along the top of the invert as an electrical conductor. Two corrosion products produced by the alteration of elemental copper (copper oxide and copper sulfide) can strongly sorb iodine and technetium species (Balsley et al. 1998 [DIRS 154439], Tables 1 and 2), an important feature for decreasing releases of two elements that generally have minimal sorption in oxidizing environments.

\subsection{Conceptual Model for the In-Drift Sorption Environment}

In this section, the conceptual model of the in-drift environment as it affects sorption is described. Although sorption can also take place on crushed tuff, the focus in this section is on corrosion products (metal oxides), because these materials have the greatest potential for sorption in the EBS.

The mild steel and stainless steel in the waste package and invert are expected to degrade to iron oxyhydroxides more rapidly than the corrosion-resistant materials in the EBS (e.g., Alloy 22 and titanium). The time sequence for corrosion of iron-based components in the EBS is:

- Mild steel in the invert (e.g., support beams, cap plate, and gantry rails) will begin to degrade after closure of the repository because the invert is directly exposed to the relative humidity and temperature environment within the drifts. Corrosion begins when the relative humidity becomes great enough to produce aqueous conditions on the metal surface, although the presence of deliquescent salts can result in aqueous conditions at lower humidity (if the in-drift humidity is higher than the minimum deliquescent point of the salts; Campbell and Smith 1951 [DIRS 163817], p. 237).

The steel and copper are in the top portion of the invert. More specifically, the longitudinal and transverse support beams are in the top half of the invert (BSC 2004 [DIRS 169776], Section A). The transverse support beams are spaced at 1.524-m intervals (BSC 2004 [DIRS 169503]), so the corrosion products from the beam will not always be directly beneath the emplacement pallet or stress corrosion cracks. Below and on either side of these beams, the invert is filled to depth with a granular ballast that does not contain any steel.

- Stainless steel tubes in the emplacement pallet will corrode more slowly than mild steel (for mild carbon steel and stainless steel corrosion rates see DTN: MO0409SPAACRWP.000 [DIRS 172059]). Again, the tubes are directly exposed to the in-drift temperature and relative humidity after closure. The tubes in the emplacement pallet are located directly beneath the waste package, close to, if not directly in, the anticipated flow path from the waste package. 
- Mild steel (i.e., carbon steel Type A 516) inside the waste package can begin to degrade after the waste package is breached by stress corrosion cracks, localized corrosion, or general corrosion. Water vapor can enter the waste package once it is breached, and this vapor will be adsorbed on the steel surfaces, providing an environment for corrosion within the waste package.

- Stainless steel inside the waste package can also corrode, albeit more slowly than mild steel, after the waste package is breached.

Aluminum thermal shunts in 21-PWR and 44-BWR waste packages comprise less than two percent of the total mass of the waste package. Because the amount of aluminum is small, it is ignored in the EBS RT Abstraction. The Ni-Gd Alloy absorber plates in the CSNF waste package design are modeled as being composed of Neutronit, as in the previous waste package design; Neutronit is treated as having the same corrosion rate as stainless steel, resulting in corrosion products containing $\mathrm{Fe}_{2} \mathrm{O}_{3}$ in proportion to its iron content (see Section 6.3.4.2.3).

Because the corrosion rate of the carbon steel used for invert components is greater than that of the Alloy 22 waste package outer corrosion barrier, all mild steel components in the invert will degrade to iron oxyhydroxides by the time the waste package is breached by general corrosion. In other words, iron oxyhydroxides will be present in the invert before any radionuclides are transported from the waste package. After the waste package outer corrosion barrier is breached, the stainless steel inner vessel is expected to breach quickly due to localized corrosion, and the mild steel internal components in the waste package will degrade rapidly, adding iron oxyhydroxides to the in-package environment. The inner vessel will degrade to corrosion products by 205,000 years, based on a thickness of the inner vessel of stainless steel of $50.8 \mathrm{~mm}$ (BSC 2004 [DIRS 169472]; BSC 2004 [DIRS 166953], Section B-B) and a mean corrosion rate of $0.248 \mu \mathrm{m} \mathrm{yr}^{-1}$ (DTN: MO0409SPAACRWP.000 [DIRS 172059]).

The degradation products in the waste package will include hydrous metal oxides from corrosion of steel and aluminum materials (YMP 1998 [DIRS 104441], p. C-23; BSC 2005 [DIRS 174583]) and clays from degradation of HLW glass (BSC 2004 [DIRS 169988], Section 6.5.3.3). Because they comprise the great majority of the corrosion products, and because of their strong sorptive characteristics, the iron oxyhydroxides will dominate the sorptive properties of the corrosion products, although the aluminum oxides and manganese oxides are also highly sorptive, depending on $\mathrm{pH}$ and the zero point of charge.

The degradation products in the invert will include iron oxyhydroxides and other hydrous metal oxides from the corrosion of steels and copper-based materials, and minerals from the granular invert backfill. The invert corrosion products occur in the top portion of the invert because all steel and copper is located in the top half of the invert (BSC 2001 [DIRS 154441]).

The in-package degradation products are envisioned to be composed of unconsolidated particulates and larger agglomerations of clays, iron oxyhydroxides, and other mineral assemblages that slump to the bottom of the waste package. Any seepage through the waste package is expected to flow through the sludge at the bottom of the waste package. The invert degradation products are initially located near the top of the invert, but may move into the mass of granular invert backfill during thermal changes or seismic events. 
The sludge of corrosion products in the waste package is represented as a single porosity medium, a reasonable approach given the granularity of the corrosion products and the randomness of the slumping process. Channelized flow paths with no sorption, as in the discrete fractures of a dual porosity medium, are not anticipated to occur in this unconsolidated sludge. One conceptual model is for the radionuclides to have access to the mass of corrosion products in the waste package. An alternative conceptual model, with corrosion products that form a contiguous mass that has a low permeability and tight pore structure, would limit access to the full sorptive capacity of the corrosion products.

The bulk of the mass of materials in a CSNF waste package, excluding the SNF and the outer corrosion barrier, consists of various types of steel. The iron content of these steels (Table 4.1-14) ranges from 61.935 weight percent (Type 316, used in the inner vessel; DTN: MO0003RIB00076.000 [DIRS 153044]) to 98.37 weight percent (A 516 carbon steel, used in the basket components; DTN: MO0107TC240032.000 [DIRS 169970]). It is thus reasonable to treat all corrosion products as iron oxide.

In the EBS RT Abstraction, the products of the corrosion of all internal waste package components except for fuel rods and spent nuclear fuel (SNF) are modeled as a mixed assemblage of iron oxides, specifically $\mathrm{Fe}_{2} \mathrm{O}_{3}$ (hematite), $\mathrm{FeOOH}$ (goethite), and ferrihydrite (HFO). Establishing the mineralogical type of iron oxide corrosion products enables the amount of water adsorbed onto surfaces to be estimated. In addition, specifying the mineralogical composition of the corrosion products allows the surface charge (or site) density for adsorption of certain radionuclides that undergo irreversible adsorption to be determined, which provides a basis for calculating the mass of radionuclides that are irreversibly sorbed.

Geochemical analyses of the basket degradation process (YMP 1998 [DIRS 104441], p. C-23) have demonstrated that the iron oxide produced from corrosion of carbon steel and borated stainless steels will remain in the waste package as insoluble hematite. A more recent analysis (BSC 2005 [DIRS 174583], p. 6-21) states:

Although the formation of large masses of ferric (hydr)oxide corrosion products is inevitable, it is difficult to predict which one will dominate the mineralogy of the whole. Goethite and hematite are expected to eventually be the most abundant iron oxides in corrosion products (Schwertmann and Cornell 1991 [DIRS 144629], Section 4.2.2). Poorly crystalline solids such as ferrihydrite $\left(\mathrm{Fe}_{5} \mathrm{HO}_{8} \cdot 4 \mathrm{H}_{2} \mathrm{O}\right)$ and $\mathrm{Fe}(\mathrm{OH})_{3}$ that form during rapid oxidation of $\mathrm{Fe}(\mathrm{II})$ and hydrolysis of $\mathrm{Fe}(\mathrm{III})$, will probably be present throughout the period of steel degradation in the waste package (Schwertmann and Cornell 1991 [DIRS 144629], Sections 1.3 and 8.1). These poorly crystalline iron oxides are unstable with respect to hematite and goethite, but their transformation is significantly inhibited or retarded by their adsorption or structural substitution, or both, of silicate, phosphate, and $\mathrm{Cr}(\mathrm{III})$, which are common components of the waste package solution. To summarize, the corrosion product assemblage is likely to be made up of some mixture of hematite, goethite, and ferrihydrite.

For consistency with In-Package Chemistry Abstraction (BSC 2005 [DIRS 174583]), the EBS $R T$ Abstraction uses hematite properties for determining the degree of water adsorption and 
water saturation in corrosion products, while goethite and HFO properties are used for modeling corrosion product surface chemistry (specifically, irreversible sorption). Because the water vapor adsorption isotherms (expressed as water layer thickness) for HFO and goethite are similar to that of hematite (Section 6.3.4.3.1), the hematite isotherm (Jurinak 1964 [DIRS 154381], p. 486) is representative of the mixed iron oxide assemblage and is used to compute the water content in the corrosion products. The specific surface areas of HFO and goethite are generally greater than that of hematite (Langmuir 1997 [DIRS 100051], Table 10.2), meaning that the water content and the potential for radionuclide diffusion is greater at any given relative humidity for ferrihydrite and goethite than for hematite. However, the diffusion rate is dependent on the dissolved concentration of radionuclides in the corrosion products. The mass of radionuclides in solution is given by the waste form degradation rate. Because the water content or volume will tend to be less using hematite specific surface area rather than those of goethite or HFO, the given mass of radionuclides will result in the radionuclide concentration being higher for hematite corrosion products. Consequently, releases will be overestimated by using hematite properties for water adsorption calculations.

\subsection{Sorption Parameters for the Invert}

In the invert, radionuclide sorption can potentially take place on the crushed tuff ballast material and on products of corrosion of the metallic components such as steel support beams and copper conductor bars. In the EBS RT Abstraction, sorption onto the crushed tuff is included so as to be consistent with the model for sorption onto tuff in UZ transport (BSC 2004 [DIRS 164500], Section 6.1.2.3). As a bounding approach, sorption of radionuclides on corrosion products in the invert is ignored (Assumption 5.6).

\subsection{Sorption onto Crushed Tuff in the Invert}

Sorption onto the crushed tuff is included in the EBS transport abstraction. $K_{d}$ values and distributions for nine selected radionuclides are presented in Table 4.1-15 (DTN: LA0408AM831341.001 [DIRS 171584]); $K_{d}$ values for sorption of carbon, iodine and technetium on tuff are zero. The ranges of $K_{d}$ values for sorption onto devitrified tuff are used because the crushed tuff in the invert will be the same tuff that is removed when the drifts are bored; most of the repository will be developed in the TSw33 through TSw36 stratigraphic units, which are composed of devitrified tuff. The $K_{d}$ values selected are summarized in Table 6.5-6. Correlations of $K_{d}$ values among various radionuclides for sorption on tuff are given by a correlation matrix presented in Table 4.1-16. Invert $K_{d}$ values are implemented in TSPA-LA by first computing unsaturated zone $K_{d}$ values for devitrified tuff and then assigning those values to the invert.

\subsection{Sorption onto Corrosion Products in the Invert}

Invert corrosion products will tend to be localized and widely spaced, with the possibility being that seepage from the waste package could completely miss corrosion products in the invert. In this case, even small $K_{d}$ values could overestimate the amount of retardation of radionuclides in the invert. Furthermore, invert corrosion products will have a smaller sorptive capacity than waste package corrosion products simply because the masses of sorptive corrosion products in 
the invert are much less than in the waste packages. Therefore, as a bounding approach, sorption of radionuclides on corrosion products in the invert is ignored (Assumption 5.6).

To compare with the mass of sorbing material in the waste packages, the mass of sorbing material in the invert is estimated below using the data from Repository Subsurface Emplacement Drifts Steel Invert Structure Sect. \& Committed Materials (BSC 2004 [DIRS 169776], Committed Materials table). The iron content of the steel invert support beams, stiffeners, base plates, gantry runway beams, runway beam cap plates, stub columns and top plates, miscellaneous stiffener plates, and the gantry rails is included in this calculation. The iron in the steel set ground support, the rock bolts, and the welded wire fabric steel has been ignored, even though the corrosion products from these components may fall on the invert.

As in Table 6.3-4 (Section 6.3.4.2.3.1), the mass of corrosion products is estimated by assuming that iron converts to $\mathrm{Fe}_{2} \mathrm{O}_{3}$ during the corrosion process. The mass of A 588 carbon steel per unit length of drift in the invert is $893 \mathrm{~kg} \mathrm{~m}^{-1}$ (BSC 2004 [DIRS 169776], Committed Materials table), having an iron content of $859 \mathrm{~kg} \mathrm{~m}^{-1}$ (using an iron content of 96.16 percent for the composition of A 588 steel; ASTM A 588/A 588M-01 [DIRS 162724], Table 1). The mass of A 759 steel in the gantry rails is $134 \mathrm{~kg} \mathrm{~m}^{-1}$ (BSC 2004 [DIRS 169776], Committed Materials table), which has an iron content of 97.47 percent (ASTM A 759-00 [DIRS 159971]), or $131 \mathrm{~kg} \mathrm{~m}^{-1}$. The total iron content of the invert is then $990 \mathrm{~kg} \mathrm{~m}^{-1}$, which converts to $1,415 \mathrm{~kg} \mathrm{~m}^{-1}$ of $\mathrm{Fe}_{2} \mathrm{O}_{3}$. As a comparison, the average mass of $\mathrm{Fe}_{2} \mathrm{O}_{3}$ in the invert under a 21-PWR or 44-BWR waste package, having a nominal length of $5.02 \mathrm{~m}$ (BSC 2004 [DIRS 169472], Table 1), would be $7,100 \mathrm{~kg}$, or approximately one-third the amount of iron corrosion products inside a waste package (Table 6.3-4). Thus, while not negligible, the sorptive capacity of the invert is small compared to that of the waste packages, and ignoring retardation by corrosion products in the invert (Assumption 5.6) will overestimate radionuclide transport.

The impact of copper in the invert on retarding iodine and technetium is discussed here to complete the analysis of neglecting retardation by corrosion products in the invert and thus overestimating radionuclide transport. The amount of elemental copper in the drift is given by the nominal weight of the solid copper conductor bar rail, $4.0 \mathrm{~kg} \mathrm{~m}^{-1}$ (BSC 2001 [DIRS 154441], Section 3.1.7), plus the copper in the communication cable, which is 50 percent by weight of the total cable weight of $2.00 \mathrm{~kg} \mathrm{~m}^{-1}$ (BSC 2001 [DIRS 154441], Sections 3.1.9 and 3.2.1.3). The total weight of elemental copper per meter of drift is then $[4.0+(0.5)(2.00)]$ or a total of $5.0 \mathrm{~kg} \mathrm{~m}^{-1}$. These values are based on the nominal mass of elemental copper, rather than the upper bound values, to avoid overestimating potential sorption on copper. The mass of elemental copper is not explicitly represented in the TSPA-LA model, but its presence when oxidized is noted because of its role as a potential sorber for iodine and technetium.

The mass of copper is large relative to the mass of iodine and technetium. Using a waste package length of $5.024 \mathrm{~m}$ for the CSNF waste package (BSC 2004 [DIRS 169472], Table 1), there is nominally $25.1 \mathrm{~kg}$ (395 mol) of elemental copper in the invert per CSNF waste package. This value $(25.1 \mathrm{~kg})$ can be compared to approximately $7.64 \mathrm{~kg}(77.2 \mathrm{~mol})$ of technetium-99 and $1.75 \mathrm{~kg}$ (13.6 mol) of iodine-129 per CSNF waste package (DTN: SN0310T0505503.004 [DIRS 168761]). Thus, there is more elemental copper than iodine or technetium using a mass or molar basis. Similarly, the 5 DHLW/DOE SNF - Short codisposal waste package has a length 
of $3.45 \mathrm{~m}$ (BSC 2004 [DIRS 169472], Table 3), so there is nominally $17.3 \mathrm{~kg}$ (272 mol) of elemental copper per 5 DHLW/DOE SNF - Short waste package in the invert. This mass is greater than the approximately $1.256 \mathrm{~kg}(12.7 \mathrm{~mol})$ of technetium- 99 or the $114 \mathrm{~kg}(0.88 \mathrm{~mol})$ of iodine-129 in the codisposal waste packages (DTN: SN0310T0505503.004 [DIRS 168761]). Based simply on a gross comparison of quantities present, there is ample copper in the invert to adsorb all iodine and technetium that might be released from the waste packages if a mole of copper adsorbs a mole of technetium or iodine. Nevertheless, because the presence of copper is highly localized, the probability of iodine or technetium released from the waste package actually contacting the copper is low. Therefore, iodine and technetium are assumed not to sorb onto corrosion products in the invert.

To summarize, no credit is taken for radionuclide sorption onto corrosion products of iron or copper contained in the invert (Assumption 5.6), through which radionuclides must be transported to reach the accessible environment. By ignoring sorption in the invert, there is added confidence that the radionuclide inventory actually transported is less than the calculated value used in assessing dose to the individual.

\subsection{Sorption Parameters for the Waste Package}

This section presents and analyzes appropriate sorption parameters for the EBS. First, the mass of corrosion products (sorbers) is calculated for the repository design. Second, the available data on irreversible sorption of radionuclides that are relevant to EBS transport are presented.

In order to avoid ambiguity in competition for adsorption sites, the conceptual model for sorption of radionuclides in waste package corrosion products precludes reversible sorption. Therefore, $K_{d}$ values for all radionuclides are set to zero for sorption onto waste package corrosion products (BSC 2005 [DIRS 174695]). Irreversible sorption of Pu and Am is included in the sorption conceptual model. No other radionuclides are sorbed onto waste package corrosion products reversibly or irreversibly in this model. The surface properties of potential corrosion products, even just the potential iron corrosion phases, vary tremendously, and a more rigorous model to evaluate radionuclide sorption, such as a surface complexation model, would be difficult to parameterize.

\subsection{Waste Package Corrosion Product Mass}

The mass of sorbing material in the waste package has been estimated using compositional information from Table 4.1-14 and numbers and masses of components listed in design drawings. The mass of sorbing material in the waste package is based on the iron contents of Stainless Steel Type 304L, Stainless Steel Type 316L, Stainless Steel Type 316 (these three types of stainless steel have similar iron contents), Carbon Steel Type A 516, Neutronit A 978, and the masses of these alloys in the four most common waste package types. The estimated masses of corrosion products are shown in Table 6.3-4 and described in Appendix A. For purposes of estimating the mass of corrosion products, the corrosion products are modeled as $\mathrm{Fe}_{2} \mathrm{O}_{3}$ (Section 6.3.4.2.1), and the mass of corrosion products is calculated based on the ratio of molecular weight of $\mathrm{Fe}_{2} \mathrm{O}_{3}$ to the atomic weight of $\mathrm{Fe}$, accounting for stoichiometry (footnote $\mathrm{f}$ in Table 6.3-4). The results shown in Table 6.3-4 are based on an earlier version of the waste package design (IED 800-IED-WIS0-00202-000-00B, BSC 2004 [DIRS 167207]). Due to minor 
design changes for the 5 DHLW/DOE Short waste package (see Section 4.1.3, preceding Table 4.1-18), the mass of iron in that waste package is larger using the current design (IED 800-IED-WIS0-00601-000-00A, BSC 2005 [DIRS 173501], Table 7) than for the earlier design version (BSC 2004 [DIRS 167207], Table 5). In addition, in the calculation of the corrosion product mass (see Figure A-2), a mass of $1 \mathrm{~kg}$ for the Interface Ring for the $5 \mathrm{DHLW} / \mathrm{DOE}$ Short waste package is erroneously used; the correct value is $44.6 \mathrm{~kg}$. Lastly, the mass of the spread ring was increased from $31.9 \mathrm{~kg}$ in the earlier design version (BSC 2004 [DIRS 167207], Table 5) to $33.8 \mathrm{~kg}$ in the current design (BSC 2005 [DIRS 173501], Table 7). Using the updated 5 DHLW/DOE Short waste package design data and correcting the Interface Ring mass result in an increase in the estimated mass of corrosion products, from 14,230 kg (Table 6.3-4) to $14,320 \mathrm{~kg}$ (updated, corrected value). The difference ( 0.6 percent) is negligible, so the earlier estimate of $14,230 \mathrm{~kg}$ shown in Table 6.3-4 is suitable for TSPA-LA calculations.

In a revision to the 21-PWR and 44-BWR waste package design (Anderson 2004 [DIRS 171637], BSC 2004 [DIRS 170710], BSC 2004 [DIRS 170838]), the Neutronit used for the absorber plates is replaced with a nickel-chromium-molybdenum-gadolinium alloy, N06464 (ASTM B 932-04 [DIRS 168403]), denoted as Ni-Gd Alloy. The mass of Neutronit in a 21-PWR waste package $(2,120 \mathrm{~kg}$; see Table $6.3-4)$ is replaced by $2400 \mathrm{~kg}$ of Ni-Gd Alloy. The mass of Neutronit in a 44-BWR waste package (2,990 kg; see Table 6.3-4) is replaced by 3,290 kg of Ni-Gd Alloy. Whereas Neutronit contains 66.06 percent iron (Kügler 1991 [DIRS 155761], p. 15), N06464 contains a maximum of 1.0 percent iron (ASTM B 932-04 [DIRS 168403]). In the analysis summarized in Table 6.3-4, only the iron in the waste package components contributes to the corrosion product mass that is used in water adsorption calculations in the in-package diffusion submodel, Section 6.3.4.3. This corrosion product mass also is used in the radionuclide sorption calculations. Using N06464 instead of Neutronit in a 21-PWR waste package would reduce the total iron mass from $13,600 \mathrm{~kg}$ to $12,220 \mathrm{~kg}$; the equivalent mass of $\mathrm{Fe}_{2} \mathrm{O}_{3}$ would be reduced from $19,440 \mathrm{~kg}$ to $17,470 \mathrm{~kg}$, a reduction of 10.1 percent. Using N06464 instead of Neutronit in a 44-BWR waste package would reduce the total iron mass from $15,550 \mathrm{~kg}$ to $13,610 \mathrm{~kg}$; the equivalent mass of $\mathrm{Fe}_{2} \mathrm{O}_{3}$ would be reduced from $22,240 \mathrm{~kg}$ to $19,460 \mathrm{~kg}$, a reduction of 12.5 percent.

For purposes of TSPA-LA calculations, iron and corrosion product mass estimates are based on the earlier waste package design. For a 21-PWR waste package, the calculations use Revision 00C of Design and Engineering, 21-PWR Waste Package Configuration (BSC 2004 [DIRS 167394]) rather than Revision 00D (BSC 2004 [DIRS 170710]). For a 5 DHLW/DOE Short waste package, the calculations use Revision 00B of $D \& E / P A / C$ IED Typical Waste Package Components Assembly (BSC 2004 [DIRS 167207], Table 5), instead of Revision 00C (BSC 2004 [DIRS 169472], Table 5). The estimated masses of corrosion products in 44-BWR and Naval Long waste packages shown in Table 6.3-4 are not used directly in TSPA-LA calculations. 
Table 6.3-4. Estimated Masses of Steels and Iron Content in Waste Packages and Equivalent Masses $(\mathrm{kg})$ of Iron Corrosion Products $\left(\mathrm{Fe}_{2} \mathrm{O}_{3}\right)$ for Use in Modeling Retardation in the Waste Package

\begin{tabular}{|c|c|c|c|c|c|c|c|c|c|}
\hline \multirow[b]{2}{*}{ Material } & \multirow[b]{2}{*}{$\begin{array}{c}\mathrm{Fe} \\
\text { Content }^{\mathrm{a}} \\
(\%)\end{array}$} & \multicolumn{2}{|c|}{ 21-PWR } & \multicolumn{2}{|c|}{ 44-BWR } & \multicolumn{2}{|c|}{$\begin{array}{c}\text { 5-DHLWIDOE } \\
\text { SNF - Short }\end{array}$} & \multicolumn{2}{|c|}{ Naval Long } \\
\hline & & $\begin{array}{c}\text { Total } \\
\text { Mass } \\
(\mathrm{kg})\end{array}$ & $\begin{array}{c}\mathrm{Fe} \\
\text { Mass } \\
(\mathrm{kg})\end{array}$ & $\begin{array}{c}\text { Total } \\
\text { Mass }^{c} \\
(\mathrm{~kg})\end{array}$ & $\begin{array}{c}\mathrm{Fe} \\
\text { Mass } \\
(\mathrm{kg})\end{array}$ & $\begin{array}{c}\text { Total } \\
\text { Mass }{ }^{d} \\
(\mathrm{~kg})\end{array}$ & $\begin{array}{c}\text { Fe } \\
\text { Mass } \\
(\mathrm{kg})\end{array}$ & $\begin{array}{c}\text { Total } \\
\text { Mass } \\
(\mathrm{kg})\end{array}$ & $\begin{array}{c}\mathrm{Fe} \\
\text { Mass } \\
(\mathrm{kg})\end{array}$ \\
\hline $\begin{array}{l}\text { Stainless Steel } \\
\text { Type } 316\end{array}$ & 61.935 & 10,800 & 6,690 & 11,120 & 6,890 & 10,160 & 6,300 & 14,420 & 8,930 \\
\hline $\begin{array}{l}\text { A } 516 \text { Carbon } \\
\text { Steel }\end{array}$ & 98.37 & 5,600 & 5,510 & 6,800 & 6,690 & 3,720 & 3,660 & - & - \\
\hline $\begin{array}{l}\text { Neutronit } \\
\text { A } 978\end{array}$ & 66.06 & 2,120 & 1,400 & 2,990 & 1,970 & - & - & - & - \\
\hline Total & - & 18,520 & 13,600 & 20,910 & 15,550 & 13,880 & 9,960 & 14,420 & 8,930 \\
\hline $\begin{array}{l}\text { Percentage of } \\
\text { Total as iron }\end{array}$ & - & - & 73.4 & - & 74.4 & - & 71.7 & - & 61.9 \\
\hline $\begin{array}{l}\text { Equivalent } \\
\mathrm{Fe}_{2} \mathrm{O}_{3} \text { mass }\end{array}$ & - & - & 19,440 & - & 22,240 & - & 14,230 & - & 12,770 \\
\hline
\end{tabular}

NOTE: Microsoft Excel calculation of equivalent $\mathrm{Fe}_{2} \mathrm{O}_{3}$ mass is described in Appendix $\mathrm{A}$.

${ }^{a}$ Calculated "Balance" from Table 4.1-14 compositions: 100 - (sum of non-Fe constituents); see Appendix A.

${ }^{\mathrm{b}}$ Total Mass in 21-PWR for each material in Table 4.1-20: sum of (mass $\times$ number) of each component (BSC 2004 [DIRS 169472], Table 2; Material Table in Design and Engineering, 21-PWR Waste Package Configuration (BSC 2004 [DIRS 167394]); see Appendix A.

'Total Mass in 44-BWR for each material: sum of (mass $\times$ number) of each component (BSC 2004 [DIRS 169472], Table 3; Material Table in Design and Engineering, 44-BWR Waste Package Configuration (BSC 2004 [DIRS 167555]); see Appendix A.

${ }^{d}$ Total Mass in 5-DHLW/DOE SNF - Short for each material in Table 4.1-20: sum of (mass $\times$ number) of each component (BSC 2004 [DIRS 167207], Table 5; Material Table in Design \& Engineering, 5 DHLW/DOE SNF Short Waste Package Configuration (BSC 2004 [DIRS 166947]). Interface Ring mass of $1 \mathrm{~kg}$ erroneously used (Figure A-2); correct mass is $44.6 \mathrm{~kg}$ (BSC 2004 [DIRS 167207], Table 5); see Appendix A.

${ }^{\mathrm{e}}$ Total Mass in Naval Long for each material: sum of (mass $\times$ number) of each component (BSC 2004 [DIRS 169472], Table 4; Material Table in Design and Engineering, Naval Long Waste Package Configuration (BSC 2003 [DIRS 165159]); see Appendix A.

${ }^{\mathrm{f}} \mathrm{Fe}_{2} \mathrm{O}_{3}$ mass $=($ Fe mass, $\mathrm{kg}) \times\left(\right.$ molecular weight $\left.\mathrm{Fe}_{2} \mathrm{O}_{3}\right) \times\left(1 \mathrm{~mol} \mathrm{Fe}_{2} \mathrm{O}_{3} / 2 \mathrm{~mol} \mathrm{Fe}\right) /($ atomic weight $\mathrm{Fe})$ $=(\mathrm{Fe}$ mass, $\mathrm{kg}) \times\left(0.15969 \mathrm{~kg} \mathrm{Fe} \mathrm{O}_{3} / \mathrm{mol}\right) \times\left(1 \mathrm{~mol} \mathrm{Fe} \mathrm{O}_{3} / 2 \mathrm{~mol} \mathrm{Fe}\right) /(0.055847 \mathrm{~kg} \mathrm{Fe} / \mathrm{mol})$ $=1.4297 \times$ Fe mass.

$\mathrm{BWR}=$ boiling water reactor, $\mathrm{DHLW}=$ defense high-level (radioactive) waste, SNF = spent nuclear fuel; DOE = U.S. Department of Energy.

This reduction in $\mathrm{Fe}_{2} \mathrm{O}_{3}$ mass compared with the previous waste package design has two competing effects on predicted releases of radionuclides from a breached waste package. First, the mass of sorbant of radionuclides is reduced, which could potentially increase predicted releases; however, as shown in Appendix B (p. B-25), the sorption capacity of a 21-PWR waste package is more than double the available radionuclide inventory of a waste package, so using the previous design with a 10-to-12 percent higher sorption capacity is inconsequential. Second, using the larger mass of $\mathrm{Fe}_{2} \mathrm{O}_{3}$ in the previous design results in a higher water saturation in a no-seep case (as given by the in-package diffusion submodel, Section 6.3.4.3), which will overestimate diffusive releases of radionuclides.

If corrosion products were modeled as goethite or HFO instead of hematite, the mass of corrosion products (shown in Table 6.3-4 as hematite) would be increased by 11 percent (for 
a 21-PWR, 21,640 kg FeOOH vs. 19,440 kg Fe $\mathrm{O}_{3}$; for a $5 \mathrm{DHLW} / \mathrm{DOE}$ Short, 15,940 $\mathrm{kg}$ $\mathrm{FeOOH}$ vs. 14,320 $\mathrm{kg} \mathrm{Fe} \mathrm{O}_{3}$ ). The increase is obtained from the percentage change from the molecular weight of hematite $\left(0.15969 \mathrm{~kg} \mathrm{~mol}^{-1}\right)$ to that of goethite or HFO (both having the chemical formula $\mathrm{FeOOH}$ with molecular weight of $0.08885 \mathrm{~kg} \mathrm{~mol}{ }^{-1}$ ), accounting for stoichiometry: $100 \times\left[\left(2 \mathrm{~mol} \mathrm{FeOOH} / \mathrm{mol} \mathrm{Fe}_{2} \mathrm{O}_{3}\right) \times(0.08885) /(0.15969)-1\right]=11.3 \%$. This increase in mass of corrosion products is approximately the same as the 10 to $12 \%$ decrease in corrosion product mass resulting from using the current waste package design instead of the previous design. Thus, using hematite as corrosion products together with the iron content of the previous waste package design approximately offsets treating corrosion products as goethite and HFO with the current waste package design.

\subsection{Irreversible Sorption onto Waste Package Corrosion Products}

Irreversible sorption of a limited number of radionuclides ( $\mathrm{Pu}$ and $\mathrm{Am}$ only) is allowed to take place in recognition of field and laboratory observations that this process does occur. Uncertainty is accounted for by specifying a range and distribution for parameters governing the irreversible sorption model.

Recent reviews of field and laboratory measurements indicate that the fraction of sorbed plutonium that is available for desorption rarely exceeds 1 percent (Brady et al. 1999 [DIRS 154421], Appendix F, pp. 141 to 142; Davis and Kent 1990 [DIRS 143280]; see also Section 6.3.4.2). Observations of this sort have led to the concept that most of the plutonium sorbed onto soil materials and particularly iron oxyhydroxides is irreversibly attached. Recognition of the strong role of "irreversible sorption" is implicit in models for watershed transport (Graf 1994 [DIRS 154419]) that focus solely on particulate transport. At the Rocky Flats site in Colorado, soil plutonium is largely associated with the negatively charged organic macromolecular fraction and not with the more abundant iron oxides and clays (Santschi et al. 2002 [DIRS 170923]; Ibrahim and Salazar 2000 [DIRS 170882]). Litaor and Ibrahim (1996 [DIRS 161667]) used $0.01 \mathrm{M} \mathrm{CaCl}_{2}$ as an extractant and measured plutonium in Rocky Flats soil to be 0.04 to 0.08 percent exchangeable. Transport of minute quantities of colloidal plutonium $\left(10^{-14} \mathrm{M}\right)$ over hundreds of meters was observed at the Nevada Test Site (Kersting et al. 1999 [DIRS 103282]), although the presence of organics may limit the relevance of these data to Yucca Mountain. Laboratory experiments of plutonium sorption onto iron oxide colloids have shown that approximately 1 percent of the initially sorbed plutonium can be desorbed into solution over a period of several months (Lu et al. 2000 [DIRS 166315]; BSC 2004 [DIRS 170025], Section 6.3.3.2), which is broadly consistent with field observations, although much shorter in time scale. However, because the time scales for all of these observations are much shorter than the regulatory time period for repository performance $(10,000$ years), parameters describing irreversible sorption of plutonium in TSPA-LA calculations have a large uncertainty.

Although the field studies describe contaminant plumes that appear to be up to 50 years old, these occurrences of plutonium have not been studied, nor data collected, during that period. In addition, the mechanism(s) of attachment have not been addressed in these studies. Possible mechanisms of plutonium sorption and desorption are described in Section 6.6.7. In that section an alternative conceptual model is presented that incorporates a two-site model of iron oxyhydroxide substrates, based on published studies, that is supported by the data from Lu et al. 
(2000 [DIRS 166315]). A plausible mechanism for the strong sorption of plutonium is described in Section 6.6.7 based on the reduction of $\mathrm{Pu}(\mathrm{V})$ to $\mathrm{Pu}(\mathrm{IV})$ at the surface of the iron oxyhydroxide substrates. However, it is not known if this process explains strong sorption of plutonium over long periods of time. In any case, neither this mechanism nor any other has been invoked to explain the field occurrences of plutonium nor, until recently, the laboratory data (Lu et al. 2000 [DIRS 166315]) that suggest slow desorption.

Effectively irreversible uptake may be the dominant control over contaminant transport in soils. Evidence for soil sequestering of bomb-pulse plutonium and americium and of uranium, iodine, technetium, cesium, and strontium from ore processing and reactor operations has been documented in the literature (Coughtrey et al. 1983 [DIRS 132164]). Pu and Am sorb more strongly than the others listed (see BSC 2004 [DIRS 170025], Section 6.3.3.1).

Estimates of the mean fraction of irreversible sorption for various radionuclides on soil are derived in Site Screening and Technical Guidance for Monitored Natural Attenuation at DOE Sites (Brady et al. 1999 [DIRS 154421], Appendix F, pp. 141 to 142). The value of the irreversible fraction for the EBS will differ from that for soils and will depend on the material that the specific radionuclide encounters, the speciation of the radionuclide, and other factors in the material and chemical environment. For the TSPA-LA model, irreversible sorption of Pu and Am is included, with appropriate fractions of the total mass adsorbed being based on field observations. The implementation of the irreversible radionuclide sorption component of the EBS transport model is described in Section 6.5.3.4.

For the irreversible sorption submodel, the composition of the iron oxyhydroxide corrosion products is modeled as goethite, ranging from 45 - 80 percent, with the balance being HFO (Section 6.3.4.2.1). The goethite and HFO content has a uniform distribution. Justification for these composition ranges is as follows.

Ferrihydrite will convert to the more stable phase goethite under repository conditions so the latter will most likely be the dominant phase after long periods of time. Under controlled laboratory conditions, this conversion occurs rapidly, with time frames on the order of days to even months depending on temperatures and solution composition. A study by Hamzaoui et al. (2002 [DIRS 173866]), for example, on the transformation of ferrihydrite to goethite at alkaline conditions for a given range of temperatures indicates that full conversion will occur in a period of about 80 hours at $\mathrm{pH} 11$ and about 20 hours at $\mathrm{pH} 12.2$ and a temperature of $40^{\circ} \mathrm{C}$. A similar result at $\mathrm{pH} 12.2$ was obtained by Cornell and Giovanoli (1988 [DIRS 173864]) but at a temperature of $70^{\circ} \mathrm{C}$, where full conversion to goethite was obtained in about 24 hours. Hamzaoui et al. (2002 [DIRS 173866]) also show that transformation rates increases with increasing $\mathrm{pH}$. The studies by Cornell and Giovanoli (1988) and Cornell et al. (1989 [DIRS 173865]) indicate that the presence of some metals in solution and organics tends to retard the transformation of HFO to more crystalline phases. Slower rates are expected at ambient temperatures and near-neutral pH conditions. Schwertmann et al. (2000 [DIRS 173863]) studied long-term transformation of ferrihydrite to more crystalline oxyhydroxides at $\mathrm{pH} 4-7$ and $25^{\circ} \mathrm{C}$. Their results show that the presence of other metals in soils, such as Al, can slow down the conversion process. Even at low metal concentration, the full transformation process can be on the order of many months. However, whereas laboratory data show fast conversion rates from ferrihydrite to goethite, field-type corrosion experiments under 
atmospheric conditions indicate the consistent presence of amorphous ferric oxyhydroxide material for long periods of time (Misawa et al. 1974 [DIRS 159327]). The field experiments of Misawa et al. (1974) exposed mild and low-alloy steels to a semi-rural environment for 2.5 years. Phase identification analyses of the generated rusted material showed a larger proportion of amorphous ferric oxyhydroxide compared to goethite. Still, the former will transform to the latter with further aging. Dillmann et al. (2004 [DIRS 171480]) studied the corrosion products in ancient artifacts open to indoor atmospheric environments. Even for time periods on the order of a few to tens of years, the proportion of the ferric amorphous phase observed in the corrosion products can be roughly in the range of $20-70$ percent (Dillmann et al. (2004 [DIRS 171480], Table 1, p. 1405). Therefore, field evidence indicates that conversion of amorphous ferric oxyhydroxide to goethite can be slower than observed under laboratory conditions due to various factors inherent to local corrosion environments, such as the presence of additional metals in solution, $\mathrm{pH}$, wet and dry cycles, and temperature. Given these large differences observed for the apparent speed of conversion between laboratory and field experiments, it is difficult to constraint transformation rates with a high level of confidence, and the range of compositions advanced above ( 45 to 80 percent goethite, the rest being HFO; see Section 6.3.4.2.1) is reasonable in capturing this variability.

The lack of data for both corrosion and phase transformation kinetics to reflect the inherent complexities of the in-package chemical environment precludes any attempts at estimating a well-constrained fraction of corrosion products with time. For model details on the in-package chemical environment and justification for the use goethite and ferrihydrite as the metal sorbing corrosion product phases see Section 6.3.2 of In-Package Chemistry Abstraction (BSC 2005 [DIRS 174583]. This in-package chemistry abstraction model assumes a mixture of sorbing ferric Fe oxyhydroxide corrosion products consistent with the irreversible sorption submodel considered in the current report. For these reasons, the adopted range is a reasonable representation that captures the presence of these two phases at any given time. The limited data available are still useful to support the argument for a rapid transformation as represented by the selected bounds for goethite fraction, considering the expected environmental repository conditions. However, the data also indicate that retardation of this conversion may be a result of other metals present in solution as it would be expected during waste package degradation.

The composition of HFO is not well defined given the variable content of $\mathrm{H}_{2} \mathrm{O}$ adsorbed, yielding a range of $\mathrm{Fe}: \mathrm{O}: \mathrm{H}$ ratios with respect to the phase structural properties (Cornell and Schwertmann 2003 [DIRS 173037]). Due to the arbitrary designation of ferrihydrite as amorphous hydrous ferric oxide with the formula $\mathrm{Fe}(\mathrm{OH})_{3}$, as often found in the literature, a more accurate representation of its composition should be considered based on chemical and structural analyses. Cornell and Schwertmann (2003 [DIRS 173037]) suggested that the chemical formula representation of ferrihydrite should be expressed as $\mathrm{FeO}_{1.07}(\mathrm{OH})_{0.86}$ and $\mathrm{FeO}_{0.89}(\mathrm{OH})_{1.22}$ for 6-line ferrihydrite and 2-line ferrihydrite, respectively. The work of Towe and Bradley (1967 [DIRS 155334]) advanced a ferrihydrite composition $\left(4 \mathrm{Fe}_{2} \mathrm{O}_{3} \cdot 6 \mathrm{H}_{2} \mathrm{O}\right)$ with larger amounts of $\mathrm{H}_{2} \mathrm{O}$. As discussed by Eggleton and Fitzpatrick (1988 [DIRS 173878]), many of the structural models for ferrihydrite do not conform to the reported bulk compositions, probably due to added adsorption effects caused by the aggregation of small particles, thus generating the emplacement of additional $\mathrm{OH}$ onto the surface. Eggleton and Fitzpatrick (1988 [DIRS 173878]) also concluded that any relations assessed from the structural analysis of ferrihydrite should be associated to a structural formula of $\mathrm{FeO}(\mathrm{OH})$. This chemical formula is 
consistent with that adopted for $\mathrm{HFO}\left(\mathrm{Fe}_{2} \mathrm{O}_{3} \cdot \mathrm{H}_{2} \mathrm{O}\right)$ along with the conversion factor of $89 \mathrm{~g}$ HFO/mol Fe by Dzombak and Morel (1990 [DIRS 105483]). Therefore, the adopted chemical formula for ferrihydrite/HFO in this analysis is $\mathrm{FeO}(\mathrm{OH})$, which is equivalent to that of goethite. Adoption of this chemical composition is consistent with that used in the HFO sorption analysis presented by Dzombak and Morel (1990 [DIRS 105483]). The close correspondence of the adopted chemical formula for ferrihydrite/HFO when compared to the range of reported compositions given above for ferrihydrite (Cornell and Schwertmann 2003) supports the use of this chemical formula in this report.

The sorptive capacity of the corrosion products is directly proportional to the surface area of the solids. Data for the specific surface area of goethite and HFO are compiled in Table 4.1-10 and qualified for use in TSPA-LA in Section 4.1.2. These data provide a range of values to be sampled in TSPA-LA for both goethite and HFO. The data in Table 4.1-10 are used to develop a discrete distribution, shown in Table 6.3-6. To calculate the discrete probability distribution, the data in Table 4.1-10 were first sorted into ascending order. Multiple occurrences of the same number were removed from the sorted data list, but their occurrence frequency was assigned for probability calculation. The probability levels were calculated by dividing the frequency of the each data number by the total number of original data points in the data list. The specific surface area of HFO is given by a single value, $600 \mathrm{~m}^{2} \mathrm{~g}^{-1}$ (Dzombak and Morel 1990 [DIRS 105483], Table 5.3; Hofmann et al. 2005 [DIRS 173711], Table 2).

Irreversible sorption of radionuclides occurs only on specific sites on the surface of corrosion product particles. The number of sites per unit area of surface, or site density (typically in units of sites $\mathrm{nm}^{-2}$ ), determines the total quantity of radionuclides that can be adsorbed. Site density data for goethite and HFO are compiled in Table 4.1-10 and qualified for use in TSPA-LA in Section 4.1.2. Site density data for goethite in Table 4.1-10 in units other than sites $\mathrm{nm}^{-2}$ are converted to sites $\mathrm{nm}^{-2}$ in Table 6.3-4a. These data provide a range of values to be sampled in TSPA-LA for both goethite and HFO. The data in Table 4.1-10 are used to develop discrete distributions, shown in Table 6.3-6, by applying the same technique used for goethite specific surface area. 
Table 6.3-4a. Site Densities Conversions for Goethite

\begin{tabular}{|c|c|c|c|}
\hline $\begin{array}{l}\text { Site Density } \\
\text { (Various Units) }\end{array}$ & Source & Conversion & $\begin{array}{l}\text { Site Density } \\
\left(\text { sites } \mathrm{nm}^{-2}\right)\end{array}$ \\
\hline $\begin{array}{l}3.28 \times 10^{-6} \\
\mathrm{~mol} \mathrm{~m}^{-2}\end{array}$ & $\begin{array}{l}\text { Rodda et al. } 1996 \\
\text { [DIRS 173710], Table } 1\end{array}$ & $\begin{array}{l}\text { Model fitting (2-site Langmuir adsorption model for } \mathrm{Zn} \text { and } \mathrm{Pb} \text { ). } \\
\text { Site density value represents the summation of low- and high-affinity sites: } 2.90 \times 10^{-6}+ \\
3.75 \times 10^{-7}=3.28 \times 10^{-6} \mathrm{~mol} \mathrm{~m}^{-2} \text {. Value converted to sites } \mathrm{nm}^{-2} \text { using the following relation: } \\
\qquad 3.28 \times 10^{-6} \mathrm{~mol} / \mathrm{m}^{2}\left(\frac{6.022 \times 10^{23}}{\mathrm{~mol}}\right)\left(\frac{1 \times 10^{-18} \mathrm{~m}^{2}}{\mathrm{~nm}^{2}}\right)\end{array}$ & 1.97 \\
\hline $\begin{array}{l}1.43 \times 10^{-5} \\
\mathrm{~mol} \mathrm{~m}^{-2}\end{array}$ & $\begin{array}{l}\text { Rodda et al. } 1996 \\
\text { [DIRS 173710], Table } 1\end{array}$ & $\begin{array}{l}\text { Model fitting (2-site Langmuir adsorption model for } \mathrm{Zn} \text { and } \mathrm{Pb} \text { ). } \\
\text { Site density value represent the summation of low- and high-affinity sites: } 1.30 \times 10^{-5}+ \\
1.26 \times 10^{-6}=1.43 \times 10^{-5} \mathrm{~mol} \mathrm{~m}^{-2} \text {. Value converted to sites } \mathrm{nm}^{-2} \text { using the following relation: } \\
\qquad 1.43 \times 10^{-5} \mathrm{~mol} / \mathrm{m}^{2}\left(\frac{6.022 \times 10^{23}}{\mathrm{~mol}}\right)\left(\frac{1 \times 10^{-18} \mathrm{~m}^{2}}{\mathrm{~nm}^{2}}\right)\end{array}$ & 8.59 \\
\hline $\begin{array}{l}2.2 \times 10^{-6} \\
\mathrm{~mol} \mathrm{~m}^{-2}\end{array}$ & $\begin{array}{l}\text { Rodda et al. } 1996 \\
\text { [DIRS 173710], Table } 5\end{array}$ & $\begin{array}{l}\text { Model fitting (BET adsorption model for } \mathrm{Zn} \text { ). } \\
\text { Value converted to sites } \mathrm{nm}^{-2} \text { using the following relation: } \\
\qquad 2.2 \times 10^{-6} \mathrm{~mol} / \mathrm{m}^{2}\left(\frac{6.022 \times 10^{23}}{\mathrm{~mol}}\right)\left(\frac{1 \times 10^{-18} \mathrm{~m}^{2}}{\mathrm{~nm}^{2}}\right)\end{array}$ & 1.32 \\
\hline $\begin{array}{l}1.79 \times 10^{-5} \\
\mathrm{~mol} \mathrm{~g}^{-1}\end{array}$ & $\begin{array}{l}\text { Trivedi et al. } 2001 \\
\text { [DIRS 173021], Table } 3\end{array}$ & $\begin{array}{l}\text { Fe adsorption edges. Value converted to sites } \mathrm{nm}^{-2} \text { using the following relation: } \\
\qquad 1.79 \times 10^{-4} \mathrm{~mol} / \mathrm{g}\left(\frac{6.022 \times 10^{23}}{\mathrm{~mol}}\right)\left(\frac{\mathrm{g}}{55.4 \mathrm{~m}^{2}}\right)\left(\frac{1 \times 10^{-18} \mathrm{~m}^{2}}{\mathrm{~nm}^{2}}\right)\end{array}$ & 1.95 \\
\hline $\begin{array}{l}4.22 \times 10^{-5} \\
\mathrm{~mol} \mathrm{~g}^{-1}\end{array}$ & $\begin{array}{l}\text { Trivedi et al. } 2001 \\
\text { [DIRS 173021], Table } 3\end{array}$ & $\begin{array}{l}\text { NiEDTA adsorption edges. Value converted to sites } \mathrm{nm}^{-2} \text { using the following relation: } \\
\qquad 4.22 \times 10^{-5} \mathrm{~mol} / \mathrm{g}\left(\frac{6.022 \times 10^{23}}{\mathrm{~mol}}\right)\left(\frac{\mathrm{g}}{21 \mathrm{~m}^{2}}\right)\left(\frac{1 \times 10^{-18} \mathrm{~m}^{2}}{\mathrm{~nm}^{2}}\right)\end{array}$ & 1.21 \\
\hline $\begin{array}{l}3.54 \times 10^{-5} \\
\mathrm{~mol} \mathrm{~g}^{-1}\end{array}$ & $\begin{array}{l}\text { Trivedi et al. } 2001 \\
\text { [DIRS 173021], Table } 3\end{array}$ & $\begin{array}{l}\text { PbEDTA adsorption edges. Value converted to sites } \mathrm{nm}^{-2} \text { using the following relation: } \\
\qquad 3.54 \times 10^{-5} \mathrm{~mol} / \mathrm{g}\left(\frac{6.022 \times 10^{23}}{\mathrm{~mol}}\right)\left(\frac{\mathrm{g}}{21 \mathrm{~m}^{2}}\right)\left(\frac{1 \times 10^{-18} \mathrm{~m}^{2}}{\mathrm{~nm}^{2}}\right)\end{array}$ & 1.02 \\
\hline $140 \mu \mathrm{mol} \mathrm{g}^{-1}$ & $\begin{array}{l}\text { Hansmann and Anderson } \\
1985 \text { [DIRS 173742], p. } 547\end{array}$ & $\begin{array}{l}\text { Maximum theoretical value estimated from crystal morphology. Value converted to } \\
\text { sites } \mathrm{nm}^{-2} \text { using the following relation: } \\
\qquad 140 \frac{\mu \mathrm{mol}}{\mathrm{g}}\left(\frac{1 \times 10^{-6} \mathrm{~mol}}{\mu \mathrm{mol}}\right)\left(\frac{6.022 \times 10^{23}}{\mathrm{~mol}}\right)\left(\frac{\mathrm{g}}{33 \mathrm{~m}^{2}}\right)\left(\frac{1 \times 10^{-18} \mathrm{~m}^{2}}{\mathrm{~nm}^{2}}\right)\end{array}$ & 2.55 \\
\hline
\end{tabular}


Table 6.3-4a. Site Densities Conversions for Goethite (Continued)

\begin{tabular}{|c|c|c|c|}
\hline $\begin{array}{l}\text { Site Density } \\
\text { (Various Units) }\end{array}$ & Source & Conversion & $\begin{array}{l}\text { Site Density } \\
\left(\text { sites } \mathrm{nm}^{-2}\right)\end{array}$ \\
\hline $80 \mu \mathrm{mol} \mathrm{g}^{-1}$ & $\begin{array}{l}\text { Hansmann and Anderson } \\
1985 \text { [DIRS 173742], p. } 547\end{array}$ & $\begin{array}{l}\text { Estimated from maximum sorption data for selenite. Value converted to sites } \mathrm{nm}^{-2} \text { using the } \\
\text { following relation: } \\
\qquad 80 \frac{\mu \mathrm{mol}}{\mathrm{g}}\left(\frac{1 \times 10^{-6} \mathrm{~mol}}{\mu \mathrm{mol}}\right)\left(\frac{6.022 \times 10^{23}}{\mathrm{~mol}}\right)\left(\frac{\mathrm{g}}{33 \mathrm{~m}^{2}}\right)\left(\frac{1 \times 10^{-18} \mathrm{~m}^{2}}{\mathrm{~nm}^{2}}\right)\end{array}$ & 1.46 \\
\hline $0.31 \mathrm{mmol} \mathrm{g}^{-1}$ & $\begin{array}{l}\text { Gabriel et al. } 1998 \\
\text { [DIRS 130407], pp. 124, } 126\end{array}$ & $\begin{array}{l}\text { Uranyl adsorption SCM. Value converted to sites } \mathrm{nm}^{-2} \text { using the following relation: } \\
\qquad 0.31 \frac{\mathrm{mmol}}{\mathrm{g}}\left(\frac{1 \times 10^{-3} \mathrm{~mol}}{\mathrm{mmol}}\right)\left(\frac{6.022 \times 10^{23}}{\mathrm{~mol}}\right)\left(\frac{\mathrm{g}}{80.5 \mathrm{~m}^{2}}\right)\left(\frac{1 \times 10^{-18} \mathrm{~m}^{2}}{\mathrm{~nm}^{2}}\right)\end{array}$ & 2.32 \\
\hline $\begin{array}{l}9.18 \times 10^{-6} \\
\mathrm{~mol} \mathrm{~m}^{-2}\end{array}$ & $\begin{array}{l}\text { Müller and Sigg } 1992 \\
\text { [DIRS 173760], p } 519\end{array}$ & $\begin{array}{l}\text { Acid-base surface titration. Value converted to sites } \mathrm{nm}^{-2} \text { using the following relation: } \\
\qquad 9.18 \times 10^{-6} \frac{\mathrm{mol}}{\mathrm{m}^{2}}\left(\frac{6.022 \times 10^{23}}{\mathrm{~mol}}\right)\left(\frac{1 \times 10^{-18} \mathrm{~m}^{2}}{\mathrm{~nm}^{2}}\right)\end{array}$ & 5.53 \\
\hline $3.2 \mu \mathrm{mol} \mathrm{m}{ }^{-2}$ & $\begin{array}{l}\text { Gräfe et al. 2004 } \\
\text { [DIRS 173751], p. } 6561\end{array}$ & $\begin{array}{l}\text { Arsenate isotherm }(\mathrm{pH} 4) \text {. Value converted to sites } \mathrm{nm}^{-2} \text { using the following relation: } \\
\qquad 3.2 \frac{\mu \mathrm{mol}}{\mathrm{m}^{2}}\left(\frac{1 \times 10^{-6} \mathrm{~mol}}{\mu \mathrm{mol}}\right)\left(\frac{6.022 \times 10^{23}}{\mathrm{~mol}}\right)\left(\frac{1 \times 10^{-18} \mathrm{~m}^{2}}{\mathrm{~nm}^{2}}\right)\end{array}$ & 1.93 \\
\hline $2.2 \mu \mathrm{mol} \mathrm{m}{ }^{-2}$ & $\begin{array}{l}\text { Gräfe et al. 2004 } \\
\text { [DIRS 173751], p. } 6561\end{array}$ & $\begin{array}{l}\text { Arsenate isotherm }(\mathrm{pH} 7) \text {. Value converted to sites } \mathrm{nm}^{-2} \text { using the following relation: } \\
\qquad 2.2 \frac{\mu \mathrm{mol}}{\mathrm{m}^{2}}\left(\frac{1 \times 10^{-6} \mathrm{~mol}}{\mu \mathrm{mol}}\right)\left(\frac{6.022 \times 10^{23}}{\mathrm{~mol}}\right)\left(\frac{1 \times 10^{-18} \mathrm{~m}^{2}}{\mathrm{~nm}^{2}}\right)\end{array}$ & 1.32 \\
\hline
\end{tabular}


Of the surface sites available for sorption, only a fraction are capable of binding irreversibly to a radionuclide. These are referred to as high-affinity sites, expressed as a percentage of the site density for each mineral comprising the corrosion products. Data for the low- and high-affinity site densities for goethite are compiled in Table 4.1-11, and high-affinity site densities for HFO are compiled in Table 4.1-12. The percentage of high-affinity sites for goethite is calculated in Table 6.3-4b.

Table 6.3-4b. Percentage of High-Affinity Sites for Goethite

\begin{tabular}{|c|c|c|c|c|c|}
\hline $\begin{array}{l}\text { Low-Affinity } \\
\text { Site Density }\end{array}$ & $\begin{array}{l}\text { High-Affinity } \\
\text { Site Density }\end{array}$ & $\begin{array}{l}\text { Site } \\
\text { Density } \\
\text { Units }\end{array}$ & $\begin{array}{l}\text { Low/High } \\
\text { Affinity Site } \\
\text { Ratio }\end{array}$ & $\begin{array}{c}\% \text { of High } \\
\text { Affinity Sites }\end{array}$ & Source \\
\hline $7.70 \times 10^{-7}$ & $2.52 \times 10^{-7}$ & $\mathrm{~mol} \mathrm{~m}^{-2}$ & 3.06 & 24.66 & $\begin{array}{l}\text { Rodda et al. } 1996 \\
\text { [DIRS 173710], Table } 1\end{array}$ \\
\hline $2.90 \times 10^{-6}$ & $3.75 \times 10^{-7}$ & $\mathrm{~mol} \mathrm{~m}^{-2}$ & 7.73 & 11.45 & $\begin{array}{l}\text { Rodda et al. } 1996 \\
\text { [DIRS 173710], Table } 1\end{array}$ \\
\hline $1.30 \times 10^{-5}$ & $1.26 \times 10^{-6}$ & $\mathrm{~mol} \mathrm{~m}^{-2}$ & 10.32 & 8.84 & $\begin{array}{l}\text { Rodda et al. } 1996 \\
\text { [DIRS 173710], Table } 1\end{array}$ \\
\hline $1.00 \times 10^{-6}$ & $1.41 \times 10^{-7}$ & $\mathrm{~mol} \mathrm{~m}^{-2}$ & 7.09 & 12.36 & $\begin{array}{l}\text { Rodda et al. } 1996 \\
\text { [DIRS 173710], Table } 1\end{array}$ \\
\hline 3.45 & 2.7 & sites $\mathrm{nm}^{-2}$ & 1.28 & 43.90 & $\begin{array}{l}\text { Hiemstra and Van } \\
\text { Riemsdijk 1996 } \\
\text { [DIRS 173023], p. } 498\end{array}$ \\
\hline $2.40 \times 10^{-5}$ & $8.80 \times 10^{-6}$ & $\mathrm{~mol} \mathrm{~g}^{-1}$ & 2.73 & 26.83 & $\begin{array}{l}\text { Christophi and Axe } 2000 \\
\text { [DIRS 173020], Table } 5\end{array}$ \\
\hline $7.50 \times 10^{-6}$ & $7.40 \times 10^{-6}$ & $\mathrm{~mol} \mathrm{~g}^{-1}$ & 1.01 & 49.66 & $\begin{array}{l}\text { Christophi and Axe } 2000 \\
\text { [DIRS 173020], Table } 5\end{array}$ \\
\hline $2.40 \times 10^{-6}$ & $6.80 \times 10^{-6}$ & $\mathrm{~mol} \mathrm{~g}^{-1}$ & 0.35 & 73.91 & $\begin{array}{l}\text { Christophi and Axe } 2000 \\
\text { [DIRS 173020], Table } 5\end{array}$ \\
\hline $3.47 \times 10^{-5}$ & $1.04 \times 10^{-5}$ & $\mathrm{~mol} \mathrm{~g}^{-1}$ & 3.34 & 23.06 & $\begin{array}{l}\text { Trivedi et al. 2001 } \\
\text { [DIRS 173021], Table } 3\end{array}$ \\
\hline $3.88 \times 10^{-5}$ & $1.14 \times 10^{-5}$ & $\mathrm{~mol} \mathrm{~g}^{-1}$ & 3.40 & 22.71 & $\begin{array}{l}\text { Trivedi et al. 2001 } \\
\text { [DIRS 173021], Table } 3\end{array}$ \\
\hline
\end{tabular}

Source: Output DTN: SN0508T0503305.003.

NOTE: $\quad \%$ of High Affinity Sites $=100 /(1+$ Low/High Affinity Site Ratio $)$.

To estimate the percentage range of high-affinity sites for HFO, the data listed Table 4.1-12 and Table 4.1-13 (number of high-affinity sites and total site densities, respectively) were convoluted to generate a complete range of high-affinity site percentages. The compilation of data given by Dzombak and Morel (1990 [DIRS 105483]) in these tables are considered to generate this range of values. Also, a set of values for high-affinity sites capturing the whole range given in Table 5.2 of Dzombak and Morel (1990 [DIRS 105483]) were selected as inputs in this report. The convolution is done by first determining the percentage of total vs. high-affinity sites $\left(S_{f}\right)$ computed as:

$$
S_{f}=\frac{S_{H A}}{S_{\text {total }}} \times 100
$$


where $S_{H A}$ (Table 4.1-12) and $S_{\text {total }}$ (Table 4.1-13) are high-affinity and total sites, respectively. This operation is done for each value of $S_{\text {total }}$ listed in Table 4.1-13 (see DTN: SN0508T0503305.003, Spreadsheet 'sorption data.xls', Worksheet 'HFO \% of high affinity sites'). That is, $S_{f}$ is calculated using the set of values listed in Table 4.1-12 for each value of given in Table 4.1-13. For example, the range of values in Table 4.1-12 are all divided by a total site density of 0.2 (see Table 6-3.5) and the operation is repeated for the subsequent total site density in Table 4.1-13.

The objective of this approach is to capture an all-encompassing range of percentage of highaffinity sites for the given bounds of total site densities for HFO tabulated by Dzombak and Morel (1990 [DIRS 105483]). This approach reduces bias in the eventual sampling range of high-affinity site densities for a given set of total site density values. The percentage of high-affinity sites for HFO are listed in Table 6.3-5.

The percentage of high-affinity data are used to develop discrete distributions for goethite and HFO for sampling in TSPA-LA by applying the same technique used for goethite specific surface area and site densities; the distributions are shown in Table 6.3-6. 
Table 6.3-5. Percentage of High-Affinity Sites for HFO

\begin{tabular}{|c|c|c|}
\hline $\begin{array}{c}\text { Total Site } \\
\text { Density } \\
\left(\text { sites } \mathrm{nm}^{-2}\right)\end{array}$ & $\begin{array}{c}\text { High-Affinity } \\
\text { Site Density } \\
\text { (mol Sites/mol Fe) }\end{array}$ & $\begin{array}{c}\% \text { of High } \\
\text { Affinity Sites }\end{array}$ \\
\hline 0.2 & 0.005 & 2.50 \\
\hline 0.2 & 0.003 & 1.50 \\
\hline 0.2 & 0.01 & 5.00 \\
\hline 0.2 & 0.002 & 1.00 \\
\hline 0.2 & 0.002 & 1.00 \\
\hline 0.2 & 0.005 & 2.50 \\
\hline 0.2 & 0.002 & 1.00 \\
\hline 0.2 & 0.001 & 0.50 \\
\hline 0.2 & 0.005 & 2.50 \\
\hline 0.2 & 0.001 & 0.50 \\
\hline 0.2 & 0.002 & 1.00 \\
\hline 0.2 & 0.003 & 1.50 \\
\hline 0.2 & 0.007 & 3.50 \\
\hline 0.2 & 0.005 & 2.50 \\
\hline 0.2 & 0.01 & 5.00 \\
\hline 0.2 & 0.001 & 0.50 \\
\hline 0.2 & 0.003 & 1.50 \\
\hline 0.2 & 0.005 & 2.50 \\
\hline 0.2 & 0.001 & 0.50 \\
\hline 0.2 & 0.005 & 2.50 \\
\hline 0.2 & 0.001 & 0.50 \\
\hline 0.2 & 0.005 & 2.50 \\
\hline
\end{tabular}

\begin{tabular}{|c|c|c|}
\hline $\begin{array}{c}\text { Total Site } \\
\text { Density } \\
\left(\text { sites } \mathrm{nm}^{-2}\right) \\
\end{array}$ & $\begin{array}{c}\text { High-Affinity } \\
\text { Site Density } \\
\text { (mol Sites/mol Fe) }\end{array}$ & $\begin{array}{c}\% \text { of High } \\
\text { Affinity Sites }\end{array}$ \\
\hline 0.1 & 0.005 & 5.00 \\
\hline 0.1 & 0.003 & 3.00 \\
\hline 0.1 & 0.01 & 10.00 \\
\hline 0.1 & 0.002 & 2.00 \\
\hline 0.1 & 0.002 & 2.00 \\
\hline 0.1 & 0.005 & 5.00 \\
\hline 0.1 & 0.002 & 2.00 \\
\hline 0.1 & 0.001 & 1.00 \\
\hline 0.1 & 0.005 & 5.00 \\
\hline 0.1 & 0.001 & 1.00 \\
\hline 0.1 & 0.002 & 2.00 \\
\hline 0.1 & 0.003 & 3.00 \\
\hline 0.1 & 0.007 & 7.00 \\
\hline 0.1 & 0.005 & 5.00 \\
\hline 0.1 & 0.01 & 10.00 \\
\hline 0.1 & 0.001 & 1.00 \\
\hline 0.1 & 0.003 & 3.00 \\
\hline 0.1 & 0.005 & 5.00 \\
\hline 0.1 & 0.001 & 1.00 \\
\hline 0.1 & 0.005 & 5.00 \\
\hline 0.1 & 0.001 & 1.00 \\
\hline 0.1 & 0.005 & 5.00 \\
\hline
\end{tabular}

\begin{tabular}{|c|c|c|}
\hline $\begin{array}{c}\text { Total Site } \\
\text { Density } \\
\left(\text { sites } \mathrm{nm}^{-2}\right)\end{array}$ & $\begin{array}{c}\text { High-Affinity } \\
\text { Site Density } \\
\text { (mol Sites/mol Fe) }\end{array}$ & $\begin{array}{c}\% \text { of High } \\
\text { Affinity Sites }\end{array}$ \\
\hline 0.2 & 0.005 & 2.50 \\
\hline 0.2 & 0.003 & 1.50 \\
\hline 0.2 & 0.01 & 5.00 \\
\hline 0.2 & 0.002 & 1.00 \\
\hline 0.2 & 0.002 & 1.00 \\
\hline 0.2 & 0.005 & 2.50 \\
\hline 0.2 & 0.002 & 1.00 \\
\hline 0.2 & 0.001 & 0.50 \\
\hline 0.2 & 0.005 & 2.50 \\
\hline 0.2 & 0.001 & 0.50 \\
\hline 0.2 & 0.002 & 1.00 \\
\hline 0.2 & 0.003 & 1.50 \\
\hline 0.2 & 0.007 & 3.50 \\
\hline 0.2 & 0.005 & 2.50 \\
\hline 0.2 & 0.01 & 5.00 \\
\hline 0.2 & 0.001 & 0.50 \\
\hline 0.2 & 0.003 & 1.50 \\
\hline 0.2 & 0.005 & 2.50 \\
\hline 0.2 & 0.001 & 0.50 \\
\hline 0.2 & 0.005 & 2.50 \\
\hline 0.2 & 0.001 & 0.50 \\
\hline 0.2 & 0.005 & 2.50 \\
\hline
\end{tabular}


Table 6.3-5. Percentage of High-Affinity Sites for HFO (Continued)

\begin{tabular}{|c|c|c|}
\hline $\begin{array}{c}\text { Total Site } \\
\text { Density } \\
\left(\text { sites } \mathrm{nm}^{-2}\right)\end{array}$ & $\begin{array}{c}\text { High-Affinity } \\
\text { Site Density } \\
\text { (mol Sites/mol Fe) }\end{array}$ & $\begin{array}{c}\% \text { of High } \\
\text { Affinity Sites }\end{array}$ \\
\hline 0.2 & 0.005 & 2.50 \\
\hline 0.2 & 0.003 & 1.50 \\
\hline 0.2 & 0.01 & 5.00 \\
\hline 0.2 & 0.002 & 1.00 \\
\hline 0.2 & 0.002 & 1.00 \\
\hline 0.2 & 0.005 & 2.50 \\
\hline 0.2 & 0.002 & 1.00 \\
\hline 0.2 & 0.001 & 0.50 \\
\hline 0.2 & 0.005 & 2.50 \\
\hline 0.2 & 0.001 & 0.50 \\
\hline 0.2 & 0.002 & 1.00 \\
\hline 0.2 & 0.003 & 1.50 \\
\hline 0.2 & 0.007 & 3.50 \\
\hline 0.2 & 0.005 & 2.50 \\
\hline 0.2 & 0.01 & 5.00 \\
\hline 0.2 & 0.001 & 0.50 \\
\hline 0.2 & 0.003 & 1.50 \\
\hline 0.2 & 0.005 & 2.50 \\
\hline 0.2 & 0.001 & 0.50 \\
\hline 0.2 & 0.005 & 2.50 \\
\hline 0.2 & 0.001 & 0.50 \\
\hline 0.2 & 0.005 & 2.50 \\
\hline
\end{tabular}

\begin{tabular}{|c|c|c|}
\hline $\begin{array}{c}\text { Total Site } \\
\text { Density } \\
(\text { sites nm }\end{array}$ & $\begin{array}{c}\text { High-Affinity } \\
\text { Site Density } \\
\text { (mol Sites/mol Fe) }\end{array}$ & $\begin{array}{c}\text { \% of High } \\
\text { ffinity Sites }\end{array}$ \\
\hline 0.18 & 0.005 & 2.78 \\
\hline 0.18 & 0.003 & 1.67 \\
\hline 0.18 & 0.01 & 5.56 \\
\hline 0.18 & 0.002 & 1.11 \\
\hline 0.18 & 0.002 & 1.11 \\
\hline 0.18 & 0.005 & 2.78 \\
\hline 0.18 & 0.002 & 1.11 \\
\hline 0.18 & 0.001 & 0.56 \\
\hline 0.18 & 0.005 & 2.78 \\
\hline 0.18 & 0.001 & 0.56 \\
\hline 0.18 & 0.002 & 1.11 \\
\hline 0.18 & 0.003 & 1.67 \\
\hline 0.18 & 0.007 & 3.89 \\
\hline 0.18 & 0.005 & 2.78 \\
\hline 0.18 & 0.01 & 5.56 \\
\hline 0.18 & 0.001 & 0.56 \\
\hline 0.18 & 0.003 & 1.67 \\
\hline 0.18 & 0.005 & 2.78 \\
\hline 0.18 & 0.001 & 0.56 \\
\hline 0.18 & 0.005 & 2.78 \\
\hline 0.18 & 0.001 & 0.56 \\
\hline 0.18 & 0.005 & 2.78 \\
\hline & & \\
\hline
\end{tabular}

\begin{tabular}{|c|c|c|}
\hline $\begin{array}{c}\text { Total Site } \\
\text { Density } \\
\text { (sites nm }\end{array}$ - $^{-}$ & $\begin{array}{c}\text { High-Affinity } \\
\text { Site Density } \\
\text { (mol Sites/mol Fe) }\end{array}$ & $\begin{array}{c}\text { \% of High } \\
\text { Affinity Sites }\end{array}$ \\
\hline 0.23 & 0.005 & 2.17 \\
\hline 0.23 & 0.003 & 1.30 \\
\hline 0.23 & 0.01 & 4.35 \\
\hline 0.23 & 0.002 & 0.87 \\
\hline 0.23 & 0.002 & 0.87 \\
\hline 0.23 & 0.005 & 2.17 \\
\hline 0.23 & 0.002 & 0.87 \\
\hline 0.23 & 0.001 & 0.43 \\
\hline 0.23 & 0.005 & 2.17 \\
\hline 0.23 & 0.001 & 0.43 \\
\hline 0.23 & 0.002 & 0.87 \\
\hline 0.23 & 0.003 & 1.30 \\
\hline 0.23 & 0.007 & 3.04 \\
\hline 0.23 & 0.005 & 2.17 \\
\hline 0.23 & 0.01 & 4.35 \\
\hline 0.23 & 0.001 & 0.43 \\
\hline 0.23 & 0.003 & 1.30 \\
\hline 0.23 & 0.005 & 2.17 \\
\hline 0.23 & 0.001 & 0.43 \\
\hline 0.23 & 0.005 & 2.17 \\
\hline 0.23 & 0.001 & 0.43 \\
\hline 0.23 & 0.005 & 2.17 \\
\hline & & \\
\hline
\end{tabular}


Table 6.3-5. Percentage of High-Affinity Sites for HFO (Continued)

\begin{tabular}{|c|c|c|}
\hline $\begin{array}{c}\text { Total Site } \\
\text { Density } \\
\left(\text { sites } \mathrm{nm}^{-2}\right)\end{array}$ & $\begin{array}{c}\text { High-Affinity } \\
\text { Site Density } \\
\text { (mol Sites/mol Fe) }\end{array}$ & $\begin{array}{c}\% \text { of High } \\
\text { Affinity Sites }\end{array}$ \\
\hline 0.24 & 0.005 & 2.08 \\
\hline 0.24 & 0.003 & 1.25 \\
\hline 0.24 & 0.01 & 4.17 \\
\hline 0.24 & 0.002 & 0.83 \\
\hline 0.24 & 0.002 & 0.83 \\
\hline 0.24 & 0.005 & 2.08 \\
\hline 0.24 & 0.002 & 0.83 \\
\hline 0.24 & 0.001 & 0.42 \\
\hline 0.24 & 0.005 & 2.08 \\
\hline 0.24 & 0.001 & 0.42 \\
\hline 0.24 & 0.002 & 0.83 \\
\hline 0.24 & 0.003 & 1.25 \\
\hline 0.24 & 0.007 & 2.92 \\
\hline 0.24 & 0.005 & 2.08 \\
\hline 0.24 & 0.01 & 4.17 \\
\hline 0.24 & 0.001 & 0.42 \\
\hline 0.24 & 0.003 & 1.25 \\
\hline 0.24 & 0.005 & 2.08 \\
\hline 0.24 & 0.001 & 0.42 \\
\hline 0.24 & 0.005 & 2.08 \\
\hline 0.24 & 0.001 & 0.42 \\
\hline 0.24 & 0.005 & 2.08 \\
\hline
\end{tabular}

\begin{tabular}{|c|c|c|}
\hline $\begin{array}{l}\text { Total Site } \\
\text { Density } \\
\left(\text { sites } \mathrm{nm}^{-2}\right) \\
\end{array}$ & $\begin{array}{c}\text { High-Affinity } \\
\text { Site Density } \\
\text { (mol Sites/mol Fe) }\end{array}$ & $\begin{array}{c}\% \text { of High } \\
\text { Affinity Sites }\end{array}$ \\
\hline 0.14 & 0.005 & 3.57 \\
\hline 0.14 & 0.003 & 2.14 \\
\hline 0.14 & 0.01 & 7.14 \\
\hline 0.14 & 0.002 & 1.43 \\
\hline 0.14 & 0.002 & 1.43 \\
\hline 0.14 & 0.005 & 3.57 \\
\hline 0.14 & 0.002 & 1.43 \\
\hline 0.14 & 0.001 & 0.71 \\
\hline 0.14 & 0.005 & 3.57 \\
\hline 0.14 & 0.001 & 0.71 \\
\hline 0.14 & 0.002 & 1.43 \\
\hline 0.14 & 0.003 & 2.14 \\
\hline 0.14 & 0.007 & 5.00 \\
\hline 0.14 & 0.005 & 3.57 \\
\hline 0.14 & 0.01 & 7.14 \\
\hline 0.14 & 0.001 & 0.71 \\
\hline 0.14 & 0.003 & 2.14 \\
\hline 0.14 & 0.005 & 3.57 \\
\hline 0.14 & 0.001 & 0.71 \\
\hline 0.14 & 0.005 & 3.57 \\
\hline 0.14 & 0.001 & 0.71 \\
\hline 0.14 & 0.005 & 3.57 \\
\hline
\end{tabular}

\begin{tabular}{|c|c|c|}
\hline $\begin{array}{c}\text { Total Site } \\
\text { Density } \\
\left(\text { sites } \mathrm{nm}^{-2}\right)\end{array}$ & $\begin{array}{c}\text { High-Affinity } \\
\text { Site Density } \\
\text { (mol Sites/mol Fe) }\end{array}$ & $\begin{array}{c}\% \text { of High } \\
\text { Affinity Sites }\end{array}$ \\
\hline 0.2 & 0.005 & 2.50 \\
\hline 0.2 & 0.003 & 1.50 \\
\hline 0.2 & 0.01 & 5.00 \\
\hline 0.2 & 0.002 & 1.00 \\
\hline 0.2 & 0.002 & 1.00 \\
\hline 0.2 & 0.005 & 2.50 \\
\hline 0.2 & 0.002 & 1.00 \\
\hline 0.2 & 0.001 & 0.50 \\
\hline 0.2 & 0.005 & 2.50 \\
\hline 0.2 & 0.001 & 0.50 \\
\hline 0.2 & 0.002 & 1.00 \\
\hline 0.2 & 0.003 & 1.50 \\
\hline 0.2 & 0.007 & 3.50 \\
\hline 0.2 & 0.005 & 2.50 \\
\hline 0.2 & 0.01 & 5.00 \\
\hline 0.2 & 0.001 & 0.50 \\
\hline 0.2 & 0.003 & 1.50 \\
\hline 0.2 & 0.005 & 2.50 \\
\hline 0.2 & 0.001 & 0.50 \\
\hline 0.2 & 0.005 & 2.50 \\
\hline 0.2 & 0.001 & 0.50 \\
\hline 0.2 & 0.005 & 2.50 \\
\hline
\end{tabular}


Table 6.3-5. Percentage of High-Affinity Sites for HFO (Continued)

\begin{tabular}{|c|c|c|}
\hline $\begin{array}{c}\text { Total Site } \\
\text { Density } \\
\text { sites nm }^{-2} \text { ) }\end{array}$ & $\begin{array}{c}\text { High-Affinity } \\
\text { Site Density } \\
\text { (mol Sites/mol Fe) }\end{array}$ & $\begin{array}{c}\text { \% of High } \\
\text { Affinity Sites }\end{array}$ \\
\hline 0.15 & 0.005 & 3.33 \\
\hline 0.15 & 0.003 & 2.00 \\
\hline 0.15 & 0.01 & 6.67 \\
\hline 0.15 & 0.002 & 1.33 \\
\hline 0.15 & 0.002 & 1.33 \\
\hline 0.15 & 0.005 & 3.33 \\
\hline 0.15 & 0.002 & 1.33 \\
\hline 0.15 & 0.001 & 0.67 \\
\hline 0.15 & 0.005 & 3.33 \\
\hline 0.15 & 0.001 & 0.67 \\
\hline 0.15 & 0.002 & 1.33 \\
\hline 0.15 & 0.003 & 2.00 \\
\hline 0.15 & 0.007 & 4.67 \\
\hline 0.15 & 0.005 & 3.33 \\
\hline 0.15 & 0.01 & 6.67 \\
\hline 0.15 & 0.001 & 0.67 \\
\hline 0.15 & 0.003 & 2.00 \\
\hline 0.15 & 0.005 & 3.33 \\
\hline 0.15 & 0.001 & 0.67 \\
\hline 0.15 & 0.005 & 3.33 \\
\hline 0.15 & 0.001 & 0.67 \\
\hline 0.15 & 0.005 & 3.33 \\
\hline & & \\
\hline
\end{tabular}

\begin{tabular}{|c|c|c|}
\hline $\begin{array}{c}\text { Total Site } \\
\text { Density } \\
\text { (sites nm }^{-2} \text { ) }\end{array}$ & $\begin{array}{c}\text { High-Affinity } \\
\text { Site Density } \\
\text { (mol Sites/mol Fe) }\end{array}$ & $\begin{array}{c}\text { \% of High } \\
\text { Affinity Sites }\end{array}$ \\
\hline 0.2 & 0.005 & 2.50 \\
\hline 0.2 & 0.003 & 1.50 \\
\hline 0.2 & 0.01 & 5.00 \\
\hline 0.2 & 0.002 & 1.00 \\
\hline 0.2 & 0.002 & 1.00 \\
\hline 0.2 & 0.005 & 2.50 \\
\hline 0.2 & 0.002 & 1.00 \\
\hline 0.2 & 0.001 & 0.50 \\
\hline 0.2 & 0.005 & 2.50 \\
\hline 0.2 & 0.001 & 0.50 \\
\hline 0.2 & 0.002 & 1.00 \\
\hline 0.2 & 0.003 & 1.50 \\
\hline 0.2 & 0.007 & 3.50 \\
\hline 0.2 & 0.005 & 2.50 \\
\hline 0.2 & 0.01 & 5.00 \\
\hline 0.2 & 0.001 & 0.50 \\
\hline 0.2 & 0.003 & 1.50 \\
\hline 0.2 & 0.005 & 2.50 \\
\hline 0.2 & 0.001 & 0.50 \\
\hline 0.2 & 0.005 & 2.50 \\
\hline 0.2 & 0.001 & 0.50 \\
\hline 0.2 & 0.005 & 2.50 \\
\hline & & \\
\hline
\end{tabular}

\begin{tabular}{|c|c|c|}
\hline $\begin{array}{c}\text { Total Site } \\
\text { Density } \\
\text { (sites nm }^{-2} \text { ) }\end{array}$ & $\begin{array}{c}\text { High-Affinity } \\
\text { Site Density } \\
\text { (mol Sites/mol Fe) }\end{array}$ & $\begin{array}{c}\text { \% of High } \\
\text { Affinity Sites }\end{array}$ \\
\hline 0.5 & 0.005 & 1.00 \\
\hline 0.5 & 0.003 & 0.60 \\
\hline 0.5 & 0.01 & 2.00 \\
\hline 0.5 & 0.002 & 0.40 \\
\hline 0.5 & 0.002 & 0.40 \\
\hline 0.5 & 0.005 & 1.00 \\
\hline 0.5 & 0.002 & 0.40 \\
\hline 0.5 & 0.001 & 0.20 \\
\hline 0.5 & 0.005 & 1.00 \\
\hline 0.5 & 0.001 & 0.20 \\
\hline 0.5 & 0.002 & 0.40 \\
\hline 0.5 & 0.003 & 0.60 \\
\hline 0.5 & 0.007 & 1.40 \\
\hline 0.5 & 0.005 & 1.00 \\
\hline 0.5 & 0.01 & 2.00 \\
\hline 0.5 & 0.001 & 0.20 \\
\hline 0.5 & 0.003 & 0.60 \\
\hline 0.5 & 0.005 & 1.00 \\
\hline 0.5 & 0.001 & 0.20 \\
\hline 0.5 & 0.005 & 1.00 \\
\hline 0.5 & 0.001 & 0.20 \\
\hline 0.5 & 0.005 & 1.00 \\
\hline & & \\
\hline
\end{tabular}


Table 6.3-5. Percentage of High-Affinity Sites for HFO (Continued)

\begin{tabular}{|c|c|c|}
\hline $\begin{array}{c}\text { Total Site } \\
\text { Density } \\
\left(\text { sites } \mathrm{nm}^{-2}\right) \\
\end{array}$ & $\begin{array}{c}\text { High-Affinity } \\
\text { Site Density } \\
\text { (mol Sites/mol Fe) }\end{array}$ & $\begin{array}{c}\% \text { of High } \\
\text { Affinity Sites }\end{array}$ \\
\hline 0.15 & 0.005 & 3.33 \\
\hline 0.15 & 0.003 & 2.00 \\
\hline 0.15 & 0.01 & 6.67 \\
\hline 0.15 & 0.002 & 1.33 \\
\hline 0.15 & 0.002 & 1.33 \\
\hline 0.15 & 0.005 & 3.33 \\
\hline 0.15 & 0.002 & 1.33 \\
\hline 0.15 & 0.001 & 0.67 \\
\hline 0.15 & 0.005 & 3.33 \\
\hline 0.15 & 0.001 & 0.67 \\
\hline 0.15 & 0.002 & 1.33 \\
\hline 0.15 & 0.003 & 2.00 \\
\hline 0.15 & 0.007 & 4.67 \\
\hline 0.15 & 0.005 & 3.33 \\
\hline 0.15 & 0.01 & 6.67 \\
\hline 0.15 & 0.001 & 0.67 \\
\hline 0.15 & 0.003 & 2.00 \\
\hline 0.15 & 0.005 & 3.33 \\
\hline 0.15 & 0.001 & 0.67 \\
\hline 0.15 & 0.005 & 3.33 \\
\hline 0.15 & 0.001 & 0.67 \\
\hline 0.15 & 0.005 & 3.33 \\
\hline
\end{tabular}

\begin{tabular}{|c|c|c|}
\hline $\begin{array}{c}\text { Total Site } \\
\text { Density } \\
\left(\text { sites } \mathrm{nm}^{-2}\right)\end{array}$ & $\begin{array}{c}\text { High-Affinity } \\
\text { Site Density } \\
\text { (mol Sites/mol Fe) }\end{array}$ & $\begin{array}{c}\% \text { of High } \\
\text { Affinity Sites }\end{array}$ \\
\hline 0.16 & 0.005 & 3.13 \\
\hline 0.16 & 0.003 & 1.88 \\
\hline 0.16 & 0.01 & 6.25 \\
\hline 0.16 & 0.002 & 1.25 \\
\hline 0.16 & 0.002 & 1.25 \\
\hline 0.16 & 0.005 & 3.13 \\
\hline 0.16 & 0.002 & 1.25 \\
\hline 0.16 & 0.001 & 0.63 \\
\hline 0.16 & 0.005 & 3.13 \\
\hline 0.16 & 0.001 & 0.63 \\
\hline 0.16 & 0.002 & 1.25 \\
\hline 0.16 & 0.003 & 1.88 \\
\hline 0.16 & 0.007 & 4.38 \\
\hline 0.16 & 0.005 & 3.13 \\
\hline 0.16 & 0.01 & 6.25 \\
\hline 0.16 & 0.001 & 0.63 \\
\hline 0.16 & 0.003 & 1.88 \\
\hline 0.16 & 0.005 & 3.13 \\
\hline 0.16 & 0.001 & 0.63 \\
\hline 0.16 & 0.005 & 3.13 \\
\hline 0.16 & 0.001 & 0.63 \\
\hline 0.16 & 0.005 & 3.13 \\
\hline
\end{tabular}

\begin{tabular}{|c|c|c|}
\hline $\begin{array}{l}\text { Total Site } \\
\text { Density } \\
\left(\text { sites } \mathrm{nm}^{-2}\right) \\
\end{array}$ & $\begin{array}{c}\text { High-Affinity } \\
\text { Site Density } \\
\text { (mol Sites/mol Fe) }\end{array}$ & $\begin{array}{c}\% \text { of High } \\
\text { Affinity Sites }\end{array}$ \\
\hline 0.05 & 0.005 & 10.00 \\
\hline 0.05 & 0.003 & 6.00 \\
\hline 0.05 & 0.01 & 20.00 \\
\hline 0.05 & 0.002 & 4.00 \\
\hline 0.05 & 0.002 & 4.00 \\
\hline 0.05 & 0.005 & 10.00 \\
\hline 0.05 & 0.002 & 4.00 \\
\hline 0.05 & 0.001 & 2.00 \\
\hline 0.05 & 0.005 & 10.00 \\
\hline 0.05 & 0.001 & 2.00 \\
\hline 0.05 & 0.002 & 4.00 \\
\hline 0.05 & 0.003 & 6.00 \\
\hline 0.05 & 0.007 & 14.00 \\
\hline 0.05 & 0.005 & 10.00 \\
\hline 0.05 & 0.01 & 20.00 \\
\hline 0.05 & 0.001 & 2.00 \\
\hline 0.05 & 0.003 & 6.00 \\
\hline 0.05 & 0.005 & 10.00 \\
\hline 0.05 & 0.001 & 2.00 \\
\hline 0.05 & 0.005 & 1.11 \\
\hline 0.05 & 0.001 & 2.00 \\
\hline 0.05 & 0.005 & 10.00 \\
\hline
\end{tabular}


Table 6.3-5. Percentage of High-Affinity Sites for HFO (Continued)

\begin{tabular}{|c|c|c|}
\hline $\begin{array}{c}\text { Total Site } \\
\text { Density } \\
\left(\text { sites } \mathrm{nm}^{-2}\right)\end{array}$ & $\begin{array}{c}\text { High-Affinity } \\
\text { Site Density } \\
\text { (mol Sites/mol Fe) }\end{array}$ & $\begin{array}{c}\% \text { of High } \\
\text { Affinity Sites }\end{array}$ \\
\hline 0.18 & 0.005 & 2.78 \\
\hline 0.18 & 0.003 & 1.67 \\
\hline 0.18 & 0.01 & 5.56 \\
\hline 0.18 & 0.002 & 1.11 \\
\hline 0.18 & 0.002 & 1.11 \\
\hline 0.18 & 0.005 & 2.78 \\
\hline 0.18 & 0.002 & 1.11 \\
\hline 0.18 & 0.001 & 0.56 \\
\hline 0.18 & 0.005 & 2.78 \\
\hline 0.18 & 0.001 & 0.56 \\
\hline 0.18 & 0.002 & 1.11 \\
\hline 0.18 & 0.003 & 1.67 \\
\hline 0.18 & 0.007 & 3.89 \\
\hline 0.18 & 0.005 & 2.78 \\
\hline 0.18 & 0.01 & 5.56 \\
\hline 0.18 & 0.001 & 0.56 \\
\hline 0.18 & 0.003 & 1.67 \\
\hline 0.18 & 0.005 & 2.78 \\
\hline 0.18 & 0.001 & 0.56 \\
\hline 0.18 & 0.005 & 2.78 \\
\hline 0.18 & 0.001 & 0.56 \\
\hline 0.18 & 0.005 & 2.78 \\
\hline
\end{tabular}

\begin{tabular}{|c|c|c|}
\hline $\begin{array}{c}\text { Total Site } \\
\text { Density } \\
\left(\text { sites } \mathrm{nm}^{-2}\right) \\
\end{array}$ & $\begin{array}{c}\text { High-Affinity } \\
\text { Site Density } \\
\text { (mol Sites/mol Fe) }\end{array}$ & $\begin{array}{c}\% \text { of High } \\
\text { Affinity Sites }\end{array}$ \\
\hline 0.1 & 0.005 & 5.00 \\
\hline 0.1 & 0.003 & 3.00 \\
\hline 0.1 & 0.01 & 10.00 \\
\hline 0.1 & 0.002 & 2.00 \\
\hline 0.1 & 0.002 & 2.00 \\
\hline 0.1 & 0.005 & 5.00 \\
\hline 0.1 & 0.002 & 2.00 \\
\hline 0.1 & 0.001 & 1.00 \\
\hline 0.1 & 0.005 & 5.00 \\
\hline 0.1 & 0.001 & 1.00 \\
\hline 0.1 & 0.002 & 2.00 \\
\hline 0.1 & 0.003 & 3.00 \\
\hline 0.1 & 0.007 & 7.00 \\
\hline 0.1 & 0.005 & 5.00 \\
\hline 0.1 & 0.01 & 10.00 \\
\hline 0.1 & 0.001 & 1.00 \\
\hline 0.1 & 0.003 & 3.00 \\
\hline 0.1 & 0.005 & 5.00 \\
\hline 0.1 & 0.001 & 1.00 \\
\hline 0.1 & 0.005 & 5.00 \\
\hline 0.1 & 0.001 & 1.00 \\
\hline 0.1 & 0.005 & 5.00 \\
\hline
\end{tabular}

\begin{tabular}{|c|c|c|}
\hline $\begin{array}{l}\text { Total Site } \\
\text { Density } \\
\left(\text { sites } \mathrm{nm}^{-2}\right) \\
\end{array}$ & $\begin{array}{c}\text { High-Affinity } \\
\text { Site Density } \\
\text { (mol Sites/mol Fe) }\end{array}$ & $\begin{array}{c}\% \text { of High } \\
\text { Affinity Sites }\end{array}$ \\
\hline 0.13 & 0.005 & 3.85 \\
\hline 0.13 & 0.003 & 2.31 \\
\hline 0.13 & 0.01 & 7.69 \\
\hline 0.13 & 0.002 & 1.54 \\
\hline 0.13 & 0.002 & 1.54 \\
\hline 0.13 & 0.005 & 3.85 \\
\hline 0.13 & 0.002 & 1.54 \\
\hline 0.13 & 0.001 & 0.77 \\
\hline 0.13 & 0.005 & 3.85 \\
\hline 0.13 & 0.001 & 0.77 \\
\hline 0.13 & 0.002 & 1.54 \\
\hline 0.13 & 0.003 & 2.31 \\
\hline 0.13 & 0.007 & 5.38 \\
\hline 0.13 & 0.005 & 3.85 \\
\hline 0.13 & 0.01 & 7.69 \\
\hline 0.13 & 0.001 & 0.77 \\
\hline 0.13 & 0.003 & 2.31 \\
\hline 0.13 & 0.005 & 3.85 \\
\hline 0.13 & 0.001 & 0.77 \\
\hline 0.13 & 0.005 & 3.85 \\
\hline 0.13 & 0.001 & 0.77 \\
\hline 0.13 & 0.005 & 3.85 \\
\hline
\end{tabular}

Source: DTN: SN0508T0503305.003, Spreadsheet 'sorption data.xls', Worksheet 'HFO \% of high affinity sites.' 
The values currently used in TSPA-LA for goethite and HFO specific surface area, site density, and high-affinity site percentages, and the discrete distributions for these parameters, are based on preliminary DTN: SN0503T0503305.001. Three data values in this DTN are incorrect. In addition, the data currently used in preliminary DTN: SN0503T0503305.001 contain up to 15 significant digits, whereas the source data in Tables 4.1-10, 4.1-11, and 4.1-12 are accurate to one to three digits. The parameter values for the discrete distributions in Table 6.3-6 are given to three significant digits, while the probability levels are reported to five decimal places. Details of the data errors and the discrete distributions currently used in TSPA-LA are described in Appendix J.

The capacity (in moles of high-affinity sites per gram of corrosion products) for irreversible sorption on stationary corrosion products is computed based on these four parameters, combining the capacity of goethite and HFO:

$$
\frac{10^{16}}{N_{A}}\left[\omega_{G} \bar{s}_{G}+\left(1-\omega_{G}\right) \bar{s}_{H F O}\right]\left[\omega_{G} N_{S, G}+\left(1-\omega_{G}\right) N_{S, H F O}\right]\left[\omega_{G} f_{H A, G}+\left(1-\omega_{G}\right) f_{H A, H F O}\right]
$$

where:

$$
\begin{array}{ll}
\omega_{G} & =\text { mass fraction of corrosion products as goethite (dimensionless) } \\
\bar{s}_{G} & =\text { specific surface area of goethite }\left(\mathrm{m}^{2} \mathrm{~g}^{-1}\right) \\
\bar{s}_{H F O} & =\text { specific surface area of } \mathrm{HFO}\left(\mathrm{m}^{2} \mathrm{~g}^{-1}\right) \\
N_{S, G} & =\text { sorption site density for goethite }\left(\text { sites } \mathrm{nm}^{-2}\right) \\
N_{S, H F O} & =\text { sorption site density for HFO }\left(\text { sites } \mathrm{nm}^{-2}\right) \\
f_{H A, G} & =\text { percentage of high-affinity sites for goethite (percent) } \\
f_{H A, H F O} & =\text { percentage of high-affinity sites for HFO (percent) } \\
N_{A} & \left.=\text { Avogadro's number (sites mol }{ }^{-1}\right)
\end{array}
$$

The factor of $10^{16}$ includes a conversion factor from $\mathrm{nm}^{2}$ to $\mathrm{m}^{2}$ and from percentage of high-affinity sites to fraction of high-affinity sites.

Table 6.3-6 shows discrete probabilities for various values of several parameters. The sum of these parameters is 1.0, and the cumulative sum at any parameter value is the cumulative (probability) distribution function, CDF.

From the parameter values given in Table 6.3-6, the sorption capacity of corrosion products ranges from $3.90 \times 10^{-6} \mathrm{~mol} \mathrm{~g}^{-1}$ to $2.18 \times 10^{-3} \mathrm{~mol} \mathrm{~g}^{-1}$. To put these values into perspective, the amount of radionuclides capable of being irreversibly sorbed can be estimated for a 21-PWR. The inventory of $\mathrm{Pu}$ and $\mathrm{Am}$ and their isotopes is $83.6 \mathrm{~kg}$ per CSNF waste package (DTN: SN0310T0505503.004 [DIRS 168761]). Using an approximate atomic weight of $240 \mathrm{~g} \mathrm{~mol}^{-1}$ (to represent various $\mathrm{Pu}$ and Am isotopes), this inventory of $\mathrm{Pu}$ and Am in a fully-degraded 21-PWR containing 19,440 kg corrosion products (as $\mathrm{Fe}_{2} \mathrm{O}_{3}$, from Table 6.3-4) 
corresponds to about $1.79 \times 10^{-5} \mathrm{~mol} \mathrm{~g}^{-1}$. Thus, the sorption capacity of goethite and HFO corrosion products ranges from about 0.2 to 120 times the $\mathrm{Pu}$ and $\mathrm{Am}$ inventory of a CSNF waste package.

Table 6.3-6. Sample Ranges and Distributions Used for Irreversible Sorption on Stationary Corrosion Products

\begin{tabular}{|c|c|c|c|}
\hline Input Name & Input Description & Range & Distribution \\
\hline Relative_Abundance_Goethite_a & $\begin{array}{l}\text { Fraction of total iron oxide that is } \\
\text { goethite }\end{array}$ & $0.45-0.8$ & Uniform \\
\hline \multirow[t]{33}{*}{ Goethite_SA_a } & \multirow[t]{33}{*}{$\begin{array}{l}\text { Goethite surface area; discrete } \\
\text { distribution }\end{array}$} & $\frac{\text { Specific Surface Area }}{\left(\mathrm{m}^{2} \mathrm{~g}^{-1}\right)}$ & Probability Level \\
\hline & & 14.7 & 0.01887 \\
\hline & & 20.0 & 0.05660 \\
\hline & & 21.0 & 0.03774 \\
\hline & & 21.4 & 0.01887 \\
\hline & & 27.7 & 0.01887 \\
\hline & & 28.5 & 0.03774 \\
\hline & & 30.8 & 0.01887 \\
\hline & & 32.0 & 0.03774 \\
\hline & & 33.0 & 0.05660 \\
\hline & & 35.0 & 0.01887 \\
\hline & & 37.0 & 0.01887 \\
\hline & & 38.0 & 0.01887 \\
\hline & & 39.9 & 0.01887 \\
\hline & & 43.0 & 0.01887 \\
\hline & & 45.0 & 0.03774 \\
\hline & & 47.5 & 0.01887 \\
\hline & & 49.0 & 0.07547 \\
\hline & & 50.0 & 0.01887 \\
\hline & & 52.0 & 0.03774 \\
\hline & & 54.0 & 0.01887 \\
\hline & & 55.0 & 0.05660 \\
\hline & & 55.4 & 0.01887 \\
\hline & & 64.3 & 0.01887 \\
\hline & & 66.0 & 0.03774 \\
\hline & & 70.0 & 0.03774 \\
\hline & & 80.0 & 0.03774 \\
\hline & & 80.5 & 0.01887 \\
\hline & & 81.0 & 0.07547 \\
\hline & & 85.0 & 0.01887 \\
\hline & & 86.0 & 0.01887 \\
\hline & & 105. & 0.03774 \\
\hline & & 110. & 0.01881 \\
\hline \multirow[t]{2}{*}{ HFO_SA_a } & \multirow[t]{2}{*}{$\begin{array}{l}\text { HFO surface area; discrete } \\
\text { distribution }\end{array}$} & $\frac{\text { Specific Surface Area }}{\left(\mathrm{m}^{2} \mathrm{~g}^{-1}\right)}$ & Probability Level \\
\hline & & 600.0 & 1.000 \\
\hline
\end{tabular}


Table 6.3-6. Sample Ranges and Distributions Used for Irreversible Sorption on Stationary Corrosion Products (Continued)

\begin{tabular}{|c|c|c|c|}
\hline Input Name & Input Description & Range & Distribution \\
\hline \multirow[t]{42}{*}{ Goethite_Site_Density_a } & \multirow{42}{*}{$\begin{array}{l}\text { Goethite site density; discrete } \\
\text { distribution }\end{array}$} & Density (sites $\mathrm{nm}^{-2}$ ) & Probability Level \\
\hline & & 1.02 & 0.01786 \\
\hline & & 1.21 & 0.01786 \\
\hline & & 1.32 & 0.03571 \\
\hline & & 1.46 & 0.01786 \\
\hline & & 1.50 & 0.01786 \\
\hline & & 1.66 & 0.01786 \\
\hline & & 1.68 & 0.03571 \\
\hline & & 1.70 & 0.01786 \\
\hline & & 1.80 & 0.01786 \\
\hline & & 1.87 & 0.01786 \\
\hline & & 1.93 & 0.01786 \\
\hline & & 1.95 & 0.01786 \\
\hline & & 1.97 & 0.01786 \\
\hline & & 2.20 & 0.01786 \\
\hline & & 2.30 & 0.07143 \\
\hline & & 2.31 & 0.01786 \\
\hline & & 2.32 & 0.01786 \\
\hline & & 2.55 & 0.01786 \\
\hline & & 2.60 & 0.03571 \\
\hline & & 2.70 & 0.01786 \\
\hline & & 2.89 & 0.01786 \\
\hline & & 2.90 & 0.03571 \\
\hline & & 3.00 & 0.01786 \\
\hline & & 3.12 & 0.01786 \\
\hline & & 3.13 & 0.01786 \\
\hline & & 3.30 & 0.03571 \\
\hline & & 3.40 & 0.01786 \\
\hline & & 4.00 & 0.01786 \\
\hline & & 4.20 & 0.01786 \\
\hline & & 4.60 & 0.01786 \\
\hline & & 4.84 & 0.01786 \\
\hline & & 4.90 & 0.01786 \\
\hline & & 5.00 & 0.01786 \\
\hline & & 5.53 & 0.01786 \\
\hline & & 6.15 & 0.01786 \\
\hline & & 6.30 & 0.01786 \\
\hline & & 6.31 & 0.03571 \\
\hline & & 6.60 & 0.01786 \\
\hline & & 7.00 & 0.05357 \\
\hline & & 7.20 & 0.01786 \\
\hline & & 7.40 & 0.01786 \\
\hline
\end{tabular}


Table 6.3-6. Sample Ranges and Distributions Used for Irreversible Sorption on Stationary Corrosion Products (Continued)

\begin{tabular}{|c|c|c|c|}
\hline Input Name & Input Description & Range & Distribution \\
\hline \multirow{4}{*}{$\begin{array}{l}\text { Goethite_Site_Density_a } \\
\text { (continued) }\end{array}$} & & 8.00 & 0.01786 \\
\hline & & 8.16 & 0.01786 \\
\hline & & 8.38 & 0.01786 \\
\hline & & 8.59 & 0.01778 \\
\hline \multirow[t]{13}{*}{ HFO_Site_Density_a } & \multirow{13}{*}{$\begin{array}{l}\text { HFO site density; discrete } \\
\text { distribution }\end{array}$} & Density (sites $\mathrm{nm}^{-2}$ ) & Probability Level \\
\hline & & 0.56 & 0.05263 \\
\hline & & 1.13 & 0.10526 \\
\hline & & 1.47 & 0.05263 \\
\hline & & 1.58 & 0.05263 \\
\hline & & 1.69 & 0.10526 \\
\hline & & 1.81 & 0.05263 \\
\hline & & 2.03 & 0.10526 \\
\hline & & 2.26 & 0.26316 \\
\hline & & 2.60 & 0.05263 \\
\hline & & 2.71 & 0.05263 \\
\hline & & 4.00 & 0.05263 \\
\hline & & 5.65 & 0.05265 \\
\hline \multirow[t]{23}{*}{ HFO_Strong_Sites_a } & \multirow{23}{*}{$\begin{array}{l}\text { Percentage of high affinity HFO } \\
\text { sites; discrete distribution }\end{array}$} & Percentage & Probability Level \\
\hline & & 0.2000 & 0.01263 \\
\hline & & 0.4000 & 0.01010 \\
\hline & & 0.4167 & 0.01263 \\
\hline & & 0.4348 & 0.01263 \\
\hline & & 0.5000 & 0.06313 \\
\hline & & 0.5556 & 0.02525 \\
\hline & & 0.6000 & 0.00758 \\
\hline & & 0.6250 & 0.01263 \\
\hline & & 0.6667 & 0.02525 \\
\hline & & 0.7143 & 0.01263 \\
\hline & & 0.7692 & 0.01263 \\
\hline & & 0.8333 & 0.01010 \\
\hline & & 0.8696 & 0.01010 \\
\hline & & 1.0000 & 0.09343 \\
\hline & & 1.1111 & 0.02020 \\
\hline & & 1.2500 & 0.01768 \\
\hline & & 1.3043 & 0.00758 \\
\hline & & 1.3333 & 0.02020 \\
\hline & & 1.4000 & 0.00253 \\
\hline & & 1.4286 & 0.01010 \\
\hline & & 1.5000 & 0.03788 \\
\hline & & 1.5385 & 0.01010 \\
\hline
\end{tabular}


Table 6.3-6. Sample Ranges and Distributions Used for Irreversible Sorption on Stationary Corrosion Products (Continued)

\begin{tabular}{|c|c|c|c|}
\hline Input Name & Input Description & Range & Distribution \\
\hline \multirow{35}{*}{$\begin{array}{l}\text { HFO_Strong_Sites_a } \\
\text { (continued) }\end{array}$} & & 1.6667 & 0.01515 \\
\hline & & 1.8750 & 0.00758 \\
\hline & & 2.0000 & 0.05303 \\
\hline & & 2.0833 & 0.01768 \\
\hline & & 2.1429 & 0.00758 \\
\hline & & 2.1739 & 0.01768 \\
\hline & & 2.3077 & 0.00758 \\
\hline & & 2.5000 & 0.08838 \\
\hline & & 2.7778 & 0.03535 \\
\hline & & 2.9167 & 0.00253 \\
\hline & & 3.0000 & 0.01515 \\
\hline & & 3.0435 & 0.00253 \\
\hline & & 3.1250 & 0.01768 \\
\hline & & 3.3333 & 0.03535 \\
\hline & & 3.5000 & 0.01263 \\
\hline & & 3.5714 & 0.01768 \\
\hline & & 3.8462 & 0.01768 \\
\hline & & 3.8889 & 0.00505 \\
\hline & & 4.0000 & 0.01010 \\
\hline & & 4.1667 & 0.00505 \\
\hline & & 4.3478 & 0.00505 \\
\hline & & 4.3750 & 0.00253 \\
\hline & & 4.6667 & 0.00505 \\
\hline & & 5.0000 & 0.06313 \\
\hline & & 5.3846 & 0.00253 \\
\hline & & 5.5556 & 0.01010 \\
\hline & & 6.0000 & 0.00758 \\
\hline & & 6.2500 & 0.00505 \\
\hline & & 6.6667 & 0.01010 \\
\hline & & 7.0000 & 0.00505 \\
\hline & & 7.1429 & 0.00505 \\
\hline & & 7.6923 & 0.00505 \\
\hline & & 10.0000 & 0.02778 \\
\hline & & 14.0000 & 0.00253 \\
\hline & & 20.0000 & 0.00499 \\
\hline \multirow[t]{7}{*}{ Goethite_Strong_Sites_a } & \multirow{7}{*}{$\begin{array}{l}\text { Percentage of high affinity } \\
\text { goethite sites; discrete } \\
\text { distribution }\end{array}$} & Percentage & Probability Level \\
\hline & & 8.8 & 0.1 \\
\hline & & 11.5 & 0.1 \\
\hline & & 12.4 & 0.1 \\
\hline & & 22.7 & 0.1 \\
\hline & & 23.1 & 0.1 \\
\hline & & 24.7 & 0.1 \\
\hline
\end{tabular}


Table 6.3-6. Sample Ranges and Distributions Used for Irreversible Sorption on Stationary Corrosion Products (Continued)

\begin{tabular}{|l|c|c|c|}
\hline \multicolumn{1}{|c|}{ Input Name } & Input Description & Range & Distribution \\
\hline Goethite_Strong_Sites_a & \multirow{3}{*}{ (continued) } & 26.8 & 0.1 \\
\cline { 3 - 4 } & \multirow{2}{*}{} & 43.9 & 0.1 \\
\cline { 3 - 4 } & & 49.7 & 0.1 \\
\cline { 3 - 4 } & & 73.9 & 0.1 \\
\hline
\end{tabular}

Output DTN: SN0508T0503305.003.

\subsubsection{In-Package Diffusion Submodel for Commercial Spent Nuclear Fuel Waste Packages}

The objective of this submodel is to compute the effective diffusion coefficient, cross sectional area for diffusion, and the path length for diffusion of radionuclides in a breached waste package. From these output parameters, the rate of diffusion of radionuclides from the waste package to the invert can be determined.

The focus in this submodel is on diffusive releases from CSNF waste packages in no-seep regions of the repository (where no seepage into the drift or condensation on drift walls occurs). In a no-seep environment, the water saturation inside the CSNF waste package is computed as a function of relative humidity. In a seep environment (where seepage into the drift and condensation on drift walls occur), the water saturation in a CSNF waste package is set to 1.0, and is not dependent on the relative humidity in the waste package. For HLW packages, the water saturation is set to 1.0 in both seep and no-seep environments independently of the relative humidity in the waste package. HLW packages are treated differently from CSNF waste packages because the hygroscopic nature of HLW glass will result in a comparatively high water saturation at lower relative humidities than for CSNF.

The fundamental basis of this submodel is that the only liquid water present is the thin film of adsorbed water that uniformly covers all surfaces exposed to humid air (Assumption 5.5). The relative humidity inside a breached waste package is assumed to be the same as the relative humidity in the drift (Assumption 5.5). In this submodel, all dissolution and diffusion of radionuclides occur in this thin film.

As the steel internal components corrode, the interior of the waste package becomes filled with a mass of porous corrosion products. Diffusion will occur on the thin water films coating the surfaces of particles of corrosion products. The extent of corrosion will determine the amount of corrosion products and, in turn, the amount of adsorbed water that is present, from which the water saturation is computed. Together with estimates of the porosity, the effective diffusion coefficient is calculated using Archie's law. A bulk cross sectional area for diffusion is estimated for each domain, and the length of the diffusion path is a sampled parameter for each leg of the path from the waste form domain to the corrosion products domain to the invert domain. The extent of corrosion is taken to vary linearly over the lifetime of the waste package steels. The amount of water adsorbed is a function of the relative humidity. Consequently, the rate of diffusive releases varies over time. 
A number of uncertain parameters are associated with this submodel. The lengths of the various diffusive pathways are uncertain because the location of the failed fuel rods and therefore the distance from the points of failure to the openings in the waste package outer corrosion barrier cannot be known. In addition, the surface area available for adsorption of water is uncertain because the condition of the corrosion products cannot be determined - they may be finely powdered with a high specific surface, or agglomerate into an impermeable mass with low specific surface area, all depending on unpredictable circumstances and material behaviors.

\subsection{Adsorption of Water Vapor in Commercial Spent Nuclear Fuel Waste Packages}

All surfaces exposed to water vapor will adsorb water. The amount of adsorbed water vapor depends principally on the nature of the material and the relative humidity. In many cases, the first layer of water adsorbed is chemically bound to the surface (McCafferty and Zettlemoyer 1971 [DIRS 154378], p. 239) and is difficult to remove except at high temperatures, higher than will exist in the repository. Subsequent layers are less tightly bound, being attracted simply by van der Waals forces to lower water layers. The first few layers of water often form an ice-like structure with little mobility. As the relative humidity approaches 100 percent, the outer layers of water begin to behave more like bulk liquid. At 100 percent relative humidity, bulk condensation of water occurs, forming a liquid phase.

Most metals, except for inert metals such as gold and platinum, form an oxide or oxyhydroxide surface layer when exposed to oxygen or water. Thus, all metals in a waste package contain a surface oxide layer on which water adsorption takes place. In the case of Alloy 22, stainless steel, Zircaloy, and aluminum - metals found in the waste package or waste form - the surface oxide layer is passivating, where the resistance to oxygen diffusion protects the metal underneath.

Adsorption isotherms define the amount of water adsorbed as a function of relative humidity or relative pressure, provided sufficient time is allowed for equilibrium to be achieved. Isotherms have been measured for powdered samples of some metal oxides found in waste packages, for example, $\mathrm{NiO}, \mathrm{Fe}_{2} \mathrm{O}_{3}$ and other iron (hydr)oxides (oxidized components of stainless steel and carbon steel), and $\mathrm{ZrO}_{2}$ (oxidized surface of Zircaloy fuel rods and assembly components). Figure 6.3-6 presents the adsorption isotherms for $\mathrm{Fe}_{2} \mathrm{O}_{3}, \mathrm{NiO}$, and $\mathrm{ZrO}_{2}$ as a function of relative humidity (RH), with the amount of water adsorbed being represented as the number of monolayers of water present if it uniformly covers the entire surface area of the sample. Figure 6.3-7 compares water vapor adsorption isotherms for hematite, goethite, and HFO.

Water at solid surfaces varies in nature from a highly structured form on hydrophilic substrates to a loose, entropic form on more hydrophobic substrates possessing hydrophilic sites (Lee and Staehle 1994 [DIRS 154380], p. 74). The adsorption of water on solids depends on the capacity of the surface to orient the water dipoles, usually with the proton outward. Near polar surfaces of solids such as metal and oxides, the cause of the orientation of water molecules at the interface could be either hydrogen bonding or dipole-dipole interactions, depending on the chemical nature of the solid. Depending on the dissimilarity between the ordered (dipole-dipole), induced structure near the interface and the bulk structure, various thicknesses of the ordered layers are possible (Lee and Staehle 1994 [DIRS 154380], p. 75). 
The structure of liquid water is considered to consist of unbonded molecules and of molecules hydrogen-bonded in clusters that have a mean size of about 90 molecules at $0^{\circ} \mathrm{C}$ (Lee and Staehle 1994 [DIRS 154380], p. 79). At hydrophilic surfaces, such as most metal oxides, the structure of water resembles that of ice (McCafferty and Zettlemoyer 1971 [DIRS 154378], p. 239). This behavior is attributed to the existence of a monolayer in which the adsorbed water is held rigidly to the solid surface at fixed sites. The first layer is localized by double hydrogen bonding of a single water molecule to two surface hydroxyls. This highly constrained first layer relaxes in the next layers, where the water molecules start to possess a rotational degree of freedom, being singly hydrogen-bonded. The second layer becomes more ordered when hydrogen bonds to a third layer, and so on, until the ordering effect of the surface is overcome and bulk liquid layers form farther from the surface. On a hydrophobic surface, such as silica, different behavior is observed. When half of the surface hydroxyls on silica are occupied by water, the water starts to agglomerate into clusters instead of adsorbing uniformly over the surface.

Layers of water adsorbed on an oxide surface can promote lateral ion movement, which sets up localized electrochemical cells due to inhomogeneities in the underlying metal (Lee and Staehle 1994, [DIRS 154380] p. 141). Such cells promote localized corrosion. Surface water dipoles may act to shield oxygen ions from an internal field that promotes ion movement. On the other hand, the gel-like structure of a metal oxyhydroxide may not support the charge separation that normally accounts for the field-driven process. Instead, ion movement may take place under the influence of a concentration gradient. The first layers of adsorbed water often do not contain ions from the solid (Lee and Staehle 1994 [DIRS 154380], p. 73), which indicates that multiple water layers are needed in order for solid species (such as radionuclides) to dissolve and diffuse.

As a bounding assumption in the EBS RT Abstraction, it is assumed (Assumption 5.5) that the adsorbed water film behaves as a bulk liquid in that radionuclides dissolve in this film and that colloids as well as radionuclides diffuse through it. 


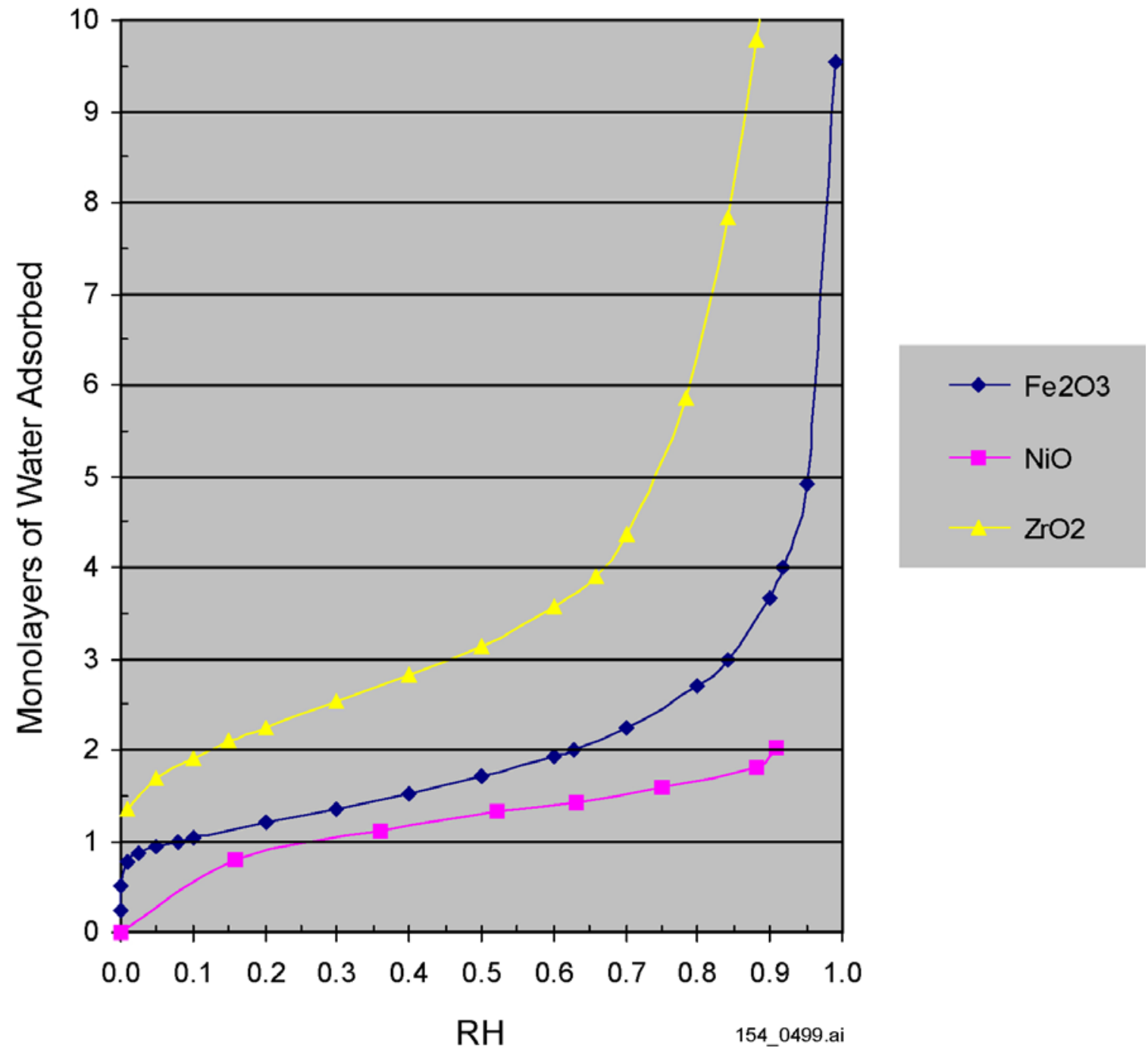

Sources: $\mathrm{Fe}_{2} \mathrm{O}_{3}$ : Jurinak 1964 [DIRS 154381], p. 486.

NiO: Lee and Staehle 1994 [DIRS 154380], Figure 4.48.

$\mathrm{ZrO}_{2}$ : Holmes et al. 1974 [DIRS 154379], Figure 3.

Figure 6.3-6. Comparison of Adsorption Isotherms for Water Vapor on $\mathrm{Fe}_{2} \mathrm{O}_{3}, \mathrm{NiO}$, and $\mathrm{ZrO}_{2}$ 


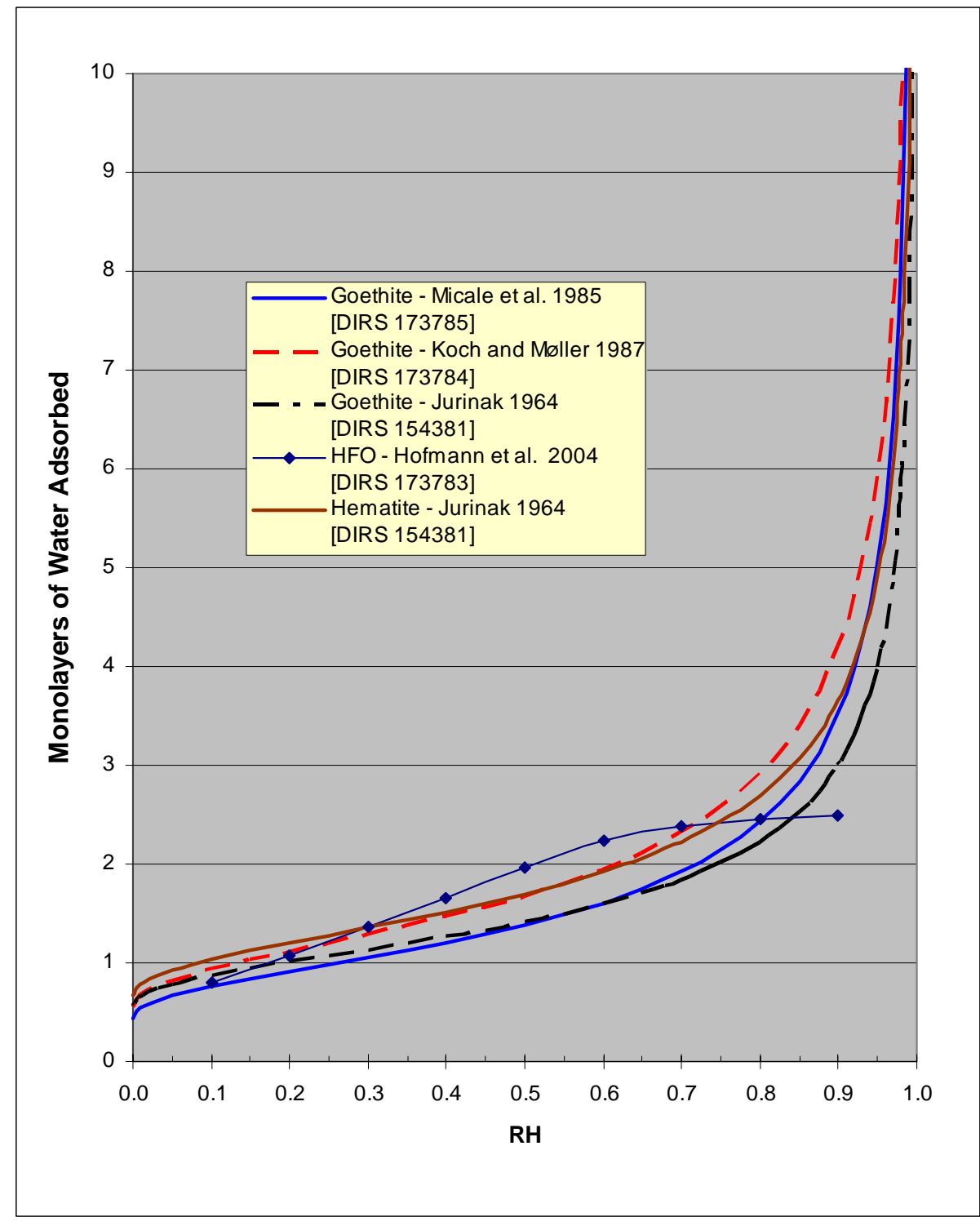

Sources: $\quad$ Micale et al. 1985 [DIRS 173785], goethite isotherm: Fig. 3;

Koch and Møller 1987 [DIRS 173784], goethite isotherm: Fig. 6,

Jurinak 1964 [DIRS 154381],

goethite $\mathrm{N}_{2}$ specific surface area: $71.6-73.0 \mathrm{~m}^{2} \mathrm{~g}^{-1}$ (Table 1); goethite isotherm: Fig. 6 , goethite $\mathrm{N}_{2}$ specific surface area: $12.0-81.5 \mathrm{~m}^{2} \mathrm{~g}^{-1}$ (Table I);

Jurinak 1964 [DIRS 154381],

Hofmann et al. 2004 [DIRS 173783], hematite isotherm: Fig. 5 and equation on p. 486

hematite $\mathrm{N}_{2}$ specific surface area: $9.60-9.70 \mathrm{~m}^{2} \mathrm{~g}^{-1}$ (Table I); HFO isotherm: Fig. 8,

HFO $\mathrm{N}_{2}$ specific surface area: $366.5 \mathrm{~m}^{2} \mathrm{~g}^{-1}$ (Table 1).

Figure 6.3-7. Comparison of Adsorption Isotherms for Water Vapor on Goethite and HFO with Isotherm for Hematite

Although waste package corrosion products are considered to be a mixed assemblage of iron oxides (see Section 6.3.4.2.1), the properties of hematite $\left(\mathrm{Fe}_{2} \mathrm{O}_{3}\right)$ are used for calculating the amount of water adsorbed onto stationary corrosion product surfaces. The justification for using hematite rather than goethite or HFO is as follows. Figure 6.3-7 shows that the range 
encompassed by the isotherms for goethite and HFO are similar to and almost coincident with that of hematite to the extent of the experimentally measured data from various sources, which is limited to about 97 percent RH. Thus, the adsorptive behavior of the three iron oxides is similar, and any difference in surface area can be ignored. In the vicinity of these higher values of RH, bulk condensation begins to occur. As the thickness of water layers increases, the surface properties that give rise to adsorption isotherms become less influential, and adsorbed water behavior would tend toward bulk water behavior in a generic porous medium rather than in any specific mineral. Furthermore, HFO will tend to convert to goethite, with concomitant reduction in specific surface area (Dzombak and Morel 1990 [DIRS 105483], p. 90), so that the quantity of HFO will be self-limiting. At any point in time, HFO will comprise a fraction of the total quantity of iron (hydr)oxides (Section 6.3.4.2.1) and is not likely to dominate the corrosion product assemblage. Therefore, the adsorptive properties of hematite are suitably representative of the mixed assemblage of iron oxides.

The water adsorption isotherm for hematite (from Figure 6.3-6) is compared with water retention characteristics of fine-grained soils. While it is difficult to predict the precise nature of corrosion products in terms of texture and grain size, it is reasonable that corrosion products will accumulate within the waste package as fine-grained masses of material. As described in Section 6.3.4.2.1, the in-package degradation products are envisioned to be composed of unconsolidated particulates and larger agglomerations of clays, iron oxyhydroxides, and other mineral assemblages that slump to the bottom of the waste package. Any seepage through the waste package is expected to flow through the sludge at the bottom of the waste package. This comparison shows that hematite as fine-grained corrosion products exhibits similar water retention behavior as a fine-grained geologic porous medium and can thus be described in terms of the behavior of porous media such as soils. Figure 6.3-8 (adapted from Or and Tuller 1999 [DIRS 173799], Figure 5) presents data for clay-dominated soils plotted as water film thickness as a function of water vapor partial pressure. Water film thickness is a function of the number of adsorbed water layers. Water vapor partial pressure is proportional to $\mathrm{RH}$; as the partial pressure approaches the vapor pressure $\left(3169 \mathrm{~Pa}\right.$ at $25^{\circ} \mathrm{C}$; Lide 1981 [DIRS 162229], p. 6-10), RH approaches 1.0, and the adsorbed water film thickness increases rapidly, with bulk condensation occurring when $\mathrm{RH}=1.0$. 


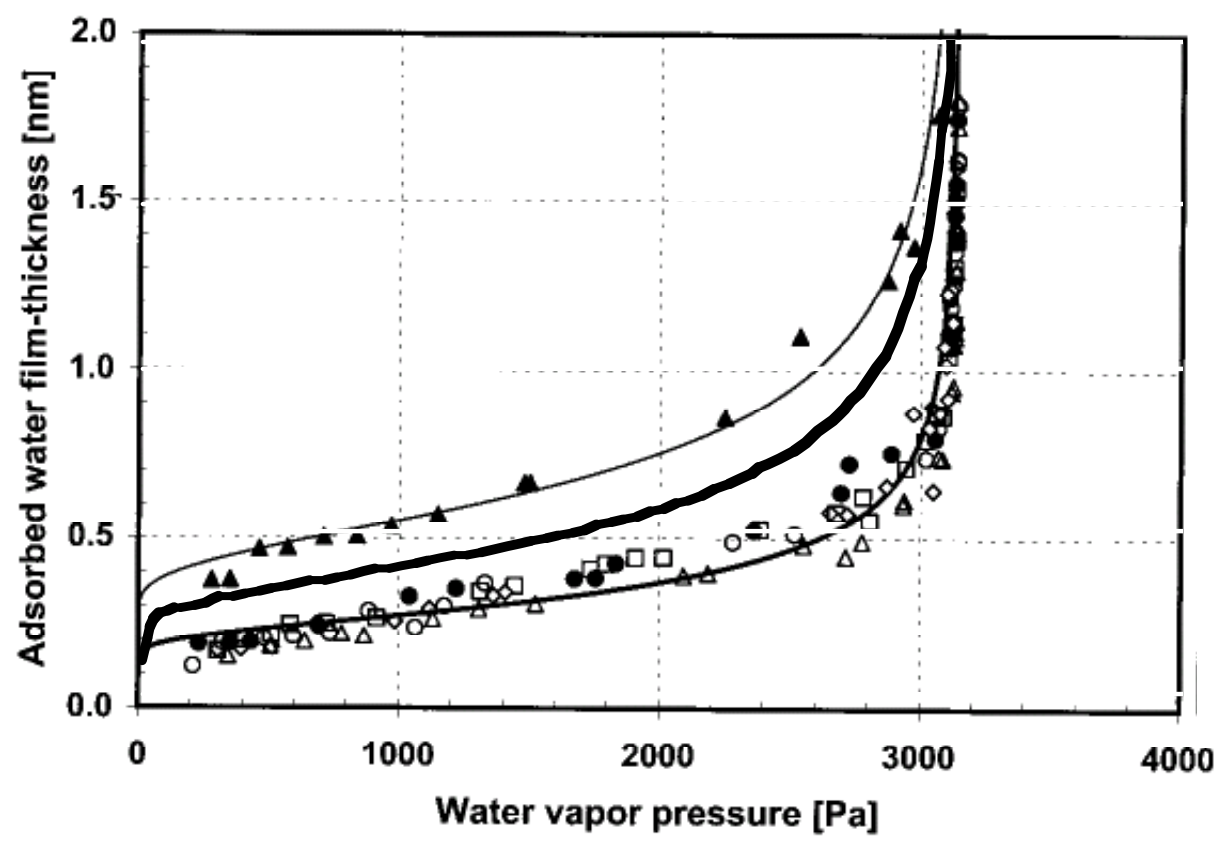

NOTE: $\quad$ The middle curve is the isotherm from Figure 6.3-6. The data points and upper and lower curves are from Or and Tuller 1999 [DIRS 173799], Figure 5.

Figure 6.3-8. Comparison of the Hematite Water Adsorption Isotherm with Water Adsorption Behavior of Seven Clay-Dominated Soils

The data points in Figure 6.3-8 represent measured water retention data for seven soils with varying mixtures of clays (montmorillonite and kaolinite); the upper and lower curves are functions calculated in Or and Tuller (1999 [DIRS 173799]). The middle curve is the hematite water adsorption isotherm from Figure 6.3-6 plotted as a function of water film thickness and water vapor pressure. The water adsorption isotherm for hematite agrees well with empirical water retention data for clays having a range of compositions. This indicates that the porous media characteristics of fine-grained hematite and clay are similar.

The waste package corrosion products will begin to adsorb water after the temperature falls below the boiling point and the $\mathrm{RH}$ begins to rise. Information on water adsorption isotherms is scarce at temperatures above $25^{\circ} \mathrm{C}$, although sources indicate that at some higher temperatures the water sorption isotherm for hematite shows no significant dependence on temperature at a given $\mathrm{RH}$, and that an adsorption isotherm for $25^{\circ} \mathrm{C}$ is a good approximation for isotherms for higher temperatures. For example, McCafferty and Zettlemoyer 1970 [DIRS 154382] experimentally determined the entropy of adsorption for water on hematite $\left(\alpha-\mathrm{Fe}_{2} \mathrm{O}_{3}\right)$ at several temperatures and up to $\mathrm{RH}$ of about 0.7 at $25^{\circ} \mathrm{C}$ and 0.5 and at $35^{\circ} \mathrm{C}$. Figure $6.3-9$ presents the data of McCafferty and Zettlemoyer 1970 [DIRS 154382] in terms of relative pressure (i.e., RH) and number of water layers. The low scatter of the data indicates that the isotherm for $35^{\circ} \mathrm{C}$ could be extrapolated to higher relative pressure with confidence. 


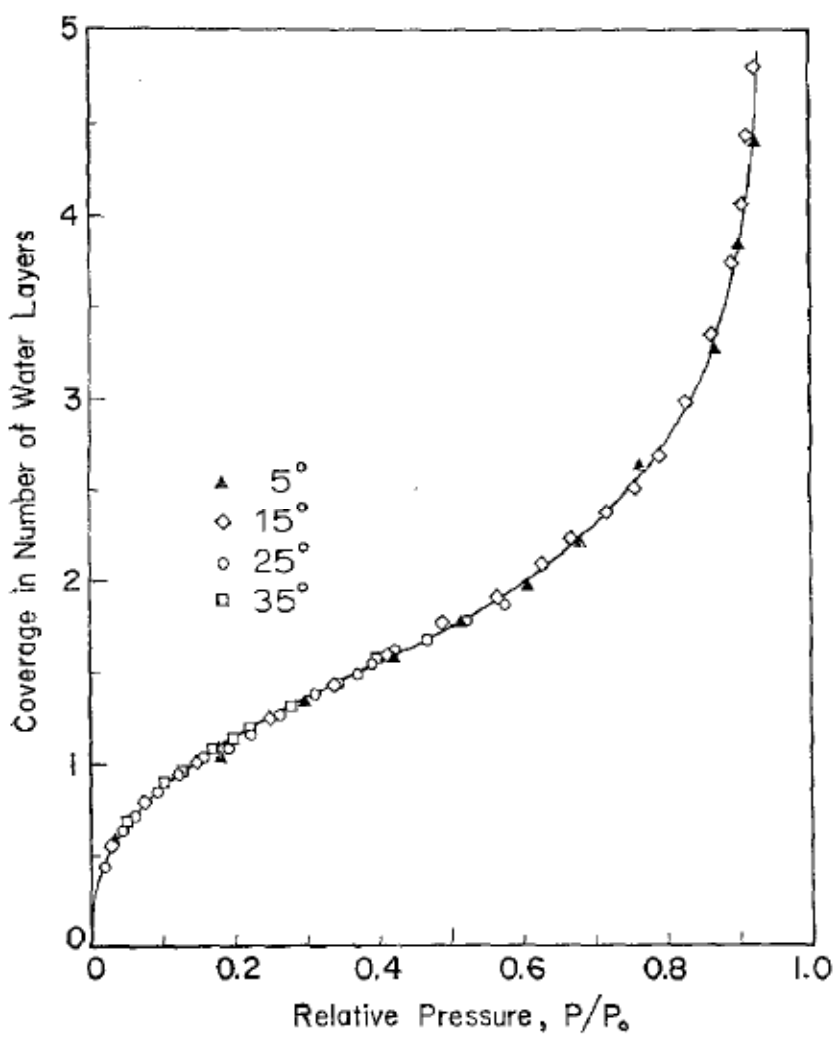

Source: McCafferty and Zettlemoyer 1970 [DIRS 154382], Figure 3.

Figure 6.3-9. Isotherms for Water Vapor on $\alpha-\mathrm{Fe}_{2} \mathrm{O}_{3}$

Lee and Staehle 1997 [DIRS 104943] investigated the adsorption of water on iron at $\mathrm{RH}$ values up to about 0.95 under humidified air and temperatures ranging from $7^{\circ} \mathrm{C}$ to $85^{\circ} \mathrm{C}$. They determined that under the experimental conditions an oxide layer formed on the surface of the iron (Lee and Staehle 1997 [DIRS 104943], pp. 34-5, p. 41). The authors experimentally determined the increased mass of the samples due to water adsorption using the quartz-crystal microbalance technique (Lee and Staehle 1997 [DIRS 104943]). They showed that the measurements of mass increase due to water adsorption were similar for the five temperatures used, within the scatter of the data; scatter increased with increasing temperature (Lee and Staehle 1997 [DIRS 104943], Figure 9). The authors concluded that water coverage of one monolayer thickness was exhibited at 10 percent $\mathrm{RH}$ at $25^{\circ} \mathrm{C}, 10$ percent $\mathrm{RH}$ at $45^{\circ} \mathrm{C}$, and 6 percent $\mathrm{RH}$ at $85^{\circ} \mathrm{C}$. Furthermore, multilayer adsorption and capillary condensation occurred as RH increased. Based on the shapes of the isotherms, they concluded that capillary condensation and filling of pores occurred at all temperatures and RH ranges investigated (Lee and Staehle 1997 [DIRS 104943]).

The temperature dependence of water retention curves has not been extensively studied but in recent years has been receiving more attention. The most important physical factors affecting the capillary pressure (also called matric suction) for a given water content are probably pore space topology, interfacial tension, and temperature (Bachmann and van der Ploeg 2002 [DIRS 174739], p. 468). In general, an increase in temperature results in a decrease in liquid 
surface tension, which causes a decrease of the contact angle and capillary pressure (i.e., less negative values) at a given degree of saturation. Further, in most cases, surface tension of a soil solution is somewhat lower than that of pure water (Bachmann and van der Ploeg 2002 [DIRS 174739], p. 473), and the temperature effect on the surface tension of soil solutions is larger than for pure water (Bachmann and van der Ploeg 2002 [DIRS 174739], p. 474; Nimmo and Miller 1986 [DIRS 174124], p. 1112).

Capillary pressure is generally thought to decrease linearly as a function of temperature at a given volumetric water content. A detailed treatment of this relationship is beyond the scope of this report, but the following relationships are pertinent to this discussion. The dependence on temperature and volumetric water content of the capillary pressure due to liquid surface tension effect may be expressed as (Bachmann and van der Ploeg 2002 [DIRS 174739], p. 474):

$$
\left.\psi(T, \theta)\right|_{\theta} \approx a_{0}(\theta)+b(\theta) T,
$$

where:

$$
\begin{aligned}
& \begin{array}{ll}
\theta \quad & \text { volumetric water content (percent) } \\
\left.\psi(T, \theta)\right|_{\theta}= & \text { capillary pressure as function of temperature and volumetric water content } \\
& \quad(\mathrm{Pa})
\end{array} \\
& \begin{array}{ll}
T & \text { temperature }(\mathrm{K})
\end{array} \\
& a_{0}(\mathrm{~Pa}) \text { and } b\left(\mathrm{~Pa} \mathrm{~K}^{-1}\right) \text { are fitting parameters. }
\end{aligned}
$$

This leads to a generalized expression for the temperature dependence of capillary pressure (Bachmann and van der Ploeg 2002 [DIRS 174739], p. 475; Grant and Salehzadeh 1996 [DIRS 174738], p. 266):

$$
\psi(T)=\psi_{T_{r}}\left(\frac{\beta_{0}+T}{\beta_{0}+T_{r}}\right)
$$

where:

$$
\begin{aligned}
& \psi_{T_{t}}=\text { capillary pressure at reference temperature, } T_{r}(\mathrm{~Pa}) \\
& T_{r}=\text { reference temperature }(\mathrm{K}) \\
& \beta_{0}=a / b .
\end{aligned}
$$

Equation 6.3.4.3.1-2 may be incorporated into any empirical capillary pressure function (Grant and Salehzadeh 1996 [DIRS 174738], p. 266). Incorporation into the closed-form equation of van Genuchten 1980 [DIRS 100610] yields (Bachmann et al. 2002 [DIRS 173887], Equation 7):

$$
\theta(\psi, T)=\theta_{r}+\frac{\theta_{s}-\theta_{r}}{\left\{[1+a \psi(T)]^{n}\right\}^{m}}
$$

where: 


$$
\begin{aligned}
& \begin{array}{ll}
\psi(T)= & \text { capillary pressure }(\mathrm{Pa}) \\
\theta(\psi, T)= & \text { volumetric water content as a function of capillary pressure and temperature } \\
& \left(\mathrm{m}^{3} \mathrm{~m}^{-3}\right) \\
\theta_{r} \quad= & \text { residual water content (percent) } \\
\theta_{s} \quad= & \text { saturated water content (percent) } \\
a\left(\mathrm{~m}^{-1}\right), m, & \text { and } n \text { are fitting parameters. }
\end{array}
\end{aligned}
$$

The results of several investigations of temperature dependence of capillary pressure are presented below.

Bachmann et al. (2002 [DIRS 173887]), in the course of investigating the effects of temperature on capillary pressure and angle of contact, studied drying and wetting of three soil types and determined maximum and minimum saturations as a function of temperature up to $38^{\circ} \mathrm{C}$. The particle sizes were in the sand and silt ranges, in contrast to the soil data from Or and Tuller (1999 [DIRS 173799]) shown in Figure 6.3-8, which are clay mixtures.

The samples of Bachmann et al. (2002 [DIRS 173887]) included a sand and a silt. The sand exhibited a temperature dependence of water content at saturation $\left(\Delta \theta_{s} / \Delta T\right)$ (percent ${ }^{\circ} \mathrm{C}^{-1}$ ) of -17.3 , and the $\Delta \theta_{s} / \Delta T$ for silt was -14.0 . While the data represent only two samples, the two values for $\Delta \theta_{s} / \Delta T$ are in close agreement. These indicate that maximum saturation from wetting decreases with temperature.

Romero et al. (2001 [DIRS 174022]) conducted a series of experiments with clay samples to investigate the influence of temperature on the hydraulic properties of fine-grained soils. The authors adapted vapor equilibrium and axis translation techniques to the measurement of hydraulic properties of prepared clayey samples at temperatures to $80^{\circ} \mathrm{C}$ for a range of matric suctions and water contents.

Samples of clay powder were prepared from natural Boom clay (from Mol, Belgium). Results from the vapor equilibrium technique at four different temperatures are presented in Figure 6.3-10. The figure presents the data at total constant suction, $\psi(\mathrm{MPa})$, in terms of water content (for which Romero et al. use the symbol $w$ ), and temperature, $T\left({ }^{\circ} \mathrm{C}\right.$ ). Suction values of $32 \mathrm{MPa}$ to $6 \mathrm{MPa}$ correspond to $R H$ values of roughly 80 to $97 \%$. The changes in water content as a function of temperature are small; for $\psi=6 \mathrm{MPa}$ and $\mathrm{w}$ approximately $12 \%, \Delta W / \Delta T$ was only $-0.038 \times 10^{-3} \mathrm{~K}^{-1}$. 


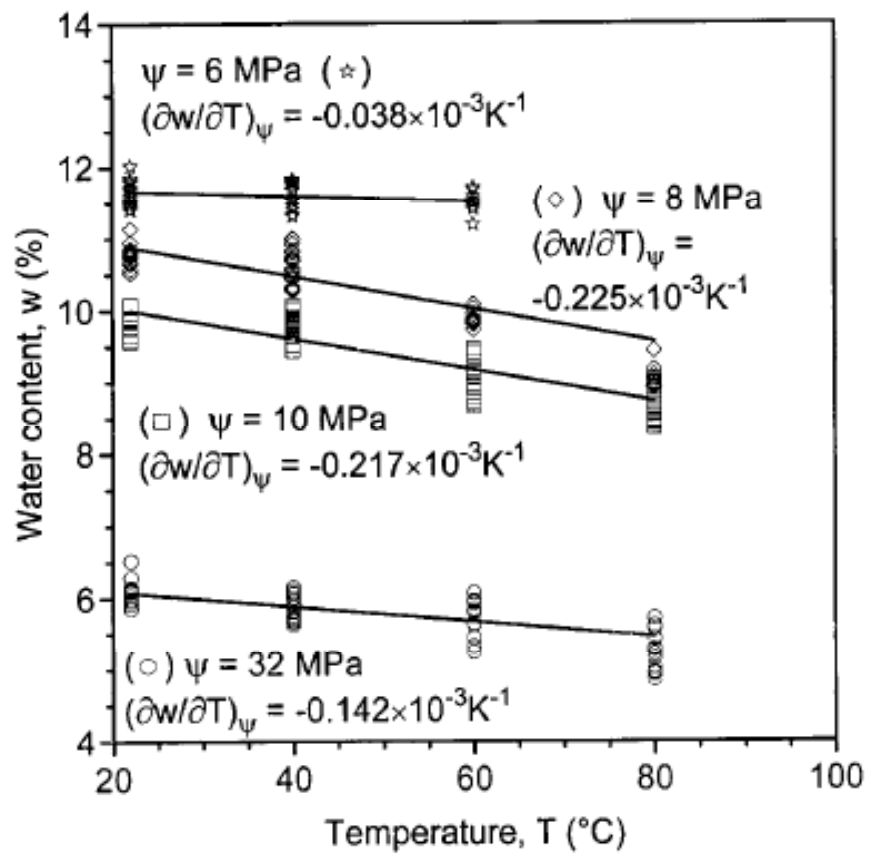

Source: Romero et al. 2001 [DIRS 174022], Figure 4.

NOTE: Samples are clay powder prepared from natural Boom clay, Mol, Belgium.

Figure 6.3-10. Water Content versus Temperature at Four Constant Suction Values

Figure 6.3-11 presents the same data at constant water content, $w$ (percent), in terms of total suction, $\psi(\mathrm{MPa})$, and temperature, $T\left({ }^{\circ} \mathrm{C}\right)$. Changes in suction with respect to temperature at constant water content are also relatively small. For $w=11$ percent and $\psi$ approximately $7 \mathrm{MPa}$, $\Delta \psi / \Delta T$ is only $-0.015 \mathrm{MPa} \mathrm{K}^{-1}$. The figure also presents the slopes of $\Delta \psi / \Delta T$ for constant water content as predicted by surface tension theory. The effect of temperature is greater than surface tension theory alone would predict. Other investigators of unsaturated soil properties have reached the same conclusion (Nimmo and Miller 1986 [DIRS 174124]; Hopmans and Dane 1986 [DIRS 174122]; Haridasan and Jensen 1972 [DIRS 174125]). 


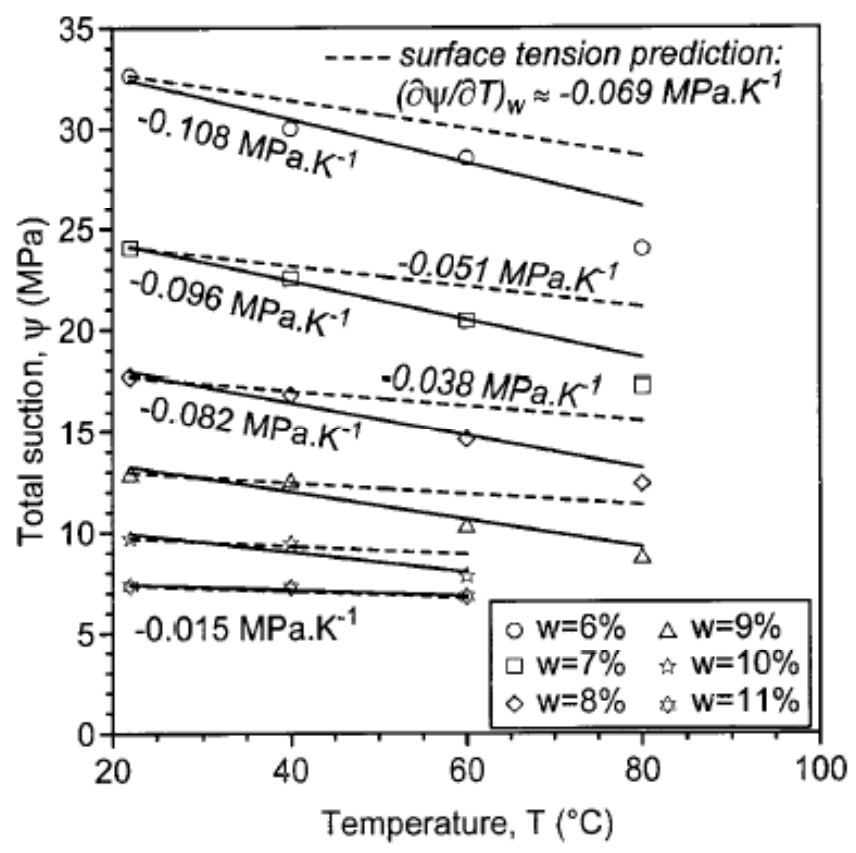

Source: Romero et al. 2001 [DIRS 174022], Figure 4.

NOTE: Samples are clay powder prepared from natural Boom clay, Mol, Belgium. Dashed curves represent values as predicted by surface tension theory.

Figure 6.3-11. Total Suction versus Temperature at Six Constant Water Contents

Constantz (1991 [DIRS 174120]) investigated isothermal and isobaric water retention in two different porous materials, a sand (the Oakley Sand, from Contra Costa County, California, bulk density $1.77 \mathrm{~g} \mathrm{~cm}^{-3}$, porosity 0.34 ) and a nonwelded tuff core sample (part of the Paint Brush Tuff, Yucca Mountain, Nevada, bulk density $1.30 \mathrm{~g} \mathrm{~cm}^{-3}$, porosity 0.52 ).

Isothermal water retention tests were conducted at $20^{\circ} \mathrm{C}$ and $80^{\circ} \mathrm{C}$. The author states, "[a]s expected, measurably less water was held within each matrix at $80^{\circ} \mathrm{C}$ compared to $20^{\circ} \mathrm{C}$, except near saturation" (Constantz 1991 [DIRS 174120], p. 3167). Figure 6.3-12 shows hysteresis loops for the two samples generated by cycling the pressure on the samples up and then down at constant temperature; this procedure was followed at each temperature. The curves illustrate the small response to temperature at near saturation conditions. 

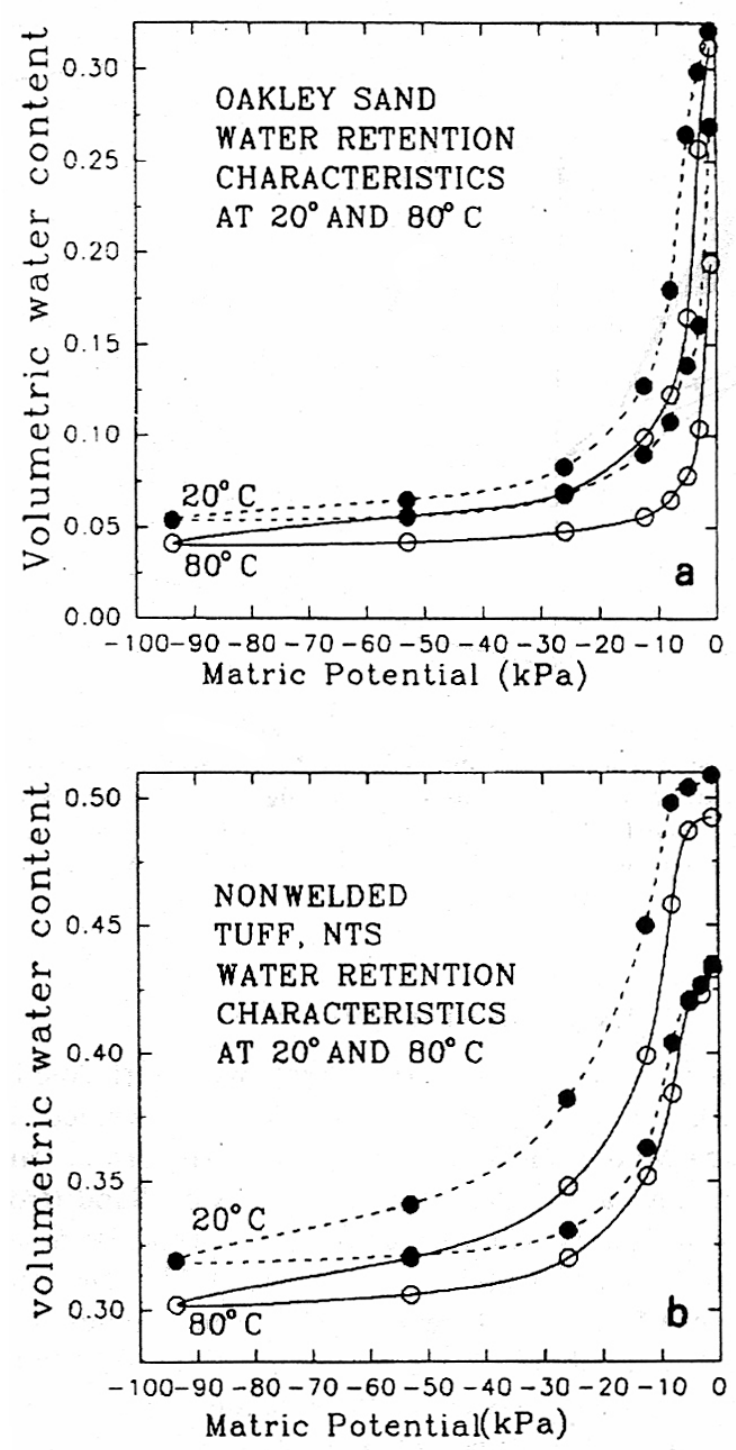

Source: Constantz 1991 [DIRS 174120], Figure 3.

Figure 6.3-12. Water Content (Expressed as Fraction, or $\mathrm{m}^{3} \mathrm{~m}^{-3}$ ) versus Matric Potential at $20^{\circ} \mathrm{C}$ and $80^{\circ} \mathrm{C}$ Hysteresis Curves for a Sand and a Nonwelded Tuff

The isobaric tests were conducted by determining water content at $20^{\circ} \mathrm{C}$, then $80^{\circ} \mathrm{C}$, and then back to $20^{\circ} \mathrm{C}$ at constant pressure to effect a drying-wetting cycle. Figure $6.3-13$ shows the results of these tests at four pressures $(-3 \mathrm{kPa},-5 \mathrm{kPa},-8 \mathrm{kPa}$, and $-12.5 \mathrm{kPa})$ for the sand, and three pressures $(-8 \mathrm{kPa},-12.5 \mathrm{kPa}$, and $-26 \mathrm{kPa})$ for the tuff. The drying part of the cycle, i.e., from $20^{\circ} \mathrm{C}$ to $80^{\circ} \mathrm{C}$, results in a significant reduction in water content, particularly at the lower pressures. However, for the wetting part of the cycle, i.e., from $80^{\circ} \mathrm{C}$ to $20^{\circ} \mathrm{C}$, results indicate that little water was reincorporated into the samples. This is as expected; the gain in water content from $80^{\circ} \mathrm{C}$ to $20^{\circ} \mathrm{C}$ represents only a few percent. 

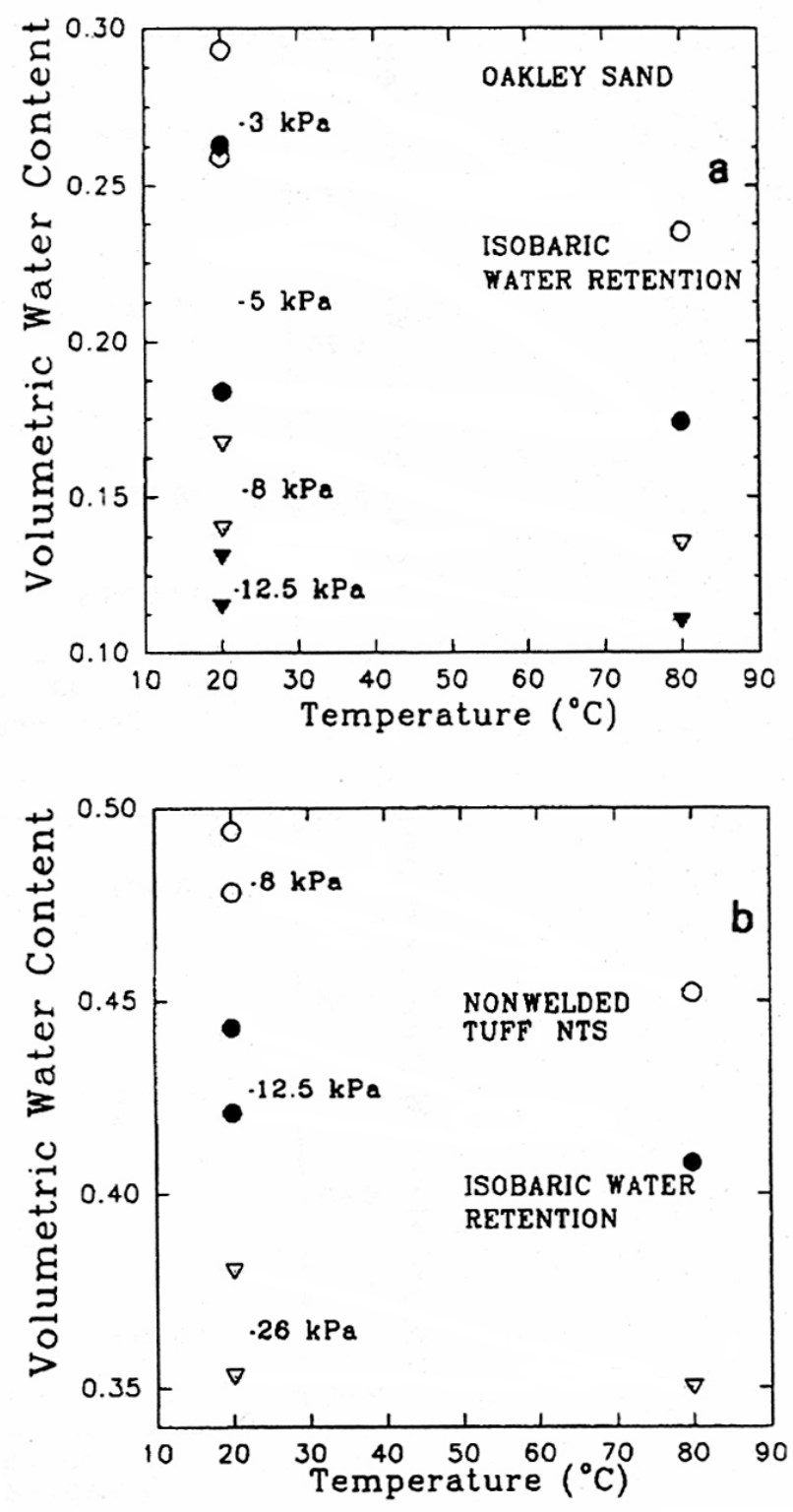

Source: Constantz 1991 [DIRS 174120], Figure 4.

NOTE: For each matric potential, water content was determined at $20^{\circ} \mathrm{C}$, then $80^{\circ} \mathrm{C}$, then again at $20^{\circ} \mathrm{C}$.

Figure 6.3-13. Water Content (Expressed as Fraction, or $\mathrm{m}^{3} \mathrm{~m}^{-3}$ ) versus Temperature at Constant Matric Potential for a Sand and a Nonwelded Tuff

During cooldown after the thermal period, humidity will rise and water will adsorb onto surfaces. The results of Constantz (1991 [DIRS 174120]) support the thesis that temperature has a small effect on water content near saturation, i.e., at low suction, high $R H$ conditions.

Experimental studies of water adsorption and soil water retention have been limited to RH values below about 98\%. This is due at least in some cases to difficulties with condensation in the experimental apparatus. For example, McCafferty and Zettlemoyer (1970 [DIRS 154382]) noted that their $25^{\circ} \mathrm{C}$ runs were limited to relative pressures $(\mathrm{RH})$ of about 0.7 due to condensation of 
water vapor in the dosing bulbs. The soils data from Or and Tuller (1999 [DIRS 173799]) presented in Figure 6.3-8 have a maximum RH of about 98\%. The Lee and Staehle (1997 [DIRS 104943]) data described above were obtained at maximum RH of about $95 \%$.

The transition from "water layer behavior" to "bulk liquid behavior" begins in the vicinity of the high RH values at which experimental difficulties with condensation begin to occur. However, the $\mathrm{RH}$ values at which porous media approach saturation are higher, well above $99 \%$. Two arguments support extrapolation of film thickness-scale water adsorption isotherms to high RH, with concomitant high saturation and bulk water behavior. First, the goodness of fit shown by the hematite water adsorption isotherm and the calculated soils isotherms (which are based on empirical retention curve data), shown in Figure 6.3-8, indicate that water behavior in corrosion products may be approximated by the water retention behavior of clays. Second, the goodness of fit of all cited data to similarly shaped isotherms adds confidence to the extrapolation of those isotherms to the high RH values where more generic porous medium behavior is exhibited.

\subsection{Hematite Water Vapor Adsorption Isotherm}

The isotherm for adsorption of water onto $\alpha-\mathrm{Fe}_{2} \mathrm{O}_{3}$, a form of hematite, has been extensively measured and reported in the literature (McCafferty and Zettlemoyer 1970 [DIRS 154382]; Jurinak 1964 [DIRS 154381]). Jurinak (1964 [DIRS 154381], p. 486) provides a functional relationship for the coverage (i.e., number of monolayers of water adsorbed) as a function of relative humidity based on the Frenkel-Halsey-Hill (FHH) equation for multilayer adsorption:

$$
\log _{10}\left(p_{w} / p_{w}^{\mathrm{o}}\right)=-\frac{k}{\left(V / V_{m}\right)^{s}},
$$

where

$$
\begin{aligned}
p_{w}= & \text { partial pressure of water }(\mathrm{Pa}) \\
p_{w}^{\circ}= & \text { vapor pressure of water }(\mathrm{Pa}) \\
k= & \text { FHH adsorption isotherm fitting parameter (dimensionless) } \\
s= & \text { FHH adsorption isotherm fitting parameter (dimensionless) } \\
V= & \text { volume of water vapor adsorbed at reference conditions }\left(\mathrm{m}^{3} \mathrm{H}_{2} \mathrm{O} \mathrm{kg}^{-1} \mathrm{Fe}_{2} \mathrm{O}_{3}\right) \\
V_{m}= & \text { volume of adsorbed water vapor that provides a one-monolayer coverage on the } \\
& \text { surface }\left(\mathrm{m}^{3} \mathrm{H}_{2} \mathrm{O} \mathrm{kg} \mathrm{Fe}_{2} \mathrm{O}_{3}\right) .
\end{aligned}
$$

The ratio of water vapor partial pressure to vapor pressure, sometimes referred to as the relative pressure, is the relative humidity (RH). The ratio of $V$ to $V_{m}$ is the number of monolayers of water (i.e., the number of layers of individual water molecules) adsorbed on the surface, assuming complete and uniform coverage. Letting $\theta_{a}=V / V_{m}$ and $R H=p_{w} / p_{w}^{0}$, and making use of the relationship to convert base 10 logarithms to natural logarithms $\left(\log _{10} R H=\log _{10} e^{\ln R H}=\ln R H \log _{10} e\right)$, Jurinak's correlation may be written in general terms with parameters $k$ and $s$ : 


$$
\ln (R H)=-\frac{k}{\theta_{a}^{s} \log _{10} e}
$$

or

$$
\theta_{a}=\left(\frac{k}{\log _{10} e}\right)^{\frac{1}{s}}[-\ln (R H)]^{-1 / s}
$$

For $\mathrm{Fe}_{2} \mathrm{O}_{3}, k=1.1$ and $s=2.45$ (Jurinak 1964 [DIRS 154381], p. 486):

$$
\ln (R H)=-2.53 \theta_{a}^{-2.45}
$$

or

$$
\theta_{a}=1.46[-\ln (R H)]^{-0.408}
$$

This isotherm is plotted in Figures 6.3-6 and 6.3-8.

Adsorption isotherms for goethite and HFO are shown in Figure 6.3-7 along with the isotherm for hematite from Jurinak. The isotherms for goethite and HFO are similar to the isotherm for hematite, which indicates that the hematite isotherm is suitable for representing the water adsorption behavior of the mixed assemblage of iron oxides that comprises the waste package corrosion products. For HFO, the amount of adsorbed water does not increase any further at high RH values; Hofmann et al. (2004 [DIRS 173783], p. 170) explain this by stating that the external surface area of the HFO aggregates is almost negligible.

The average thickness of a monolayer of water can be computed from the cross-sectional area of a water molecule. Values reported in the literature for the cross-sectional area of a water molecule range from about $10.5 \AA^{2}$ (Gregg and Sing 1982 [DIRS 153010], p. 188), corresponding to a "close-packed" monolayer of water, to $10.8 \AA^{2}$ (Jurinak 1964 [DIRS 154381]). Holmes et al. (1974 [DIRS 154379], p. 368) and McCafferty and Zettlemoyer (1970 [DIRS 154382], p. 453) assume a cross-sectional area of the water molecule of $10.6 \AA^{2}$. In this report, a value for the cross-sectional area of a water molecule of $A_{w}=10.6 \AA^{2}$ per molecule (McCafferty and Zettlemoyer 1970 [DIRS 154382], p. 454) is used. Using a water density at $25^{\circ} \mathrm{C}$ of $\rho_{w}=997.0449 \mathrm{~kg} \mathrm{~m}^{-3}$ (Weast 1985 [DIRS 111561], p. F-5), the thickness of a water monolayer film, $t_{f}$, is:

$$
\begin{aligned}
t_{f} & =\frac{M_{w}}{A_{w} \rho_{w} N_{A}} \\
& =\frac{18.01528 \times 10^{-3} \frac{\mathrm{kg}}{\mathrm{mol}}}{\left(10.6 \times 10^{-20} \frac{\mathrm{m}^{2}}{\mathrm{molec}}\right)\left(997.0449 \frac{\mathrm{kg}}{\mathrm{m}^{3}}\right)\left(6.02214199 \times 10^{23} \frac{\mathrm{molec}}{\mathrm{mol}}\right)} \\
& =2.83 \times 10^{-10} \mathrm{~m},
\end{aligned}
$$


where $N_{A}$ is Avogadro's number (Lide 2002 [DIRS 160832], p. 1-7), and $M_{w}$ is the molecular weight of water $\left(\mathrm{kg} \mathrm{mol}^{-1}\right)$. Using a water molecule cross-sectional area of $10.8 \AA^{2}$ would have a negligible effect, giving a monolayer thickness of $2.78 \times 10^{-10} \mathrm{~m}$.

At $50^{\circ} \mathrm{C}$, the density of water is $988.0363 \mathrm{~kg} \mathrm{~m}^{-3}$ (Weast 1985 [DIRS 111561], p. F-5) and the adsorbed water monolayer thickness is $2.86 \times 10^{-10} \mathrm{~m}$, which shows that the monolayer thickness sensitivity to temperature is small.

\subsection{Specific Surface Area of Metal Oxides}

Values for the specific surface area of $\alpha-\mathrm{Fe}_{2} \mathrm{O}_{3}$ (hematite) shown in Table 6.3-7 range from 1.8 to $21.4 \mathrm{~m}^{2} \mathrm{~g}^{-1}$. At the low end is "natural" hematite, with a specific surface area of $1.8 \mathrm{~m}^{2} \mathrm{~g}^{-1}$ (Langmuir 1997 [DIRS 100051], Table 10.2). At the high end is a sample of $\mathrm{Fe}_{2} \mathrm{O}_{3}$ used in an analysis of its catalytic activity (Briand et al. 2001 [DIRS 161617], Table 4). Morimoto et al. (1969 [DIRS 162877], Table I) and Tamura et al. (1999 [DIRS 161625], Table 1) each report two values for $\mathrm{Fe}_{2} \mathrm{O}_{3}$ samples prepared by different methods that differ by factors of 1.5 and 2.8 , respectively. These results illustrate how the method of preparation can have a large effect on the specific surface area of a material. Gregg and Sing (1982 [DIRS 153010], p. 188) report surface area measurements of a material identified only as "iron oxide" by mercury porosimetry and by nitrogen adsorption.

Jurinak (1964 [DIRS 154381], p. 480) measured surface area of $\mathrm{Fe}_{2} \mathrm{O}_{3}$ by nitrogen adsorption ranging from 9.60 to $9.70 \mathrm{~m}^{2} \mathrm{~g}^{-1}$, whereas water adsorption surface areas ranged from 6.52 to $9.10 \mathrm{~m}^{2} \mathrm{~g}^{-1}$. It was concluded that about one-third of the $\mathrm{Fe}_{2} \mathrm{O}_{3}$ is covered with chemisorbed water that, unless removed by activation (i.e., heating to at least $425^{\circ} \mathrm{C}$ ), blocks water adsorption sites on the surface. The latter value $\left(9.10 \mathrm{~m}^{2} \mathrm{~g}^{-1}\right)$ is used in sample calculations in the EBS RT Abstraction, because it is consistent with the water adsorption isotherm of Jurinak that is used. The value of $10.0 \mathrm{~m}^{2} \mathrm{~g}^{-1}$ reported by McCafferty and Zettlemoyer (1970 [DIRS 154382], p. 453) is close to that of Jurinak and is consistent with their water adsorption isotherm, which is used in Section 7.2.1 to corroborate the isotherm of Jurinak (1964 [DIRS 154381]). 
Table 6.3-7. Specific Surface Area of $\mathrm{Fe}_{2} \mathrm{O}_{3}$

\begin{tabular}{|c|l|}
\hline Specific Surface Area $\left(\mathbf{~}^{\mathbf{2}} \mathbf{~}^{-\mathbf{1}}\right)$ & \multicolumn{1}{|c|}{ Source } \\
\hline 1.8 & Langmuir 1997 [DIRS 100051], Table 10.2 (natural hematite) \\
\hline 3.1 & Langmuir 1997 [DIRS 100051], Table 10.2 (synthetic hematite) \\
\hline 5.60 & Tamura et al. 1999 [DIRS 161625], Table 1 (Grignard method) \\
\hline 9.1 & Jurinak 1964 [DIRS 154381], p. 480 \\
\hline 10 & McCafferty and Zettlemoyer 1970 [DIRS 154382], p. 453 \\
\hline $13.3-14.3$ & Gregg and Sing 1982 [DIRS 153010], Table 3.17 \\
\hline 14.5 & $\begin{array}{l}\text { Morimoto et al. 1969 [DIRS 162877], Table I (treated at 250 } \\
\text { calcinations of FeSO from }\end{array}$ \\
\hline 15.9 & Tamura et al. 1999 [DIRS 161625], Table 1 ( $\mathrm{NaOH}_{2}$ method) \\
\hline 21.2 & $\begin{array}{l}\text { Morimoto et al. 1969 [DIRS 162877], Table I (treated at 250 }{ }^{\circ} \mathrm{C} ; \text { from } \\
\text { calcinations of } \alpha-F e O O H)\end{array}$ \\
\hline 21.4 & Briand et al. 2001 [DIRS 161617], Table 4 \\
\hline &
\end{tabular}

The specific surface areas of some other waste package component corrosion products are shown in Table 6.3-8 for comparison with hematite. Except for the iron oxyhydroxides (goethite and HFO), which can have exceptionally large specific surface areas, most corrosion products exhibit adsorption characteristics similar to those of hematite.

Table 6.3-8. Specific Surface Area of Various Waste Package Corrosion Products

\begin{tabular}{|c|c|c|}
\hline $\begin{array}{c}\text { Corrosion } \\
\text { Product }\end{array}$ & $\begin{array}{l}\text { Specific Surface } \\
\text { Area }\left(\mathrm{m}^{2} \mathrm{~g}^{-1}\right)\end{array}$ & Source \\
\hline Goethite & $14.7-110$ & See Table 4.1-10 \\
\hline $\mathrm{HFO}$ & 600 & $\begin{array}{l}\text { Dzombak and Morel } 1990 \text { [DIRS 105483], } \\
\text { Table } 5.3\end{array}$ \\
\hline \multirow[t]{3}{*}{$\mathrm{Cr}_{2} \mathrm{O}_{3}$} & 3.0 & Briand et al. 2001 [DIRS 161617], Table 4 \\
\hline & 1.09 & Tamura et al. 1999 [DIRS 161625], Table 1 \\
\hline & 12.0 & Nagao et al. 1995 [DIRS 162878], p. 222 \\
\hline \multirow[t]{2}{*}{$\mathrm{NiO}$} & 1.1 & Briand et al. 2001 [DIRS 161617], Table 4 \\
\hline & 22.4 & $\begin{array}{l}\text { Matsuda et al. } 1992 \text { [DIRS 154383], p. } 1839 \\
\text { [for NiO(II)] }\end{array}$ \\
\hline $\mathrm{CoO}$ & 0.4 & Briand et al. 2001 [DIRS 161617], Table 4 \\
\hline $\mathrm{MoO}_{3}$ & 5.0 & Briand et al. 2001 [DIRS 161617], Table 4 \\
\hline $\begin{array}{l}\mathrm{UO}_{2} \\
(\mathrm{SNF})\end{array}$ & 0.4 & $\begin{array}{l}\text { BSC } 2004 \text { [DIRS 172453], Table 6-9 (Group } \\
\text { 8b) }\end{array}$ \\
\hline $\mathrm{TiO}_{2}$ & 9.94 & Morimoto et al. 1969 [DIRS 162877], Table I \\
\hline \multirow[t]{2}{*}{$\mathrm{ZrO}_{2}$} & 14.5 & $\begin{array}{l}\text { Holmes et al. } 1974 \text { [DIRS 154379], p. 368; } \\
\text { average of } 2 \text { values }\end{array}$ \\
\hline & 39.0 & Briand et al. 2001 [DIRS 161617], Table 4 \\
\hline
\end{tabular}




\subsection{Interior Surface Area, Volume, and Porosity of 21-PWR Waste Package}

The internal surface area of an as-emplaced waste package (i.e., in an undegraded state) containing CSNF can be approximated given the dimensions and numbers of fuel rods, baskets, side guides, and other support components. Since the surface area will increase by orders of magnitudes as the waste package components degrade, the initial surface area is useful only as a bounding value, but one that can be estimated accurately (unlike the surface area of corrosion products). Typical measurements for a 21-PWR waste package are used (BSC 2004 [DIRS 169472], Table 1). The surface areas of fuel assembly spacer grids and end connections are ignored. The total internal surface area of a 21-PWR waste package as emplaced is approximately $1061 \mathrm{~m}^{2}$. The surface area of basket components is computed as shown in Table 6.3-9 (footnote h) by dividing the total mass of each component by the density of the material (which gives the volume of material), then dividing by the thickness of the component. This results in the area of component material as though it were a plate, ignoring the area of edges. To account for both sides of the component being exposed to air and able to adsorb water, the area is multiplied by two.

The calculation of pore volume for a CSNF waste package is also summarized in Table 6.3-9. From these results, the initial porosity of a $21-\mathrm{PWR}$ waste package is $5.62 / 9.62=0.58$.

Table 6.3-9. Characteristics of a 21-PWR Waste Package

\begin{tabular}{|c|c|c|c|c|c|c|}
\hline Component & Dimensions $^{a}$ & $\begin{array}{c}\text { Qty. in } \\
\text { WP }^{\mathrm{b}}\end{array}$ & $\begin{array}{c}\text { Mass }^{b} \\
(\mathrm{~kg})\end{array}$ & $\begin{array}{l}\text { Density } \\
\left(\mathrm{kg} \mathrm{m}^{-3}\right)\end{array}$ & $\begin{array}{c}\text { Total } \\
\text { Surface } \\
\text { Area }\left(\mathrm{m}^{2}\right) \\
\end{array}$ & $\begin{array}{c}\text { Total } \\
\text { Volume } \\
\left(\mathrm{m}^{3}\right)\end{array}$ \\
\hline Fuel Rods & $\begin{array}{l}0.94996 \mathrm{~cm} \mathrm{OD}^{\mathrm{c}} ; \\
384.962 \mathrm{~cm} \text { length }\end{array}$ & 5,544 & - & - & 636.93 & 1.513 \\
\hline Basket Side Guide & $9.525 \mathrm{~mm}$ thickness & 16 & 24.9 & $7,850^{d}$ & $10.66^{\mathrm{h}}$ & 0.051 \\
\hline Basket Side Guide Stiffener & $9.525 \mathrm{~mm}$ thickness & 32 & 0.615 & $7,850^{d}$ & $0.53^{h}$ & 0.003 \\
\hline Basket End Side Guide & $9.525 \mathrm{~mm}$ thickness & 32 & 32.7 & $7,850^{d}$ & $27.99^{h}$ & 0.133 \\
\hline Basket End Guide Stiffener & $9.525 \mathrm{~mm}$ thickness & 64 & 1.38 & $7,850^{d}$ & $2.36^{\mathrm{h}}$ & 0.011 \\
\hline Basket Corner Guide & $9.525 \mathrm{~mm}$ thickness & 16 & 40.1 & $7,850^{d}$ & $17.16^{\mathrm{h}}$ & 0.082 \\
\hline Basket Corner Guide Stiffener & $9.525 \mathrm{~mm}$ thickness & 32 & 2.07 & $7,850^{d}$ & $1.77^{\mathrm{h}}$ & 0.008 \\
\hline Fuel Basket A-Plate & $7 \mathrm{~mm}$ thickness & 8 & 86.8 & $7,760^{\mathrm{e}}$ & $25.57^{h}$ & 0.089 \\
\hline Fuel Basket B-Plate & $7 \mathrm{~mm}$ thickness & 8 & 86.8 & $7,760^{\mathrm{e}}$ & $25.57^{h}$ & 0.089 \\
\hline Fuel Basket C-Plate & $7 \mathrm{~mm}$ thickness & 16 & 45.8 & $7,760^{\mathrm{e}}$ & $26.98^{h}$ & 0.094 \\
\hline Fuel Basket D-Plate & $6.35 \mathrm{~mm}$ thickness & 8 & 27.4 & $2,700^{f}$ & $25.57^{h}$ & 0.081 \\
\hline Fuel Basket E-Plate & $6.35 \mathrm{~mm}$ thickness & 8 & 27.4 & $2,700^{f}$ & $25.57^{h}$ & 0.081 \\
\hline Basket Tube & $\begin{array}{l}\text { 4,572 } \mathrm{mm} \text { length }{ }^{\prime} ; \\
231.648 \mathrm{~mm}^{\mathrm{m}} \text { interior } \\
\text { dimension }^{\mathrm{k}} ; \\
241.173 \mathrm{~mm}^{\mathrm{m}} \text { exterior } \\
\text { dimension }^{\mathrm{m}} \\
\end{array}$ & 21 & 159 & $7,850^{d}$ & 181.59 & 0.425 \\
\hline $\begin{array}{l}\text { Inner Vessel, } \\
\text { including Lower Lid }\end{array}$ & 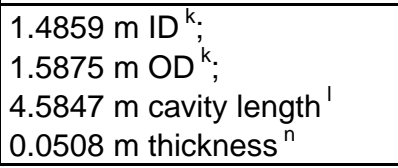 & 1 & 9,920 & $7,980^{9}$ & 49.10 & 1.243 \\
\hline Inner Lid & $\begin{array}{l}1.4859 m \text { vessel ID }^{k} \\
0.0508 m \text { thickness }^{n}\end{array}$ & 1 & 739 & $7,980^{\mathrm{g}}$ & 3.37 & 0.093 \\
\hline Interface ring & $\begin{array}{l}1.5875 \mathrm{~m} \mathrm{OD}^{\mathrm{k}} \\
0.0302 \mathrm{~m}^{\mathrm{m}} \text { thickness } \\
0.0302 \mathrm{~m}^{\mathrm{n}} \text { estimated } \text { width }^{\circ}\end{array}$ & 1 & 35.6 & $7,980^{g}$ & 0.59 & 0.004 \\
\hline
\end{tabular}


Table 6.3-9. Characteristics of a 21-PWR Waste Package (Continued)

\begin{tabular}{|c|c|c|c|c|c|c|}
\hline Component & Dimensions $^{a}$ & $\begin{array}{l}\text { Qty. in } \\
\text { WP }\end{array}$ & $\begin{array}{c}\text { Mass }^{b} \\
(\mathrm{~kg})\end{array}$ & $\begin{array}{l}\text { Density } \\
\left(\mathrm{kg} \mathrm{m}^{-3}\right)\end{array}$ & $\begin{array}{c}\text { Total } \\
\text { Surface } \\
\text { Area }\left(\mathrm{m}^{2}\right) \\
\end{array}$ & $\begin{array}{c}\text { Total } \\
\text { Volume } \\
\left(\mathrm{m}^{3}\right)\end{array}$ \\
\hline Spread Ring & $\begin{array}{l}1.4859 \mathrm{~m} \mathrm{ID}^{\mathrm{n}} ; \\
0.0222 \mathrm{~m} \text { thickness }^{\mathrm{n}} \\
0.0302 \mathrm{~m} \text { width }^{\mathrm{n}}\end{array}$ & 1 & 25.5 & $7,980^{9}$ & 0.56 & 0.003 \\
\hline Total Surface Area & & & & & 1,061 & - \\
\hline Total Volume $^{i}$ & & & & & - & 9.622 \\
\hline Total Solids Volume & & & & & - & 4.005 \\
\hline Total Void Volume & & & & & - & 5.617 \\
\hline
\end{tabular}

a Thicknesses from BSC 2004 [DIRS 169472], Table 2.

b Quantity (number) and mass of components in a 21-PWR waste package from BSC 2004 [DIRS 169472 ], Table 2.

c DOE 1992 [DIRS 102588], Volume 1, p. 2A-30. 264 rods/assembly. W1717WL chosen as average assembly.

d ASTM A 20/A20M-99a [DIRS 147578] (A 516 carbon steel).

e Kügler 1996 [DIRS 107760], p. 17 (Neutronit A 978).

f ASTM G 1-90 [DIRS 103515], p. 7, Table X1.1 (Al 6061).

${ }^{g}$ ASTM G 1-90 [DIRS 103515], p. 8, Table X1.1 (316 stainless steel).

h Surface Area $=2 \mathrm{mN} /(\rho \Delta \mathrm{x}) ; \mathrm{m}=$ mass $(\mathrm{kg}) ; \mathrm{N}=$ quantity; $\rho=$ density $\left(\mathrm{kg} \mathrm{m}^{-3}\right) ; \Delta \mathrm{x}=$ thickness (m); "2" accounts for 2 sides of a plate; edges ignored.

1 Volume enclosed by Alloy 22 outer corrosion barrier having an inside diameter of $1.597 \mathrm{~m}$ (BSC 2004 [DIRS 166953], Section B-B) and inside length of $4.80374 \mathrm{~m}=5,024.4 \mathrm{~mm}$ (total length, BSC 2004 [DIRS 166953], Section A-A) - $25.4 \mathrm{~mm}$ (lid lifting device thickness, BSC 2004 [DIRS 167394], Detail C) $101.6 \mathrm{~mm}$ (bottom skirt, BSC 2004 [DIRS 167394], Detail B) - $25.4 \mathrm{~mm}$ (top outer lid thickness, BSC 2004 [DIRS 167394], Detail A) - 25.4 m (bottom outer lid thickness, BSC 2004 [DIRS 167394], Detail B) - 30.16 mm (middle lid to outer lid gap, BSC 2004 [DIRS 167394], Detail A) - 12.7 mm (middle lid, BSC 2004 [DIRS 167394], Detail A).

j Except for fuel rod volume, Volume $=\mathrm{mN} / \rho$. See footnote $\mathrm{h}$ for nomenclature.

k BSC 2004 [DIRS 166953], Section B-B.

I BSC 2004 [DIRS 166953], Section A-A.

${ }^{m}$ Outside dimension $=$ inside dimension $+2 \times$ thickness $=9.12$ in. (BSC 2004 [DIRS 166953], Section B-B) + $2 \times 3 / 16$ in(BSC 2004 [DIRS 169472], Table 2) $=231.648 \mathrm{~mm}+2(4.7625 \mathrm{~mm})=241.173 \mathrm{~mm}$.

${ }^{n}$ BSC 2004 [DIRS 167394], Details A and B.

${ }^{\circ}$ Estimate based on apparent square cross section in BSC 2004 [DIRS 167394], Detail B.

ID = inside diameter; OD = outside diameter; $\mathrm{WP}=$ waste package.

An estimate of the waste package porosity in a fully degraded state can be obtained using the total potential equivalent mass of $\mathrm{Fe}_{2} \mathrm{O}_{3}$ in a 21-PWR from the corrosion of non-SNF components as shown in Table 6.3-4. Using the density of $\mathrm{Fe}_{2} \mathrm{O}_{3}$ of $5240 \mathrm{~kg} \mathrm{~m}^{-3}$ from Weast (1985 [DIRS 111561], p. B-104), the 19,440 kg equivalent mass of corrosion products from the iron comprising the steel internal components has a volume of:

$$
\frac{19440 \mathrm{~kg} \mathrm{Fe}_{2} \mathrm{O}_{3}}{5240 \frac{\mathrm{kg} \mathrm{Fe} \mathrm{O}_{3}}{\mathrm{~m}^{3} \mathrm{Fe}_{2} \mathrm{O}_{3}}}=3.710 \mathrm{~m}^{3} \mathrm{Fe}_{2} \mathrm{O}_{3} .
$$

The internal volume of a 21-PWR waste package outer corrosion barrier, with an inside diameter of $1.597 \mathrm{~m}$ and length of $4.8037 \mathrm{~m}$, is $9.622 \mathrm{~m}^{3}$ (from Table 6.3-9). The 5,544 fuel rods have a total volume of $1.513 \mathrm{~m}^{3}$. Then the void volume that can be occupied by corrosion products is $8.109 \mathrm{~m}^{3}$, and the bulk porosity of the corrosion products, if distributed throughout the interior of the waste package, is $1-(3.710 / 8.109)=0.54$. The bulk porosity of the fully degraded 
internal components within the waste package outer corrosion barrier, where the solids consist of the fuel rods and $\mathrm{Fe}_{2} \mathrm{O}_{3}$, is $1-(3.710+1.513) / 9.622=0.46$.

Another approach to estimating the waste package porosity in a fully degraded state includes the nonferrous constituents of the steel components, which are not included in the 19,440 $\mathrm{kg}$ of $\mathrm{Fe}_{2} \mathrm{O}_{3}$ corrosion products in a 21-PWR in Table 6.3-4. The mass of these constituents in a 21-PWR is 4,920 kg (from Table 6.3-4). As seen in Table 4.1-14, the bulk of the nonferrous constituents is chromium and nickel, which comprise 18 percent and 14 percent, respectively, of 316 stainless steel (DTN: MO0003RIB00076.000 [DIRS 153044]), so the nonferrous portion can be approximately considered to be composed of just these two metals, proportioned as 56 weight percent $\mathrm{Cr}$ and 44 weight percent $\mathrm{Ni}$. These metals will corrode to form $\mathrm{Cr}_{2} \mathrm{O}_{3}$, having a density of $5,220 \mathrm{~kg} / \mathrm{m}^{3}$ (Lide 2000 [DIRS 162229], p. 4-54) and a molecular weight of $0.151990 \mathrm{~kg} / \mathrm{mol}$ (Lide 2000 [DIRS 162229], p. 4-54), and $\mathrm{NiO}$, having a density of $6,720 \mathrm{~kg} / \mathrm{m}^{3}$ (Lide 2000 [DIRS 162229], p. 4-75) and a molecular weight of $0.074692 \mathrm{~kg} / \mathrm{mol}$ (Lide 2000 [DIRS 162229], p. 4-75). These two metals, when fully oxidized, will occupy $1.181 \mathrm{~m}^{3}$ of volume within the outer corrosion barrier. Then the bulk porosity of the fully degraded internal components within the waste package outer corrosion barrier, where the solids consist of the fuel rods, $\mathrm{Fe}_{2} \mathrm{O}_{3}, \mathrm{Cr}_{2} \mathrm{O}_{3}$, and $\mathrm{NiO}$, is: $1-(3.710+1.513+1.181) / 9.622=0.33$. The porosity of corrosion products themselves, $\mathrm{Fe}_{2} \mathrm{O}_{3}$, $\mathrm{Cr}_{2} \mathrm{O}_{3}$, and $\mathrm{NiO}$ distributed among the fuel rods, is: $1-(3.710+1.181) / 8.109=0.40$.

The various approaches in this section to estimating the bulk porosity of waste package corrosion products result in porosities ranging from 0.33 to 0.54 . For comparison, the porosity of unconsolidated geologic materials ranges from 0.25 to 0.70 (Freeze and Cherry 1979 [DIRS 101173], Table 2.4).

Lamination and flaking of corrosion products is expected to redistribute this material within the waste package pore space (Knight 1982 [DIRS 106733], p. 50), rather than leave it uniformly distributed throughout the waste package void volume. If the oxide settles to the bottom of a waste package, the physical geometry of the granular iron oxide that has settled can be represented by that of tightly packed sand, which has a solid content of 58 percent (Brown and Richards 1970 [DIRS 131479], Table 2.2), or a porosity of 0.42 (CRWMS M\&O 1997 [DIRS 102824], p. 29). This value (0.42) for corrosion products porosity within a waste package has been used in criticality studies (CRWMS M\&O 1997 [DIRS 102824], p. 29) and in an independent performance assessment of the Yucca Mountain repository (EPRI 2000 [DIRS 154149], p. 6-21 to 6-22). A porosity of 0.4 has been used in other criticality studies (YMP 1998 [DIRS 104441], p. C-23 to C-25) and in a model of diffusive releases from breached waste packages (Lee et al. 1996 [DIRS 100913], p. 5-67). Although some uncertainty exists and small-scale variability is likely, for the waste package as a whole, a fixed value of 0.4 is used for the porosity of corrosion products in TSPA-LA.

The calculations just discussed do not account for water adsorbed on the spent fuel itself because this water constitutes the "rind" water (i.e., water in the conceptual waste form domain). The rind water does not directly affect diffusion to the exterior of the waste package because the fuel is the source, rather than part of the corrosion products that comprise the diffusive path to the exterior. 
The surface area inside a waste package can be computed as a function of time, if the degradation rates of the basket components and the stainless steel inner vessel are known. The calculation is complicated by the different compositions of each component of the waste package. Spatial variability in degradation rates due to variations in accessibility to water vapor further complicate the picture. However, an average corrosion rate for a 21-PWR waste package provides a reasonable approximation from which surface areas and quantities of adsorbed water can be computed.

The complete degradation of a 21-PWR waste package gives an estimated upper bound on the surface area available for adsorption. The total amount of $\mathrm{Fe}_{2} \mathrm{O}_{3}$ in a 21-PWR waste package (from Table 6.3-4) is $19,440 \mathrm{~kg} \mathrm{Fe}_{2} \mathrm{O}_{3}$. Using a specific surface area of $9.1 \mathrm{~m}^{2} \mathrm{~g}^{-1}$ for the oxide (Jurinak 1964 [DIRS 154381], p. 480), the estimated upper bound for total surface area for adsorption in a 21-PWR waste package is $1.8 \times 10^{8} \mathrm{~m}^{2} /$ package.

The corrosion rates for the two types of steel are known with some uncertainty, as shown by the data presented in Table 4.1-1 for carbon steel and for stainless steel (DTN: MO0409SPAACRWP.000 [DIRS 172059]). The data set used is for corrosion rates at $60^{\circ} \mathrm{C}$ in simulated dilute well $\mathrm{J}-13$ water. The average corrosion rate for carbon steel is $77.43 \mu \mathrm{m} \mathrm{yr}^{-1}$, with a standard deviation of $8.83 \mu \mathrm{m} \mathrm{yr}^{-1}$ (DTN: MO0409SPAACRWP.000 [DIRS 172059]). An empirical cumulative distribution function developed in DTN: MO0409SPAACRWP.000 [DIRS 172059] is used for parameter CS_Corrosion_Rate to be sampled in TSPA-LA. The TSPA-LA implementation in GoldSim requires that the cumulative distribution functions (CDFs) cover the entire range of probabilities of 0.0 to 1.0. To accommodate this, another row for the zero-th percentile is added using a corrosion rate that is slightly lower than the minimum in the empirical cumulative distribution function (ECDF); this row is $65.76 \mu \mathrm{m} \mathrm{yr}^{-1}$ and zero probability.

The mean corrosion rate for Stainless Steel Type $316 \mathrm{~L}$ is $0.248 \mu \mathrm{m} \mathrm{yr}^{-1}$, with a standard deviation of $0.146 \mu \mathrm{m} \mathrm{yr}^{-1}$ (DTN: MO0409SPAACRWP.000 [DIRS 172059]). The data set used is for corrosion rates in fresh water for the temperature range of $50^{\circ} \mathrm{C}$ to $100^{\circ} \mathrm{C}$. An ECDF developed in DTN: MO0409SPAACRWP.000 [DIRS 172059] is used for parameter SS_Corrosion_Rate to be sampled in TSPA-LA. As with carbon steel, the TSPA-LA implementation in GoldSim requires that the CDFs cover the entire range of probabilities of 0.0 to 1.0. To accommodate this, another row for the zero-th percentile is added using a corrosion rate that is slightly lower than the minimum in the ECDF; this row is $0.03699 \mu \mathrm{m} \mathrm{yr}^{-1}$ and zero probability.

From these rates and the thicknesses of the steel components, the lifetime of each type of steel is computed. From Table 6.3-4 above, carbon steel comprises about one-third of the total mass of steel in a CSNF waste package (30 percent in a 21-PWR; 33 percent in a 44-BWR). Based on this fraction, the surface area is interpolated over time. The implementation of this interpolation scheme in TSPA-LA is presented in Section 6.5.3.2.

Although this interpolation provides a reasonable means for approximating the surface area of the interior of a waste package over time as it degrades, there is still uncertainty as to the actual surface area. The corrosion rates themselves are uncertain. In addition, many factors affect the surface area of the corrosion products. The chemical and physical conditions under which 
corrosion takes place impacts the morphology of the corrosion products. Seismic occurrences and collapse of the internal components as they degrade will affect the surface area. The hematite samples used in adsorption isotherm measurements are typically finely ground and highly purified, and have a higher specific surface area than typical corrosion products. At the same time, the morphology of corrosion products inside a waste package over the course of thousands of years is uncertain so specific surface areas higher than purified hematite are possible.

Therefore, when the surface area of the corrosion products is computed, it is justifiable to factor in this uncertainty by using a sampled specific surface area for corrosion products, ranging from $1.0 \mathrm{~m}^{2} \mathrm{~g}^{-1}$ to $22 \mathrm{~m}^{2} \mathrm{~g}^{-1}$, which encompasses the range of measured specific surface areas of hematite listed in Table 6.3-7. This range is large enough to reflect the uncertainty in the condition of the corrosion products. It reflects the uncertainty observed in measurements of the specific surface area of hematite (Table 6.3-7), as well as the fact that iron oxides do not adhere to the metal surface and may slough off in a finely divided state. Swelling as oxygen is incorporated into the crystal structure may provide a mechanism for breaking up the corrosion products more finely. Under certain conditions, iron oxyhydroxide colloid particles $(0.001$ to $1 \mu \mathrm{m}$ ) having a potentially enormous surface area (up to $720 \mathrm{~m}^{2} \mathrm{~g}^{-1}$; DTN: SN0309T0504103.010 [DIRS 165540]; BSC 2004 [DIRS 170025], Section 6.3.3.2) may form in the waste package (BSC 2004 [DIRS 170025], Section 6.3.1.3). At the same time, in such a static environment as an enclosed waste package, where, as is the case here, no water is flowing through the waste package to stir up or erode the corrosion products, it is unlikely that such finely divided materials will form. The range attempts to account for the absence of mechanisms that actively break up the mass of corrosion products, the lack of water with which to suspend and move particles apart, and the possibility that swelling against enclosures may agglomerate particles into low-surface-area masses.

\subsection{Diffusion Coefficient in Corrosion Products}

The rate of diffusion of radionuclide species $i, q_{i}\left(\mathrm{~kg} i \mathrm{~s}^{-1}\right)$, through corrosion products to the exterior of a waste package is given by:

$$
\begin{aligned}
q_{i} & =-\phi S_{w} D_{s} A \frac{\partial C_{i}}{\partial x} \\
& \approx-\phi S_{w} D_{s} A \frac{\Delta C_{i}}{\Delta x}
\end{aligned}
$$

where

$$
\begin{aligned}
& D_{s}=\text { effective diffusion coefficient }\left(\mathrm{m}^{2} \mathrm{~s}^{-1}\right) \\
& \phi=\text { porosity }\left(\mathrm{m}^{3} \text { void volume } \mathrm{m}^{-3} \text { bulk volume }\right) \\
& S_{w}=\text { water saturation }\left(\mathrm{m}^{3} \text { water volume } \mathrm{m}^{-3} \text { void volume }\right) \\
& A=\text { cross-sectional area of the diffusive pathway }\left(\mathrm{m}^{2}\right) \\
& C_{i}=\text { concentration of the radionuclide }\left(\mathrm{kg} \mathrm{m}^{-3}\right) \\
& x=\text { length of the diffusive pathway }(\mathrm{m})
\end{aligned}
$$


The effective diffusion coefficient, $D_{s}$, as defined and used in this section, implicitly includes the effects of tortuosity. The area used for TSPA-LA calculations depends on the scenario class and is presented in Section 6.5.3.1. The length of the diffusive path is also variable because the radionuclide sources may develop at random locations within a waste package, and the path length will depend on the geometry of the film connecting the source to a breach. Finally, the effective diffusion coefficient itself depends on the complex interactions of source term composition, water chemistry, porosity, water saturation, and temperature, none of which can be characterized in a deterministic fashion. Thus, each term in the above equation- $A, \Delta x$, and parameters affecting $D_{s}$ and $S_{w}$-needs to be sampled or specified for each modeling case, and a reasonable range and distribution for each has to be determined. All terms are interrelated through the geometry used for the waste package interior, and all are effectively a function of relative humidity and time.

In CSNF waste packages, the water saturation in the corrosion products is set to 1.0 in a seep environment. In a no-seep environment, the effective water saturation in the corrosion products in CSNF waste packages results from adsorbed water, as described in the rest of this section. In CDSP waste packages, the water saturation in the corrosion products is set to 1.0 in both a seep and no-seep environment.

Archie's law, discussed in Section 6.3.4.1.1, gives the diffusion coefficient as a function of porosity and saturation in a partly saturated, granular medium as:

$$
\phi S_{w} D_{s}=D_{0} \phi^{1.3} S_{w}^{2}
$$

where $D_{0}$ is the free water diffusion coefficient $\left(\mathrm{m}^{2} \mathrm{~s}^{-1}\right)$. The diffusion coefficient $D_{s}$ again is an effective value that implicitly includes the effect of tortuosity in a porous medium. The exponents in Archie's law are typical values, and will vary for different materials (Bear 1988 [DIRS 101379], p. 116). Whereas exponents of 1.863 are used for invert materials, based on experimental measurements of diffusion coefficients for crushed rock, the typical values (1.3 and 2) are used throughout this section to estimate in-package diffusion coefficients for corrosion products.

The effective water saturation within the corrosion products, $S_{w e, C P}$, can be obtained as a function of $R H$ by dividing the water volume by the pore volume of the corrosion products. The water volume is given by the adsorbed water film thickness multiplied by the surface area covered by water. The film thickness is $t_{f} \theta_{a}$, where $t_{f}$ is the thickness of a water monolayer (Equation 6.3.4.3.2-6), and $\theta_{a}$ is the number of monolayers of coverage, a function of $R H$. The porosity of corrosion products is $\phi_{C P}$.

The surface area of the corrosion products $\left(\mathrm{m}^{2} \mathrm{Fe}_{2} \mathrm{O}_{3}\right)$, given by:

$$
\begin{aligned}
s_{C P} & =m_{C P} \bar{s}_{C P} \\
& =\rho_{F e O x} V_{C P} \bar{s}_{C P}\left(\frac{1-\phi_{C P}}{\phi_{C P}}\right) .
\end{aligned}
$$


In this equation, $m_{C P}$ is the mass of corrosion products $\left(\mathrm{kg} \mathrm{Fe}_{2} \mathrm{O}_{3}\right), \bar{s}_{C P}$ is the specific surface area $\left(\mathrm{m}^{2} \mathrm{~kg}^{-1}\right), \rho_{\mathrm{FeOx}}$ is the solid density of $\mathrm{Fe}_{2} \mathrm{O}_{3}\left(\mathrm{~kg} \mathrm{Fe}_{2} \mathrm{O}_{3} \mathrm{~m}^{-3}\right)$, and $V_{C P}$ the pore volume of the corrosion products $\left(\mathrm{m}^{3}\right)$. The factor $\left(1-\phi_{C P}\right) / \phi_{C P}$ is the ratio of solids volume to void volume within the bulk volume of corrosion products, which is multiplied by $\rho_{F e O x} V_{C P}$ to give the mass of solids, $m_{C P}$. The ratio of surface area to pore volume of the corrosion products can be expressed as:

$$
\frac{s_{C P}}{V_{C P}}=\rho_{F e O x} \bar{s}_{C P}\left(\frac{1-\phi_{C P}}{\phi_{C P}}\right)
$$

Using a solid density for $\mathrm{Fe}_{2} \mathrm{O}_{3}$ of $\rho_{F e O x}=5,240 \mathrm{~kg} \mathrm{~m}^{-3}$ (Weast 1985 [DIRS 111561], p. B-104), the monolayer thickness $\left(t_{f}\right)$ of $2.86 \times 10^{-10} \mathrm{~m}$ (from Equation 6.3.4.3.2-6) with the density of water at $50^{\circ} \mathrm{C}\left(\rho_{w}\right)$ of $988.0363 \mathrm{~kg} \mathrm{~m}^{-3}$ (Weast 1985 [DIRS 111561], p. F-5), the number of monolayers of water $\left(\theta_{a}\right)$ given by Equation 6.3.4.3.2-5, the specific surface area of corrosion products $\left(\bar{s}_{C P}\right)$ in units of $\mathrm{m}^{2} \mathrm{~kg}^{-1}$, and a porosity for corrosion products $\left(\phi_{C P}\right)$ of 0.4 (Section 6.3.4.3.4), the effective water saturation of the corrosion products is given by:

$$
\begin{aligned}
S_{w e, C P} & =\frac{s_{C P}}{V_{C P}} t_{f} \theta_{a} \\
& =\rho_{F e O x} \bar{s}_{C P} t_{f}\left(\frac{1-\phi_{C P}}{\phi_{C P}}\right)\left(1.46[-\ln R H]^{-1 / 2.45}\right) \\
& =3.28 \times 10^{-6} \bar{s}_{C P}(-\ln R H)^{-1 / 2.45} .
\end{aligned}
$$

Table 6.3-10 gives values of $S_{w e, C P}$ for a range of $\mathrm{RH}$ values to show some typical values that can be obtained using properties of $\mathrm{Fe}_{2} \mathrm{O}_{3}$ (porosity of 0.4 and specific surface area ranging from 1,000 to $22,000 \mathrm{~m}^{2} \mathrm{~kg}^{-1}$ ) as well as properties of goethite and HFO (porosities up to 0.7 and specific surface areas up to $600,000 \mathrm{~m}^{2} \mathrm{~kg}^{-1}$ ). 
Table 6.3-10. Values of Effective Water Saturation and Diffusion Coefficient in Corrosion Products from Equations 6.3.4.3.5-5 and 6.3.4.3.5-6, Respectively, over a Range of Relative Humidities for Various Specific Surface Areas and Porosities

\begin{tabular}{|c|c|c|c|c|c|c|c|c|}
\hline \multirow[b]{3}{*}{$R H$} & \multicolumn{8}{|c|}{$S_{w e, C P}$} \\
\hline & \multicolumn{2}{|c|}{$\bar{s}_{C P}=1,000 \mathrm{~m}^{2} \mathrm{~kg}^{-1}$} & \multicolumn{2}{|c|}{$\bar{s}_{C P}=22,000 \mathrm{~m}^{2} \mathrm{~kg}^{-1}$} & \multicolumn{2}{|c|}{$\bar{s}_{C P}=100,000 \mathrm{~m}^{2} \mathrm{~kg}^{-1}$} & \multicolumn{2}{|c|}{$\bar{s}_{C P}=600,000 \mathrm{~m}^{2} \mathrm{~kg}^{-1}$} \\
\hline & $\phi_{C P}=0.4$ & $\phi_{C P}=0.7$ & $\phi_{C P}=0.4$ & $\phi_{C P}=0.7$ & $\phi_{C P}=0.4$ & $\phi_{C P}=0.7$ & $\phi_{C P}=0.4$ & $\phi_{C P}=0.7$ \\
\hline 0.1 & $2.3 \times 10^{-3}$ & $6.7 \times 10^{-4}$ & $5.1 \times 10^{-2}$ & $1.5 \times 10^{-2}$ & $2.3 \times 10^{-1}$ & $6.7 \times 10^{-2}$ & 1.0 & $4.0 \times 10^{-1}$ \\
\hline 0.5 & $3.8 \times 10^{-3}$ & $1.1 \times 10^{-3}$ & $8.4 \times 10^{-2}$ & $2.4 \times 10^{-2}$ & $3.8 \times 10^{-1}$ & $1.1 \times 10^{-1}$ & 1.0 & $6.5 \times 10^{-1}$ \\
\hline 0.8 & $6.1 \times 10^{-3}$ & $1.7 \times 10^{-3}$ & $1.3 \times 10^{-1}$ & $3.8 \times 10^{-2}$ & $6.1 \times 10^{-1}$ & $1.7 \times 10^{-1}$ & 1.0 & 1.0 \\
\hline 0.9 & $8.2 \times 10^{-3}$ & $2.3 \times 10^{-3}$ & $1.8 \times 10^{-1}$ & $5.2 \times 10^{-2}$ & $8.2 \times 10^{-1}$ & $2.3 \times 10^{-1}$ & 1.0 & 1.0 \\
\hline 0.95 & $1.1 \times 10^{-2}$ & $3.2 \times 10^{-3}$ & $2.4 \times 10^{-1}$ & $6.9 \times 10^{-2}$ & 1.0 & $3.2 \times 10^{-1}$ & 1.0 & 1.0 \\
\hline 0.98 & $1.6 \times 10^{-2}$ & $4.6 \times 10^{-3}$ & $3.5 \times 10^{-1}$ & $1.0 \times 10^{-1}$ & 1.0 & $4.6 \times 10^{-1}$ & 1.0 & 1.0 \\
\hline 0.99 & $2.1 \times 10^{-2}$ & $6.1 \times 10^{-3}$ & $4.7 \times 10^{-1}$ & $1.3 \times 10^{-1}$ & 1.0 & $6.1 \times 10^{-1}$ & 1.0 & 1.0 \\
\hline 0.999 & $5.5 \times 10^{-2}$ & $1.6 \times 10^{-2}$ & 1.0 & $3.5 \times 10^{-1}$ & 1.0 & 1.0 & 1.0 & 1.0 \\
\hline 0.9999 & $1.4 \times 10^{-1}$ & $4.0 \times 10^{-2}$ & 1.0 & $8.9 \times 10^{-1}$ & 1.0 & 1.0 & 1.0 & 1.0 \\
\hline
\end{tabular}

NOTE: $\quad$ Because the effective water saturation given by Equation 6.3.4.3.5-5 is unbounded as $R H$ approaches 1.0 , values of $S_{w e, C P}>1.0$ can result, which is physically unrealistic; values of $S_{w e, C P}>1.0$ are truncated to 1.0 .

\begin{tabular}{|c|c|c|c|c|c|c|c|c|}
\hline \multirow[b]{3}{*}{$R H$} & \multicolumn{8}{|c|}{$\phi S_{w} D_{s}\left(m^{2} s^{-1}\right)$} \\
\hline & \multicolumn{2}{|c|}{$s_{C P}=1,000 \mathrm{~m}^{2} \mathrm{~kg}^{-1}$} & \multicolumn{2}{|c|}{$s_{C P}=22,000 \mathrm{~m}^{2} \mathrm{~kg}^{-1}$} & \multicolumn{2}{|c|}{$s_{C P}=100,000 \mathrm{~m}^{2} \mathrm{~kg}^{-1}$} & \multicolumn{2}{|c|}{$s_{C P}=600,000 \mathrm{~m}^{2} \mathrm{~kg}^{-1}$} \\
\hline & $\phi_{C P}=0.4$ & $\phi_{C P}=0.7$ & $\phi_{C P}=0.4$ & $\phi_{C P}=0.7$ & $\phi_{C P}=0.4$ & $\phi_{C P}=0.7$ & $\phi_{C P}=0.4$ & $\phi_{C P}=0.7$ \\
\hline 0.1 & $3.8 \times 10^{-15}$ & $6.4 \times 10^{-16}$ & $1.8 \times 10^{-12}$ & $3.1 \times 10^{-13}$ & $3.8 \times 10^{-11}$ & $6.4 \times 10^{-12}$ & $7.0 \times 10^{-10}$ & $2.3 \times 10^{-10}$ \\
\hline 0.5 & $1.0 \times 10^{-14}$ & $1.7 \times 10^{-15}$ & $4.9 \times 10^{-12}$ & $8.3 \times 10^{-13}$ & $1.0 \times 10^{-10}$ & $1.7 \times 10^{-11}$ & $7.0 \times 10^{-10}$ & $6.2 \times 10^{-10}$ \\
\hline 0.8 & $2.6 \times 10^{-14}$ & $4.3 \times 10^{-15}$ & $1.2 \times 10^{-11}$ & $2.1 \times 10^{-12}$ & $2.6 \times 10^{-10}$ & $4.3 \times 10^{-11}$ & $7.0 \times 10^{-10}$ & \\
\hline 0.9 & $4.7 \times 10^{-14}$ & $8.0 \times 10^{-15}$ & $2.3 \times 10^{-11}$ & $3.9 \times 10^{-12}$ & $4.7 \times 10^{-10}$ & $8.0 \times 10^{-11}$ & $7.0 \times 10^{-10}$ & $1.4 \times 10^{-9}$ \\
\hline 0.95 & $8.5 \times 10^{-14}$ & $1.4 \times 10^{-14}$ & $4.1 \times 10^{-11}$ & $6.9 \times 10^{-12}$ & $7.0 \times 10^{-10}$ & $1.4 \times 10^{-10}$ & $7.0 \times 10^{-10}$ & $1.4 \times 10^{-9}$ \\
\hline 0.98 & $1.8 \times 10^{-13}$ & $3.1 \times 10^{-14}$ & $8.8 \times 10^{-11}$ & $1.5 \times 10^{-11}$ & $7.0 \times 10^{-10}$ & $3.1 \times 10^{-10}$ & $7.0 \times 10^{-10}$ & $1.4 \times 10^{-9}$ \\
\hline 0.99 & $3.2 \times 10^{-13}$ & $5.4 \times 10^{-14}$ & $1.6 \times 10^{-10}$ & $2.6 \times 10^{-11}$ & $7.0 \times 10^{-10}$ & $5.4 \times 10^{-10}$ & $7.0 \times 10^{-10}$ & $1.4 \times 10^{-9}$ \\
\hline 0.999 & $2.1 \times 10^{-12}$ & $3.6 \times 10^{-13}$ & $7.0 \times 10^{-10}$ & $1.7 \times 10^{-10}$ & $7.0 \times 10^{-10}$ & $3.6 \times 10^{-9}$ & $7.0 \times 10^{-10}$ & $1.4 \times 10^{-9}$ \\
\hline 0.9999 & $1.4 \times 10^{-11}$ & $2.3 \times 10^{-12}$ & $7.0 \times 10^{-10}$ & $1.1 \times 10^{-9}$ & $7.0 \times 10^{-10}$ & $2.3 \times 10^{-8}$ & $7.0 \times 10^{-10}$ & $1.4 \times 10^{-9}$ \\
\hline
\end{tabular}

The effective diffusion coefficient for the corrosion products based on Archie's law and using the effective water saturation from Equation 6.3.4.3.5-5 is a function of time-dependent $\mathrm{RH}$ and the sampled specific surface area of corrosion products:

$$
\begin{aligned}
\phi S_{w} D_{s} & =\phi_{C P}^{1.3} S_{w e, C P}^{2} D_{0} \\
& =(0.4)^{1.3}\left[3.28 \times 10^{-6} \bar{s}_{C P}(-\ln R H)^{-1 / 2.45}\right]^{2} D_{0} \\
& =3.27 \times 10^{-12} \bar{s}_{C P}^{2}(-\ln R H)^{-0.816} D_{0} .
\end{aligned}
$$

Table 6.3-10 gives values of $\phi S_{w} D_{s}$ for a range of $\mathrm{RH}$ values to show some typical values that can be obtained using properties of $\mathrm{Fe}_{2} \mathrm{O}_{3}$ (porosity of 0.4 and specific surface area ranging from 1,000 to $22,000 \mathrm{~m}^{2} \mathrm{~kg}^{-1}$ ) as well as properties of goethite and HFO (porosities up to 0.7 and 
specific surface areas up to $600,000 \mathrm{~m}^{2} \mathrm{~kg}^{-1}$ ). For values of $\bar{s}_{C P}$ and $R H$ that result in effective water saturations greater than 1.0 in Table 6.3-10, the effective diffusion coefficient is obtained using the first line of Equation 6.3.4.3.5-6 with $S_{w e, C P}=1.0$.

For additional comparisons using $R H=0.95, \phi=0.4$, and $\bar{s}_{C P}=9.1 \times 10^{3} \mathrm{~m}^{2} \mathrm{~kg}^{-1}$ as an example, and with the self-diffusion coefficient for water (Section 6.3.4.1) of $D_{0}=2.299 \times 10^{-9} \mathrm{~m}^{2} \mathrm{~s}^{-1}$, the effective diffusion coefficient for the corrosion products using Archie's law (Equation 6.3.4.3.5-6) is $\phi S_{w} D_{s}=7.03 \times 10^{-12} \mathrm{~m}^{2} \mathrm{~s}^{-1}$ (where $S_{w}=0.100$, from Equation 6.3.4.3.5-5). For the range of porosities of geologic media, 0.25 to 0.7 (Freeze and Cherry 1979 [DIRS 101173], p. 37), $\phi S_{w} D_{s}$ ranges from $1.53 \times 10^{-11} \mathrm{~m}^{2} \mathrm{~s}^{-1}$ to $1.19 \times 10^{-12} \mathrm{~m}^{2} \mathrm{~s}^{-1}$ using $R H=0.95$ and $\bar{s}_{C P}=9.1 \times 10^{3} \mathrm{~m}^{2} \mathrm{~kg}^{-1}$.

The diffusion coefficient for the corrosion products and waste form domains is not modified for temperature as it is for the invert diffusion coefficient (Section 6.3.4.1.2). As shown in Figure 6.3-5, the diffusion coefficient can increase by a factor of 4 from $25^{\circ} \mathrm{C}$ to $100^{\circ} \mathrm{C}$. Not including this factor is justified in part because some uncertainty in the corrosion products diffusion coefficient is accounted for by the dependence on specific surface area (Equation 6.3.4.3.5-6), an uncertain parameter that ranges from 1,000 to $22,000 \mathrm{~m}^{2} \mathrm{~kg}^{-1}$. Thus the corrosion product diffusion coefficient varies by more than two orders of magnitude due to the uncertainty in specific surface area alone; the temperature effect is small in comparison. In addition, not accounting for temperature is partially compensated for by the use of the selfdiffusion coefficient for water rather than radionuclide-specific diffusion coefficients. For comparison, the self-diffusion coefficient for water is a factor of 1.5 greater than that of $\mathrm{TcO}_{4}{ }^{-}$ $\left(1.48 \pm 0.01 \times 10^{-5} \mathrm{~cm}^{2} \mathrm{~s}^{-1}\right.$ at $25^{\circ} \mathrm{C}$; Mills and Lobo 1989 [DIRS 138725], p. 105) and 1.1 greater than that of $\mathrm{I}^{-}\left(2.045 \times 10^{-5} \mathrm{~cm}^{2} \mathrm{~s}^{-1}\right.$ at $25^{\circ} \mathrm{C}$; Mills and Lobo 1989 [DIRS 138725], p. 318). For other important radionuclide species, the self-diffusion coefficient for water is even greater than that of specific radionuclides. For example, the self-diffusion coefficient for water is greater than that of $\mathrm{Am}^{3+}$ by a factor of $4\left(5.78 \times 10^{-6} \mathrm{~cm}^{2} \mathrm{~s}^{-1}\right.$ at $25^{\circ} \mathrm{C}$; Rosch and Khalkin 1990 [DIRS 138739], p. 103) and greater than that of $\mathrm{UO}_{2}\left(\mathrm{CO}_{3}\right)_{3}{ }^{4-}$ by a factor of about 8 $\left(3.0 \pm 0.7 \times 10^{-6} \mathrm{~cm}^{2} \mathrm{~s}^{-1}\right.$ at $25^{\circ} \mathrm{C}$; Perry et al. 1988 [DIRS 138732], p. 302). The water-versus-radionuclide and temperature effects offset differently, depending on temperature and the particular radionuclide. For $\mathrm{TcO}_{4}{ }^{-}$and $\mathrm{I}^{-}$, for example, the two effects could result in the model underpredicting diffusion by a factor of 2 to 4 at $100^{\circ} \mathrm{C}$, while overpredicting diffusion by about a factor of 1.1 to 1.5 at $25^{\circ} \mathrm{C}$. However, for actinides, the radionuclide effect is stronger than the temperature effect at all temperatures of interest, such that the model will overpredict diffusion of actinides by a factor of 1 to 2 at $100^{\circ} \mathrm{C}$ and a factor of 4 to 8 at $25^{\circ} \mathrm{C}$.

\subsubsection{Colloidal Transport}

Radionuclide transport from the waste package occurs as dissolved species at the appropriate solubility or dissolution rate limit and as colloidal particles. Three types of colloids are anticipated to exist in the EBS (BSC 2004 [DIRS 170025]): (a) waste form colloids from degradation of HLW glass, (b) iron oxyhydroxide colloids due to products from the corrosion of steel waste packages, and (c) groundwater or seepage water colloids. All three types of colloids 
may have reversibly sorbed radionuclides. The waste form colloids may have irreversibly attached (embedded) or reversibly attached (sorbed) radionuclides. The corrosion products colloids may have irreversibly attached (strongly sorbed) or reversibly attached (weakly sorbed) radionuclides. The stability and mass concentrations of colloids are functions of the ionic strength and $\mathrm{pH}$ of the groundwater or local liquid chemistry in the waste package and invert. Both groundwater and waste form colloids are modeled using smectite mineralogy, and therefore sorption distribution coefficients $\left(K_{d}\right)$ values associated with radionuclide sorption onto smectite colloids are used in the TSPA-LA model (BSC 2004 [DIRS 170025], Table 6-6). The $K_{d}$ values for colloids used in the TSPA-LA calculations are presented in Table 6.3-11.

The potential mass of radionuclides irreversibly attached (embedded) to the waste form colloids (BSC 2004 [DIRS 170025], Section 6.3.3.3) is determined from reactions within the waste package. The mass of radionuclides reversibly attached to all three types of colloids is determined primarily by three parameters:

- Mass concentration of dissolved (aqueous) radionuclide in the liquid

- Mass concentration of colloid material in the liquid

- Radionuclide distribution coefficient $\left(K_{d}\right)$ of a specific radionuclide on a specific colloid mineralogical type.

The potential concentrations of colloids in the drifts and EBS have also been assessed (BSC 2004 [DIRS 170025]). In a DOE-funded research project at the University of Nevada at Las Vegas to evaluate the corrosion of scaled-down miniature waste packages, the data indicate a preponderance of amorphous corrosion products released as colloids, including magnetite $\left(\mathrm{Fe}_{3} \mathrm{O}_{4}\right)$, lepidocrocite $(\mathrm{FeOOH})$, and goethite (FeOOH) (DTN: MO0302UCC034JC.003 [DIRS 162871]; BSC 2004 [DIRS 170025], Section 6.3.1.3).

Colloidal transport of radionuclides occurs by advective and diffusive processes. Advective transport moves colloids (and the associated radionuclides) at approximately the same velocity as the liquid flux through the EBS. Longitudinal dispersion, which could potentially enable colloids to travel faster than the bulk average liquid velocity, is ignored because of the short travel distance through the EBS (see Section 6.3.1.2). Diffusive transport moves colloids due to the concentration gradient and the medium diffusive properties. In the absence of a rigorous theory of solute diffusion in liquids, order of magnitude estimates may be made on the basis of hydrodynamic theory. Based on the Stokes-Einstein equation (Bird et al. 1960 [DIRS 103524], p. 514, Equation 16.5-4), the diffusivity of a solute in a liquid is inversely proportional to the radius of the diffusing particles.

Rates of diffusion of colloidal particles can be estimated by scaling those experimentally determined free water diffusion coefficients for dissolved actinides to dissolved colloidal materials on the basis of size (Stokes-Einstein relationship) as follows:

$$
D_{\text {coll }}=D_{\text {ion }}\left(\frac{r_{\text {ion }}}{r_{\text {coll }}}\right) \text {, }
$$


where

$D_{\text {coll }}=$ diffusion constant for a colloidal actinide of radius $r_{\text {coll }}$

$D_{i o n}=$ diffusion constant for a dissolved actinide of radius $r_{i o n}$

$r_{\text {coll }}=$ radius of the colloidal actinide

$r_{i o n}=$ radius of the dissolved actinide.

For example, given an ionic radius $r_{i o n}=1 \AA(0.1 \mathrm{~nm})$ and a colloidal particle radius $r_{\text {coll }}=10 \mathrm{~nm}$, the free water diffusion coefficient for the colloidal particle would be that of the dissolved actinide reduced by a factor of $100\left(D_{\text {coll }}=D_{\text {ion }}[0.1 \mathrm{~nm} / 10 \mathrm{~nm}]=D_{\text {ion }} / 100\right.$, from Equation 6.3.4.4-1). This approach is consistent with discussions in Principles of Colloid and Surface Chemistry (Hiemenz 1986 [DIRS 117358], p. 81).

Radionuclides may sorb irreversibly onto stationary corrosion products from the degradation of waste package internal components (Section 6.5.3) as well as onto mobile colloids. This sorption process will compete with reversible sorption onto colloids. A portion of plutonium and americium sorb irreversibly onto mobile colloids as well as onto stationary corrosion products in the waste package. In order to model both reversible and irreversible sorption of plutonium and americium onto iron oxyhydroxide colloids, the TSPA model reduces the upper bounds for the $K_{d}$ values in Table 6.3-11 for plutonium and americium by a factor of 100 (BSC 2004 [DIRS 170025], Section 6.3.3.2), which constrains the $K_{d}$ values to the lower bound. 
Table 6.3-11. Sorption Distribution Coefficient $\left(K_{d}\right)$ Values and Interval Probabilities Used for Reversible Radionuclide Sorption on Colloids in TSPA-LA Calculations

\begin{tabular}{|c|c|c|c|c|}
\hline Radionuclide & Colloid & $\begin{array}{c}K_{d} \text { Value Range } \\
\left(\mathrm{ml} \mathrm{g}^{-1}\right)\end{array}$ & $\begin{array}{c}K_{d} \text { Value Intervals } \\
\left(\mathrm{ml} \mathrm{g}^{-1}\right)\end{array}$ & $\begin{array}{c}K_{d} \text { Value Interval } \\
\text { Probabilities }\end{array}$ \\
\hline \multirow[t]{2}{*}{$\mathrm{Pu}$} & Iron Oxyhydroxide & $10^{4}$ to $10^{6}$ & $\begin{array}{l}<1 \times 10^{4} \\
1 \times 10^{4} \text { to } 5 \times 10^{4} \\
5 \times 10^{4} \text { to } 1 \times 10^{5} \\
1 \times 10^{5} \text { to } 5 \times 10^{5} \\
5 \times 10^{5} \text { to } 1 \times 10^{6} \\
>1 \times 10^{6}\end{array}$ & $\begin{array}{l}0 \\
0.15 \\
0.2 \\
0.5 \\
0.15 \\
0\end{array}$ \\
\hline & Smectite & $10^{3}$ to $10^{6}$ & $\begin{array}{l}<1 \times 10^{3} \\
1 \times 10^{3} \text { to } 5 \times 10^{3} \\
5 \times 10^{3} \text { to } 1 \times 10^{4} \\
1 \times 10^{4} \text { to } 5 \times 10^{4} \\
5 \times 10^{4} \text { to } 1 \times 10^{5} \\
1 \times 10^{5} \text { to } 5 \times 10^{5} \\
5 \times 10^{5} \text { to } 1 \times 10^{6} \\
>1 \times 10^{6}\end{array}$ & $\begin{array}{l}0 \\
0.04 \\
0.08 \\
0.25 \\
0.2 \\
0.35 \\
0.08 \\
0\end{array}$ \\
\hline \multirow[t]{2}{*}{$\mathrm{Am}, \mathrm{Th}, \mathrm{Pa}$} & Iron Oxyhydroxide & $10^{5}$ to $10^{7}$ & $\begin{array}{l}<1 \times 10^{5} \\
1 \times 10^{5} \text { to } 5 \times 10^{5} \\
5 \times 10^{5} \text { to } 1 \times 10^{6} \\
1 \times 10^{6} \text { to } 5 \times 10^{6} \\
5 \times 10^{6} \text { to } 1 \times 10^{7} \\
>1 \times 10^{7}\end{array}$ & $\begin{array}{l}0 \\
0.15 \\
0.2 \\
0.55 \\
0.1 \\
0\end{array}$ \\
\hline & Smectite & $10^{4}$ to $10^{7}$ & $\begin{array}{l}<1 \times 10^{4} \\
1 \times 10^{4} \text { to } 5 \times 10^{4} \\
5 \times 10^{4} \text { to } 1 \times 10^{5} \\
1 \times 10^{5} \text { to } 5 \times 10^{5} \\
5 \times 10^{5} \text { to } 1 \times 10^{6} \\
1 \times 10^{6} \text { to } 5 \times 10^{6} \\
5 \times 10^{6} \text { to } 1 \times 10^{7} \\
>1 \times 10^{7}\end{array}$ & $\begin{array}{l}0 \\
0.07 \\
0.1 \\
0.23 \\
0.2 \\
0.32 \\
0.08 \\
0\end{array}$ \\
\hline \multirow[t]{2}{*}{ Cs } & Iron Oxyhydroxide & $10^{1}$ to $10^{3}$ & $\begin{array}{l}<1 \times 10^{1} \\
1 \times 10^{1} \text { to } 5 \times 10^{1} \\
5 \times 10^{1} \text { to } 1 \times 10^{2} \\
1 \times 10^{2} \text { to } 5 \times 10^{2} \\
5 \times 10^{2} \text { to } 1 \times 10^{3} \\
>1 \times 10^{3}\end{array}$ & $\begin{array}{l}0 \\
0.13 \\
0.22 \\
0.55 \\
0.1 \\
0\end{array}$ \\
\hline & Smectite & $10^{2}$ to $10^{4}$ & $\begin{array}{l}<1 \times 10^{2} \\
1 \times 10^{2} \text { to } 5 \times 10^{2} \\
5 \times 10^{2} \text { to } 1 \times 10^{3} \\
1 \times 10^{3} \text { to } 5 \times 10^{3} \\
5 \times 10^{3} \text { to } 1 \times 10^{4} \\
>1 \times 10^{4}\end{array}$ & $\begin{array}{l}0 \\
0.2 \\
0.25 \\
0.5 \\
0.05 \\
0\end{array}$ \\
\hline
\end{tabular}

DTN: SN0306T0504103.006 [DIRS 164131], Table 1.

NOTE: In engineered barrier system calculations, upper bound of $K_{d}$ ranges for plutonium $(\mathrm{Pu})$ and americium (Am) on iron oxyhydroxide reduced by a factor of 100 to be compatible with mechanistic sorption model described in Waste Form and In-Drift Colloids-Associated Radionuclide

Concentrations: Abstraction and Summary (BSC 2004 [DIRS 170025], Section 6.3.3.2). Thus the $K_{d}$ values for Pu and Am on iron oxyhydroxide are effectively fixed at $10^{4}$ and $10^{5}$, respectively. 


\subsubsection{Transport through Stress Corrosion Cracks}

Transport through stress corrosion cracks in the waste package is limited to diffusion. Once stress corrosion cracks form in the lid of the waste package, all surfaces inside the waste package are assumed to be coated with a thin film of water (per Assumption 5.5). This thin film provides the medium for diffusion from the waste form, through the stress corrosion crack, and out of the waste package. The diffusive area is calculated as the product of the area and number of cracks. The area of each crack is estimated from the data in Table 6.3-3. The maximum cross-sectional area of each crack for diffusive transport is calculated to be $7.7 \times 10^{-6} \mathrm{~m}^{2}$ (Section 6.3.3.1.2.1).

\subsection{CONSIDERATION OF ALTERNATIVE CONCEPTUAL MODELS}

Alternative conceptual models considered in the EBS radionuclide transport abstraction are discussed in this section. A summary of models that are analyzed is presented in Table 6.4-1.

Table 6.4-1. Alternative Conceptual Models Considered

\begin{tabular}{|c|c|c|}
\hline $\begin{array}{l}\text { Alternative } \\
\text { Conceptual } \\
\text { Models }\end{array}$ & Key Assumptions & Screening Assessment and Basis \\
\hline $\begin{array}{l}\text { Bathtub flow } \\
\text { model (alternative } \\
\text { to flow-through } \\
\text { model) }\end{array}$ & $\begin{array}{l}\text { Seepage water flowing into breached waste } \\
\text { package accumulates until void volume is filled } \\
\text { before water containing dissolved radionuclides } \\
\text { flows out. Various cases, such as changing inflow } \\
\text { rates and effect of solubility and dissolution rate } \\
\text { limits, are evaluated. }\end{array}$ & $\begin{array}{l}\text { Screened out in analysis in Section 6.6.1. } \\
\text { For several of the most pertinent cases, } \\
\text { the flow-through model is bounding with } \\
\text { respect to releases of radionuclides. }\end{array}$ \\
\hline $\begin{array}{l}\text { Water vapor } \\
\text { diffusion limitations } \\
\text { through stress } \\
\text { corrosion cracks } \\
\text { (alternative to } \\
\text { unlimited access } \\
\text { to water vapor) }\end{array}$ & $\begin{array}{l}\text { If the rate of corrosion of steel components inside } \\
\text { waste package is greater than the rate of diffusion } \\
\text { of water vapor into waste package, a film of } \\
\text { adsorbed water cannot form, which delays diffusive } \\
\text { releases until all steel is fully corroded. } \\
\text { Water vapor concentration inside waste package is } \\
\text { assumed to be zero to maximize concentration } \\
\text { gradient. } \\
\text { Alternative cases consider stress corrosion cracks } \\
\text { that are assumed to be (1) fully open and (2) filled } \\
\text { with corrosion products but still permeable. } \\
\text { Alternative corrosion stoichiometry is considered for } \\
\text { formation of (1) Fe } \mathrm{O}_{3} \text { and (2) Fe(OH) } \\
\text { Alternative corrosion rates are considered } \\
\text { assuming (1) only carbon steel corrodes, }(2) \text { all } \\
\text { internal components corrode at carbon steel rate } \\
\text { and at stainless steel rate, with mass of iron } \\
\text { computed as in the in-package diffusion submodel. }\end{array}$ & $\begin{array}{l}\text { Screened out. } \\
\text { Potentially delays releases for hundreds } \\
\text { to thousands of years, which requires } \\
\text { unattainable reduction in model } \\
\text { uncertainties. } \\
\text { The assumption that no water is } \\
\text { physically adsorbed until all steel is } \\
\text { corroded is questionable, since } \\
\text { adsorption is typically a fast process. On } \\
\text { the other hand, if water consumption by } \\
\text { corrosion keeps the relative humidity } \\
\text { inside the waste package low, the } \\
\text { effective water saturation, as computed in } \\
\text { the in-package diffusion submodel, will be } \\
\text { so low that bulk liquid phase behavior } \\
\text { allowing dissolution and diffusion of } \\
\text { dissolved radionuclides will not exist until } \\
\text { corrosion is complete. }\end{array}$ \\
\hline $\begin{array}{l}\text { Oxygen diffusion } \\
\text { limitations through } \\
\text { stress corrosion } \\
\text { cracks (alternative } \\
\text { to unlimited } \\
\text { access to oxygen) }\end{array}$ & $\begin{array}{l}\text { Same as for water vapor diffusion limitation model, } \\
\text { but less restrictive in that oxygen as well as water } \\
\text { vapor can corrode steels, potentially reducing time } \\
\text { needed for complete corrosion of internal } \\
\text { components. } \\
\text { Assumes that oxic corrosion occurs at the same } \\
\text { rate as anoxic corrosion with water. } \\
\text { Assumes oxygen and water vapor can diffuse } \\
\text { independently of each other without interfering. } \\
\text { Oxygen concentration inside waste package is } \\
\text { assumed to be zero to maximize concentration } \\
\text { gradient. }\end{array}$ & $\begin{array}{l}\text { Screened out. } \\
\text { Potentially delays releases, which is not } \\
\text { justifiable in view of large model } \\
\text { uncertainties. } \\
\text { Comparative rates of oxic and anoxic } \\
\text { corrosion should be considered. } \\
\text { Competing diffusion with water vapor } \\
\text { should also be addressed. }\end{array}$ \\
\hline
\end{tabular}


Table 6.4-1. Alternative Conceptual Models Considered (Continued)

\begin{tabular}{|c|c|c|}
\hline $\begin{array}{l}\text { Alternative } \\
\text { Conceptual } \\
\text { Models }\end{array}$ & Key Assumptions & Screening Assessment and Basis \\
\hline $\begin{array}{l}\text { Dual-continuum } \\
\text { invert model }\end{array}$ & $\begin{array}{l}\text { Crushed tuff invert ballast is modeled as a dual- } \\
\text { continuum material consisting of intergranular pore } \\
\text { space and intragranular pore space. } \\
\text { All seepage flow into the drift flows through the } \\
\text { intergranular pore space and into the UZ fractures. } \\
\text { Imbibition from UZ host rock into the invert flows } \\
\text { through the intragranular pore space. } \\
\text { Diffusion of radionuclides also occurs in both the } \\
\text { intergranular and intragranular pore spaces, from } \\
\text { the waste package corrosion products into UZ } \\
\text { fractures and matrix, as well as between the two } \\
\text { invert continua. }\end{array}$ & $\begin{array}{l}\text { Screened out. } \\
\text { Insufficient data to validate diffusion } \\
\text { coefficients in individual continua. } \\
\text { Insufficient data to confirm whether this is } \\
\text { a bounding approach with respect to } \\
\text { chemical behavior in the invert. }\end{array}$ \\
\hline $\begin{array}{l}\text { Invert diffusion } \\
\text { coefficient model } \\
\text { with lower limit on } \\
\text { water content }\end{array}$ & $\begin{array}{l}\text { As the water content of the crushed tuff ballast } \\
\text { decreases, the water films that connect pore } \\
\text { spaces become disconnected, and the effective } \\
\text { diffusion coefficient drops more rapidly than } \\
\text { predicted by Archie's law. Below some critical } \\
\text { water content, the diffusion coefficient becomes } \\
\text { zero. Based on models of diffusion in soils. }\end{array}$ & $\begin{array}{l}\text { Screened out. } \\
\text { Insufficient data to validate diffusive } \\
\text { behavior at very low water contents. } \\
\text { Does not provide upper bounds on } \\
\text { diffusion coefficients. }\end{array}$ \\
\hline $\begin{array}{l}\text { Reversible } \\
\text { sorption of } \\
\text { radionuclides onto } \\
\text { waste package } \\
\text { corrosion products }\end{array}$ & $\begin{array}{l}\text { Iron oxyhydroxide corrosion products sorb many } \\
\text { radionuclide species. Sorption is assumed to be } \\
\text { reversible and not compete with other radionuclides } \\
\text { nor compete for irreversible sorption sites. }\end{array}$ & $\begin{array}{l}\text { Screened out. } \\
\text { Does not account for limitations on total } \\
\text { number of sorption sites. } \\
\text { Does not account for competition with } \\
\text { other radionuclides for sorption sites. } \\
\text { Does not account for competition with } \\
\text { irreversible sorption for sorption sites. }\end{array}$ \\
\hline $\begin{array}{l}\text { Pu sorption from } \\
\text { stationary } \\
\text { corrosion products } \\
\text { and colloids }\end{array}$ & $\begin{array}{l}\text { Plutonium sorbs strongly to iron oxyhydroxide } \\
\text { corrosion product colloids and stationary corrosion } \\
\text { products. Sorption may be considered "slowly } \\
\text { reversible" (as opposed to irreversible). The model } \\
\text { is applicable to the range of pH values expected in } \\
\text { the repository environment. }\end{array}$ & $\begin{array}{l}\text { Experiment durations are short (hours to } \\
\text { weeks) compared to the repository time } \\
\text { scale. } \\
\text { The mechanisms of plutonium sorption } \\
\text { are not well-enough understood to fully } \\
\text { interpret the data. } \\
\text { Plutonium sorption and desorption data } \\
\text { are not available for the highest pH } \\
\text { ranges expected in the repository } \\
\text { environment. }\end{array}$ \\
\hline
\end{tabular}

\subsubsection{Bathtub Model for the Waste Package}

The bathtub model is an alternative conceptual EBS flow model in which seepage collects within the waste package before being released to the EBS. This is an alternative to the "flow-through" geometry, and is analyzed in Section 6.6.1. It is concluded that, with respect to releases of radionuclides, the flow-through model increases releases relative to the bathtub model and is therefore bounding for the following cases:

1. Primary case, in which the water inflow rate is constant, the rate of radionuclide dissolution is limited, and the radionuclide concentration is solubility-limited. Unlike the bathtub model, there is no delay in release of radionuclides in the flow-through model. 
2. Secondary case 1 , in which the inflow rate undergoes a step change. The response of the bathtub model is identical to the flow-through model for solubility-limited radionuclides. For dissolution-rate-limited radionuclides, the flow-through model overestimates releases of radionuclides for the case of decreasing inflow, or increasing concentration, which is of primary interest from a performance or regulatory standpoint.

3. Secondary case 2 , a step change in groundwater chemistry. The flow-through model overestimates releases of radionuclides relative to the bathtub model when the solubility or dissolution rate increases because it has an instantaneous change to the higher equilibrium value, whereas the bathtub geometry delays the change. For decreasing solubility or dissolution rate, the bathtub overestimates fractional releases of radionuclides, but this case is of no interest from a performance or regulatory point of view, because the overall rate decreases.

4. Secondary case 3 , wherein a second corrosion patch opens instantaneously beneath the water level in the waste package in the bathtub model. The impact of this alternative flow path was screened out because of the potential mitigation from sorption and because the variability of corrosion rates provides large uncertainty in radionuclide release rates from the waste package.

As a result of this analysis, the bathtub model has been screened out as an alternative conceptual model in order to overestimate radionuclide transport.

\subsubsection{Limited Water Vapor Diffusion Rate into Waste Package}

This alternative conceptual model accounts for the resistance to diffusion of water vapor into a waste package through stress corrosion cracks. In the base model, there is no limit to the amount of water vapor available to adsorb onto surfaces within a waste package, which creates a pathway for diffusive transport of radionuclides out of the waste package. (This applies to the in-package diffusion submodel, Section 6.3.4.3.) However, the base model currently used for the TSPA to calculate dose overestimates releases of radionuclides, particularly at early times when the only breaches in a waste package are small stress corrosion cracks. If the diffusion rate is limited, the rate of steel corrosion is limited by the rate of diffusion of water vapor. The result is that no water is available to adsorb and form a thin liquid film on corrosion products, and no water would be available for radionuclide transport. This is because all water is consumed by the corrosion process as quickly as it diffuses into the waste package. This prevents formation of a diffusive path until all of the internal steel components are fully corroded, which in turn delays diffusive releases until that time. Since this may take hundreds to thousands of years, the delay in releases of radionuclides from breached waste packages could be extensive. During this delay, radioactive decay will decrease the quantity of radionuclides in the waste package, ultimately reducing releases to the environment.

A mathematical description of this model is presented in Section 6.6.2. 


\subsubsection{Limited Oxygen Diffusion Rate into Waste Package}

This alternative conceptual model is similar to the alternative conceptual model dealing with limited water vapor diffusion into a waste package through stress corrosion cracks described in Section 6.4.2. In both models, the rate of steel corrosion is limited by the rate of diffusion of reactive gases. They also imply that no adsorbed water film can form until all of the steel is corroded, as long as the rate of water consumption by corrosion is greater than the rate of diffusion of reactants into the waste package. The difference in this model is that oxygen in the waste package is also diffusion limited, yet oxygen also reacts readily with the steel internal components. Depending on how oxygen competes with water vapor in diffusing through stress corrosion cracks and reacting with steel, the time required for all internal components to react and stop consuming water would be shortened. Then diffusive releases through the film of adsorbed water (given by the in-package diffusion submodel, Section 6.3.4.3) can begin earlier than predicted by the water vapor limited diffusion model alone.

A mathematical description of this model is presented in Section 6.6.3.

\subsubsection{Dual-Continuum Invert}

This alternative conceptual model treats the crushed tuff in the invert as a dual continuum comprised of two pore spaces - intragranular pore space (tuff particle matrix) and intergranular pore space. Although radionuclide transport by both advection and diffusion can occur in both pore spaces, the dominant flow and transport processes in each of these two pore spaces is generally different. In order to simulate flow and transport through the invert accurately, the invert is conceptualized in this alternative conceptual model as overlapping dual continua using a dual-permeability approach, wherein flow and transport occur in both pore spaces, and mass transfer takes place between the two pore spaces.

A mathematical description of this model is presented in Section 6.6.4.

\subsubsection{Alternative Invert Diffusion Coefficient Models}

The following two alternative models for determining the diffusion coefficient in the invert are assessed: the single-continuum invert diffusion coefficient model and the dual-continuum invert diffusion coefficient model. In the single-continuum invert diffusion coefficient model, an alternative to the Archie's law approach for determination of the diffusion coefficient for the single-continuum crushed tuff invert ballast (Section 6.3.4.1) is modeled using an approach that has been applied to diffusion in soils. In the dual-continuum invert diffusion coefficient model, the bulk diffusion coefficient is dominated by the intergranular diffusion coefficient above the critical bulk moisture content, while below this critical value, the intragranular diffusion coefficient dominates.

Mathematical descriptions of these models are presented in Section 6.6.5.

\subsubsection{Reversible Sorption of Radionuclides onto Waste Package Corrosion Products}

In this alternative conceptual model, reversible sorption of radionuclides takes place on waste package corrosion products. Iron oxyhydroxides are generated through corrosion of mild steel 
and stainless steels within the waste package. The iron oxyhydroxides are known to be excellent sorbers (as indicated by their high $K_{d}$ values) of many radionuclide species. In this alternative conceptual model, sorption is modeled as being completely reversible for all radionuclides and represented by linear adsorption isotherms in the form of $K_{d}$ values. The $K_{d}$ values allow retardation factors to be computed for transport through the EBS.

$K_{d}$ values for 13 radionuclides are discussed in Section 6.6.6.

\subsubsection{Pu Sorption from Stationary Corrosion Products and Colloids}

The TSPA-LA model accounts for limited plutonium desorption from iron oxyhydroxides by incorporating an irreversible sorption component. In contrast, this alternative conceptual model (ACM) accounts for the slow desorption of plutonium observed in experiments investigating absorption and desorption of plutonium from iron oxyhydroxide. Postulated mechanisms of plutonium sorption are described and the experimentally observed desorption is interpreted in the context of these mechanisms. $K_{d}$ values are calculated for application to plutonium transport in the EBS and comparison with the TSPA-LA model base case. This ACM is not incorporated into the base-case model because the durations of sorption-desorption experiments are short relatively to the repository time scale, the mechanisms of plutonium sorption are not yet well understood, and data on plutonium sorption and desorption are not available for high $\mathrm{pH}$ ranges.

This model is described in detail in Section 6.6.7.

\subsection{MODEL FORMULATION FOR BASE CASE MODEL}

\subsubsection{Mathematical Description of Base Case Conceptual Model}

A solute transport model typically consists of two component models: a model to solve the flow equation and another to solve the transport equation (Anderson and Woessner 1992 [DIRS 123665], p. 327). The solution of the flow equation yields the flow velocities or flow rates. These flow rates are input to the transport model, which predicts the concentration distribution in time and space. Development of the EBS flow model and the EBS transport model are discussed separately in the next two subsections.

\subsubsection{EBS Flow Model}

The EBS flow model is essentially a mass balance on water in the EBS. Because the microscopic details of processes that occur in the EBS are not important on a drift or waste package scale, an appropriate starting point for developing the EBS flow model is a general macroscopic balance on water within a drift (Bird et al. 1960 [DIRS 103524], p. 686):

$$
\frac{d m_{w}}{d t}=-\Delta w_{w}+w_{w}^{m}+r_{w}
$$

Here, $m_{w}(\mathrm{~kg})$ is the instantaneous total mass of water within the walls of a drift, which encompass the EBS. This equation states that the rate of change of water mass in the EBS is equal to the mass rate of flow out of minus the mass rate of flow into the $\operatorname{EBS}\left(\Delta w_{w}\left[\mathrm{~kg} \mathrm{~s}^{-1}\right]\right)$, 
plus $w_{w}^{m}\left(\mathrm{~kg} \mathrm{~s}^{-1}\right)$, the net mass flow rate of water across bounding surfaces into the EBS by mass transfer (e.g., condensation or evaporation transfer water across a liquid surface, which is a boundary between gas-phase flow and transport and liquid-phase flow and transport), plus the rate of production of water by chemical reactions, $r_{w}\left(\mathrm{~kg} \mathrm{~s}^{-1}\right)$. Per Assumption 5.4, production or consumption of water by chemical reactions is assumed to be zero, resulting in:

$$
\frac{d m_{w}}{d t}=-\Delta w_{w}+w_{w}^{m}
$$

At steady state or when the mass of water in the EBS changes slowly, the time derivative can be set to zero:

$$
-\Delta w_{w}+w_{w}^{m}=0
$$

The alternative bathtub conceptual model, using Equation 6.5.1.1-2 for the waste package, is screened out as an alternative conceptual model in Section 6.6.1. By neglecting changes in the density of the water within a drift as it passes through the EBS, Equation 6.5.1.1-3 can be divided by the density of water, $\rho_{w}\left(\mathrm{~kg} \mathrm{~m}^{-3}\right)$, to transform it into a volume balance involving volumetric flow rates:

$$
-\Delta F_{w}+F_{w}^{m}=0
$$

where $F_{w}=w_{w} / \rho_{w}$ is the volumetric flow rate $\left(\mathrm{m}^{3} \mathrm{~s}^{-1}\right)$, and the superscript $m$ still refers to mass transfer processes. Since both $-\Delta F_{w}$ and $F_{w}^{m}$ represent a net inflow minus outflow, Equation 6.5.1.1-4 simply states that outflow is equal to inflow. This is the general form of the water mass balance that is used for individual flow paths in the EBS in the EBS RT Abstraction. It is applicable to the EBS as a whole as well as to individual components of the EBS. In particular, the terms $\Delta w_{w}$ and $w_{w}^{m}$ can be broken down into the separate and distinct flow paths listed in Section 6.3.1.1.

The volumetric flow rate of water into the top of the EBS is referred to as the total dripping flux, designated $F_{1}$ in Table 6.3-1, and is comprised of seepage flux into the top of the drift and condensation on walls of the drift. The seepage flux is computed in the GoldSim TSPA model using Abstraction of Drift Seepage (BSC 2004 [DIRS 169131]), and condensation on the drift walls is represented in the TSPA-LA model through the In-Drift Natural Convection and Condensation Model (BSC 2004 [DIRS 164327]); these are inputs or sources of inflow into the EBS flow model.

Over the entire EBS, Equation 6.5.1.1-4 becomes

$$
F_{1}+F_{7}=F_{8},
$$

where $F_{1}$ is the total dripping flux into the top of the drift and $F_{7}$ is the imbibition flux into the invert; see Figure 6.3-1. $F_{8}$ is the flow rate of water leaving the invert and entering the unsaturated zone. 
For the drip shield, the flux through corrosion breaches in the drip shield is $F_{2}$, and the flux of water diverted by the drip shield is $F_{3}$, so the water balance on the drip shield is:

$$
F_{1}=F_{2}+F_{3} .
$$

For the waste package, the water mass balance is:

$$
F_{2}=F_{4}+F_{5} \text {. }
$$

As modeled, there is no water storage in the waste package. Therefore, the flow rate of water from the waste package to the invert is equal to the flow into the waste package, $F_{4}$. The water balance over the invert includes this influx of water that has flowed through the waste package as well as water diverted around the waste package and water diverted around the drip shield. The total flow into the invert that originates from seepage flux and condensation $\left(F_{1}\right)$, is:

$$
\begin{aligned}
F_{6} & =F_{3}+F_{4}+F_{5} \\
& =F_{1} .
\end{aligned}
$$

A water mass balance over the invert indicates that the sum of the seepage flux $\left(F_{1}\right)$ and imbibition flux $\left(F_{7}\right)$ flows out of the invert (Equation 6.5.1.1-5):

$$
\begin{aligned}
F_{8} & =F_{6}+F_{7} \\
& =F_{1}+F_{7} .
\end{aligned}
$$

\subsection{Water Flux through a Breached Drip Shield}

Key features of the drip shield flux splitting algorithm include: (1) the seepage flux into the drift falls as droplets from the top of the drift onto the crown of the drip shield (Assumption 5.1), (2) droplets fall randomly along the length of the drip shield, (3) only flow through general corrosion patches is considered, (4) evaporation from the drip shield is neglected (Assumption 5.2); all of the seepage flux either flows through corrosion patches or drains down the sides of the drip shield, (5) all water that flows through breaches in the drip shield flows onto the waste package.

In the conceptual model of the breached drip shield corrosion patches are represented by square holes, with dimensions specified in an earlier version of the WAPDEG corrosion model as approximately $27 \mathrm{~cm}$ in width (CRWMS M\&O 2000 [DIRS 151566], p. 36, where the patch area is specified to be $7.214 \times 10^{4} \mathrm{~mm}^{2}$ ). The breached drip shield experiments (BSC 2003 [DIRS 163406]) were designed using holes of this size.

Consider first some simple cases with idealized behavior, in which drops falling onto the drip shield either fall straight through corrosion patches or, after impacting the drip shield surface, flow straight down the sides of the drip shield. These will provide bounding cases for comparison as more realism is added to the flux splitting submodel. Let $2 \ell$ be the width $(\mathrm{m})$ of a 
square corrosion patch, $L_{D S}$ the axial length (m) of the drip shield, and $N_{b}$ the number of patches on the drip shield, assumed to not overlap each other.

In the simplest case, $N_{c}$ patches are located on the crown of the drip shield, none off the crown. Since all of the seepage flux $F_{1}$ falls on the crown of the drip shield, the amount that passes straight through breaches in the drip shield $\left(F_{2}\right)$ is simply the ratio of the total length of the $N_{b}=N_{c}$ patches to the total length of the drip shield multiplied by the seepage flux:

$$
F_{2}=F_{1} \frac{2 \ell N_{c}}{L_{D S}} .
$$

Next, suppose a single patch exists, randomly located on the top of the drip shield, but fully off the crown so that none of the seepage flux falls directly through the patch, but instead lands on the drip shield crown and then flows straight down the surface. Ideally, exactly half of the seepage flux drains down one side of the drip shield, and half down the other side. The reality is not far removed from the ideal: when drops strike the drip shield, they splatter in a random pattern; the region where splattered droplets fall is roughly circular. After a large number of drops have fallen, on average half of the droplets will have landed on each of the two sides of the drip shield. Since only half of the seepage flux drains down one side of the drip shield, a single patch can only capture $2 \ell / L_{D S}$ of the flow down one side $\left(F_{1} / 2\right)$, so the flux through a single patch in the drip shield is:

$$
F_{2}=F_{1} \frac{\ell}{L_{D S}} .
$$

If two patches exist, with one patch on each side of the drip shield, the total flux will clearly be twice what flows through a single patch:

$$
F_{2}=F_{1} \frac{2 \ell}{L_{D S}} .
$$

If two patches are located on one side of the drip shield, away from the crown, and located randomly except that they do not interfere with each other (i.e., one patch is not upstream from another where it would intercept flow that would be captured by a lower patch), then a fraction $2 \ell / L_{D S}$ of the flow down one side $\left(F_{1} / 2\right)$ will enter each patch. The total flux through the drip shield in this case is:

$$
F_{2}=2\left(\frac{F_{1}}{2}\right) \frac{2 \ell}{L_{D S}}=F_{1} \frac{2 \ell}{L_{D S}} .
$$


In the general case where $N_{c}$ patches are randomly distributed on the drip shield, off the crown and not interfering with each other, Equation 6.5.1.1.1-4 becomes:

$$
F_{2}=F_{1} \frac{N_{c} \ell}{L_{D S}}
$$

Different behavior is clearly seen depending on whether the patch is located directly on the crown such that drops fall straight through it, or whether the seepage is split by falling on the drip shield first, causing half of the dripping flux to flow down each side of the drip shield. If $N_{c}$ patches are located on the crown $\left(N_{c} \leq N_{b}\right)$, the most general form of the flux splitting algorithm for this idealization is:

$$
\begin{aligned}
F_{2} & =F_{1} \frac{\ell}{L_{D S}}\left[2 N_{c}+\left(N_{b}-N_{c}\right)\right] \\
& =F_{1} \frac{\left(N_{b}+N_{c}\right) \ell}{L_{D S}} .
\end{aligned}
$$

Although this equation is general, it requires a distinction between patches on the crown and off the crown. However, the location of patches is completely random, so the location cannot be specified a priori. To account for the different flux through crown patches, note that crown patches occur within a distance $\pm 2 \ell$ from the crown, or over an area $4 \ell L_{D S}$. The total surface area of a drip shield is $W_{D S} L_{D S}$, where $W_{D S}$ is the total unfolded width of the drip shield (m) as measured from the bottom edge of one side, over the top, and down to the bottom of the other side. Then the probability of a patch occurring on the crown is:

$$
\frac{4 \ell L_{D S}}{W_{D S} L_{D S}}=\frac{4 \ell}{W_{D S}} .
$$

Equation 6.5.1.1.1-6 can be rewritten to account for the probability of seepage flux falling into a crown patch or onto intact drip shield, and for the flux through a single crown patch being twice the flux through an off-crown patch for a given seepage flux:

$$
\begin{aligned}
F_{2} & =F_{1}\left(\frac{2 N_{b} \ell}{L_{D S}}\right)\left(\frac{4 \ell}{W_{D S}}\right)+F_{1}\left(\frac{N_{b} \ell}{L_{D S}}\right)\left(1-\frac{4 \ell}{W_{D S}}\right) \\
& =F_{1} \frac{N_{b} \ell}{L_{D S} W_{D S}}\left(4 \ell+W_{D S}\right) \\
& =F_{1} \frac{N_{b} \ell}{L_{D S}}\left(\frac{4 \ell}{W_{D S}}+1\right) .
\end{aligned}
$$


For a patch size of $2 \ell=27 \mathrm{~cm}$ and a total drip shield width of $W_{D S}=6.94 \mathrm{~m}$, the term $4 \ell / W_{D S}=0.078$. To a good approximation, the term $4 \ell / W_{D S}$ can be neglected, yielding:

$$
F_{2}=F_{1} \frac{N_{b} \ell}{L_{D S}},
$$

which is identical to Equation 6.5.1.1.1-5. This result indicates that, although the flux is higher through crown patches, the probability of patches occurring on the crown is small $\left(4 \ell / W_{D S}\right.$, or 7.8 percent) and may be ignored in light of the uncertainties discussed in Section 6.3.2.4.

The simple model presented thus far assumes ideal drops that do not splatter and that run down the drip shield in straight, nondiverging paths. Next, realism is added to the flux splitting submodel by taking into account observations and data from breached drip shield experiments, which account for drop splattering and the nature of rivulet flow along the surface of the drip shield.

\subsection{Breached Drip Shield Experiments}

The breached drip shield experiments (BSC 2003 [DIRS 163406]) are described in Section 6.3.2.4. The tests were performed at three different drip rates, which represent the range of expected liquid water influx rates over a single drip shield. The bulk of the tests were performed at a drip rate of $2 \mathrm{~m}^{3} \mathrm{yr}^{-1}$. Additional bounding flow rate tests were performed at a lower rate of $0.2 \mathrm{~m}^{3} \mathrm{yr}^{-1}$ and a higher rate of $20 \mathrm{~m}^{3} \mathrm{yr}^{-1}$. The tests were performed by dripping water at specified drip locations, one location at a time for a period that allowed a measurable amount of liquid to be collected through breaches in the drip shield (typically 30 to $60 \mathrm{~min}$ at $2 \mathrm{~m}^{3} \mathrm{yr}^{-1}, 10 \mathrm{~min}$ at $20 \mathrm{~m}^{3} \mathrm{yr}^{-1}$, and $5-5 \frac{1}{2} \mathrm{hr}$ at $0.2 \mathrm{~m}^{3} \mathrm{yr}^{-1}$ ).

Four basic types of tests were performed: (1) "q(splash)" test, in which the splash distance was measured when a drop falls onto the drip shield surface; (2) "q(film)" tests, where the primary goals were to measure rivulet spread and the amount of flow into a single breach in the drip shield; (3) multiple breach tests, which were similar to the q(film) tests, except that multiple breaches existed in the drip shield mock-up; and (4) bounding flow rate tests, which repeated the $\mathrm{q}($ film) and multiple breach tests using different drip rates. Most of the tests were performed on both a smooth drip shield and a rough drip shield.

The dripping distance was based on design parameters and carried out at full scale. Thus the dripping distance used for dripping onto the crown of the drip shield was $2.173 \mathrm{~m}$ (BSC 2003 [DIRS 163406]). The splash radius on the drip shield was measured for both the smooth surface (DTN: MO0207EBSATBWP.022 [DIRS 163400]) and the rough surface (DTN: MO0207EBSATBWP.021 [DIRS 163399]). The maximum lateral splash radius observed in Splash Radius Test \#1 on the smooth surface was $72.5 \mathrm{~cm}$ after 60 drops; in Test \#2, the maximum splash radius was $53.0 \mathrm{~cm}$ after 66 drops. On the rough surface, the maximum lateral splash radius in the five tests that were conducted was $106.5 \mathrm{~cm}$ after 203 drops. In addition to the splash radius tests, splash distances were recorded for some of the single patch $\mathrm{q}($ film) rivulet flow tests; a maximum splash distance of $86 \mathrm{~cm}$ (DTN: M0207EBSATBWP.023 [DIRS 163402]) was observed for drip location Patch $4,8 \mathrm{~cm}$ right of center, onto the crown of 
the drip shield. The distribution of droplet formation on the surface as a function of distance from the impact location was not measured, although an approximate determination was made to distinguish an "inner cluster" of droplets from an "outer fringe," where the droplets were noticeably smaller (Table 4.1-4). It was observed that the outer splashes on the fringe tended to be smaller and less frequent on the rough surface than on the smooth surface.

Observations during the breached drip shield tests revealed that the primary mechanism for water to enter breaches is via rivulet flow that originates from an area around the point of drip impact. Following droplet impact at the crown, beads formed and increased in size around the center of impact with each successive drop. After a time, the beads closest to the downhill curvature would reach a critical mass and roll down the face of the drip shield in the form of a rivulet. The rivulet flow area spreads out in a delta formation (i.e., the maximum spread was located on the vertical section of the drip shield and the minimum spread was located at the point of impact). No film flow was observed during tests on the smooth or the rough drip shield surfaces.

For a given drip location onto the crown of the drip shield (Assumption 5.1), the spreading of the rivulet flow is defined by a spread angle, $\alpha$, which is half of the total spread angle, formed with the vertical plane through the impact point. The total lateral spread of the rivulet flow is given by $2 x \tan \alpha$, where $x$ is the arc length from the crown of the drip shield down to a location of interest. In the breached drip shield experiments (BSC 2003 [DIRS 163406]), the lateral rivulet spread to one side of the vertical plane, or $x \tan \alpha$, was measured. These definitions are illustrated in Figure 6.3-2. The curvature/shape of the drip shield is not shown in Figure 6.3-2 for simplicity and clarity.

The spread of rivulets from drips onto the crown of the experimental drip shield is reported in DTNs: MO0207EBSATBWP.023 [DIRS 163402], MO0207EBSATBWP.024 [DIRS 163401], and MO0207EBSATBWP.025 [DIRS 163403] and summarized in Table 4.1-6. The data are analyzed in Microsoft Excel spreadsheet: Flux Split Drip Shield Model, Worksheet: Spread angles, which is documented in Appendix C. The average spread at $33^{\circ}$ from the crown in 26 measurements was $20.1 \mathrm{~cm}$, corresponding to an average spread angle of about $13.2^{\circ}$. The range of spread angles, from one standard deviation smaller and greater than the mean, was about $8.9^{\circ}$ to $17.3^{\circ}$. The distribution for spread angle is not clearly defined by the experimental data, and therefore a uniform distribution is considered appropriate.

The initial simple model wherein drips flow straight down the curved top of the drip shield is made more realistic by incorporating the random spread of rivulets over an angle $\alpha$ as they flow down the drip shield surface. The spreading of rivulets increases the probability that they will flow into a breach (corrosion patch). Three cases are considered, two for a centrally located breach at different distances from the crown such that different proportions of the rivulet spread will encounter a breach, and one for a breach at the end of the drip shield.

\subsection{Drip Shield Flux for a Centrally Located Breach, Case 1}

Consider a breach that is centrally located on the drip shield. The breach is centrally located if Points A and B (defined below) are located on the same segment of the drip shield as the breach itself. In other words, the ends of the drip shield lie beyond Point A and Point B. Figure 6.5-1 illustrates the location and geometry for potential rivulet flows into a breach with length $2 \ell$ and 
whose top edge is located a curved distance of $x$ from the crown. For simplicity in evaluating coordinates, the zero point of the $y$-axis is coincident with the center of the breach.

In Case $1, \ell>x \tan \alpha$; in other words, the breach is wider than the rivulet spread at the top of the breach.

Points A through D are defined as follows:

- Point A corresponds to the leftmost point from which the edge of the fan from the rivulet can enter the left side of the breach.

- Point B corresponds to the leftmost point from which all rivulets will enter the top edge of the breach. Point B lies between $-\ell$ (left side of the breach) and the origin, $y=0$.

- Point $\mathrm{C}$ corresponds to the rightmost point from which all rivulets will enter the top edge of the breach. Point $\mathrm{C}$ lies between the origin and $+\ell$ (right side of the breach).

- Point D corresponds to the rightmost point at which the edge of the fan from the rivulet can enter the right side of the breach.

Rivulets originating between Point A and Point $-\ell$ can (all or partially) flow into the left side or the top of the breach. Symmetrically, rivulets originating between Point $+\ell$ and Point D can (all or partially) flow into the right side or the top of the breach. All rivulets originating between Point $-\ell$ and $+\ell$ completely flow only into the top of the breach, not into the sides. The $y$-coordinates of Points A through D are:

$$
\begin{aligned}
& y_{A}=-\ell-(x+2 \ell) \tan \alpha \\
& y_{B}=-\ell+x \tan \alpha \\
& y_{C}=\ell-x \tan \alpha \\
& y_{D}=\ell+(x+2 \ell) \tan \alpha .
\end{aligned}
$$

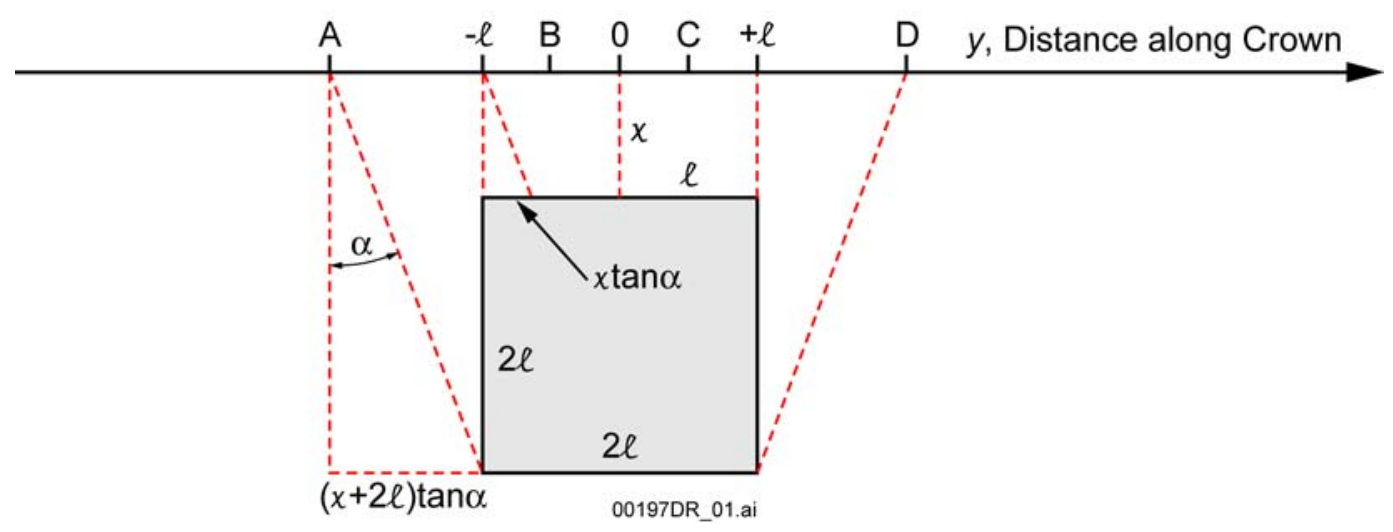

Figure 6.5-1. Geometry and Nomenclature for a Centrally Located Breach with $\ell>x \tan \alpha$ 
For a uniform distribution of rivulet flow between $-\alpha$ and $+\alpha$, the fraction $f$ of the random rivulet flow that enters the breach depends on the origin $y$ of the rivulet:

- For $y \leq y_{A} \quad f_{A-}=0$

- For $y_{A}<y \leq-\ell$,

$$
f_{A \ell}=\frac{y+\ell+(x+2 \ell) \tan \alpha}{2(x+2 \ell) \tan \alpha}
$$

- For $-\ell<y<y_{B}$,

$$
f_{\ell B}=\frac{y+\ell+x \tan \alpha}{2 x \tan \alpha}
$$

- For $y_{B} \leq y \leq y_{C}$,

$$
f_{0}=1
$$

- For $y_{C}<y<\ell$,

$$
f_{C \ell}=\frac{-y+\ell+x \tan \alpha}{2 x \tan \alpha}
$$

- For $\ell \leq y<y_{D}$,

$$
f_{\ell D}=\frac{-y+\ell+(x+2 \ell) \tan \alpha}{2(x+2 \ell) \tan \alpha}
$$

- For $y \geq y_{D}, f_{D+}=0$

In this context, $f$ is essentially a probability distribution function (i.e., the probability that a rivulet will intersect the square corrosion patch). Integrating $f$ over the full length of the drip shield (from $-L_{D S} / 2$ to $+L_{D S} / 2$ ) gives the total water flux through a breach of width $2 \ell$. Then the fraction $F\left(=F_{2} / F_{1}\right)$ of seepage flux passing through the breach is:

$$
\begin{gathered}
F=\frac{1}{2 L_{D S}} \int_{-L_{D S} / 2}^{L_{D S} / 2} f(y) d y \\
=\frac{1}{2 L_{D S}}\left[\int_{y_{A}}^{-\ell} f_{A \ell}(y) d y+\int_{-\ell}^{y_{B}} f_{\ell B}(y) d y+\int_{y_{B}}^{y_{C}} f_{0} d y+\int_{y_{C}}^{+\ell} f_{C \ell}(y) d y+\int_{+\ell}^{y_{D}} f_{\ell D}(y) d y\right] \\
=\frac{\ell}{L_{D S}}+\frac{\ell \tan \alpha}{2 L_{D S}} .
\end{gathered}
$$

The factor of 2 in the denominator starting in Equation 6.5.1.1.2-7 accounts for the seepage flux being split in two when it drips onto the crown of the drip shield, and half of the flux flows down each side. 
The result is independent of $x$, the distance from the crown. The amount of seepage flux that flows into a breach is, however, dependent on the rivulet spread angle $\alpha$. This is reasonable because a wider spread angle allows rivulets from a wider span of the crown to access the breach. In effect, the width of the drip shield crown from which rivulets can flow into a breach is expanded from $2 \ell$ to $2 \ell+\ell \tan \alpha$. Flow into the sides of the breach contributes only a small amount to the total if the spread angle is small. If, for example, $\alpha=13.2^{\circ}$ (the mean spread angle from the drip shield experiments), the total flow into a breach, from Equation 6.5.1.1.2-9, is $\left(\ell / L_{D S}\right)(1+0.117)$, so only about $0.117 / 1.117 \approx 1 / 10$ of the total breach flow enters through the sides of the breach.

As a check on this result, consider the case where the rivulets do not spread out over an angle $\alpha$, but instead flow straight down (i.e., $\alpha=0=\tan \alpha$ ). Then Equation 6.5.1.1.2-9 becomes:

$$
F=\frac{\ell}{L_{D S}}
$$

or

$$
F_{2}=F_{1} \frac{\ell}{L_{D S}} .
$$

Equation 6.5.1.1.2-11 is identical to Equation 6.5.1.1.1-2, which was obtained from simple logic arguments.

As a further check on the validity of Equation 6.5.1.1.2-9, consider a single patch located adjacent to the crown, just far enough away from the crown that the dripping seepage flux can impinge on the crown and flow down both sides (i.e., $x \approx 0$, about the width of a drop). Water flowing from the crown toward the patch will immediately enter the patch, since the spread over the angle $\alpha$ is negligible. Seepage flux dripping onto the drip shield crown to the left and right of the patch will flow down the drip shield in rivulets, fanning out over the angle $\alpha$. In this case, $y_{A}=-\ell-2 \ell \tan \alpha, y_{B}=-\ell, y_{C}=+\ell$, and $y_{D}=\ell+2 \ell \tan \alpha$. The fractions of the rivulet flow down one side of the drip shield into the patch are:

- For $y \leq y_{A}, \quad f_{A-}=0$

- For $y \leq y_{A}, \quad f_{A-}=0$,

$$
f_{A \ell}=\frac{y+\ell+2 \ell \tan \alpha}{4 \ell \tan \alpha}
$$

- For $-\ell \leq y \leq \ell$,

$$
f_{0}=1
$$


- For $y_{C}=\ell<y<y_{D}$,

$$
f_{\ell D}=\frac{-y+\ell+2 \ell \tan \alpha}{4 \ell \tan \alpha}
$$

- For $y \geq y_{D}, f_{D+}=0$.

Moving right from $y=y_{A}$, where $f=0, f$ increases linearly until $y=-\ell^{-}$(on the left side of $-\ell$ ), where $f=1 / 2$; because half of the rivulet fan is directed away from the patch at that point, at most half of the rivulet will enter the patch. Between $-\ell$ and $+\ell$, all of the rivulets flow directly into the patch, so $f=1$. As on the left side of the patch, to the right of the patch, from $y=\ell$ to $y=y_{D}=\ell+2 \ell \tan \alpha, f$ decreases linearly from $1 / 2$ to 0 . Performing the same integration as in Equations 6.5.1.1.2-7 and 6.5.1.1.2-8 results in:

$$
F=\frac{\ell}{L_{D S}}+\frac{\ell \tan \alpha}{2 L_{D S}},
$$

which is again identical to Equation 6.5.1.1.2-9. Since, as seen earlier, the flow into the top edge of the patch is $\ell / L_{D S}$, the term $\ell \tan \alpha /\left(2 L_{D S}\right)$ accounts for rivulet flow into the sides of the patch for this bounding example.

Multiple patches increase the flow into patches in direct proportion to the number of patches, assuming that patches do not interfere:

$$
F=N_{b}\left[\frac{\ell}{L_{D S}}+\frac{\ell \tan \alpha}{2 L_{D S}}\right],
$$

or

$$
F_{2}=F_{1} N_{b}\left[\frac{\ell}{L_{D S}}+\frac{\ell \tan \alpha}{2 L_{D S}}\right] .
$$

If patches are located below other patches, the rivulets are intercepted by the higher patches, and none or less flows into lower patches. In that case, the flux through the drip shield, $F_{2}$, is less than predicted by Equation 6.5.1.1.2-17. That is, neglecting interference among multiple patches and using Equation 6.5.1.1.2-17 overestimates releases of radionuclides.

\subsection{Drip Shield Flux for a Centrally Located Breach, Case 2}

In Case 2, $\ell<x \tan \alpha$; in other words, the breach is narrower than the rivulet spread at the top of the breach (see Figure 6.5-2). In Case 1, over some range of $y$ centered at $y=0$, all of the rivulet flow enters the top edge of the breach $\left(f_{0}=1\right)$. In contrast, in Case 2, the rivulet spread is too wide for all of the rivulet flow to enter the breach at any point $\left(f_{0}<1\right)$. 
Points A through D are defined as follows:

- Point A corresponds to the leftmost point from which the edge of the fan from the rivulet can enter the left side and top of the breach.

- Point B corresponds to the rightmost point from which rivulets cannot spread beyond the upper right corner of the breach. Point B lies between $-\ell$ (left side of the breach) and the origin, $y=0$. Rivulets originating between $-\ell$ and Point $\mathrm{B}$ enter only a portion of the top edge of the breach.

- Point $\mathrm{C}$ corresponds to the leftmost point from which rivulets cannot spread beyond the upper left corner of the breach. Point $\mathrm{C}$ lies between the origin and $+\ell$ (right side of the breach). Rivulets originating between Point $\mathrm{C}$ and $+\ell$ enter only a portion of the top edge of the breach. Rivulets originating between Point $\mathrm{B}$ and Point $\mathrm{C}$ can enter the entire top edge of the breach.

- Point D corresponds to the rightmost point at which the edge of the fan from the rivulet can enter the right side and top of the breach.

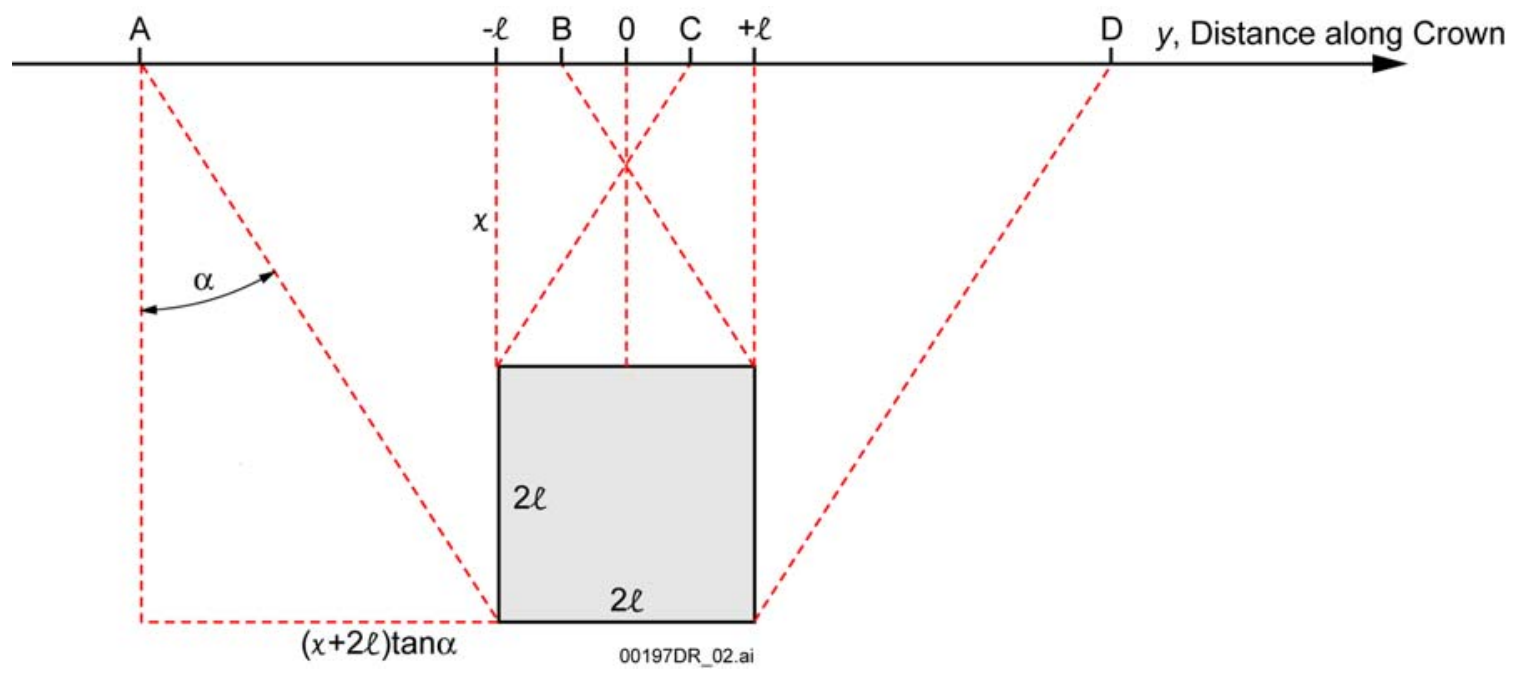

Figure 6.5-2. Geometry and Nomenclature for a Centrally Located Breach with $\ell<x \tan \alpha$

As in Case 1, rivulets originating between Point A and Point $-\ell$ can flow into the left side or the top of the breach. Symmetrically, rivulets originating between Point $+\ell$ and Point $D$ can flow into the right side or the top of the breach. All rivulets originating between Point $-\ell$ and $+\ell$ flow only into the top of the breach, not into the sides. The $y$-coordinates of Points A through D are:

$$
\begin{aligned}
& y_{A}=-\ell-(x+2 \ell) \tan \alpha \\
& y_{B}=\ell-x \tan \alpha \\
& y_{C}=-\ell+x \tan \alpha \\
& y_{D}=\ell+(x+2 \ell) \tan \alpha .
\end{aligned}
$$


The central region boundaries, $y_{B}$ and $y_{C}$, are different for Case 2 than for Case 1.

For a uniform distribution of rivulet flow between $-\alpha$ and $+\alpha$, the fraction $f$ of the random rivulet flow that enters the breach depends on the origin $y$ of the rivulet. These fractions are identical for corresponding regions to those in Case 1 except for the region $y_{B} \leq y \leq y_{C}$, where now $f_{0}<1$ instead of $f_{0}=1$.

- For $y \leq y_{A}, f_{A-}=0$

- For $y_{A}<y \leq-\ell$,

$$
f_{A \ell}=\frac{y+\ell+(x+2 \ell) \tan \alpha}{2(x+2 \ell) \tan \alpha}
$$

- For $-\ell<y<y_{B}$,

$$
f_{\ell B}=\frac{y+\ell+x \tan \alpha}{2 x \tan \alpha}
$$

- For $y_{B} \leq y \leq y_{C}$,

$$
f_{0}=\frac{2 \ell}{2 x \tan \alpha}
$$

- For $y_{C}<y<\ell$,

$$
f_{C \ell}=\frac{-y+\ell+x \tan \alpha}{2 x \tan \alpha}
$$

- For $\ell \leq y<y_{D}$,

$$
f_{\ell D}=\frac{-y+\ell+(x+2 \ell) \tan \alpha}{2(x+2 \ell) \tan \alpha}
$$

- For $y \geq y_{D}, f_{D+}=0$.

Integrating $f$ over the full length of the drip shield (from $-L_{D S} / 2$ to $+L_{D S} / 2$ ), as in Case 1, gives the total water flux through a breach of width $2 \ell$. The fraction $F\left(=F_{2} / F_{1}\right)$ of seepage flux passing through the breach is:

$$
\begin{gathered}
F=\frac{1}{2 L_{D S}} \int_{-L_{D S} / 2}^{L_{D S} / 2} f(y) d y \\
=\frac{1}{2 L_{D S}}\left[\int_{y_{A}}^{-\ell} f_{A \ell}(y) d y+\int_{-\ell}^{y_{B}} f_{\ell B}(y) d y+\int_{y_{B}}^{y_{C}} f_{0} d y+\int_{y_{C}}^{+\ell} f_{C \ell}(y) d y+\int_{+\ell}^{y_{D}} f_{\ell D}(y) d y\right] \\
=\frac{\ell}{L_{D S}}+\frac{\ell \tan \alpha}{2 L_{D S}} .
\end{gathered}
$$


For Case 2, the seepage flux passing through the breach is identical to Case 1 (Equation 6.5.1.1.2-9). This is reasonable considering that $F$ is independent of $x$. In other words, the breach can be located at any distance from the crown, and the same fraction of seepage flux will flow into it. The two cases are really a single case where the breach in Case 2 is simply located further from the crown than in Case 1.

\subsection{Drip Shield Flux for an End-Located Patch}

The drip shield design (BSC 2004 [DIRS 168275], Sheet 1) includes a connector guide at one end and a connector plate at the other end that, being thicker than the plates comprising the top and sides of the drip shield, should survive intact longer than the plates. These components will prevent any rivulets from flowing off the ends of the drip shield. This will alter the fraction of rivulet flow that enters patches that are located at the ends of the drip shield. If the patch is located a short distance from the end, the space between the patch and the connector guide will allow water diverted by the guide to flow down the drip shield instead of into the patch. This distance is unknown, but for simplicity is chosen to be zero (i.e., if the patch is not coincident with the connector guide, it behaves as a centrally located patch).

Consider a breach that is located at one end of the drip shield. Figure 6.5-3 illustrates the location and geometry for potential rivulet flows into a breach with length $2 \ell$ and whose top edge is located a distance of $x$ from the crown. For simplicity in evaluating coordinates, the zero point of the $y$-axis is again coincident with the center of the patch, and the end of the patch as well as the drip shield are at $y=-\ell$.

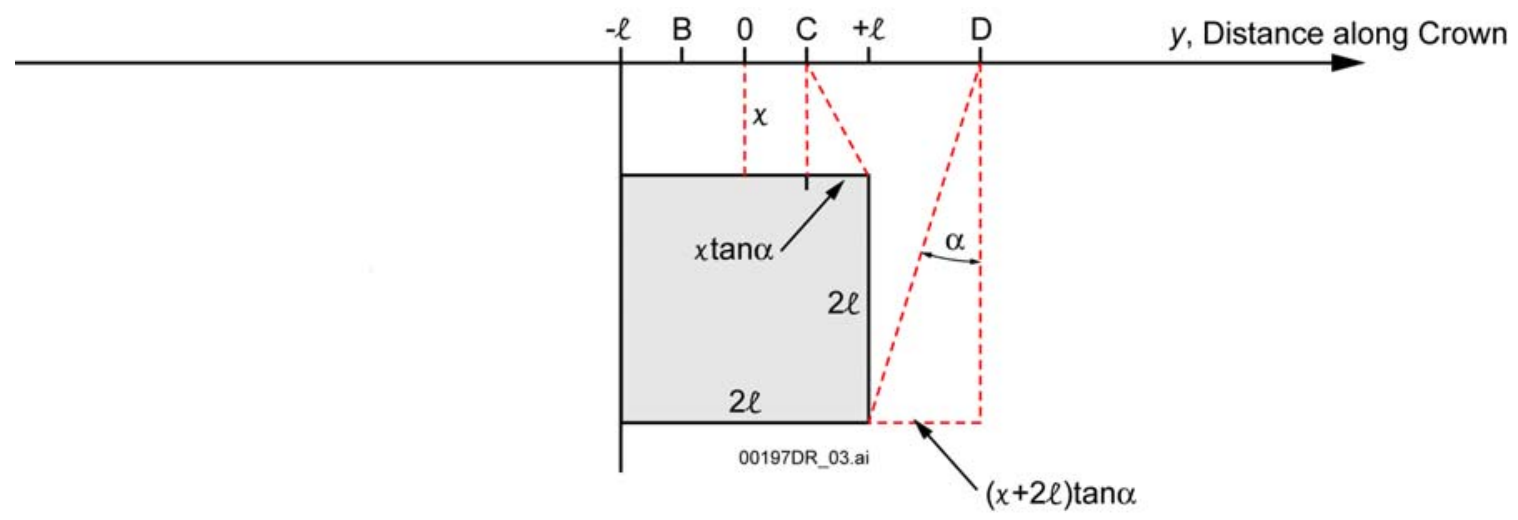

Figure 6.5-3. Geometry and Nomenclature for an End-Located Breach with $\ell>x \tan \alpha$

The Points $\mathrm{C}$ and $\mathrm{D}$ are defined as above for Case 1. Point $\mathrm{A}$ is beyond the end of the drip shield, and distinguishing Point $\mathrm{B}$ is unimportant because all rivulets originating to the left of Point $\mathrm{C}$ flow completely into the breach.

$$
\begin{aligned}
& y_{B}=-\ell+x \tan \alpha \\
& y_{C}=\ell-x \tan \alpha \\
& y_{D}=\ell+(x+2 \ell) \tan \alpha .
\end{aligned}
$$


It is shown above that the result is independent of $x$ for the centrally located breach. Therefore, either case is adequate for analysis. For the case where $\ell>x \tan \alpha$, corresponding to Case 1 above, the fraction $f$ of rivulet flow into the patch over ranges of $y$ are:

- For $y \leq-\ell, f=0$

- For $-\ell \leq y \leq y_{C}$,

$$
f_{0}=1
$$

- For $y_{C}<y<\ell$,

$$
f_{C \ell}=\frac{-y+\ell+x \tan \alpha}{2 x \tan \alpha}
$$

- For $\ell \leq y<y_{D}$,

$$
f_{\ell D}=\frac{-y+\ell+(x+2 \ell) \tan \alpha}{2(x+2 \ell) \tan \alpha}
$$

- For $y \geq y_{D}, f_{D+}=0$.

Integrating $f$ over the full length of the drip shield (from $-L_{D S} / 2$ to $+L_{D S} / 2$ ) gives the total water flux through a breach of width $2 \ell$. The fraction $F\left(=F_{2} / F_{1}\right)$ of seepage flux passing through the breach is:

$$
\begin{aligned}
F & =\frac{1}{2 L_{D S}} \int_{-L_{D S} / 2}^{L_{D S} / 2} f(y) d y \\
& =\frac{1}{2 L_{D S}}\left[\int_{-\ell}^{y_{C}} f_{0} d y+\int_{y_{C}}^{+\ell} f_{C \ell}(y) d y+\int_{+\ell}^{y_{D}} f_{\ell D}(y) d y\right] \\
& =\frac{\ell}{L_{D S}}+\frac{\ell \tan \alpha}{4 L_{D S}} .
\end{aligned}
$$

Thus, the seepage flux fraction $F$ for breaches at the end of the drip shield is independent of the distance $x$ from the crown. The only difference from centrally located breaches is the term that accounts for flow into the side of a breach $\left[\ell \tan \alpha /\left(4 L_{D S}\right)\right]$. Since only one side of the breach is accessible to rivulet flow, the flow through the one side of the breach at the end of the drip shield is just half of the flow through two sides in a centrally located breach.

As seen above, for a small rivulet spread angle, the portion of the flow into a breach that enters through the side is small. For an end breach, that fraction is even smaller. In the example given in Section 6.5.1.1.2.1, for a mean spread angle of $\alpha=13.2^{\circ}$, flow through the sides of the breach 
accounts for only about $1 / 10$ of the total. For an end breach, based on Equation 6.5.1.1.2-33, side flow will account for only 6 percent in this example. In Section 6.5.1.1.2, experimental results are discussed that show the spread angle is approximately $13.2^{\circ}$ and that the amount of seepage flux that actually enters a breach varies widely. Differences of 6 percent are negligible. Since the end-located breach model (Equation 6.5.1.1.2-33) applies only to breaches that are exactly at the ends of the drip shield, which will be an infrequent occurrence, it is reasonable to ignore the distinction between end breaches and centrally located breaches.

Then the flux through one patch in the drip shield is:

$$
F_{2}=F_{1} \frac{\ell}{L_{D S}}\left(1+\frac{\tan \alpha}{2}\right) .
$$

\subsection{Analysis of Breached Drip Shield Experiments}

The breached drip shield experiments (BSC 2002 [DIRS 158193]; BSC 2003 [DIRS 163406]) provide estimates of the rivulet spread factor from which the spread angle $\alpha$ can be determined (DTN: MO0207EBSATBWP.022 [DIRS 163400]), the splash radius from drops falling from the roof of the drift to the crown of the drip shield (DTN: MO0207EBSATBWP.022 [DIRS 163400]), and the flow into breaches from a number of discrete drip locations (DTN: MO0207EBSATBWP.023 [DIRS 163402]). In addition, the tests characterized the flow behavior on the drip shield surface, determining that flow occurs as rivulets rather than as film flow.

In Splash Radius Test \#1 (DTN: MO0207EBSATBWP.022 [DIRS 163400]), water was dripped onto the drip shield crown, and the distance that the water splattered was measured. In 12 separate sets of measurements (Table 4.1-4), using from 1 to 90 drips, splash distances to the right ranged from $1.6 \mathrm{~cm}$ (single drip) to $63.2 \mathrm{~cm}$ (49 drips); splash distances to the left ranged from $1.6 \mathrm{~cm}$ (single drip) to $72.5 \mathrm{~cm}$ (60 drips). Tests using larger numbers of drips tended to result in larger maximum splash distances. "Outer fringe" measurements using more than 20 drips ranged from $31.5 \mathrm{~cm}$ to $72.5 \mathrm{~cm}$, whereas "inner cluster" measurements using more than 20 drips ranged from $25.0 \mathrm{~cm}$ to $48.0 \mathrm{~cm}$. The definition of the grouping as "outer fringe" and "inner cluster" was not specified, but the results indicate a distribution of splashed water heavily weighted to a median radius of about $40 \mathrm{~cm}$.

The splash radius is useful for providing a distribution of rivulet origins based on limited experimental data. In the flow tests, water was dripped onto the drip shield in only a few discrete locations. In order to make greater use of the data to determine the uncertainty in applying the drip shield flux splitting submodel (Equation 6.5.1.1.2-34), the distribution of splattered water can be treated as multiple drip locations in comparing Equation 6.5.1.1.2-34 to the experimental data.

Rivulet spread was measured in single patch q(film) tests (DTN: MO0207EBSATBWP.023 [DIRS 163402]), multiple patch tests (DTN: MO0207EBSATBWP.024 [DIRS 163401]), and in bounding flow rate tests (DTN: MO0207EBSATBWP.025 [DIRS 163403]). Table 4.1-3 summarizes the maximum rivulet spread to the left and right of a straight line down the drip shield from the drip impact point. The rivulet spread data are analyzed in Microsoft Excel 
spreadsheet: Flux Split Drip Shield Model, Worksheet: Spread angles, which is documented in Appendix C. The results-the mean and range of spread angles-are reported in Section 6.5.1.1.2.

Rivulet spread measurements at the top edge of patches in the drip shield mock-up are used. The distance $x$ from the drip location on the crown of the drip shield to the point of measurement is determined from the drawing of the drip shield mock-up shown in Figure 4.1-1, which is reproduced from Howard (2002 [DIRS 161516], p. 14). Various dimensions used in the Microsoft Excel spreadsheet analysis of the data are listed in Table 6.5-1. Because the drip shield top surface is a circular arc (Figure 4.1-1), the $16.5^{\circ}$ line is at half the distance from the crown to the $33^{\circ}$ line, or $0.43 \mathrm{~m}$ from the crown.

Table 6.5-1. Dimensions Used in the Analysis of Breached Drip Shield Experiments, Based on Dimensions Shown in Figure 4.1-1

\begin{tabular}{|l|l|c|}
\hline \multicolumn{1}{|c|}{ Dimension } & \multicolumn{1}{|c|}{ Calculation } & Distance $(\mathrm{m})$ \\
\hline Crown to $33^{\circ}$ line & $2.44 \mathrm{~m}-0.94 \mathrm{~m}-0.64 \mathrm{~m}$ & 0.86 \\
\hline Crown to $16.5^{\circ}$ line & $1 / 2$ distance from Crown to $33^{\circ}$ line & 0.43 \\
\hline Crown to top edge of Patch 4 & $2.44 \mathrm{~m}-0.94 \mathrm{~m}-0.135 \mathrm{~m}$ & 1.365 \\
\hline Crown to top edge of Patch 5 & $2.44 \mathrm{~m}-0.94 \mathrm{~m}-0.64 \mathrm{~m}$ & 0.86 \\
\hline Crown to transition line & $2.44 \mathrm{~m}-0.94 \mathrm{~m}$ & 1.50 \\
\hline $16.5^{\circ}$ line to transition line & $0.43 \mathrm{~m}$ (Crown to $16.5^{\circ}$ line) $+0.64 \mathrm{~m}$ & 1.07 \\
\hline $16.5^{\circ}$ line to $33^{\circ}$ line & $1 / 2$ distance from Crown to $33^{\circ}$ line & 0.43 \\
\hline $16.5^{\circ}$ line to Patch 4 & $0.43 \mathrm{~m}$ (Crown to $16.5^{\circ}$ line) $+0.64 \mathrm{~m}-0.135 \mathrm{~m}$ & 0.935 \\
\hline $16.5^{\circ}$ line to Patch 5 & $1 / 2$ distance from Crown to $33^{\circ}$ line & 0.43 \\
\hline $33^{\circ}$ line to Patch 4 & $0.64 \mathrm{~m}-0.135 \mathrm{~m}$ & 0.505 \\
\hline $33^{\circ}$ line to transition line & $0.64 \mathrm{~m}$ & 0.64 \\
\hline $\begin{array}{l}1 / 2 \text { distance between Crown and } 16.5^{\circ} \\
\text { line to Patch 4 }\end{array}$ & $\begin{array}{l}1 / 2\left(0.43 \mathrm{~m} \text { [Crown to } 16.5^{\circ} \text { line]) }+0.43 \mathrm{~m}\left(16.5^{\circ} \text { line to }\right.\right. \\
33^{\circ} \text { line) }+0.64 \mathrm{~m}-0.135 \mathrm{~m}\end{array}$ & 1.15 \\
\hline
\end{tabular}

Source: Howard 2002 [DIRS 161516], p. 14.

Since the experiments involved dripping at a few discrete locations, it is not possible to calculate the flux through the drip shield as given by Equation 6.5.1.1.2-34 using experimental data. Instead, the fraction $f$ of dripping flux at an individual drip location that flows into a given breach can be computed for the tests and compared with the fraction expected using one of the Equations 6.5.1.1.2-1 to 6.5.1.1.2-6 (Case 1) or 6.5.1.1.2-18 to 6.5.1.1.2-23 (Case 2). The appropriate equation to be used depends on the drip location relative to the breach. The variability in the experimental values $\left(f_{\text {expt }}\right)$ and comparisons with calculated values $\left(f_{\text {calc }}\right)$ show the range of uncertainty in the drip shield flux ratio $F=F_{2} / F_{1}$. The values of $f_{\text {expt }}$ and $f_{\text {calc }}$ are calculated in Microsoft Excel spreadsheet: Flux Split Drip Shield Model, Worksheet: f calculations, which is documented in Appendix C.

Experimental data from two breaches are pertinent to this analysis-Breach 4 and Breach 5. Breach 4 straddled the transition line between the top of the drip shield and the vertical side, with the top edge $136.5 \mathrm{~cm}$ from the crown. Breach 5 was located on the top of the drip shield, about half way between the crown and the transition line, with the top edge $86 \mathrm{~cm}$ from the crown. 
Table 6.5-2 shows the fraction of the total dripping flux that entered a breach in each of 14 tests. The data sources are single patch $\mathrm{q}(\mathrm{film})$ test results (DTN: MO0207EBSATBWP.023 [DIRS 163402]), multiple patch test results (DTN: MO0207EBSATBWP.024 [DIRS 163401]), and bounding flow rate test results (DTN: MO0207EBSATBWP.025 [DIRS 163403]), and are given in Table 4.1-2. The results are compared with calculated fractions for the mean spread angle as well as for the spread angles corresponding to plus or minus one standard deviation from the mean rivulet spread angle. The experimentally observed fractions, $f_{\text {expt }}$, were calculated assuming that one-half of the measured total dripping flux flowed down the side of the drip shield where the breaches were located. This is necessary for $f_{\text {expt }}$ to be consistent with the fractions in Sections 6.5.1.1.2.1 and 6.5.1.1.2.2, which are the fractions of flow down one side of the drip shield that enters a breach. 
Table 6.5-2. Comparison of Experimental Breach Inflow Fractions with Model Calculations from Appendix C

\begin{tabular}{|c|c|c|c|c|c|c|c|}
\hline \multirow[b]{2}{*}{$\begin{array}{l}\text { Drip Location } \\
\text { (Test Description) }\end{array}$} & \multirow[b]{2}{*}{$\begin{array}{l}\text { Breach } \\
\text { No. }\end{array}$} & \multirow{2}{*}{$\begin{array}{c}y, \text { Drip } \\
\text { Location } \\
\text { Relative to } \\
\text { Breach Center } \\
\text { (cm) }\end{array}$} & \multirow{2}{*}{$\begin{array}{c}\boldsymbol{x}, \text { Vertical } \\
\text { Distance from } \\
\text { Crown (drip) } \\
\text { to Top of } \\
\text { Breach }(\mathbf{c m})\end{array}$} & \multirow[b]{2}{*}{$\boldsymbol{f}_{\text {expt }}$} & \multicolumn{3}{|c|}{$\boldsymbol{f}_{\text {calc }}$} \\
\hline & & & & & $\alpha=8.9^{\circ}$ & $\alpha=13.2^{\circ}$ & $\alpha=17.3^{\circ}$ \\
\hline $\begin{array}{l}8 \mathrm{~cm} \text { right of Patch } 4 \\
\text { centerline (Q[film] Test) }\end{array}$ & 4 & 8 & 136.5 & 0.247 & 0.629 & 0.423 & 0.318 \\
\hline $\begin{array}{l}\text { Patch } 5 \text { centerline (Q[film] } \\
\text { Test) }\end{array}$ & 5 & 0 & 86.0 & 0.258 & 1.000 & 0.672 & 0.504 \\
\hline $\begin{array}{l}4 \mathrm{~cm} \text { left of Patch } 5 \\
\text { centerline (Q[film] Test) }\end{array}$ & 5 & -4 & 86.0 & 0.136 & 0.854 & 0.680 & 0.504 \\
\hline $\begin{array}{l}\text { Patch } 4 \text { centerline (Q[film] } \\
\text { Test) }\end{array}$ & 4 & 0 & 136.5 & 0.236 & 0.634 & 0.423 & 0.318 \\
\hline $\begin{array}{l}27 \mathrm{~cm} \text { right of drip shield } \\
\text { center (Multiple Patch } \\
\text { Test) }\end{array}$ & 5 & -27 & 86.0 & 0.033 & 0.117 & 0.244 & 0.504 \\
\hline $\begin{array}{l}27 \mathrm{~cm} \text { left of drip shield } \\
\text { center (Multiple patch test) }\end{array}$ & 4 & 27 & 136.5 & 0.019 & 0.236 & 0.323 & 0.318 \\
\hline $\begin{array}{l}81 \mathrm{~cm} \text { left of drip shield } \\
\text { center (Multiple Patch } \\
\text { Test) }\end{array}$ & 4 & -27 & 136.5 & 0.031 & 0.236 & 0.323 & 0.318 \\
\hline $\begin{array}{l}81 \mathrm{~cm} \text { right of drip shield } \\
\text { center (Multiple Patch } \\
\text { Test) }\end{array}$ & 5 & 27 & 86.0 & 0.032 & 0.117 & 0.244 & 0.504 \\
\hline $\begin{array}{l}54 \mathrm{~cm} \text { left of drip shield } \\
\text { center (High Flow Rate } \\
\text { Test) }\end{array}$ & 4 & 0 & 136.5 & 0.275 & 0.634 & 0.423 & 0.318 \\
\hline $\begin{array}{l}54 \mathrm{~cm} \text { left of drip shield } \\
\text { center (Low Flow Rate } \\
\text { Test) }\end{array}$ & 4 & 0 & 136.5 & 0.177 & 0.634 & 0.423 & 0.318 \\
\hline $\begin{array}{l}27 \mathrm{~cm} \text { left of drip shield } \\
\text { center (High Flow Rate } \\
\text { Test) }\end{array}$ & 4 & 27 & 136.5 & 0.020 & 0.236 & 0.323 & 0.318 \\
\hline $\begin{array}{l}27 \mathrm{~cm} \text { left of drip shield } \\
\text { center (Low Flow Rate } \\
\text { Test) }\end{array}$ & 4 & 27 & 136.5 & 0.013 & 0.236 & 0.323 & 0.318 \\
\hline $\begin{array}{l}27 \mathrm{~cm} \text { right of drip shield } \\
\text { center (High Flow Rate } \\
\text { Test) }\end{array}$ & 5 & -27 & 86.0 & 0.013 & 0.117 & 0.244 & 0.504 \\
\hline $\begin{array}{l}27 \mathrm{~cm} \text { right of drip shield } \\
\text { center (Low Flow Rate } \\
\text { Test) }\end{array}$ & 5 & -27 & 86.0 & 0.065 & 0.117 & 0.244 & 0.504 \\
\hline \multicolumn{4}{|l|}{ Mean } & 0.111 & 0.414 & 0.380 & 0.398 \\
\hline \multicolumn{4}{|l|}{ Std. Dev. } & 0.106 & 0.305 & 0.144 & 0.096 \\
\hline \multicolumn{4}{|l|}{ Median } & 0.049 & 0.236 & 0.323 & 0.318 \\
\hline \multicolumn{4}{|l|}{ Minimum } & 0.013 & 0.117 & 0.244 & 0.318 \\
\hline \multicolumn{4}{|l|}{ Maximum } & 0.275 & 1.000 & 0.680 & 0.504 \\
\hline
\end{tabular}

DTNS: MO0207EBSATBWP.023 [DIRS 163402]; MO0207EBSATBWP.024 [DIRS 163401];

MO0207EBSATBWP.025 [DIRS 163403]. 
The experimentally observed fraction of drip seepage flowing into a breach varies widely. This variability is primarily due to the drip location-when the drip location is centered over the breach, much of the flow enters the breach, and when the drip is far off to the side of a breach, little of it enters the breach. However, the variability also includes differences in drip rate, the distance from the crown to the breach, evaporation from the drip shield surface, and random variability in drop splashing and rivulet flow behavior.

The fraction of drip seepage flowing into a breach calculated from the model is found always to be higher than observed experimentally, particularly when the drip location is far from the breach. When the drip location is well away from the patch center, and little water flows into the breaches ( $f_{\text {expt }}$ less than about 0.1), the model overestimates the experimental fraction increasingly as the estimated spread angle increases (see Table 6.5-3). In contrast, the model predicts that ever-increasing amounts of water flow into a breach as the spread angle increases. This can be seen in Equation 6.5.1.1.2-34, which shows that the flow into breaches is proportional to $(1+1 / 2 \tan \alpha)$, so as the spread angle $\alpha$ increases, so does the flow into breaches. Evaporation also plays a part. The model assumes no evaporative losses (Assumption 5.2), whereas evaporation from the drip shield occurred in the experiments because the relative humidity was less than 100 percent. Using a larger spread angle in the model results in increased predicted flow into a breach, whereas evaporation consistently reduces the experimentally measured inflow. Thus, ignoring the observed occurrence of evaporation in the development of the drip shield flux splitting submodel will overestimate the transport of radionuclides.

When the drip location is directly above the breach, the model agrees more closely with experiments as the spread angle increases. Again, the model generally overestimates the flow into breaches. In this case, as the estimated spread angle increases, less flow into breaches is predicted, so the model agrees more closely with experiments.

A major reason for the differences between the flux splitting submodel calculations and the experimental results is that splashing of the drops when they impinged on the drip shield resulted in a dispersed source of rivulets. In contrast, the model supposes that the entire dripping flux flows down the drip shield from the point of impact. Splattering spreads the dripping flux over a wide span of the drip shield crown. The splash radius tests recorded splashes that extended up to $72.5 \mathrm{~cm}$ from the drip location, with an "inner cluster" radius of 25 to $48 \mathrm{~cm}$ (DTN: MO0207EBSATBWP.022 [DIRS 163400]). In three of the $q($ film) rivulet flow tests, lateral splash distances ranging from $54.5 \mathrm{~cm}$ to $86 \mathrm{~cm}$ from the drip point on the crown were observed (DTN: MO0207EBSATBWP.023 [DIRS 163402], Drip Location: Patch 5, center, crown; Patch 4, center, crown; and Patch 4, $8 \mathrm{~cm}$ right of center, crown). Since a large portion of the dripping flux in the tests splattered beyond the range of rivulet flow into individual breaches, the flow into breaches was much less than predicted by the model. Thus, ignoring the observed occurrence of splattering in the development of the drip shield flux splitting submodel will overestimate the transport of radionuclides. 
Table 6.5-3. Additional Comparisons of Experimental Breach Inflow Fractions with Model Calculations from Appendix C

\begin{tabular}{|c|c|c|c|c|c|c|c|}
\hline \multirow{2}{*}{$\begin{array}{c}\text { Drip Location } \\
\text { (Test Description) }\end{array}$} & \multirow[b]{2}{*}{$f_{\text {expt }}$} & \multicolumn{3}{|c|}{$\boldsymbol{f}_{\text {calc }}-\boldsymbol{f}_{\text {expt }}$} & \multicolumn{3}{|c|}{$\boldsymbol{f}_{\text {calc }} / \boldsymbol{f}_{\text {expt }}$} \\
\hline & & $\alpha=8.9^{\circ}$ & $\alpha=13.2^{\circ}$ & $\alpha=17.3^{\circ}$ & $\alpha=8.9^{\circ}$ & $\alpha=13.2^{\circ}$ & $\alpha=17.3^{\circ}$ \\
\hline $\begin{array}{l}8 \mathrm{~cm} \text { right of Patch } 4 \text { centerline } \\
(\mathrm{Q}[\mathrm{film}] \text { Test) }\end{array}$ & 0.247 & 0.382 & 0.176 & 0.071 & 2.545 & 1.713 & 1.286 \\
\hline $\begin{array}{l}\text { Patch } 5 \text { centerline } \\
\text { (Q[film] Test) }\end{array}$ & 0.258 & 0.742 & 0.414 & 0.246 & 3.876 & 2.604 & 1.955 \\
\hline $\begin{array}{l}4 \mathrm{~cm} \text { left of Patch } 5 \text { centerline } \\
\text { (Q[film] Test) }\end{array}$ & 0.136 & 0.718 & 0.544 & 0.368 & 6.277 & 4.998 & 3.707 \\
\hline $\begin{array}{l}\text { Patch } 4 \text { centerline (Q[film] } \\
\text { Test) }\end{array}$ & 0.236 & 0.398 & 0.187 & 0.082 & 2.686 & 1.794 & 1.347 \\
\hline $\begin{array}{l}27 \mathrm{~cm} \text { right of drip shield } \\
\text { center (Multiple Patch Test) }\end{array}$ & 0.033 & 0.085 & 0.212 & 0.472 & 3.606 & 7.515 & 15.507 \\
\hline $\begin{array}{l}27 \mathrm{~cm} \text { left of drip shield center } \\
\text { (Multiple patch test) }\end{array}$ & 0.019 & 0.217 & 0.304 & 0.299 & 12.393 & 17.016 & 16.722 \\
\hline $\begin{array}{l}81 \mathrm{~cm} \text { left of drip shield center } \\
\text { (Multiple Patch Test) }\end{array}$ & 0.031 & 0.205 & 0.293 & 0.287 & 7.720 & 10.600 & 10.417 \\
\hline $\begin{array}{l}81 \mathrm{~cm} \text { right of drip shield } \\
\text { center (Multiple Patch Test) }\end{array}$ & 0.032 & 0.085 & 0.212 & 0.472 & 3.662 & 7.632 & 15.750 \\
\hline $\begin{array}{l}54 \mathrm{~cm} \text { left of drip shield center } \\
\text { (High Flow Rate Test) }\end{array}$ & 0.275 & 0.359 & 0.148 & 0.043 & 2.306 & 1.540 & 1.156 \\
\hline $\begin{array}{l}54 \mathrm{~cm} \text { left of drip shield center } \\
\text { (Low Flow Rate Test) }\end{array}$ & 0.177 & 0.456 & 0.246 & 0.140 & 3.574 & 2.387 & 1.792 \\
\hline $\begin{array}{l}27 \mathrm{~cm} \text { left of drip shield center } \\
\text { (High Flow Rate Test) }\end{array}$ & 0.020 & 0.215 & 0.303 & 0.298 & 11.693 & 16.055 & 15.777 \\
\hline $\begin{array}{l}27 \mathrm{~cm} \text { left of drip shield center } \\
\text { (Low Flow Rate Test) }\end{array}$ & 0.013 & 0.223 & 0.310 & 0.305 & 18.286 & 25.108 & 24.673 \\
\hline $\begin{array}{l}27 \mathrm{~cm} \text { right of drip shield } \\
\text { center (High Flow Rate Test) }\end{array}$ & 0.013 & 0.104 & 0.231 & 0.491 & 9.064 & 18.888 & 38.978 \\
\hline $\begin{array}{l}27 \mathrm{~cm} \text { right of drip shield } \\
\text { center (Low Flow Rate Test) }\end{array}$ & 0.065 & 0.053 & 0.180 & 0.440 & 1.815 & 3.781 & 7.804 \\
\hline Mean & 0.111 & 0.303 & 0.269 & 0.287 & 6.393 & 8.688 & 11.205 \\
\hline Std. Dev. & 0.106 & 0.221 & 0.107 & 0.155 & 4.885 & 7.672 & 11.033 \\
\hline Median & 0.049 & 0.220 & 0.239 & 0.298 & 3.769 & 6.256 & 9.110 \\
\hline Minimum & 0.013 & 0.053 & 0.1484 & 0.043 & 1.8145 & 1.540 & 1.156 \\
\hline Maximum & 0.275 & 0.742 & 0.5439 & 0.491 & 18.286 & 25.108 & 38.978 \\
\hline
\end{tabular}


Table 6.5-4. Water Collected in Drip Shield Experiment Q(film); Drip Location: Patch 4, $8 \mathrm{~cm}$ Right of Center, Crown

\begin{tabular}{|l|c|c|c|c|}
\hline Collection Station & Initial Mass (g) & Final Mass (g) & Net Water Mass (g) & $\begin{array}{c}\text { Water Collected in } \\
\text { Each Group of } \\
\text { Collection Stations (g) }\end{array}$ \\
\hline Input Water & -50.32 & -228.52 & -178.20 & 178.20 \\
\hline Gutter 1-1 & 7.652 & 16.434 & 8.782 & \multirow{2}{*}{36.351} \\
\hline Gutter 3-1 & 7.611 & 8.677 & 1.066 & \\
\hline Gutter 3-2 & 7.600 & 23.213 & 15.613 & \\
\hline Gutter 3-3 & 7.612 & 8.899 & 1.287 & \\
\hline Gutter 3-4 & 7.521 & 17.124 & 9.603 & \multirow{2}{*}{24.00} \\
\hline Breach 2 & 107.02 & 109.00 & 1.98 & \multirow{2}{*}{72.685} \\
\hline Breach 4 & 107.60 & 129.62 & 22.02 & \\
\hline Drip Shield OUT 1 & 7.634 & 8.738 & 1.104 & \\
\hline Drip Shield OUT 2 & 7.578 & 19.681 & 12.103 & \\
\hline Drip Shield OUT 3 & 7.574 & 34.446 & 26.872 & \\
\hline Drip Shield OUT 4 & 7.702 & 40.308 & 32.606 & \\
\hline
\end{tabular}

DTN: MO0207EBSATBWP.023 [DIRS 163402].

One other cause for the discrepancies between experimental and predicted flow fractions is that, in the model, all dripping flux flows down the drip shield surface. In the experiments, a large amount of water remained on the drip shield as splattered drops that had not yet grown large enough to flow down the surface. For example, Table 6.5-4 shows the amount of water collected in the first experiment listed in Table 6.5-2. Of the $178.2 \mathrm{~g}$ of water that was dripped onto the surface, only $60.35 \mathrm{~g}$ was collected from the breaches or drainage gutters, whereas $72.685 \mathrm{~g}$, or 41 percent, remained on the surface ("Drip Shield OUT" entries). This is a source of uncertainty in the experimental results that could be reduced by increasing the duration of the experiment far beyond the one-hour length of the test, but is inherent in the experiment and cannot be eliminated. The result is that less of the dripping flux actually flowed down the drip shield surface than is predicted by the model. This also causes the model to overestimate the fraction that flows into breaches, and, therefore, overestimates the transport of radionuclides.

Results presented in Table 6.5-2 and Table 6.5-3 show a large uncertainty in the fraction of rivulet flow that enters breaches. The integrated fraction of flow into breaches, which is the desired result, is not readily discerned from the uncertainty in the inflow fractions, even though the flows obtained experimentally are more clearly quantified.

Another approach, which is used to develop an uncertainty factor for use in TSPA-LA, is to apply the integrated flow fraction approach to a drip shield whose length is about as wide as the splash diameter. If the rivulet source is dispersed along the crown, the integrated flow into a breach, Equation 6.5.1.1.2-34, can be applied. However, instead of the full drip shield length, the splash diameter is used for $L_{D S}$. Thus, for the breached drip shield experiments, $L_{D S}$ has a range that is double the measured range for "inner cluster" splash radius (25 to $48 \mathrm{~cm}$, as discussed at the beginning of this section, Section 6.5.1.1.2.4), or 50 to $96 \mathrm{~cm}$. 
The uncertainty in the effective drip shield length and in the spread angle is accounted for in a parameter $f_{D S}$, and the fraction of seepage flux that enters a breach, $F_{2} / F_{1}$, is written as in Equation 6.3.2.4-2:

$$
F_{2} / F_{1}=\frac{N_{b} \ell}{L_{D S}}\left(1+\frac{\tan \alpha}{2}\right) f_{D S}
$$

In this approach, the uncertainty factor $f_{D S}$ is obtained by replacing $F_{2} / F_{1}$ with $f_{\text {expt }}$, the experimental fraction of drip flow that enters a breach:

$$
\begin{aligned}
f_{D S}= & \frac{F_{2} / F_{1}}{\frac{\ell}{L_{D S}}\left(1+\frac{\tan \alpha}{2}\right)} \\
= & \frac{f_{\text {expt }}}{\frac{\ell}{L_{D S}}\left(1+\frac{\tan \alpha}{2}\right)} .
\end{aligned}
$$

The range of values for $f_{D S}$ is obtained by evaluating it with the appropriate minimum and maximum values of $L_{D S}$ and $\alpha$ so as to minimize and maximize $f_{D S}$. The minimum value of $f_{D S}$, using $L_{D S}=50 \mathrm{~cm}$ and $\alpha=17.3^{\circ}$, is $f_{D S}=3.205 f_{\text {expt }}=0.356$ using the mean value of 0.111 for $f_{\text {expt }}$. The maximum value of $f_{D S}$, using $L_{D S}=96 \mathrm{~cm}$ and $\alpha=8.9^{\circ}$, is $f_{D S}=6.5947 f_{\text {expt }}=0.732$ using the mean value of 0.111 for $f_{\text {expt }}$. Because zero must be the low end of the range of $f_{D S}$, these estimates are regarded as a range for the maximum value of $f_{D S}$. By treating the experimental drip shield as a segment whose length is the splash diameter, a maximum value of 0.36 to 0.73 for the flux splitting uncertainty factor $f_{D S}$ is obtained.

It is also reasonable to use the median value for $f_{\text {expt }}(0.0486)$ instead of the mean to define the range for $f_{D S}$. In this case, $f_{D S}$ would range from 0.16 to 0.32 , a factor of 2.3 lower than when the mean is used, which gives some indication of the degree of uncertainty in the experimental measurements and the resulting flux splitting submodel.

The drip shield flux splitting submodel, Equation 6.3.2.4-4, includes the rivulet spread angle, $\alpha$. As discussed in Section 6.3.2.4, this equation can be simplified by lumping the uncertainty in $\alpha$ with the range in $f_{D S}$. In Section 6.5.1.1.2, $\alpha$ was found based on experiments to range from about $8.9^{\circ}$ to $17.3^{\circ}$. The uncertainty in $\alpha$ appears as a factor $(1+\tan \alpha / 2)$, ranging from 1.08 to 1.16 , which multiplies $f_{D S}$, resulting in a range for the product $f_{D S}^{\prime}=(1+\tan \alpha / 2) f_{D S}$. The maximum for $f_{D S}^{\prime}$ based on experimental results is $(1.16)(0.73)=0.85$ (using the maximum spread angle of $17.3^{\circ}$ in the factor $(1+\tan \alpha / 2)$ and the minimum spread angle of $8.9^{\circ}$ to define $\left.f_{D S}\right)$. 
The sampled parameter is then $f_{D S}^{\prime}$, and the drip shield flux splitting algorithm is:

$$
F_{2}=\min \left[F_{1} \frac{N_{b} \ell}{L_{D S}} f_{D S}^{\prime}, F_{1}\right]
$$

which is identical to Equation 6.3.2.4-6. Using the higher value of maximum for $f_{D S}^{\prime}$ of 0.85 is both more reliable, being based on experimental data, and overestimates releases of radionuclides by predicting a higher water flow rate through the drip shield. The range for $f_{D S}^{\prime}$ to be used in TSPA-LA is 0 to 0.85 . A uniform distribution is appropriate for $f_{D S}^{\prime}$ because insufficient data are available to define any other distribution.

\subsection{Water Flux through a Breached Waste Package}

The submodel for flow through a breached waste package is conceptually identical to the submodel for flow through a breached drip shield. Key features listed at the start of Section 6.5.1.1.1 apply to both the drip shield and waste package cases. The waste package and drip shield flow submodels differ in two important respects: (1) the radius of curvature of the waste package is less than that of the drip shield; and (2) the nominal corrosion patch size as modeled by WAPDEG (BSC 2004 [DIRS 169996]) is smaller for a waste package than for the drip shield. These differences have no affect on the formulation of the waste package flow model. However, they have an affect on the values of uncertainty parameters that are part of the model. Because experiments were performed on a breached drip shield mock-up but not on a breached waste package mock-up, application of drip shield data to the waste package flow model introduces additional uncertainty in development of the model; however, these uncertainties cannot be quantified.

The water flux through a breached waste package, $F_{4}$, as developed in Section 6.3.3.2, is given by:

$$
F_{4}=\min \left[F_{2} \frac{N_{b W P} \ell_{W P}}{L_{W P}} f_{W P}^{\prime}, F_{2}\right],
$$

where $F_{2}$ is the flux through the breached drip shield. This is a simplification of a more rigorous expression:

$$
F_{4}=\min \left[F_{2} \frac{N_{b W P} \ell_{W P}}{L_{W P}}\left(1+\frac{\tan \alpha}{2}\right) f_{W P}, F_{2}\right],
$$

which explicitly accounts for the rivulet spread angle $\alpha$. Because $\alpha$ is an uncertainty parameter itself, it can be lumped in with the parameter $f_{W P}$ to give $f_{W P}^{\prime}$. Equation 6.5.1.1.3-2 is considered first in order to examine the dependence on $\alpha$. 
As with the drip shield model, the primary mechanism for water to enter breaches is via rivulet flow that originates from an area around the point of drip impact. The rivulets spread out in a delta formation from the point of impact defined by a half-angle, $\alpha$, and the lateral spread of the rivulet flow is given by $2 x \tan \alpha$, where $x$ is the distance along the surface from the crown to the top edge of the breach. The smaller radius of curvature of the waste package would be expected to result in a smaller spread angle, although the difference may be lost in the variability and uncertainty of rivulet flow. The radius of curvature of the drip shield is $1.40 \mathrm{~m}$, whereas waste package radii range from $0.859 \mathrm{~m}$ for a 21-PWR (BSC 2004 [DIRS 169472], Table 1) to $1.063 \mathrm{~m}$ for a 5 DHLW/DOE SNF - Short (BSC 2004 [DIRS 169472], Table 1).

Rivulet spread measurements (DTNs: MO0207EBSATBWP.023 [DIRS 163402] and MO0207EBSATBWP.025 [DIRS 163403]) at the $16.5^{\circ}$ line, at the $33^{\circ}$ line, and at the transition line between the curved top surface and the vertical side of the drip shield mock-up are used. The distance $x$ from the drip location to the point of measurement is determined from the drawing of the drip shield mock-up shown in Figure 4.1-1, which is reproduced from Howard (2002 [DIRS 161516], p. 14); various dimensions used in analyzing the data are listed in Table 6.5-1. The rivulet spread angle data are analyzed in Microsoft Excel spreadsheet: Flux Split Waste Package Model, Worksheet: Spread angles, which is documented in Appendix D.

To capture some of the effect of the smaller radius, namely the steeper incline closer to the crown, the data from drip locations that are off the crown of the smooth drip shield surface experiments are used to develop parameters for the waste package model. Additionally, the drop distance to drip locations that are off the crown was greater than for drips on the crown $(2.17 \mathrm{~m}$ to the crown, $2.22 \mathrm{~m}$ to the $16.5^{\circ}$ line, and $2.31 \mathrm{~m}$ to the $33^{\circ}$ line; BSC 2003 [DIRS 163406], p. 6), which more closely mimics the greater drop distance from the drift to the waste package compared with the drip shield surface. The results varied widely. In 20 measurements at the $33^{\circ}$ line with drips at the $16.5^{\circ}$ line, the mean spread angle was $17.0^{\circ}\left( \pm 11.2^{\circ}=\right.$ one standard deviation). In 17 measurements at the transition line with drips at the $16.5^{\circ}$ line, the mean spread angle was $11.1^{\circ}\left( \pm 4.1^{\circ}\right)$. In 10 measurements at the transition line with drips at the $33^{\circ}$ line, the mean spread angle was $11.5^{\circ}\left( \pm 3.3^{\circ}\right)$. For all 47 measurements the mean spread angle was $13.7^{\circ}$ $\left( \pm 8.2^{\circ}\right)$, which is just slightly larger than the spread angle measured for drips on the crown of the drip shield mock-up, although the variability is greater (standard deviation of $8.2^{\circ}$, compared with $4.1^{\circ}$ for drips from the crown). Utilizing all of the data available, the spread angle for rivulet flow on the waste package can be assigned a mean value of about $13.7^{\circ}$ and a range ( \pm one standard deviation) from $5.5^{\circ}$ to $22.0^{\circ}$.

The splash distance is uncertain for drip locations off the crown. In four of the $\mathrm{q}($ film) rivulet flow tests, maximum lateral splash distances ranging from $56 \mathrm{~cm}$ to $122 \mathrm{~cm}$ from the drip point were observed (DTN: MO0207EBSATBWP.023 [DIRS 163402]) for drip locations at the $16.5^{\circ}$ line. However, no further observations indicated any change in the "inner cluster" splash distance range of $50 \mathrm{~cm}$ to $96 \mathrm{~cm}$ from Splash Radius Test \#1 (DTN: MO0207EBSATBWP.022 [DIRS 163400]).

The parameter $f_{W P}^{\prime}$ is obtained from an analysis of experimental data for flow into breaches in the drip shield mock-up from DTNs: MO0207EBSATBWP.023 [DIRS 163402] and MO0207EBSATBWP.025 [DIRS 163403]. Analogous to the analysis of data for the drip shield 
flux splitting model in Section 6.5.1.1.2, values of $f_{\text {expt }}$ are computed. The flow data are analyzed in Microsoft Excel spreadsheet: Flux Split Waste Package Model, Worksheet: f calculations, which is documented in Appendix D. In Microsoft Excel spreadsheet: Flux Split Waste Package Model, Worksheet: Summary, documented in Appendix D, tables analogous to Tables 6.5-2 and 6.5-3 are presented.

An uncertainty factor $f_{W P}$ that can be obtained by replacing the fraction $F_{4} / F_{2}$ with $f_{\text {expt }}$ :

$$
\begin{aligned}
f_{W P} & =\frac{F_{4} / F_{2}}{\frac{\ell}{L_{W P}}\left(1+\frac{\tan \alpha}{2}\right)} \\
& =\frac{f_{\text {expt }}}{\frac{\ell}{L_{W P}}\left(1+\frac{\tan \alpha}{2}\right)} .
\end{aligned}
$$

The range of values for $f_{W P}$ is obtained by evaluating it with the appropriate minimum and maximum values of $L_{W P}$ and $\alpha$ so as to minimize and maximize $f_{W P}$. The half-width of the patch used in the experiments $(\ell=13.5 \mathrm{~cm})$ is used to evaluate $f_{W P}$. The minimum value of $f_{W P}$, using $L_{W P}=50 \mathrm{~cm}$ and $\alpha=22.0^{\circ}$, is $f_{W P}=3.081 f_{\text {expt }}=0.909$ using the mean value of 0.295 for $f_{\text {expt }}$. The maximum value of $f_{W P}$, using $L_{W P}=96 \mathrm{~cm}$ and $\alpha=5.5^{\circ}$, is $f_{W P}=6.784 f_{\text {expt }}=2.001$ using the mean value of 0.295 for $f_{\text {expt }}$.

A much lower range could also be justified by using the median inflow fraction of 0.014 instead of the mean $(0.295)$ to define $f_{W P}$. In this case, $f_{W P}$ would range from 0.043 to 0.095 , which demonstrates the large degree of uncertainty in the experimental measurements and the resulting flux splitting submodel.

The values for $f_{W P}$ discussed in this section actually represent a range for the maximum value of $f_{W P}$, since the minimum must be zero. If the factor $(1+1 / 2 \tan \alpha)$ that accounts for the rivulet spread angle is lumped in with $f_{W P}$, the sampled uncertain factor $f_{W P}^{\prime}$ has an upper bound (using the maximum rivulet spread angle, $\alpha=22^{\circ}$ ) of 2.41 . The range for $f_{W P}^{\prime}$ to be used in TSPA-LA is 0 to 2.41. The parameter $f_{W P}^{\prime}$ is assigned a uniform distribution.

\subsubsection{EBS Transport Model}

The EBS transport model consists of mass balances on radionuclides. The transport model is more complex than the flow model for two basic reasons. First, the transport model is necessarily transient because the mass of each radionuclide at any particular location is dependent on its history (i.e., how far it has traveled, the quantity remaining at the source, and the extent of radioactive decay or ingrowth). Second, several complex interacting processes occur in transport, including dissolution and precipitation, sorption, advective transport, 
diffusion, and colloid-facilitated transport. The term "colloid-facilitated transport" includes numerous phenomena, including adsorption and desorption of radionuclides onto mobile and immobile colloids, capture of colloids by solid surfaces and the air-water interface, filtering, dispersion, and diffusion. Transport can take place at any degree of water saturation greater than zero, so the model has to account for water saturation. Dissolution and precipitation may occur at finite rates or sufficiently fast to reach equilibrium. Solubility limits that determine whether, or to what extent, these processes occur are dependent on the chemical environment of the EBS. The EBS transport model applies to the waste package, the invert, and the invert/UZ interface.

Mass Balance for Dissolved and Reversibly and Irreversibly Sorbed Radionuclides in the Aqueous Phase

As with the flow model, the details of pore structure within the EBS are not important, and macroscopic mass balances using phenomenological rate expressions are appropriate. The starting point is the equation of continuity, or mass balance equation, for each dissolved radionuclide species $i$ (Bird et al. 1960 [DIRS 103524], p. 561):

$$
\frac{\partial \rho_{i}}{\partial t}=-\nabla \cdot \boldsymbol{J}_{i}+Q_{i}^{m}+r_{i} .
$$

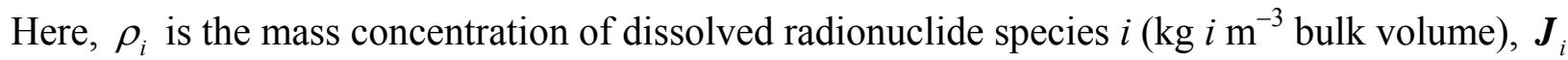
is the mass flux vector (or mass specific discharge) $\left(\mathrm{kg} \mathrm{m}^{-2} \mathrm{~s}^{-1}\right)$ of dissolved radionuclide species $i$ in the mobile water phase and accounts for advection, hydrodynamic dispersion, and diffusion of the dissolved radionuclide species $i$. The term $Q_{i}^{m}$ is the net rate on a bulk volume basis $\left(\mathrm{kg} \mathrm{m}^{-3} \mathrm{~s}^{-1}\right)$ of the various mass transfer processes, including reversible and irreversible sorption onto solid stationary materials in the EBS, dissolution and precipitation, and the various colloid-facilitated transport processes. The reaction term, $r_{i}$, accounts for radioactive decay and ingrowth on a bulk volume basis (i.e., production by decay of the parent of $i)\left(\mathrm{kg} \mathrm{m}^{-3} \mathrm{~s}^{-1}\right)$. Each of these terms is expanded and described in more detail below, then simplified as appropriate for application in the TSPA-LA model.

It is convenient to develop the transport model following the approach normally taken in the literature (Corapcioglu and Jiang 1993 [DIRS 105761], pp. 2217 to 2219; Choi and Corapcioglu 1997 [DIRS 161621], p. 306), with an emphasis on colloid-facilitated transport, since the complexity of those processes tends to dominate the analysis. First, Equation 6.5.1.2-1 is rewritten in terms of concentrations of radionuclides in an unsaturated porous medium. The density, or mass concentration, of dissolved radionuclide species $i$ is given by:

$$
\rho_{i}=C_{i} \phi S_{w},
$$


where $C_{i}$ is the concentration on a water volume basis of radionuclide species $i\left(\mathrm{~kg} \mathrm{~m}^{-3}\right), \phi$ is the porosity ( $\mathrm{m}^{3}$ void $\mathrm{m}^{-3}$ bulk volume) of a representative elemental volume of EBS, and $S_{w}$ is the water saturation $\left(\mathrm{m}^{3}\right.$ water $\mathrm{m}^{-3}$ void). The expression for $\rho_{i}$ is inserted into Equation 6.5.1.2-1, resulting in

$$
\frac{\partial\left(\phi S_{w} C_{i}\right)}{\partial t}=-\nabla \cdot \boldsymbol{J}_{i}+Q_{i}^{m}+r_{i} .
$$

The concentration $C_{i}$ is constrained by the solubility limit, $C_{s i}$, which is defined in Dissolved Concentration Limits of Radioactive Elements (BSC 2005 [DIRS 174566], Table 8-3) for each of 14 elements (U, Np, Pu, Am, Ac, Th, Tc, C, I, Ra, Pa, Pb, Cs, and Sr). The solubility limits for $\mathrm{U}, \mathrm{Np}, \mathrm{Pu}, \mathrm{Am}, \mathrm{Ac}, \mathrm{Th}$, and $\mathrm{Pa}$ are given as functions of $\mathrm{pH}, \mathrm{CO}_{2}$ fugacity, and fluoride concentration.

The mass flux vector is expressed as

$$
\boldsymbol{J}_{i}=-\phi S_{w} D_{i} \nabla C_{i}+\boldsymbol{q}_{w} C_{i},
$$

where $D_{i}$ is the hydrodynamic dispersion coefficient of species $i\left(\mathrm{~m}^{2} \mathrm{~s}^{-1}\right)$, and $\boldsymbol{q}_{w}$ is the specific discharge vector, or Darcy velocity, of water $\left(\mathrm{m} \mathrm{s}^{-1}\right)$. The specific discharge vector is related to the water flow rates $F_{j}\left(\mathrm{~m}^{3} \mathrm{~s}^{-1}\right)$ in each pathway $j$ of the EBS flow model (Section 6.5.1.1) by:

$$
\boldsymbol{q}_{w}=\frac{F_{j}}{A} \boldsymbol{i},
$$

where $A$ is the spatially dependent cross sectional flow area within the pathway $j\left(\mathrm{~m}^{2}\right)$, and $\boldsymbol{i}$ is a unit vector in the direction of the flow path. Because of the complex flow geometry in the EBS, assigning a value to $A$ is not always straightforward; for example, for pathway 4 (Section 6.5.1.1), flow through the waste package, $A$ can be the cross sectional area of corrosion patches or some fraction of the cross sectional area of a waste package.

The hydrodynamic dispersion coefficient, $D_{i}$, can be expressed in terms of two components (Freeze and Cherry 1979 [DIRS 101173], pp. 389 to 390):

$$
D_{i}=\alpha \bar{v}+D_{m i},
$$

where $\alpha$ is the dispersivity (m), $\bar{v}$ is the average interstitial water velocity $\left(\mathrm{m} \mathrm{s}^{-1}\right)$, and $D_{m i}$ is the effective molecular diffusion coefficient $\left(\mathrm{m}^{2} \mathrm{~s}^{-1}\right)$, which implicitly includes the effects of tortuosity. The dispersivity can be further broken down into lateral and longitudinal dispersivities. However, the dispersivity in the EBS is ignored (see Section 6.3.1.2). Consequently, the hydrodynamic dispersion is accounted for solely by molecular diffusion. The free water diffusion coefficient for self-diffusion of water, $D_{0}$, is used as a bounding value of the molecular diffusion coefficient for all radionuclides in the EBS. Modifications to the diffusion coefficient for the porosity and saturation within the waste package are described in 
Section 6.3.4.3 The effects of concentrated solutions are ignored. Throughout the mathematical description of the radionuclide transport, $D_{i}$ represents the effective diffusion coefficient for species $i$.

The term $Q_{i}^{m}\left(\mathrm{~kg} \mathrm{~m}^{-3} \mathrm{~s}^{-1}\right)$ in Equation 6.5.1.2-3 is expanded to account for individual contributions of different processes to radionuclide transport:

$$
Q_{i}^{m}=Q_{i d}-Q_{i p r e c i p}-Q_{i s}^{r e v}-Q_{i s}^{i r r e v}-Q_{i c m}^{r e v}-Q_{i c m}^{i r r e v}-Q_{i c c}-Q_{i c c}^{i n t} \pm Q_{i m t}-Q_{i c m}^{e m b e d} .
$$

The first term is the source term, $Q_{i d}$, accounting for the rate of dissolution of species $i$, and $Q_{\text {iprecip }}$ is the rate of precipitation of species $i$. If the concentration of species $i$ is below the solubility limit, then $Q_{\text {iprecip }}=0$; otherwise, the precipitation rate is determined from the mass balance so as to honor the solubility limit.

The next six terms in Equation 6.5.1.2-7 account for sorption-related processes. $Q_{i s}^{r e v}$ is the net rate of reversible sorption of radionuclide species $i$ onto the stationary solid matrix (internal waste package corrosion products and invert matrix). $Q_{i s}^{\text {irrev }}$ is the rate of irreversible sorption of radionuclide species $i$ onto the stationary solid matrix (internal waste package corrosion products). $Q_{i c m}^{r e v}$ is the net rate of reversible sorption of radionuclide species $i$ onto mobile colloid surfaces. Development of this term requires assumptions regarding the reversibility of radionuclide sorption onto colloids and is discussed below. $Q_{i c m}^{\text {irrev }}$ is the rate of irreversible sorption of radionuclide species $i$ onto mobile colloid surfaces.

The terms $Q_{i c c}$ and $Q_{i c c}^{i n t}$ are the net rates of sorption of radionuclide species $i$ onto immobile colloid surfaces captured by the stationary solid matrix and by the air-water interface, respectively. Wan and Wilson (1994 [DIRS 124994]) found that "particle transport was tremendously retarded by the air-water interface acting as a strong sorption phase" (Choi and Corapcioglu 1997 [DIRS 161621], p. 301). However, as a bounding assumption (BSC 2004 [DIRS 170025], Assumption 5.4), sorption by the air-water interface is assumed not to occur $\left(Q_{i c c}^{i n t}=0\right)$. Distribution coefficients for sorption onto the stationary solid matrix and onto immobile colloid surfaces will generally be different. However, it is difficult to distinguish among various types of matrixes and immobile colloids. Therefore, no distinction is made, and the term $Q_{i c c}$ (sorption onto immobile colloids) is lumped in with $Q_{i s}^{\text {rev }}$ or $Q_{i s}^{\text {irrev }}$ (sorption onto the stationary solid matrix). Sorption and retardation in the waste package are discussed in more detail in Section 6.3.4.2.

The term $Q_{i m t}$ is the net rate of interface transfer of dissolved mass between the continua in a dual continuum. The sign of this transfer term is determined by the sign of the concentration difference between the media and which medium is associated with the mass balance equation. This term is included even though it is zero in the single-continuum domains that represent the EBS in the EBS RT Abstraction in order to keep the mass balance equations as generally 
applicable as possible. In particular, the equations apply in the dual-continuum invert model presented as an alternative conceptual model in Section 6.6.4.

The term $Q_{i c m}^{\text {embed }}$ is the rate of mass conversion from dissolved state to embedded state onto waste form colloids for radionuclide species $i$. Radionuclides become embedded only in waste form colloids, not in iron oxyhydroxide or groundwater colloids. The conversion rate to embedded species is represented by a first order conversion of the species in solution:

$$
Q_{i c m}^{\text {embed }}=\phi S_{w} \lambda_{i}^{\text {embed }} C_{i},
$$

where is the $\lambda_{i}^{\text {embed }}$ is the first order rate constant $\left(\mathrm{s}^{-1}\right)$ for mass conversion from the dissolved state to the embedded state onto waste form colloids for radionuclide species $i$.

Ingrowth and decay are expressed as:

$$
r_{i}=\lambda_{i p} r_{i p}^{M} \phi S_{w} C_{i p}-\lambda_{i} \phi S_{w} C_{i}
$$

Ingrowth is the production of radionuclide species $i$ by the decay of its parent species and occurs at a rate proportional to the concentration of the parent, $C_{i p}\left(\mathrm{~kg} \mathrm{~m}^{-3}\right)$, and the parent species decay constant, $\lambda_{i p}\left(\mathrm{~s}^{-1}\right)$. The decay constant is related to the half-life, $t_{1 / 2, i p}(\mathrm{~s})$, of the radionuclide by:

$$
\lambda_{i p}=\frac{\ln (2)}{t_{1 / 2, i p}}
$$

The term $r_{i p}^{M}$ in the production rate is the dimensionless ratio of the mass $(\mathrm{kg})$ of species $i$ produced by decay of the parent species to the mass $(\mathrm{kg})$ of the parent species lost by decay. This is equal to the ratio of the atomic weight of species $i$ to that of its parent. Similarly, species $i$ is lost by decay at a rate $\lambda_{i} C_{i}\left(\mathrm{~kg} \mathrm{~m}^{-3} \mathrm{~s}^{-1}\right)$, where $\lambda_{i}$ is the decay constant for species $i$ $\left(\mathrm{s}^{-1}\right)$, defined analogously to $\lambda_{i p}$.

Transport of dissolved and reversibly sorbed radionuclide species $i$ in the aqueous phase is then given by:

$$
\begin{aligned}
\frac{\partial\left(\phi S_{w} C_{i}\right)}{\partial t}= & \nabla \cdot\left(\phi S_{w} D_{i} \nabla C_{i}\right)-\nabla \cdot \boldsymbol{q}_{w} C_{i} \\
& +Q_{i d}-Q_{i p r e c i p}-Q_{i s}^{r e v}-Q_{i s}^{i r r e v}-Q_{i c m}^{r e v}-Q_{i c m}^{i r r e v} \\
& \pm Q_{i m t}-Q_{i c m}^{\text {embed }}+\phi S_{w}\left(\lambda_{i p} r_{i p}^{M} C_{i p}-\lambda_{i} C_{i}\right)
\end{aligned}
$$

which is essentially identical to Equations 19 and 20 by Choi and Corapcioglu (1997 [DIRS 161621], p. 306), with the addition of decay and ingrowth terms and a dissolution source term, $Q_{i d}$. A further modification of the equations by Choi and Corapcioglu involves the 
diffusive term, $\nabla \cdot\left(\phi S_{w} D_{i} \nabla C_{i}\right)$, which Choi and Corapcioglu write as $\nabla \cdot\left[D_{i} \nabla\left(\phi S_{w} C_{i}\right)\right]$. This form of the term incorrectly allows diffusion to occur in the absence of a concentration gradient as long as the water content, $\phi S_{w}$, varies.

The source term for radionuclide species $i$ reversibly sorbed onto the stationary solid matrix (corrosion products or invert matrix) is given by:

$$
Q_{i s}^{r e v}=\frac{\partial\left(\rho_{b} K_{d i s} C_{i}\right)}{\partial t}-\rho_{b}\left(\lambda_{i p} r_{i p}^{M} K_{d i p s} C_{i p}-\lambda_{i} K_{d i s} C_{i}\right),
$$

where $\rho_{b}$ is the dry bulk density of the stationary solid matrix $\left(\mathrm{kg} \mathrm{m}^{-3}\right.$ bulk volume). A linear adsorption isotherm is used for the relationship between the aqueous and solid phase equilibrium concentration, expressed in terms of a sorption distribution coefficient of the dissolved species $i$, $K_{\text {dis }}\left(\mathrm{m}^{3}\right.$ water $\mathrm{kg}^{-1}$ solid [usually reported in units of $\left.\left.\mathrm{ml} \mathrm{g}^{-1}\right]\right) . K_{\text {dis }}$ depends both on the radionuclide species $i$ being sorbed and on the solid substrate, either stationary iron oxyhydroxide corrosion products or invert material or both, in this case. As a bounding approach, no credit is taken for retardation due to reversible sorption of radionuclides on stationary waste package corrosion products. Thus, sorption distribution coefficients for stationary corrosion products are set to zero for all radionuclides. Nonzero $K_{d}$ values for stationary corrosion products constitute an alternative conceptual model described in Section 6.6.6.

The source term for radionuclide species $i$ irreversibly sorbed onto the stationary solid iron oxyhydroxide corrosion products is given by:

$$
Q_{i s}^{i r r e v}=\rho_{b} \bar{s}_{C P} k_{i} C_{i},
$$

where $\bar{s}_{C P}$ is the specific surface area of iron oxyhydroxide corrosion products [ $\mathrm{m}^{2} \mathrm{CP} \mathrm{kg}-1 \mathrm{CP}$ ], and $k_{i}$ is the irreversible forward rate constant $\left(\mathrm{m}^{3}\right.$ water $\left.\mathrm{m}^{-2} \mathrm{CP} \mathrm{s}^{-1}\right)$. The reaction is modeled as first order in the solution concentration.

The source term for radionuclide species $i$ reversibly sorbed onto the mobile colloids is given by:

$$
\begin{aligned}
Q_{i c m}^{r e v}= & \frac{\partial\left[\phi S_{w}\left(K_{d i c W F} C_{c W F}+K_{d i c F e x} C_{c F e O x}+K_{d i c G W} C_{c G W}\right) C_{i}\right]}{\partial t} \\
& +\nabla \cdot\left(\boldsymbol{J}_{i c W F}+\boldsymbol{J}_{i c F e O x}+\boldsymbol{J}_{i c G W}\right) \\
& -\phi S_{w}\left[\lambda_{i p} r_{i p}^{M}\left(C_{i p c W F}+C_{i p c F e O x}+C_{i p c G W}\right)-\lambda_{i}\left(C_{i c W F}+C_{i c F e O x}+C_{i c G W}\right)\right],
\end{aligned}
$$

where $C_{i c W F}, C_{i c F e O x}$, and $C_{i c G W}$ are the concentrations on a water volume basis of radionuclide species $i$ reversibly sorbed onto the mobile waste form, iron oxyhydroxide ( $\mathrm{FeOx}$ ), and groundwater (GW) colloids, respectively $\left(\mathrm{kg} i \mathrm{~m}^{-3}\right.$ water). The subscript $i p$ refers to the parent of radionuclide species $i$. The terms $C_{c W F}, C_{c F e O x}$, and $C_{c G W}$ are the concentrations on a water volume basis of mobile waste form, iron oxyhydroxide, and groundwater colloids, respectively ( $\mathrm{kg}$ colloid $\mathrm{m}^{-3}$ water). The $K_{d}$ values of radionuclide species $i$ for the respective colloids are 
$K_{d i c W F}, K_{d i c F e O x}$, and $K_{d i c G W}$ (typical units: $\mathrm{ml} \mathrm{g}^{-1}$ ). The right side of the first line of Equation 6.5.1.2-14 accounts for the accumulation of radionuclide species $i$ reversibly sorbed to colloids. The second line of Equation 6.5.1.2-14 accounts for movement by advection and diffusion of radionuclide species $i$ reversibly sorbed to colloids. The third line of Equation 6.5.1.2-14 accounts for production or loss of radionuclide species $i$ reversibly sorbed to colloids by ingrowth and decay.

The vectors for mass fluxes of colloids, $\boldsymbol{J}_{i c W F}, \boldsymbol{J}_{i c F e O x}$, and $\boldsymbol{J}_{i c G W}$, are:

$$
\begin{gathered}
\boldsymbol{J}_{i c W F}=-\phi S_{w} D_{c} \nabla\left(K_{d i c W F} C_{c W F} C_{i}\right)+\boldsymbol{q}_{w} K_{d i c W F} C_{c W F} C_{i} \\
\boldsymbol{J}_{i c F e O x}=-\phi S_{w} D_{c} \nabla\left(K_{d i c F e O x} C_{c F e O x} C_{i}\right)+\boldsymbol{q}_{w} K_{d i c F e O x} C_{c F e O x} C_{i} \\
\boldsymbol{J}_{i c G W}=-\phi S_{w} D_{c} \nabla\left(K_{d i c G W} C_{c G W} C_{i}\right)+\boldsymbol{q}_{w} K_{d i c G W} C_{c G W} C_{i} .
\end{gathered}
$$

The source term for radionuclide species $i$ irreversibly sorbed onto the mobile iron oxyhydroxide corrosion products colloids is given by:

$$
Q_{i c m}^{i r r e v}=\phi S_{w} C_{c F e O x} \bar{s}_{c} k_{i} C_{i}
$$

where $\bar{s}_{c}$ is the specific surface area of mobile corrosion products colloids $\left(\mathrm{m}^{2}\right.$ colloids $\mathrm{kg}^{-1}$ colloids), and $k_{i}$ is the forward rate constant for irreversible sorption $\left(\mathrm{m}^{3}\right.$ water $\mathrm{m}^{-2} \mathrm{FeOx}$ colloids s${ }^{-1}$ ). The rate constant $k_{i}$ for mobile iron oxyhydroxide corrosion products colloids is the same as for stationary iron oxyhydroxide corrosion products. The reaction is modeled as first order in the solution concentration. Irreversible sorption onto mobile colloids occurs only onto mobile iron oxyhydroxide corrosion products colloids, not onto mobile waste form or mobile groundwater colloids. As discussed earlier, radionuclides may become embedded in waste form colloids, which has a similar net effect as irreversible sorption but is modeled as a distinctly separate process.

The term $Q_{i m t}$ is the net rate of interface transfer of dissolved and reversibly sorbed mass between the continua in a dual continuum material (as in the dual continuum invert alternative conceptual model; see Section 6.6.4) on a bulk volume basis $\left(\mathrm{kg} \mathrm{m}^{-3} \mathrm{~s}^{-1} \mathrm{]}\right)$. It is given by (Corapcioglu and Wang 1999 [DIRS 167464], p. 3265; Gerke and van Genuchten 1996 [DIRS 167466], p. 345):

$$
\begin{aligned}
Q_{i m t}= & \gamma_{d}\left[\left(C_{i}\right)_{\text {intra }}-\left(C_{i}\right)_{\text {inter }}\right] \\
& +\gamma_{c}\left[\left(C_{i c W F}\right)_{\text {intra }}-\left(C_{i c W F}\right)_{\text {inter }}\right. \\
& \left.+\left(C_{i c F e O x}\right)_{\text {intra }}-\left(C_{i c F e O x}\right)_{\text {inter }}+\left(C_{i c G W}\right)_{\text {intra }}-\left(C_{i c G W}\right)_{\text {inter }}\right] .
\end{aligned}
$$


In a single-continuum material, $Q_{i m t}=0$. The dissolved and colloid mass transfer coefficients, $\gamma_{d}$ and $\gamma_{c}$, respectively, depend on which continuum the mass balance represents. For the dissolved mass transfer term:

$$
\begin{gathered}
\gamma_{d}=\alpha \phi_{\text {intra }} S_{w_{-} \text {intra }}, \text { for the intragranular mass balance, } \\
\gamma_{d}=\alpha \phi_{\text {intra }} S_{w_{-} \text {intra }}\left(\frac{1-w_{\text {inter }}}{w_{\text {inter }}}\right), \text { for the intergranular mass balance, (Eq. 6. 6. 2.1.2-21) }
\end{gathered}
$$

where $\alpha$ is the first-order mass transfer coefficient $\left(\mathrm{s}^{-1}\right)$ of the form:

$$
\alpha=\frac{\beta}{d^{2}} D_{i e}
$$

$\beta$ is a dimensionless geometry-dependent coefficient, $d$ is a characteristic length (m) of the matrix structure (e.g., half the aggregate width or half the fracture spacing), and $D_{i e}$ is an effective diffusion coefficient $\left(\mathrm{m}^{2} \mathrm{~s}^{-1}\right)$ that represents the diffusion properties of the interface between the two continua for radionuclide species $i$. Because the intergranular continuum is open pore space, diffusion is expected to be controlled by the diffusive properties of the intragranular continuum. Thus, $D_{i e}$ is taken to be the effective diffusion coefficient in the intragranular continuum. The colloid coefficient $\gamma_{c}$ is evaluated similarly to the dissolved coefficient, but uses an effective colloid diffusion coefficient to evaluate $\alpha$ in Equation 6.5.1.2-22. The mass transfer function between the two invert continua is described in Section 6.6.4.1.

In a dual-continuum material, the intergranular porosity $\phi_{\text {inter }}$ and intragranular porosity $\phi_{\text {intra }}$ are defined as follows. Let $V_{p}$ be the total volume of pore space in the bulk material, which has a total volume of $V_{t}$. The intergranular pore space has a total volume designated by $V_{t_{-} \text {inter }}$ and a pore volume of $V_{p_{-} i n t e r}$. Similarly, the intragranular pore space has a total volume designated by $V_{t_{-} \text {intra }}$ and a pore volume of $V_{p_{-} \text {intra }} . \quad V_{p}=V_{p_{-} \text {intra }}+V_{p_{-} \text {inter }}$ and $V_{t}=V_{t_{-} \text {intra }}+V_{t_{-} \text {inter }}$. The porosities are defined as:

$$
\phi_{\text {inter }}=\frac{V_{p_{\text {_inter }}}}{V_{t}}
$$

and

$$
\phi_{\text {intra }}=\frac{V_{p_{-} \text {intra }}}{V_{t}} .
$$

The total bulk porosity of the material is: 


$$
\phi_{I}=\frac{V_{p}}{V_{t}}=\phi_{\text {inter }}+\phi_{\text {intra }}
$$

The parameter $w_{\text {inter }}$ is the ratio of the intergranular continuum volume to the total bulk volume:

$$
w_{\text {inter }}=\frac{V_{t_{-} \text {inter }}}{V_{t}} .
$$

Then $\left(\frac{1-w_{\text {inter }}}{w_{\text {inter }}}\right)$ is the ratio of intragranular continuum volume to intergranular continuum volume:

$$
\frac{1-w_{\text {inter }}}{w_{\text {inter }}}=\frac{1-\frac{V_{t_{-} \text {inter }}}{V_{t}}}{\frac{V_{t_{-} \text {inter }}}{V_{t}}}=\frac{V_{t}-V_{t_{-} \text {inter }}}{V_{t_{-} \text {inter }}}=\frac{V_{t_{-} \text {intra }}}{V_{t_{-} \text {inter }}} .
$$

Mass Balance for Irreversibly Adsorbed Radionuclides on Iron Oxyhydroxide Stationary Corrosion Products and Mobile Colloids

The mass balance for irreversibly adsorbed radionuclides on mobile iron oxyhydroxide colloids, which originate in the corrosion products, accounts for advection, diffusion, and decay and is given by:

$$
\begin{aligned}
\frac{\partial\left(\phi S_{w} C_{i c F e O x}^{i r r e v}\right)}{\partial t}= & -\nabla \cdot\left(\boldsymbol{J}_{i c F e O x}^{i r r e v}\right)+Q_{i c m}^{i r r e v} \pm Q_{i m t}^{i r r e v} \\
& +\phi S_{w}\left(\lambda_{i p} r_{i p}^{M} C_{i p c F e O x}^{i r r e v}-\lambda_{i} C_{i c F e O x}^{i r r e v}\right)
\end{aligned},
$$

where

$$
\begin{gathered}
Q_{\text {imt }}^{\text {irrev }}=\gamma_{c}\left[\left(C_{i c F e O x}^{\text {irrev }}\right)_{\text {intra }}-\left(C_{i c F e O x}^{\text {irrev }}\right)_{i n t e r}\right], \\
\boldsymbol{J}_{\text {icFeOx }}^{\text {irrev }}=-\phi S_{w} D_{c} \nabla\left(C_{i c F e O x}^{\text {irrev }}\right)+\boldsymbol{q}_{w} C_{i c F e O x}^{\text {irrev }} .
\end{gathered}
$$


The quantity $C_{i c F e O x}^{i r e v}$ is the concentration of radionuclide species $i$ irreversibly adsorbed onto

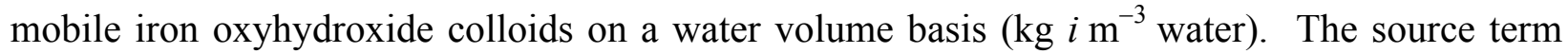
for radionuclide species $i$ irreversibly sorbed onto the mobile corrosion products colloids, $Q_{i c m}^{i \text { rrev }}$, is given by Equation 6.5.1.2-18.

The mass balance for irreversibly adsorbed radionuclides onto stationary iron oxyhydroxide corrosion products accounts for decay and is given by:

$$
\frac{\partial\left(\phi S_{w} C_{i C P F e O x}^{i \text { irev }}\right)}{\partial t}=Q_{i s}^{i \text { irev }}+\phi S_{w}\left(\lambda_{i p} r_{i p}^{M} C_{i p C P F e O x}^{i \text { irev }}-\lambda_{i} C_{i C P F O O x}^{\text {irrev }}\right),
$$

where $C_{i C P F e O x}^{i r r e v}$ is the concentration of radionuclide species $i$ irreversibly adsorbed onto stationary

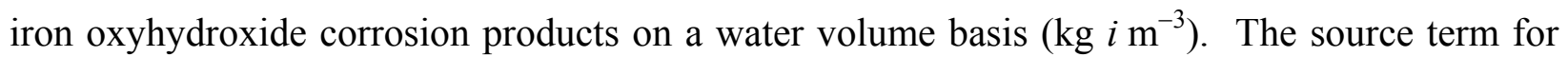
radionuclide species $i$ irreversibly sorbed onto the solid stationary iron oxyhydroxide corrosion products, $Q_{i s}^{\text {irrev }}$, is given by Equation 6.5.1.2-13.

\section{Mass Balance for Waste Form Colloid Particles}

The waste form colloids are generated in the waste form domain and are transported in accordance with an advective/diffusive mass balance. The waste form colloid concentration is subject to stability constraints based on the local domain chemistry. The iron oxyhydroxide and ground water colloids both exist in the corrosion products and invert domains; their stability and concentrations are dependent on the local domain chemistry (BSC 2004 [DIRS 170025]). Because seepage brings the groundwater colloids into the EBS, it has the same concentration of groundwater colloids whether seepage is entering the waste package or invert. Similarly, due to the presence of steel in both waste package and invert it is reasonable for iron oxyhydroxide to have the similar concentrations as well, if the colloids are stable under the local conditions. Hence, no transport mass balance equations are required for iron oxyhydroxide and ground water colloids. Since waste form colloids can only be generated in the waste form domain, it is necessary to know how much of the waste form colloid mass has moved by advection and diffusion into the corrosion product and invert domains. Thus, an advective/diffusive mass balance must be applied to compute the waste form colloid mass in each of the downstream domains. The stability for waste form colloids is checked in each domain, since they may be stable in the corrosion product domain but precipitate in the invert domain.

The mass balance for waste form colloidal particles suspended in the aqueous phase can be expressed as (Choi and Corapcioglu 1997 [DIRS 161621], p. 302):

$$
\frac{\partial\left(\phi S_{w} C_{c W F}\right)}{\partial t}=-\nabla \cdot \boldsymbol{J}_{c W F}-Q_{c W F}-Q_{c W F}^{i n t}-Q_{c W F g}+Q_{c W F s} \pm Q_{c W F m t} .
$$

The quantity $C_{c W F}$ is the concentration of suspended waste form colloids in the aqueous phase ( $\mathrm{kg}$ waste form colloids $\mathrm{m}^{-3}$ water), and $\boldsymbol{J}_{c W F}$ is the mass flux vector of waste form colloids $\left(\mathrm{kg} \mathrm{m}^{-2} \mathrm{~s}^{-1}\right)$. The term $Q_{c W F f g}$ is the net rate of waste form colloid removal from suspension 
$\left(\mathrm{kg} \mathrm{m}^{-3} \mathrm{~s}^{-1}\right)$ by means of physical filtering (pore clogging, sieving, and straining) and by gravitational settling. Physical filtering and gravitational settling are assumed not to occur (Assumption 5.7). Thus, the term $Q_{c W F f g}$ is neglected. The term $Q_{c W F}\left(\mathrm{~kg} \mathrm{~m}^{-3} \mathrm{~s}^{-1}\right)$ is the net rate of waste form colloid capture on the solid surface. Although colloid capture on the solid surface is akin to sorption and a different process from physical filtration, the net effect is indistinguishable from physical filtration, and it is also neglected $\left(Q_{c W F}=0\right)$. The term $Q_{c W F}^{i n t}$ $\left(\mathrm{kg} \mathrm{m}^{-3} \mathrm{~s}^{-1}\right)$ represents capture at the air-water interface; as mentioned earlier, this term is neglected as a bounding assumption (BSC 2004 [DIRS 170025], Assumption 5.4).

With these assumptions, Equation 6.5.1.2-32 simplifies to:

$$
\frac{\partial\left(\phi S_{w} C_{c W F}\right)}{\partial t}=-\nabla \cdot \boldsymbol{J}_{c W F}+Q_{c W F s} \pm Q_{c W F m t} .
$$

The source term, $Q_{c W F s}\left(\mathrm{~kg} \mathrm{~m}^{-3} \mathrm{~s}^{-1}\right)$, in Equation 6.5.1.2-33 represents the formation or degradation of waste form colloids. Colloid formation may be rate limited, or it may be instantaneous, with equilibrium between the colloids and their dissolved components. In either case, colloid stability is strongly dependent on the chemical environment, specifically on the $\mathrm{pH}$ and ionic strength of the aqueous phase. The colloid source term is the subject of Waste Form and In-Drift Colloids-Associated Radionuclide Concentrations: Abstraction and Summary (BSC 2004 [DIRS 170025]), and is discussed further below.

The term $Q_{c W F m t}$ is the net rate of interface transfer of waste form colloidal mass between the intergranular and intragranular continua in a dual continuum model, such as the dual continuum invert alternative conceptual model (Section 6.6.4). For a single continuum, $Q_{c W F m t}=0$. The sign of this transfer term is determined by the sign of the waste form colloid concentration difference between the media and which medium is associated with the mass balance equation. This is analogous to the colloid transfer term in Equation 6.5.1.2-19:

$$
Q_{c W F m t}=\gamma_{c}\left[\left(C_{c W F}\right)_{\text {intra }}-\left(C_{c W F}\right)_{\text {inter }}\right] .
$$

Since Equation 6.5.1.2-34 is for the waste form colloid particles themselves, as opposed to radionuclides sorbed onto the particles, there are no decay or ingrowth terms.

The mass flux vector for waste form colloids is expressed as (Choi and Corapcioglu 1997 [DIRS 161621], p. 303, Equation 4):

$$
\begin{aligned}
\boldsymbol{J}_{c W F} & =\boldsymbol{J}_{c B}+\boldsymbol{J}_{c M D}+\boldsymbol{q}_{w} C_{c W F} \\
& =-\phi S_{w} D_{B} \nabla C_{c W F}-\phi S_{w} D_{M D} \nabla C_{c W F}+\boldsymbol{q}_{w} C_{c W F} \\
& =-\phi S_{w} D_{c} \nabla C_{c W F}+\boldsymbol{q}_{w} C_{c W F},
\end{aligned}
$$

where subscript $B$ refers to Brownian diffusion, and $M D$ refers to mechanical dispersion. The mechanical dispersion and Brownian diffusion terms can be lumped together in a colloid hydrodynamic dispersion term with a colloid dispersion or diffusion coefficient $D_{c}\left(\mathrm{~m}^{2} \mathrm{~s}^{-1}\right)$. 
The diffusion coefficient of colloids is estimated to be a factor of 100 less than that of the free water diffusivity (Section 6.3.4.4) (i.e., $D_{c}=D_{0} / 100$ ). The mass balance on waste form colloid particles, Equation 6.5.1.2-33, then becomes:

$$
\begin{aligned}
\frac{\partial\left(\phi S_{w} C_{c W F}\right)}{\partial t}= & \nabla \cdot\left(\phi S_{w} D_{c} \nabla C_{c W F}\right)-\nabla \cdot\left(\boldsymbol{q}_{w} C_{c W F}\right)+Q_{c W F s} \\
& \pm \gamma_{c}\left[\left(C_{c W F}\right)_{\text {intra }}-\left(C_{c W F}\right)_{\text {inter }}\right] .
\end{aligned}
$$

Mass Balance for Embedded Mass on Waste Form Colloids

The mass balance for the radionuclide species $i$ embedded on waste form colloids is:

$$
\begin{aligned}
\frac{\partial\left(\phi S_{w} C_{i}^{e m b e d}\right)}{\partial t}= & \nabla \cdot\left(\phi S_{w} D_{c} \nabla C_{i}^{\text {embed }}\right)-\nabla \cdot\left(q_{w} C_{i}^{\text {embed }}\right) \\
& +\phi S_{w}\left(\lambda_{i p} r_{i p}^{M} C_{i p}^{e m b e d}-\lambda_{i} C_{i}^{\text {embed }}\right)+Q_{i c m}^{\text {embed }},
\end{aligned}
$$

where $C_{i}^{\text {embed }}$ and $C_{i p}^{\text {embed }}$ are the concentrations of species $i$ and the parent of species $i$, respectively, embedded on waste form colloids.

\section{Summary of Mass Balances}

Inserting the source terms into Equation 6.5.1.2-11 gives the equation for the transport of radionuclides dissolved in the aqueous phase and reversibly sorbed:

$$
\begin{aligned}
\frac{\partial}{\partial t}\left[\phi S_{w} R_{f i} C_{i}\right]= & \nabla \cdot\left(\phi S_{w} D_{i} \nabla C_{i}\right) \\
& +\nabla \cdot\left\{\phi S_{w} D_{c} \nabla\left[\left(K_{d i c W F} C_{c W F}+K_{d i c F e O x} C_{c F e O x}+K_{d i c G W} C_{c G W}\right) C_{i}\right]\right\} \\
& -\nabla \cdot\left[\boldsymbol{q}_{w}\left(1+K_{d i c W F} C_{c W F}+K_{d i c F e O x} C_{c F e O x}+K_{d i c G W} C_{c G W}\right) C_{i}\right] \\
& +Q_{i d}-Q_{i p r e c i p}-\left(\rho_{b} \bar{s}_{C P}+\phi S_{w} C_{c F e O x} \bar{s}_{c}\right) k_{i} C_{i}-\phi S_{w} \lambda_{i}^{e m b e d} C_{i} \\
& \pm \gamma_{d}\left[\left(C_{i}\right)_{\text {intra }}-\left(C_{i}\right)_{\text {inter }}\right] \\
& \pm \gamma_{c}\left[\left(C_{i c W F}+C_{i c F e O x}+C_{i c G W}\right)_{i n t r a}-\left(C_{i c W F}+C_{i c F e O x}+C_{i c G W}\right)_{i n t e r}\right] \\
& +\phi S_{w}\left[\lambda_{i p} r_{i p}^{M} R_{f i p} C_{i p}-\lambda_{i} R_{f i} C_{i}\right],
\end{aligned}
$$

where

$$
R_{f i}=1+\frac{\rho_{b} K_{d i s}}{\phi S_{w}}+K_{d i c W F} C_{c W F}+K_{d i c F e O x} C_{c F e O x}+K_{d i c G W} C_{c G W}
$$

and $R_{f i p}$ is the corresponding factor for the parent species ip of radionuclide species $i$ :

$$
R_{f i p}=1+\frac{\rho_{b} K_{d i p s}}{\phi S_{w}}+K_{d i p c W F} C_{c W F}+K_{d i p c F e O x} C_{c F e O x}+K_{d i p c G W} C_{c G W}
$$


In Equation 6.5.1.2-38, the left side of the equation represents the accumulation of dissolved and reversibly sorbed radionuclide species $i$. The term in brackets is the mass of species $i$ present in a unit bulk volume of EBS material, so the equation units are mass of species $i$ per unit bulk volume of EBS per time. The first term on the right side represents the rate of diffusion of dissolved species $i$ in the aqueous phase. The second term accounts for diffusion of mobile colloids on which species $i$ is adsorbed. The third term is the rate at which species $i$ dissolved mass and mass reversibly sorbed to mobile colloids is transported by advection. The fourth and fifth terms represent the net rate of dissolution and precipitation of species $i$, respectively. The sixth term is the conversion rate due to irreversible sorption on both iron oxyhydroxide stationary corrosion products and colloids. The seventh term is the rate of irreversible capture of species $i$ by embedding in waste form colloids. The eighth and ninth terms represent respectively the mass flux of dissolved and reversibly sorbed species $i$ between the continua in a dual-continuum material; for a single-continuum material, these terms are omitted. The last (tenth) term accounts for ingrowth, or production of species $i$ by decay of the parent of $i$, and decay of species $i$, as dissolved species and as sorbed onto colloids and immobile matrix.

Inserting the source terms into Equation 6.5.1.2-28, the mass balance for irreversibly adsorbed radionuclides on iron oxyhydroxide corrosion product colloids becomes:

$$
\begin{aligned}
\frac{\partial\left(\phi S_{w} C_{i c F e O x}^{i r r e v}\right)}{\partial t} & =\nabla \cdot\left[\phi S_{w} D_{c} \nabla\left(C_{i c F e O x}^{i r r e v}\right)\right]-\nabla \cdot\left(\boldsymbol{q}_{w} C_{i c F e O x}^{\text {irrev }}\right) \\
& +\phi S_{w} C_{c F e O x} \bar{s}_{c} k_{i} C_{i} \pm \gamma_{c}\left[\left(C_{i c F e O x}^{i r r e v}\right)_{\text {intra }}-\left(C_{i c F e O x}^{i r r e v}\right)_{\text {inter }}\right] \\
& +\phi S_{w}\left(\lambda_{i p} r_{i p}^{M} C_{i p c F e O x}^{i r r e v}-\lambda_{i} C_{i c F e O x}^{i r r e v}\right) .
\end{aligned}
$$

The term $\phi S_{w} C_{c F e O x} \bar{S}_{c} k_{i} C_{i}$ in Equation 6.5.1.2-41 couples this equation to Equation 6.5.1.2-38.

The mass balance for irreversibly adsorbed radionuclides onto stationary iron oxyhydroxide corrosion products accounts for decay and is given by:

$$
\frac{\partial\left(\phi S_{w} C_{i C P F e O x}^{i r r e v}\right)}{\partial t}=\rho_{b} \bar{s}_{C P} k_{i} C_{i}+\phi S_{w}\left(\lambda_{i p} r_{i p}^{M} C_{i p C P F e O x}^{i r r e v}-\lambda_{i} C_{i C P F e O x}^{i r r e v}\right) .
$$

The source term in Equation 6.5.1.2-42, $\rho_{b} \bar{s}_{C P} k_{i} C_{i}$, couples this equation to Equation 6.5.1.2-38.

For a single continuum medium with no colloids or corrosion products present, Equation 6.5.1.2-38 reduces to the conventional advection/diffusion transport equation (with source and sink terms):

$$
\begin{aligned}
\frac{\partial\left(\phi S_{w} R_{f i} C_{i}\right)}{\partial t}= & \nabla \cdot\left(\phi S_{w} D_{i} \nabla C_{i}\right)-\nabla \cdot\left(\boldsymbol{q}_{w} C_{i}\right)+Q_{i d}-Q_{i p r e c i p} \\
& +\phi S_{w}\left(\lambda_{i p} r_{i p}^{M} C_{i p} R_{f i p}-\lambda_{i} C_{i} R_{f i}\right),
\end{aligned}
$$


with the conventional retardation factors for radionuclide species $i$ and parent species $i p$, respectively:

$$
R_{f i}=1+\frac{\rho_{b} K_{d i s}}{\phi S_{w}}
$$

and

$$
R_{f i p}=1+\frac{\rho_{b} K_{d i p s}}{\phi S_{w}} .
$$

Equations 6.5.1.2-38 (mass balance for dissolved and reversibly sorbed radionuclide species $i$ ), 6.5.1.2-41 (mass balance for radionuclide species $i$ irreversibly sorbed onto iron oxyhydroxide colloids) and 6.5.1.2-42 (mass balance radionuclide species $i$ irreversibly sorbed onto stationary iron oxyhydroxide corrosion products) are solved simultaneously for all radionuclides to obtain the dependent variables, $C_{i}, C_{i c F e O x}^{i r r e v}$, and $C_{i C P F e O x}^{i r r e v}$, the concentration of dissolved radionuclide species $i$, the concentration of species $i$ irreversibly sorbed onto iron oxyhydroxide colloids, and species $i$ irreversibly sorbed onto stationary iron oxyhydroxide corrosion products, respectively.

The initial conditions are $C_{i}=C_{i c F e O x}^{i r r e v}=C_{i C P F e O x}^{i r r e v}=0$ for all $i$. Upstream of the waste form domain, all radionuclide concentrations are zero. Consequently, the upstream boundary maintains a zero flux condition. Radionuclide concentrations will remain zero until a waste package failure occurs. A treatment of the zero concentration boundary within the UZ is provided in Section 6.5.3.6. The radionuclides are released or mobilized within the waste form domain. Flow is expected to be predominately downward. Then the resulting transport will be in a downward direction from the waste form to the corrosion products, which will accumulate in the bottom of the waste container. From the corrosion products, the radionuclides will migrate down to the invert, and from there they will enter the UZ. The representation for the radionuclide transport is consequently a one-dimensional mass balance equation for radionuclide species. For the one-dimensional EBS radionuclide transport model (in the downward $+z$-direction), the specific discharge (Darcy velocity) vector, $\boldsymbol{q}_{w}$, is in the downward $+z$-direction only and is denoted by $\boldsymbol{q}_{w}=q_{w z} \boldsymbol{i}$, where $\boldsymbol{i}$ is a unit vector in the $z$-direction, and $q_{w z}$ is the scalar specific discharge in the $z$-direction (zero in the other two directions). In one dimension, the mass balance equations can be written as scalar equations and are summarized as follows. 
The one-dimensional mass balance equation describing transport of dissolved and reversibly sorbed radionuclide species $i$ (from Equation 6.5.1.2-38) is:

$$
\begin{aligned}
\frac{\partial}{\partial t}\left[\phi S_{w} R_{f i} C_{i}\right]= & \frac{\partial}{\partial z}\left(\phi S_{w} D_{i} \frac{\partial C_{i}}{\partial z}\right) \\
& +\frac{\partial}{\partial z}\left(\phi S_{w} D_{c} \frac{\partial}{\partial z}\left[\left(K_{d i c W F} C_{c W F}+K_{d i c F e O x} C_{c F e O x}+K_{d i c G W} C_{c G W}\right) C_{i}\right]\right) \\
& -\frac{\partial}{\partial z}\left[q_{w z}\left(1+K_{d i c W F} C_{c W F}+K_{d i c F e O x} C_{c F e O x}+K_{d i c G W} C_{c G W}\right) C_{i}\right] \\
& +Q_{i d}-Q_{i p r e c i p}-\left(\rho_{b} \bar{s}_{C P}+\phi S_{w} C_{c F e O x} \bar{s}_{c}\right) k_{i} C_{i}-\phi S_{w} \lambda_{i}^{e m b e d} C_{i} \\
& \pm \gamma_{d}\left[\left(C_{i}\right)_{i n t r a}-\left(C_{i}\right)_{i n t e r}\right] \\
& \pm \gamma_{c}\left[\left(C_{i c W F}+C_{i c F e O x}+C_{i c G W}\right)_{i n t r a}-\left(C_{i c W F}+C_{i c F e O x}+C_{i c G W}\right)_{i n t e r}\right] \\
& +\phi S_{w}\left[\lambda_{i p} r_{i p}^{M} R_{f i p} C_{i p}-\lambda_{i} R_{f i} C_{i}\right] .
\end{aligned}
$$

Similarly, the one-dimensional mass balance equation for irreversibly sorbed radionuclide species $i$ on mobile iron oxyhydroxide colloids (from Equation 6.5.1.2-41) is:

$$
\begin{aligned}
\frac{\partial\left(\phi S_{w} C_{i c F e O x}^{i r r e v}\right)}{\partial t}= & \frac{\partial}{\partial z}\left(\phi S_{w} D_{c} \frac{\partial}{\partial z}\left(C_{i c F e O x}^{\text {irrev }}\right)\right)-\frac{\partial}{\partial z}\left(q_{w z} C_{i c F e O x}^{\text {irrev }}\right) \\
& +\phi S_{w} C_{c F e O x} \bar{S}_{c} k_{i} C_{i} \pm \gamma_{c}\left[\left(C_{i c F e O x}^{\text {irrev }}\right)_{\text {intra }}-\left(C_{i c F e O x}^{\text {irrev }}\right)_{\text {inter }}\right] \\
& +\phi S_{w}\left(\lambda_{i p} r_{i p}^{M} C_{i p c F e O x}^{\text {irrev }}-\lambda_{i} C_{i c F e O x}^{\text {irrev }}\right) .
\end{aligned}
$$

The one-dimensional mass balance equation for irreversibly sorbed radionuclide species $i$ on stationary iron oxyhydroxide corrosion products is the same as Equation 6.5.1.2-42, since there is no advection or diffusion of corrosion products:

$$
\frac{\partial\left(\phi S_{w} C_{i C P F e O x}^{i r r e v}\right)}{\partial t}=\rho_{b} \bar{s}_{C P} k_{i} C_{i}+\phi S_{w}\left(\lambda_{i p} r_{i p}^{M} C_{i p C P F e O x}^{i r r e v}-\lambda_{i} C_{i C P F e O x}^{i r r e v}\right) .
$$

The one-dimensional mass balance equation for waste form colloid transport (from Equation 6.5.1.2-36) is:

$$
\begin{aligned}
\frac{\partial\left(\phi S_{w} C_{c W F}\right)}{\partial t}= & \frac{\partial}{\partial z}\left(\phi S_{w} D_{c} \frac{\partial}{\partial z} C_{c W F}\right)-\frac{\partial}{\partial z}\left(q_{w z} C_{c W F}\right) \\
& +Q_{c W F s} \pm \gamma_{c}\left[\left(C_{c W F}\right)_{\text {intra }}-\left(C_{c W F}\right)_{\text {inter }}\right]
\end{aligned}
$$

Within the waste package, the media supporting transport are represented as single continua. In the UZ, however, the bulk medium is conceptualized as a dual continuum, characterized by two sets of local-scale properties unique to each continuum. Transport in the dual continuum media is represented by a mass balance equation for each continuum. The single invert continuum interfaces a dual continuum (fracture/matrix) UZ medium. Advective transport from the invert enters both the UZ fracture and matrix continua. 
The diffusive fluxes to the dual UZ continua are determined from the continuity of flux at the interface. This requirement states that the diffusive flux exiting the invert domain is equal to the sum of the diffusive fluxes entering the two UZ continua. The diffusive flux split will depend on the diffusive properties in the invert domain and both UZ continua together with the concentration gradients across the interface.

For discussion of the diffusive flux treatment at the invert/UZ interface consider a diffusive flux term, either aqueous or colloid flux, within the transport mass balance equation. Let $z_{\text {interface }}$ denote the spatial location of the invert/UZ interface. Then for $z<z_{\text {interface }}$, the diffusive flux for radionuclide species $i$ at a location within the invert domain is:

$$
\phi_{I} S_{w I} D_{i I} \frac{\partial C_{i I}}{\partial z}
$$

where $\phi_{I}$ is the porosity of the single-continuum invert domain.

For $z>z_{\text {interface }}$, the diffusive fluxes within the UZ matrix and UZ fracture continua are, respectively,

$$
\begin{aligned}
& \phi_{m} S_{w m} D_{i m} \frac{\partial C_{i m}}{\partial z}, \\
& \phi_{f} S_{w f} D_{i f} \frac{\partial C_{i f}}{\partial z} .
\end{aligned}
$$

For the case with no advection, the mass transport via diffusion across this interface is coupled by the flux continuity condition at the interface:

$$
\phi_{I} S_{w I} D_{i I} \frac{\partial C_{i I}}{\partial z^{-}}=\phi_{m} S_{w m} D_{i m} \frac{\partial C_{i m}}{\partial z^{+}}+\phi_{f} S_{w f} D_{i f} \frac{\partial C_{i f}}{\partial z^{+}}
$$

where

$$
\frac{\partial}{\partial z^{-}} \text {and } \frac{\partial}{\partial z^{+}}
$$

are the derivative from above and the derivative from below, respectively, at the interface.

The waste form colloids are generated in the waste form domain and are transported in accordance with an advective/diffusive mass balance. The waste form colloid concentration is subject to stability constraints based on the local domain chemistry. The waste form colloids transport both reversibly sorbed radionuclide mass and embedded (irreversibly sorbed) radionuclide mass. The iron oxyhydroxide colloids exist in the corrosion products and invert domains, and their concentrations are dependent on the local domain chemistry. The iron oxyhydroxide colloids transport both reversibly sorbed and irreversibly sorbed radionuclide 
mass; the irreversibly sorbed radionuclides are sorbed onto the surface of these colloids, rather than being embedded within the colloid matrix, as are the radionuclides associated with the waste form colloids. The ground water colloids exist in the corrosion products and invert domains, and their concentrations are dependent on the local domain chemistry. The ground water colloids transport only reversibly sorbed radionuclide mass. The iron oxyhydroxide corrosion products are immobile and found only in the corrosion products domain. These corrosion products support both reversibly sorbed and irreversibly sorbed radionuclide mass; however, as a bounding approach, reversible sorption is ignored by setting the $K_{d}$ values to zero (BSC 2005 [DIRS 174695]). Since corrosion products are immobile, all radionuclide mass sorbed to corrosion products is not transported but is retarded.

All of the features of the EBS radionuclide transport abstraction are accounted for in Equations 6.5.1.2-38, 6.5.1.2-36, 6.5.1.2-41, and 6.5.1.2-42 (or the one-dimensional versions of these equations, Equations 6.5.1.2-46, 6.5.1.2-49, 6.5.1.2-47, and 6.5.1.2-48, respectively), including invert diffusion, retardation in the waste package, in-package diffusion, and transport facilitated by reversible and irreversible colloids. Implementation of these equations into TSPA-LA involves additional simplifications and restrictions that are discussed in Section 6.5.3.

\subsubsection{Nomenclature}

Symbols used in Sections 6, 7, and 8 are summarized in Table 6.5-5.

Table 6.5-5. Nomenclature

\begin{tabular}{|c|c|c|c|}
\hline Variable & Definition & Units & Where First Used \\
\hline$A$ & Cross sectional area of diffusive or flow pathway & $\mathrm{m}^{2}$ & Eq. 6.5.1.2-5 \\
\hline$A_{f}$ & Diffusive area of UZ fracture cell & $\mathrm{m}^{2}$ & Eq. 6.5.3.5-21 \\
\hline$A_{g}$ & Surface area of crushed tuff granule & $\mathrm{m}^{2}$ & Section 6.6.4.1 \\
\hline$A_{I}$ & Invert cross sectional area (circle segment) & $\mathrm{m}^{2}$ & Eq. $6 \cdot 5 \cdot 3 \cdot 3-2$ \\
\hline$A_{I}$ & Diffusive area of invert cell & $\mathrm{m}^{2}$ & Eq. 6.5.3.5-21 \\
\hline$A_{I s}$ & $\begin{array}{l}\text { Intercepted flow area of a drift over the length of } \\
\text { one waste package }\end{array}$ & $\mathrm{m}^{2}$ & Eq. $6 \cdot 5 \cdot 3 \cdot 3-12$ \\
\hline$A_{I / U Z}$ & Diffusive area between invert and UZ cells & $\mathrm{m}^{2}$ & Eq. $6 \cdot 5 \cdot 3 \cdot 3-4$ \\
\hline$A_{m}$ & Diffusive area of UZ matrix cell & $\mathrm{m}^{2}$ & Eq. $6 \cdot 5 \cdot 3 \cdot 5-21$ \\
\hline$A_{s c c}$ & Cross sectional area of stress corrosion crack & $\mathrm{cm}^{2}$ & Eq. 6.6.2-8 \\
\hline$A_{s c c, e f f}$ & $\begin{array}{l}\text { Effective cross sectional area of stress corrosion } \\
\text { crack }\end{array}$ & $\mathrm{cm}^{2}$ & Section 6.6 .2 \\
\hline$A_{U Z}$ & Projected area of UZ normal to vertical flux & $\mathrm{m}^{2}$ & Eq. 6.5.3.6-1 \\
\hline$A_{w}$ & Cross sectional area of water molecule & $\mathrm{m}^{2}$ & $\begin{array}{l}\text { Table 4.1-9; } \\
\text { Eq. 6.3.4.3.2-6 }\end{array}$ \\
\hline$a$ & One-half the length of a stress corrosion crack & $\mathrm{m}$ & Eq. 6.3.3.1-1 \\
\hline$a$ & $\begin{array}{l}\text { Constant in equation for binary diffusion } \\
\text { coefficient }\end{array}$ & dimensionless & Eq. 6.6.2-6 \\
\hline$a$ & Empirical parameter in Archie's law & dimensionless & Eq. 6.3.4.1.1-1 \\
\hline
\end{tabular}


Table 6.5-5. Nomenclature (Continued)

\begin{tabular}{|c|c|c|c|}
\hline Variable & Definition & Units & Where First Used \\
\hline$a_{g}$ & Effective length of tuff granule matrix pore system & $\mathrm{m}$ & Section 6.6.4.1 \\
\hline$b$ & One-half the stress corrosion crack gap width & $\mathrm{m}$ & Section 6.3.3.1.2.1 \\
\hline$b$ & $\begin{array}{l}\text { Exponent in equation for binary diffusion } \\
\text { coefficient }\end{array}$ & dimensionless & Eq. 6.6.2-6 \\
\hline$b$ & Slope of the $\ln \psi$ versus $\ln \theta$ curve & dimensionless & Eq. 6.6.5.1-2 \\
\hline$C_{c F e O x}$ & $\begin{array}{l}\text { Concentration of mobile iron oxyhydroxide (FeOx) } \\
\text { colloids }\end{array}$ & $\mathrm{kg} \mathrm{m}^{-3}$ & Eq. 6.5.1.2-14 \\
\hline$C_{c G W}$ & $\begin{array}{l}\text { Concentration of mobile groundwater (GW) } \\
\text { colloids }\end{array}$ & $\mathrm{kg} \mathrm{m}^{-3}$ & Eq. 6.5.1.2-14 \\
\hline$C_{c W F}$ & Concentration of mobile waste form colloids & $\mathrm{kg} \mathrm{m}^{-3}$ & Eq. $6.5 .1 .2-14$ \\
\hline$C_{i}$ & Concentration of radionuclide species $i$ & $\mathrm{~kg} \mathrm{~m}^{-3}$ & Eq. 6.5.1.2-2 \\
\hline$C_{i}^{\text {embed }}$ & $\begin{array}{l}\text { Concentration of radionuclide species } i \text { embedded } \\
\text { on waste form colloids }\end{array}$ & $\mathrm{kg} \mathrm{m}^{-3}$ & Eq. 6.5.1.2-37 \\
\hline$C_{i I}$ & $\begin{array}{l}\text { Concentration of radionuclide species } i \text { in the } \\
\text { invert cell }\end{array}$ & $\mathrm{kg} \mathrm{m}^{-3}$ & Eq. 6.5.3.5-11 \\
\hline$C_{i I / U Z}$ & $\begin{array}{l}\text { Concentration of radionuclide species } i \text { at the } \\
\text { interface between the invert and UZ cells }\end{array}$ & $\mathrm{kg} \mathrm{m}^{-3}$ & Eq. $6 \cdot 5 \cdot 3 \cdot 5-11$ \\
\hline$C_{i f}$ & $\begin{array}{l}\text { Concentration of radionuclide species } / \text { in the UZ } \\
\text { fracture cell }\end{array}$ & $\mathrm{kg} \mathrm{m}^{-3}$ & Eq. $6 \cdot 5 \cdot 3 \cdot 5-12$ \\
\hline$C_{i m}$ & $\begin{array}{l}\text { Concentration of radionuclide species } i \text { in the UZ } \\
\text { matrix cell }\end{array}$ & $\mathrm{kg} \mathrm{m}^{-3}$ & Eq. 6.5.3.5-13 \\
\hline$C_{i, \text { new }}$ & $\begin{array}{l}\text { "New" input concentration of radionuclide species } \\
i\end{array}$ & $\mathrm{~kg} \mathrm{~m}^{-3}$ & Eq. 6.6.1.2.1-1 \\
\hline$C_{i, \text { old }}$ & "Old" input concentration of radionuclide species $i$ & $\mathrm{~kg} \mathrm{~m}^{-3}$ & Eq. 6.6.1.2.1-1 \\
\hline$C_{i p}^{\text {embed }}$ & $\begin{array}{l}\text { Concentration of parent } i p \text { of radionuclide species } \\
i \text { embedded on waste form colloids }\end{array}$ & $\mathrm{kg} \mathrm{m}^{-3}$ & Eq. 6.5.1.2-37 \\
\hline$C_{i c F e O x}$ & $\begin{array}{l}\text { Concentration of radionuclide species } i \text { sorbed } \\
\text { onto mobile iron oxyhydroxide (FeOx) colloids }\end{array}$ & $\mathrm{kg} \mathrm{m}^{-3}$ & Eq. 6.5.1.2-14 \\
\hline$C_{i c F e O x}^{i r r e v}$ & $\begin{array}{l}\text { Concentration of radionuclide species } i \\
\text { irreversibly adsorbed onto iron oxyhydroxide } \\
\text { (FeOx) colloids }\end{array}$ & $\mathrm{kg} \mathrm{m}^{-3}$ & Eq. 6.5.1.2-28 \\
\hline$C_{i c G W}$ & $\begin{array}{l}\text { Concentration of radionuclide species } i \text { sorbed } \\
\text { onto mobile GW colloids }\end{array}$ & $\mathrm{kg} \mathrm{m}^{-3}$ & Eq. 6.5.1.2-14 \\
\hline$C_{i C P}$ & $\begin{array}{l}\text { Concentration of dissolved radionuclide species } i \\
\text { in corrosion products domain or cell }\end{array}$ & $\mathrm{kg} \mathrm{m}^{-3}$ & Eq. $6.5 \cdot 1 \cdot 2-50$ \\
\hline$C_{i \mathrm{CPFeOx}}^{\text {irrev }}$ & $\begin{array}{l}\text { Concentration of radionuclide species } i \\
\text { irreversibly adsorbed onto iron oxyhydroxide } \\
\text { corrosion products }\end{array}$ & $\mathrm{kg} \mathrm{m}^{-3}$ & Eq. 6.5.1.2-31 \\
\hline$C_{i C P / \text { invint }}$ & $\begin{array}{l}\text { Concentration of radionuclide species } i \text { at the } \\
\text { interface between the corrosion products and } \\
\text { invert cells }\end{array}$ & $\mathrm{kg} \mathrm{m}^{-3}$ & Eq. 6.5.3.5-7 \\
\hline$C_{i c W F}$ & $\begin{array}{l}\text { Concentration of radionuclide species } i \text { sorbed } \\
\text { onto mobile waste form colloids }\end{array}$ & $\mathrm{kg} \mathrm{m}^{-3}$ & Eq. $6.5 \cdot 1.2-14$ \\
\hline$C_{\text {iinter }}$ & $\begin{array}{l}\text { Concentration of dissolved radionuclide species } i \\
\text { in invert intergranular continuum }\end{array}$ & $\mathrm{kg} \mathrm{m}^{-3}$ & Eq. 6.5.1.2-51 \\
\hline$C_{\text {iintra }}$ & $\begin{array}{l}\text { Concentration of dissolved radionuclide species } i \\
\text { in invert intragranular continuum }\end{array}$ & $\mathrm{kg} \mathrm{m}^{-3}$ & Eq. $6 \cdot 5 \cdot 1 \cdot 2-52$ \\
\hline
\end{tabular}


Table 6.5-5. Nomenclature (Continued)

\begin{tabular}{|c|c|c|c|}
\hline Variable & Definition & Units & Where First Used \\
\hline$C_{i p}$ & $\begin{array}{l}\text { Concentration of parent ip of radionuclide } \\
\text { species I }\end{array}$ & $\mathrm{kg} \mathrm{m}^{-3}$ & Eq. 6.5.1.2-9 \\
\hline$C_{i p c F e O x}$ & $\begin{array}{l}\text { Concentration of parent ip of radionuclide species } \\
i \text { sorbed onto mobile iron oxyhydroxide (FeOx) } \\
\text { colloids }\end{array}$ & $\mathrm{kg} \mathrm{m}^{-3}$ & Eq. 6.5.1.2-14 \\
\hline$C_{i p c F e O x}^{i r r e v}$ & $\begin{array}{l}\text { Concentration of parent ip of radionuclide species } \\
i \text { irreversibly adsorbed onto iron oxyhydroxide } \\
\text { (FeOx) colloids }\end{array}$ & $\mathrm{kg} \mathrm{m}^{-3}$ & Eq. 6.5.1.2-28 \\
\hline$C_{i p c G W}$ & $\begin{array}{l}\text { Concentration of parent ip of radionuclide species } \\
i \text { sorbed onto mobile (GW) colloids }\end{array}$ & $\mathrm{kg} \mathrm{m}^{-3}$ & Eq. 6.5.1.2-14 \\
\hline$C_{i p C P F e O x}^{\text {irrev }}$ & $\begin{array}{l}\text { Concentration of parent } i p \text { of radionuclide species } \\
i \text { irreversibly adsorbed onto iron oxyhydroxide } \\
\text { corrosion products }\end{array}$ & $\mathrm{kg} \mathrm{m}^{-3}$ & Eq. 6.5.1.2-31 \\
\hline$C_{i p c W F}$ & $\begin{array}{l}\text { Concentration of parent ip of radionuclide species } \\
i \text { sorbed onto mobile waste form colloids }\end{array}$ & $\mathrm{kg} \mathrm{m}^{-3}$ & Eq. 6.5.1.2-14 \\
\hline$C_{s i}$ & $\begin{array}{l}\text { Maximum concentration (solubility limit) of } \\
\text { radionuclide species } i\end{array}$ & $\mathrm{~kg} \mathrm{~m}^{-3}$ & Eq. 6.6.1.1.2-1 \\
\hline$C_{\text {si,new }}$ & $\begin{array}{l}\text { Maximum concentration (solubility limit) of } \\
\text { radionuclide species } i \text { in "new" chemistry }\end{array}$ & $\mathrm{kg} \mathrm{m}^{-3}$ & Eq. 6.6.1.2.2-9 \\
\hline$C_{\text {si,old }}$ & $\begin{array}{l}\text { Maximum concentration (solubility limit) of } \\
\text { radionuclide species } i \text { in "old" chemistry }\end{array}$ & $\mathrm{kg} \mathrm{m}^{-3}$ & Eq. 6.6.1.2.2-9 \\
\hline COV & Coefficient of variance $[=\sigma(x) / E(x)]$ & dimensionless & Table 6.6-5 \\
\hline$C_{O_{2}}$ & Molar concentration of oxygen in air & $\mathrm{mol} \mathrm{cm}{ }^{-3}$ & Eq. 6.6.3-2 \\
\hline$C_{w v}$ & Molar concentration of water vapor in air & $\mathrm{mol} \mathrm{cm}^{-3}$ & Eq. 6.6.2-5 \\
\hline$c_{i}$ & Concentration of radionuclide species $i$ & $\mathrm{~mol} \mathrm{~m}^{-1}$ & Eq. 6.3.4.1.1-10 \\
\hline$D_{A B}$ & Binary diffusion coefficient & $\mathrm{cm}^{2} \mathrm{~s}^{-1}$ & Eq. 6.6.2-6 \\
\hline$D_{B}$ & Diffusion coefficient for Brownian motion & $\mathrm{cm}^{2} \mathrm{~s}^{-1}$ & Eq. 6.5.1.2-35 \\
\hline$D_{c}$ & Colloid dispersion or diffusion coefficient & $\mathrm{m}^{2} \mathrm{~s}^{-1}$ & Eq. 6.5.1.2-35 \\
\hline$D_{c_{-} A / B}$ & $\begin{array}{l}\text { Interface diffusive conductance between cell } A \\
\text { and cell } B\end{array}$ & $\mathrm{~cm}^{3} \mathrm{~s}^{-1}$ & Eq. 6.5.3.5-6 \\
\hline$D_{c_{-} B / C}$ & $\begin{array}{l}\text { Interface diffusive conductance between cell } B \\
\text { and cell } C\end{array}$ & $\mathrm{~cm}^{3} \mathrm{~s}^{-1}$ & Eq. 6.5.3.5-8 \\
\hline$D_{\text {coll }}$ & Colloid diffusion coefficient & $\mathrm{m}^{2} \mathrm{~s}^{-1}$ & Eq. 6.3.4.4-1 \\
\hline$D_{C P}$ & Diffusion coefficient in corrosion products domain & $\mathrm{cm}^{2} \mathrm{~s}^{-1}$ & Eq. 6.6.4-1 \\
\hline$\hat{D}_{C P}$ & Diffusive conductance in corrosion products cell & $\mathrm{cm}^{3} \mathrm{~s}^{-1}$ & Eq. 6.6.4.2-1 \\
\hline$\hat{D}_{C P / C P-i n t}$ & $\begin{array}{l}\text { Diffusive conductance between corrosion } \\
\text { products cell and corrosion products interface cell }\end{array}$ & $\mathrm{cm}^{3} \mathrm{~s}^{-1}$ & Eq. 6.6.4.2-15 \\
\hline$\hat{D}_{C P-\text { int } / \text { inter }}$ & $\begin{array}{l}\text { Diffusive conductance between corrosion } \\
\text { products interface cell and invert intergranular cell }\end{array}$ & $\mathrm{cm}^{3} \mathrm{~s}^{-1}$ & Eq. 6.6.4.2-16 \\
\hline$\hat{D}_{C P-\text { int / intra }}$ & $\begin{array}{l}\text { Diffusive conductance between corrosion } \\
\text { products interface cell and invert intragranular cell }\end{array}$ & $\mathrm{cm}^{3} \mathrm{~s}^{-1}$ & Eq. 6.6.4.2-17 \\
\hline$\hat{D}_{C P / \text { inter }}$ & $\begin{array}{l}\text { Effective diffusive conductance between corrosion } \\
\text { products cell and invert intergranular cell }\end{array}$ & $\mathrm{cm}^{3} \mathrm{~s}^{-1}$ & Eq. 6.6.4.2-8 \\
\hline
\end{tabular}


Table 6.5-5. Nomenclature (Continued)

\begin{tabular}{|c|c|c|c|}
\hline Variable & Definition & Units & Where First Used \\
\hline$\hat{D}_{C P / \text { intra }}$ & $\begin{array}{l}\text { Effective diffusive conductance between corrosion } \\
\text { products cell and invert intragranular cell }\end{array}$ & $\mathrm{cm}^{3} \mathrm{~s}^{-1}$ & Eq. 6.6.4.2-9 \\
\hline$\hat{D}_{\text {intralinter }}$ & $\begin{array}{l}\text { Effective diffusive conductance between } \\
\text { intragranular and invert intergranular cells }\end{array}$ & $\mathrm{cm}^{3} \mathrm{~s}^{-1}$ & Eq. 6.6.4.2-10 \\
\hline$D_{e}$ & Effective diffusion coefficient & $\mathrm{cm}^{2} \mathrm{~s}^{-1}$ & Eq. 6.5.1.2-22 \\
\hline$D_{f}$ & $\begin{array}{l}\text { Effective diffusion coefficient within the UZ } \\
\text { fracture cell }\end{array}$ & $\mathrm{cm}^{2} \mathrm{~s}^{-1}$ & Eq. $6 \cdot 5 \cdot 3 \cdot 5-12$ \\
\hline$D_{I}$ & Effective diffusion coefficient within the invert cell & $\mathrm{cm}^{2} \mathrm{~s}^{-1}$ & Eq. 6.3.4.1.1-18 \\
\hline$\hat{D}_{I f}$ & $\begin{array}{l}\text { Effective diffusive conductance between invert } \\
\text { cell and UZ fracture cell }\end{array}$ & $\mathrm{cm}^{3} \mathrm{~s}^{-1}$ & Eq. 6.5.3.5-18 \\
\hline$\hat{D}_{\text {Im }}$ & $\begin{array}{l}\text { Effective diffusive conductance between invert } \\
\text { cell and UZ matrix cell }\end{array}$ & $\mathrm{cm}^{3} \mathrm{~s}^{-1}$ & Eq. 6.5.3.5-19 \\
\hline$\hat{D}_{I / I-i n t}$ & $\begin{array}{l}\text { Diffusive conductance between the invert cell and } \\
\text { the invert interface cell }\end{array}$ & $\mathrm{cm}^{3} \mathrm{~s}^{-1}$ & Eq. 6.5.3.5-25 \\
\hline$\hat{D}_{I-i n t / f}$ & $\begin{array}{l}\text { Diffusive conductance between the invert } \\
\text { interface cell and the UZ fracture cell }\end{array}$ & $\mathrm{cm}^{3} \mathrm{~s}^{-1}$ & Eq. $6.5 \cdot 3.5-26$ \\
\hline$\hat{D}_{I-i n t / m}$ & $\begin{array}{l}\text { Diffusive conductance between the invert } \\
\text { interface cell and the UZ matrix cell }\end{array}$ & $\mathrm{cm}^{3} \mathrm{~s}^{-1}$ & Eq. 6.5.3.5-27 \\
\hline$D_{i}$ & Diffusion coefficient of species $i$ & $\mathrm{~m}^{2} \mathrm{~s}^{-1}$ & Eq. 6.3.4.1.1-10 \\
\hline$D_{i}$ & $\begin{array}{l}\text { Hydrodynamic dispersion coefficient, or effective } \\
\text { diffusion coefficient, of radionuclide species } i\end{array}$ & $m^{2} s^{-1}$ & Eq. 6.5.1.2-4 \\
\hline$D_{i e}$ & $\begin{array}{l}\text { Effective diffusion coefficient of the interface } \\
\text { between two continua for radionuclide species } i\end{array}$ & $\mathrm{~m}^{2} \mathrm{~s}^{-1}$ & Eq. 6.5.1.2-22 \\
\hline$D_{\text {inter }}$ & $\begin{array}{l}\text { Diffusion coefficient for invert intergranular } \\
\text { continuum }\end{array}$ & $\mathrm{cm}^{2} \mathrm{~s}^{-1}$ & Eq. 6.6.4-2 \\
\hline$\hat{D}_{\text {inter }}$ & Diffusive conductance in invert intergranular cell & $\mathrm{cm}^{3} \mathrm{~s}^{-1}$ & Eq. 6.6.4.2-2 \\
\hline$\hat{D}_{\text {inter } / \text { inter-int }}$ & $\begin{array}{l}\text { Diffusive conductance between the invert } \\
\text { intergranular cell and the invert intergranular } \\
\text { interface cell }\end{array}$ & $\mathrm{cm}^{3} \mathrm{~s}^{-1}$ & Eq. 6.6.4.2-19 \\
\hline$\hat{D}_{\text {intra-int } / U Z m}$ & $\begin{array}{l}\text { Diffusive conductance between the invert } \\
\text { intergranular cell and the invert intragranular } \\
\text { interface cell }\end{array}$ & $\mathrm{cm}^{3} \mathrm{~s}^{-1}$ & Eq. 6.6.4.2-23 \\
\hline$\hat{D}_{\text {intra-int/UZf }}$ & $\begin{array}{l}\text { Diffusive conductance between the invert } \\
\text { intergranular cell and the UZ fracture cell }\end{array}$ & $\mathrm{cm}^{3} \mathrm{~s}^{-1}$ & Eq. 6.6.4.2-24 \\
\hline$D_{\text {intra }}$ & $\begin{array}{l}\text { Diffusion coefficient for invert intragranular } \\
\text { continuum }\end{array}$ & $\mathrm{cm}^{2} \mathrm{~s}^{-1}$ & Eq. 6.6.4-3 \\
\hline$\hat{D}_{\text {intra }}$ & Diffusive conductance in invert intragranular cell & $\mathrm{cm}^{3} \mathrm{~s}^{-1}$ & Eq. 6.6.4.2-3 \\
\hline$\hat{D}_{\text {intralintra-int }}$ & $\begin{array}{l}\text { Diffusive conductance between the invert } \\
\text { intragranular cell and the UZ matrix cell }\end{array}$ & $\mathrm{cm}^{3} \mathrm{~s}^{-1}$ & Eq. 6.6.4.2-21 \\
\hline$\hat{D}_{\text {inter-int } / U Z m}$ & $\begin{array}{l}\text { Diffusive conductance between the invert } \\
\text { intragranular cell and the invert intragranular } \\
\text { interface cell }\end{array}$ & $\mathrm{cm}^{3} \mathrm{~s}^{-1}$ & Eq. 6.6.4.2-20 \\
\hline$\hat{D}_{\text {inter-int/UZf }}$ & $\begin{array}{l}\text { Diffusive conductance between the invert } \\
\text { intragranular cell and the UZ fracture cell }\end{array}$ & $\mathrm{cm}^{3} \mathrm{~s}^{-1}$ & Eq. 6.6.4.2-22 \\
\hline$D_{m}$ & $\begin{array}{l}\text { Effective diffusion coefficient within the UZ matrix } \\
\text { cell }\end{array}$ & $\mathrm{cm}^{2} \mathrm{~s}^{-1}$ & Eq. $6 \cdot 5 \cdot 3 \cdot 5-13$ \\
\hline$\hat{D}_{m f}$ & $\begin{array}{l}\text { Effective diffusive conductance between UZ } \\
\text { fracture and matrix cells }\end{array}$ & $\mathrm{cm}^{3} \mathrm{~s}^{-1}$ & Eq. $6.5 .3 .5-20$ \\
\hline
\end{tabular}


Table 6.5-5. Nomenclature (Continued)

\begin{tabular}{|c|c|c|c|}
\hline Variable & Definition & Units & Where First Used \\
\hline$D_{\text {ion }}$ & Ion diffusion coefficient & $\mathrm{m}^{2} \mathrm{~s}^{-1}$ & Eq. 6.3.4.4-1 \\
\hline$D_{\text {limit }}$ & Diffusion coefficient measurement limit & $\mathrm{cm}^{2} \mathrm{~s}^{-1}$ & Eq. 6.6.5.2-5 \\
\hline$D_{M D}$ & Mechanical dispersion coefficient & $\mathrm{cm}^{2} \mathrm{~s}^{-1}$ & Eq. 6.5.1.2-35 \\
\hline$D_{m i}$ & Molecular diffusion coefficient of species $i$ & $\mathrm{~m}^{2} \mathrm{~s}^{-1}$ & Eq. 6.5.1.2-6 \\
\hline$D_{m s}$ & Diffusion coefficient for saturated tuff matrix & $\mathrm{cm}^{2} \mathrm{~s}^{-1}$ & Eq. 6.5.3.6-2 \\
\hline$D_{s}$ & Effective diffusion coefficient & $\mathrm{m}^{2} \mathrm{~s}^{-1}$ & Eq. 6.3.4.3.5-1 \\
\hline$D_{T}$ & Diffusion coefficient at temperature $T$ & $\mathrm{~m}^{2} \mathrm{~s}^{-1}$ & Eq. 6.3.4.1.2-1 \\
\hline$D_{T_{0}}$ & Diffusion coefficient at temperature $T_{0}$ & $\mathrm{~m}^{2} \mathrm{~s}^{-1}$ & Eq. 6.3.4.1.2-1 \\
\hline$D_{W F}$ & Diffusion coefficient in waste form domain & $\mathrm{cm}^{2} \mathrm{~s}^{-1}$ & Table 8.2-1 \\
\hline$D_{0}$ & Free water diffusion coefficient & $\mathrm{m}^{2} \mathrm{~s}^{-1}$ & Eq. 6.3.4.1.1-10 \\
\hline$D^{*}$ & Molecular diffusion coefficient & $\mathrm{cm}^{2} \mathrm{~s}^{-1}$ & Table 7.2-1, footnote a \\
\hline$d$ & Depth of stress corrosion crack & $\mathrm{m}$ & Figure $6.3-3$ \\
\hline$d$ & Characteristic length of the tuff matrix structure & $\mathrm{m}$ & Eq. 6.5.1.2-22 \\
\hline$d_{D}$ & Diameter of drift & $\mathrm{m}$ & Eq. 6.5.3.6-1 \\
\hline$d_{g}$ & Geometric particle diameter & $\mathrm{mm}$ & Eq. 6.6.5.1-3 \\
\hline$E$ & Modulus of elasticity & $\mathrm{Pa}$ & Eq. 6.3.3.1-1 \\
\hline$E(x)$ & Expected value of the $K_{d}$ distribution & $\mathrm{ml} \mathrm{g}^{-1}$ & Table 6.6-5 \\
\hline$e$ & Elementary charge & $\mathrm{C}$ & Table 7.2-1, footnote a \\
\hline$e$ & Natural logarithm base & dimensionless & Eq. 6.3.4.3.2-2 \\
\hline$F$ & Faraday constant & $\mathrm{C} \mathrm{mol}^{-1}$ & Eq. 6.3.4.1.1.-6 \\
\hline$F$ & $\begin{array}{l}\text { Fraction of seepage flux onto drip shield or waste } \\
\text { package that flows into a breach }\end{array}$ & dimensionless & Eq. 6.5.1.1.2-7 \\
\hline$F_{\text {alt }}$ & $\begin{array}{l}\text { Radionuclide release rate from waste package in } \\
\text { alternative patch geometry model }\end{array}$ & $\mathrm{kg} \mathrm{s}^{-1}$ & Eq. 6.6.1.2.3-2 \\
\hline$F_{i C P}$ & $\begin{array}{l}\text { Diffusive flux of radionuclide species } i \text { in corrosion } \\
\text { products cell }\end{array}$ & $\mathrm{kg} \mathrm{s}^{-1}$ & Eq. 6.6.4.2-1 \\
\hline$F_{i f}$ & $\begin{array}{l}\text { Diffusive fluxes of radionuclide species } i \text { within the } \\
\text { UZ fracture cell }\end{array}$ & $\mathrm{kg} \mathrm{s}^{-1}$ & Eq. $6 \cdot 5 \cdot 3 \cdot 5-12$ \\
\hline$F_{i I}$ & $\begin{array}{l}\text { Diffusive fluxes of radionuclide species } i \text { within the } \\
\text { invert cell }\end{array}$ & $\mathrm{kg} \mathrm{s}^{-1}$ & Eq. 6.5.3.5-11 \\
\hline$F_{\text {iinter }}$ & $\begin{array}{l}\text { Diffusive flux of radionuclide species } i \text { in invert } \\
\text { intergranular cell }\end{array}$ & $\mathrm{kg} \mathrm{s}^{-1}$ & Eq. 6.6.4.2-2 \\
\hline$F_{\text {iintra }}$ & $\begin{array}{l}\text { Diffusive flux of radionuclide species } i \text { in invert } \\
\text { intragranular cell }\end{array}$ & $\mathrm{kg} \mathrm{s}^{-1}$ & Eq. 6.6.4.2-3 \\
\hline$F_{i m}$ & $\begin{array}{l}\text { Diffusive fluxes of radionuclide species } i \text { within the } \\
\text { UZ matrix cell }\end{array}$ & $\mathrm{kg} \mathrm{s}^{-1}$ & Eq. $6 \cdot 5 \cdot 3 \cdot 5-13$ \\
\hline$F_{j}$ & $\begin{array}{l}\text { Volumetric flow rate or flux of water in flow path } j \\
(j=1 \text { to } 8)\end{array}$ & $\mathrm{m}^{3} \mathrm{~s}^{-1}$ & Table 6.3-1; Eq. 6.5.1.1-5 \\
\hline
\end{tabular}


Table 6.5-5. Nomenclature (Continued)

\begin{tabular}{|c|c|c|c|}
\hline Variable & Definition & Units & Where First Used \\
\hline$F_{p r i}$ & $\begin{array}{l}\text { Radionuclide release rate from waste package in } \\
\text { primary patch geometry model }\end{array}$ & $\mathrm{kg} \mathrm{s}$ & Eq. 6.6.1.2.3-1 \\
\hline$F_{R}$ & Formation factor & dimensionless & Section 6.3.4.1.1 \\
\hline$F_{w}$ & Volumetric flow rate of water & $\mathrm{m}^{3} \mathrm{~s}^{-1}$ & Eq. 6.5.1.1-4 \\
\hline$f_{A \ell}$ & $\begin{array}{l}\text { Theoretical fraction of dripping flux falling at Point } \\
y<y_{A} \text { that flows into a drip shield breach }\end{array}$ & dimensionless & Eq. 6.5.1.1.2-2 \\
\hline$f_{A-}$ & $\begin{array}{l}\text { Theoretical fraction of dripping flux falling between } \\
\text { Points }-I \text { and } B \text { that flows into a drip shield breach }\end{array}$ & dimensionless & Eq. 6.5.1.1.2-2 \\
\hline$f_{B+}$ & $\begin{array}{l}\text { Theoretical fraction of dripping flux falling at Point } \\
y>y_{B} \text { that flows into a drip shield breach }\end{array}$ & dimensionless & Eq. 6.5.1.1.2-14 \\
\hline$f_{C \ell}$ & $\begin{array}{l}\text { Theoretical fraction of dripping flux falling between } \\
\text { Points } C \text { and }+1 \text { that flows into a drip shield breach }\end{array}$ & dimensionless & Eq. 6.5.1.1.2-5 \\
\hline$f_{\text {calc }}$ & $\begin{array}{l}\text { Calculated fraction of dripping flux that flows into } \\
\text { a drip shield breach }\end{array}$ & dimensionless & Section 6.5.1.1.2.4 \\
\hline$f_{D S}$ & Uncertain drip shield flux splitting factor & dimensionless & Eq. 6.3.2.4-2 \\
\hline$f_{D S}^{\prime}$ & $\begin{array}{l}\text { Sampled drip shield flux splitting factor that } \\
\text { accounts for rivulet spread angle uncertainty }\end{array}$ & dimensionless & Eq. 6.3.2.4-5 \\
\hline$f_{D+}$ & $\begin{array}{l}\text { Theoretical fraction of dripping flux falling at Point } \\
y>y_{D} \text { that flows into a drip shield breach }\end{array}$ & dimensionless & Eq. 6.5.1.1.2-6 \\
\hline$f_{\text {expt }}$ & $\begin{array}{l}\text { Experimentally measured fraction of dripping flux } \\
\text { that flows into a drip shield breach }\end{array}$ & dimensionless & Section 6.5.1.1.2.4 \\
\hline$f_{H A, G}$ & Percentage of high-affinity sites for goethite & percent & Eq. 6.3.4.2.3.2-1 \\
\hline$f_{H A, H F O}$ & Percentage of high-affinity sites for HFO & percent & Eq. 6.3.4.2.3.2-1 \\
\hline$f_{\ell B}$ & $\begin{array}{l}\text { Theoretical fraction of dripping flux falling between } \\
\text { Points }-I \text { and } B \text { that flows into a drip shield breach }\end{array}$ & dimensionless & Eq. 6.5.1.1.2-3 \\
\hline$f_{\ell D}$ & $\begin{array}{l}\text { Theoretical fraction of dripping flux falling between } \\
\text { Points }-I \text { and } D \text { that flows into a drip shield breach }\end{array}$ & dimensionless & Eq. 6.5.1.1.2-6 \\
\hline$f_{V D}$ & $\begin{array}{l}\text { Model validation uncertain drip shield flux splitting } \\
\text { factor }\end{array}$ & dimensionless & Eq. 7.1.1.1-1 \\
\hline$f_{V D}^{\prime}$ & $\begin{array}{l}\text { Model validation sampled drip shield flux splitting } \\
\text { factor that accounts for rivulet spread angle } \\
\text { uncertainty }\end{array}$ & dimensionless & Eq. $7 \cdot 1 \cdot 1 \cdot 1-3$ \\
\hline$f_{V W}$ & $\begin{array}{l}\text { Model validation uncertain waste package flux } \\
\text { splitting factor }\end{array}$ & dimensionless & Eq. $7 \cdot 1 \cdot 1 \cdot 2-1$ \\
\hline$f_{V W}^{\prime}$ & $\begin{array}{l}\text { Model validation sampled waste package flux } \\
\text { splitting factor that accounts for rivulet spread } \\
\text { angle uncertainty }\end{array}$ & dimensionless & Eq. $7 \cdot 1 \cdot 1 \cdot 2-3$ \\
\hline$f_{W P}$ & Uncertain waste package flux splitting factor & dimensionless & Eq. 6.3.3.2-1 \\
\hline$f_{W P}^{\prime}$ & Sampled waste package flux splitting factor & dimensionless & Eq. 6.3.3.2-3 \\
\hline$f_{0}$ & $\begin{array}{l}\text { Theoretical fraction of dripping flux falling between } \\
\text { Points B and C that flows into a drip shield breach }\end{array}$ & dimensionless & Eq. 6.5.1.1.2-4 \\
\hline$G_{t}$ & Conductance of bulk porous medium & S & Eq. 6.3.4.1.1-5 \\
\hline$G_{w}$ & Conductance of water & S & Eq. 6.3.4.1.1-5 \\
\hline
\end{tabular}


Table 6.5-5. Nomenclature (Continued)

\begin{tabular}{|c|c|c|c|}
\hline Variable & Definition & Units & Where First Used \\
\hline$H_{m}$ & Absolute humidity of air & $\mathrm{kg} \mathrm{kg}^{-1}$ & Eq. 6.6.2-3 \\
\hline$H_{m o l}$ & Molal humidity of air & $\mathrm{mol} \mathrm{mol}^{-1}$ & Eq. 6.6.2-4 \\
\hline$I_{s}$ & Hydraulic head gradient in the invert & $\mathrm{m} \mathrm{m}^{-1}$ & Eq. 6.5.3.3-12 \\
\hline $\mathbf{i}$ & $\begin{array}{l}\text { Unit vector in the } x \text {-direction or the direction of } \\
\text { flow }\end{array}$ & dimensionless & Eq. 6.5.1.2-5 \\
\hline $\boldsymbol{J}_{c B}$ & $\begin{array}{l}\text { Mass flux of waste form colloids due to Brownian } \\
\text { motion }\end{array}$ & $\mathrm{kg} \mathrm{m}^{-2} \mathrm{~s}^{-1}$ & Eq. 6.5.1.2-35 \\
\hline $\boldsymbol{J}_{c M D}$ & $\begin{array}{l}\text { Mass flux of waste form colloids due to } \\
\text { mechanical dispersion }\end{array}$ & $\mathrm{kg} \mathrm{m}^{-2} \mathrm{~s}^{-1}$ & Eq. 6.5.1.2-35 \\
\hline $\boldsymbol{J}_{c W F}$ & Mass flux of waste form colloids & $\mathrm{kg} \mathrm{m}^{-2} \mathrm{~s}^{-1}$ & Eq. 6.5.1.2-32 \\
\hline $\boldsymbol{J}_{i}$ & $\begin{array}{l}\text { Mass flux (mass specific discharge) of } \\
\text { radionuclide species } i\end{array}$ & $\mathrm{~kg} \mathrm{~m}^{-2} \mathrm{~s}^{-1}$ & Eq. 6.5.1.2-1 \\
\hline $\boldsymbol{J}_{i c F e O x}$ & $\begin{array}{l}\text { Total mass flux of mobile iron oxyhydroxide } \\
\text { (FeOx) colloids containing adsorbed radionuclide } \\
\text { species } i\end{array}$ & $\mathrm{~kg} \mathrm{~m}^{-2} \mathrm{~s}^{-1}$ & Eq. 6.5.1.2-14 \\
\hline $\boldsymbol{J}_{i c F e O x}^{i r r e v}$ & $\begin{array}{l}\text { Total mass flux of mobile iron oxyhydroxide } \\
\text { (FeOx) colloids containing irreversibly adsorbed } \\
\text { radionuclide species } i\end{array}$ & $\mathrm{~kg} \mathrm{~m}^{-2} \mathrm{~s}^{-1}$ & Eq. 6.5.1.2-28 \\
\hline $\boldsymbol{J}_{i c G W}$ & $\begin{array}{l}\text { Total mass flux of mobile GW colloids containing } \\
\text { adsorbed radionuclide species } i\end{array}$ & $\mathrm{~kg} \mathrm{~m}^{-2} \mathrm{~s}^{-1}$ & Eq. $6.5 .1 .2-14$ \\
\hline $\boldsymbol{J}_{i c W F}$ & $\begin{array}{l}\text { Total mass flux of mobile waste form colloids } \\
\text { containing adsorbed radionuclide species } i\end{array}$ & $\mathrm{~kg} \mathrm{~m}^{-2} \mathrm{~s}^{-1}$ & Eq. 6.5.1.2-14 \\
\hline$K_{d}$ & Sorption distribution (or distribution) coefficient & $\mathrm{ml} \mathrm{g}^{-1}$ & Section 4.1.2 \\
\hline$K_{d i c F e O x}$ & $\begin{array}{l}\text { Sorption distribution (or distribution) coefficient of } \\
\text { iron oxyhydroxide colloids containing adsorbed } \\
\text { radionuclide species } i\end{array}$ & $\mathrm{ml} \mathrm{g}^{-1}$ & Eq. 6.5.1.2-14 \\
\hline$K_{d i c G W}$ & $\begin{array}{l}\text { Sorption distribution (or distribution) coefficient of } \\
\text { groundwater colloids containing adsorbed } \\
\text { radionuclide species } i\end{array}$ & $\mathrm{ml} \mathrm{g}^{-1}$ & Eq. 6.5.1.2-14 \\
\hline$K_{d i c W F}$ & $\begin{array}{l}\text { Sorption distribution (or distribution) coefficient of } \\
\text { waste form colloids containing adsorbed } \\
\text { radionuclide species } i\end{array}$ & $\mathrm{ml} \mathrm{g}^{-1}$ & Eq. 6.5.1.2-14 \\
\hline$K_{\text {dips }}$ & $\begin{array}{l}\text { Sorption distribution (or distribution) coefficient of } \\
\text { parent ip of radionuclide species } i\end{array}$ & $\mathrm{ml} \mathrm{g}^{-1}$ & Eq. 6.5.1.2-12 \\
\hline$K_{\text {dis }}$ & $\begin{array}{l}\text { Sorption distribution (or distribution) coefficient of } \\
\text { radionuclide species } i\end{array}$ & $\mathrm{ml} \mathrm{g}^{-1}$ & Eq. 6.5.1.2-12 \\
\hline$K_{u s}$ & Unsaturated hydraulic conductivity of invert & $\mathrm{m} \mathrm{s}^{-1}$ & Eq. 6.5.3.3-12 \\
\hline$k$ & Boltzmann constant & $\mathrm{J} \mathrm{K}^{-1}$ & Table 7.2-1, footnote a \\
\hline$k$ & Parameter in $\mathrm{FHH}$ adsorption isotherm & dimensionless & Eq. 6.3.4.3.2-2 \\
\hline$k_{i}$ & Irreversible forward rate constant & $\mathrm{m}^{3} \mathrm{~m}^{-2} \mathrm{~s}^{-1}$ & Eq. 6.5.1.2-13 \\
\hline$k_{m}$ & Intrinsic permeability of saturated tuff matrix & $\mathrm{m}^{2}$ & Eq. 6.5.3.6-3 \\
\hline$k_{m e}$ & Effective permeability of tuff matrix & $\mathrm{m}^{2}$ & Eq. 6.5.3.6-2 \\
\hline$k_{r m}$ & Relative permeability of tuff matrix & dimensionless & Eq. 6.5.3.6-3 \\
\hline
\end{tabular}


Table 6.5-5. Nomenclature (Continued)

\begin{tabular}{|c|c|c|c|}
\hline Variable & Definition & Units & Where First Used \\
\hline$L_{A}$ & $\begin{array}{l}\text { Diffusive lengths from the cell centers to the cell } \\
\text { interface within cell } A\end{array}$ & $\mathrm{~m}$ & Eq. 6.5.3.5-5 \\
\hline$L_{B}$ & $\begin{array}{l}\text { Diffusive lengths from the cell centers to the cell } \\
\text { interface within cell } B\end{array}$ & $\mathrm{~m}$ & Eq. 6.5.3.5-5 \\
\hline$L_{D S}$ & Axial length of drip shield & $\mathrm{m}$ & Table 6.3-1 \\
\hline$L_{D S_{-} \text {Patch }}$ & $\begin{array}{l}\text { Axial half-length of each drip shield patch due to } \\
\text { general corrosion }\end{array}$ & $\mathrm{m}$ & Table 6.3-1 \\
\hline$L_{f}$ & Diffusive length within the UZ fracture cell & $\mathrm{m}$ & Eq. 6.5.3.5-12 \\
\hline$L_{I}$ & Diffusive length within the invert cell & $\mathrm{m}$ & Eq. 6.5.3.5-11 \\
\hline$L_{\text {inter }}$ & Diffusive length within the invert intergranular cell & $\mathrm{m}$ & Eq. 6.6.4.2-2 \\
\hline$L_{\text {intra }}$ & Diffusive length within the invert intragranular cell & $\mathrm{m}$ & Eq. 6.6.4.2-3 \\
\hline$L_{m}$ & Diffusive length within the UZ matrix cell & $\mathrm{m}$ & Eq. 6.5.3.5-13 \\
\hline$L_{W P}$ & Length of waste package & $\mathrm{m}$ & Table 6.3-1 \\
\hline$L_{W P_{-} \text {Patch }}$ & $\begin{array}{l}\text { Axial half-length of each drip waste package due } \\
\text { to general corrosion }\end{array}$ & $\mathrm{m}$ & Table 6.3-1 \\
\hline $\bar{l}$ & Average ionic conductivity at infinite dilution & $\mathrm{S} \mathrm{cm}^{2}$ equivalent ${ }^{-1}$ & Eq. 6.3.4.1.1-7 \\
\hline$l_{+}^{0}, l_{-}^{0}$ & Cationic and anionic conductivity at infinite dilution & $\mathrm{S} \mathrm{cm}^{2}$ equivalent ${ }^{-1}$ & Eq. 6.3.4.1.1-6 \\
\hline$\ell$ & One-half width of corrosion patch in drip shield & $\mathrm{m}$ & Eq. 6.3.2.4-2 \\
\hline$\ell_{W P}$ & $\begin{array}{l}\text { One-half width of corrosion patch in waste } \\
\text { package }\end{array}$ & $\mathrm{m}$ & Eq. 6.3.3.2-1 \\
\hline$M_{A}, M_{B}$ & Molecular weights of components $A$ and $B$ & $\mathrm{~g} \mathrm{~mol}^{-1}$ & Eq. 6.6.2-6 \\
\hline$M_{a}$ & Molecular weight of air & $\mathrm{kg} \mathrm{mol}^{-1}$ & Eq. 6.6.2-3 \\
\hline$M_{w}$ & Molecular weight of water & $\mathrm{kg} \mathrm{mol}^{-1}$ & Eq. 6.3.4.3.2-6 \\
\hline$m$ & Exponent on porosity in Archie's law & dimensionless & Eq. 6.3.4.1.1-1 \\
\hline$m$ & Mass of waste package internal components & $\mathrm{kg}$ & Table 6.3-9, footnote $\mathrm{h}$ \\
\hline$m_{C P}$ & $\begin{array}{l}\text { Mass of corrosion products inside waste package; } \\
\text { function of time } t\end{array}$ & $\mathrm{~kg}$ & Eq. 6.3.4.3.5-3 \\
\hline$m_{C P f}$ & $\begin{array}{l}\text { Mass of corrosion products inside waste package } \\
\text { from complete corrosion of all steel internal } \\
\text { components }\end{array}$ & $\mathrm{kg}$ & Eq. 6.5.3.2-3 \\
\hline$m_{C P 1}$ & $\begin{array}{l}\text { Mass of corrosion products inside waste package } \\
\text { from corrosion of carbon steel }\end{array}$ & $\mathrm{kg}$ & Eq. 6.5.3.2-3 \\
\hline$m_{C P 2}$ & $\begin{array}{l}\text { Mass of corrosion products inside waste package } \\
\text { from corrosion of stainless steel }\end{array}$ & $\mathrm{kg}$ & Eq. 6.5.3.2-4 \\
\hline$m_{i}$ & Mass of radionuclide species $i$ in waste package & $\mathrm{kg}$ & Eq. 6.6.1.1.1-2 \\
\hline$\dot{m}_{i}$ & $\begin{array}{l}\text { Rate of release of radionuclide species } i \text { into } \\
\text { water in waste package }\end{array}$ & $\mathrm{kg} \mathrm{s}^{-1}$ & Eq. 6.6.1.1.1-1 \\
\hline$m_{w}$ & $\begin{array}{l}\text { Instantaneous total mass of water within the walls } \\
\text { of a drift }\end{array}$ & $\mathrm{kg}$ & Eq. 6.5.1.1-1 \\
\hline
\end{tabular}


Table 6.5-5. Nomenclature (Continued)

\begin{tabular}{|c|c|c|c|}
\hline Variable & Definition & Units & Where First Used \\
\hline$N$ & Number of waste package internal components & dimensionless & Table 6.3-9, footnote $\mathrm{h}$ \\
\hline$N_{A}$ & Avogadro's number & molecules $\mathrm{mol}^{-1}$ & Eq. 6.3.4.3.2-6 \\
\hline$N_{b}$ & $\begin{array}{l}\text { Number of breaches (corrosion patches) in drip } \\
\text { shield }\end{array}$ & dimensionless & Eq. 6.3.2.4-2 \\
\hline$N_{b D S}$ & $\begin{array}{l}\text { Number of breaches (corrosion patches) in drip } \\
\text { shield }\end{array}$ & dimensionless & Table 6.3-1 \\
\hline$N_{b W P}$ & $\begin{array}{l}\text { Number of breaches (corrosion patches) in waste } \\
\text { package }\end{array}$ & dimensionless & Table 6.3-1 \\
\hline$N_{c}$ & $\begin{array}{l}\text { Number of breaches (corrosion patches) on crown } \\
\text { of drip shield }\end{array}$ & dimensionless & Eq. 6.5.1.1.1-6 \\
\hline$N D$ & Normal distribution & dimensionless & Eq. 6.3.4.1.1-22 \\
\hline$N_{S, G}$ & Sorption site density for goethite & sites $\mathrm{nm}^{-2}$ & Eq. 6.3.4.2.3.2-1 \\
\hline$N_{S, H F O}$ & Sorption site density for HFO & sites $\mathrm{nm}^{-2}$ & Eq. 6.3.4.2.3.2-1 \\
\hline$n$ & $\begin{array}{l}\text { Exponent on saturation or water content in power } \\
\text { law dependence of diffusion coefficient (e.g., } \\
\text { Archie's law) }\end{array}$ & dimensionless & Eq. 6.3.4.1.1-2 \\
\hline$n$ & Time step number & dimensionless & Eq. 6.5.3.5-1 \\
\hline$p$ & Slope of the model function & dimensionless & Eq. 6.6.5.2-6 \\
\hline$p$ & Total pressure & atm & Eq. 6.6.2-6 \\
\hline$p_{c A}, p_{c B}$ & Critical pressure of components $A$ and $B$ & atm & Eq. 6.6.2-6 \\
\hline$p_{w}$ & Partial pressure of water & $\mathrm{Pa}$ & Eq. 6.3.4.3.2-1 \\
\hline$p_{w}^{o}$ & Vapor pressure of water & $\mathrm{Pa}$ & Eq. 6.3.4.3.2-1 \\
\hline$Q_{a d v / d i f f}^{w f c}$ & $\begin{array}{l}\text { Total mass flux (combined advective and diffusive } \\
\text { mass flux) of waste form colloids per unit bulk } \\
\text { volume }\end{array}$ & $\mathrm{kg} \mathrm{m}^{-3} \mathrm{~s}^{-1}$ & Eq. $6 \cdot 5 \cdot 3 \cdot 5-10$ \\
\hline$Q_{c W F}$ & $\begin{array}{l}\text { Net rate of waste form colloid capture on the solid } \\
\text { surface }\end{array}$ & $\mathrm{kg} \mathrm{m}^{-3} \mathrm{~s}^{-1}$ & Eq. 6.5.1.2-32 \\
\hline$Q_{c W F}^{i n t}$ & $\begin{array}{l}\text { Net rate of waste form colloid capture at the air- } \\
\text { water interface }\end{array}$ & $\mathrm{kg} \mathrm{m}^{-3} \mathrm{~s}^{-1}$ & Eq. 6.5.1.2-32 \\
\hline$Q_{c W F f g}$ & $\begin{array}{l}\text { Net rate of waste form colloid removal from } \\
\text { suspension by means of physical filtering (pore } \\
\text { clogging, sieving, and straining) and by } \\
\text { gravitational settling }\end{array}$ & $\mathrm{kg} \mathrm{m}^{-3} \mathrm{~s}^{-1}$ & Eq. 6.5.1.2-32 \\
\hline$Q_{c W F m t}$ & $\begin{array}{l}\text { Net rate of interface transfer of waste form } \\
\text { colloidal mass between the continua in the dual } \\
\text { continuum invert }\end{array}$ & $\mathrm{kg} \mathrm{m}^{-3} \mathrm{~s}^{-1}$ & Eq. 6.5.1.2-32 \\
\hline$Q_{c W F s}$ & Net rate of waste form colloid formation & $\mathrm{kg} \mathrm{m}^{-3} \mathrm{~s}^{-1}$ & Eq. 6.5.1.2-32 \\
\hline$Q_{I}$ & Volumetric discharge into the invert & $\mathrm{m}^{3} \mathrm{~s}^{-1}$ & Eq. 6.5.3.3-12 \\
\hline$Q_{i}^{m}$ & $\begin{array}{l}\text { Net rate of various mass transfer process } \\
\text { involving radionuclide species } i\end{array}$ & $\mathrm{~kg} \mathrm{~m}^{-3} \mathrm{~s}^{-1}$ & Eq. 6.5.1.2-1 \\
\hline$Q_{i c c}$ & $\begin{array}{l}\text { Net rate of sorption of radionuclide species } i \text { onto } \\
\text { immobile colloid surfaces captured by the solid } \\
\text { matrix }\end{array}$ & $\mathrm{kg} \mathrm{m}^{-3} \mathrm{~s}^{-1}$ & Eq. 6.5.1.2-7 \\
\hline
\end{tabular}


Table 6.5-5. Nomenclature (Continued)

\begin{tabular}{|c|c|c|c|}
\hline Variable & Definition & Units & Where First Used \\
\hline$Q_{i c c}^{i n t}$ & $\begin{array}{l}\text { Net rate of sorption of radionuclide species } i \text { onto } \\
\text { immobile colloid surfaces captured by the air- } \\
\text { water interface }\end{array}$ & $\mathrm{kg} \mathrm{m}^{-3} \mathrm{~s}^{-1}$ & Eq. 6.5.1.2-7 \\
\hline$Q_{i c m}^{\text {embed }}$ & $\begin{array}{l}\text { Rate of mass conversion from dissolved state to } \\
\text { embedded state onto waste form colloids for } \\
\text { radionuclide species } i\end{array}$ & $\mathrm{~kg} \mathrm{~m}^{-3} \mathrm{~s}^{-1}$ & Eq. 6.5.1.2-7 \\
\hline$Q_{i c m}^{i r r e v}$ & $\begin{array}{l}\text { Rate of irreversible sorption of radionuclide } \\
\text { species } i \text { onto mobile colloid surfaces }\end{array}$ & $\mathrm{kg} \mathrm{m}^{-3} \mathrm{~s}^{-1}$ & Eq. 6.5.1.2-7 \\
\hline$Q_{i c m}^{r e v}$ & $\begin{array}{l}\text { Net rate of reversible sorption of radionuclide } \\
\text { species } i \text { onto mobile colloid surfaces }\end{array}$ & $\mathrm{kg} \mathrm{m}^{-3} \mathrm{~s}^{-1}$ & Eq. 6.5.1.2-7 \\
\hline$Q_{i d}$ & Net rate of dissolution of radionuclide species $i$ & $\mathrm{~kg} \mathrm{~m}^{-3} \mathrm{~s}^{-1}$ & Eq. 6.5.1.2-7 \\
\hline$Q_{i m t}$ & $\begin{array}{l}\text { Net rate of interface transfer of dissolved mass } \\
\text { between the continua in the dual continuum invert }\end{array}$ & $\mathrm{kg} \mathrm{m}^{-3} \mathrm{~s}^{-1}$ & Eq. 6.5.1.2-7 \\
\hline$Q_{\text {imt }}^{\text {irrev }}$ & $\begin{array}{l}\text { Net rate of interface transfer between the continua } \\
\text { in the dual continuum invert of radionuclide } \\
\text { species } i \text { irreversibly sorbed onto mobile colloids }\end{array}$ & $\mathrm{kg} \mathrm{m}^{-3} \mathrm{~s}^{-1}$ & Eq. 6.5.1.2-28 \\
\hline$Q_{\text {iprecip }}$ & Net rate of precipitation of radionuclide species $i$ & $\mathrm{~kg} \mathrm{~m}^{-3} \mathrm{~s}^{-1}$ & Eq. 6.5.1.2-7 \\
\hline$Q_{i s}^{i r r e v}$ & $\begin{array}{l}\text { Rate of irreversible sorption of radionuclide } \\
\text { species } i \text { onto the solid matrix }\end{array}$ & $\mathrm{kg} \mathrm{m}^{-3} \mathrm{~s}^{-1}$ & Eq. 6.5.1.2-7 \\
\hline$Q_{i s}^{r e v}$ & $\begin{array}{l}\text { Net rate of reversible sorption of radionuclide } \\
\text { species } i \text { onto the solid matrix }\end{array}$ & $\mathrm{kg} \mathrm{m}^{-3} \mathrm{~s}^{-1}$ & Eq. 6.5.1.2-7 \\
\hline$Q_{w z}$ & Advective water volume flux per unit bulk volume & $\mathrm{m}^{3} \mathrm{~m}^{-3} \mathrm{yr}^{-1}$ & Eq. $6.5 \cdot 3 \cdot 5-3$ \\
\hline$q$ & Rate of diffusion of water vapor through air & $\mathrm{mol} \mathrm{s}^{-1}$ & Eq. 6.6.2-8 \\
\hline$q_{i}$ & Rate of diffusion of radionuclide species $i$ & $\mathrm{~kg} \mathrm{~s}^{-1}$ & Eq. 6.3.4.3.5-1 \\
\hline$q_{\text {in }}$ & Rate of water flow into waste package & $\mathrm{m}^{3} \mathrm{~s}^{-1}$ & Section 6.6.1.1.1 \\
\hline$q_{\text {in,new }}$ & "New" rate of water flow into waste package & $\mathrm{m}^{3} \mathrm{~s}^{-1}$ & Section 6.6.1.2.1 \\
\hline$q_{\text {in,old }}$ & "Old" rate of water flow into waste package & $\mathrm{m}^{3} \mathrm{~s}^{-1}$ & Section 6.6.1.2.1 \\
\hline$q_{\text {out }}$ & Rate of water flow out of waste package & $\mathrm{m}^{3} \mathrm{~s}^{-1}$ & Section 6.6.1.1.1 \\
\hline$q_{\text {out }, \text { new }}$ & "New" rate of water flow out of waste package & $\mathrm{m}^{3} \mathrm{~s}^{-1}$ & Section 6.6.1.2.1 \\
\hline$q_{w z}$ & $\begin{array}{l}\text { Scalar specific discharge (Darcy velocity) of water } \\
\text { in the downward }+z \text {-direction }\end{array}$ & $\mathrm{m} \mathrm{s}^{-1}$ & Eq. $6.5 .1 .2-46$ \\
\hline $\boldsymbol{q}_{w}$ & Specific discharge (Darcy velocity) of water & $\mathrm{m} \mathrm{s}^{-1}$ & Eq. 6.5.1.2-4 \\
\hline$R$ & Universal gas constant & $\mathrm{J} \mathrm{mol}^{-1} \mathrm{~K}^{-1}$ & Eq. 6.3.4.1.1-10 \\
\hline$R^{2}$ & Coefficient of determination & dimensionless & Figure $6.3-4$ \\
\hline$R_{b}$ & $\begin{array}{l}\text { Resistance of a porous medium in Rhoades et al. } \\
1976 \text { [DIRS 173835], Equation } 11\end{array}$ & $\Omega$ & Section 6.3.4.1.1 \\
\hline$R_{f}$ & Retardation factor & dimensionless & Eq. 6.3.4.2.2-1 \\
\hline$R_{f i}$ & Retardation factor for radionuclide species $i$ & dimensionless & Eq. 6.5.1.2-38 \\
\hline$R_{f i p}$ & $\begin{array}{l}\text { Retardation factor for parent ip of radionuclide } \\
\text { species } i\end{array}$ & dimensionless & Eq. 6.5.1.2-38 \\
\hline
\end{tabular}


Table 6.5-5. Nomenclature (Continued)

\begin{tabular}{|c|c|c|c|}
\hline Variable & Definition & Units & Where First Used \\
\hline RH & Relative humidity & $\mathrm{kg} \mathrm{kg}^{-1}$ & Eq. 6.3.4.3.2-2 \\
\hline$R_{t}$ & Resistance of a porous medium & $\Omega$ & Eq. 6.3.4.1.1-4 \\
\hline$r_{\text {coll }}$ & Colloid particle radius & $\mathrm{m}$ & Eq. 6.3.4.4-1 \\
\hline$r_{\text {corr }}$ & Steel corrosion rate & $\mathrm{mol} \mathrm{yr}^{-1}$ & Table 6.6-1 \\
\hline$r_{D}$ & Drift radius & $\mathrm{m}$ & Eq. 6.5.3.3-1 \\
\hline$r_{i}$ & $\begin{array}{l}\text { Reaction term accounting for decay and ingrowth } \\
\text { of species } i\end{array}$ & $\mathrm{~kg} \mathrm{~m}^{-3} \mathrm{~s}^{-1}$ & Eq. 6.5.1.2-1 \\
\hline$r_{i o n}$ & Ion radius & $\mathrm{m}$ & Eq. 6.3.4.4-1 \\
\hline$r_{i p}^{M}$ & $\begin{array}{l}\text { Ratio of the mass of radionuclide species } i \\
\text { produced by decay of the parent species ip to the } \\
\text { mass of the parent species lost by decay }\end{array}$ & $\mathrm{kg} \mathrm{kg}^{-1}$ & Eq. 6.5.1.2-9 \\
\hline$r_{s}$ & Dissolution rate of the waste form & $\mathrm{kg} \mathrm{s}^{-1}$ & Eq. 6.6.1.1.1-1 \\
\hline$r_{w}$ & Rate of production of water by chemical reactions & $\mathrm{kg} \mathrm{s}^{-1}$ & Eq. 6.5.1.1-1 \\
\hline$r_{1}$ & $\begin{array}{l}\text { Sampled value for the corrosion rate of carbon } \\
\text { steel }\end{array}$ & $\mu \mathrm{m} \mathrm{yr}^{-1}$ & Eq. 6.5.3.2-1 \\
\hline$r_{2}$ & $\begin{array}{l}\text { Sampled value for the corrosion rate of stainless } \\
\text { steel }\end{array}$ & $\mu \mathrm{m} \mathrm{yr}^{-1}$ & Eq. 6.5.3.2-2 \\
\hline$S_{e f}$ & Effective UZ fracture saturation & $\mathrm{m}^{3} \mathrm{~m}^{-3}$ & Eq. 6.5.3.6-4 \\
\hline$S_{f}$ & Percentage of total vs. high-affinity sorption sites & percent & Eq. 6.3.4.2.3.2-1 \\
\hline$S_{H A}$ & High-affinity site density & mol sites $/ \mathrm{mol} \mathrm{Fe}$ & Eq. 6.3.4.2.3.2-1 \\
\hline$S_{\text {total }}$ & Total site density & mol sites/mol Fe & Eq. 6.3.4.2.3.2-1 \\
\hline$S_{w}$ & Water saturation & $\mathrm{m}^{3} \mathrm{~m}^{-3}$ & Eq. 6.5.1.2-2 \\
\hline$S_{w e, C P}$ & $\begin{array}{l}\text { Effective water saturation within a corrosion patch } \\
\text { or corrosion products }\end{array}$ & $\mathrm{m}^{3} \mathrm{~m}^{-3}$ & Eq. 6.3.4.3.5-5 \\
\hline$S_{w_{-} C P}$ & Water saturation in corrosion products domain & $\mathrm{m}^{3} \mathrm{~m}^{-3}$ & Eq. 6.6.4-1 \\
\hline$S_{w f}$ & UZ fracture water saturation & $\mathrm{m}^{3} \mathrm{~m}^{-3}$ & Eq. 6.5.1.2-52 \\
\hline$S_{w f r}$ & UZ fracture residual water saturation & $\mathrm{m}^{3} \mathrm{~m}^{-3}$ & Eq. 6.5.3.6-4 \\
\hline$S_{w I}$ & Invert water saturation & $\mathrm{m}^{3} \mathrm{~m}^{-3}$ & Eq. $6.5 \cdot 1 \cdot 2-50$ \\
\hline$S_{w_{-} \text {inter }}$ & Water saturation in invert intergranular continuum & $\mathrm{m}^{3} \mathrm{~m}^{-3}$ & Eq. 6.6.4-2 \\
\hline$S_{w_{-} \text {intra }}$ & Water saturation in invert intragranular continuum & $\mathrm{m}^{3} \mathrm{~m}^{-3}$ & Eq. 6.5.3.3-7 \\
\hline$S_{w m}$ & UZ matrix water saturation & $m^{3} m^{-3}$ & Eq. 6.5.1.2-51 \\
\hline$S$ & Exponent in $\mathrm{FHH}$ adsorption isotherm & dimensionless & Eq. 6.3.4.3.2-2 \\
\hline$s_{C P}$ & Surface area of corrosion products & $\mathrm{m}^{2}$ & Eq. 6.3.4.3.5-5 \\
\hline $\bar{S}_{c}$ & Specific surface area of colloids & $m^{2} g^{-1}$ & Eq. $6.5 .1 .2-18$ \\
\hline
\end{tabular}


Table 6.5-5. Nomenclature (Continued)

\begin{tabular}{|c|c|c|c|}
\hline Variable & Definition & Units & Where First Used \\
\hline $\bar{s}_{C P}$ & $\begin{array}{l}\text { Specific surface area of iron oxyhydroxide } \\
\text { corrosion products }\end{array}$ & $\mathrm{m}^{2} \mathrm{~kg}^{-1}$ & Eq. 6.5.1.2-13 \\
\hline$T$ & Temperature & K & Table 4.1-7 \\
\hline$T^{*}$ & Transmission coefficient & dimensionless & Eq. 6.3.4.1.1-14 \\
\hline$T_{c A}, T_{c B}$ & Critical temperatures of components $A$ and $B$ & K & Eq. 6.6.2-6 \\
\hline$T_{0}$ & Reference temperature & K & Eq. 6.3.4.1.2-1 \\
\hline$t$ & Time & $\mathrm{s}$ & Eq. 6.5.1.1-1 \\
\hline$t_{\text {corr }}$ & Lifetime of steel & $\mathrm{yr}$ & Table 6.6-1 \\
\hline$t_{f}$ & Thickness of a water monolayer & $\mathrm{m}$ & Eq. 6.3.4.3.2-6 \\
\hline$t_{\text {fill }}$ & Time for a waste package to fill with water & s & Section 6.6.1.1 \\
\hline$t_{f 1}$ & Lifetime of carbon steel & $\mathrm{yr}$ & Eq. 6.5.3.2-1 \\
\hline$t_{f 2}$ & Lifetime of stainless steel & $\mathrm{yr}$ & Eq. $6.5 \cdot 3 \cdot 2-2$ \\
\hline$t_{I, \max }$ & Maximum thickness of the invert & $\mathrm{m}$ & Eq. 6.5.3.3-1 \\
\hline $\bar{t}_{I}$ & Average thickness of the invert & $\mathrm{m}$ & Eq. 6.5.3.5-5 \\
\hline$t_{i}$ & Transport number for the $i^{\text {th }}$ ion & dimensionless & Eq. 6.3.4.1.1-10 \\
\hline$t_{0}$ & Time of first breach of the waste package & $\mathrm{yr}$ & Eq. 6.5.3.2-3 \\
\hline$t_{1 / 2, i p}$ & Half-life of parent $i p$ of radionuclide species $i$ & $\mathrm{~s}$ & Eq. $6.5 .1 .2-10$ \\
\hline$u$ & Ion mobility & $\mathrm{cm}^{2} \mathrm{~s}^{-1} \mathrm{~V}^{-1}$ & Table 7.2-1, footnote a \\
\hline$V$ & $\begin{array}{l}\text { Volume of water vapor adsorbed at reference } \\
\text { conditions }\end{array}$ & $\mathrm{m}^{3} \mathrm{~kg}^{-1}$ & Eq. 6.3.4.3.2-1 \\
\hline$V(t)$ & Volume of water within a waste package at time $t$ & $\mathrm{~m}^{3}$ & Section 6.6.1.1 \\
\hline$V_{B}$ & Volume of cell $B$ & $\mathrm{~m}^{3}$ & Eq. 6.5.3.5-4 \\
\hline$V_{b}$ & Bulk volume of UZ matrix cell & $\mathrm{m}^{3} \mathrm{~kg}^{-1}$ & Section 6.5.3.6 \\
\hline$V_{C P}$ & $\begin{array}{l}\text { Pore volume (water volume when fully saturated) } \\
\text { of corrosion products }\end{array}$ & $\mathrm{m}^{3}$ & Eq. 6.3.4.3.5-3 \\
\hline$V_{D S N F}$ & Volume of degraded DSNF & $\mathrm{m}^{3}$ & Table 8.2-1 \\
\hline$V_{g}$ & Volume of crushed tuff granule & $\mathrm{m}^{3}$ & Section 6.6.4.1 \\
\hline$V_{m}$ & $\begin{array}{l}\text { Volume of water adsorbed that provides one } \\
\text { monolayer coverage on the surface }\end{array}$ & $\mathrm{m}^{3} \mathrm{~kg}^{-1}$ & Eq. 6.3.4.3.2-1 \\
\hline$V_{\text {new }}$ & Volume of "new" water in waste package & $\mathrm{m}^{3}$ & Section 6.6.1.2.2 \\
\hline$V_{\text {old }}$ & Volume of "old" water in waste package & $\mathrm{m}^{3}$ & Section 6.6.1.2.1 \\
\hline$V_{p}$ & Total volume of pore space in bulk invert & $\mathrm{m}^{3}$ & Eq. 6.5.1.2-23 \\
\hline$V_{p_{-} \text {inter }}$ & Intergranular pore space pore volume & $\mathrm{m}^{3}$ & Eq. 6.5.1.2-23 \\
\hline
\end{tabular}


Table 6.5-5. Nomenclature (Continued)

\begin{tabular}{|c|c|c|c|}
\hline Variable & Definition & Units & Where First Used \\
\hline$V_{p_{-} \text {intra }}$ & Intragranular pore space pore volume & $\mathrm{m}^{3}$ & Eq. $6.5 .1 .2-24$ \\
\hline$V_{t}$ & Bulk invert total volume & $\mathrm{m}^{3}$ & Eq. 6.5.1.2-23 \\
\hline$V_{\text {t_inter }}$ & Intergranular pore space total volume & $\mathrm{m}^{3}$ & Eq. $6.5 .1 .2-26$ \\
\hline$V_{\text {tintra }}$ & Intragranular pore space total volume & $\mathrm{m}^{3}$ & Eq. 6.5.1.2-27 \\
\hline$V_{t u b}$ & $\begin{array}{l}\text { Volume of water that can be retained within a } \\
\text { waste package before it overflows }\end{array}$ & $\mathrm{m}^{3}$ & Section 6.6.1.1 \\
\hline$V_{w I}$ & Volume of water in invert & $\mathrm{m}^{3}$ & Eq. 6.5.3.3-3 \\
\hline$V_{w_{-} \text {inter }}$ & Volume of water in invert intergranular pore space & $\mathrm{m}^{3}$ & Eq. 6.5.3.3-6 \\
\hline$V_{w \_ \text {intra }}$ & Volume of water in invert intragranular pore space & $\mathrm{m}^{3}$ & Eq. 6.5.3.3-6 \\
\hline$v$ & Average water velocity & $\mathrm{m} \mathrm{yr}^{-1}$ & Eq. 6.3.4.2.2-1 \\
\hline$v_{c}$ & Average contaminant front velocity & $\mathrm{m} \mathrm{yr}^{-1}$ & Eq. 6.3.4.2.2-1 \\
\hline$W_{D S}$ & Total unfolded width of drip shield & $\mathrm{m}$ & Eq. 6.5.1.1.1-7 \\
\hline$w$ & Water content & percent & Figure $6.3-10$ \\
\hline$w_{I}$ & Width of top surface of invert & $\mathrm{m}$ & Eq. 6.5.3.3-1 \\
\hline$w_{\text {inter }}$ & $\begin{array}{l}\text { Volumetric ratio of the intergranular continuum } \\
\text { volume to the total bulk invert volume }\end{array}$ & $\mathrm{m}^{3} \mathrm{~m}^{-3}$ & Eq. $6.5 .1 .2-26$ \\
\hline$w_{w}^{m}$ & $\begin{array}{l}\text { Net mass flow rate of water across bounding } \\
\text { surfaces by mass transfer }\end{array}$ & $\mathrm{kg} \mathrm{s}^{-1}$ & Eq. 6.5.1.1-1 \\
\hline$x$ & One-dimensional coordinate or distance & $\mathrm{m}$ & Figure $6.3-2$ \\
\hline$y$ & Distance along drip shield crown & $\mathrm{m}$ & Section 6.5.1.1.2.1 \\
\hline$y_{A}$ & $\begin{array}{l}\text { Distance along drip shield crown from center of } \\
\text { breach - farthest point to the left from which } \\
\text { rivulets can enter breach }\end{array}$ & $\mathrm{m}$ & Eq. 6.5.1.1.2-1 \\
\hline$y_{B}$ & $\begin{array}{l}\text { Distance along drip shield crown from center of } \\
\text { breach - farthest point to the left from which } \\
\text { rivulets can enter top of breach }\end{array}$ & $\mathrm{m}$ & Eq. 6.5.1.1.2-1 \\
\hline$y_{C}$ & $\begin{array}{l}\text { Distance along drip shield crown from center of } \\
\text { breach - farthest point to the right from which } \\
\text { rivulets can enter top of breach }\end{array}$ & $\mathrm{m}$ & Eq. 6.5.1.1.2-1 \\
\hline$y_{D}$ & $\begin{array}{l}\text { Distance along drip shield crown from center of } \\
\text { breach - farthest point to the right from which } \\
\text { rivulets can enter breach }\end{array}$ & $\mathrm{m}$ & Eq. 6.5.1.1.2-1 \\
\hline$z$ & One-dimensional coordinate or distance & $\mathrm{m}$ & Eq. 6.5.1.2-46 \\
\hline$z$ & Valence of an ion & dimensionless & Table 7.2-1, footnote a \\
\hline$z_{i}$ & Charge valence of the $i^{\text {th }}$ ion & dimensionless & Eq. 6.3.4.1.1-10 \\
\hline$z_{\text {interface }}$ & $\begin{array}{l}\text { Spatial location of the corrosion products } \\
\text { domain/invert interface }\end{array}$ & $\mathrm{m}$ & Section 6.5.1.2 \\
\hline$z_{+}, z_{-}$ & $\begin{array}{l}\text { Valence of cation and anion, respectively; } \\
\text { magnitude only - no sign }\end{array}$ & dimensionless & Eq. 6.3.4.1.1-6 \\
\hline
\end{tabular}


Table 6.5-5. Nomenclature (Continued)

\begin{tabular}{|c|c|c|c|}
\hline Variable & Definition & Units & Where First Used \\
\hline$\Delta C_{i}$ & Concentration difference & $\mathrm{kg} \mathrm{m}^{-3}$ & Section 6.3.4.3.5 \\
\hline$\Delta C_{O_{2}}$ & Oxygen concentration difference & $\mathrm{kg} \mathrm{m}^{-3}$ & Eq. 6.6.3-3 \\
\hline$\Delta C_{w v}$ & Water vapor concentration difference & $\mathrm{kg} \mathrm{m}^{-3}$ & Eq. 6.6.2-8 \\
\hline$\Delta F_{w}$ & $\begin{array}{l}\text { Difference between volumetric flow rate into and } \\
\text { out of the EBS }\end{array}$ & $\mathrm{m}^{3} \mathrm{~s}^{-1}$ & Eq. 6.5.1.1-4 \\
\hline$\Delta t$ & Time to empty retained water in waste package & $\mathrm{s}$ & Eq. 6.6.1.2.3-2 \\
\hline$\Delta t$ & Time step size from the $n^{\text {th }}$ to the $(n+1)^{\text {th }}$ time & s or yr & Eq. 6.5.3.5-1 \\
\hline$\Delta w_{w}$ & $\begin{array}{l}\text { Difference between mass rate of flow into and out } \\
\text { of the EBS }\end{array}$ & $\mathrm{kg} \mathrm{s}^{-1}$ & Eq. 6.5.1.1-1 \\
\hline$\Delta x$ & Thickness or length of flow or diffusion path & $\mathrm{m}$ & Table 6.3-9, footnote $\mathrm{h}$ \\
\hline$\Theta$ & Cell constant & $\mathrm{m}^{-1}$ & Eq. 6.3.4.1.1-14 \\
\hline$\Lambda_{0}$ & $\begin{array}{l}\text { Equivalent electrolyte conductivity at infinite } \\
\text { dilution }\end{array}$ & $\mathrm{S} \mathrm{cm}^{2}$ equivalent ${ }^{-1}$ & Eq. 6.3.4.1.1-6 \\
\hline$\Omega$ & Colloid target flux out ratio & dimensionless & Eq. 6.5.3.4-1 \\
\hline$\Phi$ & Volumetric water content & percent & Eq. $7 \cdot 2 \cdot 1 \cdot 2-1$ \\
\hline$\alpha$ & $\begin{array}{l}\text { Drip shield or waste package rivulet spread half } \\
\text { angle }\end{array}$ & radian or degree & Eq. 6.3.2.4-2 \\
\hline$\alpha$ & Dispersivity & $\mathrm{m}$ & Eq. 6.5.1.2-6 \\
\hline$\alpha$ & First-order mass transfer coefficient & $\mathrm{s}^{-1}$ & Eq. 6.5.1.2-20 \\
\hline$\beta$ & $\begin{array}{l}\text { Geometry-dependent factor in expression for } \\
\text { dual-continuum invert interface mass transfer } \\
\text { coefficient }\end{array}$ & dimensionless & Eq. 6.5.1.2-22 \\
\hline$\beta$ & $\begin{array}{l}\text { Volume fraction of "old" water in total water } \\
\text { volume of waste package }\end{array}$ & $\mathrm{m}^{3} \mathrm{~m}^{-3}$ & Eq. 6.6.1.2.1-2 \\
\hline$\gamma$ & UZ active fracture parameter & dimensionless & Section 6.5.3.6 \\
\hline$\gamma_{c}$ & Colloid mass transfer coefficient & $\mathrm{s}^{-1}$ & Eq. 6.5.1.2-19 \\
\hline$\gamma_{d}$ & Dissolved species mass transfer coefficient & $\mathrm{s}^{-1}$ & Eq. 6.5.1.2-19 \\
\hline$\delta$ & Stress corrosion crack gap width & $\mathrm{m}$ & Eq. 6.3.3.1-1 \\
\hline$\delta_{i}$ & Stress corrosion crack gap width, inner surface & $\mathrm{m}$ & Figure 6.3-3 \\
\hline$\delta_{o}$ & Stress corrosion crack gap width, outer surface & $\mathrm{m}$ & Figure 6.3-3 \\
\hline$\zeta$ & Dimensionless surface-area-to-volume ratio & dimensionless & Section 6.6.4.1 \\
\hline$\eta_{T}$ & Viscosity of water at temperature $T$ & $\mathrm{Pas}$ & Table 4.1-7 \\
\hline$\eta_{T_{0}}$ & Viscosity of water at temperature $T_{0}$ & $\mathrm{Pas}$ & Eq. 6.3.4.1.2-1 \\
\hline$\eta_{20}$ & Viscosity of water at temperature $T=20^{\circ} \mathrm{C}$ & Pas & Table 4.1-7 \\
\hline$\theta$ & Volumetric moisture content & percent & Eq. 6.3.4.1.1-18 \\
\hline$\theta_{C}$ & Critical volumetric moisture content & percent & Eq. 6.6.5.2-2 \\
\hline$\theta_{a}$ & Number of monolayers of adsorbed water & dimensionless & Eq. 6.3.4.3.2-2 \\
\hline
\end{tabular}


Table 6.5-5. Nomenclature (Continued)

\begin{tabular}{|c|c|c|c|}
\hline Variable & Definition & Units & Where First Used \\
\hline$\theta_{\text {inter }}$ & Intergranular moisture content & percent & Eq. 6.6.5.1-5 \\
\hline$\theta_{\text {intra }}$ & Moisture content of invert intragranular continuum & percent & Eq. 6.6.5.2-5 \\
\hline$\theta_{m}$ & Moisture content of UZ matrix & percent & Eq. 6.5.3.6-2 \\
\hline$\theta_{\min }$ & $\begin{array}{l}\text { Minimum volumetric moisture content for } \\
\text { diffusivity to be greater than limiting diffusivity }\end{array}$ & percent & Eq. 6.6.5.2-5 \\
\hline$\theta_{s}$ & Saturated moisture content & percent & Eq. 6.6.5.1-2 \\
\hline$\kappa_{a}$ & Bulk soil or rock conductivity & $\Omega^{-1} \mathrm{~m}^{-1}$ or $\mathrm{mho} / \mathrm{m}$ & Eq. 6.3.4.1.1-10 \\
\hline$\kappa_{s}$ & Electrical conductivity of the solution & $\Omega^{-1} \mathrm{~m}^{-1}$ or $\mathrm{mho} / \mathrm{m}$ & Eq. 6.3.4.1.1-10 \\
\hline$\kappa_{w}$ & Electrical conductivity of the solution & $\Omega^{-1} \mathrm{~m}^{-1}$ or $\mathrm{mho} / \mathrm{m}$ & Eq. 6.3.4.1.1-10 \\
\hline$\lambda_{i}$ & Radioactive decay constant for species $i$ & $\mathrm{~s}^{-1}$ or $\mathrm{yr}^{-1}$ & Eq. 6.5.1.2-9 \\
\hline$\lambda_{i p}$ & $\begin{array}{l}\text { Radioactive decay constant for parent ip of } \\
\text { species } i\end{array}$ & $\mathrm{~s}^{-1}$ or $\mathrm{yr}^{-1}$ & Eq. 6.5.1.2-9 \\
\hline$\lambda_{i}^{e m b e d}$ & $\begin{array}{l}\text { First order rate constant for mass conversion from } \\
\text { dissolved state to embedded state onto waste } \\
\text { form colloids for radionuclide species } i\end{array}$ & $\mathrm{~s}^{-1}$ or $\mathrm{yr}^{-1}$ & Eq. 6.5.1.2-8 \\
\hline$\mu$ & Mean value & dimensionless & Eq. 6.3.4.1.1-22 \\
\hline $\bar{v}$ & Average linear interstitial water velocity & $\mathrm{m} \mathrm{s}^{-1}$ & Eq. 6.3.4.2.2-1 \\
\hline$v_{c}$ & $\begin{array}{l}\text { Average velocity of front of the contaminant } \\
\text { concentration profile }\end{array}$ & $\mathrm{m} \mathrm{s}^{-1}$ & Eq. 6.3.4.2.2-1 \\
\hline$\rho$ & Density of waste package internal components & $\mathrm{kg} \mathrm{m}^{-3}$ & Table 6.3-9, footnote $\mathrm{h}$ \\
\hline$\rho_{b}$ & Dry bulk density of the solid matrix & $\mathrm{kg} \mathrm{m}^{-3}$ & Eq. 6.3.4.2.2-1 \\
\hline$\rho_{\mathrm{FeOx}}$ & Density of $\mathrm{Fe}_{2} \mathrm{O}_{3}$ & $\mathrm{~kg} \mathrm{~m}^{-3}$ & Eq. 6.3.4.3.5-3 \\
\hline$\rho_{i}$ & Mass concentration of radionuclide species $i$ & $\mathrm{~kg} \mathrm{~m}^{-3}$ & Eq. 6.5.1.2-1 \\
\hline$\rho_{s}$ & Electrical resistivity of a porous medium & $\Omega \mathrm{m}$ & Eq. 6.3.4.1.1-1 \\
\hline$\rho_{t}$ & $\begin{array}{l}\text { Bulk resistivity of a partially saturated porous } \\
\text { medium }\end{array}$ & $\Omega \mathrm{m}$ & Eq. 6.3.4.1.1-2 \\
\hline$\rho_{w}$ & Density of water & $\mathrm{kg} \mathrm{m}^{-3}$ & Eq. 6.5.1.1-4 \\
\hline$\rho_{w}^{e}$ & Electrical resistivity of liquid water & $\Omega \mathrm{m}$ & Eq. 6.3.4.1.1-1 \\
\hline$\sigma$ & Standard deviation & dimensionless & Eq. 6.3.4.1.1-22 \\
\hline$\sigma(x)$ & Standard deviation of the $K_{d}$ distribution & $\mathrm{ml} \mathrm{g}^{-1}$ & Table 6.6-5 \\
\hline$\sigma_{a}$ & Applied stress & $\mathrm{Pa}$ & Eq. 6.3.3.1-1 \\
\hline$\sigma_{g}$ & Standard deviation of the pore size & $\mathrm{mm}$ & Eq. 6.6.5.1-4 \\
\hline$\sigma_{s}$ & Sample standard deviation & dimensionless & Section 7.3.1.2 \\
\hline
\end{tabular}


Table 6.5-5. Nomenclature (Continued)

\begin{tabular}{|c|c|c|c|}
\hline Variable & Definition & Units & Where First Used \\
\hline$\phi$ & Porosity & $\mathrm{m}^{3} \mathrm{~m}^{-3}$ & Eq. 6.3.4.2.2-1 \\
\hline$\phi_{C P}$ & Porosity of corrosion products & $\mathrm{m}^{3} \mathrm{~m}^{-3}$ & Eq. 6.3.4.3.5-3 \\
\hline$\phi_{f}$ & Porosity of UZ fractures & $\mathrm{m}^{3} \mathrm{~m}^{-3}$ & Eq. $6.5 .1 .2-52$ \\
\hline$\phi_{I}$ & Bulk porosity of invert & $m^{3} m^{-3}$ & Eq. 6.5.1.2-25 \\
\hline$\phi_{\text {inter }}$ & Porosity of invert intergranular continuum & $\mathrm{m}^{3} \mathrm{~m}^{-3}$ & Eq. $6.5 \cdot 3 \cdot 3-10$ \\
\hline$\phi_{\text {intra }}$ & Porosity of invert intragranular continuum & $\mathrm{m}^{3} \mathrm{~m}^{-3}$ & Eq. 6.5.3.3-7 \\
\hline$\phi_{m}$ & Porosity of saturated tuff matrix & $m^{3} m^{-3}$ & Eq. 6.5.1.2-51 \\
\hline$\psi$ & Moisture potential & $\mathrm{J} \mathrm{kg}^{-1}$ & Eq. 6.6.5.1-2 \\
\hline$\psi_{e}$ & Air-entry moisture potential & $\mathrm{J} \mathrm{kg}^{-1}$ & Eq. 6.6.5.1-2 \\
\hline$\psi_{e s}$ & $\begin{array}{l}\text { Air-entry moisture potential at a bulk density of } \\
1,300 \mathrm{~kg} \mathrm{~m}^{-3}\end{array}$ & $\mathrm{~J} \mathrm{~kg}^{-1}$ & Eq. 6.6.5.1-3 \\
\hline$\omega_{G}$ & Mass fraction of corrosion products as goethite & dimensionless & Eq. 6.3.4.2.3.2-1 \\
\hline$\omega_{i}$ & $\begin{array}{l}\text { Mass fraction of radionuclide species } i \text { released } \\
\text { per unit mass of waste form }\end{array}$ & $\mathrm{kg} \mathrm{kg}^{-1}$ & Eq. 6.6.1.1.1-1 \\
\hline$\nabla$ & $\begin{array}{l}\text { Del operator: } \mathbf{i} \frac{\partial}{\partial x}+\mathbf{j} \frac{\partial}{\partial y}+\boldsymbol{k} \frac{\partial}{\partial z} \text {, where } \boldsymbol{i}, \boldsymbol{j}, \\
\text { and } \boldsymbol{k} \text { are unit vectors in the } x-, y-\text {, and } z- \\
\text { directions, respectively }\end{array}$ & $m^{-1}$ & Eq. 6.5.1.2-1 \\
\hline
\end{tabular}

$\mathrm{BET}=$ Brunauer, Emmett and Teller; $\mathrm{CP}=$ corrosion products; COV = coefficient of variance;

DSNF = defense spent nuclear fuel; $\mathrm{FHH}=$ Frenkel-Halsey-Hill adsorption isotherm equation.

\subsubsection{Base Case Model Inputs}

Table 6.5-6 summarizes model inputs used in the EBS RT Abstraction that are sampled in the TSPA-LA model calculations. The uncertainty associated with each parameter is indicated by the range and distribution shown for the parameter and is discussed in this section. The type of uncertainty is listed for each parameter. Aleatoric uncertainty refers to uncertainty for which sufficient knowledge is unobtainable because features, events, and processes involve chance occurrences. This type of uncertainty cannot be reduced through further testing and data collection. Epistemic uncertainty arises from a lack of knowledge about a parameter because the data are limited or there are alternative interpretations of the available data. The parameter is variable because an analyst does not know what the precise value of the parameter should be, but the state of knowledge about the exact value of the parameter can increase through testing and data collection. 


\begin{tabular}{|c|c|c|c|c|c|}
\hline Input Name & Input Description & Input Source & \multicolumn{2}{|c|}{ Range and Distribution * } & $\begin{array}{c}\text { Type of } \\
\text { Uncertainty }\end{array}$ \\
\hline Invert_Diff_Coeff_Uncert & Invert diffusion coefficient uncertainty & $\begin{array}{l}\text { Developed in Section 6.3.4.1.1, based on Conca } \\
\text { and Wright (1992 [DIRS 100436], Figure 2), Conca } \\
\text { et al. (1993 [DIRS 170709], Figure 2) }\end{array}$ & \multicolumn{2}{|c|}{$\begin{array}{l}10^{\mathrm{ND}} ; \mathrm{ND}=\text { Truncated Normal } \\
\text { Distribution; Range: } 10^{\mu \pm 3 \sigma} \\
\text { Mean } \mu=0.033 ; \text { Std. Dev. } \sigma= \\
0.218\end{array}$} & Epistemic \\
\hline Kd_Am_Invert & $K_{d}$ of Am on crushed tuff in the invert & DTN: LA0408AM831341.001 [DIRS 171584] & \multicolumn{2}{|c|}{$\begin{array}{l}\text { Range }=1,000-10,000 \mathrm{ml} \mathrm{g}^{-1} ; \\
\text { Mean }=5,500 \mathrm{ml} \mathrm{g}^{-1} ; \\
\text { Std. Dev. }=1,500 \mathrm{ml} \mathrm{g}^{-1} \\
\text { Truncated Normal }\end{array}$} & $\begin{array}{l}\text { Epistemic and } \\
\text { Aleatoric }\end{array}$ \\
\hline Kd_Cs_Invert & $K_{d}$ of $\mathrm{Cs}$ on crushed tuff in the invert & DTN: LA0408AM831341.001 [DIRS 171584] & \multicolumn{2}{|c|}{$1-15 \mathrm{ml} \mathrm{g}^{-1}$; Uniform } & $\begin{array}{l}\text { Epistemic and } \\
\text { Aleatoric }\end{array}$ \\
\hline Kd_Np_Invert & $K_{d}$ of $\mathrm{Np}$ on crushed tuff in the invert & DTN: LA0408AM831341.001 [DIRS 171584] & \multicolumn{2}{|c|}{$\begin{array}{l}(0,0)(0.5,0.5)(6 ., 1.0) \\
\text { Cumulative }\end{array}$} & $\begin{array}{l}\text { Epistemic and } \\
\text { Aleatoric }\end{array}$ \\
\hline Kd_Pa_Invert & $K_{d}$ of $\mathrm{Pa}$ on crushed tuff in the invert & DTN: LA0408AM831341.001 [DIRS 171584] & \multicolumn{2}{|c|}{$\begin{array}{l}\text { Range }=1,000-10,000 \mathrm{ml} \mathrm{g}^{-1} ; \\
\text { Mean }=5,500 \mathrm{ml} \mathrm{g}^{-1} ; \\
\text { Std. Dev. }=1,500 \mathrm{ml} \mathrm{g}^{-1} \\
\text { Truncated Normal }\end{array}$} & $\begin{array}{l}\text { Epistemic and } \\
\text { Aleatoric }\end{array}$ \\
\hline Kd_Pu_Invert & $K_{d}$ of Pu on crushed tuff in the invert & DTN: LA0408AM831341.001 [DIRS 171584] & \multicolumn{2}{|c|}{$\begin{array}{l}(10 ., 0)(70 ., 0.5)(200 ., 1.0) \\
\text { Cumulative }\end{array}$} & $\begin{array}{l}\text { Epistemic and } \\
\text { Aleatoric }\end{array}$ \\
\hline Kd_Ra_Invert & $K_{d}$ of Ra on crushed tuff in the invert & DTN: LA0408AM831341.001 [DIRS 171584] & \multicolumn{2}{|c|}{$100-1,000 \mathrm{ml} \mathrm{g}^{-1}$; Uniform } & $\begin{array}{l}\text { Epistemic and } \\
\text { Aleatoric }\end{array}$ \\
\hline Kd_Sr_Invert & $K_{d}$ of Sr on crushed tuff in the invert & DTN: LA0408AM831341.001 [DIRS 171584] & \multicolumn{2}{|c|}{$10-70 \mathrm{ml} \mathrm{g}^{-1} ;$ Uniform } & $\begin{array}{l}\text { Epistemic and } \\
\text { Aleatoric }\end{array}$ \\
\hline Kd_Th_Invert & $K_{d}$ of Th on crushed tuff in the invert & DTN: LA0408AM831341.001 [DIRS 171584] & \multicolumn{2}{|c|}{$1,000-10,000 \mathrm{ml} \mathrm{g}^{-1}$ Uniform } & $\begin{array}{l}\text { Epistemic and } \\
\text { Aleatoric }\end{array}$ \\
\hline Kd_U_Invert & $K_{d}$ of $\mathrm{U}$ on corrosion products & DTN: LA0408AM831341.001 [DIRS 171584] & \multicolumn{2}{|c|}{$\begin{array}{l}(0,0)(0.2,0.5)(4 ., 1.0) \\
\text { Cumulative }\end{array}$} & $\begin{array}{l}\text { Epistemic and } \\
\text { Aleatoric }\end{array}$ \\
\hline SS_Corrosion_Rate & Stainless steel corrosion rate & $\begin{array}{l}\text { DTN: MO0409SPAACRWP.000 [DIRS 172059]; } \\
\text { Spreadsheet “ECDF_metals2.xIs"; Worksheet “316 } \\
\text { sS", Columns L \& M, } \\
\text { Rows 5-15 } \\
\text { Empirical cumulative distribution function }\end{array}$ & $\begin{array}{l}\text { Rate }\left(\mu \mathrm{m} \mathrm{yr}^{-1}\right) \\
\quad 0.03699 \\
0.037 \\
0.1016 \\
0.109 \\
0.1524 \\
0.154 \\
0.1778 \\
0.2032 \\
0.2286 \\
0.254 \\
0.2794 \\
0.51\end{array}$ & $\begin{array}{l}\text { ECDF } \\
0.000 \\
0.063 \\
0.125 \\
0.188 \\
0.250 \\
0.313 \\
0.375 \\
0.438 \\
0.563 \\
0.750 \\
0.813 \\
1.000 \\
\end{array}$ & $\begin{array}{l}\text { Epistemic and } \\
\text { Aleatoric }\end{array}$ \\
\hline
\end{tabular}




\begin{tabular}{|c|c|c|c|c|c|}
\hline Input Name & Input Description & Input Source & \multicolumn{2}{|c|}{ Range and Distribution ${ }^{*}$} & $\begin{array}{c}\text { Type of } \\
\text { Uncertainty }\end{array}$ \\
\hline CS_Corrosion_Rate & Carbon steel corrosion rate & $\begin{array}{l}\text { DTN: MO0409SPAACRWP.000 [DIRS 172059]; } \\
\text { Spreadsheet "ECDF_metals2.xIs"; Worksheet } \\
\text { "A516-Carbon Steel", Columns } \\
\text { B \& C, Rows 5-30 } \\
\text { Empirical cumulative distribution function }\end{array}$ & $\begin{array}{c}\text { Rate }\left(\mu \mathrm{m} \mathrm{yr}^{-1}\right) \\
65.76 \\
65.77 \\
66.75 \\
69.84 \\
70.00 \\
71.25 \\
72.21 \\
72.64 \\
72.87 \\
72.89 \\
73.47 \\
74.29 \\
74.51 \\
74.60 \\
75.41 \\
77.31 \\
79.29 \\
80.00 \\
80.87 \\
83.26 \\
83.66 \\
83.74 \\
85.68 \\
90.97 \\
106.93\end{array}$ & $\begin{array}{l}\text { ECDF } \\
0.000 \\
0.042 \\
0.083 \\
0.125 \\
0.167 \\
0.208 \\
0.250 \\
0.292 \\
0.333 \\
0.375 \\
0.417 \\
0.458 \\
0.500 \\
0.542 \\
0.583 \\
0.625 \\
0.667 \\
0.708 \\
0.750 \\
0.792 \\
0.833 \\
0.875 \\
0.917 \\
0.958 \\
1.000\end{array}$ & $\begin{array}{l}\text { Epistemic and } \\
\text { Aleatoric }\end{array}$ \\
\hline Diff_Path_Length_CP_CSNF & $\begin{array}{l}\text { Diffusive path length through corrosion } \\
\text { products domain for CSNF packages }\end{array}$ & Developed in Section 6.5.3.1.1 & \multicolumn{2}{|c|}{$0.02-0.859 \mathrm{~m} ;$ Uniform } & $\begin{array}{l}\text { Epistemic and } \\
\text { Aleatoric }\end{array}$ \\
\hline Diff_Path_Length_CP_CDSP & $\begin{array}{l}\text { Diffusive path length through corrosion } \\
\text { products domain for codisposal waste } \\
\text { packages }\end{array}$ & Developed in Section 6.5.3.1.1 & \multicolumn{2}{|c|}{ 0.025-1.063 m; Uniform } & $\begin{array}{l}\text { Epistemic and } \\
\text { Aleatoric }\end{array}$ \\
\hline Surface_Area_CP & $\begin{array}{l}\text { Specific surface area of } \mathrm{Fe}_{2} \mathrm{O}_{3} \\
\text { corrosion products }\end{array}$ & Developed in Section 6.3.4.3.3 & \multicolumn{2}{|c|}{ 1.0-22 $\mathrm{m}^{2} \mathrm{~g}^{-1} ;$ Uniform } & $\begin{array}{l}\text { Epistemic and } \\
\text { Aleatoric }\end{array}$ \\
\hline Flux_Split_DS_Uncert & DS flux splitting uncertainty factor & Developed in Section 6.5.1.1.2.4 & \multicolumn{2}{|l|}{$\begin{array}{l}0-0.85 \\
\text { (dimensionless); } \\
\text { Uniform }\end{array}$} & $\begin{array}{l}\text { Epistemic and } \\
\text { Aleatoric }\end{array}$ \\
\hline Flux_Split_WP_Uncert & WP flux splitting uncertainty factor & Developed in Section 6.5.1.1.3 & \multicolumn{2}{|l|}{$\begin{array}{l}0-2.41 \\
\text { (dimensionless); } \\
\text { Uniform }\end{array}$} & $\begin{array}{l}\text { Epistemic and } \\
\text { Aleatoric }\end{array}$ \\
\hline
\end{tabular}


Table 6.5-6. Sampled Model Inputs Used in the EBS Radionuclide Transport Abstraction (Continued)

\begin{tabular}{|c|c|c|c|c|}
\hline Input Name & Input Description & Input Source & Range and Distribution * & $\begin{array}{c}\text { Type of } \\
\text { Uncertainty }\end{array}$ \\
\hline Fracture_Frequency & UZ fracture frequency & BSC 2004 [DIRS 170040], Appendix A, Table A-1 & $\begin{array}{l}\text { Mean }=3.16 \mathrm{~m}^{-1} \\
\text { Std. Dev. }=2.63 \mathrm{~m}^{-1} \\
\text { Log-normal }\end{array}$ & Epistemic \\
\hline UZ_Fracture_Fraction & UZ fracture porosity & BSC 2004 [DIRS 170040], Appendix D, Table D-1 & $\begin{array}{l}0-1 \text { (fraction); Beta } \\
E(x)=9.6 \times 10^{-3} ; \\
\sigma(x)=2.82 \times 10^{-3}\end{array}$ & Epistemic \\
\hline UZ_Matrix_Porosity & UZ matrix porosity & BSC 2004 [DIRS 170040], Appendix D, Table D-1 & $\begin{array}{l}0-1 \text { (fraction); Beta } \\
E(x)=0.131 \\
\sigma(x)=0.031\end{array}$ & Epistemic \\
\hline Fracture_Saturation & Unsaturated zone fracture saturation & $\begin{array}{l}\text { Uniform sampling from } 433 \text { locations for each } \\
\text { infiltration case (DTN: LB0307FMRADTRN.001 } \\
\text { [DIRS 165451]) }\end{array}$ & Provided in source DTN & Epistemic \\
\hline Fracture_Residual_Sat & $\begin{array}{l}\text { Unsaturated zone fracture residual } \\
\text { saturation }\end{array}$ & $\begin{array}{l}\text { Uniform sampling from } 433 \text { locations } \\
\text { (DTN: LB0307FMRADTRN.001 [DIRS 165451]) }\end{array}$ & Provided in source DTN & Epistemic \\
\hline Fracture_Percolation_Flux & $\begin{array}{l}\text { Unsaturated zone fracture percolation } \\
\text { flux }\end{array}$ & $\begin{array}{l}\text { Uniform sampling from } 433 \text { locations for each } \\
\text { infiltration case (DTN: LB0307FMRADTRN.001 } \\
\text { [DIRS 165451]) }\end{array}$ & Provided in source DTN & Epistemic \\
\hline Flow_Focus_Factor & $\begin{array}{l}\text { Unsaturated zone fracture percolation } \\
\text { flow-focusing factor }\end{array}$ & $\begin{array}{l}\text { Uniform sampling from } 433 \text { locations for each } \\
\text { infiltration case (DTN: LB0307FMRADTRN.001 } \\
\text { [DIRS 165451]) }\end{array}$ & Provided in source DTN & Epistemic \\
\hline UZ_Matrix_Saturation & Unsaturated zone matrix saturation & $\begin{array}{l}\text { Uniform sampling from } 433 \text { locations for each } \\
\text { infiltration case (DTN: LB0307FMRADTRN.001 } \\
\text { [DIRS 165451]) }\end{array}$ & Provided in source DTN & Epistemic \\
\hline Matrix_Percolation_Flux & $\begin{array}{l}\text { Unsaturated zone matrix percolation } \\
\text { flux }\end{array}$ & $\begin{array}{l}\text { Uniform sampling from } 433 \text { locations for each } \\
\text { infiltration case (DTN: LB0307FMRADTRN.001 } \\
\text { [DIRS 165451]) }\end{array}$ & Provided in source DTN & Epistemic \\
\hline $\begin{array}{l}\text { Matrix_Rel_Perm_Low, } \\
\text { Matrix_Rel_Perm_Mean, } \\
\text { Matrix_Rel_Perm_High }\end{array}$ & $\begin{array}{l}\text { Unsaturated zone matrix relative } \\
\text { permeability for all three infiltration } \\
\text { cases }\end{array}$ & $\begin{array}{l}\text { Uniform sampling from } 433 \text { locations for each } \\
\text { infiltration case (DTN: LB0307FMRADTRN.001 } \\
\text { [DIRS 165451]) }\end{array}$ & Provided in source DTN & Epistemic \\
\hline Goethite_SA_a & Goethite specific surface area & Developed in Section 6.3.4.2.3.2 & $\begin{array}{l}14.7-110 \mathrm{~m}^{2} \mathrm{~g}^{-1} \text {; discrete } \\
\text { distribution (Table 6.3-6) }\end{array}$ & $\begin{array}{l}\text { Epistemic and } \\
\text { Aleatoric }\end{array}$ \\
\hline $\begin{array}{l}\text { Relative_Abundance_ } \\
\text { Goethite_a }\end{array}$ & $\begin{array}{l}\text { Fraction of total iron oxide that is } \\
\text { goethite }\end{array}$ & Developed in Section 6.3.4.2.3.2 & $\begin{array}{l}0.45-0.8 \text { (dimensionless); } \\
\text { discrete distribution (Table } \\
6.3-6 \text { ) }\end{array}$ & $\begin{array}{l}\text { Epistemic and } \\
\text { Aleatoric }\end{array}$ \\
\hline Goethite_Site_Density_a & Goethite sorption site density & Developed in Section 6.3.4.2.3.2 & $\begin{array}{l}1.00-8.59 \text { sites } \mathrm{nm}^{-2} \text {; discrete } \\
\text { distribution (Table 6.3-6) }\end{array}$ & $\begin{array}{l}\text { Epistemic and } \\
\text { Aleatoric }\end{array}$ \\
\hline
\end{tabular}


Table 6.5-6. Sampled Model Inputs Used in the EBS Radionuclide Transport Abstraction (Continued)

\begin{tabular}{|l|l|l|l|}
\hline \multicolumn{1}{|c|}{ Input Name } & \multicolumn{1}{|c|}{\begin{tabular}{c}
\multicolumn{1}{c|}{ Input Description } \\
Input Source
\end{tabular}} & \multicolumn{1}{c|}{$\begin{array}{c}\text { Type of } \\
\text { Uncertainty }\end{array}$} \\
\hline HFO_Site_Density_a & HFO sorption site density & Developed in Section 6.3.4.2.3.2 & $\begin{array}{l}0.56-5.65 \text { sites nm } \\
\text { distribution (Table 6.3-6) }\end{array}$ \\
\hline HFO_Strong_Sites_a & $\begin{array}{l}\text { Percentage of high affinity HFO } \\
\text { sorption sites }\end{array}$ & $\begin{array}{l}\text { Epistemic and } \\
\text { Aleatoric }\end{array}$ \\
\hline Goethite_Strong_Sites_a & $\begin{array}{l}\text { Percentage of high affinity goethite } \\
\text { sorption sites }\end{array}$ & $\begin{array}{l}\text { Developed in Section } 6.3 .4 .2 .3 .2 \\
\text { distribution (Table 6.3-6) }\end{array}$ & $\begin{array}{l}\text { Epistemic and } \\
\text { Aleatoric }\end{array}$ \\
\hline
\end{tabular}

*For distribution type beta, $\mathrm{E}(\mathrm{x})$ = expected value, $\sigma(\mathrm{x})$ = standard deviation.

$\mathrm{CP}=$ corrosion products, $\mathrm{CDSP}=$ codisposal, $\mathrm{WP}=$ waste package, $\mathrm{BET}=$ Brunauer, Emmett and Teller, ECDF = empirical cumulative distribution function $\mathrm{HFO}=$ hydrous ferric oxide.

Correlation of invert $K_{d}$ values is shown in Table 4.1-16 


\subsubsection{Invert Diffusion Coefficient}

The invert diffusion coefficient is used to calculate the rate of diffusion of radionuclides through the invert, after they have been released from the waste package. The uncertainty in the invert diffusion coefficient is epistemic. The values were derived from measured values of diffusion coefficients in various granular materials, including tuff. However, the data were scattered. This was particularly true at lower values of volumetric water content, where experimental difficulties are more pronounced - achieving uniform and consistent degrees of water saturation is difficult, resulting in uncertainties in the actual water content. The use of electrical conductivity measurements as an analog for diffusivity becomes more uncertain at low water content due to uncertainty in the electrical connectivity between electrodes and the porous material as well as between the particles themselves. The reported uncertainty approximates a normal distribution for the residuals in the statistical fit to the experimental data. Uncertainty in the porosity of the invert is included in the greater uncertainty associated with the measurements of the diffusion coefficient, which were made on a variety of geologic materials having a range of porosities; thus the porosity uncertainty can be considered to be accounted for in the effective diffusion coefficient.

\subsubsection{Irreversible Sorption onto Iron Oxyhydroxides}

The irreversible sorption model developed in Section 6.3.4.2.3.2 involves six parameters for which the uncertainty is both epistemic and aleatoric. These parameters are the specific surface area of goethite, the relative abundance of goethite (compared to HFO) in stationary corrosion products, the sorption site densities of goethite and HFO, and the percentage of high-affinity sorption sites for goethite and HFO. The epistemic uncertainty in sorption site densities and the percentage of high-affinity sorption sites arises from the difficulty in making precise measurements of these properties. One result of this experimental epistemic uncertainty is the inability to assign greater weight to individual experiments, so discrete distributions are used that give equal weight to all experimental results. Aleatoric uncertainty is due to the unpredictable variability in the circumstances and environment under which the iron oxyhydroxides will be formed in the repository, which will result in variations in specific surface area, relative abundance of goethite, and sorption properties.

\subsubsection{Sorption Distribution Coefficients for Calculating Invert Sorption}

Sorption on crushed devitrified tuff in the invert also involves some epistemic uncertainty for most radionuclides. The exceptions are $\mathrm{C}$, I, and Tc, which do not sorb measurably on tuff $\left(K_{d}\right.$ values are zero). As with $K_{d}$ values for sorption on corrosion products, the invert $K_{d}$ values also involve some aleatoric uncertainty due to the evolving chemistry of the seepage water and changes resulting from chemical processes that occur as EBS components degrade. Invert $K_{d}$ values are correlated as shown in Table 4.1-16 (DTN: LA0311AM831341.001 [DIRS 167015]). In the implementation of sorption distribution coefficients in the invert in TSPA-LA, the devitrified tuff $K_{d}$ values developed for the UZ submodel are assigned to the invert. 


\subsubsection{In-Package Diffusion Submodel}

The general corrosion rates for carbon steel and stainless steel are known with some uncertainty, as shown in the data presented in Table 4.1-1 (DTN: MO0409SPAACRWP.000 [DIRS 172059]). An empirical cumulative distribution function developed in DTN: MO0409SPAACRWP.000 [DIRS 172059] is used for parameter CS_Corrosion_Rate to be sampled in TSPA-LA. An empirical cumulative distribution function developed in DTN: MO0409SPAACRWP.000 [DIRS 172059] is used for parameter SS_Corrosion_Rate to be sampled in TSPA-LA. In view of the large range in the measured data even among multiple samples under identical conditions, some epistemic uncertainty exists in corrosion rates. In addition, the future physiochemical environment of the waste package interior will influence corrosion rates, as evidenced by the variability in rates under different conditions (DTN: MO0409SPAACRWP.000 [DIRS 172059]). Thus, aleatoric uncertainty also exists in the corrosion rates owing to the uncertain future waste package environment.

The parameters Diff_Path_Length_CP_CSNF and Diff_Path_Length_CP_CDSP are developed in Sections 6.5.3.1.1 and 6.5.3.1.2. These are the diffusion path lengths from the internal waste package corrosion products domain to the invert domain of the EBS transport abstraction for CSNF (e.g., 21-PWR and 44_BWR) and codisposal (CDSP) (e.g., 5 DHLW/DOE SNF - Short) waste packages, respectively. The radionuclide source (failed fuel rods or glass logs) and the porous corrosion products are treated as being uniformly distributed throughout the volume of the breached waste package. Breached fuel rods or glass logs may lie adjacent to the interior of a breach in the waste package or nearby. Some aleatoric uncertainty exists in the location of the radionuclide source embedded in the corrosion products. The minimum path length is the thickness of the waste package outer corrosion barrier, $0.02 \mathrm{~m}$ for CSNF waste packages and $0.025 \mathrm{~m}$ for codisposal waste packages. The maximum is the radius of a waste package, $0.859 \mathrm{~m}$ for CSNF waste packages and $1.063 \mathrm{~m}$ for codisposal waste packages. A uniform distribution is appropriate for this parameter.

The parameter Surface_Area_CP, the specific surface area of corrosion products, is developed in Section 6.3.4.3.3, where uncertainties are discussed. This parameter accounts for the uncertainty in the computed surface area of corrosion products that is available for water adsorption inside a breached waste package. The calculated mass of corrosion products is multiplied by their specific surface area to compute the bulk surface area. The uncertainties are both aleatoric and epistemic. Unpredictable processes or events may occur that impact the morphology of corrosion products and alter their surface area, including seismic events, collapse of waste package internal structures, and changes in seepage rates. The nature of corrosion products formed under the conditions in a breached waste package in a humid environment, from a mixture of various types of steel, and their behavior in response to events and process that may occur is also uncertain. Due to the sparseness of the data for the specific surface area of corrosion products, only a uniform distribution can be justified for this parameter.

\subsubsection{EBS-UZ Boundary Condition Implementation in TSPA-LA}

The EBS-UZ boundary condition implementation, discussed in Section 6.5.3.6, is applied when the EBS transport abstraction is discretized and implemented in GoldSim. This model provides the radionuclide concentration boundary condition at the invert-UZ boundary such that the 
far-field concentration is approximately zero. To compute this boundary condition, a portion of the UZ is modeled, so input parameters for the UZ are used and therefore become EBS transport input parameters. The uncertainty in sampled parameters is discussed in this section; details about how UZ parameters are used are provided in Section 6.5.3.6.

Most of the parameters used for the EBS-UZ boundary condition implementation are taken from the output of Drift-Scale Radionuclide Transport (BSC 2004 [DIRS 170040]), in which specification of the ranges and distributions for the parameters is discussed. The parameters were developed for the discrete fracture-matrix partitioning model (BSC 2004 [DIRS 170040]). Although the modeling approach used in the EBS RT Abstraction is different, the parameter values remain unchanged. The parameter values are given in DTN: LB0307FMRADTRN.001 ([DIRS 165451], Folder: U0230_excel_files.zip). These parameters were developed for the lower, mean, and upper bound flow fields for the glacial transition climate and recommended for use in TSPA-LA for the entire duration of the simulation. The glacial transition lower, mean, and upper infiltration cases cover a range of conditions that encompass all of the monsoon climates and all but the present-day lower infiltration climate. Furthermore, most of the regulatory compliance period (2,000 to 10,000 years) is modeled as being under glacial transition climate. Because of the predominance in time and wide range of the glacial transition infiltration cases, these three cases are used as representative for the low, mean, and high infiltration cases for the entire compliance period.

\subsection{Matrix and Fracture Percolation Fluxes}

Similar to the approach taken in Drift-Scale Radionuclide Transport (BSC 2004 [DIRS 170040]), in the EBS-UZ interface model, the parameter uncertainty is included through uniform sampling of the 433 different repository locations that have been assigned model parameters such as fracture and matrix flux and water saturation values. These values have been taken from the output of the UZ flow model for the repository host rock; see Sections 6.4.5 and 6.4.6 of Drift-Scale Radionuclide Transport (BSC 2004 [DIRS 170040]) for additional information. The sampled parameters that are based on repository locations are sampled such that if a flux for a certain location is considered then the saturation for the same location is also used.

\subsection{Fracture Frequency}

The fracture frequency distribution for each UZ model layer is presented in Table A-1 of Drift-Scale Radionuclide Transport (BSC 2004 [DIRS 170040], Appendix A, Table A-1). Since approximately 80 percent of the waste emplacement drift area is occupied by the TSw35 (Topopah Spring welded tuff lower lithophysal) unit of the UZ model (Appendix H of Drift-Scale Radionuclide Transport, BSC 2004 [DIRS 170040]), and because of the small variation in fracture frequency among various units, it is sufficient to use the fracture frequency distribution for TSw35 as given in Table A-1 of Drift-Scale Radionuclide Transport (BSC 2004 [DIRS 170040], Appendix A, Table A-1). 


\subsection{Fracture Fraction}

The average fraction of the UZ that is occupied by fractures (also referred to as fracture porosity) is given as a distribution in Table D-1 of Drift-Scale Radionuclide Transport (BSC 2004 [DIRS 170040], Appendix D). As with fracture frequency, the fracture porosity distribution for TSw35 given in Table D-1 of Drift-Scale Radionuclide Transport (BSC 2004 [DIRS 170040], Appendix D) is sufficient for EBS modeling purposes.

\subsection{Fracture Flow-Focusing Factor}

The focusing of fracture flux is included through a flow-focusing factor to account for flow heterogeneities at the drift scale that do not exist at the coarser scale of the UZ flow model. The sampled fracture flux is adjusted by multiplying it by the sampled flow-focusing factor (see BSC 2004 [DIRS 170040], Equation G-3 and Appendix C). A separate flow-focusing factor is sampled for each of the 433 repository locations.

\subsection{Matrix Porosity}

A distribution for matrix porosity for various UZ model layers is given in Table D-1 of Drift-Scale Radionuclide Transport (BSC 2004 [DIRS 170040], Appendix D, Table D-1). Matrix porosity distribution for TSw35 is used for EBS modeling purposes.

\subsection{Fracture Saturation}

The physical saturation of the fracture is computed in Drift-Scale Radionuclide Transport (BSC 2004 [DIRS 170040], Appendix G, Equation G-6). This takes into account the effect of flow focusing to account for sub-grid-block-scale heterogeneity for the mountain-scale flow fields in the fracture continuum. This value is calculated for the 433 repository locations for all three infiltration cases.

\subsection{Fracture Residual Saturation}

The fracture residual saturation is computed in Drift-Scale Radionuclide Transport (BSC 2004 [DIRS 170040], Appendix G). It is developed for 433 repository locations and does not vary by the infiltration case.

\subsection{Matrix Intrinsic Permeability and Relative Permeability}

The matrix effective permeability to water is derived from Drift-Scale Radionuclide Transport (BSC 2004 [DIRS 170040], Equation 6-57), by multiplying the matrix intrinsic permeability by the matrix relative permeability. The matrix intrinsic permeability for all four UZ model layers at the repository horizon (TSw33, TSw34, TSw35, and TSw36) are given in Drift-Scale Radionuclide Transport (BSC 2004 [DIRS 170040], Table 4-6) for each infiltration case. The relative permeability is sampled for 433 repository locations and varies with the infiltration case; it is given in Drift-Scale Radionuclide Transport (BSC 2004 [DIRS 170040], Table B-1). 


\subsubsection{Summary of Computational Model}

The object of the EBS radionuclide transport abstraction is to determine the rate of radionuclide releases from the EBS to the unsaturated zone. In the EBS transport model, the EBS is spatially partitioned into the following domains: (1) waste form, consisting of, for example, fuel rods, HLW glass, and DSNF; (2) waste package corrosion products; and (3) invert. In addition, the UZ immediately underlying the invert is conceptualized as a dual continuum consisting of (4) UZ matrix continuum and (5) UZ fracture continuum. The inclusion of a portion of the UZ is needed for an accurate calculation of the invert-to-UZ interface fluxes by providing a diffusive path length that is sufficiently long such that the concentration at the outlet of the UZ can realistically be assigned a value of zero.

In the waste form domain, degradation processes occur, including breaching and axial splitting of fuel rods, dissolution of SNF and HLW glass, and formation of waste form colloids wherever applicable. Dissolved species are transported by advection and/or diffusion to the waste package corrosion products domain. The primary interactions in the corrosion products domain involving radionuclide species are irreversible sorption onto stationary corrosion products, reversible and irreversible sorption of dissolved species onto iron oxyhydroxide colloids, and reversible sorption onto groundwater colloids and waste form colloids (when present). In the invert domain, radionuclides released from the corrosion products domain are transported by advection and diffusion, and interact with the crushed tuff by adsorption processes. The properties of each domain, including the volume, porosity, water saturation, diffusion cross sectional area, and diffusive path length, affect the rate of advective and diffusive transport of radionuclides through the domain. The invert domain interfaces with both continua of the UZ. The properties of the domains are defined in the following sections.

\subsubsection{Waste Form and Waste Package Diffusion Properties}

This section summarizes the general approach, major assumptions, main steps in the computational algorithm, and the stochastic parameters for the in-package diffusion submodel for TSPA-LA. The mathematical equations for the in-package diffusion submodel are described in Section 6.3.4.3

The general approach for the commercial SNF (21-PWR and 44-BWR) waste packages is to consider two pathways for diffusion: (1) through porous waste form products inside the package, and (2) through porous corrosion products filling the bottom of the waste package. Starting from the time when a package is first breached, the extent of degradation is determined. This parameter is the basis for estimating the amount of corrosion products present inside a package, and allows the water saturation and effective diffusion coefficient to be computed.

Implementation of the three-domain EBS abstraction requires that properties be specified for each domain, including the volume, diffusive cross-sectional area, the diffusive path length, porosity, water saturation, and the procedure for calculating the diffusion coefficient. These properties must be specified for each type of waste package (CSNF and codisposal waste packages) and for the drip and no-seep environments. 


\subsubsection{1 ～CSNF Waste Packages Properties}

This section discusses the CSNF waste package properties in the following two domains: CSNF waste form and CSNF corrosion products.

\subsection{CSNF Waste Form Domain}

In CSNF waste packages, the waste form domain consists of fuel rods. Except for ${ }^{14} \mathrm{C}$, which is released from fuel hardware at the time of waste package breach (DTN: SN0310T0505503.004 [DIRS 168761]), radionuclides are released only from failed rods. Fuel rods initially fail either by perforations in the cladding as a result of corrosion or by damage in handling or in seismic events; however, it is assumed that the fuel rod cladding instantly splits along its length when the waste package fails (BSC 2005 [DIRS 172895], Assumption 5.3). Fuel rods split when the SNF reacts with the oxygen and moisture inside the waste package, forming metaschoepite. The resulting material, having a greater volume than SNF (mostly $\mathrm{UO}_{2}$ ), causes the fuel rod to split open. The configuration of the failed rod is a mostly intact tube with the slit along the length exposing the SNF inside.

The reacted SNF constitutes a porous "rind" that is modeled as saturating quickly and completely with water, both in a seep and no-seep environment. The volume of the rind as a function of time and the rind porosity are provided by Cladding Degradation Summary for LA (BSC 2005 [DIRS 172895]). Radionuclides dissolve in the water that fully saturates the pore volume of the rind.

The diffusive area of the waste form domain is the total exposed surface area of the SNF in all of the axially split fuel rods, i.e., the area of the slit times the number of failed fuel rods. This area is provided by Cladding Degradation Summary for LA (BSC 2005 [DIRS 172895]).

The diffusive path length is the thickness of the rind, which is a function of time as the SNF reacts to form metaschoepite.

The diffusion coefficient is computed using Archie's law (Equation 6.3.4.3.5-2), with the porosity of the rind and the assigned water saturation of 1.0. As discussed in Section 6.5.3.5, the discretized mass balance equations use a diffusive conductance, which is a harmonic average of diffusion coefficient terms (including diffusivity, porosity, saturation, diffusive path length, and cross-sectional area for diffusion; see Equation 6.5.3.5-7), in this case, for the waste form and corrosion products domains. Since the TSPA-LA model, GoldSim (GoldSim Technology Group 2002 [DIRS 160579]) computes the diffusive conductance, only the diffusion coefficients need to be input, rather than the diffusive conductances themselves.

\subsection{2 ～CSNF Corrosion Products Domain}

The second domain consists of the corrosion products inside the waste package. The mass of corrosion products $\left(m_{C P}\right)$ is given as a function of time by Equation 6.5.3.2-5 below. In Section 6.3.4.3.4, a porosity $\left(\phi_{C P}\right)$ of 0.4 for corrosion products is shown to be appropriate. For purposes of calculating the water content of a breached waste package, the corrosion products 
are assumed to be $\mathrm{Fe}_{2} \mathrm{O}_{3}$. With the known density of $\mathrm{Fe}_{2} \mathrm{O}_{3}\left(\rho_{\mathrm{FeOx}}\right)$, the pore volume of the corrosion products domain is computed from:

$$
V_{C P}=\frac{m_{C P}}{\rho_{F e O x}}\left(\frac{\phi_{C P}}{1-\phi_{C P}}\right) .
$$

In a seep environment, the water saturation $\left(S_{w}\right)$ is assigned a value of 1.0. In a no-seep environment, the only water present is adsorbed water, and the saturation is the effective saturation of corrosion products given by Equation 6.3.4.3.5-5. Uncertainty in the water saturation of the corrosion products is provided for in the sampled specific surface area of the corrosion products.

In a seep environment, the effective diffusion coefficient for corrosion products is given by Archie's law (Equation 6.3.4.3.5-2), with the porosity $\phi_{C P}=0.4$ and the assigned water saturation of 1.0 .

In a non-seep environment, the effective diffusion coefficient is given by Eq. 6.3.4.3.5-6. The diffusive area of the corrosion products domain for diffusion to the invert domain is the total area of all waste package breaches, including corrosion patches and stress corrosion cracks. The breached area is determined differently for each scenario class:

- For the nominal scenario class:

- Without early failure modeling cases and with no localized corrosion, the breached area is provided by the integrated waste package degradation model developed in WAPDEG Analysis of Waste Package and Drip Shield Degradation (BSC 2004 [DIRS 169996], Section 7.1.1.1).

- In the early failure modeling cases (no localized corrosion), the entire surface area of the waste package is breached (WAPDEG Analysis of Waste Package and Drip Shield Degradation [BSC 2004 (DIRS 169996), Section 6.3.8]).

- For the seismic scenario class:

- With ground motion damage only (no localized corrosion), the breached area is provided by the Seismic Consequence Abstraction (BSC 2005 [DIRS 173247], Section 6.5.3). This breached area is applied to the thickness of the waste package outer shell only. For the rest of the corrosion products domain, the waste package plan area, equal to the waste package diameter times its length, is used.

- Localized corrosion could result from seepage flux when seismic damage to the drip shield has occurred. The breached area is provided by the General Corrosion and Localized Corrosion of Waste Package Outer Barrier (BSC 2004 [DIRS 169984], Section 8.3.1).

- For the igneous scenario class: 
- In the igneous intrusive modeling case, the entire waste package is breached, and the waste package and cladding provide no further protection to the waste forms (BSC 2004 [DIRS 168960], Section 6.7.1). Transport begins with transport through the invert.

- In the igneous eruptive modeling case, the entire inventory of affected waste packages is made available for release to the air as ash. The EBS transport model does not apply.

In all scenario classes, the corrosion products diffusive path length is a sampled parameter (see Table 6.5-6) ranging from $0.02 \mathrm{~m}$ (the thickness of the CSNF waste package outer corrosion barrier) to $0.859 \mathrm{~m}$ (the outside radius of a 21-PWR) (BSC 2004 [DIRS 169472], Table 1).

\subsection{Codisposal Waste Packages Properties}

Codisposal waste packages consist of five cylindrical canisters containing HLW glass (glass "logs") surrounding a central canister of defense spent nuclear fuel (DSNF). After the codisposal waste package is breached, the HLW glass slowly degrades to a clay-like alteration product. However, the DSNF is modeled as degrading instantaneously (within a single TSPA-LA time step) once the waste package is breached (BSC 2004 [DIRS 172453], Section 8.1). In addition to the on-going fuel degradation, the steel support framework inside the waste package also corrodes gradually, allowing the HLW glass logs to collapse onto each other such that the general cylindrical shape of the logs is retained. On the other hand, since DSNF is modeled as degrading instantaneously with no credit taken for the canister, it is expected that DSNF will not retain its cylindrical geometry, and may mix with the steel degradation products (iron oxyhydroxides) as a porous medium. With this assumption of the internal configuration of a degraded codisposal waste package, two separate waste form subdomains are conceptualized, one for HLW and the other for DSNF. The transport characteristics in each waste form subdomain are expected to be different.

Since the EBS transport model is a one-dimensional model, the two waste form subdomains are modeled sequentially, such that the HLW subdomain is upstream of the DSNF subdomain. The mass released from the degradation of HLW glass moves to the DSNF subdomain by advection and/or diffusion and is then transported to the corrosion product domain. This sequential representation is consistent with the conceptualization that the DSNF will degrade quickly and mix with the down-gradient steel corrosion products while the HLW glass logs will retain their cylindrical geometry and remain up-gradient of the corrosion products. The seepage flux through the waste package is also conceptualized to pass in series so that each waste form subdomain and the corrosion product domain have the same seepage flux.

The diffusive area in the HLW waste form subdomain, for the mass transport calculation, is calculated to be the combined initial surface areas of the five glass logs. The diffusive area in the DSNF waste form subdomain is set equal to the diffusive area of the corrosion product domain, which varies by the scenario class being modeled. This is reasonable because the corroded mass of uranium oxide, formed from degradation of DSNF waste form, is expected to mix with the iron oxyhydroxides formed from corrosion of steel components inside the waste package and be dispersed throughout the waste package, occupying the same area. In the 
seismic scenario class for the ground motion damage case, an inner and an outer diffusive area is modeled for the corrosion product domain because the breached area of the waste package from the ground motion damage only applies to the outer barrier thickness of the waste package. In this instance, the DSNF waste form diffusive area is set equal to the inner diffusive area of the corrosion product domain, which is equal to the waste package plan area.

The volume of the HLW waste form subdomain is set equal to the volume of the degraded glass, which is determined by the Defense HLW Glass Degradation Model (BSC 2004 [DIRS 169988], Section 8.1). The volume of the DSNF waste form subdomain is set equal to the initial volume of DSNF in a codisposal waste package, which is equal to $1 \mathrm{~m}^{3}$ (BSC 2004 [DIRS 172453], Section 8.1). So, unlike the volume increase in the HLW subdomain as degradation continues, the volume of DSNF is fixed because all the mass is degraded almost instantaneously.

The diffusive path length from the HLW waste form subdomain to the DSNF waste form subdomain is determined as the thickness of the degraded glass alteration product (the rind thickness) by the Defense HLW Glass Degradation Model (BSC 2004 [DIRS 169988], Section 8.1). This thickness varies as more mass is degraded. The diffusive path length from the DSNF waste form subdomain to the corrosion product domain is determined by dividing the DSNF volume of $1 \mathrm{~m}^{3}$ by the diffusive area of the DSNF subdomain.

The diffusion coefficient for the HLW subdomain is computed using Archie's law (Equation 6.3.4.3.5-2). For the DSNF subdomain the effective diffusion coefficient is computed by multiplying the free water diffusion coefficient with porosity and saturation. The exponents on porosity and saturation, as used in the Archie's Law, are set to unity in order to maximize the diffusion coefficient without taking credit for tortuosity, as the powdered mass of DSNF is conceptualized to be mixed in with the stationary corrosion products. The porosity of the HLW glass degradation products (rind) is given as 17 percent by the Defense HLW Glass Degradation Model (BSC 2004 [DIRS 169988], Table 8-1), and the assigned water saturation is 1.0 (as inferred by the volume of pore water being equal to the pore volume in Equations 54 and 55 in BSC 2004 [DIRS 169988], Section 8.1). A porosity of 0.2 is used for DSNF, as degraded DSNF is conceptualized to be in a powdered form. The porosity is based on the porosity of unconsolidated sand, which ranges from 0.25 to 0.50 (Freeze and Cherry 1979 [DIRS 101173], Table 2.4). A value lower than this range is used to account for some consolidation; the porosity of sandstone, for example, ranges from 0.05 to 0.30 (Freeze and Cherry 1979 [DIRS 101173], Table 2.4). This value is adequate as smaller water volume results in higher radionuclide concentrations and hence overestimates releases. The DSNF is also considered fully saturated, yielding a water volume of $0.2 \mathrm{~m}^{3}$.

The volume in the corrosion products domain is proportional to the mass of steel that has corroded. The mass of corrosion products is estimated as a function of time based on sampled corrosion rates for carbon and stainless steels. As shown in Table 6.3-4, the total mass of steel in a codisposal waste package (5 DHLW/DOE SNF - Short) is slightly less than in a 21-PWR. Using this mass and the porosity and density of corrosion products, the volume of the corrosion products domain in a codisposal waste package is computed using Equation 6.5.3.1.1-1. Because of the deliquescent nature of glass and glass degradation products, the waste form is modeled as being fully saturated (BSC 2004 [DIRS 169988], Section 8.1), and the corrosion products that surround those materials are considered to be fully saturated as well. 
Because the degraded DSNF and the corrosion products are conceptualized to be physically mixed together, the water volume associated with the corrosion products is expected to dominate the water volume associated with DSNF due to the larger mass of steel. For this reason, the water volume associated with DSNF can be considered as the lower bound for the water volume in the corrosion products domain. Once the water volume associated with corrosion products exceeds the water volume associated with DSNF, then the corrosion products water volume is used.

The diffusive area in the corrosion products domain is the total area of all breaches in the Alloy 22 outer corrosion barrier of the waste package. The diffusive area is dependent on the scenario class; the determination of diffusive areas as discussed in Section 6.5.3.1.1 for CSNF waste packages also applies to CDSP waste packages.

The diffusive path length in the corrosion products domain is uncertain because the actual source of dissolved radionuclides inside the waste package may be located anywhere within the waste package at any given time. As a result, the path length is sampled, ranging from the minimum value equal to the thickness of the outer corrosion barrier $(0.025 \mathrm{~m})$ to the maximum value equal to the nominal radius of the $5 \mathrm{DHLW} / \mathrm{DOE} \mathrm{SNF}$ - Short codisposal waste package, $1.063 \mathrm{~m}$ (BSC 2004 [DIRS 169472], Table 1).

The diffusion coefficient in the codisposal waste package corrosion products domain is computed the same as for the CSNF corrosion products domain using Archie's law (Equation 6.3.4.3.5-2), with the porosity of the corrosion products $\left(\phi_{C P}=0.4\right)$ and the assigned water saturation of 1.0 .

\subsubsection{Calculation of Corrosion Products Mass and Saturation}

The mass of corrosion products in a breached waste package varies over time, from zero when the waste package is first breached to a maximum amount given in Table 6.3-4 that depends on the type of waste package. The mass is computed by linearly interpolating over the lifetime of each of the two major types of steel comprising the internal components of a waste packagecarbon steel and stainless steel. The major steps in the computational procedure are:

- Determine the extent of degradation of the iron-based internal components of the waste package and the resulting surface area available for adsorption of water vapor. This is a two-step process.

First Step-Suppose the iron-based internal components have a lifetime equal to that of either the carbon steel components (maximum $10 \mathrm{~mm}$ thick) or the stainless steel inner vessel, which is $50 \mathrm{~mm}$ thick. Compute the lifetime by dividing the thickness by the corrosion rate for each type of steel. From Table 6.3-4, carbon steel comprises 30 percent of the total mass of steel in a 21-PWR and 33 percent in a 44-BWR. As an approximation, one-third of the iron-based internal components in all waste packages is carbon steel and two-thirds is stainless steel. Each type of steel corrodes at a different rate, determined by sampling its rate distribution. The lifetime of carbon steel (yr) is then given by: 


$$
t_{f 1}=\frac{1000 \text { (Max_Thick_CS) }}{r_{1}},
$$

where $r_{1}$ is the sampled value for the corrosion rate of carbon steel $\left(\mu \mathrm{m} \mathrm{yr}^{-1}\right)$, and Max_Thick_CS is the maximum thickness of carbon steel components (mm). From $D \& \bar{E} / P A / C^{-}$IED Typical Waste Package Components Assembly (BSC 2004 [DIRS 169472], Table 2), the maximum thickness of a carbon steel waste package component is $3 / 8 \mathrm{in}$. $=9.525 \mathrm{~mm}$, which is rounded to $10 \mathrm{~mm}$ for this parameter value. For carbon steel corrosion rates ranging from 106.93 to $65.76 \mu \mathrm{m} \mathrm{yr}^{-1}$ (Table 6.5-6), $t_{f 1}$ ranges from 94 to $152 \mathrm{yr}$.

Similarly, the lifetime of stainless steel (yr) is given by:

$$
t_{f 2}=\frac{1000 \text { (Max_Thick_SS) }}{r_{2}},
$$

where $r_{2}$ is the sampled value for the corrosion rate of stainless steel $\left(\mu \mathrm{m} \mathrm{yr}^{-1}\right)$, and Max_Thick_SS is the maximum thickness of stainless steel components (mm). From Design and Engineering, 21-PWR Waste Package Configuration (BSC 2004 [DIRS 167394], Detail A), the maximum thickness of a stainless steel in a waste package is the inner vessel thickness of $50.8 \mathrm{~mm}$. For stainless steel corrosion rates ranging from 0.51 to $0.03699 \mu \mathrm{m} \mathrm{yr}^{-1}$ (Table 6.5-6), $t_{f 2}$ ranges from $1.0 \times 10^{5}$ to $1.37 \times 10^{6} \mathrm{yr}$.

Second Step-One-third of the total mass of the internal components is assigned to carbon steel components and two-thirds are assigned to stainless steel components, similar to the assumption for the first step. When these components are fully corroded, the same proportions hold, but the rate of formation of corrosion products depends on the sampled rates of the two types of steel. The total mass of corrosion products when internal components are fully degraded, $m_{C P f}\left(19,440 \mathrm{~kg} \mathrm{Fe}_{2} \mathrm{O}_{3}\right.$ in a 21-PWR; see Section 6.3.4.2.2), is based on data presented in Table 6.3-4. The initial mass of corrosion products is zero. For each type of steel, the mass of corrosion products present at time $t(\mathrm{yr})$ is proportional to the fraction of the lifetime of each steel since the waste package was breached:

$$
\text { Carbon steel: } \quad m_{C P 1}= \begin{cases}\left(\frac{t-t_{0}}{t_{f 1}}\right) \frac{1}{3} m_{C P f}, t-t_{0} \leq t_{f 1} \\ \frac{1}{3} m_{C P f}, & t-t_{0}>t_{f 1},\end{cases}
$$


Stainless steel: $\quad m_{C P 2}= \begin{cases}\left(\frac{t-t_{0}}{t_{f 2}}\right) \frac{2}{3} m_{C P f}, t-t_{0} \leq t_{f 2} \\ \frac{2}{3} m_{C P f}, & t-t_{0}>t_{f 2},\end{cases}$

where $t_{0}$ is the time $(\mathrm{yr})$ when the first breach appears in the waste package.

Then the total mass of corrosion products present is $m_{C P}(t)=m_{C P 1}+m_{C P 2}$, or, inserting Equations 6.5.3.2-3 and 6.5.3.2-4:

Total corrosion products: $\quad m_{C P}(t)=\frac{m_{C P f}}{3}\left\{\min \left(\frac{t-t_{0}}{t_{f 1}}, 1\right)+2 \min \left(\frac{t-t_{0}}{t_{f 2}}, 1\right)\right\}$

(Eq. 6.5.3.2-5)

The total surface area of corrosion products, $s_{C P}$, is obtained using the sampled value for the specific surface area of corrosion products, $\bar{s}_{C P}$ :

Total surface area: $\quad s_{C P}=\bar{s}_{C P} m_{C P}$.

(Eq. 6.5.3.2-6)

- Let the water saturation in the waste package corrosion products be 1.0 in the seep environment for both CSNF and codisposal waste packages and in the no-seep environment for codisposal waste packages. For CSNF waste packages in the no-seep environment, use the adsorption isotherm for $\mathrm{Fe}_{2} \mathrm{O}_{3}$ and compute the amount of water vapor adsorbed (number of monolayers and film thickness) and the water saturation in the waste package corrosion products as follows (see Section 6.3.4.3.5):

$$
S_{w e, C P}=3.28 \times 10^{-6} \bar{s}_{C P}(-\ln R H)^{-1 / 2.45}
$$

- Compute the effective diffusion coefficient for steel corrosion products, $D_{s}$, using Archie's law (see Section 6.3.4.3.5, Equation 6.3.4.3.5-6) with a fixed porosity of 0.4 (see Section 6.3.4.3.4) and the water saturation $S_{w e}$ obtained from the preceding bullet (either 1.0 or Equation 6.5.3.2-7). 


\subsubsection{Invert Domain Properties}

The volume of the invert is equal to its cross sectional area (i.e., the area of a segment of a circle) times the axial length. Based on the drift diameter of $5.5 \mathrm{~m}$ (BSC 2004 [DIRS 169503]) (or drift radius $r_{D}=2.75 \mathrm{~m}$ ) and maximum invert thickness of $t_{I, \max }=2 \mathrm{ft} 10 \mathrm{in} .=0.8636 \mathrm{~m}(\mathrm{BSC} 2004$ [DIRS 169503]), the width of the top surface of the invert is (Perry et al. 1963 [DIRS 119529], p. 2-6):

$$
w_{I}=2 \sqrt{r_{D}^{2}-\left(r_{D}-t_{I, \max }\right)^{2}}=4.00 \mathrm{~m} \text {. }
$$

The frontal cross sectional area of the invert is (Perry et al. 1963 [DIRS 119529], p. 2-6):

$$
\begin{aligned}
A_{I} & =r_{D}^{2} \cos ^{-1}\left(\frac{r_{D}-t_{I, \max }}{r_{D}}\right)-\left(r_{D}-t_{I, \max }\right) \sqrt{2 r_{D} t_{I, \max }-t_{I, \max }^{2}} \\
& =2.39 \mathrm{~m}^{2} .
\end{aligned}
$$

The invert volume is this area $\left(A_{I}\right)$ multiplied by the length of interest, for example, the length of a waste package, $L_{W P}$. The volume of water in the invert beneath a waste package of length $L_{W P}$ is:

$$
V_{w I}=\phi S_{w} A_{I} L_{W P}
$$

where $\phi$ is the porosity of the invert, and $S_{w}$ is the water saturation of the invert.

For purposes of modeling flow and diffusion through the invert, the invert is regarded as having a rectangular cross section with a top surface being the actual top surface of the invert. The cross sectional area for flow or diffusion between the invert and the unsaturated zone is:

$$
A_{I / U Z}=w_{I} L_{W P}
$$

The average thickness of the invert is given by:

$$
\bar{t}_{I}=\frac{A_{I}}{w_{I}}=0.597 \mathrm{~m}
$$

Using this value preserves the top surface area and volume of the invert.

Sorption of radionuclides to the invert crushed tuff is modeled by applying the devitrified tuff $K_{d}$ values from the $\mathrm{UZ}$ submodel to the invert. Ranges and distributions for these $K_{d}$ values are shown in Table 4.1-15. The $K_{d}$ values are correlated using the correlation matrix shown in Table 4.1-16.

The bulk water content in the invert, $\theta$ (percent), is used to compute the diffusion coefficient in the invert, Equation 6.3.4.1.1-22 (in which $\phi^{1.863} S_{w}^{1.863}=(\theta / 100)^{1.863}$ ). The bulk water content in 
the invert is determined from the intragranular water saturation provided by Multiscale Thermohydrologic Model (BSC 2005 [DIRS 173944], Appendix X) and the seepage flux provided by the Seepage Model for PA Including Drift Collapse (BSC 2004 [DIRS 167652]).

The relationship between the bulk water content and the intergranular and intragranular water contents is based on the definitions of water content using the volumes of water, solids, and pore spaces:

$$
\begin{aligned}
& \theta=100 \frac{V_{w \_ \text {inter }}+V_{w \_ \text {intra }}}{V_{t}}=100 \frac{V_{w \_ \text {inter }}}{V_{t}}+100 \frac{V_{w \_ \text {intra }}}{V_{t}} \\
& =\theta_{\text {inter }}+100 \frac{V_{w \_ \text {intra }}}{V_{t}} \text {, }
\end{aligned}
$$

where $V_{w_{-} \text {inter }}$ is the volume of water in the intergranular pore space $\left(\mathrm{m}^{3}\right), V_{w_{-} \text {intra }}$ is the volume of water in the intragranular (matrix) pore space $\left(\mathrm{m}^{3}\right), V_{t}$ is the total bulk invert volume $\left(\mathrm{m}^{3}\right)$, and $\theta_{\text {inter }}$ is the intergranular water content (percent).

The ratio of intragranular water volume to total invert bulk volume, $V_{w-i n t r a} / V_{t}$, is related to the porosity of the of the intragranular (tuff matrix) pore space, $\phi_{\text {intra }}$ $\left(\mathrm{m}^{3}\right.$ pore volume $\mathrm{m}^{-3}$ matrix volume):

$$
\frac{V_{w \_ \text {intra }}}{V_{t}}=\frac{V_{t \_ \text {intra }} S_{w_{-} \text {intra }}}{V_{t}}=\frac{\phi_{\text {intra }}\left(V_{t}-V_{t \_ \text {inter }}\right) S_{w_{-} \text {intra }}}{V_{t}},
$$

where $S_{w_{-} \text {intra }}$ is the water saturation of the matrix $\left(\mathrm{m}^{3}\right.$ water $\mathrm{m}^{-3}$ pore volume), $V_{t_{-} \text {intra }}$ is the total pore volume of the matrix $\left(\mathrm{m}^{3}\right)$, and $V_{t_{-} \text {inter }}$ is the total pore volume of the intergranular pore space $\left(\mathrm{m}^{3}\right)$. This expression makes use of the definition of matrix porosity, $\phi_{\text {intra }}$, as the ratio of matrix pore volume to total matrix volume, where the latter is the difference between the bulk invert volume, $V_{t}$, and the intergranular pore volume, $V_{t_{-} \text {inter }}$ :

$$
\phi_{\text {intra }}=\frac{V_{t \text { intra }}}{V_{t}-V_{t \_ \text {inter }}},
$$

which can be rearranged to give:

$$
V_{t_{-} \text {intra }}=\phi_{\text {intra }}\left(V_{t}-V_{t_{-} \text {inter }}\right) \text {. }
$$

Substituting the definitions of percent water content $\left(\theta_{\text {intra }}=100 \phi_{\text {intra }} S_{w_{-} \text {intra }}\right)$ and porosity (fraction) of the intergranular pore space, $\left(\phi_{\text {inter }}=V_{t_{-} \text {inter }} / V_{t}\right)$, the ratio $V_{w_{-} \text {intra }} / V_{t}$ in Equation 6.5.3.3-6 can be written: 


$$
100 \frac{V_{w-\text { intra }}}{V_{t}}=\theta_{\text {intra }}\left(1-\phi_{\text {inter }}\right)
$$

Inserting this into Equation 6.5.3.3-6 results in the expression for the bulk water content of the invert:

$$
\theta=\theta_{\text {inter }}+\left(1-\phi_{\text {inter }}\right) \theta_{\text {intra }} .
$$

The intragranular water content, $\theta_{\text {intra }}$, is calculated by multiplying the intragranular water saturation provided by the Multiscale Thermohydrologic Model (BSC 2005 [DIRS 173944]) with the intragranular porosity of $\phi_{\text {intra }}=0.131$ (DTN: LB0207REVUZPRP.002 [DIRS 159672]; Spreadsheet “Matrix_Props.xls", Row 20, Column C).

The intergranular water content, $\theta_{\text {inter }}$, is evaluated indirectly from the total dripping flux into the drift. The volumetric discharge into the invert, $Q_{I}\left(\mathrm{~m}^{3}\right.$ water $\left.\mathrm{s}^{-1}\right)$, is equal to the total dripping flux (seepage plus condensation) into the drift (see Equation 6.5.1.1-8, where $F_{6}=F_{1}$ ); the imbibition flux, $F_{7}$, does not enter the intergranular continuum and is not included in $Q_{I}$, which is given by:

$$
Q_{I}=K_{u s} I_{s} A_{I s}
$$

where $K_{u s}$ is the unsaturated hydraulic conductivity of the invert $\left(\mathrm{m} \mathrm{s}^{-1}\right), I_{s}$ is the hydraulic head gradient in the invert $\left(\mathrm{m} \mathrm{m}^{-1}\right)$, and $A_{I s}$ is the intercepted flow area of a drift over the length of one waste package, having a value of $28.05 \mathrm{~m}^{2}$ (BSC 2004 [DIRS 167652], Section 6.3.1). For vertical one-dimensional flow, a hydraulic head gradient of unity $\left(I_{s}=1 \mathrm{~m} / \mathrm{m}\right)$ is a bounding value for saturated rock with a free surface exposed to the open drift. Unsaturated crushed rock in the invert will have a lower head gradient, but by using a gradient of unity, Equation 6.5.3.3-12 simplifies and allows the unsaturated hydraulic conductivity of the invert to be evaluated given the seepage flux into the drift:

$$
K_{u s}=\frac{Q_{I}}{A_{I s}} .
$$

The moisture potential, $\psi$ (bar), of the invert has been evaluated as a function of unsaturated hydraulic conductivity in Multiscale Thermohydrologic Model (BSC 2005 [DIRS 173944], Appendix X, Table X-6) for various particle sizes. The determination of intergranular water content uses a particle size of $3 \mathrm{~mm}$ (BSC 2005 [DIRS 173944], Section 6.3.11). Interpolating in Table X-6 of Multiscale Thermohydrologic Model (BSC 2005 [DIRS 173944]) for the unsaturated hydraulic conductivity of the invert, $K_{u s}$, as given by Equation 6.5.3.3-13, results in a value for the moisture potential, $\psi$, which is inserted into a van Genuchten fitting function (BSC 2005 [DIRS 173944], Equation X.4) to give the intergranular water content: 


$$
\theta_{\text {inter }}=\theta_{r}+\frac{\left(\theta_{s}-\theta_{r}\right)}{\left[1+(\psi \alpha)^{n}\right]^{m}},
$$

Parameters in Equation 6.5.3.3-14 are:

$$
\begin{aligned}
& \theta_{r}=\text { residual volumetric water content in the invert (percent) } \\
& =5.0(\text { BSC } 2005 \text { [DIRS 173944], Appendix X, Table X-7) } \\
& \theta_{s}=\text { saturated volumetric water content in the invert (percent) } \\
& =45.0(\text { BSC } 2005 \text { [DIRS 173944], Appendix X, Table X-7) } \\
& \alpha \quad=\text { van Genuchten air-entry parameter }\left(\mathrm{bar}^{-1}\right) \\
& =624 \text { bar }^{-1} \text { (BSC } 2005 \text { [DIRS 173944], Appendix X, Table X-7) } \\
& n \quad=\text { van Genuchten } n \text { value (dimensionless) } \\
& =8.013(\text { BSC } 2005 \text { [DIRS 173944], Appendix X, Table X-7) } \\
& m \quad=\text { van Genuchten } m \text { value (dimensionless) } \\
& =0.875(\text { BSC } 2005 \text { [DIRS 173944], Appendix X, Table X-7) }
\end{aligned}
$$

With the algorithm and parameters described in this section, the bulk volumetric water content in the invert is obtained.

\subsubsection{Irreversible Sorption onto Iron Oxyhydroxide Colloids and Stationary Corrosion Products}

Irreversible sorption of $\mathrm{Pu}$ and $\mathrm{Am}$ onto iron oxyhydroxide colloids and stationary corrosion products in the corrosion product domain is included in the TSPA-LA model, as described in Section 6.3.4.2.3.2. A linear forward rate constant, $k_{i}$, for irreversible sorption reactions is needed for the source terms in the mass balances for radionuclides that undergo irreversible sorption. In Equation 6.5.1.2-46, the mass balance for dissolved and reversibly sorbed radionuclide species $i$, the forward rate constant appears in a term that removes dissolved radionuclides from solution. In Equations 6.5.1.2-47 and 6.5.1.2-48, the mass balances for irreversibly sorbed radionuclide species $i$ on mobile iron oxyhydroxide colloids and stationary corrosion products, respectively, the forward rate constant appears in a term that increases the concentration of irreversibly sorbed radionuclide species $i$.

In the no-seep case or where iron oxyhydroxide colloids are unstable, the forward rate constant is randomly sampled from a range developed in Waste Form and In-Drift Colloids-Associated Radionuclide Concentrations: Abstraction and Summary (BSC 2004 [DIRS 170025], Section 6.3.3.2) from experimental data of $0.01 \mathrm{~m}^{3} \mathrm{~m}^{-2} \mathrm{yr}^{-1}$ to $0.24 \mathrm{~m}^{3} \mathrm{~m}^{-2} \mathrm{yr}^{-1}$, with a log-uniform distribution (DTN: SN0309T0504103.010 [DIRS 165540]).

For the seep case and where colloids are stable, the forward rate constant $k_{i}$ describing irreversible sorption to iron oxyhydroxide corrosion products and colloids (Equations 6.5.1.2-13 and 6.5.1.2-18, respectively) is computed as a fitting parameter to match a specified target flux out ratio for the corrosion products domain (BSC 2004 [DIRS 170025], Section 6.3.3.2). The 
target flux out ratio $(\Omega)$ is the ratio of radionuclide flux exiting the corrosion product domain that is transported by colloids to the total radionuclide flux exiting the corrosion product domain (in dissolved state or sorbed onto colloids). The mass of radionuclides in the fluid exiting the corrosion products domain is expected to be proportioned such that the mass of radionuclide species $i$ both reversibly and irreversibly sorbed onto all colloids is some fraction of the total mass of radionuclide species $i$ exiting the system in all forms-aqueous, reversibly sorbed, and irreversibly sorbed. Observations in nature, such as the transport of Pu from the Benham test site (Kersting et al. 1999 [DIRS 103282]) indicate that this fraction is about 95 percent.

This is expressed as:

$$
\Omega=\frac{\text { colloid mass flux out }}{\text { total mass flux out }}=0.95
$$

This target flux out ratio value of 95 percent is uncertain with an uncertainty range of 0.9 to 0.99 and a uniform distribution associated with it (BSC 2004 [DIRS 170025], Table 6-12, p. 6-72). It also may be a function of time, since the observation time for the Benham test is only about 50 years. In TSPA-LA, irreversible sorption occurs only for Pu and Am.

The dependence of the forward rate constant on the target flux out ratio is obtained from an analytical solution of a finite difference approximation of transport in the corrosion products domain. The function for evaluating the forward rate constant is given by Equation B-72 in Appendix B.

This treatment applies in a seep environment. The calculated forward rate constant is constrained to be less than or equal to the experimentally derived maximum value of the sampled range for the no-seep environment, $0.24 \mathrm{~m}^{3} \mathrm{~m}^{-2} \mathrm{yr}^{-1}$ (DTN: SN0309T0504103.010 [DIRS 165540]). This approach is adopted because honoring the experimentally derived value is deemed more appropriate than honoring the target flux out ratio.

\subsubsection{Discretization and Development of Computational Model for TSPA-LA}

The continuum mass balance equations for EBS transport model are described and developed in Section 6.5.1.2. The one-dimensional mass balance equation describing transport of dissolved and reversibly sorbed radionuclide species $i$ is provided by Equation 6.5.1.2-46. The one-dimensional mass balance equations for irreversibly sorbed radionuclide species $i$ on iron oxyhydroxide colloids and corrosion products are given by Equations 6.5.1.2-47 and 6.5.1.2-48, respectively. The solution of these continuum-form mass balance equations is approximated for the purpose of numerical modeling by the solution of discrete forms of these equations using a finite-difference approach. This requires the discretization of the time derivative (or mass accumulation term) and the advective and diffusive terms for both dissolved and colloidal transport. All other source terms and decay terms do not require discretization in either time or space.

Numerical modeling of the EBS radionuclide transport is performed using the GoldSim software (Golder Associates 2003 [DIRS 166572]) cell pathway capability, available in the GoldSim Contaminant Transport Module. The cell pathway acts as a batch reactor, where radionuclide 
mass is assumed to be instantaneously and completely mixed and partitioned among all media (fluid or solid) within the cell. Both advective and diffusive transport mechanisms can be explicitly represented using the cell pathways. When multiple cells are linked together via advective and diffusive mechanisms, the behavior of the cell network is mathematically described using a coupled system of differential equations, and is mathematically equivalent to a finite difference network. GoldSim numerically solves the coupled system of equations to compute the radionuclide mass present in each cell and the mass fluxes between cells as a function of time. Both initial and boundary conditions for a cell can be defined explicitly, and systems of varying geometry can be modeled.

Within a computational cell network, each cell is allowed to communicate by advection and/or diffusion with any other cell. This concept is crucial in implementing the bifurcation of diffusive fluxes across an interface between a single continuum domain and a dual continuum domain, such as at the interface between the invert domain and the unsaturated zone. Each computational cell is provided with parameters describing water volumes, diffusive properties, and advective and diffusive flux links to other cells. Between any two cells, the diffusive flux can be bidirectional, depending on the concentration gradient, while the advective flux is unidirectional. The output of a cell is given in terms of the advective and diffusive mass fluxes for radionuclide species $i$ and its concentration at the cell center.

The number of cells in the finite-difference network and the discretization of the cells is chosen in such a way as to capture the unique physical and chemical properties of the EBS components with respect to radionuclide transport. The abstractions are in the form of logic statements and stochastic distributions that provide a method for linking various cells in the network. Implementation of the EBS flow and transport model for TSPA-LA uses the output of the drift seepage model (BSC 2004 [DIRS 169131]), the models for drip shield and waste package degradation (BSC 2004 [DIRS 169996]), the EBS physical and chemical environment model (BSC 2005 [DIRS 173727]), the thermal-hydrologic environment model (BSC 2005 [DIRS 173944]), and the waste form degradation and mobilization model (BSC 2004 [DIRS 172453]); Defense HLW Glass Degradation Model (BSC 2004 [DIRS 169988]); and CSNF Waste Form Degradation: Summary Abstraction (BSC 2004 [DIRS 169987]). The flow through various cells is based on the continuity equations and conservation of mass, as discussed in Section 6.3. An overview of the computational model for TSPA-LA, as implemented using GoldSim, is provided below.

Radionuclide transport through the waste package is modeled by spatially discretizing the waste package into two domains: an upstream waste form domain and a downstream corrosion products domain. As implemented using GoldSim, a single waste form cell represents the entire volume of the CSNF waste form domain, and two waste form cells represent the two CDSP waste form subdomains (HLW and DSNF subdomains, which together comprise the single CDSP waste form domain), while a single corrosion products cell represents the entire volume of the corrosion products domain. These are illustrated in Figure 6.5-4 below by the EBS portion of the cell network - waste form cell, corrosion products cell, and invert cell.

The waste form cell receives mass from a specialized GoldSim "Source" cell, which models the waste package failure, degradation of the waste form, and release of the inventory for possible transport through the EBS. The "Source" cell provides the specified flux boundary condition for 
solving the mass transport equations. Both advective and diffusive transport can occur from the waste form cell to the corrosion products cell. Reversible and irreversible sorption of radionuclides to the corrosion products along with colloid facilitated transport of radionuclides is modeled as described in Appendix B. Three types of colloids, namely, waste form colloids, iron oxyhydroxide colloids, and groundwater colloids, are considered that can facilitate the transport of radionuclides by reversible and/or irreversible sorption. The waste form colloids are generated in the waste form cell (for the co-disposal waste package only), while the iron oxyhydroxide colloids and groundwater colloids are modeled in the corrosion products cell. All three types of colloids can transport to the downstream cells by diffusion and advection.

The discretization of the invert domain, using GoldSim, consists of one cell. Both advective and diffusive flux communication exist between the corrosion product and invert cells. Advective flux due to imbibition from the host rock to the invert may enter the invert cell.

Below the invert, part of the near-field UZ is modeled by an array of cells. The inclusion of the UZ portion in the model serves to establish a far field zero-concentration boundary and an accurate representation of the radionuclide flux at the invert-to-UZ interface. The EBS-UZ interface model is described in more detail in Section 6.5.3.6. The dual continuum approach for modeling the UZ is achieved by creating UZ matrix and fracture cells. The invert cell communicates with the UZ matrix and fracture cells directly below it in the UZ cell array (see Section 6.5.3.6).

The following description focuses on discretization of the mass balance equation for the dissolved and reversibly sorbed mass (Equation 6.5.1.2-46). Similar treatments apply to the mass balance transport equations for the irreversibly sorbed radionuclide species. In order to describe the time discretization, let the superscript $n$ represent a solution at the $n^{\text {th }}$ time. The $n^{\text {th }}$ time step assumes the radionuclide concentrations are known at time step $n$, and the solution provides the concentrations at time step $n+1$. Over this time step, the accumulation term uses a first order backward-in-time discretization:

$$
\frac{\partial}{\partial t}\left[\phi S_{w} R_{f i} C_{i}\right] \approx \frac{\phi S_{w} R_{f i}^{n}\left(C_{i}^{n+1}-C_{i}^{n}\right)}{\Delta t},
$$

where the adsorption retardation factor,

$$
R_{f i}=1+\frac{\rho_{b} K_{d i s}}{\phi S_{w}}+K_{d i c W F} C_{c W F}+K_{d i c F e O x} C_{c F e O x}+K_{d i c G W} C_{c G W},
$$

and the cell water content are evaluated at the beginning of the time step, and $\Delta t$ is the time step size from the $n^{\text {th }}$ to the $(n+1)^{\text {th }}$ time.

The advective transport is discretized with a first order backward (with respect to the flow direction) difference approximation. If the mass balance is applied to cell $B$, and the advective flux is from cell $A$ to cell $B$ with magnitude $q_{w z}\left(\mathrm{~m}^{3}\right.$ water $\left.\mathrm{m}^{-2} \mathrm{yr}^{-1}\right)$, then 


$$
\begin{aligned}
\frac{\partial}{\partial z}[ & \left.q_{w z}\left(1+K_{d i c W F} C_{c W F}+K_{d i c F e O x} C_{c F e O x}+K_{d i c G W} C_{c G W}\right) C_{i}\right] \approx \\
& {\left[Q_{w z}^{n}\left(1+K_{d i c W F} C_{c W F}+K_{d i c F e O x} C_{c F e O x}+K_{d i c G W} C_{c G W}\right)^{n} C_{i}^{n+1}\right]_{A} } \\
& -\left[Q_{w z}^{n}\left(1+K_{d i c W F} C_{c W F}+K_{d i c F e O x} C_{c F e O x}+K_{d i c G W} C_{c G W}\right)^{n} C_{i}^{n+1}\right]_{B},
\end{aligned}
$$

where $Q_{w z}\left(\mathrm{~m}^{3}\right.$ water $\mathrm{m}^{-3}$ cell $\left.B \mathrm{yr}^{-1}\right)$ is the advective water volume flux per unit bulk volume. The advective flux and colloid concentrations are evaluated at the beginning of the time step. The concentration of radionuclide species $i$ is evaluated at the end of time step. The first term in the difference approximation is the advective mass flux entering cell $B$ from cell $A$. The second term is the advective mass flux exiting cell $B$.

Consider the accumulation of solute mass in cell $B$ due to diffusion. Suppose there are diffusive flux links from cell $A$ to cell $B$ and from cell $B$ to cell $C$. The dissolved mass diffusive flux accumulation in cell $B$ is approximated by:

$$
\frac{\partial}{\partial z}\left(\phi S_{w} D \frac{\partial C_{i}}{\partial z}\right) \approx \frac{F_{A / B}-F_{B / C}}{V_{B}},
$$

where $F_{A / B}$ is the diffusive mass flux (mass/time) across the cell $A$ and $B$ interface. Similarly, $F_{B / C}$ is the diffusive mass flux (mass/time) across the cell $B$ and $C$ interface.

Consider the discretization of the diffusive flux at the $A / B$ interface. A similar representation occurs at the $B / C$ interface. Apply Fick's First Law and continuity of flux at the interface. Then the flux entering the $A / B$ interface from cell $A$ must equal the flux exiting the $A / B$ interface to cell $B$. This interface flux continuity condition is expressed as:

$$
\begin{aligned}
F_{A / B} & =\left(\frac{\phi S_{w} D A}{L}\right)_{A}\left(\left[C_{i}^{n+1}\right]_{A}-\left[C_{i}^{n+1}\right]_{A / B}\right) \\
& =\left(\frac{\phi S_{w} D A}{L}\right)_{B}\left(\left[C_{i}^{n+1}\right]_{A / B}-\left[C_{i}^{n+1}\right]_{B}\right),
\end{aligned}
$$

where $\left[C_{i}^{n+1}\right]_{A / B}$ is the concentration at time step $n+1$ at the interface, as indicated by the subscript $A / B$, and $D, A$, and $L$ are the cell effective diffusion coefficient, diffusive area, and diffusive length, respectively. If the $A / B$ interface diffusive flux is expressed as an interface diffusive conductance times the concentration difference between cells $A$ and $B$ :

$$
F_{A / B}=D_{c_{-} A / B}\left(C_{A}-C_{B}\right),
$$

then the flux continuity condition provided by Equation 6.5.3.5-5 gives the interface diffusive conductance as: 


$$
D_{c_{-} A / B}=\frac{1}{\left(\frac{L}{\phi S_{w} D A}\right)_{A}+\left(\frac{L}{\phi S_{w} D A}\right)_{B}} \text {. }
$$

The diffusive conductance is the harmonic average of $\frac{\phi S_{w} D A}{2 L}$ between the two cells. At the $B / C$ interface a similar expression gives:

$$
D_{c_{-} B / C}=\frac{1}{\left(\frac{L}{\phi S_{w} D A}\right)_{B}+\left(\frac{L}{\phi S_{w} D A}\right)_{C}} .
$$

The discretization of the accumulation of solute mass in cell $B$ due to diffusive transport is:

$$
\frac{\partial}{\partial z}\left(\phi S_{w} D \frac{\partial C_{i}}{\partial z}\right) \approx \frac{\left.\left.D_{c_{-} B / C}\left(\mid C_{i}^{n+1}\right\rfloor_{C}-\left\lfloor C_{i}^{n+1}\right\rfloor_{B}\right)-D_{c_{-} A / B}\left(\mid C_{i}^{n+1}\right\rfloor_{B}-\left\lfloor C_{i}^{n+1}\right\rfloor_{A}\right)}{V_{B}} .
$$

The mass balance equations are discretized with the dependent concentration variable for the spatially dependent terms evaluated at the end of time step, $C_{i}^{n+1}$. This is stated explicitly in the discretization of the advective/diffusive terms. For other source terms, such as radionuclide decay, irreversible sorption reaction onto iron oxyhydroxide material and so forth, the concentration is also evaluated at the end of the time step. In this sense, the mass balance equations are fully implicit and the discretization provides numerical stability. However, coefficient terms such as the moisture content are evaluated at the beginning of the time step. This formulation results in a linear system of equations that is solved for concentrations. If the coefficients depending on concentration were evaluated at the end of time step, then the resulting discretized algebraic equations would be nonlinear. The nonlinear system would require much more computational effort. Furthermore, the computational modeling tool (GoldSim) only solves linear systems. For this reason, all concentration-dependent coefficient terms are evaluated explicitly at time step $n$.

Within the waste form domain, some part of the dissolved mass of $\mathrm{Pu}$ and $\mathrm{Am}$ made available from the degradation of HLW glass is converted to "embedded" mass on the waste form colloids. This conversion is required to satisfy the condition that some mass of Pu and Am is "embedded" as an intrinsic part of the colloid and is not in equilibrium with the aqueous system, when generated from the degradation of HLW. This mass is thus transported separately as a distinct species [Waste Form and In-Drift Colloids-Associated Radionuclide Concentrations: Abstraction and Summary (BSC 2004 [DIRS 170025], Sections 6.3.1 \& 6.3.3.3)]. The mass rate of conversion per unit volume of water is modeled as a first order reaction given by $\lambda_{i}^{\text {embed }} C_{i}$, where $\lambda_{i}^{\text {embed }}$ is the linear rate constant, and concentration $C_{i}$ is the dissolved concentration of $\mathrm{Pu}$ and Am species in the waste form domain. The conversion rate $\lambda_{i}^{\text {embed }}$ is calculated at each time step in the waste form domain. Its calculation is discussed below. 
The concentration of the embedded radionuclide mass with respect to the water volume in the waste form domain, $C_{i}^{\text {embed }}$, and the concentration of waste form colloids, $C_{c W F}$, are determined at each time step based on the logic given in the Waste Form and In-Drift Colloids-Associated Radionuclide Concentrations: Abstraction and Summary (BSC 2004 [DIRS 170025], Section 6.5.1.1). Taking the ratio of embedded radionuclide concentration to the waste form colloid concentration, $\frac{C_{i}^{\text {embed }}}{C_{c W F}}$, gives the embedded radionuclide mass per unit mass of the waste form colloid.

Suppose that the solution for embedded radionuclide concentration $\left(C_{i}^{\text {embed }}\right)^{n}$ and colloid concentration $\left(C_{c W F}\right)^{n}$ has been determined at time step $n$ and the solution at current time step $n+1$ is required. Furthermore, suppose that the total mass flux (combined advective and diffusive mass flux) of waste form colloids per unit bulk volume, $\left(Q_{a d v / d i f f}^{w f}\right)^{n}$, is available from the solution at time step $n$ from the waste form colloid mass balance equation (Eq. 6.5.1.2-36). Then the quantity, $\left(Q_{a d v / d i f f}^{w f c} \frac{C_{i}^{\text {embed }}}{C_{c W F}}\right)^{n}$, represents the mass flux at time level $n$ of embedded radionuclide species $i$ from the waste form subdomain containing the HLW glass logs to the waste form subdomain containing the DSNF. A continuum mass balance for embedded radionuclide mass within the waste form domain is:

$$
\frac{\partial\left(\phi S_{w} C_{i}^{e m b e d}\right)}{\partial t}=-Q_{a d v / d i f f}^{w f c} \frac{C_{i}^{e m b e d}}{C_{c W F}}+\lambda_{i}^{\text {embed }} \phi S_{w} C_{i} .
$$

Discretization of this equation gives:

$$
\begin{aligned}
& \frac{\left(\phi S_{w} C_{i}^{\text {embed }}\right)^{n+1}-\left(\phi S_{w} C_{i}^{\text {embed }}\right)^{n}}{t^{n+1}-t^{n}} \\
& =-\left(Q_{a d v / d i f f}^{w f c} \frac{C_{i}^{\text {embed }}}{C_{c W F}}\right)^{n}+\lambda_{i}^{\text {embed }}\left(\phi S_{w} C_{i}\right)^{n} .
\end{aligned}
$$

This equation is solved for the conversion rate:

$$
\lambda_{i}^{\text {embed }}=\frac{\frac{\left(\phi S_{w} C_{i}^{\text {embed }}\right)^{n+1}-\left(\phi S_{w} C_{i}^{\text {embed }}\right)^{n}}{\Delta t}+\left(Q_{a d v / d \text { diff }}^{\text {wfc }} \frac{C_{i}^{\text {embed }}}{C_{c W F}}\right)^{n}}{\left(\phi S_{w} C_{i}\right)^{n}} .
$$

$\left(C_{i}^{\text {embed }}\right)^{n+1}$ is calculated from the logic provided in the Waste Form and In-Drift Colloids-Associated Radionuclide Concentrations: Abstraction and Summary (BSC 2004 [DIRS 170025], Section 6.5.1.1). The concentration $\left(C_{i}^{\text {embed }}\right)^{n+1}$ in the waste form domain is a function 
of the ionic strength and $\mathrm{pH}$. This waste form domain conversion rate is applied to the $i$ species mass balance equation for the solution mass, Eq. 6.5.1.2-38, and for the embedded mass, Eq. 6.5.1.2-37.

The above diffusive flux discussion considers the diffusive flux communication from cells within a single continuum. For transport from the invert domain (single continuum) to the UZ (dual continuum), the flux continuity condition at the interface provides the diffusive flux bifurcation between the single continuum and the dual continuum.

The diffusive fluxes of radionuclide species $i$ within the invert cell, the UZ fracture cell, and the UZ matrix cell are, respectively,

$$
\begin{aligned}
F_{i I} & =\frac{\phi S_{w} D_{I} A_{I / U Z}}{L_{I}}\left(C_{i I}-C_{i I / U Z}\right) \\
& =\hat{D}_{I}\left(C_{i I}-C_{i I / U Z}\right), \\
F_{i f} & =\frac{\phi S_{w} D_{f} A_{I / U Z}}{L_{f}}\left(C_{i I / U Z}-C_{i f}\right) \\
& =\hat{D}_{f}\left(C_{i I / U Z}-C_{i f}\right), \\
F_{i m} & =\frac{\phi S_{w} D_{m} A_{I / U Z}}{L_{m}}\left(C_{i I / U Z}-C_{i m}\right) \\
& =\hat{D}_{m}\left(C_{i I / U Z}-C_{i m}\right),
\end{aligned}
$$

where

$$
\begin{array}{ll}
D_{I} & =\text { effective diffusion coefficient within the invert cell }\left(\mathrm{cm}^{2} \mathrm{~s}^{-1}\right), \\
D_{f} & =\text { effective diffusion coefficient within the } \mathrm{UZ} \text { fracture cell }\left(\mathrm{cm}^{2} \mathrm{~s}^{-1}\right), \\
D_{m} & =\text { effective diffusion coefficient within the } \mathrm{UZ} \text { matrix cell }\left(\mathrm{cm}^{2} \mathrm{~s}^{-1}\right), \\
A_{I / U Z} & =\text { diffusive area between the invert and } \mathrm{UZ} \text { cells }\left(\mathrm{m}^{2}\right), \\
L_{I} & =\text { diffusive length within the invert cell }(\mathrm{m}), \\
L_{f} & =\text { diffusive length within the } \mathrm{UZ} \text { fracture cell }(\mathrm{m}), \\
L_{m} & =\text { diffusive length within the } \mathrm{UZ} \text { matrix cell }(\mathrm{m})=L_{f}, \\
C_{i I} & =\text { concentration of radionuclide species } i \text { in the invert cell }\left(\mathrm{kg} i \mathrm{~m}^{-3}\right), \\
C_{i f} & =\text { concentration of radionuclide species } i \text { in the } \mathrm{UZ} \text { fracture cell }\left(\mathrm{kg} i \mathrm{~m}^{-3}\right), \\
C_{i m} & =\text { concentration of radionuclide species } i \text { in the } \mathrm{UZ} \text { matrix cell }\left(\mathrm{kg} i \mathrm{~m}^{-3}\right), \\
C_{i I / U Z} & =\text { concentration of radionuclide species } i \text { at the interface between the invert } \\
& \text { and } \mathrm{UZ} \text { cells }\left(\mathrm{kg} i \mathrm{~m}^{-3}\right),
\end{array}
$$

and the $\hat{D}=\frac{\phi S_{w} D A}{L}$ are respective diffusive conductances $\left(\mathrm{cm}^{3} \mathrm{~s}^{-1}\right)$. 
The flux continuity at the interface requires:

$$
F_{i I}=F_{i f}+F_{i m}
$$

From the flux continuity, the interface concentration of radionuclide species $i$ is determined as a function of the diffusive parameters and the cell concentrations as:

$$
C_{i I / U Z}=\frac{\hat{D}_{I} C_{i I}+\hat{D}_{f} C_{i f}+\hat{D}_{m} C_{i m}}{\hat{D}_{I}+\hat{D}_{f}+\hat{D}_{m}} .
$$

This provides the invert intergranular and intragranular diffusive fluxes of radionuclide species $i$, respectively, as:

$$
\begin{gathered}
F_{i f}=\frac{\hat{D}_{I} \hat{D}_{f}}{\hat{D}_{I}+\hat{D}_{f}+\hat{D}_{m}}\left(C_{i I}-C_{i f}\right)+\frac{\hat{D}_{f} \hat{D}_{m}}{\hat{D}_{I}+\hat{D}_{f}+\hat{D}_{m}}\left(C_{i m}-C_{i f}\right) \\
F_{i m}=\frac{\hat{D}_{I} \hat{D}_{m}}{\hat{D}_{I}+\hat{D}_{f}+\hat{D}_{m}}\left(C_{i I}-C_{i m}\right)-\frac{\hat{D}_{f} \hat{D}_{m}}{\hat{D}_{I}+\hat{D}_{f}+\hat{D}_{m}}\left(C_{i m}-C_{i f}\right) .
\end{gathered}
$$

The expression for the diffusive flux of radionuclide species $i$ from the invert cell to the UZ fracture cell can be expressed as a diffusive conductance multiplied by a concentration difference of radionuclide species $i$ between the invert cell and the UZ fracture cell plus a corrective flux between the UZ fracture and matrix cells. Similarly, the expression for the diffusive flux from the invert to the UZ matrix cell is expressed as a diffusive flux between the invert and the UZ matrix cell minus the same corrective flux between the UZ cells. The corrective flux term accounts for coupling among the invert cell and UZ fracture and matrix cells, as the following explains. The flux to both UZ cells should depend on the diffusive properties in the invert cell and the two UZ cells, together with the concentrations in these three cells. Therefore, the flux to the UZ fracture cell cannot be expressed only in terms of the concentration drawdown between the invert cell and the UZ fracture cell. The corrective term includes the dependence of the UZ fracture flux on the concentration of radionuclide species $i$ in the UZ matrix cell due to the requirement that the sum of the two UZ continua receive exactly the flux leaving the invert. The corrective flux term is not a true flux expression between the two UZ cells, since the diffusive conductance coefficient is dependent on the diffusive area between the invert and the UZ, and the diffusive lengths are the lengths with respect to flow from the invert cell to the UZ cells. The model also explicitly includes diffusion between the UZ fracture and matrix continua, as shown in Figure 6.5-4. 
The UZ fluxes result in defining three diffusive conductances from the flux expressions:

$$
\begin{gathered}
\hat{D}_{I f}\left(C_{i I}-C_{i f}\right)=\frac{\hat{D}_{I} \hat{D}_{f}}{\hat{D}_{I}+\hat{D}_{f}+\hat{D}_{m}}\left(C_{i I}-C_{i f}\right), \\
\hat{D}_{I m}\left(C_{i I}-C_{i m}\right)=\frac{\hat{D}_{I} \hat{D}_{m}}{\hat{D}_{I}+\hat{D}_{f}+\hat{D}_{m}}\left(C_{i I}-C_{i m}\right), \\
\hat{D}_{m f}\left(C_{i m}-C_{i f}\right)=\frac{\hat{D}_{m} \hat{D}_{f}}{\hat{D}_{I}+\hat{D}_{f}+\hat{D}_{m}}\left(C_{i m}-C_{i f}\right),
\end{gathered}
$$

where

$$
\begin{aligned}
\hat{D}_{I f}= & \text { effective diffusive conductance between invert cell and UZ fracture cell } \\
& \left(\mathrm{cm}^{3} \mathrm{~s}^{-1}\right) ; \\
\hat{D}_{I m} & \text { effective diffusive conductance between invert cell and UZ matrix cell } \\
& \left(\mathrm{cm}^{3} \mathrm{~s}^{-1}\right) ; \\
= & \text { effective diffusive conductance between UZ fracture and matrix cells } \\
\hat{D}_{m f} & \left(\mathrm{~cm}^{3} \mathrm{~s}^{-1}\right) .
\end{aligned}
$$

In order to accommodate the GoldSim representation of diffusive conductance as a two-term expression, the diffusive conductances of radionuclide species $i$ are written as:

$$
\begin{aligned}
& \hat{D}_{I f}=\frac{1}{\left(\phi S_{w} D A\right)_{I}\left[\frac{L_{I}}{\left(\phi S_{w} D\right)_{f}+\left(\phi S_{w} D\right)_{m}}\right]}+\frac{L_{f}}{\left(\phi S_{w} D A\right)_{f}}, \\
& \hat{D}_{I m}=\frac{1}{\left(\phi S_{w} D A\right)_{I}\left[\frac{L_{I}}{\left(\phi S_{w} D\right)_{f}+\left(\phi S_{w} D\right)_{m}}\right]}+\frac{L_{m}}{\left(\phi S_{w} D A\right)_{m}}, \\
& \hat{D}_{m f}=\frac{1}{\left(\phi S_{w} D A\right)_{f}\left[\frac{L_{f}\left(\phi S_{w} D\right)_{m}}{L_{I}\left(\phi S_{w} D\right)_{m}+L_{m}\left(\phi S_{w} D\right)_{I}}\right]}+\frac{L_{m}}{\left(\phi S_{w} D A\right)_{m}}
\end{aligned}
$$

Although the above approach is rigorous, it is complex and difficult to implement in the TSPA-LA model. A second approach that is easier to understand and simpler to implement, 
while providing the same results as the above approach, is presented here and is implemented in TSPA-LA. This approach requires introduction of an interface cell, located between the invert cell and the UZ cells. This interface cell provides an approximate interface concentration and the resulting flux split at the invert-to-UZ cell interface. The interface cell is conceptualized as a very thin slice of the invert cell. This implies the interface cell takes on the invert diffusive properties, with the exception of diffusive length. Let the diffusive length within the interface cell be some small fraction (a scale factor) of the invert diffusive length, say, Interface_Scale_Factor $=10^{-6}$ :

$$
L_{I-i n t}=10^{-6} L_{I}
$$

As in Equation 6.5.3.5-7, the diffusive conductance between the invert cell and the invert interface cell is calculated as the harmonic average:

$$
\hat{D}_{I / I-i n t}=\frac{1}{\frac{L_{I}}{\left(\phi S_{w} D A\right)_{I}}+\frac{L_{I-i n t}}{\left(\phi S_{w} D A\right)_{I-i n t}}} .
$$

For diffusion between the interface cell and the UZ fracture and matrix cells, the diffusive conductances of radionuclide species $i$ are, respectively,

$$
\begin{aligned}
\hat{D}_{I-i n t / f}= & \frac{1}{\frac{L_{I-i n t}}{\left(\phi S_{w} D A\right)_{I-i n t}}+\frac{L_{U Z}}{\left(\phi S_{w} D A\right)_{f}}}, \\
\hat{D}_{I-i n t / m}= & \frac{1}{\frac{L_{I-i n t}}{\left(\phi S_{w} D A\right)_{I-i n t}}+\frac{L_{U Z}}{\left(\phi S_{w} D A\right)_{m}}} .
\end{aligned}
$$

The interface cell concentration of radionuclide species $i$ is computed as part of the cell network solution. Because the transport mass balance equations conserve mass, the mass flux leaving the interface cell must equal the sum of the mass fluxes entering the two UZ cells. The solution provides the flux continuity across the interface between the invert interface cell and UZ cells. This formulation expects the flux exiting the invert cell (or entering the interface cell) is approximately equal to the flux exiting the interface cell. This approximation is dependent on the diffusive length within the interface cell. The error in this approximate solution approaches zero as the diffusive length of the interface cell approaches zero.

\subsubsection{EBS-UZ Boundary Condition Implementation in TSPA-LA}

For TSPA-LA, a semi-infinite zero-concentration boundary condition is used for the EBS-UZ interface. This is approximated by applying an effective zero-concentration boundary at approximately three drift diameters below the invert-UZ boundary into the UZ. In an alternative approach, a zero-concentration boundary condition can be used at the interface between the invert and the UZ, which will result in an unrealistically high diffusive gradient through the 
invert. By moving the zero-concentration boundary some distance below the invert, a more realistic diffusive gradient through the invert is achieved.

In the EBS-UZ interface model, the near-field UZ is modeled as a dual continuum of overlapping UZ-matrix and UZ-fracture media. This approach is consistent with the dual-permeability modeling approach used by the UZ transport model, as described in Particle Tracking Model and Abstraction of Transport Processes (BSC 2004 [DIRS 170041]). The matrix and fracture continua are represented in the EBS RT Abstraction by a two-dimensional vertical array of cells oriented parallel to a cross section of a drift and located immediately beneath a drift (Figure 6.5-4). This array consists of three columns or vertical zones, with each zone containing both a fracture cell and a matrix cell. The invert is in direct communication with the second or center zone of UZ matrix/fracture cells. Each zone is four layers deep in the vertical direction. Thus, the array consists of twelve pairs of matrix and fracture cells within the UZ. Laterally, each zone is one drift diameter wide(5.5 m; BSC 2004 [DIRS 169503]), with the middle zone centered beneath the drift, so that each layer of the array extends one drift diameter on either side of the drift. In the longitudinal direction of a drift, the length of the array is equal to the length of the waste package being modeled.

The thickness of the first (top) layer of cells is 10 percent greater than the average invert thickness $(0.597 \mathrm{~m}$; see Equation $6.5 .3 .3-5)$, or $0.6567 \mathrm{~m}$. The thickness of the second layer is double that of the first layer, or $1.3134 \mathrm{~m}$. The third and fourth layers are given an arbitrary thickness of $5 \mathrm{~m}$ and $10 \mathrm{~m}$, respectively. A "collector cell" is placed beneath the fourth layer and is given a very large, numerically infinite, water volume $\left(10^{10} \mathrm{~m}^{3}\right)$ to simulate an effective zero-concentration boundary. This collector cell acts as a sink for all the mass flow from the invert and UZ cells.

As depicted in Figure 6.5-4, each fracture cell interacts, via diffusive connection only, with the matrix cell of the same zone. The fracture cell also interacts via diffusive connection vertically with the fracture cell of underlying and overlying layers of the same zone. The matrix cell of each zone interacts via diffusive connection laterally with the matrix cells of adjacent zones and vertically with the matrix cell of underlying and overlying layers of the same zone. Radionuclides diffuse based on the concentration gradient between cells. Advection occurs downward only, from the fracture cell of one layer to the fracture cell of the underlying layer in the same zone, and from the matrix cell of one layer to the matrix cell of the underlying layer in the same zone; advection does not occur across zones. Each zone is spatially distinct. Each is one drift diameter in width. The only connection possible between left and right adjacent zones is by diffusion through the middle zone. 


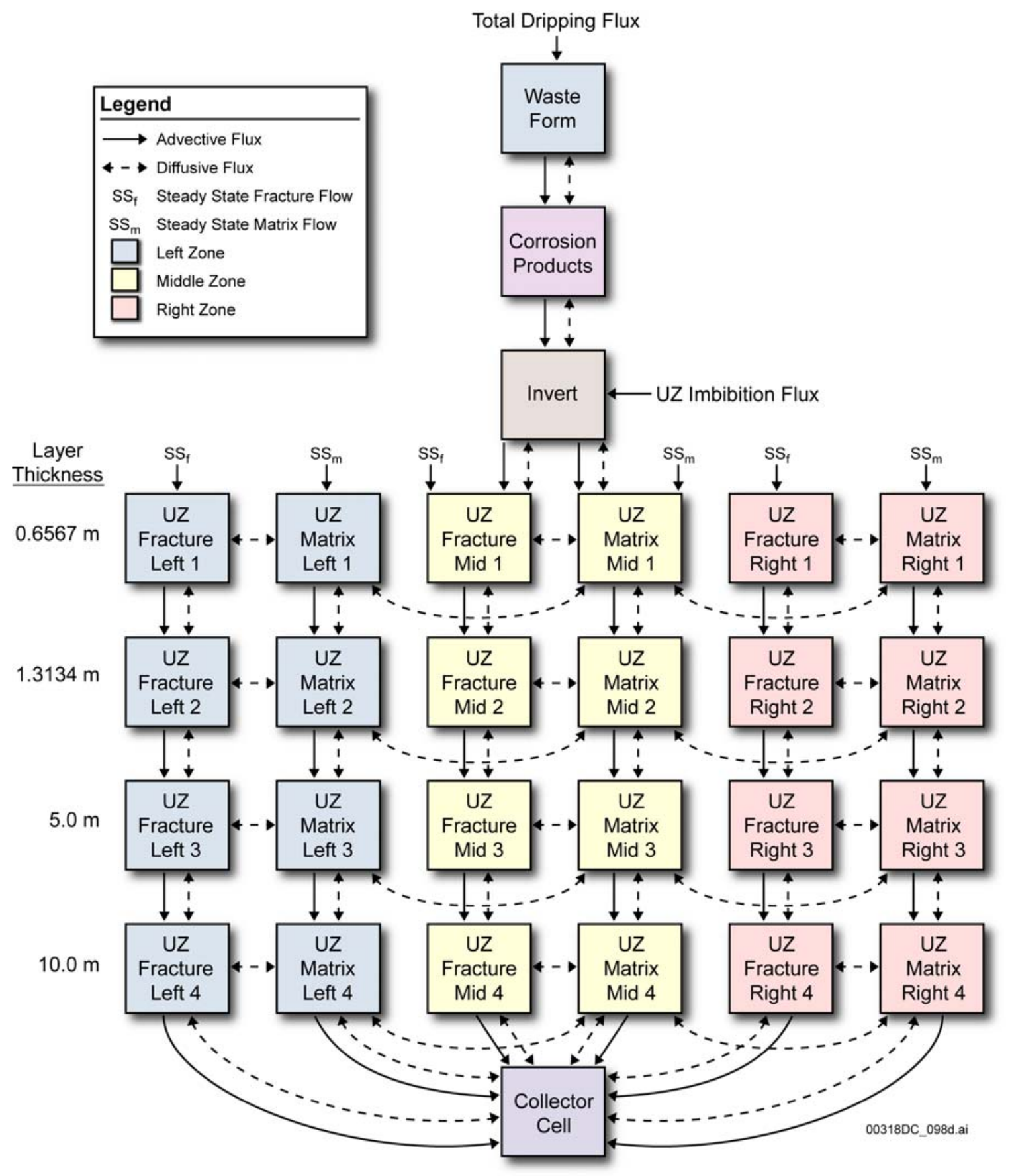

Figure 6.5-4. Computational Grid in the EBS-UZ Interface Model 
The mass flux from the invert flows into the top layer of the middle zone in the UZ. The portion of the advective flux from the invert that is attributable to the total dripping flux $\left(F_{1}\right)$ flows into the UZ fractures. The imbibition flux into the invert $\left(F_{7}\right)$ flows out of the invert into the UZ matrix. The diffusive flux from the invert can go into both UZ continua based on the concentration gradient and effective diffusion coefficient. The advective flux flowing through the UZ fracture cells in the middle zone is given by the greater of the advective flux out of the invert $\left(F_{1}\right)$ and the steady state $\mathrm{UZ}$ fracture flux. Because of the application of a flow focusing factor in the calculation of the total dripping flux $\left(F_{1}\right)$, the flux going into UZ fractures in the EBS-UZ interface model can be greater than the steady state UZ fracture flux. The advective flux in the two outer zones is given by the steady state UZ flow in each continuum at the repository horizon; the drift shadow effects are ignored in the transport calculation.

For the advective mass transport calculation shown in Equation 6.5.3.5-3, volumetric discharges for the fracture and matrix continua are needed. Since fracture and matrix percolation fluxes (described in Section 6.5.2 and provided by DTN: LB0307FMRADTRN.001 [DIRS 165451]) are given as specific discharge, the volumetric flux is calculated by multiplying the percolation flux for each continuum by the projected bulk area normal to the flux, where the projected area $A_{U Z}$ is calculated as:

$$
A_{U Z}=d_{D} L_{W P}
$$

where $d_{D}$ is the drift diameter $(\mathrm{m})$ and $L_{W P}$ is the length of a waste package (m). This area is used for the diffusive and advective flux calculations between UZ cells. For the calculation between the invert and UZ, the area $A_{I / U Z}$ given by Equation 6.5.3.3-4 $\left(A_{I / U Z}=w_{I} L_{W P}\right)$ is used.

The void volume for each continuum is computed by multiplying the bulk volume for each discretized zone in each layer (based on the geometry) by either the fracture porosity (fracture fraction) or matrix porosity. Similarly, the water volume is calculated by multiplying the void volume of each continuum by its respective saturation.

For diffusive mass transport, in the calculation shown in Equation 6.5.3.5-5, the effective diffusion coefficient for the matrix continuum is calculated based on Equation 2.5 in Reimus et al. (2002 [DIRS 163008], p. 2.25). This correlation (shown in Table 4.1-9) establishes a quantitative relationship between the porosity and permeability of a saturated rock matrix to the effective diffusion coefficient. This correlation may be extended for unsaturated conditions by using the water content as an equivalent parameter for porosity under saturated conditions and the unsaturated effective permeability for the saturated permeability (BSC 2004 [DIRS 170040], Equation 6-52). This extension to unsaturated conditions is appropriate because, for unsaturated flow, the character of the gas phase is not significant other than the space that it occupies. The gas phase could be replaced by solid (rock mineral) which would result in exact equivalence between the unsaturated water content and porosity and effective unsaturated permeability and permeability. The correlation is then:

$$
\log _{10} D_{m s}=-3.49+0.0138 \theta_{m}+0.165 \log _{10} k_{m e},
$$


where $D_{m s}$ is the effective UZ matrix diffusion coefficient $\left(\mathrm{cm}^{2} \mathrm{~s}^{-1}\right), \theta_{m}$ is the matrix water content (percent), and $k_{m e}$ is the matrix effective permeability $\left(\mathrm{m}^{2}\right)$ (BSC 2004 [DIRS 170040], Equation 6-57):

$$
k_{m e}=k_{r m} k_{m},
$$

where $k_{r m}$ is the relative permeability of unsaturated zone tuff matrix (dimensionless), which is a sampled parameter (Table 6.5-6), and $k_{m}$ is the intrinsic permeability of unsaturated zone tuff matrix $\left(\mathrm{m}^{2}\right)$ from Table 4.1-8. The value obtained for the effective UZ matrix diffusion coefficient is applied to the fracture diffusion coefficient as recommended by the Drift-Scale Radionuclide Transport (BSC 2004 [DIRS 170040], Section 6.4.5, p. 6-42). The sampling of the input parameters is described in Section 6.5.2.

The diffusive area between the fracture and matrix continua is computed by multiplying the bulk volume by the fracture interface area, which provides the connection area per unit bulk volume. This diffusive area is further reduced by the fracture-matrix interface reduction factor, given as $S_{e f}^{1+\gamma}$, where $S_{e f}$ is the effective fracture saturation, and $\gamma$ is the active fracture parameter (BSC 2004 [DIRS 169861]). The effective fracture saturation $\left(S_{\text {ef }}\right)$ is computed as:

$$
S_{e f}=\frac{S_{w f}-S_{w f r}}{1-S_{w f r}},
$$

where $S_{w f}$ is the fracture water saturation, and $S_{w f r}$ is the fracture residual saturation.

The mass flux of radionuclides from the invert domain to the dual continuum UZ, computed at the boundary of the EBS-UZ interface (between the invert cell and the adjacent UZ matrix and fracture cells), is passed to the UZ transport model for TSPA-LA calculations as described in Particle Tracking Model and Abstraction of Transport Processes (BSC 2004 [DIRS 170041]). In addition to the total mass flux, the relative fraction of the mass going into each of the fracture and the matrix cells at the EBS-UZ boundary is required by the UZ transport model. This fracture-matrix partitioning of mass is calculated on the basis of the mass fraction going into the fracture continuum (compared to the matrix continuum) from the invert domain in the EBS-UZ interface model. This partitioning is time dependent and captures the temporal processes active in the EBS, such as varying radionuclide concentrations in the waste form, corrosion products, and invert domains, and the changing water flux through various subcomponents of the EBS. Furthermore, this partitioning is computed by solving the mass transport equations for the EBS and part of the UZ as a coupled system with appropriate boundary conditions and adopting a modeling approach using the dual continuum invert model saturation results presented in Multiscale Thermohydrologic Model (BSC 2005 [DIRS 173944]), and the dual continuum transport model for the UZ (BSC 2004 [DIRS 170041]).

Sorption of radionuclides to the UZ matrix continuum is modeled by applying the devitrified tuff $K_{d}$ values from the $\mathrm{UZ}$ submodel. For sorption calculations, the mass of $\mathrm{UZ}$ matrix continuum is 
calculated as: $V_{b} \rho_{b}\left(1-\phi_{f}\right)$, where $V_{b}$ is the bulk volume of the matrix cell considered $\left(\mathrm{m}^{3}\right), \phi_{f}$ is the fracture porosity (fraction), and $\rho_{b m}$ is the dry bulk density of TSw35 matrix $\left(\mathrm{kg} \mathrm{m}^{-3}\right)$.

All three types of colloids are transported from the invert to the UZ cells. Groundwater colloids are present in all four layers. The iron oxyhydroxide and waste form colloids with reversibly sorbed radionuclides are modeled to be present in only the first two layers of the middle column, making the groundwater colloid the only type of colloid available for far-field transport, consistent with colloid-facilitated transport modeled in the UZ as described in Particle Tracking Model and Abstraction of Transport Processes (BSC 2004 [DIRS 170041]).

\subsection{MODEL FORMULATION FOR ALTERNATIVE CONCEPTUAL MODELS}

\subsubsection{Bathtub Flow Model}

The conceptual model for the TSPA-LA is based on the presence of continuous flow paths through the patches and stress corrosion cracks that penetrate the waste package. More specifically, the TSPA-LA model conceptualizes that vertical flow of seepage into the waste package, through the waste form and out of the waste package is not impeded by the location of patches and stress corrosion cracks on the surface of the waste package. There is no long-term build-up and retention of liquid within the waste package for flow and transport. There is also no resistance to the flow through the waste form. The TSPA-LA approach attempts to maximize the immediate release and mobilization of radionuclides into the local groundwater environment. This approach is referred to as the "flow through" geometry.

An alternative conceptual model to the "flow through" geometry is the "bathtub" geometry (Mohanty et al. 1996 [DIRS 130419]). The bathtub geometry allows seepage to collect within the waste package before being released to the EBS. In theory, a bathtub geometry could result in the sudden release of a large pulse of radionuclides when a package overflows with liquid or when a second patch appears abruptly beneath the water line.

The "bathtub" effect would be most important during the period when only a few patches or cracks have penetrated the drip shield and waste package. In this situation, there may be penetrations through the top of the waste package while the bottom surface remains intact, leading to retention of liquid. At later times, the presence of multiple penetrations makes a "flow-through" geometry the more likely configuration.

The response of the bathtub geometry is evaluated for a primary case and for three secondary cases. The primary case includes consideration of two limiting conditions on radionuclide releases: dissolution rate limited and solubility limited. Tc is typical of dissolution rate limited radionuclides. The Tc released due to waste dissolution can always be dissolved in the available water because the solubility limit of Tc is high (BSC 2005 [DIRS 174566], Section 6.14). Np is typical of the solubility limited type of radionuclide, where the release of $\mathrm{Np}$ from dissolution is limited by its low solubility (BSC 2005 [DIRS 174566], Section 6.6).

The results for the primary case are based on a closed form analytic solution with constant values of inflow rate, dissolution rate, and solubility. The three secondary cases consider a step change in inflow rate, such as would occur from a climatic change, a step change in water chemistry, or 
a step change in flow geometry, as would occur if a patch suddenly appeared beneath the waterline. The basic geometry and flow pattern for the primary bathtub model is shown in Figure 6.6-1 (from Mohanty et al. 1996 [DIRS 130419], Figure 2-7); $q_{\text {in }}$ is identical to $F_{4}$ and in Section 6.3.1.1.

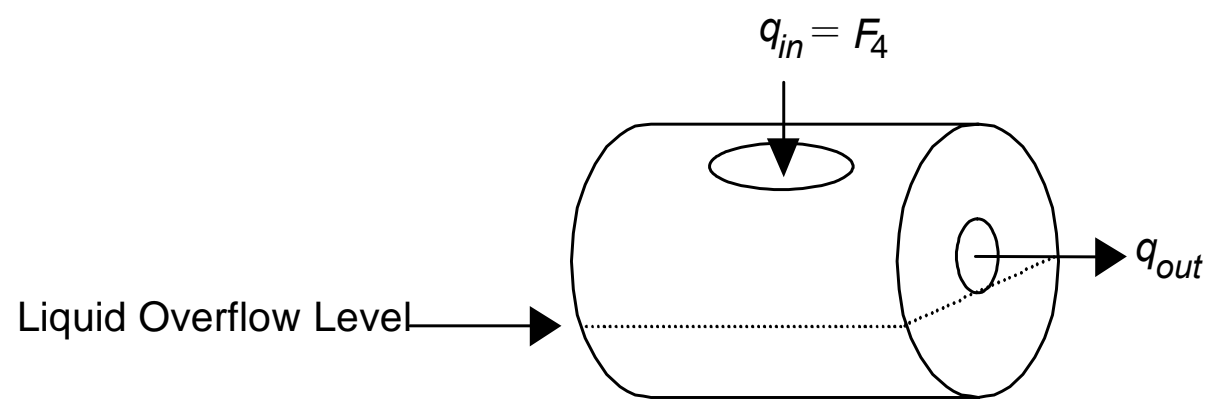

Figure 6.6-1. Schematic of the Bathtub Geometry for the Waste Package

\subsubsection{Primary Case}

\subsection{Dissolution-Rate-Limited Radionuclide}

In this case, the concentration of radionuclides is limited by the rate of dissolution. Consider the system shown in Figure 6.6-1, with a constant inflow rate, $q_{i n}$, and let $V_{t u b}$ be the total volume of liquid that can be retained within the waste package before it overflows. The response of the waste package is a two step process. During Step 1, the package is filling with liquid and the outflow rate, $q_{\text {out }}$, is zero. This condition continues until the waste package fills with liquid at a time, $t_{\text {fill }}$, given by $V_{t u b} / q_{\text {in }}$. Step 2 occurs after time $t_{\text {fill }}$; the amount of liquid inside the waste package remains constant, and $q_{\text {out }}=q_{\text {in }}$. This is a steady state condition, consistent with the assumption that $q_{\text {in }}$ is constant and that liquid does not continue to accumulate within the package. The following analysis also supposes there is complete contact between the liquid and the waste form within the waste package, and that the dissolution rate is constant.

During Step 1, for time $t$ such that $0<t<t_{\text {fill }}$, the dissolution of a radioisotope into the water inside the waste package can be represented as:

$$
\dot{m}_{i}=r_{s} \omega_{i}
$$

where

$\dot{m}_{i}=$ the rate of release of radionuclide into the liquid $\left(\mathrm{kg} \mathrm{s}^{-1}\right)$

$r_{s}=$ the dissolution rate of the waste form $\left(\mathrm{kg} \mathrm{s}^{-1}\right)$

$\omega_{i}=$ the mass fraction of radioisotope $i$ released per unit mass of waste form (dimensionless); $\omega_{i}$ is less than one for a waste form with multiple radionuclides. 
During the fill period $q_{\text {out }}$ is zero, so the mass, $m_{i}(t)$, of radioisotope dissolved within the liquid in the waste package at time $t$ is given by:

$$
m_{i}(t)=r_{s} \omega_{i} t
$$

because $r_{s}$ and $\omega_{i}$ are constant. Similarly, the volume of liquid in the waste package at time $t$, $V(t)$, is given by:

$$
V(t)=q_{\text {in }} t
$$

so the concentration of dissolved isotope $i$ in the waste package, $C_{i}(t)$, is

$$
C_{i}(t)=\frac{m_{i}(t)}{V(t)}=\frac{r_{s} \omega_{i} t}{q_{\text {in }} t}=\frac{r_{s} \omega_{i}}{q_{\text {in }}} .
$$

The concentration, $C_{i}(t)$, is constant during the fill phase because the values of $r_{s}, \omega_{i}$, and $q_{\text {in }}$ are chosen to be constant. This condition is appropriate because the dissolved mass, $m_{i}$, and the volume of liquid, $V$, are linear functions of the time (and initially both are zero), so their ratio remains constant.

The result in Equation 6.6.1.1.1-4 holds for each dissolution-rate-limited radioisotope $i$ in the waste form, although the numerical value of $C_{i}(t)$ differs because the mass fraction, $\omega_{i}$, is different for each isotope.

During Step 2, when $t>t_{\text {fill }}$, the radioisotope mass within the waste package is a balance between the dissolution of radioisotope into the groundwater within the waste package and the loss of radioisotope due to outflow from the waste package:

$$
\dot{m}_{i}=r_{s} \omega_{i}-q_{\text {out }} C_{i}(t)
$$

Because the water inflow rate, waste form solubility, and mass fraction of radioisotope $i$ all remain constant, the concentration $C_{i}(t)$ remains constant even when the solution is removed at a rate $q_{\text {out }}$. Therefore, at $t>t_{\text {fill }}$, the net rate of radionuclide release into the water inside the waste package is zero (i.e., the dissolution rate is exactly offset by the outflow rate):

$$
\dot{m}_{i}=r_{s} \omega_{i}-q_{\text {out }} C_{i}(t)=0
$$

For constant $q_{\text {in }}$, with $q_{\text {out }}=q_{\text {in }}$,

$$
C_{i}(t)=\frac{r_{s} \omega_{i}}{q_{\text {in }}} .
$$


The dissolved mass in the waste package is constant for $t>t_{\text {fill }}$. In addition, the concentration of dissolved radionuclide is constant for all time $t>0$ (until all of the waste form is dissolved), as shown by Equations 6.6.1.1.1-4 and 6.6.1.1.1-7. These results are reasonable because the waste package is in steady state for $t>t_{\text {fill }}$. This means that the inflow rate equals the outflow rate and that any loss of dissolved radionuclide mass in the outflow from the waste package is exactly balanced by the addition of dissolved radionuclide mass from dissolution of the waste form.

The response for the comparable flow-through model has the same radionuclide concentration, $C_{i}(t)$, and the same release flux, given by $C_{i}(t) q_{\text {out }}$, as the bathtub geometry. The sole difference between the flow-through and bathtub models is that the flux from the flow-through model starts from $t=0$ while the flux from the bathtub model is zero until time $t_{\text {fill }}$. The bathtub model introduces a delay in the response but does not change the concentration in the package or the mass flux out of the package.

Therefore, for the dissolution-rate-limited case, the flow-through model is bounding relative to the bathtub model for radionuclide releases from the waste package. The bathtub analysis considers advective transport with no sorption of radionuclides, whereas the current EBS transport model includes sorption onto stationary corrosion products (retardation in the waste package) as well as colloid-facilitated transport. In this bathtub analysis of alternative conceptual models, sorption onto stationary corrosion products inside the waste package would effectively reduce the dissolution rate. Since that rate is still constant and the same for both the flow-through and bathtub models, sorption would affect the concentrations of radionuclides in the outflow, but would have no impact on the conclusion that the bathtub model introduces a delay in releases compared to the flow-through model. Sorption onto colloids would have the opposite net effect of increasing the effective solubility and again would have no impact on the conclusions regarding release delay.

\subsection{Solubility-Limited Radionuclide}

The response for a solubility-limited radionuclide, in which the solubility limit of the radionuclide is instantaneous achieved, is similar to that for a dissolution-rate-limited radionuclide, in the sense that the bathtub model delays the release from the waste package but does not change the dose rate.

During Step 1, $0<t<t_{\text {fill }}$, the amount of radionuclide dissolved in the groundwater in the waste package can be represented as:

$$
\dot{m}_{i}=C_{s i} q_{i n},
$$

where $C_{s i}$ is the solubility limit of the radionuclide. If the groundwater chemistry is constant, the solubility is constant and the mass, $m_{i}$, of radioisotope retained in the waste package at time $t$ is:

$$
m_{i}(t)=C_{s i} q_{i n} t .
$$


The volume of liquid in the waste package at time $t, V(t)$, is given by:

$$
V(t)=q_{\text {in }} t
$$

so that the concentration of dissolved isotope in the waste package is:

$$
C_{i}(t)=\frac{m_{i}(t)}{V(t)}=\frac{C_{s i} q_{i n} t}{q_{i n} t}=C_{s i} .
$$

The concentration is constant during the fill phase and equal to the solubility limit, as would be expected. This is true for each radionuclide in the system, although the numerical values of the solubility limit vary.

For $t>t_{\text {fill }}$, the mass balance within the waste package is a steady state condition given by:

$$
\dot{m}_{i}=C_{s i} q_{\text {in }}-C_{i}(t) q_{\text {out }}=C_{s i} q_{\text {in }}-\frac{m_{i}(t)}{V_{\text {tub }}} q_{\text {out }}=0
$$

The solution to Equation 6.6.1.1.2-5 with $q_{\text {out }}=q_{\text {in }}$ is:

$$
m_{i}(t)=C_{s i} V_{t u b}
$$

with

$$
C_{i}(t)=C_{s i}
$$

Again the dissolved mass in the waste package is constant for $t>t_{\text {fill }}$ (until all of the waste form is dissolved) and the concentration of dissolved radionuclide is constant at the solubility limit for all times $t>0$.

The comparable flow-through model has the same radionuclide concentration, $C_{s i}$, and the same release flux, given by $C_{s i} q_{\text {out }}$, as the bathtub geometry. The sole difference is that the flux from the flow-through model starts from $t=0$ while the flux from the bathtub model is zero until time $t_{\text {fill }}$. The bathtub model introduces a delay in the response but does not change the dose rate. Therefore, the flow-through model is again bounding relative to the bathtub model because radionuclides are released with no delay time to the EBS.

\subsubsection{Secondary Cases}

The secondary cases evaluate the response of the bathtub model when changes occur in the groundwater inflow rate, in inflow chemistry, or in the flow geometry. 


\subsection{Change in Inflow Rate}

The response of a bathtub model to a change in inflow rate differs for a solubility-limited or a dissolution-rate-limited radionuclide. The solubility-limited case is simpler because of chemical equilibrium and is discussed first.

Consider a step change in inflow rate after the bathtub has filled for a solubility-limited radionuclide. Since kinetic effects are ignored, the chemical system is always at equilibrium and the concentration within the waste package remains unchanged at the solubility limit. The only change in the system is that the radionuclide mass flux out of the waste package changes instantaneously from $C_{i} q_{\text {out }}$ to $C_{i} q_{\text {out new }}$. This response is exactly the same as it would be for the flow-through model, so the response of the bathtub model is identical to that for the flow-through model.

Now consider a step change in inflow rate after the bathtub has filled for a dissolution-rate-limited radionuclide. In this case, the mass released per unit time remains constant because the dissolution rate remains constant, but the radionuclide concentration comes to a new equilibrium value. This new equilibrium value can be determined by Equation 6.6.1.1.1-7, with the product of concentration and liquid inflow remaining constant:

$$
C_{i, \text { new }} q_{\text {in, new }}=C_{i, \text { old }} q_{\text {in,old }}=r_{s} \omega_{i}
$$

If the inflow rate decreases, the final concentration increases because the product of concentration and liquid inflow remains constant. A flow-through model has an instantaneous increase in concentration, whereas the bathtub model shows an exponential growth to the new concentration. Thus, the flow-through model is bounding for concentration released into the EBS because there is no delay in changing to the new increased radionuclide concentration.

The exponential growth to the new concentration can be seen as follows. The replacement of "old" inflow with concentration $C_{i, \text { old }}$ with "new" inflow with concentration $C_{i, \text { new }}$ is represented through a parameter, $\beta$, the volume fraction of old inflow to $V_{t u b}$, the total liquid volume in the bathtub. The rate of change of the volume of old inflow, $V_{\text {old }}$, is given by:

$$
\frac{d V_{\text {old }}}{d t}=-\beta q_{\text {out new }}=-\beta q_{\text {in, new }} \text {. }
$$

Equation 6.6.1.2.1-2 represents the loss of old inflow through outflow, with the factor $\beta$ representing the (decreasing) volume fraction of old inflow that is lost. By definition,

$$
\beta \equiv \frac{V_{\text {old }}}{V_{\text {tub }}}
$$


Substituting this definition into the left-hand side of Equation 6.6.1.2.1-2 gives:

$$
\frac{d \beta}{d t}=-\frac{q_{\text {in, new }}}{V_{\text {tub }}} \beta .
$$

The solution to Equation 6.6.1.2.1-4 with initial condition $\beta=1$ at $t=0$ is:

$$
\beta=\exp \left(-\frac{q_{\text {in,new }}}{V_{\text {tub }}} t\right),
$$

which corresponds to an exponential decay of $C_{i}$ from $C_{i, \text { old }}$ to $C_{i, n e w}$.

If the inflow rate were to increase, the concentration would decrease. In a flow-through model, the concentration would instantaneously decrease, whereas in the bathtub model, the concentration would exponentially relax to the new concentration. The flow-through model is then not bounding for concentration released into the EBS. The mass of radionuclide mobilized is identical, as implied by Equation 6.6.1.2.1-1, but the dissolved concentration varies with the amount of fluid flowing through the system. However, the TSPA-LA model passes mass to the unsaturated zone, rather than concentration, so the difference between the flow through model and the bathtub model for this case is not critical to performance.

Finally, a change in inflow rate during the initial period, when the bathtub is filling, only affects the value of $t_{\text {fill }}$ and hence the delay until the bathtub fills, after which it behaves as described in Section 6.6.1.1.

In summary, the response of the bathtub model to a change in inflow rate is identical to that of the flow-through model for solubility-limited radionuclides. For dissolution-rate-limited radionuclides, the response of the bathtub model is less bounding than the flow-through model when the inflow rate decreases (and concentration increases). If the inflow rate increases (resulting in a decrease in the outflow concentration of radionuclides), the bathtub model is more bounding than the flow-through model for dissolution-rate-limited radionuclides.

\subsection{Change in Inflow Chemistry}

Consider a step change in inflow chemistry after the bathtub has filled. Initially, there will be minor changes in concentration within the bathtub because the bulk of the water retains the original inflow composition. Eventually the "old" groundwater is flushed out and replaced with the "new" inflow, resulting in new concentrations within the bathtub. 
As in the preceding section where a change in inflow rate was examined, the replacement of old with new inflow can be represented through a parameter $\beta$, representing the volume fraction of old inflow in $V_{t u b}$, the total liquid volume in the bathtub. The rates of change of the volumes of old and new inflow are given by:

$$
\frac{d V_{\text {old }}}{d t}=-\beta q_{\text {out }}
$$

and

$$
\frac{d V_{\text {new }}}{d t}=q_{\text {in }}-(1-\beta) q_{\text {out }}
$$

where $V_{\text {old }}$ and $V_{\text {new }}$ represent the volumes of inflow with the old and new chemistries, respectively. Equation 6.6.1.2.2-1 represents the loss of old inflow through outflow, with the factor $\beta$ representing the volume fraction of old inflow that is lost. Equation 6.6.1.2.2-2 represents the addition of new inflow and its partial loss through outflow. Remembering that $q_{\text {out }}=q_{\text {in }}$ because of the steady state assumption, it follows that:

$$
\frac{d V_{\text {old }}}{d t}=-\beta q_{\text {in }} ; \quad \frac{d V_{\text {new }}}{d t}=+\beta q_{\text {in }} .
$$

By definition:

$$
\beta \equiv \frac{V_{\text {old }}}{V_{\text {tub }}}
$$

Substituting this definition into the left-hand equation in 6.6.1.2.2-3, it follows that:

$$
\frac{d \beta}{d t}=-\frac{q_{\text {in }}}{V_{\text {tub }}} \beta=-\frac{1}{t_{\text {fill }}} \beta .
$$

The solution to Equation 6.6.1.2.2-5 with the initial condition $\beta(0)=1$ is given by:

$$
\beta(t)=e^{-\frac{t}{t_{\text {fil }}}}
$$

It follows that the old and new volumes of inflow are given by:

$$
V_{\text {old }}=V_{\text {tub }} e^{-\frac{t}{t_{\text {fill }}}}
$$


and:

$$
V_{n e w}=V_{t u b}\left(1-e^{-\frac{t}{t_{\text {fil }}}}\right)
$$

These equations say that the volume fraction of inflow with the old chemistry decays exponentially with the characteristic time $t_{\text {fill }}$. Alternatively, the volume fraction of new inflow increases to 1.0 with a characteristic time of $t_{\text {fill }}$ for the exponential growth given by Equation 6.6.1.2.2-8.

The impact of changing inflow chemistry on dissolution rate or solubility is much more difficult to predict analytically because chemical interactions are nonlinear. More specifically, the $\mathrm{pH}$ of mixtures of inflows is not proportional to $\beta$ because the $\mathrm{pH}$ scale is proportional to the $\log$ of the hydrogen ion concentration and inherently nonlinear and because potential chemical interactions in mixtures, such as buffering, produce a nonlinear response. In addition, solubility and dissolution rate are often complex nonlinear functions of the $\mathrm{pH}$.

Nonlinear response makes it particularly difficult to predict the time-dependent response for solubility; however, because the starting state and the ending state, for $t>>t_{\text {fill }}$, are well defined, the evolution can be approximated to first order by:

$$
C_{s i}(t) \approx C_{s i, o l d} e^{-\left(\frac{t}{t_{\text {fill }}}\right)}+C_{\text {si,new }}\left(1-e^{-\left(\frac{t}{t_{\text {fil }}}\right)}\right)
$$

Consider the response when $C_{s i, n e w}>C_{s i, o l d}$. This condition can easily occur for the actinides, where solubility increases by several orders of magnitude as $\mathrm{pH}$ changes from between 7 and 8 to a value below 6 or above 10. In the limit of large $C_{s i, n e w}$, Equation 6.6.1.2.2-9 becomes:

$$
\left(C_{s i, \text { new }}>>C_{s i, \text { old }}\right): \quad C_{s i}(t) \approx C_{\text {si,new }}\left(1-e^{-\left(\frac{t}{t_{\text {fll }}}\right)}\right) \text {. }
$$

In effect the initial solubility is negligible compared to $C_{s i, n e w}$, and solubility at late times increases to $C_{s i, n e w}$ from below. Alternatively, if $C_{s i, n e w}<<C_{s i, \text { old }}$,

$$
\left(C_{s i, \text { new }}<<C_{s i, \text { old }}\right): \quad C_{s i}(t) \approx C_{s i, \text { old }} e^{-\left(\frac{t}{t_{\text {fil }}}\right)}+C_{\text {si,new }} \text {. }
$$

Here the solubility decays towards a much smaller value in the new inflow mixture. 
While the details of the time-dependent behavior are only approximated, the starting and ending states must be accurate and Equations 6.6.1.2.2-10 and 6.6.1.2.2-11 provide a simplified transition from one chemical regime to another. The dissolution rate could replace solubility in Equations 6.6.1.2.2-9 through 6.6.1.2.2-11, and the same general conclusions would hold.

In summary, the response of the bathtub model to a change in inflow chemistry is slower than that of a flow-through model, where the solubility or dissolution rate changes abruptly with a step change in inflow chemistry. The bathtub dampens or delays the response to a change in inflow chemistry over a time scale on the order of $t_{\text {fill }}$ to $7 t_{\text {fill }}$. The upper estimate of $7 t_{\text {fill }}$ corresponds to an exponential factor of $e^{-7}$ or 0.0009, at which point Equation 6.6.1.2.2-11 has reached an asymptote of $C_{s i, n e w}$. The analytic models cannot predict the precise time dependence because of the nonlinear effects of mixing on $\mathrm{pH}$ and of $\mathrm{pH}$ on solubility and dissolution rate.

The flow-through model overestimates radionuclide releases compared to the bathtub model when solubility increases because the bathtub geometry delays the increase in radionuclide concentrations and mass fluxes from the waste package to the EBS. The case of increasing solubility or increasing dissolution rate is important because it will increase the peak dose rate. The fact that the flow-through model is not bounding when solubility or dissolution rate decreases is therefore of less importance for performance assessment and is of secondary importance in selecting the conceptual model for flow through the waste package.

\subsection{Change in Patch Geometry}

The geometry for the bathtub model allows seepage to collect within the waste package before being released to the EBS. In the primary model (Figure 6.6-1), the patch is positioned such that release is governed by the condition $q_{\text {out }}=q_{\text {in }}$ after the package fills with liquid.

As an alternative to the primary patch model, consider a waste package that does not have an existing (outflow) patch on the side of the package, but instead has a second patch open abruptly beneath the water line. While the radionuclide concentration within the waste package is unchanged by the alternative location, failure results in the sudden release of a larger pulse of radionuclide mass at the time the second patch opens. Mathematically, the flux of radionuclides leaving the waste package in the primary model, $F_{p r i}$, is given by:

$$
F_{\text {pri }}=C_{i} q_{\text {out }}=C_{i} q_{\text {in }}=C_{i} \frac{V_{\text {tub }}}{t_{\text {fill }}}
$$

and the flux of radionuclides leaving the waste package in the alternative model, $F_{a l t}$, is given by:

$$
F_{\text {alt }}=C_{i} \frac{V_{t u b}}{\Delta t}
$$

where $\Delta t$ is the time to empty the retained liquid through the second patch. In theory, it is possible that $\Delta t<<t_{\text {fill }}$, so that $F_{\text {alt }}>>F_{p r i}$. 
Equations 6.6.1.2.3-1 and 6.6.1.2.3-2 have the same value for radionuclide concentration, $C_{i}$, in the retained liquid because the chemistry of the groundwater is independent of patch location. Implicit in Equations 6.6.1.2.3-1 and 6.6.1.2.3-2 is that the second patch in the alternative conceptual model occurs after the volume of liquid in the waste package in the primary model has reached steady state.

The flow-through model produces an average release continuously, while the bathtub model with the alternative flow path produces zero release initially, followed by a high pulse that soon returns to the same flux as the flow-through model. In other words, the flow-through model represents a time average of the response of the bathtub model. From this viewpoint, the potential difference between $F_{\text {alt }}$ and $F_{p r i}$ is partly mitigated by the sorption and diffusion processes in the unsaturated and saturated zones. The potential difference between $F_{a l t}$ and $F_{p r i}$ is also small if the second patch appears shortly after the first penetration because there is less retained liquid.

This alternative can also be thought of as being equivalent to the appearance of additional penetrations in the waste package. This analogy is appropriate because additional penetrations in the waste package increase the inflow flux into the waste form, resulting in higher releases to the EBS. The main effect of the alternative patch geometry model is to generate the increase earlier. This is not considered a major difference because there is a wide range of variability in corrosion rates for the TSPA-LA model (BSC 2004 [DIRS 169996]). The effect of the alternative patch geometry model can then be reasonably considered to be captured within this variability.

The results and observations in this section (6.6.1.2.3) and throughout Section 6.6.1 are appropriate for the general boundary conditions considered here. In other words, this comparison is based on the full fluid flux into the waste package having access to all radioisotopes in the waste. The model implemented in TSPA-LA, in which radionuclides are mobilized in a mass of corrosion products around the fuel pellets, partly mitigates the differences discussed here. This mitigation occurs because a large fluid flux will not transport radionuclides at the solubility limit if the mass in solution is limited by the pore volume in a mass of corrosion products. The situation is then similar to that mentioned at the end of Section 6.6.1.2.1, where mass transfer to the unsaturated zone is the dominant issue, rather than dissolved concentration.

\subsubsection{Summary}

The response of the bathtub geometry has been evaluated for a primary case, with constant boundary conditions and material properties, and for three secondary cases. Analyses for the three secondary cases consider a step change in inflow rate, a step change in inflow chemistry, and a change in flow geometry as would occur if a patch suddenly appeared beneath the waterline. All cases include consideration of two types of radionuclide release mechanisms: dissolution-rate-limited and solubility-limited. The comparisons are based on closed form analytic solutions. 
The key conclusions from the evaluation follow:

- The bathtub model introduces a time delay in the release of radionuclides from the waste package to the EBS in comparison to the flow-through model for the primary case. The base case flow-through model overestimates releases of radionuclides in relation to the bathtub geometry for the primary case because there is no delay in release of radionuclides to the EBS.

- The response of the bathtub model to a step change in inflow rate (secondary case 1) is identical to the flow-through model for solubility-limited radionuclides. The response of the bathtub model for dissolution-rate-limited radionuclides is to delay the change in concentration and mass flux associated with the new inflow rate. The base case flow-through model overestimates releases of radionuclides with respect to the bathtub geometry for the case of decreasing inflow, when the concentration of radionuclide increases. The case of increasing radionuclide concentration is of primary interest from a performance or regulatory viewpoint since this case will result in greater releases.

- The response of the bathtub model to a step change in inflow chemistry (secondary case 2) is to delay the change in concentration and mass flux associated with the new inflow chemistry. Analytical models cannot define the exact time delay, which is sensitive to nonlinear chemical effects when inflows mix. Limiting cases, when solubility increases or decreases by several orders of magnitude, have been examined to define a first order approximation to the response of the chemical system.

The base case flow-through model overestimates releases of radionuclides relative to the bathtub geometry when solubility or dissolution rate increase with changing inflow chemistry. The flow-through model has an instantaneous change to the higher equilibrium value while the bathtub geometry delays the change as the initial inflow is flushed out of the waste package. Increases in radionuclide concentrations and fluxes are of primary interest from a performance or regulatory viewpoint, so the underestimation of releases of radionuclides in the flow-through model for decreasing solubility or dissolution rate can reasonably be excluded from the TSPA-LA.

- The response of the bathtub model when a second patch opens instantaneously beneath the water level in the waste package (secondary case 3 ) has also been analyzed. The impact of the instantaneous opening is to release a pulse of radionuclides in comparison to the base case flow-through model. The impact of this alternative conceptual model is mitigated by the time delays introduced through sorption and diffusion in the unsaturated and saturated zones. In addition, the higher mass flux from the alternative flow path is similar to the impact from additional patches opening in the waste package. There is a wide range of variability in corrosion rates for the TSPA-LA model, and the impact from the instantaneous opening is encompassed in the uncertainty in corrosion rates. The impact of this alternative flow model has therefore been screened out of TSPA-LA analyses because of the potential mitigation from sorption and diffusion and because the variability of corrosion rates provides large uncertainty in radionuclide release rates from the waste package. 


\subsubsection{Limited Water Vapor Diffusion Rate into Waste Package}

In this alternative conceptual model, a film of adsorbed water cannot form on the surface of corrosion products if the rate of water consumption by corrosion reactions is greater than the rate of diffusion of water vapor into the waste package. Until a film of water forms on internal corrosion products surfaces, diffusive releases of radionuclides through the adsorbed water cannot occur (according to the in-package diffusion submodel). Thus, the resistance to diffusion of water vapor through stress corrosion cracks delays releases until all of the corrodible materials inside a waste package are fully degraded. It is implicit in this alternative conceptual model that stress corrosion cracks appear before general corrosion patches form; this will not necessarily be the outcome of TSPA-LA calculations.

The objective is to determine the length of time required to complete the corrosion of internal component steels, which is equivalent to the delay from the time a waste package is first breached by stress corrosion cracks until diffusive releases can first take place. This delay can potentially be important since it provides additional time for decay to reduce the concentration of radionuclides before they are released from a waste package. The rate of diffusion of water vapor through stress corrosion cracks into the waste package is estimated and compared with the rate of consumption of water by corrosion of steel internal components to show that diffusion rates are less than corrosion rates. Then, at the rate limited by diffusion, the time needed to corrode the steels completely is calculated to give the delay before diffusive releases of radionuclides can occur.

An example calculation is presented for a typical set of conditions in the drift and waste package to estimate the time lag between appearance of stress corrosion cracks and the earliest times when an adsorbed water film can first form through which radionuclides can diffuse. Suppose that the temperature of the waste package and drift air is $50^{\circ} \mathrm{C}$, the relative humidity in the drift is 95 percent, and the relative humidity is zero inside the waste package. Letting the humidity be zero inside the waste package maximizes the water vapor concentration gradient between the exterior and interior of the waste package. The diffusion distance is $\Delta x=2.54 \mathrm{~cm}$, the thickness of the waste package outer lid (BSC 2004 [DIRS 169472]; BSC 2004 [DIRS 167394], Detail A). This is the outer closure lid, made of Alloy 22, with a circumferential weld in which stress corrosion cracks may develop. The average diffusive distance is greater - half the length of the waste package interior, or about $240 \mathrm{~cm}$ for a 21-PWR (Note i in Table 6.3-9) - but the cross sectional area is less in the stress corrosion cracks than in the waste package, so diffusion through the cracks is the limiting segment of the path.

To calculate the diffusion rate, the concentration of water vapor in humid air is obtained from psychrometric data. Equations for the determination of psychrometric properties are given by Singh et al. (2002 [DIRS 161624]). At relative humidity $R H$ (fraction) and temperature $T\left({ }^{\circ} \mathrm{C}\right)$, the partial pressure of water $p_{w}(\mathrm{~Pa})$ is:

$$
p_{w}=R H \cdot p_{w}^{o}
$$


where $p_{w}^{o}(\mathrm{~Pa})$ is the vapor pressure of water at $T\left({ }^{\circ} \mathrm{C}\right)$, given by:

$$
p_{w}^{o}= \begin{cases}610.78 \exp \left[\frac{17.269 T}{237.3+T}\right] & \left(0^{\circ} \mathrm{C}<T<63.0^{\circ} \mathrm{C}\right) \\ 610.78 \exp \left[\frac{17.269 T}{236.3+1.01585 T}\right] & \left(63.0^{\circ} \mathrm{C}<T<110^{\circ} \mathrm{C}\right) .\end{cases}
$$

The absolute humidity $H_{m}\left(\mathrm{~kg}\right.$ water $\mathrm{kg}^{-1}$ dry air $)$ is then:

$$
H_{m}=\left(\frac{M_{w}}{M_{a}}\right)\left(\frac{p_{w}}{p-p_{w}}\right)
$$

where $p$ is the total pressure, chosen to be one atmosphere $(101325 \mathrm{~Pa}), M_{w}$ is the molecular weight of water $\left(0.01801528 \mathrm{~kg} \mathrm{~mol}^{-1}\right)$, and $M_{a}$ is the molecular weight of air $\left(0.028964 \mathrm{~kg} \mathrm{~mol}^{-1}\right)$ (Weast 1985 [DIRS 111561], p. F-150).

At $50^{\circ} \mathrm{C}$ and a relative humidity in the drift of 95 percent, the vapor pressure of water, from Equation 6.6.2-2, is $p_{w}^{o}=12,334 \mathrm{~Pa}$, so the partial pressure at $R H=0.95$ is $p_{w}=11,717 \mathrm{~Pa}$. Then the absolute humidity is $0.0815 \mathrm{~kg}_{\text {water }} \mathrm{kg}^{-1}$ dry air.

The molal humidity is:

$$
H_{m o l}=\frac{H_{m} M_{a}}{M_{w}}=\frac{p_{w}}{p-p_{w}}=0.1308 \mathrm{~mol} \mathrm{H}_{2} \mathrm{O} \mathrm{mol}^{-1} \text { dry air }
$$

or $0.1156 \mathrm{~mol} \mathrm{H}_{2} \mathrm{O} \mathrm{mol}{ }^{-1}$ wet air. Assuming ideal gas behavior, with an ideal gas molar volume of $22,414 \mathrm{~cm}^{3} \mathrm{~mol}^{-1}$ (at $0^{\circ} \mathrm{C}$ and 1 atm pressure) (Weast 1985 [DIRS 111561], p. F-194), the concentration of water vapor in air at $50^{\circ} \mathrm{C}$ and 95 percent relative humidity is:

$$
C_{w v}=\frac{\left(0.1156 \frac{\mathrm{mol} \mathrm{H}_{2} \mathrm{O}}{\mathrm{mol} \mathrm{air}}\right)}{\left(22414 \frac{\mathrm{cm}^{3}}{\mathrm{~mol}}\right)\left(\frac{323.15 \mathrm{~K}}{273.15 \mathrm{~K}}\right)}=4.361 \times 10^{-6} \mathrm{~mol} \mathrm{H}_{2} \mathrm{O} \mathrm{cm}^{-3}
$$

To calculate the binary diffusion coefficient, the following equation is used (Bird et al. 1960 [DIRS 103524], Equation 16.3-1):

$$
D_{A B}=a\left(\frac{T}{\sqrt{T_{c A} T_{c B}}}\right)^{b}\left(p_{c A} p_{c B}\right)^{1 / 3}\left(T_{c A} T_{c B}\right)^{5 / 12}\left(\frac{1}{M_{A}}+\frac{1}{M_{B}}\right)^{1 / 2} p^{-1}
$$


where:

$$
\begin{aligned}
& \begin{array}{ll}
D_{A B} & =\text { the diffusion coefficient }\left(\mathrm{cm}^{2} \mathrm{~s}^{-1}\right) \text { for water }(A) \text { in air }(B) \\
T & =\text { absolute temperature }(\mathrm{K}) \\
p & =\text { pressure }(\mathrm{atm}) \\
M & =\text { molecular weight }\left(\mathrm{g} \mathrm{mol}^{-1}\right) \\
a \quad & =3.640 \times 10^{-4} \text { for } \mathrm{H}_{2} \mathrm{O} \text { with a nonpolar gas } \\
b \quad= & 2.334 \text { for } \mathrm{H}_{2} \mathrm{O} \text { with a nonpolar gas }
\end{array} \\
& \text { subscript } c \text { refers to critical properties. }
\end{aligned}
$$

For water $(A), T_{c A}=374.1^{\circ} \mathrm{C}=647.25 \mathrm{~K}, p_{c A}=218.3$ atm (Weast 1985 [DIRS 111561], p. F-64), and $M_{A}=18.01528 \mathrm{~g} \mathrm{~mol}^{-1}$; for air $(B), T_{c B}=132 \mathrm{~K}, p_{c B}=36.4$ atm (Bird et al. 1960 [DIRS 103524], Table B-1), and $M_{B}=28.964 \mathrm{~g} \mathrm{~mol}^{-1}$ (Weast 1985 [DIRS 111561], p. F-150). Substituting these values into the above equation, the binary diffusion coefficient for water vapor in air is:

$$
\begin{aligned}
D_{A B}= & \left(3.640 \times 10^{-4}\right)\left(\frac{323.15}{\sqrt{(647.25)(132 .)}}\right)^{2.334}[(218.3)(36.4)]^{1 / 3} \\
& {[(647.25)(132 .)]^{5 / 12}\left(\frac{1}{18.01528}+\frac{1}{28.964}\right)^{1 / 2}(1.0)^{-1} } \\
= & 0.3126 \mathrm{~cm}^{2} \mathrm{~s}^{-1}
\end{aligned}
$$

For diffusion of water vapor through stagnant air in the stress corrosion cracks, the rate of diffusion is, from Fick's first law (Bird et al. 1960 [DIRS 103524], p. 503) for a binary system with constant molar density:

$$
\begin{aligned}
q & =D_{A B} A_{s c c} \frac{\partial C_{w v}}{\partial x} \\
& =D_{A B} A_{s c c} \frac{\Delta C_{w v}}{\Delta x}=D_{A B} A_{s c c} \frac{C_{w v}}{\Delta x} \\
& =\left(0.3126 \frac{\mathrm{cm}^{2}}{\mathrm{~s}}\right) A_{s c c}\left(\frac{4.361 \times 10^{-6} \frac{\mathrm{mol}}{\mathrm{cm}^{3}}}{2.54 \mathrm{~cm}}\right) \\
& =5.37 \times 10^{-7} \mathrm{~mol} \mathrm{~cm}^{-2} \mathrm{~s}^{-1} \cdot A_{s c c},
\end{aligned}
$$

where $A_{s c c}$ is the cross-sectional area $\left(\mathrm{cm}^{2}\right)$ of stress corrosion cracks through which water vapor can diffuse. The typical cross-sectional area of a stress corrosion crack is $7.7 \times 10^{-6} \mathrm{~m}^{2}$ per stress corrosion crack (Section 6.3.3.1.2.1). Using the example of 25 stress corrosion cracks per waste package (BSC 2004 [DIRS 169996], Figure 26), $A=1.93 \times 10^{-4} \mathrm{~m}^{2}=1.93 \mathrm{~cm}^{2}$, and the rate of diffusion of water vapor is $q=1.04 \times 10^{-6} \mathrm{~mol} \mathrm{~s}^{-1}=32.7 \mathrm{~mol} \mathrm{H}_{2} \mathrm{O} \mathrm{yr}^{-1}$. 
When the waste package is first breached by stress corrosion cracks, water vapor that diffuses through will probably be consumed by corrosion of the most reactive materials within a waste package, namely the A 516 carbon steel that makes up the baskets. These steel components have an average corrosion rate of $77.43 \mu \mathrm{m} \mathrm{yr}^{-1}$ (DTN: MO0409SPAACRWP.000 [DIRS 172059]; Spreadsheet "aqueous-A516.xls"; Worksheet "Freshwater", 1-year data at $60^{\circ} \mathrm{C}$ ) and a maximum thickness of $3 / 8$ in. (9.525 mm) (BSC 2004 [DIRS 169472], Table 1), for an average lifetime of about 123 yr. From Table 6.3-4, the total Fe mass in A 516 steel in a 21-PWR waste package is $5,510 \mathrm{~kg}$, or $98,600 \mathrm{~mol}$. The rate of iron consumption over the average lifetime of this steel is

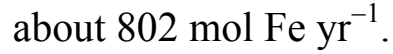

Consider the following corrosion reaction stoichiometries, which result in hematite, goethite, and ferrihydrite (written in a more-hydrated form that maximizes water consumption; Langmuir 1997 [DIRS 100051], Table 10.2, with $n=0$ ), respectively. These are not necessarily the actual reactions that will take place, but rather are potential net reactions that illustrate the range of water consumed by corrosion.

$$
\begin{gathered}
\mathrm{Fe}+3 / 2 \mathrm{H}_{2} \mathrm{O}=1 / 2 \mathrm{Fe}_{2} \mathrm{O}_{3}+3 / 2 \mathrm{H}_{2} \\
\mathrm{Fe}+2 \mathrm{H}_{2} \mathrm{O}=\mathrm{FeOOH}+3 / 2 \mathrm{H}_{2} \\
\mathrm{Fe}+3 \mathrm{H}_{2} \mathrm{O}=\mathrm{Fe}(\mathrm{OH})_{3}+3 / 2 \mathrm{H}_{2} .
\end{gathered}
$$

For these reactions, the stoichiometric ratio of water consumed to iron consumed ranges from 1.5 to $3 \mathrm{~mol} \mathrm{H}_{2} \mathrm{O} / \mathrm{mol} \mathrm{Fe}$. Therefore, this analysis will only examine the reactions producing hematite and ferrihydrite, which bound the range of water consumption by iron corrosion for the reactions under consideration.

Using a stoichiometry of $3 \mathrm{~mol} \mathrm{H}_{2} \mathrm{O} / 2 \mathrm{~mol} \mathrm{Fe}$, to form $\mathrm{Fe}_{2} \mathrm{O}_{3}$, the water diffusion rate $\left(q=32.7 \mathrm{~mol} \mathrm{H}_{2} \mathrm{O} \mathrm{yr}^{-1}\right)$ allows carbon steel to corrode at a rate of $21.8 \mathrm{~mol} \mathrm{Fe} \mathrm{yr}^{-1}$. For a stoichiometry of $3 \mathrm{~mol} \mathrm{H} \mathrm{H}_{2} \mathrm{O} / \mathrm{mol} \mathrm{Fe}$, to form $\mathrm{Fe}(\mathrm{OH})_{3}$, the water diffusion rate allows carbon

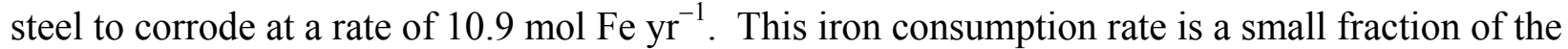

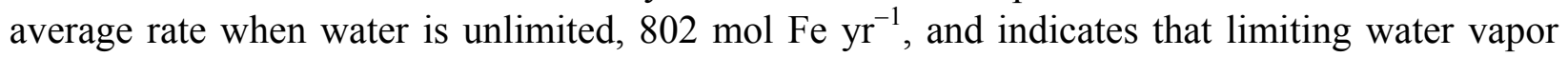
diffusion through the stress corrosion cracks may delay formation of a diffusive pathway for radionuclide diffusion through adsorbed water.

Water consumption rates when water availability is limited can be compared with the average water consumption rate due to A 516 carbon steel corrosion when water is unlimited. To form $\mathrm{Fe}_{2} \mathrm{O}_{3}$, corrosion of $802 \mathrm{~mol} \mathrm{Fe} \mathrm{yr}^{-1}$ consumes $1,200 \mathrm{~mol} \mathrm{H}_{2} \mathrm{O} \mathrm{yr}^{-1}$, which is a factor of 37 greater than the rate of diffusion of water vapor through stress corrosion cracks. For the formation of $\mathrm{Fe}(\mathrm{OH})_{3}$, water is consumed at a rate of $2,410 \mathrm{~mol} \mathrm{H}_{2} \mathrm{O} \mathrm{yr}$, a factor of 74 greater than the diffusion rate of water vapor through stress corrosion cracks.

If the stress corrosion cracks are filled with porous corrosion products, the cross sectional area for diffusion is less, and the water vapor diffusion rate is proportionately less. For a porosity $\phi_{s c c}$ of the stress corrosion crack, the effective cross sectional area is $A_{s c c, e f f}=\phi_{s c c} A_{s c c}$. For a porosity of $0.4, A_{\text {scc,eff }}=0.4\left(1.93 \mathrm{~cm}^{2}\right)=0.77 \mathrm{~cm}^{2}$. The corrosion rates given above are now higher than 
the diffusion rate by an additional factor of $1 / \phi_{s c c}=2.5$, or a factor of 92 higher than the diffusion rate for $\mathrm{Fe}_{2} \mathrm{O}_{3}$ formation and a factor of 184 higher for $\mathrm{Fe}(\mathrm{OH})_{3}$ formation.

Another way to show the effect of the corrosion rate being limited by the rate of diffusion of water vapor is to calculate the time required to corrode all of the steel in a waste package. As shown above, the lifetime of the carbon steel components is 123 years when not limited by the availability of water. When the corrosion rate is limited by the water vapor diffusion rate, the lifetime is greater than 123 years. The diffusion rate of $32.7 \mathrm{~mol} \mathrm{H}_{2} \mathrm{O} \mathrm{yr}^{-1}$ allows $21.8 \mathrm{~mol}$ $\mathrm{Fe} \mathrm{yr}^{-1}$ to corrode to $\mathrm{Fe}_{2} \mathrm{O}_{3}$, thereby requiring $98,600 \mathrm{~mol} \mathrm{Fe} /\left(21.8 \mathrm{~mol} \mathrm{Fe} \mathrm{yr}^{-1}\right)=4,530 \mathrm{yr}$ for all A 516 steel components to degrade fully once stress corrosion cracks first breach the waste package. To degrade to $\mathrm{Fe}(\mathrm{OH})_{3}$, where the stoichiometry is $1 \mathrm{~mol} \mathrm{Fe} / 3 \mathrm{~mol} \mathrm{H}_{2} \mathrm{O}$, and the

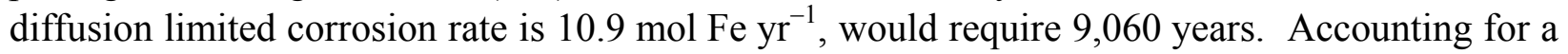
typical 40 percent porosity in the corrosion products increases these estimates to 11,300 years and 22,600 years, respectively.

A further refinement of these estimates includes corrosion of the stainless steel components in addition to the carbon steel. Suppose that all internal components corrode, and the composition of the component materials is treated as in Section 6.3.4.2.1 and Table 6.3-4. Effectively 13,600 $\mathrm{kg} \mathrm{Fe}=244,000 \mathrm{~mol} \mathrm{Fe}$ are to be corroded at a rate limited by water diffusion through stress corrosion cracks. Then $11,200 \mathrm{yr}$ are required to consume all of the material to $\mathrm{Fe}_{2} \mathrm{O}_{3}$, at the

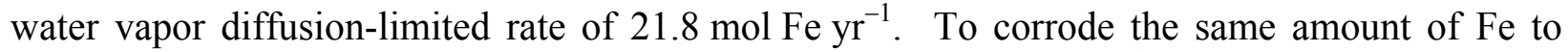

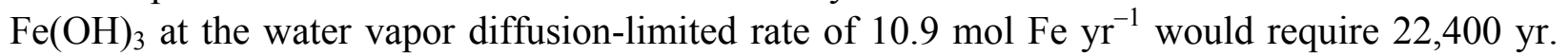
At the mean stainless steel corrosion rate of $0.248 \mu \mathrm{m} \mathrm{yr}^{-1}$ (DTN: MO0409SPAACRWP.000 [DIRS 172059]; Spreadsheet "aqueous-316L.xls"; Worksheet "freshwater", 50-100C data), the 50.8-mm-thick inner vessel (BSC 2004 [DIRS 169472]; BSC 2004 [DIRS 167394], Detail A) has a lifetime of 205,000 yr. Assuming that all 6,690 kg Fe in the 316 stainless steel listed in Table 6.3-4 is part of the inner vessel or lids, equivalent to $120,000 \mathrm{~mol} \mathrm{Fe}$, the mean molar corrosion rate is $120,000 \mathrm{~mol} / 205,000 \mathrm{yr}=0.58 \mathrm{~mol} \mathrm{yr}^{-1}$. A stoichiometrically equivalent rate of water consumption due to stainless steel corrosion to $\mathrm{Fe}_{2} \mathrm{O}_{3}$ is $0.88 \mathrm{~mol} \mathrm{H}_{2} \mathrm{O} \mathrm{yr}{ }^{-1}$, which is a factor of 37 less than the rate of diffusion of water vapor through open stress corrosion cracks (32.7 $\mathrm{mol} \mathrm{H}_{2} \mathrm{O} \mathrm{yr}^{-1}$ ). For formation of $\mathrm{Fe}(\mathrm{OH})_{3}$, the equivalent rate of water consumption due to stainless steel corrosion is $1.75 \mathrm{~mol} \mathrm{yr}^{-1}$, a factor of 19 less than the rate of diffusion of water vapor open stress corrosion cracks. In this case, water vapor diffusion through the stress corrosion cracks does not control the rate of corrosion and water consumption. If the cracks are filled with corrosion products to a porosity of 0.4 , the rate of water vapor diffusion is less, as discussed earlier, and may then control the rate of corrosion.

In Table 6.6-1, the time required to corrode all of the carbon steel or all of the stainless steel is shown for various assumptions and conditions (temperature, relative humidity in the drift). If no diffusive path can form until all of the steels are fully corroded, the time needed to corrode the steel is effectively the time lag between the first appearance of stress corrosion cracks and the first diffusive releases from the breached waste package. Depending on conditions and assumptions, this delay can range from $1,570 \mathrm{yr}\left(\right.$ at $\left.70^{\circ} \mathrm{C}\right)$ to more than $34,000 \mathrm{yr}\left(\right.$ at $\left.30^{\circ} \mathrm{C}\right)$ even at 100 percent relative humidity in the drift. At lower relative humidities, the delay can be longer, for example, more than $103,000 \mathrm{yr}$ at $30^{\circ} \mathrm{C}$ and 80 percent relative humidity. In this 
table, the water vapor concentration, $C_{w v}$, is obtained from Equations 6.6.2-4 and 6.6.2-5 as a function of relative humidity and temperature. The water vapor flux through stress corrosion cracks, $q$, is given by Equation 6.6.2-8. The corrosion rate, $r_{\text {corr }}$, is the stoichiometrically equivalent rate of iron consumption that occurs when limited by the water vapor influx, $q$. The release delay is the time, $t_{\text {corr }}$, required to corrode from one side through $10 \mathrm{~mm}$ of carbon steel or $50.8 \mathrm{~mm}$ of stainless steel at the rate, $r_{\text {corr }}$.

This alternative conceptual model provides additional realism compared to the base model by accounting for the delay in formation of a diffusive pathway for transport of radionuclides due to water consumption by corrosion reactions. However, data and analyses are not available to support certain assumptions used in this alternative model. For example, it is not known whether water will in fact be consumed by corrosion reactions so preferentially that none will adsorb anywhere inside a breached waste package. In addition, this alternative conceptual model does not account for possible spatial variations in the extent of corrosion. As an example, if the iron near the breaches in the outer corrosion barrier is completely corroded before the iron far from a breach has even begun to corrode, then water adsorption could occur there, forming a diffusive release pathway before all of the iron in the waste package has been consumed. In that case, this model would be non-conservative. Because of the lack of data and potentially non-conservative results, this alternative conceptual model has not been implemented in the TSPA-LA model.

Table 6.6-1. Summary of Release Delays Resulting from Limitations on Diffusion of Water Vapor Through Stress Corrosion Cracks

\begin{tabular}{|c|c|c|c|c|c|}
\hline Drift $R H$ & 0.8 & 0.9 & 0.95 & 0.99 & 1.00 \\
\hline \multicolumn{6}{|c|}{$\boldsymbol{T}=\mathbf{5 0} 0^{\circ} \mathrm{C}, D_{A B}=0.313 \mathrm{~cm}^{2} \mathrm{~s}^{-1}$} \\
\hline$C_{w v}\left(\mathrm{~mol} \mathrm{~cm}^{-3}\right)$ & $3.67 \times 10^{-6}$ & $4.13 \times 10^{-6}$ & $4.36 \times 10^{-6}$ & $4.54 \times 10^{-6}$ & $4.59 \times 10^{-6}$ \\
\hline$q\left(\mathrm{~mol} \mathrm{H}_{2} \mathrm{O} \mathrm{yr}{ }^{-1}\right)$ & 27.5 & 30.9 & 32.7 & 34.0 & 34.4 \\
\hline 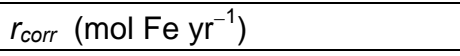 & 18.3 & 20.6 & 21.8 & 22.7 & 22.9 \\
\hline $\begin{array}{l}t_{\text {corr, }} \text { Carbon steel only, } \mathrm{Fe}_{2} \mathrm{O}_{3} \\
\text { stoichiometry, open stress } \\
\text { corrosion cracks (yr) }\end{array}$ & 5,380 & 4,780 & 4,530 & 4,350 & 4,300 \\
\hline $\begin{array}{l}t_{\text {corr, }} \text { Carbon steel only, } \mathrm{Fe}(\mathrm{OH})_{3} \\
\text { stoichiometry, open stress } \\
\text { corrosion cracks (yr) }\end{array}$ & 10,900 & 9,720 & 9,210 & 8,840 & 8,750 \\
\hline $\begin{array}{l}t_{c o r r}, \text { Carbon steel only, } \mathrm{Fe}_{2} \mathrm{O}_{3} \\
\text { stoichiometry, } \phi_{s c c}=0.4(\mathrm{yr})\end{array}$ & 13,400 & 12,000 & 11,300 & 10,900 & 10,800 \\
\hline $\begin{array}{l}t_{\text {corr, }} \text { Carbon steel only, } \mathrm{Fe}(\mathrm{OH})_{3} \\
\text { stoichiometry, } \phi_{\mathrm{scc}}=0.4(\mathrm{yr})\end{array}$ & 26,900 & 23,900 & 22,600 & 21,700 & 21,500 \\
\hline $\begin{array}{l}t_{\text {corr, }} \text { Stainless steel only, } \mathrm{Fe}_{2} \mathrm{O}_{3} \\
\text { stoichiometry, open stress } \\
\text { corrosion cracks (yr) }\end{array}$ & 6,530 & 5,810 & 5,500 & 5,280 & 5,230 \\
\hline $\begin{array}{l}t_{\text {corr }} \text { Stainless steel only, } \\
\text { Fe(OH })_{3} \text { stoichiometry, open } \\
\text { stress corrosion cracks (yr) }\end{array}$ & 13,100 & 11,600 & 11,000 & 10,600 & 10,500 \\
\hline $\begin{array}{l}t_{c o r r}, \text { Stainless steel only, } \mathrm{Fe}_{2} \mathrm{O}_{3} \\
\text { stoichiometry, } \\
\phi_{s c c}=0.4(\mathrm{yr})\end{array}$ & 16,300 & 14,500 & 13,800 & 13,200 & 13,100 \\
\hline
\end{tabular}


Table 6.6-1. Summary of Release Delays Resulting from Limitations on Diffusion of Water Vapor Through Stress Corrosion Cracks (Continued)

\begin{tabular}{|c|c|c|c|c|c|}
\hline Drift $R H$ & 0.8 & 0.9 & 0.95 & 0.99 & 1.00 \\
\hline $\begin{array}{l}t_{c o r r}, \text { Stainless steel only, } \\
\mathrm{Fe}(\mathrm{OH})_{3} \text { stoichiometry, } \\
\phi_{s c c}=0.4(\mathrm{yr})\end{array}$ & 32,700 & 29,000 & 27,500 & 26,400 & 26,100 \\
\hline \multicolumn{6}{|c|}{$T=70^{\circ} \mathrm{C}, D_{A B}=0.360 \mathrm{~cm}^{2} \mathrm{~s}^{-1}$} \\
\hline$C_{w v}\left(\mathrm{~mol} \mathrm{~cm}^{-3}\right)$ & $8.75 \times 10^{-6}$ & $9.84 \times 10^{-6}$ & $1.04 \times 10^{-5}$ & $1.08 \times 10^{-5}$ & $1.09 \times 10^{-5}$ \\
\hline$q\left(\mathrm{~mol} \mathrm{H}_{2} \mathrm{O} \mathrm{yr}{ }^{-1}\right)$ & 75.4 & 84.8 & 89.5 & 93.3 & 94.2 \\
\hline$r_{\text {corr }}\left({\left.\mathrm{mol} \mathrm{Fe} \mathrm{yr}^{-1}\right)}^{-1}\right.$ & 50.3 & 56.5 & 59.7 & 62.2 & 62.8 \\
\hline $\begin{array}{l}t_{\text {corr, }} \text { Carbon steel only, } \mathrm{Fe}_{2} \mathrm{O}_{3} \\
\text { stoichiometry, open stress } \\
\text { corrosion cracks (yr) }\end{array}$ & 1,960 & 1,740 & 1,650 & 1,590 & 1,570 \\
\hline $\begin{array}{l}t_{\text {corr, }} \text { Carbon steel only, } \mathrm{Fe}(\mathrm{OH})_{3} \\
\text { stoichiometry, open stress } \\
\text { corrosion cracks (yr) }\end{array}$ & 3,990 & 3,550 & 3,360 & 3,220 & 3,190 \\
\hline $\begin{array}{l}t_{\text {corr, }} \text { Carbon steel only, } \mathrm{Fe}_{2} \mathrm{O}_{3} \\
\text { stoichiometry, } \phi_{s c c}=0.4(\mathrm{yr})\end{array}$ & 4,910 & 4,360 & 4,130 & 3,960 & 3,920 \\
\hline $\begin{array}{l}t_{c o r r}, \text { Carbon steel only, } \mathrm{Fe}(\mathrm{OH})_{3} \\
\text { stoichiometry, } \phi_{s c c}=0.4(\mathrm{yr})\end{array}$ & 9,810 & 8,720 & 8,260 & 7,930 & 7,850 \\
\hline $\begin{array}{l}t_{\text {corr, }} \text { Stainless steel only, } \mathrm{Fe}_{2} \mathrm{O}_{3} \\
\text { stoichiometry, open stress } \\
\text { corrosion cracks (yr) }\end{array}$ & 2380 & 2,120 & 2,010 & 1,930 & 1,910 \\
\hline $\begin{array}{l}t_{\text {corr }} \text { Stainless steel only, } \\
\text { Fe }(\mathrm{OH})_{3} \text { stoichiometry, open } \\
\text { stress corrosion cracks (yr) }\end{array}$ & 4,770 & 4,240 & 4,010 & 3,850 & 3,810 \\
\hline $\begin{array}{l}t_{\text {corr }}, \text { Stainless steel only, } \mathrm{Fe}_{2} \mathrm{O}_{3} \\
\text { stoichiometry, } \\
\phi_{s c c}=0.4(\mathrm{yr})\end{array}$ & 5,960 & 5,300 & 5,020 & 4,810 & 4,770 \\
\hline $\begin{array}{l}t_{c o r r}, \text { Stainless steel only, } \\
\text { Fe }(\mathrm{OH})_{3} \text { stoichiometry, } \\
\phi_{s c c}=0.4(\mathrm{yr})\end{array}$ & 11,900 & 10,600 & 10,000 & 9,630 & 9,530 \\
\hline \multicolumn{6}{|c|}{$T=30^{\circ} \mathrm{C}, D_{A B}=0.269 \mathrm{~cm}^{2} \mathrm{~s}^{-1}$} \\
\hline$C_{w v}\left(\mathrm{~mol} \mathrm{~cm}^{-3}\right)$ & $1.35 \times 10^{-6}$ & $1.51 \times 10^{-6}$ & $1.60 \times 10^{-6}$ & $1.67 \times 10^{-6}$ & $1.68 \times 10^{-6}$ \\
\hline$q\left(\mathrm{~mol} \mathrm{H}_{2} \mathrm{O} \mathrm{yr}{ }^{-1}\right)$ & 8.7 & 9.8 & 10.3 & 10.8 & 10.9 \\
\hline$r_{\text {corr }}\left(\mathrm{mol} \mathrm{Fe} \mathrm{yr}^{-1}\right)$ & 5.8 & 6.5 & 6.9 & 7.2 & 7.2 \\
\hline $\begin{array}{l}t_{\text {corr, }} \text { Carbon steel only, } \mathrm{Fe}_{2} \mathrm{O}_{3} \\
\text { stoichiometry, open stress } \\
\text { corrosion cracks (yr) }\end{array}$ & 17,000 & 15,100 & 14,300 & 13,800 & 13,600 \\
\hline $\begin{array}{l}t_{\text {corr, }} \text { Carbon steel only, } \mathrm{Fe}(\mathrm{OH})_{3} \\
\text { stoichiometry, open stress } \\
\text { corrosion cracks (yr) }\end{array}$ & 34,600 & 30,800 & 29,200 & 28,000 & 27,700 \\
\hline $\begin{array}{l}t_{\text {corr, }} \text { Carbon steel only, } \mathrm{Fe}_{2} \mathrm{O}_{3} \\
\text { stoichiometry, } \phi_{s c c}=0.4(\mathrm{yr})\end{array}$ & 42,600 & 37,800 & 35,900 & 34,400 & 34,100 \\
\hline $\begin{array}{l}t_{c o r r}, \text { Carbon steel only, } \mathrm{Fe}(\mathrm{OH})_{3} \\
\text { stoichiometry, } \phi_{s c c}=0.4(\mathrm{yr})\end{array}$ & 85,100 & 75,700 & 71,700 & 68,800 & 68,100 \\
\hline $\begin{array}{l}t_{\text {corr, }} \text { Stainless steel only, } \mathrm{Fe}_{2} \mathrm{O}_{3} \\
\text { stoichiometry, open stress } \\
\text { corrosion cracks (yr) }\end{array}$ & 20,700 & 18,400 & 17,400 & 16,700 & 16,500 \\
\hline
\end{tabular}


Table 6.6-1. Summary of Release Delays Resulting from Limitations on Diffusion of Water Vapor Through Stress Corrosion Cracks (Continued)

\begin{tabular}{|c|c|c|c|c|c|}
\hline Drift $R H$ & 0.8 & 0.9 & 0.95 & 0.99 & 1.00 \\
\hline $\begin{array}{l}t_{\text {corr, }} \text { Stainless steel only, } \\
\text { Fe(OH) })_{3} \text { stoichiometry, open } \\
\text { stress corrosion cracks (yr) }\end{array}$ & 41,400 & 36,800 & 34,800 & 33,400 & 33,100 \\
\hline $\begin{array}{l}t_{\text {corr, }} \text { Stainless steel only, } \mathrm{Fe}_{2} \mathrm{O}_{3} \\
\text { stoichiometry, } \\
\phi_{s c c}=0.4(\mathrm{yr})\end{array}$ & 51,700 & 46,000 & 43,500 & 41,800 & 41,400 \\
\hline $\begin{array}{l}t_{\text {corr }} \text { Stainless steel only, } \\
\mathrm{Fe}(\mathrm{OH})_{3} \text { stoichiometry, } \\
\phi_{s c c}=0.4(\mathrm{yr})\end{array}$ & 103,000 & 91,900 & 87,100 & 83,600 & 82,700 \\
\hline
\end{tabular}

\subsubsection{Limited Oxygen Diffusion Rate into Waste Package}

Dry air oxidation under atmospheric conditions can also proceed once stress corrosion cracks appear (CRWMS M\&O 2000 [DIRS 135968], p. 14). Therefore, the rate of oxygen diffusion through cracks should also be considered, since oxygen diffusion may limit the corrosion rate.

The mean corrosion rate of Stainless Steel Type 316L under atmospheric conditions, $0.113 \mu \mathrm{m} \mathrm{yr}^{-1}$ (DTN: MO0407SPAPCEML.005 [DIRS 172097], Spreadsheet: atmospheric.xls, Worksheet: 316) is lower than under aqueous conditions, $0.248 \mu \mathrm{m} \mathrm{yr}^{-1}$ (DTN: MO0409SPAACRWP.000 [DIRS 172059]; Spreadsheet "aqueous-316L.xls"; Worksheet "freshwater", $50-100^{\circ} \mathrm{C}$ data). To compare the corrosion rate with the oxygen diffusion rate, the lifetime of the waste package inner vessel is estimated, since this is the thickest component of a waste package and will provide the longest component lifetime. The inner vessel is $50.8 \mathrm{~mm}$ thick (BSC 2004 [DIRS 169472]; BSC 2004 [DIRS 167394], Detail A); with unlimited oxygen availability, its lifetime is $50.8 \mathrm{~mm} /\left(0.113 \times 10^{-3} \mathrm{~mm} \mathrm{yr}^{-1}\right)=4.50 \times 10^{5} \mathrm{yr}$ for corrosion from one side. An estimate of the molar corrosion rate can be obtained by letting the effective $\mathrm{Fe}$ content of the Stainless Steel Type 316 listed in Table 6.3-4 be inner vessel and lid material.

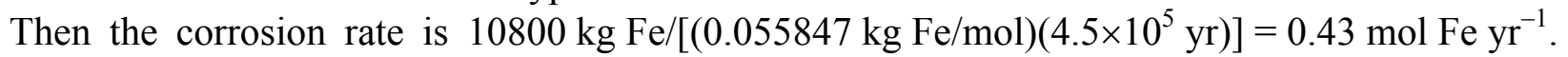
Consider the following net stoichiometry (not necessarily the actual reaction path) for dry air oxidation to produce $\mathrm{Fe}_{2} \mathrm{O}_{3}\left(3 \mathrm{~mol} \mathrm{O}_{2} / 4 \mathrm{~mol} \mathrm{Fe}\right)$ :

$$
4 \mathrm{Fe}+3 \mathrm{O}_{2} \rightarrow 2 \mathrm{Fe}_{2} \mathrm{O}_{3}
$$

This is equivalent to an oxygen consumption rate of $0.32 \mathrm{~mol} \mathrm{O}_{2} \mathrm{yr}^{-1}$.

For nonpolar gas pairs, parameters $a$ and $b$ in the diffusion coefficient expression, Equation 5.4.2-6, are 2.745 $\times 10^{-4}$ and 1.823, respectively (Bird et al. 1960 [DIRS 103524], Equation 16.3-1). Using the appropriate parameters for oxygen $(A)$ diffusing in air, $T_{c A}=154.58 \mathrm{~K}, p_{c A}=5.043 \mathrm{MPa}=49.77 \mathrm{~atm}$ (Weast 1985 [DIRS 111561], p. F-62), and $M_{A}=31.9988 \mathrm{~g} \mathrm{~mol}^{-1}$, it follows that: 


$$
\begin{aligned}
D_{A B}= & \left(2.745 \times 10^{-4}\right)\left(\frac{323.15}{\sqrt{(154.58)(132 .)}}\right)^{1.823}[(49.7)(36.4)]^{1 / 3} \\
& {[(154.58)(132 .)]^{5 / 12}\left(\frac{1}{31.9988}+\frac{1}{28.964}\right)^{1 / 2}(1.0)^{-1} } \\
= & 0.237 \mathrm{~cm}^{2} \mathrm{~s}^{-1} .
\end{aligned}
$$

Let the oxygen concentration in air in a drift outside a waste package be the same as in the atmosphere: 20.946 volume-percent (Weast 1985 [DIRS 111561], p. F-156) or $0.20946 \mathrm{~mol}$ $\mathrm{O}_{2} \mathrm{~mol}^{-1}$ air. As an example, suppose the temperature is a uniform $50^{\circ} \mathrm{C}$. With $22,414 \mathrm{~cm}^{3} \mathrm{~mol}^{-1}$, the $\mathrm{O}_{2}$ concentration is:

$$
\begin{aligned}
C_{O_{2}} & =\frac{\left(0.20946 \frac{\mathrm{mol} \mathrm{O}_{2}}{\mathrm{~mol} \mathrm{air}}\right)}{\left(22414 \frac{\mathrm{cm}^{3}}{\mathrm{~mol}}\right)\left(\frac{323.15}{273.15}\right)} \\
& =7.899 \times 10^{-6} \mathrm{~mol} \mathrm{O}_{2} \mathrm{~cm}^{-3} \text { air. }
\end{aligned}
$$

Inside a waste package, suppose the oxygen concentration is essentially zero. For an example with 25 stress corrosion cracks with a total cross-sectional area of $1.93 \mathrm{~cm}^{2}$, the rate of diffusion of oxygen is:

$$
\begin{aligned}
q & =D_{A B} A \frac{\Delta C_{O_{2}}}{\Delta x} \\
& =\left(0.237 \frac{\mathrm{cm}^{2}}{\mathrm{~s}}\right)\left(1.93 \mathrm{~cm}^{2}\right)\left(\frac{7.899 \times 10^{-6} \frac{\mathrm{mol} \mathrm{O}_{2}}{\mathrm{~cm}^{3}}}{1 \mathrm{~cm}}\right)\left(3.1556926 \times 10^{7} \frac{\mathrm{s}}{\mathrm{yr}}\right) \\
& =114 \mathrm{~mol} \mathrm{O}_{2} \mathrm{yr}^{-1} .
\end{aligned}
$$

In this case, the corrosion rate is limited by the reaction kinetics, rather than the rate of diffusion of oxygen, since the oxygen diffusion rate is about 360 times greater than the oxygen

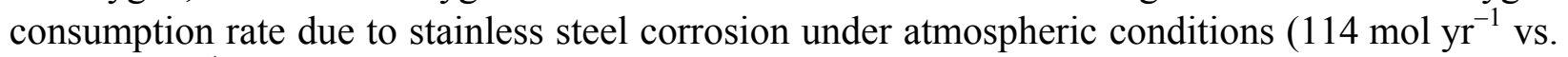
$0.32 \mathrm{~mol} \mathrm{yr}^{-1}$ ). If corrosion products fill the stress corrosion cracks to a porosity of, say 0.4 , the diffusion rate is still 140 times greater than the oxygen consumption rate due to stainless steel corrosion.

Accounting for the stoichiometry to produce $\mathrm{Fe}_{2} \mathrm{O}_{3}\left(3 \mathrm{~mol} \mathrm{O}_{2} / 4 \mathrm{~mol} \mathrm{Fe}\right)$, the oxygen diffusion

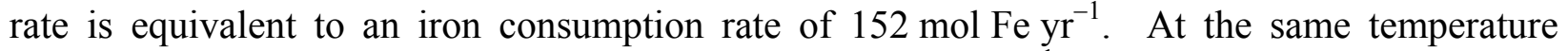
$\left(50^{\circ} \mathrm{C}\right)$, water vapor diffusion allows, at most, $58.2 \mathrm{~mol} \mathrm{Fe} \mathrm{yr}^{-1}$ (Table 6.6-1, $\left.R H=1.0\right)$ to be consumed, primarily because the water vapor concentration in air is much less than the oxygen concentration, so the gradient into the waste package is smaller. However, the reaction rate of 
iron with oxygen is lower than that of iron with water, so the steel components inside a waste package have a lesser affinity for oxygen than for water.

These calculations indicate that a more accurate mass balance for water and oxygen inside a waste package could reduce predicted releases of radionuclides to the invert, and thus releases to the accessible environment. Releases could be delayed for several thousand years compared with current estimates as the corrosion of fuel baskets and inner vessel components scavenges water and oxygen that diffuse through small stress corrosion cracks (providing general corrosion patches do not form first). Formation of a diffusive pathway could then be delayed until corrosion of iron-based materials is largely completed.

Despite the potential for delays in releases of radionuclides predicted by these models, uncertainty exists in the processes that are modeled. The assumption that no water is physically adsorbed until all steel is corroded is questionable, since adsorption is typically a fast process. On the other hand, if water consumption by corrosion does keep the relative humidity lower inside the waste package than outside, the effective water saturation could be less than when calculated using the humidity of the drift. If this occurs, calculated diffusion coefficients are simply lower than given by the in-package diffusion submodel, rather than zero, but for the time required for the internal components to corrode. The net effect is similar to what these alternative conceptual models predict. The corrosion rates that have been used are for aqueous conditions, which might exist on a microscopic scale. However, to be consistent with the assumption here that no adsorbed water film forms, rates in a low-humidity gaseous environment should be used. This increased realism would increase the time required for complete corrosion of the steel.

This alternative conceptual model provides additional realism compared to the base model by accounting for the delay in formation of a diffusive pathway for transport of radionuclides due to oxygen consumption by corrosion reactions. However, as with the alternative conceptual model for limited water vapor diffusion rate into waste package (Section 6.6.2), data and analyses are not available to support all of the assumptions used in this alternative model. Examples include to what extent oxygen is needed for corrosion and the extent to which water vapor will compete with or interfere in diffusion and corrosion reactions. This alternative conceptual model also does not account for possible spatial variations in the extent of corrosion. Because of the lack of data and potentially non-conservative results, this alternative conceptual model has not been implemented in the TSPA-LA model.

\subsubsection{Dual-Continuum Invert}

The LA invert design (BSC 2004 [DIRS 169503]) uses crushed tuff as the invert ballast material. This material is actually comprised of two pore spaces - intragranular pore space (tuff particle matrix) and intergranular pore space. Although radionuclide transport by both advection and diffusion can occur in both pore spaces, the dominant flow and transport processes in each of these two pore spaces is generally different. In order to simulate flow and transport through the invert accurately, the invert may be conceptualized as overlapping dual continua and modeled using a dual-permeability approach (Šimůnek et al. 2003 [DIRS 167469], p. 22), wherein flow and transport occur in both pore spaces, and mass transfer takes place between the two pore spaces. 
Transport through the drift invert can occur either through the intergranular porosity of the invert ballast material or through the intragranular porosity. Advective transport depends upon the liquid flux through each of these porosities. Diffusive transport through each of these porosities depends upon the diffusive properties associated with each pathway. For this alternative conceptual model, the invert is modeled as overlapping dual continua in which one continuum is represented by the intergranular porosity and the other continuum is represented by the intragranular porosity, as shown in Figure 6.6-2.

Whereas the single-continuum invert model, as shown in Figure 6.3-1, has a single advective flow path (Pathway 8) from the invert to the unsaturated zone, the dual-continuum invert has two potential advective flow pathways, as shown in Figure 6.6-2:

Pathway 8 Flux from the Intragranular Invert Continuum to the Unsaturated Zone - Advective flux from the invert intragranular continuum flows directly into the UZ matrix.

Pathway 9 Flux from the Intergranular Invert Continuum to the Unsaturated Zone All advective flux from the invert intergranular continuum flows directly into the UZ fractures.

In this model, no advective flux occurs between the two invert continua. Thus, the flux through pathway 8 is identical to the imbibition flux, pathway 7: $F_{8}=F_{7}$.

Ignoring three-dimensional effects (e.g., flow along the axis of the drift), the quasi-steady state flux through the intergranular invert continuum is equal to the seepage flux: $F_{9}=F_{1}$.

This alternative conceptual model for flow and transport through the EBS includes five domains: the waste form (e.g., fuel rods or HLW glass), waste package corrosion products, the intergranular invert continuum, the intragranular invert continuum, and the invert/UZ interface domain. The first two domains are the same as in the base case model. The third domain (the intergranular invert continuum) is modeled as being in intimate contact with the waste package and has an average thickness of $0.597 \mathrm{~m}$ (Section 6.5.3). The fourth domain (the intragranular invert continuum) is also modeled as being in intimate contact with the waste package and has the same average thickness, $0.597 \mathrm{~m}$, as the intergranular invert continuum.

Table 6.6-2 summarizes the transport modes and transport parameters for the transport pathways in the EBS when the invert is modeled as a dual continuum.

The diffusive fluxes to the dual invert continua are determined from the flux continuity at the interface between the corrosion products domain and the invert continua. This requirement states that the diffusive flux exiting the corrosion products domain is equal to the sum of the diffusive fluxes entering the two invert continua. The diffusive flux split will depend on the diffusive properties in the corrosion products domain and both invert continua together with the concentration gradients across the corrosion products domain/invert interface. 


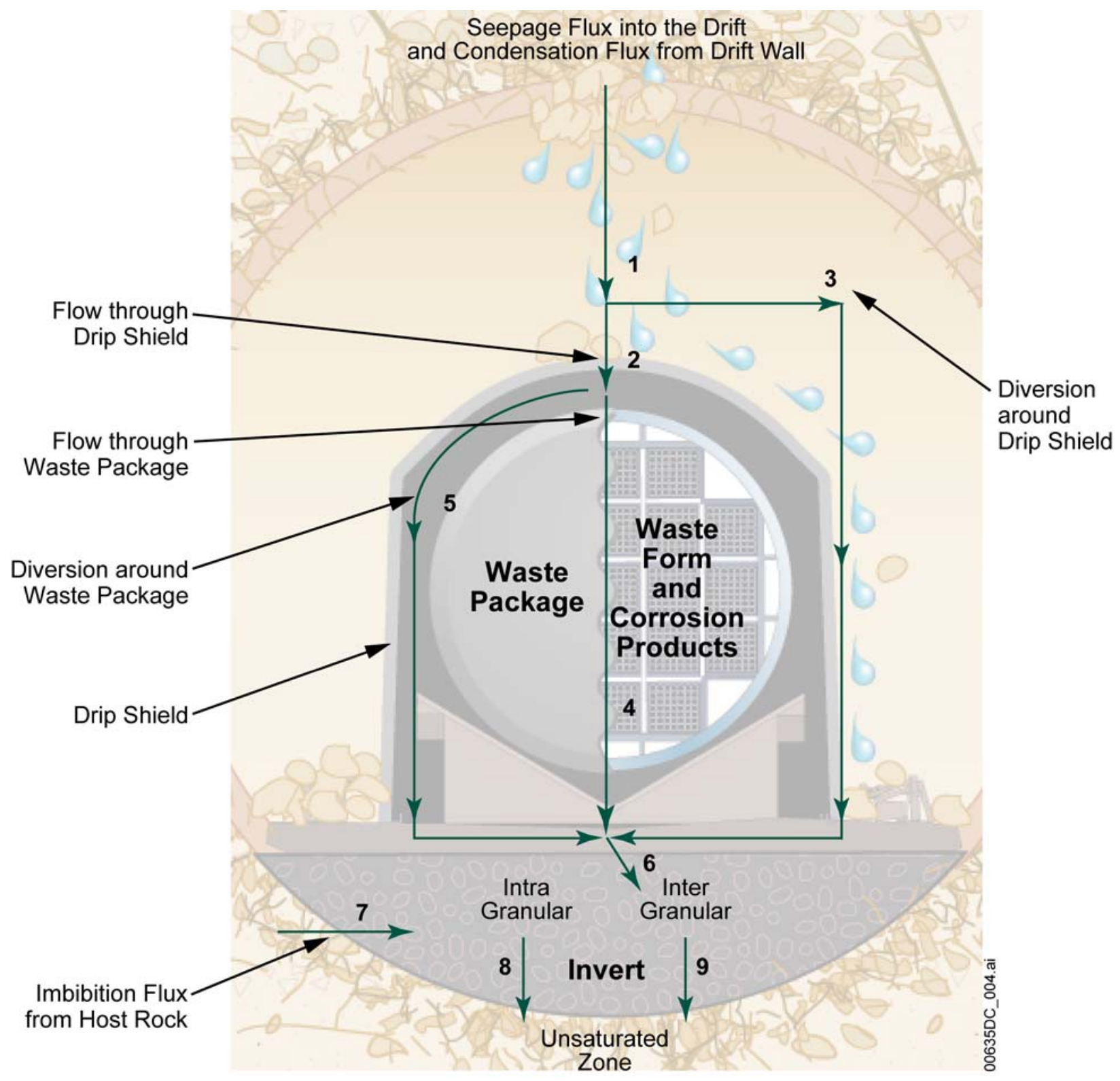

Figure 6.6-2. Schematic of the Potential Flow Pathways in the EBS 
Table 6.6-2. Summary of Transport Modes and Parameters for the EBS Transport Pathways with Dual-Continuum Invert

\begin{tabular}{|c|c|c|}
\hline Transport Pathway & Transport Modes & Transport Parameters and Data Sources \\
\hline $\begin{array}{l}\text { 1. Waste form and } \\
\text { corrosion products } \\
\text { domains }\end{array}$ & $\begin{array}{l}\text { Diffusion through stress } \\
\text { corrosion cracks (no } \\
\text { advective transport through } \\
\text { stress corrosion cracks). } \\
\text { Diffusion and advection } \\
\text { through corrosion products } \\
\text { and patches. }\end{array}$ & $\begin{array}{l}\text { No lateral or forward dispersion. } \\
\text { Colloidal particles will transport radionuclides. } \\
\text { Diffusive area for each stress corrosion crack is } \\
7.7 \times 10^{-6} \mathrm{~m}^{2} \text { (see Section } 6.3 .3 .1 .2 .1 \text { ). } \\
\text { Diffusive area for each patch is provided by WAPDEG } \\
\text { (BSC } 2004 \text { [DIRS } 169996] \text { ). } \\
\text { Diffusion coefficient (all radionuclides): } \\
\text { - } 2.299 \times 10^{-5} \mathrm{~cm}^{2} \mathrm{~s}^{-1} \text { at } 25^{\circ} \mathrm{C} \text { (Mills } 1973 \\
\text { [DIRS } 13332 \text { ], Table III) } \\
\text { - Modified for porosity and saturation (see Section } \\
\text { 6.3.4.3.5); not modified for temperature. } \\
\text { - Reduced by a factor of } 100 \text { if radionuclide is } \\
\text { bound to a colloid (see Section } 6.3 .4 .4 \text { ). } \\
\text { The cross-sectional area } A_{C P \text { linvert }} \text { for radionuclide } \\
\text { transport is given by the interface between the waste } \\
\text { package corrosion products domain and the invert } \\
\text { domain. } \\
\text { See Section } 6.5 .3 \text { for further details. }\end{array}$ \\
\hline $\begin{array}{l}\text { 2. Intragranular invert } \\
\text { continuum }\end{array}$ & $\begin{array}{l}\text { Diffusion from corrosion } \\
\text { products domain through the } \\
\text { invert intragranular } \\
\text { continuum. }\end{array}$ & $\begin{array}{l}\text { No advection from corrosion products domain into } \\
\text { invert intragranular continuum. Advection UZ into } \\
\text { invert intragranular continuum }\left(F_{7}\right) \text {. } \\
\text { Diffusion coefficient (all radionuclides): } \\
\text { - } 2.299 \times 10^{-5} \mathrm{~cm}^{2} \mathrm{~s}^{-1} \text { at } 25^{\circ} \mathrm{C} \text { (Mills } 1973 \\
\text { [DIRS } 133392] \text {, Table III) } \\
\text { - Modified for porosity and saturation (see } \\
\text { Section 6.3.4.1) } \\
\text { - Temperature modification defined in } \\
\text { Section 6.3.4.1.2; invert temperature is provided } \\
\text { by Multiscale Thermohydrologic Model } \\
\text { calculations (BSC } 2004 \text { [DIRS 173944]) } \\
\text { - Reduced by a factor of } 100 \text { if radionuclide is } \\
\text { bound to a colloid (see Section 6.3.4.4). } \\
\text { Flow cross-sectional areas given by the top surface } \\
\text { area of the invert, } A_{/ / J z} \text { (Equation 6.5.3.3-4). }\end{array}$ \\
\hline $\begin{array}{l}\text { 3. Intergranular invert } \\
\text { continuum }\end{array}$ & $\begin{array}{l}\text { Diffusion and advection }\left(F_{6}\right) \\
\text { from corrosion products } \\
\text { domain through the invert } \\
\text { intergranular continuum. }\end{array}$ & $\begin{array}{l}\text { Liquid flux for advection }=F_{6}=F_{5} \text { (diverted by WP) }+ \\
F_{4} \text { (flux through WP) }+F_{3} \text { (diverted by drip shield). } \\
\text { Diffusion coefficient (all radionuclides): } \\
\text { - } 2.299 \times 10^{-5} \mathrm{~cm}^{2} \mathrm{~s}^{-1} \text { at } 25^{\circ} \mathrm{C} \text { (Mills } 1973 \\
\text { [DIRS } 133392], \text { Table III) } \\
\text { - Modified for porosity and saturation (see } \\
\text { Section 6.3.4.1) } \\
\text { - Temperature modification defined in } \\
\text { Section 6.3.4.1.2; invert temperature is provided } \\
\text { by Multiscale Thermohydrologic Model } \\
\text { calculations (BSC } 2005 \text { [DIRS } 173944 \text { ) } \\
\text { - Reduced by a factor of } 100 \text { if radionuclide is } \\
\text { bound to a colloid (see Section } 6.3 .4 .4 \text { ). } \\
\text { The cross-sectional area } A_{/ / U z} \text { for radionuclide } \\
\text { transport is the top surface area of the invert } \\
\text { (Equation 6.5.3.3-4). }\end{array}$ \\
\hline
\end{tabular}


Table 6.6-2. Summary of Transport Modes and Parameters for the EBS Transport Pathways with Dual-Continuum Invert (Continued)

\begin{tabular}{|c|c|c|}
\hline Transport Pathway & Transport Modes & Transport Parameters and Data Sources \\
\hline $\begin{array}{l}\text { 4. Invert intragranular - } \\
\text { intergranular } \\
\text { interface }\end{array}$ & $\begin{array}{l}\text { Diffusion between the invert } \\
\text { intergranular continuum and } \\
\text { the intragranular continuum. }\end{array}$ & $\begin{array}{l}\text { Mass transfer coefficient uses (see Section 6.6.4.1): } \\
\text { - Diffusion coefficient of the intragranular continuum } \\
\text { - Sampled geometry-dependent factor, } \beta \\
\text { (Invert_Geometry_Coef) } \\
\text { - Diffusive path length equal to mean invert tuff } \\
\text { particle radius, } 5 \mathrm{~mm} \text {. } \\
\text { Parameters are dependent on discretization of the } \\
\text { invert model; see Section 6.5.3.5 for discretization and } \\
\text { implementation details. }\end{array}$ \\
\hline 5. Invert-UZ interface & $\begin{array}{l}\text { Advection from the invert } \\
\text { intragranular continuum to } U Z \\
\text { matrix }\left(F_{8}\right) \text {. } \\
\text { Advection from the invert } \\
\text { intergranular continuum to } U Z \\
\text { fractures }\left(F_{9}\right) \text {. } \\
\text { Diffusion from the invert } \\
\text { intragranular continuum to } \cup Z \\
\text { fractures and matrix. } \\
\text { Diffusion from the invert } \\
\text { intergranular continuum to } U Z \\
\text { fractures and matrix. }\end{array}$ & $\begin{array}{l}\text { The invert diffusion calculation uses radionuclide } \\
\text { concentrations in the WP corrosion products domain } \\
\text { as the boundary condition at the top of the invert and a } \\
\text { series of unsaturated zone computational cells below } \\
\text { the invert that provide a gradient to a zero radionuclide } \\
\text { concentration at some distance from the bottom of the } \\
\text { invert. See Section 6.5.3.6. }\end{array}$ \\
\hline
\end{tabular}

WP = waste package

For discussion of the diffusive flux treatment at the corrosion products domain/invert interface consider a diffusive flux term, either aqueous or colloid flux, within the transport mass balance equation. Let $z_{\text {interface }}$ denote the spatial location of the corrosion products domain/invert interface. Then for $z<z_{\text {interface }}$, the diffusive flux for radionuclide species $i$ at a location within the corrosion products domain is:

$$
\phi_{C P} S_{w_{-} C P} D_{C P} \frac{\partial C_{i C P}}{\partial z}
$$

where $\phi_{C P}$ is the porosity of the single-continuum corrosion products domain.

For $z>z_{\text {interface }}$, the diffusive fluxes within the intergranular invert and intragranular invert media are, respectively,

$$
\begin{gathered}
\phi_{\text {inter }} S_{w_{-} \text {inter }} D_{\text {inter }} \frac{\partial C_{\text {inter }}}{\partial z}, \\
\phi_{\text {intra }} S_{w_{-} \text {intra }} D_{\text {intra }} \frac{\partial C_{\text {intra }}}{\partial z} .
\end{gathered}
$$


The mass transport across this interface is coupled by the flux continuity condition at the interface:

$$
\begin{aligned}
\phi_{C P} S_{w_{-} C P} D_{C P} \frac{\partial C_{i C P}}{\partial z^{-}} & =\phi_{\text {inter }} S_{w_{-} \text {inter }} D_{\text {inter }} \frac{\partial C_{\text {inter }}}{\partial z^{+}} \\
& +\phi_{\text {intra }} S_{w_{-} \text {intra }} D_{\text {intra }} \frac{\partial C_{\text {intra }}}{\partial z^{+}},
\end{aligned}
$$

where

$$
\frac{\partial}{\partial z^{-}} \text {and } \frac{\partial}{\partial z^{+}}
$$

are the derivative from above and the derivative from below, respectively, at the interface.

A similar flux continuity condition for each invert continuum is applied at the invert/UZ interface.

\subsubsection{Invert Dual Continuum Interface Transfer}

If a gradient exists in the concentration of dissolved radionuclide species $i$ or of colloids that contain radionuclide species $i$, mass will be transferred across the interface between the two continua. The mass transfer coefficients for dissolved species and colloids, $\alpha$ ( $\mathrm{s}^{-1}$, given by Equation 6.5.1.2-22), are dependent on the geometry and diffusivity in the neighborhood of the interface.

Mass will also be transferred with advective flow across the interface as a result of head or pressure gradients between the two continua, for example, when imbibition into the tuff matrix (i.e., intragranular continuum) occurs. This effect is ignored in the invert since it should be a short term and infrequent occurrence.

When advective interface mass transfer is neglected, the mass transfer coefficient has the form (Gerke and van Genuchten 1996 [DIRS 167466], p. 345; Corapcioglu and Wang 1999 [DIRS 167464], p. 3263; Šimůnek et al. 2003 [DIRS 167469], pp. 28 and 30):

$$
\alpha=\frac{\beta}{d^{2}} D_{e}
$$

where $\beta$ is a dimensionless geometry-dependent coefficient, $d$ is a characteristic length (m) of the matrix structure (e.g., half the aggregate width or half the fracture spacing), and $D_{e}$ is an effective diffusion coefficient $\left(\mathrm{m}^{2} \mathrm{~s}^{-1}\right)$ that represents the diffusion properties of dissolved species at the interface between the two continua for radionuclide species $i$. For colloids containing sorbed radionuclides, $D_{e}$ represents the diffusion properties of those colloids at the interface between the two continua. Since the self-diffusion coefficient of water is used as a bounding value for all radionuclides, the subscript on the diffusion coefficient in Equation 6.5.1.2-22 can be dropped in Equation 6.6.4.1-1. 
Mass transfer coefficients obtained analytically using Laplace transform comparisons derived values for $\beta$ of 3 for rectangular slabs, 8 for solid cylinders, and 15 for spheres (Gerke and van Genuchten 1996 [DIRS 167466], p. 345). Values of $\beta$ have also been obtained (Gerke and van Genuchten 1996 [DIRS 167466]) by directly matching analytical solutions of the diffusion models to results obtained with the first-order model such as Equation 6.5.1.2-18. Gerke and van Genuchten (1996 [DIRS 167466]) derived an empirical expression to estimate $\beta$ for complex and mixed types of structural geometry. A dimensionless surface-area-to-volume ratio of a particle, $\zeta=\frac{A_{g}}{V_{g}} a_{g}$, is defined, where $a_{g}$ is the effective length of the matrix pore system; for example, for a solid cylinder, $a_{g}$ is the radius; for a cube, $a_{g}$ is half the length of a side; for a sphere, $a_{g}$ is the radius. Thus, for a solid cylinder, $\zeta=2$, and for a sphere and a cube, $\zeta=3$. For values $2<\zeta \leq 10$, Gerke and van Genuchten (1996 [DIRS 167466], p. 354) give the following fitted empirical expression:

$$
\beta=11.4275-7.4438 \zeta+3.5473 \zeta^{2}
$$

For cubes and spheres, Equation 6.6.4.1-2 gives a value for $\beta$ of 21.0 (compared to 15 for a sphere using the analytical method), and for a solid cylinder, $\beta=10.7$ (compared to 8 from the analytical method). Since the geometry of crushed tuff invert particles is uncertain, these estimates of $\beta$ help to establish a range of values over which $\beta$ can be sampled.

The crushed tuff invert material will be produced by a tunnel boring machine that will excavate the drifts for the repository. The cuttings from tunnel boring machines can be characterized as generally well graded material containing large flat and elongated chips and moderate excess of fines (Gertsch et al. 1993 [DIRS 107880], p. 20). Tests done on samples of TSw2 tuff using a linear cutting machine produced cuttings that, in the plus inch fraction, were elongated and flat, while the finer particles were more cubic (Gertsch et al. 1993 [DIRS 107880], p. 42-43). The operating parameters expected to be utilized in the Yucca Mountain Project tunnel boring machine will reduce the maximum particle size and result in the particles being more cubic (Gertsch et al. 1993 [DIRS 107880], p. 44). Particle sizes for the invert material will range from $0.075 \mathrm{~mm}$ (No. 200 sieve) to $50 \mathrm{~mm}$, with 50 percent of the particles passing a 10-mm sieve (BSC 2004 [DIRS 170559], Sheet 2). Therefore, the average diameter for invert crushed tuff particles (spherical or cylindrical) is $10 \mathrm{~mm}$; and if the particles are treated as cubes, the average length of a side is $10 \mathrm{~mm}$. The characteristic length $d$ (Diff_Length_Inv_Inter_Intra) is the radius or half the distance through a cube, or $5 \mathrm{~mm}$.

The invert material will be composed of particles that are roughly spherical or cubic, along with elongated particles that can be considered roughly cylindrical. For cylinders, cubes, and spheres, estimates of $\beta$ (Invert_Geometry_Coef) range from 8 to 21 . A particle shape distribution is not available; therefore, a uniform distribution for $\beta$ is appropriate.

The model for the mass transfer between overlapping continua is represented by the diffusion of solute on a macroscopic control volume scale, i.e., between two entire domains or computational cells, rather than on the elemental volume scale used to formulate the mass balance equations in 
Section 6.5.1.2. Consequently, the mass transfer between the two invert continua is not written as a gradient of diffusive mass flux with respect to the coordinate dimensions. In the discrete formulation, this flux is modeled as a diffusive flux between two invert cells. For the discrete realization of the invert continua mass transfer, the diffusive length within the intergranular continuum is taken to be zero. This is a result of the water within the intergranular continuum consisting of a film of negligible thickness on the surface of the intragranular materials. The diffusive length within the intragranular continuum depends on some mean diffusive length within the crushed tuff material. This diffusive length is taken as a mean radius of spherical particles, $5 \mathrm{~mm}$. The diffusive area is estimated as the surface area of all spherical particles necessary to fill the invert volume. Therefore, the characteristic length parameter, $d$, is identified as the diffusive length $(5 \mathrm{~mm})$ within the intragranular continuum.

\subsubsection{Discretization of Dual-Continuum Invert Alternative Computational Model}

Discretization of the continuum mass balance equations for EBS transport model is described in Section 6.5.3.5 for a single-continuum invert. Numerical modeling of the EBS radionuclide transport is performed using the GoldSim software (Golder Associates 2003 [DIRS 166572]) cell pathway capability. The cell pathway acts as a batch reactor, where radionuclide mass is assumed to be instantaneously and completely mixed and partitioned among all media (fluid or solid) within the cell. When multiple cells are linked together in a cell network via advective and diffusive mechanisms, GoldSim numerically solves the coupled system of equations to compute the radionuclide mass present in each cell and the mass fluxes between cells as a function of time.

Within a computational cell network, each cell is allowed to communicate by advection and/or diffusion with any other cell. This concept is crucial in implementing the bifurcation of diffusive fluxes across an interface between a single continuum domain and a dual continuum domain, such as at the interface between the corrosion products domain and the dual continuum invert domains. Each computational cell is provided with parameters describing water volumes, diffusive properties, and advective and diffusive flux links to other cells. Between any two cells, the diffusive flux can be bidirectional, depending on the concentration gradient, while the advective flux is unidirectional. The output of a cell is given in terms of the advective and diffusive mass fluxes for radionuclide species $i$ and its concentration at the cell center.

In this alternative conceptual model, the invert is conceptualized as a dual continuum domain of intergranular and intragranular continua. The discretization of the invert domain, using GoldSim, consists of two cells - one representing the invert intergranular continuum and the other representing the invert intragranular continuum.

Between the corrosion products and invert domains, an advective flux communication exists from the corrosion products cell to the invert intergranular cell only; none enters the intragranular invert cell. Any advective flux due to imbibition from the host rock to the invert enters the intragranular cell only. The advective exchange from the intergranular continuum to the intragranular continuum is excluded by capillary pressure differences. Diffusive flux communication exists between the single continuum corrosion products and dual continuum invert. It is shown subsequently in this section how the diffusive flux bifurcation at this interface satisfies the flux continuity condition (Equation 6.5.1.2-53). The mass balance transport 
equations for the dual continuum invert cells are coupled by the radionuclide mass transfer flux (Section 6.6.4.1), which is represented within GoldSim as a diffusive flux link between the intergranular and intragranular invert cells.

Below the invert, part of the near-field UZ is modeled by an array of cells, which serves to establish a far field zero-concentration boundary and an accurate representation of the flux at the invert-to-UZ interface. The EBS-UZ interface model is described in more detail in Section 6.5.3.6. The dual continuum approach for modeling the UZ is considered by creating UZ matrix and fracture cells. The two invert cells communicate with the UZ matrix and fracture cells directly below them in the UZ cell array (Section 6.5.3.6).

For transport from the corrosion products domain (single continuum) to the invert domain (dual continuum), the flux continuity condition at the interface provides the diffusive flux bifurcation between the single continuum and the dual continuum.

The diffusive fluxes of radionuclide species $i$ within the corrosion products cell, the invert intergranular cell, and the invert intragranular cell are, respectively,

$$
\begin{aligned}
F_{i C P} & =\frac{\left(\phi S_{w} D A\right)_{C P}}{L_{C P}}\left(C_{i C P}-C_{i C P / \text { invint }}\right) \\
& =\hat{D}_{C P}\left(C_{i C P}-C_{i C P / \text { invint }}\right), \\
F_{\text {iinter }} & =\frac{\left(\phi S_{w} D A\right)_{\text {inter }}}{L_{\text {inter }}}\left(C_{i C P / \text { invint }}-C_{\text {iinter }}\right) \\
& =\hat{D}_{\text {inter }}\left(C_{i C P / \text { invint }}-C_{\text {inter }}\right), \\
F_{\text {iintra }} & =\frac{\left(\phi S_{w} D A\right)_{\text {intra }}}{L_{\text {intra }}}\left(C_{i C P / \text { invint }}-C_{\text {intra }}\right) \\
& =\hat{D}_{\text {intra }}\left(C_{i C P / \text { invint }}-C_{\text {intra }}\right),
\end{aligned}
$$

where

$$
\begin{aligned}
D_{C P}= & \text { effective diffusion coefficient of radionuclide species } i \text { within the corrosion } \\
& \text { products cell }\left(\mathrm{cm}^{2} \mathrm{~s}^{-1}\right) \\
= & \text { effective diffusion coefficient of radionuclide species } i \text { within the invert } \\
& \text { intergranular cell }\left(\mathrm{cm}^{2} \mathrm{~s}^{-1}\right) \\
= & \text { effective diffusion coefficient of radionuclide species } i \text { within the invert } \\
& \text { intragranular cell }\left(\mathrm{cm}^{2} \mathrm{~s}^{-1}\right) \\
= & \text { diffusive length within the corrosion products cell }(\mathrm{m}) \\
= & \text { diffusive length within the invert intergranular cell }(\mathrm{m}) \\
L_{C P} & \text { diffusive length within the invert intragranular cell }(\mathrm{m}) \\
L_{\text {inter }} & =
\end{aligned}
$$


$C_{i C P}=$ concentration of radionuclide species $i$ in the corrosion products cell $\left(\mathrm{kg} i \mathrm{~m}^{-3}\right)$

$C_{\text {inter }}=$ concentration of radionuclide species $i$ in the invert intergranular cell $\left(\mathrm{kg} i \mathrm{~m}^{-3}\right)$

$C_{\text {intra }}=$ concentration of radionuclide species $i$ in the invert intragranular cell $\left(\mathrm{kg} i \mathrm{~m}^{-3}\right)$

$C_{i C P / \text { invint }}=$ concentration of radionuclide species $i$ at the interface between the corrosion products and invert cells $\left(\mathrm{kg} i \mathrm{~m}^{-3}\right)$

and the $\hat{D}=\frac{\phi S_{w} D A}{L}$ are respective diffusive conductances $\left(\mathrm{cm}^{3} \mathrm{~s}^{-1}\right)$.

The flux continuity at the interface requires:

$$
F_{i C P}=F_{\text {iinter }}+F_{\text {iintra }} .
$$

From the flux continuity, the interface concentration of radionuclide species $i$ is determined as a function of the diffusive parameters and the cell concentrations as:

$$
C_{i C P \text { /invint }}=\frac{\hat{D}_{C P} C_{i C P}+\hat{D}_{\text {inter }} C_{\text {inter }}+\hat{D}_{\text {intra }} C_{\text {intra }}}{\hat{D}_{C P}+\hat{D}_{\text {inter }}+\hat{D}_{\text {intra }}} .
$$

This provides the invert intergranular and intragranular diffusive fluxes of radionuclide species $i$, respectively, as:

$$
\begin{aligned}
F_{\text {inter }}= & \frac{\hat{D}_{C P} \hat{D}_{\text {inter }}}{\hat{D}_{C P}+\hat{D}_{\text {inter }}+\hat{D}_{\text {intra }}}\left(C_{i C P}-C_{\text {inter }}\right) \\
& +\frac{\hat{D}_{\text {inter }} \hat{D}_{\text {intra }}}{\hat{D}_{C P}+\hat{D}_{\text {inter }}+\hat{D}_{\text {intra }}}\left(C_{\text {intrta }}-C_{\text {inter }}\right) \\
F_{\text {intra }} & =\frac{\hat{D}_{C P} \hat{D}_{\text {intra }}}{\hat{D}_{C P}+\hat{D}_{\text {inter }}+\hat{D}_{\text {intra }}}\left(C_{\text {iCP }}-C_{\text {intra }}\right) \\
& -\frac{\hat{D}_{\text {inter }} \hat{D}_{\text {intra }}}{\hat{D}_{C P}+\hat{D}_{\text {inter }}+\hat{D}_{\text {intra }}}\left(C_{\text {intra }}-C_{\text {inter }}\right) .
\end{aligned}
$$

The expression for the diffusive flux of radionuclide species $i$ from the corrosion products cell to the invert intergranular cell can be expressed as a diffusive conductance multiplied by a concentration difference of radionuclide species $i$ between the corrosion products cell and the invert intergranular cell plus a corrective flux between the invert intergranular and intragranular cells. Similarly, the expression for the diffusive flux from the corrosion products to the invert intragranular cell is expressed as a diffusive flux between the corrosion products and the invert intragranular cell minus the same corrective flux between the invert cells. The inclusion of the corrective flux term is explained as follows. The flux to both invert cells should depend on the 
diffusive properties in the corrosion products cell and the two invert cells, together with the concentrations in these three cells. Therefore, the flux to the invert intergranular cell cannot be expressed only in terms of the concentration drawdown between the corrosion products cell and the invert intergranular cell. The corrective term includes the dependence of the invert intergranular flux on the concentration of radionuclide species $i$ in the invert intragranular cell. Further, the corrective flux term is not a true flux expression between the two invert cells, since the diffusive conductance coefficient is dependent on the diffusive area between the corrosion products and the invert, and the diffusive lengths are the lengths with respect to flow from the corrosion products cell to the invert cells.

The invert fluxes result in defining three diffusive conductances from the flux expressions:

$$
\begin{aligned}
& \hat{D}_{C P / \text { inter }}\left(C_{i C P}-C_{\text {inter }}\right)=\frac{\hat{D}_{C P} \hat{D}_{\text {inter }}}{\hat{D}_{C P}+\hat{D}_{\text {inter }}+\hat{D}_{\text {intra }}}\left(C_{i C P}-C_{\text {inter }}\right), \\
& \hat{D}_{C P / \text { intra }}\left(C_{i C P}-C_{\text {intra }}\right)=\frac{\hat{D}_{C P} \hat{D}_{\text {intra }}}{\hat{D}_{C P}+\hat{D}_{\text {inter }}+\hat{D}_{\text {intra }}}\left(C_{i C P}-C_{\text {iintra }}\right), \\
& \hat{D}_{\text {intra/inter }}\left(C_{\text {intra }}-C_{\text {inter }}\right)=\frac{\hat{D}_{\text {intra }} \hat{D}_{\text {inter }}}{\hat{D}_{C P}+\hat{D}_{\text {inter }}+\hat{D}_{\text {intra }}}\left(C_{\text {intra }}-C_{\text {inter }}\right),
\end{aligned}
$$

where

$$
\begin{aligned}
D_{C P / \text { inter }}= & \text { effective diffusive conductance between corrosion products cell and invert } \\
& \text { intergranular cell }\left(\mathrm{cm}^{3} \mathrm{~s}^{-1}\right) \\
\hat{D}_{C P / \text { intra }}= & \text { effective diffusive conductance between corrosion products cell and invert } \\
& \text { intragranular cell }\left(\mathrm{cm}^{3} \mathrm{~s}^{-1}\right) \\
\hat{D}_{\text {intra/inter }}= & \text { effective diffusive conductance between invert intragranular and } \\
& \text { intergranular cells }\left(\mathrm{cm}^{3} \mathrm{~s}^{-1}\right) .
\end{aligned}
$$

In order to accommodate the GoldSim representation of diffusive conductance as a two-term expression, the diffusive conductances of radionuclide species $i$ are written as:

$$
\begin{aligned}
& \hat{D}_{C P / \text { inter }}=\frac{1}{\left(\phi S_{w} D A\right)_{C P}\left[\frac{L_{C P}}{\left(\phi S_{w} D A\right)_{\text {inter }}+\left(\phi S_{w} D A\right)_{\text {intra }}}\right]}+\frac{L_{\text {inter }}}{\left(\phi S_{w} D A\right)_{\text {inter }}} \text {, } \\
& \hat{D}_{C P / \text { intra }}=\frac{1}{\left(\phi S_{w} D A\right)_{C P}\left[\frac{L_{C P}\left[\frac{\left(\phi S_{w} D A\right)_{\text {intra }}}{\left(\phi S_{w} D A\right)_{\text {inter }}+\left(\phi S_{w} D A\right)_{\text {intra }}}\right]}{\left(\phi S_{w} D A\right)_{\text {intra }}}\right.},
\end{aligned}
$$




$$
\hat{D}_{\text {intralinter }}=\frac{1}{\frac{L_{\text {inter }}}{\left(\phi S_{w} D A\right)_{\text {inter }}\left[\frac{L_{C P}\left(\phi S_{w} D A\right)_{\text {intra }}}{L_{C P}\left(\phi S_{w} D A\right)_{\text {intra }}+L_{\text {intra }}\left(\phi S_{w} D A\right)_{C P}}\right]}+\frac{L_{\text {intra }}}{\left(\phi S_{w} D A\right)_{\text {intra }}}} .
$$

Another approach to discretizing the dual-continuum invert requires introduction of an interface cell, located between the corrosion products cell and the invert cells. This approach is used for this alternative invert model. The interface cell provides an approximate interface concentration and the resulting flux split at the corrosion products to invert cell interface. The interface cell is conceptualized as a very thin slice of the corrosion products cell.

This implies the interface cell takes on the corrosion products diffusive properties, with the exception of diffusive length. Let the diffusive length within the interface cell be some small fraction (an Interface_Scale_Factor) of the corrosion products diffusive length, say, Interface_Scale_Factor $=10^{-6}$ :

$$
L_{C P-i n t}=10^{-6} L_{C P}
$$

The use of a Interface_Scale_Factor of $10^{-6}$ is examined in Section 6.6.4.4.

The diffusive conductance between the corrosion products cell and the corrosion products interface cell is calculated as the harmonic average:

$$
\hat{D}_{C P / C P-i n t}=\frac{1}{\frac{L_{C P}}{\left(\phi S_{w} D A\right)_{C P}}+\frac{L_{C P-i n t}}{\left(\phi S_{w} D A\right)_{C P}}} .
$$

For diffusion between the interface cell and the invert intergranular and intragranular cells, the diffusive conductances are, respectively,

$$
\begin{aligned}
\hat{D}_{C P \text {-int } / \text { inter }}= & \frac{1}{\frac{L_{C P-\text { int }}}{\left(\phi S_{w} D A\right)_{C P}}+\frac{L_{\text {invert }}}{\left(\phi S_{w} D A\right)_{\text {inter }}}}, \\
\hat{D}_{C P \text {-int } / \text { intra }}= & \frac{1}{\frac{L_{C P-\text { int }}}{\left(\phi S_{w} D A\right)_{C P}}+\frac{L_{\text {invert }}}{\left(\phi S_{w} D A\right)_{\text {intra }}}} .
\end{aligned}
$$

The interface cell concentration of radionuclide species $i$ is computed as part of the cell network solution. Because the transport mass balance equations conserve mass, the mass flux leaving the interface cell must equal the sum of the mass fluxes entering the two invert cells. The solution provides the flux continuity across the interface between the corrosion products interface cell and invert cells. This formulation expects the flux exiting the corrosion products cell (or entering the interface cell) to be approximately equal to the flux exiting the interface cell. This 
approximation is dependent on the diffusive length within the interface cell. The error in this approximate solution will approach zero as the diffusive length of the interface cell approaches zero.

At the invert-to-UZ interface, there is diffusive transport between both the invert cells and the UZ matrix and fracture cells. This implies four connections: from invert intergranular to UZ matrix, from invert intergranular to UZ fracture, invert intragranular to UZ matrix, and from invert intragranular to UZ fracture. An analysis similar to that for the diffusive conductances between the corrosion products cell and the dual invert cells (Equations 6.6.4.25-11 through 6.6.4.2-13) would provide expressions for diffusive conductances for each of the four diffusive flux links. However, for the TSPA-LA, the approximation provided by introducing an interface cell when diffusing from a single to a dual continuum exits is used. An approximate solution is obtained by the introduction of two interface cells at the invert-UZ interface. This approach is identical to that used above for the interface between the corrosion products cell and the invert dual continuum cells. One interface cell represents a thin slice of the invert intergranular cell, and the other represents a thin slice of the invert intragranular cell. Let the length of both invert interface cells be a fraction (an Interface_Scale_Factor) of the invert diffusive length, say, Interface_Scale_Factor $=10^{-6}$ :

$$
L_{\text {invert_int }}=10^{-6} L_{\text {invert }} \text {. }
$$

The use of an Interface_Scale_Factor of $10^{-6}$ is examined in Section 6.6.4.4.

The diffusive conductance between the invert intergranular cell and the invert intergranular interface cell is:

$$
\hat{D}_{\text {inter/inter-int }}=\frac{1}{\frac{L_{\text {invert }}}{\left(\phi S_{w} D A\right)_{\text {inter }}}+\frac{L_{\text {invert_int }}}{\left(\phi S_{w} D A\right)_{\text {inter }}}},
$$

while the diffusive conductance between the invert intragranular cell and the invert intragranular interface cell is:

$$
\hat{D}_{\text {intra/intra-int }}=\frac{1}{\frac{L_{\text {invert }}}{\left(\phi S_{w} D A\right)_{\text {intra }}}+\frac{L_{\text {invert_int }}}{\left(\phi S_{w} D A\right)_{\text {intra }}}} .
$$

The fluxes of radionuclide species $i$ from the invert intergranular interface cell to the matrixfracture UZ cells are computed with diffusive conductances:

$$
\hat{D}_{\text {inter-int } / U Z m}=\frac{1}{\frac{L_{\text {invert_int }}}{\left(\phi S_{w} D A\right)_{\text {inter }}}+\frac{L_{U Z}}{\left(\phi S_{w} D A\right)_{U Z m}}},
$$




$$
\hat{D}_{\text {inter-int } / U Z f}=\frac{1}{\frac{L_{\text {invert_int }}}{\left(\phi S_{w} D A\right)_{\text {inter }}}+\frac{L_{U Z}}{\left(\phi S_{w} D A\right)_{U Z f}}} .
$$

Similarly, the fluxes of radionuclide species $i$ from the invert intragranular interface cell to the matrix-fracture UZ cells are computed with diffusive conductances:

$$
\begin{aligned}
& \hat{D}_{\text {intra-int/UZm }}=\frac{1}{\frac{L_{\text {invert_int }}}{\left(\phi S_{w} D A\right)_{\text {intra }}}+\frac{L_{U Z}}{\left(\phi S_{w} D A\right)_{U Z m}}}, \\
& \hat{D}_{\text {intra-int/UZf }}=\frac{1}{\frac{L_{\text {invert_int }}}{\left(\phi S_{w} D A\right)_{\text {intra }}}+\frac{L_{U Z}}{\left(\phi S_{w} D A\right)_{U Z f}}} .
\end{aligned}
$$

One last term to be discussed is the mass transfer term, $Q_{i m t}$, between the two invert continua given by Equation 6.5.1.2-19. This term appears in the mass balance for the transport of radionuclides dissolved in the aqueous phase and reversibly sorbed (Equation 6.5.1.2-38, or, for the one-dimensional case, Equation 6.5.1.2-46), and in the mass balance for irreversibly adsorbed radionuclides on iron oxyhydroxide colloids (Equation 6.5.1.2-41, or Equation 6.5.1.2-47 in one dimension). In these equations, the mass transfer between overlapping continua is represented by the diffusion of solute on a macroscopic control volume scale. Consequently, the mass transfer between the two invert continua is not written as a gradient of diffusive mass flux with respect to the coordinate dimensions, and the treatment described above for diffusive conductances does not directly apply. For the discrete realization of the invert continua mass transfer, the diffusive length within the intergranular continuum is taken to be zero. This is a result of the water within the intergranular continuum consisting of a thin film on the surface of the intragranular materials. The diffusive length within the intragranular continuum depends on some mean diffusive length within the crushed tuff material. This diffusive length is taken as a mean radius of spherical particles. The effective diffusive area is estimated as the surface area of all spherical particles necessary to fill the invert volume. Therefore, the characteristic length parameter, $d(\mathrm{~m})$, is identified as the diffusive length within the intragranular continuum, and the diffusive area to length ratio is:

$$
\left(\frac{A}{L}\right)_{\text {inter rintra }}=\frac{\beta \theta_{\text {intra }} V_{t_{\text {intra }}}}{100 d^{2}}
$$

where $V_{t_{-} \text {intra }}$ is the volume of the invert intragranular continuum $\left(\mathrm{m}^{3}\right), \theta_{\text {intra }}$ is the water content in the invert intragranular continuum (percent), and $\beta$ is the sampled geometry-dependent factor, Invert_Geometry_Coef (dimensionless). The effective diffusive conductance is:

$$
\hat{D}_{c}=D_{\text {intra }}\left(\frac{A}{L}\right)_{\text {inter intra }} .
$$




\subsubsection{Dual-Continuum EBS-UZ Boundary Condition}

The EBS-UZ boundary condition implementation described in Section 6.5.3.6 is used to obtain a realistic concentration boundary condition at the invert-UZ interface. For the dual-continuum invert alternative model, the boundary condition implementation is modified to account for diffusive fluxes from each invert continuum to both UZ fractures and matrix. This implementation is represented in Figure 6.6-3.

The mass flux from either invert continuum flows into the top layer of the middle zone in the UZ. The intergranular invert advective flux flows into the top middle UZ fracture cell, while the intragranular invert advective flux flows into the top middle UZ matrix cell. Advective transfer of water between the two continua is ignored. The diffusive flux from each of the invert continua can go into both UZ continua based on the concentration gradient and effective diffusion coefficient. The advective flux flowing through the UZ fracture cells in the middle zone is given by the greater of the advective flux out of the invert and the steady state UZ fracture flux. The advective flux in the two outer zones is given by the steady state UZ flow in each continuum at the repository horizon; the drift shadow effects are ignored in the transport calculations as a bounding approximation.

The mass flux from the dual continuum invert domain to the dual continuum UZ, computed at the boundary of the EBS-UZ interface, would be passed to the UZ transport model, which is described in Particle Tracking Model and Abstraction of Transport Processes (BSC 2004 [DIRS 170041]). In addition to the total mass flux, the relative fraction of the mass going into each of the fracture and the matrix cells at the EBS-UZ boundary is required by the UZ transport model. This fracture-matrix partitioning of mass is calculated on the basis of the mass fraction going into the fracture continuum (compared to the matrix continuum) from the dual continuum invert domain in the EBS-UZ interface model. This partitioning is time dependent and captures the temporal processes active in the EBS, such as varying radionuclide concentrations in the waste form, corrosion products, and invert domains and changing water flux through various subcomponents of the EBS.

\subsubsection{Verification of Dual Invert/Dual UZ Diffusive Flux Bifurcation}

In this section, calculation of the diffusive flux from a single cell (corrosion products) to dual invert cells (intergranular invert and intragranular invert) and then to two UZ cells (UZ matrix and UZ fracture) is tested. These tests show that the approximations in the GoldSim implementation using an Interface_Scale_Factor of $1.0 \times 10^{-6}$ are correct and that the implementation in GoldSim agrees with Microsoft Excel calculations.

In this verification test calculation, there is no diffusive communication between the dual continuum invert cells, and there is no diffusive communication between the UZ matrix/fracture cells. The corrosion products cell provides a diffusive flux to the dual continuum invert cells. Each invert cell provides a diffusive flux to both the UZ matrix and fracture cells. For this verification, at time zero, an initial mass of one gram is released in the corrosion products cell, while all other cells have initial mass of zero. Parameters controlling diffusion through this test network were not determined strictly from TSPA-LA data, but were set so that measurable mass transport to all cells within the network occurs in a reasonable time frame. No parameters were 
assigned a value of one (other than the initial mass in the waste form cell), because any mistake in multiplication or division by a unit parameter would not be readily detectable.
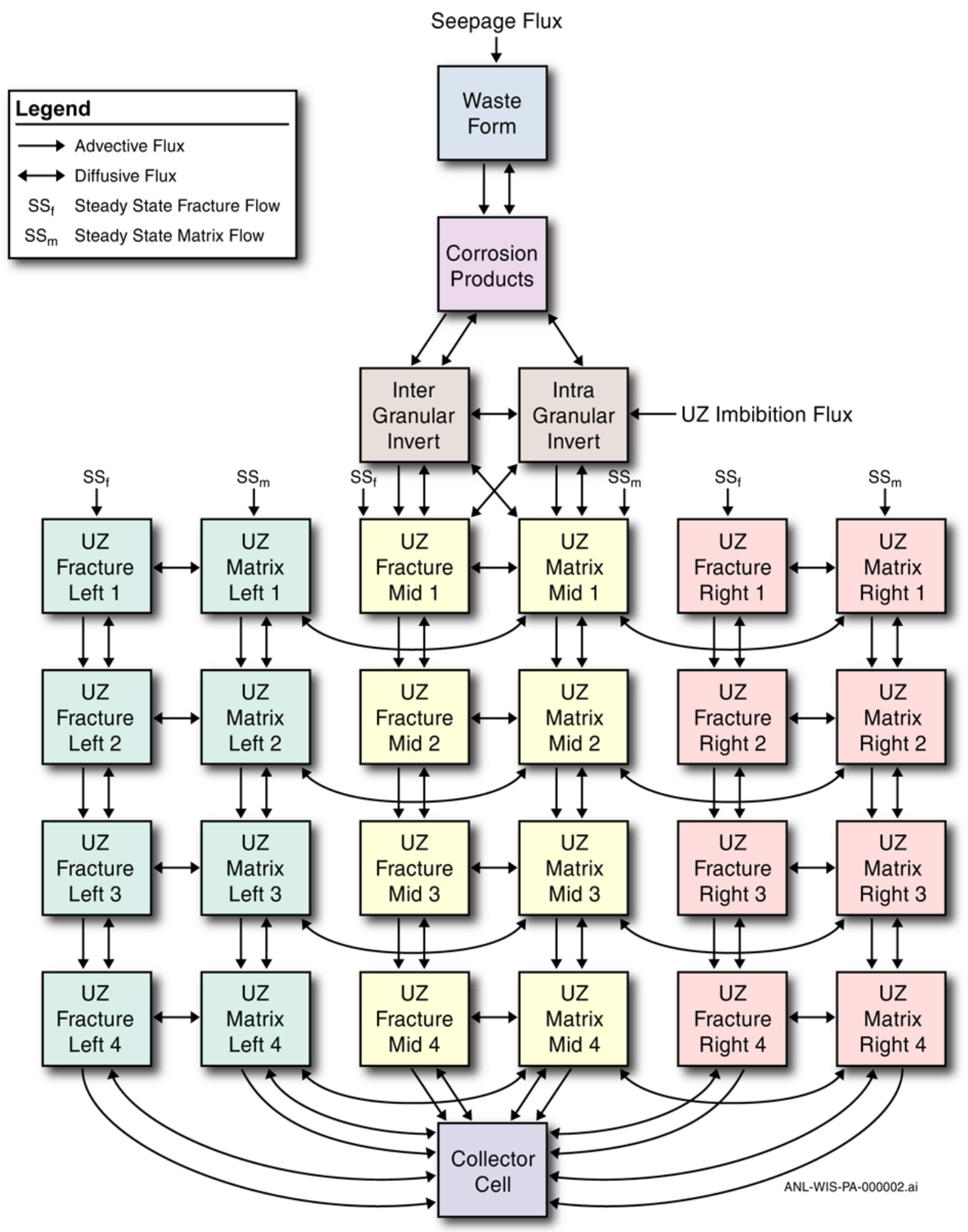

Figure 6.6-3. Computational Grid in the EBS-UZ Interface Model (Dual-Continuum Invert) 
Two analytical approaches (A1 and A2) to the flux bifurcation can be taken when diffusion occurs from a single cell to dual cells:

A1: The first approach computes diffusive conductances between the single cell and each dual continuum cell; an auxiliary conductance is required between the dual continuum cells. This formulation presents the appearance of a diffusive flux communication between the dual continuum cells, when physically there is no such flux. This approach requires a five-cell network (corrosion products, invert intergranular, invert intragranular, UZ matrix, and UZ fracture) and provides an exact representation of the fluxes.

A2: The second approach incorporates an interface cell between cells where diffusion bifurcates from a single continuum cell to dual continuum cells. The interface cell provides an approximate concentration at the flux bifurcation interface. For diffusion from a single continuum cell to dual continuum cells, the interface cell is conceptualized as a thin slice of the single continuum cell. This implies that, for the proposed cell network, an interface cell is located between the corrosion products cell and the dual invert continuum cells. This cell is assigned representative properties of the corrosion products cell, with the exception of the diffusive length. The diffusive length for the interface cell is taken to be an Interface_Scale_Factor times the diffusive length of the corrosion products cell. Between the intergranular invert cell and the dual UZ cells, an intergranular invert interface cell is introduced with diffusive properties of the intergranular invert and a diffusive length of the Interface_Scale_Factor times the diffusive length of the invert. Similarly, between the intragranular invert cell and the dual UZ cells, an intragranular invert interface cell is introduced. This conceptualization requires an eight-cell network (five cells of A1 plus three interface cells) and provides an approximate solution.

Three solutions to the diffusion problem are presented:

S1: The first solution is an Excel calculation using A1 approach. This provides an exact solution for the transport network.

S2: The second solution is an Excel calculation using A2 approach. This provides an approximate solution dependent on the Interface_Scale_Factor parameter. A successive refinement of the Interface_Scale_Factor demonstrates the convergence of the approximate solution (S2) to the exact solution (S1).

S3: The third solution is a GoldSim stand-alone calculation using the A2 approach. This solution is compared with solution $\mathbf{S} 2$ to verify the GoldSim implementation of the model within the EBS transport abstraction.

The convergence of the approximate solution S2 to the exact solution S1 with refinement of the Interface_Scale_Factor is shown in Figure 6.6-4, where the relative error $[|(\mathbf{S 1}-\mathbf{S 2})| / \mathbf{S 1}]$ of the mass in place for each network cell is plotted as a function of the Interface_Scale_Factor. Figure 6.6-4 shows that the solution S2 converges to the exact solution S1 (i.e., a relative error of zero) with first order convergence rate with respect to the Interface_Scale_Factor. The error in the UZ matrix cell is not observed in Figure 6.6-4, since it is overlain by the error in the UZ fracture cell. 
Figure 6.6-5 presents the GoldSim solution S3 and the Microsoft Excel solution S2. The Microsoft Excel solution S2 and GoldSim solution S3 use an Interface_Scale_Factor of $1.0 \times 10^{-6}$. Figure 6.6-5 shows the mass in place for each of the five cells and demonstrates the excellent agreement between the Microsoft Excel solution and GoldSim solution. After 2 years, the maximum relative error for the corrosion products cell and the two invert cells is 0.2 percent, and the maximum relative error for the two UZ cells is 1.5 percent.

These results confirm that the bifurcation of diffusive flux from a single continuum (corrosion products domain) to a dual continuum (invert domain) and then to another dual continuum (UZ) is accurate and properly implemented in GoldSim.

\subsubsection{Summary of Dual-Continuum Invert Alternative Conceptual Model}

This alternative conceptual model treats the crushed tuff in the invert as a dual continuum comprised of two pore spaces - intragranular pore space (tuff particle matrix) and intergranular pore space. Although radionuclide transport by both advection and diffusion can occur in both pore spaces, the dominant flow and transport processes in each of these two pore spaces is generally different. The invert is conceptualized in this alternative conceptual model as overlapping dual continua using a dual-permeability approach, wherein flow and transport occur in both pore spaces, and mass transfer takes place between the two pore spaces. Despite the potential for increased accuracy compared to the base case, single-continuum model, insufficient data exist to validate diffusion coefficients in the individual continua. There are also insufficient data to confirm whether this is a bounding approach with respect to chemical behavior in the invert. Therefore, the single-continuum model is used in TSPA-LA.

\subsubsection{Alternative Invert Diffusion Coefficient Models}

The following two alternative models for determining the diffusion coefficient in the invert are assessed in this section: the single-continuum invert diffusion coefficient model and the dual-continuum invert diffusion coefficient model.

\subsubsection{Alternative Single-Continuum Invert Diffusion Coefficient Model}

As an alternative to the Archie's law approach for determination of the diffusion coefficient for the single-continuum invert (Section 6.3.4.1), diffusion through the crushed tuff invert ballast is modeled using an approach that has been applied to diffusion in soils. Studies generally show that the bulk diffusion coefficients of soils at high water content decline with the moisture content and that a Millington-Quirk power law developed for high moisture content overpredicts the diffusion coefficient at low moisture content (Nye 1979 [DIRS 167377]; Olesen et al. 1999 [DIRS 154588]). The studies also show that, below a critical moisture content, the diffusion coefficient for granular materials becomes negligible (So and Nye 1989 [DIRS 170588]). 
Olesen et al. (1996 [DIRS 155700]) found the best description of the bulk diffusion coefficient of granular soils is the following:

$$
\begin{array}{ll}
D=0.0045 D_{0} \theta \frac{(\theta-2.2 b)}{(100 \phi-2.2 b)}, & \theta \geq 2.2 b \\
D=0, & \theta<2.2 b,
\end{array}
$$

where $D, \theta$, and $\phi$ are the bulk diffusion coefficient $\left(\mathrm{cm}^{2} \mathrm{~s}^{-1}\right)$, moisture content (percent), and bulk porosity of the soil (fraction), respectively, $D_{0}$ is the free water diffusion coefficient for self-diffusion of water, $2.299 \times 10^{-5} \mathrm{~cm}^{2} \mathrm{~s}^{-1}$ at $25^{\circ} \mathrm{C}$ (Mills 1973 [DIRS 133392], Table III), and the term $2.2 b$ (percent) corresponds to the critical moisture content for these soils. In this expression, the parameter $b$ corresponds to the dimensionless slope of the Campbell moisture retention curve on a log-log plot that varies with the pore and grain size distribution of the soil (Olesen et al. 1996 [DIRS 155700]).

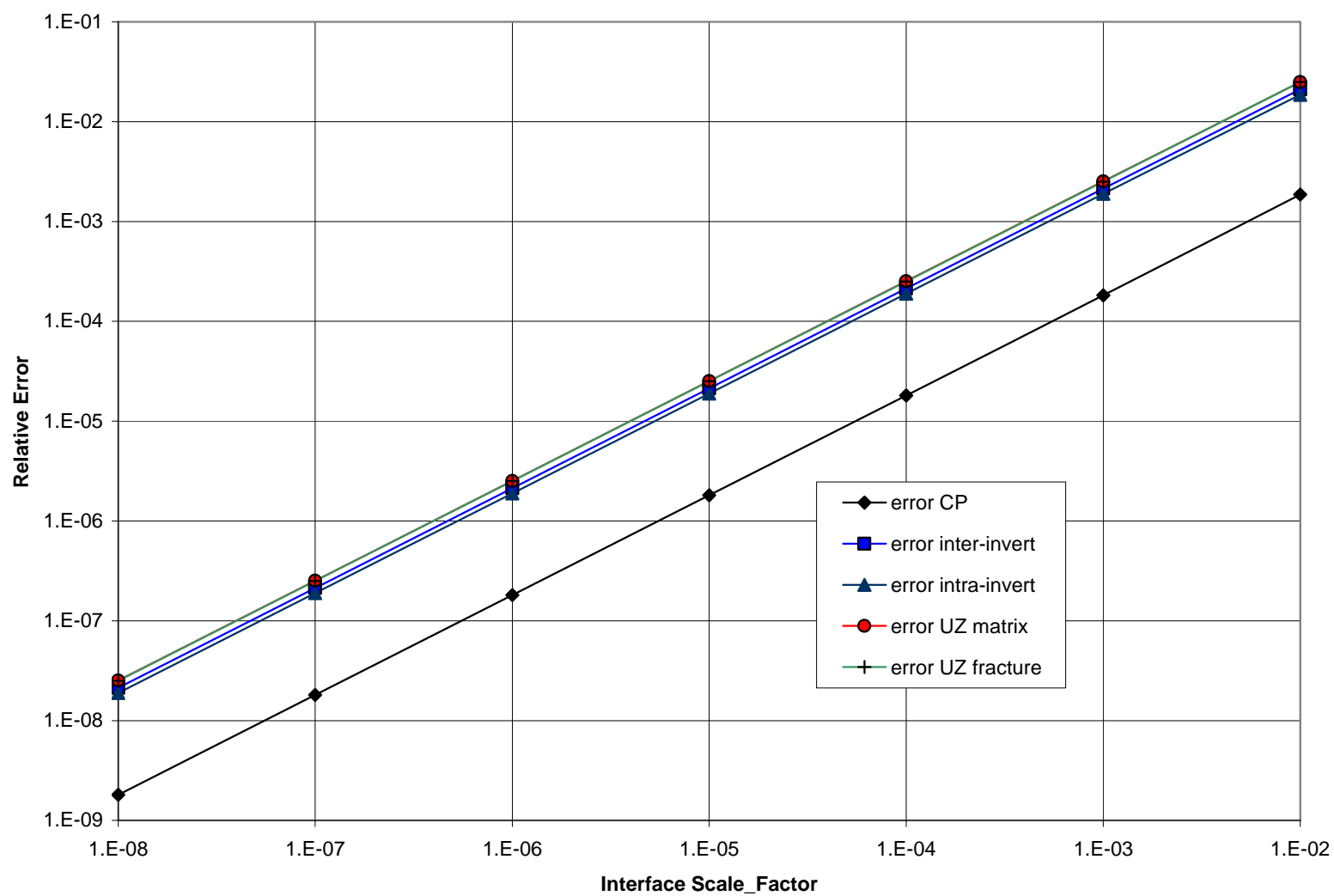

Source: DTN: MO0508SPAUZDIF.000.

Figure 6.6-4. Relative Error of Mass-in-Place for Microsoft Excel Approximate Solution 


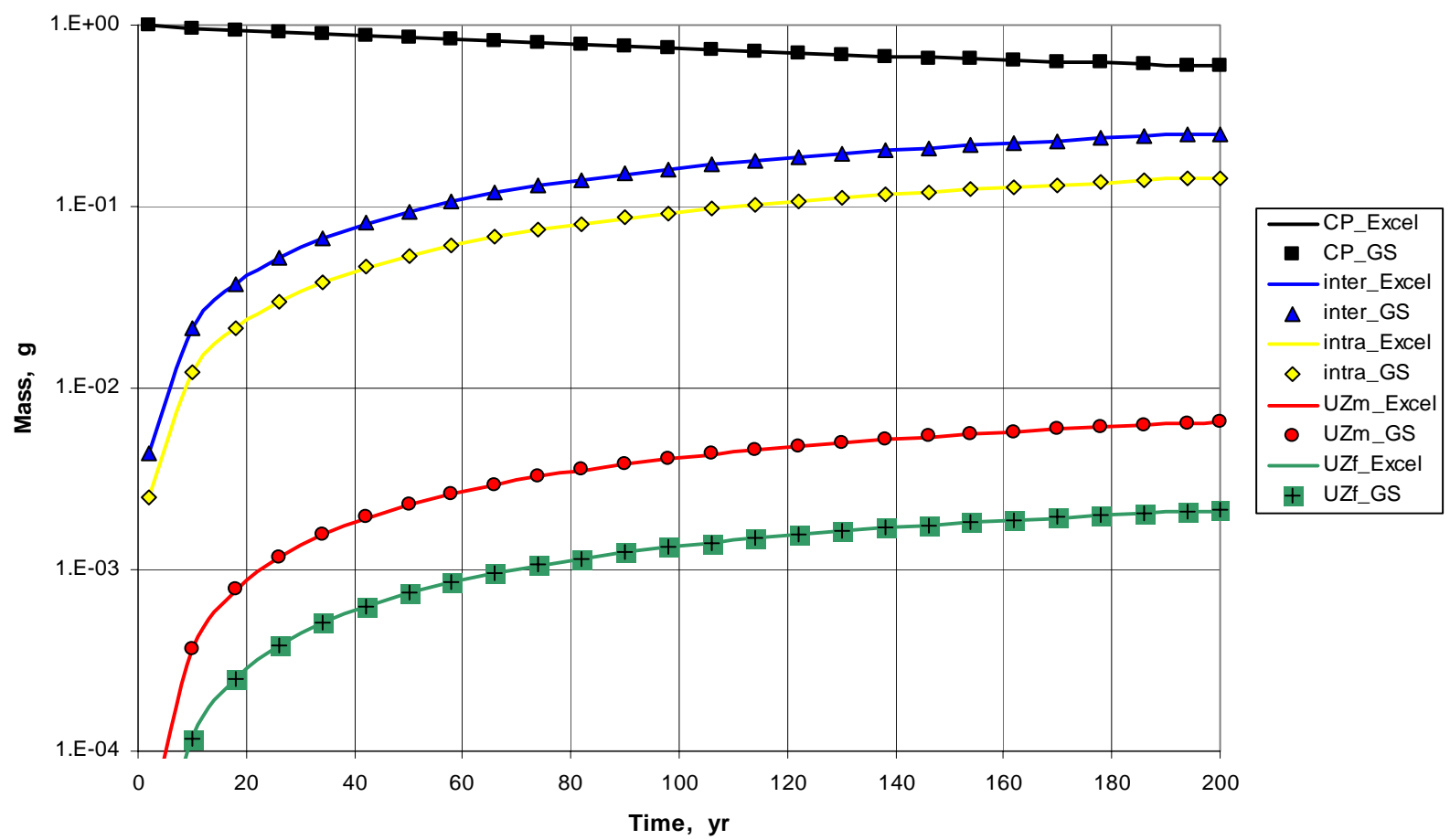

Source: DTN: MO0508SPAUZDIF.000.

Figure 6.6-5. Comparison of Microsoft Excel and GoldSim Flux Bifurcation Solutions

This behavior for granular materials is generally explained (Olesen et al. 1999 [DIRS 154588]) in terms of a picture in which:

- Above the critical moisture content, the bulk diffusion coefficient of granular materials is dominated by diffusion coefficient in films of moisture on the grain surfaces

- The diffusion coefficient declines as the moisture content decreases and the tortuosity associated with these films increases

- Below the critical moisture content, diffusion by the surface films cannot be supported and the diffusion coefficient is reduced to a very low value.

Conca and Wright (1990 [DIRS 101582]) have concluded that this picture is consistent with their measurements of crushed tuff.

A moisture retention relation proposed by Campbell (1985 [DIRS 100565], pp. 45-47) is used to develop the moisture potential relation for the crushed tuff invert. The relationship between moisture potential, $\psi\left(\mathrm{J} \mathrm{kg}^{-1}\right)$, and volumetric moisture content, $\theta$ (percent), is the soil moisture retention curve, described by the function (Campbell 1985 [DIRS 100565], p. 43):

$$
\psi=\psi_{e}\left(\theta / \theta_{s}\right)^{-b}
$$


where $\psi_{e}$ is the air-entry moisture potential (i.e., water potential at which the largest water-filled pore in the soil will drain) $\left(\mathrm{J} \mathrm{kg}^{-1}\right), \theta_{s}$ is the saturated moisture content (percent), and $b$ is the slope (dimensionless) of the $\ln \psi$ versus $\ln \theta$ curve. As the mean pore diameter becomes smaller, the air-entry moisture potential decreases (becomes more negative). The $b$ parameter increases as the standard deviation $\sigma_{g}(\mathrm{~mm})$ of the pore size increases. Campbell studied the relationships between geometric particle diameter, $d_{g}(\mathrm{~mm})$, geometric standard deviation, $\sigma_{g}$ $(\mathrm{mm})$, and air entry potential, $\psi_{e}\left(\mathrm{~J} \mathrm{~kg}^{-1}\right)$. By fitting Equation 6.6.5.1-2 to measured data, he obtained the following approximate relationships for soils (Campbell 1985 [DIRS 100565], p. 45) having a bulk density of $1,300 \mathrm{~kg} \mathrm{~m}^{-3}$ :

$$
\begin{gathered}
\psi_{e s}=-0.5 d_{g}^{-1 / 2}, \\
b=-2 \psi_{e s}+0.2 \sigma_{g},
\end{gathered}
$$

where $\psi_{e s}$ is the air-entry moisture potential $\left(\mathrm{J} \mathrm{kg}^{-1}\right)$; the subscript es refers to the bulk density of $1,300 \mathrm{~kg} \mathrm{~m}^{-3}$. The geometric standard deviation depends on the soil texture. The geometric standard deviation can be estimated from a soil texture diagram as equal to 1 for coarse sand particles and 5 for fine-grained material (Campbell 1985 [DIRS 100565], Figure 2.1).

The results for the Campbell retention relation for crushed tuff of 0.45 bulk porosity and grain sizes ranging from $0.317 \mathrm{~mm}$ to $20 \mathrm{~mm}$ (BSC 2005 [DIRS 173944], Appendix X) are shown in Table 6.6-3. Table 6.6-3 also shows the associated range of the critical bulk moisture content in Equation 6.6.5.1-1.

\begin{tabular}{|c|c|c|c|c|}
\hline \multicolumn{5}{|l|}{ Parameter } \\
\hline Grain Size $(\mathrm{mm})^{\mathrm{a}}$ & 0.317 & 3 & 10 & 20 \\
\hline Bulk Porosity $^{b}$ & 0.45 & 0.45 & 0.45 & 0.45 \\
\hline Standard Deviation, $\sigma_{g}(\mathrm{~mm})^{\mathrm{c}}$ & 5 & 1 & 1 & 1 \\
\hline Slope of the Campbell retention curve, $b$ & 2.78 & 0.777 & 0.516 & 0.424 \\
\hline Critical bulk moisture content, $2.2 b(\%)$ & 6.12 & 1.71 & 1.14 & 0.932 \\
\hline
\end{tabular}

Table 6.6-3. Parameters Developed for Crushed Tuff

${ }^{a}$ BSC 2005 [DIRS 173944], Appendix X, Section X.4.

${ }^{b}$ BSC 2005 [DIRS 173944], Appendix X, Section X.3.

${ }^{\text {c }}$ Campbell 1985 [DIRS 100565], Figure 2.1.

Figure 6.6-6 shows the corresponding range in the diffusion coefficient evaluated according to Equation 6.6.5.1-1. In general, the invert will include a distribution of tuff grain sizes. Therefore, the determination of the critical bulk moisture content is made by sampling from a uniform distribution between 0.932 percent and 6.12 percent. This corresponds to the range of tuff grain sizes from $20 \mathrm{~mm}$ to $0.317 \mathrm{~mm}$, as shown in Table 6.6-3; a uniform distribution is appropriate for covering the range for an initial analysis of an alternative conceptual model. The corresponding diffusion coefficient would then be evaluated for this sampled moisture content according to Equation 6.6.5.1-1. 


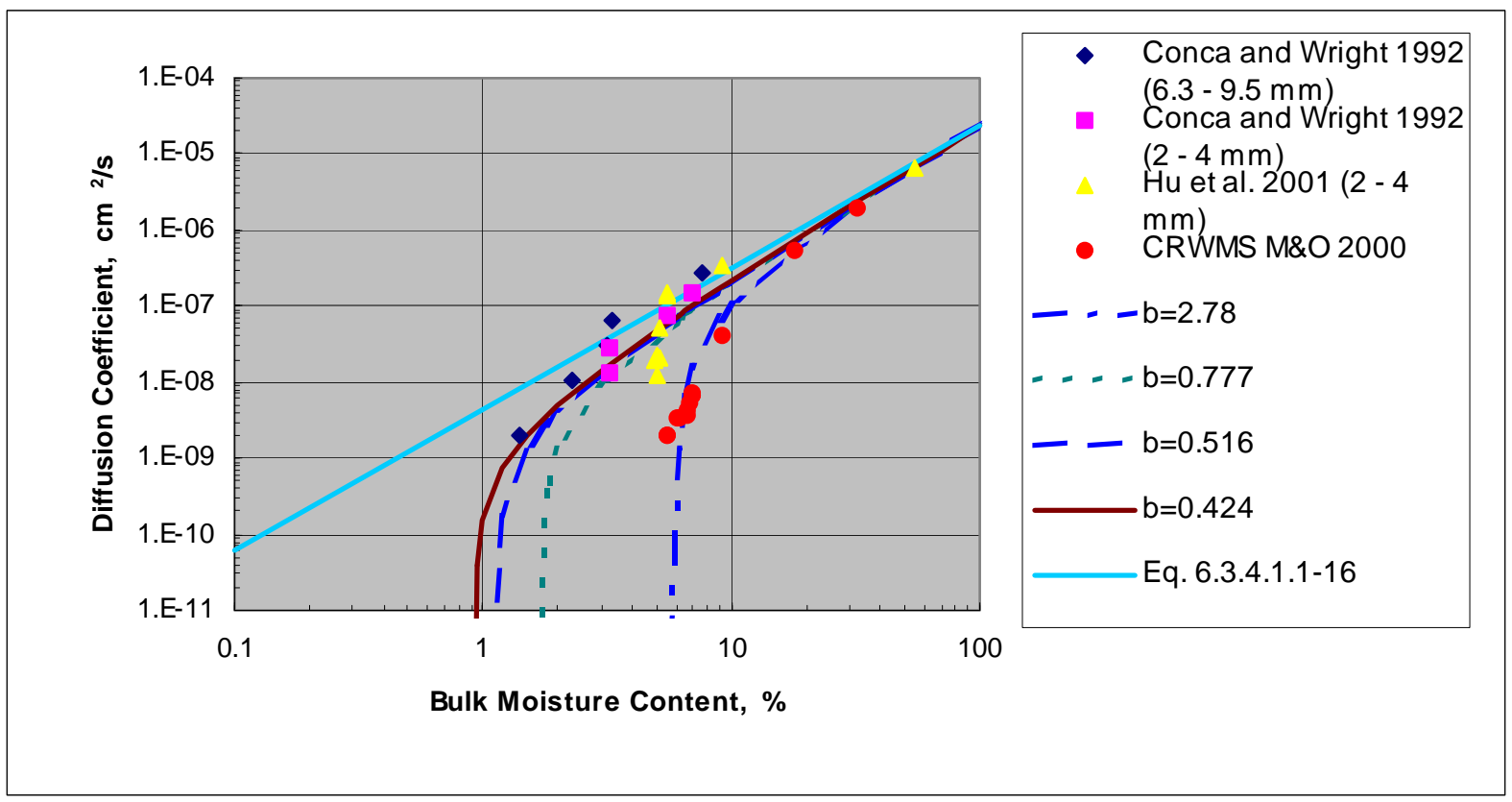

Source: Conca and Wright 1992 [DIRS 100436]; CRWMS M\&O 2000 [DIRS 156680]; Hu et al. 2001 [DIRS 161623].

Figure 6.6-6. Range of the Bulk Diffusion Coefficients for Crushed Tuff

For conditions in which advective flow does not occur in the crushed tuff, observations indicate that the intergranular moisture content will generally be negligible. Conca and Wright (1990 [DIRS 101582]) observed that tuff gravel samples allowed to stand for several hours in the presence of 100 percent relative humidity reached moisture contents between 0.5 and 1.5 percent and negligible surface moisture. The measured diffusion coefficients were found in these cases to be below their measurement limit of $1.03 \times 10^{-11} \mathrm{~cm}^{2} \mathrm{~s}^{-1}$. Therefore, in the portion of the invert in which there is no flow, the diffusion coefficient is expected to be negligible.

For conditions in which flow does occur in the crushed tuff, the bulk diffusion coefficient can be directly evaluated from Equation 6.6.5.1-1 as described above. The uncertainty is accounted for by expressing the threshold in terms of the critical bulk moisture content:

$$
\begin{array}{ll}
D=0.0045 D_{0} \theta \frac{\left(\theta-\theta_{C}\right)}{\left(100 \phi-\theta_{C}\right)}, & \theta \geq \theta_{C} \\
D=0, & \theta<\theta_{C},
\end{array}
$$

where $\theta$ is the bulk moisture content (percent), given by Equation 6.5.3.3-11, and $\theta_{C}$ is the critical value of the bulk moisture content, $2.2 b$ (percent). The critical bulk moisture content is selected by sampling a uniform distribution between 0.932 percent and 6.12 percent, as discussed earlier in this section.

Diffusion coefficients of crushed tuff have been estimated using the ultracentrifuge technique and measurements of electrical resistivity. Conca and Wright (1992 [DIRS 100436]) and Conca et al. (1993 [DIRS 170709]) measured the bulk diffusion coefficients for a variety of granular materials, including crushed tuff, as a function of moisture content. Figure 6.6-6 shows the 
results of their measurements of crushed tuff samples with tuff grains sizes between $6.3 \mathrm{~mm}$ and $9.5 \mathrm{~mm}$, and between $2 \mathrm{~mm}$ and $4 \mathrm{~mm}$. Diffusion coefficients for crushed tuff with grain sizes between $2 \mathrm{~mm}$ and $4 \mathrm{~mm}$ have also been measured by $\mathrm{Hu}$ et al. (2001 [DIRS 161623]); these results are also shown in Figure 6.6-6. Finally, the diffusion coefficient measured for samples of crushed tuff with an unspecified distribution of grain sizes (CRWMS M\&O 2000 [DIRS 156680]) are also shown in Figure 6.6-6. Comparison of all of these measurements for crushed tuff indicates that the model provides a reasonable representation of the diffusion coefficient for these measured moisture contents (1.4 to 55 percent).

\subsubsection{Alternative Dual-Continuum Invert Diffusion Coefficient Model}

In general, the literature supports a dual continuum picture of the diffusive conductance by the invert granular material. For example, Roberts and Lin (1997 [DIRS 101710]) observed multiple conduction pathways in their measurements of the electrical conductance of unsaturated tuff samples. Their measurements indicated conduction by adsorbed water on the solid surfaces of the tuff samples and conduction by water within the tuff rock. These measurements support a dual continuum picture of the tuff samples in which the water on the surface of the samples corresponds to the intergranular continuum and the water within the samples corresponds to the intragranular continuum.

Other observations also support this picture. Porter et al. (1960 [DIRS 123115]) studied the way in which chloride ions move through soil and the effect of the moisture content of the soil on this movement. These characteristics were interpreted in terms of diffusion within the soil grains and diffusion on the solid surfaces of those grains. Nye (1979 [DIRS 167377]) concluded that, to a first approximation at least, diffusion can be considered to occur through two independent pathways in soil: through moisture between the soil grains and through the grains themselves. In this picture, the bulk diffusion coefficient, $D$, is represented by:

$$
D=D_{\text {inter }} \phi_{\text {inter }}+D_{\text {intra }}\left(1-\phi_{\text {inter }}\right) \text {, }
$$

where $D_{\text {inter }}$ is the diffusion coefficient for the intergranular continuum determined by the moisture films on the surfaces of the grains, $D_{\text {intra }}$ is the diffusion coefficient for the intragranular continuum determined by the moisture within the grains, and $\phi_{\text {inter }}$ is the intergranular porosity of the material.

In this picture, the bulk diffusion coefficient is dominated by the saturation-dependent intergranular diffusion coefficient above the critical bulk moisture content, while below this critical value, the intragranular diffusion coefficient dominates. That is, Equation 6.6.5.2-1 becomes:

$$
\begin{array}{ll}
D \approx D_{\text {inter }}(\theta) \phi_{\text {inter }}, & \theta \geq \theta_{C} \\
D=D_{\text {intra }}\left(1-\phi_{\text {inter }}\right), & \theta<\theta_{C},
\end{array}
$$

where $\theta_{C}$ is the critical moisture content (percent). In this picture, the intergranular diffusion coefficient is represented by the bulk diffusion coefficient model in Equation 6.6.5.1-1, divided by the intergranular porosity: 


$$
\begin{array}{ll}
D_{\text {inter }}=0.45 D_{0}\left(\frac{\theta}{100 \phi_{\text {inter }}}\right)\left(\frac{\theta-\theta_{C}}{100 \phi_{I}-\theta_{C}}\right), & \theta \geq \theta_{C} \\
D_{\text {inter }}=D_{\text {limit }}, & \theta<\theta_{C} .
\end{array}
$$

$D_{\text {limit }}$ is the measurement limit, $10^{-12} \mathrm{~cm}^{2} \mathrm{~s}^{-1}, \phi_{I}$ is the bulk porosity of the invert, $\phi_{I}=\phi_{\text {inter }}+\left(1-\phi_{\text {inter }}\right) \phi_{\text {intra }}$ (fraction), and $\theta_{C}$ (percent) corresponds to $2.2 b$ in Equation 6.6.5.1-1.

The intragranular diffusion coefficient is determined by the following considerations.

Reimus et al. (2002 [DIRS 163008]) measured diffusion coefficients for saturated whole rock samples of tuff. The measured values for the samples ranged from $1.5 \times 10^{-7} \mathrm{~cm}^{2} \mathrm{~s}^{-1}$ to $2 \times 10^{-5} \mathrm{~cm}^{2} \mathrm{~s}^{-1}$. From these measurements, Reimus et al. (2002 [DIRS 163008], p. 2.25, Equation 2.5) developed a correlation between the saturated diffusion coefficient, $D_{m s}$, and the porosity, $\phi_{m}$, and intrinsic permeability, $k_{m}$, of the tuff rock matrix:

$$
\log _{10} D_{m s}=-3.49+1.38 \phi_{m}+0.165 \log _{10} k_{m} .
$$

The tuff samples were from Pahute Mesa, Nevada, but many of them are similar to tuff rocks at Yucca Mountain. To evaluate the flow characteristics of the drift invert, matrix porosity and intrinsic permeability for tuff from two different Topopah Spring welded tuff units, TSw35 and TSw36, were identified (DTN: LB0207REVUZPRP.002 [DIRS 159672]; Spreadsheet: Matrix_Props.xls, Row 20, Column C). These properties are summarized in Table 6.6-4. Using the correlation in Equation 6.6.5.2-4, the diffusion coefficient for saturated tuff whole rock with a saturated moisture content of 10.3 percent is $3.69 \times 10^{-7} \mathrm{~cm}^{2} \mathrm{~s}^{-1}$, and the diffusion coefficient for a saturated moisture content of 13.1 percent is $6.73 \times 10^{-7} \mathrm{~cm}^{2} \mathrm{~s}^{-1}$.

Table 6.6-4. Tuff Matrix Properties for TSw35 and TSw36

\begin{tabular}{|l|c|c|}
\hline \multicolumn{1}{|c|}{ Parameter } & TSw36 & TSw35 \\
\hline Porosity of the rock matrix in an individual granule, $\phi_{m}$ & 0.103 & 0.131 \\
\hline Intrinsic Permeability, $k_{m}\left(\mathrm{~m}^{2}\right)$ & $2.00 \times 10^{-19}$ & $4.48 \times 10^{-18}$ \\
\hline Saturated diffusion coefficient (from Equation 6.6.5.2-4), $D_{m s}\left(\mathrm{~cm}^{2} \mathrm{~s}^{-1}\right)$ & $3.69 \times 10^{-7}$ & $6.73 \times 10^{-7}$ \\
\hline
\end{tabular}

DTN: LB0208UZDSCPMI.002 [DIRS 161243]; Spreadsheet "drift-scale calibrated properties for mean infiltration2.xls," Rows 17-18, Columns B-C.

A laser ablation microprofiling technique has been used to estimate the diffusion characteristics for an unsaturated whole tuff rock sample (Hu et al. 2001 [DIRS 161623]). Hu et al. (2001 [DIRS 161623], p. 25) found that, for a measured moisture content of the sample of 8.9 percent, the internal diffusion coefficients were on the order of $10^{-12} \mathrm{~cm}^{2} \mathrm{~s}^{-1}$ (Hu et al. 2001 [DIRS 161623], p. 25). This result indicates a very low intragranular diffusion coefficient for tuff at intragranular saturations below about 80 percent.

The model developed for the intragranular diffusion coefficient considering this information is the following. For intragranular moisture content, $\theta_{\text {intra }}$, below 8.9 percent, a value of 
$10^{-12} \mathrm{~cm}^{2} \mathrm{~s}^{-1}$ is used to represent the diffusion coefficient. For saturated conditions $\left(\frac{\theta_{\text {intra }}}{100}=\phi_{\text {intra }}\right.$, the intragranular porosity), the diffusion coefficient is set to a value corresponding to Equation 6.6.5.2-4. For unsaturated grains with moisture content above 8.9 percent, a power-law extrapolation from the saturated value is used. The overall model proposed for the intragranular diffusion coefficient is the following power law model:

$$
\begin{array}{ll}
\left.D_{\text {intra }}=D_{m s}\left(\frac{\left(\frac{\theta_{\text {intra }}}{100}\right)}{\phi_{\text {intra }}}\right)\right)^{p}, & \theta_{\text {intra }} \geq \theta_{\text {min }} \\
D_{\text {intra }}=D_{\text {limit }}, & \theta_{\text {intra }}<\theta_{\text {min }},
\end{array}
$$

where $\theta_{\text {intra }}$ is the intragranular moisture content (percent), $\phi_{\text {intra }}$ is the intragranular porosity (fraction), $D_{\text {limit }}$ is the measurement limit, $10^{-12} \mathrm{~cm}^{2} \mathrm{~s}^{-1}$, and $\theta_{\min }$ is equal to 8.9 percent. The exponent $p$ is the slope of Equation 6.6.5.2-5 in a plot of $\log _{10}\left(D_{\text {intra }}\right)$ versus $\log _{10}\left(\theta_{\text {intra }}\right)$. This plot is a straight line (in log-log space) between points $\left(\frac{\theta_{\text {min }}}{100}, D_{\text {limit }}\right)$ and $\left(\phi_{\text {intra }}, D_{m s}\right)$. Thus, $p$ is given by:

$$
p=\frac{\log _{10}\left(D_{\text {limit }}\right)-\log _{10}\left(D_{m s}\right)}{\log _{10}\left(\frac{\theta_{\text {min }}}{100}\right)-\log _{10}\left(\phi_{\text {intra }}\right)} .
$$

The dual porosity model for the invert diffusion coefficient follows by specifying values for the intergranular and intragranular diffusion coefficients. The intergranular diffusion coefficient is evaluated from Equation 6.6.5.1-5 and dividing by the intergranular porosity (i.e., Equation 6.6.5.2-3). The intragranular diffusion coefficient is evaluated from Equation 6.6.5.2-5. The effective bulk diffusion coefficient is determined from Equation 6.6.5.2-2.

\subsubsection{Summary of Alternative Invert Diffusion Coefficient Conceptual Models}

These conceptual models consider alternatives to Archie's law for determining the diffusion coefficient in the crushed tuff invert. One variation treats the invert as a single continuum, as in the base model; the second variation models the invert as a dual continuum comprised of two pore spaces - intragranular pore space (tuff particle matrix) and intergranular pore space. Despite the potential for increased accuracy compared to the base case single-continuum model using Archie's law, insufficient data exist to validate diffusion behavior at very low water contents. In addition, these alternative conceptual models do not provide upper bounds on diffusion coefficients, as the Archie's law approach does. Therefore, invert diffusion coefficients are computed in TSPA-LA using Archie's law. 


\subsubsection{Reversible Sorption of Radionuclides onto Waste Package Corrosion Products}

Reversible sorption of radionuclides onto stationary waste package corrosion products will occur to some extent. However, as a bounding approach in TSPA-LA, reversible sorption of radionuclides onto stationary corrosion products has been eliminated, i.e., $K_{d}$ values for all radionuclides are set to zero (see Section 6.3.4.2.3), and only irreversible sorption of $\mathrm{Pu}$ and $\mathrm{Am}$ is modeled as occurring on stationary corrosion products. The alternative conceptual model in this section describes the alternative approach of allowing for reversible sorption onto stationary corrosion products by using non-zero $K_{d}$ values.

Descriptions of sorption based on a $K_{d}$ are approximate because this approach is empirical, with little information about underlying mechanisms, and is therefore not easily extendable to different chemical environments and physical substrates (sorptive media). The use of a linear isotherm is also approximate because it does not predict saturation of the sorption sites with sorbed species that may include natural components of the groundwater. The mass of iron oxyhydroxides from waste package corrosion is large (Table 6.3-4), so each waste package provides many sites for sorption. For these reasons, the $K_{d}$ approach is an order of magnitude measure of contaminant uptake in geologic environments (Davis and Kent 1990 [DIRS 143280]).

The use of the linear isotherm $\left(K_{d}\right)$ approach to represent the subsequent release of radionuclides into fresh recharge (i.e., the desorption process) can be inconsistent with observations in geologic media. Typically, contaminants become more closely attached to a mineral surface after sorption, either adsorbed at high energy sites on the surface or absorbed through overcoating and buried due to other mineral surface reactions. The net result is that only a fraction of the original sorbed population remains available at the surface and able to react with adjacent solutions or be accessed by microorganisms. A linear isotherm $\left(K_{d}\right)$ approach, on the other hand, assumes that all sorbed radionuclides are freely able to desorb from the substrate.

Sorption distribution coefficients are typically measured for groundwaters and substrates at ambient or near ambient temperatures. There are few experimental data for sorption distribution coefficients at the elevated temperatures that may occur in the EBS with either the repository design and operating mode described in Yucca Mountain Science and Engineering Report (DOE 2001 [DIRS 153849]) or an alternative thermal operating mode. In this situation, the available data for sorption distribution coefficients were used to define the ranges of $K_{d}$ values for the earlier TSPA-LA analyses, but it is not possible to distinguish alternative thermal operating modes. The effect of temperature on sorption coefficients was reviewed by Meijer (1990 [DIRS 100780], p. 17). Measured sorption coefficients onto tuffs were higher at elevated temperature for all elements studied: $\mathrm{Am}, \mathrm{Ba}, \mathrm{Ce}, \mathrm{Cs}, \mathrm{Eu}, \mathrm{Pu}, \mathrm{Sr}$, and $\mathrm{U}$. The conclusion was drawn that sorption coefficients measured at ambient temperatures should be applicable and generally bounding when applied to describing aqueous transport from a repository at elevated temperatures. This conclusion must be tempered by the possibility that elevated temperatures could result in changes in the near-field mineralogy and water chemistry that are not predictable by short-term laboratory and field experiments. 
Table 6.6-5 includes ranges and distributions of $K_{d}$ values from DTN: LA0003AM831341.001 ([DIRS 148751], SEP table S00191_002) for 11 radionuclides for sorption onto "iron oxide," which is the "Rock type" specified in the reference, for unsaturated zone units. The data in Table 6.6-5 were developed in the analysis report Unsaturated Zone and Saturated Zone Transport Properties (U0100) (BSC 2001 [DIRS 160828], Section 6.4.2). This document has been cancelled because some of the output data, specifically, the transport properties of tuff, have been revised and updated in more recent YMP reports. However, the ranges and distributions of sorption distribution coefficients on iron oxide have not been revised, and they demonstrate the properties of interest for the analysis of sorption parameters for the waste package corrosion products. Corroborating data are available, and the values in Table 6.6-5 are compared with these data in Table 6.6-7.

Table 6.6-5. Sorption Distribution Coefficient $\left(K_{d}\right)$ Ranges on Iron Oxide in Unsaturated Zone Units; All Distributions Are Uniform Except as Noted

\begin{tabular}{|l|c|c|}
\hline \multicolumn{1}{|c|}{ Element } & Minimum $\boldsymbol{K}_{\boldsymbol{d}}\left(\mathbf{m l ~ g}^{-\mathbf{1}}\right)$ & Maximum $\boldsymbol{K}_{\boldsymbol{d}}\left(\mathbf{m l ~}^{\mathbf{- 1}}\right)$ \\
\hline $\mathrm{Ac}$ & 1,000 & 5,000 \\
\hline $\mathrm{Am}$ & 1,000 & 5,000 \\
\hline $\mathrm{C}$ & 10 & 100 \\
\hline $\mathrm{Cs}^{\mathrm{a}}$ & 0 & 300 \\
\hline $\mathrm{Np}$ & 500 & 1,000 \\
\hline $\mathrm{Pa}$ & 500 & 1,000 \\
\hline $\mathrm{Pu}$ & 1,000 & 5,000 \\
\hline $\mathrm{Ra}^{\mathrm{a}}$ & 0 & 500 \\
\hline $\mathrm{Sr}^{\mathrm{b}}$ & 0 & 20 \\
\hline $\mathrm{Th}$ & 1,000 & 5,000 \\
\hline $\mathrm{U}$ & 100 & 1,000 \\
\hline
\end{tabular}

Source: DTN: LA0003AM831341.001 ([DIRS 148751] SEP table S00191_002).

NOTES: $E(x)=$ expected value of the distribution; $\mathrm{COV}=$ coefficient of variance $=\sigma(x) / E(x) ; \sigma(x)=$ standard deviation of the distribution.

${ }^{a}$ Distribution type: Beta; $E(x)=30 ; \mathrm{COV}=1.0$.

${ }^{\mathrm{b}}$ Distribution type: Beta; $E(x)=10 ; \mathrm{COV}=0.25$.

In DTN: LA0003AM831341.001 [DIRS 148751], the $K_{d}$ value for iodine and technetium is listed as zero for "all rock types" for unsaturated zone units; $K_{d}$ values for sorption onto "iron oxide" are not listed. In DTN: LA0003AM831341.001 ([DIRS 148751] SEP table S00191_001), the $K_{d}$ value for iodine in saturated zone units is listed as ranging from 0.32 to $0.63 \mathrm{ml} \mathrm{g}^{-1}$ with a uniform distribution for rock type "alluvium." In the same SEP table, the $K_{d}$ value for technetium in saturated zone units is listed as ranging from 0.27 to $0.62 \mathrm{ml} \mathrm{g}^{-1}$ with a uniform distribution for rock type "alluvium." The data for iodine and technetium in saturated zone units for rock type "alluvium" are suitable for modeling retardation in corrosion products because they provide evidence that some small degree of sorption of these elements is possible onto unspecified mineral assemblages, yet the uncertainty is small because the maximum $K_{d}$ values are small.

As discussed previously, the use of a linear isotherm is an empirical, order-of-magnitude description of mineral surface processes because it is not based on underlying physical or 
chemical mechanisms. In essence, a $K_{d}$ value is valid only for the specific substrate and chemical conditions under which it is measured. More defensible models of contaminant uptake by mineral surfaces require a more comprehensive mechanistic understanding of the chemical reactions involved (Davis et al. 1998 [DIRS 154436]). In lieu of a more involved mechanistic treatment based on surface complexation that includes a provision for irreversible sorption, $K_{d}$ values can provide a first-order picture of the sorption process, using generic ranges based on soils and iron oxyhydroxides. The rationale for this approach is described below.

Based on previous TSPA calculations, the $\mathrm{pH}$ of waste package fluids (CRWMS M\&O 2000 [DIRS 153246], Tables 3.3-7 through 3.3-9) is expected to fall within the range observed in soils and groundwaters ( $\mathrm{pH}$ values between 4 and 10). Although the composition of in-package fluids will vary with time due to degradation of the waste package components (primarily steels, Zircaloy cladding, SNF, and waste glass), major characteristics (such as alkalinity and system redox state) will be controlled by equilibrium with atmospheric carbon dioxide and free oxygen. The primary reactive components in the degraded waste package environment are iron hydroxides, the same mineral phases that tend to dominate trace element sorption in soils. The only major element species that will be present in waste package fluids, but that tend to be scarcer in natural soils and groundwaters, are those containing uranium.

The trace element composition of waste package fluids will differ due to the presence of metal components and various radiogenic isotopes. On the other hand, the waste package environment is expected to contain greater volumes of iron hydroxides than all but the most iron-rich soils. Consequently, sorption calculations using ranges of $K_{d}$ values measured on iron-containing soils or iron hydroxides provide a reasonable measure of sorption inside the waste package.

Sorption distribution coefficients often vary by at least an order of magnitude. Each range of $K_{d}$ represents the compilation of many experimental measurements with wide variations in sorbant composition and characteristics, contaminant level, solution composition and temperature, and method of measurement.

Sorption distribution coefficient values for a linear, reversible isotherm can be interpreted physically (Stumm 1992 [DIRS 141778], Section 4.12) in terms of retarding the movement of a contaminant relative to the velocity of the water carrying it. If the average water velocity is $\bar{v}$ $\left(\mathrm{m} \mathrm{s}^{-1}\right)$ and the front of the contaminant concentration profile has an average velocity $v_{c}$, the retardation of the front relative to the bulk mass of water is described by the relation:

$$
R_{f}=\frac{\bar{v}}{v_{c}}=1+\frac{\rho_{b}}{\phi} K_{d}
$$

where $R_{f}$ is the retardation factor (dimensionless ratio of water velocity to the concentration front velocity), $\rho_{b}$ is the bulk density of the rock $\left(\mathrm{kg} \mathrm{m}^{-3}\right)$ having a porosity $\phi$ (fraction). For example, a contaminant with a $K_{d}$ of $1,000 \mathrm{ml} \mathrm{g}^{-1}$ will move at one ten-thousandth the rate of the carrier water for a rock porosity of 20 percent and a rock density of $2,000 \mathrm{~kg} \mathrm{~m}^{-3}$. A contaminant with a $K_{d}$ of $1 \mathrm{ml} \mathrm{g}^{-1}$ will move at one-eleventh the velocity of the carrier water, and a contaminant with a $K_{d}$ of 0 moves at the velocity of the water, both for the same values of rock porosity and rock density. These effective transport velocities provide an estimate of the delay 
for first breakthrough of the contaminant; after the sorption sites are completely saturated, changes in mass flow rate will be delayed only by the water transport time through the system.

The corrosion product assemblage is predicted by the in-package chemistry model reaction path calculations to be made up primarily of iron oxyhydroxides (e.g., goethite, hematite, ferrihydrite) and aluminum oxides. Lesser amounts of manganese oxides, metal phosphates and clay minerals are anticipated. The integrated sorptive properties of the assemblage might therefore be approximated as being that of iron oxyhydroxides with some aluminum oxides. The latter possess high specific surface areas and a strong chemical affinity for many radionuclides. Cesium primarily exchanges onto clay minerals. Strontium and radium tend to exchange onto clay lattices in soils, although strontium does sorb onto iron oxyhydroxides, particularly above $\mathrm{pH}$ 7. The fact that strontium and radium behave similarly in soils indicates that limited radium uptake by iron oxyhydroxides can be expected as well. Under oxidizing conditions technetium and iodide sorb negligibly to most soil components. However, reduction of technetium on solid surfaces containing reduced elements (e.g., iron metal) can cause strong retardation.

Table 6.6-6 summarizes the observations above by listing the components of soils that tend to control sorption. Iron oxyhydroxides are an important sorbing component of soils for all radioelements except iodine and technetium.

Table 6.6-6. Influences Over Radionuclide Sorption in Soils

\begin{tabular}{|c|c|}
\hline Element & $\begin{array}{l}\text { Important Solid Phase and Aqueous-Phase Parameters } \\
\text { Influencing Contaminant Sorption* }\end{array}$ \\
\hline Americium & [Clay Minerals], [Iron/Aluminum Oxide Minerals], pH \\
\hline Cesium & $\begin{array}{l}\text { [Aluminum/Iron Oxide Minerals], [Ammonium], Cation Exchange Capacity, [Clay Mineral], } \\
\text { [Mica-like Clays], } \mathrm{pH}, \text { [Potassium] }\end{array}$ \\
\hline lodine & [Dissolved Halides], [Organic Matter], Redox, Volatilization, $\mathrm{pH}$ \\
\hline Neptunium & [Clay Minerals], [Iron/Aluminum Oxide Minerals], $\mathrm{pH}$ \\
\hline Radium & $\begin{array}{l}\mathrm{BaSO}_{4} \text { Coprecipitation, [Dissolved Alkaline Earth Elements], Cation Exchange Capacity, } \\
\text { [Clay Minerals], Ionic Strength, [Iron-/Aluminum-Oxide Minerals], [Organic Matter], pH }\end{array}$ \\
\hline Technetium & [Organic Matter], Redox \\
\hline Plutonium & $\begin{array}{l}\text { [Aluminum/Iron Oxide Minerals], [Carbonate, Fluoride, Sulfate, Phosphate], [Clay Mineral], } \\
\text { [Organic Matter], pH, Redox }\end{array}$ \\
\hline Strontium & Cation Exchange Capacity, [Calcium], [Carbonate], pH, [Stable Strontium] \\
\hline Thorium & [Aluminum/Iron Oxide Minerals], [Carbonate], [Organic Matter], $\mathrm{pH}$ \\
\hline Uranium & $\begin{array}{l}\text { [Aluminum/Iron-Oxide Minerals], [Carbonate, Fluoride, Sulfate, Phosphate], [Clay Mineral], } \\
\text { [Organic Matter], pH, Redox, [U] }\end{array}$ \\
\hline \multicolumn{2}{|c|}{$\begin{array}{ll}\text { Source: } & \text { EPA (2004 [DIRS 172215]), Table } 5.35 . \\
& \text { EPA (1999 [DIRS 170376]), Table 5.20. } \\
\text { *Parameters listed in alphabetical order. Square brackets represent concentration. }\end{array}$} \\
\hline
\end{tabular}

Corrosion product $K_{d}$ ranges have been compiled by the Electric Power Research Institute (EPRI) (2000 [DIRS 154149], Table 6-9) from a literature review of iron oxyhydroxide sorption measurements. Ranges and distributions of $K_{d}$ values for sorption of radionuclides onto iron oxide are also evaluated and compiled in DTN: LA0003AM831341.001 ([DIRS 148751] SEP table S00191_002); these are listed in Table 6.6-5. The U.S. Environmental Protection Agency (EPA) has compiled $K_{d}$ values for soils for many of the same radionuclides (EPA 1999 [DIRS 170376]; EPA 2004 [DIRS 172215]). 
The large role of iron and aluminum oxyhydroxides minerals in controlling overall soil $K_{d}$ values is explicitly recognized in the EPA documents. For this reason, one would expect EPA soil $K_{d}$ values and EPRI iron oxyhydroxides $K_{d}$ values to be similar and both to provide a reasonable approximation of retardation in the waste package corrosion products. There are some caveats, however, the most important one being that $K_{d}$ values for a given material and radionuclide are approximate values that can vary widely depending on the specifics of the measurement (solid/solution ratio, radionuclide level, time allowed for equilibration). General coherence in an order-of-magnitude sense is the best that can be expected as the $K_{d}$ approach does a poor job of reproducing actual transport profiles; see, for example, Bethke and Brady (2000 [DIRS 154437]) and Reardon (1981 [DIRS 154434]).

Table 6.6-7 gives $K_{d}$ ranges describing retardation in the waste package corrosion products for the 13 radionuclides that were tracked in the earlier TSPA-LA model, with the minimum $K_{d}$ and maximum $K_{d}$ being the ranges used in this alternative conceptual model. For all but iodine and technetium, the maximum $K_{d}$ values are from DTN: LA0003AM831341.001 ([DIRS 148751], SEP table S00191_002). The maximum $K_{d}$ value for iodine and technetium is chosen to be $0.6 \mathrm{ml} \mathrm{g}^{-1}$, which is the approximate maximum $K_{d}$ value for iodine and technetium specified for alluvium in saturated zone units in DTN: LA0003AM831341.001 ([DIRS 148751], SEP table S00191_001).

The minimum $K_{d}$ values for carbon, cesium, iodine, radium, strontium, and technetium are the minimum $K_{d}$ values specified in DTN: LA0003AM831341.001 ([DIRS 148751], SEP table S00191_002). In order to provide more of a bounding estimate of releases of radionuclides that have a large impact on dose, the minimum $K_{d}$ values for actinium, americium, plutonium, and thorium are reduced by a factor of 10 from the minimum $K_{d}$ values specified in DTN: LA0003AM831341.001 ([DIRS 148751] SEP table S00191_002). For the same reason, the minimum $K_{d}$ value for protactinium is reduced by a factor of 5 from the minimum $K_{d}$ value of $500 \mathrm{ml} \mathrm{g}^{-1}$ specified in DTN: LA0003AM831341.001 ([DIRS 148751], SEP table S00191_002); this minimum value is corroborated by Evaluation of the Candidate High-Level Radioactive Waste Repository at Yucca Mountain Using Total System Performance Assessment, Phase 5 (EPRI 2000 [DIRS 154149], Table 6-9).

The minimum $K_{d}$ value for neptunium is reduced by a factor of 500 from the minimum $K_{d}$ value of $500 \mathrm{ml} \mathrm{g}^{-1}$ specified in DTN: LA0003AM831341.001 ([DIRS 148751], SEP table S00191_002); this minimum value is corroborated by Evaluation of the Candidate High-Level Radioactive Waste Repository at Yucca Mountain Using Total System Performance Assessment, Phase 5 (EPRI 2000 [DIRS 154149], Table 6-9) and Review of Geochemistry and Available $K_{d}$ Values for Cadmium, Cesium, Chromium, Lead, Plutonium, Radon, Strontium, Thorium, Tritium $\left({ }^{3} H\right)$, and Uranium. Volume II of Understanding Variation in Partition Coefficient, $K_{d}$, Values (EPA 1999 [DIRS 170376], Table 5.17).

Table 6.6-7 also gives distributions for $K_{d}$ values. For cesium, radium, and strontium, a beta distribution, as specified in Table 6.6-5 (DTN: LA0003AM831341.001 [DIRS 148751], SEP table S00191_002), is used in this alternative conceptual model. For carbon, iodine, protactinium, and technetium, a uniform distribution, as specified in Table 6.6-5 (DTN: LA0003AM831341.001 [DIRS 148751] SEP table S00191_001), is used in this alternative conceptual model. Whereas a uniform distribution is also specified in Table 6.6-5 
(DTN: LA0003AM831341.001 ([DIRS 148751] SEP table S00191_002) for americium, neptunium, plutonium, thorium, and uranium, all of which have $K_{d}$ values that range over more than an order of magnitude, a log-uniform distribution is used in this alternative conceptual model. A log-uniform distribution is specified to avoid the high-end bias that results from sampling from a uniform distribution that has a large range.

Table 6.6-7 also gives corroborating ranges and data source(s) described in recent literature. To capture the secondary role of iron oxyhydroxides in soil sorption of strontium, radium and cesium, clay-poor soil $K_{d}$ values from the EPA compilation are used in the comparison. In all cases the corroborating $K_{d}$ ranges overlap the ranges used in this alternative conceptual model. Moreover, in most cases the alternative conceptual model $K_{d}$ values tend to be on the low end of the $K_{d}$ range considered in aggregate.

Table 6.6-7. Summary of Partition Coefficient $\left(K_{d}\right)$ Ranges and Distributions for Retardation in the Waste Package Corrosion Products

\begin{tabular}{|c|c|c|c|c|c|}
\hline Element & $\begin{array}{c}\text { Minimum } \\
K_{d} \\
\left(\mathrm{ml} \mathrm{g}^{-1}\right)\end{array}$ & $\begin{array}{c}\operatorname{Maximum} \\
K_{d} \\
\left(\mathrm{ml} \mathrm{g}^{-1}\right)\end{array}$ & $\begin{array}{c}\text { Distribution } \\
\text { Type }\end{array}$ & $\begin{array}{c}\text { Corroborating } K_{d} \\
\text { Range }\left(\mathrm{ml} \mathrm{g}^{-1}\right)\end{array}$ & Corroborating $K_{d}$ Range Source \\
\hline Ac & 100 & 5,000 & Log-Uniform & $1,000-20,000$ & EPRI 2000 [DIRS 154149], Table 6-9 \\
\hline Am & 100 & 5,000 & Log-Uniform & $\begin{array}{l}1,000->100,000 \\
1,000-20,000\end{array}$ & $\begin{array}{l}\text { EPA } 2004 \text { [DIRS 172215], } \\
\text { Section 5.2.5.1; } \\
\text { EPRI } 2000 \text { [DIRS 154149], Table 6-9 }\end{array}$ \\
\hline $\mathrm{C}$ & 10 & 100 & Uniform & $0-100$ & EPRI 2000 DIRS 154149], Table 6-9 \\
\hline Cs & 0 & 300 & $\begin{array}{l}\text { Beta } \\
E(x)=30 \\
\sigma(x)=30\end{array}$ & $\begin{array}{l}10-3,500 \\
1-200\end{array}$ & $\begin{array}{l}\text { EPA } 1999 \text { [DIRS 170376], } \\
\text { Table D.10 (low clay soils); } \\
\text { EPRI } 2000 \text { [DIRS 154149], Table 6-9 }\end{array}$ \\
\hline 1 & 0 & 0.6 & Uniform & $0-1$ & EPRI 2000 [DIRS 154149], Table 6-9 \\
\hline $\mathrm{Np}$ & 1 & 1,000 & Log-Uniform & $\begin{array}{l}0.16-929 \\
10-1,000 \\
(0.1-1,000)\end{array}$ & $\begin{array}{l}\text { EPA } 2004 \text { [DIRS 172215], } \\
\text { Section 5.6.5.4; } \\
\text { EPRI } 2000 \text { [DIRS 154149], Table 6-9 } \\
\text { (reduced by factor of } 100 \text { for } U \text { site } \\
\text { saturation) }\end{array}$ \\
\hline $\mathrm{Pa}$ & 100 & 1,000 & Uniform & $100-10,000$ & EPRI 2000 [DIRS 154149], Table 6-9 \\
\hline $\mathrm{Pu}$ & 100 & 5,000 & Log-Uniform & $\begin{array}{l}60-15,000 \\
1,000-20,000\end{array}$ & $\begin{array}{l}\text { EPA } 1999 \text { [DIRS 170376], p. G-4 } \\
\text { EPRI } 2000 \text { [DIRS 154149], Table 6-9 }\end{array}$ \\
\hline $\mathrm{Ra}$ & 0 & 500 & $\begin{array}{l}\text { Beta } \\
E(x)=30 \\
\sigma(x)=30\end{array}$ & $\begin{array}{l}1-120 \\
50-1,000 \\
\end{array}$ & $\begin{array}{l}\text { EPA } 2004 \text { [DIRS 172215] } \\
\text { (Section 5.7.5.1: use Sr values) } \\
\text { EPRI } 2000 \text { [DIRS 154149], Table 6-9 }\end{array}$ \\
\hline $\mathrm{Sr}$ & 0 & 20 & $\begin{array}{l}\text { Beta } \\
E(x)=10 \\
\sigma(x)=2.5\end{array}$ & $\begin{array}{l}1-120 \\
10-100 \\
\end{array}$ & $\begin{array}{l}\text { EPA } 1999 \text { [DIRS 170376], Table 5.13 } \\
\text { EPRI } 2000 \text { [DIRS 154149], Table 6-9 }\end{array}$ \\
\hline Tc & 0 & 0.6 & Uniform & $0-1,000$ & EPRI 2000 [DIRS 154149], Table 6-9 \\
\hline Th & 100 & 5,000 & Log-Uniform & $\begin{array}{l}20-300,000 \\
1,000-20,000\end{array}$ & $\begin{array}{l}\text { EPA } 1999 \text { [DIRS 170376], Table 5.15 } \\
\text { EPRI } 2000 \text { [DIRS 154149], Table 6-9 }\end{array}$ \\
\hline$U$ & 100 & 1,000 & Log-Uniform & $\begin{array}{l}0-630,000 \\
50-10,000\end{array}$ & $\begin{array}{l}\text { EPA } 1999 \text { [DIRS 170376], Table } 5.17 \\
\text { EPRI } 2000 \text { [DIRS 154149], Table 6-9 }\end{array}$ \\
\hline
\end{tabular}

EPA = Environmental Protection Agency 
This alternative conceptual model is not used as the base model in TSPA-LA for several reasons. First, it does not account for limitations on the number of sites available for sorption. Second, it does not account for competition for sorption sites among the radionuclides that can sorb. Third, it does not account for competition for sorption sites with radionuclides such as $\mathrm{Pu}$ and Am that sorb irreversibly, which thereby reduce the number of sites available for reversible sorption.

\subsubsection{Pu Sorption onto Stationary Corrosion Products and Colloids}

As described in Section 6.3.4.2.3.2, the base case TSPA model accounts for limited $\mathrm{Pu}$ desorption from iron oxyhydroxides by incorporating an irreversibly sorbed component. This is based on available field and laboratory data, which suggest that $\mathrm{Pu}$ strongly sorbs onto iron oxyhydroxide substrates and does not desorb over time periods ranging from months (experimental studies), to approximately 50 years (field studies of $\mathrm{Pu}$ transport at contaminated sites).

Iron oxides and hydroxides are a primary sorptive sink for many metal ions and metal oxyion complexes in natural systems. Desorption studies have been done with ferrihydrite and goethite using $\mathrm{Mn}(\mathrm{II}), \mathrm{Co}(\mathrm{II}), \mathrm{Ni}(\mathrm{II}), \mathrm{Cu}(\mathrm{II}), \mathrm{Pb}(\mathrm{II}), \mathrm{Zn}(\mathrm{II}), \mathrm{Cd}(\mathrm{II}), \mathrm{Cr}(\mathrm{III})$, and the metal complexes arsenate, chromate, selenate, selenite, and uranyl; $\mathrm{Pu}(\mathrm{IV})$ and $\mathrm{Pu}(\mathrm{V})$ have also bee examined (Barney 1984 [DIRS 174702]; Schultz et al. 1987 [DIRS 173028]; Ainsworth et al. (1994 [DIRS 173033]); Payne et al., 1994 [DIRS 174707]; Coughlin and Stone 1995 [DIRS 173030]; Manning and Burau 1995 [DIRS 174725]; Davis and Upadhyaya 1996 [DIRS 173743]); Eick et al. 1999 [DIRS 174704]; Fendorf et al. 1996 [DIRS 173034]; Fendorf et al. 1997 [DIRS 173031]; Ford et al. 1997 [DIRS 174727]; Grossl et al. 1997 [DIRS 173032]; Sanchez et al. 1985 [DIRS 107213]; Lu et al. 1998 [DIRS 100946]; Lu et al 1998 [DIRS 174714]). Adsorption of these metal species onto iron oxyhydroxides is initially very rapid, reaching a steady-state concentration within minutes to hours; however, slow uptake commonly continues indefinitely. Desorption is also initially rapid, though generally slower than adsorption. It is often incomplete, with the fraction of readily desorbed metal a function of the metal/oxide contact (pre-equilibration) time, the time allowed for desorption, and, in some cases, the pre-equilibration $\mathrm{pH}$ (Schultz et al. 1987 [DIRS 173028]). Continued slow desorption is commonly observed for the duration of the experiment. For this reason, Schultz et al. (1987 [DIRS 173028]) have stated that the term "slowly reversible sorption" should be preferred over "irreversible sorption" when discussing metals that remain bound to the sorbent during desorption re-equilibration. In many cases, though, a fraction of the metal does appear to be irreversibly sequestered by the iron oxyhydroxide. As a result, there is a decrease in the labile, or readily available, fraction of metal ions in the system and a drop in the net metal toxicity. As the sorptive capacity of iron oxides is high, the development of an "irreversibly sorbed" metal fraction has been suggested to be an efficient mechanism for sequestering inorganic contaminants in natural environments (Brady et al. 1999 [DIRS 154421]).

However, the National Research Council (NRC) has taken the position that the assumption of irreversible sorption is tenuous, because there has been no agreement to date on the mechanism(s) responsible for permanent sequestration. The NRC published a report (NRC 2000 [DIRS 174394]) that stated that irreversible sorption models should not be applied to quantitative models of environmental contamination that aid decision-making on performance or exposure. With regard to the report on contaminant attenuation of Brady et al. (1999 [DIRS 154421]), the 
NRC report states (NRC 2000 [DIRS 174394], p. 224): “irreversible sorption...is not understood for either organic or inorganic contaminants; much more scientific research is needed before this process can be quantified.". In addition, the NRC report judged the likelihood of success of long-term $\mathrm{Pu}$ immobilization as low, at the current level of knowledge (NRC 2000 [DIRS 174394], p. 9).

Many mechanisms have been proposed for slowly reversible sorption; most would result in the observed continued slow uptake of metal from solution as well. Possible mechanisms include:

- Incorporation of metal ions into the FeOOH structure by isomorphic substitution. This mechanism has been suggested to occur during recrystallization of ferrihydrite as goethite, but may also be effective during growth or coarsening (Ostwald ripening) of goethite in suspension. Irreversible adsorption of divalent metal ions, of similar size to $\mathrm{Fe}^{+3}$, has been attributed to this process (Schultz et al. (1987 [DIRS 173028]); Ainsworth et al. 1994 [DIRS 173033]; Ford et al. 1997 [DIRS 174727]; Coughlin and Stone 1995 [DIRS 173030]). Watson (1996 [DIRS 173035]) has shown that entrapment of adsorbed contaminant ions by crystal growth permanently sequesters such ions from the environment, as solid-state diffusion of ions out of mineral structures is too slow at nearsurface temperatures to allow for re-equilibration.

A related mechanism, potentially important during recrystallization of ferrihydrite as goethite, is overgrowth and encapsulation of sorbed or precipitated phases during goethite formation and growth.

- Formation of slowly dissolving metal hydroxide surface precipitates (Fendorf et al. 1996 [DIRS 173034]). However, such precipitates are unlikely to form at concentrations much lower than the solubility of the contaminant.

- Sorption of ions onto high-energy sites on the FeOOH surface. If such sites are numerous relative to the concentration of the sorbent, then with time, an increasing number of sorbent ions will become bound in the more stable high-energy sites relative to the lower energy sites, and the proportion of slowly reversible or irreversibly bound metal will increase. This is consistent with virtually all proposed surface complexation models for iron oxyhydroxide, which advocate the presence of a fraction of high-energy sites, and is the basis for the irreversible sorption model implemented in this document (see Section 6.5.3.4 and Appendix B).

- A time-dependent change in the metal-surface site stoichiometry, resulting in a higher energy bond. Fendorf et al. (1997 [DIRS 173031]) and Grossl et al. (1997 [DIRS 173032]) demonstrated that arsenate and chromate initially formed monodentate surface complexes on goethite, but with time these transformed into more stable bidentate complexes, resulting in progressively larger fractions of slowly desorbing adsorbate. Adsorption of ions to the $\mathrm{FeOOH}$ surface in two or more distinct stoichiometries will yield a progressive increase in the amount of adsorbed metal, and an increase in the fraction of slowly desorbing metal, if the formation rate constant for the more stable surface complex is considerably slower than that of the less stable complex. The degree of adsorption would level out with time, as secular equilibrium is reached. 
- Creation of and adsorption to sites higher in binding energy than those initially available, e.g., changes in the surface properties of the substrate with aging. Such changes occur during the transformation of ferrihydrite to goethite. However, Schultz et al. (1987 [DIRS 173028]) performed experiments with $\mathrm{Ni}, \mathrm{Zn}$, and $\mathrm{Cr}$ and showed that the relative proportion of quickly and slowly desorbed adsorbate did not vary with the age of the ferrihydrite used (goethite progressively ingrows as the material ages), indicating that goethite and ferrihydrite do not "irreversibly adsorb" differing amounts of adsorbate. (This is consistent with the irreversible sorption model implemented in this document [Section 6.5.3.4]; there are fewer sites per unit surface area on HFO relative to goethite, but HFO has a higher surface area. The net number of high energy sites is nearly the same on both materials.)

- Slow diffusion of ions into and out of the crystal structure. Coughlin and Stone (1995 [DIRS 173030]) have suggested that divalent metal ions first adsorb onto the mineral surface, and then slowly diffuse into internal binding sites; hence, the slow continued uptake of metals by iron oxyhydroxides. The slow desorption would presumably be the result of diffusion out of the internal sites. However, as stated earlier, solid-state diffusion rates are too slow under natural conditions for this mechanism to be effective (Watson, 1996 [DIRS 173035]).

- Slow diffusion of ions into and out micropores and microfractures on the mineral surface, or into and out of mineral aggregates (e.g., ferrihydrite floc). Ainsworth et al. (1994 [DIRS 173033)]) suggest that the observed variations in metal ion behavior indicate that this mechanism is not an important cause of slowly reversible or irreversible adsorption. The degree to which a metal ion is irreversibly adsorbed is dependent upon its coordination chemistry (Coughlin and Stone, 1995 [DIRS 173030]); if diffusion into micropores were the causal mechanism, then all metal ions should be similarly affected.

- For $\mathrm{Pu}$, a special mechanism has been proposed (Keeney-Kennicutt and Morse 1985 [DIRS 106313]); Sanchez et al. 1985 [DIRS 107213]; Morse and Choppin 1986 [DIRS 174703]; Runde et al. 2002 [DIRS 168432]; Powell et al. 2005 [DIRS 174726]). $\mathrm{Pu}(\mathrm{V})$ reduces to a more stable $\mathrm{Pu}(\mathrm{IV})$ on the goethite surface, which is both stabilized in the reduced oxidation state and more strongly sorbed, and thus, less sensitive to changes in solution chemistry such as $\mathrm{pH}$ or ionic strength. For instance, the $\mathrm{Pu}(\mathrm{V})$ sorption edge occurs in the $\mathrm{pH}$ range 5 to 7 , while the $\mathrm{Pu}(\mathrm{IV})$ sorption edge occurs at $\mathrm{pH} 3$ to 5 . The mechanisms for $\mathrm{Pu}(\mathrm{V})$ reduction to $\mathrm{Pu}(\mathrm{IV})$ during sorption are not known, and Sanchez et al. (1985 [DIRS 107213]) hypothesized that it could either happen upon adsorption onto the surface or in the adsorbed layer near solid-solution interface. Sanchez et al. (1985 [DIRS 107213]) suggested a few possible causes for $\mathrm{Pu}(\mathrm{V})$ reduction, including reducing impurities in the sorbent material or, as proposed earlier by Keeney-Kennicutt and Morse (1985 [DIRS 106313]) a heterogeneous $\mathrm{Pu}(\mathrm{V})$ disproportionation reaction to produce $\mathrm{Pu}(\mathrm{IV})$ and $\mathrm{Pu}(\mathrm{VI})$. Sanchez et al. confirmed the presence of $\mathrm{Pu}(\mathrm{IV})$ in the solid and solution through solvent extraction and also noticed that $\mathrm{Pu}(\mathrm{V})$ was stable in solution whereas $\mathrm{Pu}(\mathrm{IV})$ was stable on the goethite solid. Runde et al. (2002 [DIRS 168432]) offer supporting data; they evaluated redox thermodynamic data for $\mathrm{Pu}$ and concluded that $\mathrm{Pu}(\mathrm{IV})$ solids are likely to control $\mathrm{Pu}$ solubilities under water chemistries typical of natural environments. 
The degree to which these processes permanently sequester the contaminant varies. Incorporation into the iron oxyhydroxide crystal structure or sequestration by overgrowth is effectively permanent, as release is limited by dissolution of the iron oxide. Release from surface precipitates is limited to the solubility of the precipitated species. Migration into higher affinity sites, or changes in the stoichiometry of the sorbed phase, raises the $K_{d}$ and stabilizes the sorbed species with respect to changes in water chemistry. Even reversible sorption effectively immobilizes a contaminant, if sufficient iron oxyhydroxide is present, the $\mathrm{K}_{\mathrm{d}}$ is large enough, and the water chemistry is restricted to the range at which sorption is high. Because many metals and metal-oxyanions sorb so strongly to Fe-oxyhydroxides at near-neutral $\mathrm{pH}$, desorption experiments commonly require either adjusting the $\mathrm{pH}$ to values too low to represent natural conditions or adding chelating agents which would not be present in natural environments.

Because the mechanism by which $\mathrm{Pu}$ and $\mathrm{Am}$ are fixed on Fe-oxyhydroxide surfaces is not well known, it is difficult to evaluate the degree to which sorption is truly irreversible, and the sensitivity of that assumption to changes in chemical conditions. Therefore, alternative conceptual models to irreversible sorption are considered here. To determine the appropriate form for that $\mathrm{ACM}$, we evaluate project data for sorption of $\mathrm{Pu}$ onto goethite and hematite from DTN: LA0004NL831352.001 [DIRS 150272]; development of this data is described by Lu et al. (1998 [DIRS 100946]) and Lu et al (1998 [DIRS 174714]). The same data is used to determine the fraction of irreversibly sorbed $\mathrm{Pu}$ in Section 6.5.3.4. These data also offer insights into the appropriateness of a reversible versus an irreversible sorption model.

\subsubsection{Yucca Mountain Project Experimental Sorption-Desorption Data for Pu}

The Yucca Mountain Project has performed sorption and desorption experiments with $\mathrm{Pu}(\mathrm{V})$ in natural and synthetic J-13 waters, using hematite and goethite colloids. The experimental procedures used in these experiments are documented by Lu et al. (1998 [DIRS 100946]); however, the sorption data presented there contains errors; the actual sorption data used is from DTN: LA0004NL831352.001 [DIRS 150272], and is described by Lu et al. (1998 [DIRS 174714]). The desorption data from Lu et al. (1998 [DIRS 100946]) is used, however, as there is no project DTN containing this information.

In this model report, corrosion products are assumed to be a mixture of goethite and HFO, and in this alternative conceptual model, Kds derived from goethite experiments are used as the basis for a model involving reversible sorption. The hematite data are presented for comparison.

Sorption experiments-The sorption experiments are described by $\mathrm{Lu}$ et al. (1998 [DIRS 100946], pp. 10-12; Sorption \#2 experiments). They were performed at room temperature using air-equilibrated natural and synthetic J-13 waters, with $\mathrm{pH}$ values of 8.2 and 8.5 , respectively. In these experiments, $1 \mathrm{~mL}$ of $2.74 \times 10^{-7} \mathrm{M}^{239} \mathrm{Pu}$ solution was added to $20 \mathrm{~mL}$ of colloid solution containing approximately $1 \mathrm{~g} \mathrm{~L}^{-1}$ colloids ( $\mathrm{Lu}$ et al 1998 [DIRS 174714], Table 1), resulting in a sample containing $0.02 \mathrm{~g}$ (nominal) colloid in $21 \mathrm{~mL}$ of $1.3 \times 10^{-8} \mathrm{M}$ $\mathrm{Pu}(\mathrm{V})$ solution. Samples were collected over a period of 5760 minutes (4 days). The remaining $\mathrm{Pu}$ in solution was determined by liquid scintillation counting (LSC), a standard analytical technique for measuring radiation from $\alpha$ - and $\beta$-emitting radionuclides by detecting small flashes of light emitted by radionuclides placed in an organic solution. The results of these experiments are presented in Table 6.6-8. For both hematite and goethite, in both natural and 
synthetic J-13 water, sorption is initially very rapid, reaching a high value within minutes to hours; however, slow uptake continues until the end of the experiment. Behavior is slightly different in natural and synthetic water, but in three of the four cases examined, sorption exceeded 99 percent, resulting in $K_{d}$ values of $10^{5}$ to $10^{6}$ (DTN: LA0004NL831352.001 [DIRS 150272]). In the fourth case, goethite in natural J-13 water, sorption continued to increase through the experiment, but had only reached $90 \%$ after 4 days; the final $K_{d}$ value was about $8.7 \times 10^{3} \mathrm{~mL} \mathrm{~g}^{-1}$ (DTN: LA0004NL831352.001 [DIRS 150272]).

In each of these cases, the measured $K_{d}$ value is considered to be a minimum value. Either concentrations in solution decreased below the detection limit, or concentrations were continuing to drop when the experiment was terminated.

Table 6.6-8. Sorption of $\mathrm{Pu}(\mathrm{V})$ onto Hematite and Goethite Colloids

\begin{tabular}{|c|c|c|c|c|c|}
\hline \multirow[b]{2}{*}{ Minerals } & \multirow[b]{2}{*}{ Time (min.) } & \multicolumn{2}{|c|}{ Fraction of Pu Sorbed } & \multicolumn{2}{|c|}{$K_{d}\left(\mathrm{~mL} \mathrm{~g}^{-1}\right)$} \\
\hline & & $\mathrm{J}-13$ & SYN.J-13 & $\mathrm{J}-13$ & SYN.J-13 \\
\hline \multirow{8}{*}{ Hematite } & 10 & 0.539 & 0.933 & $1.20 \times 10^{3}$ & $1.67 \times 10^{4}$ \\
\hline & 30 & 0.565 & 0.966 & $1.32 \times 10^{3}$ & $3.39 \times 10^{4}$ \\
\hline & 60 & 0.594 & 0.957 & $1.51 \times 10^{3}$ & $2.78 \times 10^{4}$ \\
\hline & 240 & 0.674 & 0.996 & $2.22 \times 10^{3}$ & $3.66 \times 10^{5}$ \\
\hline & 360 & 0.740 & 0.998 & $3.03 \times 10^{3}$ & $5.91 \times 10^{5}$ \\
\hline & 1440 & 0.907 & 0.999 & $9.98 \times 10^{3}$ & $2.08 \times 10^{6}$ \\
\hline & 2880 & 0.948 & 1.000 & $1.87 \times 10^{4}$ & NC \\
\hline & 5760 & 0.994 & 0.999 & $1.96 \times 10^{5}$ & $\mathrm{NC}$ \\
\hline \multirow{8}{*}{ Goethite } & 10 & 0.303 & 0.831 & $3.97 \times 10^{2}$ & $5.06 \times 10^{3}$ \\
\hline & 30 & 0.328 & 0.831 & $4.40 \times 10^{2}$ & $4.98 \times 10^{3}$ \\
\hline & 60 & 0.360 & 0.837 & $5.18 \times 10^{2}$ & $5.36 \times 10^{3}$ \\
\hline & 240 & 0.515 & 0.911 & $1.01 \times 10^{3}$ & $1.03 \times 10^{4}$ \\
\hline & 360 & 0.595 & 0.932 & $1.39 \times 10^{3}$ & $1.40 \times 10^{4}$ \\
\hline & 1440 & 0.793 & 0.987 & $3.45 \times 10^{3}$ & $7.65 \times 10^{4}$ \\
\hline & 2880 & 0.869 & 0.997 & $6.00 \times 10^{3}$ & $7.63 \times 10^{5}$ \\
\hline & 5760 & 0.902 & 0.991 & $8.72 \times 10^{3}$ & $1.39 \times 10^{5}$ \\
\hline
\end{tabular}

Source: LA0004NL831352.001 [DIRS 150272].

Desorption experiments-Procedures for the $\mathrm{Pu}$ desorption experiments are described by Lu et al. (1998 [DIRS 100946]). Substrate for the desorption experiments was produced by equilibrating $0.5 \mathrm{~g}$ of colloids with $20 \mathrm{ml}$ of $\mathrm{J}-13$ or synthetic J-13 water, with a $\mathrm{Pu}(\mathrm{V})$ concentration of $2.74 \times 10^{-7} \mathrm{M}$. Following equilibration, the samples were centrifuged, and the colloids resuspended in $5 \mathrm{ml}$ of unspiked electrolyte. Periodically over a period of 150 days, these samples were centrifuged and the electrolyte extracted and replaced with fresh solution. The extracted liquid was filtered and analyzed by LSC. The results of this analysis are listed in Table 6.6-9, as presented by Lu et al. (1998 [DIRS 100946], Tables 10 and 11), and are plotted in Figure 6.6-7. Lu et al. (1998 [DIRS 100946]; 1998 [DIRS 174714]) and Runde et al. (2002 [DIRS 168432]) interpreted the small amounts of desorbed $\mathrm{Pu}$ to indicate that kinetics of $\mathrm{Pu}$ desorption from Fe-oxides/oxyhydroxides are much slower than the kinetics of sorption, a conclusion at odds with the calculated "desorption $K_{d}$ values," which are smaller than those for 
sorption, and decrease with time. The change in "desorption $K_{d}$ values" would imply that the affinity of $\mathrm{Pu}$ for the surface of the substrate actually decreases with time. However, these data have been misinterpreted, and the calculated "desorption $K_{d}$ values" are incorrect.

Lu et al. (1998 [DIRS 100946]) misinterpreted the data in assuming that low concentrations of $\mathrm{Pu}$ in the desorption experiments do not necessarily imply slow desorption. Sorption-desorption is a steady-state phenomenon. When the goethite and hematite colloids were equilibrated with $\mathrm{Pu}$-spiked groundwater, 97 percent to 100 percent of the $\mathrm{Pu}$ was adsorbed. Hence, $K_{d}$ values were high. Extracting the nearly radionuclide-depleted water and replacing it with unspiked water provided no significant driving force for desorption. Even if the $\mathrm{Pu}$ were instantly exchangeable, concentrations in the solution would remain low because of the high $K_{d}$ value; anything that desorbed would immediately re-sorb. Thus, the low degree of desorption may only indicate a high $K_{d}$ value. In addition, because desorption was viewed as an irreversible process, the cumulative percentage of $\mathrm{Pu}$ sorbed was used to calculate the "desorption $K_{d}$ value." Hence, the "desorption $K_{d}$ value" was observed to decrease with time. To evaluate the desorption data properly, each successive equilibration and extraction must be viewed as a separate desorption experiment, in which the total amount of $\mathrm{Pu}$ in the system is nearly constant (a total of less than 1 percent of the $\mathrm{Pu}$ was extracted in the worst case), and the applicable $K_{d}$ value can be calculated from the Pu concentrations in solution and on the solid.

The results of this new analysis are presented in Table 6.6-10 and in Figure 6.6-8. For hematite, sorption is so complete that the tiny amount of $\mathrm{Pu}$ in solution represents values near the detection limit for the analysis. There is no significant trend with time, and predicted $K_{d}$ values are consistent with, or higher than, those measured in the sorption experiments (Table 6.6-8), on the scale of $10^{5}$ to $10^{6} \mathrm{ml} \mathrm{g}^{-1}$. Sorption was less complete on goethite, but $K_{d}$ values continued to increase with time; the final few extractions yielded $K_{d}$ values of $10^{4}$ to $10^{5} \mathrm{ml} \mathrm{g}^{-1}$.

In this alternative conceptual model, it is assumed that sorption is completely reversible, and that a single $K_{d}$ value will be applicable at any given $\mathrm{pH}$. Given the time scales for the repository, the longer-term $K_{d}$ values derived from these 150-day experiments, rather than the values derived from the 4-day sorption experiments, are more applicable. 

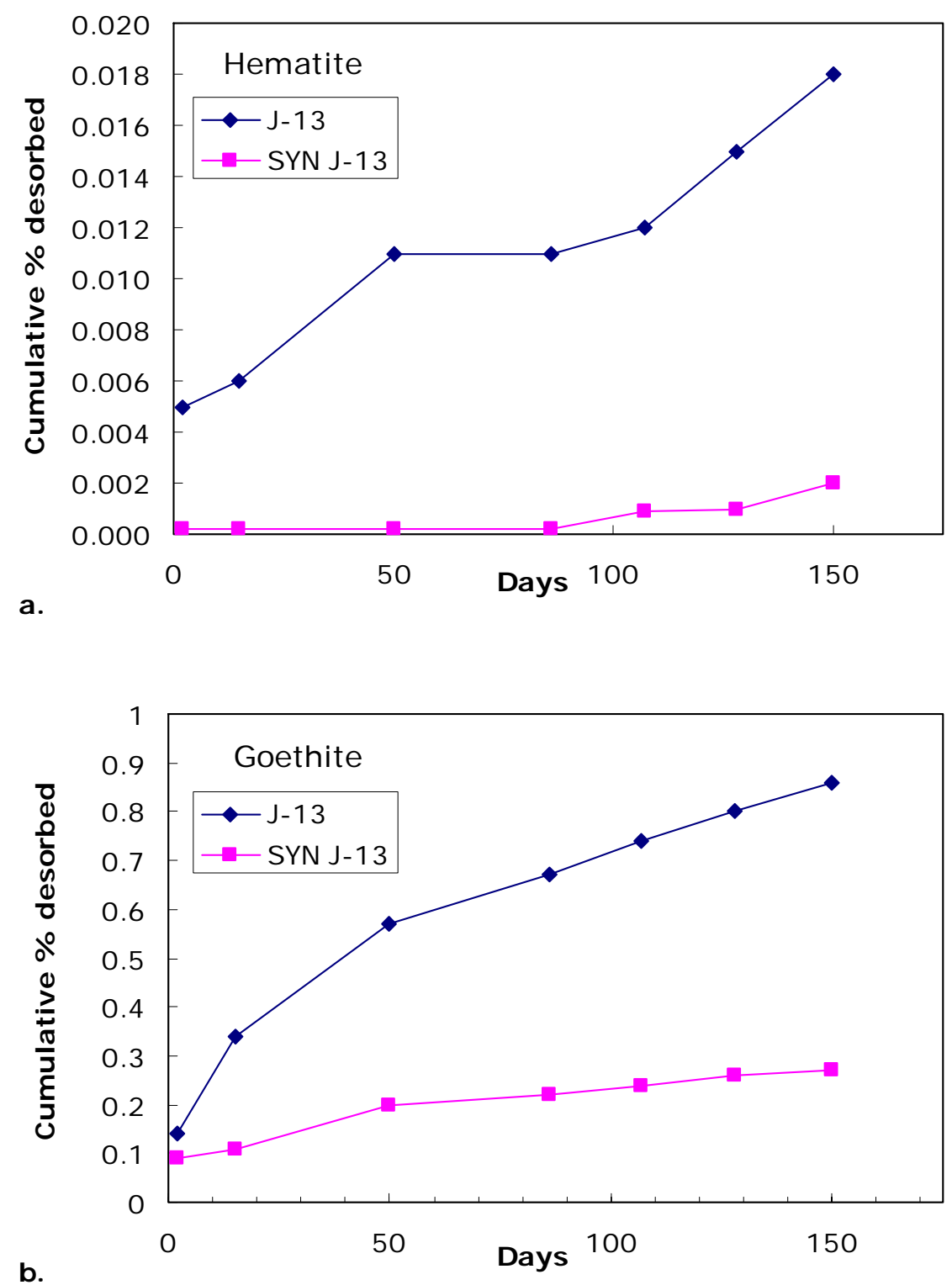

Source: DTN: SN0508T0507703.020, spreadsheet Pu sorption-desorption.x/s, worksheet "Desorp data."

NOTE: The cumulative Pu desorbed was measured by successive extractions with J-13 or synthetic J-13 water.

Figure 6.6-7. Desorption of Pu from Hematite (a) and Goethite (b) 
Table 6.6-9. Lu Data for Desorption of Pu(V) from Hematite and Goethite Colloids

\begin{tabular}{|l|c|c|c|c|c|}
\hline \multirow{4}{*}{ Minerals } & \multirow{2}{*}{$\begin{array}{c}\text { Time } \\
\text { (days) }\end{array}$} & \multicolumn{2}{|c|}{$\begin{array}{c}\text { Cumulative \% of Pu } \\
\text { desorbed }\end{array}$} & \multicolumn{2}{c|}{ Desorption $\boldsymbol{K}_{\boldsymbol{d}}\left(\mathbf{m L ~ g}^{-\mathbf{1}}\right)$} \\
\cline { 2 - 6 } & 2 & $\mathbf{J}-13$ & SYN.J-13 & J-13 & SYN.J-13 \\
\cline { 2 - 6 } & 15 & 0.005 & 0.0002 & $1.33 \times 10^{5}$ & $2.88 \times 10^{6}$ \\
\cline { 2 - 6 } & 50 & 0.006 & 0.0002 & $1.12 \times 10^{5}$ & $2.88 \times 10^{6}$ \\
\cline { 2 - 6 } & 86 & 0.011 & 0.0002 & $6.61 \times 10^{4}$ & $2.88 \times 10^{6}$ \\
\cline { 2 - 6 } & 107 & 0.011 & 0.0002 & $6.61 \times 10^{4}$ & $2.88 \times 10^{6}$ \\
\cline { 2 - 6 } & 128 & 0.015 & 0.0010 & $4.83 \times 10^{4}$ & $7.53 \times 10^{5}$ \\
\cline { 2 - 6 } & 150 & 0.018 & 0.0020 & $4.33 \times 10^{4}$ & $4.95 \times 10^{5}$ \\
\hline \hline \multirow{5}{*}{ Hematite } & 2 & 0.14 & 0.09 & $5.18 \times 10^{4}$ & $8.12 \times 10^{3}$ \\
\cline { 2 - 6 } & 15 & 0.34 & 0.11 & $2.08 \times 10^{3}$ & $6.11 \times 10^{3}$ \\
\cline { 2 - 6 } & 50 & 0.57 & 0.20 & $1.24 \times 10^{3}$ & $3.32 \times 10^{3}$ \\
\cline { 2 - 6 } & 86 & 0.67 & 0.22 & $1.04 \times 10^{3}$ & $3.09 \times 10^{3}$ \\
\cline { 2 - 6 } & 107 & 0.74 & 0.24 & $9.49 \times 10^{2}$ & $2.81 \times 10^{3}$ \\
\cline { 2 - 6 } & 128 & 0.80 & 0.26 & $8.87 \times 10^{2}$ & $2.67 \times 10^{3}$ \\
\cline { 2 - 6 } & 150 & 0.86 & 0.27 & $8.41 \times 10^{2}$ & $2.60 \times 10^{3}$ \\
\hline
\end{tabular}

Source: Lu et al. 1998 [DIRS 100946], Tables 10 and 11. 


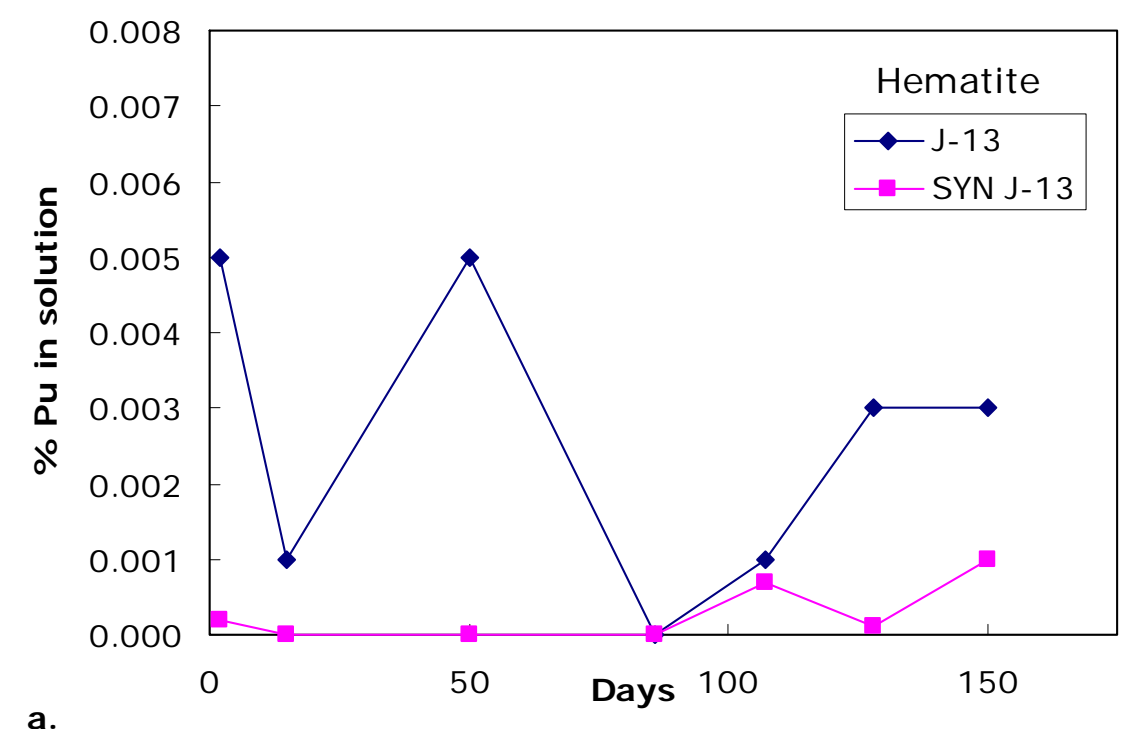

a.

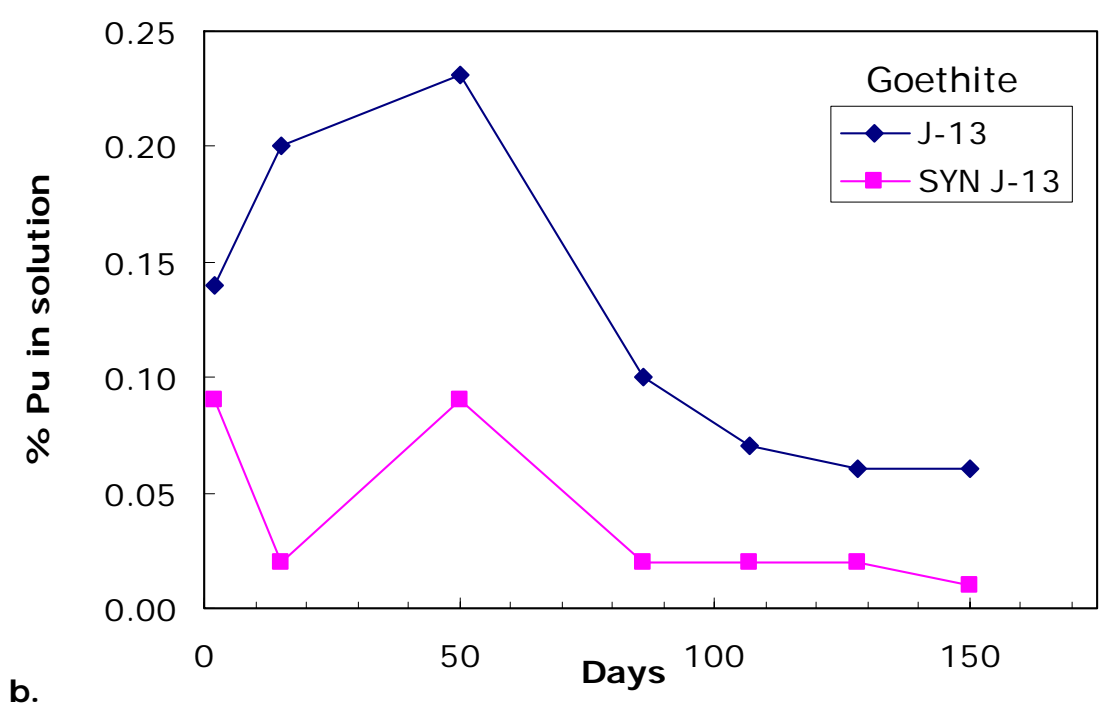

Source: DTN: SN0508T0507703.020, spreadsheet Pu sorption-desorption.xls, worksheet "Desorp data, reinterpreted."

NOTE: Desorption data for hematite are near detection limits for the method, and are scattered. Data for goethite show an overall decrease in the amount in solution with time.

Figure 6.6-8. Reinterpretation of Lu et al. (1998 [DIRS 100946]) Desorption Data for (a) Hematite and (b) Goethite 
Table 6.6-10. Lu Data for Desorption of Pu(V) from Hematite and Goethite Colloids

\begin{tabular}{|c|c|c|c|c|c|}
\hline \multirow[b]{2}{*}{ Minerals } & \multirow{2}{*}{$\begin{array}{c}\text { Time } \\
\text { (days) }\end{array}$} & \multicolumn{2}{|c|}{$\%$ of $\mathrm{Pu}$ in aqueous phase } & \multicolumn{2}{|c|}{ Desorption $K_{d}\left(\mathrm{~mL} \mathrm{~g}^{-1}\right)$} \\
\hline & & $\mathrm{J}-13$ & SYN.J-13 & $\mathrm{J}-13$ & SYN.J-13 \\
\hline \multirow{7}{*}{ Hematite } & 2 & 0.005 & 0.0002 & $2.0 E+05$ & $5.0 E+06$ \\
\hline & 15 & 0.001 & 0.0000 & $1.0 E+06$ & \\
\hline & 50 & 0.005 & 0.0000 & $2.0 E+05$ & \\
\hline & 86 & 0.000 & 0.0000 & & \\
\hline & 107 & 0.001 & 0.0007 & $1.0 E+06$ & $1.4 \mathrm{E}+06$ \\
\hline & 128 & 0.003 & 0.0001 & $3.3 E+05$ & $1.0 \mathrm{E}+07$ \\
\hline & 150 & 0.003 & 0.0010 & $3.3 E+05$ & $1.0 \mathrm{E}+06$ \\
\hline \multirow{7}{*}{ Goethite } & 2 & 0.14 & 0.09 & $7.1 E+03$ & $1.1 E+04$ \\
\hline & 15 & 0.20 & 0.02 & $5.0 \mathrm{E}+03$ & $5.0 \mathrm{E}+04$ \\
\hline & 50 & 0.23 & 0.09 & $4.3 E+03$ & $1.1 E+04$ \\
\hline & 86 & 0.10 & 0.02 & $9.9 E+03$ & $5.0 \mathrm{E}+04$ \\
\hline & 107 & 0.07 & 0.02 & $1.4 \mathrm{E}+04$ & $5.0 \mathrm{E}+04$ \\
\hline & 128 & 0.06 & 0.02 & $1.7 \mathrm{E}+04$ & $5.0 \mathrm{E}+04$ \\
\hline & 150 & 0.06 & 0.01 & 1.7E+04 & $1.0 E+05$ \\
\hline
\end{tabular}

Source: DTN: SN0508T0507703.020, spreadsheet Pu sorption-desorption.x/s, worksheet "Desorp data, reinterpreted."

The sorption and desorption data presented here provide information on the relative applicability of the irreversible or reversible sorption model. For a single site, reversible sorption model, the relative rate of $\mathrm{Pu}$ transfer to and from the mineral surface is a first-order function of the solution concentration and the concentration on the solid, and hence, the concentration in solution can be fitted as a decaying exponential with time. Two aspects of the data are inconsistent with this. First, there is in all cases a nearly instantaneous decrease in the amount in solution (in the first 10 minutes), in which 30-93 percent of the $\mathrm{Pu}$ is sorbed. Then there is a sharp inflection in the sorption curve, and more gradual uptake occurs. This is inconsistent with modeling Pu sorption as first-order with respect to solution concentration, and zero-order with respect to time, as a $K_{d}$ model indicates.

The long term increase in the proportion of Pu adsorbed in the goethite "desorption" experiments is also inconsistent with the single site $K_{d}$ model, which would predict equilibrium, based on the rapid short term sorption data, in much shorter time intervals. However, the desorption data cannot be uniquely interpreted. Each point represents the concentration in solution after 20 to 30 days of re-equilibration; however, it is not clear whether, during that particular extraction step, the concentration was still increasing, or decreasing, when the sample was taken. In the first case, release from the surface would be very slow, and equilibration with the solution would not have been accomplished. The progressively lower solution concentrations in each extraction would indicate progressively slower equilibration rates, and, presumably conversion of a larger fraction of sorbed $\mathrm{Pu}$ to a more stable form. In the second case, equilibration with $\mathrm{Pu}$ on the surface would occur very rapidly in each extraction, with the fast, readily exchanging sites largely controlling the solution concentration. The concentration would rapidly rise to approximately the same value as at the end of the previous extraction. The decrease in the equilibrium concentration with time would then indicate $\mathrm{Pu}$ transfer from the fast sites to a more 
stabilized form. In this case, the factor of 3-5 drop in concentration over the course of the sampling would indicate that the amount of $\mathrm{Pu}$ in the readily exchangeable site dropped by that factor. However, regardless of whether the sampled concentration represents a point on the "up" or the "down" part of the desorption curve, the measured value gets progressively smaller with time, and the rate at which this change occurs indicates that the $\mathrm{Pu}$ is somehow being converted to a more stable form on the surface of the mineral.

Thus, both the sorption and desorption data suggest that two reactions or processes are occurring, leading to rapid uptake followed by slower stabilization of $\mathrm{Pu}$ on the mineral surface, although no information on the form, or the resistance to remobilization, of the "stabilized" $\mathrm{Pu}$ is available. If we assume that sorption is occurring onto two sites on the mineral surface (consistent with the two-site model for irreversible sorption implemented in the EBS RT Abstraction), then this would imply some kinetic inhibition of sorption onto the higher affinity site. Eventually, however, most of the Pu would transfer to the high affinity site.

Painter et al. (2002 [DIRS 174071]) fitted the LANL sorption data for Pu using a two-site sorption model. Their model is a $K_{d}$ model—forward and backward rate coefficients for sorption onto both sites are derived by fitting the experimental data, and the rate of mass transfer to and from the surface is only a function of the concentrations in solution and on the solid. The $K_{d}$ value for each of the two sites can be calculated from the forward and backward rate coefficients. Therefore, the Painter et al. (2002 [DIRS 174071]) approach can be used to fit the goethite sorption data from DTN: LA0004NL831352.001 [DIRS 150272], and the forward and backward rate constants for the fast and slow sorbing sites determined. These can be used to estimate the long-term equilibrium $K_{d}$ value for Pu sorption onto goethite.

The model assumes that there are two sorption sites available on the solid, and that the total amount of $\mathrm{Pu}$ is small relative to the number of sites - that is, sorption is not site-limited. It is assumed that one site is a "fast" site, a lower affinity site that reaches equilibrium with the solution quickly and controls sorption in the short term. The other site is a "slow" site, a higher affinity site that only gradually reaches equilibrium with the solution. Different forward and backward rate constants are associated with mass transfer to and from the two sorption sites, and the rate constants are related by the $K_{d}$ value that applies to each site. For the fast site:

$$
k_{f}=k_{r} K_{c} C_{c}
$$

where $k_{f}\left(\mathrm{hr}^{-1}\right)$ is the forward rate constant for the fast site, $k_{r}\left(\mathrm{hr}^{-1}\right)$ the reverse rate constant for the fast site, $K_{c}\left(\mathrm{~L} \mathrm{~g}^{-1}\right)$, the partitioning coefficient for the fast site, and $C_{c}\left(\mathrm{~g} \mathrm{~L}^{-1}\right)$, the substrate load in solution.

For the slow site:

$$
\alpha=\beta K_{c}^{\prime} C_{c}
$$

where $\alpha\left(\mathrm{hr}^{-1}\right)$ is the forward rate constant for the slow site, $\beta\left(\mathrm{hr}^{-1}\right)$ the reverse rate constant for the slow site, $K_{c}^{\prime}\left(\mathrm{L} \mathrm{g} \mathrm{g}^{-1}\right)$ the partitioning coefficient for the slow site, and $C_{c}\left(\mathrm{~g} \mathrm{~L}^{-1}\right)$, is, again, the substrate load in solution. 
The analytical solution describing the concentration in solution over time is as follows Painter et al. (2002 [DIRS 174071], Equation 7):

$$
X(t)=f(t)+\beta F(t)
$$

where

$$
\begin{aligned}
& f(t)=\frac{1}{2} e^{(b-a / 2) t}+\frac{1}{2} e^{-(b+a / 2) t}+\frac{1}{2 b}\left(k_{r}-\frac{a}{2}\right)\left[e^{(b-a / 2) t}-e^{-(b+a / 2) t}\right] \\
& F(t)=\frac{1}{2(b-a / 2)}\left[e^{(b-a / 2) t}-1\right]+\frac{1}{2(b+a / 2)}\left[1-e^{-(b+a / 2) t}\right]+\frac{1}{2 b}\left(k_{r}-\frac{a}{2}\right)\left\{\frac{1}{b-a / 2}\left[e^{(b-a / 2) t}-1\right]-\frac{1}{b+a / 2}\left[1-e^{-(b+a / 2) t}\right]\right\}
\end{aligned}
$$

and

$$
\begin{gathered}
a \equiv k_{f}+k_{r}+\alpha+\beta \\
b^{2} \equiv \frac{a^{2}}{4}-k_{r} \alpha-k_{r} \beta-k_{f} \beta
\end{gathered}
$$

Note that the definition of $b^{2}$ given by Painter et al. (2002 [DIRS 174071]) is missing the final term; it has been corrected here. To solve the analytical solution, Painter et al. (2002 [DIRS 174071]) first make a simplifying assumption, that the fast sites have reached steady state once the sorption curves level out, and that the slow increase beyond that point is due to uptake by the slow sites. This allows the complex analytical solution (Equation 6.6.7-3) to be reduced to a simpler form (Painter et al. (2002 [DIRS 174071], equation 10) for the fraction of Pu adsorbed $(\phi)$, which only depends on two parameters, $\alpha$ and $K_{c}$ :

$$
\phi=\frac{K_{c} C_{c}}{1+K_{c} C_{c}}+\frac{\alpha t}{\left(1+K_{c} C_{c}\right)^{2}}
$$

In the Painter et al. (2002 [DIRS 174071]) approach, the last few data points in the sorption dataset are fitted using Equation 6.6.7-4 to estimate values for $\alpha$ and $K_{c}$. This was done using the EXCEL Solver add-in to optimize the fit to the data (see DTN: SN0508T0507703.020 spreadsheet $P$ u sorption-desorption.xls, worksheet "2-site fit"). Then, the full analytical solution is fit, using the estimates for $\alpha$ and $K_{c}$ from the longer-term data, and optimizing the fit on $k_{r}$ and $\beta$, while holding $k_{f}=k_{r} K_{c} C_{c}$, and constraining $\alpha \geq \beta$, and all forward and backward rate constants greater than or equal to 0 .

Once this has been done, $K_{c}$ represents the short-term $K_{d}$, and $K_{c}^{\prime}$, representing the slow site partitioning coefficient, can be calculated using:

$$
K_{c}^{\prime}=\frac{\alpha}{\beta C_{c}}
$$


The long-term $K_{d}$ value for Pu sorption onto the substrate of interest is equal to the sum of $K_{c}$ and $K_{c}$ '. For the cases examined here, $K_{c}$, is much larger than $K_{c}$, and dominates the sorption behavior at long time intervals.

The Painter et al. (2002 [DIRS 174071]) method was used to evaluate the project data for Pu sorption onto goethite and hematite in DTN: LA0004NL831352.001 [DIRS 150272]. The results are presented in Figure 6.6-9 and Table 6.6-11. The fits are poor, especially for the shortterm data. They are also highly sensitive to the number of data points used in the first step, in which the longer-term data are fitted to determine $\alpha$ and $K_{c}$. The sorption data only extend out to 100 hours, and the few long-term points are insufficient to accurately constrain the values for $\alpha$ and $K_{c}$.

Because the long-term data are insufficient to constrain any of the fitting parameters, the Painter et al. (2002 [DIRS 174071]) method was applied a second time, using only Equation 6.6.7-3, and finding the best fit by adjusting all four rate parameters at once, subject only to the constraints that all rates are positive, and that forward rates must be larger than reverse rates (Table 6.6-12 and Figure 6.6-10). The data fits are much better using this method. There is considerable variability in the data, with hematite sorbing more rapidly and more completely that goethite, and both minerals sorbing more completely in the synthetic water relative to the natural J-13 water. The calculated $K_{c}$ and $K_{c}^{\prime}$ values show these variations. The $\left(K_{c}+K_{c}^{\prime}\right)$ values for goethite are $1.1 \times 10^{4}$ and $1.3 \times 10^{5} \mathrm{~mL} \mathrm{~g}^{-1}$, for $\mathrm{J}-13$ and synthetic $\mathrm{J}-13$, respectively. These are consistent with the $K_{d}$ values determined from the desorption experiments, of $1.7 \times 10^{4}$ and $1.0 \times 10^{5} \mathrm{~mL} \mathrm{~g}^{-1}$, respectively (Table 6.6-10).

The reason for the variability in sorption $K_{d}$ values between the J-13 and synthetic J-13 water is not known. Synthetic J-13 water was made by dissolving sodium carbonate and sodium bicarbonate in deionized water, and had a $\mathrm{pH}$ of 8.5 , an ionic strength of $0.005 \mathrm{M}$, and an alkalinity of $22.5 \mathrm{meq} \mathrm{L}^{-1}$. The natural J-13 water had a $\mathrm{pH}$ of 8.2 , an ionic strength of $0.005 \mathrm{M}$, and an alkalinity of 22.5 meq L ${ }^{-1}$, but also contained many other components, most notably 13 ppm $\mathrm{Ca}$ and $30 \mathrm{ppm}$ silica. These differences in chemistry may account for the differences in $\mathrm{Pu}$ sorption, and offer some indication of the sensitivity of sorption to water composition. 

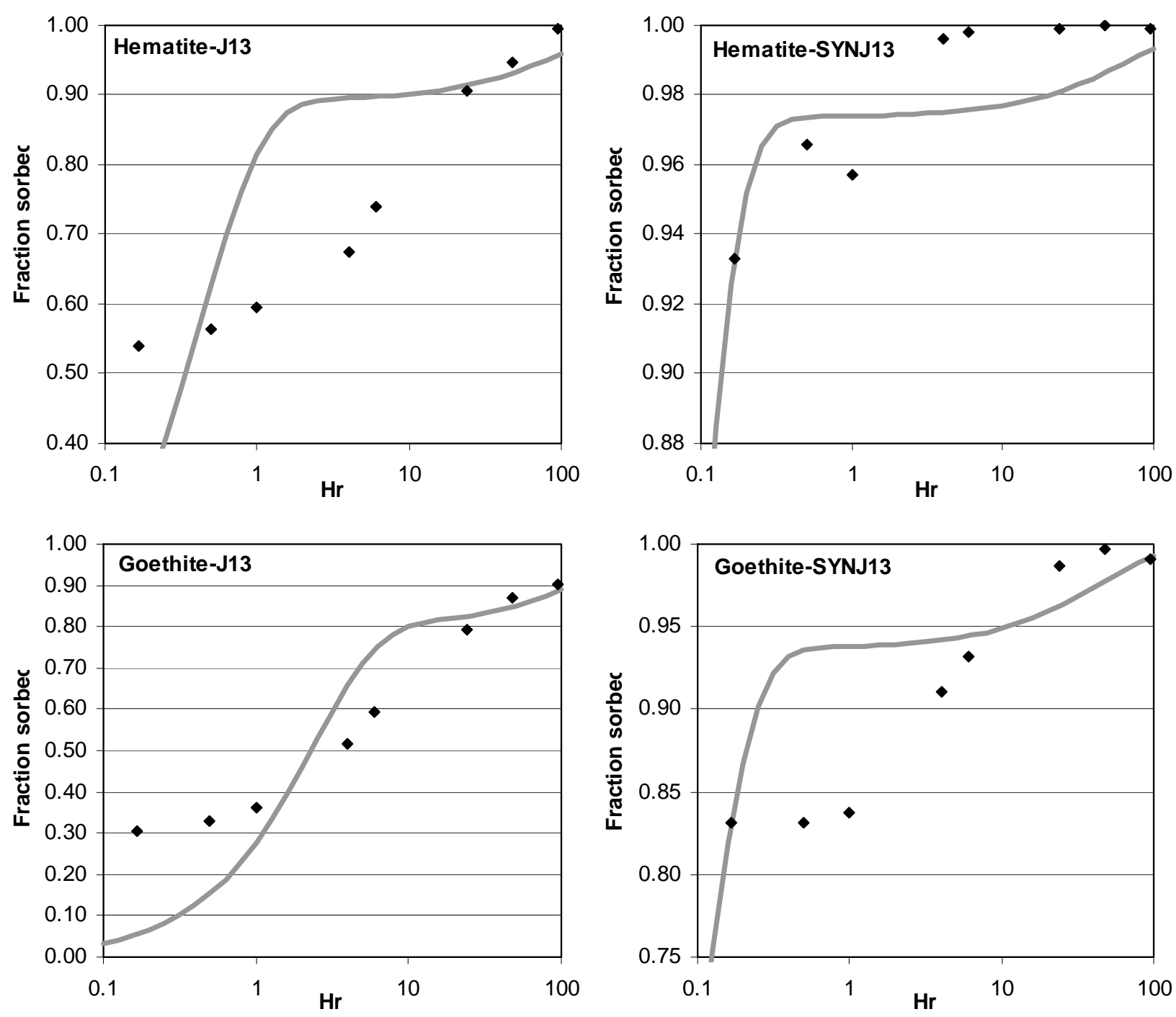

Figure 6.6-9. Two-Site Model of Painter et al. (2002 [DIRS 174071]), Fitted to Pu Sorption Data for Hematite and Goethite Using Two-Step Fitting Process of Painter et al.

Table 6.6-11. Fitting Pu Sorption Data of Lu et al. (1998 [DIRS 174714]) with the Two-Site Model of Painter et al. (2002 [DIRS 174071]); Two Steps

\begin{tabular}{|c|c|c|c|c|c|c|c|c|}
\hline Mineral & Water & $\begin{array}{c}C_{c} \\
\left(g L^{-1}\right)\end{array}$ & $\begin{array}{c}k_{f} \\
\left(\mathrm{hr}^{-1}\right)\end{array}$ & $\begin{array}{c}k_{r} \\
\left(\mathrm{hr}^{-1}\right)\end{array}$ & $\begin{array}{c}\alpha \\
\left(\mathrm{hr}^{-1}\right)\end{array}$ & $\begin{array}{c}\beta \\
\left(\mathrm{hr}^{-1}\right)\end{array}$ & $\begin{array}{c}K_{c} \\
(\mathrm{~mL} / \mathrm{g})\end{array}$ & $\begin{array}{c}K_{c}^{\prime} \\
(\mathrm{mL} / \mathrm{g})\end{array}$ \\
\hline \multirow{2}{*}{ Hematite } & $\mathrm{J}-13$ & 0.99 & 2.08 & 0.272 & 0.0871 & 0.0 & $7.69 \times 10^{3}$ & $9.48 \times 10^{4}$ \\
\hline & Syn. J-13 & 0.85 & 18.0 & 0.515 & 0.508 & 0.0 & $4.12 \times 10^{4}$ & $\infty$ \\
\hline \multirow{2}{*}{ Goethite } & $\mathrm{J}-13$ & 1.11 & 0.313 & 0.0900 & 0.0279 & 0.0 & $3.12 \times 10^{3}$ & $4.02 \times 10^{4}$ \\
\hline & Syn. J-13 & 0.98 & 11.9 & 0.847 & 0.335 & 0.0 & $1.43 \times 10^{4}$ & $\infty$ \\
\hline
\end{tabular}

Source: DTN: SN0508T0507703.020, spreadsheet Pu sorption-desorption.xls, worksheet "2-site fit, best fit 2 par."

NOTE: Values of $C_{c}$ are corrected from Lu et al. (1998 [DIRS 174714], Table 1) by multiplying by a factor of 20/21 to account for dilution when Pu-spiked water was added. 

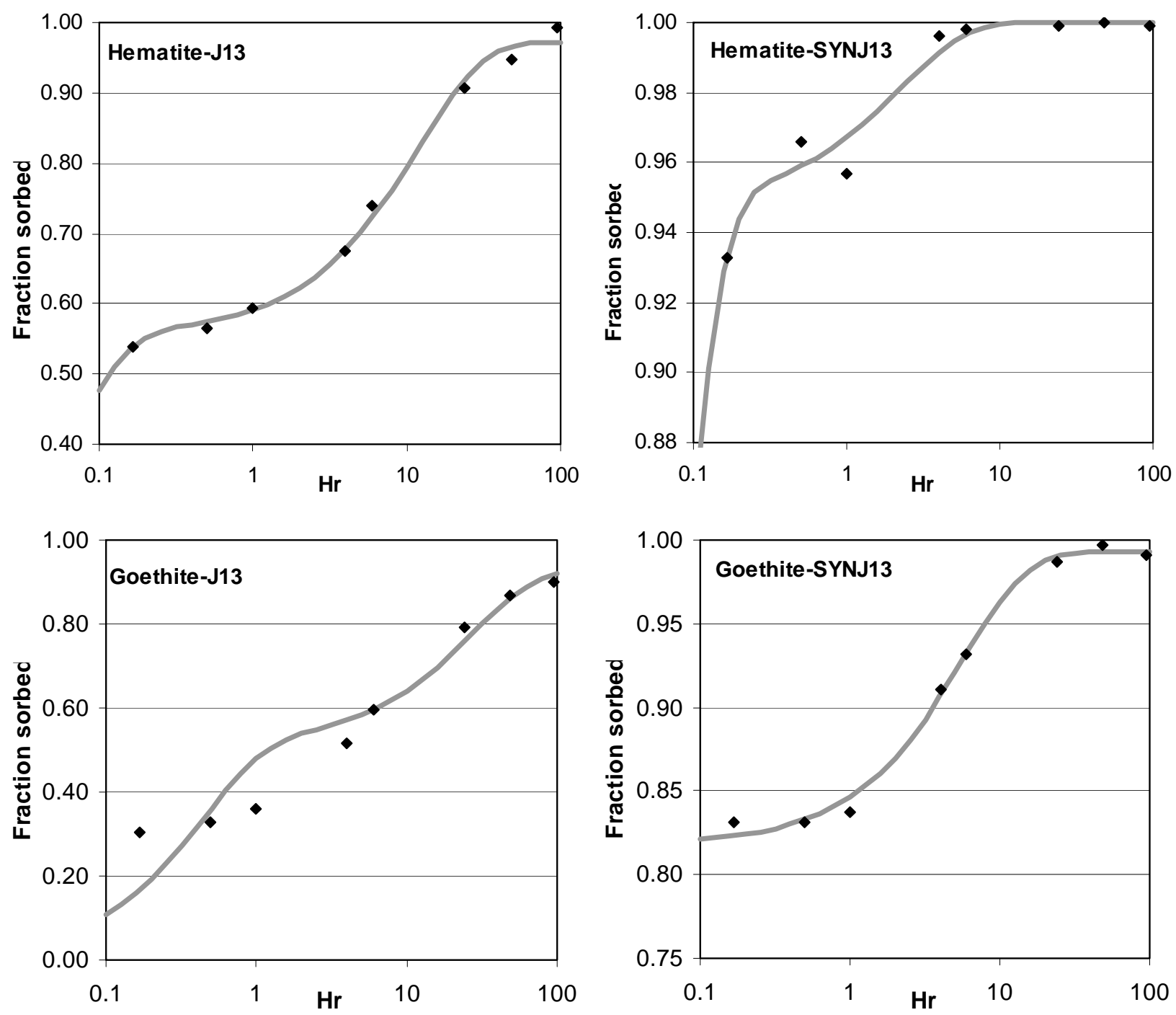

Figure 6.6-10. Two-site model of Painter et al. (2002 [DIRS 174071]), applied to Pu sorption data for hematite and goethite, and fitted in a single step

Table 6.6-12. Fitting Pu Sorption Data of Lu et al. (1998 [DIRS 174714]) Using the Two-Site Model of Painter et al. (2002 [DIRS 174071]), One Step

\begin{tabular}{|c|c|c|c|c|c|c|c|c|}
\hline Mineral & Water & $\begin{array}{c}\boldsymbol{C}_{\boldsymbol{c}} \\
\left(\mathbf{g ~ L}^{-\mathbf{1}}\right)\end{array}$ & $\begin{array}{c}\boldsymbol{k}_{\boldsymbol{f}} \\
\left(\mathbf{h r}^{-1}\right)\end{array}$ & $\begin{array}{c}\boldsymbol{k}_{\boldsymbol{r}} \\
\left(\mathbf{h r}^{-1}\right)\end{array}$ & $\begin{array}{c}\boldsymbol{\alpha} \\
\left(\mathbf{h r}^{-1}\right)\end{array}$ & $\begin{array}{c}\boldsymbol{\beta} \\
\left(\mathbf{h r}^{-1}\right)\end{array}$ & $\begin{array}{c}\boldsymbol{K}_{\boldsymbol{c}} \\
\left(\mathbf{m L ~ g}^{-\mathbf{1}}\right)\end{array}$ & $\begin{array}{c}\boldsymbol{K}_{\mathbf{c}}^{\prime} \\
\left(\mathbf{m L ~ g}^{-\mathbf{1}}\right)\end{array}$ \\
\hline \multirow{2}{*}{ Hematite } & J-13 & 0.99 & 10.4 & 8.41 & 0.186 & $5.28 \times 10^{-3}$ & $1.25 \times 10^{3}$ & $3.43 \times 10^{4}$ \\
\cline { 2 - 9 } & Syn. J-13 & 0.85 & 15.7 & 1.62 & 6.43 & 0.0 & $1.14 \times 10^{4}$ & $\infty$ \\
\hline \multirow{2}{*}{ Goethite } & J-13 & 1.11 & 5.64 & 1.14 & 0.136 & $1.95 \times 10^{-2}$ & $8.97 \times 10^{2}$ & $1.10 \times 10^{4}$ \\
\cline { 2 - 9 } & Syn. J-13 & 0.98 & 71.0 & 16.1 & 0.954 & $6.93 \times 10^{-3}$ & $4.49 \times 10^{3}$ & $1.36 \times 10^{5}$ \\
\hline
\end{tabular}

Source: DTN: SN0508T0507703.020, spreadsheet Pu sorption-desorption.xls, worksheet "2-site fit, best fit 4 par."

NOTE: Values of $C_{c}$ are corrected from Lu et al. (1998 [DIRS 174714], Table 1) by multiplying by a factor of 20/21 to account for dilution when Pu-spiked water was added. 
The two site model fits the data very well. Given the small number of data points, this does not prove that a two-site model is correct; however, it does indicate that a model able to capture the complexities of multiple, heterogeneous processes at the mineral-solution interface is necessary to describe the behavior of $\mathrm{Pu}$ sorption onto goethite and hematite. The data do not show the smoothly decaying exponential curve that sorption onto a single site would produce; instead, there appear to be at least two processes involved - rapid sorption followed by slow conversion into a less exchangeable form. In the case of the two-site model, this would be transfer into the higher-affinity site, but other processes, such as the $\mathrm{Pu}(\mathrm{V})$ reduction step described earlier, would yield the same results. These results, based on analysis of the sorption data, are entirely consistent with the experimental desorption results discussed earlier.

Another method of evaluating the sorption rate data, and useful for checking against the model described above, is through use of the 'Elovich' rate formulation (Low 1960 [DIRS 174812]) which has been widely adopted in soil sciences (Sposito 1984 [DIRS 127253]; Chien and Clayton 1980 [DIRS 174705]; Havlin et al. 1985 [DIRS 174706]). This equation has also been applied extensively to data relevant to chemisorption and is known for its accurate representation of rate data whether fast and slow kinetics are present (Low 1960 [DIRS 174812]). The Elovich equation as applied to sorption has the following form (Low 1960 [DIRS 174812]):

$$
\frac{d \Gamma}{d t}=a e^{-\alpha \Gamma}
$$

where $\Gamma$ delineates the amount sorbed per unit area at time $t$, and $\alpha$ and $a$ are constants. Integration of Equation 6.6.7-6 assuming $\Gamma=0$ and $t=0$ yields (Low 1960 [DIRS 174812]):

$$
\Gamma=\frac{1}{\alpha} \ln (1+a \alpha t)
$$

Equation 6.6.7-7 can also be expressed as:

$$
\Gamma=\frac{1}{\alpha} \ln \left(t+t_{0}\right)-\frac{1}{\alpha} \ln t_{0}
$$

where $t_{0}=\frac{1}{(a \alpha)}$.

Fitting the $\mathrm{Pu}$ sorption data for goethite and hematite ( $\mathrm{J}-13$ water only) from DTN: LA0004NL831352.001 [DIRS 150272] using the Elovich equation rate law (Figure 6.6-11) indicates very similar values for the $\alpha$ rate parameter. These rate data are only valid at $\mathrm{pH} \sim 8$. Overall, the model fit to the data is very good; both goethite and hematite have similar trends, and generate very similar rates. The values obtained for $a$ and $\alpha$ for hematite are 0.88 and 51.5, respectively, while for goethite, the values are 0.01 and 51.78. It is assumed that the rate data extracted from these sources is taken as representative of forward rates for the formation of the predominant surface complex at this $\mathrm{pH}, \mathrm{SO}^{-}-\mathrm{Pu}(\mathrm{OH})_{4}$, as proposed by Sanchez et al. (1985 [DIRS 107213]). The equation was fitted only to the 'J-13' data; the 'SYN J-13' 
could not be fit because the early stage of sorption was not captured-83-93 percent sorbed in the first time step.

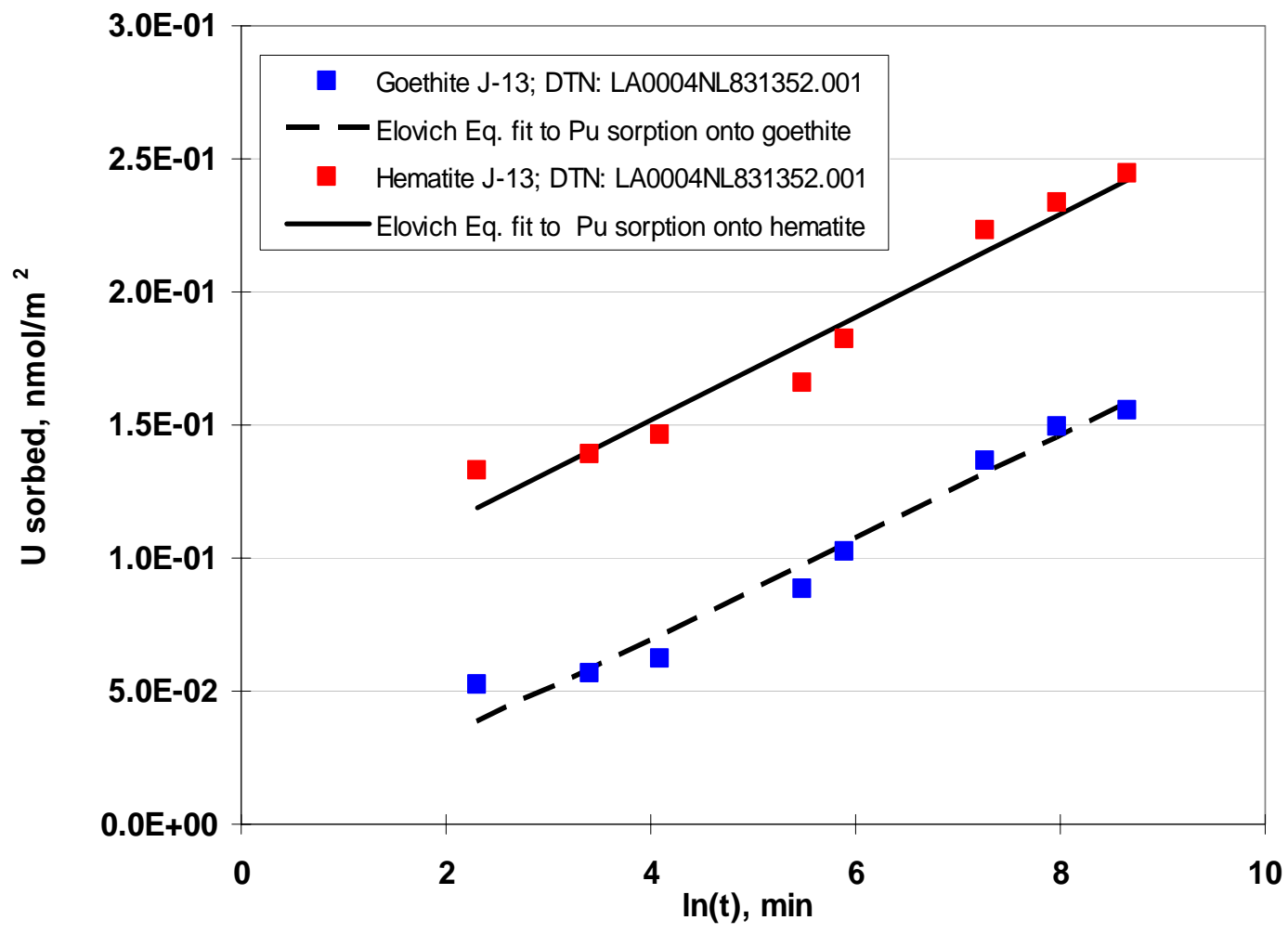

Figure 6.6-11. Kinetic data for $\mathrm{Pu}$ Adsorption onto Hematite and Goethite at $\mathrm{pH}$-8-8.5 from DTN: LA0004NL831352.001 [DIRS 150272] Showing the Linear Fits to the Elovich Equation (see text)

Therefore, analysis of the LANL sorption-desorption experiments shows, using two approaches for the sorption and desorption data, that the long-term $K_{d}$ values for $\mathrm{Pu}$ sorption onto goethite, assuming that sorption is completely reversible, are on the range of 8,700 to $140,000 \mathrm{~mL} \mathrm{~g}^{-1}$, for the chemical conditions examined. In some cases, these are minimum values, limited by the detection limits of the analysis.

\subsubsection{Sorption Dependence on Solution Composition}

The experimental work described above for $\mathrm{Pu}(\mathrm{V})$ sorption onto goethite and hematite was performed under only a limited set of conditions (two water compositions, with two slightly different $\mathrm{pH}$ values). Hence, the sensitivity of $\mathrm{Pu}(\mathrm{V})$ sorption to water chemistry is not well constrained. However, studies available in the scientific literature provide ways of evaluating this. $\mathrm{Pu}(\mathrm{V})$ sorption onto goethite and hematite was examined by Powell et al. (2005 [DIRS 174726]). They found that the sorption rate was strongly $\mathrm{pH}$-dependent for hematite, but only weakly $\mathrm{pH}$-dependent for goethite. For both minerals, they found that, at $\mathrm{pH}$ values greater than $\mathrm{pH} 4.5, \mathrm{Pu}(\mathrm{V})$ reduced to $\mathrm{Pu}(\mathrm{IV})$ on the surface of the goethite, with nearly complete adsorption and conversion within days or weeks, depending on the pH (Powell et al. 2005 [DIRS 174726], Figures 2 and 3). For hematite, sorption of $\mathrm{Pu}(\mathrm{V})$ onto the surface was the rate- 
limiting step in the transformation; for goethite, reduction was the rate-limiting step. They hypothesized that this mechanism occurred because of the semiconductor properties of hematite and goethite (the rate of reduction appears to be light sensitive) and because $\mathrm{Pu}(\mathrm{IV})$ forms a highly stable surface hydroxide species. This is consistent with the earlier work of Sanchez et al. (1985 [DIRS 107213]) and Keeney-Kennicutt and Morse (1985 [DIRS 106313]), who proposed a similar reduction reaction for $\mathrm{Pu}$ sorption onto goethite. To summarize, Powell et al. (2005 [DIRS 174726]) found that, over the $\mathrm{pH}$ range 5-8, the $\mathrm{Pu}(\mathrm{V})$ sorption rate is very $\mathrm{pH}$ dependent, but that $\mathrm{Pu}(\mathrm{V})$ converts to a very stable $\mathrm{Pu}(\mathrm{IV})$ complex on the mineral surface. Uptake of $\mathrm{Pu}(\mathrm{V})$ continues as surface reduction consumes sorbed $\mathrm{Pu}(\mathrm{V})$, and although sorption rate varies with $\mathrm{pH}$, eventually, over the $\mathrm{pH}$ range they studied, nearly complete conversion and sorption occurs.

Thus, at time intervals of more than a few weeks, $\mathrm{Pu}(\mathrm{V})$ sorbs and converts to stable $\mathrm{Pu}(\mathrm{IV})$ inner sphere surface complexes; therefore to evaluate the effects of solution chemistry on $\mathrm{Pu}$ sorption, the sorption behavior of $\mathrm{Pu}(\mathrm{IV})$ must be examined. Two studies provide information on this. Duro et al. (2004 [DIRS 174716], Figure 3a), showed that the Pu (IV) sorption edge for goethite occurs between 3 and 4 , and the sorption $K_{d}$ value reaches about $10^{5}$ by $\mathrm{pH} 5$ (Figure 6.6-12). $K_{d}$ values at different $\mathrm{pHs}$ were extracted from this plot by hand, and are listed in Table 6.6-13. The data of Duro et al. are consistent with the results of Sanchez et al. (1985 [DIRS 107213]), who found that the $\mathrm{Pu}(\mathrm{V})$ sorption edge onto goethite occurred at $\mathrm{pH} \mathrm{7}$, and the $\mathrm{Pu}(\mathrm{IV})$ sorption edge, at $\mathrm{pH} 3-5$.

Sanchez et al. also found that sorption of $\mathrm{Pu}$ in either oxidation state was not affected by changes in ionic strength $\left(0.1 \mathrm{M}\right.$ to $3 \mathrm{M} \mathrm{NaCl}$ or $\mathrm{NaNO}_{3}$ and $0.03 \mathrm{M}$ to $\left.0.3 \mathrm{M} \mathrm{Na}_{2} \mathrm{SO}_{4}\right)$, suggesting inner-sphere sorption, and developed a surface complexation model for $\mathrm{Pu}(\mathrm{IV})$ based on their observations. This model involves four adsorption reactions, each successively becoming important with increasing $\mathrm{pH}$ :

$$
\begin{aligned}
& \mathrm{SOH}+\mathrm{Pu}^{4+}+\mathrm{H}_{2} \mathrm{O} \Leftrightarrow \mathrm{SO}^{-}-\mathrm{Pu}(\mathrm{OH})_{2}{ }^{3+}+2 \mathrm{H}^{+} \\
& \mathrm{SOH}+\mathrm{Pu}^{4+}+2 \mathrm{H}_{2} \mathrm{O} \Leftrightarrow \mathrm{SO}^{-}-\mathrm{Pu}(\mathrm{OH})_{2}{ }^{2+}+3 \mathrm{H}^{+} \\
& \mathrm{SOH}+\mathrm{Pu}^{4+}+3 \mathrm{H}_{2} \mathrm{O} \Leftrightarrow \mathrm{SO}^{-}-\mathrm{Pu}(\mathrm{OH})_{3}{ }^{+}+4 \mathrm{H}^{+} \\
& \mathrm{SOH}+\mathrm{Pu}^{4+}+4 \mathrm{H}_{2} \mathrm{O} \Leftrightarrow \mathrm{SO}^{-}-\mathrm{Pu}(\mathrm{OH})_{4}{ }^{0}+5 \mathrm{H}^{+}
\end{aligned}
$$

The resulting sorption edge is shown in Figure 6.6-13 (Sanchez et al. 1985 [DIRS 107213], Figure 3). It should be noted however, that these data are for a carbonate-free system. In systems with carbonate, carbonate complexation in solution at $\mathrm{pH}$ values greater than 8 are likely to reduce sorption, although formation of $\mathrm{Pu}$-carbonate surface complexes partially offsets this. Sanchez et al. (1985 [DIRS 107213], p. 2304) found that at pH 8.6, relatively high alkalinities (above $100 \mathrm{meq} \mathrm{L}^{-1}$ ) are necessary to significantly affect Pu sorption. 


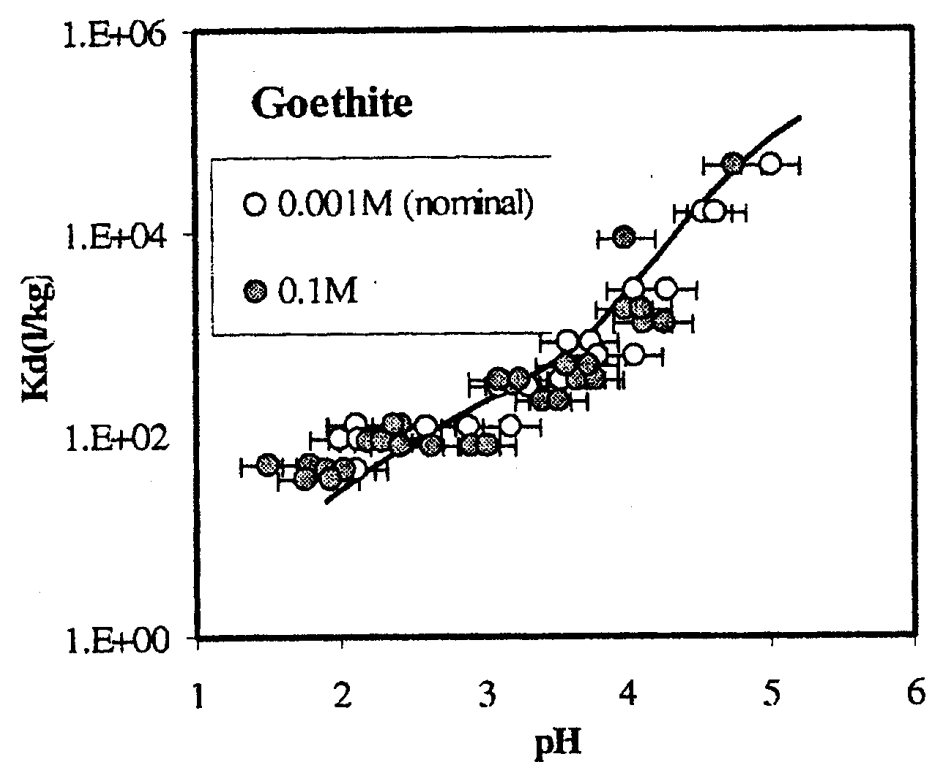

Source: Reproduced from Duro et al. 2004 [DIRS 174716], Figure 3a.

Figure 6.6-12. $\mathrm{pH}$ Dependence of Pu (IV) Sorption onto Goethite for the pH Range 2 to 5

Table 6.6-13. $\quad K_{d}$ Values for Pu(IV) Sorption onto Goethite

\begin{tabular}{|c|c|}
\hline $\mathbf{p H}$ & $\boldsymbol{K}_{\boldsymbol{d}}, \mathbf{~ m L ~}^{-\mathbf{1}}$ \\
\hline \hline 2.0 & $3 \times 10^{1}$ \\
\hline 2.5 & $8.5 \times 10^{1}$ \\
\hline 3.0 & $2.0 \times 10^{2}$ \\
\hline 3.5 & $5.7 \times 10^{2}$ \\
\hline 4.0 & $2.5 \times 10^{3}$ \\
\hline 4.5 & $1.7 \times 10^{4}$ \\
\hline 5.0 & $8.5 \times 10^{4}$ \\
\hline 5.2 & $1.3 \times 10^{5}$ \\
\hline
\end{tabular}

Source: Duro et al. 2004 [DIRS 174716], Figure 3a. 


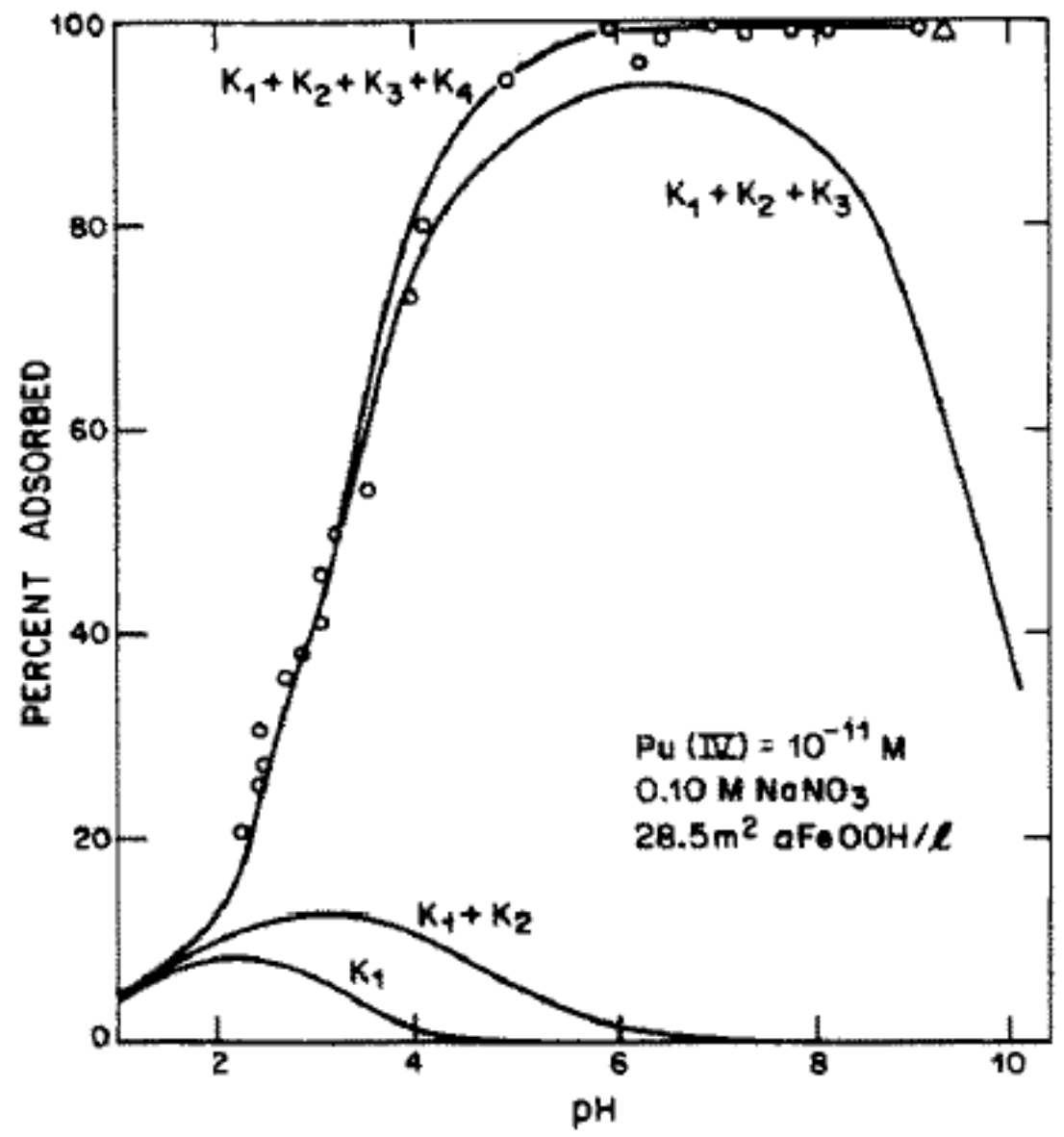

Source: Sanchez et al. 1985 [DIRS 107213], Figure 3.

NOTE: $\quad$ Raw data (open circles) and calculated model fits, using a Triple Layer Model (TLM) and the surface speciation corresponding to reactions R1 through R4, given here as K1 through K4.

Figure 6.6-13. $\mathrm{pH}$ Dependence of Pu(IV) Sorption in a Carbonate-Free System

Sanchez et al. (1985 [DIRS 107213]) provide surface complexation constants for reactions R1 through R4 obtained using a Triple Layer Model (TLM) (Davis and Leckie 1978 [DIRS 125591]), based on experiments with sufficient time given for stabilization. These data could be utilized to estimate $K_{d}$ values as a function of $\mathrm{pH}$, at least over the $\mathrm{pH}$ range from 3 to 8 . To do this, a geochemical speciation code implementing the TLM for surface complexation would be necessary to calculate the amount $\mathrm{Pu}(\mathrm{IV})$ sorbed as a function of $\mathrm{pH}$. No qualified version of such a code currently exists.

\subsubsection{Summary of Alternative Conceptual Model for Pu Adsorption}

An evaluation of available Yucca Mountain Project-specific data on Pu adsorption to iron oxides indicates that at least two processes are occurring when $\mathrm{Pu}$ adsorbs to goethite or hematite, a rapid sorption step, followed by a second process that stabilizes the $\mathrm{Pu}$ on the mineral surface. For goethite, measured $K_{d}$ values at $\mathrm{pH}$ values of 8.2 and 8.5 are in the range of $10^{4}$ to $10^{5} \mathrm{~mL} \mathrm{~g}^{-1}$ for sorption data in DTN: LA0004NL831352.001 [DIRS 150272], and desorption data from 
Lu et al. (1998 [DIRS 100946]), based on both direct measurements and fits of the available data using a two-site model from Painter et al. (2002 [DIRS 174071]). A review of literature studies shows that reduction of $\mathrm{Pu}(\mathrm{V})$ to $\mathrm{Pu}(\mathrm{IV})$ on the mineral surface has been observed experimentally (Keeney-Kennicutt and Morse 1985 [DIRS 106313]; Sanchez et al. 1985 [DIRS 107213]; Morse and Choppin 1986 [DIRS 174703]; Powell et al. 2005 [DIRS 174726]). It is probable that this redox reaction is the second process occurring in the project $\mathrm{Pu}$ sorption experiments, as suggested by Runde et al. (2002 [DIRS 168432]). Pu(IV) forms highly stable surface complexes which, relative to $\mathrm{Pu}(\mathrm{V})$, are less readily stripped from the mineral surface. The sorption behavior therefore becomes that of $\mathrm{Pu}(\mathrm{IV})$. Pu(IV) sorption $K_{d}$ values vary with pH; between pH 2 and 5, the data of Duro et al. (2004 [DIRS 174716]) can be used to estimate the applicable $K_{d}$ value. At for $\mathrm{pH}$ values from 5 to 8, Powell et al. (2005 [DIRS 174726]) present a triple layer surface complexation model (TLM) for $\mathrm{Pu}(\mathrm{V})$, which includes the reduction step. $K_{d}$ values could be calculated from the results of that model, but qualified software with the capability of running a TLM is not available. However, their sorption data indicate that $\mathrm{K}_{\mathrm{d}} \mathrm{S}$ remain high over this range, and the values indicated by the YMP experimental data are assumed to be applicable. At higher $\mathrm{pH}$ values, $\mathrm{Pu}$ sorption should drop, as $\mathrm{Pu}$-carbonate complexes become stable in solution. Sanchez et al. (1985 [DIRS 107213]) suggest that this is not important unless alkalinities exceed 100 meq $\mathrm{L}^{-1}$, however, and the high measured $K_{d}$ values for the LANL data, collected at $\mathrm{pH}$ values of 8.2 and 8.5, in air-equilibrated systems with alkalinities of 22.5 and $25 \mathrm{meq} \mathrm{L}^{-1}$, respectively, confirm this. There is insufficient information to develop a model for Pu sorption above $\mathrm{pH} 8.5$.

To summarize, the sorption behavior of $\mathrm{Pu}(\mathrm{V})$ onto goethite is assumed to be that of $\mathrm{Pu}(\mathrm{IV})$, because of the documented reduction reaction that occurs. Applicable $K_{d}$ values from $\mathrm{pH} 2$ to 5 are derived from the data of Duro et al. (2004 [DIRS 174716]) and tabulated in Table 6.6-13; in the $\mathrm{pH}$ range from 5 to $8.5, K_{d}$ values derived from the LANL Yucca Mountain-specific experimental data are assumed to be applicable. These values range from $8.7 \times 10^{3}$ to $1.4 \times 10^{5} \mathrm{~mL} \mathrm{~g}^{-1}$. Above $\mathrm{pH} 8.5$, there are no data available, but $K_{d}$ values are expected to drop sharply, as Pu-carbonate aqueous complexes increase in importance.

This alternative conceptual model has been screened out for several reasons. First, the alternative conceptual model described in this section proposing, $\mathrm{Pu}(\mathrm{V})$ reduction to $\mathrm{Pu}(\mathrm{IV})$ in the iron oxide/hydroxide surface, is based on short-term laboratory studies; it is not clear that the long-term sorption behavior of $\mathrm{Pu}$ is controlled by this mechanism. Also, this process has not been identified in field studies, which reflect $\mathrm{Pu}$ sorption and transport of over times scales of up to $50-60$ years. Second, the durations of the experiments for which sorption and desorption data are available are short (hours to weeks) compared to the repository time scale of interest (10,000 years or more), and equilibrium was evidently not reached in the course of most of the experiments; such an extreme extrapolation over time reduces the confidence in this alternative conceptual model. Finally, this alternative conceptual model is not applicable to the full range of expected environmental conditions in the repository, because plutonium sorption and desorption data are available for low and intermediate $\mathrm{pH}$ ranges but not for the highest $\mathrm{pH}$ ranges expected in the repository environment. 


\subsection{DESCRIPTION OF BARRIER CAPABILITY}

This section discusses the ability of barriers to prevent or delay the movement of water or radioactive materials and deals specifically with the features comprising the engineered barrier that are addressed in this report - the drip shield, the waste package, and the invert. In assessing these features, a number of assumptions are made (see Section 5).

The engineered barrier addressed in this report is subject to disruption under conditions assumed for the seismic and igneous scenario classes. Analyses and discussions presented in this report are confined to the nominal scenario class. Disruption of barrier capability from volcanic processes may be found in Atmospheric Dispersal and Deposition of Tephra from a Potential Volcanic Eruption at Yucca Mountain, Nevada (BSC 2004 [DIRS 170026]), Dike/Drift Interactions (BSC 2004 [DIRS 170028]), and Number of Waste Packages Hit by Igneous Intrusion (BSC 2004 [DIRS 170001]. Disruption of barrier capability from seismic events may be found in Seismic Consequence Abstraction (BSC 2005 [DIRS 173247]) and Characterize Framework for Seismicity and Structural Deformation at Yucca Mountain, Nevada (BSC 2004 [DIRS 168030]).

The drip shield prevents groundwater seepage that enters the drift from dripping onto the waste package. It will be completely effective until it is breached, and it is partially effective thereafter. Condensation on the underside of the drip shield has been screened out due to low consequence (BSC 2005 [DIRS 173781], Section 6.2.41). In this case, the presence of the drip shield can potentially increase the amount of water that contacts the waste package, but the effect is negligible. The EBS RT Abstraction presents an algorithm to determine the fraction of seepage entering the drift that passes through a breached drip shield, based on the number and size of breaches (Section 6.3.2.4). In the case where no groundwater seepage or dripping of drift-wall condensation into the drift occurs, there will be no water flux through the drip shield. The flux of water into the waste package is equal to the groundwater and dripping condensation flux passing through the drip shield, less the fraction that is diverted by intact portions of the waste package. In this way, the effectiveness of the drip shield as a feature of the engineered barrier can be quantified.

The waste package outer corrosion barrier consists of corrosion-resistant material that will prevent and delay water from entering the waste package. Once breaches occur, water may enter the waste package, dissolve radionuclides, and flow out, thereby generating advective releases of radionuclides. (Although the waste package stainless steel inner vessel provides structural stability to the Alloy 22 outer barrier, no other performance credit is taken for the waste package inner vessel, and it is modeled as breaching quickly after the outer barrier is breached; BSC 2004 [DIRS 169996], Section 6.1.) The EBS RT Abstraction presents an algorithm to determine the fraction of the water flux impinging on the waste package (having passed through drip shield breaches) that enters the waste package, depending on the size and number of breaches, as well as the total water flux through the waste package (Section 6.3.3.2). Flow is modeled as steady state and passing through the waste package without accumulating. Submodels not detailed in this report provide the concentration of radionuclides that are dissolved in the water flowing through the waste package (BSC 2005 [DIRS 174566]) and the behavior of colloids (BSC 2004 [DIRS 170025]). Advective and diffusive transport of radionuclides from breached waste packages is limited by sorption of radionuclides onto steel internal component corrosion 
products; sorption and retardation characteristics of radionuclides inside the waste package are discussed in this report (Section 6.3.4.2). When there is no advective transport, diffusive releases may still occur; a submodel for diffusion inside the waste package is presented (Section 6.3.4.3). With these models implemented in TSPA-LA, the effectiveness of the waste package as a feature of the engineered barrier can be quantified with respect to radionuclide transport.

The invert consists of crushed tuff that can delay releases of radionuclides to the unsaturated zone. The invert limits diffusive transport of radionuclides out of the engineered barriers by maintaining unsaturated conditions under the waste package. The invert limits advective and diffusive transport of radionuclides by sorbing radionuclides onto crushed tuff. A simple model for computing the diffusion coefficient of the invert as a function of the porosity and water saturation is presented in this report (Section 6.3.4.1). This enables the effectiveness of the invert as a feature of the engineered barrier to be quantified when implemented in TSPA-LA. 
INTENTIONALLY LEFT BLANK 


\section{VALIDATION}

Model validation for the EBS Radionuclide Transport Abstraction was performed in accordance with LP-2.29Q-BSC, Planning for Science Activities, and LP-SIII.10Q-BSC, Models, and follows the validation guidelines in the Technical Work Plan for: Near-Field Environment and Transport: Engineered Barrier System: Radionuclide Transport Abstraction Model Report Integration (BSC 2005 [DIRS 173617]).

LP-SIII.10Q-BSC, Models, requires that TSPA-LA model components be validated for their intended purpose and stated limitations, and to the level of confidence required by the relative importance of the component to the potential performance of the repository system. Three levels of model validation are defined in LP-2.29Q-BSC, Planning for Science Activities, Attachment 3, with the level of validation increasing with an increasing level of model importance ranging from low to moderate to high. Models whose variation could lead to a potentially large effect on the estimate of mean annual dose (e.g., a change greater than $1 \mathrm{mrem} \mathrm{yr}^{-1}$ ) should receive a high or Level III model validation. Models whose variation could lead to moderate effect on the estimate of mean annual dose (less than $1 \mathrm{mrem} \mathrm{yr}^{-1}$, but greater than $0.1 \mathrm{mrem} \mathrm{yr}^{-1}$ ) should receive Level II model validation. Level I validation is sufficient for models of less importance to the estimate of mean annual dose.

The levels of confidence required for the models of the EBS RT Abstraction, as stated in Section 2.2.2 of the TWP, are given as follows.

The required level of confidence for the EBS flow model is Level I. The required level of confidence for the EBS transport model is Level II. The required level of confidence for radionuclide transport from the waste package to the drift wall through the invert is Level I (also specified in Table 1 of LP-2.29Q-BSC, Planning for Science Activities). The EBS-UZ interface model of the EBS RT Abstraction provides input to the unsaturated zone radionuclide transport model as described in Particle Tracking Model and Abstraction of Transport Processes (BSC 2004 [DIRS 170041]). The appropriate level of confidence identified for unsaturated zone radionuclide transport is Level II. Therefore, Level II also represents appropriate level of confidence for the EBS-UZ interface model of the EBS RT Abstraction.

\section{Confidence Building During Model Development to Establish Scientific Basis and Accuracy for Intended Use}

For Level I validation, Section 2.2.3 of the TWP (BSC 2005 [DIRS 173617]) cites Attachment 3 of LP-2.29Q-BSC as guidance for documenting a discussion of decisions and activities for confidence building during model development. Additionally, the development of the model will be documented in accordance with the requirements of Section 5.3.2(b) of LP-SIII.10Q-BSC. The development of the EBS RT Abstraction model has been conducted according to these requirements and the requisite criteria have been met as discussed below:

1. Selection of input parameters and/or input data, and a discussion of how the selection process builds confidence in the model [LP-SIII.10Q-BSC 5.3.2(b) (1) and LP-2.29Q-BSC Attachment 3 Level I (a)]. 
The inputs to the EBS RT Abstraction have been obtained from appropriate sources as described in Section 4.1. All the data are qualified project data developed by or for the Yucca Mountain Project. Tables 4.1-1 through 4.1-20 describe the input parameters, the values of the parameters and the source of the information. Inputs were selected because they are expected to represent conditions at the repository and therefore build confidence in the model. Thus, this requirement can be considered satisfied.

2. Description of calibration activities, initial boundary condition runs, run convergences, simulation conditions set up to span the range of intended use and avoid inconsistent outputs, and a discussion of how the activity or activities build confidence in the model. Inclusion of a discussion of impacts of any non-convergence runs [(LP-SIII.10Q-BSC 5.3.2(b)(2) and LP-2.29Q-BSC Attachment 3 Level I (e)].

A detailed discussion of the computational implementation of the EBS RT Abstraction is described in Section 6.5.3. The discretization and development of the computational cell network of the sub-model domains is described in Section 6.5.3.5. Section 6.5.3.6 provides special emphasis and discussion of the EBS-UZ boundary condition. Simulation conditions account for both seepage or no seepage boundary conditions and the flux splitting algorithm accounts for the eight key flow pathways in the engineered barrier system. Discussion about non-convergence runs is not relevant for this model report. Thus, this requirement can also be considered satisfied.

3. Discussion of the impacts of uncertainties to the model results including how the model results represent the range of possible outcomes consistent with important uncertainties [( LP-SIII.10Q-BSC 5.3.2(b)(3) and LP-2.29Q-BSC Attachment 3 Level 1 (d) and (f)].

Data uncertainty is addressed in Section 6 and parameter uncertainties are summarized in Table 6.5-6. In particular, corrosion rates of carbon and stainless steels are listed as model input with ranges and distributions determined from the data in Table 4.1-1. Sorption coefficient distribution ranges are summarized in Table 4.1-15 and sampling correlations are given in Table 4.1-16. Table 4.1-8 provides uncertainty for unsaturated zone parameters. The breached drip shield experimental test data in Tables 4.1-2 through 4.1-6 and Figure 4.1-1 are evaluated in Section 6.5.1, resulting in uncertain model input parameters listed in Table 6.5-6 (Flux_Split_DS_Uncert and Flux_Split_WP_Uncert).

Model uncertainty is addressed through the evaluation of alternative conceptual models. In considering alternative conceptual models for radionuclide release rates and solubility limits (Sections 6.4. and 6.6), the EBS radionuclide transport abstraction uses models and analyses that are sensitive to the processes modeled for both natural and engineering systems.

Conceptual model uncertainties are defined and documented, and effects on conclusions regarding performance are assessed. The fundamental relationships, e.g., mass balance and flow equations, upon which the EBS RT Abstraction is based, are well-established with a long history of use in the scientific community and as such are not subject to significant uncertainty. In addition, the alternative conceptual models have been screened out (Section 6.4), thereby increasing confidence in the selected conceptual 
model. Other sources of uncertainty involve modeling choices (e.g., assumptions, geometry) that, because of their conservative nature, effectively bound uncertainty. Therefore this requirement can be considered satisfied.

4. Formulation of defensible assumptions and simplifications [LP-2.29Q-BSC Attachment 3 Level I (b)].

A discussion of assumptions is provided in Section 5. The conceptual model for $E B S R T$ Abstraction are documented in Section 6.3.1 and the simplifications necessary for implementation based on EBS design details and failure mechanisms are presented in Sections 6.3.3 and 6.3.4. Thus, this requirement can also be considered satisfied.

5. Consistency with physical principles, such as conservation of mass, energy, and momentum [LP-2.29Q-BSC Attachment 3 Level I (c)].

Consistency with physical principles is demonstrated by the development of the mass balance mathematical formulations in Section 6.5.1. Thus, this requirement can also be considered satisfied.

\section{Confidence Building After Model Development to Support the Scientific Basis of the Model}

Level II validation includes the above Level I criteria and a single post development model validation method described in Paragraph 5.3.2c of LP-SIII.10Q-BSC, Models, consistent with a model of moderate importance to mean annual dose.

To build further confidence in the EBS RT Abstraction, an independent model validation technical review was conducted as specified by the TWP (BSC 2005 [DIRS 173617], Sections 2.2.3 and 2.2.4) for the EBS flow model, the EBS transport model, and the EBS-UZ interface model. This approach is based on requirements of LP-SIII.10Q-BSC, Section 5.3.2 c), where independent technical review is listed as an appropriate method for model validation. Validation is achieved if the review determines that the questions/criteria for this model, listed in Section 2.2.4 of the TWP, are met. Qualifications of and review tasks to be completed by the independent technical reviewer are described in Section 2.2.4 of the TWP. The model validation criteria are described as follows (BSC 2005 [DIRS 173617], Section 2.2.4).

\section{EBS Flow Model Validation Criteria}

Criteria that the validation of the EBS flow model is met are as follows. Each shall be confirmed by the independent model validation technical reviewer.

a) The approach and algorithms described in the document and provided to the TSPA capture all known flow pathways into and from EBS components.

b) Modeling assumptions are clearly defined, discussed, and justified as appropriate for the intended use of the model.

c) Uncertainties in parameters, processes, and assumptions are sufficiently described, and impacts of these uncertainties discussed. 
d) The overall technical credibility of the approach, including assumptions, parameters, equations, and the TSPA implementation, are sufficient for the model's intended use.

\section{EBS Transport Model Validation Criteria}

Criteria that the validation of the EBS transport model is met are as follows. Each shall be confirmed by the independent model validation technical reviewer.

a) The approach and algorithms described in the document and provided to TSPA address all known modes of radionuclide transport within and from the EBS components.

b) Modeling assumptions are clearly defined, discussed, and justified as appropriate for the intended use of the model.

c) Uncertainties in parameters, processes, and assumptions are sufficiently described, and impacts of these uncertainties discussed.

d) The overall technical credibility of the approach, including assumptions, parameters, equations, and the TSPA implementation, are sufficient for the model's intended use.

\section{EBS-UZ Interface Model Validation Criteria}

The criterion that the validation of the EBS-UZ interface model is met shall consist of concurrence by an independent technical reviewer that the invert fracture-matrix partitioning results obtained using this model compare favorably with the fracture-matrix partitioning cumulative distribution function obtained using a discrete fracture model described in the Drift-Scale Radionuclide Transport model (BSC 2004 [DIRS 170040]). Results of the comparison shall show qualitative agreement between the two methods. The report shall document equivalent trends and correlations between input parameter variation and predicted results, identification of differences between the model results, and a discussion of the reasons and potential significance of these differences, and shall also demonstrate that the EBS-UZ interface model provided to TSPA does not underestimate radionuclide transport from the EBS to the UZ.

The results of the independent model validation technical review for the flow and transport models demonstrate that the appropriate criteria from above have been met, and are presented in Section 7.2.3. The results of the EBS-UZ interface model review demonstrate that the appropriate criteria listed above have been met, and are presented in Section 7.3.2.

The validation guidelines in the TWP (BSC 2005 [DIRS 173617]) also state that the Subject Matter Expert (author) may elect, as deemed appropriate, to provide additional validation in the form of:

- Corroboration of model results with data previously acquired from laboratory experiments or other relevant observations

- Corroboration of model results with results of alternative models 
- Corroboration with information published in refereed journals or literature.

In addition to the independent model validation technical review, the post development model validation for the EBS-UZ interface model, as delineated in the TWP, includes corroboration by comparison to an alternative mathematical model developed for a closely comparable description of the relevant EBS-UZ features. This validation approach is consistent with Paragraph 5.3.2(c)(2) of LP-SIII.10Q-BSC, Models, which lists corroboration of results with alternative mathematical models as one of the validation methods for Level II validation. This comparison is documented in Section 7.3.1.

Additional validation of the flux splitting portion of the flow model was performed through corroboration of model results of experimental data. The results of that validation exercise are presented in Section 7.1.1.

Additional validation of the in-package diffusion portion of the transport model was performed through corroboration with alternative models. The results of that validation exercise are presented below in Section 7.2.

\subsection{EBS FLOW MODEL}

The EBS flow is modeled as a one-dimensional, steady advective flow through the components of the EBS. The sources of flow to the model include a seepage flux from the roof of the drift, condensation on the walls of the drift above the drift shield, and an imbibition flux from the unsaturated zone into the crushed tuff invert. The output of the flow model includes an advective flux from the invert into the unsaturated zone.

The conceptual model divides the EBS components into three domains: waste form, waste package corrosion products, and the invert. Flow and transport in these domains are treated separately. The output of the waste form domain feeds into the corrosion products domain. The output of the corrosion products domain in turn feeds the invert.

The flow through the EBS may occur along eight pathways: (1) total dripping flux (seepage inflow from the crown of the drift plus any condensation that may occur on the walls of the drift above the drift shield), (2) flux through the drip shield, (3) diversion around the drip shield, (4) flux through the waste package, (5) diversion around the waste package, (6) total flux into the invert, (7) imbibition flux from the unsaturated zone matrix to the invert, and (8) flux from the invert to the unsaturated zone fractures.

The magnitude of seepage fluid passing through the drip shield and the waste package is accounted for using the flux splitting submodel. This submodel determines how much water flows through the drip shield or waste package and how much is diverted around these components. Below is the validation of the submodel and validation criteria for both the drip shield and waste package applications. Further discussions relevant to the validation of the flow model can be found in Sections 5, 6.3.2, 6.3.3, 6.5.1.1.1, 6.5.1.1.2, and 6.5.1.1.3. 


\subsubsection{Flux Splitting Submodel}

The EBS flux splitting submodel, which is part of the EBS RT Abstraction flow model, determines the fraction of total dripping flux that will flow through the drip shield and/or waste package. This submodel is directly related to the waste isolation attribute (i.e., the limited release of radionuclides from engineered barriers). The amount of water flowing through engineered barriers, when combined with radionuclide solubility limits and diffusive transport, defines the mass flux of radionuclides that is mobilized for transport through the EBS to the unsaturated zone.

Level I validation is appropriate for the flux splitting submodel, because it is part of the process for radionuclide transport from waste package to the drift wall through the invert (see Section 7 above). In addition, the flux splitting submodel has the following features:

- The submodel is not extrapolated over large distances, spaces or time.

- The submodel has large uncertainties because of the chaotic nature of the flow of droplets or rivulets on corroded, roughened surfaces.

- Sensitivity analyses in the prioritization report Risk Information to Support Prioritization of Performance Assessment Models (BSC 2003 [DIRS 168796], Sections 3.3.6 through 3.3.11) show that the flux splitting abstraction will not have a large impact on dose in the first 10,000 years.

- The flux splitting submodel plays a minor role in TSPA-LA. In the nominal scenario class, neither the drip shield nor the waste package fails due to general corrosion within the 10,000-year regulatory period (BSC 2004 [DIRS 169996], Section 7.2); if the TSPA-LA model is run to compute the peak dose, which occurs beyond the 10,000-year regulatory period, then the flux splitting model will be used in the nominal scenario class. When the drip shield does fail (beyond the 10,000-year regulatory period in the nominal scenario class), it is modeled as failing completely in a single time step (BSC 2004 [DIRS 169996], Section 6.3). The early waste package failure modeling case is part of the nominal scenario class, where the drip shield does not fail within the 10,000-year regulatory period; thus, the flux splitting submodel is not used. In the igneous scenario class, neither the drip shield nor the waste package survives an igneous intrusion, so the flux splitting submodel is not used. Stress corrosion cracking of the drip shield occurs in the seismic scenario class, but since no advective flux is allowed through the cracks, the flux splitting submodel is not used. Thus, the flux splitting submodel is actually applied only in the seismic scenario class when seismic damage occurs to the waste package from fault displacement leading to fractional failure of the waste package.

This flux splitting submodel is validated through comparison to experimental data. A work plan entitled Test Plan for: Atlas Breached Waste Package Test and Drip Shield Experiments (BSC 2002 [DIRS 158193]) defines the experiments used for validation of this flux splitting submodel. 
The flux splitting submodel is applied to two components of the EBS-the drip shield and the waste package-and is validated for each. Validation is achieved through comparison of the models developed in this document (based in part on the qualified experimental data) to other qualified data collected during associated testing. This comparison is limited because the validation experiments are based on flow measurements from a single fixed source for dripping, whereas the abstraction is based on randomly located drips relative to multiple patches on the drip shield. In this situation, the appropriate criterion for model validation is that the ranges of predictions of the abstraction, based on smooth drip shield mock-up surface data, overlap the ranges of experimental measurements made on the rough drip shield mock-up surface. This criterion is appropriate because of the large spread of the experimental data.

The rough drip shield surface experiments replicate the smooth drip shield surface experiments and constitute a consistent set of data that can be compared with and serve as validation for the smooth drip shield surface data. The rough surface would be expected to yield results (specifically, the flux splitting uncertainty factors) that differ from those obtained for the smooth surface. However, because the only difference in the experiments is the surface texture, the trends in the data and the values obtained for the uncertainty factors should be similar, which validates the flux splitting submodel.

Experimental data used to develop the flux splitting submodel include the splash radius, the rivulet spread distance or angle, and the fraction of dripping flux that flowed into breaches. For the drip shield and waste package flux splitting submodels, data from smooth drip shield experiments were used (DTNs: MO0207EBSATBWP.022 [DIRS 163400]; MO0207EBSATBWP.023 [DIRS 163402]; MO0207EBSATBWP.024 [DIRS 163401]; MO0207EBSATBWP.025 [DIRS 163403]). For validation of the models, data from the rough drip shield experiments are used (DTNs: MO0207EBSATBWP.021 [DIRS 163399]; MO0208EBSATBWP.027 [DIRS 163404]; MO0208EBSATBWP.028 [DIRS 163405]). Each of the types of data used is discussed below, first for the drip shield submodel validation and then for the waste package flux splitting submodel validation.

\subsubsection{Drip Shield Flux Splitting Submodel}

Splash radius data for dripping onto the crown of the rough drip shield surface are listed in Table 7.1-1. The data are analyzed in the Microsoft Excel spreadsheet: Flux Splitting Validation, Worksheet: Splash Rad vs Number, which is documented in Appendix E. As shown in Figure 7.1-1, the splash radius tends to increase as the number of drips increases. The inner cluster radius is of interest because it is used to define the effective length of the drip shield in developing the flux splitting submodel (see Section 6.5.1.1.2). While the data do not indicate that a maximum splash radius was achieved, it stands to reason that a maximum must exist, simply because the distance a splashed droplet can travel is finite, limited by the kinetic energy of a falling drop. The uncertain parameter in the drip shield flux splitting submodel, $f_{D S}^{\prime}$, was based on the maximum splash distance observed for the inner cluster of droplets on a smooth drip shield, $48 \mathrm{~cm}$ (see Section 6.5.1.1.2.4 for a discussion of the development of $f_{D S}^{\prime}$ based on the $48-\mathrm{cm}$ maximum inner cluster splash radius). For the rough drip shield tests, the maximum inner cluster splash radius for dripping onto the crown was again $48 \mathrm{~cm}$. Another approach is to use the splash radius at which rivulets begin to flow from coalesced droplets. In Splash Radius 
Test \#1, rivulet flow began after 143 drips; in Test \#2, after 145 drips; and in Test \#3, after 133 drips (DTN: MO0207EBSATBWP.021 [DIRS 163399]), for an average of 140 drips. Using the Microsoft Excel Trendline application (least squares fitting routine) for the inner cluster data in Figure 7.1-1, the splash radius when rivulets began to flow was $31 \mathrm{~cm}$. The minimum splash radius was about $3.5 \mathrm{~cm}$ for more than 20 drips (see Table 7.1-1). The range of uncertainty is bounded using the extreme values of splash radius $(3.5-48 \mathrm{~cm})$. Since the value of splash radius at which rivulets begin to flow $(31 \mathrm{~cm})$ is between those extremes, an estimate of uncertainty based on that value will not affect the estimated bounds on uncertainty.

The flux splitting submodel also depends on the rivulet spread angle. These data are analyzed in the Microsoft Excel spreadsheet: Flux Splitting Validation, Worksheet: Rough DS, which is documented in Appendix E. For the smooth drip shield, the spread angle from crown drip locations ranged from $8.9^{\circ}$ to $17.3^{\circ}$ ( \pm one standard deviation from the mean of $13.2^{\circ}$; see Section 6.5.1.1.2.4). For drip locations on the crown, the rough drip shield surface had a mean rivulet spread angle of $7.3^{\circ}$, with a range of $0^{\circ}$ to $14.4^{\circ}$ ( \pm one standard deviation from the mean). Rivulet spread data for the rough surface are shown in Table 7.1-2. In Table 7.1-4, the spread angle calculation results are shown.

The amount of water dripped onto the crown and water flow into breaches on the rough drip shield surface are listed in Table 7.1-3. The fraction of the dripping flux that flowed into the pertinent breach, $f_{\text {expt }}$, is shown along with the rivulet spread angle for each particular test in Table 7.1-4. 
Table 7.1-1. Atlas Breached Drip Shield Experiments on Rough Drip Shield Surface - Dripping on Crown - Splash Radius Tests

\begin{tabular}{|c|c|c|c|}
\hline \multirow[b]{2}{*}{ No. Drips } & \multicolumn{2}{|c|}{ Splash Radius (cm) } & \multirow[b]{2}{*}{ Comments } \\
\hline & Left & Right & \\
\hline \multicolumn{4}{|c|}{ Splash Radius Test \#1 } \\
\hline 10 & 2.0 & 2.0 & Measured inner cluster (bulk) \\
\hline 10 & 15.0 & 25.5 & Measured outer fringe \\
\hline 21 & 5.0 & 4.0 & Measured inner cluster (bulk) \\
\hline 21 & 15.0 & 42.5 & Measured outer fringe \\
\hline 60 & 18.0 & 22.0 & Measured inner cluster (bulk) \\
\hline 60 & 72.5 & 75.5 & Measured outer fringe \\
\hline 143 & 35.0 & 48.0 & Measured inner cluster (bulk) \\
\hline 143 & 54.0 & 82.5 & Measured outer fringe \\
\hline 203 & 35.0 & 48.0 & Measured inner cluster (bulk) \\
\hline 203 & 79.5 & 106.5 & Measured outer fringe \\
\hline \multicolumn{4}{|c|}{ Splash Radius Test \#2 } \\
\hline 21 & 3.5 & 4.0 & Measured inner cluster (bulk) \\
\hline 21 & 37.5 & 7.0 & Measured outer fringe \\
\hline 82 & 10.5 & 19.0 & Measured inner cluster (bulk) \\
\hline 82 & 63.0 & 32.0 & Measured outer fringe \\
\hline 149 & 31.5 & 30.0 & Measured inner cluster (bulk) \\
\hline 207 & 45.0 & 40.0 & Measured inner cluster (bulk) \\
\hline \multicolumn{4}{|c|}{ Splash Radius Test \#3 } \\
\hline 30 & 7.5 & 9.0 & Measured inner cluster (bulk) \\
\hline 82 & 19.0 & 17.5 & Measured inner cluster (bulk) \\
\hline 137 & 28.0 & 27.5 & Measured inner cluster (bulk) \\
\hline 205 & 29.0 & 28.0 & Measured inner cluster (bulk) \\
\hline
\end{tabular}

DTN: MO0207EBSATBWP.021 [DIRS 163399]. 


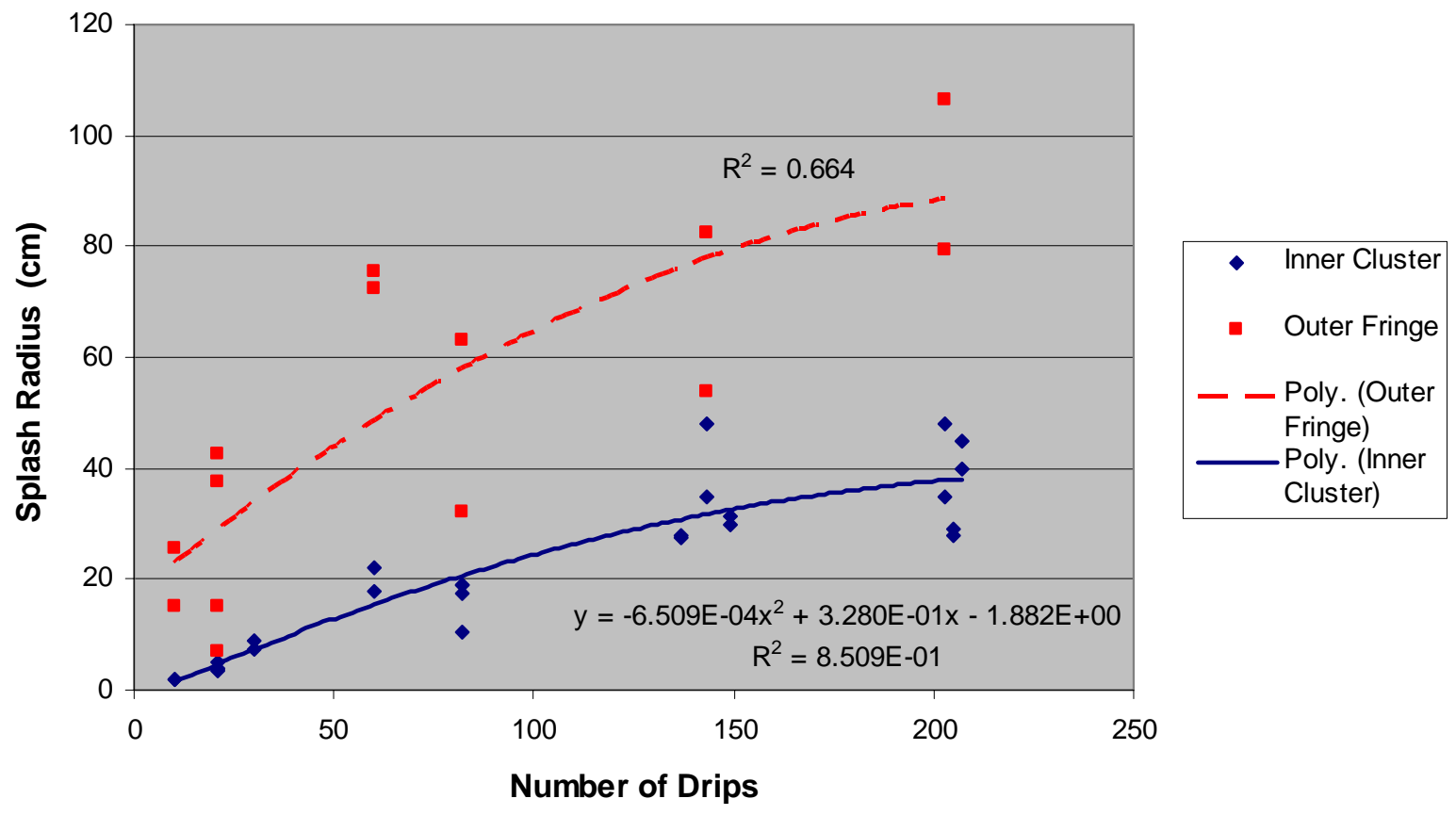

Figure 7.1-1. Splash Radius Dependence on Number of Drips for Rough Drip Shield Tests

Table 7.1-2. Atlas Breached Drip Shield Experiments on Rough Drip Shield Surface - Dripping on Crown - Rivulet Spread Data $-33^{\circ}$ from Crown

\begin{tabular}{|l|c|c|c|}
\hline \multicolumn{1}{|c|}{$\begin{array}{c}\text { Drip Location } \\
\text { Multiple Patch Tests (DTN: MO0208EBSATBWP.027 [DIRS 163404]) }\end{array}$} & $\begin{array}{c}\text { Relevant } \\
\text { Patch }\end{array}$ \\
\hline \multicolumn{2}{|c|}{ Left (cm) } & Right (cm) & 4 \\
\hline $81 \mathrm{~cm}$ left of drip shield center & 32.5 & 17.5 & 4 \\
\hline $27 \mathrm{~cm}$ left of drip shield center & 21.5 & 18.0 & 5 \\
\hline $27 \mathrm{~cm}$ right of drip shield center & 10.0 & 10.0 & 5 \\
\hline $27 \mathrm{~cm}$ right of drip shield center & 1.0 & 0 & 5 \\
\hline $81 \mathrm{~cm}$ right of drip shield center & 17.0 & 34.0 & \\
\hline \multicolumn{2}{|l|}{ Bounding Flow Rate Tests (DTN: MO0208EBSATBWP.028 [DIRS 163405]) } \\
\hline $54 \mathrm{~cm}$ left of drip shield center (High Flow Rate) & 2 & 0 & 4 \\
\hline $27 \mathrm{~cm}$ left of drip shield center (High Flow Rate) & 15 & 15 & 4 \\
\hline $27 \mathrm{~cm}$ right of drip shield center (High Flow Rate) & 6 & 6 & 5 \\
\hline $27 \mathrm{~cm}$ right of drip shield center (Low Flow Rate) & 50.0 & 16.0 & 5 \\
\hline $27 \mathrm{~cm}$ right of drip shield center (Low Flow Rate) & - & 1.0 & 5 \\
\hline $27 \mathrm{~cm}$ left of drip shield center (Low Flow Rate) & 25.5 & 12.0 & 4 \\
\hline $54 \mathrm{~cm}$ left of drip shield center (Low Flow Rate) & 0 & 0 & 4 \\
\hline
\end{tabular}


Table 7.1-3. Atlas Breached Drip Shield Experiments on Rough Drip Shield Surface - Dripping on Crown - Flow into Breaches

\begin{tabular}{|c|c|c|c|c|c|}
\hline \multirow[b]{2}{*}{ Drip Location } & \multicolumn{2}{|c|}{ Drip Location Relative to: } & \multirow[b]{2}{*}{$\begin{array}{c}\text { Water } \\
\text { Input (g) }\end{array}$} & \multicolumn{2}{|c|}{ Water Collected in: } \\
\hline & $\begin{array}{l}\text { Breach B4 } \\
(\mathrm{cm})\end{array}$ & $\begin{array}{l}\text { Breach B5 } \\
\quad(\mathrm{cm})\end{array}$ & & $\begin{array}{c}\text { Breach B4 } \\
(\mathrm{g})\end{array}$ & $\begin{array}{l}\text { Breach B5 } \\
\text { (g) }\end{array}$ \\
\hline \multicolumn{6}{|c|}{ Multiple Patch Tests (DTN: MO0208EBSATBWP.027 [DIRS 163404]) } \\
\hline $81 \mathrm{~cm}$ left of drip shield center & -27 & -135 & 292.35 & 0.27 & 0.00 \\
\hline $27 \mathrm{~cm}$ left of drip shield center & 27 & -81 & 288.45 & 5.27 & 0.00 \\
\hline $27 \mathrm{~cm}$ right of drip shield center & 81 & -27 & 291.62 & 0.00 & 0.08 \\
\hline $27 \mathrm{~cm}$ right of drip shield center & 81 & -27 & 294.13 & 0.00 & 0.27 \\
\hline $81 \mathrm{~cm}$ right of drip shield center & 135 & 27 & 290.10 & 0.00 & 1.01 \\
\hline \multicolumn{6}{|c|}{ Bounding Flow Rate Tests (DTN: MO0208EBSATBWP.028 [DIRS 163405]) } \\
\hline $\begin{array}{l}54 \mathrm{~cm} \text { left of drip shield center } \\
\text { (High Flow Rate) }\end{array}$ & 0 & -108 & 330.74 & 193.87 & 0.00 \\
\hline $\begin{array}{l}27 \mathrm{~cm} \text { left of drip shield center } \\
\text { (High Flow Rate) }\end{array}$ & 27 & -81 & 328.65 & 0.63 & 0.00 \\
\hline $\begin{array}{l}27 \mathrm{~cm} \text { right of drip shield center } \\
\text { (High Flow Rate) }\end{array}$ & 81 & -27 & 306.65 & 0.00 & 0.35 \\
\hline $\begin{array}{l}27 \mathrm{~cm} \text { right of drip shield center } \\
\text { (Low Flow Rate) }\end{array}$ & 81 & -27 & 545.14 & 0.00 & 11.11 \\
\hline $\begin{array}{l}27 \mathrm{~cm} \text { right of drip shield center } \\
\text { (Low Flow Rate) }\end{array}$ & 81 & -27 & 70.80 & 0.00 & 0.00 \\
\hline $\begin{array}{l}27 \mathrm{~cm} \text { left of drip shield center } \\
\text { (Low Flow Rate) }\end{array}$ & 27 & -81 & 113.32 & 1.36 & 0.00 \\
\hline $\begin{array}{l}54 \mathrm{~cm} \text { left of drip shield center } \\
\text { (Low Flow Rate) }\end{array}$ & 0 & -108 & 118.10 & 0.00 & 0.00 \\
\hline
\end{tabular}

Table 7.1-4. Atlas Breached Drip Shield Experiments on Rough Drip Shield Surface - Dripping on Crown - Fraction of Dripping That Flowed into Breaches and Rivulet Spread Angle

\begin{tabular}{|l|c|c|c|c|}
\hline \multicolumn{1}{|c|}{ Drip Location } & \multirow{2}{*}{$\begin{array}{c}\text { Breach } \\
\text { Collecting Flow }\end{array}$} & $\boldsymbol{f}_{\text {expt }}$ & \multicolumn{2}{c|}{ Spread Angle (degree) } \\
\cline { 4 - 5 } & 4 & 0.0018 & 13.4 & Right \\
\hline $81 \mathrm{~cm}$ left of drip shield center & 4 & 0.0365 & 9.0 & 7.5 \\
\hline $27 \mathrm{~cm}$ left of drip shield center & 5 & 0.0005 & 6.6 & 6.6 \\
\hline $27 \mathrm{~cm}$ right of drip shield center & 5 & 0.0018 & 0 & 0.7 \\
\hline $27 \mathrm{~cm}$ right of drip shield center & 5 & 0.0070 & 11.2 & 21.6 \\
\hline $81 \mathrm{~cm}$ right of drip shield center & 4 & 1.1723 & 0.8 & 0 \\
\hline $\begin{array}{l}54 \mathrm{~cm} \text { left of drip shield center } \\
\text { (High Flow Rate) }\end{array}$ & 4 & 0.0038 & 6.3 & 6.3 \\
\hline $\begin{array}{l}27 \mathrm{~cm} \text { left of drip shield center } \\
\text { (High Flow Rate) }\end{array}$ & 5 & 0.0023 & 4.0 & 4.0 \\
\hline $27 \mathrm{~cm}$ right of drip shield center (High Flow Rate) & 5 & 0.0408 & 30.2 & 10.5 \\
\hline $\begin{array}{l}27 \mathrm{~cm} \text { right of drip shield center } \\
\text { (Low Flow Rate) }\end{array}$ & 5 & 0.0110 & - & 0.7 \\
\hline $\begin{array}{l}27 \mathrm{~cm} \text { right of drip shield center } \\
\text { (Low Flow Rate) }\end{array}$ & 5 & & \\
\hline
\end{tabular}


Table 7.1-4. Atlas Breached Drip Shield Experiments on Rough Drip Shield Surface - Dripping on Crown - Fraction of Dripping That Flowed into Breaches and Rivulet Spread Angle (Continued)

\begin{tabular}{|c|c|c|c|c|}
\hline \multirow[b]{2}{*}{ Drip Location } & \multirow{2}{*}{$\begin{array}{c}\text { Breach Collecting } \\
\text { Flow }\end{array}$} & \multirow[b]{2}{*}{$f_{\text {expt }}$} & \multicolumn{2}{|c|}{ Spread Angle (degree) } \\
\hline & & & Left & Right \\
\hline $27 \mathrm{~cm}$ left of drip shield center (Low Flow Rate) & 4 & 0.0240 & 10.6 & 5.0 \\
\hline $54 \mathrm{~cm}$ left of drip shield center (Low Flow Rate) & 4 & 0.0 & 0 & 0 \\
\hline Mean & - & 0.108 & \multicolumn{2}{|c|}{7.25} \\
\hline Standard Deviation & - & 0.335 & \multicolumn{2}{|c|}{7.18} \\
\hline Median & - & 0.005 & \multicolumn{2}{|c|}{6.29} \\
\hline
\end{tabular}

Source: Microsoft Excel spreadsheet: Flux Splitting Validation, Worksheet: Rough DS, documented in Appendix E.

NOTES: $\quad-=$ no measurement.

Mean, standard deviation, and median for spread angle are for all (left and right) measurements.

Following the approach used in Section 6.5.1.1.2.4, the "inner cluster" splash diameter is used for the effective length of the drip shield in the validation of the flux splitting algorithm, which is given by Equations 6.3.2.4-4 and 6.3.2.4-6 (or 6.5.1.1.2-35). The form of the equation is:

$$
F=\frac{N_{b} \ell}{L_{D S}}\left(1+\frac{\tan \alpha}{2}\right) f_{V D},
$$

where $F$ is the fraction of dripping flux that flows through breaches, $\ell$ is one-half the width of a breach or patch, $L_{D S}$ is the effective length of the drip shield (i.e., the length over which dripping or splattering occurs), $\alpha$ is the rivulet spread angle, and $f_{V D}$ is the uncertainty factor for the drip shield developed for validation, corresponding to the drip shield uncertainty factor, $f_{D S}$. For the validation tests, the number of breaches, $N_{b}$, is one.

The splash diameter is used for the effective length, $L_{D S}$. As shown in Table 7.1-1, the "inner cluster" splash radius on the rough drip shield surface ranged from $3.5 \mathrm{~cm}$ to $48 \mathrm{~cm}$ (for more than 20 drops), giving a range for $L_{D S}$ of $7 \mathrm{~cm}$ to $96 \mathrm{~cm}$. The spread angle ranged (one standard deviation from the mean) from zero to $14.4^{\circ}$. For a drip shield patch width of $27 \mathrm{~cm}, \ell=$ $13.5 \mathrm{~cm}$. Then, as shown in Table 7.1-5, $F / f_{V D}=\frac{N_{b} \ell}{L_{D S}}\left(1+\frac{\tan \alpha}{2}\right)$ ranges from 0.141 to 2.17 .

Table 7.1-5. Range of Estimates for $F / f_{V D}$

\begin{tabular}{|c|c|c|}
\hline \multirow{2}{*}{$L_{D S}(\mathbf{c m})$} & \multicolumn{2}{|c|}{$\begin{array}{c}\text { Drip Shield } \\
\text { F/f }\end{array}$} \\
\cline { 2 - 3 } & $\alpha=0^{\circ}$ & $\alpha=14.4^{\circ}$ \\
\hline 7 & 1.93 & 2.17 \\
\hline 96 & 0.141 & 0.158 \\
\hline
\end{tabular}


The fraction of dripping flux, $f_{\text {expt }}$, that entered breaches in 12 rough drip shield experiments ranged from zero to 1.17 , with a mean of 0.108 and a median of 0.0054 . The wide range of uncertainty and randomness in the experiments is demonstrated in two of the tests having the same drip location (54 $\mathrm{cm}$ to the left of the drip shield center). The high drip rate test yielded the highest flow into a breach with a negligible spread, which is the expected result. What appears to be an unphysical result for this test, $f_{\text {expt }}=1.17$, is obtained from the assumption that half of the dripping flux onto the crown flows down each side of the drip shield. This was evidently not the case in this particular test, since more than half of the dripping flux flowed into the breach. However, since there are no data available to determine what fraction of the dripping flux flowed down the side with the breach, the procedure for calculating $f_{\text {expt }}$ is followed without limiting the values that are obtained (e.g., by limiting $f_{\text {expt }}$ to a maximum of 1.0). The low drip rate test at the same drip location, which had zero rivulet spread, unexpectedly resulted in no flow into the breach. Statistics for $f_{\text {expt }}$ are compared in Table 7.1-6 between the smooth drip shield surface experimental results (Table 6.5-2) and the rough surface results discussed in this section.

Table 7.1-6. Comparison of $f_{\text {expt }}$ Statistics for Smooth and Rough Drip Shield Surfaces

\begin{tabular}{|l|l|l|l|c|}
\hline \multicolumn{1}{|c|}{ Experiments } & Mean $\boldsymbol{f}_{\text {expt }}$ & Minimum $\boldsymbol{f}_{\text {expt }}$ & Maximum $\boldsymbol{f}_{\text {expt }}$ & Median $\boldsymbol{f}_{\text {expt }}$ \\
\hline Drip Shield (Smooth Surface) & 0.111 & 0.013 & 0.275 & 0.049 \\
\hline Drip Shield Validation (Rough Surface) & 0.108 & 0.0 & 1.17 & 0.0054 \\
\hline
\end{tabular}

The rough surface experimental results are now used to calibrate the drip shield flux splitting submodel that is developed for validation purposes, yielding the uncertainty factor $f_{V D}$ :

$$
f_{V D}=\frac{f_{\text {expt }}}{\frac{\ell}{L_{D S}}\left(1+\frac{\tan \alpha}{2}\right)} \text {. }
$$

$f_{V D}$ is at a minimum using the minimum value for $L_{D S}(7 \mathrm{~cm})$ and the maximum value for $\alpha$ $\left(14.4^{\circ}\right)$, resulting in $f_{V D}=0.46 f_{\text {expt }}$. The maximum for $f_{V D}$ is obtained using the maximum value for $L_{D S}(96 \mathrm{~cm})$ and the minimum value for $\alpha\left(0^{\circ}\right)$, resulting in $f_{V D}=7.1 f_{\text {expt }}$. Using the mean value for $f_{\text {expt }}(0.108)$ results in a range for $f_{V D}$ of 0.050 to 0.77 . The drip shield flux splitting algorithm developed in Section 6.5.1.1.2.4 produced the corresponding factor $f_{D S}$ ranging from about 0.36 to 0.73 . These factors $\left(f_{V D}\right.$ and $\left.f_{D S}\right)$ actually represent the estimates of the upper bound on the uncertainty, since a lower bound is necessarily zero (i.e., no flow through a breach). Using the actual measured range of $f_{\text {expt }}(0.0$ to 1.17) instead of the mean increases the range estimated for $f_{V D}$ to 0.0 to $(7.1)(1.17)=8.3$. The corresponding range for $f_{D S}$, using the measured range of $f_{\text {expt }}(0.013$ to 0.275$)$ (Table 6.5-2) for the smooth surface tests instead of the mean (0.111), is $0.013 / 0.31=0.041$ (for $L_{D S}=50 \mathrm{~cm}, \alpha=17.3^{\circ}$ ) to $0.275 / 0.152=1.8$ (for $L_{D S}=96 \mathrm{~cm}, \alpha=8.9^{\circ}$ ). Thus, using the extreme values of $f_{\text {expt }}$ for estimating $f_{D S}$ and $f_{V D}$, the 
upper bound on $f_{V D}$ actually spans the uncertainty in the upper bound estimate of $f_{D S}$, as summarized in Table 7.1-7.

Table 7.1-7. Summary of $f_{D S}$ and $f_{V D}$ Values

\begin{tabular}{|c|c|c|c|c|}
\hline \multirow{2}{*}{} & \multicolumn{2}{|c|}{ Based on Mean $\boldsymbol{f}_{\text {expt }}$} & Based on Minimum $\boldsymbol{f}_{\text {expt }}$ & Based on Maximum $\boldsymbol{f}_{\text {expt }}$ \\
\cline { 2 - 5 } & Minimum & Maximum & Minimum & Maximum \\
\hline$f_{D S}$ & 0.36 & 0.73 & 0.041 & 1.8 \\
\hline$f_{V D}$ & 0.050 & 0.77 & 0 & 8.3 \\
\hline
\end{tabular}

Based on mean values for the experimentally measured fraction of the dripping flux that flows through a breach, the rough drip shield surface factor shows that less of the dripping flux will flow through a breach, compared with the smooth surface results used to develop the drip shield flux splitting submodel. The rough surface data validate the drip shield submodel by confirming an estimate of the upper bound on the uncertainty of 0.77 , based on mean values for $f_{\text {expt }}$. The range on the estimate for $f_{V D}$ is also about 0.7 , which is comparable (about a factor of 2 ) to the uncertainty in $f_{D S}$. While the upper bound on the uncertainty factor is about the same for both the smooth and rough surfaces $(0.73$ vs. 0.77$)$, the lower bound is much higher for the smooth surface (0.36 vs. 0.05). A random sampling from these ranges will give a mean value of about 0.54 for the smooth surface versus about 0.42 for the rough surface. So the smooth surface range will, on average, overestimate the flux through the drip shield compared to the rough surface range. Both the smooth surface and the rough surface results include a wide range of variability that is incorporated in the sampled uncertainty parameter $f_{D S}$ for the drip shield flux splitting submodel. The rough drip shield surface data provide confirmation that the drip shield submodel will generally overestimate the flux through that barrier.

A final comparison is made between $f_{D S}^{\prime}$, which lumps the uncertainty in the rivulet spread angle into $f_{D S}$, and a corresponding parameter for the rough drip shield surface, $f_{V D}^{\prime}$, is derived, where

$$
f_{V D}^{\prime}=\left(1+\frac{\tan \alpha}{2}\right) f_{V D}
$$

Since $\alpha$ ranges from $0^{\circ}$ to $14.4^{\circ}$, applying the maximum value for $\alpha$ will result in the range for $f_{V D}^{\prime}$ of 0 to 0.87 , based on the mean value of $f_{\text {expt }}(0.108)$ that gives a range of 0.050 to 0.77 for $f_{V D}$. For comparison, $f_{D S}^{\prime}$ was estimated to range from 0 to 0.85 . The nearly-identical ranges for $f_{D S}^{\prime}$ and $f_{V D}^{\prime}$ validate the drip shield flux splitting submodel.

\subsubsection{Waste Package Flux Splitting Submodel}

Whereas the drip shield flux splitting submodel is based on data from dripping on the crown of the smooth drip shield mock-up surface, the waste package flux splitting submodel is based on data from off-crown drip locations on the smooth drip shield mock-up surface. Off-crown drip 
locations are used because the steeper slope on the mock-up surface at those locations simulates more closely the higher radius of curvature of the waste package compared with the drip shield (Section 6.5.1.1.3). Additionally, the drop distance to drip locations that are off the crown was greater than for drips on the crown $\left(2.17 \mathrm{~m}\right.$ to the crown, $2.22 \mathrm{~m}$ to the $16.5^{\circ}$ line, and $2.31 \mathrm{~m}$ to the $33^{\circ}$ line; BSC 2003 [DIRS 163406], p. 6), which more closely mimics the greater drop distance from the drift to the waste package compared with the drip shield surface. Consistent with the validation of the drip shield flux splitting submodel, the validation of the waste package flux splitting submodel is based on data from the rough drip shield mock-up surface, but for off-crown drip locations, to be consistent with the waste package flux splitting submodel. Using off-crown drip location data for the rough waste package surface (Table 7.1-8), the rivulet spread angle was found to depend strongly on the drip rate. These data are analyzed in the Microsoft Excel spreadsheet: Flux Splitting Validation, Worksheet: Rough off crown WP model, which is documented in Appendix E. The high drip rate resulted in an average spread angle of $27.1^{\circ}$; the nominal drip rate had a mean spread angle of $20.6^{\circ}$; and the low drip rate had a mean spread angle of $3.1^{\circ}$. However, to be consistent with the development of the spread angle for the waste package submodel, and to incorporate the real possibility of widely varying drip rates, all 50 data points are combined. The mean spread angle for the rough waste package surface with off-crown drip locations is therefore $9.4^{\circ}$, with a range ( \pm one standard deviation of $9.6^{\circ}$ ) of $0^{\circ}$ to $19.0^{\circ}$.

In the off-crown splash radius tests \#4 and \#5 (Table 7.1-9) (Microsoft Excel spreadsheet: Flux Splitting Validation, Worksheet: Splash Radius, which is documented in Appendix E), the drip location was $33^{\circ}$ and $16.5^{\circ}$ off the crown. The mean splash radius was $8.9 \mathrm{~cm}$, with a measured range of $3.0 \mathrm{~cm}$ to $15.0 \mathrm{~cm}$. This gives an effective waste package length of about $6 \mathrm{~cm}$ to $30 \mathrm{~cm}$ for the tests.

Table 7.1-8. Atlas Breached Waste Package Experiments on Rough Mock-Up Surface - Dripping off Crown - Rivulet Spread Data

\begin{tabular}{|c|c|c|c|c|c|}
\hline \multirow[b]{2}{*}{ Drip Location on Mock-Up } & \multicolumn{2}{|c|}{ Spread at $33^{\circ}$} & \multicolumn{2}{|c|}{ Spread at Transition } & \multirow{2}{*}{$\begin{array}{c}\text { Relevant } \\
\text { Patch }\end{array}$} \\
\hline & Left (cm) & Right (cm) & Left (cm) & Right (cm) & \\
\hline \multicolumn{6}{|c|}{ Multiple Patch Tests (DTN: MO0208EBSATBWP.027 [DIRS 163404]) } \\
\hline $81 \mathrm{~cm}$ right of center, $16.5^{\circ}$ & $-{ }^{a}$ & - & - & - & 5 \\
\hline $27 \mathrm{~cm}$ right of center, $16.5^{\circ}$ & 8 & 12 & 6 & 8 & 5 \\
\hline $27 \mathrm{~cm}$ left of center, $16.5^{\circ}$ & 21 & 19 & 12 & 13 & 4 \\
\hline $81 \mathrm{~cm}$ left of center, $16.5^{\circ}$ & 16 & 22 & 14 & 12 & 4 \\
\hline $81 \mathrm{~cm}$ right of center, $33^{\circ}$ & - & - & 2 & 2 & 5 \\
\hline $27 \mathrm{~cm}$ right of center, $33^{\circ}$ & - & - & 3 & 1 & 5 \\
\hline $27 \mathrm{~cm}$ left of center, $33^{\circ}$ & - & - & 2 & 1 & 4 \\
\hline $81 \mathrm{~cm}$ left of center, $33^{\circ}$ & - & - & 3 & 4 & 4 \\
\hline \multicolumn{6}{|c|}{ Bounding Flow Rate Tests (DTN: MO0208EBSATBWP.028 [DIRS 163405]) } \\
\hline $54 \mathrm{~cm}$ left of center, $33^{\circ}$ (Low Flow Rate) & - & - & - & - & 4 \\
\hline $54 \mathrm{~cm}$ left of center, $33^{\circ}$ (High Flow Rate) & - & - & - & - & 4 \\
\hline $27 \mathrm{~cm}$ left of center, $33^{\circ}$ (High Flow Rate) & $6^{b}$ & $9^{b}$ & 8 & 14 & 4 \\
\hline $27 \mathrm{~cm}$ right of center, $33^{\circ}$ (High Flow Rate) & $5^{b}$ & $3^{b}$ & 12 & 11 & 5 \\
\hline $27 \mathrm{~cm}$ right of center, $33^{\circ}$ (Low Flow Rate) & - & - & 2.5 & 2.5 & 5 \\
\hline $27 \mathrm{~cm}$ right of center, $16.5^{\circ}$ (High Flow Rate) & 16 & 15 & 17 & 10 & 5 \\
\hline
\end{tabular}


Table 7.1-8. Atlas Breached Waste Package Experiments on Rough Mock-Up Surface - Dripping off Crown - Rivulet Spread Data (Continued)

\begin{tabular}{|l|c|c|c|c|c|}
\hline \multicolumn{1}{|c|}{ Drip Location on Mock-Up } & \multicolumn{2}{|c|}{ Spread at 33 } & Spread at Transition & $\begin{array}{c}\text { Relevant } \\
\text { Patch }\end{array}$ \\
\hline $27 \mathrm{~cm}$ left of center, $16.5^{\circ}$ (High Flow Rate) & 26 & 32 & 13 & 34 & 4 \\
\hline $54 \mathrm{~cm}$ left of center, $16.5^{\circ}$ (High Flow Rate) & 25 & 20 & 26 & 19 & 4 \\
\hline $54 \mathrm{~cm}$ left of center, $16.5^{\circ}$ (Low Flow Rate) & 3 & 6 & - & - & 4 \\
\hline $27 \mathrm{~cm}$ left of center, $16.5^{\circ}$ (Low Flow Rate) & 3 & 2 & 1 & 0 & 4 \\
\hline $27 \mathrm{~cm}$ right of center, $16.5^{\circ}$ (Low Flow Rate) & 0 & 0 & 0 & 0 & 5 \\
\hline $27 \mathrm{~cm}$ left of center, $33^{\circ}$ (Low Flow Rate) & - & - & 6 & 4.5 & 4 \\
\hline
\end{tabular}

a $-=$ rivulet spread not measured.

b These data are ignored due to inconsistent behavior - rivulet spread should not occur at the drip location.

Table 7.1-9. Atlas Breached Waste Package Experiments on Rough Mock-Up Surface - Dripping off Crown - Splash Radius Tests

\begin{tabular}{|c|c|c|c|}
\hline \multirow[b]{2}{*}{ No. Drips } & \multicolumn{2}{|c|}{ Splash Radius (cm) } & \multirow[b]{2}{*}{ Comments } \\
\hline & Left & Right & \\
\hline \multicolumn{4}{|c|}{ Splash Radius Test \#4 $\left(33^{\circ}\right)$ (DTN: MO0207EBSATBWP.021 [DIRS 163399]) } \\
\hline 31 & 3.0 & 3.5 & Measured inner cluster (bulk) \\
\hline 82 & 5.5 & 6.0 & Measured inner cluster (bulk) \\
\hline 158 & 6.5 & 6.5 & Measured inner cluster (bulk) \\
\hline \multicolumn{4}{|c|}{ Splash Radius Test \#5 (16.5') (DTN: MO0207EBSATBWP.021 [DIRS 163399] } \\
\hline 22 & 9.0 & 10.0 & Measured inner cluster (bulk) \\
\hline 82 & 13.0 & 14.5 & Measured inner cluster (bulk) \\
\hline 156 & 14.0 & 15.0 & Measured inner cluster (bulk) \\
\hline
\end{tabular}

The experimentally measured fraction of the drip flux that flowed into all breaches $\left(f_{\text {expt }}\right)$ from off-crown drip locations is given in Table 7.1-10. The breaches that were the focus of a particular test or into which flow was expected have $f_{\text {expt }}$ values shown in bold. For $f_{\text {expt }}$ values in bold, $f_{\text {expt }}$ had a mean of 0.12 , with a standard deviation of 0.23 . The measured minimum fraction was 0.0 and the maximum was 0.621 .

Following the approach used in Section 6.5.1.1.3, the "inner cluster" splash diameter is used for the effective length of the waste package in the validation of the flux splitting algorithm, which is given by Equations 6.3.3.2-1 (or 6.5.1.1.3-2) and 6.3.3.2-3 (or 6.5.1.1.3-1). The form of the equation is:

$$
F=\frac{N_{b} \ell}{L_{W P}}\left(1+\frac{\tan \alpha}{2}\right) f_{V W}
$$

where $F$ is the fraction of dripping flux that flows through breaches, $\ell$ is one-half the width of a breach or patch, $L_{W P}$ is the effective length of the waste package (i.e., the length over which dripping or splattering occurs), $\alpha$ is the rivulet spread angle, and $f_{V W}$ is the uncertainty factor 
for the waste package developed for validation, corresponding to the waste package uncertainty factor, $f_{W P}$. For the validation tests, the number of breaches, $N_{b}$, is one. $f_{V W}$ is obtained by inserting $f_{\text {expt }}$, the measured fraction of the dripping flux that flowed into breaches, for $F$ in Equation 7.1.1.2-1:

$$
f_{V W}=\frac{f_{\text {expt }}}{\frac{N_{b} \ell}{L_{W P}}\left(1+\frac{\tan \alpha}{2}\right)} .
$$

Table 7.1-10. Atlas Breached Waste Package Experiments on Rough Mock-Up Surface - Dripping off Crown - Flow into Breaches

\begin{tabular}{|c|c|c|c|c|c|}
\hline Drip Location on Mock-Up & $\begin{array}{l}\text { Water Input } \\
(\mathrm{g})\end{array}$ & $\begin{array}{l}\text { Breach } 4 \\
\text { Inflow (g) }\end{array}$ & $\begin{array}{c}\text { Breach } 4 \\
f_{\text {expt }} \\
\end{array}$ & $\begin{array}{l}\text { Breach } 5 \\
\text { Inflow }(g)\end{array}$ & $\begin{array}{c}\text { Breach } 5 \\
f_{\text {expt }}\end{array}$ \\
\hline $81 \mathrm{~cm}$ right of center, $16.5^{\circ}$ & 282.96 & 0 & 0 & 0.76 & 0.0027 \\
\hline $27 \mathrm{~cm}$ right of center, $16.5^{\circ}$ & 316.74 & 0 & 0 & 0.35 & 0.0011 \\
\hline $27 \mathrm{~cm}$ left of center, $16.5^{\circ}$ & 309.57 & 0.48 & 0.0016 & 0.44 & 0.0014 \\
\hline $81 \mathrm{~cm}$ left of center, $16.5^{\circ}$ & 242.56 & 0.94 & 0.0039 & 0 & 0 \\
\hline $81 \mathrm{~cm}$ right of center, $33^{\circ}$ & 109.4 & 0 & 0 & 0.22 & 0.0020 \\
\hline $27 \mathrm{~cm}$ right of center, $33^{\circ}$ & 108.44 & 0 & 0 & 0.30 & 0.0028 \\
\hline $27 \mathrm{~cm}$ left of center, $33^{\circ}$ & 107.33 & 0.33 & 0.0031 & 0 & 0 \\
\hline $81 \mathrm{~cm}$ left of center, $33^{\circ}$ & 106.75 & 0.01 & 0.0001 & 0 & 0 \\
\hline $\begin{array}{l}54 \mathrm{~cm} \text { left of center, } 33^{\circ} \text { (Low Flow } \\
\text { Rate) }\end{array}$ & 123.13 & 53.27 & 0.4326 & 0 & 0 \\
\hline $\begin{array}{l}54 \mathrm{~cm} \text { left of center, } 33^{\circ} \text { (High Flow } \\
\text { Rate) }\end{array}$ & 330.03 & 204.99 & 0.6211 & 0 & 0 \\
\hline $\begin{array}{l}27 \mathrm{~cm} \text { left of center, } 33^{\circ} \text { (High Flow } \\
\text { Rate) }\end{array}$ & 339.24 & 0.06 & 0.0002 & 0 & 0 \\
\hline $\begin{array}{l}27 \mathrm{~cm} \text { right of center, } 33^{\circ} \text { (High } \\
\text { Flow Rate) }\end{array}$ & 330.22 & 0.10 & 0.0003 & 1.23 & 0.0037 \\
\hline $\begin{array}{l}27 \mathrm{~cm} \text { right of center, } 33^{\circ} \text { (Low } \\
\text { Flow Rate) }\end{array}$ & 112.36 & 0 & 0 & 0.80 & 0.0071 \\
\hline $\begin{array}{l}27 \mathrm{~cm} \text { right of center, } 16.5^{\circ} \text { (High } \\
\text { Flow Rate) }\end{array}$ & 313.82 & 0 & 0 & 1.14 & 0.0036 \\
\hline $\begin{array}{l}27 \mathrm{~cm} \text { left of center, } 16.5^{\circ} \text { (High } \\
\text { Flow Rate) }\end{array}$ & 322.07 & 1.34 & 0.0042 & 0.19 & 0.00059 \\
\hline $\begin{array}{l}54 \mathrm{~cm} \text { left of center, } 16.5^{\circ} \text { (High } \\
\text { Flow Rate) }\end{array}$ & 328.27 & 197.92 & 0.6029 & 0 & 0 \\
\hline $\begin{array}{l}54 \mathrm{~cm} \text { left of center, } 16.5^{\circ} \text { (Low } \\
\text { Flow Rate) }\end{array}$ & 94.41 & 57.18 & 0.6056 & 0 & 0 \\
\hline $\begin{array}{l}27 \mathrm{~cm} \text { left of center, } 16.5^{\circ} \text { (Low } \\
\text { Flow Rate) }\end{array}$ & 115.97 & 0.34 & 0.0029 & 0.45 & 0.0039 \\
\hline $\begin{array}{l}27 \mathrm{~cm} \text { right of center, } 16.5^{\circ} \text { (Low } \\
\text { Flow Rate) }\end{array}$ & 119.76 & 0 & 0 & 0.09 & 0.0008 \\
\hline $\begin{array}{l}27 \mathrm{~cm} \text { left of center, } 33^{\circ} \text { (Low Flow } \\
\text { Rate) }\end{array}$ & 115.81 & 0.36 & 0.0031 & 0 & 0 \\
\hline
\end{tabular}

DTNs: MO0208EBSATBWP.027 [DIRS 163404], MO0208EBSATBWP.028 [DIRS 163405].

NOTE: For all fexpt values in bold: mean $=0.115$; standard deviation $=0.234$; median $=0.0031 ;$ minimum $=$ 0.00014 ; maximum $=0.621$. 
Statistics for $f_{\text {expt }}$ are compared in Table 7.1-11 between the smooth surface experimental results used for the waste package flux splitting submodel (Appendix D) and the rough surface results discussed in this section (Table 7.1-10).

Table 7.1-11. Comparison of $f_{\text {expt }}$ Statistics for Smooth and Rough Surfaces

\begin{tabular}{|l|l|l|l|c|}
\hline \multicolumn{1}{|c|}{ Experiments } & Mean $\boldsymbol{f}_{\text {expt }}$ & Minimum $\boldsymbol{f}_{\text {expt }}$ & Maximum $\boldsymbol{f}_{\text {expt }}$ & Median $\boldsymbol{f}_{\text {expt }}$ \\
\hline Waste Package (Smooth Surface) & 0.295 & 0.0 & 1.066 & 0.0142 \\
\hline WP Validation (Rough Surface) & 0.115 & 0.0001 & 0.621 & 0.0031 \\
\hline
\end{tabular}

$\mathrm{WP}=$ waste package

With the values for the breach flow fraction $\left(f_{\text {expt }}\right)$, the effective waste package length $\left(L_{W P}\right)$, and the spread angle $(\alpha)$ as determined above using off-crown rough surface test data, the range for $f_{V W}$ is be determined. The half-width of the patch used in the experiments $(\ell=13.5 \mathrm{~cm})$ is used to evaluate $f_{V W}$. The minimum for $f_{V W}$ is obtained using the minimum effective waste package length $\left(L_{W P}=6.0 \mathrm{~cm}\right)$ and the maximum spread angle $\left(\alpha=19.0^{\circ}\right)$, resulting in $f_{V W}=0.379 f_{\text {expt }}$. The maximum for $f_{V W}$ is obtained using the maximum effective waste package length $\left(L_{W P}=30 \mathrm{~cm}\right)$ and the minimum spread angle $\left(\alpha=0^{\circ}\right)$, resulting in $f_{V W}=2.22 f_{\text {expt }}$. Using the mean value of $f_{\text {expt }}(0.115), f_{V W}$ for the waste package ranges from 0.044 to 0.26 . Over the measured range of $f_{\text {expt }}$ (0 to 0.621$), f_{V W}$ ranges from 0.0 to $(2.22)(0.621)=1.38$. The range obtained for $f_{W P}(0.909$ to 2.00$)$, based on the mean smooth surface value of $f_{\text {expt }}(0.295)$, is higher. When the measured range of smooth surface $f_{\text {expt }}$ values ( 0.0 to 1.066 ; see Figure D-10) for the waste package flux splitting analysis is used instead of the mean, $f_{W P}$ ranges from 0.0 to 3.28. The waste package flux splitting submodel (based on smooth surface data) overestimates flow through breaches compared to the model validation estimates (based on rough surface data), which in turn overestimates the advective releases of radionuclides compared to the model validation estimates. The estimated values for $f_{W P}$ and $f_{V W}$ are summarized in Table 7.1-12.

Table 7.1-12. Summary of $f_{W P}$ and $f_{V W}$ Values

\begin{tabular}{|c|c|c|c|c|}
\hline & \multicolumn{2}{|c|}{ Based on Mean $\boldsymbol{f}_{\text {expt }}$} & Based on Minimum $\boldsymbol{f}_{\text {expt }}$ & Based on Maximum $\boldsymbol{f}_{\text {expt }}$ \\
\cline { 2 - 5 } & Minimum & Maximum & Minimum & Maximum \\
\hline$f_{W P}$ & 0.909 & 2.001 & 0.0 & 3.28 \\
\hline$f_{V W}$ & 0.044 & 0.26 & 0.0 & 1.38 \\
\hline
\end{tabular}


As with the drip shield flux splitting submodel, a final comparison is between $f_{W P}^{\prime}$, which lumps the uncertainty in the rivulet spread angle into $f_{W P}$, and a corresponding parameter for the rough waste package surface, $f_{V W}^{\prime}$, where

$$
f_{V W}^{\prime}=\left(1+\frac{\tan \alpha}{2}\right) f_{V W} .
$$

For the rough surface, $\alpha$ ranges from $0^{\circ}$ to $19.0^{\circ}$. Applying the maximum value for $\alpha$ results in the range for $f_{V W}^{\prime}$ of 0 to 0.30 , based on the mean value of $f_{\text {expt }}$. For comparison, $f_{W P}^{\prime}$ was estimated to range from 0 to 2.41. The wider range for $f_{W P}^{\prime}$ means that the waste package flux splitting submodel tends to overestimate the flow through breaches in the waste package compared to the rough surface validation tests. The overlapping ranges for $f_{W P}^{\prime}$ and $f_{V W}^{\prime}$ validate the waste package flux splitting submodel.

Sections 7.1.1.1 and 7.1.1.2 have demonstrated that the drip shield and waste package flux splitting submodels based on experiments using smooth drip shield mock-up surfaces overestimate fluxes when compared to the experimental data using rough drip shield mock-up surfaces. The validations discussed uncertainties in relevant parameters. Based on these validation results, the EBS flow model is adequate for its intended use.

\subsubsection{Results of Independent Model Validation Technical Review of the EBS Flow Model}

The results of the independent model validation technical review of the EBS flow model are given in a memo presented in Section 7.2.3 that combines the technical reviews of the EBS flow and transport models.

\subsection{EBS TRANSPORT MODEL}

The transport of radionuclides through the EBS is modeled, using assumptions in Section 5, as a combination of advective and diffusive transport including retardation between a series of three domains:

- Waste form domain

- Corrosion products domain

- Invert domain.

Advective transport is considered when water enters the waste form domain and is able to flow through the EBS and enter the UZ. The EBS flow model (Section 7.1) calculates the water flux between each domain and a separate model provides radionuclide concentrations.

Diffusive transport between each of the domains occurs regardless of whether water is flowing though the EBS, since, by Assumption 5.5, a continuous film of water is always present on all surfaces of internal waste package components and corrosion products in a breached waste package when the temperature is below $100^{\circ} \mathrm{C}$. Diffusive transport between each domain is 
modeled in one dimension and therefore is dependent upon the following parameters that can vary as a function of time and according to the specific transport pathway:

- Effective diffusion coefficient

- Diffusive area

- Diffusion length.

The effective diffusion coefficient is calculated from Archie's law and is dependent upon the free water diffusion coefficient, porosity, and saturation in each domain. Additionally a temperature correction is made for diffusion in the invert domain. Porosity is either assumed to be constant or is provided by a separate model (e.g., BSC 2005 [DIRS 172895]). Saturation varies with relative humidity. The diffusive area is calculated differently for each domain, but is either a function of the number of breaches in the waste package (corrosion patches or stress corrosion cracks) or it is calculated from the geometry of the different components of the EBS. The diffusive area of breaches also depends on the scenario class being modeled. The diffusion length is either calculated from EBS geometry or is sampled, depending upon the domain.

As stated in Section 7, the level of confidence required for the EBS transport model is Level II. Level II validation is described in Section 7. In Sections 6.3 and 6.5, a detailed explanation and justification is presented on the formulation of the transport model. These sections include a great amount of information that is relevant to Level II validation. In addition, the following sections include auxiliary information aimed to validate further certain components of the transport model.

Section 7.2.1 describes a comparison between the in-package diffusion submodel and two similar, independently developed models of transport from a waste package to the invert. The comparison shows that although each model uses a different set of assumptions, the assumptions used and the final diffusion coefficients calculated by each model generally agree and thus the transport model is valid for its intended purpose.

Section 7.2.2 compares the invert diffusion coefficient of free water diffusivity for radionuclides at different temperatures and with other cations and anions and shows that the self-diffusion coefficient of water at $25^{\circ} \mathrm{C}$ is an upper bound.

\subsubsection{In-Package Diffusion Submodel}

Diffusive transport within the waste package will limit the release of radionuclides for those waste packages in a no-seep environment. The in-package diffusion submodel is directly related to the waste isolation attribute, limited release of radionuclides from the engineered barriers, because the model predicts delays in the release of mass from the waste package in comparison to the TSPA-SR model, which immediately mobilized radionuclides at the external surface of the waste package.

Level II validation is appropriate for the in-package diffusion submodel, as it is part of the EBS radionuclide transport model (see Section 7 above). In addition, the in-package diffusion submodel has the following features: 
- The in-package diffusion submodel is not extrapolated over large distances or spaces. There is an inherent time extrapolation in the model.

- The in-package diffusion submodel bounds the uncertainties by considering two bounding states. In the first state, the waste package internal components are considered to be in their intact, as-emplaced condition. For the second state, the iron-based waste package internal components are considered to be completely degraded to a porous material. Although these are two bounding end states, uncertainties exist in the time- and spatially-dependent intermediate conditions.

- The in-package diffusion submodel has a minor impact on dose time history in the first 10,000 years, based on sensitivity calculations performed for the prioritization report Risk Information to Support Prioritization of Performance Assessment Models (BSC 2003 [DIRS 168796], Sections 3.3.6 through 3.3.11). Those studies indicate that the estimate of mean annual dose in the first 10,000 years has only a minor dependence on in-package conditions that impact diffusion.

The in-package diffusion submodel is validated by comparison to two other models:

- Electric Power Research Institute (EPRI) Phase 5 report (EPRI 2000 [DIRS 154149])

- A model by Lee et al. (1996 [DIRS 100913]) for diffusive releases from waste package containers with multiple perforations.

The in-package diffusion submodel is based on the one-dimensional diffusion equation, Fick's first law of diffusion (Bird et al. 1960 [DIRS 103524], p. 503):

$$
\frac{q_{i}}{A}=-D \frac{\partial C_{i}}{\partial x}
$$

That is, the fundamental process being modeled is diffusion through a porous medium, a process that is well understood and fully accepted throughout the scientific and engineering community.

Certain underlying assumptions need to be addressed. It is assumed that the bulk of the corrosion products inside a waste package is hematite, $\mathrm{Fe}_{2} \mathrm{O}_{3}$, based simply on the predominance of iron in the composition of internal non-waste form components. This assumption is also used in the EPRI report (EPRI 2000 [DIRS 154149], p. 6-22), based on cited studies (EPRI 2000 [DIRS 154149], p. 6-31) of corrosion products of carbon steel in humid, oxidizing environments that indicate that in the presence of an abundant supply of oxygen, iron would be expected to exist as $\mathrm{Fe}_{2} \mathrm{O}_{3}$, or $\mathrm{FeOOH}$ or $\mathrm{Fe}(\mathrm{OH})_{3}$.

The specific surface area of hematite has been measured by numerous investigators. The range of values obtained varies widely, depending on the morphology of the sample. As can be seen in the expressions for effective saturation and diffusion coefficient, Equations 6.3.4.3.5-5 and 6.3.4.3.5-6, the diffusion coefficient is proportional to the square of the specific surface area, which from Table 6.3-7 varies by about a factor of about 12. This uncertainty is accounted for in the uncertain parameter, Surface_Area_CP (Table 6.5-6), which ranges from 1.0 to $22 \mathrm{~m}^{2} \mathrm{~g}^{-1}$. 
The water adsorption isotherm used for the in-package diffusion submodel is compared with another measured isotherm (McCafferty and Zettlemoyer 1971 [DIRS 154378], Figure 3) in Figure 7.2-1, which shows the close agreement between independent investigators. In addition, Figure 6.3-6 shows that hematite over-predicts the amount of water adsorbed compared to nickel oxide, which is one of the other major components of stainless steel (DTN: MO0003RIB00076.000 [DIRS 153044]) that would comprise the products of corrosion of the waste package internal components.

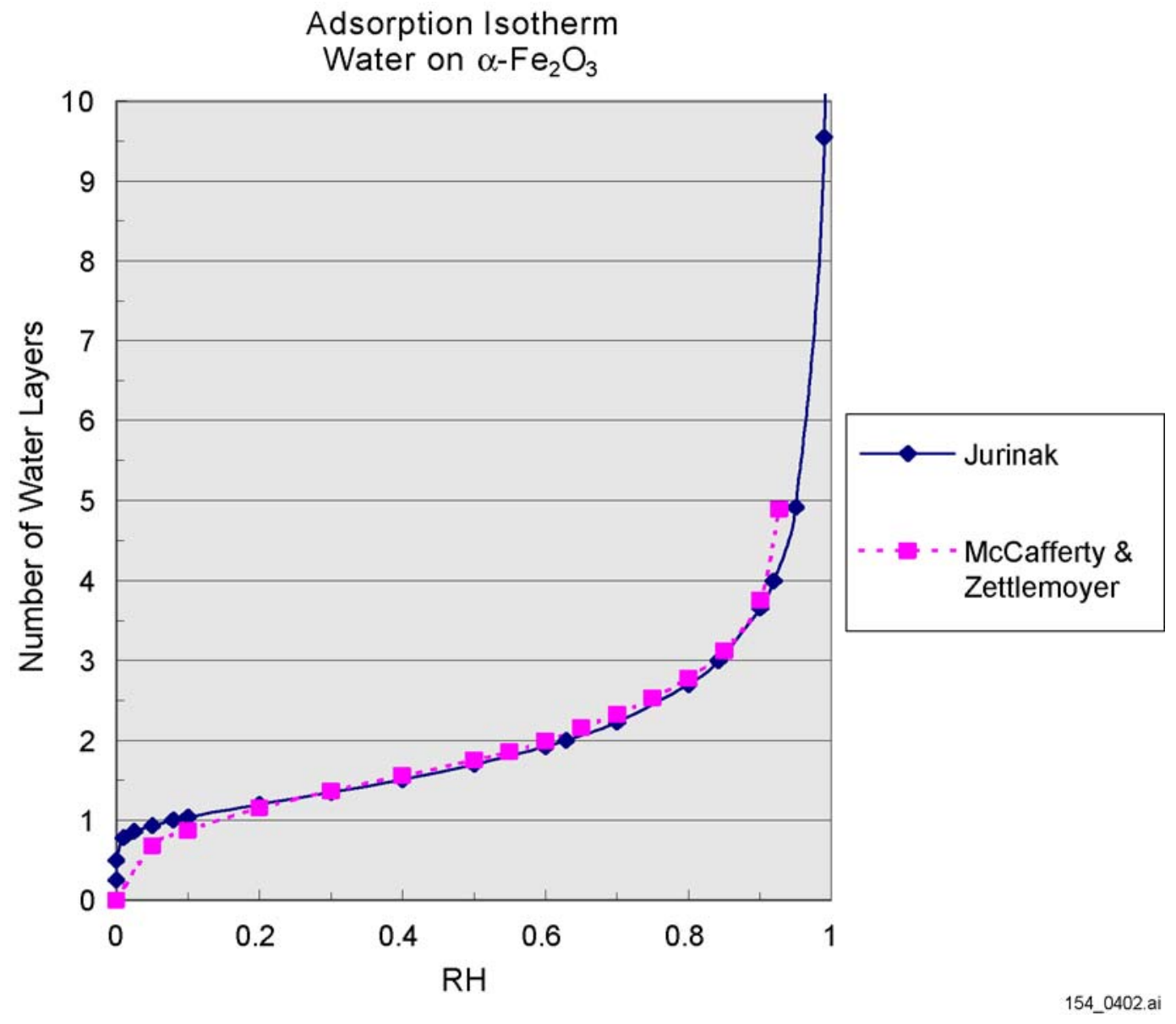

Source: Jurinak curve: Jurinak 1964 [DIRS 154381]; McCafferty and Zettlemoyer curve: McCafferty and Zettlemoyer 1971 [DIRS 154378].

Figure 7.2-1. Adsorption Isotherms for Water Vapor on $\alpha-\mathrm{Fe}_{2} \mathrm{O}_{3}$

\subsubsection{Comparison with Electric Power Research Institute 2000}

Validation of the in-package diffusion submodel is provided in part by qualitative comparison with a similar model developed independently by a reputable performance assessment program (EPRI 2000 [DIRS 154149]).

The EPRI source-term model, COMPASS2000, implements five compartments-Waste, Corrosion Products, Canister, Invert, Near-Field Rock-of which two (Corrosion Products and Canister) are analogous to portions of the in-package diffusion submodel. The Corrosion 
Products compartment represents the porous material that is formed after the basket materials are corroded. The Canister compartment represents the failed metal canisters. As with the GoldSim TSPA-LA model, each compartment is treated as a mixing cell in which radionuclide concentrations are assumed to be uniform. Mass balances in each compartment account for the various processes that comprise the model, including transport by diffusion and advection, radioactive decay and ingrowth, sorption, dissolution, and precipitation.

In the EPRI model, EBS transport parameters are assigned fixed values. Both the Corrosion Products and corroded Canister compartments have a porosity of 0.42 (EPRI 2000 [DIRS 154149], p. 6-21), less than the initial porosity of a CSNF waste package, 0.58, as estimated in Section 6.3.4.3.4. The EPRI value accounts for the volume occupied by the oxide. A lower value for porosity overestimates releases of radionuclides. However, in the in-package diffusion submodel (Equation 6.3.4.3.5-6), the higher value of porosity increases the estimated diffusion coefficient by only a factor of 1.5 , which is small compared to other uncertainties in the model.

The EPRI model assumes a fixed water saturation of 0.35 in both the Corrosion Products and corroded Canister compartments (EPRI 2000 [DIRS 154149], p. 6-21). This value is appropriate for modeling cases involving advective transport, but overestimates releases of radionuclides for the expected large fraction of the repository that has no seepage flux, where the only water present is adsorbed water. The in-package diffusion submodel specifically applies to those regions and provides a more realistic estimate of saturation as a function of relative humidity.

The EPRI model uses a fixed value for effective diffusion coefficient of $4.645 \times 10^{-4} \mathrm{~m}^{2} \mathrm{yr}^{-1}$ in both the Corrosion Products and corroded Canister compartments (EPRI 2000 [DIRS 154149], p. 6-22). This converts to $1.472 \times 10^{-7} \mathrm{~cm}^{2} \mathrm{~s}^{-1}$ or to $1.472 \times 10^{-11} \mathrm{~m}^{2} \mathrm{~s}^{-1}$. For diffusion through a fully degraded waste package (Equation 6.3.4.3.5-5), this corresponds to a relative humidity of 97.9 percent. Thus, when the humidity is high, the EPRI model and the in-package diffusion submodel agree well. In contrast, the in-package diffusion submodel provides humidity-dependent diffusion coefficient values.

The EPRI model also specifies fixed diffusive lengths, which are defined as the distance from the center of the compartment to the interface of the two contacting compartments. For the Corrosion Products compartment, the diffusion length is $0.046 \mathrm{~m}$; for the Canister compartment, the diffusion length is $0.025 \mathrm{~m}$ (EPRI 2000 [DIRS 154149], p. 6-22). In a well-degraded waste package, these are reasonable values, comparable to those used in the in-package diffusion submodel. However, the in-package diffusion submodel accounts for the uncertainty in diffusion lengths at all times, and provides special treatment at early times when large masses of corrosion products are not yet formed.

For the conditions assumed in the EPRI model, namely, at later times when the waste package is extensively corroded, the in-package diffusion submodel agrees quite well with the EPRI model. The primary differences are that the in-package diffusion submodel accounts for a wider range of conditions, including times just after breaches first appear in the waste package. In addition, the in-package diffusion submodel accounts explicitly for the relative humidity, which realistically is the only source of water when seepage does not occur. And finally, in contrast to the EPRI model, the in-package diffusion submodel accounts for uncertainty in diffusive path lengths. 
Thus, there is agreement between the models, and where differences occur, it is primarily to increase the realism of the diffusive release calculation and to account for uncertainty.

\subsubsection{Comparison with Lee et al. 1996}

Validation of the in-package diffusion submodel is provided in part by comparison with a similar model developed independently and published in technical literature (Lee et al. 1996 [DIRS 100913]).

Lee et al. (1996 [DIRS 100913]) developed a model for steady-state and "quasi-transient" diffusive releases from waste packages into the invert. In this model, perforations in the package are assumed to be cylindrical in shape. The diffusion path consists of the approach to the opening of the perforation from the waste form side; the path through the cylindrical portion of the perforation, which is filled with corrosion products; and the path through the exit disk separating the perforation from the invert. The waste is assumed to be distributed uniformly inside the waste container. The package is approximated by an equivalent spherical configuration, and the underlying invert is represented by a spherical shell surrounding the package.

The model of Lee et al. (1996 [DIRS 100913]) is suitable for the late stages of package degradation, when the waste form has become a mass of porous corrosion products. Although Lee et al. (1996 [DIRS 100913]) assumed the packages failed by localized corrosion, this model should be equally applicable to failure by general corrosion.

The assumption of Lee et al. (1996 [DIRS 100913]) that the waste (i.e., the radionuclide source) is uniformly distributed inside the waste package restricts the applicability of the model and comparison to the in-package diffusion submodel to the times when the waste package has extensively corroded. The object of the in-package diffusion submodel is to provide more realism at earlier and intermediate times, when the waste cannot yet be considered a uniform porous medium. (In the in-package diffusion submodel, the dependence of the diffusive properties of the waste package on the extent of degradation is computed explicitly as a function of time; see Sections 6.3.4.3.5 and 6.5.3.2.) On the other hand, the fundamental assumption that diffusive releases are controlled by diffusion through breaches that are filled with porous corrosion products may be valid over much of the waste package lifetime, including early times, when stress corrosion cracks are the first breaches to appear. Lee et al. (1996 [DIRS 100913], p. 5-67) assume that the porosity of the perforations is $\phi_{C P}=0.4$, and the volumetric water content is $\Phi=10$ percent (so the water saturation in the perforations is a constant $\left.S_{w}=\Phi /\left(100 \phi_{C P}\right)=0.25\right)$. Based on data by Conca and Wright (1990 [DIRS 101582]; 1992 [DIRS 100436]), Lee et al. compute a diffusion coefficient, $D\left(\mathrm{~cm}^{2} \mathrm{~s}^{-1}\right)$, for the porous corrosion products filling the perforations (Lee et al. 1996 [DIRS 100913], p. 5-67):

$$
\log _{10} D=-8.255( \pm 0.0499)+1.898( \pm 0.0464) \log _{10} \Phi
$$

where the numbers in parentheses are one standard deviation. From the discussion in Section 6.3.4.1.1, it is likely that this equation, being based on data by Conca and Wright (1990 [DIRS 101582]; 1992 [DIRS 100436]), should be written using $\log _{10}\left(\phi_{C P} S_{w} D\right)$ rather than 
$\log _{10} D$; however, this model validation comparison will use the equation as given by Lee et al., since not enough information is available to repeat their analysis.

For $\Phi=10$ percent (the assumed volumetric water content of the perforations), Equation 7.2.1.2-1 gives $D=4.4 \times 10^{-7} \mathrm{~cm}^{2} \mathrm{~s}^{-1}$. Lee et al. assume that the diffusion coefficient inside the waste package (as opposed to the perforations) is $10^{-5} \mathrm{~cm}^{2} \mathrm{~s}^{-1}$ (Lee et al. 1996 [DIRS 100913], p. 5-67). As a comparison, the self-diffusion coefficient for water is $2.299 \times 10^{-5} \mathrm{~cm}^{2} \mathrm{~s}^{-1}$ (Mills 1973 [DIRS 133392], Table III), and for many actinides the diffusion coefficient in water is roughly $5 \times 10^{-6} \mathrm{~cm}^{2} \mathrm{~s}^{-1}$ (Table 7.2-11). The value for $D$ obtained from Equation 7.2.1.2-1 $\left(4.4 \times 10^{-7} \mathrm{~cm}^{2} \mathrm{~s}^{-1}\right)$ accounts for porosity, saturation, and tortuosity, and thus is comparable to the values for $D_{s}$ obtained from Equation 6.3.4.3.5-6. Table 6.3-10 tabulates values of $\phi S_{w} D_{s}$ using Equation 6.3.4.3.5-6. At appropriate ranges of conditions in Table 6.3-10 for a water content of 10 percent, $D_{s}$ ranges from about $1.4 \times 10^{-6} \mathrm{~cm}^{2} \mathrm{~s}^{-1}$ to about $4.1 \times 10^{-6} \mathrm{~cm}^{2} \mathrm{~s}^{-1}$ (in Table 6.3-10, where, for the lower bound on specific surface area of $\bar{s}_{C P}=1,000 \mathrm{~m}^{2} \mathrm{~kg}^{-1}$, the closest entry for 10 percent water content, $\phi S_{w}$, is $\phi S_{w} D_{s}=1.4 \times 10^{-7} \mathrm{~cm}^{2} \mathrm{~s}^{-1}$, at $R H=0.9999$, and $S_{w e}=0.14$; for the upper bound on specific surface area of $\bar{s}_{C P}=22,000 \mathrm{~m}^{2} \mathrm{~kg}^{-1}$, at a water content of approximately 10 percent, $\phi S_{w} D_{s}=4.1 \times 10^{-7} \mathrm{~cm}^{2} \mathrm{~s}^{-1}$, at $R H=0.95$ and $\left.S_{w e}=0.24\right)$. This comparison indicates that the model developed by Lee et al. (1996 [DIRS 100913]) for $D$ represents high relative humidity and reasonable specific surface area (i.e., within the sampled range specified for the EBS $R T$ Abstraction) if adsorption is the sole mechanism for water appearing in the corrosion products.

A more detailed calculation can be performed to estimate the surface area of corrosion patches, the amount of water adsorbed at various relative humidity values, the resulting water saturation of the patches, and obtain a diffusion coefficient using Equation 6.3.4.3.5-6. Alternatively, the diffusion coefficient can be obtained using a modification of Equation 7.2.1.2-1, in which the water content, $\Phi$ (percent), is:

$$
\Phi=100 S_{w e, C P} \phi_{C P}=1.194(-\ln R H)^{-0.408}
$$

This equation uses a porosity of $\phi_{C P}=0.4$, but obtains the effective water saturation from Equation 6.3.4.3.5-5, which is based on the assumption that all water comes from adsorption of water vapor onto hematite having a specific surface area of $9.1 \mathrm{~m}^{2} \mathrm{~g}^{-1}$. Then, substituting Equation 7.2.1.2-2 into Equation 7.2.1.2-1:

$$
\begin{aligned}
\log _{10} D & =-8.255+1.898 \log _{10} \Phi \\
& =-8.255+1.898\left[0.07707-0.408 \log _{10}(-\ln R H)\right] \\
& =-8.109-0.775 \log _{10}(-\ln R H) .
\end{aligned}
$$

For example, at $R H=0.95$, the effective diffusion coefficient for the patch using Archie's law (Equation 6.3.4.3.5-6) is $\phi S_{w} D_{s}=7.03 \times 10^{-12} \mathrm{~m}^{2} \mathrm{~s}^{-1}$ (for $\phi=0.4$ and, 
from Equation 6.3.4.3.5-5, $\left.S_{w}=0.100\right)$, or $\quad D_{s}=1.75 \times 10^{-10} \mathrm{~m}^{2} \mathrm{~s}^{-1}$, whereas using Equation 7.2.1.2-3, the diffusion coefficient for the corrosion patch is $D=7.77 \times 10^{-12} \mathrm{~m}^{2} \mathrm{~s}^{-1}$.

Thus, for those cases where the release rate is controlled by diffusion through porous corrosion products, the in-package diffusion submodel results in more rapid diffusive releases than the model of Lee et al. (1996 [DIRS 100913]).

If the value obtained by Lee et al. is actually $\log _{10}\left(\phi_{C P} S_{w} D\right)$ rather than $\log _{10} D$, then the two models agree well. For example, at a water content $\phi S_{w}=\Phi$ of 10 percent, Equation 7.2.1.2-1 would give $\phi S_{w} D=4.4 \times 10^{-7} \mathrm{~cm}^{2} \mathrm{~s}^{-1}$ or $D=4.4 \times 10^{-6} \mathrm{~cm}^{2} \mathrm{~s}^{-1}$, which compares well with the range of $D_{s}$ from Table $6.3-10$ of $1.4 \times 10^{-6} \mathrm{~cm}^{2} \mathrm{~s}^{-1}$ to $4.1 \times 10^{-6} \mathrm{~cm}^{2} \mathrm{~s}^{-1}$ at a water content of approximately 10 percent, as discussed earlier in this section.

The in-package diffusion submodel provides a means for quantifying the uncertainty in diffusion coefficients for diffusion of radionuclides from within the waste form to the invert. Whereas other models consider only the times when the waste package is largely degraded, the in-package diffusion submodel presented here also considers earlier times, starting from the time of the initial waste package breach. The time period between initial breach and complete degradation of the internal components may span many thousands of years. Thus, the in-package diffusion submodel fills a major time gap in modeling diffusive releases from a waste package. In effect, it provides a rationale for interpolating between essentially a zero diffusion coefficient (due to the absence of water) when a waste package is first breached to a value at a time when porous corrosion products can be expected to fill the waste package with a degree of water saturation capable of transporting radionuclides. The in-package diffusion submodel is considered validated based on corroborating data for input parameters such as water adsorption isotherms and specific surface areas, and based on the agreement with two other waste package diffusion models in areas where these models apply.

\subsubsection{Invert Diffusion Submodel}

Level I validation is appropriate for the invert diffusion submodel, as it is part of the mechanisms for radionuclide transport from waste package to the drift wall through the invert (see Section 7). In addition, the invert diffusion submodel has the following features:

- Diffusive release from the engineered barrier system does not result in significant releases from the repository system. Under expected conditions, there is a small probability of waste package breaching, and only limited release at all is likely. Therefore, the diffusion properties of the invert that might affect this release are expected to play a small role in the estimate of performance of the system under these conditions. The invert diffusion coefficient is also expected to play a small role for disruptive conditions under which more significant breaching of the waste package might occur. In this case, transport through the invert would be dominated by advection, and diffusion would therefore provide only a minor contribution. Therefore, the diffusion submodel is not expected to play a major role in the assessment of system performance. 
- In addition to the above, the invert diffusion properties submodel is not extrapolated beyond the conditions and distances considered in the development of the model. The model applies only on the scale of the EBS and is not applied to larger scales, for example to the unsaturated zone rock.

The invert diffusion coefficient abstraction considers the free water diffusivity for radionuclides as an upper bound. The validation of each of these factors is considered in the following sections.

Section 6.3.4.1.2 describes modification of the self-diffusion coefficient due to temperature. The modification is based on established principles of diffusion in fluids and thus no validation is necessary. The temperature modification is based on the relationship between diffusion and viscosity and temperature (Cussler 1997 [DIRS 111468], p. 114). The relationship between temperature and viscosity of water is available in text books. Thus, it is straightforward to establish a direct relationship between diffusion coefficient and temperature.

\subsubsection{Self-Diffusion Coefficient of Water}

The self-diffusion coefficient of water at $25^{\circ} \mathrm{C}, 2.299 \times 10^{-5} \mathrm{~cm}^{2} \mathrm{~s}^{-1}$ (Mills 1973 [DIRS 133392], Table III), provides an upper bound for the diffusion of ionic and neutral inorganic, and organo-metal species that may be released from a waste package. This assertion is based on the following points, which are discussed in the text following this list:

1. A survey of compiled diffusion coefficients at $25^{\circ} \mathrm{C}$ shows that simple cation and anion species (excluding the proton and hydroxyl species, which are not appropriate analogs to diffusing radionuclide species) have diffusion coefficients that are smaller than that of water.

2. The self-diffusion coefficient for water at $90^{\circ} \mathrm{C}$ is larger than compiled diffusion coefficients for simple inorganic species at $100^{\circ} \mathrm{C}$.

3. Diffusion coefficients for simple lanthanide and actinide cations are much smaller than the self-diffusion coefficient of water and are expected to be even smaller for their hydroxyl and carbonate complexes.

In a compilation of diffusion coefficients for 97 ionic species, only 3 species, $\mathrm{H}^{+}, \mathrm{OH}^{-}$, and $\mathrm{OD}^{-}$ have diffusion coefficients at $25^{\circ} \mathrm{C}$ that are larger than the self-diffusion of water at $25^{\circ} \mathrm{C}$ (Mills and Lobo 1989 [DIRS 138725], Appendix A, Tables 1.1 to 1.6, pages 314 to 319). Of the 33 ionic species for which Mills and Lobo list diffusion coefficients at $100^{\circ} \mathrm{C}$ in Tables 1.1 through Table 1.7, only 2 species, $\mathrm{H}^{+}$and $\mathrm{OH}^{-}$, have diffusion coefficients larger than the self-diffusion of water $\left(\mathrm{H}_{2}{ }^{18} \mathrm{O}\right)$ at $90^{\circ} \mathrm{C}$ (Mills and Lobo 1989 [DIRS 138725]; Table 1, page 17). The fact that the self-diffusion of $\mathrm{H}_{2}{ }^{18} \mathrm{O}$ is less than that of $\mathrm{H}_{2} \mathrm{O}$, and that the self-diffusion of $\mathrm{H}_{2} \mathrm{O}$ at $90^{\circ} \mathrm{C}$ would be greater than that of various ionic species at $100^{\circ} \mathrm{C}$, further supports the contention that the self-diffusion of water at $25^{\circ} \mathrm{C}$ is bounding. 
Using the self-diffusion coefficient for water as a bounding value for all radionuclides partially compensates for not accounting for the effect of temperature on the diffusion coefficient in the corrosion product domain. See the discussion at the end of Section 6.3.4.3.5.

The compilation below (Table 7.2-1) lists a selection of diffusion coefficients for some trivalent lanthanides and actinides. Table 7.2-1 also includes some anions not listed in most compilations but relevant and/or analogous to those expected for radionuclides released from the waste package. The listing shows that the diffusion coefficients for these species are all smaller than the self-diffusion of water, by factors ranging from 1.6 to 14.7. In the case of uranium, the carbonate complexes of the metal species have even smaller diffusion coefficients. Based on the Stokes-Einstein equation (Bird et al. 1960 [DIRS 103524], p. 514, Equation 16.5-4), the diffusivity of a solute in a liquid is inversely proportional to the radius of the diffusing particles. It is therefore expected that other carbonate and hydroxyl complexes, on the basis of the greater size of the complexes relative to the metal species, will also have smaller diffusion coefficients than the metal species listed in Table 7.2-1.

As an alternative, four diffusion coefficients could be used. One coefficient could be used for each charge (mono-, di-, and tri-valent species) and one for the hydroxyl and carbonate complexes of the actinides and lanthanides. At $25^{\circ} \mathrm{C}$, the mono-, di-, and trivalent species have bounding values of $2.2 \times 10^{-5} \mathrm{~cm}^{2} \mathrm{~s}^{-1}, 1.2 \times 10^{-5} \mathrm{~cm}^{2} \mathrm{~s}^{-1}, 0.7 \times 10^{-5} \mathrm{~cm}^{2} \mathrm{~s}^{-1}$, respectively, as shown in Figure 7.2-2. Although this alternative model is not used for TSPA-LA, it provides further evidence that the use of the self-diffusion coefficient of water bounds the diffusion coefficients of diffusing radionuclide species in the EBS. 
Limiting diffusion coefficients for anions and simple (non-complexed) cations

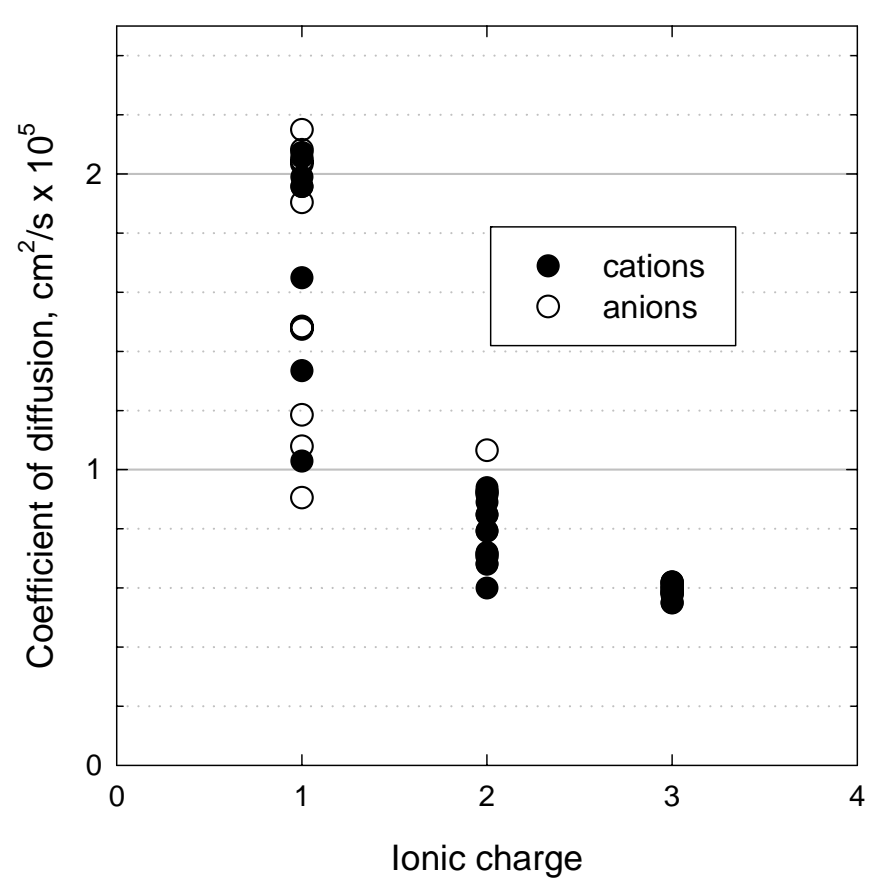

Source: $\quad$ Selected from Mills and Lobo 1989 [DIRS 138725], Appendix I, Tables 1.1 to 1.6; pp. 314 to 319.

Figure 7.2-2. Limiting Diffusion Coefficients for Anions and Simple (Non-Complexed) Cations

Table 7.2-1. Compilation of Diffusion Coefficients for Yttrium, Technetium, Molecular lodine, and Lanthanide and Actinide Species

\begin{tabular}{|c|c|c|c|}
\hline Species & $D^{*}, \mathrm{~cm}^{2} \mathrm{~s}^{-1}$ & Comments & Reference \\
\hline $\mathrm{Y}^{3+}$ & $5.7 \pm 0.06 \times 10^{-6}$ & $25^{\circ} \mathrm{C}$ & $\begin{array}{l}\text { Mills and Lobo } 1989 \text { [DIRS 138725], } \\
\text { p. } 220 .\end{array}$ \\
\hline $\mathrm{TcO}_{4}^{-}$ & $1.48 \pm 0.01 \times 10^{-5}$ & $25^{\circ} \mathrm{C}$ & $\begin{array}{l}\text { Mills and Lobo } 1989 \text { [DIRS 138725], } \\
\text { p. } 105 .\end{array}$ \\
\hline $\mathrm{I}_{2}$ & $1.36 \pm 0.04 \times 10^{-5}$ & $25^{\circ} \mathrm{C} ; 0.075 \mathrm{M} \mathrm{H}_{2} \mathrm{SO}_{4}$ & $\begin{array}{l}\text { Cantrel et al. } 1997 \text { [DIRS 138551], } \\
\text { Table } 5 .\end{array}$ \\
\hline $\mathrm{La}^{3+}$ & $5.42 \times 10^{-6}$ & $\begin{array}{l}25^{\circ} \mathrm{C} ; 0.1 \mathrm{M} \mathrm{NaClO}_{4} \\
u=6.33 \mathrm{~cm}^{2} \mathrm{~s}^{-1} \mathrm{~V}^{-1}\end{array}$ & $\begin{array}{l}\text { Rosch and Khalkin } 1990 \text { [DIRS 138739], } \\
\text { calculated from mobility data reported in } \\
\text { Table 1, p. 103. }\end{array}$ \\
\hline $\mathrm{La}^{3+}$ & $6.18 \pm 0.06 \times 10^{-6}$ & $25^{\circ} \mathrm{C}$ & $\begin{array}{l}\text { Mills and Lobo } 1989 \text { [DIRS 138725], } \\
\text { p. } 93 .\end{array}$ \\
\hline $\begin{array}{l}\mathrm{Ce}(\mathrm{III})- \\
\text { carbonate }\end{array}$ & $2.68 \pm 0.12 \times 10^{-6}$ & $\begin{array}{l}5.5 \mathrm{M} \mathrm{K}_{2} \mathrm{CO}_{3}, \mathrm{pH} 13 \text {, } \\
\text { presumably at } 25^{\circ} \mathrm{C} \text {. }\end{array}$ & Haltier et al. 1990 [DIRS 138643], p. 111. \\
\hline $\begin{array}{l}\mathrm{Ce}(\mathrm{IV})- \\
\text { carbonate }\end{array}$ & $1.56 \pm 0.07 \times 10^{-6}$ & $\begin{array}{l}5.5 \mathrm{M} \mathrm{K}_{2} \mathrm{CO}_{3}, \mathrm{pH} 13 \text {, } \\
\text { presumably at } 25^{\circ} \mathrm{C} \text {. }\end{array}$ & Haltier et al. 1990 [DIRS 138643], p. 111. \\
\hline $\mathrm{Eu}^{3+}$ & $4.38 \times 10^{-6}$ & $\begin{array}{l}25^{\circ} \mathrm{C} ; 0.1 \mathrm{M} \mathrm{NaClO}_{4} \\
u=5.12 \mathrm{~cm}^{2} \mathrm{~s}^{-1} \mathrm{~V}^{-1}\end{array}$ & $\begin{array}{l}\text { Rosch and Khalkin } 1990 \text { [DIRS 138739]; } \\
\text { calculated from mobility data reported in } \\
\text { Table 1, p. 103. }\end{array}$ \\
\hline
\end{tabular}


Table 7.2-1. Compilation of Diffusion Coefficients for Yttrium, Technetium, Molecular lodine, and Lanthanide and Actinide Species (Continued)

\begin{tabular}{|c|c|c|c|}
\hline Species & $D^{*}, \mathrm{~cm}^{2} \mathrm{~s}^{-1}$ & Comments & Reference \\
\hline $\mathrm{Gd}^{3+}$ & $5.24 \times 10^{-6}$ & $\begin{array}{l}25^{\circ} \mathrm{C} ; 0.1 \mathrm{M} \mathrm{NaClO}_{4} \\
u=6.12 \mathrm{~cm}^{2} \mathrm{~s}^{-1} \mathrm{~V}^{-1}\end{array}$ & $\begin{array}{l}\text { Rosch and Khalkin } 1990 \text { [DIRS 138739]; } \\
\text { calculated from mobility data reported in } \\
\text { Table 1, p. 103. }\end{array}$ \\
\hline $\mathrm{Tb}^{3+}$ & $5.01 \times 10^{-6}$ & $\begin{array}{l}25^{\circ} \mathrm{C} ; 0.1 \mathrm{M} \mathrm{NaClO}_{4} \\
u=5.85 \mathrm{~cm}^{2} \mathrm{~s}^{-1} \mathrm{~V}^{-1}\end{array}$ & $\begin{array}{l}\text { Rosch and Khalkin } 1990 \text { [DIRS 138739]; } \\
\text { calculated from mobility data reported in } \\
\text { Table 1, p. 103. }\end{array}$ \\
\hline $\mathrm{Tm}^{3+}$ & $5.10 \times 10^{-6}$ & $\begin{array}{l}25^{\circ} \mathrm{C} ; 0.1 \mathrm{M} \mathrm{NaClO}_{4} \\
u=5.96 \mathrm{~cm}^{2} \mathrm{~s}^{-1} \mathrm{~V}^{-1}\end{array}$ & $\begin{array}{l}\text { Rosch and Khalkin } 1990 \text { [DIRS 138739], } \\
\text { calculated from mobility data reported in } \\
\text { Table 1; p. 103. }\end{array}$ \\
\hline $\mathrm{Yb}^{3+}$ & $5.23 \times 10^{-6}$ & $\begin{array}{l}25^{\circ} \mathrm{C} ; 0.1 \mathrm{M} \mathrm{NaClO}_{4} \\
u=6.11 \mathrm{~cm}^{2} \mathrm{~s}^{-1} \mathrm{~V}^{-1}\end{array}$ & $\begin{array}{l}\text { Rosch and Khalkin } 1990 \text { [DIRS 138739], } \\
\text { calculated from mobility data reported in } \\
\text { Table 1; p. 103. }{ }^{a}\end{array}$ \\
\hline $\mathrm{Lu}^{3+}$ & $5.01 \times 10^{-6}$ & $\begin{array}{l}25^{\circ} \mathrm{C} ; 0.1 \mathrm{M} \mathrm{NaClO}_{4} \\
u=5.85 \mathrm{~cm}^{2} \mathrm{~s}^{-1} \mathrm{~V}^{-1}\end{array}$ & $\begin{array}{l}\text { Rosch and Khalkin } 1990 \text { [DIRS 138739], } \\
\text { calculated from mobility data reported in } \\
\text { Table 1; p. 103. }\end{array}$ \\
\hline $\mathrm{UO}_{2}\left(\mathrm{CO}_{3}\right)_{3}{ }^{4-}$ & $3.6 \times 10^{-6}$ & $1 \mathrm{M}$ total carbonate, $22^{\circ} \mathrm{C}$ & Perry et al. 1988 [DIRS 138732], p. 302. \\
\hline $\mathrm{UO}_{2}\left(\mathrm{CO}_{3}\right)_{3}{ }^{4-}$ & $3.0 \pm 0.7 \times 10^{-6}$ & $\begin{array}{l}0.2 \mathrm{M} \text { total carbonate, } \mathrm{pH} 9.8, \\
25^{\circ} \mathrm{C}\end{array}$ & Perry et al. 1988 [DIRS 138732], p. 302. \\
\hline $\mathrm{UO}_{2}\left(\mathrm{CO}_{3}\right)_{3}{ }^{5-}$ & $3.81 \pm 0.26 \times 10^{-6}$ & $\begin{array}{l}0.75 \mathrm{M} \mathrm{Na}_{2} \mathrm{CO}_{3}, 0.6 \mathrm{M} \mathrm{NaClO}_{4} \\
\text { pH 11.5, presumably at } 25^{\circ} \mathrm{C}\end{array}$ & Haltier et al. 1990 [DIRS 138643], p. 110. \\
\hline $\mathrm{UO}_{2}^{++}$ & $6.8 \times 10^{-6}$ & $25^{\circ} \mathrm{C}$ & $\begin{array}{l}\text { Millard and Hedges } 1996 \text { [DIRS 138677], } \\
\text { p. } 2141 .\end{array}$ \\
\hline $\mathrm{UO}_{2}$-carbonate & $1.9 \times 10^{-6}$ & $\begin{array}{l}\text { Calculated using Stokes- } \\
\text { Einstein with a radius of } \\
8 \AA \text { at } 10^{\circ} \mathrm{C}\end{array}$ & $\begin{array}{l}\text { Millard and Hedges } 1996 \text { [DIRS 138677], } \\
\text { p. } 2141 .\end{array}$ \\
\hline $\mathrm{Np}(\mathrm{V})$-carbonate & $7 \times 10^{-6}$ & $\begin{array}{l}\text { Calculated using Stokes- } \\
\text { Einstein with a radius of } \\
3.4 \AA \text { at } 25^{\circ} \mathrm{C}\end{array}$ & $\begin{array}{l}\text { Tsukamoto et al. } 1994 \text { [DIRS 138747]; } p . \\
469 .\end{array}$ \\
\hline $\mathrm{Am}^{3+}$ & $5.78 \times 10^{-6}$ & $\begin{array}{l}25^{\circ} \mathrm{C} ; 0.1 \mathrm{M} \mathrm{NaClO}_{4} \\
u=6.75 \mathrm{~cm}^{2} \mathrm{~s}^{-1} \mathrm{~V}^{-1}\end{array}$ & $\begin{array}{l}\text { Rosch and Khalkin } 1990 \text { [DIRS 138739]; } \\
\text { calculated from mobility data reported in } \\
\text { Table 1; p. 103. }\end{array}$ \\
\hline $\mathrm{Am}^{3+}$ & $5.95 \pm 0.06 \times 10^{-6}$ & $25^{\circ} \mathrm{C}$, in $0.0002 \mathrm{M} \mathrm{Nd}\left(\mathrm{ClO}_{4}\right)_{3}$ & $\begin{array}{l}\text { Mills and Lobo } 1989 \text { [DIRS 138725]; } \\
\text { p. } 131 .\end{array}$ \\
\hline $\mathrm{Cf}^{3+}$ & $4.39 \times 10^{-6}$ & $\begin{array}{l}25^{\circ} \mathrm{C} ; 0.1 \mathrm{M} \mathrm{NaClO}_{4} \\
u=5.13 \mathrm{~cm}^{2} \mathrm{~s}^{-1} \mathrm{~V}^{-1}\end{array}$ & $\begin{array}{l}\text { Rosch and Khalkin } 1990 \text { [DIRS 138739]; } \\
\text { calculated from mobility data reported in } \\
\text { Table 1; p. 103. }^{\text {a }}\end{array}$ \\
\hline $\mathrm{Cf}^{3+}$ & $5.50 \pm 0.06 \times 10^{-6}$ & $25^{\circ} \mathrm{C}$, in $0.0002 \mathrm{M} \mathrm{Nd}\left(\mathrm{ClO}_{4}\right)_{3}$ & $\begin{array}{l}\text { Mills and Lobo } 1989 \text { [DIRS 138725]; } \\
\text { p. } 132 .\end{array}$ \\
\hline $\mathrm{Es}^{3+}$ & $5.50 \pm 0.06 \times 10^{-6}$ & $25^{\circ} \mathrm{C}$, in $0.0002 \mathrm{M} \mathrm{Nd}\left(\mathrm{ClO}_{4}\right)_{3}$ & $\begin{array}{l}\text { Mills and Lobo } 1989 \text { [DIRS 138725]; } \\
\text { p. } 132 .\end{array}$ \\
\hline
\end{tabular}

${ }^{a}$ Calculation of diffusion coefficients from reported ionic mobilities (Rosch and Khalkin 1990 [DIRS 138739]; Table 1). The mobilities $(u)$ were measured in $0.1 \mathrm{M} \mathrm{NaClO} 4$ at various $\mathrm{pHs}$ (below the $\mathrm{pH}$ of hydrolysis) and were slightly larger at $\mathrm{pHs}$ greater than 5 , and these are the data that were used for the calculation. The equation used to calculate the diffusion coefficient is: $D^{*}=(k T /(|z| e)) u$, where $k$ is Boltzmann constant $\left(\mathrm{J} \mathrm{K}^{-1}\right), T$ is the temperature $(K), z$ is the valence of the ion, $e$ is the elementary charge $(C)$, and $u$ is the mobility $\left(\mathrm{cm}^{2} \mathrm{~s}^{-1} \mathrm{~V}^{-1}\right)$ (Atkins 1990 [DIRS 111464], Box 25.1, Einstein relation, p. 765). 


\subsubsection{Modification for Porosity and Saturation}

Validation of the dependence of invert diffusion coefficient on porosity and saturation is provided by comparison with measured data obtained independently of the data used for model development. Data used for validation are obtained from diffusivity measurements for crushed tuff using electrical conductivity measurements (CRWMS M\&O 2000 [DIRS 156680]) and from direct measurements of diffusivity between machined cubes of tuff (Hu et al. 2001 [DIRS 161623]).

Conca and Wright (1992 [DIRS 100436]) and Conca et al. (1993 [DIRS 170709]) obtained diffusion coefficients from electrical conductivity measurements for various granular materials, including tuff, with volumetric moisture content ranging from 0.5 percent to 66.3 percent. A statistical fit of the data (Conca and Wright 1992 [DIRS 100436], Figure 2; Conca et al. 1993 [DIRS 170709], Figure 2; listed in Table 4.1-17) ranging from 1.5 percent to 66.3 percent volumetric moisture content, based on Archie's law, results in the model used in TSPA-LA (Section 6.3.4.1.1 and Appendix G):

$$
\begin{aligned}
\theta D_{I} & =D_{0} \phi^{1.863} S_{w}^{1.863} 10^{N D(\mu=0.033, \sigma=0.218)} \\
& =D_{0} \theta^{1.863} 10^{N D(\mu=0.033, \sigma=0.218)}
\end{aligned}
$$

where $\theta=\phi S_{w}$ is the volumetric moisture content (fraction: $\mathrm{m}^{3}$ water $\mathrm{m}^{-3}$ rock), and $N D$ represents a normal distribution with a mean, $\mu$, of 0.033 and a standard deviation, $\sigma$, of 0.218 . The object of this validation is to show that the diffusion coefficient given by Equation 7.2.2.2-1 obtained from the electrical conductivity measurements of Conca and Wright (1992 [DIRS 100436]) and Conca et al. (1993 [DIRS 170709]) tends to overestimate the diffusivity of invert materials.

The diffusion coefficient has also been determined specifically for tuff, also using electrical conductivity measurements (CRWMS M\&O 2000 [DIRS 156680], Tables A-1 and A-2). These data are listed in Table 7.2-2 and are plotted in Figure 7.2-3, along with the mean value and plus and minus three standard deviations from Equation 7.2.2.2-1. This plot shows that the fit to the measured diffusion coefficient data (Equation 7.2.2.2-1) overestimates the diffusion coefficient relative to The Determination of Diffusion Coefficient of Invert Materials (CRWMS M\&O 2000 [DIRS 156680], Tables A-1 and A-2). This plot was created using Microsoft Excel; see Appendix G, Worksheet: Validation, p. VII-10.

The electrical conductivity measurements by Conca and Wright (1992 [DIRS 100436]) and Conca et al. (1993 [DIRS 170709]) use conductivity as an analog for diffusivity. While the analog is known to be valid in fully saturated media, its application to unsaturated media, particularly at low moisture contents, is questionable due to the difficulty in preparing samples and in making reliable electrical contact between the electrical leads and the samples. To avoid these problems, Hu et al. (2001 [DIRS 161623]) measured diffusive tracer concentrations in tuff cubes directly using laser ablation coupled with inductively coupled plasma-mass spectrometry (LA-ICP-MS), rather than relying on electrical analogs. 


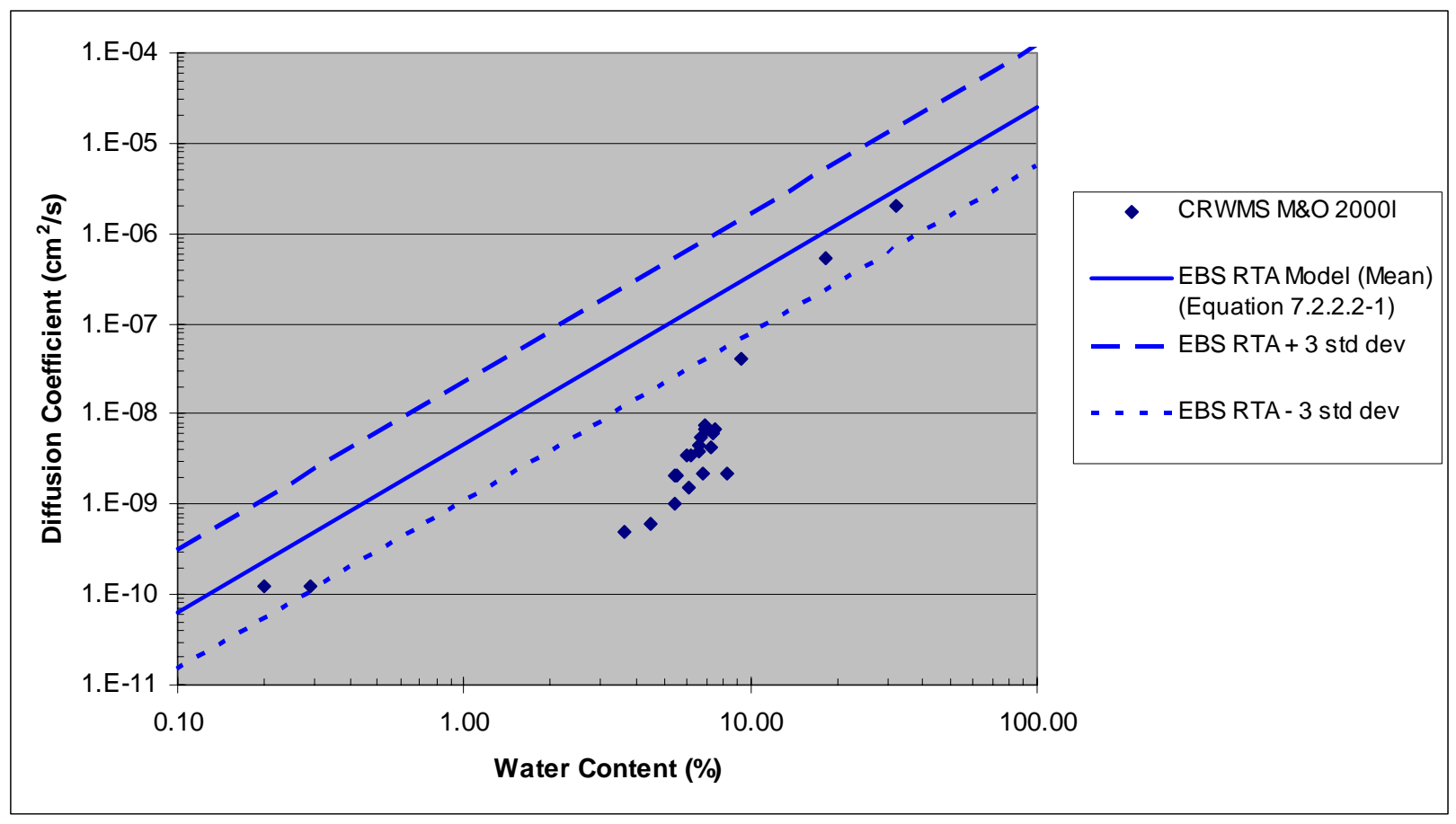

Source: CRWMS M\&O 2000 [DIRS 156680].

Figure 7.2-3. Comparison of EBS Radionuclide Transport Abstraction Invert Diffusion Submodel (Equation 7.2.2.2-1) with Measured Diffusion Coefficients for Tuff

Table 7.2-2. Diffusion Coefficient of Crushed Tuff Invert Materials

\begin{tabular}{|c|c|c|}
\hline Sample & $\begin{array}{c}\text { Volumetric Moisture } \\
\text { Content (\%) }\end{array}$ & $\begin{array}{c}\text { Diffusion Coefficient } \\
\left(\mathbf{c m}^{\mathbf{2}} \mathbf{~ s}^{\mathbf{1}} \text { ) }\right.\end{array}$ \\
\hline 1 & 32.13 & $2.02 \times 10^{-6}$ \\
\hline 2 & 18.15 & $5.40 \times 10^{-7}$ \\
\hline 3 & 9.26 & $4.05 \times 10^{-8}$ \\
\hline 4 & 7.03 & $6.75 \times 10^{-9}$ \\
\hline 5 & 6.97 & $7.45 \times 10^{-9}$ \\
\hline 6 & 6.89 & $6.73 \times 10^{-9}$ \\
\hline 7 & 6.75 & $5.42 \times 10^{-9}$ \\
\hline 8 & 6.63 & $4.39 \times 10^{-9}$ \\
\hline 9 & 6.63 & $3.76 \times 10^{-9}$ \\
\hline 10 & 6.23 & $3.40 \times 10^{-9}$ \\
\hline 11 & 6.00 & $3.43 \times 10^{-9}$ \\
\hline 12 & 5.55 & $2.04 \times 10^{-9}$ \\
\hline 13 & 5.46 & $2.04 \times 10^{-9}$ \\
\hline 14 & 8.29 & $2.24 \times 10^{-9}$ \\
\hline
\end{tabular}


Table 7.2-2. Diffusion Coefficient of Crushed Tuff Invert Materials (Continued)

\begin{tabular}{|c|c|c|}
\hline Sample & $\begin{array}{c}\text { Volumetric Moisture } \\
\text { Content (\%) }\end{array}$ & $\begin{array}{c}\text { Diffusion Coefficient } \\
\left(\mathbf{c m}^{\mathbf{2}} \mathbf{~ s}^{\mathbf{1}} \mathbf{)}\right.\end{array}$ \\
\hline 15 & 7.54 & $6.81 \times 10^{-9}$ \\
\hline 16 & 7.36 & $6.21 \times 10^{-9}$ \\
\hline 17 & 7.22 & $4.38 \times 10^{-9}$ \\
\hline 18 & 6.84 & $2.19 \times 10^{-9}$ \\
\hline 19 & 6.11 & $1.55 \times 10^{-9}$ \\
\hline 20 & 5.41 & $9.97 \times 10^{-10}$ \\
\hline 21 & 4.45 & $6.19 \times 10^{-10}$ \\
\hline 22 & 3.64 & $5.00 \times 10^{-10}$ \\
\hline 23 & 0.29 & $1.24 \times 10^{-10}$ \\
\hline 24 & 0.20 & $1.25 \times 10^{-10}$ \\
\hline
\end{tabular}

Source: CRWMS M\&O 2000 [DIRS 156680], Tables A-1 and A-2.

LA-ICP-MS has recently evolved as a powerful analytical tool for solid samples (Russo et al. 2000 [DIRS 155697]). It can simultaneously determine a large number of chemical elements with low detection limits. Laser ablation uses an intense burst of energy delivered by a short laser pulse to vaporize a minute sample (in the range of nanograms) from a small area. Several spot sizes can be selected (from $25 \mu \mathrm{m}$ to $200 \mu \mathrm{m}$ in diameter), allowing a choice of appropriate spot size for different applications. A smaller spot size will sample less solid material, leading to lower analytical precision, but allowing more heterogeneity to be observed. A single laser pulse reveals surface compositions, while multiple pulses allows compositions to measured at various depths below the surface, with the crater depth proportional to the number of laser pulses applied. For example, two pulses reach about $4 \mu \mathrm{m}$ into the tuff matrix (Hu et al. 2001 [DIRS 161623], p. 22), and 50 pulses ablates to a depth of about $35 \mu \mathrm{m}$ (Hu et al. 2001 [DIRS 161623], Figure 6).

In the approach of $\mathrm{Hu}$ et al. (2001 [DIRS 161623]), a machined 1.5-cm tuff cube containing a tracer was placed in contact with a cube not containing the tracer, both under the same thermodynamic conditions. The tracer is allowed to diffuse from the tracer-containing cube to the other. Tracers were chosen based on their chemical similarity to radionuclides of interest. The source cube was vacuum-saturated with a tracer solution mixture of $\mathrm{NaBr}, \mathrm{NaReO}_{4}, \mathrm{CsBr}$, and $\mathrm{RbBr}$; both $\mathrm{Br}^{-}$and perrhenate $\left(\mathrm{ReO}_{4}{ }^{-}\right)$act as nonsorbing tracers. The sink cube was also vacuum-saturated, but had no tracers. Source and sink cubes were separately placed inside a humidity chamber within an incubator maintained at $22^{\circ} \mathrm{C}$ until the cubes equilibrated to a constant weight (13 days). The cubes were then clamped together in the relative humidity $(R H)$ chamber to start the diffusion test. After 87 days, the diffusion test was stopped by separating the source and sink cubes. The surface and depth distribution of the tracer was then mapped using LA-ICP-MS. The mapping was done on the interface, the far side face (opposite side from the interface), and along the side perpendicular to the interface.

Measurements along the outside surface of the sink cube indicated that a nonsorbing tracer $\left(\mathrm{ReO}_{4}{ }^{-}\right)$diffused along the surface at a rate similar to its aqueous diffusion rate in bulk water (Hu et al. 2001 [DIRS 161623], pp. 21 and 22). This result was reasonable because the tuff cubes were located in the high-RH chamber, with the likely presence on the outside of the cube 
of a thick water film that behaves like bulk water. These measurements provided a bounding value for the diffusivity of the tracer, comparable to the diffusion coefficient of $1.48 \times 10^{-5} \mathrm{~cm}^{2} \mathrm{~s}^{-1}$ (Table 7.2-1) for its analog, $\mathrm{TcO}_{4}^{-}$. In other words, in regions on the tuff samples that were saturated or at least had high water saturation, the direct diffusivity measurements agreed with theoretical predictions.

$\mathrm{Hu}$ et al. also measured tracer concentrations at greater depths into the cube by using the laser ablation technique to probe into the surface. They found that internal diffusion coefficients, at depths of 60-410 $\mu \mathrm{m}$, were on the order of $10^{-12} \mathrm{~cm}^{2} \mathrm{~s}^{-1}$ (Hu et al. 2001 [DIRS 161623], p. 22). The measured volumetric water content of the tuff matrix was 8.9 percent (Hu et al. 2001 [DIRS 161623], p. 25). The mean diffusion coefficient predicted by the invert diffusion properties submodel (Equation 7.2.2.2-1) would then be $2.6 \times 10^{-7} \mathrm{~cm}^{2} \mathrm{~s}^{-1}$. This is a factor of $10^{5}$ larger than the measurement. Thus, the diffusion coefficient throughout most of a grain of crushed tuff is lower than that predicted by the invert diffusion properties submodel. This provides corroborating evidence that the invert diffusion properties submodel overestimates releases of radionuclides from the EBS. These data also show that the overestimation of diffusivities in the invert diffusion properties submodel may be excessive. However, insufficient data exist to reduce the uncertainty in this model, and, if this additional uncertainty were included in the invert diffusion submodel, estimated releases of radionuclides from the EBS would be reduced and no longer be bounding. Because the model has a low impact on repository performance, the degree of uncertainty in this model is acceptable for TSPA-LA.

The study by Hu et al. (2001 [DIRS 161623]) was primarily a development of the technique for using LA-ICP-MS of microscale profiling of the distribution of diffusing tracers. However, in the process, some preliminary data were obtained that can be used to corroborate the electrical conductivity measurements of Conca and Wright (1992 [DIRS 100436]) and Conca et al. (1993 [DIRS 170709]).

Sections 7.2.1 and 7.2.2 have demonstrated that the component models of the EBS transport model meet Level II validation. Based on the validation results, the EBS transport model is adequate for its intended use.

\subsubsection{Results of Independent Model Validation Technical Review of the EBS Flow and Transport Models}

An independent model validation technical review of the EBS flow and transport models was conducted, as specified in the TWP (BSC 2005 [DIRS 173617], Section 2.2.3). This model validation approach is justified based on requirements of LP-SIII.10Q-BSC, Section 5.3.2c), where independent technical review is listed as an appropriate method for model validation. The results of the independent model validation technical review of the EBS flow and transport models are presented in a memo, a facsimile of which follows. 

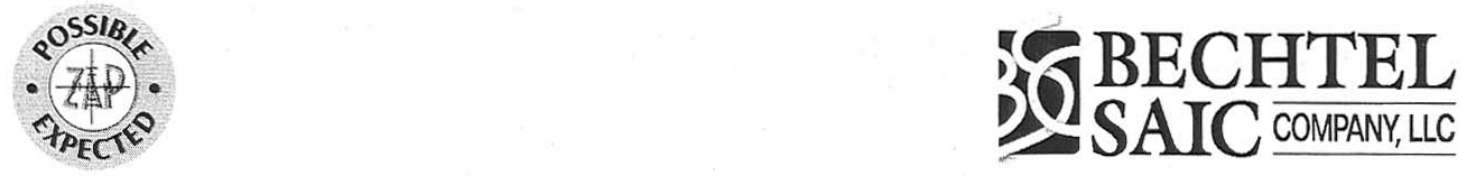

\section{Interoffice Memorandum}

QA: QA

To: James D. Schreiber, Ernest Hardin

Re: Independent Model Validation Review of ANL-WIS-PA-000001 Rev 2
No.: $\quad 0801056250$

Date: 16 Aug 05

CC: $\quad$ W. J. Duffy, E. F. Loros, Roberta

Stambaugh

This IOM was included in draft form in the 2.14 review of the subject AMR. It was finalized prior to final checking.

I have completed the independent model validation review of the "Engineered Barrier System Radionuclide Transport Abstraction" AMR, ANL-WIS-PA-000001 Rev 2.

This review was conducted in accordance with "Technical Work Plan for: Near-Field Environment and Transport: Engineered Barrier System: Radionuclide Transport Abstraction Model Report Integration", TWP-MGR-PA-000020 Rev 1.

\section{REVIEWER QUALIFICATIONS:}

I have met the qualification requirements to do this review, as established by Section 2.2 .4 of the cited TWP, as follows:

- "Reviewer shall not have contributed to the development of model assumptions, parameters, or implementing algorithms." I was not on the author team and have not had a management relationship with that team for the past three years.

- "Reviewer shall have an appropriate technical background (i.e., advanced degree in an appropriate technical field) and demonstrated expertise in fluid flow and transport of radionuclides in porous media." I have a B.S. in Engineering Science from the University of Nevada, Reno; an M.S. in Nuclear Engineering from the Georgia Institute of Technology, and a Ph.D. in Engineering from the University of California - Davis. In addition to a variety of courses in physics and engineering that are pertinent to this subject, my nuclear engineering coursework included formal training in neutron transport, which uses the same mathematical methods as this AMR. Further, I have over 33 years of engineering experience in the U.S. Army and at Lawrence Livermore National Laboratory. That experience includes over 15 years of experience on the Yucca Mountain Project in a variety of technical areas, including the Engineered Barrier System and Design Basis 
0801056250

Page 2

Models. My education and experience are included in records submitted to the Record Information System by Lawrence Livermore National Laboratory.

\section{REVIEW REQUIREMENTS:}

The TWP requires me, as the independent model validation technical reviewer, to do the following:

- "Review the validation criteria in this TWP." I have reviewed those criteria, which are listed below.

- "Review relevant sections of the RTA report and meet with the document author and representatives from TSPA organization in order to obtain a full understanding of the model(s) and TSPA implementation." I have read the entire report in detail, with the exception of the spreadsheet details listed in Appendices A, C, D, E, F, and G. I have had a number of discussions with the author (J. Schreiber) and the TSPA Analyst (S. Mehta). The author was also an appropriate TSPA-implementation point of contact for this AMR because the implementation was controlled using one or more Parameter Entry Forms accepted by the author, the TSPA implementing analyst and the TSPA Inputs Manager.

- "Assess whether or not the model(s) as documented in the RTA report meet the validation criteria." My assessment is documented below in this memorandum.

- "Assess whether or not the model(s) are adequate for their intended use, meet with the author to resolve comments, and recommend actions, as appropriate, to resolve any inadequacies found as part of the review." My assessment is documented below in this memorandum.

- "Document this review process as a memo to be included in the records package for the RTA report." My review is documented in this memorandum.

\section{REVIEW CRITERIA:}

The TWP specifies the following validation criteria for the EBS Flow Model and the EBS Transport Model: "Criteria ... are as follows. Each shall be confirmed by the independent model validation technical reviewer."

- "The approach and algorithms described in the document and provided to TSPA capture all known flow pathways into and from the EBS components." [Flow Model]

- "The approach and algorithms described in the document and provided to TSPA address all known modes of radionuclide transport within and from the EBS components." [Transport Model]

- "Modeling assumptions are clearly defined, discussed, and justified as appropriate for the intended use of the model." [Both models] 
0801056250

Page 3

- "Uncertainties in parameters, processes, and assumptions are sufficiently described, and impacts of these uncertainties discussed." [Both models]

- "The overall technical credibility of the approach, including assumptions, parameters, equations, and the TSPA implementation, are sufficient for the model's intended use." [Both models]

The TWP also includes a separate criterion for the EBS-UZ Interface Model, which was reviewed by another reviewer in Revision 01 of the AMR. I have read the memorandum of that review which was included in the draft of Revision 02, and concur with it. In addition, my review of the Flow Model includes its lower boundary condition, which is described as the EBS-UZ Interface Model in the AMR and TWP.

\section{CONCEPTUAL MODEL:}

Based on the discussion below, I conclude that the conceptual models for EBS Flow, EBS Transport, and the EBS-UZ Interface are technically credible, are appropriate for their intended TSPA use, and that they capture the known flow pathways and transport modes.

Sections 6.1.2 and 6.7.1 state that this AMR applies only to the nominal scenario class, and it cites igneous and seismic AMRs to be used for the igneous and seismic scenario classes. It then discusses how those AMRs calculate EBS Flow and Transport, as follows: The igneous eruption modeling case results in waste being moved by the event to the mountain surface, making the EBS flow and transport models non-relevant. The igneous intrusion modeling case destroys the drip shield and waste packages in the affected repository area and makes the radionuclides available for transport into the UZ as calculated by the cited Dike/Drift Interactions AMR. The (lowprobability) seismic scenario class also has two modeling cases: mechanical damage failure of waste packages and later failure of waste packages due to corrosion (primarily stress corrosion cracking due to seismically-induced stresses). Section 6.1.2 cites the Seismic Consequence Abstraction AMR and the Characterize Framework for Seismicity and Structural Deformation at Yucca Mountain, Nevada AMRs for these modeling cases. Section 6.5.3.1.1.2 discusses the WP breach area and its influence on the flow model for each scenario class and modeling case:

- Nominal scenario class with no early failures modeling case: The breach area comes from the cited WAPDEG Analysis of Waste Package and Drip Shield Degradation AMR. However, Section 7.1.1 notes that no waste packages fail due to general corrosion within 10,000 years. Beyond 10,000 yr, if the TSPA-LA model were to be extended, the drip shield general corrosion is modeled as a single patch, and the EBS Flow model would then become dripping from the drift crown onto the waste package crown

- Nominal scenario class early failure modeling case: The entire waste package surface area is breached (WAPDEG Analysis of Waste Package and Drip Shield Degradation AMR), 
0801056250

Page 4

and conservatively unfolds onto the invert for diffusive transport calculation purposes. However, Section 7.1.1 notes that no drip shields fail within 10,000 years and hence the waste package breach area receives no seepage flux that can drive advection.

- Igneous intrusion modeling case: The entire waste package area is breached and there is no cladding protection. Transport begins at the top of the invert.

- Seismic ground motion modeling case: The cited Seismic Consequence Abstraction AMR calculates the breach area, and transport is sequentially through the waste package plan area (diameter times length) and then the breached area of the outer shell.

- Seismic localized corrosion modeling case: The breach area is calculated by the cited AMR (General Corrosion and Localized Corrosion of Waste Package Outer Barrier). The drip shield also is breached by stress corrosion cracking. However, the drip shield cracks are too small to support advective flux and no seepage is received by the waste package breaches.

The conceptual models for EBS Flow, EBS Transport, and the EBS/UZ Interface are discussed in Sections 1, 6.3, 6.5, and 7, and Appendix B. Section 8.1 (in the Conclusions chapter) provides a succinct summary of the conceptual models. These models are briefly summarized below, including notation of conservatism used to simplify the models.

The Flow Model is based on conservation of mass for the TSPA nominal scenario class. Three potential sources of moisture to the EBS (which is defined by the perimeter of the excavated emplacement drifts) were identified (seepage, condensation, and flow from the rock to the invert). One significant sink for water leaving the emplacement drifts was identified (flow into the UZ). The minor sink by evaporation and movement of vapor from the EBS into the rock or longitudinally into the mains was conservatively neglected.

Within the EBS, the movement of water is calculated along potential pathways. The analysis included diversion by the drip shield and flow through breaches in the drip shield. Condensation under the drip shield was excluded as a FEP in the EBS FEP AMR. Water moving through the breaches in the drip shield could be diverted by the waste package or enter the waste package through breaches. The invert receives water from these three sources (drip shield diversion, waste package diversion, and flow through waste package), as well as receiving water from the UZ.

Conservatism is used in the EBS Flow model as follows:

- All seepage (and in-drift condensation) is assumed to be from the crown (with the largest probability of reaching breaches). Dripping outboard of the drip shield and film flow down the drift wall are conservatively ignored (their flux is part of the conservatively consolidated crown seepage).

- All flow through the drip shield breaches is assumed to drip on the waste package crown. Dripping outboard of the waste package and film flow down the underside of the drip 
0801056250

Page 5

shield are conservatively ignored (their flux is part of the conservatively consolidated dripping on the waste package crown).

- All flow into the waste package is assumed to contact the waste form and then move through the corrosion products to an exit breach from the waste package

- No seepage liquid evaporates after it enters the drift

- The exit breach from the waste package is assumed to be in direct contact with the invert

- Flow through the invert is assumed to be through the tuff ballast, with the oxidized steel components not being contacted; this reduces the sorption in the invert

The neglect of condensation on the underside of the drip shield is non-conservative, but the AMR states in Sections 6.3.3.2, 6.3.3.3 and 6.7.1 that a cited FEP AMR justifies its neglect based on low consequence.

The EBS Transport conceptual model includes all the significant processes that contribute either positively or negatively to radionuclide transport. These are advective transport in solution, diffusive transport in solution, reversible and irreversible sorption on immobile solids, reversible and irreversible sorption on colloids, and both advective and diffusive movement of colloids. The implemented numerical model conservatively neglects reversible sorption on immobile solids.

Conservatism is used in the EBS Transport model as follows:

- Lateral and longitudinal dispersion are neglected (Section 6.3.1.2) which results in somewhat more focused transport than the real situation. However, the effect is justified as being small because the EBS is such a small part of the overall transport path.

- Advective flux into the UZ just below the invert is the greater of the steady state UZ flux and $\mathrm{F}_{8}$. At locations with flow focusing, the (higher) focused flow will be used for transport calculation, and at locations with flow defocusing, the steady state (no flow defocusing) value will be used. The overall result is more flow from the EBS into the UZ than enters the EBS from the UZ, which will conservatively increase radionuclide release from the EBS.

- Reversible sorption of radionuclides onto stationary corrosion products is neglected (Sections 1, 6.3.4.2.3, 6.5.1.2, and Appendix B).

- Physical filtering and gravitational settling of colloids during transport is neglected (Section 6.5.1.2).

- For waste packages with early failures, the diffusion cross sectional area between the corrosion products domain and the invert domain is the entire waste package surface area.

- No sorption on oxidized iron components of the invert is calculated.

- A continuous path of water film is assumed within the waste package and invert when the temperature is below $100^{\circ} \mathrm{C}$, allowing diffusion from shortly after the waste package breaches.

- Reduction in diffusion effectiveness due to discontinuous intergranular films at low humidity in the invert is not included in the model. 
0801056250

Page 6

The EBS/UZ Interface model has two key features. The first is that the location of zeroconcentration sink is significantly (about three drift diameters) below the bottom of the invert and extends laterally one drift diameter on each side (the domain of the interface model is three drift diameters wide and about three high). Second, the invert is a single (equivalent) continuum that couples to the dual fracture-matrix continuum of the UZ. Diffusion from the invert independently enters both UZ continua below the drift and can also diffuse, in the UZ, both between continua and laterally. Advective flux in the invert has two distinct sources, seepage from above (including the flux which transits a breached waste package) and percolation from the drift wall. The percolation flux into the invert exits the invert into the UZ matrix, and the seepage flux into the invert exits the invert into the $\mathrm{UZ}$ fractures.

The EBS/UZ Interface model uses the same properties as the UZ transport model and results in a radionuclide flux into the $\mathrm{UZ}$ at the bottom of the invert. That flux is the time-dependent boundary condition for the $\mathrm{UZ}$ transport model.

The EBS/UZ Interface model conservatively ignores the drift shadow effect, in which advective fluxes below the drift are expected to be less than those in the pillars between the drifts.

\section{NUMERICAL MODEL:}

Based on the discussion below, I conclude that the numerical implementation of the conceptual models for EBS Flow, EBS Transport, and the EBS-UZ Interface are technically credible, are appropriate for their intended TSPA use, and that they capture the known flow pathways and transport modes.

The conceptual models for EBS Flow, EBS Transport, and the EBS/UZ Interface are implemented in numerical models. Because these models will be run as part of the TSPA-LA runs (using TSPA software), the EBS Radionuclide Transport Abstraction AMRs develops the equations and the input parameters for those equations, and provides them to TSPA. The numerical implementation to be used by TSPA is discussed in Sections 6.5.1 and 6.5.3.

The development of the equations of flow through breaches in the waste package and drip shield in Section 6.5.1.1 is rigorous and clear. The development of the transport equations in Section 6.5.1.2 is extremely thorough and easy to follow. The derivation is supplemented by additional equation development in Appendix B, to produce models that were used to verify the accuracy of the base case derivation; readers seeking additional explanation of the development in Section 6.5.1.2 can find that information in Appendix B. Section 6.5.3 is a step-by-step prescription for implanting the numerical model in TSPA. Equation B-72 is also directly used by TSPA, using input parameters from controlled sources or calculated within the TSPA model. 
0801056250

Page 7

Dimensional units are provided throughout the AMR for each symbol in each equation, and Section 6.5.1.3 is a comprehensive listing of the symbols used throughout the report. The authors did an excellent job of remaining consistent in their choice of symbols, and they avoided reader confusion by not reusing symbols to represent different quantities in different sections of the AMR.

Section 8.2 (in the Conclusions chapter) includes a succinct summary of the equations to be implemented in TSPA.

\section{PARAMETERS USED IN NUMERICAL MODEL:}

Based on the discussion below, I conclude that the numerical parameters developed for the numerical models for EBS Flow, EBS Transport, and the EBS-UZ Interface are technically credible and are appropriate for their intended TSPA use.

Section 6.5.2 provides an overview of the parameters to be used in the models, and the parameters are listed in Section 8.2 (in the Conclusions chapter).

The EBS Flow model parameters are based on experimental data that are analyzed in the AMR (Sections 6.5.1.1.2 and 7.1.1, and Appendices C, D, and E). The diffusion coefficient data are developed in Sections 6.3.4.1, 6.3.4.3, 6.5.2.1, and 6.5.2.4, and in Appendices $G$ and $H$. The sorption parameters for the EBS Transport model are discussed in Sections 6.3.4.2, 6.5.2.3, and 6.5.3.2, through 6.5.3.4, and Appendix J.

The carbon steel corrosion rates used in developing the characteristics of the corrosion products domain are taken from $1 \mathrm{yr}$ data, and are applied as if the corrosion of the stainless steel inner vessel or the waste package internal components is from one side only. Carbon steel corrosion rates are known to decrease until an equilibrium oxide thickness is reached (signifying a nominal equilibrium between periodic flaking of oxide and additional oxide layer formation at the interface with the base metal. The equilibrium oxide thickness depends on a number of difficult-to-quantify parameters, including the stress state of the component and the frequency and intensity of seismic events. It is possible that the overall average corrosion rate for the time to completely corrode the carbon steel components is lower than that used in this AMR. The influence of a lower corrosion rate is the following:

- For failed cladding, the early release of iodine and technetium will be prior to significant carbon steel corrosion for both the AMR's corrosion rate or a lower corrosion rate. There will be a low amount of corroded surface area and hence a low volume of adsorbed water (which may or may not be sufficient to form a thin continuous film and thus may or may not lead to diffusion). There will then be a high concentration of the radionuclide source and rapid diffusion of these radionuclides (assuming the concentration gradient factor is 
0801056250

Page 8

more important than other diffusion factors, and that there is a continuous water film pathway for diffusion).

- For intact cladding, the failure time of the cladding will likely be much later than the corrosion time of the carbon steel, and there will be little effect on diffusion of fast-release of iodine and technetium.

- For failed cladding, the release of plutonium and americium will be slow because of the slow dissolution rate of the SNF matrix. The carbon steel corrosion rate will almost certainly be faster than the SNF matrix dissolution rate. Prior to full corrosion of the carbon steel, there are competing effects of different corrosion rates. Slower corrosion of the carbon steel leads to less surface area, less water volume, higher source concentrations, and faster diffusion (assuming the concentration factor is more important than other diffusion factors), just as for iodine and technetium. Slower corrosion of the carbon steel also leads to less irreversible sorption of the plutonium and americium, which results in less colloidal transport but also less removal onto the fixed corrosion products. Eventually, the carbon steel corrosion will be complete, and the remainder of the plutonium and americium releases will be unaffected by the prior corrosion rates.

- For TSPA, the effect will not be noticeable with respect to meeting the regulatory dose limits because of the small fraction of failed cladding and the small number of waste packages that fail during the 10,000-year TSPA calculation.

Transport requires a number of parameters in the following areas:

- The saturation in all three domains is $100 \%$, except for the CSNF Corrosion Product (CP) domain in regions of no seepage. The saturation is calculated from relative humidity for that situation, and the humidity is an input from another AMR.

- Release of radionuclides from the waste form into the aqueous phase is calculated based on input from other AMRs, including solubility and WF degradation rate. The concentration of the radionuclides in the Waste Form (WF) domain is based on the amount of water in that domain, which is calculated from on the CSNF rind volume and porosity, HLW rind volume and porosity, and $1 \mathrm{~m}^{3}$ of DSNF volume with porosity of $20 \%$ (all from other AMRs).

- WF colloids are generated in the WF domain, based on another AMR, and include embedded radionuclides.

- The water content of the $\mathrm{CP}$ domain is calculated as a function of time based on the corrosion of the iron-based materials (see above) and the resulting surface area (uniform distribution of $1.0-22 \mathrm{~m}^{2} / \mathrm{g}$ to account for uncertainty).

- FeOx colloids are generated in the CP domain based on another AMR. Groundwater colloids enter the transport model at the CP domain.

- Dissolved radionuclides advect from the WF domain to the CP domain based on aqueous concentration and on flow rate. For CDSP waste packages, the advection is sequentially from the HLW WF subdomain to the DSNF WF subdomain, and then to the CP domain. For CSNF waste packages, the advection is from the WF domain to the CP domain 
0801056250

Page 9

Dissolved radionuclides diffuse through the same pathways, based on concentrations, diffusion coefficients, path lengths, and diffusion areas. These parameters are provided in Section 8 of the AMR, with some being single valued and others being distributions.

- In the $\mathrm{CP}$ domain, radionuclides can irreversibly sorb onto stationary FeOx, can irreversibly and reversibly sorb onto FeOX and waste form colloids, and can reversibly sorb onto groundwater colloids. The reversible Kd values are taken from another AMR's DTN and are listed in Table 6.3-11, with smectite being representative of both waste form and groundwater colloids. Table 6.3-11 includes 100x reductions in the $\mathrm{Kds}$ for $\mathrm{Pu}$ and $\mathrm{Am}$ on $\mathrm{FeOx}$ to be compatible with the mechanistic sorption model in another AMR. The irreversible reaction rates are a range taken from another AMR's DTN for locations without seepage. In seepage locations, the flux-out ratio is sampled from 90 to $99 \%$ based on another AMR, and the irreversible reaction rate is calculated from an expression derived in this AMR, using parameters available in TSPA from this AMR or other AMRs. Eq. B72 in this AMR defines the parameters; those from this AMR are listed in Section 8.

- FeOx, WF, and groundwater colloids advect and diffuse from the CP domain to the Invert domain, with the colloid diffusion coefficient being 100x smaller than the aqueous diffusion coefficient.

- Dissolved radionuclides and WF and FeOx colloids advect and diffuse from the CP domain to the invert domain, with no credit taken for path length between the edge of the waste package breach and the top of the invert. Diffusion out of the corrosion products uses a sampled path length between the outer barrier thickness and the waste package radius, with the diffusion area depending on the scenario class and modeling case, as described under "conceptual model" above. The aqueous diffusion coefficient in the Invert domain is calculated (based on experimental data) from the water content and temperature (both obtained from another AMR), and includes a normal distribution for uncertainty that is truncated at \pm 3 standard deviations.

- The Invert domain is modeled as a rectangular cross section that is $1 \mathrm{WP}$ long. The cross section width is the same as the actual invert top surface, and the depth is that which preserves the overall volume of the invert. The small $(10 \mathrm{~cm})$ axial gap between waste packages does not contribute radionuclide transport in the invert, for this model.

- The invert is modeled as a single continuum with a thin interface zone at its lower surface. The interface zone is the starting point for diffusion and advection into the two continua of the UZ, which is assumed to be at zero concentration about three drift diameters below the invert.

- The near field of the UZ is modeled as three columns of cells, with each column being one drift diameter wide. (The middle column is as wide as the drift diameter, rather than the rectangular width of the invert domain, to facilitate linkage to the domain for the seepage flux.) Advective transport of the seepage plus condensation flux $\left(\mathrm{F}_{6}\right)$ in the invert moves into the fracture continuum of the middle column. Advective transport of the water that directly enters the invert from the $\mathrm{UZ}\left(\mathrm{F}_{7}\right)$ moves into the matrix continuum of the middle column. Diffusive transport from the invert interface zone moves radionuclides and 
0801056250

Page 10

colloids into both continua of the middle column. Within the three columns of four zones in the EBS/UZ boundary model domain, advection is calculated vertically in both continua, and diffusion is calculated between adjacent vertical and horizontal matrix zones and between matrix and fracture continua in each zone. All three columns of zones (in both continua) end in a single zero-concentration collector cell.

- The TSPA model calculates the transport through the coupled WF, CP, Invert, and UZ boundary domains to the collector cell in a self-consistent manner, using the parameters from this AMR and other AMRs. The resulting time-dependent radionuclide fluxes into the UZ from the invert interface zone are the starting point for the UZ transport model.

\section{ALTERNATIVE CONCEPTUAL AND NUMERICAL MODELS:}

The AMR includes a number of alternative conceptual models, for the purpose of evaluating whether the base model is adequate for TSPA. These models are well described and justify use of the base model in the TSPA.

The alternative models include the following:

- Treatment of the water flow through the waste package as a bathtub conceptual model rather than a steady state flow model. Variations of this alternative model include changing the inflow rate, changing the inflow chemistry, and changing the corrosion patch geometry (formation of a draining patch after the waste package "bathtub" fills).

- Limiting water vapor and oxygen diffusion rates into the waste package. These scoping calculations uses an atmospheric pressure at sea level; however, this inaccuracy does not affect the conclusion of the alternative model.

- Treating the invert as a dual continuum with intragranular and intergranular porosities.

- Single and dual continuum invert diffusion coefficients. The single continuum alternative diffusion coefficient was modeled as decreasing more rapidly than the base case as saturation decreases, at the dry end of the saturation spectrum.

- Reversible sorption onto corrosion products within the waste package.

- Slow desorption of irreversibly sorbed radionuclides.

\section{MODEL VALIDATION AND MODEL TESTING RESULTS IN THE AMR:}

Based on the discussion below, I conclude that the model validation activities and model testing of the numerical models for EBS Flow, EBS Transport, and the EBS-UZ Interface are technically credible and support the use of these models in TSPA. All of the comparisons with alternative data sources and models described below had reasonable results. 
0801056250

Page 11

\section{Flow Through Breaches in the WP and DS:}

For the EBS Flow model, four series of tests were performed on a full-scale mock-up of one side of a drip shield. Two of the series of tests were configured to represent dripping from the drift crown onto the drip shield crown, and the other two tests were configured to represent dripping from the drip shield [or drift wall] onto the waste package crown. For each pair of test series, the initial tests were done with smooth mock-up surfaces, and the data were used to predict the splitting of flow between the outside of the drip shield and through the breaches. Then, the tests were repeated with a rough mock-up surface, and the results were compared to the smooth surface results as a means of model validation. The fraction of water through the breaches is expressed as a fraction of half the dripping water, since there is equal probability of dripping down either side of the crown of a full drip shield or waste package. Therefore, the results can conceivably range between 0 and $200 \%$. The test results (rounded to integers for values $>1 \%$ ) were the following:

- Smooth drip shield test: Range $1 \%$ to 28\%, Mean 11\%, Median 5\%

- Rough drip shield test: Range 0\% to $117 \%$, Mean 11\%, Median 0.5\%

- Smooth WP test:

Range $0 \%$ to $107 \%$, Mean $30 \%$,

Median $1 \%$

- Rough WP test:

Range $0.01 \%$ to $62 \%$, Mean $12 \%$,

Median $0.3 \%$

The values in these results were compared to a geometric prediction and to develop a multiplier range on that prediction (including the incorporation of uncertainty into the multiplier range). The actual values of the test results shown above are dependent on the selected combinations of drip and breach locations; however, the similarity and differences of the smooth and rough surface results are a combination of validation (repeatability), adequate statistics, and physical differences due to the surface texture itself. The experimental results are difficult to use to directly predict the splitting of flow because the initial drip splashing results in a distributed source of rivulets, because the flow is in rivulets with a variety of angles from the most downward, and because the experiment ends with a portion of the drip still on the surface as small mini-droplets which have neither run-off nor gone through breaches.

The model for the fraction entering breaches is a uniform distribution from zero to the computed maximum (but limited to no more than $100 \%$ of the total, both sides, source). The computed maximum is based on three multiplicative factors. The first factor is the geometric area fraction of the breach(es) length divided by the actual component length. The second factor, which normalizes the measured data, is based on three measured ranges for the smooth surface data for the component (drip shield or waste package). These three measured ranges are reduced to single values that result in a maximum multiplicative factor. The mean of the experimental breach fraction results (the first measured range) is used since it is larger than the median (it has a theoretical maximum of $200 \%$ of the single side source). The minimum of the measured rivulet spread angle (the second measured range) is used as it appears in the denominator of the multiplicative factor. The diameter of the inner cluster of splash mini-droplets is the third 
0801056250

Page 12

measured range; the maximum was used and was the source of the "effective component (DS or WP) length". The final factor in the calculation depends on the rivulet-spread angle, and it is independently maximized by using the maximum of the measured angle, even though the minimum of that angle was used in the second factor. The inconsistency in selection of the measured angle adds conservatism to the results as the maximizing end of the range is different in the second and third factors.

The net result passed to TSPA is the following:

- For the drip shield, breach flow is sampled between 0 and $85 \%$ of the source multiplied by one-half of the geometric fraction of the breach length divided by the drip shield segment length (the one-half factor accounts for only half the source flow going toward the breach side of the drip shield).

- For the waste package, breach flow is sampled between 0 and $241 \%$ of the source multiplied by the one-half of the geometric fraction of the breach length.

- In both cases, any sampled breach flow larger than the source is reduced to $100 \%$ of the source.

The drip shield multiplier maximum is somewhat less than the nominal expected maximum of $100 \%$, reflecting the combination of the experimental issues (such as remaining liquid on the surface) and the choice of maximizing measured factors in the development of the multiplier. The waste package multiplier maximum is greater than $100 \%$, reflecting the dominance of the conservatisms in the data reduction and the lesser effect of the remaining liquid issue when some of the drips are onto the sloping side surfaces.

The analysis of the rough surface (validation) experimental data resulted in maximum multipliers of $77 \%$ for the drip shield and $30 \%$ for the waste package. The drip shield breach flow model results are similar for the two surface textures, but the waste package breach flow results are much lower for the rough surface used in the validation tests. Since the TSPA model will use the larger values in both the DS and WP cases, the data selection for the TSPA is conservative (larger breach flow leads to more radionuclide transport).

\section{Transport Model:}

The EBS/UZ boundary condition involves bifurcation from a single continuum into a dual continuum. Two approaches were developed for this situation. The first is rigorous but difficult to implement efficiently. The second uses a thin interface layer at the base of the single continuum and is computationally efficient. Section 6.6.4.4 presents a test of the two methods for a simplified situation. Figures 6.6-4 and 6.6-5 present the results, which show that the two methods are in close agreement and that the GoldSim software implementation of the interface-layer method in TSPA matches a spreadsheet implementation of the same method. In addition, an alternative 
0801056250

Page 13

model from the Drift-Scale Radionuclide Transport AMR (the fracture-matrix partitioning model) was compared to the results from this AMR.

For in-package diffusion, Section 7.2.1 compares the results with two published alternative models, including one developed by the Electric Power Research Institute. Section 7.2.2 compares the electrical analog tuff diffusion experimental results to results from direct measurements of diffusivity between machined cubes of tuff.

Finally, in Appendices $\mathrm{B}$ and $\mathrm{F}$, the differential equations from the base case model were converted into a finite difference model and implemented in a spreadsheet program (with some simplifications compared to the base case model). The resulting model was exercised using reasonable input parameter values, and the results were analyzed in terms of the fraction of the release carried by irreversible sorption on colloids, and also of the temporal behavior of the modeled system.

\section{CONCLUSION:}

Based on the information above, I conclude that

- The approach and algorithms described in the document and provided to TSPA capture all known flow pathways into and from the EBS components.

- The approach and algorithms described in the document and provided to TSPA address all known modes of radionuclide transport within and from the EBS components.

- Modeling assumptions are clearly defined, discussed, and justified as appropriate for the intended use of the three models. Major assumptions are documented in Section 5 of the $\mathrm{AMR}$, and the text discusses other assumptions as they occur.

- Uncertainties in parameters, processes, and assumptions are sufficiently described, and impacts of these uncertainties discussed. The organization of Section 8 of the AMR into single-value parameters and sampled parameters makes the treatment of uncertainty easy to follow.

- The overall technical credibility of the approach, including assumptions, parameters, equations, and the TSPA implementation, are sufficient for the model's intended use. 


\subsection{EBS-UZ INTERFACE MODEL}

The output of the invert domain feeds into the unsaturated zone through the EBS-UZ interface model. In the EBS RT Abstraction, the invert is modeled as a single-continuum porous medium whereas the adjacent UZ is modeled as a dual continuum fracture-matrix medium. The model is described in detail in Section 6.5.3.6.

The mass flux from the invert flows into the top layer of the middle zone in the UZ. The portion of the advective flux from the invert that is attributable to the seepage flux $\left(F_{1}\right)$ flows into the UZ fractures. The imbibition flux into the invert $\left(F_{7}\right)$ flows out of the invert into the UZ matrix. The diffusive flux from the invert can go into both UZ continua based on the concentration gradient and effective diffusion coefficient. The diffusive area remains the same because they are overlapping continua. The advective flux flowing through the UZ fracture cells in the middle zone is given by the greater of the advective flux out of the invert and the steady state UZ fracture flux. The advective flux in the two outer zones is given by the steady state UZ flow in each continuum at the repository horizon; the drift shadow effects are ignored.

For TSPA-LA, a semi-infinite zero concentration boundary condition is used for the EBS-UZ interface. This is approximated by applying an effective zero-concentration boundary at approximately three drift diameters below the invert-UZ boundary into the UZ. By moving the zero concentration boundary some distance below the invert, a more realistic diffusive gradient through the invert is achieved.

The EBS-UZ interface model of the EBS RT Abstraction provides input to the unsaturated zone radionuclide transport model in Particle Tracking Model and Abstraction of Transport Processes (BSC 2004 [DIRS 170041]). The appropriate level of confidence identified for unsaturated zone radionuclide transport is Level II. Therefore, Level II also represents appropriate level of confidence for the EBS-UZ interface model of the EBS RT Abstraction.

Section 7.3.1.1 describes the semi-analytical fracture-matrix partitioning model that is used to validate the EBS-UZ interface model of the EBS RT Abstraction. Section 7.3.1.2 compares the two interface models, and Section 7.3.1.3 provides an evaluation of differences between the two models and discussion of the applicability and suitability of the EBS-UZ interface model for TSPA-LA transport modeling.

\subsubsection{Validation of EBS-UZ Boundary Condition Implementation in TSPA-LA}

In this section, the predictions of the analytical fracture-matrix partitioning model developed in Drift-Scale Radionuclide Transport (BSC 2004 [DIRS 170040]) are compared with the fracture-matrix partitioning at the EBS-UZ boundary predicted by the EBS RT Abstraction (Section 6.5.3.6). Because the two models are conceptually different, exact agreement in their results is not expected. The objective of the validation is to demonstrate qualitative agreement, i.e., that the trends and general qualitative behavior of the EBS-UZ boundary condition implementation in the EBS RT Abstraction are also seen in a model that has been independently developed and uses a completely different solution approach. 


\subsubsection{Description of Fracture-Matrix Partitioning Model}

The fracture-matrix partitioning model, described in Drift-Scale Radionuclide Transport (BSC 2004 [DIRS 170040]), is developed for the case where there is no seepage inside the drift. It may be used to compute the relative fraction of the radionuclide mass entering the UZ matrix and UZ fracture from the invert by the process of diffusion. The fracture-matrix partitioning model is extended to the case where there is seepage through the drift by specifying that all mass leaving the invert by advection enters the UZ fractures, i.e., there is no partitioning in this case.

The fracture-matrix partitioning model considers only that part of the invert that is directly underneath the waste package, and effectively treats the invert as a single continuum by assuming zero saturation in the intergranular pores of the invert and a fully saturated intragranular invert continuum, in order to compute a single continuum (or bulk) water content. A rectangular geometry is used for the invert, with a vertical length sampled from a uniform distribution whose maximum is the maximum thickness of the invert directly under the package and whose minimum is the thickness of the invert under the projected edges of the package. The invert width is defined to be equal to the half-fracture spacing in the UZ, which is the reciprocal of the sampled value of the fracture frequency. The model assumes two-dimensional steady state diffusion in a homogeneous invert material. The governing mass transport equation is the Laplace equation:

$$
\nabla^{2} C_{i}(x, y)=0
$$

Both lateral boundaries are considered lines of symmetry and treated as no-flow boundaries (BSC 2004 [DIRS 170040], Section 6.4.1 and Figure 6-10). Along the top of the invert, a constant concentration boundary condition is imposed. At the bottom of the invert, two flux boundary conditions are imposed - one across the interface between the invert and the saturated width of the single UZ fracture (i.e., the water film thickness), and one for the interface of the invert with UZ matrix. The model only considers a single fracture in the UZ, located directly under the left boundary of the invert. The remaining width (the half fracture spacing minus the fracture water film thickness) interfaces with the UZ matrix. Within the single UZ fracture, only diffusive transport is allowed for a vertical distance below the invert that is sampled uniformly between zero and the fracture spacing. Beneath that point, only advective transport in the fracture is allowed. The imposed boundary condition is such that the diffusive flux in the fracture is equal to the downward advective flux in the fracture at this sampled transition point between diffusion and advection. For the UZ matrix, only advective transport is allowed, and the boundary condition is such that the diffusive flux from the invert to the UZ matrix is equal to the UZ matrix advective mass flux.

The fracture-matrix partitioning first formulates the above partial differential equation for concentration with boundary conditions in dimensionless form, which is then solved analytically by infinite series expansion in cosines and hyperbolic tangent functions. The flux to the fracture is then determined by integration at the invert-UZ boundary of the gradient of the concentration. The integral over the UZ fracture portion of the UZ represents the flux to the UZ fracture, while integration of the concentration gradient over the UZ matrix portion of the boundary provides the flux to the UZ matrix. 


\subsubsection{Comparison of Results from Fracture-Matrix Partitioning Model with Results from the Modified EBS RT Abstraction}

The two models are compared for the predictions of the fraction of mass of radionuclides released to fractures of the unsaturated zone. The comparison is based on the results of the Fracture-Matrix Partitioning Model reported in Section 6.4.6 of the Drift-Scale Radionuclide Transport (BSC 2004 [DIRS 170040]). In that report, calculations are done for the three infiltration rates (lower, mean and upper) of the glacial transition climate. The calculations include parameter uncertainty. The EBS-UZ interface model is modified, as discussed below, to allow comparison of the two models without changing the conceptual design or solution algorithm. GoldSim V8.01 (Golder Associates 2003 [DIRS 166572]) is used for the EBS RT Abstraction calculations. The GoldSim run files and the analysis of the results in an Excel spreadsheet are found in DTN: MO0508SPAFRAPM.000. The results of the comparison are shown in Figure 7.3-1.

In order to compare the EBS RT Abstraction with the fracture-matrix partitioning model, all sampled and time-varying parameters in the EBS and UZ in the TSPA-LA system model are made consistent with the parameters used in the fracture-matrix partitioning model. Additional modifications made to the EBS RT Abstraction are listed below:

1. Delete the upstream waste form and corrosion products domains.

2. Apply uniform concentration at the top of the invert domain $(1000 \mathrm{mg} / \mathrm{L})$. For this purpose, the radionuclide chosen is ${ }^{99} \mathrm{Tc}$, because it has no sorption in the invert and UZ. The inventory for all other radionuclides is set to zero.

3. Set the seepage flux entering the invert domain to zero, so that the only transport mechanism is diffusion.

4. Set the water saturation of invert intragranular continuum to 1.0 (fully saturated) and the water saturation of the intergranular continuum to zero. For the single continuum representation of the invert, the bulk water content is computed.

5. Turn off the imbibition flux entering the invert domain.

6. Change the diffusive property of the invert domain to match Equation E-1 of Drift-Scale Radionuclide Transport (BSC 2004 [DIRS 170040]).

7. Change the free water diffusion coefficient $\left(D_{0}\right)$ to a lognormal distribution with the mean of $\log D_{0}$ of 4.69 and standard deviation of $\log D_{0}$ of 0.150 , where $D_{0}$ is in units of $\mathrm{mm}^{2} \mathrm{yr}^{-1}$ (thus, the value of $D_{0}$ corresponding to the mean of $\log D_{0}$ is $10^{4.69}$ $=4.90 \times 10^{4} \mathrm{~mm}^{2} \mathrm{yr}^{-1}$, or $1.55 \times 10^{-5} \mathrm{~cm}^{2} \mathrm{~s}^{-1}$ ), consistent with the approach adopted in Drift-Scale Radionuclide Transport (BSC 2004 [DIRS 170040], p. E-2 of Appendix E). 
8. Change the diffusive thickness in the invert to a uniform distribution between $0.675 \mathrm{~m}$ and $0.806 \mathrm{~m}$, as shown in Drift-Scale Radionuclide Transport (BSC 2004 [DIRS 170040], Appendix G, p. G-8).

9. Set the diffusive outflow area of the UZ matrix cells to zero, consistent with the boundary conditions imposed by the fracture-matrix partitioning model Drift-Scale Radionuclide Transport (BSC 2004 [DIRS 170040], Section 6.4.1). As a result, only diffusive transport occurs from invert domain to the UZ matrix continuum, and only advective transport occurs in the UZ matrix continuum.

10. The distance where the flow occurs in the UZ fracture is uniformly sampled between $0 \mathrm{~m}$ and the fracture spacing (inverse of fracture frequency). For the UZ matrix, the flow occurs immediately under the invert. Residual saturation is applied to the UZ fracture for the part where there is no flow. For the UZ matrix, the flow occurs immediately under the invert and thus the diffusive thickness of the first layer of the $\mathrm{UZ}$ matrix is set to a small value equal to $1 \times 10^{-5} \mathrm{~m}$.

11. Set the diffusive mass transfer term between the UZ matrix and fracture continuum to zero.

12. Ignore the transverse diffusion to the side UZ matrix and fracture cells from the UZ cells in the middle zone (These zones and cells in the EBS-UZ interface model are described in Section 6.5.3.6 and Figure 6.5-4).

13. Instead of setting the thickness of the second UZ layer as twice that of the first layer, the thickness of the second layer is changed to $1 \mathrm{~m}$.

Figure 7.3-1 (shown below) compares the fraction of the radionuclide mass released to the fractures as predicted by the fracture-matrix partitioning model (labeled as "F-M Partitioning Model" in Figure 7.3-1) with the fraction predicted by the EBS-UZ boundary condition implementation for TSPA-LA in the modified EBS RT Abstraction (labeled as "EBS RT Model" in Figure 7.3-1). The cumulative distribution function from the EBS RT Abstraction (thick red and green curves) is based on 100 realizations, while that for fracture-matrix partitioning model is based on 24 random samples selected for each infiltration case, as discussed in Section 6.4.6 of Drift-Scale Radionuclide Transport (BSC 2004 [DIRS 170040]). The 24 samples are the minimum required to ensure sampling of hydrologic parameters from each of the four host rock units (TSw33, TSw34, TSw35, and TSw36). Based on this sample size, it is estimated that for 95 percent confidence limit, the sample mean is within $\pm 0.41 \sigma_{s}$ of the population mean, where $\sigma_{s}$ is the sample standard deviation. Increasing the sample size narrows the estimated spread around the true mean and improves the accuracy of estimation. For the 100 realizations performed by the modified EBS RT Abstraction, the estimate of the sample mean for 95 percent confidence limit is within $\pm 0.2 \sigma_{s}$ of the population mean. The uncertain parameters for the 100 realizations are sampled using the Latin Hypercube Sampling methodology employed by GoldSim. 
The results for the fracture-matrix partitioning model for the three infiltration cases have been combined (weighted by the probability of each infiltration case) into a single curve (thick blue curve - "Combined Infiltration") for comparison with the EBS-UZ boundary condition implementation for TSPA-LA EBS RT Abstraction. The thick red curve shows the results for the modified EBS RT Abstraction using the single continuum representation of the invert, which is the base case model used in TSPA-LA. (Though not pertinent to model validation, the modified EBS RT Abstraction was also run using the dual continuum representation of the invert, an alternative conceptual model; results are shown as the thick green curve. These thick red and green curves virtually overlap showing little effect on the mass fraction released to fractures.)

In general, the modified EBS RT Abstraction predicts approximately the same mass fraction released to fractures compared to the fracture-matrix partitioning model. The difference is due to the fact that the two models are conceptually different with regard to the placement of fracture and matrix medium underneath the invert and in computing the flux out of the invert. The fracture-matrix partitioning model solves the transport equation semi-analytically, whereas the modified EBS RT Abstraction model uses a finite difference approach. Because of these differences, a perfect match between the two models is not expected. Nevertheless, the comparison shows a similar qualitative and quantitative behavior between the two models.

The modified EBS RT Abstraction and the fracture-matrix partitioning model (combined infiltration curve) agree within a factor about of three. The uncertainty in the three infiltration curves, shown as error bars in Figures 6-26b and 6-28 of Drift-Scale Radionuclide Transport (BSC 2004 [DIRS 170040]), is bounded by the "Upper Error Margin" and "Lower Error Margin" curves in Figure 7.3-1. The thick red (or green) curve falls within the "error margins" of the individual infiltration case curves, indicating a close match between the modified $E B S R T$ Abstraction and the fracture-matrix partitioning model.

Although conceptual differences exist between the fracture-matrix partitioning model and the EBS-UZ interface model in the EBS RT Abstraction, with appropriate modifications to bring them into closer conceptual alignment, the two models display similar qualitative and quantitative behavior. The similarity in the results gives confidence that the EBS-UZ interface model is valid for use in TSPA-LA.

\subsubsection{Applicability of EBS-UZ Interface Model in TSPA-LA in Comparison with Fracture-Matrix Partitioning Model}

The EBS-UZ interface model of the EBS RT Abstraction is more suitable for TSPA-LA compared to the fracture-matrix partitioning model for the following reasons:

- The fracture-matrix partitioning model assumes steady state mass transport and is solved with a semi-analytic solution to the Laplace equation, assuming a constant concentration boundary at the top of the invert and a variable flux boundary at the bottom. This approach is restrictive compared to the EBS RT Abstraction, wherein the radionuclide concentrations will be varying with time. Thus, important transient effects related to fuel degradation, thermal-hydrology, in-drift chemistry, and seepage are captured in the $E B S R T$ Abstraction, but may not be captured adequately in the fracture-matrix partitioning model. 


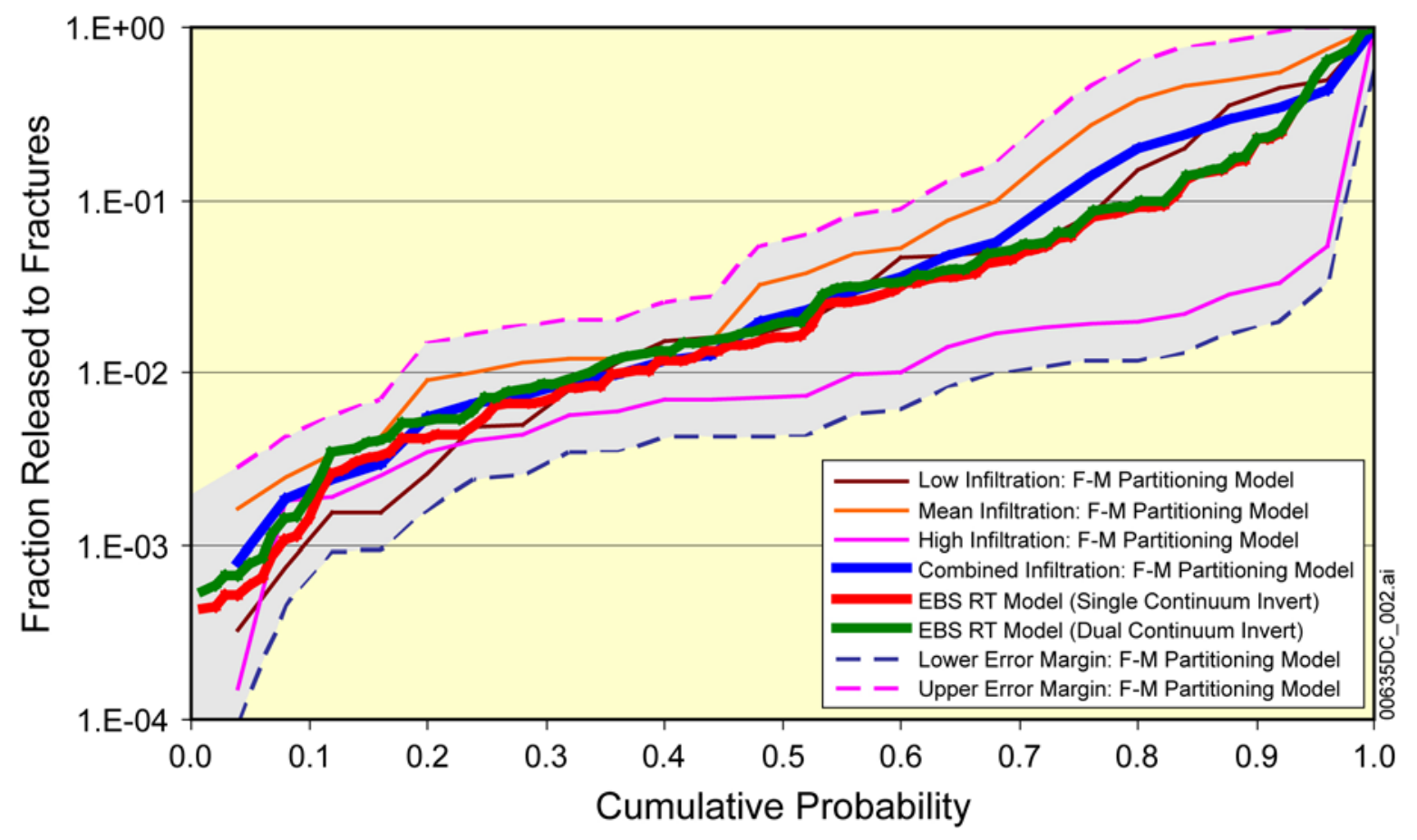

Fracture-Matrix Partitioning Model Error Margins: BSC 2004 [DIRS 170040], Figures 6-26b and 6-28b.

Output DTN: MO0508SPAFRAPM.000.

Figure 7.3-1. Fracture-Matrix Partitioning for No Seepage Case

- The EBS RT Abstraction is a finite difference type model that treats the EBS processes and the near-field UZ processes as a coupled system. The upstream boundary condition is provided by a specified mass flux based on the degradation rate of the waste form and the radionuclide solubility limits, while the downstream boundary is provided by assuming a zero concentration boundary at some distance ( $\sim 3$ drift diameters) from the invert in the UZ. Consequently, the mass flux of radionuclides from the waste package to the invert and from the invert to the UZ is based on solving the coupled system of differential equations with realistic boundary conditions. Since the mass flux from the invert to the UZ is based on the EBS-UZ boundary condition implementation for TSPA-LA in the EBS RT Abstraction, to be consistent, the mass flux partitioning into the far-field UZ transport model (FEHM) should also be based on the EBS RT Abstraction, rather than on the fracture-matrix partitioning model.

- The fracture-matrix partitioning model assumes a discrete fracture network with no coupling between the fracture and matrix domains. In contrast, the EBS-UZ boundary condition implementation for TSPA-LA in the EBS RT Abstraction treats the UZ as a dual continuum (overlapping UZ fracture and matrix continua), with diffusive mass transfer capability between the two continua. This dual continuum modeling approach is consistent with the various process-level UZ flow and transport models created for the YMP.

- The imbibition flux from the surrounding host rock into the intragranular continuum is modeled in the EBS RT Abstraction, whereas its contribution in the fracture-matrix 
partitioning model is ignored. This flux could potentially carry some radionuclide mass into the UZ matrix that could lower the partitioning to the fracture continuum, which is realistic. The fracture-matrix partitioning model may overestimate the fraction released to the fractures where imbibition flux is significant.

- In the regions of the repository where water seeps through the drift, the fracture-matrix partitioning model arbitrarily proposes putting all the mass from the invert into the UZ fracture. This is a bounding approach and ignores the matrix pathway, which occupies most of the area under the invert. The EBS-UZ boundary condition implementation for TSPA-LA in the EBS RT Abstraction, however, applies a more realistic approach, computing the fracture-matrix partitioning based on the appropriate set of boundary conditions in drifts with seepage and including transport in the UZ matrix, as discussed in the second bullet above. Sections 6.5.3.5 and 6.5.3.6 discuss how the advective flux from the invert is apportioned between fractures and matrix in the UZ.

The above comparisons of the results of the two models and their comparative suitability for TSPA-LA have demonstrated that the EBS-UZ interface model meets Level II validation criteria. Based on the validation results, the EBS-UZ interface model is suitable for its intended use.

\title{
7.3.2 Results of Independent Model Validation Technical Review of the EBS-UZ Interface Model
}

An independent model validation technical review of the EBS-UZ interface model was conducted, as specified in the TWP (BSC 2005 [DIRS 173617], Section 2.2.3). This model validation approach is justified based on requirements of LP-SIII.10Q-BSC, Section 5.3.2 c), where independent technical review is listed as an appropriate method for model validation. The results of the independent model validation technical review of the EBS-UZ interface model are presented in a memo (Baker and Grisak 2004 [DIRS 170953]), a verbatim copy of which follows.

\section{MEMO}

\author{
Date: July 27, 2004 \\ To: James Schreiber and Cliff Howard, Yucca Mountain Project \\ Cc: \\ From: Noreen A. Baker, Gerald E. Grisak, INTERA Inc., Austin, Texas \\ RE: Independent Model Validation Technical Review of the EBS-UZ Interface Sub- \\ Model of the Radionuclide Transport Abstraction Model for the Yucca Mountain \\ Project
}




\section{MEMO (Continued)}

Pursuant to your request to perform an independent model validation technical review of three sub-models of the Engineered Barrier System (EBS) Radionuclide Transport Abstraction (RTA) model as documented in ANL-WIS-PA-000001 Rev $01 \mathrm{~K}$, we have performed and documented the review consistent with the requirements of the Technical Work Plan TWP-MGR-PA-000020 Rev 00. We reviewed the EBS-UZ interface sub-model of the EBS RTA report, and the results of the review are provided in this memo.

\section{Review Qualifications}

Section 2.2.4 of the Technical Work Plan TWP-MGR-PA-000020 Rev 00 describes the qualifications and responsibilities the independent model validation technical reviewer. We are qualified to perform the work described for the following reasons. (1). we have not contributed to the development of the model assumptions, parameters, or implementing algorithms documented in ANL-WIS-PA-000001 Rev 01K, (2). Noreen A. Baker has a BS and MS degree in Geology with specialties in Engineering Geology and Hydrogeology, respectively, with more than ten years of professional experience modeling fluid flow and transport in geologic media (3) G. E. Grisak has BS (Geology) and MS (Hydrogeology) degrees, and over 30 years experience evaluating and modeling fluid flow and transport in geologic media, including several publications on fracture/matrix flow and transport, (3) Both N. A. Baker and G. E. Grisak are licensed Professional Geoscientists in the State of Texas. More detailed information regarding credentials can be found in the resumes attached.

\section{Appropriateness and Adequacy of the EBS-UZ Interface Sub-Model Conceptual Model}

Discussion of the EBS-UZ interface sub-model is provided in Section 6.5.3.6. Discussion of the EBS-UZ interface sub-model is provided in Section 6.5.3.6. In the EBS-UZ interface sub-model, the near-field UZ is modeled as a dual continuum of overlapping UZ-matrix and UZ-fracture media. This approach is consistent with current technical approaches to modeling flow and transport in fractured geologic media (Liu et al., 1998; Nitao, 1991). The matrix and fracture continua are represented by a two dimensional vertical array of cells oriented parallel to a cross section of a drift and located immediately beneath a drift. The array consists of three vertical zones, with each zone containing both a fracture cell and a matrix cell. The vertical zones are four layers deep in the vertical direction. The invert is in direct communication with the center zone of UZ matrix/fracture cells. A semi-infinite zero concentration boundary condition at the EBS-UZ interface is approximated by setting a zero concentration boundary at a distance of $3 \mathrm{drift}$ diameters below the invert-UZ boundary.

The mass flux from the invert flows into the top layer of the middle zone in the UZ. The mass flux from the invert is routed to both the fracture cell and the matrix cell in the center zone beneath the invert, with the advective flux routed to the fracture and matrix cells in a manner that is consistent with physical reality. That is, the advective flux coming out of the invert, which is attributable to the dripping flux is routed to the fracture cell in the middle zone, while the imbibition flux is routed to the matrix. The diffusive flux is allowed to enter both the matrix and the fracture cells. The advective flux in the fractures is taken as the larger of the steady-state advective flux in the fractures and the advective flux out of the invert.

The mass flux that enters the center zone cells in the UZ below the invert is then transported by advection and diffusion throughout the modeled area. The advective flux in the two outer zones is given by the steady state UZ flow in the fractures and the matrix at the repository horizon. Advection occurs downward only, from the fracture cell of one layer to the fracture cell of the underlying layer in the same zone, and from the matrix cell of one layer to the matrix cell of the underlying layer in the same zone. Advection does not occur across zones. The fracture and 


\section{MEMO (Continued)}

matrix cells of each zone interact via diffusion. The entire modeled area interacts through the matrix cells via diffusion, with the matrix cells of one zone interacting via diffusion with the matrix cells of adjacent zones, and the matrix cells of one layer in a zone interacting with adjacent overlying and underlying matrix cells in the same zone.

The conceptual model of how the EBS and UZ interface is well captured by the EBS-UZ interface model. The conceptual model recognizes the physical reality by considering both an advective and diffusive flux and by treating the UZ as a dual-permeability medium with both fracture and matrix continua. This modeling approach is consistent with the manner in which dualpermeability continua are modeled (Pruess, 2003). The conceptual model is appropriate for describing the interconnection between the EBS and the UZ because it considers the important components of mass flux out of the EBS and it conserves all the mass flux from the EBS and transfers it to the UZ. The mass transfer to the UZ also captures temporal variations, which may be due to variable radionuclide concentrations in the waste, production of corrosion products, or varying water flux through the EBS. The mass is distributed to the fractures and the matrix in the EBS-UZ interface sub-model in a manner that is conceptually logical. The mass is finally gathered from the EBS-UZ interface sub-model into a collector cell for delivery to the UZ transport model. The delivery from the collector cell to the UZ transport model retains the relative fractions of mass in the fractures and the matrix that is determined within the EBS-UZ interface sub-model.

\section{Appropriateness of the Mathematical Representation of the EBS-UZ Interface Sub-Model}

The EBS-UZ interface sub-model represents the UZ immediately below the invert as a dual continuum of UZ matrix and UZ fracture media. The dual permeability modeling approach is an appropriate way to model transport in fractured media. Mass is tracked and accounted for in the model in both fracture and matrix cells and the fracture and matrix cells have physical dimensions which adequately approximate the physical hydrogeologic system. The mathematical formulation of the dual permeability modeling approach is described in Particle Tracking Model and Abstraction of Transport Processes (BSC 2003w).

\section{EBS-UZ Interface Sub-Model Assumptions and Boundary Conditions}

The EBS-UZ sub-model assumptions and comments are provided below.

\begin{tabular}{|l|l|}
\hline \multicolumn{1}{|c|}{ Assumptions/Boundary Condition } & \multicolumn{1}{c|}{ Comments } \\
\hline $\begin{array}{l}\text { 1. A semi-infinite zero concentration boundary } \\
\text { condition is used for the EBS-UZ interface. } \\
\begin{array}{l}\text { The boundary condition is set at a distance of } \\
\text { 3 drift diameters below the invert-UZ boundary. }\end{array}\end{array}$ & $\begin{array}{l}\text { We agree with the boundary condition and with } \\
\text { the manner in which it is implemented. Placing } \\
\text { the boundary condition at the interface would } \\
\text { result in an unrealistically high diffusive flux } \\
\text { from the invert to the UZ. }\end{array}$ \\
\hline $\begin{array}{l}\text { 2. With respect to the advective flux in the } \\
\text { outer two zones of cells, drift shadow effects } \\
\text { are ignored. }\end{array}$ & $\begin{array}{l}\text { We agree with the assumption. Drift shadow } \\
\text { effects would increase the advective flux in the } \\
\text { two outer zones and result in dilution of } \\
\text { radionuclide concentrations entering the UZ } \\
\text { immediately below the invert. }\end{array}$ \\
\hline
\end{tabular}

Evaluation of Model Validation

Documentation of the model validation is presented in Section 7.3.1. The EBS-UZ sub-model is validated by comparison with an alternative mathematical model developed for a closely 


\section{MEMO (Continued)}

comparable description of the EBS-UZ interface. The alternative model used for the comparison is the fracture-matrix partitioning model described in Drift-Scale Radionuclide Transport (BSC $2004 \mathrm{~m}$ ). The primary validation criterion is corroboration of the model results with an alternative mathematical model, as described in TWP-MGR-PA-000020 Rev 00. This is a common approach to model validation where site specific or generic field or laboratory data or experiments do not adequately capture the processes involved. The EBS-UZ interface sub-model involves coupling the porous medium invert to the dual-permeability UZ with a numerical solution of a discretized model. In the fracture-matrix partitioning model, the coupling is accomplished by formulating the problem as a partial differential equation for concentration and deriving an analytical solution to the problem. In order to compare the two models, all sampled and time-varying parameters in the EBS-UZ interface sub-model are made consistent with the parameters used in the fracture-matrix partitioning model. Additionally, other changes to the EBS-UZ interface sub-model were made to more closely approximate conditions in the fracture-matrix partitioning model. The EBS-UZ interface sub-model was also run using an alternative conceptualization for the invert as a dual continuum. The results of the CDFs of the fraction released to fractures are then compared. This is a technically reasonable and appropriate approach to model validation.

\section{Evaluation of Model Validation Criteria}

In Section 2.2.4 of Technical Work Plan TWP-MGR-PA-000020 Rev 00, provides validation criteria for the EBS-UZ interface sub-model. The table below provides our assessment of these criteria.

\begin{tabular}{|c|c|c|}
\hline Criteria & $\begin{array}{l}\text { Criteria } \\
\text { met? }\end{array}$ & Response \\
\hline $\begin{array}{l}\text { 1. The results of the UBS-UZ interface } \\
\text { sub-model shall show qualitative } \\
\text { agreement with the results of the } \\
\text { fracture-matrix partitioning model. }\end{array}$ & Yes & $\begin{array}{l}\text { The two models display similar } \\
\text { qualitative results, and in addition are } \\
\text { reasonably similar quantitatively, in } \\
\text { that the results of the EBS-UZ } \\
\text { interface sub-model fall within the } \\
\text { shadow of the error bars of the low, } \\
\text { mean and high infiltration cases of the } \\
\text { fracture-matrix partitioning model. }\end{array}$ \\
\hline $\begin{array}{l}\text { 2. The report shall document equivalent } \\
\text { trends and correlations between input } \\
\text { parameter variation and predicted results }\end{array}$ & Yes & $\begin{array}{l}\text { Equivalent trends and correlations } \\
\text { between input parameter variations } \\
\text { and predicted results are visually } \\
\text { obvious on the graphical comparison } \\
\text { between the two methods. Either the } \\
\text { single or dual continuum } \\
\text { representation of the invert by the } \\
\text { EBS-UZ interface sub-model is } \\
\text { adequate. }\end{array}$ \\
\hline $\begin{array}{l}\text { 3. Identification of differences between } \\
\text { model results. }\end{array}$ & Yes & $\begin{array}{l}\text { Differences between model results } \\
\text { and the reasons for the differences } \\
\text { are provided in section } 7.3 .1 .2\end{array}$ \\
\hline $\begin{array}{l}\text { 4. Demonstrate that the EBS-UZ } \\
\text { interface sub-model does not } \\
\text { underestimate radionuclide transport } \\
\text { from the EBS to the UZ. }\end{array}$ & Yes & $\begin{array}{l}\text { The suitability and applicability of the } \\
\text { EBS-UZ interface sub-model is } \\
\text { discussed and justified in } \\
\text { Section } 7.3 .1 .3 \text {. The sub-model is } \\
\text { suitable for its intended use. }\end{array}$ \\
\hline
\end{tabular}




\section{MEMO (Continued)}

\section{Conclusions}

The EBS-UZ interface sub-model documented in report ANL-WIS-PA-000001 Rev 01K incorporates all the significant aspects contributing to mass flux from the invert to the UZ. The sub-model is validated against an alternative model developed for similar purposes and the results are comparable. The advective flux is the primary uncertainty in the mass flux to the fractures, and this uncertainty has been adequately and realistically bounded by the low, mean and high infiltration cases used in the fracture-matrix partitioning model in the validation comparison. It is our professional judgment that the EBS flow sub-model is appropriate for use in the Radionuclide Transport Abstraction.

\section{References}

Liu, H.H., C. Doughty and G.S. Bodvarsson, 1998, "An active fracture model for unsaturated flow and transport in fractured rock," Water Resources Research, vol. 34, no. 10, pages 2633-2646.

Nitao, J.J., 1991, "Theory of matrix and fracture flow regimes in unsaturated, fractured media," Proc., Second International High Level Radioactive Waste Management Conference, Las Vegas, NV, April 29-May 3, 1991.

Pruess, K. (editor), 2003, Proceedings, TOUGH Symposium 2003, Lawrence Berkeley National Laboratory, CA, May 12-14.

\subsection{VALIDATION SUMMARY}

The EBS RT Abstraction has been validated by applying acceptance criteria based on an evaluation of the model's relative importance to the potential performance of the repository system. All validation requirements defined in the Technical Work Plan for: Near-Field Environment and Transport: Engineered Barrier System: Radionuclide Transport Abstraction Model Report Integration (BSC 2005 [DIRS 173617]), Sections 2.2.1, 2.2.2, and 2.2.3 have been fulfilled. Requirements for confidence building during model development have also been satisfied. The model development activities and post-development validation activities described establish the scientific bases for the EBS RT Abstraction. Based on this, the EBS RT Abstraction is considered to be sufficiently accurate and adequate for the intended purpose and to the level of confidence required by the model's relative importance to the performance of the proposed repository system. 


\section{CONCLUSIONS}

This abstraction defines the conceptual model used to determine the rate of release of radionuclides from the EBS to the unsaturated zone in the TSPA-LA given the assumptions listed in Section 5. The EBS RT Abstraction includes algorithms used in the TSPA-LA for computing the flow of water and the transport of radionuclides through the EBS and specifies how parameters used in the model are calculated or from what other models they are obtained. This model is reasonably bounding because it overestimates flow through the drip shield and into the waste package and transport out of the EBS. At the same time, wherever possible, it is realistic, not just bounding, within the appropriate range of uncertainty for TSPA-LA calculations.

\subsection{CONCEPTUAL MODEL SUMMARY}

This section summarizes the conceptual model for transport of radionuclides from the EBS as modeled in TSPA-LA. Radionuclide transport out of the waste form and waste package, through the invert, and into the unsaturated zone is dependent on a complex series of events in the repository. After the waste packages are emplaced, radioactive decay of the waste will heat the drifts and locally perturb the normal percolation of water through the mountain. As the drifts cool, some of the water percolating through the mountain may drip into the drifts and subsequently contact some of the drip shields. Over time, the drip shield, waste package, and other components of the EBS are expected to degrade, leading to contact between the water and the waste form, resulting in the mobilization and transport of radionuclides through the EBS to the unsaturated zone. The primary transport medium through the EBS is anticipated to be water. Either a thin film of water or moving water is necessary for radionuclides to be transported out of the waste package and through the invert to the unsaturated zone.

A number of key factors will affect the mobilization and transport of radionuclides through the EBS, including barrier effectiveness and transport behavior:

- Performance of the drip shields

- Performance of the waste packages

- Protection provided by cladding

- Waste form degradation rates

- Entry and movement of water through waste packages

- Solubilities of radionuclides

- Transport of radionuclides through and out of the waste packages

- Transport of radionuclides through the invert below the waste packages

- Colloidal transport of radionuclides.

Once the drip shield is breached, water may contact the waste packages. Once a waste package is breached, water may enter the package as water vapor or as drips. If the cladding around spent fuel rods or the canister around a vitrified waste form is also breached, radionuclides may start to dissolve in the water. The concentration of each radionuclide mobilized from the waste form cannot exceed the radionuclide solubility limit, unless suspended colloids are included. Colloids are important for two reasons: they may potentially increase the release of radionuclides from the waste package, and they may potentially increase the transport velocity of radionuclides. 
Radionuclides mobilized in water as dissolved species or in association with colloidal species may then be transported by advection and/or diffusion from the waste form, through the waste package, and out of breaches in the waste packages. Once outside the package, the radionuclides may be transported through the invert predominantly by diffusion, if water is not flowing through the invert, or by advection, if water is flowing through the invert.

The conceptual model for flow of water through the EBS identifies eight key flow pathways. These pathways and their relationships are summarized in the following list and in Table 8.1-1. Sections 6.3.1.1, 6.3.2, 6.3.3, and 6.5.1.1 contain detailed technical discussions of the EBS flow abstraction portion of the EBS RT Abstraction.

- Total Dripping Flux - This is the input flux or boundary condition; it is a time- and location-dependent input to this model provided by Abstraction of Drift Seepage (BSC 2004 [DIRS 169131]). Any condensation that may occur on the walls of the drift above the drip shield is added to the seepage flux (BSC 2004 [DIRS 164327], Section 8.3.1).

- Through the Drip Shield to the Waste Package-Flux through the drip shield is proportional to the ratio of the axial lengths of breaches in the drip shield to the total axial length of the drip shield, multiplied by a sampled factor that accounts for uncertainty in the fraction of the flux that is diverted by the drip shield. This flux splitting submodel for the drip shield should only be applied when there is a time-varying failure of the drip shield.

- Drip Shield to Invert (Diversion around the Drip Shield) - Any seepage and wall condensation flux that does not go through the drip shield flows directly into the invert.

- Through the Waste Package to the Waste Form-Flux into the waste package is proportional to the product of the flux through the drip shield and the ratio of the lengths of breaches in the waste package to the total axial length of the waste package, multiplied by a sampled factor that accounts for uncertainty in the fraction of the flux that is diverted by the waste package. The number of corrosion patches in the waste package is calculated in WAPDEG Analysis of Waste Package and Drip Shield Degradation (BSC 2004 [DIRS 169996]).

- Waste Package to Invert (Diversion around the Waste Package) —Flow that does not go through the waste package is diverted directly to the invert.

- Waste Package to Invert-All of the flux from the waste package flows directly to the invert, independent of breach location on the waste package. The presence of the emplacement pallet, which maintains an air gap between the waste package and the invert and could potentially interfere with flow to the invert, is ignored in order to bound the water flow through this pathway.

- Imbibition to Invert - Water can be imbibed from the host rock matrix into the invert.

- Invert to Unsaturated Zone-All of the flux into the invert is released into the unsaturated zone. 
In the conceptual model of radionuclide transport through the EBS, the waste form is the source of all radionuclides in the repository system. Radionuclides can be transported downward, through corrosion products in the waste package, through the invert, and into the unsaturated zone. Transport can occur through advection when there is a liquid flux through the waste package, and by diffusion through any water present in the waste package. Diffusion can occur in a seep environment, when advective transport also takes place, as well as in a no-seep environment where no advective transport occurs; thin films of water are assumed to be present on all surfaces. If the only breaches in a waste package are stress corrosion cracks, advective transport does not occur, but diffusion of radionuclides out of the waste package can still take place. The concentration of each radionuclide during transport is limited by the sum of its solubility limit and the presence of any colloidal particles that may act as reversible or irreversible carriers for the radionuclide. The transport pathways and transport processes (advection or diffusion) are summarized in Table 8.1-2. Sections 6.3.4, 6.5.1.2, and 6.5.3 contain a detailed technical discussion of the EBS transport abstraction.

Table 8.1-1. Summary of EBS Flow Abstraction

\begin{tabular}{|c|c|c|}
\hline Flow Pathway, Pathway Flux & Flow Parameters & Data Sources and Notes \\
\hline $\begin{array}{l}\text { 1. Total dripping flux (seepage }+ \\
\text { wall condensation), } F_{1}\end{array}$ & $\begin{array}{l}\text { Total dripping flux is a function of } \\
\text { fracture properties, rock properties, } \\
\text { air and water properties, and the } \\
\text { percolation flux. }\end{array}$ & $\begin{array}{l}\text { Abstraction of Drift Seepage (BSC } \\
2004 \text { [DIRS 169131]) and In-Drift } \\
\text { Natural Convection and Condensation } \\
\text { Model (BSC } 2004 \text { [DIRS 164327]) } \\
\text { provide time- and location-dependent } \\
\text { values of total dripping flux. }\end{array}$ \\
\hline $\begin{array}{l}\text { 2. Flux through the drip shield, } \\
F_{2}\end{array}$ & $\begin{array}{l}L_{D S} \text { Patch is axial half-length of each } \\
\text { patch due to general corrosion of Ti. } \\
L_{D S} \text { is axial length of the drip shield. } \\
N_{b D S} \text { is number of corrosion patches } \\
\text { of length } L_{D S} \text { Patch in the drip shield. } \\
f_{D S}^{\prime} \text { is sampled uncertain parameter, } \\
\text { Flux_Split_DS_Uncert. } \\
F_{2}=\min \left[F_{1} N_{b D S} L_{D S} \text { Patch } f_{D S}^{\prime} / L_{D S}, F_{1}\right]\end{array}$ & $\begin{array}{l}\text { This flux splitting submodel for the drip } \\
\text { shield should only be applied when } \\
\text { there is a time-varying failure of the } \\
\text { drip shield. For the seismic scenario } \\
\text { class, the opening area is computed } \\
\text { based on the drip shield damage } \\
\text { fraction multiplied by the area of the } \\
\text { drip shield. }\end{array}$ \\
\hline $\begin{array}{l}\text { 3. Diversion around drip } \\
\text { shield, } F_{3}\end{array}$ & $F_{3}=F_{1}-F_{2}$ & Continuity of liquid flux. \\
\hline 4. Flux into the WP, $F_{4}$ & $\begin{array}{l}L_{W P}{ }_{\text {Patch }} \text { is axial half-length of each } \\
\text { patch due to general corrosion of } \\
\text { Alloy } 22 . \\
L_{W P} \text { is axial length of the WP. } \\
N_{b W P} \text { is number of corrosion patches } \\
\text { in the waste package. } \\
f_{W P}^{\prime} \text { is sampled uncertain parameter, } \\
\text { Flux_Split_WP_Uncert. } \\
F_{4}=\min \left[F_{2} N_{b W P} L_{W P} \text { Patch } f_{W P}^{\prime} / L_{W P}, F_{2}\right]\end{array}$ & $\begin{array}{l}\text { WAPDEG (BSC } 2004 \text { [DIRS 169996]) } \\
\text { provides the number of patches and } \\
\text { stress corrosion cracks on the WP. } \\
\text { No significant flow through stress } \\
\text { corrosion cracks due to plugging (BSC } \\
2005 \text { [DIRS 173781], Section 6.2.63). } \\
\text { Steady state flow through WP (outflow } \\
=\text { inflow in steady state; this is } \\
\text { bounding for release). }\end{array}$ \\
\hline 5. Diversion around the WP, $F_{5}$ & $F_{5}=F_{2}-F_{4}$ & Continuity of liquid flux. \\
\hline 6. Flux to the invert, $F_{6}$ & $\begin{aligned} F_{6} & =F_{5}+F_{4}+F_{3} \\
& =F_{1}\end{aligned}$ & $\begin{array}{l}\text { All advective flux enters the invert. } \\
\text { Only } F_{4} \text { can transport radionuclides } \\
\text { into the invert. }\end{array}$ \\
\hline $\begin{array}{l}\text { 7. Imbibition flux from the host } \\
\text { rock matrix into the invert, } F_{7}\end{array}$ & $F_{7}$ is an input to the EBS flow model. & $\begin{array}{l}\text { Imbibition flux is provided by } \\
\text { Multiscale Thermohydrologic Model } \\
\text { calculations (BSC } 2005 \text { [DIRS } \\
\text { 173944]). }\end{array}$ \\
\hline
\end{tabular}


Table 8.1-1. Summary of EBS Flow Abstraction (Continued)

\begin{tabular}{|c|c|l|}
\hline Flow Pathway, Pathway Flux & \multicolumn{1}{|c|}{ Flow Parameters } & \multicolumn{1}{c|}{ Data Sources and Notes } \\
\hline $\begin{array}{l}\text { 8. Flux from the invert into to the } \\
\text { unsaturated zone, } F_{8}\end{array}$ & $\begin{array}{r}F_{8}=F_{6}+F_{7} \\
=F_{1}+F_{7}\end{array}$ & $\begin{array}{l}\text { Total dripping flux portion }\left(F_{1}\right) \text { of } \\
\text { advective flux from the invert flows into } \\
\text { the UZ fractures, imbibition flux }\left(F_{7}\right) \\
\text { flows into the UZ matrix. }\end{array}$ \\
\hline
\end{tabular}

Output DTN: SN0410T0507703.018.

$\mathrm{WP}=$ waste package.

In the transport abstraction, the EBS is modeled as consisting of three domains. The first domain is the source (i.e., SNF or HLW). The second domain consists of corrosion products from the degradation of steel waste package internal components. The third domain is the invert. The physical and chemical properties and conditions are uniform throughout each domain, as though the contents of the domain were thoroughly and continuously stirred.

Parameters that define the size of the two waste package domains, specifically the volumes and diffusive path lengths, are summarized in Table 8.2-1. Parameter values that are provided by other models are identified there. The path length for diffusion through the invert is set to the average thickness of the invert, $0.597 \mathrm{~m}$.

The mass of corrosion products is a function of time and depends on the corrosion rates of carbon steel and stainless steel, which are uncertain parameters with values that are sampled in TSPA-LA. In a seep environment, the corrosion products are fully saturated with water. In a no-seep environment for CSNF, the water saturation is based on the amount of water adsorbed onto iron oxide surfaces, which is a function of the relative humidity. The RH is an input to the transport model that depends on time and location in the repository. Calculation of corrosion products mass and saturation is discussed in Section 6.5.3.2.

The diffusion coefficient in the corrosion products is based on the self-diffusion coefficient of water at $25^{\circ} \mathrm{C}$ as a bounding value for all radionuclides, modified for the porosity and time-dependent water saturation.

The diffusion coefficient in the invert is also based on the self-diffusion coefficient of water at $25^{\circ} \mathrm{C}$ as a bounding value for all radionuclides. The effects of porosity and time-dependent saturation in the invert are incorporated, based on experimental data. The effect of temperature is also incorporated into the abstraction for the diffusion coefficient. The diffusion coefficient for colloids is assumed to be $1 / 100^{\text {th }}$ of the diffusion coefficient for a dissolved species (Section 6.3.4.4).

Sorption of radionuclides may occur on corrosion products in the waste package and on crushed tuff in the invert. Values for sorption distribution coefficients on corrosion products and on crushed tuff for all radionuclides of interest are determined in Section 6.3.4.2. $K_{d}$ values for sorption on corrosion products are set to zero for all radionuclides as a bounding approach; i.e., no credit is taken for retardation due to reversibly sorbed radionuclides on stationary corrosion products. 
Table 8.1-2. Summary of EBS Transport Abstraction

\begin{tabular}{|c|c|c|}
\hline Transport Pathway & Transport Modes & Transport Parameters and Data Sources \\
\hline $\begin{array}{l}\text { 1. Waste form and } \\
\text { corrosion products } \\
\text { domains }\end{array}$ & $\begin{array}{l}\text { Waste form domain: } \\
\text { Diffusion and advection } \\
\text { (when possible) through } \\
\text { the waste form rind. } \\
\text { Corrosion product domain: } \\
\text { Diffusion through stress } \\
\text { corrosion cracks (no } \\
\text { advective transport through } \\
\text { stress corrosion cracks). } \\
\text { Diffusion and advection } \\
\text { through corrosion products } \\
\text { and corrosion patches. }\end{array}$ & $\begin{array}{l}\text { No lateral or forward dispersion. } \\
\text { Colloidal particles will transport radionuclides. } \\
\text { Diffusive area for each stress corrosion crack is } \\
7.7 \times 10^{-6} \mathrm{~m}^{2} \text { (see Section } 6.3 .3 .1 .2 .1 \text { ). } \\
\text { Diffusion coefficient (all radionuclides): } \\
\text { - } \quad \text { Free water diffusion coefficient: } 2.299 \times 10^{-5} \\
\mathrm{~cm}^{2} \mathrm{~s}^{-1} \text { at } 25^{\circ} \mathrm{C} \text { (Mills } 1973 \text { [DIRS } 133392 \text { ], } \\
\quad \text { Table III) } \\
\text { Modified for porosity and saturation (see } \\
\quad \text { Section } 6.3 .4 .3 .5 \text { ); not modified for temperature } \\
\text { Reduced by a factor of } 100 \text { if radionuclide is } \\
\text { bound to a colloid (see Section } 6.3 .4 .4 \text { ). } \\
\text { The cross-sectional area for radionuclide transport is } \\
\text { dependent on the scenario class (see } \\
\text { Sections } 6.5 .3 .1 .1 \text { and } 6.5 .3 .1 .2 \text { ). } \\
\text { Irreversible sorption of Pu and Am onto corrosion } \\
\text { products; time-dependent mass of corrosion products } \\
\text { available for sorption is calculated based on corrosion } \\
\text { rates of carbon and stainless steels. } \\
\text { See Section } 6.5 .3 \text { for further details. }\end{array}$ \\
\hline 2. Invert & $\begin{array}{l}\text { Diffusion and advection } \\
\left(F_{6}\right) \text { from corrosion } \\
\text { products domain into the } \\
\text { invert. }\end{array}$ & $\begin{array}{l}\text { Liquid flux for advection }=F_{6}=F_{5} \text { (diverted by WP) }+ \\
F_{4} \text { (flux through WP) }+F_{3} \text { (diverted by drip shield). } \\
\text { Diffusion coefficient (all radionuclides): } \\
\text { - } \quad \text { Free water diffusion coefficient: } 2.299 \times 10^{-5} \\
\mathrm{~cm}^{2} \mathrm{~s}^{-1} \text { at } 25^{\circ} \mathrm{C} \text { (Mills } 1973 \text { [DIRS } 133392 \text { ], Table } \\
\text { III) } \\
\text { - Modified for porosity and saturation (see Section } \\
6.3 .4 .1 \text { ) } \\
\text { - Temperature modification defined in Section } \\
6.3 .4 .1 .2 \text {; invert temperature is provided by } \\
\text { Multiscale Thermohydrologic Model calculations } \\
\text { (BSC } 2005 \text { [DIRS } 173944 \text { ] } \\
\text { Reduced by a factor of } 100 \text { if radionuclide is } \\
\text { bound to a colloid (see Section } 6.3 .4 .4 \text { ). } \\
\text { The cross-sectional area for radionuclide transport is } \\
\text { the width of the invert times the waste package length. } \\
\text { Transport of radionuclides is retarded by sorption onto } \\
\text { crushed tuff in invert. } \\
\text { See Section } 6.5 .3 \text { for further details. }\end{array}$ \\
\hline 3. Invert-UZ interface & $\begin{array}{l}\text { Advection from the invert } \\
\text { to } \cup Z \text { fractures }\left(F_{6}\right) \text { and } U Z \\
\text { matrix }\left(F_{7}\right) \text {; total flux is } F_{8} \text {. } \\
\text { Diffusion from the invert to } \\
\text { UZ fractures and matrix. }\end{array}$ & $\begin{array}{l}\text { The invert diffusion calculation uses radionuclide } \\
\text { concentrations in the WP corrosion products domain } \\
\text { as the boundary condition at the top of the invert and a } \\
\text { series of unsaturated zone computational cells below } \\
\text { the invert that provide a gradient to a zero radionuclide } \\
\text { concentration at some distance from the bottom of the } \\
\text { invert. See Section 6.5.3.6. }\end{array}$ \\
\hline
\end{tabular}

Output DTN: SN0410T0507703.018.

$\mathrm{WP}=$ waste package . 


\subsection{MODEL OUTPUTS}

Table 8.2-1 summarizes parameters that define the three-domain EBS transport abstraction, which is described in more detail in Section 6.5.3. These domains are comprised of:

- The waste form. In the case of CSNF waste packages, this consists of fuel rods. In codisposal waste packages, the waste form is a composite of HLW glass and DSNF and thus there are two waste form subdomains one each for HLW glass and for DSNF. Transport processes that occur in the waste form domain(s) are the dissolution of radionuclides and advection and diffusion to the corrosion products domain. Waste form colloids are generated from the alteration of HLW glass and carry radionuclides that are both reversibly and irreversibly bound to the colloid.

- Corrosion products inside the waste package. These are the result of corrosion of steel internal waste package components such as baskets, canisters, and the inner stainless steel vessel. The stationary iron-oxide-based corrosion products are strong sorbers, so irreversible sorption of $\mathrm{Pu}$ and $\mathrm{Am}$ is modeled on the corrosion products. In addition, iron oxyhydroxide colloids (released from corrosion products) and groundwater colloids (from seepage water) are available in this domain. Both reversible and irreversible sorption is modeled on iron oxyhydroxide colloids but only reversible sorption is modeled on groundwater colloids. Precipitation and dissolution can also take place in this domain. Diffusion transports radionuclides into this domain from the waste form domain and from this domain to the invert domain. In a codisposal waste package, the degraded DSNF is conceptualized to be in a powdered form mixed in with steel corrosion products and provides the minimum water volume in the domain. Once the water volume associated with corrosion products exceeds the water volume associated with DSNF, the corrosion products water volume is used.

- Invert. Advection and diffusion transport radionuclides into this domain from the corrosion products domain and from this domain to the unsaturated zone. Groundwater colloids are also available in this domain if there is any water flow. Reversible sorption of radionuclides is modeled on these colloids. Because the chemical environment of the invert may be different from the corrosion products domain, colloid stability may be affected and dissolution or precipitation of radionuclides may take place. The submodel for transport through the invert is summarized in transport pathway 3 of the transport abstraction summary, Table 8.1-2.

Transport is affected by the parameters that define the physicochemical environment, including the porosity and pore volume, water saturation, interfacial diffusive areas, diffusive path lengths, and diffusion coefficients. These diffusive transport parameters are discussed in Section 6.5.3.

Output from the EBS RT Abstraction, including algorithms and parameters, is summarized in three output DTNs: SN0410T0507703.018, SN0508T0503305.003, and MO0506SPAINPAR.000. DTN: SN0410T0507703.018 contains the tables in Sections 8.1 and 8.2 of this report (except for some of the entries in Table 8.2-3); in addition, this DTN includes the $K_{d}$ values from Table 6.6-7 for the alternative conceptual model for reversible sorption onto corrosion products. DTN: MO0506SPAINPAR.000 contains the parameters in Table 8.2-3 that 
are not included in DTN: SN0410T0507703.018, as well as the zero $K_{d}$ values specified for corrosion products. DTN: SN0508T0503305.003 contains sorption data for goethite and HFO that are summarized in Table 6.3-6.

In addition, three preliminary output DTNs were created prior to final approval of this report: DTNs: SN0403T0507703.015, SN0409T0507703.017, and SN0503T0503305.001. DTNs: SN0410T0507703.018 and MO0506SPAINPAR.000 consist of the tables found in Sections 8.1 and 8.2 of the EBS RT Abstraction. Differences between the preliminary and final DTNs are described in Appendices I and J. Both of the preliminary DTNs: SN0403T0507703.015 and SN0409T0507703.017 have been superseded by the final output DTN: SN0410T0507703.018. These two preliminary output DTNs are discussed in Appendix I solely to provide transparency and traceability for TSPA-LA applications that were initially developed based on the preliminary DTNs. These two DTNs are not intended for any other application. Preliminary DTN: SN0503T0503305.001 is used in TSPA-LA and is not intended for any other application.

Table 8.2-1. Parameters for EBS Transport Abstraction

\begin{tabular}{|c|c|c|c|}
\hline Waste Type & $\begin{array}{l}\text { Transport } \\
\text { Properties }\end{array}$ & Seep Case & No-Seep Case \\
\hline \multicolumn{4}{|c|}{ Waste Form Domain (Fuel Rods, HLW, DSNF) } \\
\hline \multirow[t]{2}{*}{ CSNF } & $\begin{array}{l}\text { Rind volume } \\
\text { and water } \\
\text { volume }\end{array}$ & $\begin{array}{l}\text { Waste form domain consists of fuel rods. } \\
\text { - } \quad \text { Rind volume provided by Cladding Degradation } \\
\text { Summary for LA (BSC } 2005 \text { [DIRS 172895]) } \\
\text { - } S_{w}=\text { water saturation in rind = } 1.0\end{array}$ & - Same as Seep Case \\
\hline & $\begin{array}{l}\text { Advection } \\
\text { and Diffusion }\end{array}$ & $\begin{array}{l}\text { Advective flux = volumetric flow rate through the WP } \\
\text { Diffusive area of Waste Form Domain: } \\
\text { - } \quad \text { Total exposed surface area of all failed (axially } \\
\text { split) fuel rods, limited to the total surface area of } \\
\text { the waste package. } \\
\text { - } \quad \text { Provided by Cladding Degradation Summary for } \\
\text { LA (BSC } 2005 \text { [DIRS 172895]) } \\
\text { Diffusion path length: } \\
\text { - } \quad \text { Thickness of rind; function of time. } \\
\text { - Provided by Cladding Degradation Summary for } \\
\text { Diffusion coefficient in Waste Form Domain, } D_{W F} \text { : } \\
\text { - } \phi S_{w} D_{W F}=\phi^{1.3} S_{w}{ }^{2} D_{0} \\
\text { - } \phi=\text { porosity of rind (BSC } 2005 \text { [DIRS } 172895] \text { ) } \\
\text { - } S_{w}=\text { water saturation in rind = 1.0 } \\
\text { - } D_{0}=\text { free water diffusion coefficient } \\
\text { ( } D_{W F} \text { is an effective value defined in the same } \\
\text { manner as } D_{S} \text { in Equation } 6.3 .4 .3 .5-2 \text {.) }\end{array}$ & $\begin{array}{l}\text { - } \quad \text { No advective flux } \\
\text { - Diffusive properties } \\
\text { same as Seep Case }\end{array}$ \\
\hline
\end{tabular}


Table 8.2-1. Parameters for EBS Transport Abstraction (Continued)

\begin{tabular}{|c|c|c|c|}
\hline Waste Type & $\begin{array}{l}\text { Transport } \\
\text { Properties }\end{array}$ & Seep Case & No-Seep Case \\
\hline \multicolumn{4}{|c|}{ Waste Form Domain (Fuel Rods, HLW, DSNF) } \\
\hline Codisposal & $\begin{array}{l}\text { Rind volume } \\
\text { and water } \\
\text { volume }\end{array}$ & $\begin{array}{l}\text { Waste form domain is divided into two subdomains: } \\
\text { HLW and DSNF subdomains. } \\
\text { HLW Subdomain: } \\
\text { - Volume of HLW rind provided as function of time } \\
\text { by Defense HLW Glass Degradation Model (BSC } \\
2004 \text { [DIRS } 169988 \text { ], Section 8.1, Eq. 54) } \\
\text { - Porosity of HLW rind provided by Defense HLW } \\
\text { Glass Degradation Model (BSC } 2004 \text { [DIRS } \\
\text { 169988], Table 8-1) } \\
\text { - } S_{W}=\text { water saturation = } 1.0 \\
\text { DSNF Subdomain: } \\
\text { - Volume of degraded DSNF (rind), V VSNF }=1 \mathrm{~m}^{3} \\
\text { provided by DSNF and Other Waste Form } \\
\text { Degradation Abstraction (BSC } 2004 \text { [DIRS } \\
\text { 172453], Table 8-1) } \\
\text { - Porosity of DSNF rind, } \phi_{D S N F}=0.2 \\
\text { - } S_{W}=\text { water saturation in DSNF = } 1\end{array}$ & $\begin{array}{l}\text { - } \quad \text { No advective flux } \\
\text { - Diffusive properties } \\
\text { same as Seep Case }\end{array}$ \\
\hline & $\begin{array}{l}\text { Advection } \\
\text { and Diffusion }\end{array}$ & $\begin{array}{l}\text { Advective flux = volumetric flow rate through the WP. } \\
\text { HLW Subdomain: } \\
\text { Diffusive area: } \\
\text { - } \quad \text { Total initial surface area of } 5 \text { glass logs } \\
\text { - Provided by Defense HLW Glass Degradation } \\
\text { Model (BSC } 2004 \text { [DIRS } 169988 \text { ], Section 8.1) } \\
\text { Diffusion path length: } \\
\text { - Thickness of degraded glass layer; function of } \\
\text { time. } \\
\text { - Provided by Defense HLW Glass Degradation } \\
\text { Model (BSC } 2004 \text { [DIRS } 169988 \text { ], Section 8.1, } \\
\text { Eq. } 56) \\
\text { Diffusion coefficient in Waste Form Domain, } D_{W F} \text { : } \\
\text { - } \phi S_{w} D_{W F}=\phi^{1.3} S_{w}{ }^{2} D_{0} \\
\text { - } \phi=\text { rind porosity } \\
\text { - } S_{w}=\text { water saturation = 1.0 } \\
\text { - } D_{0}=\text { free water diffusion coefficient } \\
\left(D_{W F} \text { is an effective value defined in the same }\right. \\
\left.\text { manner as } D_{s} \text { in Equation } 6.3 .4 .3 .5-2 .\right)\end{array}$ & $\begin{array}{l}\text { - No advective flux } \\
\text { - Diffusive properties } \\
\text { same as Seep Case }\end{array}$ \\
\hline
\end{tabular}


Table 8.2-1. Parameters for EBS Transport Abstraction (Continued)

\begin{tabular}{|c|c|c|c|}
\hline Waste Type & $\begin{array}{l}\text { Transport } \\
\text { Properties }\end{array}$ & Seep Case & No-Seep Case \\
\hline & $\begin{array}{l}\text { Advection } \\
\text { and Diffusion }\end{array}$ & $\begin{array}{l}\text { DSNF Subdomain: } \\
\text { Diffusive area: } \\
\text { - } \quad \text { Same as the diffusive area in the corrosion } \\
\text { product domain (= WP breach area). } \\
\text { Diffusion path length: } \\
\text { - } V_{D S N F}\left(=1 \mathrm{~m}^{3}\right) / \text { Diffusive area } \\
\text { Diffusion coefficient in Waste Form Domain, } D_{W F} \text { : } \\
\text { - } \phi S_{w} D_{W F}=\phi S_{w} D_{0} \\
\text { - } \phi=\text { rind porosity } \\
\text { - } S_{w}=\text { water saturation = } 1.0 \\
\text { - } D_{0}=\text { free water diffusion coefficient } \\
\left(D_{W F} \text { is an effective value defined in the same }\right. \\
\text { manner as } D_{s} \text { in Equation 6.3.4.3.5-2.) }\end{array}$ & \\
\hline \multicolumn{4}{|c|}{ Corrosion Product Domain } \\
\hline \multirow[t]{5}{*}{ CSNF } & \multirow[t]{2}{*}{$\begin{array}{l}\text { Bulk volume } \\
\text { and water } \\
\text { volume }\end{array}$} & $\begin{array}{l}\text { Pore volume of corrosion products, } V_{C P} \text { : } \\
\text { - Mass of corrosion products, } m_{C P} \text {, is function of } \\
\text { time, Table 8.2-4, Equation 8-7 } \\
\text { - } \text { Porosity } \phi_{C P}=0.4 \\
\text { - } \quad V_{C P} \text { from Table 8.2-4, Equation 8-6 }\end{array}$ & - Same as Seep Case \\
\hline & & $\begin{array}{l}\text { Volume of water: } \\
\text { - } S_{w}=\text { water saturation in CP }=1.0 \\
\text { - } \text { Water volume }=S_{w} V_{C P}\end{array}$ & $\begin{array}{l}\text { Volume of water: } \\
\text { - } S_{w e, C P}=\text { effective } \\
\text { water saturation in } \\
\text { CP from adsorbed } \\
\text { water (in-package } \\
\text { diffusion submodel); } \\
\text { Table 8.2-4, Equation } \\
\text { 8-5 } \\
\text { - } S_{w e, C P} \text { function of } \mathrm{RH} \\
\text { and sampled specific } \\
\text { surface area of CP } \\
\text { CP_Spec_Surf_Area } \\
\text { - Water volume = } \\
S_{w e, C P} V_{C P} \\
\end{array}$ \\
\hline & \multirow{3}{*}{$\begin{array}{l}\text { Advection } \\
\text { and Diffusion }\end{array}$} & Advective flux = volumetric flow rate through the WP & - No advective flux \\
\hline & & $\begin{array}{l}\text { Diffusive area: } \\
\text { - Total area of all waste package breaches }\end{array}$ & - Same as Seep Case \\
\hline & & $\begin{array}{l}\text { Diffusion path length: } \\
\text { - Sampled parameter Diff Path Length CP CSNF }\end{array}$ & - Same as Seep Case \\
\hline
\end{tabular}


Table 8.2-1. Parameters for EBS Transport Abstraction (Continued)

\begin{tabular}{|c|c|c|c|}
\hline Waste Type & $\begin{array}{l}\text { Transport } \\
\text { Properties }\end{array}$ & Seep Case & No-Seep Case \\
\hline & $\begin{array}{l}\text { Advection } \\
\text { and Diffusion }\end{array}$ & $\begin{array}{l}\text { Diffusion coefficient in corrosion products, } D_{C P} \text { : } \\
\text { - } \phi_{C P} S_{w} D_{C P}=\phi_{C P}{ }^{1.3} S_{w}{ }^{2} D_{0} \\
\text { - } \phi_{C P}=\text { porosity of } C P=0.4 \\
\text { - } S_{w}=\text { water saturation in } C P=1.0 \\
\text { - } D_{0}=\text { free water diffusion coefficient } \\
\left(D_{C P} \text { is an effective value defined in the same manner }\right. \\
\left.\text { as } D_{s} \text { in Equation } 6.3 .4 .3 .5-2 .\right)\end{array}$ & $\begin{array}{l}\text { Diffusion coefficient in } \\
\text { corrosion products, } D_{C P} \text { : } \\
\text { - } \phi_{C P} S_{w e, C P} D_{C P}= \\
\phi_{C P}{ }^{1.3} S_{w e, C P}{ }^{2} D_{0} \\
\text { - } S_{w e, C P}=\text { effective } \\
\text { water saturation in } \\
\text { CP from adsorbed } \\
\text { water (in-package } \\
\text { diffusion submodel); } \\
\text { Table 8.2-4, Equation } \\
8-5 \\
\text { - } S_{w e, C P} \text { function of RH } \\
\text { and sampled specific } \\
\text { surface area of CP } \\
\text { CP_Spec_Surf_Area } \\
\text { - } \phi_{C P}=\text { porosity of } \mathrm{CP}= \\
0.4 \\
\text { - } D_{0}=\text { free water } \\
\text { diffusion coefficient }\end{array}$ \\
\hline \multirow[t]{3}{*}{ Codisposal } & \multirow[t]{2}{*}{$\begin{array}{l}\text { Bulk volume } \\
\text { and water } \\
\text { volume }\end{array}$} & $\begin{array}{l}\text { Pore volume of corrosion products, } V_{C P} \text { : } \\
\text { - } \text { Same as for CSNF Seep Case } \\
\text { - } \phi_{C P}=\text { porosity of } \mathrm{CP}=0.4 \\
\text { - } S_{w}=\text { water saturation in } \mathrm{CP}=1.0\end{array}$ & - Same as Seep Case \\
\hline & & $\begin{array}{l}\text { Volume of water: } \\
\text { - Water volume }=\max \left[S_{w} V_{C P}, S_{w} \phi_{D S N F} V_{D S N F}\right]\end{array}$ & - Same as Seep Case \\
\hline & $\begin{array}{l}\text { Advection } \\
\text { and Diffusion }\end{array}$ & $\begin{array}{l}\text { Advective flux = volumetric flow rate through the WP } \\
\text { Diffusive area: } \\
\text { - } \quad \text { Same as for CSNF Seep Case } \\
\text { Diffusion path length: } \\
\text { - } \quad \text { Sampled parameter Diff_Path_Length_CP_CDSP } \\
\text { Diffusion coefficient in corrosion products, } D_{C P} \text { : } \\
\text { - } \phi_{C P} S_{w} D_{C P}=\phi_{C P}{ }^{1.3} S_{w}{ }^{2} D_{0} \\
\text { - } \phi_{C P}=\text { porosity of CP }=0.4 \\
\text { - } S_{w}=\text { water saturation }=1.0 \\
\text { - } D_{0}=\text { free water diffusion coefficient } \\
\left(D_{C P} \text { is an effective value defined in the same manner }\right. \\
\text { as } D_{s} \text { in Equation 6.3.4.3.5-2.) }\end{array}$ & $\begin{array}{l}\text { - } \quad \text { No advective flux } \\
\text { - Diffusive properties } \\
\text { same as Seep Case }\end{array}$ \\
\hline
\end{tabular}

Output DTN: SN0410T0507703.018.

$\mathrm{CP}=$ corrosion products; DSNF = defense spent nuclear fuel. 
As a bounding approach, no credit is taken for retardation due to reversibly sorbed radionuclides on waste package corrosion products. Thus, sorption distribution coefficients are set to zero for all radionuclides (Table 8.2-3; output DTN: MO0506SPAINPAR.000). Nonzero $K_{d}$ values, an alternative conceptual model described in Section 6.6.6, are given in DTN: SN0410T0507703.018.

The ranges and distributions of radionuclide sorption distribution coefficients for sorption on devitrified unsaturated zone tuff given in Table 4.1-15 (DTN: LA0408AM831341.001 [DIRS 171584]) are assigned to $K_{d}$ values on crushed tuff in the invert. Correlations for sampling sorption distribution coefficient probability distributions for devitrified UZ tuff given in Table 4.1-16 (DTN: LA0311AM831341.001 [DIRS 167015]) are assigned to invert crushed tuff.

Sorption distribution coefficient $\left(K_{d}\right)$ values and interval probabilities used for reversible radionuclide sorption on colloids in TSPA-LA calculations are provided by DTN: SN0306T0504103.006 [DIRS 164131], Table 1.

Parameter ranges and distributions for irreversible sorption of plutonium and americium onto stationary waste package corrosion products are given in Table 6.3-6 and summarized in output DTN: SN0508T0503305.003.

Table 8.2-2 summarizes various sampled parameters to be used in the EBS radionuclide transport abstraction, with the range and distribution of each parameter provided. This table is itself a summary of Table 6.5-6, which, along with the rest of Section 6.5.2, gives further details about each parameter and the location in this document where the parameter is developed. A summary of fixed, single-value parameters to be used in the EBS radionuclide transport abstraction is given in Table 8.2-3 (output DTNs: SN0410T0507703.018 and MO0506SPAINPAR.000). Equations used to compute various parameters in the EBS radionuclide transport abstraction are shown in Table 8.2-4. 
Table 8.2-2. Sampled Model Inputs Used in the EBS Radionuclide Transport Abstraction

\begin{tabular}{|c|c|c|c|}
\hline Input Name & Input Description & Range & Distribution \\
\hline Invert_Diff_Coeff_Uncert & $\begin{array}{l}\text { Invert diffusion coefficient uncertainty; } \\
\text { Table } 8.2-4 \text {, Equation } 8-1\end{array}$ & $\begin{array}{l}\text { Range: } 10^{\mu \pm 3 \sigma} \\
\quad \text { (dimensionless) } \\
\text { Mean: } \mu=0.033 ; \\
\text { Std. Dev. } \sigma=0.218\end{array}$ & $10^{N D}$ \\
\hline SS_Corrosion_Rate & $\begin{array}{l}\text { Stainless steel corrosion rate (DTN: } \\
\text { MO0409SPAACRWP.000 [DIRS } \\
\text { 172059]; Spreadsheet } \\
\text { "ECDF_metals2.xIs"; Worksheet } \\
\text { "316 ss", Columns L \& M, Rows 5-15); } \\
\text { cumulative distribution function }\end{array}$ & $\begin{array}{c}\text { Rate }\left(\boldsymbol{\mu m} \mathbf{y r}^{-\mathbf{1}}\right) \\
0.03699 \\
0.037 \\
0.1016 \\
0.109 \\
0.1524 \\
0.154 \\
0.1778 \\
0.2032 \\
0.2286 \\
0.254 \\
0.2794 \\
0.51 \\
\end{array}$ & $\begin{array}{l}\text { CDF } \\
0.000 \\
0.063 \\
0.125 \\
0.188 \\
0.250 \\
0.313 \\
0.375 \\
0.438 \\
0.563 \\
0.750 \\
0.813 \\
1.000 \\
\end{array}$ \\
\hline CS_Corrosion_Rate & $\begin{array}{l}\text { Carbon steel corrosion rate (DTN: } \\
\text { MO0409SPAACRWP.000 [DIRS } \\
\text { 172059]; Spreadsheet } \\
\text { "ECDF_metals2.xls"; Worksheet } \\
\text { "A516-Carbon Steel", Columns B \& C, } \\
\text { Rows 5-30);cumulative distribution } \\
\text { function }\end{array}$ & $\begin{array}{c}\text { Rate }\left(\mu \mathrm{m} \mathbf{y r}^{-1}\right) \\
65.76 \\
65.77 \\
66.75 \\
69.84 \\
70.00 \\
71.25 \\
72.21 \\
72.64 \\
72.87 \\
72.89 \\
73.47 \\
74.29 \\
74.51 \\
74.60 \\
75.41 \\
77.31 \\
79.29 \\
80.00 \\
80.87 \\
83.26 \\
83.66 \\
83.74 \\
85.68 \\
90.97 \\
106.93 \\
\end{array}$ & $\begin{array}{l}\text { CDF } \\
0.000 \\
0.042 \\
0.083 \\
0.125 \\
0.167 \\
0.208 \\
0.250 \\
0.292 \\
0.333 \\
0.375 \\
0.417 \\
0.458 \\
0.500 \\
0.542 \\
0.583 \\
0.625 \\
0.667 \\
0.708 \\
0.750 \\
0.792 \\
0.833 \\
0.875 \\
0.917 \\
0.958 \\
1.000 \\
\end{array}$ \\
\hline Diff_Path_Length_CP_CSNF & $\begin{array}{l}\text { Diffusive path length through corrosion } \\
\text { products domain for CSNF packages }\end{array}$ & $0.02-0.859 \mathrm{~m}$ & Uniform \\
\hline Diff_Path_Length_CP_CDSP & $\begin{array}{l}\text { Diffusive path length through corrosion } \\
\text { products domain for codisposal } \\
\text { packages }\end{array}$ & $0.025-1.063 \mathrm{~m}$ & Uniform \\
\hline CP_Spec_Surf_Area & $\begin{array}{l}\text { Specific surface area of } \mathrm{Fe}_{2} \mathrm{O}_{3} \\
\text { corrosion products }\end{array}$ & $1.0-22 \mathrm{~m}^{2} \mathrm{~g}^{-1}$ & Uniform \\
\hline DS_Flux_Uncertainty & $\begin{array}{l}\text { Drip shield flux splitting uncertainty } \\
\text { factor }\end{array}$ & $\begin{array}{l}0-0.85 \\
\text { (dimensionless) }\end{array}$ & Uniform \\
\hline
\end{tabular}


Table 8.2-2. Sampled Model Inputs Used in the EBS Radionuclide Transport Abstraction (Continued)

\begin{tabular}{|c|c|c|c|}
\hline Input Name & Input Description & Range & Distribution \\
\hline WP_Flux_Uncertainty & $\begin{array}{l}\text { Waste package flux splitting } \\
\text { uncertainty factor }\end{array}$ & $\begin{array}{l}0-2.41 \\
\text { (dimensionless) }\end{array}$ & Uniform \\
\hline Fracture_Frequency & $\begin{array}{l}\text { Unsaturated zone fracture frequency } \\
\text { (BSC } 2004 \text { [DIRS 170040], } \\
\text { Appendix A, Table A-1) }\end{array}$ & $\begin{array}{l}\text { Mean=3.16 } \mathrm{m}^{-1} \\
\text { Std. Dev.=2.63 } \mathrm{m}^{-1}\end{array}$ & Log-normal \\
\hline UZ_Fracture_Fraction & $\begin{array}{l}\text { Unsaturated zone fracture porosity } \\
\text { (BSC } 2004 \text { [DIRS 170040], } \\
\text { Appendix D, Table D-1) }\end{array}$ & $\begin{array}{l}0-1 \\
\text { (fraction); } \\
E(x)=9.6 \times 10^{-3} \\
\sigma(x)=2.82 \times 10^{-3}\end{array}$ & Beta \\
\hline UZ_Matrix_Porosity & $\begin{array}{l}\text { Unsaturated zone matrix porosity } \\
\text { (BSC } 2004 \text { [DIRS 170040], } \\
\text { Appendix D, Table D-1) }\end{array}$ & $\begin{array}{l}0-1 \\
\text { (fraction); } \\
E(x)=0.131 \\
\sigma(x)=0.031\end{array}$ & Beta \\
\hline Fracture_Saturation & $\begin{array}{l}\text { Unsaturated zone fracture saturation } \\
\text { (DTN: LB0307FMRADTRN.001 } \\
\text { [DIRS 165451]) }\end{array}$ & $\begin{array}{l}\text { Uniform sampling } \\
\text { from } 433 \text { locations for } \\
\text { each infiltration case }\end{array}$ & $\begin{array}{l}\text { Provided in } \\
\text { source DTN }\end{array}$ \\
\hline Fracture_Residual_Sat & $\begin{array}{l}\text { Unsaturated zone fracture residual } \\
\text { saturation } \\
\text { (DTN: LB0307FMRADTRN.001 } \\
\text { [DIRS 165451]) }\end{array}$ & $\begin{array}{l}\text { Uniform sampling } \\
\text { from } 433 \text { locations }\end{array}$ & $\begin{array}{l}\text { Provided in } \\
\text { source DTN }\end{array}$ \\
\hline Fracture_Percolation_Flux & $\begin{array}{l}\text { Unsaturated zone fracture percolation } \\
\text { flux (DTN: LB0307FMRADTRN.001 } \\
\text { [DIRS 165451]) }\end{array}$ & $\begin{array}{l}\text { Uniform sampling } \\
\text { from } 433 \text { locations for } \\
\text { each infiltration case }\end{array}$ & $\begin{array}{l}\text { Provided in } \\
\text { source DTN }\end{array}$ \\
\hline Flow_Focus_Factor & $\begin{array}{l}\text { Unsaturated zone fracture percolation } \\
\text { flow-focusing factor (DTN: } \\
\text { LB0307FMRADTRN.001 } \\
\text { [DIRS 165451]) }\end{array}$ & $\begin{array}{l}\text { Uniform sampling } \\
\text { from } 433 \text { locations for } \\
\text { each infiltration case }\end{array}$ & $\begin{array}{l}\text { Provided in } \\
\text { source DTN }\end{array}$ \\
\hline UZ_Matrix_Saturation & $\begin{array}{l}\text { Unsaturated zone matrix saturation } \\
\text { (DTN: LB0307FMRADTRN.001 } \\
\text { [DIRS 165451]) }\end{array}$ & $\begin{array}{l}\text { Uniform sampling } \\
\text { from } 433 \text { locations for } \\
\text { each infiltration case }\end{array}$ & $\begin{array}{l}\text { Provided in } \\
\text { source DTN }\end{array}$ \\
\hline Matrix_Percolation_Flux & $\begin{array}{l}\text { Unsaturated zone matrix percolation } \\
\text { flux (DTN: LB0307FMRADTRN.001 } \\
\text { [DIRS 165451]) }\end{array}$ & $\begin{array}{l}\text { Uniform sampling } \\
\text { from } 433 \text { locations for } \\
\text { each infiltration case }\end{array}$ & $\begin{array}{l}\text { Provided in } \\
\text { source DTN }\end{array}$ \\
\hline $\begin{array}{l}\text { Matrix_Rel_Perm_Low, } \\
\text { Matrix_Rel_Perm_Mean, } \\
\text { Matrix_Rel_Perm_High }\end{array}$ & $\begin{array}{l}\text { Unsaturated zone matrix relative } \\
\text { permeability for all three infiltration } \\
\text { cases (DTN: LB0307FMRADTRN.001 } \\
\text { [DIRS 165451]) }\end{array}$ & $\begin{array}{l}\text { Uniform sampling } \\
\text { from } 433 \text { locations for } \\
\text { each infiltration case }\end{array}$ & $\begin{array}{l}\text { Provided in } \\
\text { source DTN }\end{array}$ \\
\hline
\end{tabular}

Output DTN: SN0410T0507703.018.

NOTES: ND = Truncated normal distribution

$E(x)=$ Expected value

$\sigma(x)=$ Standard deviation

$\mathrm{CDF}=$ cumulative distribution function . 
Table 8.2-3. Fixed Model Inputs Used in the EBS Radionuclide Transport Abstraction

\begin{tabular}{|c|c|c|c|}
\hline Input Name & Input Description & $\begin{array}{c}\text { Source, or Developed in } \\
\text { EBS RT Abstraction }\end{array}$ & Value \\
\hline Max_Mass_CP_CSNF & $\begin{array}{l}\text { Mass of corrosion products in } \\
\text { CSNF waste package }\end{array}$ & Developed: Table 6.3-4 & $19,440 \mathrm{~kg}$ \\
\hline Max_Mass_CP_HLW & $\begin{array}{l}\text { Mass of corrosion products in } \\
\text { CDSP waste package }\end{array}$ & Developed: Table 6.3-4 & $14,230 \mathrm{~kg}$ \\
\hline Max_Thick_CS & $\begin{array}{l}\text { Maximum thickness of carbon } \\
\text { steel waste package internal } \\
\text { components }\end{array}$ & $\begin{array}{l}\text { IED BSC } 2004 \\
\text { [DIRS 169472] }\end{array}$ & $10 \mathrm{~mm}$ \\
\hline Max_Thick_SS & $\begin{array}{l}\text { Maximum thickness of stainless } \\
\text { steel waste package internal } \\
\text { components }\end{array}$ & $\begin{array}{l}\text { IED BSC } 2004 \\
\text { [DIRS 167394] }\end{array}$ & $50.8 \mathrm{~mm}$ \\
\hline DS_Total_Length & Length of drip shield & $\begin{array}{l}\text { IED BSC } 2005 \\
\text { [DIRS 173303], Table } 1\end{array}$ & $5,805 \mathrm{~mm}$ \\
\hline Density_CP & Density of corrosion products & $\begin{array}{l}\text { Weast } 1985 \\
\text { [DIRS 111561] }\end{array}$ & $5,240 \mathrm{~kg} \mathrm{~m}^{-3}$ \\
\hline Porosity_CP & Porosity of corrosion products & $\begin{array}{l}\text { Developed: } \\
\text { Section 6.3.4.3.4 }\end{array}$ & $\begin{array}{c}0.4 \\
\text { (fraction) }\end{array}$ \\
\hline Width_Invert & Width of invert & $\begin{array}{l}\text { Developed: } \\
\text { Equation 6.5.3.3-1 }\end{array}$ & $4.00 \mathrm{~m}$ \\
\hline Thick_Invert & $\begin{array}{l}\text { Average thickness of invert } \\
\text { (flow and diffusive path length) }\end{array}$ & $\begin{array}{l}\text { Developed: } \\
\text { Equation 6.5.3.3-5 } \\
\end{array}$ & $0.597 \mathrm{~m}$ \\
\hline Vert_Cross_Sect_Area_Invert & $\begin{array}{l}\text { Vertical cross sectional area of } \\
\text { invert }\end{array}$ & \begin{tabular}{|l} 
Developed: \\
Equation 6.5.3.3-2 \\
\end{tabular} & $2.39 \mathrm{~m}^{2}$ \\
\hline Density_Water & Water density at $25^{\circ} \mathrm{C}$ & $\begin{array}{l}\text { Weast } 1985 \\
\text { [DIRS 111561] }\end{array}$ & $997.0449 \mathrm{~kg} \mathrm{~m}^{-3}$ \\
\hline Viscosity_Water & Water viscosity at $25^{\circ} \mathrm{C}$ & Lide 2000 [DIRS 162229] & $\begin{array}{c}0.890 \times 10^{-3} \mathrm{~Pa} \mathrm{~s} \\
\left(0.000890 \mathrm{~kg} \mathrm{~m}^{-1} \mathrm{~s}^{-1}\right)\end{array}$ \\
\hline Intergranular_Porosity_Invert & $\begin{array}{l}\text { Porosity of crushed tuff invert } \\
\text { ballast }\end{array}$ & $\begin{array}{l}\text { BSC } 2005 \text { [DIRS 173944], } \\
\text { Appendix X }\end{array}$ & $\begin{array}{c}0.45 \\
\text { (fraction) }\end{array}$ \\
\hline Invert_Viscosity_Ref_Temp & $\begin{array}{l}\text { Reference temperature for } \\
\text { viscosity giving temperature } \\
\text { dependence of invert diffusion } \\
\text { coefficient }\end{array}$ & $\begin{array}{l}\text { Reference temperature for } \\
\text { free water diffusion } \\
\text { coefficient }\left(25^{\circ} \mathrm{C}\right)\end{array}$ & $298.15 \mathrm{~K}$ \\
\hline Interface_Scale_Factor & $\begin{array}{l}\text { Scale factor used in numerical } \\
\text { approximation for computing } \\
\text { mass flux distribution from } \\
\text { single-continuum to dual- } \\
\text { continuum medium }\end{array}$ & $\begin{array}{l}\text { Developed: } \\
\text { Section 6.5.3.5 }\end{array}$ & $\begin{array}{c}1 \times 10^{-6} \\
\text { (dimensionless) }\end{array}$ \\
\hline Intragranular_Porosity_Invert & $\begin{array}{l}\text { Porosity of TSw35 tuff rock } \\
\text { matrix (used in dual-continuum } \\
\text { invert alternative conceptual } \\
\text { model) }\end{array}$ & $\begin{array}{l}\text { DTN: } \\
\text { LB0207REVUZPRP.002 } \\
\text { [DIRS 159672], } \\
\text { Spreadsheet } \\
\text { "Matrix_Props.xIs", Row } \\
\text { 20, Column C } \\
\end{array}$ & $\begin{array}{c}0.131 \\
\text { (fraction) }\end{array}$ \\
\hline Fracture_Aperture & $\begin{array}{l}\text { Unsaturated zone fracture } \\
\text { aperture }\end{array}$ & $\begin{array}{l}\text { DTN: } \\
\text { LB0205REVUZPRP.001 } \\
\text { [DIRS 159525], } \\
\text { Spreadsheet } \\
\text { "FRACTURE_PROPERTY } \\
\text {.xls," Row 20, Column L }\end{array}$ & $1.5 \times 10^{-4} \mathrm{~m}$ \\
\hline
\end{tabular}


Table 8.2-3. Fixed Model Inputs Used in the EBS Radionuclide Transport Abstraction (Continued)

\begin{tabular}{|c|c|c|c|}
\hline Input Name & Input Description & $\begin{array}{c}\text { Source, or Developed in } \\
\text { EBS RT Abstraction }\end{array}$ & Value \\
\hline Fracture_Interface_Area & $\begin{array}{l}\text { Unsaturated zone fracture } \\
\text { interface area }\end{array}$ & $\begin{array}{l}\text { DTN: } \\
\text { LB0205REVUZPRP.001 } \\
\text { [DIRS 159525], } \\
\text { Spreadsheet } \\
\text { "FRACTURE_PROPERTY } \\
\text {.xls," Row 20, Column R } \\
\end{array}$ & $9.68 \mathrm{~m}^{2} \mathrm{~m}^{-3}$ \\
\hline Active_Fracture_Parameter & $\begin{array}{l}\text { Unsaturated zone active } \\
\text { fracture parameter for TSw35 } \\
\text { for all three infiltration cases }\end{array}$ & $\begin{array}{l}\text { DTN: } \\
\text { LB03013DSSCP3I.001 } \\
\text { [DIRS 162379] }\end{array}$ & $\begin{array}{c}\text { Low }=0.476 \\
\text { Mean }=0.569 \\
\text { High }=0.570 \\
\text { (dimensionless) }\end{array}$ \\
\hline \multirow[t]{3}{*}{ Matrix_Perm_TSW33 } & \multirow[t]{3}{*}{$\begin{array}{l}\text { Unsaturated zone matrix } \\
\text { permeability for TSw33 for all } \\
\text { three infiltration cases }\end{array}$} & $\begin{array}{l}\text { DTNs: } \\
\text { LB0208UZDSCPLI.002 } \\
\text { [DIRS 161788] }\end{array}$ & Low $=1.60 \times 10^{-18} \mathrm{~m}^{2}$ \\
\hline & & \begin{tabular}{|l} 
LB0208UZDSCPMI.002 \\
[DIRS 161243] \\
\end{tabular} & Mean $=6.57 \times 10^{-18} \mathrm{~m}^{2}$ \\
\hline & & $\begin{array}{l}\text { LB0302UZDSCPUI.002 } \\
\text { [DIRS 161787] }\end{array}$ & High $=2.39 \times 10^{-17} \mathrm{~m}^{2}$ \\
\hline \multirow[t]{3}{*}{ Matrix_Perm_TSW34 } & \multirow[t]{3}{*}{$\begin{array}{l}\text { Unsaturated zone matrix } \\
\text { permeability for TSw34 for all } \\
\text { three infiltration cases }\end{array}$} & $\begin{array}{l}\text { DTNs: } \\
\text { LB0208UZDSCPLI.002 } \\
\text { [DIRS 161788]; }\end{array}$ & Low $=1.38 \times 10^{-19} \mathrm{~m}^{2}$ \\
\hline & & $\begin{array}{l}\text { LB0208UZDSCPMI.002 } \\
\text { [DIRS 161243] }\end{array}$ & Mean $=1.77 \times 10^{-19} \mathrm{~m}^{2}$ \\
\hline & & \begin{tabular}{|l|} 
LB0302UZDSCPUI.002 \\
[DIRS 161787]
\end{tabular} & High $=2.96 \times 10^{-19} \mathrm{~m}^{2}$ \\
\hline \multirow[t]{3}{*}{ Matrix_Perm_TSW35 } & \multirow[t]{3}{*}{$\begin{array}{l}\text { Unsaturated zone matrix } \\
\text { permeability for TSw35 for all } \\
\text { three infiltration cases }\end{array}$} & $\begin{array}{l}\text { DTNs: } \\
\text { LB0208UZDSCPLI.002 } \\
\text { [DIRS 161788] }\end{array}$ & Low $=2.33 \times 10^{-18} \mathrm{~m}^{2}$ \\
\hline & & \begin{tabular}{|l} 
LB0208UZDSCPMI.002 \\
[DIRS 161243] \\
\end{tabular} & Mean $=4.48 \times 10^{-18} \mathrm{~m}^{2}$ \\
\hline & & \begin{tabular}{|l} 
LB0302UZDSCPUI.002 \\
[DIRS 161787] \\
\end{tabular} & High $=8.55 \times 10^{-18} \mathrm{~m}^{2}$ \\
\hline \multirow[t]{3}{*}{ Matrix_Perm_TSW36 } & \multirow[t]{3}{*}{$\begin{array}{l}\text { Unsaturated zone matrix } \\
\text { permeability for TSw36 for all } \\
\text { three infiltration cases }\end{array}$} & \begin{tabular}{|l} 
DTNs: \\
LB0208UZDSCPLI.002 \\
[DIRS 161788] \\
\end{tabular} & Low $=5.58 \times 10^{-19} \mathrm{~m}^{2}$ \\
\hline & & $\begin{array}{l}\text { LB0208UZDSCPMI.002 } \\
\text { [DIRS 161243] } \\
\end{array}$ & Mean $=2.00 \times 10^{-19} \mathrm{~m}^{2}$ \\
\hline & & \begin{tabular}{|l} 
LB0302UZDSCPUI.002 \\
[DIRS 161787] \\
\end{tabular} & High $=7.41 \times 10^{-19} \mathrm{~m}^{2}$ \\
\hline UZ_Matrix_Density & $\begin{array}{l}\text { Unsaturated zone dry matrix } \\
\text { density for TSw35 }\end{array}$ & $\begin{array}{l}\text { DTN: } \\
\text { SN0404T0503102.011 } \\
\text { [DIRS 169129] } \\
\end{array}$ & $1,980 \mathrm{~kg} \mathrm{~m}^{-3}$ \\
\hline Diff_Thick_OB_CDSP & $\begin{array}{l}\text { Outer barrier thickness for } \\
\text { CDSP waste package }\end{array}$ & Section 6.5.2.4 & $0.025 \mathrm{~m}$ \\
\hline Diff_Thick_OB_CSNF & $\begin{array}{l}\text { Outer barrier thickness for } \\
\text { CSNF waste package }\end{array}$ & Section 6.5.2.4 & $0.02 \mathrm{~m}$ \\
\hline DS_Patch_Area & $\begin{array}{l}\text { Area of a drip shield patch for } \\
\text { analysis of the flux splitting } \\
\text { experiments }\end{array}$ & Section 6.5.1.1.1 & $7.214 \times 10^{4} \mathrm{~mm}^{2}$ \\
\hline DS_Total_Width & Width of unfolded drip shield & Figure 4.1-1 & $4880 \mathrm{~mm}$ \\
\hline
\end{tabular}


Table 8.2-3. Fixed Model Inputs Used in the EBS Radionuclide Transport Abstraction (Continued)

\begin{tabular}{|c|c|c|c|}
\hline Input Name & Input Description & $\begin{array}{c}\text { Source, or Developed in } \\
\text { EBS RT Abstraction }\end{array}$ & Value \\
\hline Porosity_DSNF & DSNF porosity & Table 8.2-1 & $\begin{array}{c}0.2 \\
\text { (dimensionless) }\end{array}$ \\
\hline Rind_Saturation_CDSP & $\begin{array}{l}\text { Saturation of the CDSP waste } \\
\text { form rind }\end{array}$ & Table 8.2-1 & $\begin{array}{c}1 \\
\text { (dimensionless) } \\
\end{array}$ \\
\hline Rind_Saturation_CSNF & $\begin{array}{l}\text { Saturation of the CSNF waste } \\
\text { form rind }\end{array}$ & Table 8.2-1 & $\begin{array}{c}1 \\
\text { (dimensionless) }\end{array}$ \\
\hline WP_Crack_Area & $\begin{array}{l}\text { Area of a single crack on the } \\
\text { waste package }\end{array}$ & Section 6.3.3.1.2.1 & $7.7 \times 10^{-6} \mathrm{~m}^{2}$ \\
\hline X_length_1 & $\begin{array}{l}\text { Width of cells to the left and } \\
\text { right of the middle cells }\end{array}$ & Section 6.5.3.6 & $5.5 \mathrm{~m}$ \\
\hline Z_length_1 & $\begin{array}{l}\text { Depth of first layer of matrix- } \\
\text { fracture cells }\end{array}$ & Section 6.5.3.6 & $0.6567 \mathrm{~m}$ \\
\hline Z_length_2 & $\begin{array}{l}\text { Depth of second layer of } \\
\text { matrix-fracture cells }\end{array}$ & Section 6.5.3.6 & $1.3134 \mathrm{~m}$ \\
\hline Z_length_3 & $\begin{array}{l}\text { Depth of third layer of matrix- } \\
\text { fracture cells }\end{array}$ & Section 6.5.3.6 & $5 \mathrm{~m}$ \\
\hline Z_length_4 & $\begin{array}{l}\text { Depth of fourth layer of matrix- } \\
\text { fracture cells }\end{array}$ & Section 6.5.3.6 & $10 \mathrm{~m}$ \\
\hline Kd_Ac_FeOx_CP_a & $\begin{array}{l}K_{d} \text { value for reversible sorption } \\
\text { of Ac onto stationary corrosion } \\
\text { products }\end{array}$ & Section 6.3.4.2.3 & $0 \mathrm{ml} \mathrm{g}^{-1}$ \\
\hline Kd_Am_FeOx_CP_a & $\begin{array}{l}K_{d} \text { value for reversible sorption } \\
\text { of Am onto stationary corrosion } \\
\text { products }\end{array}$ & Section 6.3.4.2.3 & $0 \mathrm{ml} \mathrm{g}^{-1}$ \\
\hline Kd_C_FeOx_CP_a & $\begin{array}{l}K_{d} \text { value for reversible sorption } \\
\text { of C onto stationary corrosion } \\
\text { products }\end{array}$ & Section 6.3.4.2.3 & $0 \mathrm{ml} \mathrm{g}^{-1}$ \\
\hline Kd_Cs_FeOx_CP_a & $\begin{array}{l}K_{d} \text { value for reversible sorption } \\
\text { of Cs onto stationary corrosion } \\
\text { products }\end{array}$ & Section 6.3.4.2.3 & $0 \mathrm{ml} \mathrm{g}^{-1}$ \\
\hline Kd_I_FeOx_CP_a & $\begin{array}{l}K_{d} \text { value for reversible sorption } \\
\text { of I onto stationary corrosion } \\
\text { products }\end{array}$ & Section 6.3.4.2.3 & $0 \mathrm{ml} \mathrm{g}^{-1}$ \\
\hline Kd_Np_FeOx_CP_a & $\begin{array}{l}K_{d} \text { value for reversible sorption } \\
\text { of Np onto stationary corrosion } \\
\text { products }\end{array}$ & Section 6.3.4.2.3 & $0 \mathrm{ml} \mathrm{g}^{-1}$ \\
\hline Kd_Pu_FeOx_CP_a & $\begin{array}{l}K_{d} \text { value for reversible sorption } \\
\text { of Pu onto stationary corrosion } \\
\text { products }\end{array}$ & Section 6.3.4.2.3 & $0 \mathrm{ml} \mathrm{g}^{-1}$ \\
\hline Kd_Tc_FeOx_CP_a & $\begin{array}{l}K_{d} \text { value for reversible sorption } \\
\text { of Tc onto stationary corrosion } \\
\text { products }\end{array}$ & Section 6.3.4.2.3 & $0 \mathrm{ml} \mathrm{g}^{-1}$ \\
\hline Kd_Th_FeOx_CP_a & $\begin{array}{l}K_{d} \text { value for reversible sorption } \\
\text { of Th onto stationary corrosion } \\
\text { products }\end{array}$ & Section 6.3.4.2.3 & $0 \mathrm{ml} \mathrm{g}^{-1}$ \\
\hline Kd_U_FeOx_CP_a & $\begin{array}{l}K_{d} \text { value for reversible sorption } \\
\text { of } U \text { onto stationary corrosion } \\
\text { products }\end{array}$ & Section 6.3.4.2.3 & $0 \mathrm{ml} \mathrm{g}^{-1}$ \\
\hline
\end{tabular}


Table 8.2-3. Fixed Model Inputs Used in the EBS Radionuclide Transport Abstraction (Continued)

\begin{tabular}{|l|l|l|c|}
\hline \multicolumn{1}{|c|}{ Input Name } & \multicolumn{1}{c|}{ Input Description } & $\begin{array}{l}\text { Source, or Developed in } \\
\text { EBS RT Abstraction }\end{array}$ & Value \\
\hline Kd_Pa_FeOx_CP_a & $\begin{array}{l}K_{d} \text { value for reversible sorption } \\
\text { of Pa onto stationary corrosion } \\
\text { products }\end{array}$ & Section 6.3.4.2.3 & $0 \mathrm{ml} \mathrm{g}^{-1}$ \\
\hline Kd_Ra_FeOx_CP_a & $\begin{array}{l}K_{d} \text { value for reversible sorption } \\
\text { of Ra onto stationary corrosion } \\
\text { products }\end{array}$ & Section 6.3 .4 .2 .3 & $0 \mathrm{ml} \mathrm{g}^{-1}$ \\
\hline Kd_Sr_FeOx_CP_a & $\begin{array}{l}K_{d} \text { value for reversible sorption } \\
\text { of Sr onto stationary corrosion } \\
\text { products }\end{array}$ & Section 6.3.4.2.3 & $0 \mathrm{ml} \mathrm{g}^{-1}$ \\
\hline
\end{tabular}

Output DTNs: SN0410T0507703.018 and MO0506SPAINPAR.000.

IED = information exchange drawing

Table 8.2-4. Calculated Model Inputs Used in the EBS Radionuclide Transport Abstraction

\begin{tabular}{|c|c|}
\hline Input Description & $\begin{array}{l}\text { Input Equation and } \\
\text { Parameter Description }\end{array}$ \\
\hline $\begin{array}{l}\text { Equation 8-1 } \\
\text { Invert diffusion } \\
\text { coefficient } \\
\text { (Equation 6.3.4.1.1-22) }\end{array}$ & $\begin{aligned} \phi S_{w} D_{I}= & D_{0} \phi^{1.863} S_{w}^{1.863} 10^{N D(\mu=0.033, \sigma=0.218)} \\
D_{I} & =\text { effective invert diffusion coefficient }\left(\mathrm{cm}^{2} \mathrm{~s}^{-1}\right) \\
D_{0} & =\text { free water diffusion coefficient }\left(\mathrm{cm}^{2} \mathrm{~s}^{-1}\right) \\
\phi & =\text { invert bulk porosity (fraction) } \\
S_{w} & =\text { invert water saturation (fraction) } \\
N D & =\text { truncated normal distribution ( } \pm 3 \text { standard deviations from the mean) } \\
\mu & =\text { mean } \\
\sigma & =\text { standard deviation } \\
\left(D_{I}\right. & \text { is an effective value that includes the effects of tortuosity. })\end{aligned}$ \\
\hline $\begin{array}{l}\text { Equation 8-2 } \\
\text { Temperature } \\
\text { modification for invert } \\
\text { diffusion coefficient } \\
\text { (Equation 6.3.4.1.2-4) }\end{array}$ & $\begin{aligned} D_{T}=D_{T_{0}} & \frac{T}{T_{0}} 10^{\left[\frac{1.3272\left(293.15-T_{0}\right)-0.001053\left(T_{0}-293.15\right)^{2}}{T_{0}-168.15}\right]-\left[\frac{1.3272(293.15-T)-0.001053(T-293.15)^{2}}{T-168.15}\right]} \\
D_{T} & =\text { invert diffusion coefficient at temperature } T\left(\mathrm{~cm}^{2} \mathrm{~s}^{-1}\right) \\
D_{T_{0}} & =\text { invert diffusion coefficient at temperature } T_{0}\left(\mathrm{~cm}^{2} \mathrm{~s}^{-1}\right) \\
T & =\text { temperature (K); valid range: } 293.15 \mathrm{~K} \leq T \leq 373.15 \mathrm{~K} \\
T_{0} & =\text { reference temperature (K) (Invert_Viscosity_Ref_Temp) }\end{aligned}$ \\
\hline $\begin{array}{l}\text { Equation 8-3 } \\
\text { Diffusion coefficient of } \\
\text { unsaturated zone matrix } \\
\text { and fractures } \\
\text { (Equation } 6.5 .3 .6-2 \text { ) }\end{array}$ & $\begin{aligned} \log _{10} D_{m s} & =-3.49+0.0138 \theta_{m}+0.165 \log _{10} k_{m e} \\
D_{m s} & =\text { diffusion coefficient of unsaturated zone matrix }\left(\mathrm{cm}^{2} \mathrm{~s}^{-1}\right) \\
\theta_{m} & =\text { unsaturated zone matrix water content (percent) } \\
k_{m e} & =\text { effective permeability of unsaturated zone matrix }\left(\mathrm{m}^{2}\right) \\
\left(D_{m s}\right. & \text { is an effective value that includes the effects of tortuosity in the rock matrix.) }\end{aligned}$ \\
\hline
\end{tabular}


Table 8.2-4. Calculated Model Inputs Used in the EBS Radionuclide Transport Abstraction (Continued)

\begin{tabular}{|c|c|}
\hline Input Description & $\begin{array}{l}\text { Input Equation and } \\
\text { Parameter Description }\end{array}$ \\
\hline $\begin{array}{l}\text { Equation 8-4 } \\
\text { Effective permeability of } \\
\text { unsaturated zone matrix } \\
\text { (Equation } 6.5 .3 .6-3 \text { ) }\end{array}$ & $\begin{aligned} k_{m e}=k_{r m} & k_{m} \\
k_{m e} & =\text { effective permeability of unsaturated zone tuff matrix }\left(\mathrm{m}^{2}\right) \\
k_{r m} & =\text { relative permeability of unsaturated zone tuff matrix (dimensionless) } \\
k_{m} & =\text { intrinsic permeability of unsaturated zone tuff matrix }\left(\mathrm{m}^{2}\right) \\
& \text { (Matrix_Perm_TSWxx, } \mathrm{xx}=33,34,35,36)\end{aligned}$ \\
\hline $\begin{array}{l}\text { Equation 8-5 } \\
\text { Effective water } \\
\text { saturation of corrosion } \\
\text { products } \\
\text { (Equation } 6.3 .4 .3 .5-5 \text { ) }\end{array}$ & $\begin{aligned} S_{w e, C P}=3.28 \times 10^{-6} \bar{S}_{C P}(-\ln R H)^{-1 / 2.45} & \\
S_{w e, C P} & =\text { effective water saturation of corrosion products } \\
\bar{S}_{C P} & =\text { specific surface area of corrosion products }\left(\mathrm{m}^{2} \mathrm{~kg}^{-1}\right) \\
& \quad \text { (CP_Spec_Surf_Area) } \\
R H & =\text { relative humidity }\end{aligned}$ \\
\hline $\begin{array}{l}\text { Equation } 8-6 \\
\text { Pore volume of } \\
\text { corrosion products } \\
\text { (Equation 6.5.3.1.1-1) }\end{array}$ & $\begin{aligned} V_{C P}=\frac{m_{C P}}{\rho_{F e O x}} & \left(\frac{\phi_{C P}}{1-\phi_{C P}}\right) \\
V_{C P} & =\text { pore volume of corrosion products }\left(\mathrm{m}^{3}\right) \\
m_{C P} & =\text { mass of corrosion products }(\mathrm{kg}) \\
\rho_{F e O x} & =\text { density of corrosion products }\left(\mathrm{kg} \mathrm{m}^{-3}\right) \text { (Density_CP) } \\
\phi_{C P} & =\text { porosity of corrosion products }\left(\mathrm{m}^{3} \text { void } \mathrm{m}^{-3} \text { bulk volume) (Porosity_CP) }\right.\end{aligned}$ \\
\hline
\end{tabular}


Table 8.2-4. Calculated Model Inputs Used in the EBS Radionuclide Transport Abstraction (Continued)

\begin{tabular}{|c|c|}
\hline Input Description & $\begin{array}{l}\text { Input Equation and } \\
\text { Parameter Description }\end{array}$ \\
\hline $\begin{array}{l}\text { Equation 8-7 } \\
\text { Mass of corrosion } \\
\text { products } \\
\text { (Equations } 6.5 .3 .2-1 \text { to } \\
6.5 .3 .2-5 \text { ) }\end{array}$ & 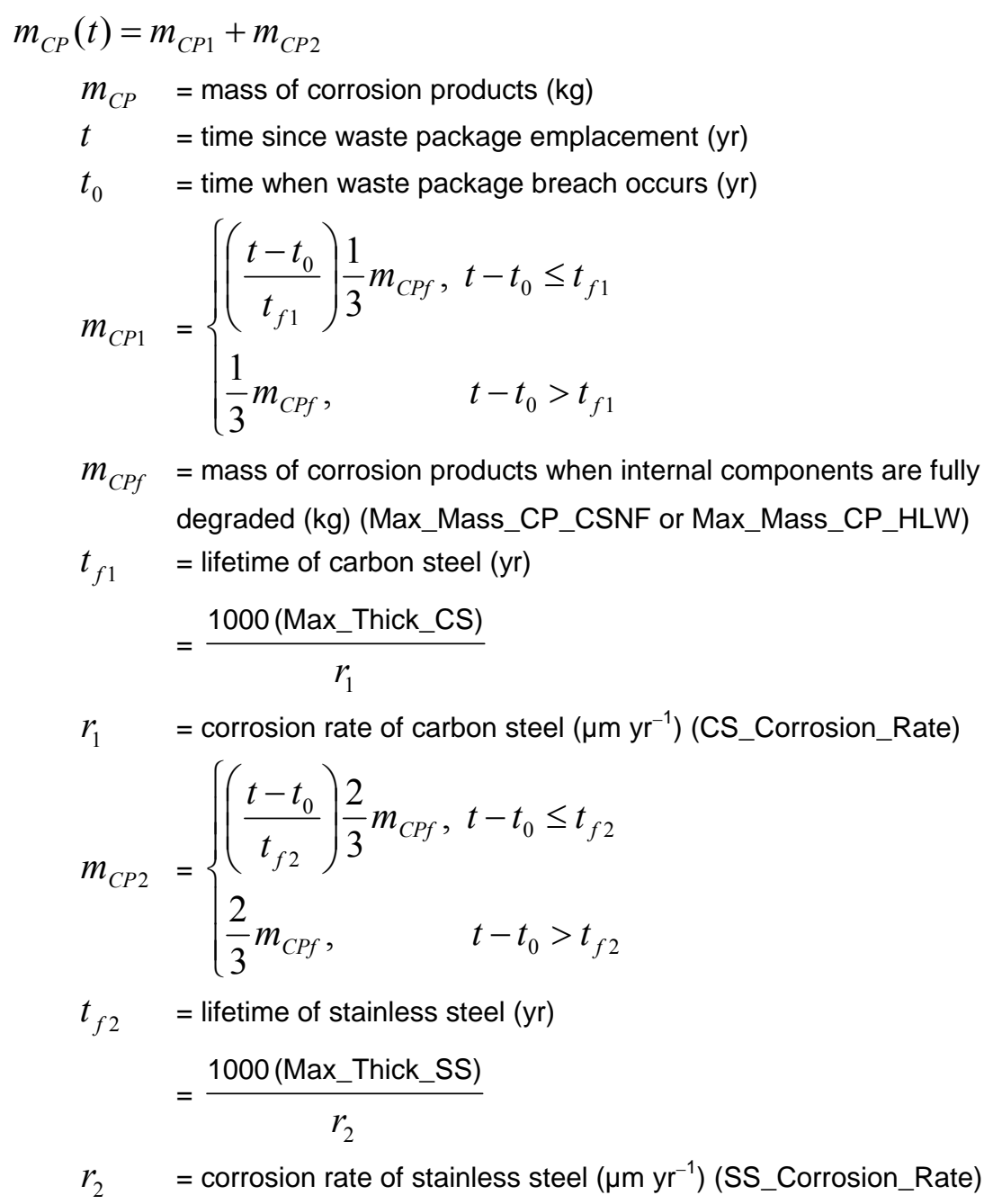 \\
\hline
\end{tabular}

Output DTN: SN0410T0507703.018. 
Input parameters for the dual-continuum invert alternative conceptual model are listed in Table 8.2-5. Equations for calculating the intergranular and intragranular diffusion coefficients are listed in Table 8.2-6.

Table 8.2-5. Invert Diffusion Coefficient Alternative Conceptual Model Parameters

\begin{tabular}{|c|c|c|c|}
\hline Input Name & Input Description & $\begin{array}{l}\text { Where Developed in } \\
\text { EBS RT Abstraction }\end{array}$ & Value \\
\hline Invert_Geometry_Coef & $\begin{array}{l}\text { Dimensionless geometry- } \\
\text { dependent coefficient for } \\
\text { intergranular-intragranular mass } \\
\text { transfer coefficient }\end{array}$ & Section 6.6.4.1 & $\begin{array}{c}8-21 \\
\text { (dimensionless) } \\
\text { Uniform }\end{array}$ \\
\hline Diff_Length_Inv_Inter_Intra & $\begin{array}{l}\text { Characteristic length of the } \\
\text { matrix structure }\end{array}$ & Section 6.6.4.1 & $5 \mathrm{~mm}$ \\
\hline Crit_Moisture_Content_Intra & $\begin{array}{l}\text { Critical moisture content of invert } \\
\text { intragranular continuum }\end{array}$ & Section 6.6.5.1 & $\begin{array}{c}0.089 \\
\text { (fraction) }\end{array}$ \\
\hline Crit_Moisture_Content_Inter & $\begin{array}{l}\text { Critical moisture content of invert } \\
\text { intergranular continuum }\end{array}$ & Section 6.6.5.1 & $\begin{array}{c}0.00932-0.0612 \\
\text { Uniform }\end{array}$ \\
\hline Diff_Threshold_Invert & $\begin{array}{l}\text { Threshold value of diffusion } \\
\text { coefficient in intragranular invert } \\
\text { continuum }\end{array}$ & Section 6.6.5.2 & $1 \times 10^{-12} \mathrm{~cm}^{2} \mathrm{~s}^{-1}$ \\
\hline Sat_Diff_Coeff_Matrix & $\begin{array}{l}\text { Diffusion coefficient in saturated } \\
\text { UZ matrix }\end{array}$ & Section 6.6.5.2 & $9.24 \times 10^{-7} \mathrm{~cm}^{2} \mathrm{~s}^{-1}$ \\
\hline
\end{tabular}

Output DTN: SN0410T0507703.018.

Table 8.2-6. Calculated Model Inputs Used in the EBS Radionuclide Transport Abstraction Invert Diffusion Coefficient Alternative Conceptual Model

\begin{tabular}{|c|c|}
\hline Input Description & $\begin{array}{l}\text { Input Equation and } \\
\text { Parameter Description }\end{array}$ \\
\hline $\begin{array}{l}\text { Equation 8-8 } \\
\text { Invert intergranular } \\
\text { continuum diffusion } \\
\text { coefficient } \\
\text { (Equation 6.6.5.2-3) }\end{array}$ & 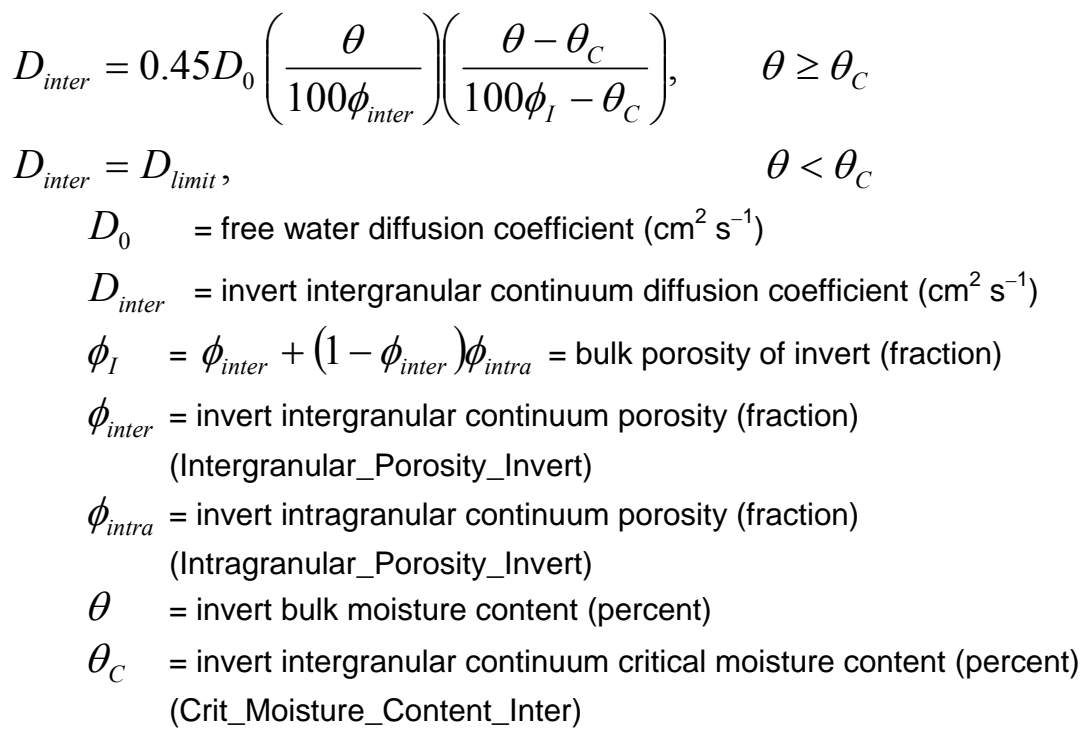 \\
\hline
\end{tabular}


Table 8.2-6. Calculated Model Inputs Used in the EBS Radionuclide Transport Abstraction Invert Diffusion Coefficient Alternative Conceptual Model (Continued)

\begin{tabular}{|c|c|}
\hline Input Description & $\begin{array}{l}\text { Input Equation and } \\
\text { Parameter Description }\end{array}$ \\
\hline $\begin{array}{l}\text { Equation 8-9 } \\
\text { Invert intragranular } \\
\text { continuum diffusion } \\
\text { coefficient } \\
\text { (Equations 6.6.5.2-5 } \\
\text { and 6.6.5.2-6) }\end{array}$ & 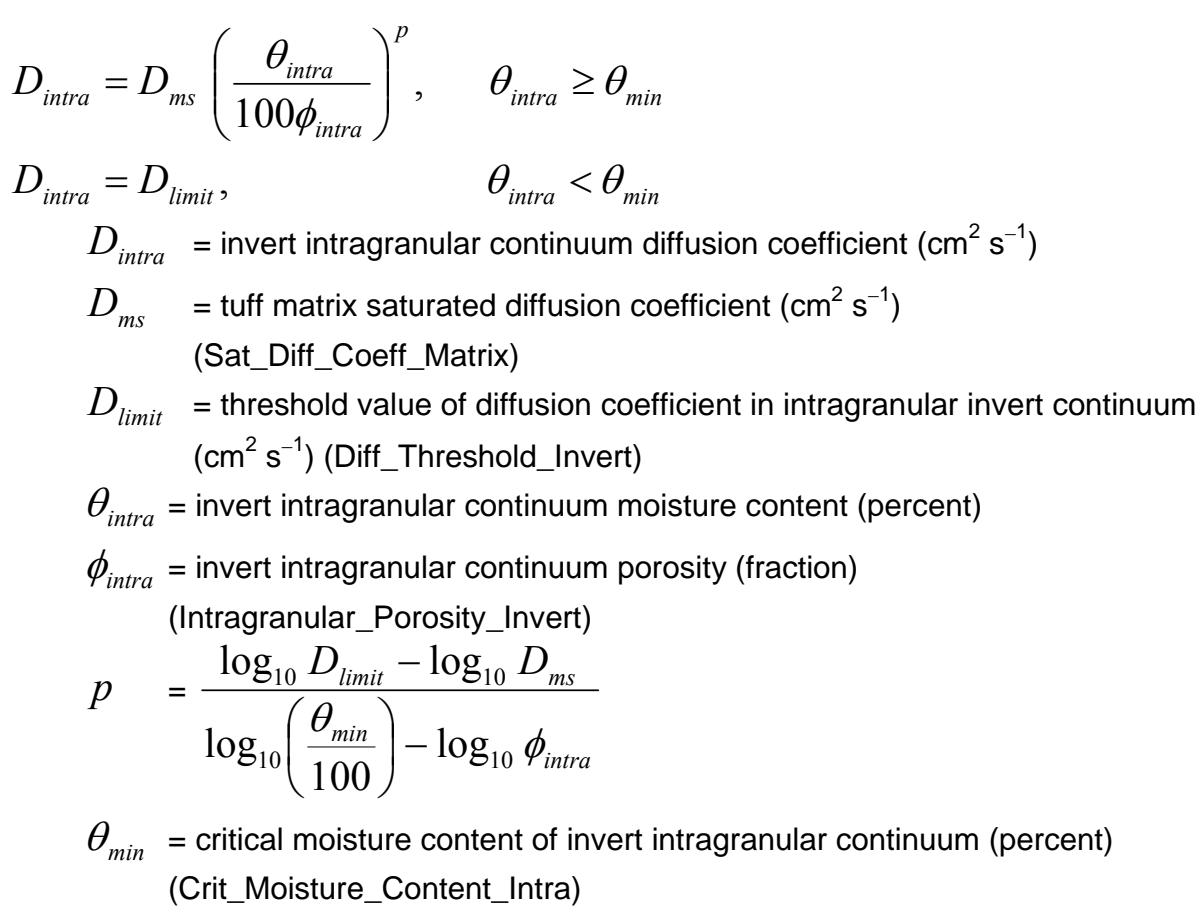 \\
\hline
\end{tabular}

Output DTN: SN0410T0507703.018.

\subsection{EVALUATION OF YUCCA MOUNTAIN REVIEW PLAN CRITERIA}

This model report documents the abstraction model for flow of liquid and transport of radionuclides through the EBS. This section provides responses to the Yucca Mountain Review Plan, Final Report acceptance criteria applicable to this model report. Being conceptual in nature, it is not possible to evaluate quantitatively many of the Yucca Mountain Review Plan, Final Report (NRC 2003 [DIRS 163274]) acceptance criteria in Section 4.2.1.

The relevance of this model report to Yucca Mountain Review Plan, Final Report (NRC 2003 [DIRS 163274], Section 2.2.1.3.3) criteria for "Quantity and Chemistry of Water Contacting Engineered Barriers and Waste Forms," which are based on meeting the requirements of 10 CFR 63.114(a)-(c) and (e)-(g) [DIRS 173273], is as follows:

\section{Acceptance Criterion 1-System Description and Model Integration are Adequate.}

(1) Total system performance assessment adequately incorporates important design features, physical phenomena, and couplings, and uses consistent and appropriate assumptions throughout the quantity and chemistry of water contacting engineered barriers and waste forms abstraction process. 
Response: The EBS radionuclide transport abstraction incorporates important design features, physical phenomena, and couplings, and uses consistent assumptions throughout the evaluation of the quantity of water contacting engineered barriers and waste forms. Sections 6.3.2 and 6.3.3 describe the conceptual model for water flux through the EBS. Section 6.5.1 describes the mathematical description of the EBS flow model. These sections provide information on seepage, effectiveness of the EBS components and mechanisms for breach or failure of the drip shield and waste package. Important general technical information related to water flow through the EBS can also be found throughout Section 6.

(2) The abstraction of the quantity and chemistry of water contacting engineered barriers and waste forms uses assumptions, technical bases, data, and models, that are appropriate and consistent with other related U.S. Department of Energy abstractions. For example, the assumptions used for the quantity and chemistry of water contacting engineered barriers and waste forms are consistent with the abstractions of "Degradation of Engineered Barriers" (NRC 2003 [DIRS 163274], Section 2.2.1.3.1); "Mechanical Disruption of Engineered Barriers" (NRC 2003 [DIRS 163274], Section 2.2.1.3.2); "Radionuclide Release Rates and Solubility Limits" (Section 2.2.1.3.4); "Climate and Infiltration" (NRC 2003 [DIRS 163274], Section 2.2.1.3.5); and "Flow Paths in the Unsaturated Zone" (NRC 2003 [DIRS 163274], Section 2.2.1.3.6). The descriptions and technical bases provide transparent and traceable support for the abstraction of quantity and chemistry of water contacting engineered barriers and waste forms.

Response: The EBS radionuclide transport abstraction uses assumptions, technical bases, data, and models that are consistent with other related U.S. Department of Energy abstractions. Sections 6.3.2, 6.3.3 and 6.5.1 of this model report provide descriptions and technical bases to support the quantity-related portion of the abstraction of quantity and chemistry of water contacting engineered barriers and waste forms. Section 5 provides assumptions that are relevant to the EBS flow model.

(3) Important design features, such as waste package design and material selection, drip shield, ground support, thermal loading strategy, and degradation processes, are considered during the determination of initial and boundary conditions for calculations of the quantity of water contacting engineered barriers and waste forms.

Response: Sections 6.3 and 6.5 provide the technical bases and details of model features for the EBS flow model. Section 6.3.2 describes drip shield design, effectiveness and breaching. Section 6.3.3 describes waste package design, breaching and impact of heat generation. Sections 6.3.3 and 6.5.3 provide invert model features.

(4) The U.S. Department of Energy reasonably accounts for the range of environmental conditions expected inside breached waste packages and in the engineered barrier environment surrounding the waste package. For example, the U.S. Department of Energy should provide a description and sufficient technical bases for its abstraction of changes in hydrologic properties in the near field, caused by coupled thermal-hydrologic-mechanical-chemical processes. 
Response: Spatial and temporal abstractions address physical couplings (thermal-hydrologicmechanical-chemical). Sections 6.3 and 6.5 provide descriptions of coupled effects for the flow model. These effects include heat generation inside the waste package and condensation on the drip shield surface. The seepage and imbibition fluxes are also the product of coupled thermal-hydrologic-mechanical-chemical processes.

(5) Sufficient technical bases and justification are provided for total system performance assessment assumptions and approximations for modeling coupled thermal-hydrologic mechanical-chemical effects on seepage and flow, the waste package chemical environment, and the chemical environment for radionuclide release. The effects of distribution of flow on the amount of water contacting the engineered barriers and waste forms are consistently addressed, in all relevant abstractions.

Response: The technical bases and justification are provided for total system performance assessment assumptions and approximations for modeling coupled thermal-hydrologicmechanical-chemical effects on flow and radionuclide release throughout Sections 5 and 6 . The effects of distribution of flow on the amount of water contacting the engineered barriers and waste forms are consistently addressed in Sections 6.3 and 6.5.

(6) The expected ranges of environmental conditions within the waste package emplacement drifts, inside of breached waste packages, and contacting the waste forms and their evolution with time are identified.

Response: These are provided in Sections 6.3, 6.5 and 6.7. Examples include the effects of the drip shield on the quantity of water (Sections 6.3.2 and 6.5.1); conditions that promote corrosion of engineered barriers and degradation of waste forms (Sections 6.3 and 6.5); wet and dry cycles; and size and distribution of penetrations of engineered barriers.

(7) The model abstraction for quantity and chemistry of water contacting engineered barriers and waste forms is consistent with the detailed information on engineered barrier design and other engineered features. For example, consistency is demonstrated for: (i) dimensionality of the abstractions; (ii) various design features and site characteristics; and (iii) alternative conceptual approaches. Analyses are adequate to demonstrate that no deleterious effects are caused by design or site features that the U.S. Department of Energy does not take into account in this abstraction.

Response: The EBS radionuclide transport abstraction is consistent with detailed information on engineered barrier design and other engineered features. Analysis discussions in Section 6 demonstrate that no deleterious effects are caused by design or site features that are not taken into account in this abstraction. Section 6.7 provides a summary discussion on the capability of the engineered barriers.

(8) Adequate technical bases are provided, including activities such as independent modeling, laboratory or field data, or sensitivity studies, for inclusion of any thermal-hydrologic-mechanical-chemical couplings and features, events, and processes. 
Response: Technical bases are provided, including activities such as independent modeling, laboratory or field data, or sensitivity studies, for inclusion of any thermal-hydrologicmechanical-chemical couplings and features, events, and processes. These are provided throughout Sections 6 and 7.

(9) Performance-affecting processes that have been observed in thermal-hydrologic tests and experiments are included into the performance assessment. For example, the U.S. Department of Energy either demonstrates that liquid water will not reflux into the underground facility or incorporates refluxing water into the performance assessment calculation, and bounds the potential adverse effects of alteration of the hydraulic pathway that result from refluxing water.

Response: Performance-affecting processes that have been observed in thermal-hydrologic tests and experiments are included primarily through the inputs (e.g., seepage values from Abstraction of Drift Seepage (BSC 2004 [DIRS 169131]), described in Section 6.3.2 of this model report, required to implement the EBS radionuclide transport abstraction.

\section{Acceptance Criterion 2-Data are Sufficient for Model Justification.}

(1) Geological, hydrological, and geochemical values used in the license application are adequately justified. Adequate description of how the data were used, interpreted, and appropriately synthesized into the parameters is provided.

Response: The EBS radionuclide transport abstraction provides the technical justification for geological, hydrological, and geochemical values used. There is also a description of how the data were used, interpreted, and synthesized into associated parameter values. Section 6.5.2 provides a summary discussion on the use and interpretation of data used in the EBS flow and transport models. The discussion includes the range, distribution and uncertainty of model data. Detailed description of data and technical justification of values used are provided throughout Sections 6.3 and 6.5.

(2) Sufficient data were collected on the characteristics of the natural system and engineered materials to establish initial and boundary conditions for conceptual models of thermal-hydrologic-mechanical-chemical coupled processes, that affect seepage and flow and the engineered barrier chemical environment.

Response: Data and sources of data are provided in Section 4.1 on the characteristics of the natural system and engineered materials needed to establish initial and boundary conditions for conceptual models of thermal-hydrologic-mechanical-chemical coupled processes that affect flow. Collection of input data used in this model report was done using acceptable techniques under the YMP quality assurance plan; specific techniques are provided in Sections 4.1.1 to 4.1.3.

(4) Sufficient information to formulate the conceptual approach(es) for analyzing water contact with the drip shield, engineered barriers, and waste forms is provided. 
Response: Information required to formulate the conceptual approaches for analyzing water contact with the drip shield, engineered barriers, and waste forms is provided in Sections 6.3 and 6.5. Sections 6.3.2, 6.3.3 and 6.5.1 present the conceptual models used for water flux through the Engineered Barrier System, together with information on drip shield effectiveness, drip shield and waste package breaching, seepage and imbibition flux from the unsaturated zone matrix.

\section{Acceptance Criterion 3-Data Uncertainty Is Characterized and Propagated Through the Model Abstraction.}

(1) Models use parameter values, assumed ranges, probability distributions, and bounding assumptions that are technically defensible, reasonably account for uncertainties and variabilities, and do not result in an under representation of the risk estimate.

Response: The EBS radionuclide transport abstraction uses parameter values, assumed ranges, probability distributions, and bounding assumptions that account for uncertainties and variabilities, and that do not result in an under-representation of the risk estimate. Section 4.1 lists the data and parameters used, together with their sources. Section 6.5.2 provides a summary of the base case model inputs together with associated uncertainties.

(2) Parameter values, assumed ranges, probability distributions, and bounding assumptions used in the total system performance assessment calculations of quantity and chemistry of water contacting engineered barriers and waste forms are technically defensible and reasonable, based on data from the Yucca Mountain region (e.g., results from large block and drift-scale heater and niche tests), and a combination of techniques that may include laboratory experiments, field measurements, natural analog research, and process-level modeling studies.

Response: Parameter values, assumed ranges, probability distributions, and bounding assumptions used in the total system performance assessment calculations of quantity of water contacting engineered barriers and waste forms are based on data from the Yucca Mountain region, laboratory experiments, field measurements, natural analog research, and process-level modeling studies. Section 4.1 lists the data and parameters used, together with their sources. Section 6.5.2 provides a summary of the base case model inputs together with associated uncertainties.

(3) Input values used in the total system performance assessment calculations of quantity and chemistry of water contacting engineered barriers (e.g., drip shield and waste package) are consistent with the initial and boundary conditions and the assumptions of the conceptual models and design concepts for the Yucca Mountain site. Correlations between input values are appropriately established in the U.S. Department of Energy total system performance assessment. Parameters used to define initial conditions, boundary conditions, and computational domain in sensitivity analyses involving coupled thermal-hydrologic-mechanical-chemical effects on seepage and flow, the waste package chemical environment, and the chemical environment for radionuclide release, are consistent with available data. Reasonable or conservative ranges of parameters or functional relations are established. 
Response: Input values used in the total system performance assessment calculations of quantity of water contacting engineered barriers (e.g., drip shield and waste package) are consistent with the initial and boundary conditions and the assumptions of the conceptual models and design concepts for the Yucca Mountain site. Reasonable or conservative ranges of parameters or functional relations have been established. Section 4.1 lists the data and parameters used, together with their sources. Section 6.5 .2 provides a summary of the base case model inputs together with associated uncertainties.

(4) Uncertainty is adequately represented in parameter development for conceptual models, process models, and alternative conceptual models considered in developing the abstraction of radionuclide release rates and solubility limits, either through sensitivity analyses or use of bounding analyses.

Response: Adequate representation of uncertainties in the characteristics of the natural system and engineered materials is provided in parameter development for conceptual models, process-level models, and alternative conceptual models. In some instances, uncertainty is constrained using conservative limits. Parameter development for the models described in this model report is provided throughout Sections 6.3, 6.4, 6.5 and 6.6.

\section{Acceptance Criterion 4-Model Uncertainty Is Characterized and Propagated Through the Model Abstraction.}

(1) Alternative modeling approaches of features, events, and processes are considered and are consistent with available data and current scientific understanding, and the results and limitations are appropriately considered in the abstraction.

Response: Alternative modeling approaches of features, events, and processes are considered in Sections 6.4 and 6.6 and are consistent with available data and current scientific understanding, and the results and limitations are considered.

(2) Alternative modeling approaches are considered and the selected modeling approach is consistent with available data and current scientific understanding. A description that includes a discussion of alternative modeling approaches not considered in the final analysis and the limitations and uncertainties of the chosen model is provided.

Response: Alternative modeling approaches are considered in Sections 6.4 and 6.6. The selected modeling approach is consistent with available data and current scientific understanding. A description that includes a discussion of alternative modeling approaches not considered in the final analysis and the limitations and uncertainties of the chosen model is provided.

(3) Consideration of conceptual model uncertainty is consistent with available site characterization data, laboratory experiments, field measurements, natural analog information and process-level modeling studies; and the treatment of conceptual model uncertainty does not result in an under-representation of the risk estimate. 
Response: Consideration of conceptual model uncertainty is consistent with available site characterization data, laboratory experiments, field measurements, natural analog information and process-level modeling studies. The fundamental relationships, e.g., mass balance and flow equations, upon which the EBS radionuclide transport abstraction is based, are well-established with a long history of use in the scientific community and as such are not subject to significant uncertainty. In addition, the alternative conceptual models have been screened out (Section 6.4), thereby increasing confidence in the selected conceptual model. Other sources of uncertainty involve modeling choices (e.g., assumptions, geometry) that, because of their conservative nature, effectively bound uncertainty. This treatment of conceptual model uncertainty does not result in an under-representation of the risk estimate.

(4) Adequate consideration is given to effects of thermal-hydrologic-mechanical-chemical coupled processes in the assessment of alternative conceptual models. These effects may include: (i) thermal-hydrologic effects on gas, water, and mineral chemistry; (ii) effects of microbial processes on the engineered barrier chemical environment and the chemical environment for radionuclide release; (iii) changes in water chemistry that may result from the release of corrosion products from the engineered barriers and interactions between engineered materials and groundwater; and (iv) changes in boundary conditions (e.g., drift shape and size) and hydrologic properties, relating to the response of the geomechanical system to thermal loading.

Response: Consideration is given in Sections 6.4 and 6.6 to effects of thermal-hydrologicmechanical-chemical coupled processes in the assessment of alternative conceptual models.

\section{Acceptance Criterion 5-Model Abstraction Output Is Supported by Objective Comparisons.}

(1) The models implemented in this total system performance assessment abstraction provide results consistent with output from detailed process-level models and/or empirical observations (laboratory and field testings and/or natural analogs).

Response: The models implemented in this total system performance assessment abstraction provide results consistent with output from detailed process-level models and/or empirical observations (laboratory testings). For example, Sections 6.5.1 and 7.1 provide comparison of the drip shield and waste package flux splitting models with breached drip shield and waste package experiments.

(2) Abstracted models for coupled thermal-hydrologic-mechanical-chemical effects on seepage and flow and the engineered barrier chemical environment, as well as on the chemical environment for radionuclide release, are based on the same assumptions and approximations demonstrated to be appropriate for process-level models or closely analogous natural or experimental systems. For example, abstractions of processes, such as thermally induced changes in hydrological properties, or estimated diversion of percolation away from the drifts, are adequately justified by comparison to results of process-level modeling, that are consistent with direct observations and field studies. 
Response: Abstracted models for coupled thermal-hydrologic-mechanical-chemical effects on flow and radionuclide release are based on the same assumptions and approximations demonstrated to be appropriate for process-level models or closely analogous natural or experimental systems, as demonstrated throughout Sections 5 and 6.

(3) Accepted and well-documented procedures are used to construct and test the numerical models that simulate coupled thermal-hydrologic-mechanical-chemical effects on seepage and flow, engineered barrier chemical environment, and the chemical environment for radionuclide release. Analytical and numerical models are appropriately supported. Abstracted model results are compared with different mathematical models, to judge robustness of results.

Response: The EBS radionuclide transport abstraction uses accepted and well-documented procedures to construct and test the numerical models that simulate coupled thermal-hydrologicmechanical-chemical effects on flow and radionuclide release, as provided throughout Sections 6 and 7. Technical support is presented for analytical and numerical models.

The relevance of this model report to the Yucca Mountain Review Plan criteria for "Radionuclide Release Rates and Solubility Limits" (NRC 2003 [DIRS 163274], Section 2.2.1.3.4), which are based on meeting the requirements of 10 CFR 63.114(a)-(c) and (e)-(g) [DIRS 173273], is as follows:

\section{Acceptance Criterion 1-System Description and Model Integration Are Adequate.}

(1) Total system performance assessment adequately incorporates important design features, physical phenomena, and couplings, and uses consistent and appropriate assumptions throughout the radionuclide release rates and solubility limits abstraction process.

Response: Total system performance assessment adequately incorporates important design features, physical phenomena, and couplings, and uses consistent and appropriate assumptions throughout the radionuclide release rates and solubility limits abstraction process. Section 6.3.4 describes the conceptual model for EBS transport model. Sections 6.5.1 and 6.5.3 describe the mathematical description of the EBS transport model components. These sections provide information on diffusion, retardation, transport through stress corrosion cracks and EBS-UZ boundary condition implementation. Important general technical information related to radionuclide transport through the EBS can also be found throughout Section 6 .

(2) The abstraction of radionuclide release rates uses assumptions, technical bases, data, and models that are appropriate and consistent with other related U.S. Department of Energy abstractions. For example, the assumptions used for this model abstraction are consistent with the abstractions of "Degradation of Engineered Barriers" (NRC 2003 [DIRS 163274], Section 2.2.1.3.1); "Mechanical Disruption of Engineered Barriers" (NRC 2003 [DIRS 163274], Section 2.2.1.3.2); "Quantity and Chemistry of Water Contacting Engineered Barriers and Waste Forms" (NRC 2003 [DIRS 163274], Section 2.2.1.3.3); "Climate and Infiltration" (NRC 2003 [DIRS 163274], Section 2.2.1.3.5); and "Flow Paths in the Unsaturated Zone" (NRC 2003 
[DIRS 163274], Section 2.2.1.3.6). The descriptions and technical bases provide transparent and traceable support for the abstraction of radionuclide release rates.

Response: The EBS radionuclide transport abstraction uses assumptions, technical bases, data, and models consistent with other related U.S. Department of Energy abstractions. The descriptions and technical bases described in Sections 6.3.4, 6.5.1, and 6.5.3 provide support for the abstraction of radionuclide release rates. Section 5 provides assumptions that are relevant to the EBS transport model.

(3) The abstraction of radionuclide release rates provides sufficient, consistent design information on waste packages and engineered barrier systems. For example, inventory calculations and selected radionuclides are based on the detailed information provided on the distribution (both spatially and by compositional phase) of the radionuclide inventory, within the various types of high-level radioactive waste.

Response: The EBS radionuclide transport abstraction provides consistent design information on waste packages and engineered barrier systems (Section 4.1 and throughout Section 6). Selected radionuclides are based on the detailed information provided on the distribution (both spatially and by compositional phase) of the radionuclide inventory, within the various types of high-level radioactive waste. Input data on radionuclides are provided in Section 4.1 and 6.5.2.

(4) The U.S. Department of Energy reasonably accounts for the range of environmental conditions expected inside breached waste packages and in the engineered barrier environment surrounding the waste package. For example, the U.S. Department of Energy should provide a description and sufficient technical bases for its abstraction of changes in hydrologic properties in the near field, caused by coupled thermal-hydrologic-mechanical-chemical processes.

Response: The EBS radionuclide transport abstraction accounts for the range of environmental conditions expected inside breached waste packages and in the engineered barrier environment surrounding the waste package. Sections 6.3 and 6.5 describe provisions for thermal, chemical, and hydrologic conditions inside and surrounding the waste package.

(5) The description of process-level conceptual and mathematical models is sufficiently complete, with respect to thermal-hydrologic processes affecting radionuclide release from the emplacement drifts. For example, if the U.S. Department of Energy uncouples coupled processes, the demonstration that uncoupled model results bound predictions of fully coupled results is adequate.

Response: The description of process-level conceptual and mathematical models, with respect to thermal-hydrologic processes affecting radionuclide release from the emplacement drifts is provided in Section 6.5.

(6) Technical bases for inclusion of any thermal-hydrologic-mechanical-chemical couplings and features, events, and processes in the radionuclide release rates and solubility Review Plan for Safety Analysis Report limits model abstraction are adequate. For example, technical bases may include activities, such as independent modeling, laboratory or field data, or sensitivity studies. 
Response: Technical bases for inclusion of thermal-hydrologic-mechanical-chemical couplings and the disposition of features, events, and processes in the EBS radionuclide transport abstraction are summarized in Section 6.2.

\section{Acceptance Criterion 2-Data Are Sufficient for Model Justification.}

(1) Geological, hydrological, and geochemical values used in the license application are adequately justified. Adequate description of how the data were used, interpreted, and appropriately synthesized into the parameters is provided.

Response: Technical justification for the geological, hydrological, and geochemical values used in the EBS radionuclide transport abstraction is provided. There is also a discussion of how the data are used, interpreted, and synthesized into associated parameters values. Section 6.5.2 provides a summary discussion on the use and interpretation of data used in the EBS flow and transport models. The discussion includes the range, distribution and uncertainty of model data. Detailed descriptions of data and technical justification of values used are provided throughout Sections 6.3 and 6.5 .

(2) Sufficient data have been collected on the characteristics of the natural system and engineered materials to establish initial and boundary conditions for conceptual models and simulations of thermal-hydrologic-chemical coupled processes. For example, sufficient data should be provided on design features, such as the type, quantity, and reactivity of materials, that may affect radionuclide release for this abstraction.

Response: Section 4.1 provides data on characteristics of the natural system and engineered materials needed to establish initial and boundary conditions for the EBS radionuclide transport abstraction conceptual models and simulations of thermal-hydrologicchemical coupled processes.

(4) The corrosion and radionuclide release testing program for high-level radioactive waste forms intended for disposal provides consistent, sufficient, and suitable data for the in-package and in-drift chemistry used in the abstraction of radionuclide release rates and solubility limits. For expected environmental conditions, the U.S. Department of Energy provides sufficient justification for the use of test results, not specifically collected from the Yucca Mountain site, for engineered barrier components, such as high-level radioactive waste forms, drip shield, and backfill.

Response: The corrosion and radionuclide release testing program for HLW forms intended for disposal provides data for the in-package and in-drift chemistry used in the EBS radionuclide transport abstraction (Section 4.1). For expected environmental conditions, the EBS radionuclide transport abstraction provides justification for the use of test results, not specifically collected from the Yucca Mountain site, for engineered barrier components, such as HLW forms and drip shield (Sections 6.3 and 6.5). 


\section{Acceptance Criterion 3-Data Uncertainty Is Characterized and Propagated Through the Model Abstraction.}

(1) Models use parameter values, assumed ranges, probability distributions, and bounding assumptions that are technically defensible, reasonably account for uncertainties and variabilities, and do not result in an under representation of the risk estimate.

Response: The EBS radionuclide transport abstraction uses parameter values, assumed ranges, probability distributions, and/or bounding assumptions that account for uncertainties and variabilities, and that do not cause an under-representation of the risk estimate. Section 4.1 lists the data and parameters used, together with their sources. Section 6.5.2 provides a summary of the base case model inputs together with associated uncertainties.

(2) Parameter values, assumed ranges, probability distributions, and bounding assumptions used in the abstractions of radionuclide release rates and solubility limits in the total system performance assessment are technically defensible and reasonable based on data from the Yucca Mountain region, laboratory tests, and natural analogs. For example, parameter values, assumed ranges, probability distributions, and bounding assumptions adequately reflect the range of environmental conditions expected inside breached waste packages.

Response: Parameter values, assumed ranges, probability distributions, and bounding assumptions used in the abstractions of radionuclide release rates and solubility limits in the total system performance assessment are based on data from the Yucca Mountain region, laboratory tests, and natural analogs. Parameter values, assumed ranges, probability distributions, and bounding assumptions reflect the range of environmental conditions expected inside breached waste packages. Section 4.1 lists the data and parameters used, together with their sources. Section 6.5.2 provides a summary of the base case model inputs together with associated uncertainties.

(3) DOE uses reasonable or conservative ranges of parameters or functional relations to determine effects of coupled thermal-hydrologic-chemical processes on radionuclide release. These values are consistent with the initial and boundary conditions and the assumptions for the conceptual models and design concepts for natural and engineered barriers at the Yucca Mountain site. If any correlations between the input values exist, they are adequately established in the total system performance assessment. For example, estimations are based on a thermal loading and ventilation strategy; engineered barrier system design (including drift liner, backfill, and drip-shield); and natural system masses and fluxes that are consistent with those used in other abstractions. 
Response: The EBS radionuclide transport abstraction uses reasonable or conservative ranges of parameters or functional relations to determine effects of coupled thermal-hydrologic-chemical processes on radionuclide release. These values are consistent with the initial and boundary conditions and the assumptions for the conceptual models and design concepts for natural and engineered barriers at the Yucca Mountain site. Section 4.1 lists the data and parameters used, together with their sources. Section 6.5 .2 provides a summary of the base case model inputs together with associated uncertainties.

(4) Uncertainty is adequately represented in parameter development for conceptual models, process models, and alternative conceptual models considered in developing the abstraction of radionuclide release rates and solubility limits, either through sensitivity analyses or use of bounding analyses.

Response: Uncertainty is represented in parameter development for conceptual models, process models, and alternative conceptual models considered in developing the abstraction of radionuclide release rates and solubility limits. Parameter development for the models described in this model report is provided throughout Sections 6.3, 6.4, 6.5, and 6.6.

(5) Parameters used to describe flow through and out of the engineered barrier, sufficiently bound the effects of backfill, excavation-induced changes, and thermally induced mechanical changes that affect flow.

Response: The EBS radionuclide transport abstraction considers the uncertainties, in the characteristics of the natural system and engineered materials, such as the type, quantity, and reactivity of material, in establishing initial and boundary conditions for conceptual models and simulations of thermal-hydrologic-chemical coupled processes that affect radionuclide release. Parameter development for the models described in this model report is provided throughout Sections 6.3, 6.4, 6.5, and 6.6.

(8) DOE adequately considers the uncertainties, in the characteristics of the natural system and engineered materials, such as the type, quantity, and reactivity of material, in establishing initial and boundary conditions for conceptual models and simulations of thermal-hydrologic-chemical coupled processes that affect radionuclide release.

Response: Parameters used to describe flow through and out of the engineered barrier bound the effects of excavation-induced changes and thermally induced mechanical changes that affect flow.

\section{Acceptance Criterion 4-Model Uncertainty Is Characterized and Propagated Through the Model Abstraction.}

(1) Alternative modeling approaches of features, events, and processes are considered and are consistent with available data and current scientific understanding, and the results and limitations are appropriately considered in the abstraction. 
Response: Alternative modeling approaches of features, events, and processes are considered in Section 6.4 and are consistent with available data and current scientific understanding, and the results and limitations are considered.

(2) In considering alternative conceptual models for radionuclide release rates and solubility limits, DOE uses appropriate models, tests, and analyses that are sensitive to the processes modeled for both natural and engineering systems. Conceptual model uncertainties are adequately defined and documented, and effects on conclusions regarding performance are properly assessed. For example, in modeling flow and radionuclide release from the drifts, DOE represents significant discrete features, such as fault zones, separately, or demonstrates that their inclusion in the equivalent continuum model produces a conservative effect on calculated performance.

Response: In considering alternative conceptual models for radionuclide release rates and solubility limits (Sections 6.4. and 6.6), the EBS radionuclide transport abstraction uses models and analyses that are sensitive to the processes modeled for both natural and engineering systems. Conceptual model uncertainties are defined and documented, and effects on conclusions regarding performance are assessed. The fundamental relationships, e.g., mass balance and flow equations, upon which the EBS radionuclide transport abstraction is based, are well-established with a long history of use in the scientific community and as such are not subject to significant uncertainty. In addition, the alternative conceptual models have been screened out (Section 6.4), thereby increasing confidence in the selected conceptual model. Other sources of uncertainty involve modeling choices (e.g., assumptions, geometry) that, because of their conservative nature, effectively bound uncertainty.

(3) Consideration of conceptual model uncertainty is consistent with available site characterization data, laboratory experiments, field measurements, natural analog information and process-level modeling studies; and the treatment of conceptual model uncertainty does not result in an under-representation of the risk estimate.

Response: Consideration of conceptual model uncertainty is consistent with available site characterization data, laboratory experiments, field measurements, natural analog information and process-level modeling studies; and the treatment of conceptual model uncertainty does not result in an under-representation of the risk estimate, as discussed throughout Section 6. Section 6.5.2 provides discussions on parameter uncertainty.

(4) The effects of thermal-hydrologic-chemical coupled processes that may occur in the natural setting, or from interactions with engineered materials, or their alteration products, on radionuclide release, are appropriately considered.

Response: The effects of thermal-hydrologic-chemical coupled processes that may occur in the natural setting or from interactions with engineered materials or their alteration products, on radionuclide release, are considered in Section 6. For example, the effect of corrosion products on the transport of radionuclides is provided in Sections 6.3.4, 6.5.1, and 6.5.3. 


\section{Acceptance Criterion 5-Model Abstraction Output Is Supported by Objective Comparisons.}

(1) The models implemented in this total system performance assessment abstraction provide results consistent with output from detailed process-level models and/or empirical observations (laboratory and field testings and/or natural analogs).

Response: The models implemented in this total system performance assessment abstraction provide results consistent with output from detailed process-level models and/or empirical observations (laboratory testings), as described in Sections 6.3, 6.5, and 7. Section 7 provides comparisons of models developed in this model report with other models and experimental results.

(3) DOE adopts well-documented procedures that have been accepted by the scientific community to construct and test the numerical models, used to simulate coupled thermal-hydrologic-chemical effects on radionuclide release. For example, DOE demonstrates that the numerical models used for high-level radioactive waste degradation and dissolution, and radionuclide release from the engineered barrier system, are adequate representations; include consideration of uncertainties; and are not likely to underestimate radiological exposures to the reasonably maximally exposed individual and releases of radionuclides into the accessible environment.

Response: The EBS radionuclide transport abstraction uses well-documented procedures in Section 6.5 that have been accepted by the scientific community to construct and test the numerical models used to simulate radionuclide release. The abstraction demonstrates that the numerical models used for radionuclide release from the EBS include consideration of uncertainties and are not likely to underestimate radiological exposures to the reasonably maximally exposed individual and releases of radionuclides into the accessible environment.

\subsection{RESTRICTIONS FOR SUBSEQUENT USE}

This abstraction was developed specifically for application in TSPA-LA. Assumptions and approximations are made in order to integrate with and be consistent with other models and abstractions incorporated in TSPA-LA. Therefore, individual submodels should not be used independently outside of the TSPA-LA framework. This abstraction must be reevaluated if any models that feed into it are modified.

Use of the three preliminary output DTNs: SN0403T0507703.015, SN0409T0507703.017, and SN0503T0503305.001 is restricted to providing traceability in TSPA-LA. For any other application, the final output DTNs: SN0410T0507703.018, MO0506SPAINPAR.000, and SN0508T0503305.003 are to be used. Differences between the preliminary and final DTNs are described in Appendix I. 


\section{INPUTS AND REFERENCES}

The following is a list of references cited in this document. Column 1 represents the unique six-digit identifier numerical identifier (the Document Input Reference System number), which is placed in the text following the reference callout (e.g., BSC 2005 [DIRS 173617]). The purpose of these numbers is to assist in locating a specific reference. Within the reference list, multiple sources by the same author (e.g., BSC 2002) are sorted alphabetically by title.

\subsection{DOCUMENTS CITED}

173033 Ainsworth, C.C.; Pilon, J.L.; Gassman, P.L.; and Van Der Sluys, W.G. 1994. "Cobalt, Cadmium, and Lead Sorption to Hydrous Iron Oxide: Residence Time Effect." Soil Science Society America Journal, 58, 1615-1623. Madison, Wisconsin: Soil Science Society of America. TIC: 257037.

171637 Anderson, M.J. 2004. "Mass for Nickel Gadolinium Neutron Absorber for Commercial Spent Nuclear Fuel (CSNF) Waste Packages--Initial Calculations (Not Yet Approved)." Interoffice memorandum from M.J. Anderson (BSC) to C. Howard, September 14, 2004, 0914043170, with enclosure.

ACC: MOL.20040928.0325.

123665 Anderson, M.P. and Woessner, W.W. 1992. Applied Groundwater Modeling, Simulation of Flow and Advective Transport. San Diego, California: Academic Press. TIC: 103227.

154430 Archie, G.E. 1942. "The Electrical Resistivity Log as an Aid in Determining Some Reservoir Characteristics." Petroleum Development and Technology, Transactions of American Institute of Mining and Metallurgical Engineers, 146, 54-62. New York, New York: American Institute of Mining and Metallurgical Engineers. TIC: 249687.

111464 Atkins, P.W. 1990. Physical Chemistry. 4th Edition. New York, New York: W.H. Freeman and Company. TIC: 245483.

174739 Bachmann, J. and van der Ploeg, R.R. 2002. “A Review on Recent Developments in Soil Water Retention Theory: Interfacial Tension and Temperature Effects." Journal of Plant Nutrition and Soil Science, 165, 468-478. Weinheim, Germany: Wiley-VCH Verlag. TIC: 257579.

173887 Bachmann, J.; Horton, R.; Grant, S.A.; and van der Ploeg, R.R. 2002.

"Temperature Dependence of Water Retention Curves for Wettable and Water-Repellent Soils." Soil Science Society America Journal, 66, 44-52. Madison, Wisconsin: Soil Science Society of America. TIC: 257501. 
170953 Baker, N.A. and Grisak, G.E. 2004. "Independent Model Validation Technical Review of the EBS-UZ Interface Sub-Model of the Radionuclide Transport Abstraction Model for the Yucca Mountain Project." Memo from N.A. Baker (INTERA) and G.E. Grisak (INTERA) to J. Schreiber and C. Howard, July 27, 2004. ACC: MOL.20040730.0182.

154439 Balsley, S.D.; Brady, P.V.; Krumhans1, J.L.; and Anderson, H.L. 1998. “Anion Scavengers for Low-Level Radioactive Waste Repository Backfills." Journal of Soil Contamination, 7, (2), 125-141. Boca Raton, Florida: Lewis Publishers.

TIC: 249779.

174702 Barney, G.S. 1984. "Radionuclide Sorption and Desorption Reactions with Interbed Materials from the Columbia River Basalt Formation.” In ACS Symposium Series 246, Chapter 1 of Geochemical Behavior of Disposed Radioactive Waste. Barney, G.S.; Navartil, J.D.; and Schulz, W.W., eds. Washington, D.C.: American Chemical Society. TIC: 206845.

101379 Bear, J. 1988. Dynamics of Fluids in Porous Media. New York, New York: Dover Publications. TIC: 217568.

154437 Bethke, C.M. and Brady, P.V. 2000. "How the Kd Approach Undermines Ground Water Cleanup." Ground Water, 38, (3), 435-443. Westerville, Ohio: National Ground Water Association. TIC: 249781.

103524 Bird, R.B.; Stewart, W.E.; and Lightfoot, E.N. 1960. Transport Phenomena. New York, New York: John Wiley \& Sons. TIC: 208957.

173707 Boily, J.F.; Lützenkirchen, J.; Balmès, O.; Beattie, J.; and Sjöberg, S. 2001. "Modeling Proton Binding at the Goethite $(\alpha-\mathrm{FeOOH})-$ Water Interface." Colloids and Surfaces A: Physicochemical and Engineering Aspects, 179, 11-27. New York, New York: Elsevier. TIC: 257303.

154421 Brady, P.V.; Spalding, B.P.; Krupka, K.M.; Waters, R.D.; Zhang, P.; Borns, D.J.; and Brady, W.D. 1999. Site Screening and Technical Guidance for Monitored Natural Attenuation at DOE Sites. SAND99-0464. Albuquerque, New Mexico: Sandia National Laboratories. TIC: 249720.

161617 Briand, L.E.; Hirt, A.M.; and Wachs, I.E. 2001. "Quantitative Determination of the Number of Surface Active Sites and the Turnover Frequencies for Methanol Oxidation over Metal Oxide Catalysts: Application to Bulk Metal Molybdates and Pure Metal Oxide Catalysts.” Journal of Catalysis, 202, ([2), 268-278. New York, New York: Academic Press. TIC: 253845.

131479 Brown, R.L. and Richards, J.C. 1970. Principles of Powder Mechanics, Essays on the Packing and Flow of Powders and Bulk Solids. Pages 17-20. New York, New York: Pergamon Press. TIC: 245119. 
154441 BSC (Bechtel SAIC Company) 2001. Committed Materials in Repository Drifts. CAL-GCS-GE-000002 REV 00. Las Vegas, Nevada: Bechtel SAIC Company. ACC: MOL.20010412.0157.

160828 BSC 2001. Unsaturated Zone and Saturated Zone Transport Properties (U0100). ANL-NBS-HS-000019 REV 00 ICN 02. Las Vegas, Nevada: Bechtel SAIC Company. ACC: MOL.20020311.0017.

158193 BSC 2002. Test Plan for: Atlas Breached Waste Package Test and Drip Shield Experiments. SITP-02-EBS-005 REV 00. Las Vegas, Nevada: Bechtel SAIC Company. ACC: MOL.20020314.0181.

158966 BSC 2002. The Enhanced Plan for Features, Events, and Processes (FEPs) at Yucca Mountain. TDR-WIS-PA-000005 REV 00. Las Vegas, Nevada: Bechtel SAIC Company. ACC: MOL.20020417.0385.

163406 BSC 2003. Atlas Breached Waste Package and Drip Shield Experiments: Breached Drip Shield Tests. TDR-EBS-MD-000025 REV 00. Las Vegas, Nevada: Bechtel SAIC Company. ACC: DOC.20030619.0001.

165159 BSC 2003. Design and Engineering, Naval Long Waste Package Configuration. 000-MW0-DNF0-00103-000-00A. Las Vegas, Nevada: Bechtel SAIC Company. ACC: ENG.20030929.0004.

168796 BSC 2003. Risk Information to Support Prioritization of Performance Assessment Models. TDR-WIS-PA-000009 REV 01 ICN 01, with errata. Las Vegas, Nevada: Bechtel SAIC Company. ACC: MOL.20021017.0045; DOC.20031014.0003.

170710 BSC 2004. 21-PWR Waste Package Configuration. 000-MW0-DSU0-00403-00000D. Las Vegas, Nevada: Bechtel SAIC Company. ACC: ENG.20040708.0005.

170838 BSC 2004. 44-BWR Waste Package Configuration. 000-MW0-DSU0-00503-00000C. Las Vegas, Nevada: Bechtel SAIC Company. ACC: ENG.20040708.0007.

169131 BSC 2004. Abstraction of Drift Seepage. MDL-NBS-HS-000019 REV 01. Las Vegas, Nevada: Bechtel SAIC Company. ACC: DOC.20041103.0003.

170026 BSC 2004. Atmospheric Dispersal and Deposition of Tephra from a Potential Volcanic Eruption at Yucca Mountain, Nevada. MDL-MGR-GS-000002 REV 01. Las Vegas, Nevada: Bechtel SAIC Company. ACC: DOC.20041025.0003; DOC.20050606.0004.

168030 BSC 2004. Characterize Framework for Seismicity and Structural Deformation at Yucca Mountain, Nevada. ANL-CRW-GS-000003 REV 00, with errata. Las Vegas, Nevada: Bechtel SAIC Company. ACC: MOL.20000510.0175; DOC.20040223.0007. 
169987 BSC 2004. CSNF Waste Form Degradation: Summary Abstraction. ANL-EBS-MD-000015 REV 02. Las Vegas, Nevada: Bechtel SAIC Company. ACC: DOC.20040908.0001.

170559 BSC 2004. D\&E / PA/C IED Emplacement Drift Configuration and Environment. 800-IED-MGR0-00202-000-00B. Las Vegas, Nevada: Bechtel SAIC Company. ACC: ENG.20040503.0001.

167207 BSC 2004. D\&E/PA/C IED Typical Waste Package Components Assembly [Sheet 2]. 800-IED-WIS0-00202-000-00B. Las Vegas, Nevada: Bechtel SAIC Company. ACC: ENG.20040202.0010.

169472 BSC 2004. D\&E/PA/C IED Typical Waste Package Components Assembly [Sheet 2]. 800-IED-WIS0-00202-000-00C. Las Vegas, Nevada: Bechtel SAIC Company. ACC: ENG.20040517.0008.

169988 BSC 2004. Defense HLW Glass Degradation Model. ANL-EBS-MD-000016 REV 02. Las Vegas, Nevada: Bechtel SAIC Company. ACC: DOC.20041020.0015.

166946 BSC 2004. Design \& Engineering, 5 DHLW/DOE SNF - Short Waste Package Configuration. 000-MW0-DS00-00102-000-00A. Las Vegas, Nevada: Bechtel SAIC Company. ACC: ENG.20040121.0002.

166947 BSC 2004. Design \& Engineering, 5 DHLW/DOE SNF - Short Waste Package Configuration. 000-MW0-DS00-00103-000-00A. Las Vegas, Nevada: Bechtel SAIC Company. ACC: ENG.20040121.0003.

166953 BSC 2004. Design and Engineering, 21-PWR Waste Package Configuration. 000-MW0-DSU0-00402-000-00B. Las Vegas, Nevada: Bechtel SAIC Company. ACC: ENG.20040119.0004.

167394 BSC 2004. Design and Engineering, 21-PWR Waste Package Configuration. 000-MW0-DSU0-00403-000-00C. Las Vegas, Nevada: Bechtel SAIC Company. ACC: ENG.20040202.0024.

167555 BSC 2004. Design and Engineering, 44-BWR Waste Package Configuration. 000-MW0-DSU0-00503-000-00B. Las Vegas, Nevada: Bechtel SAIC Company. ACC: ENG.20040213.0006.

168326 BSC 2004. Design and Engineering, Drip Shield Connector Guide. 000-M00-SSE0-02001-000-00A. Las Vegas, Nevada: Bechtel SAIC Company. ACC: ENG.20040309.0011.

168275 BSC 2004. Design and Engineering, Interlocking Drip Shield Configuration. 000-M00-SSE0-00101-000-00B. Las Vegas, Nevada: Bechtel SAIC Company. ACC: ENG.20040305.0020. 
168067 BSC 2004. Design and Engineering, Interlocking Drip Shield Configuration. 000-M00-SSE0-00102-000-00B. Las Vegas, Nevada: Bechtel SAIC Company. ACC: ENG.20040305.0021.

170028 BSC 2004. Dike/Drift Interactions. MDL-MGR-GS-000005 REV 01. Las Vegas, Nevada: Bechtel SAIC Company. ACC: DOC.20041124.0002.

170040 BSC 2004. Drift-Scale Radionuclide Transport. MDL-NBS-HS-000016 REV 01. Las Vegas, Nevada: Bechtel SAIC Company. ACC: DOC.20040927.0031.

172453 BSC 2004. DSNF and Other Waste Form Degradation Abstraction. ANL-WIS-MD-000004 REV 04. Las Vegas, Nevada: Bechtel SAIC Company. ACC: DOC.20041201.0007.

168138 BSC 2004. Estimation of Mechanical Properties of Crushed Tuff for Use as Ballast Material in Emplacement Drifts. 800-CYC-SSE0-00100-000-00A. Las Vegas, Nevada: Bechtel SAIC Company. ACC: ENG.20040309.0023.

169984 BSC 2004. General Corrosion and Localized Corrosion of Waste Package Outer Barrier. ANL-EBS-MD-000003 REV 02. Las Vegas, Nevada: Bechtel SAIC Company. ACC: DOC.20041004.0001.

168960 BSC 2004. Igneous Intrusion Impacts on Waste Packages and Waste Forms. MDL-EBS-GS-000002 REV 01. Las Vegas, Nevada: Bechtel SAIC Company. ACC: DOC.20040421.0002.

164327 BSC 2004. In-Drift Natural Convection and Condensation. MDL-EBS-MD-000001 REV 00. Las Vegas, Nevada: Bechtel SAIC Company. ACC: DOC.20041025.0006; DOC.20050330.0001.

169863 BSC 2004. In-Drift Precipitates/Salts Model. ANL-EBS-MD-000045 REV 02. Las Vegas, Nevada: Bechtel SAIC Company. ACC: DOC.20041111.0002.

170022 BSC 2004. Initial Radionuclide Inventories. ANL-WIS-MD-000020 REV 01. Las Vegas, Nevada: Bechtel SAIC Company. ACC: DOC.20040921.0003.

170001 BSC 2004. Number of Waste Packages Hit by Igneous Intrusion. ANL-MGR-GS-000003 REV 01. Las Vegas, Nevada: Bechtel SAIC Company. ACC: DOC.20041015.0001; DOC.20050602.0001.

170041 BSC 2004. Particle Tracking Model and Abstraction of Transport Processes. MDL-NBS-HS-000020 REV 01. Las Vegas, Nevada: Bechtel SAIC Company. ACC: DOC.20041020.0016.

164500 BSC 2004. Radionuclide Transport Models Under Ambient Conditions. MDL-NBS-HS-000008 REV 02. Las Vegas, Nevada: Bechtel SAIC Company. ACC: DOC.20041101.0002. 
169503 BSC 2004. Repository Subsurface Emplacement Drifts Steel Invert Structure Plan \& Elevation. 800-SS0-SSE0-00101-000-00B. Las Vegas, Nevada: Bechtel SAIC Company. ACC: ENG.20040520.0004.

169776 BSC 2004. Repository Subsurface Emplacement Drifts Steel Invert Structure Sect. \& Committed Materials. 800-SS0-SSE0-00102-000-00B. Las Vegas, Nevada: Bechtel SAIC Company. ACC: ENG.20040520.0005.

167652 BSC 2004. Seepage Model for PA Including Drift Collapse. MDL-NBS-HS-000002 REV 03. Las Vegas, Nevada: Bechtel SAIC Company. ACC: DOC.20040922.0008.

172203 BSC 2004. Stress Corrosion Cracking of the Drip Shield, the Waste Package Outer Barrier, and the Stainless Steel Structural Material. ANL-EBS-MD-000005 REV 02. Las Vegas, Nevada: Bechtel SAIC Company. ACC: DOC.20041028.0008; DOC.20050621.0003.

167083 BSC 2004. Structural Calculations of Waste Package Exposed to Vibratory Ground Motion. 000-00C-WIS0-01400-000-00A. Las Vegas, Nevada: Bechtel SAIC Company. ACC: ENG.20040217.0008.

172219 BSC 2004. Technical Management Review Board (TMRB) Decision Proposal. TMRB-2004-088. Las Vegas, Nevada: Bechtel SAIC Company.

ACC: MOL.20041027.0228.

169861 BSC 2004. UZ Flow Models and Submodels. MDL-NBS-HS-000006 REV 02. Las Vegas, Nevada: Bechtel SAIC Company. ACC: DOC.20041101.0004; DOC.20050629.0003.

169996 BSC 2004. WAPDEG Analysis of Waste Package and Drip Shield Degradation. ANL-EBS-PA-000001 REV 02. Las Vegas, Nevada: Bechtel SAIC Company. ACC: DOC.20041004.0005.

170025 BSC 2004. Waste Form and In-Drift Colloids-Associated Radionuclide Concentrations: Abstraction and Summary. MDL-EBS-PA-000004 REV 01. Las Vegas, Nevada: Bechtel SAIC Company. ACC: DOC.20041028.0007; DOC.20050425.0003.

172895 BSC 2005. Cladding Degradation Summary for LA. ANL-WIS-MD-000021 REV 03. Las Vegas, Nevada: Bechtel SAIC Company. ACC: DOC.20050222.0008.

174566 BSC 2005. Dissolved Concentration Limits of Radioactive Elements. ANL-WIS-MD-000010 REV 05. Las Vegas, Nevada: Bechtel SAIC Company. ACC: DOC.20050713.0006. 
173781 BSC 2005. Engineered Barrier System Features, Events, and Processes. ANL-WIS-PA-000002 REV 04. Las Vegas, Nevada: Bechtel SAIC Company. ACC: DOC.20050725.0003.

173727 BSC 2005. Engineered Barrier System: Physical and Chemical Environment. ANL-EBS-MD-000033 REV 04. Las Vegas, Nevada: Bechtel SAIC Company. ACC: DOC.20050718.0003.

173303 BSC 2005. IED Interlocking Drip Shield and Emplacement Pallet [Sheet 1 of 1]. 800-IED-WIS0-00401-000-00E. Las Vegas, Nevada: Bechtel SAIC Company. ACC: ENG.20050301.0007.

173501 BSC 2005. IED Waste Package Configuration [Sheet 1 of 1].

800-IED-WIS0-00601-000-00A. Las Vegas, Nevada: Bechtel SAIC Company. ACC: ENG.20050406.0005.

174583 BSC 2005. In-Package Chemistry Abstraction. ANL-EBS-MD-000037 REV 04. Las Vegas, Nevada: Bechtel SAIC Company. ACC: DOC.20050714.0003.

173944 BSC 2005. Multiscale Thermohydrologic Model. ANL-EBS-MD-000049 REV 03. Las Vegas, Nevada: Bechtel SAIC Company. ACC: DOC.20050711.0001.

174269 BSC 2005. Q-List. 000-30R-MGR0-00500-000-002. Las Vegas, Nevada: Bechtel SAIC Company. ACC: ENG.20050805.0006.

173978 BSC 2005. Screening of Features, Events, and Processes in Drip Shield and Waste Package Degradation. ANL-EBS-PA-000002 REV 04. Las Vegas, Nevada: Bechtel SAIC Company. ACC: DOC.20050620.0005.

173247 BSC 2005. Seismic Consequence Abstraction. MDL-WIS-PA-000003 REV 02E. Las Vegas, Nevada: Bechtel SAIC Company. ACC: MOL.20050718.0011.

174695 BSC 2005. Technical Management Review Board (TMRB) Decision Proposal. TMRB-2005-028. Las Vegas, Nevada: Bechtel SAIC Company. ACC: MOL.20050330.0218.

173617 BSC 2005. Technical Work Plan for: Near-Field Environment and Transport: Engineered Barrier System: Radionuclide Transport Abstraction Model Report Integration. TWP-MGR-PA-000020 REV 01. Las Vegas, Nevada: Bechtel SAIC Company. ACC: DOC.20050427.0003.

173752 Buerge-Weirich, D.; Hari, R.; Xue, H.; Behra, P.; and Sigg, L. 2002. "Adsorption of $\mathrm{Cu}, \mathrm{Cd}$, and $\mathrm{Ni}$ on Goethite in the Presence of Natural Groundwater Ligands." Environmental Science \& Technology, 36, (3), 328-336. New York, New York: American Chemical Society. TIC: 257348. 
163817 Campbell, A.N. and Smith, N.O. 1951. The Phase Rule and its Applications. 9th Edition. New York, New York: Dover Publications. TIC: 254360.

100565 Campbell, G.S. 1985. Soil Physics with BASIC Transport Models for Soil-Plant Systems. Developments in Soil Science 14. Amsterdam, The Netherlands: Elsevier. TIC: 214477.

166275 Canori, G.F. and Leitner, M.M. 2003. Project Requirements Document. TER-MGR-MD-000001 REV 02. Las Vegas, Nevada: Bechtel SAIC Company. ACC: DOC.20031222.0006.

138551 Cantrel, L.; Chaouche, R.; and Chopin-Dumas, J. 1997. "Diffusion Coefficients of Molecular Iodine in Aqueous Solutions." Journal Chemical Engineering Data, 42, 216-220. Washington, D.C.: American Chemical Society. TIC: 246757.

174705 Chien S.H. and Clayton W.R. 1980. "Application of Elovich Equation to the Kinetics of Phosphate Release and Sorption in Soils." Soil Science Society of America Journal, 44, 265-268. Madison, Wisconsin: Soil Science Society of America. TIC: 257577.

161621 Choi, H. and Corapcioglu, M.Y. 1997. "Transport of a Non-volatile Contaminant in Unsaturated Porous Media in the Presence of Colloids." Journal of Contaminant Hydrology, 25, (3-4), 299-324. New York, New York: Elsevier. TIC: 253843.

173811 Christl, I. and Kretzschmar R. 1999. "Competitive Sorption of Copper and Lead at the Oxide-Water Interface: Implications for Surface Site Density." Geochimica et Cosmochimica Acta, 63, (19/20), 2929-2938. New York, New York: Pergamon. TIC: 257338.

173020 Christophi, C. and Axe, L. 2000. "Competition of $\mathrm{Cd}, \mathrm{Cu}$, and $\mathrm{Pb}$ Adsorption on Goethite." Journal of Environmental Engineering, 126, (1), 66-74. Reston, Virginia: American Society of Civil Engineers. TIC: 257038.

101582 Conca, J.L. and Wright, J. 1990. "Diffusion Coefficients in Gravel Under Unsaturated Conditions." Water Resources Research, 26, (5), 1055-1066. Washington, D.C.: American Geophysical Union. TIC: 237421.

100436 Conca, J.L. and Wright, J. 1992. "Diffusion and Flow in Gravel, Soil, and Whole Rock." Applied Hydrogeology, 1, 5-24. Hanover, Germany: Verlag Heinz Heise GmbH. TIC: 224081.

170709 Conca, J.L.; Apted, M.; and Arthur, R. 1993. "Aqueous Diffusion in Repository and Backfill Environments." Scientific Basis for Nuclear Waste Management XVI, Symposium held November 30-December 4, 1992, Boston, Massachusetts. Interrante, C.G. and Pabalan, R.T., eds. 294, 395-402. Pittsburgh, Pennsylvania: Materials Research Society. TIC: 208880. 
174120 Constantz, J. 1991. "Comparison of Isothermal and Isobaric Water Retention Paths in Nonswelling Porous Materials." Water Resources Research, 27, (12), 3165-3170. Washington, D.C.: American Geophysical Union. TIC: 257437.

105761 Corapcioglu, M.Y. and Jiang, S. 1993. "Colloid-Facilitated Groundwater Contaminant Transport." Water Resources Research, 29, (7), 2215-2226. Washington, D.C.: American Geophysical Union. TIC: 222362.

167464 Corapcioglu, M.Y. and Wang, S. 1999. "Dual-Porosity Groundwater Contaminant Transport in the Presence of Colloids." Water Resources Research, 35, (11), 3261-3273. Washington, D.C.: American Geophysical Union. TIC: 255571.

173864 Cornell, R.M. and Giovanoli R. 1988. "The Influence of Copper on the Transformation of Ferrihydrite $\left(5 \mathrm{Fe}_{2} \mathrm{O}_{3} \cdot 9 \mathrm{H}_{2} \mathrm{O}\right)$ into Crystalline Products in Alkaline Media." Polyhedron, 7, (5), 385-391. New York, New York: Pergamon Press. TIC: 257362.

173037 Cornell, R.M. and Schwertmann, U. 2003. The Iron Oxides, Structure, Properties, Reactions, Occurrences and Uses. 2nd Edition. Weinheim, Germany: Wiley-VCH Verlagsgesellschaft. TIC: 257034.

173865 Cornell, R.M.; Schneider, W.; and Giovanoli R. 1989. "Phase Transformations in the Ferrihydrite/Cysteine System.” Polyhedron, 8, (23), 2829-2836. New York, New York: Pergamon Press. TIC: 257364.

173030 Coughlin, B.R. and Stone, A.T. 1995. "Nonreversible Adsorption of Divalent Metal Ions ( $\mathrm{Mn}^{\mathrm{II}}, \mathrm{Co}^{\mathrm{II}}, \mathrm{Ni}^{\mathrm{II}}, \mathrm{Cu}^{\mathrm{II}}$, and $\mathrm{Pb}^{\mathrm{II}}$ ) onto Goethite: Effects of Acidification, $\mathrm{Fe}^{\mathrm{II}}$ Addition, and Picolinic Acid Addition." Environmental Science Technology, 29, (9), 2445-2455. Washington, D.C.: American Chemical Society. TIC: 257061.

132164 Coughtrey, P.J.; Jackson, D.; and Thorne, M.C. 1983. Radionuclide Distribution and Transport in Terrestrial and Aquatic Ecosystems, A Critical Review of Data. Six volumes. Rotterdam, The Netherlands: A.A. Balkema. TIC: 240299.

102824 CRWMS M\&O 1997. Criticality Evaluation of Degraded Internal Configurations for the PWR AUCF WP Designs. BBA000000-01717-0200-00056 REV 00. Las Vegas, Nevada: CRWMS M\&O. ACC: MOL.19971231.0251.

135968 CRWMS M\&O 2000. Abstraction of Models for Stainless Steel Structural Material Degradation. ANL-EBS-PA-000005 REV 00. Las Vegas, Nevada: CRWMS M\&O. ACC: MOL.20000526.0337.

156680 CRWMS M\&O 2000. The Determination of Diffusion Coefficient of Invert Materials. TDR-EBS-MD-000002 REV 00. Las Vegas, Nevada: CRWMS M\&O. ACC: MOL.20000124.0320. 
153246 CRWMS M\&O 2000. Total System Performance Assessment for the Site Recommendation. TDR-WIS-PA-000001 REV 00 ICN 01. Las Vegas, Nevada: CRWMS M\&O. ACC: MOL.20001220.0045.

151566 CRWMS M\&O 2000. WAPDEG Analysis of Waste Package and Drip Shield Degradation. ANL-EBS-PA-000001 REV 00 ICN 01. Las Vegas, Nevada: CRWMS M\&O. ACC: MOL.20001208.0063.

111468 Cussler, E.L. 1997. Diffusion: Mass Transfer in Fluid Systems. 2nd Edition. Cambridge, United Kingdom: Cambridge University Press. TIC: 241150.

173743 Davis, A.P. and Upadhyaya, M. 1996. "Desorption of Cadmium from Goethite $(\alpha-\mathrm{FeOOH}) . "$ Water Research, 30, (8), 1894-1904. New York, New York: Pergamon. TIC: 257327.

143280 Davis, J.A. and Kent, D.B. 1990. "Surface Complexation Modeling in Aqueous Geochemistry." Mineral-Water Interface Geochemistry. Hochella, M.F., Jr. and White, A.F., eds. Reviews in Mineralogy Volume 23. Pages 177-260. Washington, D.C.: Mineralogical Society of America. TIC: 224085.

125591 Davis, J.A. and Leckie, J.O. 1978. "Surface Ionization and Complexation at the Oxide/Water Interface: II. Surface Properties of Amorphous Iron Oxyhydroxide and Adsorption of Metal Ions." Journal of Colloid and Interface Science, 67, (1), 90-107. Orlando, Florida: Academic Press. TIC: 223905.

154436 Davis, J.A.; Coston, J.A.; Kent, D.B.; and Fuller, C.C. 1998. "Application of the Surface Complexation Concept to Complex Mineral Assemblages." Environmental Science \& Technology, 32, (19), 2820-2828. Washington, D.C.: American Chemical Society. TIC: 249656.

171480 Dillmann, Ph.; Mazaudier, F.; and Hœrlé, S. 2004. "Advances in Understanding Atmospheric Corrosion of Iron. I. Rust Characterisation of Ancient Ferrous Artefacts Exposed to Indoor Atmospheric Corrosion.” Corrosion Science, 46, 1401 - 1429. New York, New York: Elsevier. TIC: 256483.

102588 DOE (U.S. Department of Energy) 1992. Characteristics of Potential Repository Wastes. DOE/RW-0184-R1. Four volumes. Washington, D.C.: U.S. Department of Energy, Office of Civilian Radioactive Waste Management. ACC: HQO.19920827.0001; HQO.19920827.0002; HQO.19920827.0003; HQO.19920827.0004.

123628 DOE 1998. Deficiency Report VAMO-98-D-132. Washington, D.C.: U.S. Department of Energy, Office of Civilian Radioactive Waste Management. ACC: MOL.19991029.0063. 
153849 DOE 2001. Yucca Mountain Science and Engineering Report. DOE/RW-0539. Washington, D.C.: U.S. Department of Energy, Office of Civilian Radioactive Waste Management. ACC: MOL.20010524.0272.

169875 DOE 2004. Requirements Document for: GoldSim V8.02, Rev. No. 00. Document ID: 10344-RD-8.02-00. Las Vegas, Nevada: U.S. Department of Energy, Office of Repository Development. ACC: MOL.20040623.0257.

173019 Duc, M.; Lefevre, G.; Fedoroff, M.; Jeanjean, J.; Rouchaud, J.C.; Monteil-Rivera, F.; Dumonceau, J.; and Milonjic, S. 2003. "Sorption of Selenium Anionic Species on Apatites and Iron Oxides from Aqueous Solutions." Journal of Environmental Radioactivity, 70, 61-72. New York, New York: Elsevier. TIC: 257072.

174716 Duro, L.; Missana, T.; Ripoll, S.; Grivé, M.; and Bruno, J. 2004. “Modelling of Pu Sorption onto the Surface of Goethite and Magnetite as Steel Corrosion Products." Scientific Basis for Nuclear Waste Management XXVII, Symposium held June 15-19, 2003, Kalmar, Sweden. Oversby, V.M. and Weme, L.O., eds. 807, 659-664. Warrendale, Pennsylvania: Materials Research Society. TIC: 256723.

105483 Dzombak, D.A. and Morel, F.M.M. 1990. Surface Complexation Modeling, Hydrous Ferric Oxide. New York, New York: John Wiley \& Sons. TIC: 224089.

173878 Eggleton, R.A. and Fitzpatrick, R.W. 1988. "New Data and a Revised Structural Model for Ferrihydrite." Clays and Clay Minerals, 36, (2), 111-124. Aurora, Colorado: Clay Minerals Society. TIC: 257392.

174704 Eick, M.J.; Peak, J.D.; Brady, P.V. and Pesek, J.D. 1999. "Kinetics of Lead Adsorption/Desorption on Goethite: Residence Time Effect.” Soil Science, 164, (1), 28-39. Baltimore, MD: Lippincott Williams \& Wilkins. TIC: 257580.

170376 EPA (U.S. Environmental Protection Agency) 1999. Review of Geochemistry and Available $K_{d}$ Values for Cadmium, Cesium, Chromium, Lead, Plutonium, Radon, Strontium, Thorium, Tritium $\left({ }^{3} H\right)$, and Uranium. Volume II of Understanding Variation in Partition Coefficient, $K_{d}$, Values. EPA 402-R-99-004B. Washington, D.C.: U.S. Environmental Protection Agency, Office of Radiation and Indoor Air. ACC: MOL.20040628.0034.

172215 EPA 2004. "Review of Geochemistry and Available $\mathrm{K}_{\mathrm{d}}$ Values for Americium, Arsenic, Curium, Iodine, Neptunium, Radium, and Technetium." Volume III of Understanding the Variation in Partition Coefficient, $K_{d}$, Values. EPA 402-R-04-002C. Washington, D.C.: U.S. Environmental Protection Agency. ACC: MOL.20041102.0060.

154149 EPRI (Electric Power Research Institute) 2000. Evaluation of the Candidate HighLevel Radioactive Waste Repository at Yucca Mountain Using Total System Performance Assessment, Phase 5. 1000802. Palo Alto, California: Electric Power Research Institute. TIC: 249555. 
170706 Faruque, M. 1993. LWR Fuel Assemblies PC Database (VA-M04-20004.015.C032 602465). Canyon Lake, Texas: Knowledge Dynamics. ACC: MOL.19990816.0229.

173708 Felmy, A.R. and Rustad J.R. 1998. "Molecular Statics Calculations of Proton Binding to Goethite Surfaces: Thermodynamic Modeling of the Surface Charging and Protonation of Goethite in Aqueous Solution." Geochimica et Cosmochimica Acta, 62, (1), 25-31. New York, New York: Pergamon. TIC: 257304.

173031 Fendorf, S.; Eick, M.J.; Grossl, P.; and Sparks, D.L. 1997. "Arsenate and Chromate Retention Mechanisms on Goethite. 1. Surface Structure." Environmental Science \& Technology, 31, (2), 315-320. Washington, D.C.: American Chemical Society. TIC: 257062.

173034 Fendorf, S.E.; Li, G.; and Gunter, M.E. 1996. "Micromorphologies and Stabilities of Chromium (III) Surface Precipitates Elucidated by Scanning Force Microscopy." Soil Science Society America Journal, 60, 99-106. Madison, Wisconsin: Soil Science Society America. TIC: 257036.

174727 Ford, R.G.; Bertsch, P.M.; and Farley, K.J. 1997. "Changes in Transition and Heavy Metal Partitioning during Hydrous Iron Oxide Aging." Environmental Science \& Technology, 31, (7), 2028-2033. Washington, D.C.: American Chemical Society. TIC: 257574.

154365 Freeze, G.A.; Brodsky, N.S.; and Swift, P.N. 2001. The Development of Information Catalogued in REV00 of the YMP FEP Database. TDR-WIS-MD-000003 REV 00 ICN 01. Las Vegas, Nevada: Bechtel SAIC Company. ACC: MOL.20010301.0237.

101173 Freeze, R.A. and Cherry, J.A. 1979. Groundwater. Englewood Cliffs, New Jersey: Prentice-Hall. TIC: 217571.

130407 Gabriel, U.; Gaudet, J.-P.; Spadini, L.; and Charlet, L. 1998. "Reactive Transport of Uranyl in a Goethite Column: An Experimental and Modelling Study." Chemical Geology, 151, p. 107-128. New York, New York: Elsevier. TIC: 246884.

173750 Gao, Y. and Mucci, A. 2001. "Acid Base Reactions, Phosphate and Arsenate Complexation, and Their Competitive Adsorption at the Surface of Goethite in 0.7 M NaCl Solution." Geochimica et Cosmochimica Acta, 65, (14), 2361-2378. New York, New York: Pergamon. TIC: 257331.

167466 Gerke, H.H. and van Genuchten, M.Th. 1996. "Macroscopic Representation of Structural Geometry for Simulating Water and Solute Movement in Dual-Porosity Media." Advances in Water Resources, 19, (6), 343-357. New York, New York: Elsevier. TIC: 255572. 
107880 Gertsch, R.E.; Fjeld, A.; Asbury, B.; and Ozdemir, L. 1993. Construction Applications for TSw2 TBM Cuttings at Yucca Mountain. Golden, Colorado: Colorado School of Mines. ACC: NNA.19940317.0013.

160579 GoldSim Technology Group. 2002. GoldSim Contaminant Transport Module, User's Guide. Version 1.30. Redmond, Washington: Golder Associates. TIC: 253562.

166226 GoldSim Technology Group. 2003. User's Guide, GoldSim Probabilistic Simulation Environment. Version 8.01. Redmond, Washington: Golder Associates. TIC: 255170.

154419 Graf, W.L. 1994. Plutonium and the Rio Grande, Environmental Change and Contamination in the Nuclear Age. New York, New York: Oxford University Press. TIC: 249730.

173751 Gräfe, M.; Nachtegaal, M.; and Sparks, D.L. 2004. "Formation of Metal-Arsenate Precipitates at the Goethite-Water Interface." Environmental Science \& Technology, 38, (24), 6561-6570. Washington, D.C.: American Chemical Society. TIC: 257349.

174738 Grant, S.A. and Salehzadeh, A. 1996. "Calculation of Temperature Effects on Wetting Coefficients of Porous Solids and Their Capillary Pressure Functions." Water Resources Research, 32, (2), 261-270. Washington, D.C.: American Geophysical Union. TIC: 252291.

138541 Gray, D.E., ed. 1972. American Institute of Physics Handbook. 3rd Edition. New York, New York: McGraw-Hill Book Company. TIC: 247425.

153010 Gregg, S.J. and Sing, K.S.W. 1982. Adsorption, Surface Area and Porosity. 2nd Edition. 4th Printing 1997. San Diego, California: Academic Press. TIC: 249076.

173032 Grossl, P.R.; Eick, M.; Sparks, D.L.; Goldberg, S.; and Ainsworth, C.C. 1997. "Arsenate and Chromate Retention Mechanisms on Goethite. 2. Kinetic Evaluation Using a Pressure-Jump Relaxation Technique.” Environmental Science \& Technology, 31, (2), 321-326. Washington, D.C.: American Chemical Society. TIC: 257083.

138643 Haltier, E.; Fourest, B.; and David, F. 1990. "Spectroelectrochemical Study of Uranium and Cerium in Carbonate Media." Radiochimica Acta, 51, 107-112. München, Germany: R. Oldenbourg Verlag. TIC: 246868.

173866 Hamzaoui, A.; Mgaidi, A.; Megriche, A.; and El Maaoui, M. 2002. "Kinetic Study of Goethite Formation from Ferrihydrite in Alkaline Medium." Industrial \& Engineering Chemistry Research, 41, (21), 5226-5231. Washington, D.C.: American Chemical Society. TIC: 257379. 
173742 Hansmann, D.D. and Anderson M.A. 1985. "Using Electrophoresis in Modeling Sulfate, Selenite, and Phosphate Absorption onto Goethite." Environmental Science \& Technology, 19, (6), 544-551. Washington, D.C.: American Chemical Society. TIC: 257350.

174125 Haridasan, M. and Jensen, R.D. 1972. "Effect of Temperature on Pressure HeadWater Content Relationship and Conductivity of Two Soils.” Soil Science Society of America Proceedings, 36, 703-708. Madison, Wisconsin: Soil Science Society of America. TIC: 257435.

174706 Havlin, J.L.; Westfall D.G.; and Olsen, S.R. 1985. "Mathematical Models for Potassium Release Kinetics in Calcareous Soils." Soil Science Society of America Journal, 49, 371-376. Madison, Wisconsin: Soil Science Society of America. TIC: 257578.

173817 Hayes, K.F. and Leckie, J.O. 1987. "Modeling Ionic Strength Effects on Cation Adsorption at Hydrous Oxide/Solution Interfaces." Journal of Colloid and Interface Science, 115, (2), 564-572. New York, New York: Academic Press. TIC: 226460.

117358 Hiemenz, P.C. 1986. Principles of Colloid and Surface Chemistry. 2nd Edition, Revised and Expanded. Undergraduate Chemistry Volume 9. Lagowski, J.J., ed. New York, New York: Marcel Dekker. TIC: 246392.

173023 Hiemstra, T. and Van Riemsdijk, W.H. 1996. “A Surface Structural Approach to Ion Adsorption: The Charge Distribution (CD) Model." Journal of Colloid and Interface Science, 179, 488-508. New York, New York: Academic Press. TIC: 257052.

173783 Hofmann, A.; Pelletier, M.; Michot, L.; Stradner, A.; Schurtenberger, P.; and Kretzschmar, R. 2004. "Characterization of the Pores in Hydrous Ferric Oxide Aggregates Formed by Freezing and Thawing." Journal of Colloid and Interface Science, 271, 163-173. New York, New York: Elsevier. TIC: 257504.

173711 Hofmann, A.; van Beinum, W.; Meeussen, J.C.L.; and Kretzschmar, R. 2005. "Sorption Kinetics of Strontium in Porous Hydrous Ferric Oxide Aggregates II. Comparison of Experimental Results and Model Predictions." Journal of Colloid and Interface Science, 283, 29-40. New York, New York: Elsevier. TIC: 257308.

154379 Holmes, H.F.; Fuller, E.L., Jr.; and Beh, R.A. 1974. “Adsorption of Argon, Nitrogen, and Water Vapor on Zirconium Oxide." Journal of Colloid and Interface Science, 47, (2), 365-371. New York, New York: Academic Press. TIC: 249666.

173754 Hongshao, Z. and Stanforth, R. 2001. "Competitive Adsorption of Phosphate and Arsenate on Goethite." Environmental Science \& Technology, 35, (24), 4753-4757. Washington, D.C.: American Chemical Society. TIC: 257347. 
174122 Hopmans, J.W. and Dane, J.H. 1986. "Temperature Dependence of Soil Hydraulic Properties.” Soil Science Society of America Journal, 50, 4-9. Madison, Wisconsin: Soil Science Society of America. TIC: 257434.

161516 Howard, C.L. 2002. Breached Waste Package Test and Drip Shield Experiments. Scientific Notebook SN-M\&O-SCI-043-V1. ACC: MOL.20021219.0022.

161522 Howard, C.L. 2002. Breached Waste Package Test and Drip Shield Experiments. Scientific Notebook SN-M\&O-SCI-043-V2. ACC: MOL.20021219.0023.

161623 Hu, Q.; Kneafsey, T.; Wang, J.S.Y.; Roberts, J.; and Carlson, S. 2001. Summary Report on Phase I Feasibility Study of In-Drift Diffusion. LBNL-49063. Berkeley, California: Lawrence Berkeley National Laboratory. ACC: MOL.20030225.0125.

170882 Ibrahim, S.A. and Salazar, W.R. 2000. "Physicochemical Speciation of Americium in Soils from Rocky Flats, Colorado, USA.” Journal of Radioanalytical and Nuclear Chemistry, 243, (2), 347-351. Dordrecht, The Netherlands: Kluwer Academic Publishers. TIC: 256466.

154381 Jurinak, J.J. 1964. "Interaction of Water with Iron and Titanium Oxide Surfaces: Goethite, Hematite, and Anatase." Journal of Colloid Science, 19, 477-487. New York, New York: Academic Press. TIC: 249667.

106313 Keeney-Kennicutt, W.L. and Morse, J.W. 1985. "The Redox Chemistry of $\mathrm{Pu}(\mathrm{V}) \mathrm{O}_{2}^{+}$Interaction with Common Mineral Surfaces in Dilute Solutions and Seawater." Geochimica et Cosmochimica Acta, 49, (12), 2577-2588. New York, New York: Pergamon. TIC: 237000.

111470 Keller, G.V. and Frischknecht, F.C. 1966. Electrical Methods in Geophysical Prospecting. Volume 10 of International Series in Electromagnetic Waves. Cullen, A.L.; Fock, V.A.; and Wait, J.R., eds. New York, New York: Pergamon Press. TIC: 230941.

103282 Kersting, A.B.; Efurd, D.W.; Finnegan, D.L.; Rokop, D.J.; Smith, D.K.; and Thompson, J.L. 1999. "Migration of Plutonium in Ground Water at the Nevada Test Site." Nature, 397, (6714), 56-59. London, England: Macmillan Journals. TIC: 243597.

106733 Knight, B. 1982. “Why Do Some Iron Objects Break Up In Store?” Conservation of Iron. Clarke, R.W. and Blackshaw, S.M., eds. Maritime Monographs and Reports 53-1982. Pages 50-51. London, England: National Maritime Museum. TIC: 241006.

173784 Koch, C.J.W. and Møller, P.J. 1987. "Adsorption of Nitrogen and Water Vapour onto Goethite Surfaces." Thermochimica Acta, 114, 139-144. Amsterdam, The Netherlands: Elsevier. TIC: 257505. 
173819 Kooner, Z.S. 1993. "Comparative Study of Adsorption Behavior of Copper, Lead, and Zinc onto Goethite in Aqueous Systems." Environmental Geology, 21, (4), 242-250. New York, New York: Springer-Verlag. TIC: 257356.

155761 Kügler, A. 1991. Special Sheet and Plate - Do the Job All Over the World. Mürzzuschlag, Austria: Bohler Bleche GmbH. TIC: 250553.

107760 Kügler, A. 1996. Böhler Neutronit A976 Sheet and Plate for Nuclear Engineering. Mürzzuschlag, Austria: Böhler Bleche GmbH. TIC: 240558.

100051 Langmuir, D. 1997. Aqueous Environmental Geochemistry. Upper Saddle River, New Jersey: Prentice Hall. TIC: 237107.

100913 Lee, J.H.; Chambré, P.L.; and Andrews, R.W. 1996. "Mathematical Models for Diffusive Mass Transfer from Waste Package Container with Multiple Perforations." Proceedings of the 1996 International Conference on Deep Geological Disposal of Radioactive Waste, September 16-19, 1996, Winnipeg, Manitoba, Canada. Pages 5-61-5-72. Toronto, Ontario, Canada: Canadian Nuclear Society. TIC: 233923.

154380 Lee, S. and Staehle, R.W. 1994. Report to TRW on Contract No. DX 1456KP2L, Adsorption Studies of Water on Gold, Copper, Nickel and Iron Using the Quartz-Crystal Microbalance Technique. Minneapolis, Minnesota: University of Minnesota. ACC: NNA.19940428.0129.

104943 Lee, S. and Staehle, R.W. 1997. "Adsorption of Water on Copper, Nickel, and Iron." Corrosion, 53, (1), 33-42. Houston, Texas: National Association of Corrosion Engineers. TIC: 244501.

162229 Lide, D.R., ed. 2000. CRC Handbook of Chemistry and Physics. 81st Edition. Boca Raton, Florida: CRC Press. TIC: 253056.

160832 Lide, D.R., ed. 2002. CRC Handbook of Chemistry and Physics. 83rd Edition. Boca Raton, Florida: CRC Press. TIC: 253582.

161667 Litaor, M.I. and Ibrahim, S.A. 1996. "Plutonium Association with Selected Solid Phases in Soils of Rocky Flats, Colorado, Using Sequential Extraction Technique." Journal of Environmental Quality, 25, (5), 1144-1151. Madison, Wisconsin: American Society of Agronomy. TIC: 252783.

105729 Liu, H.H.; Doughty, C.; and Bodvarsson, G.S. 1998. "An Active Fracture Model for Unsaturated Flow and Transport in Fractured Rocks." Water Resources Research, 34, (10), 2633-2646. Washington, D.C.: American Geophysical Union. TIC: 243012. 
173771 Lövgren, L.; Sjöberg, S.; and Schindler, P.W. 1990. "Acid/Base Reactions and Al(III) Complexation at the Surface of Goethite." Geochimica et Cosmochimica Acta, 54, 1301-1306. New York, New York: Pergamon Press. TIC: 257334.

174812 Low, M.J.D. 1960. "Kinetics of Chemisorption of Gases on Solids." Chemical Reviews, 60, (3), 267-312. Washington, D.C.: American Chemical Society.

166315 Lu, N.; Conca, J.; Parker, G.R.; Leonard, P.A.; Moore, B.; Strietelmeier, B.; and Triay, I.R. 2000. Adsorption of Actinides onto Colloids as a Function of Time, Temperature, Ionic Strength, and Colloid Concentration, Waste Form Colloids Report for Yucca Mountain Program (Colloid Data Summary from 1999 to 2000 Research). LA-UR-00-5121. Los Alamos, New Mexico: Los Alamos National Laboratory. ACC: MOL.20031204.0108.

174714 Lu, N.; Cotter, C.R.; Kitten, H.D.; Bentley, J.; and Triay, I.R. 1998. "Reversibility of Sorption of Plutonium-239 onto Hematite and Goethite Colloids." Radiochimica Acta, 83, 167-173. München, Germany: R. Oldenbourg Verlag. TIC: 257572.

100946 Lu, N.; Triay, I.R.; Cotter, C.R.; Kitten, H.D.; and Bentley, J. 1998. Reversibility of Sorption of Plutonium-239 onto Colloids of Hematite, Goethite, Smectite, and Silica. LA-UR-98-3057. Los Alamos, New Mexico: Los Alamos National Laboratory. ACC: MOL.19981030.0202.

173757 Lützenkirchen, J.; Boily, J-F.; Lövgren, L.; and Sjöberg, S. 2002. "Limitations of the Potentiometric Titration Technique in Determining the Proton Active Site Density of Goethite Surfaces." Geochimica et Cosmochimica Acta, 66, (19), 3389-3396. New York, New York: Pergamon. TIC: 257328.

173758 Machesky, M.L.; Andrade, W.O.; and Rose, A.W. 1991. "Adsorption of Gold(III) and Gold(I)-Thiosulfate Anions by Goethite." Geochimica et Cosmochimica Acta, 55, 769-776. Elmsford, New York: Pergamon. TIC: 257329.

174725 Manning, B.A. and Burau, R.G. 1995. "Selenium Immobilization in Evaporation Pond Sediments by In Situ Precipitation of Ferric Oxyhydroxide." Environmental Science \& Technology, 29, (10), 2639-2646. Washington, D.C.: American Chemical Society. TIC: 257575.

154383 Matsuda, T.; Taguchi, H.; and Nagao, M. 1992. "Energetic Properties of NiO Surface Examined by Heat-of-Adsorption Measurement." Journal of Thermal Analysis, 38, 1835-1845. Chichester, England: John Wiley \& Sons. TIC: 249669.

154382 McCafferty, E. and Zettlemoyer, A.C. 1970. "Entropy of Adsorption and the Mobility of Water Vapor on Alpha- $\mathrm{Fe}_{2} \mathrm{O}_{3}$." Journal of Colloid and Interface Science, 34, (3), 452-460. New York, New York: Academic Press. TIC: 249668. 
154378 McCafferty, E. and Zettlemoyer, A.C. 1971. "Adsorption of Water Vapour on Alpha-Fe ${ }_{2} \mathrm{O}_{3}$." Discussions of the Faraday Society, 52, 239-263. London, England: Gurney and Jackson. TIC: 249665.

100780 Meijer, A. 1990. Yucca Mountain Project Far-Field Sorption Studies and Data Needs. LA-11671-MS. Los Alamos, New Mexico: Los Alamos National Laboratory. ACC: MOL.19980508.1113.

173785 Micale, F.J.; Kiernan, D.; and Zettlemoyer, A.C. 1985. "Characterization of the Surface Properties of Iron Oxides.” Journal of Colloid and Interface Science, 105, (2), 570-576. New York, New York: Academic Press. TIC: 257514.

138677 Millard, A.R. and Hedges, R.E.M. 1996. "A Diffusion-Adsorption Model of Uranium Uptake by Archaeological Bone." Geochimica et Cosmochimica Acta, 60, (12), 2139-2152. New York, New York: Pergamon Press. TIC: 246791.

133392 Mills, R. 1973. "Self-Diffusion in Normal and Heavy Water in the Range 1-45․" Journal of Physical Chemistry, 77, (5), 685-688. Washington, D.C.: American Chemical Society. TIC: 246404.

138725 Mills, R. and Lobo, V.M.M. 1989. Self-Diffusion in Electrolyte Solutions, $A$ Critical Examination of Data Compiled from the Literature. Physical Sciences Data 36. Pages 314-319. New York, New York: Elsevier. TIC: 248026.

159327 Misawa, T.; Hashimoto, K.; and Shimodaira, S. 1974. "The Mechanism of Formation of Iron Oxide and Oxyhydroxides in Aqueous Solutions at Room Temperature." Corrosion Science, 14, 131-149. New York, New York: Pergamon Press. TIC: 212539.

173759 Missana, T.; García-Gutiérrez, M.; and Maffiotte, C. 2003. "Experimental and Modeling Study of the Uranium (VI) Sorption on Goethite." Journal of Colloid and Interface Science, 260, 291-301. New York, New York: Academic Press.

TIC: 257330.

130419 Mohanty, S.; Cragnolino, G.; Ahn, T.; Dunn, D.S.; Lichtner, P.C.; Manteufel, R.D.; and Sridhar, N. 1996. Engineered Barrier System Performance Assessment Code: Ebspac Version 1.0B Technical Description and User's Manual. CNWRA 96-011. San Antonio, Texas: Center for Nuclear Waste Regulatory Analyses. TIC: 233382.

162877 Morimoto, T.; Nagao, M.; and Tokuda, F. 1969. “The Relation Between the Amounts of Chemisorbed and Physisorbed Water on Metal Oxides." The Journal of Physical Chemistry, 73, (1), 243 -248. Washington, D.C.: American Chemical Society. TIC: 254165.

174703 Morse, J.W. and Choppin, G.R. 1986. "Laboratory Studies of Plutonium in Marine Systems." Marine Chemistry, 20, 73-89. Amsterdam, The Netherlands: Elsevier. TIC: 257581. 
173760 Müller, B. and Sigg, L. 1992. "Adsorption of Lead(II) on the Goethite Surface: Voltammetric Evaluation of Surface Complexation Parameters." Journal of Colloid and Interface Science, 148, (2), 517-532. New York, New York: Academic Press. TIC: 257336.

162878 Nagao, M.; Kumashiro, R.; Matsuda, T.; and Kuroda, Y. 1995. "Calorimetric Study of Water Two-Dimensionally Condensed on the Homogeneous Surface of a Solid." Thermochimica Acta, 253, (1-2), 221-233. New York, New York: Elsevier. TIC: 254099.

174394 National Research Council 2000. Natural Attenuation for Groundwater Remediation. Washington, D.C.: National Academy Press. TIC: 257470.

173018 Naveau, A.; Monteil-Rivera, F.; Dumonceau, J.; and Boudesocque, S. 2005. "Sorption of Europium on a Goethite Surface: Influence of Background Electrolyte." Journal of Contaminant Hydrology, 77, 1-16. New York, New York: Elsevier. TIC: 257071.

174124 Nimmo, J.R. and Miller, E.E. 1986. "The Temperature Dependence of Isothermal Moisture vs. Potential Characteristics of Soils." Soil Science Society of America Journal, 50, 1105-1113. Madison, Wisconsin: Soil Science Society of America. TIC: 257436.

163274 NRC (U.S. Nuclear Regulatory Commission) 2003. Yucca Mountain Review Plan, Final Report. NUREG-1804, Rev. 2. Washington, D.C.: U.S. Nuclear Regulatory Commission, Office of Nuclear Material Safety and Safeguards. TIC: 254568.

167377 Nye, P.H. 1979. "Diffusion of Ions and Uncharged Solutes in Soils and Soil Clays." Advances in Agronomy, 31, 225-272. New York, New York: Academic Press.

TIC: 255345.

154588 Olesen, T.; Moldrup, P.; and Gamst, J. 1999. "Solute Diffusion and Adsorption in Six Soils along a Soil Texture Gradient." Soil Science Society of America Journal, 63, (3), 519-524. Madison, Wisconsin: Soil Science Society of America.

TIC: 249743.

155700 Olesen, T.; Moldrup, P.; Henriksen, K.; and Petersen, L.W. 1996. "Modeling Diffusion and Reaction in Soils: IV. New Models for Predicting Ion Diffusivity." Soil Science, 161, (10), 633-645. Baltimore, Maryland: Williams \& Wilkins. TIC: 250477.

173799 Or, D. and Tuller, M. 1999. "Liquid Retention and Interfacial Area in Variability Saturated Porous Media: Upscaling from Single-Pore To Sample-Scale Model." Water Resources Research, 35, (12), 3591-3605. Washington, D.C.: American Geophysical Union. TIC: 257326. 
174071 Painter, S.; Cvetkovic, V.; Pickett, D.; and Turner, D.R. 2002. "Significance of Kinetics for Sorption of Inorganic Colloids: Modeling and Experiment Interpretation Issues." Environmental Science \& Technology, 36, (24), 5369-5375. Washington, D.C.: American Chemical Society. TIC: 257438.

174707 Payne, T.E.; Davis, J.A.; and Waite, T.D. 1994. "Uranium Retention by Weathered Schists - The Role of Iron Minerals.” Radiochimica Acta, 66/67, 297-303. München, Germany: R. Oldenbourg Verlag. TIC: 257571.

138732 Perry, D.L.; Phillips, S.L.; and Chung, J.D. 1988. "Potentiostatic Measurement of the Diffusion Coefficient of $\mathrm{UO}_{2}{ }^{2+}$ in Carbonate Media." Inorganica Chimica Acta, 149, 301-304. Lausanne, Switzerland: Elsevier. TIC: 246806.

104946 Perry, R.H. and Chilton, C.H., eds. 1973. Chemical Engineers' Handbook. 5th Edition. New York, New York: McGraw-Hill. TIC: 242591.

119529 Perry, R.H.; Chilton, C.H.; and Kirkpatrick, S.D., eds. 1963. Chemical Engineers' Handbook. 4th Edition. New York, New York: McGraw-Hill. TIC: 237828.

173762 Persson, P.; Nordin, J.; Rosenqvist, J.; Lövgren, L.; Öhman, L-O.; and Sjöberg, S. 1998. "Comparison of the Adsorption of o-Phthalate on Boehmite $(\gamma-\mathrm{AlOOH})$, Aged $\left(\gamma-\mathrm{Al}_{2} \mathrm{O}_{3}\right.$, and Goethite $(\alpha-\mathrm{Fe}-\mathrm{OOH})$." Journal of Colloid and Interface Science, 206, 252-266. New York, New York: Academic Press. TIC: 257283.

105743 Philip, J.R.; Knight, J.H.; and Watcher, R.T. 1989. "Unsaturated Seepage and Subterranean Holes: Conspectus, and Exclusion Problem for Circular Cylindrical Cavities." Water Resources Research, 25, (1), 16-28. Washington, D.C.: American Geophysical Union. TIC: 239117.

111477 Pirson, S.J. 1963. Handbook of Well Log Analysis for Oil and Gas Formation Evaluation. Englewood Cliffs, New Jersey: Prentice-Hall. TIC: 245393.

173714 Pivovarov, S. 1997. "Surface Structure and Site Density of the Oxide-Solution Interface." Journal of Colloid and Interface Science, 196, 321-323. New York, New York: Academic Press. TIC: 257309.

123115 Porter, L.K.; Kemper, W.D.; Jackson, R.D.; and Stewart, B.A. 1960. "Chloride Diffusion in Soils as Influenced by Moisture Content." Soil Science Society of America Proceedings, 24, (5), 460-463. Danville, Illinois: Soil Science Society of America. TIC: 246854.

174726 Powell, B.A.; Fjeld, R.A.; Kaplan, D.I.; Coates, J.T.; and Serkiz, S.M. 2005. "Pu(V)O ${ }_{2}^{+}$Adsorption and Reduction by Synthetic Hematite and Goethite." Environmental Science \& Technology, 39, (7), 2107-2114. Washington, D.C.: American Chemical Society. TIC: 257576. 
173709 Randall, S.R.; Sherman, D.M.; Ragnardottir, K.V.; and Collins, C.R. 1999. "The Mechanism of Cadmium Surface Complexation on Iron Oxyhydroxide Minerals." Geochimica et Cosmochimica Acta, 63, (19/20), 2971-2987. New York, New York: Pergamon. TIC: 257307.

154434 Reardon, E.J. 1981. "Kd's - Can They be Used to Describe Reversible Ion Sorption Reactions in Contaminant Migration?” Ground Water, 19, (3), 279-286. Worthington, Ohio: Water Well Journal Publishing Company. TIC: 249726.

163008 Reimus, P.W.; Ware, S.D.; Benedict, F.C.; Warren, R.G.; Humphrey, A.; Adams, A.; Wilson, B.; and Gonzales, D. 2002. Diffusive and Advective Transport of ${ }^{3} \mathrm{H}$, ${ }^{14} \mathrm{C}$, and ${ }^{99}$ Tc in Saturated, Fractured Volcanic Rocks from Pahute Mesa, Nevada. LA-13891-MS. Los Alamos, New Mexico: Los Alamos National Laboratory. TIC: 253905.

173846 Rhoades, J.D. and Oster, J.D. 1986. "Solute Content." Chapter 42 of Methods of Soil Analysis, Part 1 Physical and Mineralogical Methods. Klute, A., ed. 2nd Edition. Madison, Wisconsin: Soil Science Society of America. TIC: 217566.

173835 Rhoades, J.D.; Raats, P.A.C.; and Prather, R.J. 1976. "Effects of Liquid-Phase Electrical Conductivity, Water Content, and Surface Conductivity on Bulk Soil Electrical Conductivity." Soil Science Society America Journal, 40, (5), 651-655. Madison, Wisconsin: Soil Science Society of America. TIC: 257324.

101710 Roberts, J.J. and Lin, W. 1997. "Electrical Properties of Partially Saturated Topopah Spring Tuff: Water Distribution as a Function of Saturation." Water Resources Research, 33, (4), 577-587. Washington, D.C.: American Geophysical Union. TIC: 239736.

173763 Robertson, A.P. and Leckie, J.O. 1997. "Cation Binding Predictions of Surface Complexation Models: Effects of $\mathrm{pH}$, Ionic Strength, Cation Loading, Surface Complex, and Model Fit." Journal of Colloid and Interface Science, 188, 444-472. New York, New York: Academic Press. TIC: 257300.

173710 Rodda, D.P.; Johnson, B.B.; and Wells, J.D. 1996. "Modeling the Effect of Temperature on Adsorption of Lead(II) and Zinc(II) onto Goethite at Constant pH." Journal of Colloid and Interface Science, 184, 365-377. New York, New York: Academic Press. TIC: 257312.

174022 Romero E.; Gens, A.; and Lloret, A. 2001. "Temperature Effects on the Hydraulic Behaviour of an Unsaturated Clay." Geotechnical and Geological Engineering, 19, 311-332. Amsterdam, The Netherlands: Kluwer Academic Publishers.

TIC: 257400.

138739 Rosch, F. and Khalkin, V.A. 1990. "Ion Mobilities of Trivalent f-Elements in Aqueous Electrolytes." Radiochimica Acta, 51, 101-106. Munich, Germany: R. Oldenbourg Verlag. TIC: 246710. 
168432 Runde, W.; Conradson, S.D.; Efurd, D.W.; Lu, N.P.; VanPelt, C.E.; and Tait, C.D. 2002. "Solubility and Sorption of Redox-Sensitive Radionuclides (Np, Pu) in J-13 Water from the Yucca Mountain Site: Comparison between Experiment and Theory." Applied Geochemistry, 17, (6), 837-853. New York, New York: Pergamon. TIC: 254046.

155697 Russo, R.E.; Mao, X.; Borisov, O.V.; and Liu, H. 2000. "Laser Ablation in Atomic Spectroscopy." Encyclopedia of Analytical Chemistry. Meyers, R.A., ed. Pages 9485-9506. Chichester, England: John Wiley \& Sons. TIC: 250479.

173766 Rustad, J.R.; Felmy, A.R.; and Hay, B.P. 1996. "Molecular Statics Calculations of Proton Binding to Goethite Surfaces: A New Approach to Estimation of Stability Constants for Multisite Surface Complexation Models." Geochimica et Cosmochimica Acta, 60, (9), 1563-1576. New York, New York: Pergamon. TIC: 257333.

173812 Sahai, N. and Sverjensky D.A. 1997. "Evaluation of Internally Consistent Parameters for the Triple-Layer Model by the Systematic Analysis of Oxide Surface Titration Data." Geochimica et Cosmochimica Acta, 61, (14), 2801-2826. New York, New York: Pergamon. TIC: 257337.

107213 Sanchez, A.L.; Murray, J.W.; and Sibley, T.H. 1985. "The Adsorption of Plutonium IV and V on Goethite." Geochimica et Cosmochimica Acta, 49, (11), 2297-2307. New York, New York: Pergamon Press. TIC: 224091.

170923 Santschi, P.H.; Roberts, K.A.; and Guo, L. 2002. “Organic Nature of Colloidal Actinides Transported in Surface Water Environments." Environmental Science \& Technology, 36, (17), 3711-3719. Washington, D.C.: American Chemical Society. TIC: 256463.

173028 Schultz, M.F.; Benjamin, M.M.; and Ferguson, J.F. 1987. “Adsorption and Desorption of Metals on Ferrihydrite: Reversibility of the Reaction and Sorption Properties of the Regenerated Solid.” Environmental Science Technology, 21, (9), 863-869. Washington, D.C.: American Chemical Society. TIC: 257057.

144629 Schwertmann, U. and Cornell, R.M. 1991. Iron Oxides in the Laboratory: Preparation and Characterization. New York, New York: VCH Publishers. TIC: 237942.

173863 Schwertmann, U.; Friedl, J.; Stanjek, H.; and Schulze, D.G. 2000. "The Effect of $\mathrm{Al}$ on Fe Oxides. XIX. Formation of Al-Substituted Hematite from Ferrihydrite at $25^{\circ} \mathrm{C}$ and $\mathrm{pH} 4$ to 7." Clays and Clay Minerals, 48, (2), 159-172. Aurora, Colorado: Clay Minerals Society. TIC: 257393. 
173836 Shainberg, I.; Rhoades, J.D.; and Prather, R.J 1980. "Effect of Exchangeable Sodium Percentage, Cation Exchange Capacity, and Soil Solution Concentration on Soil Electrical Conductivity." Soil Science Society America Journal, 44, (3), 469-473. Madison, Wisconsin: Soil Science Society of America. TIC: 257317.

167469 Šimunek, J.; Jarvis, N.J.; van Genuchten, M.Th.; and Gardenas, A. 2003. "Review and Comparison of Models for Describing Non-Equilibrium and Preferential Flow and Transport in the Vadose Zone." Journal of Hydrology, 272, (1-4), 14-35. New York, New York: Elsevier. TIC: 255570.

161624 Singh, A.K.; Singh, H.; Singh, S.P.; and Sawhney, R.L. 2002. "Numerical Calculation of Psychrometric Properties on a Calculator." Building and Environment, 37, (4), 415-419. New York, New York: Elsevier. TIC: 253846.

170588 So, H.B. and Nye, P.H. 1989. "The Effect of Bulk Density, Water Content and Soil Type on the Diffusion of Chloride in Soil." Journal of Soil Science, 40, (4), 743-749. Oxford, England: Blackwell Scientific. TIC: 255392.

127253 Sposito, G. 1984. The Surface Chemistry of Soils. New York, New York: Oxford University Press. TIC: 217687.

141778 Stumm, W. 1992. Chemistry of the Solid-Water Interface, Processes at the Mineral-Water and Particle-Water Interface in Natural Systems. New York, New York: John Wiley \& Sons. TIC: 237213.

118706 Tada, H.; Paris, P.C.; and Irwin, G.R. 1973. The Stress Analysis of Cracks Handbook. St. Louis, Missouri: Del Research Corporation. TIC: 247050.

161625 Tamura, H.; Tanaka, A.; Mita, K.; and Furuichi, R. 1999. "Surface Hydroxyl Site Densities on Metal Oxides as a Measure for the Ion-Exchange Capacity." Journal of Colloid and Interface Science, 209, (1), 225-231. New York, New York: Academic Press. TIC: 253844.

155334 Towe, K.M. and Bradley, W.F. 1967. "Mineralogical Constitution of Colloidal 'Hydrous Ferric Oxides'." Journal of Colloid and Interface Science, 24, 384-392. New York, New York: Academic Press. TIC: 250230.

173021 Trivedi, P.; Axe, L.; and Dyer, J. 2001. "Adsorption of Metal Ions onto Goethite: Single-Adsorbate and Competitive Systems." Colloids and Surfaces, 191, 107-121. New York, New York: Elsevier. TIC: 257088.

138747 Tsukamoto, M.; Ohe, T.; Fujita, T.; Hesbol, R.; and Hermansson, H-P. 1994. "Diffusion of Neptunium(V) in Loosely Compacted Sodium Bentonite." Radiochimica Acta, 66/67, 397-403. München, Germany: R. Oldenbourg Verlag. TIC: 246893. 
144702 Van Geen, A.; Robertson, A.P.; and Leckie, J.O. 1994. "Complexation of Carbonate Species at the Goethite Surface: Implications for Adsorption of Metal Ions in Natural Waters." Geochimica et Cosmochimica Acta, 58, (9), 2073-2086. New York, New York: Elsevier. TIC: 212000.

100610 van Genuchten, M.T. 1980. "A Closed-Form Equation for Predicting the Hydraulic Conductivity of Unsaturated Soils." Soil Science Society of America Journal, 44, (5), 892-898. Madison, Wisconsin: Soil Science Society of America.

TIC: 217327.

173017 Villalobos, M.; Trotz, M.A.; and Leckie, J.O. 2003. "Variability in Goethite Surface Site Density: Evidence from Proton and Carbonate Sorption." Journal of Colloid and Interface Science, 268, 273-287. New York, New York: Elsevier. TIC: 257076.

124994 Wan, J. and Wilson, J.L. 1994. "Visualization of the Role of the Gas-Water Interface on the Fate and Transport of Colloids in Porous Media." Water Resources Research, 30, (1), 11-23. Washington, D.C.: American Geophysical Union. TIC: 246300.

173035 Watson, E.B. 1996. "Surface Enrichment and Trace-Element Uptake during Crystal Growth." Geochimica et Cosmochimica Acta, 60, (24), 5013-5020. Tarrytown, New York: Elsevier. TIC: 257077.

100833 Weast, R.C. and Astle, M.J., eds. 1981. CRC Handbook of Chemistry and Physics. 62nd Edition. Boca Raton, Florida: CRC Press. TIC: 240722.

111561 Weast, R.C., ed. 1985. CRC Handbook of Chemistry and Physics. 66th Edition. Boca Raton, Florida: CRC Press. TIC: 216054.

173713 Xue, Y. and Traina, S.J. 1996. "Cosolvent Effect on Goethite Surface Protonation." Environmental Science \& Technology, 30, (11), 3161 - 3166. Washington, D.C.: American Chemical Society. TIC: 257272.

104441 YMP (Yucca Mountain Site Characterization Project) 1998. Disposal Criticality Analysis Methodology Topical Report. YMP/TR-004Q, Rev. 00. Las Vegas, Nevada: Yucca Mountain Site Characterization Office.

ACC: MOL.19990210.0236.

\subsection{CODES, STANDARDS, REGULATIONS, AND PROCEDURES}

173273 10 CFR 63. 2005 Energy: Disposal of High-Level Radioactive Wastes in a Geologic Repository at Yucca Mountain, Nevada. ACC: MOL.20050405.0118.

AP-2.22Q, Rev. 1, ICN 1. Classification Analyses and Maintenance of the Q-List. Washington, D.C.: U.S. Department of Energy, Office of Civilian Radioactive Waste Management. ACC: DOC.20040714.0002. 
154085 ASM 1979. Properties and Selection: Nonferrous Alloys and Pure Metals. Volume 2 of Metals Handbook. 9th Edition. Metals Park, Ohio: American Society for Metals. TIC: 209800.

147578 ASTM A 20/A20M-99a. 1999. Standard Specification for General Requirements for Steel Plates for Pressure Vessels. West Conshohocken, Pennsylvania: American Society for Testing and Materials. TIC: 247403.

162724 ASTM A 588/A 588M-01. 2001. Standard Specification for High-Strength LowAlloy Structural Steel with 50 ksi [345 MPa] Minimum Yield Point to 4-in. [100 mm] Thick. West Conshohocken, Pennsylvania: American Society for Testing and Materials. TIC: 253998.

159971 ASTM A 759-00. 2001. Standard Specification for Carbon Steel Crane Rails. West Conshohocken, Pennsylvania: American Society for Testing and Materials. TIC: 253176.

168403 ASTM B 932-04. 2004. Standard Specification for Low-Carbon Nickel-ChromiumMolybdenum-Gadolinium Alloy Plate, Sheet, and Strip. West Conshohocken, Pennsylvania: American Society for Testing and Materials. TIC: 255846.

103515 ASTM G 1-90 (Reapproved 1999). 1999. Standard Practice for Preparing, Cleaning, and Evaluating Corrosion Test Specimens. West Conshohocken, Pennsylvania: American Society for Testing and Materials. TIC: 238771.

LP-2.29Q-BSC, Rev. 0, ICN 1. Planning for Science Activities. Washington, D.C.: U.S. Department of Energy, Office of Civilian Radioactive Waste Management. ACC: DOC.20050718.0002.

LP-SI.11Q-BSC, Rev. 0, ICN 01. Software Management. Washington, D.C.: U.S. Department of Energy, Office of Civilian Radioactive Waste Management.

ACC: DOC.20041005.0008

LP-SIII.2Q-BSC, Rev. 0, ICN 0. Qualification of Unqualified Data. Washington, D.C.: U.S. Department of Energy, Office of Civilian Radioactive Waste Management. ACC: DOC.20050119.0002.

LP-SIII.10Q-BSC, Rev. 0, ICN 1. Models. Washington, D.C.: U.S. Department of Energy, Office of Civilian Radioactive Waste Management.

ACC: DOC.20050623.0001. 


\subsection{SOURCE DATA, LISTED BY DATA TRACKING NUMBER}

148751 LA0003AM831341.001. Probability Distributions for Sorption Coefficients (Kd's). Submittal date: 03/29/2000.

150272 LA0004NL831352.001. Pu(IV) and Pu(V) Sorption on Hematite and Goethite Colloids with Natural and Synthetic J-13 Water (1997-98 Data). Submittal date: 04/04/2000.

167015 LA0311AM831341.001. Correlation Matrix for Sampling of Sorption Coefficient Probability Distributions. Submittal date: 11/06/2003.

171584 LA0408AM831341.001. Unsaturated Zone Distribution Coefficients (Kds) for U, Np, Pu, Am, Pa, Cs, Sr, Ra, and Th. Submittal date: 08/24/2004.

159525 LB0205REVUZPRP.001. Fracture Properties for UZ Model Layers Developed from Field Data. Submittal date: 05/14/2002.

159672 LB0207REVUZPRP.002. Matrix Properties for UZ Model Layers Developed from Field and Laboratory Data. Submittal date: 07/15/2002.

161788 LB0208UZDSCPLI.002. Drift-Scale Calibrated Property Sets: Lower Infiltration Data Summary. Submittal date: 08/26/2002.

161243 LB0208UZDSCPMI.002. Drift-Scale Calibrated Property Sets: Mean Infiltration Data Summary. Submittal date: 08/26/2002.

162379 LB03013DSSCP3I.001. 3-D Site Scale Calibrated Properties: Data Summaries. Submittal date: 01/27/2003.

161787 LB0302UZDSCPUI.002. Drift-Scale Calibrated Property Sets: Upper Infiltration Data Summary. Submittal date: 02/05/2003.

165451 LB0307FMRADTRN.001. Fracture-Matrix Partitioning Model: Spreadsheet Calculations. Submittal date: 07/31/2003.

153044 MO0003RIB00076.000. Physical and Chemical Characteristics of Type 316N Grade. Submittal date: 03/14/2000.

169973 MO0107TC239753.000. ASME Boiler and Pressure Vessel Code, Sec II B SB-575 Specification for Low-Carbon Nickel-Molybdenum-Chromium, Low-Carbon. Submittal date: 07/23/2004.

169970 MO0107TC240032.000. Standard Specification for Pressure Vessel Plates, Carbon Steel, for Moderate- and-Lower-Temperature Service. Submittal date: 07/19/2001. 
163399 MO0207EBSATBWP.021. Atlas Breached Waste Package and Drip Shield Experiments: Initial Tests for Rough Drip Shield Surface. Submittal date: 07/31/2002.

163400 MO0207EBSATBWP.022. Atlas Breached Waste Package and Drip Shield Experiments: Initial Tests for Smooth Drip Shield Surface. Submittal date: 07/31/2002.

163402 MO0207EBSATBWP.023. Atlas Breached Waste Package and Drip Shield Experiments: Single Patch Q(Splash) and Q(Film) Tests on the Smooth Drip Shield Surface. Submittal date: 07/31/2002.

163401 MO0207EBSATBWP.024. Atlas Breached Waste Package and Drip Shield Experiments: Multiple Patch Tests for Smooth Drip Shield Surface. Submittal date: 07/31/2002.

163403 MO0207EBSATBWP.025. Atlas Breached Waste Package and Drip Shield Experiments: Bounding Flow Rate Tests on the Smooth Drip Shield Surface. Submittal date: 07/31/2002.

163404 MO0208EBSATBWP.027. Atlas Breached Waste Package and Drip Shield Experiments: Multiple Patch Tests on the Rough Drip Shield Surface. Submittal date: $08 / 13 / 2002$.

163405 MO0208EBSATBWP.028. Atlas Breached Waste Package and Drip Shield Experiments: Bounding Flow Rate Tests on the Rough Drip Shield Surface. Submittal date: 08/13/2002.

162871 MO0302UCC034JC.003. Graphical X-Ray Diffractometer Data and Mineral Analysis of Filtered Solids from Effluent Solution During Miniature Waste Package Corrosion. Submittal date: 02/10/2003.

170760 MO0407SEPFEPLA.000. LA FEP List. Submittal date: 07/20/2004.

172097 MO0407SPAPCEML.005. EBS P\&CE Model Longevity of Materials Evaluation. Submittal date: 07/02/2004.

172059 MO0409SPAACRWP.000. Aqueous Corrosion Rates For Non-Waste Form Waste Package Materials. Submittal date: 09/16/2004.

164131 SN0306T0504103.006. Revised Sorption Partition Coefficients (Kd Values) for Selected Radionuclides Modeled in the TSPA (Total System Performance Assessment). Submittal date: 06/30/2003. 
165540 SN0309T0504103.010. Updated Iron Oxyhydroxide Colloid Concentration Parameters, Specific Surface Area (SA) of Iron Oxyhydroxide Colloids, Target Flux Out Ratio (FRN) and Forward Rate Constant (K) for Pu \& Am Sorption to Iron Oxyhydroxide Colloids \& Stationary Corrosion. Submittal date: 09/18/2003.

168761 SN0310T0505503.004. Initial Radionuclide Inventories for TSPA-LA. Submittal date: $10 / 27 / 2003$.

169129 SN0404T0503102.011. Thermal Conductivity of the Potential Repository Horizon Rev 3. Submittal date: 04/27/2004.

\subsection{OUTPUT DATA, LISTED BY DATA TRACKING NUMBER}

MO0506SPAINPAR.000. Input Parameters for TSPA-LA from ANL-WIS-PA000001, "Engineered Barrier System: Radionuclide Transport Abstraction."

Submittal date: 06/06/2005.

SN0403T0507703.015. Model Inputs Used in Engineered Barrier System (EBS) Radionuclide Transport Abstraction, Version 1. Submittal date: 03/12/2004. (Preliminary developed data).

SN0409T0507703.017. Model Inputs Used in Engineered Barrier System (EBS) Radionuclide Transport Abstraction. Submittal date: 09/27/2004. (Preliminary developed data).

SN0410T0507703.018. Engineered Barrier System (EBS) Radionuclide Transport Abstraction Model Inputs. Submittal date: 11/03/2004.

SN0503T0503305.001. Summary of and Sorption Site Density and Site Characteristics Obtained from Scientific Literature for Goethite and Hydrous Ferric Oxide (HFO). Submittal date: 03/22/2005. (Preliminary developed data).

SN0508T0503305.003. Summary of Sorption Site Density and Site Characteristics Obtained from Scientific Literature for Goethite and Hydrous Ferric Oxide (HFO). Submittal date: 08/18/2005.

\subsection{SOFTWARE CODES}

166572 Golder Associates. 2003. Software Code: GoldSim. V8.01 Service Pack 1. PC, Windows 2000. 10344-8.01 SP1-00. 


\subsection{UNQUALIFIED OUTPUT DATA, LISTED BY DATA TRACKING NUMBER}

MO0508SPAFRAPM.000. Comparison of Results from Fracture-Matrix Partitioning Model with Results from Modified Engineered Barrier System (EBS) Radionuclide Transport Abstraction EBS-UZ Interface Model. Submittal Date: 08/01/2005.

MO0508SPAUZDIF.000. Verification of Dual Invert/Dual UZ Diffusive Flux Bifurcation. Submittal Date: 08/18/2005.

SN0508T0507703.020. Calculations Supporting an Alternative Conceptual Model for Sorption of Pu onto In-Package Corrosion Products, for ANL-WIS-PA-000001 REV 02, EBS

Radionuclide Transport Abstraction. Submittal Date: 08/11/2005. 
INTENTIONALLY LEFT BLANK 
APPENDIX A

MICROSOFT EXCEL SPREADSHEET “MASSES OF MATERIALS” 


\section{MICROSOFT EXCEL SPREADSHEET “MASSES OF MATERIALS”}

In this spreadsheet, the mass of iron and the equivalent mass of $\mathrm{Fe}_{2} \mathrm{O}_{3}$ is calculated for four waste packages. The results are reported in Table 6.3-4. The calculation is done: 21-PWR (absorber plate), 44-BWR (absorber plate), 5-DHLW/DOE Short, and Naval Long.

The procedure for determining the equivalent mass of $\mathrm{Fe}_{2} \mathrm{O}_{3}$ is to calculate the total mass of each type of iron-containing alloy, calculate the mass of iron in all components of each alloy based on the iron content of the alloy, sum the mass of iron in the waste package, and convert the iron mass to $\mathrm{Fe}_{2} \mathrm{O}_{3}$ mass using the stoichiometry and molecular weights. Only the components within the outer corrosion barrier are included in the calculation; the outer corrosion barrier is considered to be inert.

For a 21-PWR waste package, the mass and number of each component are listed in Figures A-1 and A-2 as shown in Table 4.1-20 (BSC 2004 [DIRS 169472], Table 2). This calculation uses the previous waste package design in which the absorber plates are composed of Neutronit, rather than the current design with Ni-Gd absorber plates (BSC 2004 [DIRS 170710]). The impact of using the previous design is discussed in Section 6.3.4.2.3.1, where it is shown that the differences in absorber plate design should have negligible net effect on radionuclide transport from the EBS. In Column E (Figure A-1), the total mass of the components is computed (e.g., E2=C2*D2). The total mass of all components is summed in Cell E23. The calculation is repeated for a 44-BWR waste package (BSC 2004 [DIRS 169472], Table 3) in Column K (Figure A-1), for a 5-DHLW/DOE Short waste package (BSC 2004 [DIRS 167207], Table 5) in Column Q (Figure A-2), and for a Naval Long waste package (BSC 2004 [DIRS 169472], Table 4) in Column W (Figure A-2). Consistent with the treatment for the 21-PWR waste package, the previous design with Neutronit absorber plates is considered for a 44-BWR waste package rather than the current design (BSC 2004 [DIRS 170838]). For the 5 DHLW/DOE Short waste package, a mass of $1 \mathrm{~kg}$ is erroneously used for the Interface Ring (Column O, Row 5 in Figure A-2); the correct mass is $44.6 \mathrm{~kg}$ (BSC 2004 [DIRS 167207], Table 5). Also, the 5 DHLW/DOE Short waste package, the mass of the spread ring (Column O, Row 20 in Figure A-2) was increased from $31.9 \mathrm{~kg}$ in the earlier design version (BSC 2004 [DIRS 167207], Table 5) to $33.8 \mathrm{~kg}$ in the current design (BSC 2005 [DIRS 173501], Table 7). The impact of the design changes and corrections on the mass of corrosion products in the waste packages is summarized in Table A-1.

Table A-1. Summary of Corrosion Product Mass Changes in Waste Packages Resulting from Design Updates and Corrections

\begin{tabular}{|c|c|c|c|c|c|c|}
\hline \multirow{2}{*}{ Design } & \multicolumn{2}{|c|}{ 21-PWR } & \multicolumn{2}{c|}{ 44-BWR } & \multicolumn{2}{c|}{ 5-DHLW/DOE } \\
\cline { 2 - 7 } & $\begin{array}{c}\text { CP Mass, } \\
\text { kg }\end{array}$ & $\begin{array}{c}\text { Change from } \\
\text { Previous } \\
\text { Design, \% }\end{array}$ & $\begin{array}{c}\text { CP Mass, } \\
\text { kg }\end{array}$ & $\begin{array}{c}\text { Change from } \\
\text { Previous } \\
\text { Design, \% }\end{array}$ & $\begin{array}{c}\text { CP Mass, } \\
\text { kg }\end{array}$ & $\begin{array}{c}\text { Change from } \\
\text { Previous } \\
\text { Design, \% }\end{array}$ \\
\hline Previous & 19,443 & -10.1 & 19,463 & -12.5 & 14,233 & \\
\hline $\begin{array}{c}\text { Current, } \\
\text { corrected }\end{array}$ & 17,474 & -236 & & 14,324 & 0.6 \\
\hline
\end{tabular}

NOTE: $\mathrm{CP}=$ corrosion products $\left(\mathrm{Fe}_{2} \mathrm{O}_{3}\right)$. 


\begin{tabular}{|c|c|c|c|c|c|c|c|c|c|c|c|c|}
\hline & A & B & C & D & $E$ & $\mathrm{~F}$ & G & $\mathrm{H}$ & $\mathrm{I}$ & J & K & $\mathrm{L}$ \\
\hline 1 & 21-PVR & Component Name & Mass. kg & Quantity & TotalMass. kg & & 44-BVR & Component Name & Mass. kg & Quantity & TotalMass. kg & \\
\hline 2 & $\mathrm{~A} 516 \mathrm{CS}$ & Eoskst -Side Guids & 24.9 & 16 & 398.4 & & $\mathrm{~A} 516 \mathrm{CS}$ & Essket-Side Guide & 31.5 & 16 & 504 & \\
\hline 3 & $\mathrm{~A} .516 \mathrm{CS}$ & Eosket -Side Guide Stiffener & 0.615 & 32 & 19.68 & & $\mathrm{~A} 516 \mathrm{CS}$ & Boskst Side Guide Stiffencr & 0.487 & 32 & 15.584 & \\
\hline 4 & $\mathrm{~A} .516 \mathrm{CS}$ & Essket -End Side Guide & 32.7 & 32 & 1046.4 & & A516 CS & Evsket Corner Guids & 43.4 & 32 & 1388.8 & \\
\hline 5 & $\mathrm{~A} 516 \mathrm{CS}$ & Evoket End Sids Guids Stiffener & 1.38 & 64 & 88.32 & & $\mathrm{~A} 516 \mathrm{CS}$ & Bosket Corner Guids Stiffener & 2.23 & 64 & 142.72 & \\
\hline 6 & $\mathrm{~A} 516 \mathrm{CS}$ & Esoket Corner Guide & 40.1 & 16 & 641.6 & & $\mathrm{~A} 516 \mathrm{CS}$ & Fucl Easket Tube & 108 & 44 & 4752 & \\
\hline 7 & $\mathrm{~A} 516 \mathrm{CS}$ & Esekst Corner Guide Stiffener & 2.07 & 32 & 66.24 & & Neutronit A 978 & Fucl Eosket $A$ - Plote & 60.7 & 4 & 242.8 & \\
\hline 8 & $\mathrm{~A} 516 \mathrm{CS}$ & Fucl Basket Tubs & 159 & 21 & 3339 & & Neutronit A 978 & Fucl Basket B - Plate & 60.7 & 12 & 728.4 & \\
\hline 9 & Neutronit A 978 & Fuel Bosket $A$ - Plote & 86.8 & 8 & 694.4 & & Neutronit A 978 & Fucl Easket C - Plote & 47.8 & 16 & 764.8 & \\
\hline 10 & Neutronit A 978 & Fuel Bosket B - Plote & 86.8 & 8 & 694.4 & & Neutronit A 978 & Fucl Bosket D - Plote & 60.7 & 8 & 485.6 & \\
\hline 11 & Neutronit A 978 & Fuel Bosket C-Plote & 45.8 & 16 & 732.8 & & Neutronit A 978 & Fucl Bosket E - Plote & 47.8 & 16 & 764.8 & \\
\hline 12 & Al 6061 & Fuel Esoket D - Plote & 27.4 & 8 & 219.2 & & Al 6061 & Fucl Easket F - Ploste & 20.4 & 8 & 163.2 & \\
\hline 13 & Al 6061 & Fuel Basket E - Plote & 27.4 & 8 & 219.2 & & A. 6061 & Fucl Easket G - Plate & 20.4 & 8 & 163.2 & \\
\hline 14 & 316NG SS & Inner Vegecl wlo Guides & 9920 & 1 & 9920 & & 316NG SS & Inner Yesel wlo Guides & 10200 & 1 & 10200 & \\
\hline 15 & 316NG SS & Inner Lid $w /$ LLF & 739 & 1 & 739 & & 31ENG SS & Inner Lid $w /$ LLF & 7776 & 1 & 776 & \\
\hline 16 & 316NG SS & Interface Ring & 35.6 & 1 & 35.6 & & 316NG SS & Interfoce Ring & 36.4 & 1 & 36.4 & \\
\hline 17 & 316NG SS & Spresd Ring & 25.3 & 1 & 25.3 & & 316NG SS & Spresd Ring & 25.9 & 1 & 25.9 & \\
\hline 18 & 316NG SS & Total 316 Welds & 81 & 1 & 81 & & 316NGSS & Totol 316 Welds & 83 & 1 & 83 & \\
\hline 19 & Alloy 22 & OCB with trunnion eleseses & 5730 & 1 & 5730 & & Alloy 22 & OCE with trunnion slecves & 5890 & 1 & 5890 & \\
\hline 20 & Alloy 22 & Middls Lid w' LLF & 226 & 1 & 226 & & Alloy 22 & Middle Lid w' LLF & 237 & 1 & 237 & \\
\hline 21 & Alloy 22 & Outer Lid wi LLF & 445 & 1 & 445 & & Alloy 22 & Outer Lid wi LLF & 467 & 1 & 467 & \\
\hline 22 & Alloy 22 & Total Allloy 22 Welds & 51.8 & 1 & 51.8 & & Alloy 22 & Total Alloy 22 Welds & 53 & 1 & 53 & \\
\hline 23 & & VP Total & & & 25413.34 & & & VP Total & & & 27884.204 & \\
\hline
\end{tabular}

Figure A-1. Spreadsheet "Masses of Materials;" Calculation of Mass of 21-PWR and 44-BWR Waste Package Components

\begin{tabular}{|c|c|c|c|c|c|c|c|c|c|c|c|c|}
\hline & $\mathrm{L}$ & $\mathrm{M}$ & $\mathrm{N}$ & 0 & $\mathrm{P}$ & $Q$ & $\mathrm{R}$ & $s$ & $T$ & u & $v$ & w \\
\hline 1 & & 5-DHLY & Component Name & Mass, kg & Quantity & |Total Mass, kg & & Naval SNF & Component Name & Mass, kg & Quantity & Total Mass, kg \\
\hline 2 & & A.516 CS & Divider Plote Azsembly & 3720 & 1 & 3720 & & 316NG SS & loner $V_{\text {egase }}$ & 13300 & 1 & 13300 \\
\hline 3 & & 316NG SS & Inner Veegel & 8860 & 1 & 8860 & & 316NG SS & Inner Lid $w i$ LLF & 962 & 1 & 962 \\
\hline 4 & & 316NG SS & Inner Lid $w /$ LLF & 1170 & 1 & 1170 & & 316NG SS & Interface Ring & 40.5 & 1 & 40.5 \\
\hline 5 & & 316NG SS & Interface Ring & 1 & 1 & 1 & & 316NG SS & Spresd Ring & 28.9 & 1 & 28.9 \\
\hline 6 & & 316NG SS & Spresd Ring & 31.9 & 1 & 31.9 & & 316NG SS & Totol 316 Welds & 92.2 & 1 & 92.2 \\
\hline 7 & & 316NG SS & Totol 316 Welds & 102 & 1 & 102 & & Alloy 22 & $O C B$ with trunnion olseves & 8960 & 1 & 8960 \\
\hline 8 & & Alloy 22 & OCB with trunnion gleceres & 6540 & 1 & 6540 & & Alloy 22 & \begin{tabular}{|l} 
Middle Lid $w /$ LLF \\
\end{tabular} & 290 & 1 & 290 \\
\hline 9 & & Alloy 22 & \begin{tabular}{|l} 
Middls Lid $w$ ' LLF \\
\end{tabular} & 350 & 1 & 350 & & Alloy 22 & Outer Lid $w /$ LLF & 573 & 1 & 573 \\
\hline 10 & & Alloy 22 & Outer Lid $w /$ LLF & 693 & 1 & 693 & & Alloy 22 & Total Alloy 22 Weldz & 58.6 & 1 & 58.6 \\
\hline 11 & & Alloy 22 & Totol Alloy 22 Welds & 64.2 & 1 & 64.2 & & & VP Total & & & 24305.2 \\
\hline 12 & & & VP Total & & & 21532.1 & & & & & & \\
\hline 13 & & & & & & & & 316NG SS & Inner $Y_{\text {eegel }}$ & 13300 & 1 & 13300 \\
\hline 14 & & $\mathrm{~A} 516 \mathrm{CS}$ & Divider Plate Agzembly & 3720 & 1 & 3720 & & 316NGSS & Inner Lid $w /$ LLF & 962 & 1 & 962 \\
\hline 15 & & A.516 CS & Total & & & 3720 & & 316NG SS & Interface Ring & 40.5 & 1 & 40.5 \\
\hline 16 & & & & & & & & 316NG SS & Spresd Ring & 28.9 & 1 & 28.9 \\
\hline 17 & & 316NG SS & Inner Veagel & 8860 & 1 & 8860 & & 316NG SS & Totol $316 \mathrm{~W}$ eld $\mathrm{s}$ & 92.2 & 1 & 92.2 \\
\hline 18 & & 316NG SS & Inner Lid $w /$ LLF & 1170 & 1 & 1170 & & 316NG SS & Total & & & 14423.6 \\
\hline 19 & & 316NG SS & Interface Ring & 1 & 1 & 1 & & & & & & \\
\hline 20 & & 316NG SS & Spread Ring & 31.9 & 1 & 31.9 & & Alloy 22 & $O C B$ with trunnion oleswes & 8960 & 1 & 8960 \\
\hline 21 & & 316NGSS & Total 316 W'slds & 102 & 1 & 102 & & Alloy 22 & \begin{tabular}{|l} 
Middle Lid $w '$ LLF \\
\end{tabular} & 290 & 1 & 290 \\
\hline 22 & & 316NG SS & Total & & & 10164.9 & & Alloy 22 & Outer Lid $w /$ LLF & 573 & 1 & 573 \\
\hline 23 & & & & & & & & Alloy 22 & Total Alloy 22 Welds & 58.6 & 1 & 58.6 \\
\hline 24 & & Alloy 22 & OCB with trunnion gleserse & 6540 & 1 & 6540 & & Alloy 22 & Total & & & 9881.6 \\
\hline 25 & & Alloy 22 & Middle Lid $w$ ' LLF & 350 & 1 & 350 & & & & & & \\
\hline 26 & & Alloy 22 & Outer Lid w/ LLF & 693 & 1 & 693 & & & & & & \\
\hline 27 & & Alloy 22 & Totol Alloy 22 Welds & 64.2 & 1 & 64.2 & & & & & & \\
\hline 28 & & Alloy 22 & Total & & & 7647.2 & & & & & & \\
\hline 29 & & & & & & & & & & & & \\
\hline 30 & & & & & & & & & & & & \\
\hline
\end{tabular}

Figure A-2. Spreadsheet "Masses of Materials;" Calculation of Mass of 5-DHLW and Naval Long Waste Package Components and Materials

In Rows 25-32, the calculation (Figure A-3) is repeated for a 21-PWR waste package for A 516 carbon steel components only. The total mass of carbon steel components is shown in Cell E32. Similarly, the calculation is repeated in Rows 34-37 (Figure A-3) for Neutronit, with the total Neutronit mass shown in Cell E37; in Rows 43-48 for 316 SS, with the total 316 SS mass shown in Cell E48. The masses of Al 6061 and Alloy 22 are also calculated, but this information is not used because the aluminum alloy contains a negligible amount of iron, and the Alloy 22 is considered to be inert. The calculation is repeated for a 44-BWR waste package in Column K (Figure A-3), for a 5-DHLW Short waste package in Column Q (Figure A-2), and for a Naval Long waste package in Column W (Figure A-2). 


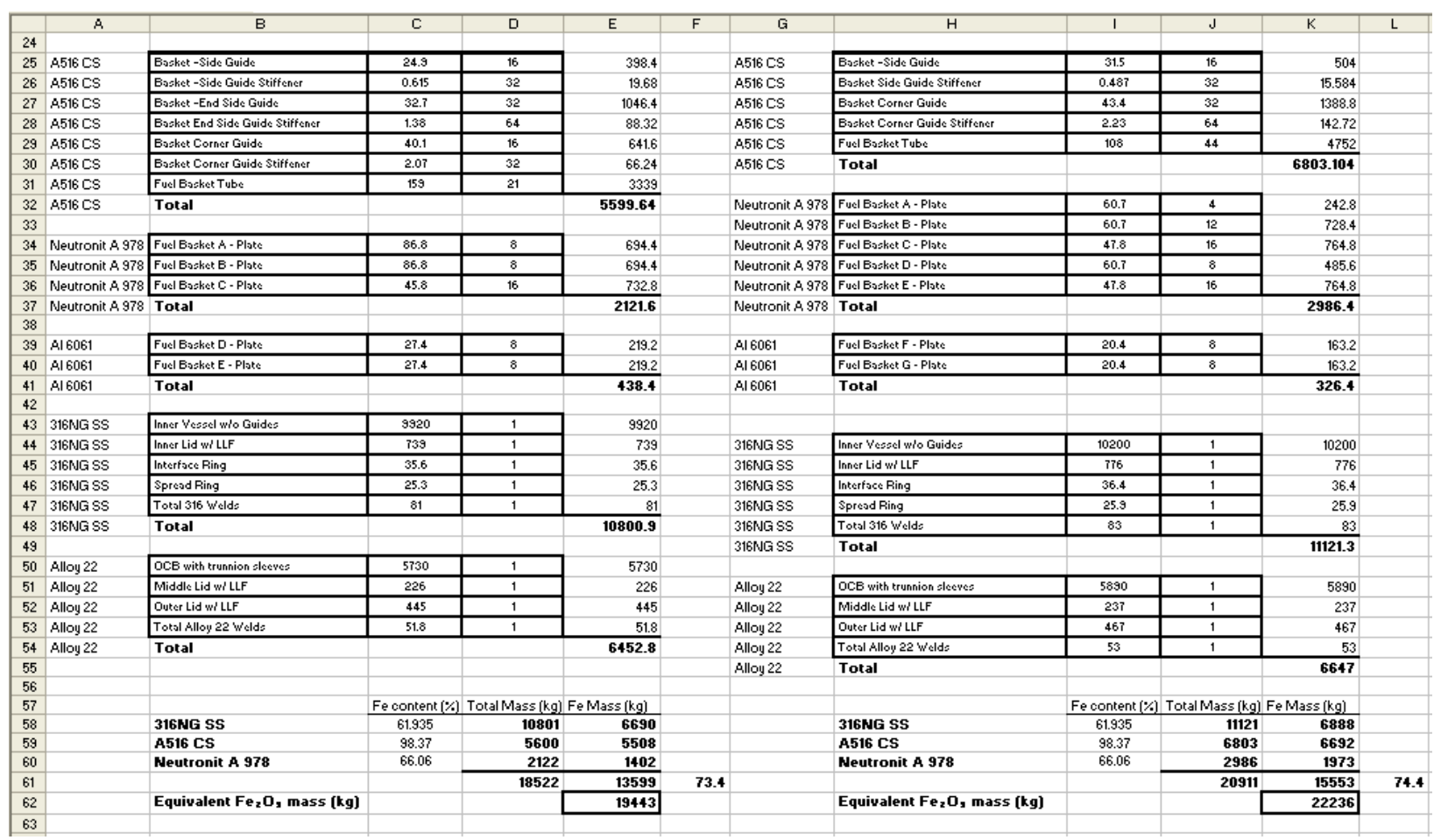

Figure A-3. Spreadsheet "Masses of Materials;" Calculation of Mass of 21-PWR and 44-BWR Waste Package Materials and Equivalent Mass of $\mathrm{Fe}_{2} \mathrm{O}_{3}$

In Row 78, Columns C-E (Figure A-4), the iron content is calculated for the three alloys of interest (316 stainless steel, A 516 carbon steel, and Neutronit A 978, respectively). The iron content of these alloys is specified as "Balance" (see Table 4.1-14). It is calculated by summing the content of all nonferrous components of the alloys (Row 77, Columns C-E) and subtracting from $100 \%$. 


\begin{tabular}{|c|c|c|c|c|c|c|}
\hline & A & $B$ & C & D & $E$ & $\mathrm{~F}$ \\
\hline \multicolumn{7}{|l|}{64} \\
\hline \multicolumn{7}{|l|}{65} \\
\hline 66 & & Element & $\begin{array}{c}\text { 316NG } \\
\text { Stainless } \\
\text { Steel }^{\mathrm{a}}\end{array}$ & $\begin{array}{l}\text { A } 516 \text { Carbon } \\
\text { Steel }^{\mathrm{b}}\end{array}$ & $\begin{array}{c}\text { Neutronit } \\
\text { A } 978^{\mathrm{C}}\end{array}$ & \\
\hline 67 & & Mo & 3 & 0 & 2.2 & \\
\hline 68 & & $\mathrm{Cr}$ & 18 & 0 & 18.5 & \\
\hline 69 & & $\mathrm{Ni}$ & 14 & 0 & 13 & \\
\hline 70 & & $\mathrm{Co}$ & 0 & 0 & 0.2 & \\
\hline 71 & & $\mathrm{Mn}$ & 2 & 1.3 & 0 & \\
\hline 72 & & $\mathrm{C}$ & 0.08 & 0.26 & 0.04 & \\
\hline 73 & & $\mathrm{P}$ & 0.045 & 0.035 & 0 & \\
\hline 74 & & $\mathrm{~s}$ & 0.03 & 0.035 & 0 & \\
\hline 75 & & $\mathrm{Si}$ & 0.75 & 0 & 0 & \\
\hline 76 & & $\mathrm{~N}$ & 0.16 & 0 & 0 & \\
\hline 77 & & Total Non-Fe & 38.065 & 1.63 & 33.94 & \\
\hline 78 & & $\mathrm{Fe}$ & 61.935 & 98.37 & 66.06 & \\
\hline \multicolumn{7}{|l|}{79} \\
\hline 80 & & ${ }^{3}$ DTN: MO0003RIB00076.000. & & & & \\
\hline 81 & & DDTN: MO0107TC240032.000. & & & & \\
\hline 82 & & 'Kügler 1991, p. 15. & & & & \\
\hline 83 & & & & & & \\
\hline
\end{tabular}

DTN: MO0003RIB00076.000 [DIRS 153044]; DTN: MO0107TC240032.000 [DIRS 169970].

Source: Kügler 1991 [DIRS 155761], p.15.

Figure A-4. Spreadsheet "Masses of Materials;" Elemental Weight Percent Compositions used in Calculation of Iron Content in Three Steel Alloys

In Figure A-3, the total masses of 316 SS (from E48), of A 516 CS (from E32), and of Neutronit A 978 (from E37) in all 21-PWR components are listed in Column D, Rows 58-60, respectively. The iron content of all components for each alloy is calculated in Column $\mathrm{E}$ (e.g., E58=C58*D58/100). The total iron content in the three alloys is summed in Cell E61. The average iron content of all components constructed of these three alloys is calculated in Cell F61 (F61=E61*100/D61); this information is not used.

The equivalent mass of $\mathrm{Fe}_{2} \mathrm{O}_{3}$ is computed in Cell E62 (Figure A-3) using the formula shown in Footnote $f$ of Table 6.3-4: E62=E61*0.15969/0.055847/2. The results of these calculations (Rows 58-62, Columns C-F) are presented in Table 6.3-4 for a 21-PWR. These calculations are repeated for a 44-BWR waste package (Rows 58-62, Columns I-L; see Figure A-3), a 5-DHLW waste package (Rows 58-62, Columns O-R; Figure A-5), and for a Naval Long waste package (Rows 58-62, Columns U-X; Figure A-5). 


\begin{tabular}{|c|c|c|c|c|c|c|c|c|c|c|c|c|}
\hline & $\mathrm{M}$ & $\mathrm{N}$ & 0 & $\mathrm{P}$ & $Q$ & $\mathrm{R}$ & $\mathrm{s}$ & $T$ & U & $\mathrm{v}$ & w & $x$ \\
\hline 56 & & & & & & & & & & & & \\
\hline 57 & & & Fe content (\%) & ) Total Mass (kg) & Fe Mass [kg] & & & & Fe content (\%) & Total Mass $(\mathrm{kg})$ & Fe Mass $[\mathrm{kg}]$ & \\
\hline 58 & & 316NG SS & 61.935 & 10165 & 6296 & & & 316NG SS & 61.935 & 14424 & 8933 & \\
\hline 59 & & A516 CS & 98.37 & 3720 & 3659 & & & A516 CS & 98.37 & $\mathbf{0}$ & $\mathbf{0}$ & \\
\hline 60 & & Neutronit A 978 & 66.06 & $\mathbf{0}$ & $\mathbf{0}$ & & & Neutronit A 978 & 66.06 & $\underline{\mathbf{0}}$ & $\mathbf{0}$ & \\
\hline 61 & & & & 13885 & 9955 & 71.7 & & & & 14424 & 8933 & 61.9 \\
\hline 62 & & Equivalent $\mathrm{Fe}_{2} \mathrm{O}$, mass $(\mathrm{kg})$ & & & 14233 & & & Equivalent $\mathrm{Fe}_{2} \mathrm{O}$, mass $(\mathrm{kg})$ & & & 12772 & \\
\hline
\end{tabular}

Figure A-5. Spreadsheet "Masses of Materials;" Calculation of Equivalent Mass of $\mathrm{Fe}_{2} \mathrm{O}_{3}$ in 5-DHLW and Naval Long Waste Packages 


\section{INTENTIONALLY LEFT BLANK}




\section{APPENDIX B}

IMPLEMENTATION OF RADIONUCLIDE SORPTION ONTO COLLOIDAL AND STATIONARY PHASES WITH FINITE DIFFERENCE SOLUTION 


\section{IMPLEMENTATION OF RADIONUCLIDE SORPTION ONTO COLLOIDAL AND STATIONARY PHASES WITH FINITE DIFFERENCE SOLUTION}

\section{CONCEPTUAL MODEL}

The general colloid model accounts for both reversible and irreversible sorption onto the iron oxyhydroxide (designated FeO) mobile colloids and the immobile FeO corrosion products together with reversible sorption onto both waste form and groundwater (GW) colloids within the engineered barrier system (EBS). Figure B-1 shows the conceptual model of radionuclide sorption onto the iron oxy-hydroxide colloidal and stationary phases. The upstream domain is considered to be degraded fuel rods, including secondary mineral phases, in equilibrium with the aqueous phase at the radionuclide solubility limit predicted by the solubility limits model (BSC 2005 [DIRS 174566]). The radionuclides of concern are the Pu and Am isotopes. Since the material balance equations are written as a mass balance, the equations are valid for any solute species. Certain system parameters, such as solubility, decay rate, and partition coefficients, will be dependent on the species. In this appendix, the species used for subsequent analysis and discussion is $\mathrm{Pu}$.

The colloid model considers the general case where both reversible sorption is modeled with non-zero $K_{d}$ values, and irreversible sorption is modeled as having “unrestricted access" to sites. As such, the irreversible sorption calculation does not account for limitations on the number of sites available for sorption; it does not account for competition for sorption sites among the radionuclides that can sorb; and it does not account for competition for sorption sites with radionuclides such as $\mathrm{Pu}$ and Am that sorb irreversibly, which would reduce the number of sites available for reversible sorption. This more general case is included as an alternative conceptual model (Section 6.6.7).

There is no sorption considered in the upstream domain. Pu at its solubility limit is considered to transport by both advection and diffusion downstream into the corrosion product domain, where it can be involved in six separate reactions:

- Reversible Pu sorption onto FeO colloidal particles

- Reversible Pu sorption onto the stationary phase FeO corrosion products

- Irreversible Pu sorption onto FeO colloidal particles

- Irreversible Pu sorption onto the stationary phase FeO corrosion products

- Reversible Pu sorption onto waste form colloids

- Reversible Pu sorption onto GW colloids.

Denote the concentrations ( $\mathrm{kg} \mathrm{Pu} \mathrm{m}^{-3}$ water) for the $\mathrm{Pu}$ in the seven possible states as

$$
\begin{array}{ll}
C_{\mathrm{Pu}_{-} \mathrm{aq}} & \text { concentration of } \mathrm{Pu} \text { in aqueous solution } \\
C_{\mathrm{Pu}_{-} \mathrm{FeO} \mathrm{O}_{-} \mathrm{C}}= & \text { concentration of } \mathrm{Pu} \text { in the FeO colloid state from reversible sorption } \\
C_{\mathrm{Pu}_{-} \mathrm{FeO} \mathrm{O}_{-} \mathrm{CP}}= & \text { concentration of } \mathrm{Pu} \text { in the stationary } \mathrm{FeO} \text { corrosion product state from } \\
& \text { reversible sorption }
\end{array}
$$




$$
\begin{aligned}
& C_{I r v_{-} \mathrm{Pu}_{-} \mathrm{FeO} \mathrm{O}_{-} \mathrm{c}}=\text { concentration of } \mathrm{Pu} \text { in the } \mathrm{FeO} \text { colloid state from irreversible sorption } \\
& C_{\text {Irrv }-P u_{-} F e O_{-} C P}=\text { concentration of } \mathrm{Pu} \text { in the stationary } \mathrm{FeO} \text { corrosion products state from } \\
& c_{P u_{-} W F_{-} c}=\text { concentration of } \mathrm{Pu} \text { in the waste form colloid state from reversible } \\
& \text { sorption } \\
& C_{P_{u_{-} G W} \mathrm{C}}=\text { concentration of Pu in the GW colloid state from reversible sorption }
\end{aligned}
$$

and let

$$
c_{s} \quad=\text { Pu solubility (concentration at the solubility limit) ( } \mathrm{kg} \mathrm{Pu} \mathrm{m}^{-3} \text { water). }
$$

The concentrations ( $\mathrm{kg}$ colloid $\mathrm{m}^{-3}$ water) of all colloids and stationary corrosion products are:

$$
\begin{array}{ll}
c_{\mathrm{FeO} \_} \mathrm{C} & =\text { concentration of } \mathrm{FeO} \text { in the colloid state } \\
c_{\mathrm{FeO} O_{-} \mathrm{CP}} & =\text { concentration of } \mathrm{FeO} \text { in the corrosion product state } \\
c_{W F_{-} c} & =\text { concentration of waste form in the colloid state } \\
c_{G W_{-} c} & =\text { concentration of } \mathrm{GW} \text { in the colloid state. }
\end{array}
$$

As indicated in Figure B-1, the mass in the fluid exiting the corrosion-product domain (reaction mixing cell) is expected to be proportioned such that the mass of Pu sorbed onto FeO colloids is some fraction of the total mass of Pu exiting the system in all forms-aqueous, reversibly sorbed, and irreversibly sorbed. Observations in nature, such as the transport of Pu from the Benham test site (Kersting et al. 1999 [DIRS 103282]), suggest that this fraction is about 95\%. This is expressed as:

$$
\Omega=\frac{\text { colloid mass flux out }}{\text { total mass flux out }}=0.95 \text {. }
$$

This value of $95 \%$ is uncertain with an uncertainty range of 0.90 to 0.99 associated with it (BSC 2004 [DIRS 170025], Table 6-12, p. 6-72). It also may be a function of time, since the observation time for the Benham test is only about 50 years.

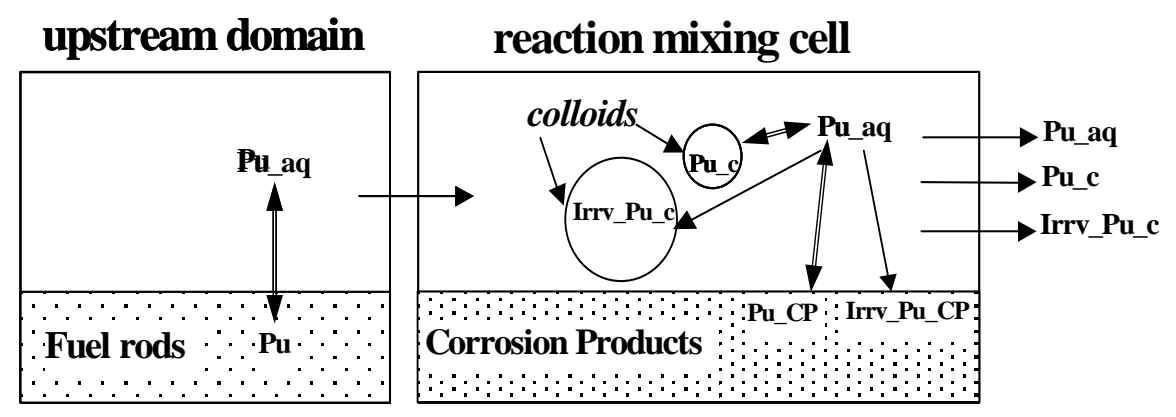

Figure B-1. Conceptual Model Schematic 
Also of interest is the ratio of the mass flux leaving the mixing cell to the mass flux entering the mixing cell. This ratio of mass out to mass in is given by:

$$
\Psi=\frac{\text { mass flux out }}{\text { mass flux in }}
$$

and is a measure of the retardation due to sorption on the stationary corrosion products. The model is set up is such a way that most of the Pu mass entering the mixing cell is expected to be sorbed onto the stationary FeO phase and only a small fraction of it flows downstream to the unsaturated zone.

\section{REACTIONS}

The reactions considered in this model are as follows, where $R_{i}$, represents the bulk reaction rate of $\mathrm{Pu}$ for the $i^{\text {th }}$ reaction, in units $\left(\mathrm{kg} \mathrm{Pu} \mathrm{m}^{-3} \mathrm{yr}^{-1}\right)$ :

$$
\begin{array}{ll}
R_{1}: & \mathrm{Pu}(\mathrm{aq}) \rightarrow \mathrm{Pu}\left(\mathrm{FeO}_{\mathrm{col}}^{\text {irev }}\right) \\
R_{2}: & \mathrm{Pu}(\mathrm{aq}) \rightarrow \mathrm{Pu}\left(\mathrm{FeO}_{\mathrm{CP}}^{\text {irev }}\right) \\
R_{3}: & \mathrm{Pu}(\mathrm{aq}) \leftrightarrow \mathrm{Pu}\left(\mathrm{FeO}_{\mathrm{col}}^{\text {rev }}\right) \\
R_{4}: & \mathrm{Pu}(\mathrm{aq}) \leftrightarrow \mathrm{Pu}\left(\mathrm{FeO}_{\mathrm{CP}}^{\mathrm{rev}}\right) \\
R_{5}: & \mathrm{Pu}(\mathrm{aq}) \leftrightarrow \mathrm{Pu}\left(\mathrm{WF}_{\mathrm{col}}^{\mathrm{rev}}\right) \\
R_{6}: & \mathrm{Pu}(\mathrm{aq}) \leftrightarrow \mathrm{Pu}\left(\mathrm{GW}_{\mathrm{col}}^{\mathrm{rev}}\right)
\end{array}
$$

Note that the reactions in Equations B-5 through B-8 are reversible equilibrium reactions, therefore their reaction rates are undefined and not included in subsequent mass balance equations. Equilibrium mass-action relationships are imposed instead, for these four reactions.

\section{KINETIC REACTIONS}

The $i^{\text {th }}$ irreversible reaction rate (where $i=1$ or 2$), R_{i}\left(\mathrm{~kg} \mathrm{Pu} \mathrm{m}^{-3}\right.$ bulk-volume $\mathrm{yr}^{-1}$ ), is expressed in terms of the $i^{\text {th }}$ bulk surface area for the mineral phase involved in the reaction, $S_{i}$ ( $\mathrm{m}^{2} \mathrm{FeO} \mathrm{\textrm {m } ^ { - 3 }}$ bulk-volume), and the $i^{\text {th }}$ intrinsic (or surface) reaction rate, $r_{i}\left(\mathrm{~kg} \mathrm{Pu} \mathrm{m}^{-2}\right.$

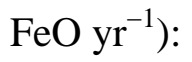

$$
R_{i}=S_{i} r_{i}
$$

The irreversible reaction of $\mathrm{Pu}$ onto FeO colloids is then

$$
R_{1}=S_{\mathrm{FeO}_{-} \mathrm{c}} r_{1}
$$

and for the irreversible reaction of $\mathrm{Pu}$ onto $\mathrm{FeO}$ corrosion products

$$
R_{2}=S_{\text {FeO_CP }} r_{2} \text {. }
$$


The bulk surface area $\left(\mathrm{m}^{2} \mathrm{FeO} \mathrm{m}^{-3}\right.$ bulk-volume) for $\mathrm{FeO}$ colloids and corrosion products are, respectively,

$$
\begin{gathered}
S_{\mathrm{FeO} \_\mathrm{c}}=\hat{S}_{\mathrm{FeO} \_c} C_{\mathrm{FeO} \_\mathrm{c}} \phi S_{w} \\
S_{\mathrm{FeO} \_\mathrm{CP}}=\hat{S}_{\mathrm{FeO} \_\mathrm{CP} C} C_{\mathrm{FeO} \_\mathrm{CP}} \phi S_{w}
\end{gathered}
$$

where $\phi$ is the porosity of the FeO matrix, $S_{w}$ is the water saturation and

$$
\begin{aligned}
\hat{S}_{\mathrm{FeO} \_}= & \text {specific surface area of FeO colloids }\left(\mathrm{m}^{2} \mathrm{FeO}-\text { colloid } \mathrm{kg}^{-1} \mathrm{FeO} \text {-colloid }\right) \\
\hat{S}_{\mathrm{FeO} \_\mathrm{CP}=} & \text { specific surface area of FeO corrosion products } \\
& \left(\mathrm{m}^{2} \mathrm{FeO}-\mathrm{CP} \mathrm{kg}{ }^{-1} \mathrm{FeO}-\mathrm{CP}\right) .
\end{aligned}
$$

The intrinsic or surface reaction rate (i.e., rate per unit mineral surface area) is considered to be the same for the colloidal and stationary phases, i.e., $r_{1}=r_{2} \equiv r$, and it only has a forward component, since the reaction is irreversible. Further, suppose that the reactions are first order in the solution concentration $C_{\mathrm{Pu}_{-} a q}$ :

$$
r=k c_{P u \_a q}
$$

where

$$
k=\text { forward rate constant, }\left(\mathrm{m}^{3} \text { water-volume } \mathrm{m}^{-2} \mathrm{FeO} \mathrm{yr}^{-1}\right) .
$$

The two irreversible reaction rates on a water volume basis are then

$$
\begin{gathered}
\frac{R_{1}}{\phi S_{w}}=\hat{S}_{\mathrm{FeO}_{-} c} C_{\mathrm{FeO}_{-} c} k c_{P u_{-} a q}=\bar{R}_{1} C_{\mathrm{Pu}_{-} a q} \\
\frac{R_{2}}{\phi S_{w}}=\hat{S}_{\mathrm{FeO} \mathrm{O}_{-} \mathrm{CP}} C_{\mathrm{FeO}{ }_{-} C P} k C_{P u_{-} a q}=\bar{R}_{2} C_{\mathrm{Pu}_{-} a q},
\end{gathered}
$$

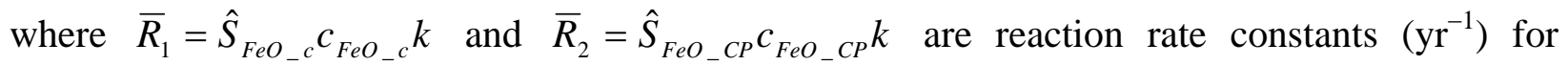
colloids and corrosion products, respectively.

\section{EQUILIBRIUM REACTIONS}

The four chemical species, $\mathrm{Pu}\left(\mathrm{FeO}_{\mathrm{col}}^{\mathrm{rev}}\right), \mathrm{Pu}\left(\mathrm{FeO}_{\mathrm{CP}}^{\mathrm{rev}}\right), \mathrm{Pu}\left(\mathrm{WF}_{\mathrm{col}}^{\mathrm{rev}}\right)$ and $\mathrm{Pu}\left(\mathrm{GW}_{\mathrm{col}}^{\mathrm{rev}}\right)$, involved in reversible equilibrium sorption reactions, Equations B-5, B-6, B-7, and B-8, follow the law of mass action according to 


$$
\begin{aligned}
& K_{3}^{e q}=\frac{\left[\mathrm{Pu}\left(\mathrm{FeO}_{\mathrm{col}}^{\mathrm{rev}}\right)\right]}{[\mathrm{Pu}(\mathrm{aq})]} \\
& K_{4}^{e q}=\frac{\left[\mathrm{Pu}\left(\mathrm{FeO}_{\mathrm{CP}}^{\mathrm{rev}}\right)\right]}{[\mathrm{Pu}(\mathrm{aq})]} \\
& K_{5}^{e q}=\frac{\left[\mathrm{Pu}\left(\mathrm{WF}_{\mathrm{col}}^{\mathrm{rev}}\right)\right]}{[\mathrm{Pu}(\mathrm{aq})]} \\
& K_{6}^{e q}=\frac{\left[\mathrm{Pu}\left(\mathrm{GW}_{\mathrm{col}}^{\mathrm{rev}}\right)\right]}{[\mathrm{Pu}(\mathrm{aq})]}
\end{aligned}
$$

where $[\mathrm{Pu}(j)]$ represents the thermodynamic activity of $\mathrm{Pu}$ in the $j^{\text {th }}$ phase (aqueous, colloidal, or corrosion product). Normally, these relationships are expressed for dilute solutions as a simple linear $\left(K_{d}\right)$ (water volume/mass $\mathrm{FeO}$ ) type of isotherm in terms of concentrations:

$$
\begin{aligned}
\hat{c}_{P u_{-} F e O_{-} c} & =K_{d_{-} F e O_{-} c} C_{P u_{-} a q} \\
\hat{c}_{P u_{-} F e O_{-} C P} & =K_{d_{-} F e O_{-} C P} C_{P u_{-} a q} \\
\hat{C}_{P u_{-} W F_{-} c} & =K_{d_{-} W F_{-} c} C_{P u_{-} a q} \\
\hat{C}_{P u_{-} G W_{-} c} & =K_{d_{-} G W_{-} c} C_{P u_{-} a q}
\end{aligned}
$$

where

$$
\begin{aligned}
& \hat{c}_{\mathrm{Pu}_{-} \mathrm{FeO}_{-} \mathrm{c}}=\text { mass ratio of Pu sorbed onto FeO colloids ( } \mathrm{kg} \mathrm{Pu} \mathrm{kg}^{-1} \mathrm{FeO} \text {-colloid) } \\
& \left.\hat{C}_{\mathrm{Pu}_{-} \mathrm{FeO}_{-} \mathrm{CP}}=\text { mass ratio of } \mathrm{Pu} \text { sorbed onto FeO corrosion products ( } \mathrm{kg} \mathrm{Pu} \mathrm{kg}^{-1} \mathrm{FeO}-\mathrm{CP}\right) \\
& \hat{C}_{\mathrm{Pu}_{-} W F_{-} c}=\text { mass ratio of Pu sorbed onto waste form colloids ( } \mathrm{kg} \mathrm{Pu} \mathrm{kg}^{-1} \text { WF-colloid) } \\
& \hat{C}_{\mathrm{Pu}_{-} G W_{-} c}=\text { mass ratio of Pu sorbed onto GW colloids ( } \mathrm{kg} \mathrm{Pu} \mathrm{kg}^{-1} \mathrm{GW} \text {-colloid). }
\end{aligned}
$$

The mass ratio for these reversible sorption reactions can be converted to water volume concentrations by the following:

$$
\begin{aligned}
& \mathrm{C}_{\mathrm{Pu}_{-} \mathrm{FeO} \mathrm{O}_{-} \mathrm{c}}=\mathrm{C}_{\mathrm{FeO} \mathrm{O}_{-} \mathrm{c}} \hat{\mathrm{P}}_{\mathrm{Pu}_{-} \mathrm{FeO} \mathrm{O}_{-} \mathrm{c}} \\
& C_{\mathrm{Pu}_{-} \mathrm{FeO} \mathrm{O}_{-} \mathrm{CP}}=\mathrm{C}_{\mathrm{FeO} \mathrm{O}_{-} \mathrm{CP}} \hat{\mathrm{C}}_{\mathrm{Pu} \mathrm{H}_{-} \mathrm{FeO} \mathrm{O}_{-} \mathrm{CP}} \\
& \mathrm{C}_{\mathrm{Pu}_{-} \mathrm{WF} F_{-} \mathrm{c}}=\mathrm{C}_{\mathrm{WF} \mathrm{F}_{-} \mathrm{c}} \hat{\mathrm{C}}_{\mathrm{Pu} \mathrm{WF}_{-} \mathrm{C}} \\
& \mathrm{C}_{\mathrm{Pu} u_{-} \mathrm{GW} W_{-} \mathrm{c}}=\mathrm{C}_{\mathrm{GW} \mathrm{W}_{-} \mathrm{c}} \hat{\mathrm{C}}_{\mathrm{Pu}_{-} \mathrm{GW} \mathrm{W}_{-} \mathrm{C}}
\end{aligned}
$$

The reversible Pu equilibrium is expressed by the partition coefficients relating the aqueous state and the two reversible states given by Equations B-25 to B-28 as

$$
C_{\mathrm{Pu}_{-} \mathrm{FeO} \_\mathrm{c}}=C_{\mathrm{FeO}_{-} \mathrm{c}} \mathrm{K}_{d_{-} \mathrm{FeO}{ }_{-} c} \mathrm{C}_{\mathrm{Pu}_{-} a q}=\bar{K}_{d_{-} \mathrm{FeO} \mathrm{O}_{-} c} C_{\mathrm{Pu} u_{-} a q}
$$




$$
\begin{aligned}
& C_{\mathrm{Pu}_{-} \mathrm{FeO} \mathrm{O}_{-} \mathrm{CP}}=C_{\mathrm{FeO} \mathrm{O}_{-} \mathrm{CP}} \mathrm{K}_{d_{-} \mathrm{FeO}_{-} \mathrm{CP}} \mathrm{C}_{\mathrm{Pu} u_{-} \mathrm{aq}}=\bar{K}_{d_{-} \mathrm{FeO} \mathrm{O}_{-} \mathrm{CP}} \mathrm{C}_{\mathrm{Pu} u_{-} \mathrm{aq}} \\
& c_{P u_{-} W F_{-} c}=C_{W F_{-} C} K_{d_{-} W F_{-} c} C_{P u_{-} a q}=\bar{K}_{d_{-} W F_{-} c} C_{P u_{-} a q} \\
& C_{P u_{-} G W_{-} c}=c_{G W_{-} c} K_{d_{-} G W_{-} c} C_{P u_{-} a q}=\bar{K}_{d_{-} G W_{-} c} C_{P u_{-} a q}
\end{aligned}
$$

where $\bar{K}_{d_{-} F e O_{-} c}, \bar{K}_{d_{-} F e O_{-} C P}, \bar{K}_{d_{-} W F_{-} c}$ and $\bar{K}_{d_{-} G W_{-} c}$ are dimensionless partition coefficients.

\section{QUANTIFICATION OF CORROSION PRODUCTS}

The corrosion products are generated from the degradation of the waste packages. It is the corrosion product mass that provides the porous matrix for the transport of radionuclides in the reaction mixing cell. The amount of corrosion products is time dependent. As modeled, the corrosion product density ( $\mathrm{kg} \mathrm{m}^{-3}$ solid) and mass (kg) are known. Let

$$
\begin{aligned}
& \rho_{\mathrm{FeO} \_\mathrm{CP}}=\text { corrosion product density } \\
& m_{\mathrm{FeO} \_\mathrm{CP}}=\text { mass of corrosion product. }
\end{aligned}
$$

The volume of corrosion products $\left(\mathrm{m}^{-3}\right.$ solid) is then

$$
V_{\mathrm{FeO} \_\mathrm{CP}}=\frac{m_{\mathrm{FeO} \_\mathrm{CP}}}{\rho_{\mathrm{FeO} \_\mathrm{CP}}} .
$$

If the porosity of the corrosion product mass is specified as

$$
\phi=\frac{V_{\text {pore }}}{V_{\text {bulk }}},
$$

then

$$
1-\phi=\frac{V_{F e O_{-} C P}}{V_{b u l k}} .
$$

The bulk volume is computed from

$$
V_{\text {bulk }}=\frac{V_{F e O_{-} C P}}{1-\phi} .
$$

The pore volume is

$$
V_{\text {pore }}=\phi V_{\text {bulk }}=\frac{\phi}{1-\phi} \frac{m_{\mathrm{FeO} \_\mathrm{CP}}}{\rho_{\mathrm{FeO} \_\mathrm{CP}}},
$$


and the water volume is:

$$
V_{\text {water }}=S_{w} V_{\text {pore }}=\phi S_{w} V_{\text {bulk }} \text {. }
$$

The stationary corrosion products concentration is defined as

$$
C_{\mathrm{FeO} \_\mathrm{CP}}=\frac{m_{\mathrm{FeO} O_{-} \mathrm{CP}}}{V_{\text {water }}} .
$$

\section{TRANSPORT EQUATIONS}

The mass balance equation for the Pu contained in the aqueous state, the reversible colloid state and the reversible corrosion product state with radionuclide decay (neglecting ingrowth) is (see development in Section 6.5.1.2 culminating in Equation 6.5.1.2-46):

$$
\begin{aligned}
& \frac{\partial \phi S_{w}\left(C_{P u_{-} a q}+C_{P u_{-} F e O_{-} c}+C_{P u_{-} F e O_{-} C P}+C_{P u_{-} W F_{-} C}+C_{P u_{-} G W_{-} c}\right)}{\partial t} \\
& +u \frac{\partial\left(C_{P u_{-} a q}+C_{P_{-} \mathrm{FeO}_{-} \mathrm{C}}+C_{\mathrm{Pu}_{-} W F_{-} \mathrm{C}}+C_{\mathrm{Pu}_{-} \mathrm{GW} \_}\right)}{\partial x}-\frac{\partial}{\partial x}\left(\phi S_{w} D_{a q} \frac{\partial c_{P u_{-} a q}}{\partial x}\right) \\
& -\frac{\partial}{\partial x}\left(\phi S_{w} D_{\text {colloid }} \frac{\partial\left(C_{\mathrm{Pu}_{-} \mathrm{FeO} \mathrm{O}_{-} \mathrm{C}}+\mathrm{C}_{\mathrm{Pu}_{-} W F_{-} \mathrm{C}}+\mathrm{C}_{\mathrm{Pu}_{-} \mathrm{GW} \mathrm{W}_{-} \mathrm{C}}\right)}{\partial x}\right) \\
& =-R_{1}-R_{2}-\lambda \phi S_{w}\left(c_{P u_{-} a q}+c_{P u_{-} F e O_{-} C}+C_{P_{u_{-}} \mathrm{FeO}_{-} \mathrm{CP}}+C_{\mathrm{Pu}_{-} \mathrm{WF}_{-} \mathrm{C}}+C_{\mathrm{Pu}_{-} \mathrm{GW}-\mathrm{C}}\right)
\end{aligned}
$$

where $\phi$ is the porosity of the FeO matrix, $S_{w}$ is the water saturation, $u$ is the Darcy velocity of the water $\left(\mathrm{m} \mathrm{yr}^{-1}\right), D_{a q}$ is the diffusivity $\left(\mathrm{m}^{2} \mathrm{yr}^{-1}\right)$ of the $\mathrm{Pu}$ in solution, $D_{\text {colloid }}$ is the colloid diffusivity $\left(\mathrm{m}^{2} \mathrm{yr}^{-1}\right)$, and $\lambda$ is the radionuclide decay rate $\left(\mathrm{yr}^{-1}\right)$. Now impose the reversible equilibrium of the Pu mass between the aqueous, colloid and corrosion products (Equations B-29 through B-32) together with representing the irreversible reactions as functions of the aqueous phase Pu concentration (Equations B-15 and B-16). The mass balance (Equation B-33) on a bulk volume basis can be expressed in terms of the concentration in the aqueous state: 


$$
\begin{aligned}
& \left(1+\bar{K}_{d_{-} F e O_{-} c}+\bar{K}_{d_{-} F e O_{-} C P}+\bar{K}_{d_{-} W F_{-} c}+\bar{K}_{d_{-} G W_{-} c}\right) \frac{\partial \phi S_{w} C_{P u_{-} a q}}{\partial t} \\
& +u\left(1+\bar{K}_{d_{-} F e O_{-} c}+\bar{K}_{d_{-} W F_{-} c}+\bar{K}_{d_{-} G W_{-} c}\right) \frac{\partial c_{P u_{-} a q}}{\partial x} \\
& -\frac{\partial}{\partial x}\left(\phi S_{w} D_{a q} \frac{\partial c_{P u_{-} a q}}{\partial x}\right) \\
& -\frac{\partial}{\partial x}\left(\phi S_{w} D_{\text {colloid }}\left(\bar{K}_{d_{-} \mathrm{FeO}_{-} \mathrm{c}}+\bar{K}_{d_{-} W F_{-} \mathrm{c}}+\bar{K}_{d_{-} G W_{-} \mathrm{c}}\right) \frac{\partial c_{P u_{-} a q}}{\partial x}\right) \\
& =-\phi S_{w}\left(\bar{R}_{1}+\bar{R}_{2}\right) C_{P u_{-} a q} \\
& -\lambda \phi S_{w}\left(1+\bar{K}_{d_{-} F e O_{-} c}+\bar{K}_{d_{-} F e O_{-} C P}+\bar{K}_{d_{-} W F_{-} c}+\bar{K}_{d_{-} G W_{-} c}\right) c_{P u_{-} a q .}
\end{aligned}
$$

Based on Equations 6.5.1.2-47 and 6.5.1.2-48, the mass balance equations for the irreversible $\mathrm{Pu}$ in the colloid and corrosion product states are, respectively,

$$
\begin{aligned}
& \frac{\partial \phi S_{w} C_{I r r v_{-} P u_{-} F e O_{-} c}}{\partial t}+u \frac{\partial C_{I r v_{-} P u_{-} F e O_{-} c}}{\partial x}-\frac{\partial}{\partial x}\left(\phi S_{w} D_{\text {colloid }} \frac{\partial c_{I r v_{-} P u_{-} F e O_{-} c}}{\partial x}\right) \\
& =\phi S_{w} \bar{R}_{1} C_{P u_{-} a q}-\lambda \phi S_{w} C_{I r r v_{-} P u_{-} F e O_{-} c}
\end{aligned}
$$

and

$$
\frac{\partial \phi S_{w} C_{I r v v_{-} P u_{-} F e O_{-} C P}}{\partial t}=\phi S_{w} \bar{R}_{2} C_{P u_{-} a q}-\lambda \phi S_{w} C_{I r r v_{-} P u_{-} F e O_{-} C P} .
$$

The boundary conditions require the upstream (left boundary cell, if flow is from left to right) conditions

$$
\begin{aligned}
& C_{P_{-} a q}=C_{S} \\
& C_{P u_{-} W F_{-} c}=\bar{K}_{d_{-} W F_{-} c} C_{s} \\
& C_{\mathrm{Pu}_{-} \mathrm{FeO} \mathrm{O}_{-} \mathrm{C}}=C_{\mathrm{Pu}_{-} \mathrm{FeO} \mathrm{O}_{-} \mathrm{CP}}=C_{\mathrm{Irrv} \mathrm{P}_{-} \mathrm{Pu}_{-} \mathrm{FeO} \mathrm{O}_{-} \mathrm{C}}=C_{\mathrm{Irrv} \mathrm{P}_{-} \mathrm{Pu} \mathrm{H}_{-} \mathrm{FeO} \mathrm{O}_{-} \mathrm{CP}}=\mathrm{C}_{\mathrm{Pu} \mathrm{G}_{-} \mathrm{GW} \mathrm{W}_{-} \mathrm{C}}=0 \text {, }
\end{aligned}
$$

where $c_{s}$ is the Pu solubility as defined earlier. In this model, no FeO or groundwater colloids exist in the upstream waste form cell. The solubility at the upstream location is dependent on the $\mathrm{CO}_{2}$ fugacity and $\mathrm{pH}$ at the upstream location (BSC 2005 [DIRS 174566], Section 8.1) and in general is time dependent: $c_{s}=c_{s}(t)$. The right boundary cell is a free flow boundary with concentrations fixed at zero for the purpose of this appendix. For diffusion calculations it is required to specify down stream diffusion parameters (porosity, diffusivity, diffusive length and diffusive area). The initial conditions within the mixing cell are zero for all Pu concentrations.

Both the colloid and corrosion product concentrations are chosen to be time dependent: 


$$
\begin{aligned}
& C_{\mathrm{FeO}_{-} \mathrm{c}}=c_{\mathrm{FeO}_{-} \mathrm{c}}(t) \\
& c_{\mathrm{FeO} O_{-} \mathrm{CP}}=c_{\mathrm{FeO}_{-} \mathrm{CP}}(t) \\
& c_{\mathrm{WF}_{-} \mathrm{c}}=c_{\mathrm{WF}_{-} \mathrm{c}}(t) \\
& c_{\mathrm{GW}_{-} \mathrm{c}}=c_{\mathrm{GW}_{-} \mathrm{c}}(t)
\end{aligned}
$$

but are independent of the Pu concentrations. This implies that the reaction rates $\bar{R}_{1}$ and $\bar{R}_{2}$ are also time dependent.

The mass balance equations are solved numerically by a finite difference method. The calculation sequence for a time step is to solve Equation B-34 for $C_{\mathrm{Pu}_{-} a q}$. Reversible equilibrium Equations B-29 through B-32 then give $C_{\mathrm{Pu}_{-} \mathrm{FeO} O_{-} c}, C_{\mathrm{Pu}_{-} \mathrm{FeO} \mathrm{O}_{-} \mathrm{CP}}, C_{\mathrm{Pu}_{-} W F_{-} \mathrm{c}}$ and $C_{\mathrm{Pu}_{-} \mathrm{GW} W_{-} \mathrm{c}}$. With $c_{P u_{-} a q}$ known the mass balance Equations B-35 and B-36 for the irreversible components are solved.

\section{DIMENSIONLESS FORM OF TRANSPORT EQUATIONS}

In order to express the governing equations in dimensionless form, dimensionless length, time and concentration, respectively, are defined:

$$
\begin{gathered}
\chi=x / L \\
\tau=\frac{u t}{\phi S_{w} L}=\frac{\bar{u} t}{L} \\
\bar{C}=c / c_{s},
\end{gathered}
$$

where $L$ is the characteristic length (m) and $\bar{u}=\frac{u}{\phi S_{w}}$ is the average linear advective velocity $\left(\mathrm{m} \mathrm{yr}^{-1}\right)$. The characteristic length would be the interval length or, for a finite difference solution, the grid block cell length. Then the variables are changed to dimensionless space and time in the mass balance equations. If the colloid/corrosion product concentrations are taken to be constant (Equations B-39), then the Pu mass balance equation in the aqueous state is:

$$
\begin{aligned}
& \left(1+\bar{K}_{d_{-} F e O_{-} c}+\bar{K}_{d_{-} F e O_{-} C P}+\bar{K}_{d_{-} W F_{-} c}+\bar{K}_{d_{-} G W_{-} c}\right) \frac{\partial \bar{c}_{P u_{-} a q}}{\partial \tau} \\
& +\left(1+\bar{K}_{d_{-} F e O_{-} c}+\bar{K}_{d_{-} W F_{-} c}+\bar{K}_{d_{-} G W_{-} c}\right) \frac{\partial \bar{c}_{P u_{-} a q}}{\partial \chi} \\
& -\left[\Delta_{a q}+\Delta_{\text {colloid }}\left(\bar{K}_{d_{-} F e O_{-} c}+\bar{K}_{d_{-} W F_{-} c}+\bar{K}_{d_{-} G W_{-} c}\right)\right] \frac{\partial^{2} \bar{c}_{P u_{-} a q}}{\partial \chi^{2}} \\
& =-\left(\Theta_{1}+\Theta_{2}\right) \bar{c}_{P u_{-} a q}-\left(1+\bar{K}_{d_{-} F e O_{-} c}+\bar{K}_{d_{-} F e O_{-} C P}+\bar{K}_{d_{-} W F_{-} c}+\bar{K}_{d_{-} G W_{-} c}\right) \Lambda \bar{c}_{P u_{-} a q}
\end{aligned}
$$


where

$$
\begin{aligned}
& \Delta_{a q}=\frac{\frac{D_{a q}}{L^{2}}}{\frac{\bar{u}}{L}} \quad=\frac{\text { diffusive rate in water }}{\text { advective rate }} \text {, } \\
& \Delta_{\text {collid }}=\frac{\frac{D_{\text {colloid }}}{L^{2}}}{\frac{\bar{u}}{L}}=\frac{\text { diffusive rate of colloids }}{\text { advective rate }} \text {, } \\
& \Theta_{1}=\frac{\bar{R}_{1}}{\frac{\bar{u}}{L}} \quad=\frac{\text { reaction rate to colloids }}{\text { advective rate }}, \\
& \Theta_{2}=\frac{\bar{R}_{2}}{\frac{\bar{u}}{L}} \quad=\frac{\text { reaction rate to corrosion products }}{\text { advective rate }} \text {, } \\
& \Lambda=\frac{\lambda}{\frac{\bar{u}}{L}} \quad=\frac{\text { decay rate }}{\text { advective rate }} .
\end{aligned}
$$

The dimensionless form of the mass balance for the irreversible $\mathrm{Pu}$ concentrations (Equations B-35 and B-36) are:

$$
\begin{aligned}
& \frac{\partial \bar{c}_{I r r v_{-} P u_{-} F e O_{-} c}}{\partial \tau}+\frac{\partial \bar{c}_{I r r v_{-} P u_{-} F e O_{-} c}}{\partial \chi}-\Delta_{\text {colloid }} \frac{\partial^{2} \bar{C}_{I r r v_{-} P u_{-} F e O_{-} c}}{\partial \chi^{2}} \\
=\Theta_{1} \bar{C}_{P u_{-} a q}-\Lambda \bar{c}_{I r r v_{-} P u_{-} F e O_{-} c} & \\
& \frac{\partial \bar{c}_{I r r v_{-} P u_{-} F e O_{-} C P}}{\partial \tau}=\Theta_{2} \bar{C}_{P u_{-} a q}-\Lambda \bar{c}_{I r v v_{-} P u_{-} F e O_{-} C P} .
\end{aligned}
$$

\section{DIFFERENCE SOLUTION OF TRANSPORT EQUATIONS}

Consider a finite difference approximation of the governing mass balance equations. The discretization uses three spatial cells. The left or first cell represents the upstream boundary conditions. The second cell represents the mixing cell with reactions. The third or right cell represents the down stream boundary conditions. Since cells one and three represent boundary conditions, this discretization is a 0 -dimensional or single cell representation of the processes. Let the time step length be $\Delta t$. Let superscript $n$ denote the $n^{\text {th }}$ time step, for example, $c_{P u_{-} a q}^{n}$ denotes the concentration at the $n^{\text {th }}$ time step. The discretization uses a first order backward difference approximation for the time derivative and the advective transport term. The diffusive 
flux uses a second order approximation. This discretization is consistent with GoldSim (GoldSim Technology Group 2002 [DIRS 160579]). In this model, diffusion of dissolved mass and waste form colloids occurs at the left boundary. At the right boundary, diffusion of both dissolved mass and all colloids occurs. In addition, the porosity and water saturation are timeindependent but may vary spatially. If the discretization is fully implicit in concentrations and time dependent velocity, irreversible reactions and solubility, then the discrete form of Equation B-34 for cell 2, in units of mass per unit water volume per unit time, is:

$$
\begin{aligned}
\bar{K}_{1} & \frac{c_{P u_{-} a q}^{n+1}-c_{P u_{-} a q}^{n}}{\Delta t}+\bar{U}^{n+1} \bar{K}_{2} c_{P u_{-} a q}^{n+1}-\bar{U}^{n+1}\left(1+\bar{K}_{d_{-} W F_{-} c}\right) c_{s}^{n+1}-\bar{D}_{\text {left_aq }}\left(c_{s}^{n+1}-c_{P u_{-} a q}^{n+1}\right) \\
& +\bar{D}_{\text {right_aq }} c_{P u_{-} a q}^{n+1}-\bar{D}_{\text {left_colloid }} \bar{K}_{d_{-} W F_{-} c}\left(c_{s}^{n+1}-c_{P u_{-} a q}^{n+1}\right)+\bar{D}_{\text {right_colloid }} \bar{K}_{3} c_{P u_{-} a q}^{n+1} \\
& =-\left(\bar{R}_{1}^{n+1}+\bar{R}_{2}^{n+1}+\lambda \bar{K}_{1}\right) c_{P u_{-} a q}^{n+1} .
\end{aligned}
$$

This equation is solved for $c_{P u_{-} a q}^{n+1}$, resulting in:

$$
\begin{aligned}
& c_{P u_{-} a q}^{n+1}= \\
& \frac{\bar{K}_{1} c_{P u_{-} a q}^{n}+\left[\bar{U}^{n+1}\left(1+\bar{K}_{d_{-} W F_{-} c}\right)+\bar{D}_{\text {left_aq }}+\bar{D}_{\text {lef_col }} \bar{K}_{d_{-} W F_{-} c}\right] c_{s}^{n+1} \Delta t}{\bar{K}_{1}+\left(\bar{U}^{n+1} \bar{K}_{2}+\bar{D}_{\text {left_aq }}+\bar{D}_{\text {left_col }} \bar{K}_{d_{-} W F_{-} c}+\bar{D}_{\text {right } a q}+\bar{D}_{\text {right_col }} \bar{K}_{3}+\bar{R}_{1}^{n+1}+\bar{R}_{2}^{n+1}+\lambda \bar{K}_{1}\right) \Delta t}
\end{aligned}
$$

where

$$
\frac{u \Delta t}{\phi S_{w} L}=\frac{U \Delta t}{V_{\text {water }}}=\bar{U} \Delta t
$$

is the Courant number (dimensionless), $L$ is the characteristic length (m), $V_{\text {water }}$ is the volume of water in the cell $\left(\mathrm{m}^{3}\right), U$ is the volumetric water flux $\left(\mathrm{m}^{3} \mathrm{yr}^{-1}\right)$, and $\bar{U}$ is the advective rate constant $\left(\mathrm{yr}^{-1}\right)$. Further,

$$
\begin{gathered}
\bar{K}_{1}=1+\bar{K}_{d_{-} F e O_{-} c}+\bar{K}_{d_{-} F e O_{-} C P}+\bar{K}_{d_{-} W F_{-} c}+\bar{K}_{d_{-} G W_{-} c} \\
\bar{K}_{2}=1+\bar{K}_{d_{-} F e O_{-} c}+\bar{K}_{d_{-} W F_{-} c}+\bar{K}_{d_{-} G W_{-} c} \\
\bar{K}_{3}=\bar{K}_{d_{-} F e O_{-} c}+\bar{K}_{d_{-} W F_{-} c}+\bar{K}_{d_{-} G W_{-} c}
\end{gathered}
$$

and

$$
\bar{D}=\frac{H\left(\frac{\phi S_{w} D}{L}\right)}{V_{\text {water }}} A_{s}
$$


is the diffusive rate constant $\left(\mathrm{yr}^{-1}\right)$ with respect to either the solution or colloid mass at either the right or left cell interface. Here, $A_{s}$ is the cross sectional area for diffusion $\left(\mathrm{m}^{2}\right)$. For determining the diffusive rate constant for a finite difference approximation to the transport equations, the condition imposed is that the flux across the interface of two adjacent cells be continuous at the interface. The resulting analysis gives the diffusive rate constant between two cells as the harmonic average of $\frac{\phi S_{w} D}{L}$, or $H\left(\frac{\phi S_{w} D}{L}\right)$, which guarantees the continuity of the diffusive flux at the cell interface. In general, the harmonic average of two numbers is:

$$
H\left(x_{1}, x_{2}\right)=\frac{2}{\frac{1}{x_{1}}+\frac{1}{x_{2}}} .
$$

For a finite difference approximation in which the cell lengths are $\Delta x_{1}$ and $\Delta x_{2}$, the harmonic average of $\frac{\phi S_{w} D}{\Delta x}$ across the Cell 1/Cell 2 interface is:

$$
\begin{aligned}
H\left(\left(\frac{\phi S_{w} D}{\Delta x}\right)_{1},\left(\frac{\phi S_{w} D}{\Delta x}\right)_{2}\right) & =\frac{2}{\frac{\Delta x_{1}}{\phi_{1} S_{w 1} D_{1}}+\frac{\Delta x_{2}}{\phi_{2} S_{w 2} D_{2}}} \\
& =\frac{1}{\frac{L_{1}}{\phi_{1} S_{w 1} D_{1}}+\frac{L_{2}}{\phi_{2} S_{w 2} D_{2}}},
\end{aligned}
$$

where $L_{1}$ and $L_{2}$ are the half-lengths (m) of Cells 1 and 2, respectively. The diffusive rate constant subscript left or right refers to the left or right diffusive boundary conditions, while the subscript_aq or_c refers to diffusion of the dissolved mass or colloid mass, respectively.

The reversible concentrations are determined from Equations B-29 through B-32

$$
\begin{aligned}
& C_{P_{-} u_{-} \mathrm{FO}_{-} \mathrm{c}}^{n+1}=\bar{K}_{d_{-} \mathrm{FeO}_{-} c} c_{P u_{-} a q}^{n+1} \\
& C_{P u_{-} \mathrm{FeO}_{-} \mathrm{CP}}^{n+1}=\bar{K}_{d_{-} \mathrm{FeO}_{-} \mathrm{CP}} C_{P u_{-} a q}^{n+1} \\
& c_{P u_{-} W F_{-} c}^{n+1}=\bar{K}_{d_{-} W_{F_{-}} c} C_{P u_{-} a q}^{n+1} \\
& c_{P u_{-} G W_{-} c}^{n+1}=\bar{K}_{d_{-} G W_{-} c} c_{P u_{-} a q}^{n+1} .
\end{aligned}
$$


The discretization of the balance Equation B-35 for irreversible Pu mass on the colloids yields

$$
c_{I r r v_{-} P u_{-} F e O_{-} c}^{n+1}=\frac{c_{I r r \nu_{-} P u_{-} F e O_{-} c}^{n}+\bar{R}_{1}^{n+1} \Delta t c_{P u_{-} a q}^{n+1}}{1+\left(\bar{U}^{n+1}+\bar{D}_{\text {right_col }}+\lambda\right) \Delta t}
$$

and for irreversible Pu mass on the corrosion products, Equation B-36 yields

$$
C_{I r r v_{-} P u_{-} F e O_{-} C P}^{n+1}=\frac{C_{I r v_{-} P u_{-} F e O_{-} C P}^{n}+\bar{R}_{2}^{n+1} \Delta t C_{P u_{-} a q}^{n+1}}{1+\lambda \Delta t} .
$$

\section{SAMPLE CALCULATION WITH REPRESENTATIVE PARAMETERS}

A sample calculation is performed to demonstrate the solution technique and illustrate the types of behavior that might be expected in this model. Parameter values used in this sample calculation are given in Table B-1. Let the solubility, flow velocity, and irreversible reaction parameters, which are actually time-dependent, be constant over time.

For this set of parameters, the irreversible reactive rates, advective rate, diffusive rates, decay rate and the dimensionless colloids and corrosion product partition coefficients are:

$$
\begin{aligned}
\bar{R}_{1} & =0.02000 \mathrm{yr}^{-1} \\
\bar{R}_{2} & =786 \mathrm{yr}^{-1} \\
\bar{U} & =0.04367 \mathrm{yr}^{-1} \\
\bar{D}_{\text {left_aq }} & =0.09127 \mathrm{yr}^{-1} \\
\bar{D}_{\text {right_aq }} & =2.229 \times 10^{-3} \mathrm{yr}^{-1} \\
\bar{D}_{\text {right_col }} & =2.229 \times 10^{-5} \mathrm{yr}^{-1} \\
\lambda & =2.875 \times 10^{-5} \mathrm{yr}^{-1} \\
\bar{K}_{d_{-} F e O_{-} c} & =0.20 \\
\bar{K}_{d_{-} F e O_{-} C P} & =1.965 \times 10^{4} \\
\bar{K}_{d_{-} W F_{-} c} & =0.60 \\
\bar{K}_{d_{-} G W_{-} c} & =0.020 .
\end{aligned}
$$

The simulation for the mixing cell (Cell 2) concentrations over a 1000-year time interval is shown in Figure B-2. The dominant rate constant, by several orders of magnitude, is the irreversible rate constant of the corrosion products, $\bar{R}_{2}=786 \mathrm{yr}^{-1}$. This is a result of the large mass of corrosion products and results in a relative large concentration of irreversibly sorbed $\mathrm{Pu}$ on the corrosion products, $C_{I r v_{-} P_{-} F e O_{-} C P}$. For this simulation, the amount of corrosion product mass is representative of the total mass of corrosion products in a waste package, and all the corrosion products are available at initial time. In the TSPA-LA abstraction model, the corrosion 
product mass is time dependent and a function of the corrosion rates for the carbon and stainless steel (see Section 6.5.3.2).

Another large mass of $\mathrm{Pu}$ is reversibly sorbed onto the corrosion products. This is a result of the large reversible partition coefficient for the corrosion products, $\bar{K}_{d_{-} \mathrm{FeO}_{-} \mathrm{CP}}=19650$, which again is a result of the large corrosion product mass. For this simulation, almost all of the $\mathrm{Pu}$ mass is sorbed onto the corrosion products either reversibly or irreversibly. Only a small amount of mass remains in solution or is sorbed onto the colloids. The qualitative behavior of the concentrations in Figure B-2 shows the concentrations approach a limiting value, with the exception of the irreversibly sorbed mass on the corrosion products. This behavior is discussed in the next section, where the concentrations are expressed analytically as solutions of difference equations, and their asymptotic-in-time values are determined.

Table B-1. Representative Parameter Values for Sample Calculation

\begin{tabular}{|c|c|c|c|}
\hline Parameter & Value & Units & Description \\
\hline$C_{s}$ & 1.0 & $\mathrm{mg} \mathrm{I}^{-1}$ & Solubility \\
\hline$S_{w}$ & 1.0 & dimensionless & Water saturation \\
\hline$\phi_{1}$ & 1.0 & dimensionless & Porosity of Cell 1 \\
\hline$\phi_{2}$ & 0.4 & dimensionless & Porosity of Cell 2 \\
\hline$\phi_{3}$ & 0.3 & dimensionless & Porosity of Cell 3 \\
\hline$U$ & 0.1 & $\mathrm{~m}^{3} \mathrm{yr}^{-1}$ & Volumetric water flux \\
\hline$K_{d_{-} \mathrm{FeO}_{-} \mathrm{c}}$ & $1 \times 10^{4}$ & $\mathrm{ml} \mathrm{g}^{-1}$ & Colloid partition coefficient \\
\hline$K_{d_{-} \mathrm{FeO}_{-} \mathrm{CP}}$ & $2.5 \times 10^{3}$ & $\mathrm{ml} \mathrm{g}^{-1}$ & Corrosion product partition coefficient \\
\hline$K_{d_{-} W F_{-} c}$ & $2 \times 10^{5}$ & $\mathrm{ml} \mathrm{g}^{-1}$ & Waste form colloids partition coefficient \\
\hline$K_{d_{-} G W_{-} c}$ & $2 \times 10^{5}$ & $\mathrm{ml} \mathrm{g}^{-1}$ & $\begin{array}{l}\text { Groundwater colloids partition } \\
\text { coefficient }\end{array}$ \\
\hline$\hat{S}_{\mathrm{FeO} \_c}$ & 100 & $\mathrm{~m}^{2} \mathrm{~g}^{-1}$ & Specific surface area of FeO colloids \\
\hline$\hat{S}_{\mathrm{FeO} \_\mathrm{CP}}$ & 10 & $\mathrm{~m}^{2} \mathrm{~g}^{-1}$ & $\begin{array}{l}\text { Specific surface area of FeO corrosion } \\
\text { products }\end{array}$ \\
\hline$C_{\mathrm{FeO}_{-} \mathrm{c}}$ & 20 & $\mathrm{mg} \mathrm{I}^{-1}$ & Concentration of FeO colloids \\
\hline$C_{\mathrm{FeO}_{-} \mathrm{CP}}$ & $7.86 \times 10^{6}$ & $\mathrm{mg} \mathrm{l}^{-1}$ & $\begin{array}{l}\text { Concentration of FeO corrosion } \\
\text { products }\end{array}$ \\
\hline$C_{W F_{-} c}$ & 3.0 & $\mathrm{mg} \mathrm{l}^{-1}$ & Concentration of waste form colloids \\
\hline$C_{G W_{-} c}$ & 0.1 & $\mathrm{mg} \mathrm{I}^{-1}$ & Concentration of groundwater colloids \\
\hline$k$ & 0.001 & $\mathrm{~cm} \mathrm{yr}^{-1}$ & Forward sorption rate constant \\
\hline$V_{\text {water }}$ & 2.290 & $\mathrm{~m}^{3}$ & $\begin{array}{l}\text { Water volume (= pore volume since } \\
\left.S_{w}=1\right)\end{array}$ \\
\hline$A_{s 12}$ & 36.0 & $\mathrm{~m}^{2}$ & $\begin{array}{l}\text { Diffusive area between Cell } 1 \text { and Cell } \\
2\end{array}$ \\
\hline$A_{\text {s23 }}$ & 1.068 & $\mathrm{~m}^{2}$ & $\begin{array}{l}\text { Diffusive area between Cell } 2 \text { and Cell } \\
3\end{array}$ \\
\hline
\end{tabular}


Table B-1. Representative Parameter Values for Sample Calculation (Continued)

\begin{tabular}{|c|c|c|l|}
\hline Parameter & Value & Units & \multicolumn{1}{|c|}{ Description } \\
\hline$L_{1}$ & 0.001 & $\mathrm{~m}$ & Half-length of Cell 1 diffusive path \\
\hline$L_{2}$ & 5.0 & $\mathrm{~m}$ & Half-length of Cell 2 diffusive path \\
\hline$L_{3}$ & 0.806 & $\mathrm{~m}$ & Half-length of Cell 3 diffusive path \\
\hline$D_{a q}$ & $2.3 \times 10^{-9}$ & $\mathrm{~m}^{2} \mathrm{~s}^{-1}$ & Aqueous diffusivity \\
\hline$D_{\text {colloid }}$ & $2.3 \times 10^{-11}$ & $\mathrm{~m}^{2} \mathrm{~s}^{-1}$ & Colloid diffusivity \\
\hline$\lambda$ & $2.875 \times 10^{-5}$ & $\mathrm{yr}^{-1}$ & Radionuclide decay rate \\
\hline
\end{tabular}

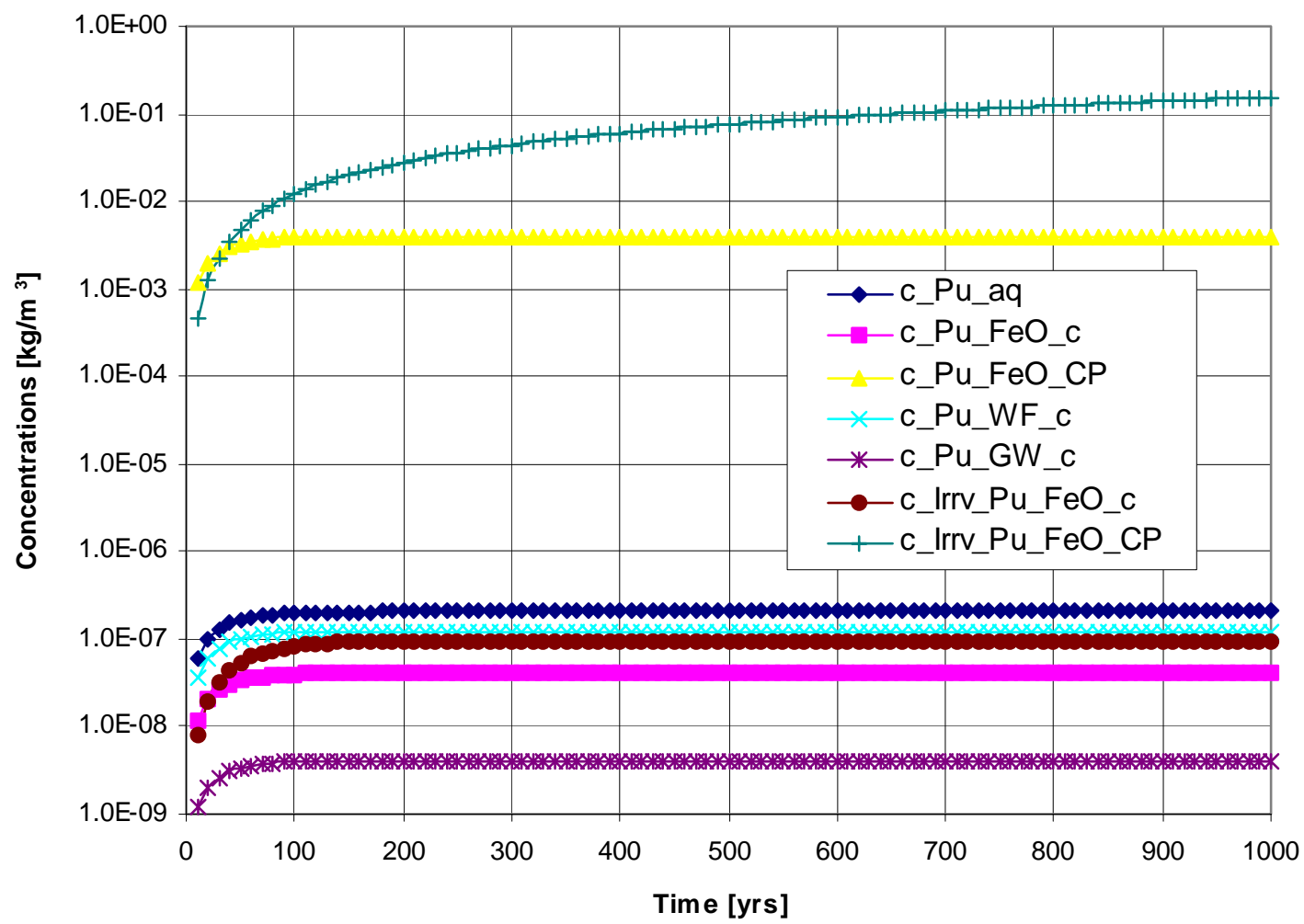

Figure B-2. Concentrations with Respect to Water Volume

\section{CLOSED FORM SOLUTIONS OF THE DIFFERENCE EQUATIONS}

If the solubility, advective flux, saturation, and irreversible rates are chosen to be constant over time, then the mass balance equation for the aqueous $\mathrm{Pu}$, Equation B-48, is a first order linear constant coefficient nonhomogeneous difference equation. This equation is of the form

$$
c_{P u_{-} a q}^{n+1}=a_{1} c_{P u_{-} a q}^{n}+a_{2}{ }^{`}
$$


where

$$
\begin{aligned}
& a_{1}=\frac{\bar{K}_{1}}{\bar{K}_{1}+\left(\bar{U} \bar{K}_{2}+\bar{D}_{\text {left_aq }}+\bar{D}_{\text {left_col }} \bar{K}_{d_{-} W F_{-} c}+\bar{D}_{\text {right_aq }}+\bar{D}_{\text {right_col }} \bar{K}_{3}+\bar{R}_{1}+\bar{R}_{2}+\lambda \bar{K}_{1}\right) \Delta t}
\end{aligned}
$$

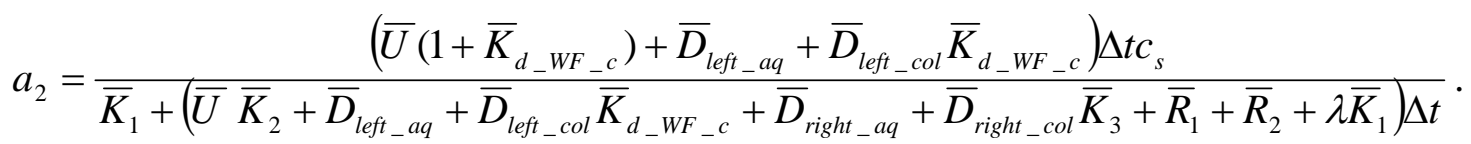

The difference equation (Equation B-55) with initial condition of zero concentration has the solution:

$$
c_{P u_{-} a q}^{n}=\frac{a_{2}\left(1-a_{1}^{n}\right)}{1-a_{1}},
$$

where $a_{1}^{n}$ is $a_{1}$ raised to the $n^{\text {th }}$ power (i.e., not $a_{1}$ at time step $n$ ). Since the condition $0<a_{1}<1$ is guaranteed (because all terms in the definition are positive, and the denominator is the sum of the numerator plus positive terms), the solution $C_{P u_{-} a q}^{n}$ for large time is asymptotic to:

$$
\begin{aligned}
& \lim _{n \rightarrow \infty} c_{P u_{-} a q}^{n}=\frac{a_{2}}{1-a_{1}}
\end{aligned}
$$

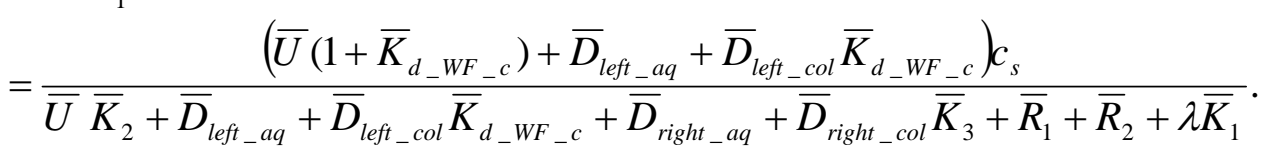

The terms in this expression represent the effects of advection, diffusion, decay, and reversible and irreversible sorption reactions.

The difference equation for the irreversible colloid concentration (Equation B-53) is first order linear and is written as:

$$
C_{I r r v_{-} P u_{-} F e O_{-} c}^{n+1}=b_{1} C_{I r v v_{-} P u_{-} F e O_{-} c}^{n}+b_{2} C_{P u_{-} a q}^{n+1}
$$

where

$$
\begin{aligned}
& b_{1}=\frac{1}{1+\left(\bar{U}+\bar{D}_{\text {right_col }}+\lambda\right) \Delta t} \\
& b_{2}=\frac{\bar{R}_{1} \Delta t}{1+\left(\bar{U}+\bar{D}_{\text {right_col }}+\lambda\right) \Delta t}
\end{aligned}
$$

and $c_{P u_{-} a q}^{n+1}$ is given by Equation B-56. The difference Equation B-58 with initial condition zero has solution 


$$
C_{I r v_{-} \mathrm{Pu}_{-} \mathrm{FeO} \mathrm{O}_{-} \mathrm{c}}^{n}=\frac{a_{2} b_{2}}{1-a_{1}}\left[\frac{1-b_{1}^{n+1}}{1-b_{1}}-\frac{a_{1}^{n+1}-b_{1}^{n+1}}{a_{1}-b_{1}}\right] .
$$

Since $0<a_{1}<1$ and $0<b_{1}<1$, this solution has asymptotic behavior

$$
\lim _{n \rightarrow \infty} c_{I r r v_{-} P u_{-} F e O_{-} c}^{n}=\frac{a_{2} b_{2}}{\left(1-a_{1}\right)\left(1-b_{1}\right)} .
$$

Thus

$$
\lim _{n \rightarrow \infty} c_{I r v_{-} P u_{-} F e O_{-} c}^{n}=\frac{b_{2}}{1-b_{1}} \lim _{n \rightarrow \infty} c_{P u_{-} a q}^{n}=\frac{\bar{R}_{1}}{\bar{U}+\bar{D}_{\text {right_col }}+\lambda} \lim _{n \rightarrow \infty} c_{P u_{-} a q}^{n} .
$$

The difference equation for the concentration of the irreversible mass on the corrosion products is first order linear and is written as

$$
C_{I r r v_{-} P u_{-} F e O_{-} C P}^{n+1}=e_{1} C_{I r r v_{-} P u_{-} F e O_{-} C P}^{n}+e_{2} C_{P u_{-} a q}^{n+1}
$$

where

$$
\begin{gathered}
e_{1}=\frac{1}{1+\lambda \Delta t} \\
e_{2}=\frac{\bar{R}_{2} \Delta t}{1+\lambda \Delta t} .
\end{gathered}
$$

If $\lambda>0$, Equation B-64 with initial concentration of zero has solution

$$
C_{I r r v_{-} P u_{-} \mathrm{FeO}_{-} \mathrm{CP}}^{n}=\frac{a_{2} e_{2}}{1-a_{1}}\left[\frac{1-e_{1}^{n+1}}{1-e_{1}}-\frac{a_{1}^{n+1}-e_{1}^{n+1}}{a_{1}-e_{1}}\right] .
$$

If $\lambda=0$, Equation B-64 with initial concentration of zero has solution

$$
C_{I r v_{-} P u_{-} \mathrm{FeO}_{-} \mathrm{CP}}^{n}=\frac{a_{2} e_{2}}{1-a_{1}}\left[n+1-\frac{1-a_{1}^{n+1}}{1-a_{1}}\right] .
$$

The solution Equation B-67 has asymptotic value

$$
\lim _{n \rightarrow \infty} C_{I r r v_{-} P u_{-} F e O_{-} C P}^{n}=\frac{e_{2}}{1-e_{1}} \lim _{n \rightarrow \infty} c_{P u_{-} a q}^{n}=\frac{\bar{R}_{2}}{\lambda} \lim _{n \rightarrow \infty} C_{P u_{-} a q},
$$

whereas the solution Equation B-68 does not have a limiting value, but is unbounded as a function of the time index $n$. 


\section{BOUNDARY FLUXES}

Now consider the two boundary flux conditions given in Equations B-1 and B-2. The left or upstream boundary flux accounts for advection/diffusion of Pu mass in solution (Pu_aq) and $\mathrm{Pu}$ mass sorbed to waste form colloids. In this section of the analysis, upstream diffusion of colloids is ignored, although the TSPA-LA implementation does account for upstream colloid diffusion. The mass flux rates $\left(\mathrm{kg} \mathrm{yr}^{-1}\right)$ at the upstream (left) boundary for the $n^{\text {th }}$ time step are:

$$
\begin{array}{ll}
\text { Advective_Pu_aq }\left(\mathrm{kg} \mathrm{yr}^{-1}\right) & =\bar{U} V_{\text {water }} C_{s} \\
\text { Diffusive_Pu_aq }\left(\mathrm{kg} \mathrm{yr}^{-1}\right) & =\bar{D}_{\text {left_aq }} V_{\text {water }}\left(c_{s}-c_{P u_{-} a q}^{n}\right) \\
\text { Advective_Pu_WF_c }\left(\mathrm{kg} \mathrm{yr}^{-1}\right) & =\bar{U} V_{\text {water }} \bar{K}_{d_{-} W F_{-} c} c_{s} \\
\text { Diffusive_Pu_WF_c }\left(\mathrm{kg} \mathrm{yr}^{-1}\right) & =\bar{D}_{\text {left_col }} V_{\text {water }} \bar{K}_{d_{-} W F_{-} c}\left(c_{s}-c_{P u_{-} a q}^{n}\right) .
\end{array}
$$

The right or downstream boundary flux has contributions from advection/diffusion of $\mathrm{Pu}$ in solution and colloid together with advection/diffusion of Irrv_Pu on colloids. There is no advective or diffusive flux associated with the immobile corrosion products. The mass flux rates $\left(\mathrm{kg} \mathrm{yr}^{-1}\right)$ at the right boundary assuming zero downstream concentrations are:

$$
\begin{aligned}
& \text { Advective_Pu_aq }\left(\mathrm{kg} \mathrm{yr}^{-1}\right) \quad=\bar{U} V_{\text {water }} C_{P u_{-} a q}^{n} \\
& \text { Diffusive_Pu_aq }\left(\mathrm{kg} \mathrm{yr}^{-1}\right) \quad=\bar{D}_{\text {right_aq }} V_{\text {water }} C_{P u_{-} a q}^{n} \\
& \text { Advective_Pu_FeO_c }\left(\mathrm{kg} \mathrm{yr}^{-1}\right) \quad=\bar{U} V_{\text {water }} \bar{K}_{d_{-} \mathrm{FeO}_{-} c} C_{\mathrm{Pu} \_a q}^{n} \\
& \text { Diffusive_Pu_FeO_c }\left(\mathrm{kg} \mathrm{yr}^{-1}\right) \quad=\bar{D}_{\text {right_col }} V_{\text {water }} \bar{K}_{d_{-} \mathrm{FeO}_{-} c} c_{\mathrm{Pu} u_{-} a q}^{n} \\
& \text { Advective_Irrv_Pu_FeO_c }\left(\mathrm{kg} \mathrm{yr}^{-1}\right)=\bar{U} V_{\text {water }} c_{I r r{ }_{-}}^{n} \mathrm{Pu} \_\mathrm{FeO} \__{-} \\
& \text {Diffusive_Irrv_Pu_FeO_c }\left(\mathrm{kg} \mathrm{yr}^{-1}\right) \quad=\bar{D}_{\text {right_col }} V_{\text {water }} c_{I r r v \_P P_{-} F e O_{-} c}^{n} \\
& \text { Advective_Pu_WF_c }\left(\mathrm{kg} \mathrm{yr}^{-1}\right) \quad=\bar{U} V_{\text {water }} \bar{K}_{d_{-} W F_{-} c} c_{P u_{-} a q}^{n} \\
& \text { Diffusive_Pu_WF_c }\left(\mathrm{kg} \mathrm{yr}^{-1}\right) \quad=\bar{D}_{\text {right_col }} V_{\text {water }} \bar{K}_{d_{-} W F_{-} c} c_{P u_{-} a q}^{n} \\
& \text { Advective_Pu_GW_c }\left(\mathrm{kg} \mathrm{yr}^{-1}\right) \quad=\bar{U} V_{\text {water }} \bar{K}_{d_{-} G W_{-} c} C_{P u_{-} a q}^{n} \\
& \text { Diffusive_Pu_GW_c }\left(\mathrm{kg} \mathrm{yr}^{-1}\right) \quad=\bar{D}_{\text {right_col }} V_{\text {water }} \bar{K}_{d_{-} G W_{-} c} c_{P P_{-} a q}^{n} \text {. }
\end{aligned}
$$

The total flux at the left boundary (upstream) at the $n^{\text {th }}$ time step, $F_{\text {left_bddy_total }}^{n}$, is

$$
\begin{aligned}
F_{\text {left_bddy_total }}^{n} & =\bar{U} V_{\text {water }} c_{s}+\bar{D}_{\text {left_aq }} V_{\text {water }}\left(c_{s}-c_{P u_{-} a q}^{n}\right) \\
& +\bar{U} V_{\text {water }} \bar{K}_{d_{-} W F_{-} c} c_{s}+\bar{D}_{\text {left_col }} V_{\text {water }} \bar{K}_{d_{-} W F_{-} c}\left(c_{s}-c_{P u_{-} a q}^{n}\right) .
\end{aligned}
$$


The condition discussed in Equation B-1 considers the ratio of the colloid mass to total mass flux out the right boundary. The right boundary colloidal flux, $F_{\text {right_bddy_colloid }}^{n}$, due to both reversibly and irreversibly sorbed $\mathrm{Pu}$ is:

$$
\begin{aligned}
& F_{\text {right_bddy_colloid }}^{n}=\bar{U} V_{\text {water }} \bar{K}_{d_{-} F e O_{-} c} c_{P u_{-} a q}^{n}+\bar{U} V_{\text {water }} c_{I r v_{-} P_{u_{-}} \mathrm{FeO}_{-} c}^{n} \\
& +\bar{U} V_{\text {water }} \bar{K}_{d_{-} W F_{-} c} c_{P u_{-} a q}^{n}+\bar{U} V_{\text {water }} \bar{K}_{d_{-} G W_{-} c} c_{P u_{-} a q}^{n} \\
& +\bar{D}_{\text {right_col }} V_{\text {water }} \bar{K}_{d_{-} \mathrm{FeO}_{-} c} c_{P u_{-} a q}^{n}+\bar{D}_{\text {right_col }} V_{\text {water }} c_{\text {Irrv_Pu_FeO_c }}^{n} \\
& +\bar{D}_{\text {right_col }} V_{\text {water }} \bar{K}_{d_{-} W_{-} c} c_{P_{u_{-} a q}}^{n}+\bar{D}_{\text {right_col }} V_{\text {water }} \bar{K}_{d_{-} G W_{-} c} c_{P_{u_{-} a q}}^{n} .
\end{aligned}
$$

The total Pu flux at the right boundary, $F_{\text {right_bddy_total }}^{n}$, is

$$
F_{\text {right_bddy_total }}^{n}=F_{\text {right_bddy_colloid }}^{n}+\bar{U} V_{\text {water }} c_{P u_{-} a q}^{n}+\bar{D}_{\text {right_aq }} V_{\text {water }} c_{P u_{-} a q}^{n} .
$$

The right boundary ratio of colloid flux out to total flux out at time level $n$ is

$$
\Omega_{n}=\frac{F_{\text {right_bddy_colloid }}^{n}}{F_{\text {right_bddy_total }}^{n} .}
$$

Then

$$
\Omega_{n}=\frac{\bar{K}_{3}+\frac{C_{I r v_{-} P u_{-} F e O_{-} c}^{n}}{c_{P u_{-} a q}^{n}}}{\frac{\bar{U} \bar{K}_{2}+\bar{D}_{\text {righ_aq }}+\bar{D}_{\text {right_col }} \bar{K}_{3}}{\bar{U}+\bar{D}_{\text {right_col }}}+\frac{c_{\text {Irrv_Pu_FeO_c }}^{n}}{c_{P u_{-} a q}^{n}}} .
$$

Now from Equation B-63

$$
\lim _{n \rightarrow \infty} \frac{C_{I r r v_{-} P u_{-} F e O_{-} c}^{n}}{C_{P u_{-} a q}^{n}}=\frac{\bar{R}_{1}}{\bar{U}+\bar{D}_{\text {right_col }}+\lambda} .
$$

The limiting value for the right boundary ratio of colloid flux to total flux is

$$
\Omega=\lim _{n \rightarrow \infty} \Omega_{n}=\frac{\bar{K}_{3}+\frac{\bar{R}_{1}}{\bar{U}+\bar{D}_{\text {right_col }}+\lambda}}{\frac{\bar{U} \bar{K}_{2}+\bar{D}_{\text {right_aq }}+\bar{D}_{\text {right_col }} \bar{K}_{3}}{\bar{U}+\bar{D}_{\text {right_col }}}+\frac{\bar{R}_{1}}{\bar{U}+\bar{D}_{\text {right_col }}+\lambda}}
$$

or 


$$
\Omega=\frac{\bar{K}_{3}\left(\bar{U}+\bar{D}_{\text {right_col }}+\lambda\right)+\bar{R}_{1}}{\left(\bar{U} \bar{K}_{2}+\bar{D}_{\text {right_aq }}+\bar{D}_{\text {right_col }} \bar{K}_{3}\left(\frac{\bar{U}+\bar{D}_{\text {right_col }}+\lambda}{\bar{U}+\bar{D}_{\text {right_col }}}\right)+\bar{R}_{1}\right.} .
$$

This can be written as

$$
\Omega=\frac{p_{1}+\bar{R}_{1}}{p_{2}+\bar{R}_{1}}
$$

where

$$
\begin{gathered}
p_{1}=\bar{K}_{3}\left(\bar{U}+\bar{D}_{\text {right_col }}+\lambda\right) \\
p_{2}=\left(\bar{U} \bar{K}_{2}+\bar{D}_{\text {right_aq }}+\bar{D}_{\text {right_col }} \bar{K}_{3}\right)\left(\frac{\bar{U}+\bar{D}_{\text {right_col }}+\lambda}{\bar{U}+\bar{D}_{\text {right_col }}}\right) .
\end{gathered}
$$

Note the limiting flux out ratio $\Omega$ satisfies

$$
0<\frac{\bar{K}_{3}\left(\bar{U}+\bar{D}_{\text {right_col }}\right)}{\bar{U} \bar{K}_{2}+\bar{D}_{\text {right_aq }}+\bar{D}_{\text {right_col }} \bar{K}_{3}}<\Omega<1,
$$

where the lower bound on $\Omega$ is obtained when $\bar{R}_{1}=0$. Qualitatively, if the advective, diffusive, and decay rates dominate the reactive rate constant $\bar{R}_{1}$, then $\Omega$ is close to the minimum value. However, if the reactive rate constant dominates, then $\Omega$ is close to one. The latter is the expected qualitative behavior of the system as alluded to in the introduction of this appendix. For the parameter values given in Table B-1, the minimum value $\Omega=0.4384$ is obtained with $\bar{R}_{1}=0$.

The limiting flux out ratio for Table B-1 parameter values $\left(\bar{R}_{1}=0.02 \mathrm{yr}^{-1}\right)$ is $\Omega=0.5487$; in other words, about 55\% of the total Pu mass exiting the cell is sorbed onto colloids. Figure B-3 shows the dependence of the flux out ratio $\Omega$ on the irreversible linear reaction rate constant $k$, where $\bar{R}_{1}=\hat{S}_{\mathrm{FeO}_{-} c} C_{\mathrm{FeO}{ }_{-} c} k$. The $\Omega$ value point obtained with the Table B-1 parameter values is also shown in Figure B-3. An increase of the irreversible linear reaction rate, $k$, of approximately one and a half orders of magnitude would increase the flux out ratio to approximately $95 \%$. 
In the expression for irreversible sorption to colloids, $\bar{R}_{1}=\hat{S}_{\mathrm{FeO}_{-} c} c_{\mathrm{FeO}} \mathrm{c} k$, consider the irreversible linear reaction rate $k$ a fitting parameter to match a specified flux out ratio $\Omega$. Then the solution of Equation B-71 for $k$ is:

$$
k=\frac{p_{2} \Omega-p_{1}}{(1-\Omega) \hat{S}_{F e O_{-} c} c_{F e O_{-} c}} .
$$

The result in Equation B-72 provides the fitting parameter, $k$, given a target flux ratio $\Omega$. From the parameter values in Table B-1 and with $\Omega=0.95$, the irreversible linear reaction rate is determined from Equation B-72 as $k=0.04184 \mathrm{~cm} \mathrm{yr}^{-1}$. The fitting parameter curve together with this point is shown in Figure B-4.

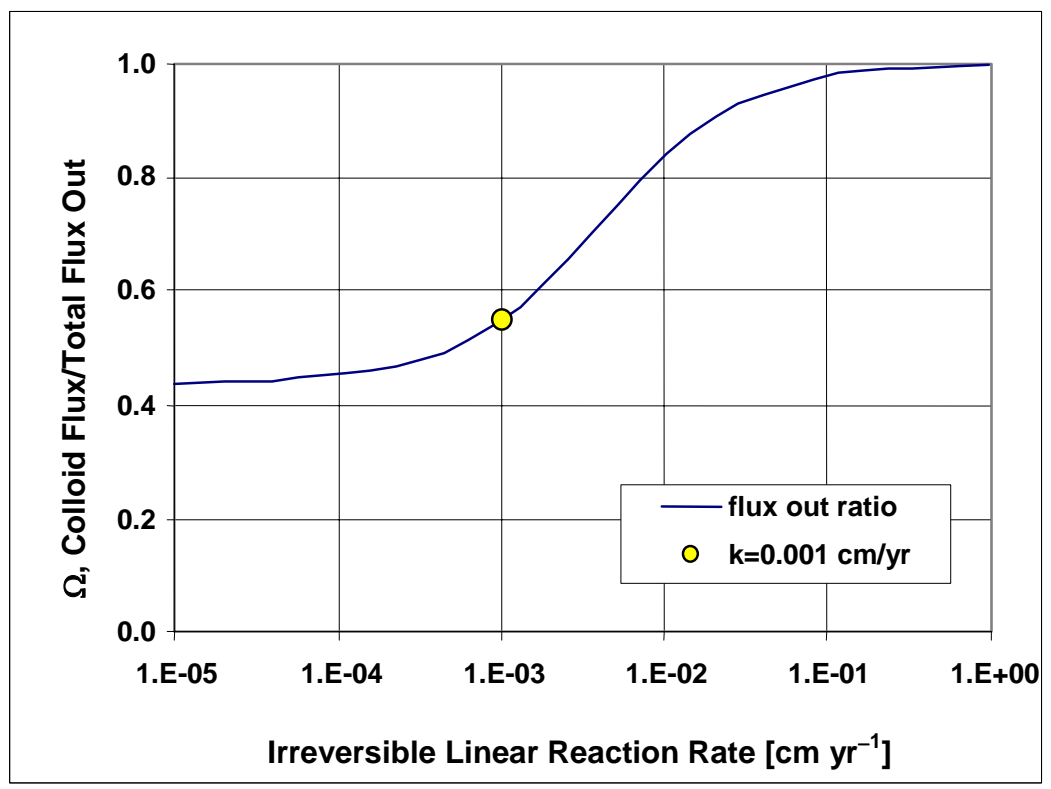

Source: Worksheet: K-surface in Appendix F.

Figure B-3. Limiting Flux Out Ratio, $\Omega$, as a Function of Irreversible Reaction Rate 


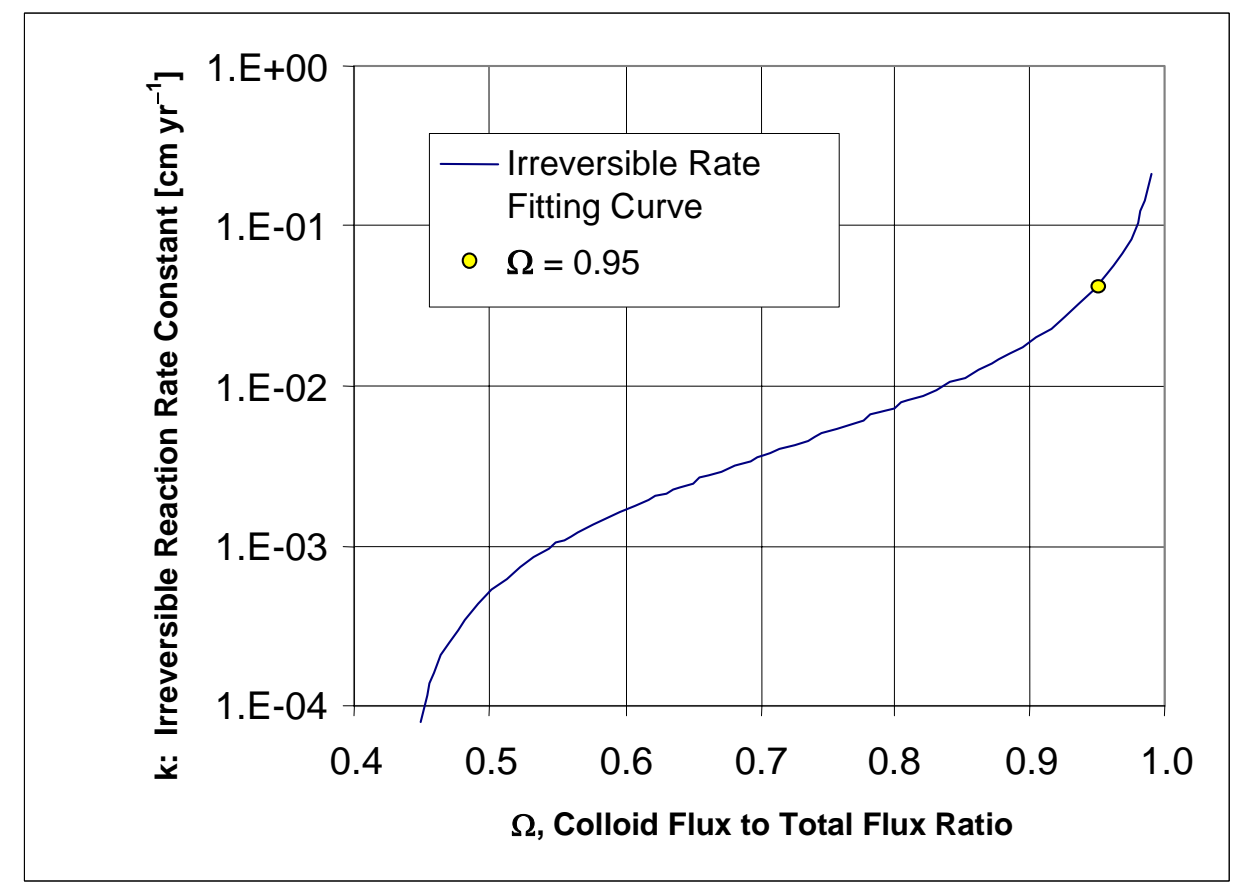

Source: Worksheet: adv_diff_decay in Appendix F.

Figure B-4. Linear Reaction Rate from Colloid to Total Flux Out Ratio, $\Omega$

The ratio of the total flux out (right boundary) to total flux in (left boundary) at time step $\mathrm{n}$ is

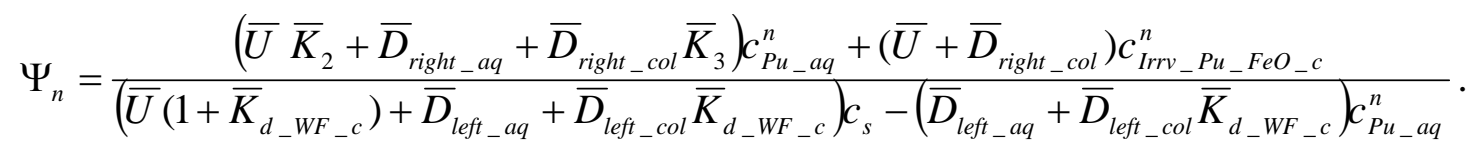

The numerator and denominator in this expression are divided by $C_{P_{u} \_a}^{n}$, and the limit is taken as $n$ goes to infinity. Equation B-63 implies:

$$
\lim \frac{C_{\text {Irrv_Pu_FeO_c }}^{n}}{C_{P u_{-} a q}^{n}}=\frac{\bar{R}_{1}}{\bar{U}+\bar{D}_{\text {right_col }}+\lambda} .
$$

Denote

$$
\mathrm{Z}=\frac{\bar{U}+\bar{D}_{\text {right_col }}+\lambda}{\bar{U}+\bar{D}_{\text {right_col }}}
$$

and multiply the numerator and denominator of the equation for $\Psi_{n}$ by $\mathrm{Z}$. The numerator reduces to $p_{2}+\bar{R}_{1}$. Now consider the denominator term multiplied by $\mathrm{Z}$. It follows from Equation B-57 that 


$$
\begin{aligned}
(\bar{U}(1 & \left.\left.+\bar{K}_{d_{-} W F_{-} c}\right)+\bar{D}_{\text {left_aq }}+\bar{D}_{\text {left_col }} \bar{K}_{d_{-} W F_{-} c}\right) \frac{c_{s}}{\lim c_{P u_{-} a q}^{n}} \\
& =\overline{U K}_{2}+\bar{D}_{\text {left_aq }}+\bar{D}_{\text {left_col }} \bar{K}_{d_{-} W F_{-} c}+\bar{D}_{\text {right_aq }}+\bar{D}_{\text {right_col }} \bar{K}_{3}+\bar{R}_{1}+\bar{R}_{2}+\lambda \bar{K}_{1}
\end{aligned}
$$

Therefore, the denominator is calculated as

$$
\begin{aligned}
\mid \overline{U K}_{2} & \left.+\bar{D}_{\text {left_aq }}+\bar{D}_{\text {left_col }} \bar{K}_{d_{-} W F_{-} c}+\bar{D}_{\text {right_aq }}+\bar{D}_{\text {right_col }} \bar{K}_{3}+\bar{R}_{1}+\bar{R}_{2}+\lambda \bar{K}_{1}-\left(\bar{D}_{\text {left_aq }}+\bar{D}_{\text {left_col }} \bar{K}_{d_{-} W F_{-} c}\right)\right] \mathrm{Z} \\
& =\left[\overline{U K}_{2}+\bar{D}_{\text {right_aq }}+\bar{D}_{\text {right_col }} \bar{K}_{3}+\bar{R}_{1}+\bar{R}_{2}+\lambda \bar{K}_{1}\right] \mathrm{Z} \\
& =p_{2}+\left(\frac{\bar{U}+\bar{D}_{\text {right_col }}+\lambda}{\bar{U}+\bar{D}_{\text {right_col }}}\right)\left(\bar{R}_{1}+\bar{R}_{2}+\lambda \bar{K}_{1}\right)
\end{aligned}
$$

The limiting flux ratio then has the limiting value:

$$
\Psi=\frac{p_{2}+\bar{R}_{1}}{p_{2}+\left(\frac{\bar{U}+\bar{D}_{\text {right_col }}+\lambda}{\bar{U}+\bar{D}_{\text {right_col }}}\right)\left(\bar{R}_{1}+\bar{R}_{2}+\lambda \bar{K}_{1}\right)} .
$$

The mass flux ratio $\Psi$ is calculated from Equation B-73 for the Table B-1 parameter values, but with irreversible linear reaction rate $k=0.04184 \mathrm{~cm} \mathrm{yr}^{-1}$ obtained from the fit to $\Omega=0.95$. Equation B-73 gives:

$$
\Psi=1.293 \times 10^{-4}
$$

which demonstrates that most of the Pu mass is reacted both reversibly and irreversibly to the corrosion products.

\section{CONVERGENCE ESTIMATES FOR CLOSED FORM SOLUTIONS}

Consider the convergence of the concentration in the aqueous state given by Equation B-56:

$$
c_{P u_{-} a q}^{n}=\frac{a_{2}}{1-a_{1}}\left(1-a_{1}^{n}\right)
$$

with limit value (Equation B-57)

$$
\lim _{n \rightarrow \infty} c_{P u_{-} a q}^{n}=\frac{a_{2}}{1-a_{1}} .
$$


The relative error estimate with tolerance $\varepsilon$ is given by

$$
\left|\frac{\lim _{n \rightarrow \infty} c_{P u_{-} a q}^{n}-c_{P u_{-} a q}^{n}}{\lim _{n \rightarrow \infty} c_{P u_{-} a q}^{n}}\right|<\varepsilon .
$$

Then the error estimate is

$$
\left|\frac{\frac{a_{2}}{1-a_{1}}-\frac{a_{2}}{1-a_{1}}\left(1-a_{1}^{n}\right)}{\frac{a_{2}}{1-a_{1}}}\right|=a_{1}^{n}<\varepsilon
$$

The bounds $0<a_{1}<1$ implies $\log _{10} a_{1}<0$ and the error estimate holds for

$$
n>\frac{\log _{10} \varepsilon}{\log _{10} a_{1}}
$$

or

$$
\text { time }=n \Delta t>\frac{\log _{10} \varepsilon}{\log _{10} a_{1}} \Delta t
$$

The time to converge to a given relative error tolerance for all reversible sorbed $\mathrm{Pu}$ concentrations is the same as the estimate for the aqueous concentration, inequality Equation B-74, since the reversibly sorbed concentration is a constant multiple of the aqueous concentration.

Now consider the convergence of the irreversible Pu concentration on colloids, $C_{I r v_{-} \mathrm{Pu}_{-} \mathrm{C}}^{n}$. An estimate of the relative error is given by

$$
\begin{aligned}
&\left|\frac{c_{I r r v_{-} P u_{-} c}^{n}-\lim _{n \rightarrow \infty} c_{I r r v_{-} P u_{-} c}^{n}}{\lim _{n \rightarrow \infty} c_{I r v_{-} P u_{-} c}^{n}}\right|=\left|\frac{\frac{a_{2} b_{2}}{1-a_{1}}\left[\frac{1-b_{1}^{n+1}}{1-b_{1}}-\frac{a_{1}^{n+1}-b_{1}^{n+1}}{a_{1}-b_{1}}\right]-\frac{a_{2} b_{2}}{\left(1-a_{1}\right)\left(1-b_{1}\right)}}{\frac{a_{2} b_{2}}{\left(1-a_{1}\right)\left(1-b_{1}\right)}}\right| \\
& \quad=\left|\left(1-b_{1}\right)\left(\frac{-b_{1}^{n+1}}{1-b_{1}}-\frac{a_{1}^{n+1}-b_{1}^{n+1}}{a_{1}-b_{1}}\right)\right| \\
&=\left|\frac{\left(1-a_{1}\right) b_{1}^{n+1}}{a_{1}-b_{1}}-\frac{\left(1-b_{1}\right) a_{1}^{n+1}}{a_{1}-b_{1}}\right| \\
& \leq \mid \frac{1-a_{1}\left|b_{1}-b_{1}\right|}{a_{1}^{n+1}+\left|\frac{1-b_{1}}{a_{1}-b_{1}}\right| a_{1}^{n+1}<\varepsilon .}
\end{aligned}
$$


This estimate holds if

$$
b_{1}^{n+1}<\left|\frac{a_{1}-b_{1}}{1-a_{1}}\right| \frac{\varepsilon}{2}=\delta_{1} \text { and } a_{1}^{n+1}<\left|\frac{a_{1}-b_{1}}{1-b_{1}}\right| \frac{\varepsilon}{2}=\delta_{2} .
$$

These two estimates are satisfied if

$$
n+1 \geq \operatorname{Integer}\left[\max \left(\frac{\log _{10} \delta_{1}}{\log _{10} b_{1}}, \frac{\log _{10} \delta_{2}}{\log _{10} a_{1}}\right)\right]+1
$$

or

$$
\text { time }=n \Delta t \geq \operatorname{Integer}\left[\max \left(\frac{\log _{10} \delta_{1}}{\log _{10} b_{1}}, \frac{\log _{10} \delta_{2}}{\log _{10} a_{1}}\right)\right] \Delta t .
$$

For a relative error tolerance of $1 \%(\varepsilon=0.01)$ and the parameter values in Table B-1, Figure B-5 shows the time to converge for time step size 0.1 to 1000 years for both the aqueous $\mathrm{Pu}$ concentration and irreversible colloid Pu concentration. For example, if the time step is small, say 10 years, the number of years to converge within the given tolerance for the aqueous phase concentration is 137 years, whereas the time to converge for the irreversible colloid concentration is 240 years. If the time step is increased to 100 years, then the time to converge to the aqueous phase concentration is 286 years (three time steps), whereas the time to converge to the irreversible colloid concentration is 500 years (5 time steps). 


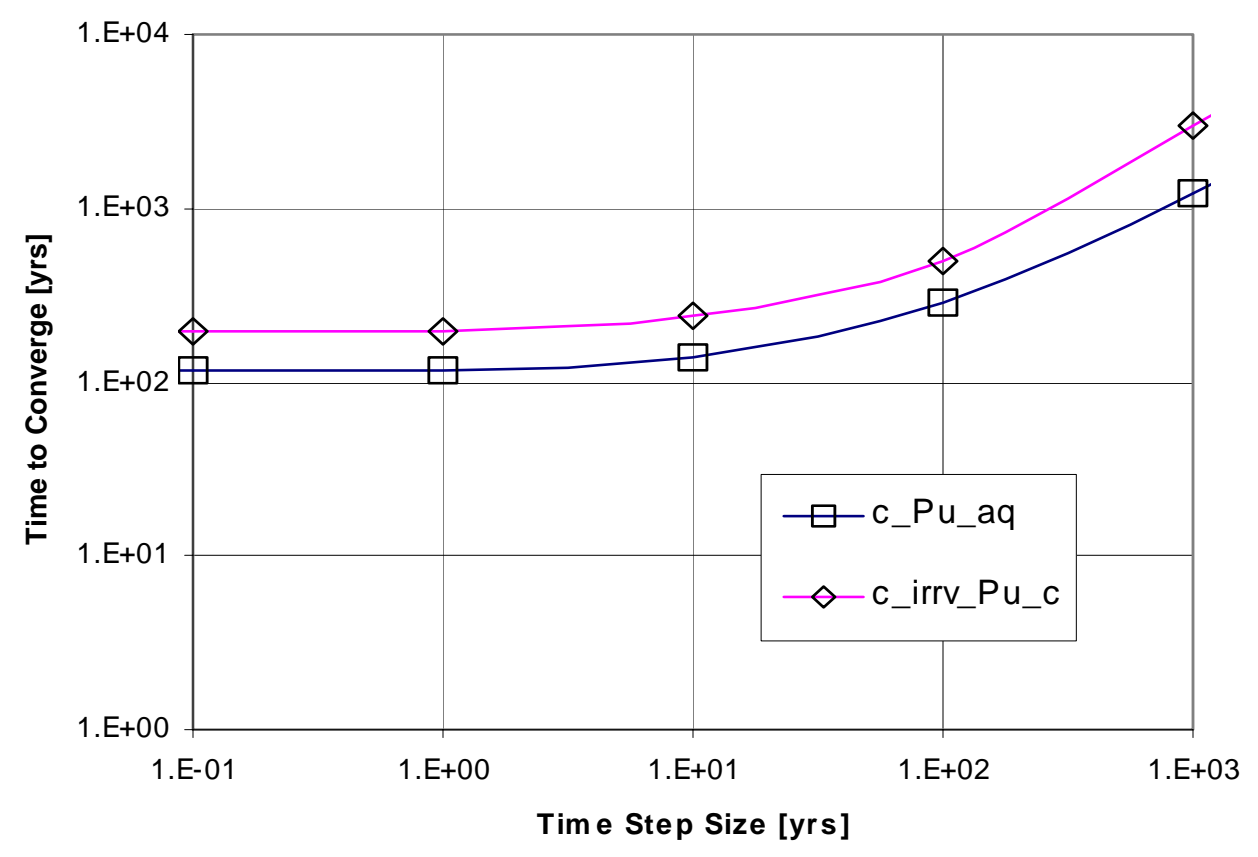

Source: Spreadsheet: time_to_conv.xls, Worksheet: plot_time_to_conv in Appendix F.

Figure B-5. Time for Concentration to Converge with 1\% Relative Error Tolerance

Appendix $\mathrm{F}$ presents the calculational spreadsheets that implement the equations in this appendix. 
APPENDIX C

MICROSOFT EXCEL SPREADSHEET "FLUX SPLIT DRIP SHIELD MODEL" 


\section{MICROSOFT EXCEL SPREADSHEET “FLUX SPLIT DRIP SHIELD MODEL”}

\section{SPREADSHEET “FLUX SPLIT DRIP SHIELD MODEL” WORKSHEET "F CALCULATIONS"}

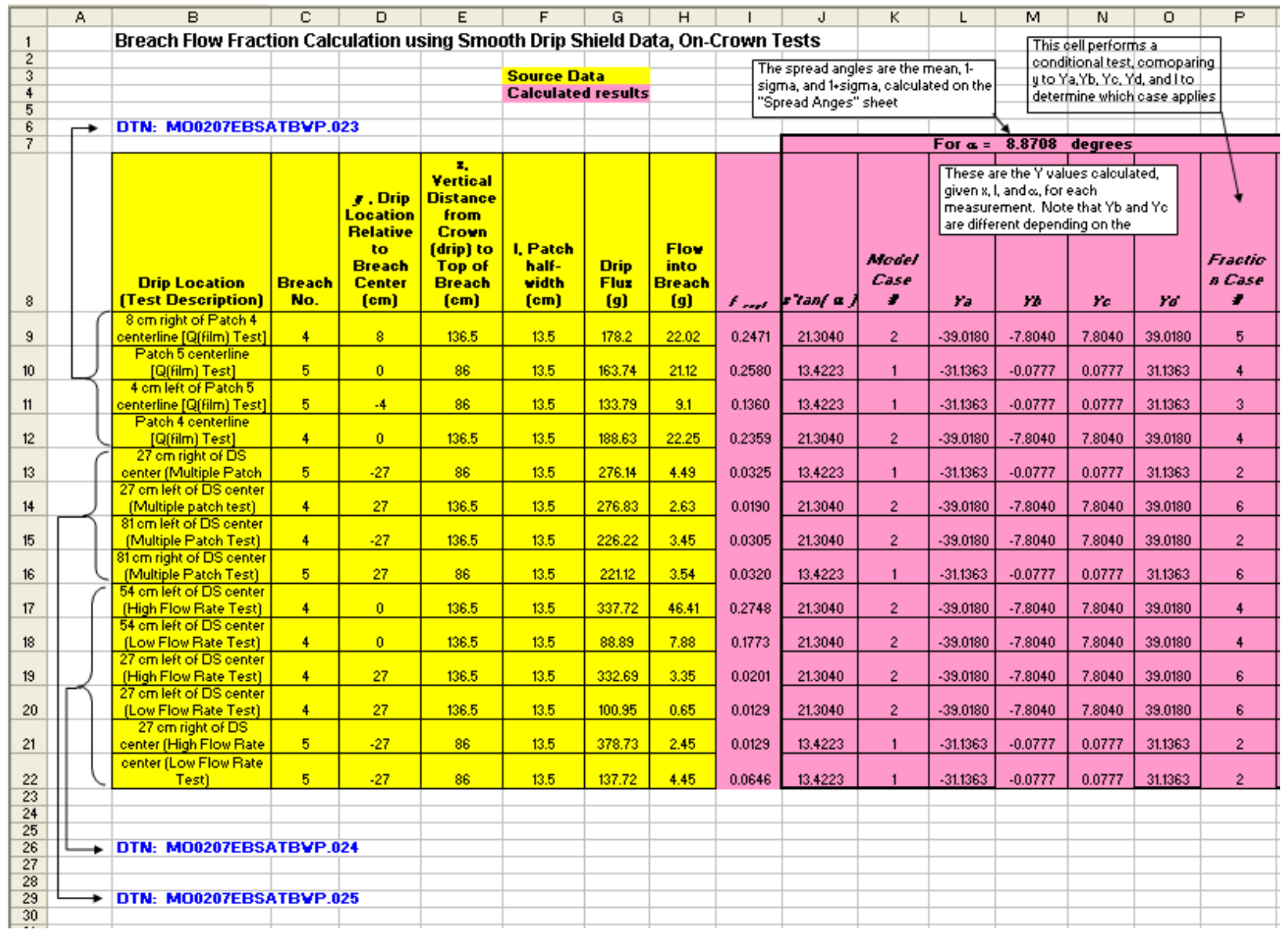

DTN: MO0207EBSATBWP.023 [DIRS 163402]; DTN: MO0207EBSATBWP.024 [DIRS 163401];

DTN: MO0207EBSATBWP.025 [DIRS 163403].

Figure C-1. Spreadsheet "Flux Split Drip Shield Model," Worksheet "f calculations;" Calculation of Experimental Breach Flow Fractions and Model Flow Fractions for Mean Minus One Standard Deviation Rivulet Spread Angle

The purpose of this spreadsheet is to develop the drip shield flux splitting submodel using experimental data from the breached drip shield experiments. The data are analyzed to estimate an average and range of the rivulet spread angle, $\alpha$. The disparity between measured fraction of dripping flux that enters a breach and the fraction calculated using the model (with the measured range of the rivulet spread angle) is then used to establish a range of uncertainty in the model.

All descriptions for this worksheet (Figures C-1 to C-4) pertain to Rows 9-22. Equations in spreadsheet format are illustrated using Row 9. 
Column B: $\quad$ Drip location as indicated for each test in the designated DTN (Figure C-1).

Column C: Breach or patch number most pertinent to this particular test, for which flow is analyzed in this row of the spreadsheet.

Column D: Drip location, $y$, relative to the center of the breach listed in Column C.

Column E: Distance along the drip shield curved surface, $x$, from the drip shield crown to the top of the breach.

Column F: Half-width, $\ell$, of the breach $(13.5 \mathrm{~cm})$, same for all breaches.

Column G: $\quad$ Measured mass of water, $F_{1}$, dripped onto the drip shield during the test. It is assumed that half of the water that dripped onto the drip shield, $F_{1} / 2$, flowed down the side that contained the breach.

Column H: Measured mass of water, $F_{2}$, that flowed into the breach during the test.

Column I: Fraction of water dripped onto the drip shield that flowed into the breach:

$$
\begin{gathered}
f_{\text {expt }}=\frac{F_{2}}{F_{1} / 2}=\frac{2 F_{2}}{F_{1}} . \\
19=\mathrm{H} 9 * 2 / \mathrm{G} 9
\end{gathered}
$$

Column J: $\quad x \tan \alpha$, where $x$ is from Column E, and $\alpha$ is the spread angle. For Columns J-X, the value used for $\alpha$ is $8.8708^{\circ}$ (Cell $\$ M \$ 7$ ), which is one standard deviation less than the mean measured spread angle for these tests (see Worksheet "Spread angles").

\section{$J 9=\$ E 9 * T A N(R A D I A N S(\$ M \$ 7))$}

Column K: $\quad$ Case number as described in Sections 6.5.1.1.2.1 and 6.5.1.1.2.2. For Case 1, $\ell>x \tan \alpha$; for Case 2, $\ell<x \tan \alpha ; x$ is from Column E, and the half-width of the breach, $\ell$, is from Column $\mathrm{F}$.

$$
\mathrm{K} 9=\mathrm{IF}(\$ F 9>J 9,1,2)
$$

Column L: Value of $y_{A}$ (Point A) as described in Sections 6.5.1.1.2.1 and 6.5.1.1.2.2, corresponding to the leftmost point from which the edge of the fan from the rivulet can enter the left side of the breach:

$$
y_{A}=-\ell-(x+2 \ell) \tan \alpha
$$

L9=-\$F9-(\$E9+2*\$F9)*TAN(RADIANS(\$M\$7)) 
Column M: Value of $y_{B}$ (Point B) as described in Sections 6.5.1.1.2.1 and 6.5.1.1.2.2, corresponding to the leftmost point from which rivulets will enter the top edge of the breach. The value of $y_{B}$ depends on the Model Case number (Column K):

$$
\begin{aligned}
& y_{B}=-\ell+x \tan \alpha \\
& \text { Case } 1 . \\
& y_{B}=\ell-x \tan \alpha \\
& \text { Case } 2 . \\
& M 9=I F(K 9=1,(-\$ F 9+\$ E 9 * T A N(R A D I A N S(\$ M \$ 7))) \text {, } \\
& \text { (\$F9-\$E9*TAN(RADIANS(\$M\$7))) }
\end{aligned}
$$

Column N: Value of $y_{C}$ (Point C) as described in Sections 6.5.1.1.2.1 and 6.5.1.1.2.2, corresponding to the rightmost point from which rivulets will enter the top edge of the breach. The value of $y_{C}$ depends on the Model Case number (Column K):

$$
\begin{gathered}
y_{C}=\ell-x \tan \alpha \\
y_{C}=-\ell+x \tan \alpha
\end{gathered}
$$

Case 2.

\section{$\mathrm{N} 9=\mathrm{IF}(\mathrm{K} 9=1,(\$ \mathrm{~F} 9-\$ \mathrm{E} 9 *$ TAN $(\mathrm{RADIANS}(\$ \mathrm{M} \$ 7)))$, $(-\$ F 9+\$ E 9 * T A N(R A D I A N S(\$ M \$ 7))))$}

Column O: Value of $y_{D}$ (Point D) as described in Sections 6.5.1.1.2.1 and 6.5.1.1.2.2, corresponding to the rightmost point from which the edge of the fan from the rivulet can enter the right side of the breach:

$$
y_{D}=\ell+(x+2 \ell) \tan \alpha
$$

$$
\mathrm{O} 9=\$ F 9+(\$ E 9+2 * \$ F 9) * \text { TAN }(\text { RADIANS }(\$ M \$ 7))
$$

Column P: Determines which region (designated as Fraction Case \#) along the crown where the drip is located:

$$
\begin{aligned}
& 1 . y \leq y_{A} \\
& 2 . y_{A}<y \leq-\ell \\
& 3 .-\ell<y<y_{B} \\
& 4 . y_{B} \leq y \leq y_{C} \\
& 5 . y_{C}<y<\ell \\
& 6 . \ell \leq y<y_{D} \\
& 7 . y \geq y_{D} \\
&\mathrm{IF}(\mathrm{D} 9<=\mathrm{N} 9,4, \mathrm{IF}(\mathrm{D} 9<\mathrm{F} 9,5, \mathrm{IF}(\mathrm{D} 9<\mathrm{O} 9,6, \mathrm{IF}(\mathrm{D} 9>=09,7)))))))
\end{aligned}
$$




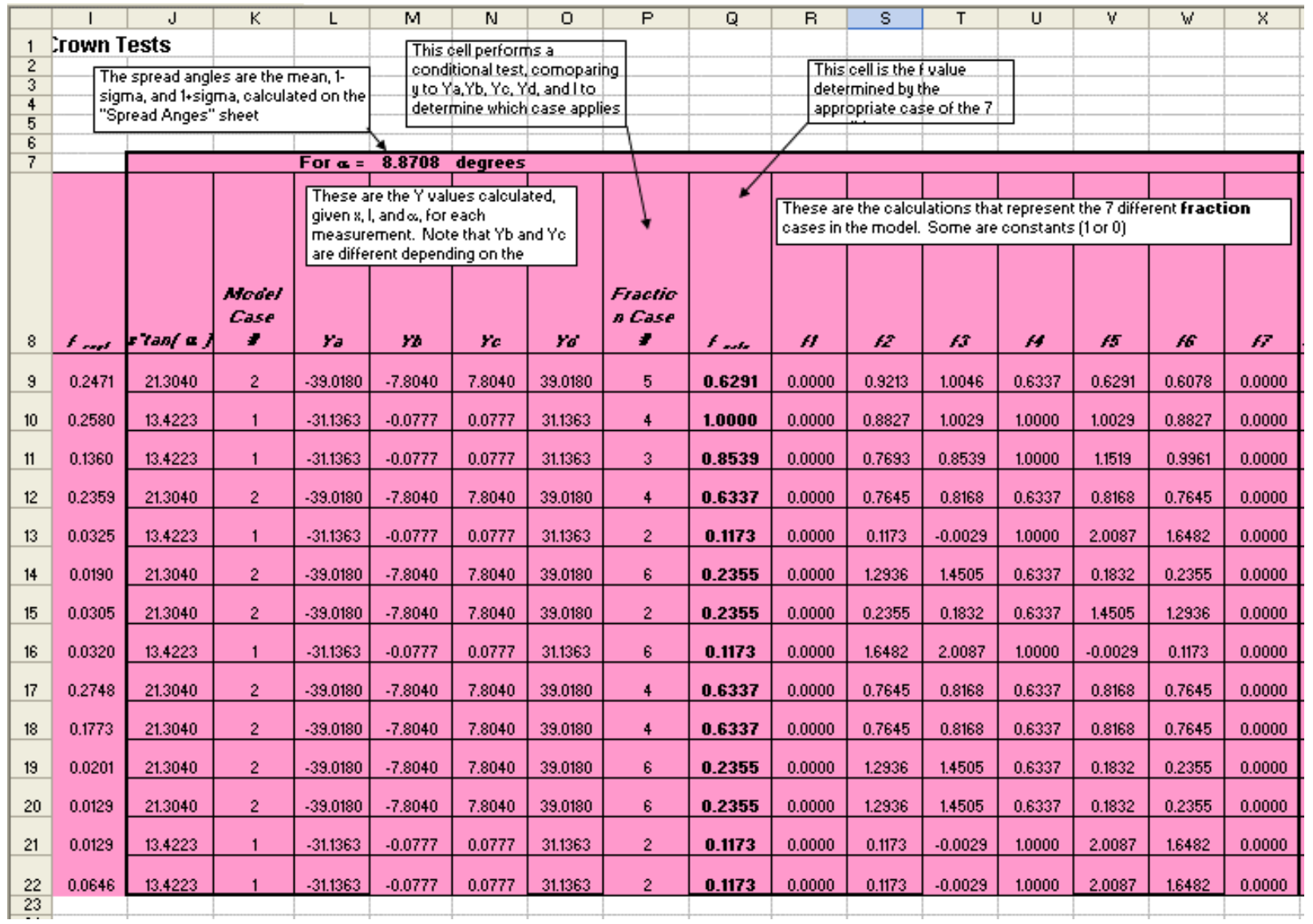

Figure C-2. Spreadsheet "Flux Split Drip Shield Model," Worksheet "f calculations;" Calculation of Model Flow Fractions for Mean Minus One Standard Deviation Rivulet Spread Angle

Columns R though X (Figure C-2) compute the fraction of dripping flux $f_{\text {calc }}$ that is predicted to flow into a breach, assuming the drip location is within each of seven regions along the crown. Although $f_{\text {calc }}$ is computed for all seven regions, it is valid in only one of the regions. The correct valid region is determined in Column P (Fraction Case \#), and the appropriate value from Columns $\mathrm{R}$ through $\mathrm{X}$ is entered in Column $\mathrm{Q}$.

Column Q: $\quad f_{\text {calc }}$ is the fraction of dripping flux onto the drip shield that is predicted by the drip shield flux splitting submodel, Equations 6.5.1.1.2-2 through 6.5.1.1.2-6 or 6.5.1.1.2-19 through 6.5.1.1.2-23, for Cases 1 and 2, respectively. $f_{\text {calc }}$ is intended to be compared with $f_{\text {expt }}$ (Column I). The value of $f_{\text {calc }}$ is selected from Columns R through X, depending on the appropriate Fraction Case \# (Column P).

$$
\begin{gathered}
\mathrm{Q} 9=\mathrm{IF}(\mathrm{P} 9=1, \mathrm{R} 9, \mathrm{IF}(\mathrm{P} 9=2, \mathrm{~S} 9, \mathrm{IF}(\mathrm{P} 9=3, \mathrm{~T} 9, \mathrm{IF}(\mathrm{P} 9=4, \mathrm{U} 9, \\
\operatorname{IF}(\mathrm{P} 9=5, \mathrm{~V} 9, \mathrm{IF}(\mathrm{P9}=6, \mathrm{~W} 9, \mathrm{IF}(\mathrm{Pg}=7, \mathrm{X9})))))))
\end{gathered}
$$


Column R: Value of $f_{\text {calc }}$ in region $1\left(y \leq y_{A}\right)$, where $f_{\text {calc }}=0$.

$$
\mathrm{R} 9=0
$$

Column S: Value of $f_{\text {calc }}$ in region $2\left(y_{A}<y \leq-\ell\right)$ :

$$
f_{\text {calc }}=\frac{y+\ell+(x+2 \ell) \tan \alpha}{2(x+2 \ell) \tan \alpha}
$$

\section{$\mathrm{S} 9=(\mathrm{D} 9+\mathrm{F} 9+(\mathrm{E} 9+2 * \mathrm{~F} 9) * \mathrm{TAN}(\mathrm{RADIANS}(\$ M \$ 7))) /$}

$(2 *(E 9+2 * F 9) \star T A N(R A D I A N S(\$ M \$ 7)))$

Column T: Value of $f_{\text {calc }}$ in region $3\left(-\ell<y<y_{B}\right)$ :

$$
f_{\text {calc }}=\frac{y+\ell+x \tan \alpha}{2 x \tan \alpha}
$$

T9=(D9+F9+E9*TAN(RADIANS $(\$ M \$ 7))) /(2 * E 9 * T A N(R A D I A N S(\$ M \$ 7)))$

Column U: Value of $f_{\text {calc }}$ in region $4\left(y_{B} \leq y \leq y_{C}\right)$ :

$$
\begin{gathered}
f_{\text {calc }}=\frac{2 \ell}{2 \times \tan \alpha} \\
\mathrm{U} 9=\mathrm{IF}(\mathrm{K} 9=1,1,(2 * \$ \mathrm{~F} 9 /(2 * \$ \mathrm{E} 9 * \operatorname{TAN}(\operatorname{RADIANS}(\$ \mathrm{M} \$ 7)))))
\end{gathered}
$$

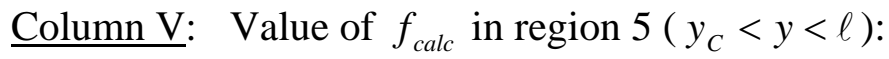

$$
f_{\text {calc }}=\frac{-y+\ell+x \tan \alpha}{2 x \tan \alpha}
$$

\section{V9=(-D9+F9+E9*TAN(RADIANS $(\$ M \$ 7))) /(2 * E 9 * T A N(R A D I A N S(\$ M \$ 7)))$}

Column W: Value of $f_{\text {calc }}$ in region $6\left(\ell \leq y<y_{D}\right)$ :

$$
\begin{gathered}
f_{\text {calc }}=\frac{-y+\ell+(x+2 \ell) \tan \alpha}{2(x+2 \ell) \tan \alpha} \\
\mathrm{W} 9=\left(-\mathrm{D} 9+\mathrm{F} 9+(\mathrm{E} 9+2 * \mathrm{~F} 9){ }^{\star} \mathrm{TAN}(\mathrm{RADIANS}(\$ \mathrm{MM} \$ 7))\right) / \\
\left(2 *(\mathrm{E} 9+2 * \mathrm{~F} 9)^{\star} \mathrm{TAN}(\mathrm{RADIANS}(\$ \mathrm{MM} \$ 7))\right)
\end{gathered}
$$

Column X: Value of $f_{\text {calc }}$ in region $7\left(y \geq y_{D}\right)$ where $f_{\text {calc }}=0$ :

$$
\times 9=0
$$




\begin{tabular}{|c|c|c|c|c|c|c|c|c|c|c|c|c|c|c|c|}
\hline & $Y$ & $z$ & $A A$ & $\mathrm{AB}$ & $A C$ & $\mathrm{AD}$ & $\mathrm{AE}$ & AF & $A G$ & $\mathrm{AH}$ & Al & Ad & $A K$ & $\mathrm{AL}$ & $A M$ \\
\hline \multicolumn{16}{|l|}{1} \\
\hline 2 & & & & & & & & & & & & & & & \\
\hline 3 & & & & & & & & & & & & & & & \\
\hline 4 & & & & & & & & & & & & & & & \\
\hline 5 & & & & & & & & & & & & & & & \\
\hline 6 & & & & & & & & & & & & & & & \\
\hline 7 & & & For $a=$ & 13.1527 & degrees & & & & & & & & & & \\
\hline 8 & r7asof $a y$ & $\begin{array}{c}\text { Mode } \\
\text { / } \\
\text { Case } \\
;\end{array}$ & $y_{a}$ & $m$ & Yc & $Y o^{\circ}$ & $\begin{array}{c}\text { Fractio } \\
\text { o Casa } \\
;\end{array}$ & שה & $f f$ & $F 2$ & $F$ & $A f$ & $A 5$ & $F G$ & $F F$ \\
\hline 9 & 31.8968 & 2 & -51.7061 & -18.3968 & 18.3968 & 51.7061 & 4 & 0.4232 & 0.0000 & 0.7814 & 0.8370 & 0.4232 & 0.5862 & 0.5720 & 0.0000 \\
\hline 10 & 20.0962 & 2 & -39.9054 & -6.5962 & 6.5962 & 39.9054 & 4 & 0.6718 & 0.0000 & 0.7556 & 0.8359 & 0.6718 & 0.8359 & 0.7556 & 0.0000 \\
\hline 11 & 20.0962 & 2 & -39.9054 & -6.5962 & 6.5962 & 39.9054 & 2 & 0.6799 & 0.0000 & 0.6799 & 0.7364 & 0.6718 & 0.9354 & 0.8314 & 0.0000 \\
\hline 12 & 31.8968 & 2 & \begin{tabular}{|l}
-51.7061 \\
\end{tabular} & -18.3968 & 18.3968 & 51.7061 & 4 & 0.4232 & 0.0000 & 0.6767 & 0.7116 & 0.4232 & 0.7116 & 0.6767 & 0.0000 \\
\hline 13 & 20.0962 & 2 & -39.9054 & -6.5962 & 6.5962 & 39.9054 & 2 & 0.2444 & 0.0000 & 0.2444 & 0.1641 & 0.6718 & 1.5077 & 1.2669 & 0.0000 \\
\hline 14 & 31.8968 & 2 & -51.7061 & -18.3968 & 18.3968 & 51.7061 & 6 & 0.3233 & 0.0000 & 1.0300 & 1.1349 & 0.4232 & 0.2884 & 0.3233 & 0.0000 \\
\hline 15 & 31.8968 & 2 & -51.7061 & -18.3968 & 18.3968 & 51.7061 & 2 & 0.3233 & 0.0000 & 0.3233 & 0.2884 & 0.4232 & 1.1349 & 1.0300 & 0.0000 \\
\hline 16 & 20.0962 & 2 & -39.9054 & -6.5962 & 6.5962 & 39.9054 & 6 & 0.2444 & 0.0000 & 1.2669 & 1.5077 & 0.6718 & 0.1641 & 0.2444 & 0.0000 \\
\hline 17 & 31.8968 & 2 & -51.7061 & -18.3968 & 18.3968 & 51.7061 & 4 & 0.4232 & 0.0000 & 0.6767 & 0.7116 & 0.4232 & 0.7116 & 0.6767 & 0.0000 \\
\hline 18 & 31.8968 & 2 & -51.7061 & -18.3968 & 18.3968 & 51.7061 & 4 & 0.4232 & 0.0000 & 0.6767 & 0.7116 & 0.4232 & 0.7116 & 0.6767 & 0.0000 \\
\hline 19 & 31.8968 & 2 & -51.7061 & -18.3968 & 18.3968 & 51.7061 & 6 & 0.3233 & 0.0000 & 1.0300 & 1.1349 & 0.4232 & 0.2884 & 0.3233 & 0.0000 \\
\hline 20 & 31.8968 & 2 & -51.7061 & -18.3968 & 18.3968 & 51.7061 & 6 & 0.3233 & 0.0000 & 1.0300 & 1.1349 & 0.4232 & 0.2884 & 0.3233 & 0.0000 \\
\hline 21 & 20.0962 & 2 & -39.9054 & -6.5962 & 6.5962 & 39.9054 & 2 & 0.2444 & 0.0000 & 0.2444 & 0.1641 & 0.6718 & 1.5077 & 1.2669 & 0.0000 \\
\hline 22 & 20.0962 & 2 & -39.9054 & -6.5962 & 6.5962 & 39.9054 & 2 & 0.2444 & 0.0000 & 0.2444 & 0.1641 & 0.6718 & 1.5077 & 1.2669 & 0.0000 \\
\hline
\end{tabular}

Figure C-3. Spreadsheet "Flux Split Drip Shield Model," Worksheet "f calculations;" Calculation of Model Flow Fractions for Mean Rivulet Spread Angle

Columns Y though AM (Figure C-3) repeat the calculations done in Columns J though X using the mean rivulet spread angle of $\alpha=13.1527^{\circ}$ (Cell $\$ A B \$ 7$ ). For Row 9, the spreadsheet equations are as follows:

Y9=\$E9*TAN(RADIANS(\$AB\$7))

$Z 9=I F(\$ F 9>Y 9,1,2)$

AA9=-\$F9-(\$E9+2*\$F9)*TAN(RADIANS $(\$ A B \$ 7))$

AB9 $=I F(Z 9=1,(-\$ F 9+\$ E 9 * T A N(R A D I A N S(\$ A B \$ 7))),(\$ F 9-\$ E 9 * T A N(R A D I A N S(\$ A B \$ 7))))$ AC9=IF(Z9=1,(\$F9-\$E9*TAN(RADIANS(\$AC\$7))),(-\$F9+\$E9*TAN(RADIANS(\$AB\$7))) $\mathrm{AD} 9=\$ F 9+(\$ E 9+2 * \$ F 9) *$ TAN $($ RADIANS $(\$ A B \$ 7))$

AE9 $=I F(D 9<=A A 9,1, I F(D 9<=-$

U9,2,IF(D9<AB9,3,IF(D9<=AC9,4,IF(D9<U9,5, IF(D9<AD9,6, IF(D9>=AD9,7)))))))

AF9=IF(AE9=1,AG9,IF(AE9=2,AH9,IF(AE9=3,AI9,IF(AE9=4,AJ9,IF(AE9=5,AK9,IF(AE9 $=6, A L 9, \operatorname{IF}(\mathrm{AE} 9=7, \mathrm{AM} 9))))))$ ) 
$A G 9=0$

$\mathrm{AH} 9=(\mathrm{D} 9+\mathrm{F} 9+(\mathrm{E} 9+2 * \mathrm{~F} 9) * \mathrm{TAN}(\mathrm{RADIANS}(\$ \mathrm{AB} \$ 7))) /$

$(2 *(E 9+2 * F 9) *$ TAN $(R A D I A N S(\$ A B \$ 7)))$

AI9 $=($ D9+F9+E9*TAN $($ RADIANS $(\$ A B \$ 7))) /(2 * E 9 * T A N(R A D I A N S(\$ A B \$ 7)))$

$A J 9=I F(Z 9=1,1,(2 * \$ F 9 /(2 * \$ E 9 * T A N(R A D I A N S(\$ A B \$ 7)))))$

AK9 $=(-D 9+F 9+E 9 * T A N(R A D I A N S(\$ A B \$ 7))) /(2 * E 9 * T A N(R A D I A N S(\$ A B \$ 7)))$

$\mathrm{AL} 9=(-\mathrm{D} 9+\mathrm{F} 9+(\mathrm{E} 9+2 * \mathrm{~F} 9) * \mathrm{TAN}(\mathrm{RADIANS}(\$ A B \$ 7))) /$

$(2 *(E 9+2 * F 9) *$ TAN $($ RADIANS $(\$ A B \$ 7)))$

$\mathrm{AM} 9=0$

Columns AN though BB (Figure C-1) repeat the calculations done in Columns $\mathrm{J}$ though $\mathrm{X}$ using a rivulet spread angle of $\alpha=17.2903^{\circ}$ (Cell \$AQ\$7), which is one standard deviation greater than the mean rivulet spread angle. For Row 9, the spreadsheet equations are as follows:

AN9=\$E9*TAN(RADIANS(\$AQ\$7))

$\mathrm{AO9}=\mathrm{IF}(\$ F 9>\mathrm{AN} 9,1,2)$

AP9=-\$F9-(\$E9+2*\$F9)*TAN(RADIANS $(\$ A Q \$ 7))$

AQ9=IF(AO9=1,(-\$F9+\$E9*TAN(RADIANS(\$AQ\$7))), (\$F9\$E9*TAN(RADIANS(\$AQ\$7))))

$\mathrm{AR} 9=\mathrm{IF}(\mathrm{AO} 9=1,($ FF9-\$E9*TAN(RADIANS(\$AQ\$7))), $(-\$ F 9+\$ E 9 * T A N(R A D I A N S(\$ A Q \$ 7))))$

AS9 $=\$ F 9+(\$ E 9+2 * \$ F 9) *$ TAN(RADIANS $(\$ A Q \$ 7))$

AT9=IF(AH9<=AP9,1,IF(AH9<=-AJ9,2,IF(AH9<AQ9,3,IF(AH9<=AR9,4, IF(AH9<AJ9,5, IF(AH9<AS9,6,IF(AH9>=AS9,7)))))))

AU9=IF(AT9=1,AV9,IF(AT9=2,AW9,IF(AT9=3,AX9,IF $(A T 9=4, A Y 9, I F(A T 9=5, A Z 9, I F$ $(\mathrm{AT} 9=6, \mathrm{BA} 9, \mathrm{IF}(\mathrm{AT} 9=7, \mathrm{BB} 9)))))))$

$\mathrm{AV} 9=0$

$\mathrm{AW} 9=(\mathrm{D} 9+\mathrm{F} 9+(\mathrm{E} 9+2 * \mathrm{~F} 9) * \mathrm{TAN}(\mathrm{RADIANS}(\$ A Q \$ 7))) /$

$(2 *(E 9+2 * F 9) *$ TAN(RADIANS $(\$ A Q \$ 7)))$

AX9=(D9+F9+E9*TAN(RADIANS(\$AQ\$7)))/(2*E9*TAN(RADIANS(\$AQ\$7)))

$A Y 9=I F(A O 9=1,1,(2 * \$ F 9 /(2 * \$ E 9 * T A N(R A D I A N S(\$ A Q \$ 7)))))$

$\mathrm{AZ9}=(-\mathrm{D} 9+\mathrm{F} 9+\mathrm{E} 9 * \mathrm{TAN}(\mathrm{RADIANS}(\$ A Q \$ 7))) /(2 * \mathrm{E} 9 * \mathrm{TAN}(\mathrm{RADIANS}(\$ A Q \$ 7)))$

$\mathrm{BA} 9=(-\mathrm{D} 9+\mathrm{F} 9+(\mathrm{E} 9+2 * \mathrm{~F} 9) * \mathrm{TAN}(\mathrm{RADIANS}($ AQ $\$ 7))) /$

$(2 *(\mathrm{E} 9+2 * \mathrm{~F} 9) * \mathrm{TAN}(\mathrm{RADIANS}(\$ A Q \$ 7)))$

$\mathrm{BB} 9=0$ 


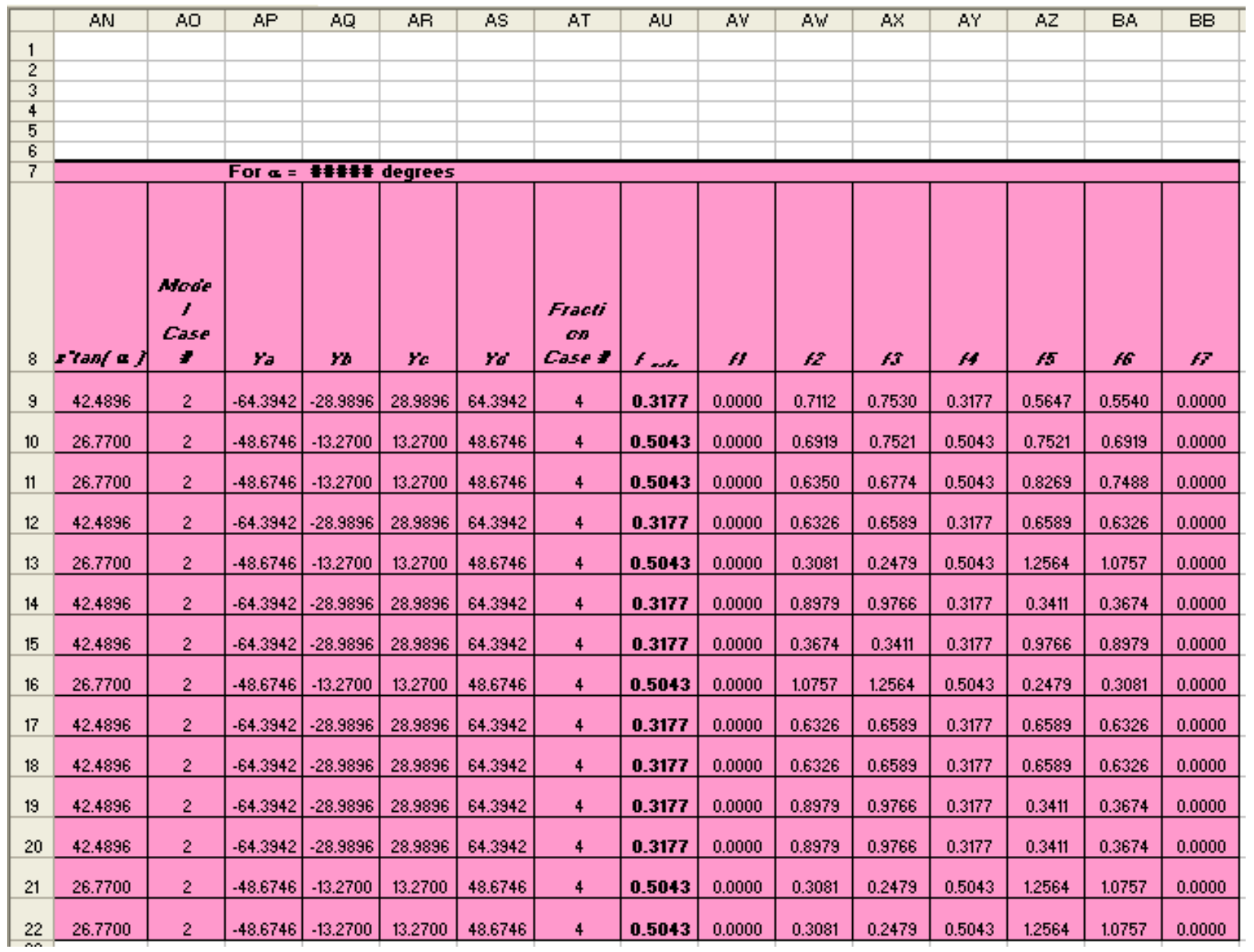

Figure C-4. Spreadsheet "Flux Split Drip Shield Model," Worksheet "f calculations;" Calculation of Model Flow Fractions for Mean Plus One Standard Deviation Rivulet Spread Angle

Rivulet spread measurements are listed in Column D, Rows 6-31 (Figure C-5), for 26 tests described in the indicated DTNs. The sketch to the right shows the relationships between measured rivulet spread (" $1 / 2$ spread") and the " $1 / 2$ spread angle," $\alpha$. The average, $\mu_{r}$, of the 26 spread measurements (Cell D33) is $20.096 \mathrm{~cm}$, with a standard deviation, $\sigma$, of $6.674 \mathrm{~cm}$. The uncertainty in the spread angle is incorporated into the drip shield flux splitting submodel by assigning a range for the rivulet spread of $\mu_{r} \pm 1 \sigma$. The mean rivulet spread and $\mu_{r} \pm 1 \sigma$ are shown in Cells K6-K8. The rivulet spread is converted to spread angle in Cells L6-L8 using the relation shown in the sketch that defines $\alpha$ :

$$
\alpha=\tan ^{-1}\left(\frac{w_{r}}{x}\right)
$$


where $w_{r}$ is the rivulet " $1 / 2$ spread" $(\mathrm{cm})$, and $x$ is the distance from the crown to the spread measurement location (cm). The Microsoft Excel equation for the mean spread angle is:

\section{L6=DEGREES(ATAN(K6/(\$N\$4)))}

where $\$ N \$ 4=x=86 \mathrm{~cm}$ for these tests. The Microsoft Excel function ATAN returns a value in radians, which must be converted to degrees using the DEGREES function.

Also included in this worksheet is a sketch (Figure C-6) showing the dimensions and locations of breaches in the drip shield mockup used in the experiments. The sketch appears in the scientific notebook from the experiments (Howard 2002 [DIRS 161516], p. 14), and is also shown in Figure 4.1-1, Section 4.1.1.

\section{SPREADSHEET “FLUX SPLIT DRIP SHIELD MODEL” WORKSHEET "SPREAD ANGLES"}

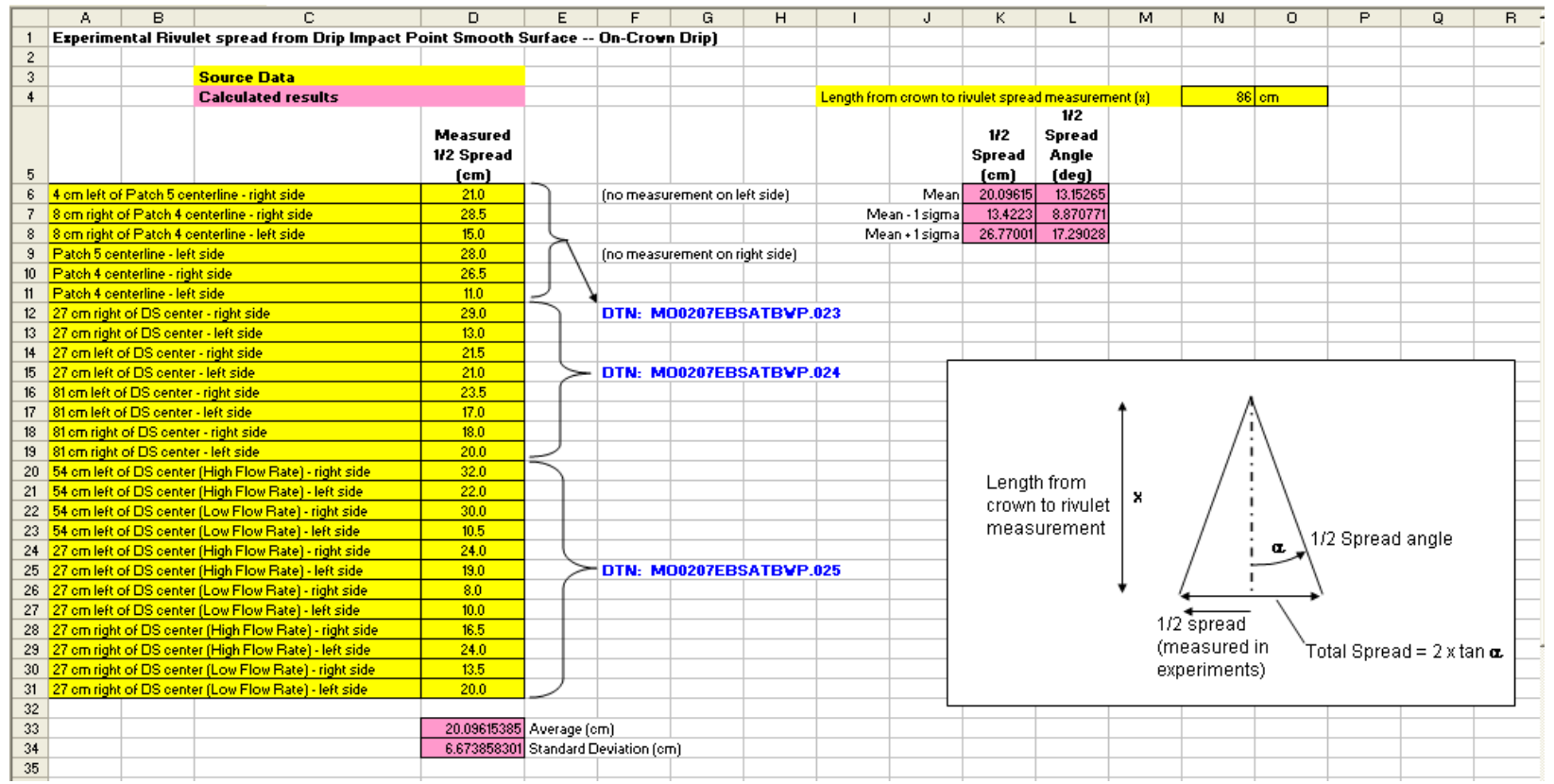

DTN: MO0207EBSATBWP.023 [DIRS 163402]; DTN: MO0207EBSATBWP.024 [DIRS 163401];

DTN: MO0207EBSATBWP.025 [DIRS 163403].

Figure C-5. Spreadsheet "Flux Split Drip Shield Model," Worksheet "Spread angles;" Calculation of Rivulet Spread Angle 


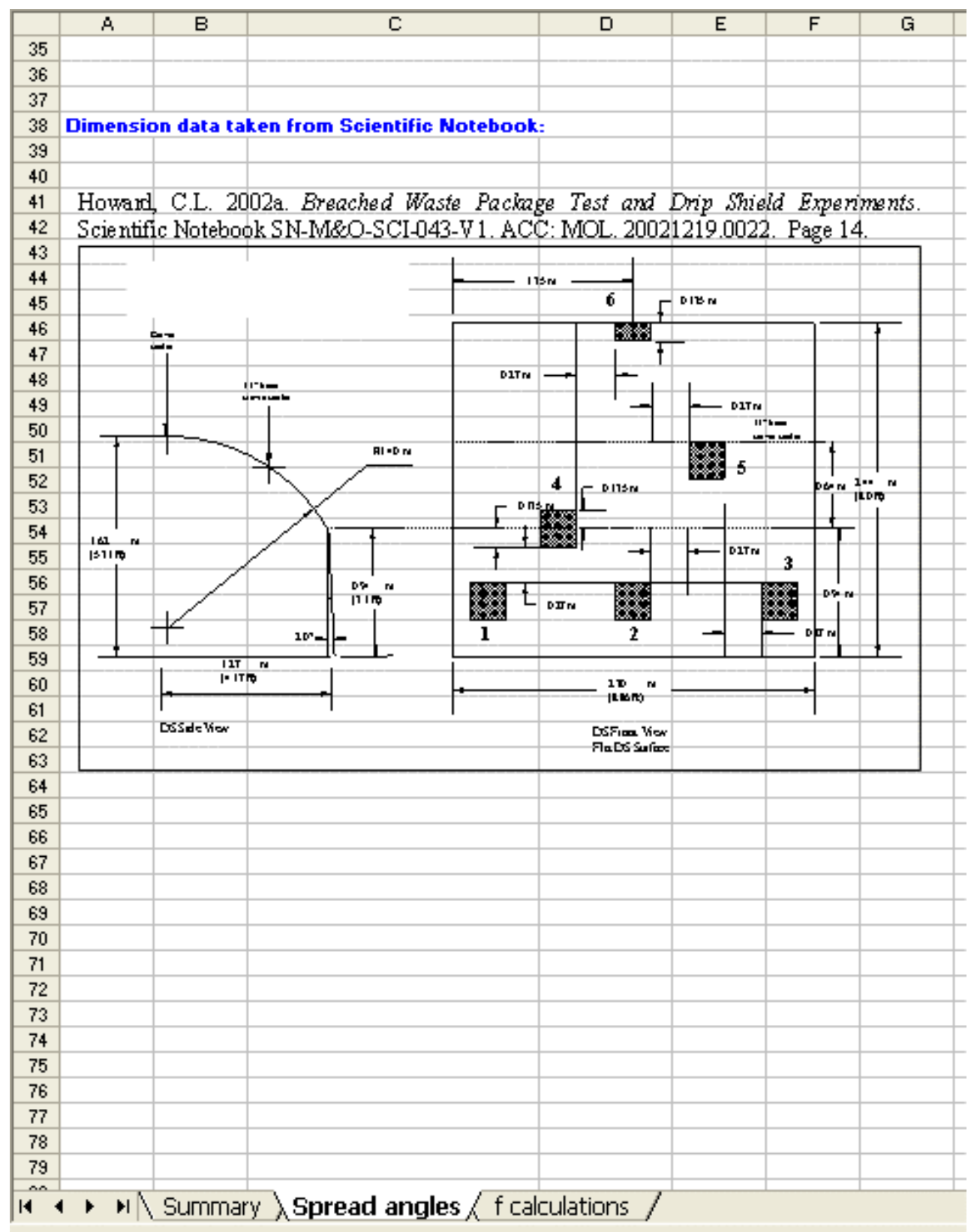

Source: Howard 2002 [DIRS 161516], p. 14.

Figure C-6. Spreadsheet "Flux Split Drip Shield Model," Worksheet "Spread Angles;" Dimensions and Locations of Breaches in Drip Shield Mockup Used in Breached Drip Shield Experiments 


\section{SPREADSHEET “FLUX SPLIT DRIP SHIELD MODEL” WORKSHEET “SUMMARY”}

\begin{tabular}{|c|c|c|c|c|c|c|c|c|c|c|c|}
\hline & A & $B$ & $\mathrm{C}$ & D & $E$ & $\mathrm{~F}$ & $G$ & $\mathrm{H}$ & 1 & J & $\mathrm{K}$ \\
\hline 1 & & & & & & & & & & & \\
\hline 2 & & \multicolumn{10}{|c|}{ Drip Shield Model: Comparison of Measured and Modeled Fraction of Drip Seepage Flowing into a Breach } \\
\hline 3 & & & & & & & & & & & \\
\hline 4 & & & & & & & & & & & \\
\hline 5 & & & & & & & & & & & \\
\hline 6 & & \multicolumn{10}{|c|}{$\begin{array}{l}\text { This spreadsheet compares results from the "Atlas Breached Waste Package and Drip Shield Experiments: Breached Drip Shield Tests" (documented } \\
\text { in TDR-EBS-MD-000025-00 REV 00) with the model developed in the "EBS Radionuclide Transport Abstraction" (ANL-W/S-PA-0000001 REV 02). Test } \\
\text { data are taken directly from the TDMS for this comparison. }\end{array}$} \\
\hline 7 & & & & & & & & & & & \\
\hline 8 & & Methodology: & & & & & & & & & \\
\hline 9 & & \multicolumn{10}{|c|}{ 1. Spreading angles are calculated from the test data in the sheet titled Spread angles } \\
\hline & & \multicolumn{10}{|c|}{ 2. Given spread angle and test geometry, seepage fractions are calculated for both the test data and the model in the worksheet $\underline{f \text { calculations: }}$} \\
\hline 10 & & & \multicolumn{9}{|c|}{$\begin{array}{l}\text { a. Geometric data for each measurement }(x, y, 1) \text { and the spread angle are used to determine which of } 7 \text { cases the } \\
\text { measurement corresponds to }\end{array}$} \\
\hline 12 & & & \multicolumn{9}{|c|}{ b. For each test result the appropriate case model is applied to calculate the seepage flow fraction $f$} \\
\hline 13 & & \multicolumn{10}{|c|}{ 3. The seepage fractions calculated from both the test and model are listed and compared in the two tables listed below in this Summary worksheet } \\
\hline 14 & & & & & & & & & & & \\
\hline 15 & & Notes: & & & & & & & & & \\
\hline 16 & & \multicolumn{10}{|c|}{ Source data DTNs are noted where source data is used } \\
\hline 17 & & \multicolumn{10}{|c|}{ Model equations are provided on the calculational sheets } \\
\hline 18 & & \multicolumn{10}{|c|}{ Data in tables below is linked directly to the calculational worksheets } \\
\hline 19 & & & & & & & & & & & \\
\hline
\end{tabular}

Source: BSC 2003 [DIRS 163406].

Figure C-7. Spreadsheet "Flux Split Drip Shield Model," Worksheet "Summary;" Summary of Drip Shield Flux Splitting Submodel

This worksheet, beginning with Figure C-7, summarizes the calculations in worksheets "Spread angles" and "f calculations."

The first table (Figure C-8), "Measured Breach Flow Fractions and Calculated Breach Flow Fractions,” Rows 25-43, Columns B-I, is identical to Table 6.5-2. Columns B-E are identical to the same respective columns described earlier for worksheet " $\mathrm{f}$ calculations." Column $\mathrm{F}$ is identical to Column I in worksheet "f calculations." Columns G-I summarize the calculated fraction of the dripping flux that the flux splitting submodel predicts should flow into the breach, for the minimum, mean, and maximum spread angles. The minimum spread angle is specified to be one standard deviation less than the mean of the measured spread angles. The maximum spread angle is specified to be one standard deviation greater than the mean of the measured spread angles. Column $\mathrm{G}$ is identical to Column Q of worksheet "f calculations." Column $\mathrm{H}$ is identical to Column AF of worksheet " $\mathrm{f}$ calculations." Column I is identical to Column AU of worksheet "f calculations."

Rows 39-43, Columns F-I, show the results of Microsoft Excel functions "AVERAGE," “STDEVA," “MEDIAN," “MIN”, and “MAX,” respectively, as applied to Rows 25-38. 


\begin{tabular}{|c|c|c|c|c|c|c|c|c|c|}
\hline & A & $\mathrm{B}$ & $\mathrm{C}$ & $\mathrm{D}$ & $\mathrm{E}$ & $\mathrm{F}$ & G & $\mathrm{H}$ & 1 \\
\hline 19 & & & & & & & & & \\
\hline 20 & & \multicolumn{6}{|c|}{ Measured Breach Flou Fractions and Calculated Breach Fho Fractions } & & \\
\hline \multicolumn{10}{|l|}{21} \\
\hline \multirow{2}{*}{$\begin{array}{l}22 \\
23\end{array}$} & & \multirow[b]{3}{*}{$\begin{array}{c}\text { Drip Location [Test } \\
\text { Description] }\end{array}$} & \multirow[b]{3}{*}{$\begin{array}{c}\text { Breach } \\
\text { No. }\end{array}$} & \multirow{3}{*}{\begin{tabular}{|c} 
g. Drip \\
Location \\
Relative \\
to Breach \\
Center \\
[cm]
\end{tabular}} & \multirow{3}{*}{$\begin{array}{l}\text { x. Yertical } \\
\text { Distance } \\
\text { from Crown } \\
\text { [drip] to Top } \\
\text { of Breach } \\
\text { [cm] }\end{array}$} & \multirow[b]{3}{*}{$t_{\text {rert }}$} & \multicolumn{3}{|c|}{ Fen } \\
\hline & & & & & & & a (deg] & a [deg] & a [deg] \\
\hline 24 & & & & & & & 8.87 & 13.15 & 17.29 \\
\hline 25 & & $\begin{array}{l}8 \mathrm{~cm} \text { right of Patch } 4 \\
\text { centerline [Q]film] Test] }\end{array}$ & 4 & 8 & 136.5 & 0.2471 & 0.6291 & 0.4232 & 0.3177 \\
\hline 26 & & $\begin{array}{l}\text { Patch } 5 \text { centerline }[\mathrm{Q}(\text { film) } \\
\text { Test] }\end{array}$ & 5 & 0 & 86.0 & 0.2580 & 1.0000 & 0.6718 & 0.5043 \\
\hline 27 & & $\begin{array}{l}4 \text { cm left of Patch } 5 \\
\text { centerline [Q]film] Test] }\end{array}$ & 5 & -4 & 86.0 & 0.1360 & 0.8539 & 0.6799 & 0.5043 \\
\hline 28 & & $\begin{array}{l}\text { Patch } 4 \text { centerline [Q(film) } \\
\text { Test] }\end{array}$ & 4 & 0 & 136.5 & 0.2359 & 0.6337 & 0.4232 & 0.3177 \\
\hline 29 & & $\begin{array}{l}27 \mathrm{~cm} \text { right of } \mathrm{DS} \text { center } \\
\text { (Multiple Patch Test) }\end{array}$ & 5 & -27 & 86.0 & 0.0325 & 0.1173 & 0.2444 & 0.5043 \\
\hline 30 & & $\begin{array}{l}27 \mathrm{~cm} \text { left of DS center } \\
\text { (Multiple patch test) }\end{array}$ & 4 & 27 & 136.5 & 0.0190 & 0.2355 & 0.3233 & 0.3177 \\
\hline 31 & & $\begin{array}{l}81 \mathrm{~cm} \text { left of DS center } \\
\text { (Multiple Patch Test) }\end{array}$ & 4 & -27 & 136.5 & 0.0305 & 0.2355 & 0.3233 & 0.3177 \\
\hline 32 & & $\begin{array}{l}81 \mathrm{~cm} \text { right of DS center } \\
\text { (Multiple Patch Test) }\end{array}$ & 5 & 27 & 86.0 & 0.0320 & 0.1173 & 0.2444 & 0.5043 \\
\hline 33 & & $\begin{array}{l}54 \mathrm{~cm} \text { left of DS center } \\
\text { [High Flow Rate Test] }\end{array}$ & 4 & 0 & 136.5 & 0.2748 & 0.6337 & 0.4232 & 0.3177 \\
\hline 34 & & $\begin{array}{l}54 \mathrm{~cm} \text { left of DS center } \\
\text { [Low Flow Rate Test] }\end{array}$ & 4 & 0 & 136.5 & 0.1773 & 0.6337 & 0.4232 & 0.3177 \\
\hline 35 & & $\begin{array}{l}27 \mathrm{~cm} \text { left of DS center } \\
\text { [High Flow Rate Test] }\end{array}$ & 4 & 27 & 136.5 & 0.0201 & 0.2355 & 0.3233 & 0.3177 \\
\hline 36 & & $\begin{array}{l}27 \mathrm{~cm} \text { left of DS center } \\
\text { [Low Flow Rate Test) }\end{array}$ & 4 & 27 & 136.5 & 0.0129 & 0.2355 & 0.3233 & 0.3177 \\
\hline 37 & & $\begin{array}{l}27 \mathrm{~cm} \text { right of } \mathrm{DS} \text { center } \\
\text { [High Flow Rate Test] }\end{array}$ & 5 & -27 & 86.0 & 0.0129 & 0.1173 & 0.2444 & 0.5043 \\
\hline 38 & & $\begin{array}{l}27 \mathrm{~cm} \text { right of DS center } \\
\text { [Low Flow Rate Testl }\end{array}$ & 5 & -27 & 86.0 & 0.0646 & 0.1173 & 0.2444 & 0.5043 \\
\hline 39 & & Mean & & & & 0.1110 & 0.4139 & 0.3797 & 0.3977 \\
\hline 40 & & Std. Dev. & & & & 0.1055 & 0.3048 & 0.1438 & 0.0958 \\
\hline 41 & & Median & & & & 0.0486 & 0.2355 & 0.3233 & 0.3177 \\
\hline 42 & & Minimum & & & & 0.0129 & 0.1173 & 0.2444 & 0.3177 \\
\hline 43 & & Maximum & & & & 0.2748 & 1.0000 & 0.6799 & 0.5043 \\
\hline 44 & & & & & & & & & \\
\hline
\end{tabular}

Figure C-8. Spreadsheet "Flux Split Drip Shield Model," Worksheet "Summary;" Summary of Drip Shield Flux Splitting Submodel

The second table (Figure C-9), "Comparison of Measured and Calculated Breach Flows," is identical to Table 6.5-3. Column $\mathrm{K}$ is again the drip location. Column $\mathrm{L}$ is the fraction of dripping flux that flowed into a breach as measured experimentally; this is identical to Column $\mathrm{F}$ of the preceding table, or Column I in worksheet " $\mathrm{f}$ calculations." The next three columns (M-O) show the difference between the predicted breach flow fraction, $f_{\text {calc }}$, and the measured fraction, $f_{\text {expt }}$, for the minimum, mean, and maximum rivulet spread angle. Columns P-R show the ratio $f_{\text {calc }} / f_{\text {expt }}$ for the minimum, mean, and maximum rivulet spread angle.

Rows 39-43, Columns L-R, show the results of Microsoft Excel functions "AVERAGE," “STDEVA,” “MEDIAN," “MIN,” and “MAX,” respectively, as applied to Rows 25-38. 


\begin{tabular}{|c|c|c|c|c|c|c|c|c|c|}
\hline & $J$ & $\mathrm{~K}$ & $\mathrm{~L}$ & $M$ & $\mathrm{~N}$ & 0 & $\mathrm{P}$ & $\mathrm{Q}$ & $\mathrm{R}$ \\
\hline 19 & & & & & & & & & \\
\hline 20 & & & & & & & & & \\
\hline 21 & & \multicolumn{5}{|c|}{ Comparison of Aleasured and Cakoulated Breach Flows } & & & \\
\hline 22 & & \multirow[b]{3}{*}{$\begin{array}{c}\text { Drip Location [Test } \\
\text { Description] }\end{array}$} & \multirow[b]{3}{*}{$f_{\text {ref }}$} & \multicolumn{3}{|c|}{$f_{\text {A }}$} & \multicolumn{3}{|c|}{$f_{\text {for }}$} \\
\hline 23 & & & & a [deg] & a (deg) & a (deg] & a (deg) & a [deg] & a (deg] \\
\hline 24 & & & & 8.87 & 13.15 & 17.29 & 8.87 & 13.15 & 17.29 \\
\hline 25 & & $\begin{array}{l}8 \mathrm{~cm} \text { right of Patch } 4 \\
\text { centerline [Q]film] Test] }\end{array}$ & 0.2471 & 0.3819 & 0.1761 & 0.0706 & 2.5455 & 1.7126 & 1.2856 \\
\hline 26 & & $\begin{array}{l}\text { Patch } 5 \text { centerline }[Q(\text { film) } \\
\text { Test] }\end{array}$ & 0.2580 & 0.7420 & 0.4138 & 0.2463 & 3.8764 & 2.6041 & 1.9549 \\
\hline 27 & & $\begin{array}{l}4 \mathrm{~cm} \text { left of Patch } 5 \\
\text { centerline [Q]film] Test] }\end{array}$ & 0.1360 & 0.7179 & 0.5439 & 0.3683 & 6.2770 & 4.9979 & 3.7071 \\
\hline 28 & & $\begin{array}{l}\text { Patch } 4 \text { centerline }[Q(\text { film }) \\
\text { Test] }\end{array}$ & 0.2359 & 0.3978 & 0.1873 & 0.0818 & 2.6861 & 1.7941 & 1.3468 \\
\hline 29 & & $\begin{array}{l}27 \mathrm{~cm} \text { right of DS center } \\
\text { (Multiple Patch Test) }\end{array}$ & 0.0325 & 0.0847 & 0.2119 & 0.4718 & 3.6060 & 7.5145 & 15.5074 \\
\hline 30 & & $\begin{array}{l}27 \mathrm{~cm} \text { left of DS center } \\
\text { [Multiple patch test] }\end{array}$ & 0.0190 & 0.2165 & 0.3043 & 0.2987 & 12.3932 & 17.0164 & 16.7216 \\
\hline 31 & & $\begin{array}{l}81 \mathrm{~cm} \text { left of DS center } \\
\text { (Multiple Patch Test) }\end{array}$ & 0.0305 & 0.2050 & 0.2928 & 0.2872 & 7.7203 & 10.6004 & 10.4168 \\
\hline 32 & & $\begin{array}{l}81 \mathrm{~cm} \text { right of } \mathrm{DS} \text { center } \\
\text { [Multiple Patch Test] }\end{array}$ & 0.0320 & 0.0852 & 0.2124 & 0.4723 & 3.6624 & 7.6321 & 15.7500 \\
\hline 33 & & $\begin{array}{l}54 \mathrm{~cm} \text { left of DS center } \\
\text { [High Flow Rate Test] }\end{array}$ & 0.2748 & 0.3588 & 0.1484 & 0.0429 & 2.3056 & 1.5399 & 1.1560 \\
\hline 34 & & $\begin{array}{l}54 \mathrm{~cm} \text { left of } \mathrm{DS} \text { center } \\
\text { [Low Flow Rate Test) }\end{array}$ & 0.1773 & 0.4564 & 0.2459 & 0.1404 & 3.5741 & 2.3872 & 1.7920 \\
\hline 35 & & $\begin{array}{l}27 \mathrm{~cm} \text { left of DS center } \\
\text { [High Flow Rate Test] }\end{array}$ & 0.0201 & 0.2153 & 0.3032 & 0.2976 & 11.6928 & 16.0548 & 15.7767 \\
\hline 36 & & $\begin{array}{l}27 \mathrm{~cm} \text { left of DS center } \\
\text { [Low Flow Rate Test] }\end{array}$ & 0.0129 & 0.2226 & 0.3104 & 0.3048 & 18.2860 & 25.1075 & 24.6725 \\
\hline 37 & & $\begin{array}{l}27 \mathrm{~cm} \text { right of DS center } \\
\text { [High Flow Rate Test] }\end{array}$ & 0.0129 & 0.1043 & 0.2314 & 0.4914 & 9.0637 & 18.8879 & 38.9779 \\
\hline 38 & & $\begin{array}{l}27 \mathrm{~cm} \text { right of } \mathrm{DS} \text { center } \\
\text { [Low Flow Rate Test) }\end{array}$ & 0.0646 & 0.0526 & 0.1797 & 0.4397 & 1.8146 & 3.7814 & 7.8035 \\
\hline 39 & & Mean & 0.1110 & 0.3029 & 0.2687 & 0.2867 & 6.3931 & 8.6879 & 11.2049 \\
\hline 40 & & Std. Dev. & 0.1055 & 0.2210 & 0.1065 & 0.1550 & 4.8845 & 7.6717 & 11.0326 \\
\hline 41 & & \begin{tabular}{|l|} 
Median \\
\end{tabular} & 0.0486 & 0.2195 & 0.2387 & 0.2982 & 3.7694 & 6.2562 & 9.1102 \\
\hline 42 & & Minimum & 0.0129 & 0.0526 & 0.1484 & 0.0429 & 1.8146 & 1.5399 & 1.1560 \\
\hline 43 & & Maximum & 0.2748 & 0.7420 & 0.5439 & 0.4914 & 18.2860 & 25.1075 & 38.9779 \\
\hline
\end{tabular}

Figure C-9. Spreadsheet "Flux Split Drip Shield Model," Worksheet "Summary;" Summary of Drip Shield Flux Splitting Submodel Comparing Measured and Calculated Breach Flows

Finally, a plot in worksheet "Summary" (Figure C-10) compares the calculated $f_{\text {calc }}$ with the measured $f_{\text {expt }}$ (Column F) for the minimum, mean, and maximum spread angles (Columns G, $\mathrm{H}$, and I, respectively); the $f_{\text {expt }}$ and $f_{\text {calc }}$ values that are plotted in Figure C-10 are shown in Figure C-8. The diagonal line in the plot represents $f_{\text {calc }}=f_{\text {expt }}$. All values of $f_{\text {calc }}$ lie above the line $f_{\text {calc }}=f_{\text {expt }}$, indicating that the drip shield flux splitting submodel overestimates the flow into breaches. 


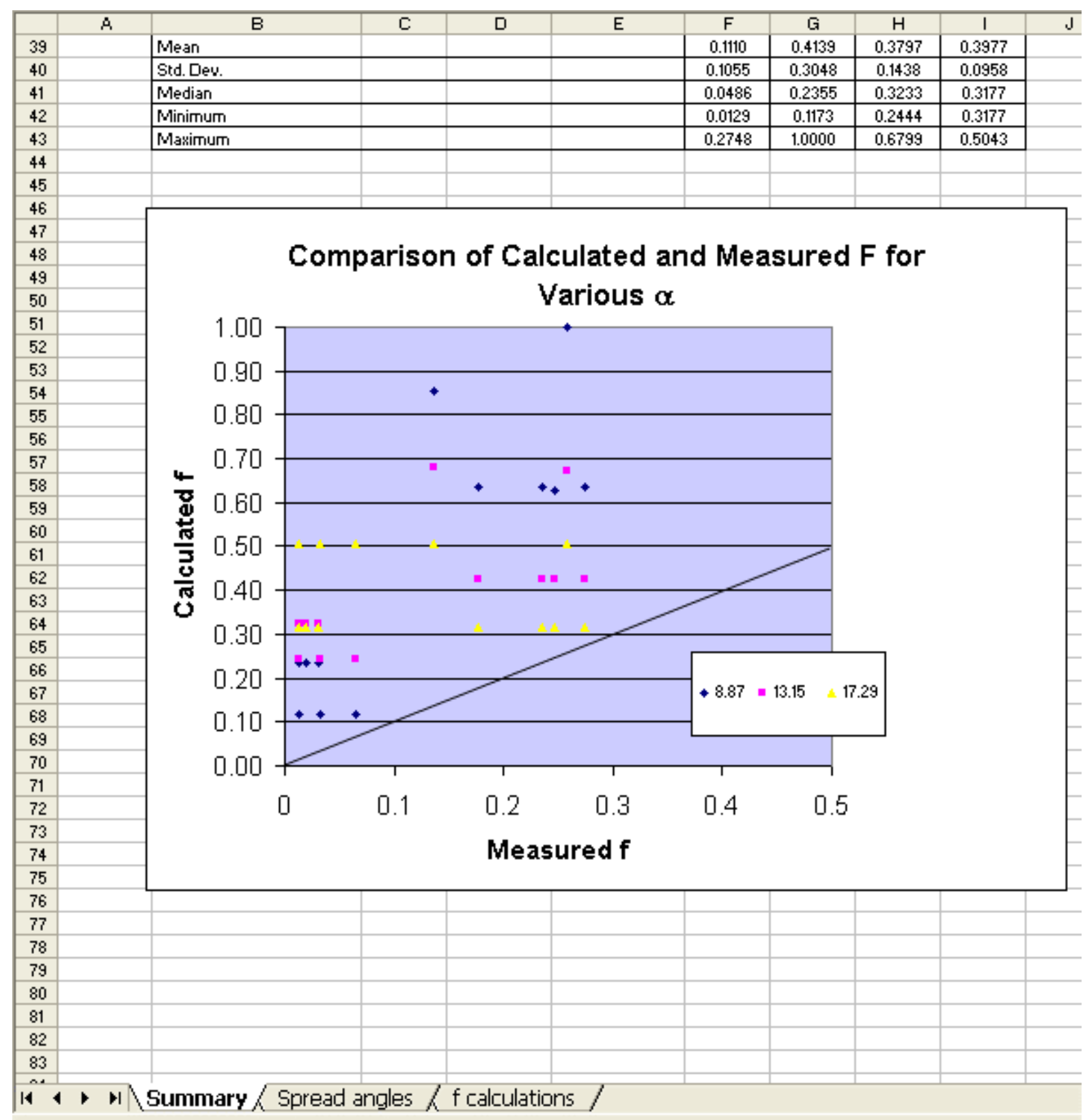

Figure C-10. Spreadsheet "Flux Split Drip Shield Model," Worksheet "Summary;" Comparison of Calculated and Measured Breach Flow Fractions for Drip Shield Flux Splitting Submodel for Minimum (8.87 $)$, Mean $\left(13.15^{\circ}\right)$, and Maximum $\left(17.29^{\circ}\right)$ Rivulet Spread Angles 
APPENDIX D

MICROSOFT EXCEL SPREADSHEET “FLUX SPLIT WASTE PACKAGE MODEL” 


\section{MICROSOFT EXCEL SPREADSHEET “FLUX SPLIT WASTE PACKAGE MODEL”}

\section{SPREADSHEET “FLUX SPLIT WASTE PACKAGE MODEL”-WORKSHEET "F CALCULATIONS"}

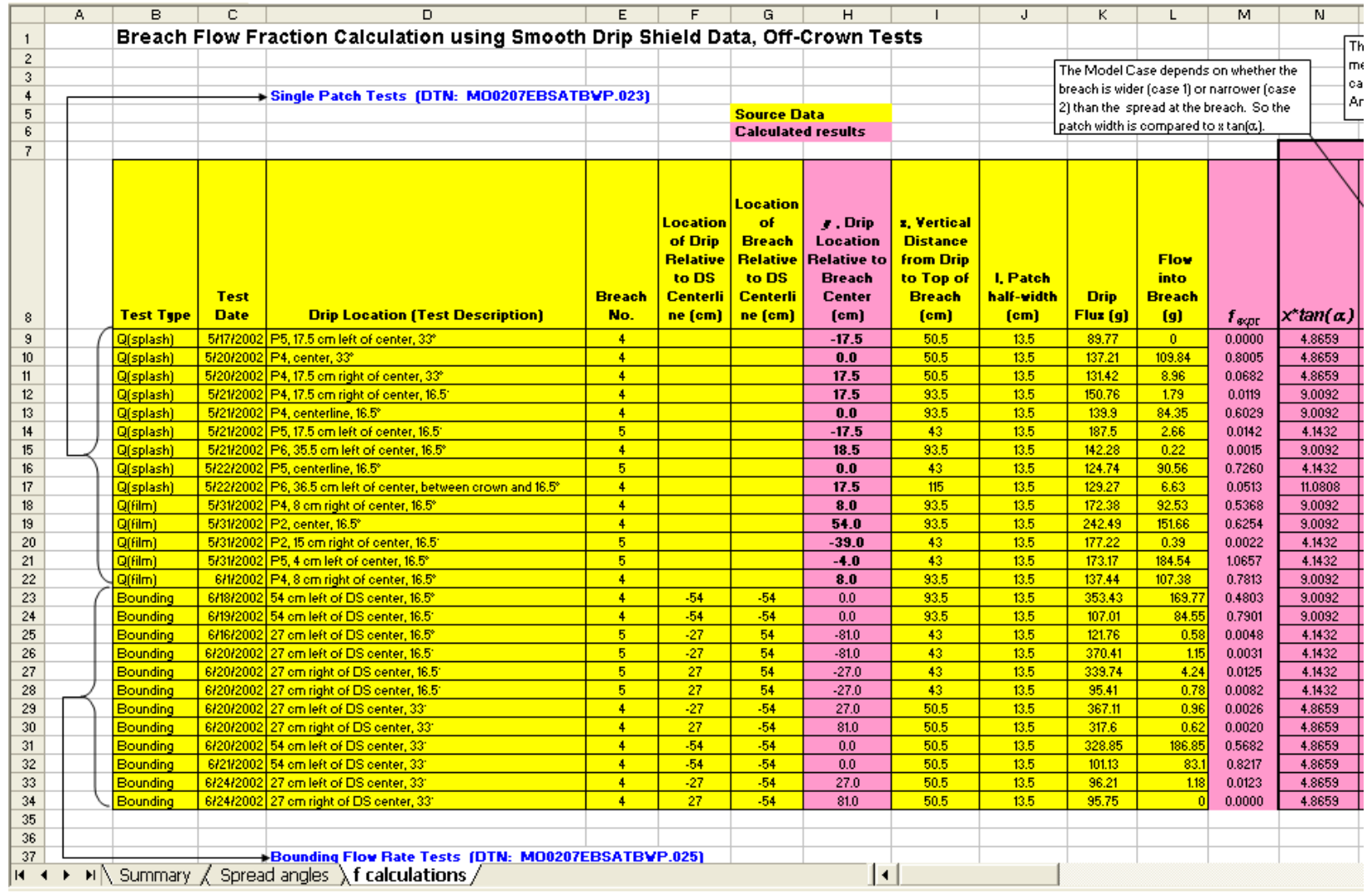

DTN: MO0207EBSATBWP.023 [DIRS 163402]; DTN: MO0207EBSATBWP.025 [DIRS 163403]

Figure D-1. Spreadsheet "Flux Split Waste Package Model," Worksheet "f calculations;" Calculation of Experimental Breach Flow Fractions and Model Flow Fractions for Mean Minus One Standard Deviation Rivulet Spread Angle

The purpose of this spreadsheet is to develop the waste package flux splitting submodel using experimental data from the breached drip shield experiments. The data are analyzed to estimate an average and range of the rivulet spread angle, $\alpha$. The disparity between measured fraction of dripping flux that enters a breach and the fraction calculated using the model (with the measured range of the rivulet spread angle) is then used to establish a range of uncertainty in the model. Whereas the drip shield submodel is based on data from on-crown drip locations, the waste package submodel uses off-crown drip data, for which the drip location is some distance away from the crown of the drip shield mockup.

All descriptions for this worksheet pertain to Rows 9-34. Equations in spreadsheet format are illustrated using Row 9.

Column B: Test type. The first three columns (B-D) help identify uniquely each test as described in the designated DTN. 
Column C: Test date.

Column D: Drip location as indicated for each test in the designated DTN.

Column E: Breach or patch number most pertinent to this particular test, for which flow is analyzed in this row of the spreadsheet.

Column F: Drip location relative to drip shield center. Applies only to Bounding tests, further defining the drip location as specified in the DTN.

Column G: Breach location relative to drip shield center. Applies only to Bounding tests, further defining the breach location as specified in the DTN.

Column H: Drip location, $y$, relative to the center of the breach listed in Column E.

Column I: Vertical distance, $x$, from the drip location to the top of the breach.

Column J: Half-width, $\ell$, of the breach-13.5 cm, same for all breaches.

Column K: Measured mass of water, $F_{1}$, dripped onto the drip shield during the test. For the on-crown drips, it is assumed that half of the water that dripped onto the drip shield, $F_{1} / 2$, flowed down the side that contained the breach. For these off-crown tests, the full dripping flux is assumed to flow down the side where the drip is located.

Column L: Measured mass of water, $F_{2}$, that flowed into the breach during the test.

Column M: Fraction of water dripped onto the drip shield that flowed into the breach:

$$
\begin{gathered}
f_{\text {expt }}=\frac{F_{2}}{F_{1}} . \\
\mathrm{M} 9=\mathrm{L} 9 / \mathrm{K} 9
\end{gathered}
$$

Columns $\mathrm{N}$ through $\mathrm{AB}$ perform calculations that result in $f_{\text {calc }}$, the fraction of dripping flux that is predicted by the model to flow into a breach.

Column $\mathrm{N}: \quad x \tan \alpha$, where $x$ is from Column I, and $\alpha$ is the spread angle. For Columns N-AB, the value used for $\alpha$ is $5.5037^{\circ}$ (Cell $\$ Q \$ 7$ ), which is one standard deviation less than the mean measured spread angle for these tests (see Worksheet "Spread angles”).

\section{$\mathrm{N} 9=\$ 19 *$ TAN $($ RADIANS $(\$ Q \$ 7))$}

Column O: Case number as described in Sections 6.5.1.1.2.1 and 6.5.1.1.2.2. For Case 1, $\ell>x \tan \alpha$; for Case 2, $\ell<x \tan \alpha$; $x$ is from Column I, and the half-width of the breach, $\ell$, is from Column $\mathrm{J}$. 


$$
O 9=I F(\$ J 9>N 9,1,2)
$$

Column P: Value of $y_{A}$ (Point A) as described in Sections 6.5.1.1.2.1 and 6.5.1.1.2.2, corresponding to the leftmost point from which the edge of the fan from the rivulet can enter the left side of the breach:

$$
\begin{gathered}
y_{A}=-\ell-(x+2 \ell) \tan \alpha \\
\mathrm{P} 9=-\$ J 9-(\$ 19+2 * \$ J 9)^{*} \text { TAN }(\text { RADIANS }(\$ Q \$ 7))
\end{gathered}
$$

Column Q: Value of $y_{B}$ (Point B) as described in Sections 6.5.1.1.2.1 and 6.5.1.1.2.2, corresponding to the leftmost point from which rivulets will enter the top edge of the breach. The value of $y_{B}$ depends on the Model Case number (Column O):

$$
\begin{array}{cr}
y_{B}=-\ell+x \tan \alpha & \text { Case } 1 . \\
y_{B}=\ell-x \tan \alpha & \text { Case } 2 . \\
\mathrm{Q} 9=\mathrm{IF}(\mathrm{O} 9=1,(-\$ \mathrm{~S} 9+\$ 19 * \operatorname{TAN}(\mathrm{RADIANS}(\$ \mathrm{Q} \$ 7))), \\
(\$ \mathrm{~J} 9-\$ 19 * \operatorname{TAN}(\mathrm{RADIANS}(\$ \mathrm{Q} \$ 7))))
\end{array}
$$

Column R: Value of $y_{C}$ (Point C) as described in Sections 6.5.1.1.2.1 and 6.5.1.1.2.2, corresponding to the rightmost point from which rivulets will enter the top edge of the breach. The value of $y_{C}$ depends on the Model Case number (Column O):

$$
\begin{array}{cc}
y_{C}=\ell-x \tan \alpha & \text { Case } 1 . \\
y_{C}=-\ell+x \tan \alpha & \text { Case } 2 .
\end{array}
$$$$
\mathrm{R} 9=\mathrm{IF}(\mathrm{O} 9=1,(\$ \mathrm{~J} 9-\$ 19 * \mathrm{TAN}(\mathrm{RADIANS}(\$ \mathrm{Q} \$ 7))) \text {, }
$$
$(-\$ J 9+\$ 19 * \operatorname{TAN}($ RADIANS $(\$ Q \$ 7))))$,

Column S: Value of $y_{D}$ (Point D) as described in Sections 6.5.1.1.2.1 and 6.5.1.1.2.2, corresponding to the rightmost point from which the edge of the fan from the rivulet can enter the right side of the breach:

$$
y_{D}=\ell+(x+2 \ell) \tan \alpha
$$

S9=\$J9+(\$19+2*\$J9)*TAN(RADIANS $(\$ Q \$ 7))$ 
Column T: Determines which region (designated as Fraction Case \#) along the drip shield relative to the center of the breach where the drip is located:

$$
\begin{array}{ll}
\text { 1. } & y \leq y_{A} \\
\text { 2. } & y_{A}<y \leq-\ell \\
\text { 3. } & -\ell<y<y_{B} \\
\text { 4. } & y_{B} \leq y \leq y_{C} \\
\text { 5. } & y_{C}<y<\ell \\
\text { 6. } & \ell \leq y<y_{D} \\
\text { 7. } & y \geq y_{D}
\end{array}
$$

$\mathrm{T} 9=\mathrm{IF}(\$ \mathrm{H} 9<=\mathrm{P} 9,1, \mathrm{IF}(\$ \mathrm{H} 9<=-\$ \mathrm{~J} 9,2, \mathrm{IF}(\$ \mathrm{H} 9<\mathrm{Q} 9,3$, $\mathrm{IF}(\$ H 9<=\mathrm{R} 9,4, \mathrm{IF}(\$ \mathrm{H} 9<\$ \mathrm{~J} 9,5, \mathrm{IF}(\$ \mathrm{H} 9<\mathrm{S} 9,6, \mathrm{IF}(\$ \mathrm{H} 9>=\mathrm{S} 9,7)))))))$

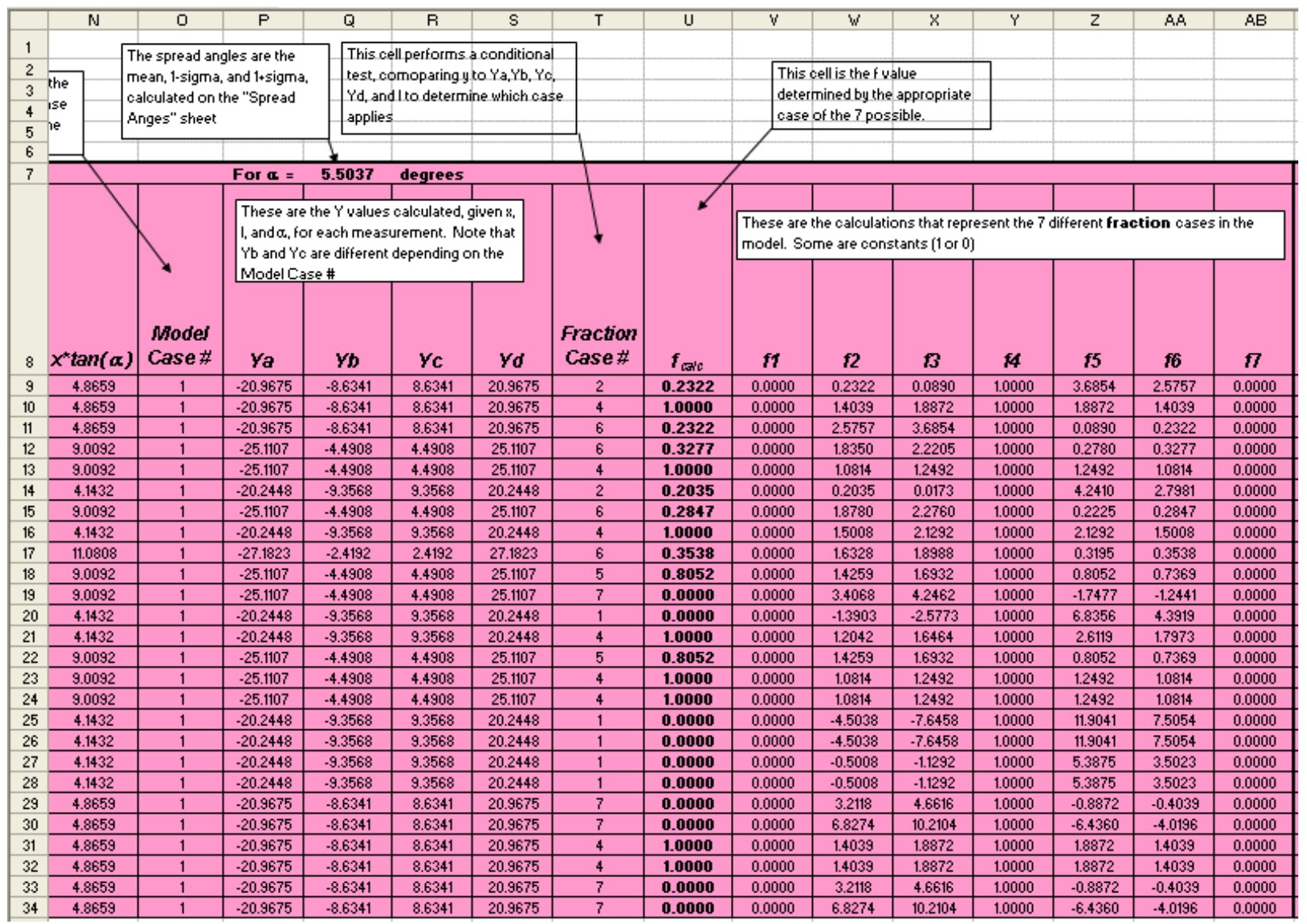

Figure D-2. Spreadsheet "Flux Split Waste Package Model," Worksheet "f calculations;" Calculation of Model Flow Fractions for Mean Minus One Standard Deviation Rivulet Spread Angle

Columns $\mathrm{V}$ though $\mathrm{AB}$ compute the fraction of dripping flux $f_{\text {calc }}$ that is predicted to flow into a breach, assuming the drip location is within each of seven regions listed above under Column $\mathrm{T}$. Although $f_{\text {calc }}$ is computed for all seven regions, it is valid in only one of the regions. The 
correct valid region is determined in Column $\mathrm{T}$ (Fraction Case \#), and the appropriate value from Columns $\mathrm{V}-\mathrm{AB}$ is entered in Column $\mathrm{U}$.

Column U: $f_{\text {calc }}$ is the fraction of dripping flux onto the drip shield that is predicted by the drip shield flux splitting submodel, Equations 6.5.1.1.2-2 through 6.5.1.1.2-6 or 6.5.1.1.2-19 through 6.5.1.1.2-23, for Cases 1 and 2, respectively. $f_{\text {calc }}$ is intended to be compared with $f_{\text {expt }}$ (Column $\mathrm{M}$ ). The value of $f_{\text {calc }}$ is selected from Columns V through AB, depending on the appropriate Fraction Case \# (Column T).

$$
\begin{aligned}
\text { U9 }= & \operatorname{IF}(T 9=1, \mathrm{~V} 9, \mathrm{IF}(\mathrm{T} 9=2, \mathrm{~W} 9, \mathrm{IF}(\mathrm{T} 9=3, \mathrm{X} 9, \mathrm{IF}(\mathrm{T} 9=4, \mathrm{Y} 9, \\
& \operatorname{IF}(\mathrm{T} 9=5, \mathrm{Z9}, \mathrm{IF}(\mathrm{T} 9=6, \mathrm{AA} 9, \mathrm{IF}(\mathrm{T} 9=7, \mathrm{AB} 9)))))))
\end{aligned}
$$

Column V: Value of $f_{\text {calc }}$ in region $1\left(y \leq y_{A}\right)$, where $f_{\text {calc }}=0$.

$$
\vee 9=0
$$

Column W: Value of $f_{\text {calc }}$ in region $2\left(y_{A}<y \leq-\ell\right)$ :

$$
\begin{gathered}
f_{\text {calc }}=\frac{y+\ell+(x+2 \ell) \tan \alpha}{2(x+2 \ell) \tan \alpha} \\
\text { W9 }=\begin{array}{c}
(\mathrm{H} 9+\mathrm{J} 9+(19+2 * \mathrm{~J} 9) \star \mathrm{TAN}(\mathrm{RADIANS}(\$ \mathrm{Q} \$ 7))) / \\
(2 *(19+2 * \mathrm{~J} 9) * \operatorname{TAN}(\mathrm{RADIANS}(\$ \mathrm{Q} \$ 7)))
\end{array}
\end{gathered}
$$

Column X: Value of $f_{\text {calc }}$ in region $3\left(-\ell<y<y_{B}\right)$ :

$$
f_{\text {calc }}=\frac{y+\ell+x \tan \alpha}{2 x \tan \alpha}
$$

X9=(H9+J9+19*TAN(RADIANS(\$Q\$7)))/(2*I9*TAN(RADIANS(\$Q\$7)))

Column Y: Value of $f_{\text {calc }}$ in region $4\left(y_{B} \leq y \leq y_{C}\right)$ :

$$
f_{\text {calc }}=\frac{2 \ell}{2 x \tan \alpha}
$$

\section{Y9=IF(O9=1,1,(2*\$J9/(2*\$19*TAN(RADIANS $(\$ Q \$ 7)))))$}

Column Z: Value of $f_{\text {calc }}$ in region $5\left(y_{C}<y<\ell\right)$ :

$$
f_{\text {calc }}=\frac{-y+\ell+x \tan \alpha}{2 x \tan \alpha}
$$

Z9=(-H9+J9+19*TAN(RADIANS(\$Q\$7)))/(2*19*TAN(RADIANS(\$Q\$7))) 
Column AA: Value of $f_{\text {calc }}$ in region $6\left(\ell \leq y<y_{D}\right)$ :

$$
f_{\text {calc }}=\frac{-y+\ell+(x+2 \ell) \tan \alpha}{2(x+2 \ell) \tan \alpha}
$$

\section{AA9 $=(-H 9+J 9+19 * T A N(R A D I A N S(\$ Q \$ 7))) /$ $(2 * 19 *$ TAN(RADIANS(AA9\$Q\$7)))}

Column AB: Value of $f_{\text {calc }}$ in region $7\left(y \geq y_{D}\right)$ where $f_{\text {calc }}=0$ :

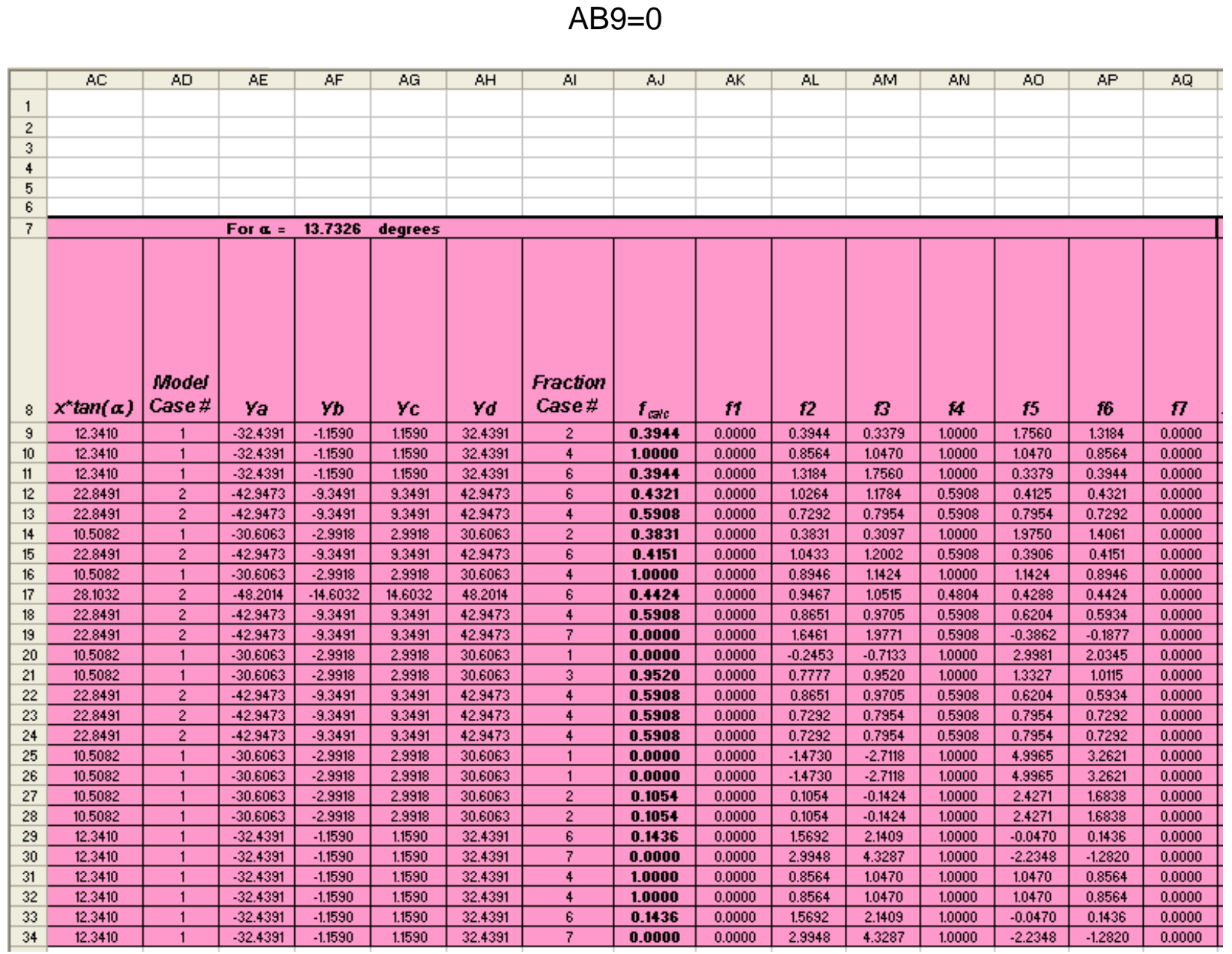

Figure D-3. Spreadsheet "Flux Split Waste Package Model," Worksheet "f calculations;" Calculation of Model Flow Fractions for Mean Rivulet Spread Angle

Columns AC though AQ repeat the calculations done in Columns $\mathrm{N}$ though $\mathrm{AB}$ using the mean rivulet spread angle of $\alpha=13.7326^{\circ}$ (Cell \$AF\$7). For Row 9, the spreadsheet equations are as follows:

$A C 9=\$ 19 *$ TAN(RADIANS(\$AF\$7)) 
$A D 9=I F(\$ J 9>A C 9,1,2)$

AE9=-\$J9-(\$19+2*\$J9)*TAN(RADIANS(\$AF\$7))

AF9=IF(AD9=1,(-\$J9+\$19*TAN(RADIANS(\$AF\$7))),(\$J9-\$19*TAN(RADIANS(\$AF\$7))))

AG9=IF(AD9=1,(\$J9-\$19*TAN(RADIANS(\$AF\$7))),(-\$J9+\$19*TAN(RADIANS(\$AF\$7))))

$A H 9=\$ J 9+(\$ 19+2 * \$ J 9) *$ TAN $($ RADIANS $(\$ A F \$ 7))$

Al9=IF $(\$ H 9<=A E 9,1, I F(\$ H 9<=-\$ J 9,2, I F(\$ H 9<A F 9,3$, IF $(\$ H 9<=A G 9,4, I F(\$ H 9<\$ J 9,5, I F(\$ H 9<A H 9,6, I F(\$ H 9>=A H 9,7)))))))$

$A J 9=I F(A I 9=1, A K 9, I F(A I 9=2, A L 9, I F(A I 9=3, A M 9, I F(A I 9=4, A N 9, I F(A I 9=5, A O 9, I F(A I 9=6, A$ $\mathrm{P} 9, \mathrm{IF}(\mathrm{Al9}=7, \mathrm{AQ} 9)))))))$

$A K 9=0$

AL9 $=\left(\mathrm{H} 9+\mathrm{J} 9+(19+2 * \mathrm{~J} 9)^{*} \mathrm{TAN}(\mathrm{RADIANS}(\$ A F \$ 7))\right) /$

$(2 *(19+2 * J 9) *$ TAN (RADIANS(\$AF\$7)))

AM9 $=(\mathrm{H} 9+\mathrm{J} 9+19 *$ TAN $($ RADIANS $(\$ A F \$ 7))) /(2 * 19 * \operatorname{TAN}($ RADIANS $(\$ A F \$ 7)))$

AN9 $=I F(A D 9=1,1,(2 * \$ J 9 /(2 * \$ 19 * \operatorname{TAN}(\operatorname{RADIANS}(\$ A F \$ 7)))))$

AO9 $=(-\mathrm{H} 9+\mathrm{J} 9+19 *$ TAN $($ RADIANS $(\$ A F \$ 7))) /(2 * 19 *$ TAN (RADIANS $(\$ A F \$ 7)))$

AP9 $=\left(-\mathrm{H} 9+\mathrm{J} 9+(19+2 * \mathrm{~J} 9)^{\star} \mathrm{TAN}(\mathrm{RADIANS}(\$ A F \$ 7))\right) /$

$(2 *(19+2 * J 9) *$ TAN (RADIANS $(\$ A F \$ 7)))$

$\mathrm{AQ} 9=0$

Columns AR though BF (next page) repeat the calculations done in Columns $\mathrm{N}$ though $\mathrm{AB}$ using a rivulet spread angle of $\alpha=21.9614^{\circ}$ (Cell \$AU\$7), which is one standard deviation greater than the mean rivulet spread angle. For Row 9, the spreadsheet equations are as follows:

AR9 $=\$ 19 *$ TAN (RADIANS $(\$ A U \$ 7))$

AS9 $=I F(\$ J 9>A R 9,1,2)$

AT9=-\$J9-(\$19+2*\$J9)*TAN(RADIANS $(\$ A \cup \$ 7))$

AU9=IF(AS9=1,(-\$J9+\$19*TAN(RADIANS(\$AU \$7))),(\$J9-\$19*TAN(RADIANS(\$AU\$7)))

AV9=IF(AS9=1,(-\$J9+\$19*TAN(AV9RADIANS(\$AU\$7))), (\$J9\$I*TAN(RADIANS(\$AU\$7))))

AW9 $=\$ J 9+(\$ 19+2 * \$ J 9) *$ TAN $($ RADIANS $(\$ A U \$ 7))$

$\mathrm{A} X 9=\mathrm{IF}(\$ \mathrm{H} 9<=\mathrm{AT} 9,1, \mathrm{IF}(\$ \mathrm{H} 9<=-\$ \mathrm{~J} 9,2, \mathrm{IF}(\$ \mathrm{H} 9<\mathrm{AU} 9,3, \mathrm{IF}(\mathbf{H} 9<=\mathrm{AV} 9,4$, $\mathrm{IF}(\$ \mathrm{H} 9<\$ 39,5, \mathrm{IF}(\$ \mathrm{H} 9<\mathrm{AW} 9,6, \mathrm{IF}(\$ \mathrm{H} 9>=\mathrm{AW} 9,7)))))))$

$A Y 9=I F(A X 9=1, A Z 9, I F(A X 9=2, B A 9, I F(A X 9=3, B B 9, I F(A X 9=4, B C 9, I F(A X 9=5, B D 9, I F$ $(A X 9=6, B E 9, \operatorname{IF}(A X 9=7, B F 9)))))))$

$A Z 9=0$ 


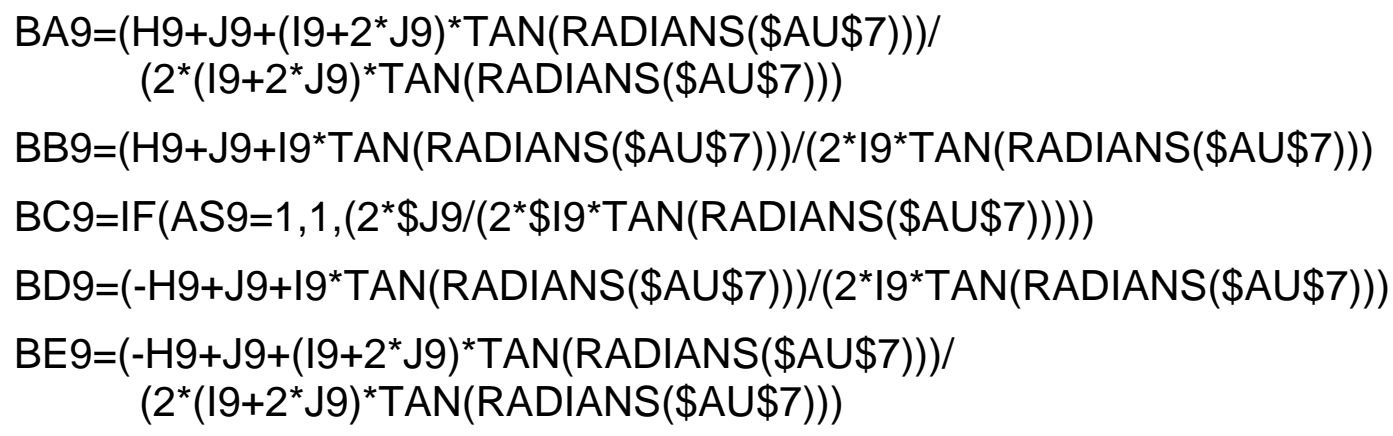

\section{$\mathrm{BF} 9=0$}

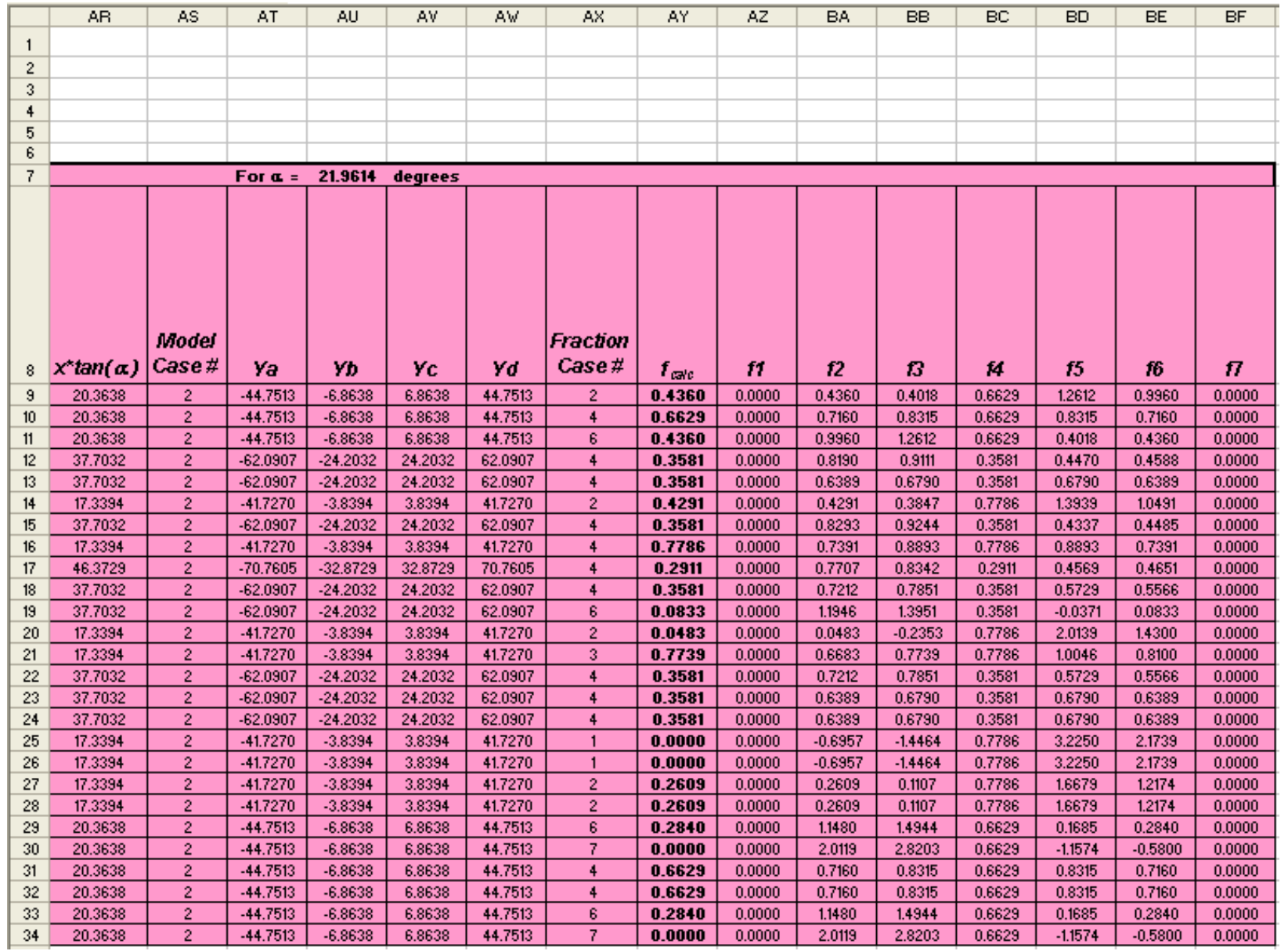

Figure D-4. Spreadsheet "Flux Split Waste Package Model," Worksheet "f calculations;" Calculation of Model Flow Fractions for Mean Plus One Standard Deviation Rivulet Spread Angle 


\section{SPREADSHEET “FLUX SPLIT WASTE PACKAGE MODEL”-WORKSHEET "SPREAD ANGLES"}

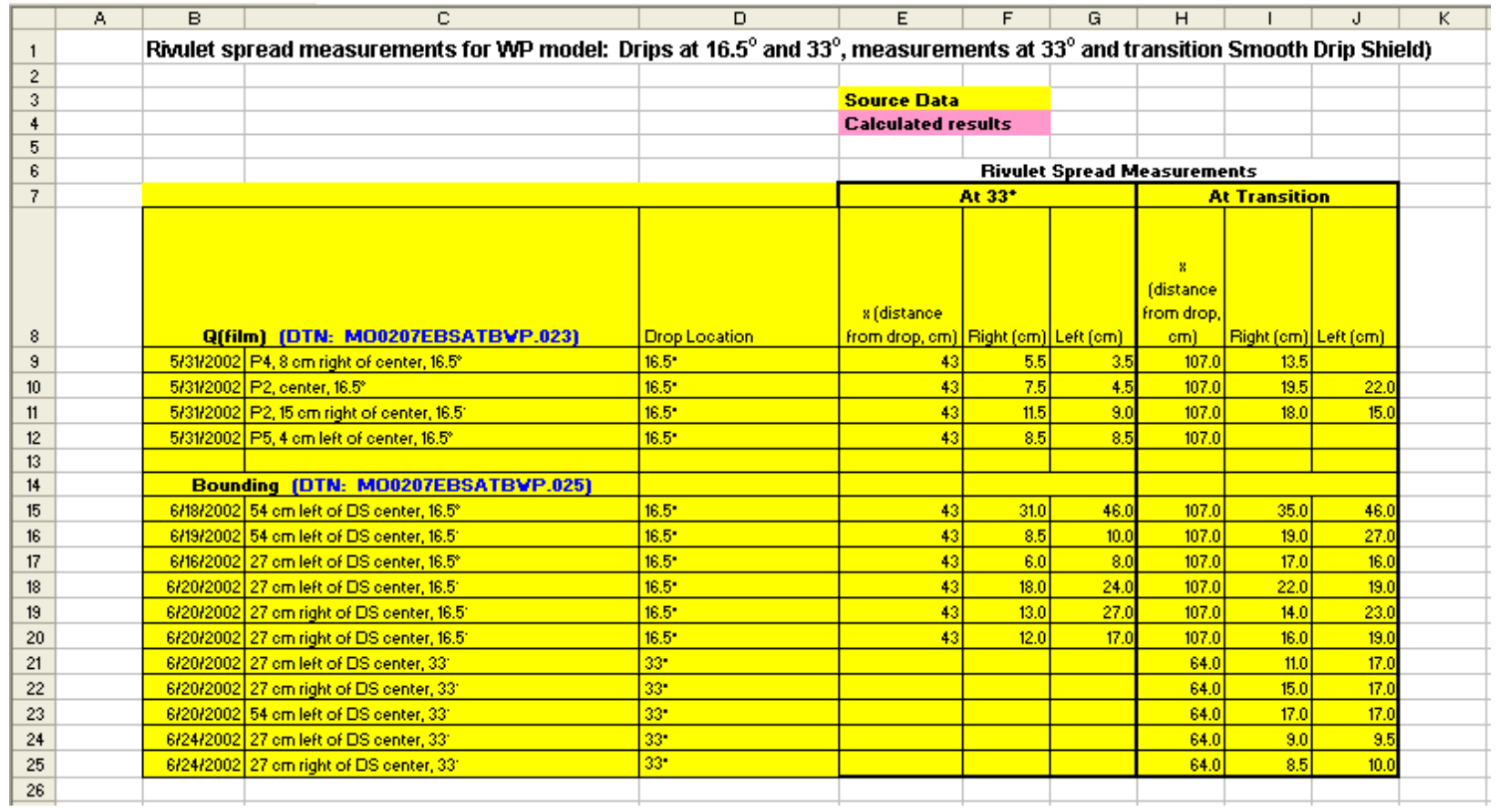

DTN: MO0207EBSATBWP.023 [DIRS 163402]; DTN: MO0207EBSATBWP.025 [DIRS 163403].

Figure D-5. Spreadsheet "Flux Split Waste Package Model," Worksheet "Spread angles;" Calculation of Rivulet Spread Angle

In this worksheet, the mean and range of the rivulet spread angle $\alpha$ is determined from spread measurements. The drip locations are off-crown, at the $16.5^{\circ}$ and $33^{\circ}$ positions on the drip shield mockup. These angles are the angular distances from the crown about the center of curvature of the drip shield; thus, the crown is at $0^{\circ}$, and the transition from the curved top surface to the vertical side of the drip shield is located about $60^{\circ}$ from vertical. The actual distance (arc length) from the crown to the $16.5^{\circ}$ line is $43 \mathrm{~cm}$; from the crown to the $33^{\circ}$ line the distance is $86 \mathrm{~cm}$; and from the crown to the transition line the distance is $150 \mathrm{~cm}$. The distance $x$ from the drip location to the spread measurement location (the $33^{\circ}$ line or the transition line) is shown in Columns E and H, respectively.

Columns B and C identify the pertinent tests as described in the designated DTNs. In each test, the spread of rivulets to the right and to the left of the drip location was measured. The spread distance measured at the $33^{\circ}$ line is listed in Columns F and G. The spread distance measured at the transition line is listed in Columns I and J. For drips at the $33^{\circ}$ location, no rivulet spread was measured, although splattering upslope may have resulted in some rivulets appearing at the drip location.

The sketch below from the scientific notebook for the experiments (Howard 2002 [DIRS 161516], p. 14) indicates the dimensions and locations of breaches on the drip shield mockup used in the tests. This sketch is also shown in Figure 4.1-1, Section 4.1.1. 


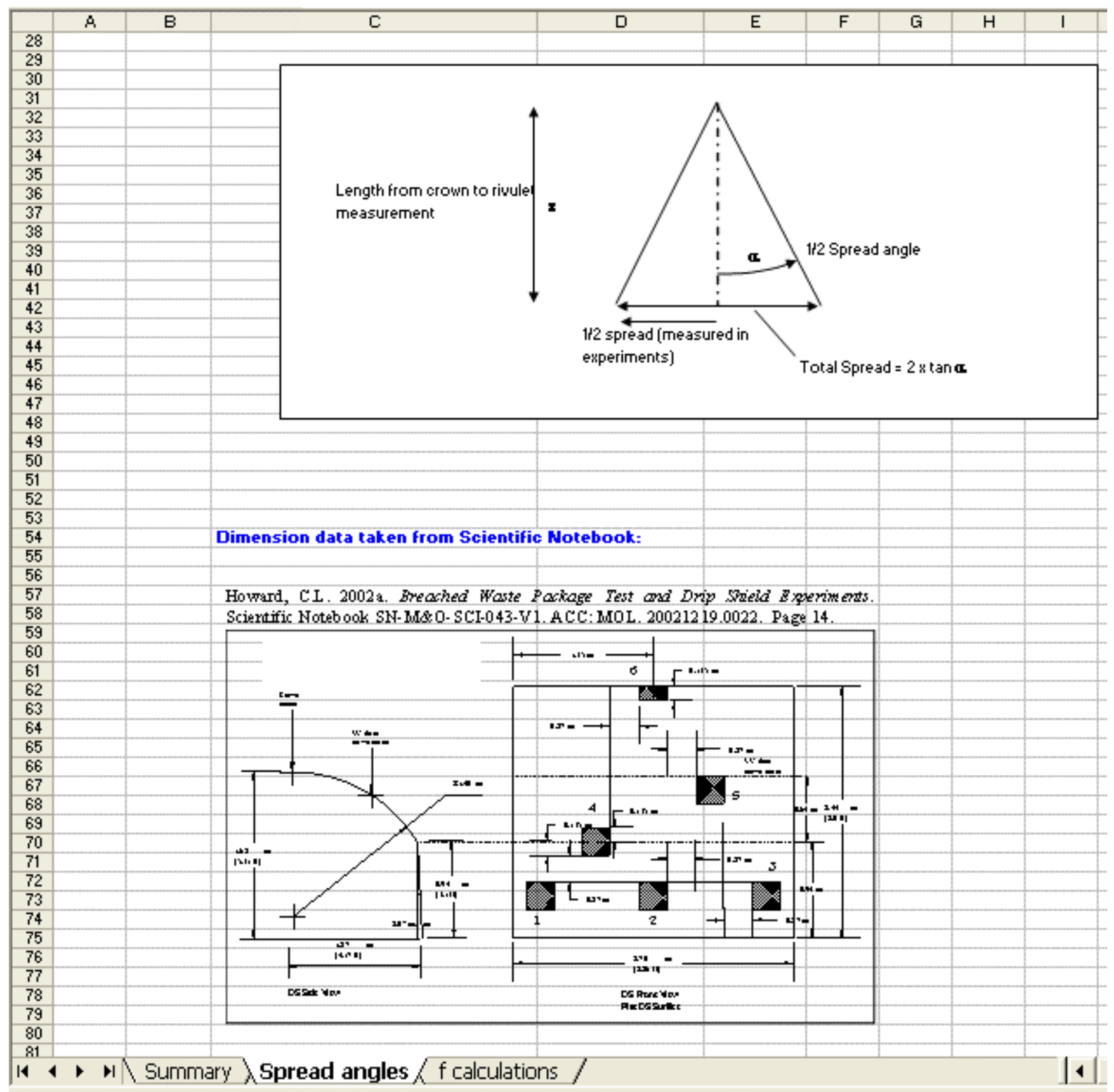

Source: Howard 2002 [DIRS 161516], p. 14.

Figure D-6. Spreadsheet "Flux Split Waste Package Model," Worksheet "Spread angles;" Dimensions and Locations of Breaches in Drip Shield Mockup Used in Breached Drip Shield Experiments 


\begin{tabular}{|c|c|c|c|c|c|c|c|c|c|c|}
\hline & $\mathrm{L}$ & $M$ & $N$ & 0 & $\mathrm{P}$ & $\mathbf{Q}$ & $\mathrm{R}$ & $\mathrm{S}$ & $T$ & $\mathrm{U}$ \\
\hline \multicolumn{11}{|l|}{1} \\
\hline \multicolumn{11}{|l|}{2} \\
\hline \multicolumn{11}{|l|}{4} \\
\hline \multicolumn{11}{|l|}{5} \\
\hline \multicolumn{11}{|l|}{6} \\
\hline 8 & & $\begin{array}{c}\text { Measurement } \\
\text { [cm] }\end{array}$ & \begin{tabular}{|c|}
$\mathbf{x}$ \\
ddistance \\
from \\
drop to \\
measure \\
ment. \\
\end{tabular} & $\begin{array}{c}\text { Spread } \\
\text { angle } \\
\text { (degrees) }\end{array}$ & & & & & & \\
\hline 12 & & 8.5 & 43 & 11.1818 & & & & & & \\
\hline 13 & & 3.5 & 43 & 4.6534 & & & & & & \\
\hline 14 & & 4.5 & 43 & 5.9743 & & & & & & \\
\hline 15 & & 9.0 & 43 & 11.8215 & & & & & & \\
\hline 16 & & 8.5 & 43 & 11.1818 & & \multicolumn{2}{|c|}{ Drip at $16.5^{-}$. } & & \multicolumn{2}{|c|}{ All Measurements } \\
\hline 17 & & 31.0 & 43 & 35.7890 & & \multicolumn{2}{|c|}{ Spread Angle } & & \multicolumn{2}{|l|}{ Spread Angle } \\
\hline 18 & & 8.5 & 43 & 11.1818 & & No. of mez & 20 & & No. of meas. & 47 \\
\hline 19 & & 6.0 & 43 & 7.9435 & & Mean & 17.0218 & & Mean & 13.7326 \\
\hline 20 & & 18.0 & 43 & 22.7144 & & Std. Dev. & 11.17224 & & Std. Dev. & 8.228837 \\
\hline 28 & & 17.0 & 43 & 21.5713 & & & & & & \\
\hline 29 & & & & & & & & & & \\
\hline
\end{tabular}

Figure D-7. $\quad$ Spreadsheet "Flux Split Waste Package Model," Worksheet "Spread angles;" Calculation of Rivulet Spread Angles and Statistical Measures

In Column M, Rows 9-28 (Figure D-7), all of the spread measurements (right and left) at the $33^{\circ}$ line are listed for the $16.5^{\circ}$ drip location from the $\mathrm{Q}$ (film) and Bounding tests. In Rows 31-47 (Figure D-7), the spread from $16.5^{\circ}$ drips measured at the transition are listed for the $\mathrm{Q}$ (film) and Bounding tests. In Rows 50-59, the spread from $33^{\circ}$ drips measured at the transition are listed for the Bounding tests. In Column $\mathrm{N}$, the distance, $x$, from the drip location to the measurement location is listed. In Column $\mathrm{O}$, the spread angle, $\alpha$, is computed from the rivulet spread, $w_{r}(\mathrm{~cm})$ :

$$
\alpha=\tan ^{-1}\left(\frac{w_{r}}{x}\right),
$$

The spreadsheet equation for Row 9 is:

O9=DEGREES(ATAN(M9/N9)) 
In Column R (Figures D-7 and D-8), the mean spread angle and standard deviation are shown for comparison for three groups of data-drip location at $16.5^{\circ}$ measured at $33^{\circ}$, drip location at $16.5^{\circ}$ measured at the transition line, and drip location at $33^{\circ}$ measured at the transition line. The statistics for all measurements are computed in Column U. The mean rivulet spread angle (Cell U19) and the bounds on the range for spread angle as defined by the mean minus one standard deviation (Cell U21) and the mean minus one standard deviation (Cell U22) are used in Worksheet "f calculations" as the basis of the waste package flux splitting submodel to compute the predicted fraction of dripping flux that flows into a breach, $f_{\text {calc }}$.

\begin{tabular}{|c|c|c|c|c|c|c|c|c|c|c|}
\hline & $\mathrm{L}$ & $M$ & $\mathrm{~N}$ & 0 & $\mathrm{P}$ & $Q$ & $\mathrm{R}$ & $\mathrm{S}$ & $T$ & $\mathrm{U}$ \\
\hline \multicolumn{11}{|l|}{29} \\
\hline \multicolumn{11}{|l|}{30} \\
\hline 31 & & 13.5 & 107 & 7.1909 & & & & & & \\
\hline 32 & & 19.5 & 107 & 10.3284 & & & & & & \\
\hline 33 & & 18.0 & 107 & 9.5491 & & & & & & \\
\hline 34 & & 22.0 & 107 & 11.6185 & & & & & & \\
\hline 37 & & 19.0 & 107 & 10.0691 & & \multicolumn{2}{|c|}{ Drip at 16.5-. } & & & \\
\hline 38 & & 17.0 & 107 & 9.0276 & & \multicolumn{2}{|c|}{ Spread Angle } & & & \\
\hline 39 & & 22.0 & 107 & 11.6185 & & No. of mez & 17 & & & \\
\hline 40 & & 14.0 & 107 & 7.4543 & & Mean & 11.1561 & & & \\
\hline 41 & & 16.0 & 107 & 8.5046 & & Std. Dev. & 4.110299 & & & \\
\hline 45 & & 19.0 & 107 & 10.0691 & & & & & & \\
\hline 46 & & 23.0 & 107 & 12.1313 & & & & & & \\
\hline 47 & & 19.0 & 107 & 10.0691 & & & & & & \\
\hline \multicolumn{11}{|l|}{48} \\
\hline \multicolumn{11}{|l|}{49} \\
\hline 50 & & 11.0 & 64 & 9.7524 & & & & & & \\
\hline 51 & & 15.0 & 64 & 13.1906 & & & & & & \\
\hline 52 & & 17.0 & 64 & 14.8757 & & \multicolumn{2}{|c|}{ Drip at $33^{-}$. } & & & \\
\hline 53 & & 9.0 & 64 & 8.0047 & & \multicolumn{2}{|l|}{ Spread Angle } & & & \\
\hline 54 & & 8.5 & 64 & 7.5653 & & No. of mez & 10 & & & \\
\hline 55 & & 17.0 & 64 & 14.8757 & & Mean & 11.5340 & & & \\
\hline
\end{tabular}

Figure D-8. $\quad$ Spreadsheet "Flux Split Waste Package Model," Worksheet "Spread angles;" Calculation of Rivulet Spread Angles 


\section{SPREADSHEET “FLUX SPLIT WASTE PACKAGE MODEL”-WORKSHEET "SUMMARY"}

\begin{tabular}{|c|c|c|c|c|c|c|c|c|c|c|c|}
\hline & A & $\mathrm{B}$ & C & D & $\mathrm{E}$ & $\mathrm{F}$ & G & $\mathrm{H}$ & I & J & K \\
\hline 1 & & & & & & & & & & & \\
\hline 2 & & & & & & & & & & & \\
\hline 3 & & & & & & & & & & & \\
\hline 4 & & \multicolumn{10}{|c|}{ Waste Package Model: Comparison of Measured and Modeled Fraction of Drip Seepage Flowing into a Breach } \\
\hline 5 & & & & & & & & & & & \\
\hline 6 & & \multicolumn{10}{|c|}{$\begin{array}{l}\text { This spreadsheet compares results from the "Atlas Breached Waste Package and Drip Shield Experiments: Breached Drip Shield Tests" (documented } \\
\text { in TDR-EBS-MD-000025-00 REV 00) with the model developed in the "EBS Radionuclide Transport Abstraction" (ANL-W/S-PA-0000001 REV 02). Test } \\
\text { data are taken directly from the TDMS for this comparison. }\end{array}$} \\
\hline 7 & & & & & & & & & & & \\
\hline 8 & & Methodology: & & & & & & & & & \\
\hline 9 & & \multicolumn{10}{|c|}{ 1. Spreading angles are calculated from the test data in the sheet titled Spread angles } \\
\hline 10 & & \multicolumn{10}{|c|}{ 2. Given spread angle and test geometry, seepage fractions are calculated for both the test data and the model in the worksheet $f$ calculations: } \\
\hline 11 & & & \multicolumn{9}{|c|}{$\begin{array}{l}\text { a. Geometric data for each measurement }(x, y, l) \text { and the spread angle are used to determine which of } 7 \text { cases the } \\
\text { measurement corresponds to }\end{array}$} \\
\hline 12 & & & \multicolumn{9}{|c|}{ b. For each test result the appropriate case model is applied to calculate the seepage flow fraction $f$} \\
\hline 13 & & \multicolumn{10}{|c|}{ 3. The seepage fractions calculated from both the test and model are listed and compared in the two tables listed below in this Summary worksheet } \\
\hline 14 & & Notes: & & & & & & & & & \\
\hline 15 & & \multicolumn{10}{|c|}{ Source data DTNs are noted where source data is used } \\
\hline 16 & & \multicolumn{10}{|c|}{ Model equations are provided on the calculational sheets } \\
\hline 17 & & \multicolumn{10}{|c|}{ Data in tables below is linked directly to the calculational worksheets } \\
\hline 18 & & & & & & & & & & & \\
\hline 19 & & & & & & & & & & & \\
\hline
\end{tabular}

Source: BSC 2003 [DIRS 163406].

Figure D-9. Spreadsheet "Flux Split Waste Package Model," Worksheet "Summary;" Summary of Waste Package Flux Splitting Submodel

This worksheet, beginning with Figure D-9, summarizes the calculations in Worksheets "Spread angles" and "f calculations."

In the first table (Figure D-10), "Measured Breach Flow Fractions and Calculated Breach Flow Fractions," Columns B, C, D, and E are identical to Columns D, E, H, and I described earlier for Worksheet "f calculations." Column F $\left(f_{\text {expt }}\right)$ is identical to Column $\mathrm{M}$ in Worksheet "f calculations." Columns G-I summarize the calculated fraction of the dripping flux that the flux splitting submodel predicts should flow into the breach, for the minimum, mean, and maximum spread angles. The minimum spread angle is specified to be one standard deviation less than the mean of the measured spread angles. The maximum spread angle is specified to be one standard deviation greater than the mean of the measured spread angles. Column $G$ is identical to Column U of Worksheet "f calculations." Column $\mathrm{H}$ is identical to Column AJ of Worksheet "f calculations.” Column I is identical to Column AY of Worksheet "f calculations.”

Rows 50-54, Columns F-I, show the results of Microsoft Excel functions "AVERAGE," "STDEVA," "MEDIAN," "MIN," and “MAX," respectively, as applied to Rows 25-49. 


\begin{tabular}{|c|c|c|c|c|c|c|c|c|c|}
\hline & A & B & $\mathrm{c}$ & D & E & $\mathbf{F}$ & G & H & 1 \\
\hline 19 & & & & & & & & & \\
\hline 20 & & \multicolumn{7}{|c|}{ 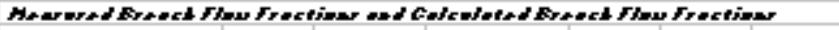 } & \\
\hline 21 & & & & & \multirow{4}{*}{ 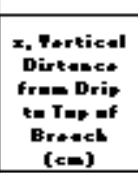 } & & & & \\
\hline 22 & & \multirow[b]{3}{*}{$\begin{array}{l}\text { Drip Lecetim: } \\
\text { (Tert Descriptims) }\end{array}$} & \multirow[b]{3}{*}{$\begin{array}{l}\text { Brese } \\
\text { B He. }\end{array}$} & \multirow{3}{*}{ 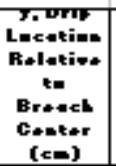 } & & \multirow[b]{3}{*}{ 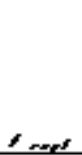 } & \multicolumn{3}{|c|}{ אלות } \\
\hline 23 & & & & & & & C(1.1) & (4.1) & C(1.1) \\
\hline 24 & & & & & & & 5.5* & 13.73 & 21.96 \\
\hline 25 & & $\begin{array}{l}\text { F5, } 17.5 \text { em left of eenter, } \\
33^{\circ}\end{array}$ & 4 & -17.5 & 50.5 & 0.0000 & 0.2322 & 0.3944 & 0.4360 \\
\hline 26 & & F4, senter, $33^{\circ}$ & 4 & 0 & 50.5 & 0.8005 & 1.0000 & 1.0000 & 0.6629 \\
\hline 27 & & $\begin{array}{l}\text { F4, } 17.5 \mathrm{sm} \text { right of } \\
\text { genter, } 33\end{array}$ & 4 & 17.5 & 50.5 & $0.06 \$ 2$ & 0.2322 & 0.3944 & 0.4360 \\
\hline 28 & & $\begin{array}{l}\mathrm{Fd}, 17.5 \mathrm{~cm} \text { right of } \\
\text { senter, } 16.5\end{array}$ & 4 & 17.5 & 43.5 & 0.0119 & 0.3277 & 0.4321 & $0.35 \% 1$ \\
\hline 29 & & F4, senterline, 16.5. & 4 & 0 & 43.5 & 0.6029 & 1.0000 & 0.5908 & $0.35 \& 1$ \\
\hline 30 & & 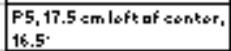 & 5 & -17.5 & 43.0 & 0.0142 & 0.2035 & 0.3831 & 0.4291 \\
\hline 31 & & $\begin{array}{l}\mathrm{P} 6,35.5 \mathrm{em} \text { left af eenter, } \\
16.5\end{array}$ & 4 & 18.5 & 93.5 & 0.0015 & 0.2847 & 0.4151 & $0.35 \$ 1$ \\
\hline 32 & & F5, esenterline, 16.5. & 5 & 0 & 43.0 & 0.7260 & 1.0000 & 1.0000 & 0.7786 \\
\hline 33 & & $\begin{array}{l}\mathrm{P} 6,36.5 \text { em left af eenter, } \\
\text { between sraun and } 16.5 \text {. }\end{array}$ & 4 & 17.5 & 115.0 & 0.0513 & 0.3538 & 0.4424 & 0.2911 \\
\hline 34 & & $\begin{array}{l}\mathrm{F} 4,8 \mathrm{~s} \text { em riaht af senter, } \\
16.5 \text {. }\end{array}$ & 4 & \& & 93.5 & 0.5368 & 0.8052 & 0.5908 & $0.35 \$ 1$ \\
\hline 35 & & $\begin{array}{l}\text { F2, } 15 \mathrm{~cm} \text { riaht af senter, } \\
16.5\end{array}$ & 5 & -39 & 43.0 & 0.0022 & 0.0000 & 0.0000 & $0.04 \$ 3$ \\
\hline 36 & & $\begin{array}{l}\text { F5, } 4 \text { em left of eenter, } \\
16.5 \text {. }\end{array}$ & 5 & -4 & 43.0 & 1.0657 & 1.0000 & 0.9520 & 0.7739 \\
\hline 37 & & $\begin{array}{l}\mathrm{FA}, \hat{8} \text { sm, riqht af senter, } \\
16.5 \text {. }\end{array}$ & 4 & 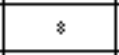 & 93.5 & $0.7 \$ 13$ & 0.8052 & 0.5908 & $0.35 \$ 1$ \\
\hline 38 & & $\begin{array}{l}54 \text { em left af DS senter, } \\
16.5^{\circ}\end{array}$ & 4 & 0 & 93.5 & $0.4 \$ 03$ & 1.0000 & 0.5908 & $0.35 \$ 1$ \\
\hline 39 & & $\begin{array}{l}54 \text { em left of DS senter, } \\
16.5 \text {. }\end{array}$ & 4 & 0 & 93.5 & 0.7901 & 1.0000 & 0.5908 & $0.35 \$ 1$ \\
\hline 40 & & $\begin{array}{l}27 \text { em left af DS senter, } \\
16.5^{\circ}\end{array}$ & 5 & -81 & 43.0 & 0.0048 & 0.0000 & 0.0000 & 0.0000 \\
\hline 41 & & $\begin{array}{l}27 \text { em left of DS senter, } \\
16.5^{\circ}\end{array}$ & 5 & $-\$ 1$ & 43.0 & 0.0031 & 0.0000 & 0.0000 & 0.0000 \\
\hline 42 & & $\begin{array}{l}27 \mathrm{~cm} \text { riaht of DS senter, } \\
16.5 \text {. }\end{array}$ & 5 & -27 & 43.0 & 0.0125 & 0.0000 & 0.1054 & 0.2609 \\
\hline 43 & & $\begin{array}{l}27 \mathrm{~cm} \text { riaht of DS senter, } \\
16.5 \text {. }\end{array}$ & 5 & -27 & 43.0 & $0.00 \$ 2$ & 0.0000 & 0.1054 & 0.2609 \\
\hline 44 & & $\begin{array}{l}27 \text { em left of DS senter, } \\
33^{\circ}\end{array}$ & 4 & 27 & 50.5 & 0.0026 & 0.0000 & 0.1436 & 0.2840 \\
\hline 45 & & $\begin{array}{l}27 \text { em riaht af DS senter, } \\
33^{\circ}\end{array}$ & 4 & $\$ 1$ & 50.5 & 0.0020 & 0.0000 & 0.0000 & 0.0000 \\
\hline 46 & & $\begin{array}{l}54 \text { sm left of DS senter, } \\
33 \text {. }\end{array}$ & 4 & 0 & 50.5 & $0.56 \$ 2$ & 1.0000 & 1.0000 & 0.6629 \\
\hline 47 & & $\begin{array}{l}54 \text { cm loft of DS senter, } \\
33^{\circ}\end{array}$ & 4 & 0 & 50.5 & 0.8217 & 1.0000 & 1.0000 & 0.6629 \\
\hline $4 \hat{8}$ & & $\begin{array}{l}27 \text { em left of DS senter, } \\
33^{\circ}\end{array}$ & 4 & 27 & 50.5 & 0.0123 & 0.0000 & 0.1436 & 0.2840 \\
\hline 49 & & $\begin{array}{l}27 \text { em riaht of } D S \text { eenter, } \\
33 \text {. }\end{array}$ & 4 & $\$ 1$ & 50.5 & 0.0000 & 0.0000 & 0.0000 & 0.0000 \\
\hline 50 & & Moan & & & & 0.2947 & 0.4498 & 0.4346 & 0.3511 \\
\hline 51 & & Std.Dov. & & & & $0.36 \% 3$ & 0.4426 & 0.3539 & 0.2316 \\
\hline 52 & & Modian & & & & 0.0142 & $0.2 \% 47$ & 0.4151 & 0.3581 \\
\hline 53 & & Minimum & & & & 0.0000 & 0.0000 & 0.0000 & 0.0000 \\
\hline 54 & & Maximum & & & & 1.0657 & 1.0000 & 1.0000 & $0.77 \% 6$ \\
\hline 55 & & & & & & & & & \\
\hline
\end{tabular}

Figure D-10. Spreadsheet "Flux Split Waste Package Model," Worksheet "Summary;" Summary of Waste Package Flux Splitting Submodel

In the second table (Figure D-11), “Comparison of Measured and Calculated Breach Flows," Column $\mathrm{K}$ is again the drip location. Column $\mathrm{L}$ is the fraction of dripping flux $\left(f_{\text {expt }}\right)$ that flowed into a breach as measured experimentally; this is identical to Column F of the preceding table, or Column $\mathrm{M}$ in Worksheet "f calculations." The next three columns (M-O) show the difference between the predicted breach flow fraction, $f_{\text {calc }}$, and the measured fraction, $f_{\text {expt }}$, for the minimum, mean, and maximum rivulet spread angle. Columns P-R show the ratio $f_{\text {calc }} / f_{\text {expt }}$ for the minimum, mean, and maximum rivulet spread angle. 
Rows 50-54, Columns L-R, show the results of Microsoft Excel functions "AVERAGE," "STDEVA," “MEDIAN," "MIN," and “MAX,” respectively, as applied to Rows 25-49.

\begin{tabular}{|c|c|c|c|c|c|c|c|c|c|}
\hline & $J$ & K & L & $M$ & $\mathrm{H}$ & 0 & $\mathbf{F}$ & Q & $\mathbf{R}$ \\
\hline 19 & & & & & & & & & \\
\hline 20 & & \multicolumn{6}{|c|}{ 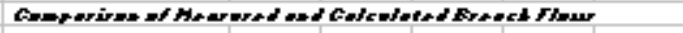 } & & \\
\hline 21 & & & & & & & & & \\
\hline 22 & & \multirow[b]{3}{*}{\begin{tabular}{|c|} 
Drip Lecetime (Tert \\
Dereriptien)
\end{tabular}} & \multirow[b]{3}{*}{ t } & \multicolumn{3}{|c|}{ 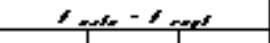 } & \multicolumn{3}{|c|}{ 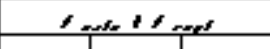 } \\
\hline 23 & & & & $\simeq$ (1.t) & $<$ (4t.1) & (1).1) & $<(1+1)$ & (1)e & $\leq(1+1)$ \\
\hline 24 & & & & $5.5 \%$ & 13.73 & 21.96 & 5.50 & 13.73 & 21.96 \\
\hline 25 & & $\begin{array}{l}\text { F5, } 17.5 \text { em left of enter, } \\
33^{\circ}\end{array}$ & 0.0000 & 0.2322 & 0.3944 & 0.4360 & & & \\
\hline 26 & & F4, senter, 33 & 0.8005 & 0.1995 & 0.1945 & -0.1376 & 1.2492 & 1.2492 & $0 . \$ 2 \$ 1$ \\
\hline 27 & & $\begin{array}{l}\mathrm{F} 4,17.5 \mathrm{~cm} \text { riaht of } \\
\text { senter, } 33^{\circ}\end{array}$ & 0.0682 & 0.1640 & 0.3262 & 0.3678 & 3.4054 & $5.7 \% 4 \%$ & 6.3950 \\
\hline 28 & & $\begin{array}{l}\text { F4, } 17.5 \text { sm, right of } \\
\text { senter, } 16.5\end{array}$ & 0.0119 & 0.3154 & 0.4202 & 0.3462 & 27.6039 & 36.3914 & 30.1570 \\
\hline 24 & & F4, eenterline, 16.5. & 0.6029 & 0.3971 & -0.0121 & -0.2449 & $1.65 \% 6$ & 0.9799 & 0.5439 \\
\hline 30 & & $\begin{array}{l}\text { F5, } 17.5 \text { em left af eenter, } \\
16.5 \text {. }\end{array}$ & 0.0142 & 0.1893 & 0.3689 & 0.4150 & 14.3428 & 27.0031 & 30.2494 \\
\hline 31 & & \begin{tabular}{|l|}
$\mathrm{P} 6,35.5 \mathrm{~cm}$ loft af senter, \\
16.5
\end{tabular} & 0.0015 & 0.2831 & 0.4136 & 0.3565 & 184.1115 & $268.45 \$ 1$ & 231.5671 \\
\hline 32 & & F5, eenterline, 16.5 & 0.7260 & 0.2740 & 0.2740 & 0.0526 & 1.3774 & 1.3774 & 1.0724 \\
\hline 33 & & \begin{tabular}{|l|}
$\begin{array}{l}\text { P6, } 36.5 \text { cm left af eenter, } \\
\text { between eraun and } 16.5\end{array}$ \\
\end{tabular} & 0.0513 & 0.3025 & 0.3911 & 0.2398 & 6.8988 & 8.6251 & 5.6761 \\
\hline 34 & & $\begin{array}{l}\mathrm{Fd}, \hat{\mathrm{s}} \mathrm{em} \text { riqht af senter, } \\
16.5 \text {. }\end{array}$ & 0.5368 & 0.2685 & 0.0541 & -0.1787 & 1.5001 & 1.1007 & 0.6671 \\
\hline 35 & & $\begin{array}{l}\text { F2, } 15 \text { cm riaht af eenter, } \\
16.5\end{array}$ & 0.0022 & -0.0022 & -0.0022 & 0.0461 & 0.0000 & 0.0000 & 21.4501 \\
\hline 36 & & $\begin{array}{l}\text { P5, } 4 \text { em left of senter, } \\
16.5 \text {. }\end{array}$ & 1.0657 & -0.0657 & -0.1136 & -0.2917 & 0.9384 & 0.8934 & 0.7263 \\
\hline 37 & & $\begin{array}{l}\text { F4, \& em, right of center, } \\
16.5 \text {. }\end{array}$ & $0.7 \$ 13$ & 0.0240 & $\mid-0.1905$ & -0.4232 & 1.0307 & 0.7562 & $0.45 \% 3$ \\
\hline 38 & & $\begin{array}{l}54 \mathrm{sm} \text { left of DS senter, } \\
16.5 \text {. }\end{array}$ & 0.4803 & 0.5197 & 0.1105 & -0.1223 & $2.0 \$ 1 \%$ & 1.2300 & 0.7454 \\
\hline 39 & & $\begin{array}{l}54 \text { em left of DS senter, } \\
16.5 \text {. }\end{array}$ & 0.7901 & 0.2094 & -0.1993 & -0.4321 & 1.2656 & 0.7478 & 0.4532 \\
\hline 40 & & $\begin{array}{l}27 \text { em left of DS senter, } \\
16.5 \text {. }\end{array}$ & 0.0048 & -0.0048 & -0.0048 & -0.0048 & 0.0000 & 0.0000 & 0.0000 \\
\hline 41 & & $\begin{array}{l}27 \mathrm{em} \text { left of DS senter, } \\
16.5 \text {. }\end{array}$ & 0.0031 & -0.0031 & -0.0031 & -0.0031 & 0.0000 & 0.0000 & 0.0000 \\
\hline 42 & & $\begin{array}{l}27 \text { sm riaht of } D S \text { eenter, } \\
16.5 \text {. }\end{array}$ & 0.0125 & -0.0125 & 0.0929 & 0.2484 & 0.0000 & 8.4461 & 20.9026 \\
\hline 43 & & \begin{tabular}{|l|}
$27 \mathrm{~m}$ right of DS senter, \\
16.5 .
\end{tabular} & $0.00 \% 2$ & $-0.00 \% 2$ & 0.0972 & 0.2527 & 0.0000 & 12.8936 & 31.9094 \\
\hline 44 & & $\begin{array}{l}27 \text { sm left of DS senter, } \\
33 \text {. }\end{array}$ & 0.0026 & -0.0026 & 0.1410 & $0.2 \$ 14$ & 0.0000 & 54.9116 & 108.6068 \\
\hline 45 & & $\begin{array}{l}27 \text { em riaht of DS eenter, } \\
33^{\circ}\end{array}$ & 0.0020 & -0.0020 & -0.0020 & -0.0020 & 0.0000 & 0.0000 & 0.0000 \\
\hline 46 & & $\begin{array}{l}54 \text { em left af DS senter, } \\
33\end{array}$ & $0.56 \$ 2$ & 0.4318 & 0.4318 & 0.0948 & 1.7600 & 1.7600 & 1.1668 \\
\hline 47 & & $\begin{array}{l}54 \text { sm left of DS senter, } \\
33^{\circ}\end{array}$ & 0.8217 & $0.17 \$ 3$ & $0.17 \% 3$ & $-0.15 \& 8$ & 1.2170 & 1.2170 & 0.8068 \\
\hline 48 & & $\begin{array}{l}27 \text { em left of DS senter, } \\
33 \text {. }\end{array}$ & 0.0123 & -0.0123 & 0.1313 & 0.2717 & 0.0000 & 11.7079 & 23.1564 \\
\hline 49 & & $\begin{array}{l}27 \text { em riaht of DS eenter, } \\
33^{\circ}\end{array}$ & 0.0000 & 0.0000 & 0.0000 & 0.0000 & & & \\
\hline 50 & & Mosn & 0.2947 & 0.1551 & 0.1399 & 0.0564 & 10.8887 & 19.3710 & 22.5256 \\
\hline 51 & & Std.Dov. & 0.3683 & 0.1670 & 0.1938 & 0.2596 & $38.26 \% 1$ & 56.0050 & 51.4010 \\
\hline 52 & & Modian & 0.0142 & $0.17 \% 3$ & 0.1105 & 0.0461 & 1.2492 & 1.2492 & 1.0724 \\
\hline 53 & & Minimum & 0.0000 & -0.0657 & -0.1993 & -0.4321 & 0.00000 & 0.0000 & 0.00000 \\
\hline 54 & & Maximum & 1.0657 & 0.5197 & 0.4318 & 0.4360 & $1 \% 4.1115$ & $26 \% .4581$ & 231.5671 \\
\hline 55 & & & & & & & & & \\
\hline & & & & & & & & & \\
\hline
\end{tabular}

Figure D-11. Spreadsheet "Flux Split Waste Package Model," Worksheet "Summary;" Summary of Waste Package Flux Splitting Submodel Comparing Measured and Calculated Breach Flows 
Lastly, a plot in Worksheet "Summary" (Figure D-12) compares the calculated $f_{\text {calc }}$ with the measured $f_{\text {expt }}$ for the minimum, mean, and maximum spread angles; the $f_{\text {expt }}$ and $f_{\text {calc }}$ values that are plotted in Figure D-12 are shown in Figure D-10. The diagonal line in the plot represents $f_{\text {calc }}=f_{\text {expt }}$. Most values of $f_{\text {calc }}$ lie above the line $f_{\text {calc }}=f_{\text {expt }}$, indicating that the waste package flux splitting submodel tends to overestimate the flow into breaches.

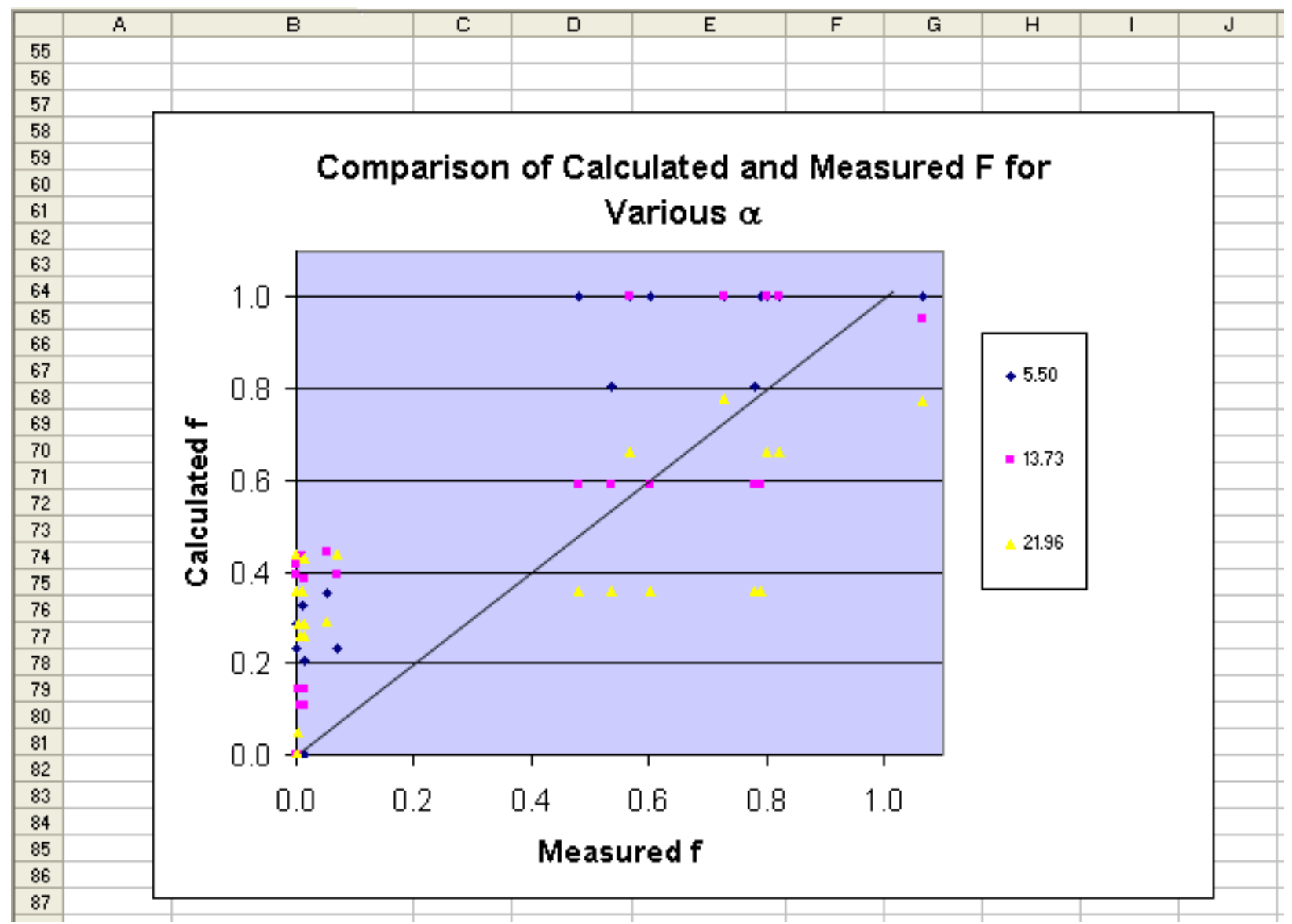

Figure D-12. Spreadsheet "Flux Waste Package Shield Model," Worksheet "Summary;" Comparison of Calculated and Measured Breach Flow Fractions for Waste Package Flux Splitting Submodel for Minimum $\left(5.50^{\circ}\right)$, Mean $\left(13.73^{\circ}\right)$, and Maximum $\left(21.96^{\circ}\right)$ Rivulet Spread Angles 


\section{APPENDIX E}

MICROSOFT EXCEL SPREADSHEET “FLUX SPLITTING VALIDATION” 


\section{MICROSOFT EXCEL SPREADSHEET “FLUX SPLITTING VALIDATION”}

\section{SPREADSHEET “FLUX SPLITTING VALIDATION"-WORKSHEET “SPLASH RAD VS NUMBER”}

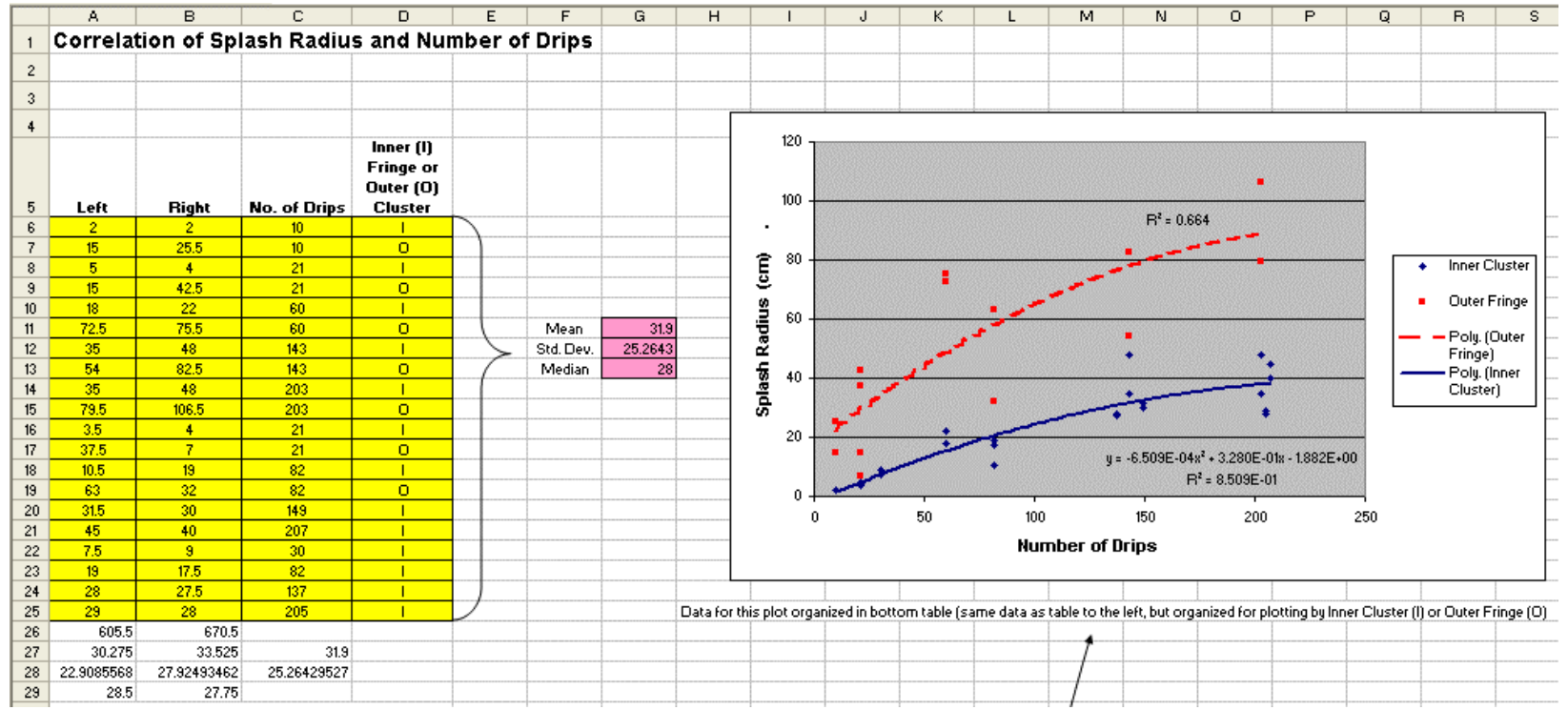

Figure E-1. Spreadsheet "Flux Splitting Validation"-Worksheet "Splash Rad vs Number;" Effect of Number of Drips on Splash Radius

In this worksheet (Figures E-1 to E-3), the effect of the number of drips on the splash radius is analyzed using data from dripping on the crown in the rough drip shield tests. This analysis is used for validation of the drip shield flux splitting submodel. The splash distance or radius $(\mathrm{cm})$ to the left and to the right of the drip location are listed in Columns A and B, respectively. The number of drips in each test is given in Column C. The type of measurement-inner cluster (I) or outer fringe $(\mathrm{O})$-is indicated in Column $\mathrm{D}$. These data and the DTN from which they were obtained (MO0207EBSATBWP.021 [DIRS 163399]) are also presented in Table 7.1-1. In Row 26, the sum of the splash radii is shown. Rows 27, 28, and 29 give the mean, standard deviation, and median for each column. The mean, standard deviation, and median for all 40 splash radius measurements are listed in Column G, Rows 11, 12, and 13, respectively.

The plot to the right in Figure E-1, which is reproduced as Figure 7.1-1, shows the dependence of splash radius on the number of drips. As indicated beneath the figure, the data are the same as in the table, but organized by type of measurement further down in this worksheet. The Trendline tool in Microsoft Excel is used to fit a quadratic curve to the inner cluster and outer fringe data. The correlation coefficient is shown for each curve, and the correlation equation is shown for the inner cluster curve. A second degree polynomial was chosen for the Trendline in order to display the expected behavior-the splash radius should increase with the number of drips, but eventually reach a maximum. A functional form such as $y=y_{\max }\left(1-e^{-a x}\right)$ may be more appropriate, but because this is nonlinear in the fitting parameter $a$, a simple linear least squares fit using Trendline is not possible. Since the object is simply to demonstrate a correlation, a more accurate fit to the data is not necessary. 
In Figure E-2, the experimental data from the top of the worksheet are reorganized by type of measurement and, in Figure E-3, all left and right measurements are consolidated for plotting in the plot at the top of the worksheet (shown in Figure E-1).

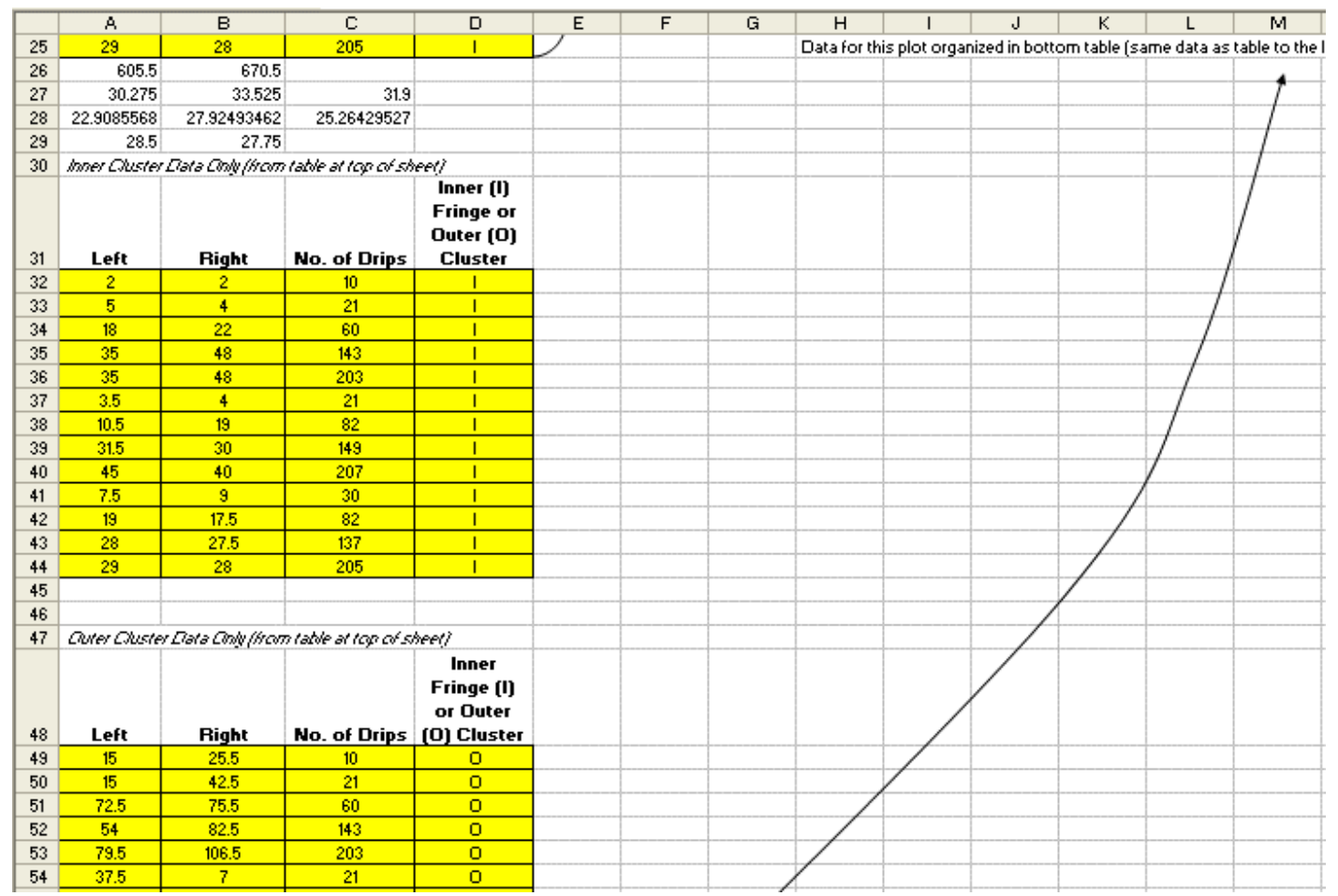

Figure E-2. Spreadsheet "Flux Splitting Validation"-Worksheet "Splash Rad vs Number;" Effect of Number of Drips on Splash Radius; Data Organized by Type of Measurement 


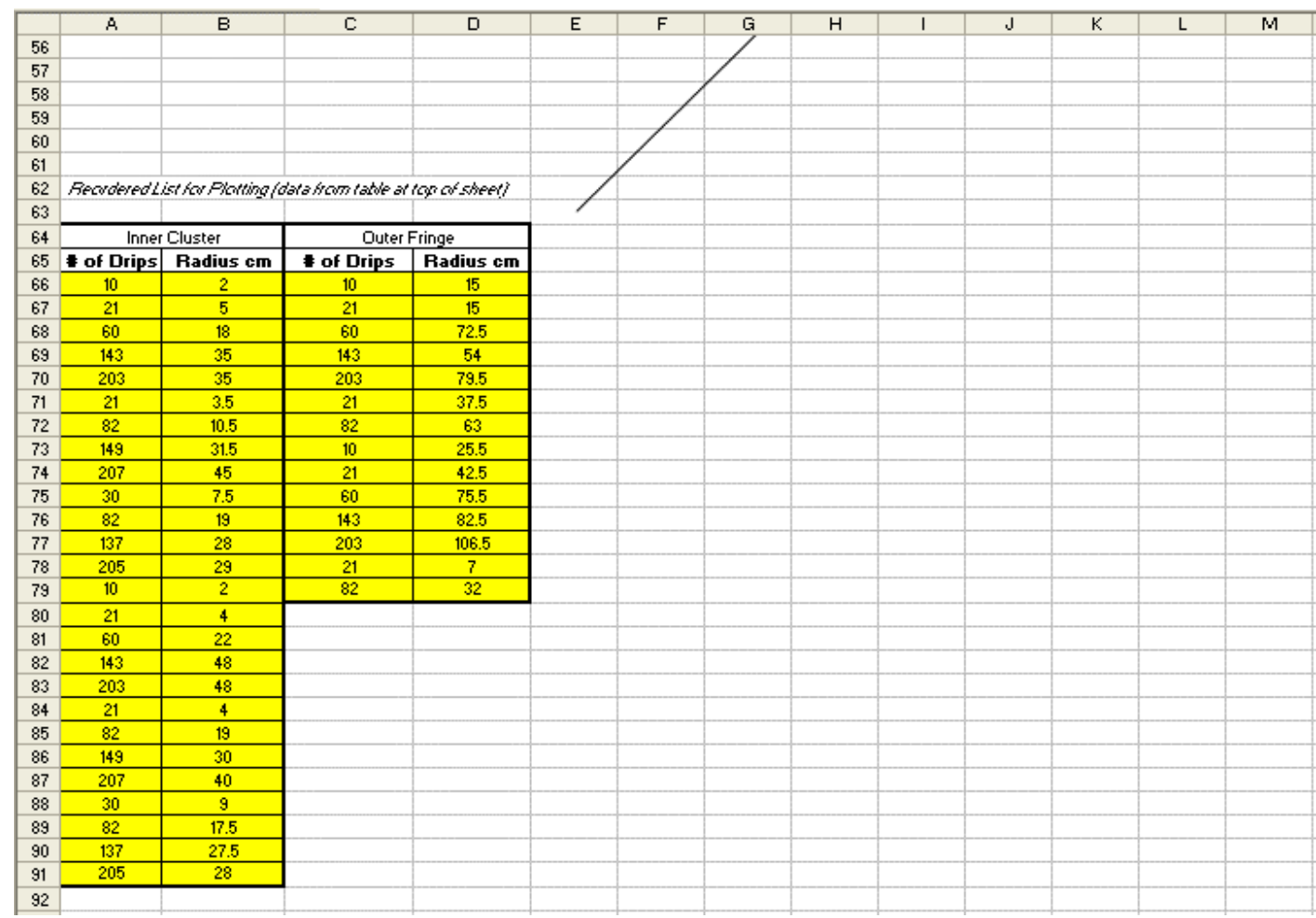

Figure E-3. Spreadsheet "Flux Splitting Validation"-Worksheet "Splash Rad vs Number;" Effect of Number of Drips on Splash Radius; All Left and Right Measurements Are Consolidated

\section{SPREADSHEET “FLUX SPLITTING VALIDATION”-WORKSHEET “SPLASH RADIUS”}

For validation of the drip shield and waste package flux splitting submodels, splash radius data are analyzed for measurements on the rough drip shield surface, with dripping on the crown and at off-crown locations. Data for crown drip locations are used for the drip shield submodel validation, and off-crown drip locations are used for the waste package submodel validation. The statistics (mean, standard deviation, median, mean plus one standard deviation, and mean minus one standard deviation) are shown in Column I, Rows 19-23 for crown drip locations, and in Rows 37-41 for off-crown locations. The data actually used in the model validation are the minimum and maximum values for more than 20 drips, Cells H11 and I9, respectively, for crown locations, and Cells H31 and I36, respectively, for off-crown locations. 


\begin{tabular}{|c|c|c|c|c|c|c|c|c|c|c|c|c|c|c|}
\hline & $\mathrm{A}$ & $\mathrm{B}$ & C & $\mathrm{D}$ & $\mathrm{E}$ & $\mathrm{F}$ & $\mathbf{G}$ & $\mathrm{H}$ & 1 & $\mathrm{~J}$ & $\mathrm{~K}$ & $\mathrm{~L}$ & $M$ & $N$ \\
\hline 1 & \multicolumn{14}{|c|}{ Splash Radius Determination, Rough Drip Shield Surface, Dripping on Crown } \\
\hline 2 & & & & & & & & & & & & & & \\
\hline 3 & \multicolumn{14}{|c|}{ Source Data } \\
\hline 4 & \multicolumn{14}{|c|}{ Calculated results } \\
\hline 5 & & & & & & & \# Drips & Left (cm) & Right (cm) & & & & & \\
\hline 6 & \multicolumn{5}{|c|}{ Splash Radius Test \#1 - Rough DS Surface - Crown } & & 10 & 2.0 & 2.0 & & & & & \\
\hline 7 & & & & & & & 21 & 5.0 & 4.0 & & & & & \\
\hline 8 & & & & & & & 60 & 18.0 & 22.0 & & & & & \\
\hline 9 & & & & & & & 143 & 35.0 & 48.0 & & & & & \\
\hline 10 & & & & & & & 203 & 35.0 & 48.0 & & & & & \\
\hline 11 & \multicolumn{5}{|c|}{ Splash Radius Test \#2 - Rough DS Surface - Crown } & & 21 & 3.5 & 4.0 & & & & & \\
\hline 12 & & & & & & & 82 & 10.5 & 19.0 & & & & & \\
\hline 13 & & & & & & & 149 & 31.5 & 30.0 & & & & & \\
\hline 14 & & & & & & & 207 & 45.0 & 40.0 & & & & & \\
\hline 15 & \multicolumn{5}{|c|}{ Splash Radius Test \#3 - Rough DS Surface - Crown } & & 30 & 7.5 & 9.0 & & & & & \\
\hline 16 & & & & & & & 82 & 19.0 & 17.5 & & & & & \\
\hline 17 & & & & & & & 137 & 28.0 & 27.5 & & & & & \\
\hline 18 & & & & & & & 205 & 29.0 & 28.0 & & & & & \\
\hline 19 & & & & & & & & Mean & 21.8 & & & & & \\
\hline 20 & & & & & & & & Std. Dev. & 14.8228 & & & & & \\
\hline 21 & & & & & & & & Median & 20.5 & & & & & \\
\hline 22 & & & & & & & & Mean-SD & 7.023354 & & & & & \\
\hline 23 & & & & & & & & Mean+SD & 36.66895 & & & & & \\
\hline \multicolumn{15}{|l|}{24} \\
\hline \multicolumn{15}{|l|}{25} \\
\hline 26 & \multicolumn{12}{|c|}{ Splash Radius Determination, Rough Drip Shield Surface, Dripping off Crown } & & \\
\hline 27 & & & & & & & & & & & & & & \\
\hline 28 & \multicolumn{14}{|c|}{ Source Data } \\
\hline 29 & \multicolumn{14}{|c|}{ Calculated results } \\
\hline 30 & & & & & & & \# Drips & Left (cm) & Right [cm] & & & & & \\
\hline 31 & \multicolumn{5}{|c|}{ Splash Radius Test \#4 - Rough DS Surface - 33 degrees } & & 31 & 3 & 3.5 & & & & & \\
\hline 32 & & & & & & & 82 & 5.5 & 6 & & & & & \\
\hline 33 & & & & & & & 158 & 6.5 & 6.5 & $\succ$ & \multicolumn{4}{|c|}{ DTN: M00207EBSATBYP.021 } \\
\hline 34 & \multicolumn{5}{|c|}{ Splash Radius Test \#5 - Rough DS Surface - 16.5 degrees } & & 22 & 9 & 10 & & & & & \\
\hline 35 & & & & & & & 82 & 13 & 14.5 & & & & & \\
\hline 36 & & & & & & & 156 & 14 & 15 & & & & & \\
\hline 37 & & & & & & & & Mean & 8.875 & & & & & \\
\hline 38 & & & & & & & & Std. Dev. & 4.349112 & & & & & \\
\hline 39 & & & & & & & & Median & 7.75 & & & & & \\
\hline 40 & & & & & & & & Mean-SD & 4.525888 & & & & & \\
\hline 41 & & & & & & & & Mean+SD & 13.22411 & & & & & \\
\hline 42 & & & & & & & & & & & & & & \\
\hline
\end{tabular}

DTN: MO0207EBSATBWP.021 [DIRS 163399].

Figure E-4. Spreadsheet "Flux Splitting Validation"-Worksheet "Splash Radius;" Splash Radius Determination 


\section{SPREADSHEET “FLUX SPLITTING VALIDATION”-WORKSHEET “ROUGH DS”}

This worksheet provides calculations for validation of the drip shield flux splitting submodel based on data from rough drip shield surface tests. An overall view of the worksheet is shown in Figure E-5 to show the layout of the worksheet, and individual tables are then presented more legibly and described in detail on following pages.

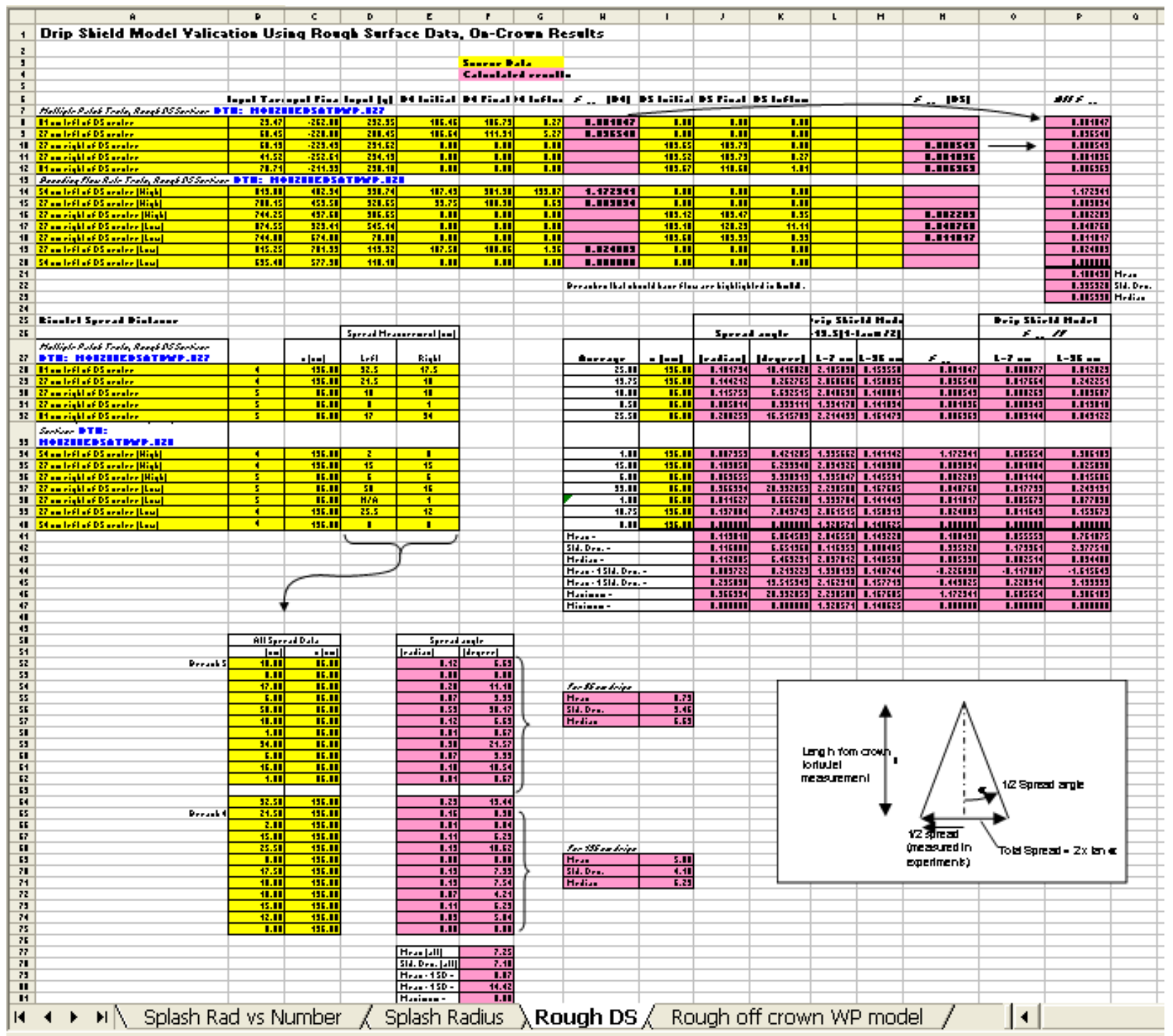

DTN: MO0208EBSATBWP.027 [DIRS 163404]; DTN: MO0208EBSATBWP.028 [DIRS 163405].

Figure E-5. Spreadsheet "Flux Splitting Validation"-Worksheet "Rough DS;" Worksheet Overview 


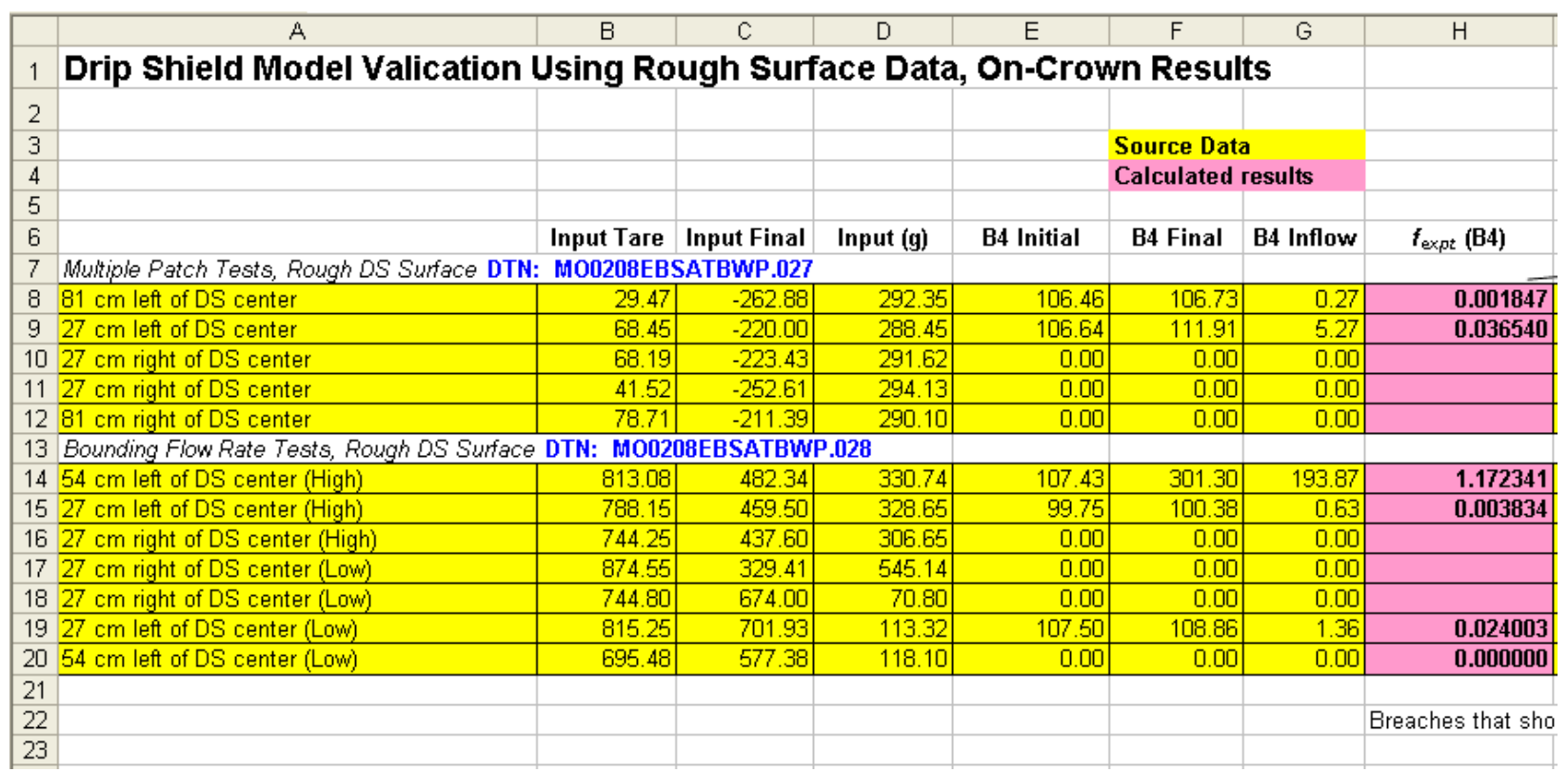

DTN: MO0208EBSATBWP.027 [DIRS 163404]; DTN: MO0208EBSATBWP.028 [DIRS 163405].

Figure E-6. Spreadsheet "Flux Splitting Validation"-Worksheet "Rough DS;" Calculation of Experimental Breach Flow Fractions

\begin{tabular}{|c|c|c|c|c|c|c|c|c|c|c|}
\hline & $\mathrm{H}$ & 1 & $J$ & $\mathrm{~K}$ & $\mathrm{~L}$ & $M$ & $\mathrm{~N}$ & 0 & $\mathrm{P}$ & $Q$ \\
\hline \multicolumn{11}{|l|}{1} \\
\hline \multicolumn{11}{|l|}{2} \\
\hline \multicolumn{11}{|l|}{3} \\
\hline \multicolumn{11}{|l|}{4} \\
\hline \multicolumn{11}{|l|}{5} \\
\hline 6 & $f_{\text {red }}[\mathrm{B4}]$ & B5 Initial & B5 Final & B5 Infloy & & & $f_{\text {mef }}$ [B5] & & AXf & \\
\hline \multicolumn{11}{|l|}{7} \\
\hline 8 & 0.001847 & 0.00 & 0.00 & 0.00 & & & & & 0.001847 & \\
\hline 9 & 0.036540 & 0.00 & 0.00 & 0.00 & & & & & 0.036540 & \\
\hline 10 & & 109.65 & 109.73 & 0.08 & & & 0.000549 & $\longrightarrow$ & 0.000549 & \\
\hline 11 & & 109.52 & 109.79 & 0.27 & & & 0.001836 & & 0.001836 & \\
\hline 12 & & 109.67 & 110.68 & 1.01 & & & 0.006963 & & 0.006963 & \\
\hline \multicolumn{11}{|l|}{13} \\
\hline 14 & 1.172341 & 0.00 & 0.00 & 0.00 & & & & & 1.172341 & \\
\hline 15 & 0.003834 & 0.00 & 0.00 & 0.00 & & & & & 0.003834 & \\
\hline 16 & & 109.12 & 109.47 & 0.35 & & & 0.002283 & & 0.002283 & \\
\hline 17 & & 109.18 & 120.29 & 11.11 & & & 0.040760 & & 0.040760 & \\
\hline 18 & & 109.60 & 109.99 & 0.39 & & & 0.011017 & & 0.011017 & \\
\hline 19 & 0.024003 & 0.00 & 0.00 & 0.00 & & & & & 0.024003 & \\
\hline 20 & 0.000000 & 0.00 & 0.00 & 0.00 & & & & & 0.000000 & \\
\hline 21 & & & & & & & & & 0.108498 & Mean \\
\hline 22 & \multicolumn{4}{|c|}{ Breaches that should have flow are highlighted in bold. } & & & & & 0.335328 & Std. Dev. \\
\hline 23 & & & & & & & & & 0.005398 & Median \\
\hline
\end{tabular}

Figure E-7. Spreadsheet "Flux Splitting Validation"-Worksheet "Rough DS;" Summary of Experimental Breach Flow Fractions 
Tests are identified in Figure E-6 in Column A. Columns B and C are raw data-the initial and final water mass in the input water container. Column D is the difference between Columns B and $\mathrm{C}$ (e.g., D8=B8-C8), giving the mass of water dripped onto the drip shield. Columns $\mathrm{E}$ and $\mathrm{F}$ are the initial and final masses of water in the Breach B4 collection vessel. The difference, in Column G (e.g., G8=F8-E8), is the mass of water that flowed into B4. In Column $\mathrm{H}$ (Figure E-7), the fraction of the dripping flux that flowed into B4, $f_{\text {expt }}$ (B4), is calculated for tests in which the flow into B4 was greater than zero (e.g., H8=2*G8/D8). Because the dripping was onto the crown, it is assumed that only half of the total input (i.e., D8/2) flowed down the side of the drip shield where B4 was located.

Columns I and $\mathrm{J}$ are the initial and final masses of water in the Breach $\mathrm{B} 5$ collection vessel. The difference, in Column $\mathrm{G}$ (e.g., $\mathrm{K} 8=\mathrm{J8}-18$ ), is the mass of water that flowed into B5. In Column $\mathrm{N}$, the fraction of the dripping flux that flowed into B5, $f_{\text {expt }}$ (B5), is calculated for tests in which the flow into B5 was greater than zero (e.g., N10=2*K10/D10). Because the drip location was the crown, it is assumed that only half of the total input (i.e., D10/2) flowed down the side of the drip shield where B5 was located.

The input water mass and flows into Breaches B4 and B5 are summarized in Table 7.1-3.

In Column $\mathrm{P}$, all values of $f_{\text {expt }}$ are consolidated. The mean, standard deviation, and median for the 12 data values are given in Rows 21, 22, and 23, respectively. The values of $f_{\text {expt }}$ are listed in Table 7.1-4.

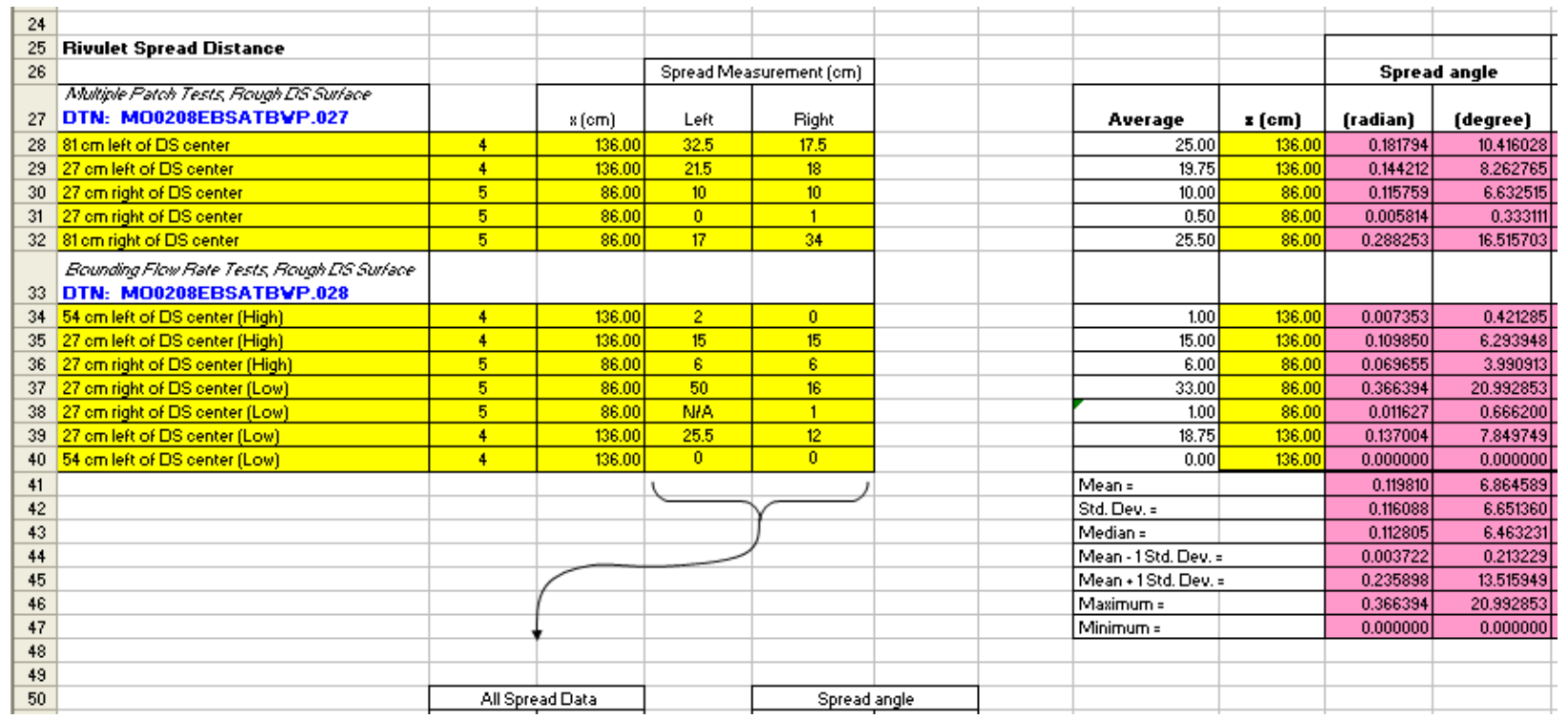

DTN: MO0208EBSATBWP.027 [DIRS 163404]; DTN: MO0208EBSATBWP.028 [DIRS 163405].

Figure E-8. Spreadsheet "Flux Splitting Validation"-Worksheet "Rough DS;" Rivulet Spread Distances

Rivulet spread distances for each test are listed in Figure E-8, Columns D and E, Rows 28-40, for drips originating on the crown of the rough drip shield surface. The spread data are reorganized in Column B, starting in Row 52 (see Figure E-9). All spread data measured $86 \mathrm{~cm}$ from the drip 
location are listed first, followed by all data measured $136 \mathrm{~cm}$ from the drip location. The corresponding $x$-distance is listed in Column C, starting in Row 52. In Column E, the spread distances, $w_{r}$, are converted to spread angles using the formula:

$$
\alpha=\tan ^{-1}\left(\frac{w_{r}}{x}\right) .
$$

In Cell E52, for example, the Microsoft Excel equation is: E52=ATAN(B52/C52). The result is the spread angle in radians, which is converted to degrees in Column $F$ (e.g., F52=DEGREES(E52)). The mean spread angle for 86-cm drips is given in Cell I55 (I55=AVERAGE(F52:F63)) and for 136-cm drips in Cell I69 (I69=AVERAGE(F65:F75)). Statistics are computed for all individual spread angle data in Column F, Rows 77-82:

$$
\begin{aligned}
& F 77=A V E R A G E(F 52: F 75) \\
& F 78=S T D E V A(F 52: F 75) \\
& F 79=F 77-F 78 \\
& F 80=F 77+F 78 \\
& \text { F81=MIN(F52:F75) } \\
& \text { F82=MAX(F52:F75) }
\end{aligned}
$$

As shown in F79 and F80, the range for the spread angle is zero (rounding down) to $14.4^{\circ}$.

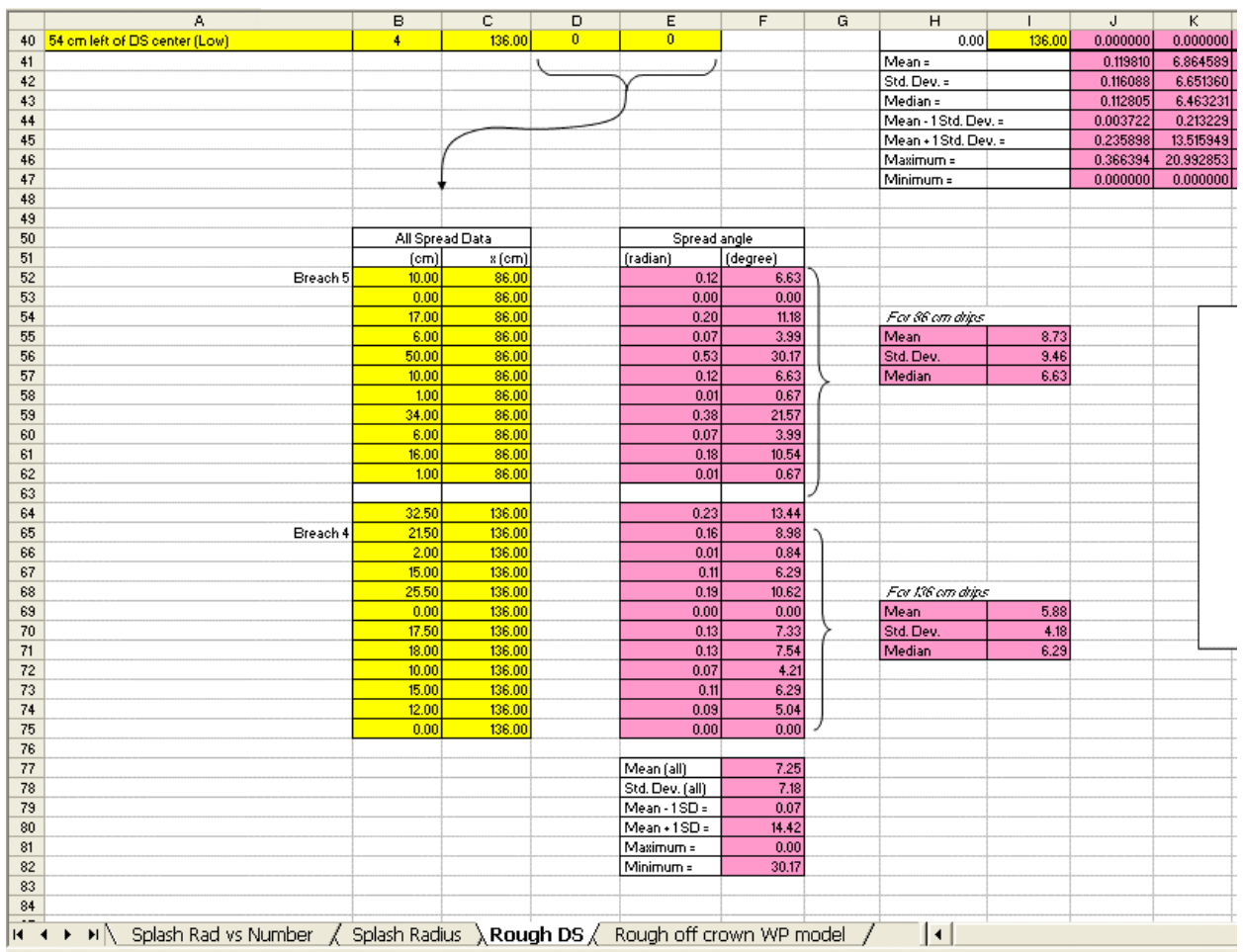

Figure E-9. Spreadsheet "Flux Splitting Validation"-Worksheet "Rough DS;" Rivulet Spread Data Reorganized 


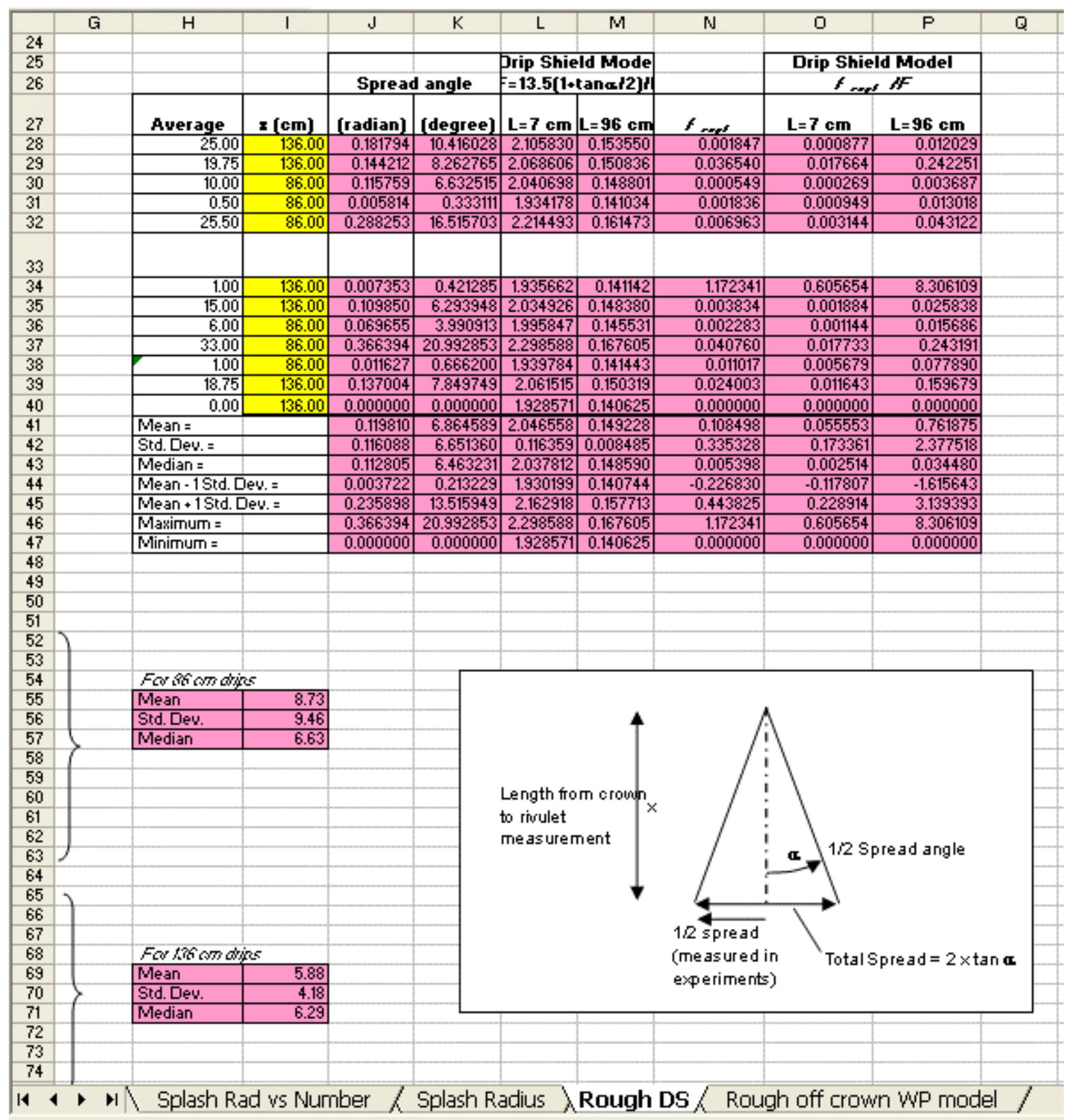

Figure E-10. Spreadsheet "Flux Splitting Validation"-Worksheet "Rough DS;" Calculation of Rivulet Spread Angles

In Column H, Rows 28-40 (see Figure E-10), the average rivulet spread is computed for each experiment (e.g., H28=(D28+E28)/2). Column I is the distance from the crown to the point where the rivulet spread was measured (identical to Column $\mathrm{C}$ ). The spread angle is computed in Column J, Rows 28-40, (e.g., J28=ATAN(H28//28)). In Column K, Rows 28-40, the 
average spread angle in radians is converted to degrees (e.g., K28=DEGREES(J28)). In Worksheet "Splash Rad vs Number," the minimum splash radius for tests using 20 or more drips was $3.5 \mathrm{~cm}$, for a total splash distance of $7 \mathrm{~cm}$. This is used as the effective drip shield length in Column L, where $f_{\text {calc }}$ is obtained using the formula

$$
\begin{aligned}
f_{\text {calc }} & =\frac{\ell}{L}\left(1+\frac{\tan \alpha}{2}\right) \\
& =\frac{13.5}{7}\left(1+\frac{\tan \alpha}{2}\right)
\end{aligned}
$$

\section{$\mathrm{L} 28=13.5^{\star}(1+\mathrm{TAN}(\mathrm{J} 28) / 2) / 7$}

The maximum splash radius tests using 20 or more drips was $48 \mathrm{~cm}$ in Worksheet "Splash Rad vs. Number," giving a total splash distance of $96 \mathrm{~cm}$. This is used as the effective drip shield length in Column M:

$$
\begin{aligned}
& f_{\text {calc }}=\frac{\ell}{L}\left(1+\frac{\tan \alpha}{2}\right) \\
&=\frac{13.5}{96}\left(1+\frac{\tan \alpha}{2}\right) \\
& \mathrm{M} 28=13.5^{\star}(1+\operatorname{TAN}(\mathrm{J} 28) / 2) / 96
\end{aligned}
$$

The values of $f_{\text {calc }}$ in Columns $\mathrm{L}$ and $\mathrm{M}$ are similar to $F / f_{V D}$ in Table 7.1-5, the only difference being the values used for spread angle. Table 7.1-5 uses the rounded values for spread angle obtained from Figure E-9, zero to $14.4^{\circ}$, whereas in Columns L and M in Figure E-10, $f_{\text {calc }}$ is calculated from a different average spread angle.. As shown in the statistics (Rows 46-47), $f_{\text {calc }}$ or $F / f_{V D}$ ranges from 0.141 to 2.30 , based on minimum and maximum average spread angles. Using the mean plus or minus one standard deviation for the spread angle, $f_{\text {calc }}$ ranges from 0.141 to 2.16 (Rows 44-45, Columns $\mathrm{L}$ and M), close to the values reported in Table 7.1-5 (0.141 to 2.17).

In Column N, Rows 28-40, the values of $f_{\text {expt }}$ are transferred from Column P, Rows 9-20. In Column $\mathrm{O}$, the ratio $f_{\text {expt }} / f_{\text {calc }}$ is computed (e.g., O28=N28/L28) for the minimum effective drip shield length of $7 \mathrm{~cm}$. In Column P, the ratio $f_{\text {expt }} / f_{\text {calc }}$ is computed (e.g., P28=N28/M28) for the maximum effective drip shield length of $96 \mathrm{~cm}$. This ratio is identical to the uncertainty factor $f_{V D}$ in Equation 7.1.1.1-2. As shown in the statistics (Rows 46-47), $F / f_{V D}$ for the experimental data ranges from 0.0 to 8.306 


\section{SPREADSHEET “FLUX SPLITTING VALIDATION”-WORKSHEET “ROUGH OFF CROWN WP MODEL”}

This worksheet provides calculations for validation of the waste package flux splitting submodel based on data from the rough drip shield surface tests. An overall view of the worksheet is shown in Figure E-11, and individual tables are then described in detail.

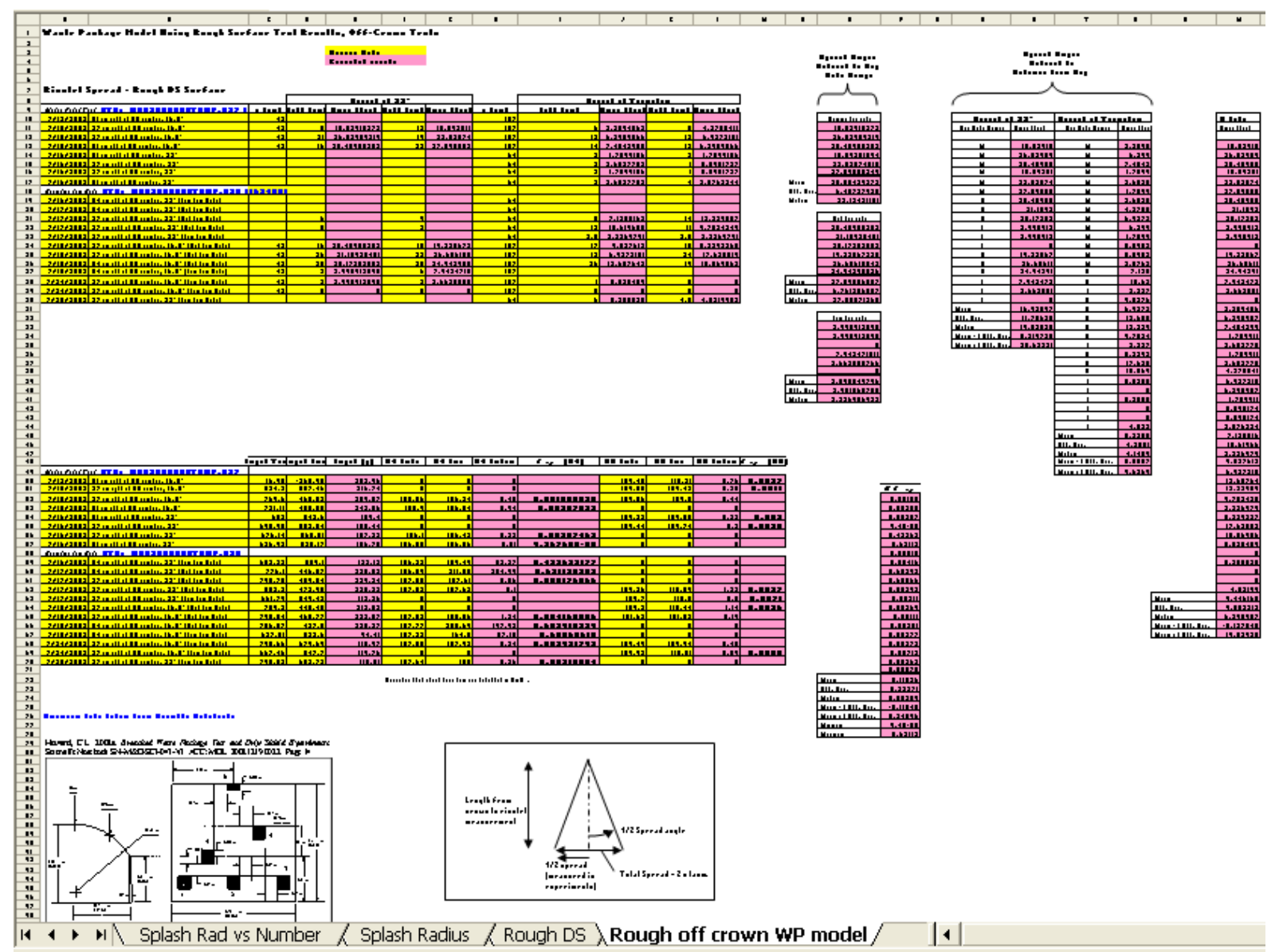

Figure E-11. Spreadsheet "Flux Splitting Validation"-Worksheet "Rough off crown WP model;" Worksheet Overview 


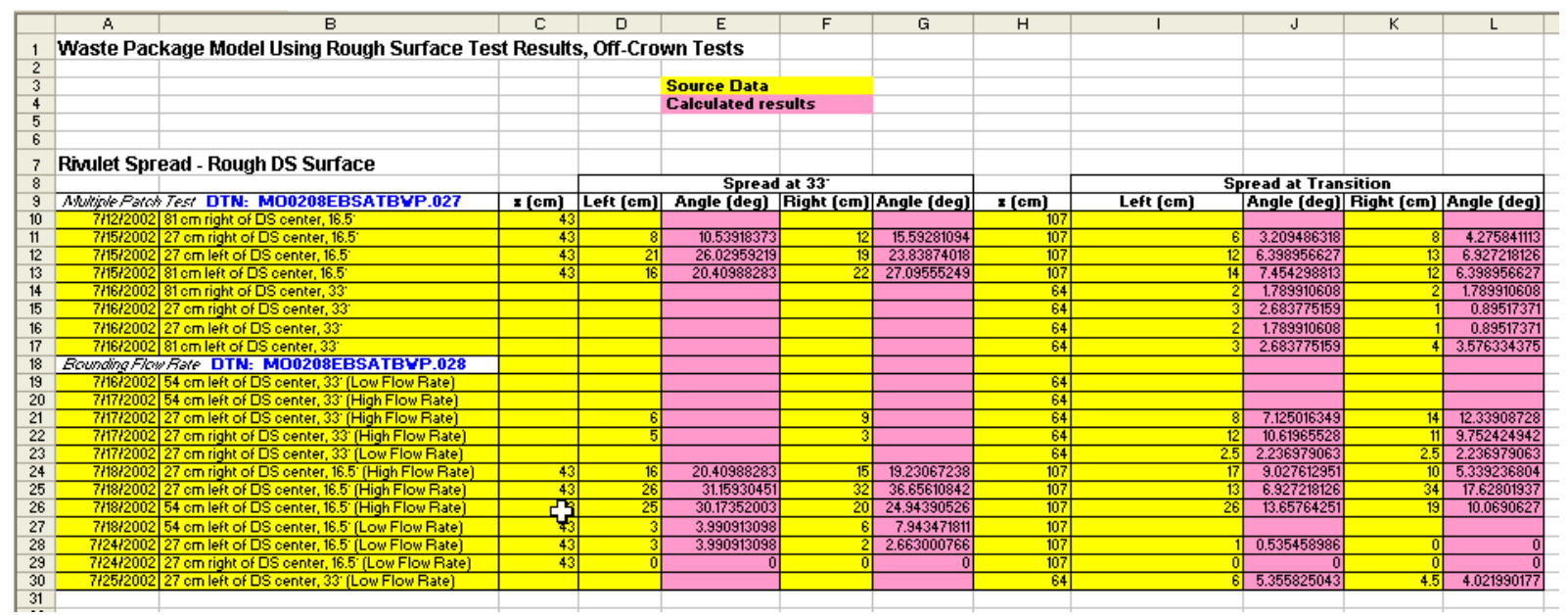

DTN: MO0208EBSATBWP.027 [DIRS 163404]; DTN: MO0208EBSATBWP.028 [DIRS 163405].

Figure E-12. Spreadsheet "Flux Splitting Validation"-Worksheet "Rough off crown WP model;" Calculation of Rivulet Spread Angles

In Figure E-12, Columns A and B, Rows 10-30, identify the tests reported in indicated DTNs. In Columns $\mathrm{C}$ and $\mathrm{H}$, the value of $x$, the distance from the drip location to the measurement point, is listed. Rivulet spread measured to the left and right of the drip location is shown in Columns D and F, respectively, for measurements at the $33^{\circ}$ line. Measurements at the transition line are listed in Columns I and K. Portions of this table are reproduced in Table 7.1-8.

The spread distance, $w_{r}$, is converted to spread angle, $\alpha$, in Columns E, G, J, and L:

$$
\alpha=\tan ^{-1}\left(\frac{w_{r}}{x}\right)
$$

An example of the Microsoft Excel equation used for this calculation is:

\section{E11=DEGREES(ATAN(D11/C11))}

where the DEGREES function converts the result of the inverse tangent function ATAN from radians to degrees.

In Figure E-13, Column O, Rows 11-38, the spread angles measured at the $33^{\circ}$ line are ordered by drip rate. The "nominal" drip rate is that used in the Multiple Patch tests, and the high and low drip rates were used in the Bounding Flow Rate tests. The mean, standard deviation, and median are computed for each of the three drip rates.

In Column S, the spread angles from Column $\mathrm{O}$ are repeated, and statistics (mean, standard deviation, median, and mean plus or minus one standard deviation) are computed for the entire set in Rows 31-35. The drip rate is indicated in Column $\mathrm{R}$, where " $\mathrm{M}$ " indicates the nominal drip rate. 
In Column U, the spread angles from Columns $\mathrm{J}$ and $\mathrm{L}$ are consolidated for measurements at the transition line. The drip rate used in each test is indicated in Column T. (The values in this column are currently incorrect, since they are just copies of the incorrect results in Column L and incorrectly recalculated values from Column J, where the actual Column J values are correct.)

All 50 spread angle measurements are compiled in Column W, with statistics (mean, standard deviation, median, and mean plus or minus one standard deviation) computed for the entire set in Rows 63-67 (Figure E-14). The mean plus or minus one standard deviation are used as the spread angle range in Section 7.1.1.2 for determination of the uncertainty in the waste package flux splitting submodel validation.

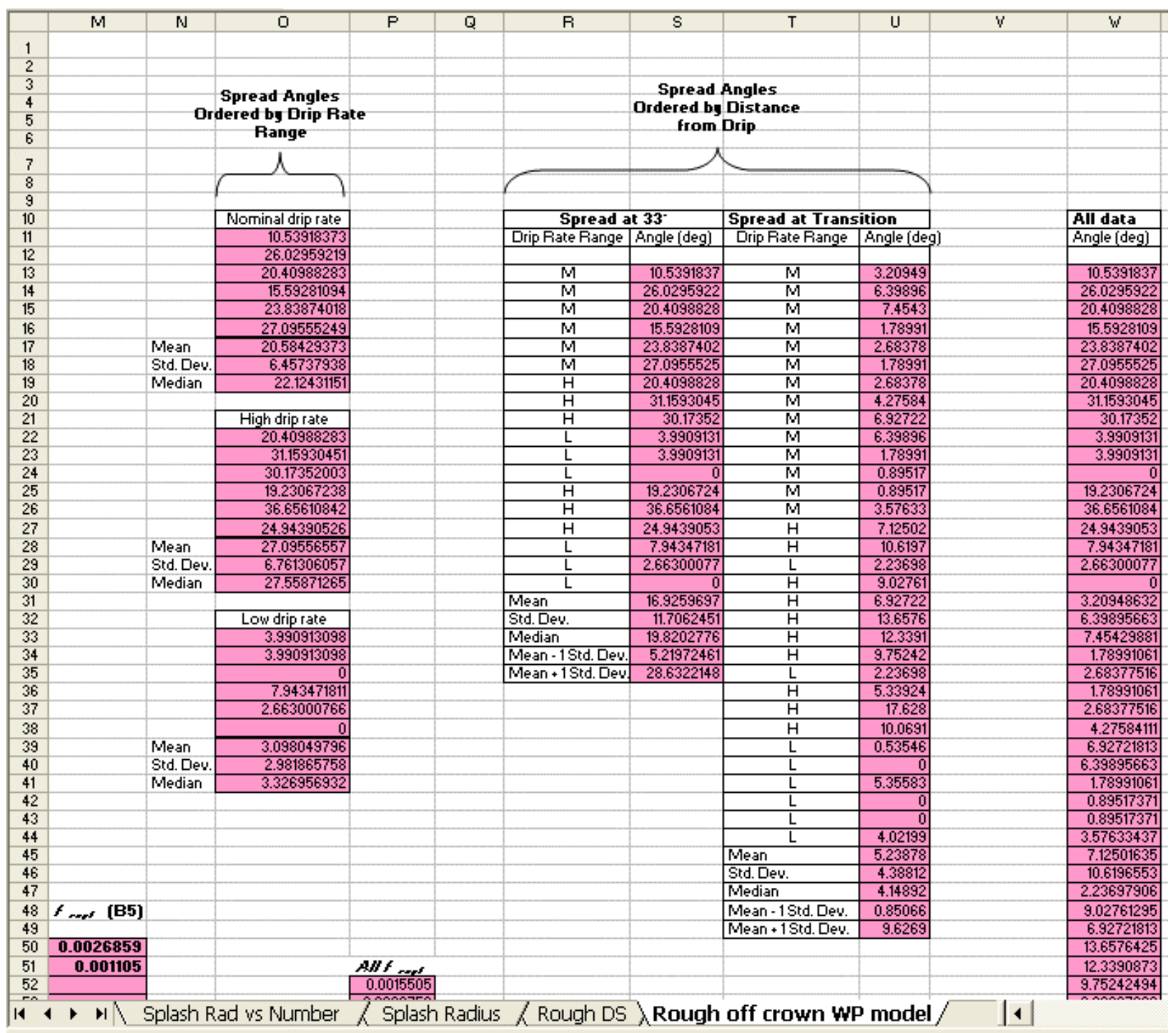

Figure E-13. Spreadsheet "Flux Splitting Validation"-Worksheet "Rough off crown WP model;" Additional Calculations of Rivulet Spread Angles 


\begin{tabular}{|c|c|c|c|c|c|}
\hline & $\mathrm{S}$ & $\mathrm{T}$ & U & $\mathrm{V}$ & 'W' \\
\hline 45 & & Mean & 5.23878 & & 7.12501635 \\
\hline 46 & & Std. Dev. & 4.38812 & & 10.6196553 \\
\hline 47 & & Median & 4.14892 & & 2.23697906 \\
\hline 48 & & Mean-1Std. Dev. & 0.85066 & & 9.02761295 \\
\hline 49 & & Mean + 1Std. Dev. & 9.6269 & & 6.92721813 \\
\hline 50 & & & & & 13.6576425 \\
\hline 51 & & & & & 12.3390873 \\
\hline 52 & & & & & 9.75242494 \\
\hline 53 & & & & & 2.23697906 \\
\hline 54 & & & & & 5.3392368 \\
\hline 55 & & & & & 17.6280194 \\
\hline 56 & & & & & 10.0690627 \\
\hline 57 & & & & & 0.53545899 \\
\hline 58 & & & & & 0 \\
\hline 59 & & & & & 5.35582504 \\
\hline 60 & & & & & 0 \\
\hline 61 & & & & & 0 \\
\hline 62 & & & & & 4.02199018 \\
\hline 63 & & & & Mean & 9.4461677 \\
\hline 64 & & & & Std. Dev. & 9.58321235 \\
\hline 65 & & & & Median & 6.39895663 \\
\hline 66 & & & & Mean-1Std. Dev. & -0.1370447 \\
\hline 67 & & & & Mean + 1Std. Dev. & 19.02938 \\
\hline
\end{tabular}

Figure E-14. Spreadsheet "Flux Splitting Validation"-Worksheet "Rough off crown WP model;" Statistics of Rivulet Spread Angles

\begin{tabular}{|c|c|c|c|c|c|c|c|c|c|}
\hline & A & $\mathrm{B}$ & C & D & $E$ & $F$ & G & $\mathrm{H}$ & 1 \\
\hline \multicolumn{10}{|l|}{47} \\
\hline 48 & & & \multicolumn{2}{|c|}{ Input Tarelnput Fina } & Input (g] & B4 Initial & B4 Final & B4 Infloy & $f_{\text {raf }}$ [B4] \\
\hline 49 & Alutiole Poral & 7est DTN: M00208EBSATBYP.027 & & & & & & & \\
\hline 50 & $7 / 12+2002$ & $81 \mathrm{~cm}$ right of DS center, $16.5^{\circ}$ & 16.98 & -265.98 & 282.96 & 0 & 0 & 0 & \\
\hline 51 & $7+15+2002$ & $27 \mathrm{~cm}$ right of DS center, $16.5^{\circ}$ & 824.2 & 507.46 & 316.74 & 0 & 0 & 0 & \\
\hline 52 & $7+15+2002$ & $27 \mathrm{~cm}$ left of DS center, $16.5^{\circ}$ & 769.6 & 460.03 & 309.57 & 105.86 & 106.34 & 0.48 & 0.001550538 \\
\hline 53 & $7115+2002$ & $81 \mathrm{~cm}$ left of DS center, $16.5^{\circ}$ & 731.11 & 488.55 & 242.56 & 105.9 & 106.84 & 0.94 & 0.00387533 \\
\hline 54 & $7+16+2002$ & $81 \mathrm{~cm}$ right of DS center, $33^{\circ}$ & 652 & 542.6 & 109.4 & 0 & 0 & 0 & \\
\hline 55 & $7+16+2002$ & $27 \mathrm{~cm}$ right of DS center, $33^{\circ}$ & 690.98 & 582.54 & 108.44 & 0 & 0 & 0 & \\
\hline 56 & $7+16+2002$ & $27 \mathrm{~cm}$ left of DS center, $33^{\circ}$ & 676.14 & 568.81 & 107.33 & 106.1 & 106.43 & 0.33 & 0.00307463 \\
\hline 57 & $7116+2002$ & $81 \mathrm{~cm}$ left of DS center, $33^{\circ}$ & 636.92 & 530.17 & 106.75 & 106.05 & 106.06 & 0.01 & $9.36768 \mathrm{E}-05$ \\
\hline 58 & Elownding $F / n$ a & Ifare DTN: M00208EBSATBYP.028 & & & & & & & \\
\hline 59 & $7+16+2002$ & $54 \mathrm{~cm}$ left of DS center, 33 (Low Flow Rate) & 682.23 & 559.1 & 123.13 & 106.22 & 159.49 & 53.27 & 0.432632177 \\
\hline 60 & $7 / 17 / 2002$ & $54 \mathrm{~cm}$ left of DS center, 33 (High Flow Rate) & 776.1 & 446.07 & 330.03 & 106.09 & 311.08 & 204.99 & 0.621125352 \\
\hline 61 & $7+17 / 2002$ & $27 \mathrm{~cm}$ left of DS center, $33^{\circ}$ (High Flow Rate) & 798.78 & 459.54 & 339.24 & 107.55 & 107.61 & 0.06 & 0.000176866 \\
\hline 62 & $7+17 / 2002$ & $27 \mathrm{~cm}$ right of DS center, $33^{\prime}$ (High Flow Rate) & 803.2 & 472.98 & 330.22 & 107.52 & 107.62 & 0.1 & \\
\hline 63 & $7 / 17 / 2002$ & $27 \mathrm{~cm}$ right of DS center, 33 (Low Flow Rate) & 661.79 & 549.43 & 112.36 & 0 & 0 & 0 & \\
\hline 64 & $7 / 18+2002$ & $27 \mathrm{~cm}$ right of DS center, $16.5^{\circ}$ (High Flow Rate) & 759.3 & 445.48 & 313.82 & 0 & 0 & 0 & \\
\hline 65 & $7+18+2002$ & \begin{tabular}{|l}
$27 \mathrm{~cm}$ left of DS center, $16.5^{\circ}$ (High Flow Rate) \\
\end{tabular} & 790.84 & 468.77 & 322.07 & 107.52 & 108.86 & 1.34 & 0.004160586 \\
\hline 66 & $7+18+2002$ & $54 \mathrm{~cm}$ left of DS center, $16.5^{\circ}$ (High Flow Rate) & 756.07 & 427.8 & 328.27 & 107.77 & 305.69 & 197.92 & 0.602918329 \\
\hline 67 & $7+18+2002$ & $54 \mathrm{~cm}$ left of DS center, $16.5^{\circ}$ (Low Flow Rate) & 627.01 & 532.6 & 94.41 & 107.32 & 164.5 & 57.18 & 0.60565618 \\
\hline 68 & $7+24+2002$ & $27 \mathrm{~cm}$ left of DS center, $16.5^{\circ}$ (Low Flow Rate) & 795.66 & 679.69 & 115.97 & 107.58 & 107.92 & 0.34 & 0.002931793 \\
\hline 69 & $7+24+2002$ & $27 \mathrm{~cm}$ right of DS center, $16.5^{\circ}$ (Low Flow Rate) & 667.46 & 547.7 & 119.76 & 0 & 0 & $\overline{0}$ & \\
\hline 70 & $7+25+2002$ & $27 \mathrm{~cm}$ left of DS center, $33^{\circ}$ (Low Flow Rate) & 798.53 & 682.72 & 115.81 & 107.64 & 108 & 0.36 & 0.00310854 \\
\hline 71 & & & & & & & & & \\
\hline 72 & & & & & & Breaches th & hould have & W are highlig & n bold. \\
\hline
\end{tabular}

DTN: MO0208EBSATBWP.027 [DIRS 163404]; DTN: MO0208EBSATBWP.028 [DIRS 163405].

Figure E-15. Spreadsheet "Flux Splitting Validation"-Worksheet "Rough off crown WP model;" Calculation of Experimental Breach Flow Fractions

For the tests identified in Columns A and B, Rows 50-70 (Figure E-15), the initial and final water mass in the input water container are listed in Columns $\mathrm{C}$ and $\mathrm{D}$, and the amount of water dripped onto the drip shield is calculated in Column E (e.g., E50=C50-D50). The initial and final mass of water in the Breach B4 collection vessel is listed in Columns F and G, respectively, and the amount of water collected from flow into Breach B4 is calculated in Column $\mathrm{H}$ (e.g., H52=G52-F52). The fraction of water dripped onto the drip shield that flowed into Breach B4, $f_{\text {expt }}(\mathrm{B} 4)$, is computed in Column I for the tests in which the inflow was greater than zero (e.g., I52=H52/E52). 


\begin{tabular}{|c|c|c|c|c|c|c|c|}
\hline & $J$ & $\mathrm{~K}$ & L & $M$ & $\mathrm{~N}$ & 0 & $\mathrm{P}$ \\
\hline \multicolumn{8}{|l|}{47} \\
\hline 48 & B5 Initial & B5 Final & B5 Infloy & $f_{\text {ref }}$ [B5] & & & \\
\hline \multicolumn{8}{|l|}{49} \\
\hline 50 & 109.45 & 110.21 & 0.76 & 0.00268589 & & & \\
\hline 51 & 109.08 & 109.43 & 0.35 & 0.00110501 & & & AWF \\
\hline 52 & 109.06 & 109.5 & 0.44 & & & & 0.001550538 \\
\hline 53 & 0 & 0 & 0 & & & & 0.00387533 \\
\hline 54 & 109.33 & 109.55 & 0.22 & 0.00201097 & & & 0.00307463 \\
\hline 55 & 109.44 & 109.74 & 0.3 & 0.00276651 & & & $9.36768 \mathrm{E}-05$ \\
\hline 56 & 0 & 0 & 0 & & & & 0.432632177 \\
\hline 57 & 0 & 0 & 0 & & & & 0.621125352 \\
\hline 58 & & & & & & & 0.000176866 \\
\hline 59 & 0 & 0 & 0 & & & & 0.004160586 \\
\hline 60 & 0 & 0 & 0 & & & & 0.602918329 \\
\hline 61 & 0 & 0 & 0 & & & & 0.60565618 \\
\hline 62 & 109.36 & 110.59 & 1.23 & 0.00372479 & & & 0.002931793 \\
\hline 63 & 109.7 & 110.5 & 0.8 & 0.00711997 & & & 0.00310854 \\
\hline 64 & 109.3 & 110.44 & 1.14 & 0.00363266 & & & 0.002685892 \\
\hline 65 & 101.63 & 101.82 & 0.19 & & & & 0.001105007 \\
\hline 66 & 0 & 0 & 0 & & & & 0.002010969 \\
\hline 67 & 0 & 0 & 0 & & & & 0.002766507 \\
\hline 68 & 109.49 & 109.94 & 0.45 & & & & 0.00372479 \\
\hline 69 & 109.92 & 110.01 & 0.09 & 0.0007515 & & & 0.007119972 \\
\hline 70 & 0 & 0 & 0 & & & & 0.003632656 \\
\hline 71 & & & & & & & 0.000751503 \\
\hline 72 & & & & & & Mean & 0.115255065 \\
\hline 73 & & & & & & Std. Dev. & 0.233709623 \\
\hline 74 & & & & & & Median & 0.003091585 \\
\hline 75 & & & & & & Mean-1Std. Dev. & -0.11845456 \\
\hline 76 & & & & & & Mean+1Std. Dev. & 0.348964688 \\
\hline 77 & & & & & & Minimum & $9.36768 \mathrm{E}-05$ \\
\hline 78 & & & & & & Maximum & 0.621125352 \\
\hline
\end{tabular}

Figure E-16. Spreadsheet "Flux Splitting Validation"-Worksheet "Rough Off Crown WP Model;" Summary of Experimental Breach Flow Fractions

The initial and final mass of water in the Breach B5 collection vessel is listed in Figure E-16, Columns I and J, respectively, and the amount of water collected from flow into Breach B5 is calculated in Column L (e.g., L50=K50-J50). The fraction of water dripped onto the drip shield that flowed into Breach B5, $f_{\text {expt }}$ (B5), is computed in Column $\mathrm{M}$ for the tests in which the inflow was greater than zero (e.g., M50=L50/E50).

The 20 values of $f_{\text {expt }}$ are compiled in Column P, with statistics (mean, standard deviation, median, and mean plus or minus one standard deviation) presented in Rows 73-76.

The input water, breach inflows, and $f_{\text {expt }}$ for each breach are reproduced in Table 7.1-10. 


\section{INTENTIONALLY LEFT BLANK}




\section{APPENDIX F}

MICROSOFT EXCEL SPREADSHEETS “TRANSPORT_CALC_ALL_COLLOIDS,” “FLUX_OUT_RATIO.XLS,”AND “TIME_TO_CONV.XLS” 


\section{MICROSOFT EXCEL SPREADSHEETS “TRANSPORT_CALC_ALL_COLLOIDS," “FLUX_OUT_RATIO.XLS,”AND “TIME_TO_CONV.XLS”}

\section{SPREADSHEET “TRANSPORT_CALC_ALL_COLLOIDS.XLS”}

The purpose of this spreadsheet is to implement the colloid model that represents the sorption of radionuclides onto the oxy-hydroxide (designated $\mathrm{FeO}$ ) corrosion material within the engineered barrier system (EBS). The model accounts for both reversible and irreversible sorption onto the $\mathrm{FeO}$ mobile colloids and the immobile corrosion products together with reversible sorption onto both waste form and groundwater (GW) colloids. This description refers to equations in Appendix B, "Implementation of Radionuclide Sorption onto Colloidal and Stationary Phases with Finite Difference Solution.”

\section{Description of Input Values}

The first 29 rows of the worksheet (see Figure F-1 for an image of the worksheet) contain parameter input values. Column D contains the typical values input from the GoldSim model. Column B contains values from Column D that are scaled appropriately for the current calculations.

Row 2: $\quad$ c_s $\left[\mathrm{kg} / \mathrm{m}^{\wedge} 3\right]$,

$c_{s}=$ Pu solubility

$\$ B \$ 2=\$ D \$ 2 / 1000$

Row 3: phi_1

$\phi_{-}$cell1, $\phi=\frac{V_{\text {pore }}}{V_{\text {bulk }}}$, porosity of the upstream boundary

\$B \$3=\$D\$3

Row 4: phi_2

$\phi \_$cell $2, \phi=\frac{V_{\text {pore }}}{V_{\text {bulk }}}$, porosity of the corrosion product mass

\$B \$4=\$D\$4

Row 5: phi_3

$\phi_{-}$cell3, $\phi=\frac{V_{\text {pore }}}{V_{\text {bulk }}}$, porosity of the downstream boundary

$\$ B \$ 5=\$ D \$ 5$

Row 6: u $\left.\quad u \mathrm{~m}^{\wedge} 3 / \mathrm{yr}\right]$

volumetric water flux, $U$ Table B-1 
$\$ \mathrm{~B} \$ 6=\$ \mathrm{D} \$ 6$

Row 7: Kd_FeO_c [m^3/kg]

partition coefficient in the $\mathrm{FeO}$ colloid state

$\$ B \$ 7=\$ D \$ 7 / 1000$

Row 8: Kd_FeO_CP $\left[\mathrm{m}^{\wedge} 3 / \mathrm{kg}\right]$

partition coefficient in the stationary FeO corrosion product state

\$B $\$ 8=\$ D \$ 8 / 1000$

Row 9: Kd_WF_c [m³/kg]

partition coefficient in the waste form colloid state

$\$ B \$ 9=\$ D \$ 9 / 1000$

\begin{tabular}{|c|c|c|c|c|}
\hline & $\mathrm{A}$ & $\mathrm{B}$ & $\mathrm{C}$ & D \\
\hline 1 & \multicolumn{2}{|c|}{ Input for Excel sreadsheet } & \multicolumn{2}{|c|}{ Input from GoldSim } \\
\hline 2 & c_s $\left[\mathrm{kg} / \mathrm{m}^{n} 3\right]$ & 0.001 & c_s [mg/L] & 1 \\
\hline 3 & phi_1 & & phi_1 & 1 \\
\hline 4 & phi 2 & 0.4 & phi 2 & 0.4 \\
\hline 5 & phi_3 & 0.3 & phi_3 & 0.3 \\
\hline 6 & $u\left[m^{n} 3 / y r\right]$ & 0.1 & $u\left[m^{\wedge} 3 / y r\right]$ & 0.1 \\
\hline 7 & $\mathrm{Kd} \_\mathrm{FeO}{ }_{-} \mathrm{c}\left[\mathrm{m}^{n} 3 / \mathrm{kg}\right]$ & $1.00000 E+01$ & Kd_FeO_c $[\mathrm{ml} / \mathrm{g}]$ & 1.00000E+04 \\
\hline 8 & $\mathrm{Kd} \_\mathrm{FeO} \_\mathrm{CP}\left[\mathrm{m}^{n} 3 / \mathrm{kg}\right]$ & $2.50000 \mathrm{E}+00$ & Kd_FeO_CP [ml/g] & $2.50000 \mathrm{E}+03$ \\
\hline 9 & $\mathrm{Kd} \mathrm{WF}_{-} \mathrm{c}\left[\mathrm{m}^{\mathrm{n}} 3 / \mathrm{kg}\right]$ & $2.00000 E+02$ & Kd_WF_c [ml/g] & $2.00000 E+05$ \\
\hline 10 & $\mathrm{Kd}{ }_{-} \mathrm{GW} W_{-} \mathrm{c}\left[\mathrm{m}^{n} \mathrm{3} / \mathrm{kg}\right]$ & $2.00000 E+02$ & Kd_GW_c [ml/g] & $2.00000 E+05$ \\
\hline 11 & mass_FeO_CP $[\mathrm{kg}]$ & $1.80000 \mathrm{E}+[04$ & mass_FeO_CP [g] & $1.80000 \mathrm{E}+07$ \\
\hline 12 & $V$ pore $\left[\mathrm{m}^{n} 3\right]$ & $2.29008 \mathrm{E}+00$ & $\checkmark$ pore [L] & $2.29008 E+03$ \\
\hline 13 & c_FeO_c [ $\left.\mathrm{kg} / \mathrm{m}^{n} 3\right]$ & 2.00000E-02 & c_FeO_c [mg/L] & $2.00000 E+01$ \\
\hline 14 & c_FeO_CP $\left[\mathrm{kg} / \mathrm{m}^{\mathrm{n}} \mathrm{3}\right]$ & $7.86000 \mathrm{E}+03$ & c_FeO_CP [mg/L] & $7.86000 \mathrm{E}+06$ \\
\hline 15 & c_WF_c $\left[\mathrm{kg} / \mathrm{m}^{n} 3\right]$ & 3.00000E-03 & c_WF_c [mg/L] & $3.00000 E+00$ \\
\hline 16 & c_GW_c $\left[\mathrm{kg} / \mathrm{m}^{n} 3\right]$ & 1.00000E-04 & c_GW_c [mg/L] & 1.00000E-01 \\
\hline 17 & rate $[\mathrm{m} / \mathrm{yr}]$ & 1.00000E-05 & rate $[\mathrm{cm} / \mathrm{yr}]$ & $1.00000 \mathrm{E}-03$ \\
\hline 18 & S_FeO_c $\left[\mathrm{m}^{n} 2 / \mathrm{kg}\right]$ & $1.00000 E+05$ & S_FeO_c[m $2 / g]$ & 1.00000E+02 \\
\hline 19 & S_FeO_CP $\left[\mathrm{m}^{n} 2 / \mathrm{kg}\right]$ & $1.00000 E+04$ & S_FeO_CP $\left[\mathrm{m}^{\wedge} 2 / \mathrm{g}\right]$ & 1.00000E+01 \\
\hline 20 & d_FeO $\left[\mathrm{kg} / \mathrm{m}^{n} 3\right]$ & $5.24000 \mathrm{E}+03$ & den FeO $\left[\mathrm{kg} / \mathrm{m}^{\wedge} 3\right]$ & $5.24000 \mathrm{E}+03$ \\
\hline 21 & diffus_aq [ $\left.\mathrm{m}^{n} 2 / \mathrm{yr}\right]$ & $7.25834 \mathrm{E}-02$ & diffus_aq $\left[m^{\wedge} 2 / s\right]$ & 2.30000E-09 \\
\hline 22 & diffus_colloid [m $\left.\mathrm{m}^{\mathrm{n}} 2 / \mathrm{yr}\right]$ & $7.25834 \mathrm{E}-04$ & diffus_colloid [m 2$]$ & 2.30000E-11 \\
\hline 23 & diff_length_1 [m] & 1.00000E-03 & diff_length_1 [m] & $1.00000 \mathrm{E}-0.3$ \\
\hline 24 & diff_length_2 [m] & $5.00000 E+00$ & diff_length_2 [m] & $5.00000 E+00$ \\
\hline 25 & diff_length_3 $[\mathrm{m}]$ & 8.06000E-01 & diff_length_3 [m] & $8.06000 \mathrm{E}-01$ \\
\hline 26 & diff_area_1_2 [m²] & $3.60000 \mathrm{E}+01$ & diff_area_1_2 $\left[\mathrm{m}^{\wedge} 2\right]$ & $3.60000 E+01$ \\
\hline 27 & diff_area_2_3 $\left[\mathrm{m}^{n} 2\right]$ & 1.06800E+00 & diff_area_2_3 $\left[\mathrm{m}^{\wedge} 2\right]$ & 1.06800E+00 \\
\hline 28 & decay $[1 / y r]$ & 2.87494E-05 & decay $[1 / \bar{y}]$ & 2.87494E-05 \\
\hline 29 & delt [yr] & 10 & delt [yr] & 10 \\
\hline
\end{tabular}

Figure F-1. Spreadsheet "Transport_Calc_all_colloids.xls;" Summary of Inputs 
Row 10: Kd_GW_c [m^3/kg]

partition coefficient in the GW colloid state

$\$ B \$ 10=\$ D \$ 10 / 1000$

Row 11: mass_FeO_CP [kg]

$m_{\mathrm{FeO} \_\mathrm{CP}}=$ mass of corrosion product

$\$ B \$ 11=\$ D \$ 11 / 1000$

Row 12: V_pore [m^3]

$V_{\text {pore }}=\phi V_{\text {bulk }}=\frac{\phi}{1-\phi} \frac{m_{\mathrm{FeO} \_} \mathrm{CP}}{\rho_{\mathrm{FeO} \_} \mathrm{CP}}$, pore volume

$\$ \mathrm{~B} \$ 12=\$ \mathrm{D} \$ 12 / 1000$

Row 13: c_FeO_c $\left[\mathrm{kg} / \mathrm{m}^{\wedge} 3\right]$

$C_{\mathrm{Pu}_{-} \mathrm{FeO} \mathrm{O}_{-} \mathrm{C}}$, concentration of $\mathrm{Pu}$ in the $\mathrm{FeO}$ colloid state from reversible sorption

$\$ B \$ 13=\$ D \$ 13 / 1000$

Row 14: C_FeO_CP $\left[\mathrm{kg} / \mathrm{m}^{\wedge} 3\right]$

$c_{P_{u_{-}} \mathrm{FeO}_{-} \mathrm{CP}}$, concentration of $\mathrm{Pu}$ in the stationary $\mathrm{FeO}$ corrosion product state from reversible sorption

\$B $\$ 14=\$ D \$ 14 / 1000$

Row 15: C_WF_c $\left[\mathrm{kg} / \mathrm{m}^{\wedge} 3\right]$

$C_{P_{u_{-} W F_{-} \mathrm{C}}}$, concentration of $\mathrm{Pu}$ in the waste form colloid state from reversible sorption $\$ B \$ 15=\$ D \$ 15 / 1000$

Row 16: c_GW_c [kg/m^3]

$C_{P_{-} G W_{-} c}$, concentration of Pu in the GW colloid state from reversible sorption $\$ \mathrm{~B} \$ 16=\$ \mathrm{D} \$ 16 / 1000$

Row 17: rate $[\mathrm{m} / \mathrm{yr}]$

$k$, forward rate constant $\left(\mathrm{m}^{3}\right.$ water $\mathrm{m}^{-2} \mathrm{FeO} \mathrm{yr}^{-1}$ )

$\$ B \$ 17=\$ D \$ 17 / 100$ 
Row 18: S_FeO_c $\left[\mathrm{m}^{\wedge} 2 / \mathrm{kg}\right]$

$\hat{S}_{F e O}=$ specific surface area of $\mathrm{FeO}\left(\mathrm{m}^{2} \mathrm{~kg}^{-1}\right)$ in the colloid state

$\$ B \$ 18=\$ D \$ 18 * 1000$

Row 19: S_FeO_CP $\left[\mathrm{m}^{\wedge} 2 / \mathrm{kg}\right]$

$\hat{S}_{\mathrm{FeO}}=$ specific surface area of $\mathrm{FeO}\left(\mathrm{m}^{2} \mathrm{~kg}^{-1}\right)$ in the corrosion product state $\$ B \$ 19=\$ D \$ 19 * 1000$

Row 20: d_FeO $\left[\mathrm{kg} / \mathrm{m}^{\wedge} 3\right]$

$\rho_{\mathrm{FeO} \_\mathrm{CP}}=$ corrosion product $(\mathrm{FeO})$ density $\left(\mathrm{kg} \mathrm{m}^{-3}\right)$

$\$ B \$ 20=\$ D \$ 20$

Row 21: diffus_aq [m^2/yr]

$D_{a q}=$ aqueous diffusivity $\left(\mathrm{m}^{2} \mathrm{yr}^{-1}\right)$

$\$ B \$ 21=\$ D \$ 21 * 31558000$

Row 22: diffus_colloid [m^2/yr]

$D_{\text {colloid }}=$ colloid diffusivity $\left(\mathrm{m}^{2} \mathrm{yr}^{-1}\right)$

$\$ B \$ 22=\$ D \$ 22 * 31558000$

Row 23: diff_length_1 [m]

$L_{1}=$ diffusive length for cell_1

$\$ B \$ 23=\$ D \$ 23$

Row 24: diff_length_2 [m]

$L_{2}=$ diffusive length for cell_2

\$B \$24=\$D 24

Row 25: diff_length_3 [m]

$L_{3}=$ diffusive length for cell_3

$\$ B \$ 25=\$ D \$ 25$

Row 26: diff_area_1_2 [m²]

$A_{s 12}=$ diffusive area at cell_1 and cell_2 interface

$\$ B \$ 26=\$ D \$ 26$ 
Row 27: diff_area_2_3 [m²]

$A_{s 23}=$ diffusive area at cell_2 and cell_3 interface

$\$ \mathrm{~B} \$ 27=\$ \mathrm{D} \$ 27$

Row 28: decay [1/yr]

$\lambda$, decay rate $\left(\mathrm{yr}^{-1}\right)$

$\$ \mathrm{~B} \$ 28=\$ \mathrm{D} \$ 28$

Row 29: delt [yr]

$\Delta t$, time step length

$\$ B \$ 29=\$ D \$ 29$

Rows 30 through 53 contain additional derived parameters for the mixing cell colloid model.

\begin{tabular}{|c|c|c|c|c|c|c|c|}
\hline & $\mathrm{A}$ & $\mathrm{B}$ & $\mathrm{C}$ & $\mathrm{D}$ & $E$ & $\mathrm{~F}$ & $G$ \\
\hline 30 & R_bar_1 [1/yr] & 2.00000E-02 & & & & & \\
\hline 31 & R_bar_2 [1/yr] & $7.86000 \mathrm{E}+02$ & & & & & \\
\hline 32 & U_bar [1/yr] & 4.36667E-02 & & & & & \\
\hline 33 & $\mathrm{Kd}$ bar_FeO_c & 2.00000E-01 & & & & & \\
\hline 34 & $\mathrm{Kd}$ bar_FeO_CP & $1.96500 E+04$ & & & & & \\
\hline 35 & Kd_bar_WF_c & 6.00000E-01 & & & & & \\
\hline 36 & Kd_bar_GW_c & 2.00000E-02 & & & & & \\
\hline 37 & K_bar_1 & 1.96518E+04 & & & & & \\
\hline 38 & K_bar_2 & $1.82000 E+00$ & & & & & \\
\hline 39 & K_bar_3 & $8.20000 \mathrm{E}-01$ & & & & & \\
\hline 40 & Diff_left_aq & $9.12736 \mathrm{E}-02$ & & & & & \\
\hline 41 & Diff_left_c & $9.12736 \mathrm{E}-04$ & & & & & \\
\hline 42 & Diff_right_aq & 2.22893E-03 & & \multicolumn{2}{|c|}{ limiting values } & & \\
\hline 43 & Diff right colloid & 2.22893E-05 & & p 1 & 3.58485E-02 & & \\
\hline 44 & denom_a_1_2 & $2.75194 \mathrm{E}+04$ & & p_2 & 8.17743E-02 & tolerence $=$ & 1.00000E-02 \\
\hline 45 & a_1 $-\cdots$ & $7.14108 \mathrm{E}-01$ & & lim c_Pu_aq & 2.05511E-07 & Pu_aq time [yr] & 137 \\
\hline 46 & a_2 & 5.87541E-08 & & lim c_irr_c & $9.40175 \mathrm{E}-08$ & delta_1 & $3.2004 \mathrm{E}-04$ \\
\hline 47 & b_1 & 6.95808E-01 & & $\lim$ c_rev_c & 4.11023E-08 & delta_2 & 3.0078E-04 \\
\hline 48 & b_2 & 1.39162E-01 & & lim c_irr_CP & $5.61862 \mathrm{E}+00$ & t_1 & 22 \\
\hline 49 & e-1 & 9.99713E-01 & & lim c_rev_cP & 4.03830E-03 & $t$ & 24 \\
\hline 50 & e_2 & $7.85774 \mathrm{E}+03$ & & flux out ratio & 5.48749E-01 & irr_Pu_c time $[y r]$ & 240 \\
\hline 51 & Omega & 9.5000E-01 & & flux out/flux in & 1.29289E-04 & & \\
\hline 52 & k_fit_Omega $[\mathrm{cm} / \mathrm{yr}]$ & 4.1837E-02 & & irr_col/rev_col & 5.57903E-01 & & \\
\hline 53 & $p 1 / p 2$ & 4.3838E-01 & & & & & \\
\hline 54 & & & & & & & \\
\hline 55 & & & & & & & \\
\hline
\end{tabular}

Figure F-2. Spreadsheet "Transport_Calc_all_colloids.xls;" Additional Derived Parameters

Row 30: R_bar_1 [1/yr]

$$
\begin{aligned}
& \bar{R}_{1}=\hat{S}_{\mathrm{FeO} O_{-}} c_{\mathrm{FeO} \_} k, \text { reaction rate for colloids } \\
& \$ \mathrm{~B} \$ 30=\$ \mathrm{~B} \$ 18^{\star} \$ \mathrm{~B} \$ 13^{\star} \$ \mathrm{~B} \$ 17
\end{aligned}
$$


Row 31: R_bar_2 [1/yr]

$\bar{R}_{2}=\hat{S}_{\mathrm{FeO} \_\mathrm{CP}} C_{\mathrm{FeO} \_} \mathrm{CP}$, reaction rate constants for corrosion products

$\$ B \$ 31=\$ B \$ 19 * \$ B \$ 14 * \$ B \$ 17$

Row 32: U_bar [1/yr]

$\bar{U}$ is the advective rate constant

$\$ \mathrm{~B} \$ 32=\$ \mathrm{~B} \$ 6 / \$ \mathrm{~B} \$ 12$

Row 33: Kd_bar_FeO_c

advective dimensionless partition coefficient in the $\mathrm{FeO}$ colloid state

$\$ B \$ 33=\$ B \$ 13 * \$ B \$ 7$

Row 34: Kd_bar_FeO_CP

advective dimensionless partition coefficient in the $\mathrm{FeO}$ corrosion product state $\$ B \$ 34=\$ B \$ 14 * \$ B \$ 8$

Row 35: Kd_bar_WF_c

advective dimensionless partition coefficient in the waste form colloid state $\$ B \$ 35=\$ B \$ 15 * \$ B \$ 9$

Row 36: Kd_bar_GW_c

advective dimensionless partition coefficient in the GW colloid state $\$ \mathrm{~B} \$ 36=\$ \mathrm{~B} \$ 16 * \$ \mathrm{~B} \$ 10$

Row 37: K_bar_1

$\bar{K}_{1}=1+\bar{K}_{d_{-} F e O_{-} c}+\bar{K}_{d_{-} F e O_{-} C P}+\bar{K}_{d_{-} W F_{-} c}+\bar{K}_{d_{-} G W_{-} c}$, combination of dimensionless partition coefficients

$\$ B \$ 37=1+\$ B \$ 33+\$ B \$ 34+\$ B \$ 35+\$ B \$ 36$

Row 38: K_bar_2

$\bar{K}_{2}=1+\bar{K}_{d_{-} F e O_{-} c}+\bar{K}_{d_{-} W F_{-} c}+\bar{K}_{d_{-} G W_{-} c}$, combination of dimensionless partition coefficients

$\$ B \$ 38=1+\$ B \$ 33+\$ B \$ 35+\$ B \$ 36$ 
Row 39: K_bar_3

$\bar{K}_{3}=\bar{K}_{d_{-} F e O_{-} c}+\bar{K}_{d_{-} W F_{-} c}+\bar{K}_{d_{-} G W_{-} c}$, combination of dimensionless partition coefficients

$\$ \mathrm{~B} \$ 39=\$ \mathrm{~B} \$ 33+\$ \mathrm{~B} \$ 35+\$ \mathrm{~B} \$ 36$

Row 40: Diff_left_aq

aqueous diffusive rate constant for left diffusive boundary condition

$\$ B \$ 40=(\$ B \$ 26 /(\$ B \$ 23 /(\$ B \$ 3 * \$ B \$ 21)+\$ B \$ 24 /(\$ B \$ 4 * \$ B \$ 21))) / \$ B \$ 12$

Row 41: Diff_left_c

colloid diffusive rate constant for left diffusive boundary condition

$\$ \mathrm{~B} \$ 41=(\$ \mathrm{~B} \$ 26 /(\$ \mathrm{~B} \$ 23 /(\$ \mathrm{~B} \$ 3 * \$ \mathrm{~B} \$ 22)+\$ \mathrm{~B} \$ 24 /(\$ \mathrm{~B} \$ 4 * \$ \mathrm{~B} \$ 22))) / \$ \mathrm{~B} \$ 12$

Row 42: Diff_right_aq

aqueous diffusive rate constant for right diffusive boundary condition

$\$ \mathrm{~B} \$ 42=(\$ \mathrm{~B} \$ 27 /(\$ \mathrm{~B} \$ 24 /(\$ \mathrm{~B} \$ 4 * \$ \mathrm{~B} \$ 21)+\$ \mathrm{~B} \$ 25 /(\$ \mathrm{~B} \$ 5 * \$ \mathrm{~B} \$ 21))) / \$ \mathrm{~B} \$ 12$

Row 43: Diff_right_colloid

colloid diffusive rate constant for right diffusive boundary condition

$\$ \mathrm{~B} \$ 43=(\$ B \$ 27 /(\$ B \$ 24 /(\$ B \$ 4 * \$ B \$ 22)+\$ B \$ 25 /(\$ B \$ 5 * \$ B \$ 22))) / \$ B \$ 12$

Row 44: denom_a_1_2

denominator of $a_{1}$ in Equation B-55 (see Row 45)

$\$ \mathrm{~B} \$ 44=\$ \mathrm{~B} \$ 37+(\$ \mathrm{~B} \$ 32 * \$ \mathrm{~B} \$ 38+\$ \mathrm{~B} \$ 40+\$ \mathrm{~B} \$ 41 * \$ \mathrm{~B} \$ 35+\$ \mathrm{~B} \$ 42+\$ \mathrm{~B} \$ 43 * \$ \mathrm{~B} \$ 39$

$+\$ \mathrm{~B} \$ 30+\$ \mathrm{~B} \$ 31+\$ \mathrm{~B} \$ 28 * \$ \mathrm{~B} \$ 37) \star \$ \mathrm{~B} \$ 29$

Row 45: a_1

first order linear constant coefficient for Equation B-55,

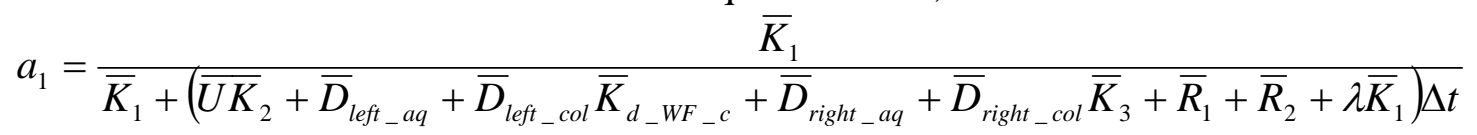
$\mathrm{B} \$ 45=\$ \mathrm{~B} \$ 37 / \$ \mathrm{~B} \$ 44$

Row 46: a_2

first order linear constant coefficient for Equation B-55,

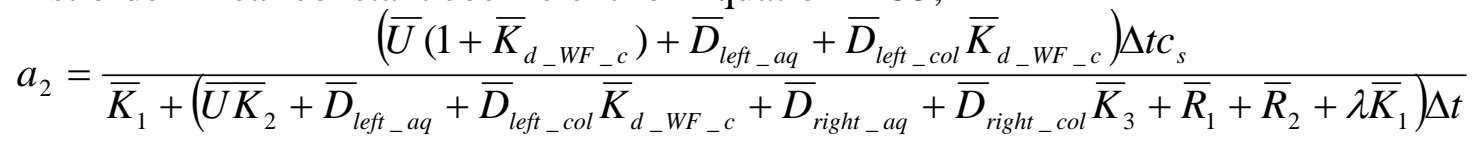

$\$ \mathrm{~B} \$ 46=((\$ \mathrm{~B} \$ 32 *(1+\$ \mathrm{~B} \$ 35)+\$ \mathrm{~B} \$ 40+\$ \mathrm{~B} \$ 41 * \$ \mathrm{~B} \$ 35) * \$ \mathrm{~B} \$ 29 * \$ \mathrm{~B} \$ 2) / \$ \mathrm{~B} \$ 44$ 
Row 47: b_1

irreversible colloid coefficient (Equation B-59) for Equation B-58, $b_{1}=\frac{1}{1+\left(\bar{U}+\bar{D}_{\text {right_col }}+\lambda\right) \Delta t}$

$\$ B \$ 47=1 /(1+(\$ B \$ 32+\$ B \$ 43+\$ B \$ 28) \star \$ B \$ 29)$

Row 48: b_2

irreversible colloid coefficient (Equation B-60) for Equation B-58,

$b_{2}=\frac{\bar{R}_{1} \Delta t}{1+\left(\bar{U}+\bar{D}_{\text {right_col }}+\lambda\right) \Delta t}$

$\$ B \$ 48=(\$ B \$ 30 * \$ B \$ 29) * \$ B \$ 47$

Row 49: e_1

irreversible corrosion products coefficient (Equation B-65) for Equation B-64, $e_{1}=\frac{1}{1+\lambda \Delta t}$

$\$ B \$ 49=1 /(1+\$ B \$ 28 * \$ B \$ 29)$

Row 50: e_2

irreversible corrosion products coefficient (Equation B-66) for Equation B-64,

$e_{2}=\frac{\bar{R}_{2} \Delta t}{1+\lambda \Delta t}$

$\$ B \$ 50=(\$ B \$ 31 * \$ B \$ 29) * \$ B \$ 49$

Row 51: Omega

$\Omega=\frac{\text { colloid mass flux out }}{\text { total mass flux out }}=0.95$ (Equation B-1)

$\$ \mathrm{~B} \$ 51=0.95$

Row 52: k_fit_Omega [cm/yr]

$k=\frac{p_{2} \Omega-p_{1}}{(1-\Omega) \hat{S}_{\mathrm{FeO} \_} c_{\mathrm{FeO} O_{-}}}$, fitting parameter, $k$, given a target flux ratio $\Omega$, Equation B-72

$\$ B \$ 52=100 *(\$ E \$ 44 * \$ B \$ 51-\$ E \$ 43) /((1-\$ B \$ 51) * \$ B \$ 18 * \$ B \$ 13)$ 
Row 53: $\quad \mathrm{p} 1 / \mathrm{p} 2$

$$
\Omega=\frac{p_{1}+\bar{R}_{1}}{p_{2}+\bar{R}_{1}} \quad \text { (Equation B-71) }
$$

\section{$\$ B \$ 53=\$ E \$ 43 / \$ E \$ 44$}

The values of parameters in Column E \& G Rows 43 through 52 under the heading "limiting values" pertain to the equations and discussion in Section "Boundary Fluxes" in Appendix B.

Row 43, Column E: p_1

$$
p_{1}=\bar{K}_{3}\left(\bar{U}+\bar{D}_{\text {right_col }}+\lambda\right)
$$

\section{$\$ \mathrm{E} \$ 43=\$ \mathrm{~B} \$ 39 *(\$ \mathrm{~B} \$ 32+\$ \mathrm{~B} \$ 43+\$ \mathrm{~B} \$ 28)$}

Row 44, Column E: p_2

$$
p_{2}=\left(\overline{U K}_{2}+\bar{D}_{\text {right_aq }}+\bar{D}_{\text {right_col }} \bar{K}_{3}\left(\frac{\bar{U}+\bar{D}_{\text {right_col }}+\lambda}{\bar{U}+\bar{D}_{\text {right_col }}}\right)\right.
$$

\$E $\$ 44=(\$ B \$ 32 * \$ B \$ 38+\$ B \$ 42+\$ B \$ 43 * \$ B \$ 39) *(\$ B \$ 32+\$ B \$ 43+\$ B \$$ $28) /(\$ B \$ 32+\$ B \$ 43)$

Row 45, Column E: lim c_Pu_aq

$$
\lim _{n \rightarrow \infty} c_{P u_{-} a q}^{n}=\frac{a_{2}}{1-a_{1}}
$$

\section{\$E $\$ 45=\$ B \$ 46 /(1-\$ B \$ 45)$}

Row 46, Column E: lim c_irr_c

$$
\lim _{n \rightarrow \infty} c_{I r r v_{-} P_{-} \mathrm{FeO}_{-} \mathrm{c}}^{n}=\frac{a_{2} b_{2}}{\left(1-a_{1}\right)\left(1-b_{1}\right)}
$$

$\$ E \$ 46=(\$ B \$ 30 * \$ E \$ 45) /(\$ B \$ 32+\$ B \$ 43+\$ B \$ 28)$

Row 47, Column E: lim c_rev_c

$$
\lim _{n \rightarrow \infty} c_{P u_{-} F e O_{-} c}^{n}=\bar{K}_{d_{-} \mathrm{FeO}_{-} c} \lim _{n \rightarrow \infty} c_{P u_{-} a q}^{n}
$$

\section{\$E $\$ 47=\$ B \$ 33 * \$ E \$ 45$}

Row 48, Column E: lim c_irr_CP

$$
\lim _{n \rightarrow \infty} C_{I r v_{-} P u_{-} F e O_{-} C P}^{n}=\frac{e_{2}}{1-e_{1}} \lim _{n \rightarrow \infty} c_{P u_{-} a q}^{n}=\frac{\bar{R}_{2}}{\lambda} \lim _{n \rightarrow \infty} c_{P u_{-} a q}^{n}
$$

\section{$\$ E \$ 48=\$ E \$ 45 * \$ B \$ 31 / \$ B \$ 28$}


Row 49, Column E: lim c_rev_CP

$$
\lim _{n \rightarrow \infty} c_{P u_{-} F e O_{-} C P}^{n}=\bar{K}_{d_{-} F e O_{-} C P} \lim _{n \rightarrow \infty} c_{P u_{-} a q}^{n}
$$

\section{$\$ \mathrm{E} \$ 49=\$ \mathrm{~B} \$ 34 * \$ \mathrm{E} \$ 45$}

Row 50, Column E: flux out ratio

$$
\begin{aligned}
& \Omega=\frac{p_{1}+\bar{R}_{1}}{p_{2}+\bar{R}_{1}} \\
& \$ \mathrm{E} \$ 50=(\$ \mathrm{E} \$ 43+\$ \mathrm{~B} \$ 30) /(\$ \mathrm{E} \$ 44+\$ \mathrm{~B} \$ 30)
\end{aligned}
$$

Row 51, Column E: flux out/flux in

$$
\begin{aligned}
& \Psi=\frac{p_{2}+\bar{R}_{1}}{p_{2}+\left(\frac{\bar{U}+\bar{D}_{\text {right_col }}+\lambda}{\bar{U}+\bar{D}_{\text {right_col }}}\right)\left(\bar{R}_{1}+\bar{R}_{2}+\lambda \bar{K}_{1}\right)} \\
& \text { \$E } \$ 51=(\$ \mathrm{E} \$ 44+\$ \mathrm{~B} \$ 30) /\left(\$ \mathrm{E} \$ 44+(\$ \mathrm{~B} \$ 32+\$ \mathrm{~B} \$ 43+\$ \mathrm{~B} \$ 28)^{\star}(\$ \mathrm{~B} \$ 30+\$ \mathrm{~B} \$ 37) /(\$ \mathrm{~B} \$ 32+\$ \mathrm{~B} \$ 43)\right)
\end{aligned}
$$

Row 52, Column E: irrv_col/rev_col

$$
0<\frac{\bar{K}_{3}\left(\bar{U}+\bar{D}_{\text {right_col }}\right)}{\overline{U K}_{2}+\bar{D}_{\text {right_aq }}+\bar{D}_{\text {right_col }} \bar{K}_{3}}<\Omega<1
$$

\section{$\$ E \$ 52=(\$ B \$ 32+\$ B \$ 43) * \$ E \$ 46 /((\$ B \$ 32+\$ B \$ 43) * \$ B \$ 39 * \$ E \$ 45)$}

Row 44, Column G: tolerance

relative error estimate with tolerance $\varepsilon$

$\$ G \$ 44=\mathrm{G} 44$

Row 45, Column G: Pu_aq time [yr]

$$
\begin{aligned}
& \text { time }=n \Delta t>\frac{\log _{10} \varepsilon}{\log _{10} a_{1}} \Delta t \text { (Equation B-74) } \\
& \$ \mathrm{G} \$ 45=\$ \mathrm{~B} \$ 29 * \mathrm{LOG} 10(\$ \mathrm{G} \$ 44) / \mathrm{LOG} 10(\$ \mathrm{~B} \$ 45)
\end{aligned}
$$

Row 46, Column G: delta_1

$$
b_{1}^{n+1}<\left|\frac{a_{1}-b_{1}}{1-a_{1}}\right| \frac{\varepsilon}{2}=\delta_{1}
$$

$\$ \mathrm{G} \$ 46=0.5^{\star} \$ \mathrm{G} \$ 44^{\star} \mathrm{ABS}((\$ \mathrm{~B} \$ 47-\$ \mathrm{~B} \$ 45) /(1-\$ B \$ 45))$ 
Row 47, Column G: delta_2

$$
a_{1}^{n+1}<\left|\frac{a_{1}-b_{1}}{1-b_{1}}\right| \frac{\varepsilon}{2}=\delta_{2}
$$

$\$ G \$ 47=0.5 * \$ G \$ 44^{*} A B S((\$ B \$ 47-\$ B \$ 45) /(1-\$ B \$ 47))$

Row 48, Column G: t__1

$$
\begin{aligned}
& \frac{\log _{10} \delta_{1}}{\log _{10} b_{1}} \\
& \$ G \$ 48=\text { LOG10 }(\$ G \$ 46) / L O G 10(\$ B \$ 47)
\end{aligned}
$$

Row 49, Column G: t_2

$$
\frac{\log _{10} \delta_{2}}{\log _{10} a_{1}}
$$

$\$$ \$ $\$ 49=$ LOG10 $(\$ G \$ 47) / L O G 10(\$ B \$ 45)$

Row 50, Column G: irrv_Pu_c time [yr]

$$
\begin{aligned}
& \text { time to converge to a given relative error tolerance, } \\
& \text { time }=n \Delta t>\frac{\log _{10} \varepsilon}{\log _{10} a_{1}} \Delta t \\
& \$ \mathrm{G} \$ 50=\mathrm{INT}(\mathrm{MAX}(\$ \mathrm{G} \$ 48, \$ \mathrm{G} \$ 49)) \star \$ \mathrm{~B} \$ 29
\end{aligned}
$$

Rows 58 thru 158 and Columns A through AC contain calculated solutions and equation terms, iterated in time, for the mixing cell colloid model. Images of this section of the spreadsheet are included at the end of this appendix (Figures F-3 through F-14).

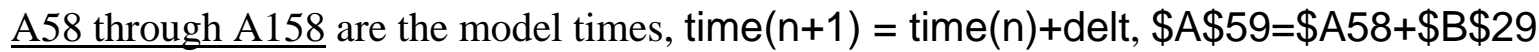

Column B: $\quad$ c_Pu_aq

$\mathrm{B} \$ 59=\$ \mathrm{~B} \$ 45 * \$ \mathrm{~B} 58+\$ \mathrm{~B} \$ 46$

Column C: c_Pu_FeO_c

$\mathrm{C} \$ 59=\$ B \$ 33 * \$ B 59$

Column D: $\quad$ c_Pu_FeO_CP

$\mathrm{D} \$ 59=\$ B \$ 34 * \$ B 59$

Column E: $\quad$ c_Pu_WF_c

$E \$ 59=\$ B \$ 35 * \$ B 59$ 
Column F: C_Pu_GW_c

$\mathrm{F} \$ 59=\$ \mathrm{~B} \$ 36 * \$ \mathrm{~B} 59$

Column G: C_irrv_Pu FeO_c

$\mathrm{G} \$ 59=\$ \mathrm{~B} \$ 47 * \$ \mathrm{G} 58+\$ \mathrm{~B} \$ 48 * \$ \mathrm{~B} 59$

Column H: c_irrv_Pu FeO_CP

$H \$ 59=\$ B \$ 49 * \$ H 58+\$ B \$ 50 * \$ B 59$

Column I: C_Pu_Fluid1 [mg/L]

$I \$ 59=1000 *$ (\$B59+\$C59+\$E59+\$F59)

Column J: C_Pu_FeO_c [g/kg]

$J \$ 59=1000 * \$ C 59 / \$ B \$ 13$

Column K: C_Pu_FeO_CP [g/kg]

$K \$ 59=1000 * \$ D 59 / \$ B \$ 14$

Column L: $\quad$ C_PU_WF_c $[\mathrm{g} / \mathrm{kg}]$

$\mathrm{L} \$ 59=1000 * \$ \mathrm{E} 59 / \$ B \$ 15$

Column M: C_Pu_GW_c [g/kg]

$M \$ 59=1000 * \$ F 59 / \$ B \$ 16$

Column N: C_Irrv_Pu_c [g/kg]

$N \$ 59=1000 * \$ G 59 / \$ B \$ 13$

Column O: $\quad$ C_Irrv_Pu_CP $[\mathrm{g} / \mathrm{kg}]$

$\mathrm{O} \$ 59=1000 * \$ \mathrm{H} 59 / \$ B \$ 14$

Column P: $\quad$ time

$\mathrm{P} \$ 59=\$ \mathrm{~A} 59$ 
Column Q: left_bddy_flux [kg]

$$
\begin{aligned}
& F_{\text {left_bddy_total }}^{n}=\bar{U} V_{\text {pore }} c_{s}+\bar{D}_{\text {left_aq }} V_{\text {pore }}\left(c_{s}-c_{P u_{-} a q}^{n}\right) \\
& +\bar{U} V_{\text {pore }} \bar{K}_{d_{-} W F_{-} c} c_{s}+\bar{D}_{\text {left_col }} V_{\text {pore }} \bar{K}_{d_{-} W F_{-} c}\left(c_{s}-c_{P u_{-} a q}^{n}\right) \\
& \mathrm{Q} \$ 59=\left(\$ \mathrm{~B} \$ 32 *(1+\$ \mathrm{~B} \$ 35) * \$ \mathrm{~B} \$ 2+(\$ \mathrm{~B} \$ 40+\$ \mathrm{~B} \$ 41 * \$ \mathrm{~B} \$ 35)^{\star}(\$ \mathrm{~B} \$ 2-\$ \mathrm{~B} 59)\right) * \mathrm{~B} \\
& \$ 12 * \$ \mathrm{~B} \$ 29
\end{aligned}
$$

Column R: right_bddy colloid flux [kg]

$$
\begin{aligned}
& F_{\text {right_bddy_colloid }}^{n}=\bar{U} V_{\text {pore }} \bar{K}_{d_{-} F e O_{-} c} c_{P u_{-} a q}^{n}+\bar{U} V_{\text {pore }} c_{\text {Irrv_ } P_{-} u_{-} F e O_{-} c}^{n} \\
& \bar{U} V_{\text {pore }} \bar{K}_{d_{-} W F_{-} c} c_{P u_{-} a q}^{n}+\bar{U} V_{\text {pore }} \bar{K}_{d_{-} G W_{-}-} c_{P u_{-} a q}^{n} \\
& +\bar{D}_{\text {right_col }} V_{\text {pore }} \bar{K}_{d_{-} F e O_{-} c} c_{P u_{-} a q}^{n}+\bar{D}_{\text {right_col }} V_{\text {pore }} C_{\text {Irrv_Pu_FeO_c }}^{n} \\
& \bar{D}_{\text {right_col }} V_{\text {pore }} \bar{K}_{d_{-} W F_{-} c} c_{P u_{-} a q}^{n}+\bar{D}_{\text {right_col }} V_{\text {pore }} \bar{K}_{d_{-} G W_{-} c} c_{P u_{-} a q}^{n} \\
& \mathrm{R} \$ 59=(\$ \mathrm{~B} \$ 32+\$ \mathrm{~B} \$ 43) *(\$ \mathrm{~B} \$ 39 * \$ \mathrm{~B} 59+\$ \mathrm{G} 59) * \$ \mathrm{~B} \$ 12 * \$ \mathrm{~B} \$ 29
\end{aligned}
$$

Column S: $\quad$ right bddy total flux [kg]

$$
\begin{aligned}
& F_{\text {right_bddy_total }}^{n}=F_{\text {right_bddy_colloid }}^{n}+\bar{U} V_{\text {pore }} C_{P u_{-} a q}^{n}+\bar{D}_{\text {right_aq }} V_{\text {pore }} C_{P u_{-} a q}^{n} \\
& \mathrm{~S} \$ 59=\$ \mathrm{R} 59+(\$ \mathrm{~B} \$ 32+\$ \mathrm{~B} \$ 42) \star \$ \mathrm{~B} 59 * \$ \mathrm{~B} \$ 12 * \$ \mathrm{~B} \$ 29
\end{aligned}
$$

Column T: col_out/total_out

$$
\Omega_{n}=\frac{F_{\text {right_bddy_colloid }}^{n}}{F_{\text {right_bddy_total }}^{n}}
$$

$\mathrm{T} \$ 59=\$ R 59 / \$ S 59$

Column U: flux_out/flux_in

$$
\mathrm{U} \$ 59=\$ S 59 / \$ \mathrm{Q} 59
$$

Column V: change mass $[\mathrm{kg}]$

$\mathrm{V} \$ 59=((\$ B 59-\$ B 58)+(\$ C 59-\$ C 58)+(\$ D 59-\$ D 58)+(\$ E 59-\$ E 58)+(\$ F 59-$ $\$ F 58) * \$ B \$ 12$

Column W: in - out $[\mathrm{kg}]$

$\mathrm{W} \$ 59=\$ Q 59-((\$ B \$ 32+\$ B \$ 43) * \$ B \$ 39+\$ B \$ 32+\$ B \$ 42) * \$ B 59 * \$ B \$ 12 * \$ B \$ 29$ 
Column X: $\quad$ react/decay $[\mathrm{kg}]$

$X \$ 59=-(\$ B \$ 30+\$ B \$ 31+\$ B \$ 28 * \$ B \$ 37) * \$ B \$ 12 * \$ B \$ 29 * \$ B 59$

Column Y: PU mass balance

$Y \$ 59=\$ V 59-\$ W 59-\$ X 59$

Column Z: change mass $[\mathrm{kg}]$

$Z \$ 59=((\$ G 59-\$ G 58)+(\$ H 59-\$ H 58)) * \$ B \$ 12$

Column AA: in-out $[\mathrm{kg}]$

$A A \$ 59=-(\$ B \$ 32+\$ B \$ 43) * \$ G 59 * \$ B \$ 12 * \$ B \$ 29$

Column AB: react/decay [kg]

$A B \$ 59=\left((\$ B \$ 30+\$ B \$ 31) \star \$ B 59-\$ B \$ 28^{\star}(\$ G 59+\$ H 59)\right) \star \$ B \$ 12 * \$ B \$ 29$

Column AC: Irrv_Pu mass balance

$A C \$ 59=\$ Z 59-\$ A A 59-\$ A B 59$

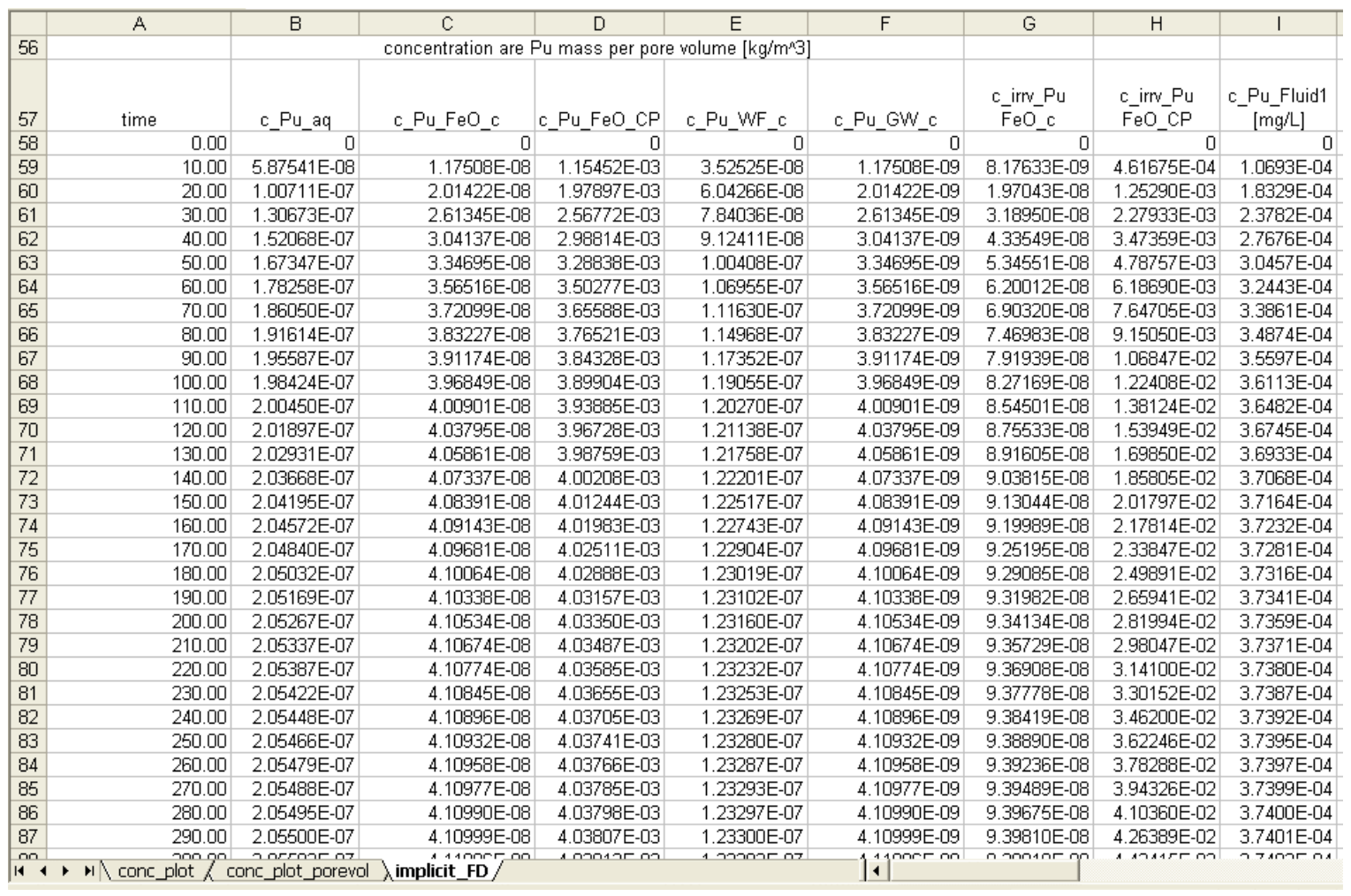

Figure F-3. Spreadsheet "Transport_Calc_all_colloids.xls;" Calculated Solutions and Equation Terms, Iterated in Time, for Mixing Cell Colloid Model, Time 0-290 Years 


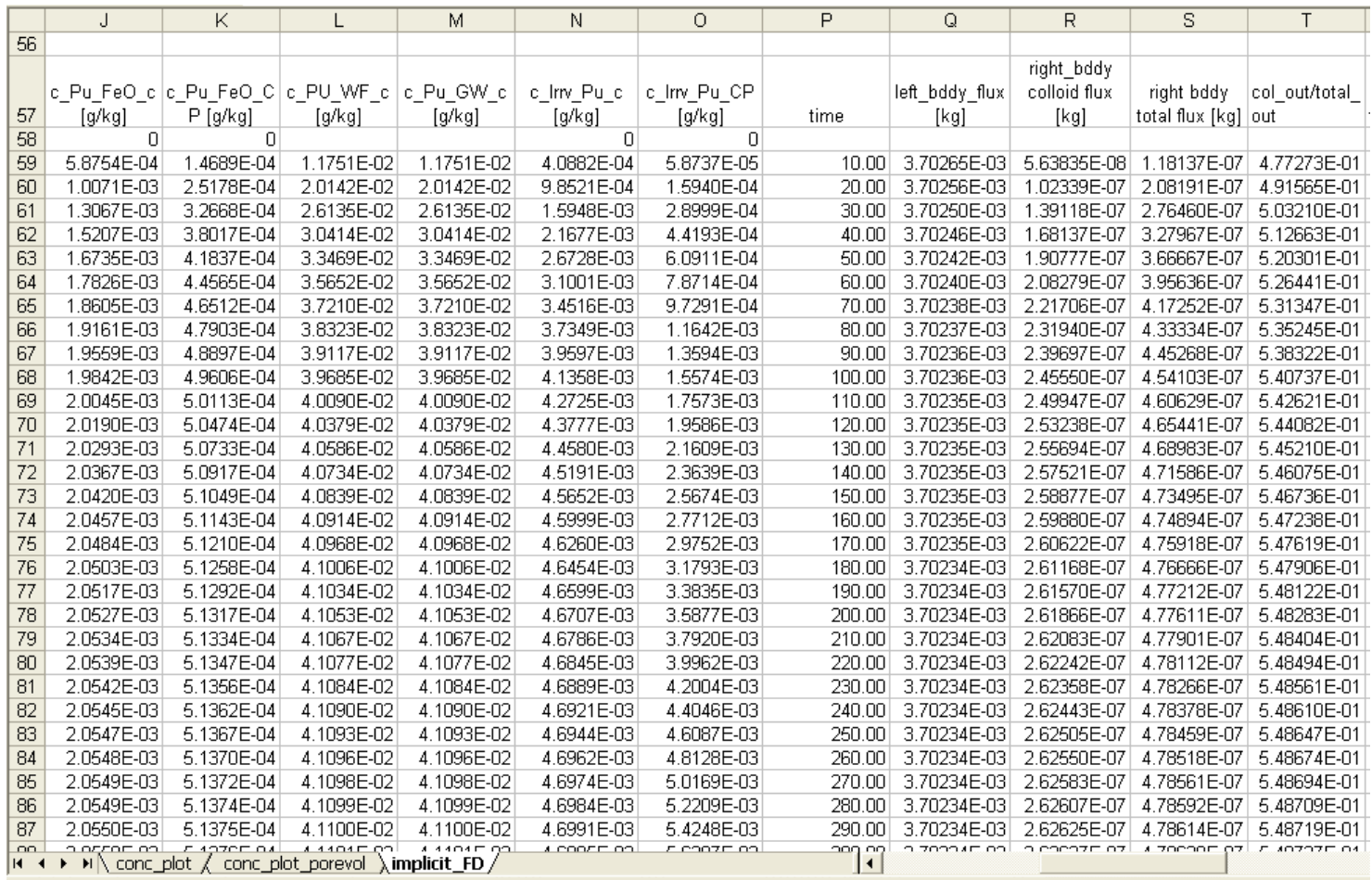

Figure F-4. Spreadsheet "Transport_Calc_all_colloids.xls;" Additional Calculated Solutions and Equation Terms, Iterated in Time, for Mixing Cell Colloid Model, Time 0 - 290 Years

\begin{tabular}{|c|c|c|c|c|c|c|c|c|c|}
\hline & $\mathrm{U}$ & $\mathrm{V}$ & $W$ & $x$ & $Y$ & Z & $\mathrm{AA}$ & $\mathrm{AB}$ & $\mathrm{AC}$ \\
\hline 56 & & \multicolumn{4}{|c|}{ Pu mass balance } & \multicolumn{4}{|c|}{ Irreversible Pu mass balance } \\
\hline 57 & flux_out/flux_in & $\begin{array}{c}\text { change mass } \\
{[\mathrm{kg}]}\end{array}$ & in - out $[\mathrm{kg}]$ & $\begin{array}{c}\text { react } / \text { decay } \\
{[\mathrm{kg}]}\end{array}$ & $\begin{array}{c}\text { PU mass } \\
\text { balance }\end{array}$ & $\begin{array}{c}\text { change } \\
\text { mass }[\mathrm{kg}]\end{array}$ & in-out $[\mathrm{kg}]$ & $\begin{array}{c}\text { react/decay } \\
{[\mathrm{kg}]}\end{array}$ & $\begin{array}{l}\text { Irv_Pu mass } \\
\text { balance }\end{array}$ \\
\hline 58 & & & & & & & & & \\
\hline 59 & 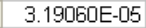 & & & 15836E-03 & $10000 E+00$ & & 09 & 05730E-03 & $E+00$ \\
\hline 60 & $2289 \mathrm{E}$ & 3823E-03 & $70238 \mathrm{E}-03$ & $-1.81415 E-03$ & $0.00000 E+00$ & 1.81200E-03 & BE-08 & 1202E-03 & 0.000 \\
\hline 61 & $6695 \mathrm{E}$ & & $70226 \mathrm{E}-03$ & $-2.35386 E-03$ & & 2.35063E-03 & 9113E-08 & $5067 \mathrm{E}-03$ & \\
\hline 62 & 15 & 14 & 70217E-03 & $-2.73927 \mathrm{E}-03$ & & 2.73497E-03 & $3771 \mathrm{E}-08$ & $3501 \mathrm{E}-03$ & \\
\hline 63 & 15 & & -03 & $-3.01449 E-03$ & & 3.00912E-03 & & 1918E-03 & \\
\hline 64 & 4 & & -03 & $-3.21104 \mathrm{E}-03$ & & 459E-03 & E-08 & J466E-03 & \\
\hline 65 & 4 & 14 & & $-3.35139 E-03$ & & $88 \mathrm{E}-03$ & 2E-08 & $394 \mathrm{E}-03$ & \\
\hline 66 & 4 & & & 161E-03 & & 3E-03 & & $E-03$ & \\
\hline 67 & 4 & & 73 & $-3.52318 E-03$ & & $4 \mathrm{E}-03$ & E-08 & $362 \mathrm{E}-03$ & \\
\hline 68 & 14 & & & $30 \mathrm{E}-03$ & & E-03 & E-08 & $67 \mathrm{E}-03$ & \\
\hline 69 & & & & 79E-03 & & & & $1 \mathrm{E}-03$ & \\
\hline 70 & & & & 6E-03 & & & & $E-03$ & \\
\hline 71 & & & & & & & & & \\
\hline 72 & & & & & & & & $=03$ & \\
\hline 73 & & & & $5 \mathrm{E}-03$ & & & & $=-03$ & \\
\hline 74 & & & & $03 \mathrm{E}-03$ & & & & $=-03$ & \\
\hline 75 & & & & & & & & -03 & \\
\hline 76 & & & & -3.6 & & & & $2 \mathrm{E}-03$ & \\
\hline 77 & 04 & & & E-03 & & & 08 & 3E-03 & \\
\hline 78 & 04 & & & $-3.69756 \mathrm{E}-03$ & & 3.6 & 08 & 3E-03 & \\
\hline 79 & & & & $-3.69882 E-03$ & & 3.6 & 08 & $4 \mathrm{E}-03$ & \\
\hline 80 & & & & $-3.69971 \mathrm{E}-03$ & & 528E-03 & E-08 & 8E-03 & \\
\hline 81 & 04 & $E-06$ & & 036E-03 & 00 & 87E-03 & E-08 & $6 \mathrm{E}-03$ & -18 \\
\hline 82 & -04 & & & 0081E-03 & 00 & 3.67527E-03 & E-08 & $36 \mathrm{E}-03$ & 0.00 \\
\hline 83 & 9231E-04 & $E-07$ & 3.7 & $-3.70114 \mathrm{E}-03$ & -00 & 3.67454E-03 & EE-08 & $3.67463 \mathrm{E}-03$ & 3.465 \\
\hline 84 & 9247E-04 & 5.83962E-07 & 3.701 & $-3.70138 \mathrm{E}-03$ & $0.00000 E+00$ & $3.67372 \mathrm{E}-03$ & E-08 & 3.67381E-03 & 9.54[ \\
\hline 85 & 9259E-04 & 17 & 3.70196E-03 & $-3.70154 \mathrm{E}-03$ & $0.00000 E+00$ & 3.67283E-03 & -9.39969E-08 & 3.67292E-03 & 1.344 \\
\hline 86 & $9267 E-04$ & & 3.70196 & $-3.70166 \mathrm{E}-03$ & $0.00000 \mathrm{E}+00$ & 3.67189E-03 & $-9.40154 \mathrm{E}-08$ & 3.67199E-03 & 0.000 \\
\hline 87 & 1.29273E-04 & 2.12655E-07 & 3.70196E-03 & $-3.70175 E-03$ & $0.00000 E+00$ & 3.67092E-03 & $-9.40290 \mathrm{E}-08$ & $3.67102 \mathrm{E}-03$ & $0.00000 E+00$ \\
\hline & 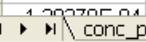 & 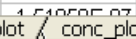 & a 7mancr m & 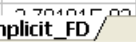 & & 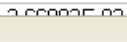 & 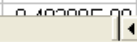 & & \\
\hline
\end{tabular}

Figure F-5. Spreadsheet "Transport_Calc_all_colloids.xls;" Final Calculated Solutions and Equation Terms, Iterated in Time, for Mixing Cell Colloid Model, Time $0-290$ Years 


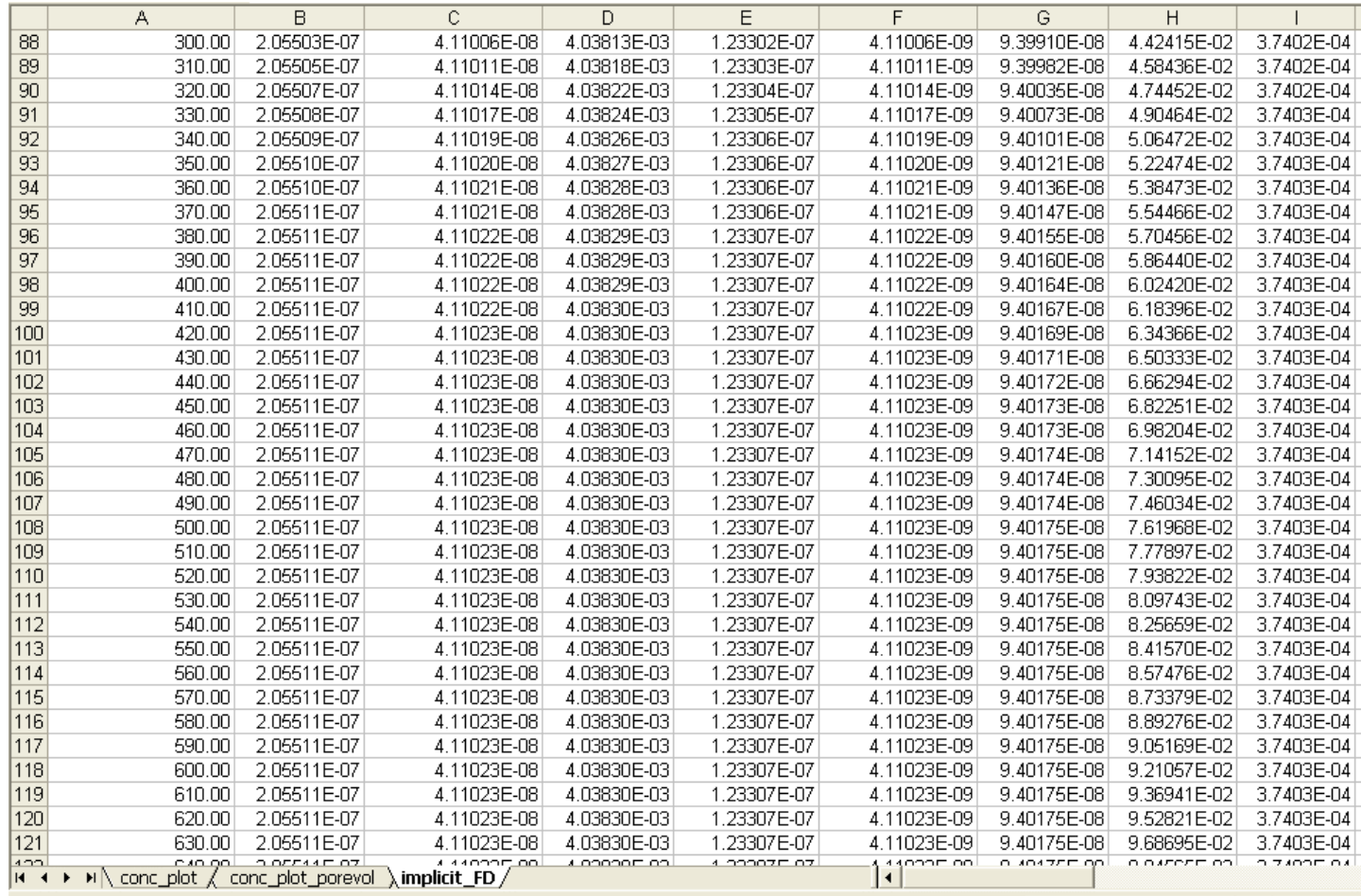

Figure F-6. Spreadsheet "Transport_Calc_all_colloids.xls;" Calculated Solutions and Equation Terms, Iterated in Time, for Mixing Cell Colloid Model, Time 300 - 630 Years

\begin{tabular}{|c|c|c|c|c|c|c|c|c|c|c|c|}
\hline & J & K & L & $M$ & $N$ & 0 & $\mathrm{P}$ & Q & $\mathrm{R}$ & $S$ & $T$ \\
\hline 88 & 2.0550E-03 & $5.1376 \mathrm{E}-04$ & $4.1101 \mathrm{E}-02$ & 4.1101E-02 & 4.6995E-03 & 5.6287E-03 & 300.00 & 3.70234E-03 & 2.62637E-07 & 4.78630E-07 & 5.48727E-01 \\
\hline 89 & $2.0551 \mathrm{E}-03$ & $5.1376 \mathrm{E}-04$ & $4.1101 \mathrm{E}-02$ & $4.1101 \mathrm{E}-02$ & 6999E-03 & $5.8325 \mathrm{E}-03$ & 310.00 & 3.70234E-03 & 2.62647E-07 & 4.78642E-07 & $5.48733 \mathrm{E}-01$ \\
\hline 90 & $2.0551 \mathrm{E}-03$ & $5.1377 \mathrm{E}-04$ & $4.1101 \mathrm{E}-02$ & $4.1101 \mathrm{E}-02$ & $4.7002 \mathrm{E}-03$ & $6.0363 \mathrm{E}-03$ & 320.00 & 3.70234E-03 & 2.62653E-07 & 4.78650E-07 & 5.48737E-01 \\
\hline 91 & $2.0551 \mathrm{E}-03$ & $5.1377 \mathrm{E}-04$ & $4.1102 \mathrm{E}-02$ & $4.1102 \mathrm{E}-02$ & 4.7004E-03 & $6.2400 \mathrm{E}-03$ & 330.00 & 3.70234E-03 & 2.62658E-07 & 4.78657E-07 & $5.48740 \mathrm{E}-01$ \\
\hline 92 & $2.0551 \mathrm{E}-03$ & $5.1377 \mathrm{E}-04$ & $4.1102 \mathrm{E}-02$ & $4.1102 \mathrm{E}-02$ & 7.7005E-03 & 6.4437E-03 & 340.00 & 3.70234E-03 & $2.62662 \mathrm{E}-07$ & $4.78661 \mathrm{E}-07$ & $5.48743 \mathrm{E}-01$ \\
\hline 93 & $2.0551 \mathrm{E}-03$ & $5.1377 \mathrm{E}-04$ & $4.1102 \mathrm{E}-02$ & & $6 \mathrm{E}-03$ & $6473 \mathrm{E}-03$ & 350.00 & $=-03$ & $2.62664 \mathrm{E}-07$ & 4.78664E-07 & 5.48744E-01 \\
\hline 94 & $551 \mathrm{E}-03$ & 1378E-04 & $1102 E-02$ & -02 & $7 \mathrm{E}-03$ & 3E-03 & .00 & -03 & 2.62666E-07 & 4.78667E-07 & $5.48745 \mathrm{E}-01$ \\
\hline 95 & $1551 \mathrm{E}-03$ & 1378E-04 & $E-02$ & & E-03 & E-03 & 1.00 & & 2.62667E-07 & $.78668 \mathrm{E}-07$ & $5.48746 \mathrm{E}-01$ \\
\hline 96 & $2.0551 \mathrm{E}-03$ & $5.1378 E-04$ & E-02 & -02 & 3E-03 & $E-03$ & 0.00 & -03 & 2.62668E-07 & 4.78669E-07 & 5.48747E-01 \\
\hline 97 & $2.0551 \mathrm{E}-03$ & $5.1378 \mathrm{E}-04$ & $102 \mathrm{E}-02$ & -02 & 3E-03 & $1 \mathrm{E}-03$ & 0.00 & -03 & $2.62669 \mathrm{E}-07$ & 4.78670E-07 & $7 \mathrm{E}-01$ \\
\hline 98 & 1551E-03 & $5.1378 \mathrm{E}-04$ & E-02 & $E-02$ & $8 \mathrm{E}-03$ & $E-03$ & 10.00 & & 2.62670E-07 & 4.78671E-07 & 48E-01 \\
\hline 99 & $2.0551 \mathrm{E}-03$ & $5.1378 E-04$ & $\mathrm{E}-02$ & $E-02$ & 3E-03 & & & & 2.62670E-07 & 4.78671E-07 & $8 \mathrm{E}-01$ \\
\hline 100 & $2.0551 \mathrm{E}-03$ & $5.1378 E-04$ & $\mathrm{E}-02$ & $E-02$ & $8 \mathrm{E}-03$ & 8E-03 & 420.00 & & 2.62670E-07 & 4.78672E-07 & $5.48748 \mathrm{E}-01$ \\
\hline 101 & $2.0551 \mathrm{E}-03$ & $5.1378 E-04$ & $4.1102 \mathrm{E}-02$ & $E-02$ & 009E-03 & $8.2740 \mathrm{E}-03$ & 430.00 & & 2.62670E-07 & $4.78672 \mathrm{E}-07$ & $5.48748 \mathrm{E}-01$ \\
\hline 102 & $2.0551 \mathrm{E}-03$ & $5.1378 \mathrm{E}-04$ & J2E-02 & $E-02$ & D09E-03 & 8.4770E-03 & & & 2.62671E-07 & 4.78672E-07 & 48748E-01 \\
\hline 103 & $2.0551 \mathrm{E}-03$ & $5.1378 E-04$ & & & 9E-03 & 8.6800E-03 & & & $2.62671 \mathrm{E}-07$ & 4.78672E-07 & $5.48748 \mathrm{E}-01$ \\
\hline 104 & $2.0551 \mathrm{E}-03$ & $5.1378 \mathrm{E}-04$ & & & E-03 & E-03 & & & 71E-07 & $4.78672 \mathrm{E}-07$ & 48749E-01 \\
\hline 105 & $2.0551 \mathrm{E}-03$ & 78E-04 & -02 & & $E-03$ & du & & & $1 \mathrm{E}-07$ & $8672 \mathrm{E}-07$ & 9E-01 \\
\hline 106 & $E-03$ & $78 \mathrm{E}-04$ & -02 & & $E-03$ & 03 & 00 & & $1 \mathrm{E}-07$ & $8672 \mathrm{E}-07$ & 49E-01 \\
\hline 107 & $2.0551 \mathrm{E}-03$ & $5.1378 E-04$ & E-02 & & $E-03$ & E- & 00 & & $1 \mathrm{E}-07$ & $8672 E-07$ & 7749E-01 \\
\hline 108 & 2.0551E-03 & $5.1378 \mathrm{E}-04$ & $\mathrm{E}-02$ & -02 & $\mathrm{E}-03$ & E-03 & 0.00 & -03 & 2.62671E-07 & 4.78672E-07 & $5.48749 \mathrm{E}-01$ \\
\hline 109 & $2.0551 \mathrm{E}-03$ & $5.1378 \mathrm{E}-04$ & $\mathrm{E}-02$ & -02 & E-03 & 69E-03 & 0.00 & -03 & 2.62671E-07 & $.78672 \mathrm{E}-07$ & 5.48749E-01 \\
\hline 110 & $2.0551 \mathrm{E}-03$ & $5.1378 \mathrm{E}-04$ & $E-02$ & & $E-03$ & $10 \mathrm{E}-02$ & 00 & & E-07 & 4.78672E-07 & 5.48749E-01 \\
\hline 111 & $2.0551 \mathrm{E}-03$ & $5.1378 E-04$ & $\mathrm{E}-02$ & $E-02$ & 9E-03 & $1.0302 \mathrm{E}-02$ & 530.00 & -03 & 2.62671E-07 & $4.78672 \mathrm{E}-07$ & $5.48749 \mathrm{E}-01$ \\
\hline 112 & $2.0551 \mathrm{E}-03$ & $5.1378 \mathrm{E}-04$ & $4.1102 \mathrm{E}-02$ & $E-02$ & 4.7009E-03 & 1.0505E-02 & 540.00 & $=-03$ & 2.62671E-07 & 4.78673E-07 & $5.48749 \mathrm{E}-01$ \\
\hline 113 & $2.0551 \mathrm{E}-03$ & $5.1378 \mathrm{E}-04$ & 2E-02 & $E-02$ & 9E-03 & D7E-02 & 550.00 & $=-03$ & 2.62671E-07 & 4.78673E-07 & $5.48749 \mathrm{E}-01$ \\
\hline 114 & $2.0551 \mathrm{E}-03$ & $5.1378 \mathrm{E}-04$ & $\mathrm{E}-02$ & $=-02$ & E-03 & E-02 & 00 & & $1 \mathrm{E}-07$ & 4.78673E-07 & 5.48749E-01 \\
\hline 115 & E-03 & $78 \mathrm{E}-04$ & & & $E-03$ & & & & $2.62671 \mathrm{E}-07$ & $4.78673 \mathrm{E}-07$ & $5.48749 \mathrm{E}-01$ \\
\hline 116 & $2.0551 \mathrm{E}-03$ & BE-04 & & & -03 & & & & $=-07$ & $673 \mathrm{E}-07$ & 3749E-01 \\
\hline 117 & $=-03$ & 3E-04 & & & E-03 & & & & $\mathrm{E}-07$ & 4.78673E-07 & 49E-01 \\
\hline 178 & E-03 & 8E-04 & $E-02$ & & E-03 & $E-02$ & .00 & & E-07 & 4.78673E-07 & 49E-01 \\
\hline 11 & E-03 & $5.1378 \mathrm{E}-04$ & $\mathrm{E}-02$ & & $E-03$ & DE-02 & 0.00 & & $2.62671 \mathrm{E}-07$ & 4.78673E-07 & $5.48749 \mathrm{E}-01$ \\
\hline 12 & 1551E-03 & $5.1378 \mathrm{E}-04$ & E-02 & & 7009E-03 & 22E-02 & 20.00 & & 2.62671E-07 & 4.78673E-07 & 48749E-01 \\
\hline 121 & $2.0551 \mathrm{E}-03$ & $5.1378 \mathrm{E}-04$ & E- -02 & $\mathrm{E}-02$ & 7009E-03 & 1.2324E-02 & 630.00 & $3.70234 \mathrm{E}-03$ & 2.62671E-07 & 4.78673E-07 & 5.48749E-01 \\
\hline & & & & & & & & & & & \\
\hline
\end{tabular}

Figure F-7. Spreadsheet "Transport_Calc_all_colloids.xls;" Additional Calculated Solutions and Equation Terms, Iterated in Time, for Mixing Cell Colloid Model, Time 300 - 630 Years 


\begin{tabular}{|c|c|c|c|c|c|c|c|c|c|}
\hline & $\mathrm{U}$ & V & $W$ & $x$ & Y & Z & AA & $\mathrm{AB}$ & $\mathrm{AC}$ \\
\hline 88 & 29278E-04 & 51859E-07 & 96E-03 & 70181 & $E+00$ & $66993 \mathrm{E}-03$ & -9.40389E-08 & $02 E-03$ & 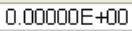 \\
\hline 89 & $1 \mathrm{~F} 0 \mathrm{~s}$ & & & & & & & & \\
\hline 90 & $9283 E-04$ & & & & & & & & \\
\hline 91 & $99285 E-04$ & & & & & 73 & & & \\
\hline 92 & 29286E-04 & 94907E-08 & E-03 & & & & & & \\
\hline 93 & 29287E-04 & 82006E-08 & $\mathrm{E}-03$ & & & & & & \\
\hline 94 & 29287E-04 & 01383E-08 & & & & & & & \\
\hline 95 & 29288E-04 & 43809E-08 & & & & & & & \\
\hline 96 & 29288E-04 & D2695E-08 & & & & & & & \\
\hline 97 & 9288E-04 & 353E-09 & & & & & & & \\
\hline 98 & 289E-04 & 23693E-09 & & & & & & & \\
\hline 99 & 289F-n4 & 3E-09 & 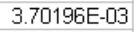 & & & & & & \\
\hline & gF- & 9 & 13 & & & & & & \\
\hline & OEOS & 9 & 03 & & & & & & \\
\hline & $\Gamma$ & 9 & & & & & & & \\
\hline & & 10 & & & & & & & \\
\hline & & & & & & & & & \\
\hline & 5 & & & & & & & & \\
\hline & BE-C & & & & & & & & $E-18$ \\
\hline & $\mathrm{EE}-\mathrm{C}$ & & & & & & & & \\
\hline & & & & & & & & & -17 \\
\hline & & & & & & & & & \\
\hline & & & & & & & & & \\
\hline & 9E- -5 & & & & & & & & \\
\hline & $9 E-5$ & & & & & & & & \\
\hline & $9 E-1$ & & & & & & & & E-17 \\
\hline & 1. & & & & & & & & 18 \\
\hline & 1. & & & & & & & & \\
\hline & 1. & & & & & & & & \\
\hline & 1. & & & & & & & & \\
\hline & 1. & 6.22 & & & & & & 3. & \\
\hline & 1. & & & & & & & 3. & 7 \\
\hline & & & & & & & & & $\mathrm{OE}+00$ \\
\hline & 9E-04 & $=-12$ & & & & & $5 E-08$ & $52 \mathrm{E}-03$ & $6 \mathrm{E}-17$ \\
\hline & & & & & & & & & \\
\hline
\end{tabular}

Figure F-8. Spreadsheet "Transport_Calc_all_colloids.xls;" Final Calculated Solutions and Equation Terms, Iterated in Time, for Mixing Cell Colloid Model, Time 300 - 630 Years

\begin{tabular}{|c|c|c|c|c|c|c|c|c|c|}
\hline & A & $B$ & C & D & $E$ & $\mathrm{~F}$ & G & $\mathrm{H}$ & 1 \\
\hline 122 & 640.00 & $2.05511 \mathrm{E}-07$ & 4.11023E-08 & $4.03830 \mathrm{E}-03$ & $1.23307 \mathrm{E}-07$ & $4.11023 \mathrm{E}-09$ & $9.40175 \mathrm{E}-08$ & 9.84565E-02 & $3.7403 \mathrm{E}-04$ \\
\hline 123 & 650.00 & $2.05511 \mathrm{E}-07$ & $4.11023 \mathrm{E}-08$ & $4.03830 \mathrm{E}-03$ & $1.23307 \mathrm{E}-07$ & $4.11023 \mathrm{E}-09$ & $9.40175 \mathrm{E}-08$ & 1.00043E-01 & $3.7403 \mathrm{E}-04$ \\
\hline 124 & 660.00 & $2.05511 \mathrm{E}-07$ & $4.11023 \mathrm{E}-08$ & $4.03830 \mathrm{E}-03$ & 1.23307E-07 & $4.11023 \mathrm{E}-09$ & $9.40175 \mathrm{E}-08$ & $1.01629 \mathrm{E}-01$ & 3.7403E-04 \\
\hline 125 & 670.00 & $2.05511 \mathrm{E}-07$ & $4.11023 \mathrm{E}-08$ & 4.03830E-03 & $1.23307 \mathrm{E}-07$ & $4.11023 \mathrm{E}-09$ & $9.40175 \mathrm{E}-08$ & $1.03215 \mathrm{E}-01$ & $3.7403 \mathrm{E}-04$ \\
\hline 126 & 680.00 & $2.05511 \mathrm{E}-07$ & $4.11023 \mathrm{E}-08$ & $4.03830 \mathrm{E}-03$ & $1.23307 \mathrm{E}-07$ & $4.11023 \mathrm{E}-09$ & $9.40175 \mathrm{E}-08$ & $1.04800 \mathrm{E}-01$ & $3.7403 \mathrm{E}-04$ \\
\hline 127 & 690.00 & $2.05511 \mathrm{E}-07$ & $4.11023 \mathrm{E}-08$ & $4.03830 \mathrm{E}-03$ & $1.23307 \mathrm{E}-07$ & $4.11023 \mathrm{E}-09$ & $9.40175 \mathrm{E}-08$ & $1.06385 \mathrm{E}-01$ & $3.7403 \mathrm{E}-04$ \\
\hline 128 & 700.00 & $2.05511 \mathrm{E}-07$ & $4.11023 \mathrm{E}-08$ & $4.03830 \mathrm{E}-03$ & $1.23307 \mathrm{E}-07$ & $4.11023 \mathrm{E}-09$ & $9.40175 \mathrm{E}-08$ & $1.07969 \mathrm{E}-01$ & $3.7403 \mathrm{E}-04$ \\
\hline 129 & 710.00 & $2.05511 \mathrm{E}-07$ & $4.11023 \mathrm{E}-08$ & $4.03830 \mathrm{E}-03$ & $1.23307 \mathrm{E}-07$ & 4.11023E-09 & $9.40175 \mathrm{E}-08$ & 1.09553E-01 & $3.7403 \mathrm{E}-04$ \\
\hline 130 & 720.00 & $2.05511 \mathrm{E}-07$ & $4.11023 \mathrm{E}-08$ & 4.03830E-03 & 1.23307E-07 & $4.11023 \mathrm{E}-09$ & $9.40175 \mathrm{E}-08$ & $1.11136 \mathrm{E}-01$ & $3.7403 \mathrm{E}-04$ \\
\hline 131 & 730.00 & $2.05511 \mathrm{E}-07$ & $4.11023 \mathrm{E}-08$ & $4.03830 \mathrm{E}-03$ & 1.23307E-07 & $4.11023 E-09$ & 9.40175E-08 & 1.12719E-01 & $3.7403 \mathrm{E}-04$ \\
\hline 132 & 740.00 & $2.05511 \mathrm{E}-07$ & 4.110 & 4.03830E-03 & $1.23307 \mathrm{E}-07$ & $4.11023 \mathrm{E}-09$ & $9.40175 \mathrm{E}-08$ & $1.14302 \mathrm{E}-01$ & $3.7403 \mathrm{E}-04$ \\
\hline 133 & 750.00 & $2.05511 \mathrm{E}-07$ & 4.11 & $4.03830 \mathrm{E}-03$ & $1.23307 \mathrm{E}-07$ & $4.11023 \mathrm{E}-09$ & $9.40175 \mathrm{E}-08$ & 1.15884E-01 & $3.7403 \mathrm{E}-04$ \\
\hline 134 & 760.00 & $2.05511 \mathrm{E}-07$ & $4.11023 \mathrm{E}-08$ & $4.03830 \mathrm{E}-03$ & $1.23307 \mathrm{E}-07$ & $4.11023 \mathrm{E}-09$ & $9.40175 \mathrm{E}-08$ & $1.17465 \mathrm{E}-01$ & $3.7403 \mathrm{E}-04$ \\
\hline 135 & 770.00 & $2.05511 \mathrm{E}-07$ & $4.11023 \mathrm{E}-08$ & 4.03830E-03 & $1.23307 \mathrm{E}-07$ & 4.11023E-09 & $9.40175 \mathrm{E}-08$ & $1.19046 \mathrm{E}-01$ & 3.7403E-04 \\
\hline 136 & 780.00 & $2.05511 \mathrm{E}-07$ & $4.11023 \mathrm{E}-08$ & 4.03830E-03 & $1.23307 \mathrm{E}-07$ & $4.11023 \mathrm{E}-09$ & $9.40175 \mathrm{E}-08$ & $1.20627 \mathrm{E}-01$ & $3.7403 \mathrm{E}-04$ \\
\hline 137 & 790.00 & $2.05511 \mathrm{E}-07$ & $4.11023 \mathrm{E}-08$ & $4.03830 \mathrm{E}-03$ & $1.23307 \mathrm{E}-07$ & $4.11023 \mathrm{E}-09$ & $9.40175 \mathrm{E}-08$ & 1.22207E-01 & $3.7403 \mathrm{E}-04$ \\
\hline 138 & 800.00 & $2.05511 \mathrm{E}-07$ & 3E-08 & $4.03830 \mathrm{E}-03$ & $1.23307 \mathrm{E}-07$ & $4.11023 \mathrm{E}-09$ & $9.40175 \mathrm{E}-08$ & 1.23787E-01 & $3.7403 \mathrm{E}-04$ \\
\hline 139 & 0.00 & 2.05511 & BE-08 & $4.03830 \mathrm{E}-03$ & 1.23307E-07 & 4.110 & $9.40175 \mathrm{E}-08$ & $1.25366 \mathrm{E}-01$ & 3.7403E-04 \\
\hline 140 & 820.00 & $2.05511 \mathrm{E}-07$ & E-08 & $4.03830 \mathrm{E}-03$ & 1.23307E-07 & 4.110 & $9.40175 \mathrm{E}-08$ & $1.26945 \mathrm{E}-01$ & $3.7403 \mathrm{E}-04$ \\
\hline 141 & 830.00 & $2.05511 \mathrm{E}-07$ & 4.110 & $4.03830 \mathrm{E}-03$ & $1.23307 \mathrm{E}-07$ & $4.11023 \mathrm{E}-09$ & $9.40175 \mathrm{E}-08$ & $1.28523 \mathrm{E}-01$ & $3.7403 \mathrm{E}-04$ \\
\hline 142 & 840.00 & $2.05511 \mathrm{E}-07$ & $4.11023 \mathrm{E}-08$ & 4.03830E-03 & $1.23307 \mathrm{E}-07$ & $4.11023 \mathrm{E}-09$ & $9.40175 \mathrm{E}-08$ & 1.30101E-01 & $3.7403 \mathrm{E}-04$ \\
\hline 143 & 850.00 & $2.05511 \mathrm{E}-07$ & $4.11023 \mathrm{E}-08$ & 4.03830E-03 & $1.23307 \mathrm{E}-07$ & 4.11023E-09 & $9.40175 \mathrm{E}-08$ & 1.31679E-01 & 3.7403E-04 \\
\hline 144 & 860.00 & $2.05511 \mathrm{E}-07$ & $4.11023 \mathrm{E}-08$ & $4.03830 \mathrm{E}-03$ & $1.23307 \mathrm{E}-07$ & $4.11023 \mathrm{E}-09$ & $9.40175 \mathrm{E}-08$ & $1.33256 \mathrm{E}-01$ & $3.7403 \mathrm{E}-04$ \\
\hline 145 & 0.00 & $2.05511 \mathrm{E}-07$ & 3E-08 & $4.03830 \mathrm{E}-03$ & 1.23307E-07 & $4.11023 \mathrm{E}-09$ & $9.40175 \mathrm{E}-08$ & 1.34832E-01 & $3.7403 \mathrm{E}-04$ \\
\hline 146 & .00 & 2.0551 & $E-08$ & 4.03830E-03 & 1.23307E-07 & E-09 & $9.40175 \mathrm{E}-08$ & $1.36408 \mathrm{E}-01$ & 3.7403E-04 \\
\hline 147 & 890.00 & $2.05511 \mathrm{E}-07$ & 3E-08 & $4.03830 \mathrm{E}-03$ & 1.23307E-07 & 4.110 & $9.40175 \mathrm{E}-08$ & 1.37984E-01 & 3.7403E-04 \\
\hline 148 & 900.00 & $2.05511 \mathrm{E}-07$ & $4.11023 \mathrm{E}-08$ & $4.03830 \mathrm{E}-03$ & $1.23307 \mathrm{E}-07$ & $4.11023 \mathrm{E}-09$ & $9.40175 \mathrm{E}-08$ & 1.39559E-01 & $3.7403 \mathrm{E}-04$ \\
\hline 149 & 910.00 & $2.05511 \mathrm{E}-07$ & $4.11023 \mathrm{E}-08$ & $4.03830 \mathrm{E}-03$ & $1.23307 \mathrm{E}-07$ & $4.11023 \mathrm{E}-09$ & $9.40175 \mathrm{E}-08$ & $1.41134 \mathrm{E}-01$ & $3.7403 \mathrm{E}-04$ \\
\hline 150 & 920.00 & $2.05511 \mathrm{E}-07$ & $4.11023 \mathrm{E}-08$ & 4.03830E-03 & $1.23307 \mathrm{E}-07$ & $4.11023 \mathrm{E}-09$ & $9.40175 \mathrm{E}-08$ & $1.42708 \mathrm{E}-01$ & $3.7403 \mathrm{E}-04$ \\
\hline 151 & 930.00 & $2.05511 \mathrm{E}-07$ & $4.11023 \mathrm{E}-08$ & $4.03830 \mathrm{E}-03$ & 1.23307E-07 & 4.11023E-09 & 9.40175E-08 & 1.44282E-01 & $3.7403 \mathrm{E}-04$ \\
\hline 152 & 940.00 & $2.05511 \mathrm{E}-07$ & 4.110 & $4.03830 \mathrm{E}-03$ & $1.23307 \mathrm{E}-07$ & $4.11023 \mathrm{E}-09$ & $9.40175 \mathrm{E}-08$ & $1.45855 \mathrm{E}-01$ & 3.7403E-04 \\
\hline 153 & 950.00 & 2.05511 & BE-08 & $4.03830 \mathrm{E}-03$ & $1.23307 \mathrm{E}-07$ & E-09 & $9.40175 \mathrm{E}-08$ & $1.47428 \mathrm{E}-01$ & $3.7403 \mathrm{E}-04$ \\
\hline 154 & 960.00 & $2.05511 \mathrm{E}-07$ & $4.11023 \mathrm{E}-08$ & $4.03830 \mathrm{E}-03$ & $1.23307 \mathrm{E}-07$ & 4.11023E-09 & $9.40175 \mathrm{E}-08$ & $1.49001 \mathrm{E}-01$ & $3.7403 \mathrm{E}-04$ \\
\hline 155 & 970.00 & $2.05511 \mathrm{E}-07$ & $4.11023 \mathrm{E}-08$ & $4.03830 \mathrm{E}-03$ & $1.23307 \mathrm{E}-07$ & $4.11023 \mathrm{E}-09$ & $9.40175 \mathrm{E}-08$ & $1.50573 \mathrm{E}-01$ & 3.7403E-04 \\
\hline $\begin{array}{l}1 \mathrm{ar} \\
14\end{array}$ & 90 & & ח & & דח זדחרר 1 & $\mid 1110$ & n Anater mo & & \\
\hline
\end{tabular}

Figure F-9. Spreadsheet "Transport_Calc_all_colloids.xls;" Calculated Solutions and Equation Terms, Iterated in Time, for Mixing Cell Colloid Model, Time 640 - 970 Years 


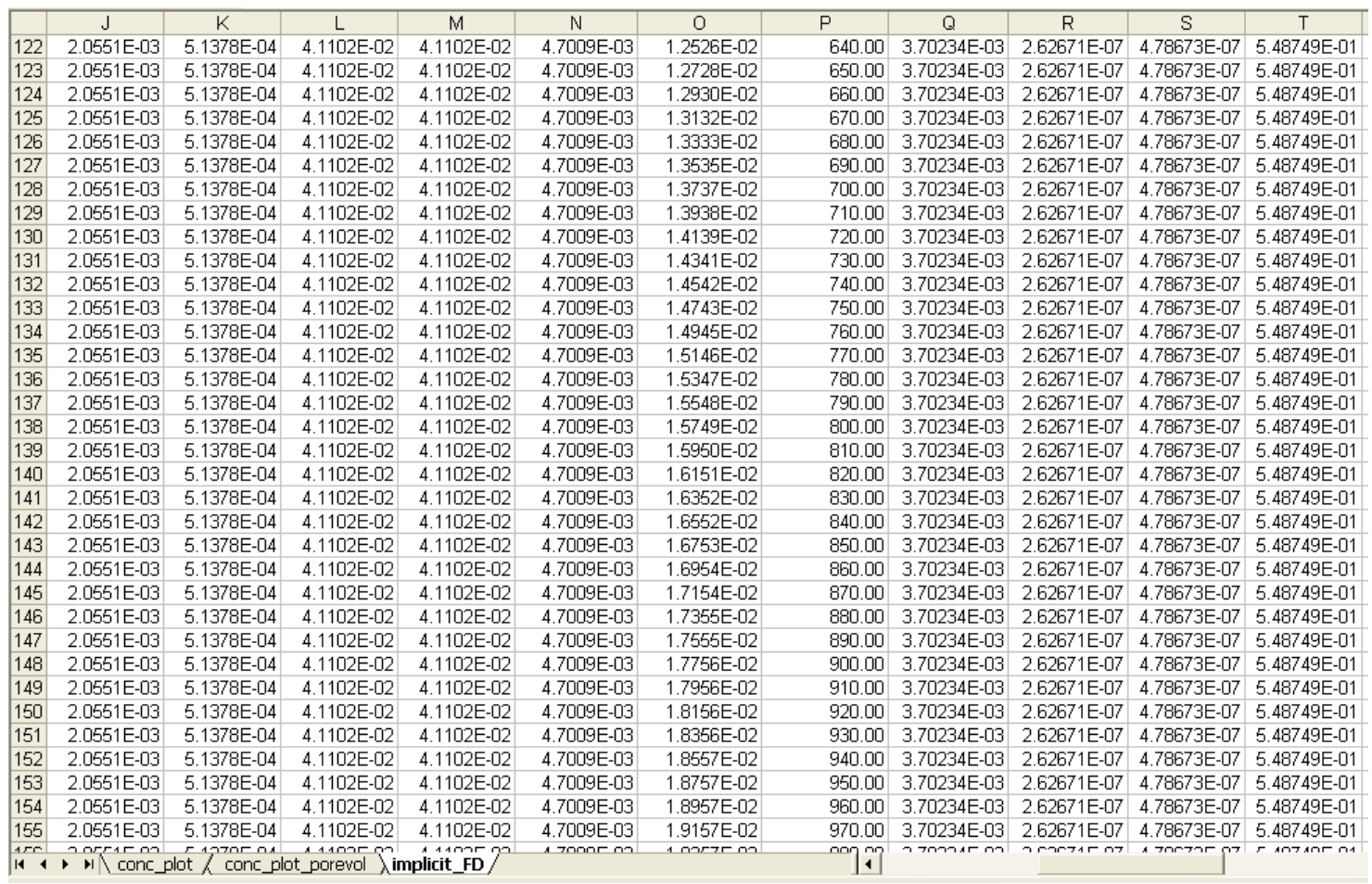

Figure F-10. Spreadsheet "Transport_Calc_all_colloids.xls;" Additional Calculated Solutions and Equation Terms, Iterated in Time, for Mixing Cell Colloid Model, Time 640 - 970 Years

\begin{tabular}{|c|c|c|c|c|c|c|c|c|c|}
\hline & U & $v$ & W & $\lambda$ & $r$ & 2 & $A \mathrm{~A}$ & AD & \\
\hline 22 & 9289E-04 & 61959E-12 & $\mathrm{E}-03$ & EE-03 & $\mathrm{E}+00$ & EE-03 & E-08 & $\mathrm{E}-03$ & 1.12757E-17 \\
\hline 23 & E-04 & -12 & & & & & & & \\
\hline 24 & 3E-04 & $E-13$ & & & & & & & \\
\hline 25 & 9E-04 & $E-13$ & & & $E+00$ & & & & \\
\hline 26 & 9E-04 & $E-13$ & & & $0 E+00$ & & & & \\
\hline 27 & 9E-04 & $=-13$ & & & $0 \mathrm{E}+00$ & & & & \\
\hline 28 & E-04 & $=-13$ & & & $00 E+00$ & & & & \\
\hline 29 & 29289E-04 & E-13 & & & $0 E+00$ & & & & $E+100$ \\
\hline 30 & E-04 & $26 \mathrm{E}-13$ & & & $\mathrm{DE}+00$ & & & & \\
\hline 31 & E-04 & E-14 & & $6 \mathrm{E}-03$ & $0 \mathrm{E}+00$ & & & & $2 \mathrm{E}-18$ \\
\hline 32 & 1.29289E-04 & E-14 & & & & & & & $9 \mathrm{E}-18$ \\
\hline a & & & & & & & & & $=-17$ \\
\hline 34 & 1 & & & & & & & & E-17 \\
\hline 0. & & -14 & & & & & & & $=-17$ \\
\hline 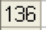 & 4 & -14 & & & & & & & E-17 \\
\hline 37 & E-04 & -14 & & & & & & & -18 \\
\hline 30 & $=-04$ & -15 & 3.7 & -3 & $E+00$ & 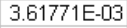 & 88 & 8Ut & E-17 \\
\hline 39 & 1.29289E-04 & 5.2880 & 3.7 & -3 & $E+00$ & & 88 & $76 \mathrm{E}$ & E-17 \\
\hline 40 & 9E-04 & -15 & 3.7 & -3 & $E+00$ & & 08 & $72 \mathrm{E}-03$ & E-17 \\
\hline 4 & 1.29 & 2.6956 & 3.7 & -3 & $E+00$ & 03 & & 03 & -17 \\
\hline 42 & 1.292 & 15 & & & 10 & & & & -17 \\
\hline 43 & $=-04$ & $=-15$ & & & 10 & & & & $=-17$ \\
\hline 44 & -04 & 16 & & & & & & & E-17 \\
\hline 145 & 04 & & & & & & & & -18 \\
\hline . & & -16 & & & $E+00$ & & & & E-18 \\
\hline 47 & 1 & & & & & & & & E-17 \\
\hline 148 & & & & & & & & & E-17 \\
\hline 149 & & & & & & & & & -17 \\
\hline 150 & & $=-16$ & & & & & & & $=-17$ \\
\hline 151 & $=-04$ & & & & & & & & $=-17$ \\
\hline 52 & $1.29289 \mathrm{E}-04$ & 6.55549E-17 & & $E-U$ & & & & 7E-03 & OE-17 \\
\hline 153 & 1.29289E-04 & E-17 & & 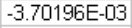 & & & & 4E-03 & $5 \mathrm{E}-17$ \\
\hline 15 & 89E-04 & -17 & & & & & & 20E-03 & 99E-17 \\
\hline 15 & 39E-04 & |E-17 & 6E-03 & $6 \mathrm{E}-03$ & $\mathrm{DE}+00$ & & 1655E-08 & 17E-03 & $78 \mathrm{E}-17$ \\
\hline & & & & & & & & & \\
\hline
\end{tabular}

Figure F-11. Spreadsheet "Transport_Calc_all_colloids.xls;" Final Calculated Solutions and Equation Terms, Iterated in Time, for Mixing Cell Colloid Model, Time 640 - 970 Years 


\begin{tabular}{|c|c|c|c|c|c|c|c|c|c|}
\hline & A & $B$ & C & D & $E$ & $\mathrm{~F}$ & $G$ & $\mathrm{H}$ & 1 \\
\hline 156 & 980.00 & 2.05511E-07 & 4.11023E-08 & 4.03830E-03 & 1.23307E-07 & 4.11023E-09 & $9.40175 \mathrm{E}-08$ & 1.52144E-01 & $3.7403 \mathrm{E}-04$ \\
\hline 157 & 990.00 & $2.05511 \mathrm{E}-07$ & 4.11023E-08 & 4.03830E-03 & 1.23307E-07 & 4.11023E-09 & $9.40175 \mathrm{E}-08$ & $1.53716 \mathrm{E}-01$ & 3.7403E-04 \\
\hline 158 & 1000.00 & $2.05511 \mathrm{E}-07$ & 4.11023E-08 & 4.03830E-03 & $1.23307 \mathrm{E}-07$ & 4.11023E-09 & $9.40175 \mathrm{E}-08$ & $1.55286 \mathrm{E}-01$ & 3.7403E-04 \\
\hline 159 & & & & & & & & & \\
\hline
\end{tabular}

Figure F-12. Spreadsheet "Transport_Calc_all_colloids.xls;" Calculated Solutions and Equation Terms, Iterated in Time, for Mixing Cell Colloid Model, Time 980 - 1000 Years

\begin{tabular}{|c|c|c|c|c|c|c|c|c|c|c|c|}
\hline & $J$ & $\mathrm{~K}$ & $L$ & $M$ & $N$ & 0 & $\mathrm{P}$ & $Q$ & $\mathrm{R}$ & $S$ & $T$ \\
\hline 156 & 2.0551E-03 & $5.1378 \mathrm{E}-04$ & $4.1102 \mathrm{E}-02$ & $4.1102 \mathrm{E}-02$ & $4.7009 \mathrm{E}-03$ & 1.9357E-02 & 980.00 & 3.70234E-03 & 2.62671E-07 & 4.78673E-07 & 5.48749E-01 \\
\hline 157 & $2.0551 \mathrm{E}-03$ & $5.1378 \mathrm{E}-04$ & 4.1102E-02 & 4.1102E-02 & $4.7009 \mathrm{E}-03$ & 1.9557E-02 & 990.00 & 3.70234E-03 & 2.62671E-07 & 4.78673E-07 & 5.48749E-01 \\
\hline 158 & $2.0551 \mathrm{E}-03$ & $5.1378 \mathrm{E}-04$ & 4.1102E-02 & 4.1102E-02 & 4.7009E-03 & 1.9757E-02 & 1000.00 & 3.70234E-03 & 2.62671E-07 & 4.78673E-07 & 5.48749E-01 \\
\hline 159 & & & & & & & & & & & \\
\hline
\end{tabular}

Figure F-13. Spreadsheet "Transport_Calc_all_colloids.xls;" Additional Calculated Solutions and

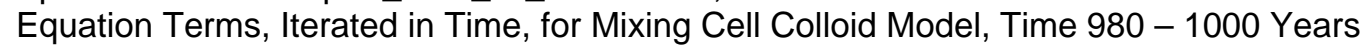

\begin{tabular}{|c|c|c|c|c|c|c|c|c|c|}
\hline & $U$ & $V$ & $W$ & $X$ & $Y$ & $Z$ & AA & AB & AC \\
\hline 156 & $1.29289 \mathrm{E}-04$ & $1.78786 \mathrm{E}-17$ & $3.70196 \mathrm{E}-03$ & $-3.70196 \mathrm{E}-03$ & $0.00000 \mathrm{E}+00$ & $3.59904 \mathrm{E}-03$ & $-9.40655 \mathrm{E}-08$ & $3.59913 \mathrm{E}-03$ & $3.94650 \mathrm{E}-17$ \\
\hline 157 & $1.29289 \mathrm{E}-04$ & $1.19191 \mathrm{E}-17$ & $3.70196 \mathrm{E}-03$ & $-3.70196 \mathrm{E}-03$ & $0.00000 \mathrm{E}+00$ & $3.59800 \mathrm{E}-03$ & $-9.40655 \mathrm{E}-08$ & $3.59810 \mathrm{E}-03$ & $4.25007 \mathrm{E}-17$ \\
\hline 158 & $1.29289 \mathrm{E}-04$ & $9.93245 \mathrm{E}-18$ & $3.70196 \mathrm{E}-03$ & $-3.70196 \mathrm{E}-03$ & $0.00000 \mathrm{E}+00$ & $3.59697 \mathrm{E}-03$ & $-9.40655 \mathrm{E}-08$ & $3.59706 \mathrm{E}-03$ & $3.90313 \mathrm{E}-18$ \\
\hline 159 & & & & & & & & & \\
\hline
\end{tabular}

Figure F-14. Spreadsheet "Transport_Calc_all_colloids.xls;" Final Calculated Solutions and Equation Terms, Iterated in Time, for Mixing Cell Colloid Model, Time 980 - 1000 Years

\section{SPREADSHEET “FLUX_OUT_RATIO.XLS”}

The purpose of this spreadsheet is to demonstrate the use of the irreversible linear reaction rate constant to fit a specified flux out ratio. The spreadsheet calculates and plots the figures "Limiting Flux Out Ratio as a function of Irreversible Reaction Rate" and "Linear reaction rate from colloid to total flux out ratio."

The calculations for flux out ratio as a function of $k$, linear irreversible reaction rate, are done in Worksheet "adv_diff_decay." The calculations for $k$ as a function of flux out ratio are done in Worksheet "K-surface." This description refers to equations from Appendix B, "Implementation of Radionuclide Sorption onto Colloidal and Stationary Phases with Finite Difference Solution.”

\section{Description of Input Values}

The first 29 rows of the worksheet contain the input data values with the exception of Row 12, where pore volume is computed. Column D contains typical input values . Column B contains values from Column D that are scaled for unit conversion of mass (kg), length (m), and time (yr). An image of the first 31 rows of the Microsoft Excel spreadsheet is shown in Figure F-15.

Row 2: $\quad$ c_s $\left[\mathrm{kg} / \mathrm{m}^{\wedge} 3\right]$

$c_{s}\left(\mathrm{mg} \mathrm{L}^{-1}\right)=$ Pu solubility

$\$ B \$ 2=\$ D \$ 2 / 1000$ 
Row 3: phi_1

$\phi \_1$, porosity of the waste form cell_1

\section{$\$ B \$ 3=\$ D \$ 3$}

\section{Row 4: phi_2}

$\phi \_2$, porosity of the corrosion product mass in waste form cell_2

\section{\$B $\$ 4=\$ D \$ 4$}

Row 5: phi_3

$\phi \_3$, porosity of the invert

\section{$\$ B \$ 5=\$ D \$ 5$}

Row 6: u $\left.\quad \mathrm{m} \mathrm{m}^{\wedge} 3 / \mathrm{yr}\right]$

$u$, volumetric water flux

\section{$\$ B \$ 6=\$ D \$ 6$}

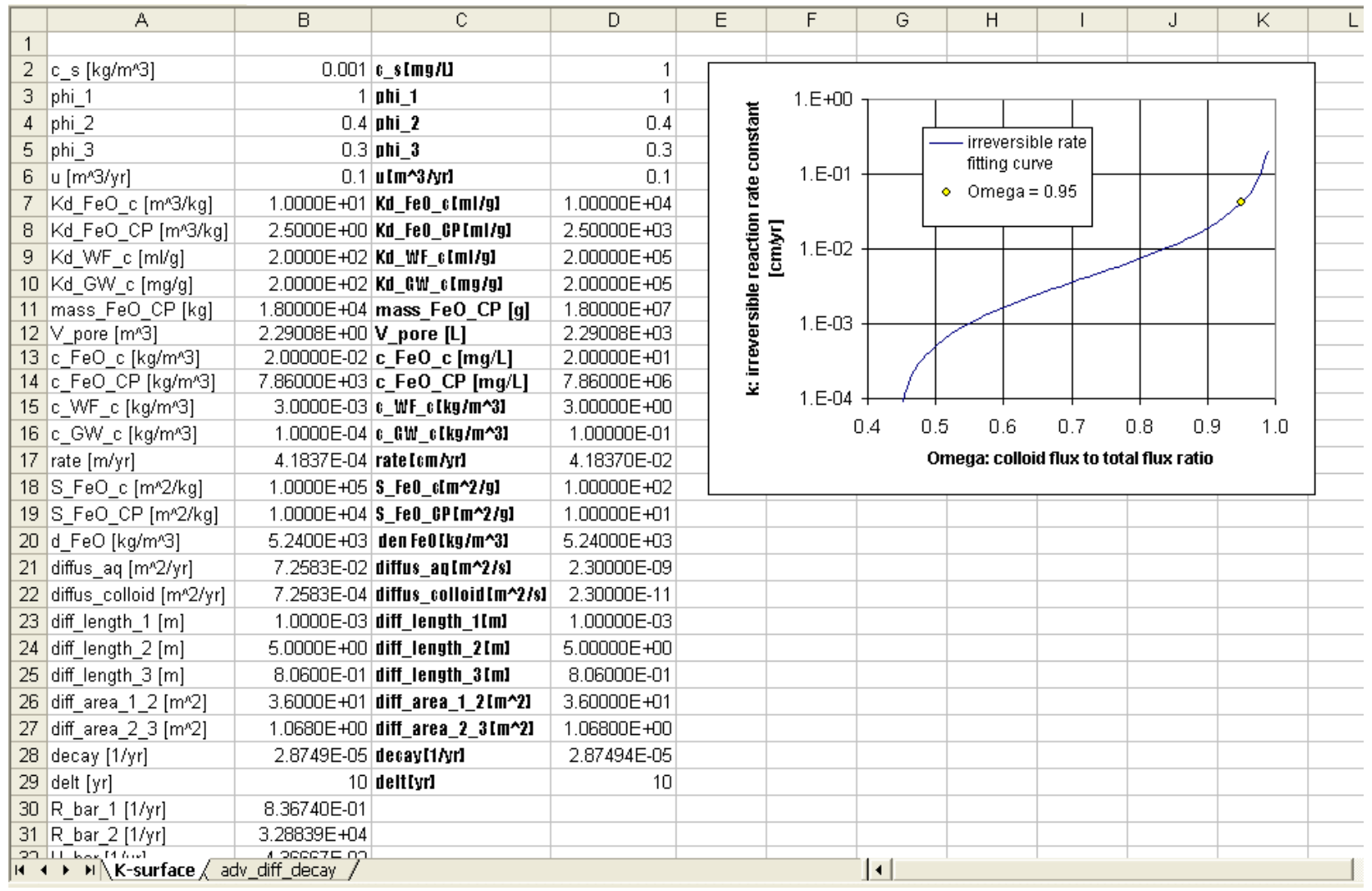

Figure F-15. Spreadsheet "flux_out_ratio.xls," Worksheet "K-surface;" Summary of Inputs

Row 7: Kd_FeO_c $\left[\mathrm{m}^{\wedge} 3 / \mathrm{kg}\right]$

$K_{d_{-} \mathrm{FeO}_{-} c}$, partition coefficient in the FeO colloid state

$\$ \mathrm{~B} \$ 7=\$ \mathrm{D} \$ 7 / 1000$ 
Row 8: Kd_FeO_CP $\left[\mathrm{m}^{\wedge} 3 / \mathrm{kg}\right]$

$K_{d_{-} F e O_{-} C P}$, partition coefficient in the stationary $\mathrm{FeO}$ corrosion product state

$\$ B \$ 8=\$ D \$ 8 / 1000$

Row 9: $\quad$ Kd_WF_c $\left[\mathrm{m}^{\wedge} 3 / \mathrm{kg}\right]$

$K_{d_{-} W F_{-} c}$, partition coefficient in the waste form colloid state

$\$ B \$ 9=\$ D \$ 9 / 1000$

Row 10: Kd_GW_c [m^3/kg]

$K_{d_{-} G W_{-} c}$, partition coefficient in the GW colloid state

$\$ \mathrm{~B} \$ 10=\$ \mathrm{D} \$ 10 / 1000$

Row 11: mass_FeO_CP [kg]

$m_{\mathrm{FeO} \_} \mathrm{CP}$, mass of corrosion products

$\$ B \$ 11=\$ D \$ 11 / 1000$

Row 12: V_pore $\left[\mathrm{m}^{\wedge} 3\right]$

$V_{\text {pore }}=\phi V_{\text {bulk }}=\frac{\phi}{1-\phi} \frac{m_{\mathrm{FeO} \_C P}}{\rho_{\mathrm{FeO} \_\mathrm{CP}}}$, pore volume

$\$ B \$ 12=\$ D \$ 12 / 1000$

$\$ D \$ 12=\$ D \$ 4 * \$ D \$ 11 /(\$ D \$ 20 *(1-\$ D \$ 4))$

Row 13: c_FeO_c $\left[\mathrm{kg} / \mathrm{m}^{\wedge} 3\right]$

$C_{\mathrm{Pu}_{-} \mathrm{FeO} \_\mathrm{c}}$, concentration of FeO colloids

$\$ B \$ 13=\$ D \$ 13 / 1000$

Row 14: C_FeO_CP $\left[\mathrm{kg} / \mathrm{m}^{\wedge} 3\right]$

$C_{P u_{-} F e O_{-} C P}$, concentration of $\mathrm{FeO}$ corrosion product

\$B \$14=\$D $\$ 14 / 1000$

Row 15: c_WF_c [kg/m^3]

$c_{\mathrm{Pu}_{-} \mathrm{WF}_{-} \mathrm{c}}$, concentration of waste form colloids

$\$ B \$ 15=\$ D \$ 15 / 1000$

Row 16: c_GW_c $\left[\mathrm{kg} / \mathrm{m}^{\wedge} 3\right]$

$C_{P_{u_{-} G W_{-} c}}$, concentration of GW colloid state

$\$ \mathrm{~B} \$ 16=\$ \mathrm{D} \$ 16 / 1000$ 
Row 17: $\quad k[\mathrm{~m} / \mathrm{yr}]$

$k$, intrinsic or surface reaction rate $\left(\mathrm{m}^{3} \mathrm{~m}^{-2} \mathrm{yr}^{-1}\right)$

$\$ B \$ 17=\$ D \$ 17 / 100$

Row 18: S_FeO_c [m^2/kg]

$\hat{S}_{\mathrm{FeO}_{-} \mathrm{c}}=$ specific surface area of FeO colloids $\left(\mathrm{m}^{2} \mathrm{~kg}^{-1}\right)$

$\$ B \$ 18=\$ D \$ 18 * 1000$

Row 19: S_FeO_CP $\left[\mathrm{m}^{\wedge} 2 / \mathrm{kg}\right]$

$\hat{S}_{\mathrm{FeO} C \mathrm{CP}}=$ specific surface area of FeO corrosion products $\left(\mathrm{m}^{2} \mathrm{~kg}^{-1}\right)$

$\$ B \$ 19=\$ D \$ 19 * 1000$

Row 20: d_FeO $\left[\mathrm{kg} / \mathrm{m}^{\wedge} 3\right]$

$\rho_{\mathrm{FeO}_{-} \mathrm{CP}}=$ density of $\mathrm{FeO}$

$\$ B \$ 20=\$ D \$ 20$

Row 21: diffus_aq [m^2/yr]

$D_{a q}=$ aqueous diffusivity

$\$ B \$ 21=\$ D \$ 21 * 31558000$

Row 22: diffus_colloid [m^2/yr]

$D_{\text {colloid }}=$ colloid diffusivity

$\$ B \$ 22=\$ D \$ 22 * 31558000$

Row 23: diff_length_1 [m]

$L_{1}=$ diffusive length for cell_1

$\$ B \$ 23=\$ D \$ 23$

Row 24: diff_length_2 [m]

$L_{2}=$ diffusive length for cell_2

\$B \$24=\$D $\$ 24$

Row 25: diff_length_3 [m]

$L_{3}=$ diffusive length for cell_3

$\$ B \$ 25=\$ D \$ 25$

Row 26: diff_area_1_2 [m²]

$A_{\text {s12 }}=$ diffusive area at cell_1 and cell_2 interface

$\$ B \$ 26=\$ D \$ 26$ 
Row 27: diff_area_2_3 [m²]

$A_{s 23}=$ diffusive area at cell_2 and cell_3 interface

$\$ B \$ 27=\$ D \$ 27$

Row 28: decay [1/yr]

$\lambda$, decay rate

$\$ B \$ 28=\$ D \$ 28$

Row 29: delt [yr]

$\Delta t$, time step length

$\$ B \$ 29=\$ D \$ 29$

Rows 30 through 51 contain additional derived parameters for the colloid model. Images of Rows 32 through 100 are shown at the end of the description of this spreadsheet.

Row 30: R_bar_1 [1/yr]

$\bar{R}_{1}=\hat{S}_{\mathrm{FeO} \_} C_{\mathrm{FeO}} c k$, reaction rate constant for colloids

$\$ B \$ 30=\$ B \$ 18 * \$ B \$ 13 * \$ B \$ 17$

Row 31: R_bar_2 [1/yr]

$\bar{R}_{2}=\hat{S}_{\mathrm{FeO} \_\mathrm{CP}} C_{\mathrm{FeO} \mathrm{C}_{-} \mathrm{CP}} k$, reaction rate constant for corrosion products

$\$ \mathrm{~B} \$ 31=\$ \mathrm{~B} \$ 19 * \$ \mathrm{~B} \$ 14 * \$ \mathrm{~B} \$ 17$

Row 32: U_bar [1/yr]

$\bar{U}=$ advective rate constant

$\$ \mathrm{~B} \$ 32=\$ \mathrm{~B} \$ 6 / \$ \mathrm{~B} \$ 12$

Row 33: Kd_bar_FeO_c

dimensionless partition coefficient in the $\mathrm{FeO}$ colloid state

$\$ B \$ 33=\$ B \$ 13 * \$ B \$ 7$

Row 34: Kd_bar_FeO_CP

dimensionless partition coefficient in the $\mathrm{FeO}$ corrosion product state $\$ B \$ 34=\$ B \$ 14 * \$ B \$ 8$

Row 35: Kd_bar_WF_c

dimensionless partition coefficient in the waste form colloid state

$\$ B \$ 35=\$ B \$ 15 * \$ B \$ 9$ 
Row 36: Kd_bar_GW_c

dimensionless partition coefficient in the GW colloid state

$\$ B \$ 36=\$ B \$ 16 * \$ B \$ 10$

Row 37: K_bar_1

$\bar{K}_{1}=1+\bar{K}_{d_{-} F e O_{-} c}+\bar{K}_{d_{-} F e O_{-} C P}+\bar{K}_{d_{-} W F_{-} c}+\bar{K}_{d_{-} G W_{-} c}$, combination of dimensionless partition coefficients

$\$ \mathrm{~B} \$ 37=1+\$ \mathrm{~B} \$ 33+\$ \mathrm{~B} \$ 34+\$ \mathrm{~B} \$ 35+\$ \mathrm{~B} \$ 36$

Row 38: K_bar_2

$\bar{K}_{2}=1+\bar{K}_{d_{-} F e O_{-} c}+\bar{K}_{d_{-} W F_{-} c}+\bar{K}_{d_{-} G W_{-} c}$, combination of dimensionless partition coefficients

$\$ \mathrm{~B} \$ 38=1+\$ \mathrm{~B} \$ 33+\$ \mathrm{~B} \$ 35+\$ \mathrm{~B} \$ 36$

Row 39: K_bar_3

$\bar{K}_{3}=\bar{K}_{d_{-} F e O_{-} c}+\bar{K}_{d_{-} W F_{-} c}+\bar{K}_{d_{-} G W_{-} c}$, combination of dimensionless partition coefficients

$\$ B \$ 39=\$ B \$ 33+\$ B \$ 35+\$ B \$ 36$

Row 40: Diff_left_aq [1/yr]

diffusive rate constant, left interface in water

$\$ B \$ 40=(\$ B \$ 26 /(\$ B \$ 23 /(\$ B \$ 3 * \$ B \$ 21)+\$ B \$ 24 /(\$ B \$ 4 * \$ B \$ 21))) / \$ B \$ 12$

Row 41: Diff_right_aq

diffusive rate constant, right interface in water

$\$ B \$ 41=(\$ B \$ 27 /(\$ B \$ 24 /(\$ B \$ 4 * \$ B \$ 21)+\$ B \$ 25 /(\$ B \$ 5 * \$ B \$ 21))) / \$ B \$ 12$

Row 42: Diff_right_colloid

diffusive rate constant, right interface colloids

$\$ \mathrm{~B} \$ 42=(\$ \mathrm{~B} \$ 27 /(\$ \mathrm{~B} \$ 24 /(\$ \mathrm{~B} \$ 4 * \$ \mathrm{~B} \$ 22)+\$ \mathrm{~B} \$ 25 /(\$ \mathrm{~B} \$ 5 * \$ \mathrm{~B} \$ 22))) / \mathrm{B} \$ 12$

Row 43: Omega

$$
\Omega=\frac{\text { colloid mass flux out }}{\text { total mass flux out }}
$$

$\$ B \$ 43=(\$ B \$ 44+\$ B \$ 30) /(\$ B \$ 45+\$ B \$ 30)$

Row 44: p_1

$p_{1}=\bar{K}_{3}\left(\bar{U}+\bar{D}_{\text {right_col }}+\lambda\right)$

$\$ B \$ 44=\$ B \$ 39 *(\$ B \$ 32+\$ B \$ 42+\$ B \$ 28)$ 
Row 45: p_2

$$
\begin{aligned}
& p_{2}=\left(\overline{U K}_{2}+\bar{D}_{\text {right_aq }}+\bar{D}_{\text {right_col }} \bar{K}_{3}\right)\left(\frac{\bar{U}+\bar{D}_{\text {right_col }}+\lambda}{\bar{U}+\bar{D}_{\text {right_col }}}\right) \\
& \$ \mathrm{~B} \$ 45=(\$ \mathrm{~B} \$ 32 * \$ \mathrm{~B} \$ 38+\$ \mathrm{~B} \$ 41+\$ \mathrm{~B} \$ 42 * \$ \mathrm{~B} \$ 39) *(\$ \mathrm{~B} \$ 32+\$ \mathrm{~B} \$ 42+\$ \mathrm{~B} \$ 28) /(\$ \mathrm{~B} \$ 3 \\
& 2+\$ B \$ 42)
\end{aligned}
$$

Row 46: delta

$$
\text { scale value for } k=2.0
$$

Row 47: comments

Rows 48 through 81 are values for the flux out ratio calculated as a function of the irreversible forward reaction rate, Equation B-71. Column A contains the values of $k$, and Column B contains the corresponding values of flux out ratio.

$\$ A \$ 48=0$

$\$ A \$ 49=1 . E-5$

$\$ A 50=\$ B \$ 46 * \$ A 49$

Row 50 is dragged down through Row 81.

Then in Column B the flux out ratio, $\Omega=\frac{\text { colloid mass flux out }}{\text { total mass flux out }}$, is calculated as a function of the irreversible reaction rate value:

$\$ B 48=(\$ B \$ 44+\$ B \$ 18 * \$ B \$ 13 * \$ A 48 * 0.01) /(\$ B \$ 45+\$ B \$ 18 * \$ B \$ 13 * \$ A 48 * 0.01)$

The factor 0.01 converts the irreversible reaction rate constant from units of $\mathrm{cm} \mathrm{yr}^{-1}$ to $\mathrm{m} \mathrm{yr}^{-1}$. The above expression is then dragged down through Row 81.

Figure B-3 in Appendix B, "Limiting Flux Out Ratio as a Function of Irreversible Reaction Rate," is plotted, where:

$x$-axis: $\$ A \$ 49: \$ A \$ 73$

$y$-axis: $\$ B \$ 49: \$ B \$ 73$

The point $k=0.001 \mathrm{~cm} \mathrm{yr}^{-1}$ is

$x$-axis: $\quad$ D $\$ 17: \$ D \$ 17$

$y$-axis: $\$ \mathrm{~B} \$ 43: \$ \mathrm{~B} \$ 43$ 
In Worksheet "K-surface,” Rows 1 through 46 are the same as for Worksheet "adv_diff_decay.” In Worksheet "K-surface," Rows 48 through 100 (Figure F-16), values for the irreversible forward reaction rate, $k$, are calculated as a function of the flux out ratio, $\Omega$, Equation B-72. Column A contains the values of flux out ratio, and Column B contains the corresponding values of $k$.

\$A\$48:

minimum flux out ratio when $\mathrm{k}=0, \Omega=\frac{p_{1}}{p_{2}}$

$\$ A \$ 48=\$ B \$ 44 / \$ B \$ 45$

\$A49 to \$A100: $\quad$ uniform spacing of omega values between the minimum and 1. $\$ A 49=\$ A 48+(1-\$ A \$ 4) / 53$.

\$A49 is dragged down to row 100.

\$B48 to \$B101: $\quad$ irreversible reaction rate. $k=\frac{p_{2} \Omega-p_{1}}{(1-\Omega) \hat{S}_{\mathrm{FeO} O_{-} C_{F e O} c}}$

$\$ B 48=100 *(\$ B \$ 35 * \$ A 48-\$ B \$ 44) /((1-\$ A 48) * \$ B \$ 18 * \$ B \$ 13)$

(The factor of 100 is a conversion from meters to $\mathrm{cm}$.)

\$B \$48 is dragged down through \$B $\$ 100$

Figure B-4 in Appendix B, "Linear Reaction Rate from Colloid to Total Flux Out Ratio," is the plot in Worksheet “K-surface,” where

$x$-axis: $\quad \$ A \$ 49: \$ A \$ 100$

$y$-axis: $\$ B \$ 49: \$ B \$ 100$

The point labeled “Omega $=0.95$ ” is

$x$-axis: $\$ \mathrm{~B} \$ 43: \$ \mathrm{~B} \$ 43$

$y$-axis: $\$ \mathrm{D} \$ 17: \$ \mathrm{D} \$ 17$ 


\begin{tabular}{|c|c|c|c|}
\hline & A & $\mathrm{B}$ & $\mathrm{C}$ \\
\hline 32 & U_bar [1/yr] & $4.36667 \mathrm{E}-02$ & \\
\hline 33 & Kd_FeO_c_bar & $2.00000 \mathrm{E}-01$ & \\
\hline 34 & Kd_FeO_CP_bar & $1.96500 \mathrm{E}+04$ & \\
\hline 35 & Kd_WF_c_bar & $6.00000 \mathrm{E}-01$ & \\
\hline 36 & Kd_GW_c_bar & 2.00000E-02 & \\
\hline 37 & K_1 & $1.96518 \mathrm{E}+[04$ & \\
\hline 38 & $K \_2$ & $1.82000 \mathrm{E}+00$ & \\
\hline 39 & K_3 & $8.200000-01$ & \\
\hline 40 & Diff_left_aq & $9.12736 \mathrm{E}-02$ & \\
\hline 41 & Diff_right_aq & 2.22893E-03 & \\
\hline 42 & Diff_right_colloid & 2.22893E-05 & \\
\hline 43 & Omega & $9.50000 \mathrm{E}-01$ & \\
\hline 44 & p_1 & 3.58485E-02 & \\
\hline 45 & p_2 & $8.17743 \mathrm{E}-02$ & \\
\hline 46 & delta & $2.00 \mathrm{E}+00$ & \\
\hline 47 & Omega & $\mathrm{k}$ & \\
\hline 48 & 0.4384 & $0.0000 \mathrm{E}+00$ & \\
\hline 49 & 0.4490 & 7.8629E-05 & \\
\hline 50 & 0.4596 & $1.6034 \mathrm{E}-04$ & \\
\hline 51 & 0.4702 & $2.4532 \mathrm{E}-04$ & \\
\hline 52 & 0.4808 & 3.3377E-04 & \\
\hline 53 & 0.4914 & $4.2591 \mathrm{E}-04$ & \\
\hline 54 & 0.5020 & $5.2196 \mathrm{E}-04$ & \\
\hline 55 & 0.5126 & $6.2220 \mathrm{E}-04$ & \\
\hline 56 & 0.5232 & 7.2688E-04 & \\
\hline 57 & 0.5338 & $8.3633 \mathrm{E}-04$ & \\
\hline 58 & 0.5443 & 9.5086E-04 & \\
\hline 59 & 0.5549 & 1.0709E-03 & \\
\hline 60 & 0.5655 & 1.1967E-03 & \\
\hline 61 & 0.5761 & 1.3288E-03 & \\
\hline 62 & 0.5867 & 1.4677E-03 & \\
\hline 63 & 0.5973 & $1.6140 \mathrm{E}-03$ & \\
\hline 64 & 0.6079 & $1.7681 \mathrm{E}-03$ & \\
\hline 65 & 0.6185 & $1.9308 \mathrm{E}-03$ & \\
\hline
\end{tabular}

\begin{tabular}{|c|c|c|}
\hline & A & B \\
\hline 66 & 0.6291 & 2.1028E-03 \\
\hline 67 & 0.6397 & 2.2849E-03 \\
\hline 68 & 0.6503 & 2.4780E-03 \\
\hline 69 & 0.6609 & 2.6832E-03 \\
\hline 70 & 0.6715 & 2.9017E-03 \\
\hline 71 & 0.6821 & 3.1347E-03 \\
\hline 72 & 0.6927 & 3.3838E-03 \\
\hline 73 & 0.7033 & $3.6506 \mathrm{E}-03$ \\
\hline 74 & 0.7139 & 3.9373E-03 \\
\hline 75 & 0.7245 & $4.2460 \mathrm{E}-03$ \\
\hline 76 & 0.7351 & 4.5794E-03 \\
\hline 77 & 0.7457 & 4.9405E-03 \\
\hline 78 & 0.7563 & $5.3331 \mathrm{E}-03$ \\
\hline 79 & 0.7669 & $5.7614 \mathrm{E}-03$ \\
\hline 80 & 0.7775 & $6.2304 \mathrm{E}-03$ \\
\hline 81 & 0.7881 & $6.7464 \mathrm{E}-03$ \\
\hline 82 & 0.7987 & $7.3166 \mathrm{E}-03$ \\
\hline 83 & 0.8093 & 7.9503E-03 \\
\hline 84 & 0.8199 & 8.6585E-03 \\
\hline 85 & 0.8305 & 9.4552E-03 \\
\hline 86 & 0.8411 & 1.0358E-02 \\
\hline 87 & 0.8516 & 1.1390E-02 \\
\hline 88 & 0.8622 & 1.2581E-02 \\
\hline 89 & 0.8728 & $1.3970 \mathrm{E}-02$ \\
\hline 90 & 0.8834 & $1.5611 \mathrm{E}-02$ \\
\hline 91 & 0.8940 & 1.7581E-02 \\
\hline 92 & 0.9046 & 1.9989E-02 \\
\hline 93 & 0.9152 & 2.2999E-02 \\
\hline 94 & 0.9258 & 2.6869E-02 \\
\hline 95 & 0.9364 & $3.2028 \mathrm{E}-02$ \\
\hline 96 & 0.9470 & $3.9252 \mathrm{E}-02$ \\
\hline 97 & 0.9576 & 5.0087E-02 \\
\hline 98 & 0.9682 & 6.8145E-02 \\
\hline 99 & 0.9788 & 1.0426E-01 \\
\hline $10 n$ & $\square x$ & $\Gamma$ \\
\hline
\end{tabular}

\begin{tabular}{|c|c|c|}
\hline & A & $\mathrm{B}$ \\
\hline 100 & 0.9894 & $2.1261 \mathrm{E}-01$ \\
\hline 101 & & \\
\hline
\end{tabular}

Figure F-16. Spreadsheet "flux_out_ratio.xls," Worksheet "K-surface;" Calculation of Irreversible Forward Reaction Rate, $k$, as Function of Flux Out Ratio, $\Omega$

\section{SPREADSHEET “TIME_TO_CONV.XLS”}

The purpose of this spreadsheet is to demonstrate the time to converge for the Pu concentration in solution and the irreversible $\mathrm{Pu}$ concentration on colloids. The spreadsheet verifies the convergence estimate discussed in Section "Convergence Estimates For Closed Form Solutions” in Appendix B. 
The calculations are done in Worksheet "time_to_conv," while the plot is in Worksheet "plot_time_to_conv." This description will refer to equations from Appendix B, "Implementation of Radionuclide Sorption onto Colloidal and Stationary Phases with Finite Difference Solution.”

\section{Description of Input Values}

The first 29 rows of each worksheet contain the input data values, with the exception of Row 12, where pore volume is computed. Column D contains input values. Column B contains values from column $\mathrm{D}$ that are scaled for unit conversion of mass (kg), length (m), time (yr). An image of Rows 1 through 33 is shown on the next page.

Row 2: $\quad$ c_s $\left[\mathrm{kg} / \mathrm{m}^{\wedge} 3\right]$

$c_{s}\left(\mathrm{mg} \mathrm{L}^{-1}\right)=$ Pu solubility

$\$ B \$ 2=\$ D \$ 2 / 1000$

Row 3: phi_1

$\phi \_1$, porosity of the waste form cell_1

$\$ B \$ 3=\$ D \$ 3$

Row 4: phi_2

$\phi \_2$, porosity of the corrosion product mass in waste form cell_2

$\$ B \$ 4=\$ D \$ 4$

Row 5: phi_3

$\phi_{-} 3$, porosity of the invert

$\$ \mathrm{~B} \$ 5=\$ \mathrm{D} \$ 5$

Row 6: $u\left[\mathrm{~m}^{\wedge} 3 / \mathrm{yr}\right]$

$u=$ volumetric water flux $\left(\mathrm{m}^{3} \mathrm{yr}^{-1}\right)$

$\$ B \$ 6=\$ D \$ 6$

Row 7: Kd_FeO_c $\left[\mathrm{m}^{\wedge} 3 / \mathrm{kg}\right]$

$K_{d_{-} \mathrm{FeO}_{-} c}$, partition coefficient in the $\mathrm{FeO}$ colloid state

$\$ B \$ 7=\$ D \$ 7 / 1000$ 


\begin{tabular}{|c|c|c|c|c|}
\hline & $\mathrm{A}$ & $\mathrm{B}$ & $\mathrm{C}$ & D \\
\hline 1 & \multicolumn{2}{|c|}{ Input for Excel sreadsheet } & \multicolumn{2}{|c|}{ Input from GoldSim } \\
\hline 2 & c_s $\left[\mathrm{kg} / \mathrm{m}^{n} 3\right]$ & 0.001 & G_s[mg/l] & 1 \\
\hline 3 & phi_1 & 1 & ahi_1 & 1 \\
\hline 4 & phi_2 & 0.4 & 口hi_2 & 0.4 \\
\hline 5 & phi_3 & 0.3 & 口hi_3 & 0.3 \\
\hline 6 & $u\left[\mathrm{~m}^{\mathrm{n}} 3 / \mathrm{yr}\right]$ & 0.1 & $u[\mathrm{~m} \wedge 3 \mathrm{hr}]$ & 0.1 \\
\hline 7 & $\mathrm{Kd} \_\mathrm{FeO} \_\mathrm{c}\left[\mathrm{m}^{n} \mathrm{3} / \mathrm{kg}\right]$ & 1.00000E+01 & Kd_FeO_c $[\mathrm{ml} / \mathrm{g}]$ & 1.00000E+[04 \\
\hline 8 & $\mathrm{Kd} \_\mathrm{FeO} \_\mathrm{CP}\left[\mathrm{m}^{n} 3 / \mathrm{kg}\right]$ & $2.50000 \mathrm{E}+00$ & $\mathrm{Kd}+\mathrm{FeO} \mathrm{CP}[\mathrm{ml} / \mathrm{g}]$ & $2.50000 \mathrm{E}+03$ \\
\hline 9 & Kd_WF_c $\left[\mathrm{m}^{n} 3 / \mathrm{kg}\right]$ & $2.00000 E+02$ & Kd_WF_c [ml/g] & $2.00000 E+05$ \\
\hline 10 & $\mathrm{Kd} G W_{-} c\left[\mathrm{~m}^{n} 3 / \mathrm{kg}\right]$ & $2.00000 E+02$ & Kd_GW_c [ml/g] & $2.00000 \mathrm{E}+05$ \\
\hline 11 & mass_FeO_CP $[\mathrm{kg}]$ & $1.80000 \mathrm{E}+104$ & mass_FeO_CP [g] & $1.80000 \mathrm{E}+07$ \\
\hline 12 & V_pore $\left[\mathrm{m}^{n} \overline{3}\right]$ & $2.29008 \mathrm{E}+00$ & V_pore [L] & $2.29008 \mathrm{E}+03$ \\
\hline 13 & c_FeO_c $\left[\mathrm{kg} / \mathrm{m}^{n} 3\right]$ & 2.00000E-02 & c_FeO_c [mg/L] & $2.00000 \mathrm{E}+01$ \\
\hline 14 & c_FeO_CP $\left[\mathrm{kg} / \mathrm{m}^{n} 3\right]$ & $7.86000 E+03$ & c_FeO_CP [mg/L] & $7.86000 \mathrm{E}+06$ \\
\hline 15 & c_WF_c $\left[\mathrm{kg} / \mathrm{m}^{n} 3\right]$ & 3.00000E-03 & c_WF_c [mg/L] & $3.00000 E+00$ \\
\hline 16 & c_GW_c $\left[\mathrm{kg} / \mathrm{m}^{n} 3\right]$ & 1.00000E-04 & c_GW_c [mg/L] & 1.00000E-01 \\
\hline 17 & rate $[\overline{\mathrm{m}} / \mathrm{yr}]$ & $1.00000 \mathrm{E}-05$ & rate $[\mathrm{cm} / \mathrm{yr}]$ & 1.00000E-03 \\
\hline 18 & S_FeO_c $\left[\mathrm{m}^{n} 2 / \mathrm{kg}\right]$ & 1.00000E+05 & S_FeO_c[m $\left.{ }^{\wedge} 2 / g\right]$ & 1.00000E+02 \\
\hline 19 & S_FeO_CP $\left[\mathrm{m}^{n} 2 / \mathrm{kg}\right]$ & 1.00000E+04 & S_FeO_CP $\left[m^{\wedge} 2 / g\right]$ & 1.00000E+01 \\
\hline 20 & d_FeO $\left[\mathrm{kg} / \mathrm{m}^{n} 3\right]$ & $5.24000 \mathrm{E}+03$ & den FeO $\left[\mathrm{kg} / \mathrm{m}^{\wedge} 3\right]$ & $5.24000 \mathrm{E}+03$ \\
\hline 21 & diffus_aq [m²/yr] & 7.25834E-02 & diffus_aq $\left[m^{\wedge} 2 / s\right]$ & 2.30000E-09 \\
\hline 22 & diffus_colloid [ $\left.\mathrm{m}^{n} 2 / \mathrm{yr}\right]$ & 7.25834E-04 & diffus_colloid [ $\left.\mathrm{m}^{\wedge} 2\right]$ & $2.30000 \mathrm{E}-11$ \\
\hline 23 & diff_length_1 [m] & $1.00000 \mathrm{E}-03$ & diff_length_1 [m] & 1.00000E-03 \\
\hline 24 & diff_length_2 [m] & $5.00000 E+00$ & diff_length_2 [m] & $5.00000 \mathrm{E}+00$ \\
\hline 25 & diff_length_ $3[\mathrm{~m}]$ & 8.06000E-01 & diff length $3[\mathrm{~m}]$ & $8.06000 \mathrm{E}-01$ \\
\hline 26 & diff_area_1_2 [ $\left.\mathrm{m}^{n} 2\right]$ & $3.60000 \mathrm{E}+01$ & diff_area_1_2 $\left[\mathrm{m}^{\wedge} 2\right]$ & $3.60000 \mathrm{E}+01$ \\
\hline 27 & diff_area_2_3 [m $\left.\mathrm{m}^{\mathrm{n}} \mathrm{2}\right]$ & $1.06800 E+00$ & diff_area_2_3 $\left[\mathrm{m}^{\wedge} 2\right]$ & $1.06800 \mathrm{E}+00$ \\
\hline 28 & decay $[1 \overline{y r}]$ & 2.87494E-05 & decay $[1 / \bar{y}]$ & 2.87494E-05 \\
\hline 29 & delt $[y r]$ & 1.00000E+01 & delt [yr] & 10 \\
\hline 30 & R_bar_1 [1/yr] & 2.00000E-02 & & \\
\hline 31 & R_bar_2 [1/yr] & $7.86000 \mathrm{E}+02$ & & \\
\hline 32 & U_bar [1/yr] & $4.36667 \mathrm{E}-02$ & & \\
\hline 33 & Kd_bar_FeO_c & 2.000000E-01 & & \\
\hline $2 x$ & 1/d hactar plot & $\begin{array}{l}1 \text { nefnnc ind } \\
\text { cony time t }\end{array}$ & & \\
\hline
\end{tabular}

Figure F-17. Spreadsheet "time_to_conv.xls," Worksheet "time_to_conv;" Summary of Inputs

Row 8: Kd_FeO_CP [m³/kg]

$K_{d_{-} \mathrm{FeO}_{-} \mathrm{CP}}$, partition coefficient in the stationary FeO corrosion product state

$\$ \mathrm{~B} \$ 8=\$ \mathrm{D} \$ 8 / 1000$

Row 9: Kd_WF_c $\left[\mathrm{m}^{\wedge} 3 / \mathrm{kg}\right]$

$K_{d_{-} W F_{-} c}$, partition coefficient in the waste form colloid state

$\$ B \$ 9=\$ D \$ 9 / 1000$ 
Row 10: Kd_GW_c [m^3/kg]

$K_{d_{-} G W_{-} c}$, partition coefficient in the GW colloid state

$\$ B \$ 10=\$ D \$ 10 / 1000$

Row 11: mass_FeO_CP [kg]

$m_{\mathrm{FeO} C \mathrm{CP}}$ mass of corrosion products

$\$ \mathrm{~B} \$ 11=\$ \mathrm{D} \$ 11 / 1000$

Row 12: V_pore [m^3]

$V_{\text {pore }}=\phi V_{\text {bulk }}=\frac{\phi}{1-\phi} \frac{m_{\mathrm{FeO} \_\mathrm{CP}}}{\rho_{\mathrm{FeO} \_} \mathrm{CP}}$, pore volume

$\$ \mathrm{~B} \$ 12=\$ \mathrm{D} \$ 12 / 1000$

$\$ D \$ 12=\$ D \$ 4 * \$ D \$ 11 /(\$ D \$ 20 *(1-\$ D \$ 4))$

Row 13: c_FeO_c $\left[\mathrm{kg} / \mathrm{m}^{\wedge} 3\right]$

$c_{\mathrm{Pu}_{-} \mathrm{FeO}_{-} \mathrm{c}}$, concentration of $\mathrm{FeO}$ colloids

$\$ \mathrm{~B} \$ 13=\$ \mathrm{D} \$ 13 / 1000$

Row 14: C_FeO_CP $\left[\mathrm{kg} / \mathrm{m}^{\wedge} 3\right]$

$C_{P_{-} \mathrm{FeO}_{-} \mathrm{CP}}$, concentration of $\mathrm{FeO}$ corrosion product

$\$ B \$ 14=\$ D \$ 14 / 1000$

Row 15: C_WF_c $\left[\mathrm{kg} / \mathrm{m}^{\wedge} 3\right]$

$C_{P_{-} W_{-}-}$, concentration of waste form colloids

$\$ B \$ 15=\$ D \$ 15 / 1000$

Row 16: c_GW_c [kg/m^3]

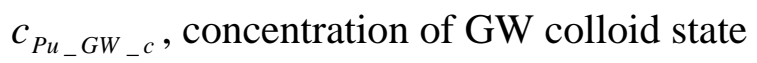

$\$ B \$ 16=\$ D \$ 16 / 1000$

Row 17: $\quad k[\mathrm{~m} / \mathrm{yr}]$

$k$, intrinsic or surface reaction rate (pore-vol/area-FeO/time)

\$B $\$ 17=\$ D \$ 17 / 100$

Row 18: S_FeO_c [m^2/kg]

$\hat{S}_{\mathrm{FeO}_{-} \mathrm{c}}=$ specific surface area of FeO colloids $\left(\mathrm{m}^{2} \mathrm{~kg}^{-1}\right)$

$\$ B \$ 18=\$ D \$ 18 * 1000$ 
Row 19: S_FeO_CP $\left[\mathrm{m}^{\wedge} 2 / \mathrm{kg}\right]$

$\hat{S}_{\mathrm{FeO} \_\mathrm{CP}}=$ specific surface area of $\mathrm{FeO}$ corrosion products $\left(\mathrm{m}^{2} \mathrm{~kg}^{-1}\right)$

$\$ B \$ 19=\$ D \$ 19 * 1000$

Row 20: d_FeO $\left[\mathrm{kg} / \mathrm{m}^{\wedge} 3\right]$

$\rho_{\mathrm{FeO} \_\mathrm{CP}}=$ density of $\mathrm{FeO}$

$\$ B \$ 20=\$ D \$ 20$

Row 21: diffus_aq [m^2/yr]

$D_{a q}=$ aqueous diffusivity

$\$ B \$ 21=\$ D \$ 21 * 31558000$

Row 22: diffus_colloid [m^2/yr]

$D_{\text {colloid }}=$ colloid diffusivity

$\$ B \$ 22=\$ D \$ 22 * 31558000$

Row 23: diff_length_1 [m]

$L_{1}=$ diffusive length for cell_1

$\$ \mathrm{~B} \$ 23=\$ \mathrm{D} \$ 23$

Row 24: diff_length_2 [m]

$L_{2}=$ diffusive length for cell_2

\$B \$24=\$D \$24

Row 25: diff_length_3 [m]

$L_{3}=$ diffusive length for cell_3

\$B $\$ 25=\$ D \$ 25$

Row 26: diff_area_1_2 [m^2]

$A_{s 12}=$ diffusive area at cell_1 and cell_2 interface

$\$ B \$ 26=\$ D \$ 26$

Row 27: diff_area_2_3 [m²]

$A_{s 23}=$ diffusive area at cell_2 and cell_3 interface

$\$ \mathrm{~B} \$ 27=\$ \mathrm{D} \$ 27$

Row 28: decay [1/yr]

$\lambda$, decay rate

$\$ B \$ 28=\$ D \$ 28$ 
Row 29: delt [yr]

$$
\begin{aligned}
& \Delta t \text {, time step length } \\
& \$ B \$ 29=\$ D \$ 29
\end{aligned}
$$

Rows 30 through 51 contains additional derived parameters for the colloid model. An image of

\begin{tabular}{|c|c|c|c|c|c|c|c|c|c|c|}
\hline & A & B & C & D & $\mathrm{E}$ & $\mathrm{F}$ & G & $\mathrm{H}$ & I & J \\
\hline 34 & Kd_bar_FeO_CP & $1.96500 \mathrm{E}+04$ & & & & & & & & \\
\hline 35 & Kd_bar_WF_c & 6.00000E-01 & & & & & & & & \\
\hline 36 & Kd_bar_GW_c & 2.00000E-02 & & & & & & & & \\
\hline 37 & K_bar_t & $1.96518 \mathrm{E}+04$ & & & & & & & & \\
\hline 38 & K_bar_2 & $1.82000 \mathrm{E}+00$ & & & & & & & & \\
\hline 39 & K_bar_3 & $8.20000 \mathrm{E}-01$ & & & & & & & & \\
\hline 40 & Diff_left_aq & $9.12736 \mathrm{E}-02$ & & & & & & & & \\
\hline 41 & Diff_left_c & $9.12736 \mathrm{E}-04$ & & & & & & & & \\
\hline 42 & Diff_right_aq & 2.22893E-03 & & & & & & & & \\
\hline 43 & Diff_right_colloid & 2.22893E-05 & & & & & & & & \\
\hline 44 & denom_a_1_2 & $2.75194 \mathrm{E}+04$ & & & & & & & & \\
\hline 45 & a_1 & $7.14108 \mathrm{E}-01$ & & & & & & & & \\
\hline 46 & a_2 & $5.87541 \mathrm{E}-08$ & & & & & & & & \\
\hline 47 & b_1 & 6.95808E-01 & & & & & & & & \\
\hline 48 & b_2 & 1.39162E-01 & & & & & & & & \\
\hline 49 & e_1 & 9.99713E-01 & & & & & & & & \\
\hline 50 & e_2 & $7.85774 \mathrm{E}+03$ & & & & & & & & \\
\hline 51 & tolerance & 1.00000E-02 & & & & & & & & \\
\hline 52 & & & & & & & & & & \\
\hline 53 & delt_time & denom_a_1_2 & a_1 & time Pu_aq [yrs] & b_1 & delta_1 & delta_2 & t_1 & t_2 & time [yrs] \\
\hline 54 & 1.0E-03 & $1.96 \overline{5} 3 \bar{E}+\overline{0} 4$ & 9.9996E-01 & 115 & $9.9 \overline{9} 96 \mathrm{E}-01$ & 4.59933E-04 & $4.2119 \bar{E}-04$ & $1.75 \overline{7} 8 \mathrm{E}+05$ & $1.94 \overline{15} \mathrm{E}+05$ & 194 \\
\hline 55 & $1.0 \mathrm{E}-02$ & $1.9660 \mathrm{E}+04$ & 9.9960E-01 & 115 & 9.9956E-01 & 4.5975E-04 & 4.2104E-04 & $1.7582 \mathrm{E}+04$ & $1.9419 \mathrm{E}+04$ & 194 \\
\hline 56 & $1.0 \mathrm{E}-01$ & $1.9730 \mathrm{E}+04$ & 9.9601E-01 & 115 & 9.9565E-01 & 4.5795E-04 & 4.1952E-04 & $1.7626 \mathrm{E}+03$ & $1.9463 \mathrm{E}+03$ & 195 \\
\hline 57 & 1.0E+00 & $2.0439 \mathrm{E}+04$ & 9.6151E-01 & 117 & $9.5811 \mathrm{E}-01$ & 4.4068E-04 & 4.0499E-04 & $1.8059 \mathrm{E}+02$ & $1.9900 \mathrm{E}+02$ & 199 \\
\hline 58 & 1.0E+01 & $2.7519 \mathrm{E}+04$ & 7.1411E-01 & 137 & $6.9581 \mathrm{E}-01$ & 3.2004E-04 & 3.0078E-04 & $2.2188 \mathrm{E}+01$ & $2.4083 \mathrm{E}+01$ & 240 \\
\hline 59 & 1.0E+02 & $9.8328 \mathrm{E}+04$ & 1.9986E-01 & 286 & 1.8616E-01 & 8.5624E-05 & $8.4182 \mathrm{E}-05$ & $5.5709 \mathrm{E}+00$ & $5.8272 \mathrm{E}+00$ & 500 \\
\hline 60 & 1.0E +03 & $8.0641 \mathrm{E}+05$ & 2.4370E-02 & 1240 & $2.2363 \mathrm{E}-02$ & 1.0286E-05 & 1.0265E-05 & $3.0220 \mathrm{E}+00$ & $3.0925 E+00$ & 3000 \\
\hline 61 & 1.0E +04 & $7.8872 \mathrm{E}+06$ & $2.4916 \mathrm{E}-03$ & 7682 & $2.2822 \mathrm{E}-03$ & 1.0497E-06 & 1.0495E-06 & $2.2633 \mathrm{E}+00$ & $2.2965 \mathrm{E}+00$ & 20000 \\
\hline
\end{tabular}
Rows 34 through 61 is shown in Figure F-18.

Figure F-18. Spreadsheet "time_to_conv.xls," Worksheet "time_to_conv;" Additional Derived Parameters and Results for Colloid Model

Row 30: R_bar_1 [1/yr]

$\bar{R}_{1}=\hat{S}_{\mathrm{FeO} \_} C_{\mathrm{FeO} \_} k$, reaction rate constant for colloids

$\$ B \$ 30=\$ B \$ 18 * \$ B \$ 13 * \$ B \$ 17$

Row 31: R_bar_2 [1/yr]

$\bar{R}_{2}=\hat{S}_{\mathrm{FeO} \_C P} C_{\mathrm{FeO} \_C P} k$, reaction rate constant for corrosion products

$\$ \mathrm{~B} \$ 31=\$ \mathrm{~B} \$ 19 * \$ \mathrm{~B} \$ 14 * \$ \mathrm{~B} \$ 17$

Row 32: U_bar [1/yr]

$\bar{U}$ advective rate constant

$\$ B \$ 32=\$ B \$ 6 / \$ B \$ 12$

Row 33: Kd_bar_FeO_c

dimensionless partition coefficient in the $\mathrm{FeO}$ colloid state

$\$ B \$ 33=\$ B \$ 13 * \$ B \$ 7$ 
Row 34: Kd_bar_FeO_CP

dimensionless partition coefficient in the $\mathrm{FeO}$ corrosion product state $\$ B \$ 34=\$ B \$ 14 * \$ B \$ 8$

Row 35: Kd_bar_WF_c

dimensionless partition coefficient in the waste form colloid state $\$ B \$ 35=\$ B \$ 15 * \$ B \$ 9$

Row 36: Kd_bar_GW_c

dimensionless partition coefficient in the GW colloid state $\$ \mathrm{~B} \$ 36=\$ \mathrm{~B} \$ 16 * \$ \mathrm{~B} \$ 10$

Row 37: K_bar_1

$\bar{K}_{1}=1+\bar{K}_{d_{-} F e O_{-} c}+\bar{K}_{d_{-} F e O_{-} C P}+\bar{K}_{d_{-} W F_{-} c}+\bar{K}_{d_{-} G W_{-} c}$, combination of dimensionless partition coefficients

$\$ \mathrm{~B} \$ 37=1+\$ \mathrm{~B} \$ 33+\$ \mathrm{~B} \$ 34+\$ \mathrm{~B} \$ 35+\$ \mathrm{~B} \$ 36$

Row 38: K_bar_2

$\bar{K}_{2}=1+\bar{K}_{d_{-} F e O_{-} c}+\bar{K}_{d_{-} W F_{-} c}+\bar{K}_{d_{-} G W_{-} c}$, combination of dimensionless partition coefficients

$\$ \mathrm{~B} \$ 38=1+\$ \mathrm{~B} \$ 33+\$ \mathrm{~B} \$ 35+\$ \mathrm{~B} \$ 36$

Row 39: K_bar_3

$\bar{K}_{3}=\bar{K}_{d_{-} F e O_{-} c}+\bar{K}_{d_{-} W F_{-} c}+\bar{K}_{d_{-} G W_{-} c}$, combination of dimensionless partition coefficients

$\$ B \$ 39=\$ B \$ 33+\$ B \$ 35+\$ B \$ 36$

Row 40: Diff_left_aq [1/yr]

diffusive rate constant, left interface in water

$\$ \mathrm{~B} \$ 40=(\$ \mathrm{~B} \$ 26 /(\$ \mathrm{~B} \$ 23 /(\$ \mathrm{~B} \$ 3 * \$ \mathrm{~B} \$ 21)+\$ \mathrm{~B} \$ 24 /(\$ \mathrm{~B} \$ 4 * \$ \mathrm{~B} \$ 21))) / \mathrm{B} \$ 12$

Row 41: Diff_left_colloid [1/yr]

diffusive rate constant, left interface colloids

$\$ \mathrm{~B} \$ 41=(\$ \mathrm{~B} \$ 26 /(\$ \mathrm{~B} \$ 23 /(\$ \mathrm{~B} \$ 3 * \$ \mathrm{~B} \$ 22)+\$ \mathrm{~B} \$ 24 /(\$ \mathrm{~B} \$ 4 * \$ \mathrm{~B} \$ 22))) / \mathrm{B} \$ 12$

Row 42: Diff_right_aq [1/yr]

diffusive rate constant, right interface in water

$\$ B \$ 41=(\$ B \$ 27 /(\$ B \$ 24 /(\$ B \$ 4 * \$ B \$ 21)+\$ B \$ 25 /(\$ B \$ 5 * \$ B \$ 21))) / \$ B \$ 12$ 
Row 43: Diff_right_colloid [1/yr]

diffusive rate constant, right interface colloids

$\$ \mathrm{~B} \$ 42=(\$ \mathrm{~B} \$ 27 /(\$ \mathrm{~B} \$ 24 /(\$ \mathrm{~B} \$ 4 * \$ \mathrm{~B} \$ 22)+\$ \mathrm{~B} \$ 25 /(\$ \mathrm{~B} \$ 5 * \$ \mathrm{~B} \$ 22))) / \mathrm{B} \$ 12$

Row 44: denom_a_1_2

denominator of Equation B-48

$\$ \mathrm{~B} \$ 44=\$ \mathrm{~B} \$ 37+(\$ \mathrm{~B} \$ 32 * \$ \mathrm{~B} \$ 38+\$ \mathrm{~B} \$ 40+\$ \mathrm{~B} \$ 41 * \$ \mathrm{~B} \$ 35+\$ \mathrm{~B} \$ 42+\$ \mathrm{~B} \$ 43 * \$ \mathrm{~B} \$ 39$

$+\$ B \$ 30+\$ B \$ 31+\$ B \$ 28 * \$ B \$ 37) * \$ B \$ 29$

Row 45: a_1

first coefficient for Equation B-55,

$a_{1}=\frac{\bar{K}_{1}}{\bar{K}_{1}+\left(\overline{U K}_{2}+\bar{D}_{\text {left_aq }}+\bar{D}_{\text {left_col }} \bar{K}_{d_{-} W F_{-} c}+\bar{D}_{\text {right_aq }}+\bar{D}_{\text {right_col }} \bar{K}_{3}+\bar{R}_{1}+\bar{R}_{2}+\lambda \bar{K}_{1}\right) \Delta t}$ $\$ B \$ 45=\$ B \$ 37 / \$ B \$ 44$

Row 46: a_2

second coefficient for Equation B-55,

$a_{2}=\frac{\left(\bar{U}\left(1+\bar{K}_{d_{-} W F_{-} c}\right)+\bar{D}_{\text {leftaq }}+\bar{D}_{\text {left_col }} \bar{K}_{d_{-} W F_{-} c}\right) \Delta t c_{s}}{\bar{K}_{1}+\left(\overline{U K}_{2}+\bar{D}_{\text {left_aq }}+\bar{D}_{\text {left_col }} \bar{K}_{d_{-} W F_{-} c}+\bar{D}_{\text {right_aq }}+\bar{D}_{\text {right_col }} \bar{K}_{3}+\bar{R}_{1}+\bar{R}_{2}+\lambda \bar{K}_{1}\right) \Delta t}$

$\$ \mathrm{~B} \$ 46=((\$ \mathrm{~B} \$ 32 *(1+\$ \mathrm{~B} \$ 35)+\$ \mathrm{~B} \$ 40+\$ \mathrm{~B} \$ 41 * \$ \mathrm{~B} \$ 35) * \$ \mathrm{~B} \$ 29 * \$ \mathrm{~B} \$ 2) / \$ \mathrm{~B} \$ 44$

Row 47: b_1

first coefficient for Equation B-58, $b_{1}=\frac{1}{1+\left(\bar{U}+\bar{D}_{\text {right_col }}+\lambda\right) \Delta t}$

$\$ \mathrm{~B} \$ 47=1 /(1+(\$ \mathrm{~B} \$ 32+\$ \mathrm{~B} \$ 43+\$ \mathrm{~B} \$ 28) * \$ \mathrm{~B} \$ 29)$

Row 48: b_2

second coefficient for Equation B-58, $b_{2}=\frac{\bar{R}_{1} \Delta t}{1+\left(\bar{U}+\bar{D}_{\text {right_col }}+\lambda\right) \Delta t}$

$\$ B \$ 48=(\$ B \$ 30 * \$ B \$ 29) * \$ B \$ 47$

Row 49: e_1

first coefficient for Equation B-64, $e_{1}=\frac{1}{1+\lambda \Delta t}$

$\$ B \$ 49=1 /(1+\$ B \$ 28 * \$ B \$ 29)$

Row 50: e_2

second coefficient for Equation B-64, $e_{2}=\frac{\bar{R}_{2} \Delta t}{1+\lambda \Delta t}$

$\$ \mathrm{~B} \$ 50=(\$ \mathrm{~B} \$ 31 * \$ \mathrm{~B} \$ 29) * \$ \mathrm{~B} \$ 49$ 
Row 51: convergence relative error tolerance $1 \%=0.01$.

Rows 54 through 61 calculates the times to converge to limit value for Pu_aq concentration and Irrv_Pu_c concentration as a function of time step size. The time step size (yr) varies by order of magnitude increments from $1 \times 10^{-3}$ to $1 \times 10^{4}$.

Column A:delt_time

Row 54: assign time step value $1 \times 10^{-3}$

Rows 55: $\$ A 55=10 * \$ A 54$

This value is dragged down through Row 61

Column B:denom_a_1_2

denominator in the calculation for a_1 and a_2 coefficients.

\$B $54=\$ B \$ 37+(\$ B \$ 32 * \$ B \$ 38+\$ B \$ 40+\$ B \$ 41 * \$ B \$ 35+\$ B \$ 42+\$ B \$ 43 * \$ B \$ 39+$ $\$ \mathrm{~B} \$ 30+\$ \mathrm{~B} \$ 31+\$ \mathrm{~B} \$ 28 * \$ \mathrm{~B} \$ 37) \star \$ A 54$

This value is dragged down through Row 61

Column C:a_1

coefficient in Pu_aq concentration Equation B-56.

Row 54: $\quad \$ C 54=\$ B \$ 37 / \$ B 54$

This result is dragged down through Row 61

Column D:time Pu_aq [yrs]

time for Pu_aq concentration to converge, estimate Equation B-74.

Row 54: $\$$ D54 = \$A54*LOG10(\$B \$51)/LOG10(\$C54)

This result is dragged down through Row 61

Column E: b_1

coefficient in Irrv_Pu_c concentration, Equation B-59.

Row 54: $\$ E 54=1 /(1+(\$ B \$ 32+\$ B \$ 43+\$ B \$ 28) * \$ A 54)$

This result is dragged down through Row 61

Column F: delta_1

intermediate tolerance $\delta_{1}$ in estimate for Irrv_Pu_c concentration convergence.

Row 54: $\quad$ \$F54 = 0.5*\$B\$51*ABS $((\$ E 54-\$ C 54) /(1-\$ C 54))$

This result is dragged down through Row 61 


\section{Column G:delta_2}

intermediate tolerance $\delta_{2}$ in estimate for Irrv_Pu_c concentration convergence.

Row 54: $\$ \mathrm{G} 54=0.5 * \$ B \$ 51 * A B S((\$ E 54-\$ C 54) /(1-\$ E 54))$

This result is dragged down through Row 61

Column H:t_1

intermediate result $\frac{\log _{10}\left(\delta_{1}\right)}{\log _{10}\left(b_{1}\right)}$ Equation B-75.

Row 54: $\quad \$ H 54=$ LOG10(\$F54)/LOG10(\$E54)

This result is dragged down through row 61

Column I: t_2

intermediate result $\frac{\log _{10}\left(\delta_{2}\right)}{\log _{10}\left(a_{1}\right)}$ Equation B-75.

Row 54: $\quad \$ G 54=\operatorname{LOG10}(\$ G 54) / L O G 10(\$ C 54)$

This result is dragged down through Row 61

Column J: time [yrs]

time for Irrv_Pu_c concentration to converge to given tolerance, Equation B-75.

Row 54: $\$ 354$

$=\$ A 54 * I N T(M A X(L O G 10(\$ F 54) / L O G 10(\$ E 54), L O G 10(\$ G 54) / L O G 10(\$ C 54)))$

This result is dragged down through Row 61.

The plot of the time to converge (shown in Figure F-19) is in Worksheet "plot_time_to_conv" and is Figure B-5 of Appendix B.

Time to converge for Pu_aq concentration is

$x$-axis: $\quad \$ A \$ 54: \$ A \$ 61$

$y$-axis: $\quad \$ D \$ 54: \$ D \$ 61$

Time to converge for Irrv_Pu_colloids is

$x$-axis: $\quad \$ A \$ 54: \$ A \$ 61$

$y$-axis: $\$ \mathrm{~J} \$ 54: \$ J 61$

Note that the $x$-axis scale is from $1 \times 10^{-3}$ to $1 \times 10^{3}$ years, so only Rows 54 through 60 are shown in the figure. 


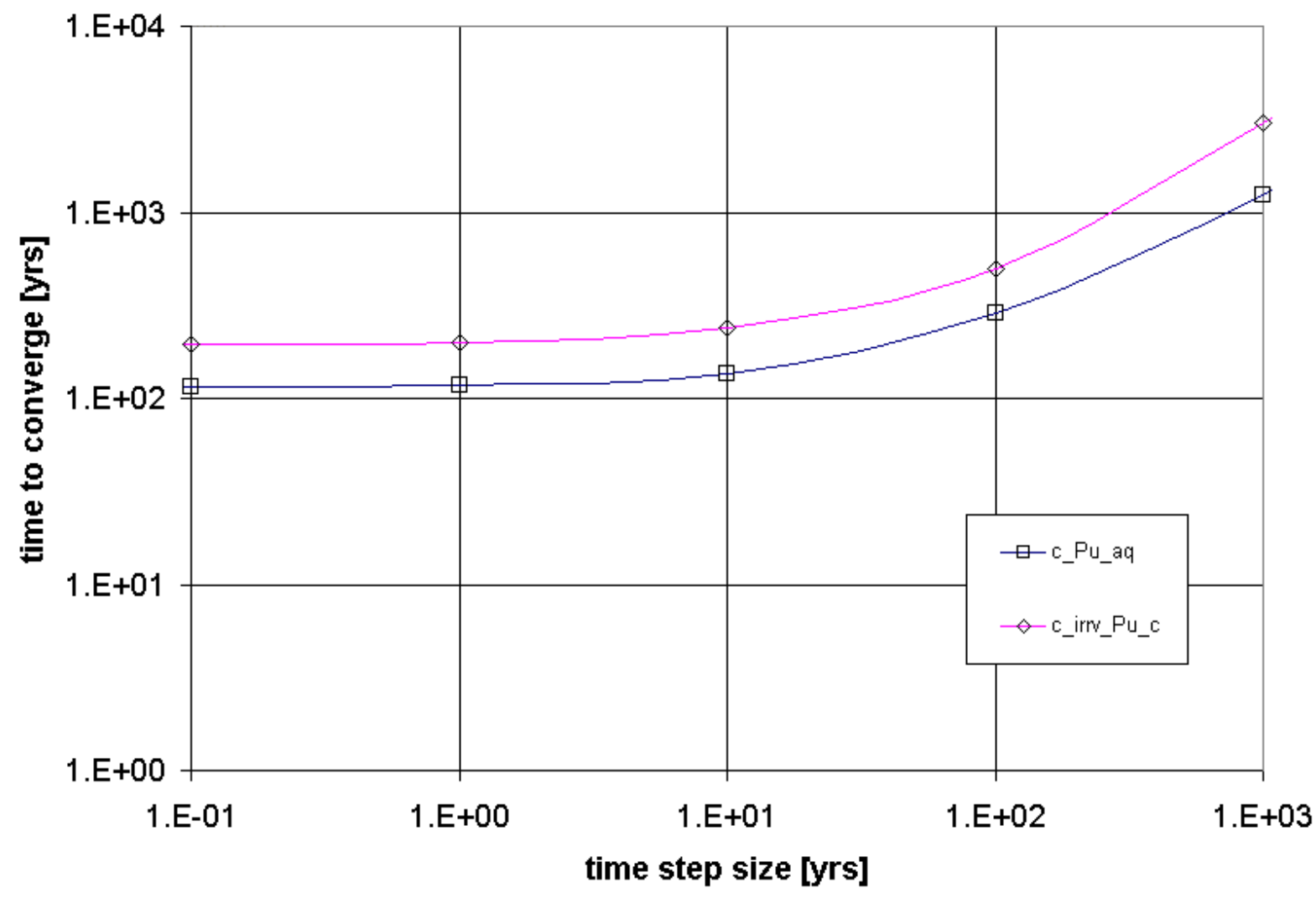

14 1 plot_time_to_conv $/$ time_to_conv

Figure F-19. Spreadsheet "time_to_conv.xls," Worksheet "plot_time_to_conv;" Plot of Colloid Model Results 


\section{INTENTIONALLY LEFT BLANK}


APPENDIX G

MICROSOFT EXCEL SPREADSHEET “INVERT DIFFUSION COEFFICIENT” 


\section{MICROSOFT EXCEL SPREADSHEET “INVERT DIFFUSION COEFFICIENT”}

\section{SPREADSHEET “INVERT DIFFUSION COEFFICIENT” WORKSHEET “MODEL”}

The purpose of this spreadsheet is to perform a statistical analysis of the dependence of effective invert diffusion coefficients, $D_{I}\left(\mathrm{~cm}^{2} \mathrm{~s}^{-1}\right)$, on volumetric moisture content, $\theta$ (percent, $100 \mathrm{~m}^{3}$ water $\mathrm{m}^{-3}$ bulk volume), as described in Section 6.3.4.1.1. The diffusion data are fit to an equation of the form

$$
\phi S_{w} D_{I}=D_{0}\left(\frac{\theta}{100}\right)^{n}
$$

where $\phi$ is the porosity ( $\mathrm{m}^{3}$ void volume $\mathrm{m}^{-3}$ bulk volume), $S_{w}$ is the water saturation ( $\mathrm{m}^{3}$ water $\mathrm{m}^{-3}$ void volume) $\left(100 \phi S_{w}=\theta\right), D_{0}$ is the self-diffusion coefficient of water $\left(2.299 \times 10^{-5}\right.$ $\mathrm{cm}^{2} \mathrm{~s}^{-1}$ ) (Mills 1973 [DIRS 133392], Table III), and the fitting parameter is the exponent, $n$. To perform a least squares fit of the data, this equation is linearized in terms of $n$ :

$$
\log _{10}\left(\frac{\phi S_{w} D_{I}}{D_{0}}\right)=n \log _{10}\left(\frac{\theta}{100}\right)
$$

Column A, Rows 1 through 125, of the spreadsheet, shown in Figures G-1 through G-4, contains the moisture content values, $\theta$ (percent) (Conca and Wright 1992 [DIRS 100436]; Conca et al. 1993 [DIRS 170709]), that are listed in Table 4.1-17. The corresponding diffusion coefficient values $\left(\phi S_{w} D_{I}\right)$ listed in Table 4.1-17 are in Column B, Rows 1 through 125 (where they are labeled $D$, which represents the effective diffusion coefficient, $\phi S_{w} D_{I}$, used in Section 6.3.4.1.1). In Column $\mathrm{C}$, the quantity $\theta / 100$ is computed (e.g., C3=A3/100], and $\phi S_{w} D_{I} / D_{0}$ is computed in Column D (e.g., D3=B3/0.00002299). The log term on the right hand side of Equation G-2, containing the moisture content, is computed Column E (e.g., E3=LOG10(A3)-2). In Column F, the left-hand side of Equation G-2 is calculated (e.g., D3=LOG10(D3)).

The least squares fit of the data is done using the Microsoft Excel Trendline tool. In Figure G-5, the results in Column $\mathrm{F}$ are plotted on the $y$-axis against the corresponding values in Column $\mathrm{E}$ on the $x$-axis in the plot located between Rows 132 and 154 of the worksheet. The type of regression is linear. The Trendline features, "Set intercept $=0$," "Display equation on chart," and "Display $\underline{\mathrm{R}}$-squared value on chart" are clicked on. In particular, the "Set intercept $=0$ " feature results in a fit to Equation G-2, in which the intercept is constrained to be zero.

As shown on the charts, the fitting parameter, $n$, has a value of 1.863. The correlation coefficient, $R^{2}$, is 0.915 , indicating a strong correlation between the diffusion coefficient and the volumetric moisture content. The regression equation is:

$$
\phi S_{w} D_{I}=D_{0}\left(\frac{\theta}{100}\right)^{1.863},
$$


In Column $\mathrm{G}$, the error, or deviation of each data point from the fitted equation, is calculated (e.g., G3=F3-1.862899^E3)); i.e., for data point $i$, the calculation in Column $G$ is the deviation $\varepsilon_{i}$

$$
\varepsilon_{i}=\log _{10}\left(\frac{\phi S_{w} D_{I}}{D_{0}}\right)-1.863 \log _{10}\left(\frac{\theta}{100}\right) .
$$

In Cell G128, the average of the 125 values of $\varepsilon_{i}$ is computed: G128=AVERAGE(G3:G127). The standard deviation of the $\varepsilon_{i}$, Cell G129 is computed: G129=STDEV(G3:G127).

\begin{tabular}{|c|c|c|c|c|c|c|c|}
\hline & $\mathrm{A}$ & $\mathrm{B}$ & $\mathrm{C}$ & $\mathrm{D}$ & $E$ & $\mathrm{~F}$ & G \\
\hline 1 & Water Content, $\theta$ & Diffusion Coefficient, $D$ & & & & & Error $=\left[\log _{10}\left(D / D_{0}\right)\right.$ \\
\hline 2 & (\%) & $\left(\mathrm{cm}^{2} / \mathrm{s}\right)$ & $8 \pi(100$ & $0 / D_{0}$ & $\log _{10} \theta-2$ & $\log _{10}\left(0 / 0_{0}\right)$ & $\left.-1.863\left(\log _{10} \theta-2\right)\right]$ \\
\hline 3 & 1.50 & $1.39 \mathrm{E}-08$ & 0.0150 & $6.046 \mathrm{E}-04$ & -1.824 & -3.219 & 0.1792 \\
\hline 4 & 1.70 & $6.60 \mathrm{E}-09$ & 0.0170 & $2.871 \mathrm{E}-04$ & -1.770 & -3.542 & -0.2455 \\
\hline 5 & 1.90 & $8.60 \mathrm{E}-09$ & 0.0190 & $3.741 \mathrm{E}-04$ & -1.721 & -3.427 & -0.2205 \\
\hline 6 & 2.17 & $2.77 \mathrm{E}-08$ & 0.0217 & $1.205 \mathrm{E}-03$ & -1.664 & -2.919 & 0.1799 \\
\hline 7 & 2.20 & $3.63 \mathrm{E}-08$ & 0.0220 & $1.579 \mathrm{E}-03$ & -1.658 & -2.802 & 0.2863 \\
\hline 8 & 2.29 & $1.09 \mathrm{E}-08$ & 0.0229 & $4.741 \mathrm{E}-04$ & -1.640 & -3.324 & -0.2687 \\
\hline 9 & 2.50 & $2.50 \mathrm{E}-08$ & 0.0250 & $1.087 \mathrm{E}-03$ & -1.602 & -2.964 & 0.0209 \\
\hline 10 & 3.10 & $3.30 \mathrm{E}-08$ & 0.0310 & $1.435 \mathrm{E}-03$ & -1.509 & -2.843 & -0.0326 \\
\hline 11 & 3.14 & $3.06 \mathrm{E}-08$ & 0.0314 & $1.331 \mathrm{E}-03$ & -1.503 & -2.876 & -0.0757 \\
\hline 12 & 3.20 & $1.35 \mathrm{E}-08$ & 0.0320 & $5.872 \mathrm{E}-04$ & -1.495 & -3.231 & -0.4465 \\
\hline 13 & 3.27 & $2.79 \mathrm{E}-08$ & 0.0327 & $1.214 \mathrm{E}-03$ & -1.485 & -2.916 & -0.1487 \\
\hline 14 & 3.33 & $6.35 \mathrm{E}-08$ & 0.0333 & $2.762 \mathrm{E}-03$ & -1.478 & -2.559 & 0.1938 \\
\hline 15 & 3.34 & $2.60 \mathrm{E}-08$ & 0.0334 & $1.131 \mathrm{E}-03$ & -1.476 & -2.947 & -0.1965 \\
\hline 16 & 3.57 & $3.37 \mathrm{E}-08$ & 0.0357 & $1.466 \mathrm{E}-03$ & -1.447 & -2.834 & -0.1377 \\
\hline 17 & 3.70 & $3.70 \mathrm{E}-08$ & 0.0370 & $1.609 \mathrm{E}-03$ & -1.432 & -2.793 & -0.1260 \\
\hline 18 & 3.70 & $6.60 \mathrm{E}-08$ & 0.0370 & $2.871 \mathrm{E}-03$ & -1.432 & -2.542 & 0.1253 \\
\hline 19 & 4.00 & $5.22 \mathrm{E}-08$ & 0.0400 & $2.271 \mathrm{E}-03$ & -1.398 & -2.644 & -0.0396 \\
\hline 20 & 4.20 & $5.94 \mathrm{E}-08$ & 0.0420 & $2.584 \mathrm{E}-03$ & -1.377 & -2.588 & -0.0230 \\
\hline 21 & 4.60 & $6.21 \mathrm{E}-08$ & 0.0460 & $2.701 \mathrm{E}-03$ & -1.337 & -2.568 & -0.0773 \\
\hline 22 & 4.90 & $7.20 \mathrm{E}-08$ & 0.0490 & 3.132E-03 & -1.310 & -2.504 & -0.0642 \\
\hline 23 & 5.10 & $1.32 \mathrm{E}-07$ & 0.0510 & $5.742 \mathrm{E}-03$ & -1.292 & -2.241 & 0.1667 \\
\hline 24 & 5.30 & $2.40 \mathrm{E}-08$ & 0.0530 & $1.044 \mathrm{E}-03$ & -1.276 & -2.981 & -0.6048 \\
\hline 25 & 5.40 & $7.60 \mathrm{E}-08$ & 0.0540 & $3.306 \mathrm{E}-03$ & -1.268 & -2.481 & -0.1193 \\
\hline 26 & 5.51 & $7.68 \mathrm{E}-08$ & 0.0551 & $3.341 \mathrm{E}-03$ & -1.259 & -2.476 & -0.1311 \\
\hline 27 & 5.83 & $1.23 \mathrm{E}-07$ & 0.0583 & $5.350 \mathrm{E}-03$ & -1.234 & -2.272 & 0.0278 \\
\hline 28 & 5.90 & $9.30 \mathrm{E}-08$ & 0.0590 & $4.045 \mathrm{E}-03$ & -1.229 & -2.393 & -0.1033 \\
\hline 29 & 6.00 & $8.92 \mathrm{E}-08$ & 0.0600 & $3.880 \mathrm{E}-03$ & -1.222 & -2.411 & -0.1350 \\
\hline 30 & 6.30 & $1.06 \mathrm{E}-07$ & 0.0630 & $4.611 \mathrm{E}-03$ & -1.201 & -2.336 & -0.0995 \\
\hline 31 & 6.90 & $6.00 \mathrm{E}-08$ & 0.0690 & $2.610 \mathrm{E}-03$ & -1.161 & -2.583 & -0.4203 \\
\hline 32 & 6.93 & $1.50 \mathrm{E}-07$ & 0.0693 & $6.525 \mathrm{E}-03$ & -1.159 & -2.185 & -0.0259 \\
\hline
\end{tabular}

Figure G-1. Spreadsheet "Invert Diffusion Coefficient," Worksheet "Model;" Invert Diffusion Coefficient Input Data (Water Content 1.50 to 6.93\%) 


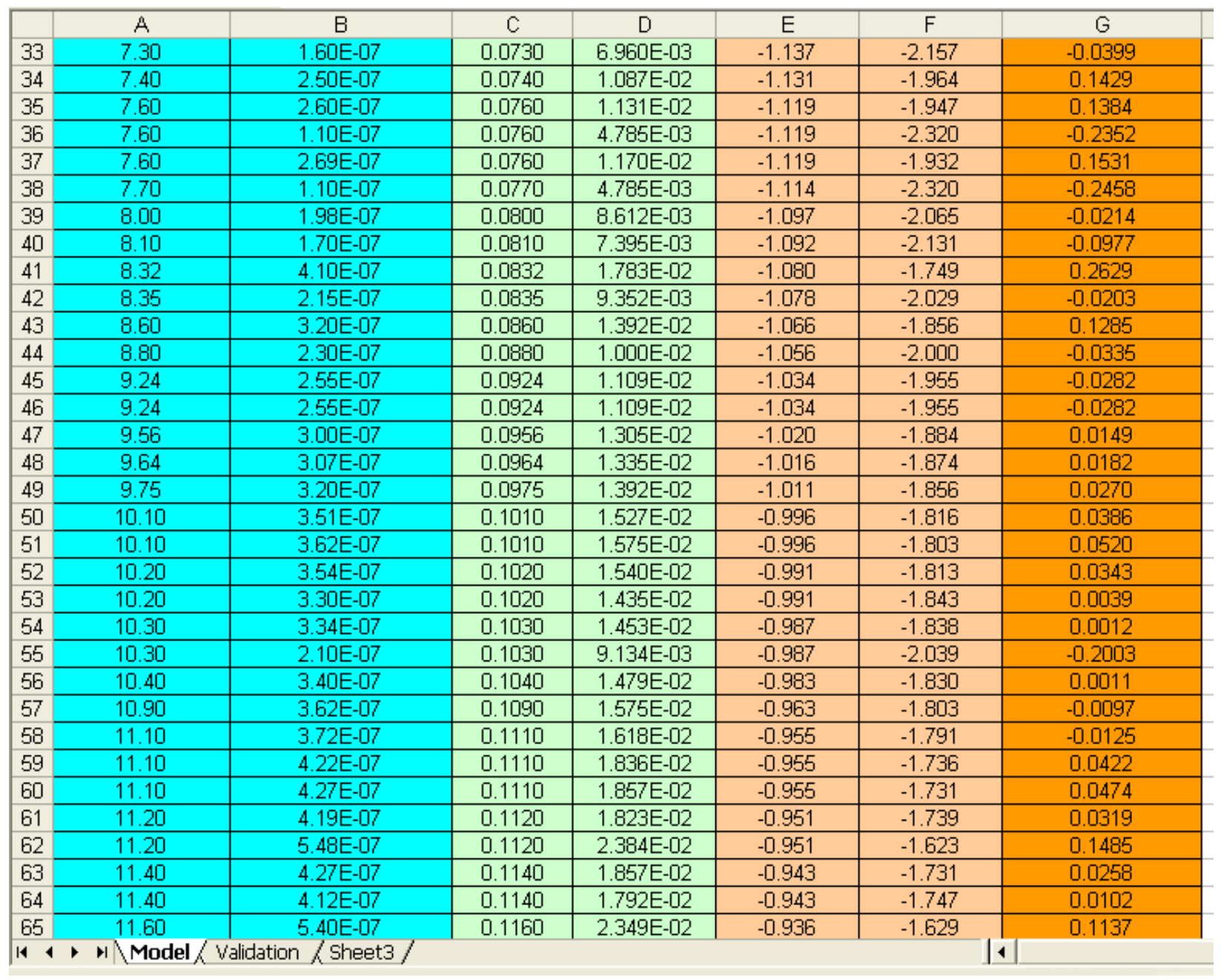

Figure G-2. Spreadsheet "Invert Diffusion Coefficient," Worksheet "Model;" Invert Diffusion Coefficient Input Data (Water Content 7.30 to $11.60 \%$ ) 


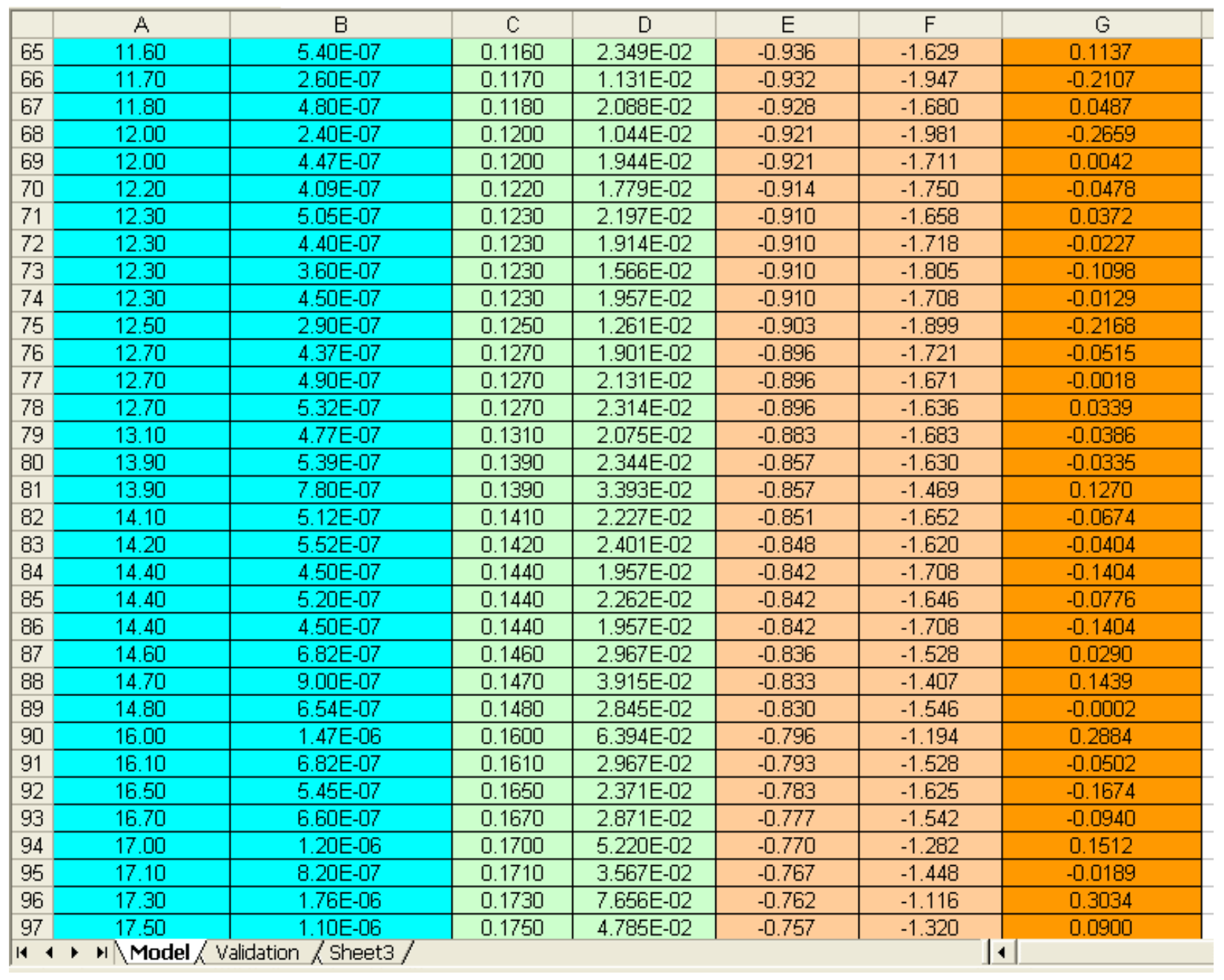

Figure G-3. Spreadsheet "Invert Diffusion Coefficient," Worksheet "Model;" Invert Diffusion Coefficient Input Data (Water Content 11.60 to $17.50 \%$ ) 


\begin{tabular}{|c|c|c|c|c|c|c|c|c|c|}
\hline & A & $\mathrm{B}$ & C & D & $E$ & $\mathrm{~F}$ & G & $\mathrm{H}$ & 1 \\
\hline 97 & 17.50 & 1.10E-06 & 0.1750 & 4.785E-02 & -0.757 & -1.320 & 0.0900 & & \\
\hline 98 & 18.80 & 1.60E-06 & 0.1880 & 6.960E-02 & -0.726 & -1.157 & 0.1948 & & \\
\hline 99 & 18.90 & 8.19E-07 & 0.1890 & 3.562E-02 & -0.724 & -1.448 & -0.1004 & & \\
\hline 100 & 19.40 & 9.89E-07 & 0.1940 & 4.302E-02 & -0.712 & -1.366 & -0.0396 & & \\
\hline 101 & 20.40 & 4.19E-06 & 0.2040 & 1.823E-01 & -0.690 & -0.739 & 0.5468 & & \\
\hline 102 & 20.80 & $3.58 \mathrm{E}-06$ & 0.2080 & 1.557E-01 & -0.682 & -0.808 & 0.4627 & & \\
\hline 103 & 21.00 & 2.34E-06 & 0.2100 & 1.018E-01 & -0.678 & -0.992 & 0.2703 & & \\
\hline 104 & 21.50 & 1.23E-06 & 0.2150 & $5.350 \mathrm{E}-02$ & -0.668 & -1.272 & -0.0280 & & \\
\hline 105 & 21.60 & 1.29E-06 & 0.2160 & $5.611 \mathrm{E}-02$ & -0.666 & -1.251 & -0.0111 & & \\
\hline 106 & 23.10 & $2.40 \mathrm{E}-06$ & 0.2310 & 1.044E-01 & -0.636 & -0.981 & 0.2042 & & \\
\hline 107 & 23.10 & $1.90 \mathrm{E}-06$ & 0.2310 & 8.264E-02 & -0.636 & -1.083 & 0.1027 & & \\
\hline 108 & 24.00 & $2.90 \mathrm{E}-06$ & 0.2400 & 1.261E-01 & -0.620 & -0.899 & 0.2555 & & \\
\hline 109 & 25.30 & $5.82 \mathrm{E}-06$ & 0.2530 & $2.532 \mathrm{E}-01$ & -0.597 & -0.597 & 0.5153 & & \\
\hline 110 & 25.40 & $2.50 \mathrm{E}-06$ & 0.2540 & 1.087E-01 & -0.595 & -0.964 & 0.1451 & & \\
\hline 111 & 25.70 & $9.26 \mathrm{E}-06$ & 0.2570 & $4.028 \mathrm{E}-01$ & -0.590 & -0.395 & 0.7043 & & \\
\hline 112 & 28.20 & $3.50 \mathrm{E}-06$ & 0.2820 & 1.522E-01 & -0.550 & -0.817 & 0.2067 & & \\
\hline 113 & 28.50 & $1.00 E-06$ & 0.2850 & $4.350 \mathrm{E}-02$ & -0.545 & -1.362 & -0.3460 & & \\
\hline 114 & 30.90 & $1.51 \mathrm{E}-06$ & 0.3090 & $6.568 \mathrm{E}-02$ & -0.510 & -1.183 & -0.2324 & & \\
\hline 115 & 31.70 & $1.23 \mathrm{E}-05$ & 0.3170 & $5.350 \mathrm{E}-01$ & -0.499 & -0.272 & 0.6578 & & \\
\hline 116 & 32.30 & $4.60 \mathrm{E}-06$ & 0.3230 & 2.001E-01 & -0.491 & -0.699 & 0.2155 & & \\
\hline 117 & 33.80 & $1.34 \mathrm{E}-05$ & 0.3380 & $5.829 \mathrm{E}-01$ & -0.471 & -0.234 & 0.6431 & & \\
\hline 118 & 35.80 & $1.57 \mathrm{E}-05$ & 0.3580 & 6.829E-01 & -0.446 & -0.166 & 0.6654 & & \\
\hline 119 & 38.50 & $4.33 \mathrm{E}-06$ & 0.3850 & 1.883E-01 & -0.415 & -0.725 & 0.0472 & & \\
\hline 120 & 39.30 & 1.36E-05 & 0.3930 & 5.916E-01 & -0.406 & -0.228 & 0.5276 & & \\
\hline 121 & 39.50 & 1.13E-05 & 0.3950 & 4.915E-01 & -0.403 & -0.308 & 0.4430 & & \\
\hline 122 & 40.00 & $6.90 \mathrm{E}-06$ & 0.4000 & 3.001E-01 & -0.398 & -0.523 & 0.2186 & & \\
\hline 123 & 42.00 & $5.80 \mathrm{E}-06$ & 0.4200 & $2.523 \mathrm{E}-01$ & -0.377 & -0.598 & 0.1037 & & \\
\hline 124 & 42.50 & $3.22 \mathrm{E}-06$ & 0.4250 & 1.401E-01 & -0.372 & -0.854 & -0.1614 & & \\
\hline 125 & 43.40 & $1.02 \mathrm{E}-05$ & 0.4340 & 4.437E-01 & -0.363 & -0.353 & 0.3224 & & \\
\hline 126 & 49.00 & $6.09 E-06$ & 0.4900 & 2.649E-01 & -0.310 & -0.577 & 0.0002 & & \\
\hline 127 & 66.30 & $1.83 \mathrm{E}-05$ & 0.6630 & $7.960 \mathrm{E}-01$ & -0.178 & -0.099 & 0.2334 & & \\
\hline 128 & & & & & & & 0.0329 & \multicolumn{2}{|c|}{ Average } \\
\hline 129 & & & & & & & 0.2181 & \multicolumn{2}{|c|}{ Standard Deviation } \\
\hline
\end{tabular}

Figure G-4. Spreadsheet "Invert Diffusion Coefficient," Worksheet "Model;" Invert Diffusion Coefficient Input Data (Water Content 17.50 to $66.30 \%$ ) 


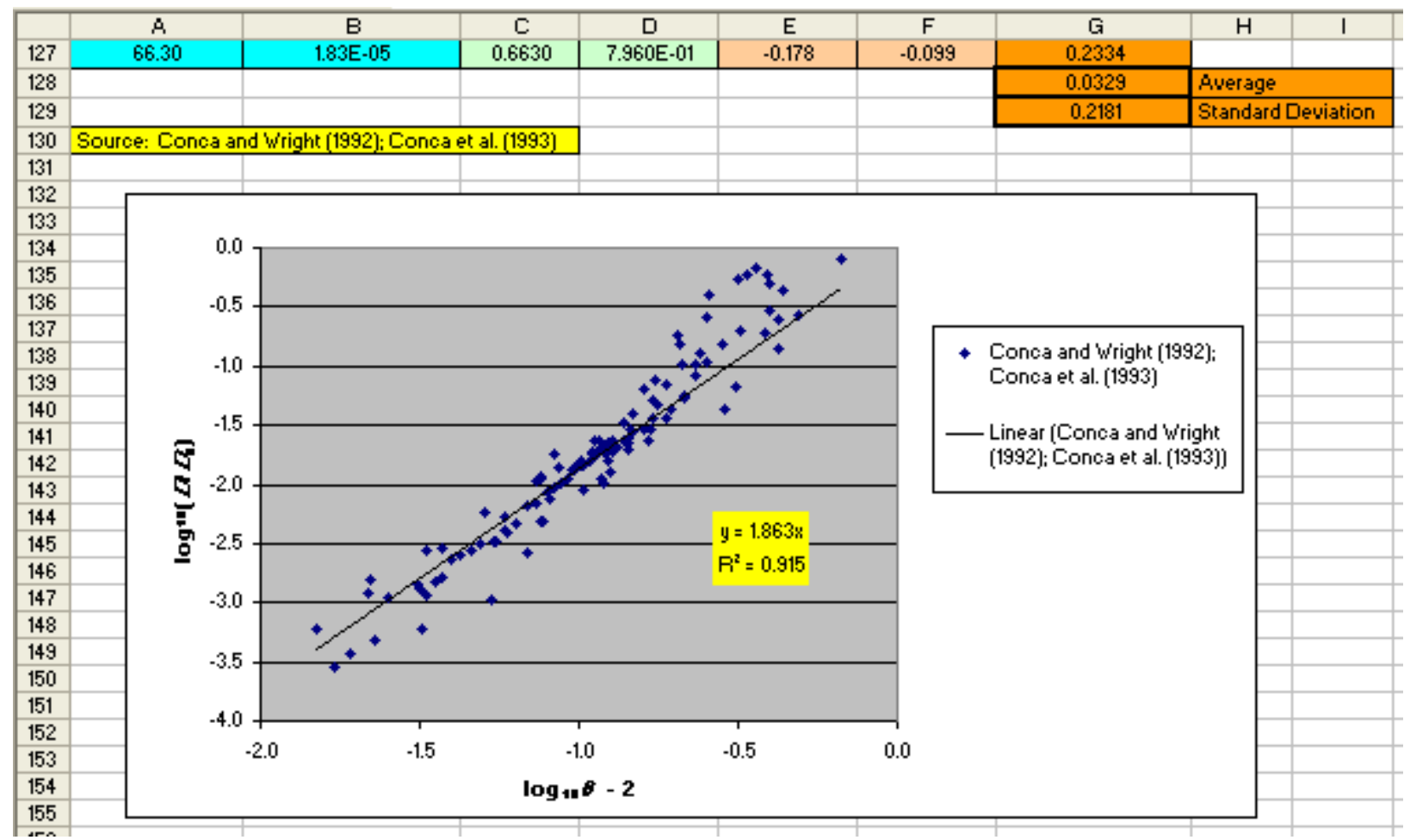

Source: Conca and Wright 1992 [DIRS 100436]; Conca et al. 1993 [DIRS 170709].

Figure G-5. Spreadsheet "Invert Diffusion Coefficient," Worksheet "Model;" Plot of Fitted Invert Diffusion Coefficient Data

In the plot in Figure G-6 between Rows 169 and 191, the lines for the mean and for the mean plus or minus three standard deviations are added to the plot shown earlier. The lines are drawn over the range of the data, i.e., for $\theta / 100$ from 0.015 to 0.663 (Column C, Rows 159 to 166). The $y$-values for the Trendline fit are computed as $\phi S_{w} D_{I} / D_{0}=(\theta / 100)^{1.863}$ (e.g., $\left.\mathrm{D} 159=\left(\mathrm{C} 159^{\wedge} 1.863\right)\right)$, and the values plotted are $\log _{10}\left(\phi S_{w} D_{I} / D_{0}\right)$ (e.g., G159=LOG10(D159)). For the mean curve, the $y$-values are computed as $\phi S_{w} D_{I} / D_{0}=(\theta / 100)^{1.863} 10^{0.033}$ (e.g., $\left.\mathrm{D} 163=\left(\mathrm{C} 163^{\wedge} 1.863\right)^{\star} 10^{\wedge}(0.033)\right)$, and the values plotted are again $\log _{10}\left(\phi S_{w} D_{I} / D_{0}\right)$ (e.g., G163=LOG10(D163)). For the mean plus three standard deviations curve, the $y$-values are computed as $\phi S_{w} D_{I} / D_{0}=(\theta / 100)^{1.863} 10^{0.033+3(0.218)}$ (e.g., $\left.\mathrm{G} 161=\left(\mathrm{C} 161^{\wedge} 1.863\right) \star 10^{\wedge}\left(0.033+3^{\star} 0.218\right)\right)$, and the values plotted are again $\log _{10}\left(\phi S_{w} D_{I} / D_{0}\right)$ (e.g., G161=LOG10(D161)). The mean minus three standard deviations curve is done similarly. This plot is shown as Figure 6.3-4 in Section 6.3.4.1.1. 


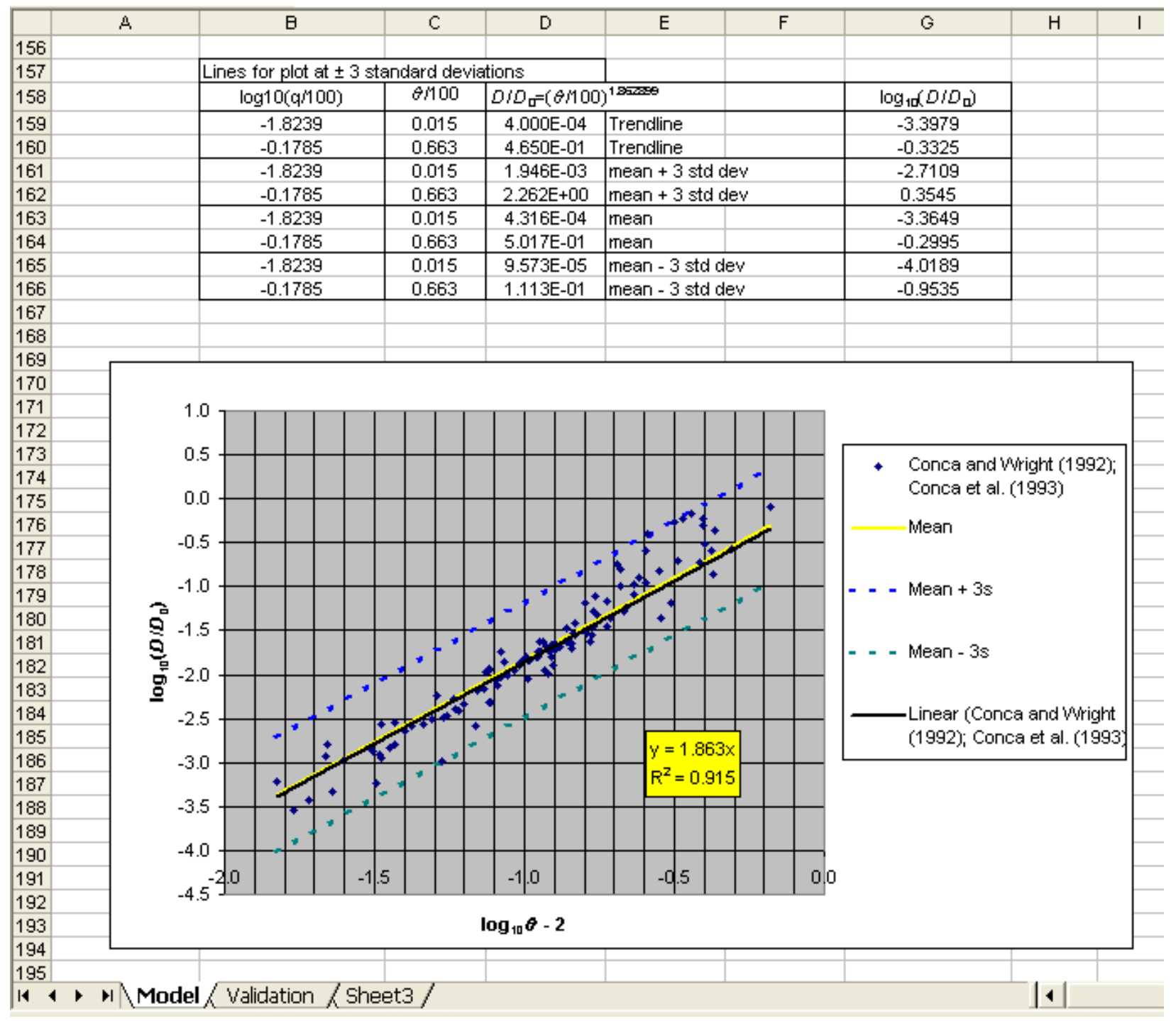

Source: Conca and Wright 1992 [DIRS 100436]; Conca et al. 1993 [DIRS 170709].

Figure G-6. Spreadsheet "Invert Diffusion Coefficient," Worksheet "Model;" Plotted Results of Invert Diffusion Coefficient Data, Showing Uncertainty Range as Mean \pm 3 Standard Deviations

The data are further analyzed in Figure G-7 to demonstrate that the deviations approximately follow a normal distribution. Under the Microsoft Excel menu item Tools, Data Analysis... is clicked, and Histogram is selected under Analysis Tools. In the Histogram window, the error data (Column G, Rows 3 to 127) are entered for the Input Range. For the Bin Range, Column I, Rows 3 to 22, is entered. The frequency distribution is output in Column J, Rows 3 to 22. For comparison, a theoretical normal distribution is computed over the same range in Column M:

$$
f(x ; \mu, \sigma)=\frac{1}{\sigma \sqrt{2 \pi}} e^{-(x-\mu)^{2} / 2 \sigma^{2}},
$$

where $x$ is the bin value, the mean $\mu \approx 0.033$, and the standard deviation $\sigma \approx 0.218$. 
The Microsoft Excel formula is (for Cell M3, for example):

$$
\begin{gathered}
M 3=\operatorname{EXP}\left(-\left((I 3-0.0329438386573088)^{\wedge} 2\right) /\left(2^{\star} 0.218121819319092^{\wedge} 2\right)\right) / \\
\left(0.218121819319092^{*}\left(2^{\star} \mathrm{PI}()\right)^{\wedge} 0.5\right)
\end{gathered}
$$

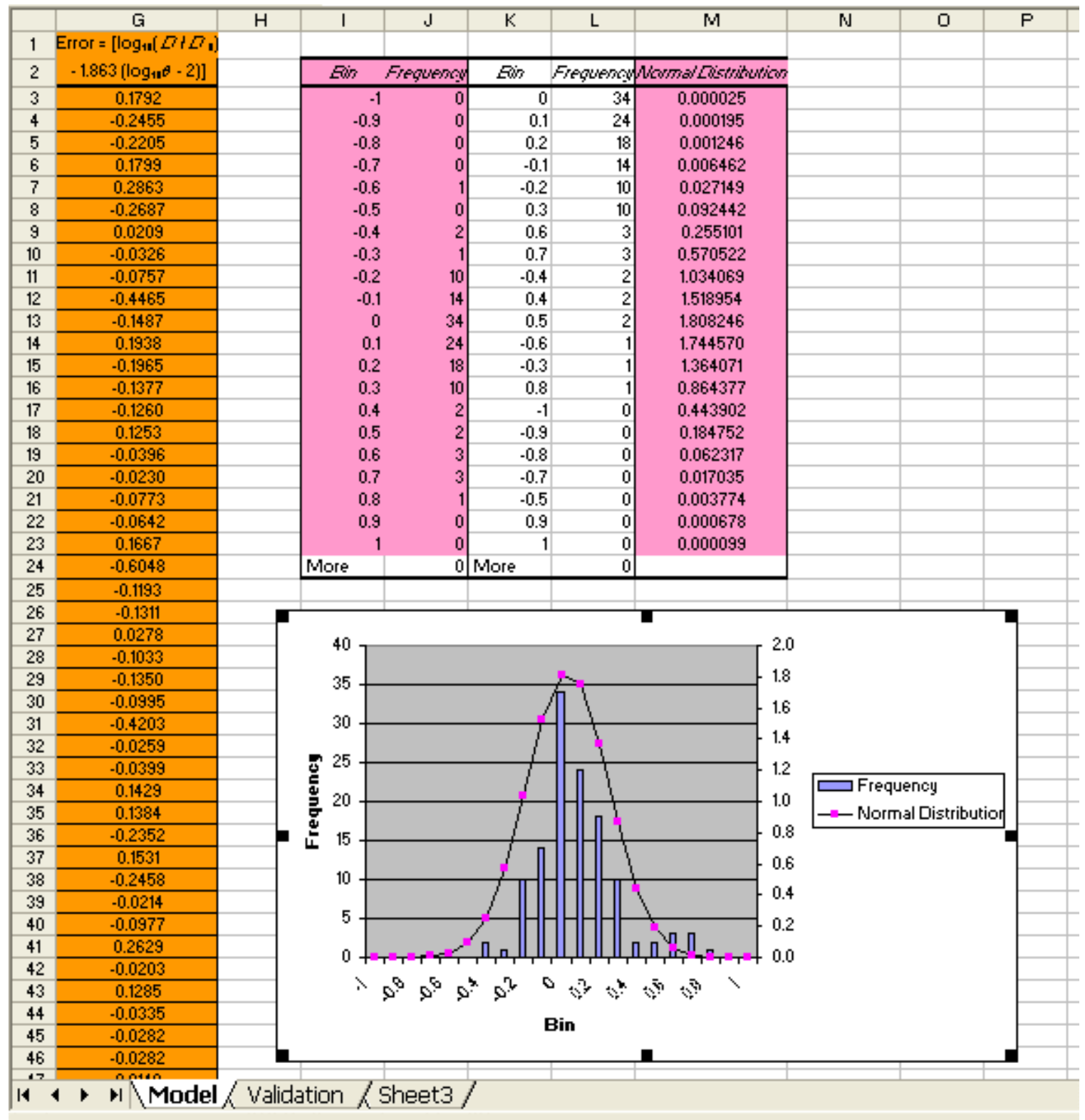

Figure G-7. Spreadsheet "Invert Diffusion Coefficient," Worksheet "Model;" Further Analysis of Invert Diffusion Coefficient Data 


\section{SPREADSHEET “INVERT DIFFUSION COEFFICIENT” WORKSHEET “VALIDATION”}

In this worksheet (Figure G-8), diffusion coefficient data (Column B) from Tables A-1 and A-2 of The Determination of Diffusion Coefficient of Invert Materials (CRWMS M\&O 2000 [DIRS 156680]) are plotted against water content (Column A), along with the results of the analysis in Worksheet "Model." The purpose of this worksheet is partially to validate the diffusion coefficient submodel by showing that the model overestimates the value of the invert diffusion coefficient, thereby overestimating diffusive releases of radionuclides through the invert. The model curve fit (Equation 6.3.4.1.1-22), also shown on p. G-7 and in Figure 6.3-4 in Section 6.3.4.1.1, is reproduced in Columns D-G, Rows 3 and 4, and plotted in the figure below.

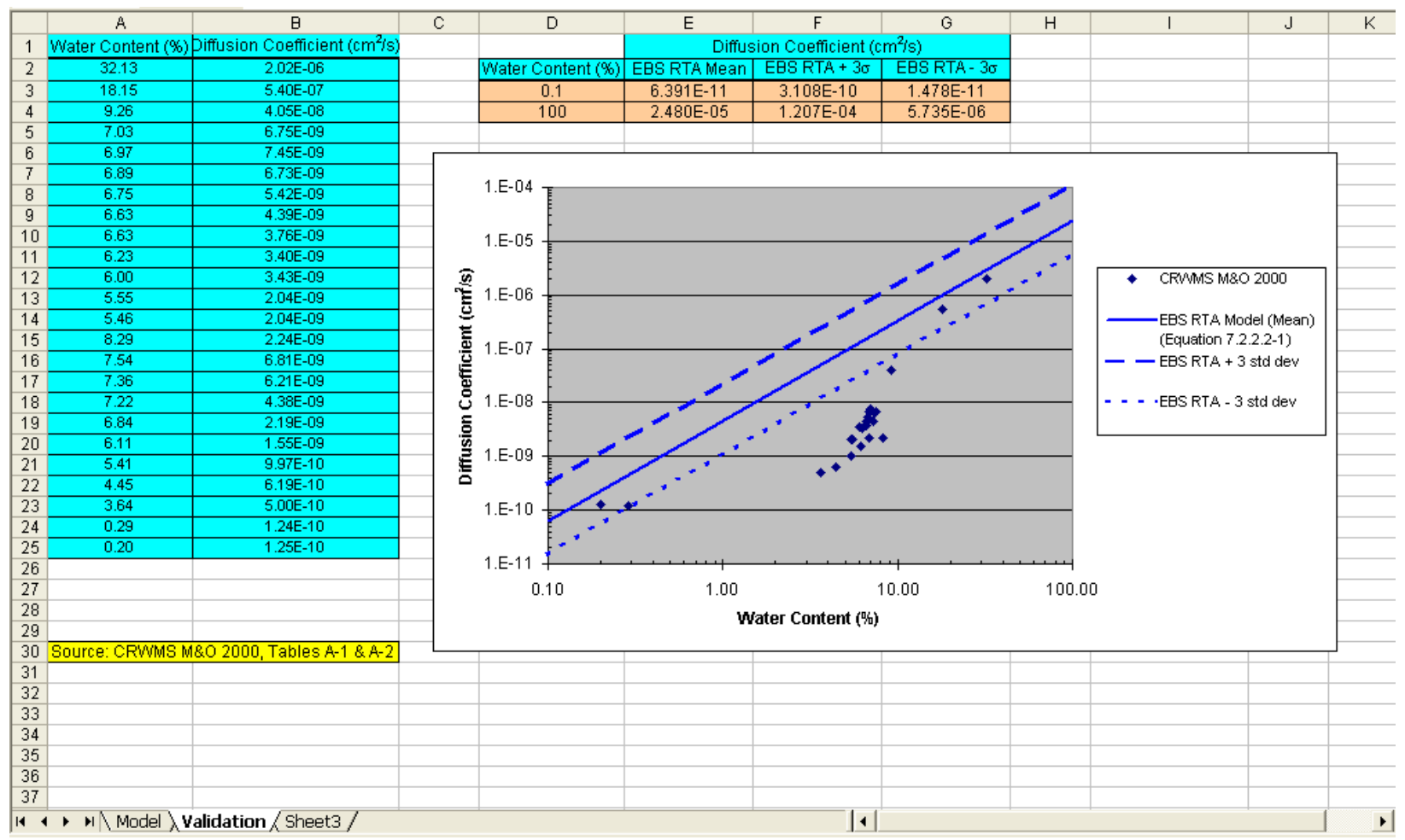

Source: CRWMS M\&O 2000 [DIRS 156680], Tables A-1 and A-2.

Figure G-8. Spreadsheet "Invert Diffusion Coefficient," Worksheet "Validation;" Validation of Invert Diffusion Coefficient Data 


\section{INTENTIONALLY LEFT BLANK}




\section{APPENDIX H \\ QUALIFICATION OF DIFFUSION COEFFICIENT DATA}




\section{QUALIFICATION OF DIFFUSION COEFFICIENT DATA}

\section{DESCRIPTION OF DATA TO BE QUALIFIED}

The data reported in Conca and Wright (1992 [DIRS 100436]) and Conca et al. (1993 [DIRS 170709]) consist of measured diffusion coefficients of unsaturated soil, gravel, bentonite, rock, and crushed tuff from Yucca Mountain, over a broad range of water contents. These data have been collected and analyzed using standard scientific practices. The diffusivity data for various granular media at volumetric moisture contents ranging between $1.5 \%$ and $66.3 \%$ are given in Section 4.1.2, Table 4.1-17. These measured data have been used to analyze the dependence of the diffusion coefficient on volumetric moisture content for a variety of granular materials (Section 6.3.4.1.1). These data are qualified in accordance with the data qualification plan included in this appendix.

\section{CORROBORATING DATA}

The diffusion coefficient data for crushed tuff materials from The Determination of Diffusion Coefficient of Invert Materials (CRWMS M\&O 2000 [DIRS 156680]) are used to qualify the data reported by Conca and Wright (1992 [DIRS 100436]) and Conca et al. (1993 [DIRS 170709]). The diffusion coefficient data found in The Determination of Diffusion Coefficient of Invert Materials (CRWMS M\&O 2000 [DIRS 156680]) were collected in the DOE Atlas Facility. The tests were performed by the EBS Testing Department under YMP-approved procedures using the Unsaturated Flow Apparatus. The Unsaturated Flow Apparatus method is reported to be an accurate and fast indirect method of determining diffusion coefficients in porous media (Conca and Wright 1992 [DIRS 100436], p. 7). The method uses measurements of electrical conductivity, at specified volumetric moisture content, which is converted to diffusion coefficient. The Determination of Diffusion Coefficient of Invert Materials (CRWMS M\&O 2000 [DIRS 156680]) reports that the error on the reported data is within $\pm 7 \%$. The reported data are shown in Table H-1.

\section{DATA EVALUATION CRITERIA}

The diffusion coefficient data from Conca and Wright (1992 [DIRS 100436]) and Conca et al. (1993 [DIRS 170709]) will be considered qualified if they are within one order of magnitude of the values reported in The Determination of Diffusion Coefficient of Invert Materials (CRWMS M\&O 2000 [DIRS 156680]); or if greater differences are observed, they result in more conservative results with regard to radionuclide releases.

\section{COMPARISON OF THE DIFFUSION COEFFICIENT DATA IN CONCA AND WRIGHT (1992 [DIRS 100436]) AND CONCA ET AL. (1993 [DIRS 170709]) TO CRWMS M\&O (2000 [DIRS 156680])}

The data reported by Conca and Wright (1992 [DIRS 100436]) and Conca et al. (1993 [DIRS 170709]) (shown in Section 4.1.2, Table 4.1-17) consist of diffusion coefficient data for the range of $1.5 \%$ to $66.3 \%$ volumetric moisture content. The data from The Determination of Diffusion Coefficient of Invert Materials (CRWMS M\&O 2000 [DIRS 156680]) ranges between $0.2 \%$ and $32.13 \%$. Figure $\mathrm{H}-1$ shows a plot of moisture content versus diffusion coefficient for data from both sources. The figure shows that overall the Conca and Wright 
(1992 [DIRS 100436]) and Conca et al. (1993 [DIRS 170709]) data have higher diffusion coefficient values over the measured range of water content. The differences are highest at low water content. At water content values below 10\%, the Conca and Wright (1992 [DIRS 100436]) and Conca et al. (1993 [DIRS 170709]) diffusion coefficient values are higher by as much as two orders of magnitude. For water content values above $10 \%$, the Conca and Wright (1992 [DIRS 100436]) and Conca et al. (1993 [DIRS 170709]) diffusion coefficient data show higher but comparable values.

The differences in diffusion coefficient at low water content values can be partly attributed to the measurement technique. As discussed in Section 6 of The Determination of Diffusion Coefficient of Invert Materials (CRWMS M\&O 2000 [DIRS 156680]), errors in measurement are higher at low diffusion coefficient values. Conca and Wright (1992 [DIRS 100436], p. 10) also reported that, at low water content, reductions in water content result in sharp declines in the measured diffusion coefficient as surface films become thin and discontinuous, and pendular water elements become small. Measurement differences could also be attributed to the different porous medium samples used. The Conca and Wright (1992 [DIRS 100436]) and Conca et al. (1993 [DIRS 170709]) data include various material samples whereas the determination report (CRWMS M\&O 2000 [DIRS 156680]) data are for crushed tuff only. The data from both sources show some scatter. The diffusion coefficient data of Conca and Wright (1992 [DIRS 100436]) and Conca et al. (1993 [DIRS 170709]) are thus comparable to those of the determination report (CRWMS M\&O 2000 [DIRS 156680]) for volumetric water content values above $10 \%$. For low volumetric water content values, the differences are greater. However, the higher diffusion coefficient values of Conca and Wright (1992 [DIRS 100436]) and Conca et al. (1993 [DIRS 170709]) will result in predicted radionuclide releases being higher.

The Conca and Wright (1992 [DIRS 100436]) data have been published in a peer-reviewed journal (Applied Hydrology), and thus have undergone strict review. The data are shown plotted in Figure 2 of Conca and Wright (1992 [DIRS 100436]).

The Conca et al. (1993 [DIRS 170709]) data have been published in the proceedings of the Scientific Basis for Nuclear Waste Management XVI Symposium held November 30 to December 4, 1992. This symposium was organized by the Materials Research Society, which was formed in 1973. The most recent Scientific Basis for Nuclear Waste Management XVI Symposium is XXVII, the proceedings of which were published in 2004. Papers published in the proceedings undergo peer review prior to publication and must be presented at the meeting in order to be published.

\section{SUMMARY OF QUALIFICATION}

The diffusion coefficient data of Conca and Wright (1992 [DIRS 100436]) and Conca et al. (1993 [DIRS 170709]) have been evaluated in the context of their use in radionuclide transport modeling, and are considered qualified for use within this report per LP-SIII.2Q-BSC, Qualification of Unqualified Data, Attachment 3, on the basis of:

- Availability of corroborating data-The corroborating data are YMP-generated data using the same measurement technique. 
- Reliability of data sources-The data are published in a peer-reviewed journal and in a peer-reviewed symposium proceedings.

- Data demonstrate properties of interest-The published data, diffusion coefficients in crushed rock, are the data required for the model of transport in the invert.

The above comparison of the diffusion coefficient data of Conca and Wright (1992 [DIRS 100436]) and Conca et al. (1993 [DIRS 170709]) with the corroborating data from CRWMS M\&O 2000 [DIRS 156680] shows that the data evaluation criteria have been met. The data to be qualified are within one order of magnitude of the values in the corroborating source for volumetric water content values above $10 \%$ (Figure $\mathrm{H}-1$ ). The differences between the two data sets are greater than one order of magnitude below 10\%; however, the higher diffusion coefficient values of Conca and Wright (1992 [DIRS 100436]) and Conca et al. (1993 [DIRS 170709]) will result in predicted radionuclide releases being higher. Therefore, the Conca and Wright (1992 [DIRS 100436]) and Conca et al. (1993 [DIRS 170709]) diffusion coefficient data shown on Table 4.1-17 are judged to be qualified for use in this report. Use of these data in other applications would require a comparable evaluation for that specific use.

Table H-1. Diffusion Coefficient of Crushed Tuff Invert Materials

\begin{tabular}{|c|c|c|}
\hline Sample & $\begin{array}{c}\text { Volumetric Moisture } \\
\text { Content (\%) }\end{array}$ & $\begin{array}{c}\text { Diffusion Coefficient } \\
\left(\mathbf{c m}^{\mathbf{2}} \mathbf{s}^{-1} \text { ) }\right.\end{array}$ \\
\hline 1 & 32.13 & $2.02 \times 10^{-6}$ \\
\hline 2 & 18.15 & $5.40 \times 10^{-7}$ \\
\hline 3 & 9.26 & $4.05 \times 10^{-8}$ \\
\hline 4 & 7.03 & $6.75 \times 10^{-9}$ \\
\hline 5 & 6.97 & $7.45 \times 10^{-9}$ \\
\hline 6 & 6.89 & $6.73 \times 10^{-9}$ \\
\hline 7 & 6.75 & $5.42 \times 10^{-9}$ \\
\hline 8 & 6.63 & $4.39 \times 10^{-9}$ \\
\hline 9 & 6.63 & $3.76 \times 10^{-9}$ \\
\hline 10 & 6.23 & $3.40 \times 10^{-9}$ \\
\hline 11 & 6.00 & $3.43 \times 10^{-9}$ \\
\hline 12 & 5.55 & $2.04 \times 10^{-9}$ \\
\hline 13 & 5.46 & $2.04 \times 10^{-9}$ \\
\hline 14 & 8.29 & $2.24 \times 10^{-9}$ \\
\hline 15 & 7.54 & $6.81 \times 10^{-9}$ \\
\hline 16 & 7.36 & $6.21 \times 10^{-9}$ \\
\hline 17 & 7.22 & $4.38 \times 10^{-9}$ \\
\hline 18 & 6.84 & $2.19 \times 10^{-9}$ \\
\hline 19 & 6.11 & $1.55 \times 10^{-9}$ \\
\hline 20 & 5.41 & $9.97 \times 10^{-10}$ \\
\hline 21 & 4.45 & $6.19 \times 10^{-10}$ \\
\hline 22 & 3.64 & $5.00 \times 10^{-10}$ \\
\hline 23 & 0.29 & $1.24 \times 10^{-10}$ \\
\hline 24 & 0.20 & $1.25 \times 10^{-10}$ \\
\hline
\end{tabular}

Source: CRWMS M\&O 2000 [DIRS 156680]. 


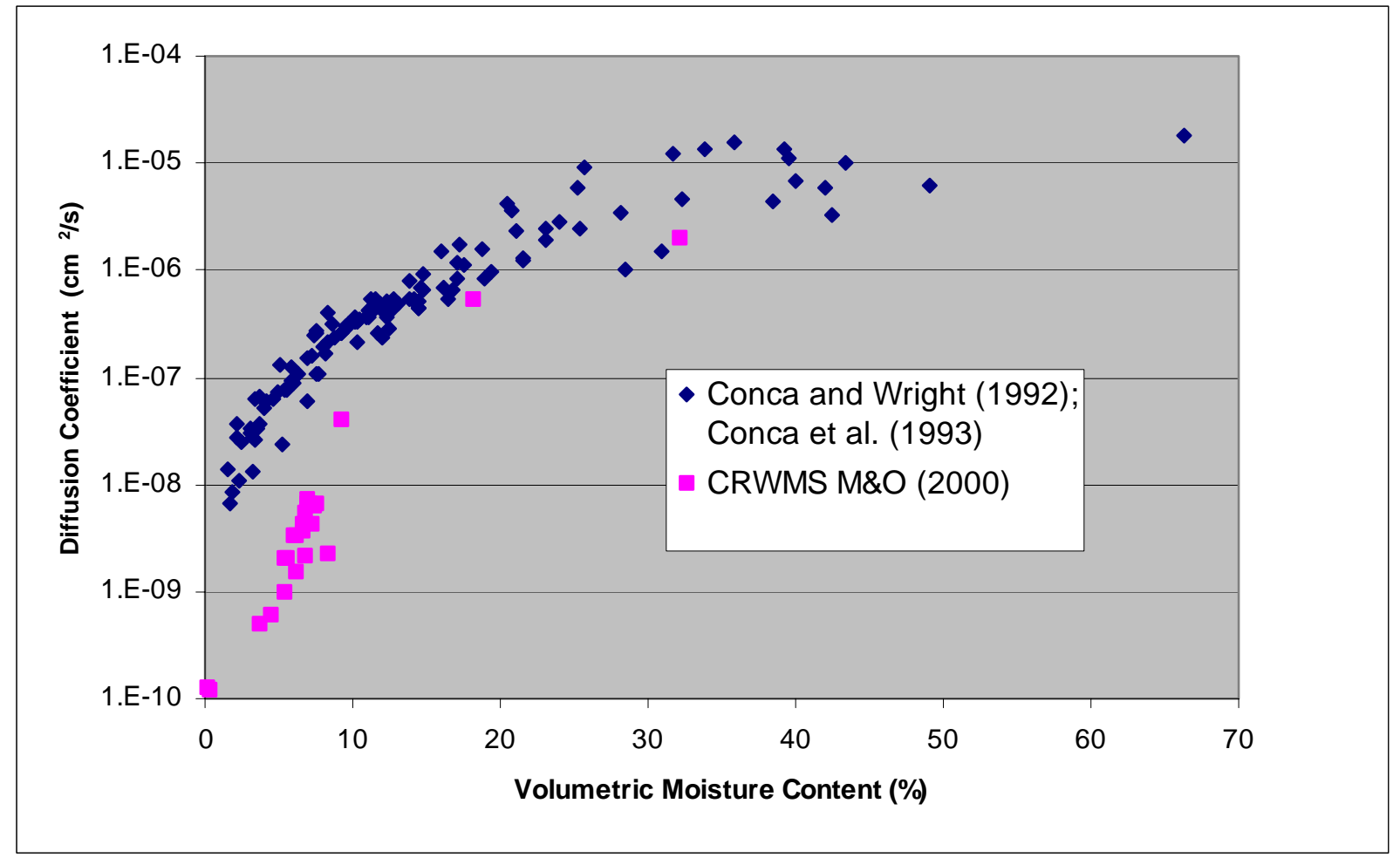

Source: Conca and Wright 1992 [DIRS 100436]; Conca et al. 1993 [DIRS 170709]; CRWMS M\&O 2000 [DIRS 156680].

Figure H-1. Comparison of Diffusion Coefficients

\section{DATA QUALIFICATION PLAN}

A facsimile of the data qualification plan developed for the above qualification effort is provided in Figure H-2. The original is included in the records package for this model report. 


\section{\begin{tabular}{c|c|c} 
BSC & $\begin{array}{c}\text { Data Qualification Plan } \\
\text { Complete only applicable items. }\end{array}$ & $\begin{array}{l}\text { QA: QA } \\
\text { Page 1 of 1 }\end{array}$
\end{tabular}}

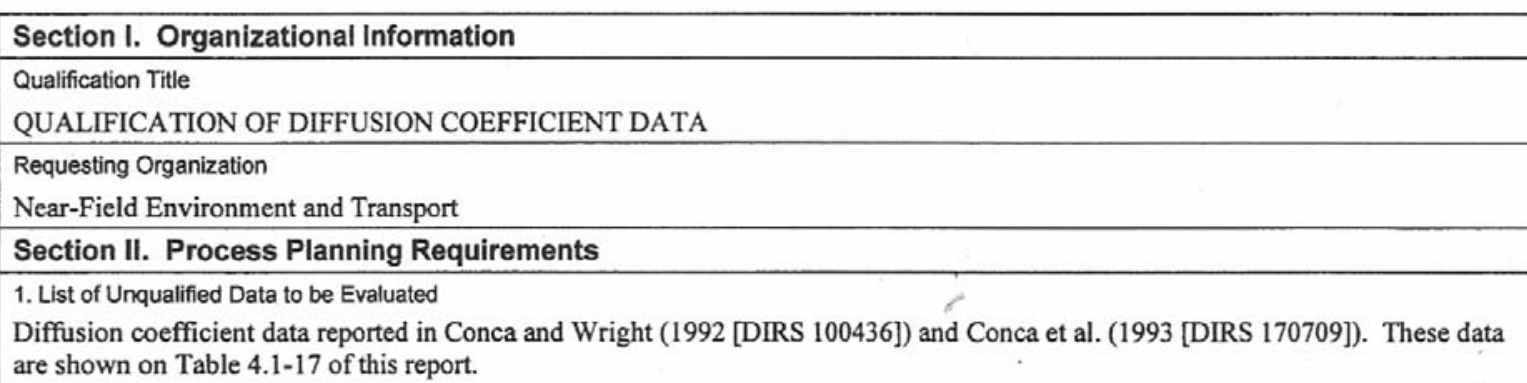

2. Type of Data Qualification Method(s) [Including rationale for selection of method(s) (Attachment 3) and qualification attributes (Attachment 4)] Qualification method, from Attachment 3 of LP-SIII.2Q-BSC, REV 0 ICN 0: Corroborating Data. The diffusion coefficient data for crushed tuff materials from the Determination of Diffusion Coefficient of Invert Materials (CRWMS M\&O 2000 [DIRS 156680]) are used to qualify the data reported by Conca and Wright (1992 [DIRS 100436]) and Conca et al. (1993 [DIRS 170709]).

Attributes used from Attachment 4: (3) The extent to which the data demonstrate the properties of interest, (8) Prior peer or other professional review of the data and their results; and (10) Extent and quality of corroborating data.

3. Data Qualification Team and Additional Support Staff Required

Chairperson: James Schreiber, Sandia National Laboratories

Technically competent individual: Teklu Hadgu, Sandia National Laboratories

4. Data Evaluation Criteria

The diffusion coefficient data from Conca and Wright (1992 [DIRS 100436]) and Conca et al. (1993 [DIRS 170709]) will be considered qualified if they are within one order of magnitude of the values reported in CRWMS M\&O 2000 [DIRS 156680]; or if greater differences are observed, they result in more conservative results with regard to radionuclide releases.

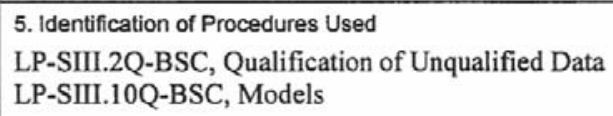

\section{Section III. Approval}

\begin{tabular}{|l|l|l|}
\hline Qualification Chairperson Printed Name \\
James Schreiber \\
$\begin{array}{l}\text { Responsible Manager Printed Name } \\
\text { Emest Hardin }\end{array}$
\end{tabular}

LP-SIII.2Q-BSC

Figure H-2. Data Qualification Plan 


\section{INTENTIONALLY LEFT BLANK}


APPENDIX I

COMPARISON OF OUTPUT DTNS 


\section{COMPARISON OF OUTPUT DTNs}

The output from this report consists of three preliminary output DTNs: SN0403T0507703.015, SN0409T0507703.017 and SN0503T0503305.001, and three final output DTNs: SN0410T0507703.018, SN0508T0503305.003, and MO0506SPAINPAR.000. In this appendix, the differences between two preliminary output DTNs (SN0403T0507703.015 and SN0409T0507703.017) are discussed. In addition, the final output DTN: SN0410T0507703.018 is compared with the second preliminary DTN: SN0409T0507703.017. These comparisons provide traceability for TSPA-LA applications that were initially developed based on the preliminary output DTNs.

The output in the three DTNs discussed in this appendix consists of tables from Section 8 (Conclusions) of the EBS RT Abstraction. Each of these tables is compared in this appendix. Numerous editorial revisions were made in converting the first preliminary version of the DTN to the second preliminary version; because these editorial revisions have no impact on TSPA-LA results, they are not discussed in this appendix.

\section{TABLE 57 (DTN: SN0403T0507703.015) VS. TABLE 8.1-1 (DTN： SN0409T0507703.017)}

Table 57 (Summary of EBS Flow Abstraction) in DTN: SN0403T0507703.015 corresponds to Table 8.1-1 in DTN: SN0409T0507703.017. The key differences in this table between the two DTN versions are the expressions for the flux through the drip shield, $F_{2}$, and the flux into the waste package, $F_{4}$. In preliminary DTN: SN0403T0507703.015, $F_{2}$ is expressed as:

$$
F_{2}=F_{1} L_{D S \_ \text {Patch }} f_{D S}^{\prime} /\left(2 L_{D S}\right) .
$$

The parameters are defined in the Table 57 in DTN: SN0403T0507703.015. This equation is technically correct, but it is expressed more completely in DTN: SN0409T0507703.017 as:

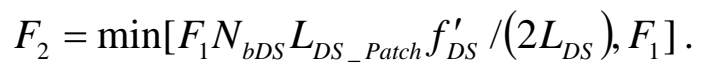

The parameters are defined in the Table 8.1-1 in DTN: SN0409T0507703.017. Equation I-2 replicates Equation 6.5.1.1.2-37 in the EBS RT Abstraction. Equations I-1 and I-2 give the same result when the number of corrosion patches in the drip shield, $N_{b D S}$, is one, which is the case in the WAPDEG model of drip shield failure (BSC 2004 [DIRS 169996], Section 6.3). The min function in Equation I-2 provides a numerical check to prevent an unrealistic result of $F_{2}>F_{1}$ from being obtained if the parameter values used in the equation were to give that result.

The same discussion applies to the flux into the waste package. In DTN: SN0403T0507703.015, $F_{4}$, is expressed as:

$$
F_{4}=F_{2} L_{W P_{-} \text {Patch }} f_{W P}^{\prime} /\left(2 L_{W P}\right) .
$$

The parameters are defined in the Table 57 in DTN: SN0403T0507703.015. 
This equation is technically correct, but it is expressed more completely in DTN: SN0409T0507703.017 as:

$$
F_{4}=\min \left[F_{2} N_{b W P} L_{W P \_P a t c h} f_{W P}^{\prime} /\left(2 L_{W P}\right), F_{2}\right]
$$

The parameters are defined in the Table 8-1 in DTN: SN0409T0507703.017. Equation I-4 replicates Equation 6.5.1.1.3-1 in the EBS RT Abstraction. The difference between Equations I-3 and I-4 is the definition of $L_{W P \_P a t c h}$. In Equation I-3, $L_{W P \_P a t c h}$, is the length of all corrosion patches in the waste package, whereas in Equation I-4, $L_{W P_{-} \text {Patch }}$ is the length of each corrosion patch; thus, the product $N_{b W P} L_{W P \_P a t c h}$ in Equation I-4 is equal to $L_{W P_{-} P a t c h}$ in Equation I-3. The min function in Equation I-4 provides a numerical check to prevent an unrealistic result of $F_{4}>F_{2}$ from being obtained if the parameter values used in the equation were to give that result.

In the Flow Parameter column for Flow Pathway 8 in Table 57 in DTN: SN0403T0507703.015, a flux $F_{9}$ is erroneously included in the equation and is deleted in the final DTN. Since this flux does not exist, its inclusion in the preliminary DTN has no impact on the TSPA-LA calculation.

The references and comments in the Data Sources \& Notes column in Table 8.1-1 in DTN: SN0409T0507703.017 are updated from Table 57 in DTN: SN0403T0507703.015; these updates have no impact on TSPA-LA calculations.

\section{TABLE 58 (DTN：SN0403T0507703.015) VS. TABLE 8.1-2 (DTN： SN0409T0507703.017)}

In DTN: SN0409T0507703.017, the cross-sectional area for radionuclide transport is clarified in Table 8.1-2, with references to sections in the report. In DTN: SN0403T0507703.015, the same parameter is referred to as the flow cross-sectional area in Table 58 and described in vague terms that prompted a revised description in the final DTN. References are updated in DTN: SN0409T0507703.017, Table 8.1-2. None of these changes has any impact on TSPA-LA calculations.

TABLE 59 (DTN: SN0403T0507703.015) VS. TABLE 8.2-1 (DTN: SN0409T0507703.017)

In Table 57 in DTN: SN0403T0507703.015, the lower end of the range on sampled parameter Diff_Path_Length_CP_CDSP is erroneously shown as $0.02 \mathrm{~m}$; this error is also found in Table 63 in DTN: SN0403T0507703.015. Because the correct value, $0.025 \mathrm{~m}$, is included in the database used for TSPA-LA, this error has no impact on TSPA-LA. In the corresponding table in DTN: SN0409T0507703.017, Table 8.2-1, the range for this parameter is not shown, since it is given correctly in Table 8.2-3.

References to parameter sources and sections in the EBS RT Abstraction are updated in DTN: SN0409T0507703.017. These changes have no impact on TSPA-LA calculations.

TABLE 60 (DTN: SN0403T0507703.015) VS. TABLE 8.2-2 (DTN: SN0409T0507703.017)

Table 8.2-2 in DTN: SN0409T0507703.017 ( $K_{d}$ values for corrosion products) is identical to Table 60 in DTN: SN0403T0507703.015. Therefore, there is no impact on TSPA-LA calculations. 


\section{TABLES 61 \& 62 (DTN：SN0403T0507703.015) VS. TEXT (DTN：SN0409T0507703.017)}

Tables 61 and 62 in DTN: SN0403T0507703.015 ( $K_{d}$ values and correlations for the invert) are replaced in DTN: SN0409T0507703.017 with text clarifying that TSPA-LA is to use UZ $K_{d}$ values for the invert. This change has no impact on TSPA-LA calculations.

\section{TABLE 63 (DTN: SN0403T0507703.015) VS. TABLE 8.2-3 (DTN: SN0409T0507703.017)}

In Table 63 in DTN: SN0403T0507703.015, sampled parameter Diff_Path_Length_CP_CDSP is erroneously shown as having a lower end of the range of $0.02 \mathrm{~m}$. Because the correct value, $0.025 \mathrm{~m}$, is included in the database used for TSPA-LA, this error has no impact on TSPA-LA. The correct range is shown in Table 8.2-3 in DTN: SN0409T0507703.017. References are updated in Table 8.2-3 in DTN: SN0409T0507703.017. These changes have no impact on TSPA-LA calculations.

\section{TABLE 64 (DTN: SN0403T0507703.015) VS. TABLE 8.2-4 (DTN： SN0409T0507703.017)}

References are updated in Table 8.2-4 in DTN: SN0409T0507703.017. Three parameters were added to this table to provide a source for the values used in TSPA-LA: DS_Total_Length $(5805 \mathrm{~mm})$, Invert_Viscosity_Ref_Temp $(298.15 \mathrm{~K})$, and Interface_Scale_Factor $\left(1 \times 10^{-6}\right)$. These changes have no impact on TSPA-LA calculations. No other changes were made in converting Table 64 to Table 8.2-4.

TABLE 65 (DTN: SN0403T0507703.015) VS. TABLE 8.2-5 (DTN: SN0409T0507703.017)

The following changes were made to convert Table 65 to Table 8.2-5. References to the equations in the EBS RT Abstraction were added to the Input Description column. In the Parameter Description for Equation 8-1, clarification of the definition of $N D$, the truncated normal distribution, was added. In Equation 8-2, the range of validity was added to the definition of temperature. In Equation 8-3, the definition of $\theta_{m}$ was changed from fraction to percent, and the equation was modified accordingly by changing the term $0.138 \theta_{m}$ to $0.00138 \theta_{m}$. Equation 8-7 was completely revised in order to clarify the calculation of corrosion product mass as computed in TSPA-LA over each time interval, from $t_{0}$, when breach occurs, to $t_{f 1}$ and $t_{f 2}$, the lifetimes of each type of steel. These changes have no impact on TSPA-LA calculations.

\section{TABLE 66 (DTN: SN0403T0507703.015) VS. TABLE 8.2-6 (DTN: SN0409T0507703.017)}

Table 8.2-6 DTN: SN0409T0507703.017 (Invert Diffusion Coefficient Alternative conceptual Model Parameters) is identical to Table 66 in DTN: SN0403T0507703.015. Therefore, there is no impact on TSPA-LA calculations. 


\section{TABLE 67 (DTN: SN0403T0507703.015) VS. TABLE 8.2-7 (DTN： SN0409T0507703.017)}

Equation 8-8 was reformulated in the EBS RT Abstraction and revised accordingly in Table 8.2-7. Because this is an alternative conceptual model, this change has no impact on TSPA-LA calculations. Equation 8-9, the definitions of $\theta_{\text {intra }}$ and $\theta_{\min }$ were changed from fractions to percent. This change has no impact on the results.

TABLE 8.1-1 (DTN: SN0410T0507703.018)VS. TABLE 8.1-1 (DTN: SN0409T0507703.017)

The differences in this table (Summary of EBS Flow Abstraction) between the two DTN versions are the expressions for the flux through the drip shield, $F_{2}$, and the flux into the waste package, $F_{4}$. In DTN: SN0409T0507703.017, $F_{2}$ is expressed as:

$$
\left.F_{2}=\min \mid F_{1} N_{b D S} L_{D S_{-} P a t c h} f_{D S}^{\prime} /\left(2 L_{D S}\right), F_{1}\right] .
$$

The parameters are defined in Table 8.1-1 in both DTNs. Because $L_{D S_{-} P a t c h}$ is defined as the axial half-length of each corrosion patch, the factor of 2 should not appear in the denominator. This equation is presented correctly in DTN: SN0410T0507703.018 as:

$$
\left.F_{2}=\min \mid F_{1} N_{b D S} L_{D S_{\_} P a t c h} f_{D S}^{\prime} / L_{D S}, F_{1}\right\rfloor .
$$

Similarly, in DTN: SN0409T0507703.017, $F_{4}$ is expressed in Table 8.1-1 as:

$$
F_{4}=\min \left[F_{2} N_{b W P} L_{W P_{-} P a t c h} f_{W P}^{\prime} /\left(2 L_{W P}\right), F_{2}\right] .
$$

This equation is presented correctly in Table 8.1-1 in DTN: SN0410T0507703.018 as:

$$
F_{4}=\min \left[F_{2} N_{b W P} L_{W P_{2} P a t c h} f_{W P}^{\prime} / L_{W P}, F_{2}\right] .
$$

These differences have no impact because the correct equations (Equations I-6 and I-8) have been implemented in the TSPA.

TABLE 8.2-4 (DTN: SN0410T0507703.018)VS. TABLE 8.2-5 (DTN: SN0409T0507703.017)

The differences in this table (Calculated Model Inputs Used in the EBS Radionuclide Transport Abstraction) between the two DTN versions include Equation 8-5 for the effective water saturation of corrosion products. In DTN: SN0409T0507703.017, this equation is:

$$
S_{w e, C P}=1.312 \times 10^{-6} \bar{s}_{C P}(-\ln R H)^{-1 / 2.45} .
$$

This equation, developed in an earlier draft of Section 6.5.1.2.1.4.2 as Equation 6.5.1.2.1-27, is incorrect. The correct equation (as shown in Section 6.3.4.3.5, Equation 6.3.4.3.5-5 of this report), is given in DTN: SN0410T0507703.018 as:

$$
S_{w e, C P}=3.28 \times 10^{-6} \bar{s}_{C P}(-\ln R H)^{-1 / 2.45} .
$$


In addition, in DTN: SN0409T0507703.017, parameter $\bar{s}_{C P}$ is defined in Table 8.2-5 as having units of $\left(\mathrm{m}^{2} \mathrm{~g}^{-1}\right)$. The correct units for use in this parameter are given in DTN: SN0410T0507703.018 as $\left(\mathrm{m}^{2} \mathrm{~kg}^{-1}\right)$.

The impact of this correction has been assessed in a Technical Management Review Board (TMRB) Decision Proposal (BSC 2004 [DIRS 172219]). Because the water saturation in the waste package corrosion products is used to calculate the diffusion coefficient, this correction has a direct impact on dose estimates. In the preliminary assessment, using Equation I-10 instead of Equation I-9 increases the total peak mean annual dose from all scenario classes by 10\% (BSC 2004 [DIRS 172219]). 


\section{INTENTIONALLY LEFT BLANK}


APPENDIX J

SORPTION DATA USED IN TSPA-LA 


\section{SORPTION DATA USED IN TSPA-LA}

The data used in TSPA-LA for the irreversible sorption submodel is contained in a preliminary output DTN: SN0503T0503305.001. Four of the data points in the preliminary DTN have been found to be incorrect. The correct data values are listed in Table 4.1-10, and included in the discrete distributions presented in Table 6.3-6. The data values and discrete distributions are also included in final output DTN: SN0508T0503305.003. This appendix describes the erroneous data and the sorption parameter distributions that are used in TSPA-LA.

The first erroneous data value in preliminary DTN: SN0503T0503305.001 is a sorption site density for goethite of 1.00 sites $\mathrm{nm}^{-2}$ attributed to Kooner (1993 [DIRS 173819]). This value is not given in Kooner (1993 [DIRS 173819]) and has been deleted from the discrete distribution for goethite site density shown in Table 6.3-6. This deletion has two effects. First, the lower end of the distribution increases from 1.00 sites $\mathrm{nm}^{-2}$ to 1.02 sites $\mathrm{nm}^{-2}$. Since the upper end of the distribution is 8.38 sites $\mathrm{nm}^{-2}$, this change results in a reduction of the range of less than 0.3 percent and is expected to have negligible impact on dose calculations in TSPA-LA. The second effect is to increase the probability of each entry in the distribution, since there are now 56 points instead of 57. Therefore, each data point now has a probability of 1/56 $=0.01786$ instead of $1 / 57=0.01754$. This change in the probability of each entry in the distribution should also have a negligible effect on TSPA-LA dose calculations.

The second data error in preliminary DTN: SN0503T0503305.001 is a total sorption site density for goethite of 5.92 sites $\mathrm{nm}^{-2}$. The correct value, as given by Hiemstra and Van Riemsdijk (1996 [DIRS 173023], p. 498), is 6.15 sites $\mathrm{nm}^{-2}$ (DTN: SN0508T0503305.003).

The third data error in preliminary DTN: SN0503T0503305.001 is a sorption site density for goethite of 8.83 sites $\mathrm{nm}^{-2}$. The correct value, as given by Robertson and Leckie (1997 [DIRS 173763], Table 4), is 8.38 sites $\mathrm{nm}^{-2}$ (DTN: SN0508T0503305.003).

These second and third data values have a minor impact on the discrete distribution for goethite site density in preliminary DTN: SN0503T0503305.001, shown in Table J-1, that is sampled in TSPA-LA. Comparing this with the correct distribution in Table 6.3-6 shows a negligible difference (see Figure J-1, where the cumulative distribution for goethite site density used in TSPA-LA, computed in Table J-2, is compared in with the distribution developed in the EBS RT Abstraction). The maximum value in the range of site densities is larger in Table $\mathrm{J}-1$ due to the erroneous data point 8.83 sites $\mathrm{nm}^{-2}$. This point expands the range by about $3 \%$, from a range of 1.02 to $8.59 \mathrm{sites} / \mathrm{nm}^{2}$ to a range of 1.02 to 8.83 sites $\mathrm{nm}^{-2}$. The value being used in TSPA-LA (8.83) is about $5 \%$ greater than the correct value. Since it represents one of 57 data points in the distribution, the probability that it will be sampled is low $(1 / 57=0.01754)$. Therefore, this error is expected to have negligible impact on dose calculations in TSPA-LA. The second error, where the value used in TSPA-LA is 5.92 sites $\mathrm{nm}^{-2}$ and the correct value is 6.15 sites $\mathrm{nm}^{-2}$, will also have a negligible effect. The value used in TSPA-LA is smaller than the correct value by about $4 \%$, and thus partially offsets the error in the maximum site density. The correct value and the erroneous value occupy the same position in the distribution, so this error does not alter the shape or range of the distribution. The net effect of these two small errors on dose calculations in TSPA-LA should be negligible. 
The fourth data error in preliminary DTN: SN0503T0503305.001 is in a value for the percentage of high-affinity sorption sites for goethite. Instead of the correct value of 2.7 sites $\mathrm{nm}^{-2}$ (Hiemstra and Van Riemsdijk 1996 [DIRS 173023], p. 498), an incorrect value of 2.47 sites $\mathrm{nm}^{-2}$ was used. This value is used to obtain a value for the percentage of highaffinity sorption sites for goethite in Table 6.3-4b. The incorrect site density value resulted in a value for the percentage of high-affinity sorption sites for goethite of 41.67 percent, whereas the correct value is 43.90 percent (see Table 6.3-4b). The effect of this error on dose calculations in TSPA-LA should be negligible, as indicated by Figure J-2, where the cumulative distribution for the percentage of high-affinity sorption sites for goethite used in TSPA-LA, computed in Table J-2, is compared in with the distribution developed in the EBS RT Abstraction.

Table J-1 shows discrete probabilities for various values of several parameters. The sum of these parameters is 1.0, and the cumulative sum at any parameter value is the cumulative (probability) distribution function, CDF.

One additional deviation from the discrete distributions shown in Table 6.3-6 as shown in preliminary DTN: SN0503T0503305.001 involves the number of digits of precision used for the parameters. As discussed in Section 6.3.4.2.3.2, specific surface areas and site density data are accurate to at most three significant digits due to the difficulty in measuring these parameters and variability in samples. The high-affinity site percentages are even less precise. The parameters comprising the discrete distributions in Table 6.3-6 are presented to three significant digits. However, in the Excel file contained in preliminary DTN: SN0503T0503305.001, the data are available to 15 digits of precision. These are shown rounded to 9 digits in Table J-1 (goethite high-affinity site percentages are shown to 11 digits). The differences in precision between the data in Table 6.3-6 and the parameters used in preliminary DTN: SN0503T0503305.001 will have a negligible effect on dose calculations and is discussed here solely to provide full traceability of the data.

Table J-1. Sample Ranges and Distributions Used for Irreversible Sorption on Stationary Corrosion Products in TSPA-LA

\begin{tabular}{|c|c|c|c|}
\hline Input Name & Input Description & Range & Distribution \\
\hline Relative_Abundance_Goethite_a & $\begin{array}{l}\text { Fraction of total iron oxide that is } \\
\text { goethite }\end{array}$ & $0.45-0.8$ & Uniform \\
\hline \multirow[t]{15}{*}{ Goethite_SA_a } & \multirow[t]{15}{*}{$\begin{array}{l}\text { Goethite surface area; discrete } \\
\text { distribution }\end{array}$} & \begin{tabular}{|c}
$\begin{array}{c}\text { Specific Surface Area } \\
\left(\mathrm{m}^{2} \mathrm{~g}^{-1}\right)\end{array}$ \\
\end{tabular} & Probability Level \\
\hline & & 14.7 & 0.018867925 \\
\hline & & 20.0 & 0.056603774 \\
\hline & & 21.0 & 0.037735849 \\
\hline & & 21.4 & 0.018867925 \\
\hline & & 27.7 & 0.018867925 \\
\hline & & 28.5 & 0.037735849 \\
\hline & & 30.8 & 0.018867925 \\
\hline & & 32.0 & 0.037735849 \\
\hline & & 33.0 & 0.056603774 \\
\hline & & 35.0 & 0.018867925 \\
\hline & & 37.0 & 0.018867925 \\
\hline & & 38.0 & 0.018867925 \\
\hline & & 39.9 & 0.018867925 \\
\hline & & 43.0 & 0.018867925 \\
\hline
\end{tabular}


Table J-1. Sample Ranges and Distributions Used for Irreversible Sorption on Stationary Corrosion Products in TSPA-LA (Continued)

\begin{tabular}{|c|c|c|c|}
\hline Input Name & Input Description & Range & Distribution \\
\hline \multirow{18}{*}{$\begin{array}{l}\text { Goethite_SA_a } \\
\text { (continued) }\end{array}$} & & 45.0 & 0.037735849 \\
\hline & & 47.5 & 0.018867925 \\
\hline & & 49.0 & 0.075471698 \\
\hline & & 50.0 & 0.018867925 \\
\hline & & 52.0 & 0.037735849 \\
\hline & & 54.0 & 0.018867925 \\
\hline & & 55.0 & 0.056603774 \\
\hline & & 55.4 & 0.018867925 \\
\hline & & 64.3 & 0.018867925 \\
\hline & & 66.0 & 0.037735849 \\
\hline & & 70.0 & 0.037735849 \\
\hline & & 80.0 & 0.037735849 \\
\hline & & 80.5 & 0.018867925 \\
\hline & & 81.0 & 0.075471698 \\
\hline & & 85.0 & 0.018867925 \\
\hline & & 86.0 & 0.018867925 \\
\hline & & 105.0 & 0.037735849 \\
\hline & & 110.0 & 0.018867925 \\
\hline \multirow[t]{2}{*}{ HFO_SA_a } & \multirow[t]{2}{*}{$\begin{array}{l}\text { HFO (hydrous ferric oxide) } \\
\text { surface area; discrete distribution }\end{array}$} & $\begin{array}{c}\text { Specific Surface Area } \\
\left(\mathrm{m}^{2} \mathrm{~g}^{-1}\right)\end{array}$ & Probability Level \\
\hline & & 600.0 & 1.000 \\
\hline \multirow[t]{31}{*}{ Goethite_Site_Density_a } & \multirow{31}{*}{$\begin{array}{l}\text { Goethite site density; discrete } \\
\text { distribution }\end{array}$} & Density $\left(\right.$ sites $\mathrm{nm}^{-2}$ ) & Probability Level \\
\hline & & 1.00000000 & 0.01754386 \\
\hline & & 1.01513714 & 0.01754386 \\
\hline & & 1.21013524 & 0.01754386 \\
\hline & & 1.32484000 & 0.03508772 \\
\hline & & 1.46000000 & 0.01754386 \\
\hline & & 1.50000000 & 0.01754386 \\
\hline & & 1.65500000 & 0.01754386 \\
\hline & & 1.68000000 & 0.03508772 \\
\hline & & 1.70000000 & 0.01754386 \\
\hline & & 1.80000000 & 0.01754386 \\
\hline & & 1.87000000 & 0.01754386 \\
\hline & & 1.92704000 & 0.01754386 \\
\hline & & 1.94573646 & 0.01754386 \\
\hline & & 1.97220500 & 0.01754386 \\
\hline & & 2.20000000 & 0.01754386 \\
\hline & & 2.30000000 & 0.07017544 \\
\hline & & 2.31000000 & 0.01754386 \\
\hline & & 2.31903106 & 0.01754386 \\
\hline & & 2.55000000 & 0.01754386 \\
\hline & & 2.60000000 & 0.03508772 \\
\hline & & 2.70000000 & 0.01754386 \\
\hline & & 2.88600000 & 0.01754386 \\
\hline & & 2.90000000 & 0.03508772 \\
\hline & & 3.00000000 & 0.01754386 \\
\hline & & 3.12251852 & 0.01754386 \\
\hline & & 3.13144000 & 0.01754386 \\
\hline & & 3.30000000 & 0.03508772 \\
\hline & & 3.40000000 & 0.01754386 \\
\hline & & 4.00000000 & 0.01754386 \\
\hline & & 4.20000000 & 0.01754386 \\
\hline
\end{tabular}


Table J-1. Sample Ranges and Distributions Used for Irreversible Sorption on Stationary Corrosion Products in TSPA-LA (Continued)

\begin{tabular}{|c|c|c|c|}
\hline Input Name & Input Description & Range & Distribution \\
\hline \multirow{16}{*}{$\begin{array}{l}\text { Goethite_Site_Density_a } \\
\text { (continued) }\end{array}$} & & 4.60000000 & 0.01754386 \\
\hline & & 4.84195023 & 0.01754386 \\
\hline & & 4.90000000 & 0.01754386 \\
\hline & & 5.00000000 & 0.01754386 \\
\hline & & 5.52819600 & 0.01754386 \\
\hline & & 5.92000000 & 0.01754386 \\
\hline & & 6.30000000 & 0.01754386 \\
\hline & & 6.31000000 & 0.03508772 \\
\hline & & 6.60000000 & 0.01754386 \\
\hline & & 7.00000000 & 0.05263158 \\
\hline & & 7.20000000 & 0.01754386 \\
\hline & & 7.40000000 & 0.01754386 \\
\hline & & 8.00000000 & 0.01754386 \\
\hline & & 8.16000000 & 0.01754386 \\
\hline & & 8.58737200 & 0.01754386 \\
\hline & & 8.83000000 & 0.01754386 \\
\hline \multirow[t]{13}{*}{ HFO_Site_Density_a } & \multirow{13}{*}{$\begin{array}{l}\text { HFO (hydrous ferric oxide) } \\
\text { site density; discrete distribution }\end{array}$} & Density $\left(\right.$ sites $\mathrm{nm}^{-2}$ ) & Probability Level \\
\hline & & 0.56480960 & 0.05263158 \\
\hline & & 1.12961921 & 0.10526316 \\
\hline & & 1.46850497 & 0.05263158 \\
\hline & & 1.58146689 & 0.05263158 \\
\hline & & 1.69442881 & 0.10526316 \\
\hline & & 1.80739073 & 0.05263158 \\
\hline & & 2.03331458 & 0.10526316 \\
\hline & & 2.25923842 & 0.26315789 \\
\hline & & 2.59812418 & 0.05263158 \\
\hline & & 2.71108610 & 0.05263158 \\
\hline & & 4.00000000 & 0.05263158 \\
\hline & & 5.64809604 & 0.05263158 \\
\hline \multirow[t]{19}{*}{ HFO_Strong_Sites_a } & \multirow{19}{*}{$\begin{array}{l}\text { Percentage of high affinity HFO } \\
\text { (hydrous ferric oxide) } \\
\text { sites; discrete distribution }\end{array}$} & Percentage & Probability Level \\
\hline & & 0.20000000 & 0.01262626 \\
\hline & & 0.40000000 & 0.01010101 \\
\hline & & 0.416666667 & 0.01262626 \\
\hline & & 0.43478261 & 0.01262626 \\
\hline & & 0.50000000 & 0.06313131 \\
\hline & & 0.55555556 & 0.02525253 \\
\hline & & 0.60000000 & 0.00757576 \\
\hline & & 0.62500000 & 0.01262626 \\
\hline & & 0.66666667 & 0.02525253 \\
\hline & & 0.71428571 & 0.01262626 \\
\hline & & 0.76923077 & 0.01262626 \\
\hline & & 0.83333333 & 0.01010101 \\
\hline & & 0.86956522 & 0.01010101 \\
\hline & & 1.00000000 & 0.09343434 \\
\hline & & 1.11111111 & 0.02020202 \\
\hline & & 1.25000000 & 0.01767677 \\
\hline & & 1.30434783 & 0.00757576 \\
\hline & & 1.33333333 & 0.02020202 \\
\hline
\end{tabular}


Table J-1. Sample Ranges and Distributions Used for Irreversible Sorption on Stationary Corrosion Products in TSPA-LA (Continued)

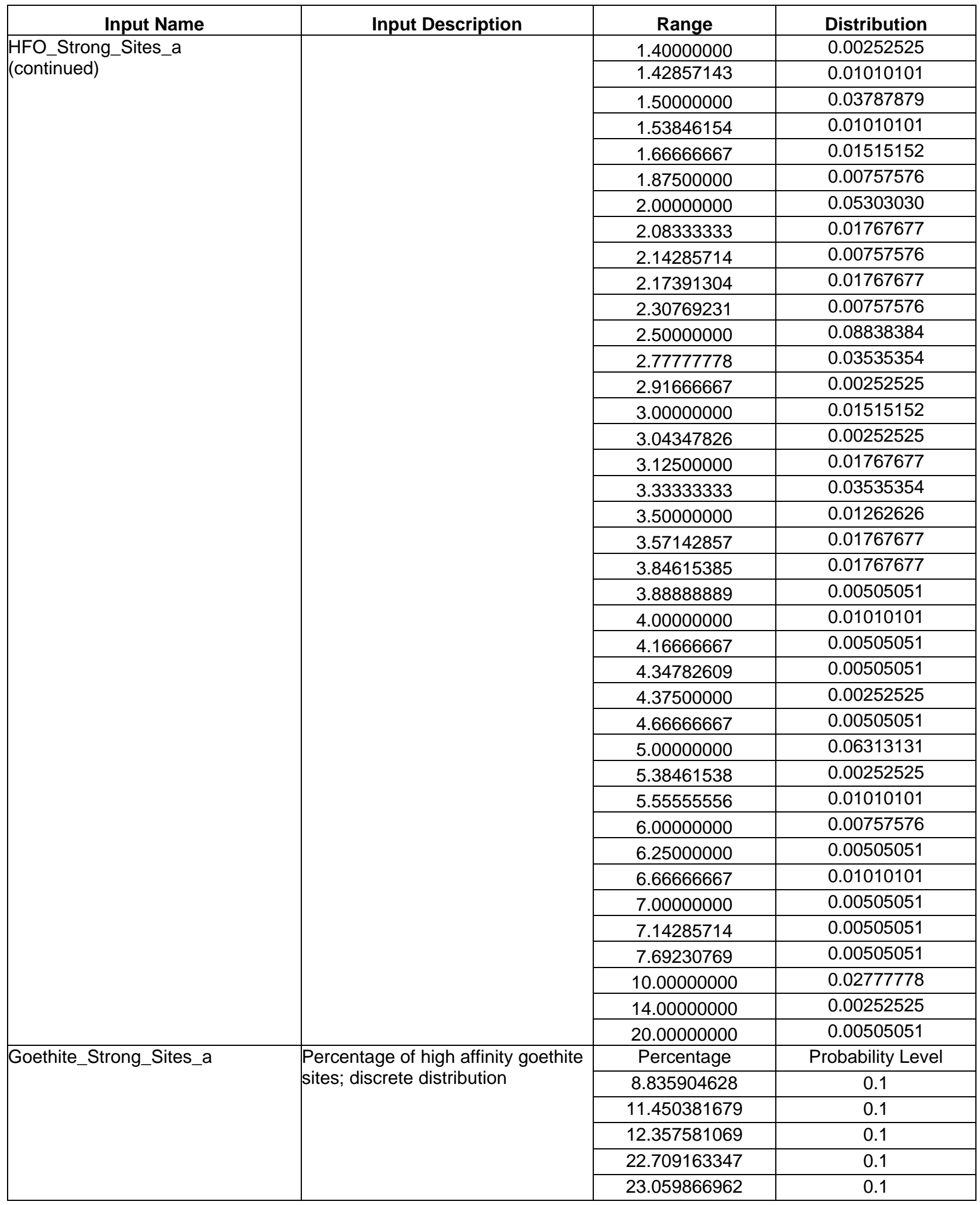


Table J-1. Sample Ranges and Distributions Used for Irreversible Sorption on Stationary Corrosion Products in TSPA-LA (Continued)

\begin{tabular}{|l|c|c|c|}
\hline \multicolumn{1}{|c|}{ Input Name } & Input Description & Range & Distribution \\
\hline Goethite_Strong_Sites_a & \multirow{3}{*}{ (continued) } & 24.657534247 & 0.1 \\
\cline { 3 - 4 } & & 26.829268293 & 0.1 \\
\cline { 3 - 4 } & & 41.666666667 & 0.1 \\
\cline { 3 - 4 } & & 49.664429530 & 0.1 \\
\cline { 3 - 4 } & & 73.913043478 & 0.1 \\
\hline
\end{tabular}

Source: Preliminary DTN: SN0503T0503305.001.

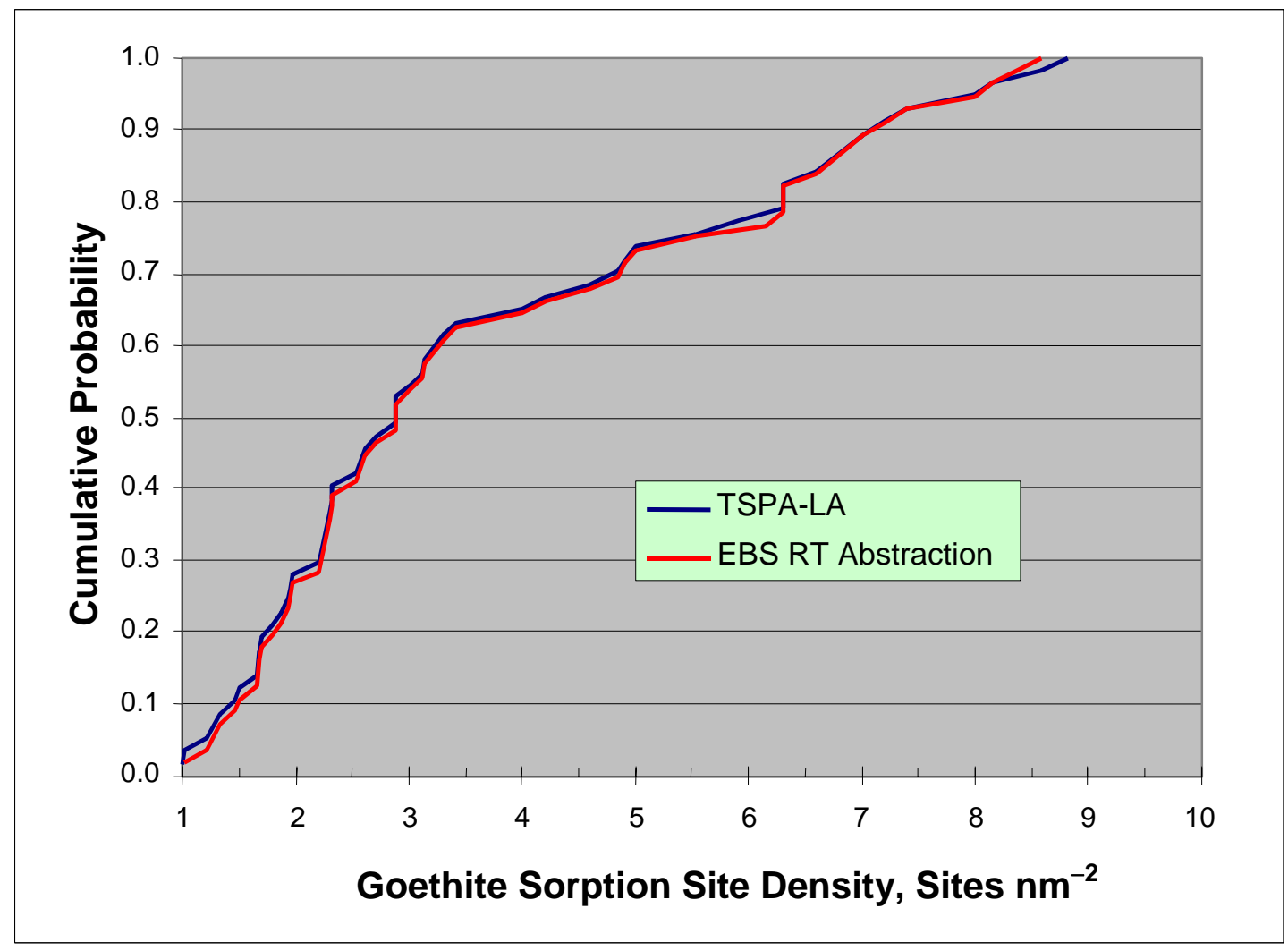

Sources: TSPA-LA: Table J-2.

EBS RT Abstraction: Output DTN: SN0508T0503305.003.

Figure J-1. Comparison of Cumulative Probabilities in Goethite Sorption Site Density Discrete Distributions Used in TSPA-LA and Developed in EBS RT Abstraction 
Table J-2. Cumulative Probability Distributions for Goethite Site Density and Percentage of High-Affinity Goethite Sites Used in TSPA-LA

\begin{tabular}{|c|c|c|c|}
\hline Input Description & Values & Probability Level & Cumulative Probability \\
\hline \multirow[t]{40}{*}{ Goethite site density (sites $\mathrm{nm}^{-2}$ ) } & 1.00000000 & 0.01754386 & 0.01754386 \\
\hline & 1.01513714 & 0.01754386 & 0.03508772 \\
\hline & 1.21013524 & 0.01754386 & 0.05263158 \\
\hline & 1.32484000 & 0.03508772 & 0.08771930 \\
\hline & 1.46000000 & 0.01754386 & 0.10526316 \\
\hline & 1.50000000 & 0.01754386 & 0.12280702 \\
\hline & 1.65500000 & 0.01754386 & 0.14035088 \\
\hline & 1.68000000 & 0.03508772 & 0.17543860 \\
\hline & 1.70000000 & 0.01754386 & 0.19298246 \\
\hline & 1.80000000 & 0.01754386 & 0.21052632 \\
\hline & 1.87000000 & 0.01754386 & 0.22807018 \\
\hline & 1.92704000 & 0.01754386 & 0.24561404 \\
\hline & 1.94573646 & 0.01754386 & 0.26315790 \\
\hline & 1.97220500 & 0.01754386 & 0.28070176 \\
\hline & 2.20000000 & 0.01754386 & 0.29824562 \\
\hline & 2.30000000 & 0.07017544 & 0.36842106 \\
\hline & 2.31000000 & 0.01754386 & 0.38596492 \\
\hline & 2.31903106 & 0.01754386 & 0.40350878 \\
\hline & 2.55000000 & 0.01754386 & 0.42105264 \\
\hline & 2.60000000 & 0.03508772 & 0.45614036 \\
\hline & 2.70000000 & 0.01754386 & 0.47368422 \\
\hline & 2.88600000 & 0.01754386 & 0.49122808 \\
\hline & 2.90000000 & 0.03508772 & 0.52631580 \\
\hline & 3.00000000 & 0.01754386 & 0.54385966 \\
\hline & 3.12251852 & 0.01754386 & 0.56140352 \\
\hline & 3.13144000 & 0.01754386 & 0.57894738 \\
\hline & 3.30000000 & 0.03508772 & 0.61403510 \\
\hline & 3.40000000 & 0.01754386 & 0.63157896 \\
\hline & 4.00000000 & 0.01754386 & 0.64912282 \\
\hline & 4.20000000 & 0.01754386 & 0.66666668 \\
\hline & 4.60000000 & 0.01754386 & 0.68421054 \\
\hline & 4.84195023 & 0.01754386 & 0.70175440 \\
\hline & 4.90000000 & 0.01754386 & 0.71929826 \\
\hline & 5.00000000 & 0.01754386 & 0.73684212 \\
\hline & 5.52819600 & 0.01754386 & 0.75438598 \\
\hline & 5.92000000 & 0.01754386 & 0.77192984 \\
\hline & 6.30000000 & 0.01754386 & 0.78947370 \\
\hline & 6.31000000 & 0.03508772 & 0.82456142 \\
\hline & 6.60000000 & 0.01754386 & 0.84210528 \\
\hline & 7.00000000 & 0.05263158 & 0.89473686 \\
\hline
\end{tabular}


Table J-2. Cumulative Probability Distributions for Goethite Site Density and Percentage of High-Affinity Goethite Sites Used in TSPA-LA (Continued)

\begin{tabular}{|l|c|c|c|}
\hline \multicolumn{1}{|c|}{ Input Description } & Values & Probability Level & Cumulative Probability \\
\hline \multirow{4}{*}{$\begin{array}{l}\text { Goethite site density }\left(\text { sites } \mathrm{nm}^{-2}\right) \\
\text { continued) }\end{array}$} & 7.20000000 & 0.01754386 & 0.91228072 \\
\cline { 2 - 4 } & 7.40000000 & 0.01754386 & 0.92982458 \\
\cline { 2 - 4 } & 8.00000000 & 0.01754386 & 0.94736844 \\
\cline { 2 - 4 } & 8.16000000 & 0.01754386 & 0.96491230 \\
\cline { 2 - 4 } & 8.58737200 & 0.01754386 & 0.98245616 \\
\cline { 2 - 4 } & 8.83000000 & 0.01754386 & 1.00000002 \\
\hline Percentage of high-affinity goethite sites & 8.835904628 & 0.1 & 0.1 \\
\cline { 2 - 4 } & 11.450381679 & 0.1 & 0.2 \\
\cline { 2 - 4 } & 12.357581069 & 0.1 & 0.3 \\
\cline { 2 - 4 } & 22.709163347 & 0.1 & 0.4 \\
\cline { 2 - 4 } & 23.059866962 & 0.1 & 0.6 \\
\cline { 2 - 4 } & 24.657534247 & 0.1 & 0.7 \\
\cline { 2 - 4 } & 26.829268293 & 0.1 & 0.8 \\
\cline { 2 - 4 } & 41.666666667 & 0.1 & 1 \\
\cline { 2 - 4 } & 49.664429530 & 0.1 & \\
\cline { 2 - 4 } & 73.913043478 & 0.1 & 0.9 \\
\hline
\end{tabular}

Source (Values and Probability Levels): Preliminary DTN: SN0503T0503305.001. 


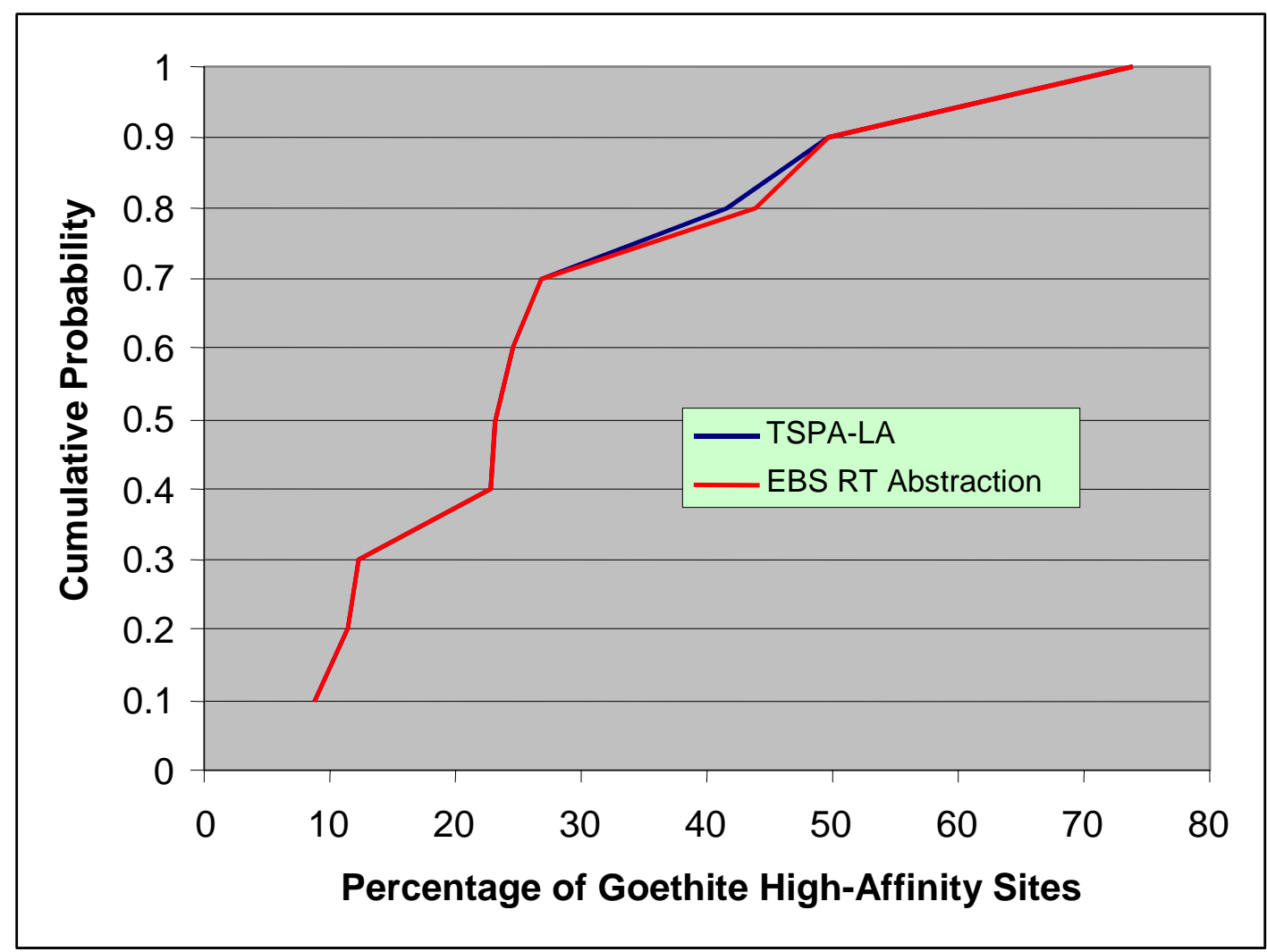

Sources: TSPA-LA: Table J-2.

EBS RT Abstraction: Output DTN: SN0508T0503305.003.

Figure J-2. Comparison of Cumulative Probabilities in Goethite Percentage of High-Affinity Sites Discrete Distributions Used in TSPA-LA and Developed in EBS RT Abstraction 


\section{INTENTIONALLY LEFT BLANK}

